Heinz Dieter Hessler

\title{
Theorie und Politik der Personalsteuern
}

Eine Kritik ihrer Einkommens- und

Vermögensbegriffe 


\section{Heinz Dieter Hessler}

\section{Theorie und Politik der Personalsteuern}

Auch in der Theorie sind die Einkommens- und Vermögensbegriffe nicht immer von Erkenntnisprinzipien, sondern von politischen Absichten geprägt. Um dieses Fehlverständnis zu entlarven, bedürfen die Begriffe neuer theoretischer Grundlegung. Diese Zielsetzung verfolgt die vorliegende Studie. Dabei wird zwischen wirtschaftstheoretischen und steuerlichen Begriffen unterschieden und ferner eine strikte analytische Trennung des allokativen vom distributiven Bereich des Wirtschaftens eingehalten. Das Ergebnis ist die Forderung nach einer Personalbesteuerung gemäß dem Leistungsfähigkeitspostulat, die kategorisch abzuspalten ist von der Unternehmensbesteuerung gemäß der Ertragsfähigkeit.

Heinz D. Hessler, geboren 1930, studierte in Münster, Mannheim und Köln Rechts-, Wirtschafts- und Sozialwissenschaften. 1958 Diplom-Kaufmann. Assistent am Seminar für Finanzwissenschaft an der Universität zu Köln. 1965 Dr. rer. pol. (Dissertation über staatliche Anleiheverschuldung). Unternehmenspraxis in Hannover. Von 1967 bis 1970 Dozentur in Kabul/Afghanistan. Dort Mitglied des Council of Economic Advisors beim Finanzminister. Lehrtätigkeit an den Universitäten Köln, Essen und TU Berlin. 1984 Habilitation. 1990 Professur Universität zu Köln. 1991 Gastprofessur Universität Leipzig. 
Theorie und Politik der Personalsteuern

Eine Kritik ihrer Einkommens- und Vermögensbegriffe mit Blick auf die Leistungsfähigkeitstheorie 


\title{
FINANZWISSENSCHAFTLICHE SCHRIFTEN
}

\author{
Herausgegeben von den Professoren
}

Albers, Krause-Junk, Littmann, Oberhauser, Pohmer, Schmidt

Band 31

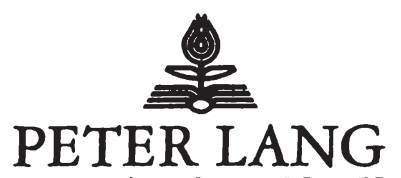

Frankfurt am Main - Berlin - Bern - New York - Paris - Wien 


\title{
Heinz Dieter Hessler
}

\section{Theorie und Politik der Personalsteuern}

\author{
Eine Kritik ihrer \\ Einkommens- und Vermögensbegriffe \\ mit Blick auf die \\ Leistungsfähigkeitstheorie
}

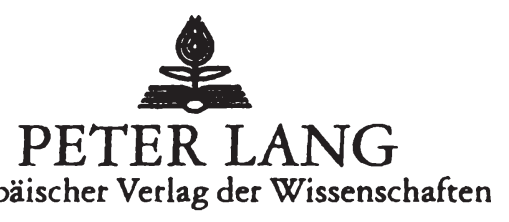


Die Deutsche Bibliothek - CIP-Einheitsaufnahme

Hessler, Heinz Dieter:

Theorie und Politik der Personalsteuern : eine Kritik ihrer

Einkommens- und Vermögensbegriffe mit Blick auf die

Leistungsfähigkeitstheorie / Heinz Dieter Hessler. - Frankfurt

am Main ; Berlin ; Bern ; New York ; Paris ; Wien : Lang, 1994

(Finanzwissenschaftliche Schriften ; Bd. 31)

ISBN 3-8204-9725-0

NE: GT

Open Access: The online version of this publication is published on www.peterlang.com and www.econstor.eu under the international Creative Commons License CC-BY 4.0. Learn more on how you can use and share this work: http://creativecommons.org/ licenses/by/4.0.

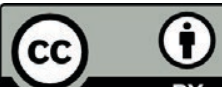

BY

This book is available Open Access thanks to the kind support of ZBW - Leibniz-Informationszentrum Wirtschaft.

ISSN 0170-8252

ISBN 3-8204-9725-0

ISBN 978-3-631-75239-5 (eBook)

(c) Verlag Peter Lang GmbH, Frankfurt am Main 1994

Alle Rechte vorbehalten.

Das Werk einschlieBlich aller seiner Teile ist urheberrechtlich geschützt. Jede Verwertung außerhalb der engen Grenzen des Urheberrechtsgesetzes ist ohne Zustimmung des Verlages unzulässig und strafbar. Das gilt insbesondere für Vervielfältigungen, Übersetzungen, Mikroverfilmungen und die Einspeicherung und Verarbeitung in elektronischen Systemen.

Printed in Germany 123467 
Für Anneliese

Heinz Hessler and Anneliese Hessler-Otte - 978-3-631-75239-5

Downloaded from PubFactory at 01/11/2019 06:44:50AM

via free access 
Heinz Hessler and Anneliese Hessler-Otte - 978-3-631-75239-5 Downloaded from PubFactory at 01/11/2019 06:44:50AM via free access 
ERSTER TEI工

Die ökonomischen Merkmale subjektiver steuerliche Leistungsfähigkeit in wirtschaftstheoretischer Sicht:

Grundlagen und Elemente einer normativen Theorie der Personalsteuern

1. Kapitel: Die allokativ-distributive Interdependenz in der Besteuerung

2. Kapitel: Das Leistungsfähigkeitsprinzip als distributive Steuerlastverteilungsnorm

3. Kapitel: Die Kritik der wirtschaftstheoretischen Bestimmungsversuche von Einkommen und Vermögen

4. Kapitel: Der "Kriterien"-Ansatz einer begrifflichen Theorie für Einkommen und Vermögen

ZWEITER TEI工

Die ökonomischen Merkmale subjektiver Leistungsfähigkeit in steuerlicher Sicht:

Theorie und Politik einer Objektivierung der Leistungsfähigkeit

5. Kapitel: Das Drei-Stufen-System der leistungsfähigkeitsorientierten Besteuerung

6. Kapitel: Theoretisch gestaltete Objektivierung: Die Leistungsfähigkeits-Indikatoren als sachliche und personale Bedingungen für die Besteuerung

7. Kapitel: Praktisch gestaltete Objektivierung I: Die Einschränkung des Allgemeinheitspostulats

8. Kapitel: Praktisch gestaltete Objektivierung II:

Die Verstöße gegen das Gleichmäßigkeitspostuiat

DRITTER TEI工

Steuerpolitik zwischen Lastverteilung und Verteilungsziel: Theoriekonzepte einer allokativ-distributiven Besteuerung

9. Kapitel: Die "Possibilitäts"-Konzepte

10. Kapitel: Die "Nominalismus"-Konzepte

11. Kapitel: Die "Utilitarismus"-Konzepte 561

12. Kapitel: Die "Distributions"-Konzepte 590

Ergebnis der Untersuchung

ANFANG mit den Exkursen I, II und III und Literaturverzeichnis 
Heinz Hessler and Anneliese Hessler-Otte - 978-3-631-75239-5 Downloaded from PubFactory at 01/11/2019 06:44:50AM via free access 


\section{Vorwort}

Die Arbeit, die ich hier vorlege, ist eine theoretische, und zwar sowohl eine allgemein-theoretische als auch eine steuertheoretische. Tatbestände steuerlicher Praxis ziehe ich heran, um den Inhalt der aktuell geltenden steuerrechtlichen und steuerlichen Einkommens- und Vermögensbegriffe beschreiben zu können.

Das Schreiben glich einer Entdeckungsreise. War es meine ursprüngliche Absicht, die Personalbesteuerung zur Gänze auszubreiten, so erkannte ich sehr bald, daB ich mich auf die oben genannten Begriffe $z u$ beschränken hatte; zu umfangreich und komplex ist die mit ihnen zusammenhängende Problematik, als daß noch Tariffragen hätten eingearbeitet werden können. Letztere mußten ausgeklammert werden.

Die zweite Entdeckung war, daß die Klärung des Einkommensbegriffes die unumgängliche Voraussetzung ist für die inhaltliche Beschreibung des Ertragsbegriffes und somit die unumgängliche Voraussetzung für ein weiteres Forschungsvorhaben, das ich $z u$ den aktuellsten der Steuertheorie und -politik zähle, nämlich für die grundlegende Reform der Unternehmensbesteuerung. $\mathrm{zu}$ Unternehmenserträgen und ihrer Besteuerung kann sich nach meiner festen Uberzeugung erst äußern, wer Klarheit über den Einkommensbegriff gewonnen hat. Nur weil ich nicht über einen ausgebauten Lehrstuhl mit den üblichen Ressourcen (Bibliothek, Sekretariat, Assistenten, Drittmittel usw.) verfüge, ist es mir selbst nicht mögliche, beiden Fortsetzungspfaden der einmal begonnenen Entdeckungsreise zu folgen.

Trotz ihres Theorieanspruchs weist die vorliegende Arbeit keine einzige mathematische Ableitung und Formel auf. Das von mir angewendete methodische Vorgehen in verbal-logischer Weise gilt ja heute beinahe schon als atheoretisch. Jedoch: Die Arbeit ist im Seminar für Finanzwissenschaft an der Universität zu Köln (als Habilitationsschrift) entstanden und konnte nur dort entstehen, wo seit dem Wirken von Günter Schmölders in verbal-logsicher Methodik eine bestimmte Denkweise und Forschungsrichtung Tradition wurde: Interdisziplinarität, offenheit für nicht-ökonomische sichtweisen und Verbindung zwischen Theorie und Politik. Beide Direktoren des Seminars, Karl-Heinrich Hansmeyer und Klaus Mackscheidt, haben diese Denktradition immer gepflegt. Daß sich die Politik der Theorie nicht immer bedient, liegt nicht an der Theorie. KarlHeinrich Hansmeyer bin ich zu sehr großem Dank verpflichtet, weil er mich $z u$ dieser Arbeit angeregt hat. 
Alle möglicherweise in dieser Arbeit vorhandenen Fehler, entstanden durch mehrfaches Umschreiben des Textes, alle Unebenheiten im Lay Out, alle Nachlässigkeiten im Korrekturlesen usw. gehen allein zu meinen Lasten.

Dem Verlag danke ich für die Geduld, die er mir gegenüber in reichlichem MaBe bewiesen hat, denn wegen mancher Lehrstuhlvertretungen und Forschungsaufträge, die es vorrangig zu erledigen galt, mußte die Publikation immer wieder verschoben werden. So hatte er auch Verständnis dafür, daß ich die Fertigstellung der letzten Fassung samt dem Einarbeiten neuester Literatur nur schleppend neben meinen jetzigen Lehrverpflichtungen als Gastprofessor an der Universität Leipzig vorantreiben konnte.

Die Arbeit widme ich meiner Frau Anneliese. Sie hat die "unsichtbaren", gewiß aber vorhandenen Lasten eines über weite Strecken perspektivelosen akademischen und wissenschaftlichen Arbeitens mit bewundernswerter Kraft und Ausdauer getragen, besonders in den Zeiten meiner Arbeitslosigkeit. Die Widmung kann nur unvollkommener Ausdruck meines Dankes an sie sein.

Jüngst las ich in einem Text über "Gutes Deutsch - Besseres Deutsch" recht Eindrucksvolles über den Usus der MeinungsäuBerungen in wissenschaftlichen Texten in der Ich-Form und der Wir-Form. Letztere gelte, sofern man eine persönliche Auffassung ausdrücke, als "affektiert", "stilistisch unpassend". Da ich den gesamten Text nicht neu schreiben wollte, erkläre ich hier deutlich und unwiderruflich, daß das von mir häufig verwendete "wir" kein Pluralis maiestatis, sondern ein Pluralis modestiae ist, also der früher übliche Plural der Bescheidenheit.

Köln und Leipzig, im Juli 1993

Heinz Dieter Hessler. 
Detailliertes Inhaltsverzeichnıs

Seite

$\$ \quad 1 \quad$ Problemstellung, Methodik und Abgrenzung

1

E R S T E R $\quad$ T E I I I

Die ökonomischen Merkmale subjektiver steuerlicher Leistungsfähigkeit in wirtschaftstheoretischer sicht:

Grundlagen und Elemente einer normativen Theorie der Personalsteuern

1. Kapite1 :

Die allokativ-distributiven Interdependenzen in der Besteuerung

S 2 Das steuerpolitische Grundproblem: Allokation versus Distribution

53 Die Systematik der allokativ-jistributiven Interdependenz

2. Kapite1:

Das Leistungsfähigkeitspostulat als distributive Steuerlastverteilungsnorm

$\$ 4$ Politisches Leistungsfähigkeitspostulat und ökonomisches Leistungsprinzip

$\$ \quad 5$ Die kritik der ökonomischen Bedingungen des Leistungsprinzips

$\$ 6$ Die distributionspolitische Zielrichtung des Leistungsfähigkeitspostulats

3. Kapite1:

Die Kritik der wirtschaftstheoretischen Bestimnungsversuche von Einkommen und Vermögen

$\$ 7$ Die Abgrenzung des allokativen vom distributiven Bereich des Wirtschaftens: Das Analyse-Instrument

$\$ 8$ Das Problem der Inhalts- und Umfangsiestimmung des Einkommens

$\$ 9$ Zeitbeziehungen und Entscheidungsabhängigkeiten als Abgrenzungskriterien zwischen Einkommen und Vermögen

$\$ 10$ Das Problem der Inhalts- und Umfangsbestimmung des Vermögens 
4. KapiteI :

Der "Kriterien"-Ansatz einer begrifflichen Theorie für Einkommen und Vermögen

\$ 11 Die "Verfügbarkeit" ökonomischer Größen als

das begriffsbildende Kriterium

$\$ 12$ Die "Konsum-Orientierung" als begriffserklärendes Kriterium

$\$ 13$ Das "Verfügungseinkommen" im Spektrum der Individualeinkommensbegriffe - Utberblick

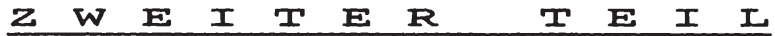

Die ökonomischen Merkmale subjektiver Leistungsfähigkeit in steuerlicher sicht:

Theorie und Politik einer objektivierung der Leistungsfähigkeit

5. Kapite1:

Das Dreistufen-System der leistungsfähigkeitsorientierten Besteuerung

\$ 14 Die "Objektivierung" als die wahl von Indikatoren der Leistungsfähigkeit

$\$ 15$ Die "Personalisierung" als Steuerlastzuweisung an unterschiedlich leistungsfähige Personen

$\$ 16$ Die "Individualisierung" als Steuerlastzuweisung an die Zahl ihrer Träger

6. Kapite1 :

Theoretisch gestaltete Objektivierung: Die Leistungsfähigkeitsindikatoren als sachliche und personale Bedingungen für die Besteuerung

$\$ 17$ Die Steuerpostulate als die begriffsbestimmenden Faktoren des steuerlichen Einkommens und Vermögens

518 Das Leistungsfähigkeitspostulat und seine erste sachliche Bedingung: Der Indikator

"steuerliches Einkommen"

\$ 19 Das Leistungsfähigkeitspostulat und seine

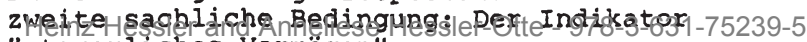
"steuerliches Vermögen" 
Seite

520 Das Leistungsfähigkeitspostulat und seine personale Bedingung: Der Leistungsträger "Individuum" / Personalbesteuerung versus Unternehmensbesteuerung

7. Kapite1:

Praktisch gestaltete Objektivierung I: Die Einschränkungen des Allgemeinheitspostulats

\$ 21 Das Allgemeinheitspostulat und seine erste sachliche Einschränkung: Die "Ausgrenzungen" aus der "freien" Verfügbarkeit - Die Gesamtproblematik

S 22 Die Einzelproblematiken der besonderen Ausgrenzungstatbestände "Zurechnungseinkommen", "Wertzuwachseinkommen" und "Transfereinkommen"

$5 \quad 23$

Das Allgemeinheitspostulat und seine zweite sachliche Einschränkung: Die "Eingrenzung" auf den "freien" Verfügungsbereich

$5 \quad 24$

Das Allgemeinheitspostulat und seine dritte sachliche Einschränkung: Das "Nominalwertprinzip" als Begrenzung der "realen" Verfügbarkeit

401

8. Kapite1:

Praktisch gestaltete Objektivierung II: Die Verstöße gegen das Gleichmäßigkeitspostulat

$\$ 25$ Die steuerliche "Gleichbehandlung" als Inhalt

des Gleichmäßigkeitspostulats

$\$ 26$ Die Verstöße gegen die Gleichbehandlung als die Determinanten des steuerlichen Einkommensbegriffs

$\$ 27$ Die Verstöße gegen die Gleichbehandlung als die Determinanten des steuerlichen Vermögensbegriffs

D R I $T$ T E R $T$ T E I I

Steuerpolitik zwischen Lastverteilung und Verteilungsziel: Theorie-Konzepte einer allokativ-distributiven Besteuerung

$\$ 2 \mathbf{8}$ Die Systematik der Personalsteuer-Konzepte 
Seite

9. Kapite1:

Die "Possibilitäts"-Konzepte

493

$\$ 29$ Die analytische Bedeutung des "Seligman-Ansatzes" 493

S 30 Die Kritik an der Potentialorientierung

495

10. Kapite1:

Die "Nominalismus"-Konzepte

505

$\$ 31$ Die Konzepte im Uberblick und im Gegensatz zueinander

S 32 Das "Reinvermögenszugangs"- (RVZ-) Konzept bzw. "Schanz-Haig-Simons"- (SHS-) Konzept

S 33 Das "reine Ausgaben"-Konzept von N. Kaldor

$\$ 34$ Die "kombinierten Ausgaben-Vermögens"-Konzepte von Dieter Schneider und Joachim Mitschke

$\$ 35$ Das "kombinierte Einkommens-Ausgaben"-Konzept von W. D. Andrews

$\$ 36$ Konzeptvergleichende Darstellung der allokativdistributiven Problematik / Zusammenfassung des 9. und 10. Kapitels

11. Kapite1=

Die "Utilitarismus"-Konzepte

$\$ \quad 37$ Die allokativ-distributive Grundproblematik der Konzepte

\$ 38 Das "Individualnutzen"-Konzept

$\$ 39$ Das "Wohlfahrts"-( oder "Budget"-)Konzept

$\$ 40$ Das "Sozialnutzen"-Konzept

12. Kapite1:

Die "Distributions"-Konzepte

\$ 41 Gesellschaftspolitische Bedarfsnormen anstelle modelltheoretischer Nutzenfunktionen: Konzeptüberblick 
$\$ 42$ Die Leistungsfähigkeitsbesteuerung als ein distributives "Handlungsrahmen"-Konzept

$\$ 4 \mathbf{3}$ Das "Verteilungs"-Konzept der Besteuerung

\$ 44 zusammenfassung des Dritten Teils 606

$\$ 45$ Ergebnis der Untersuchung

A N $\mathbf{N}$ A $\mathbf{N} \mathbf{G}$

Exkuxs $I=\quad \begin{aligned} & \text { Erläuterung zur Ubersicht 3.2: } \\ & \text { "Arten und Quellen des Zugangs }\end{aligned}$ an ökonomischen Größen" in $\$ 8$

Exkurs II:

Einzeldarstellung zu $\$ 13$ : Das "Verfügungseinkommen im Spektrum der Individualeinkommensbegriffe

ExkuIS III = Einzeldarstellung zu \$ 20: Das Leistungsfähigkeitspostulat und seine personale Bedingung: Leistungsträger "Individuum" / Personalbesteuerung versus Unternehmensbesteuerung 


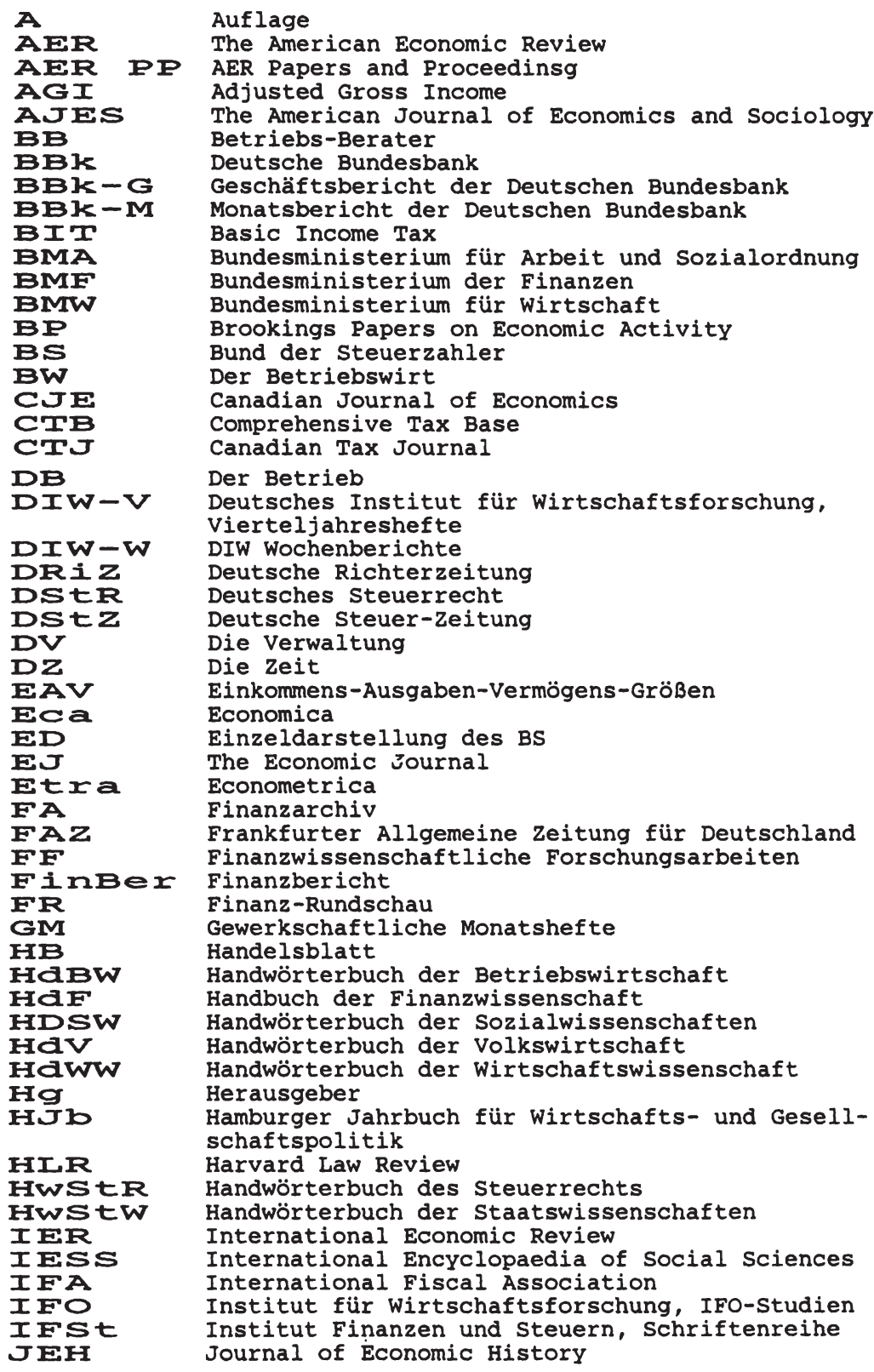




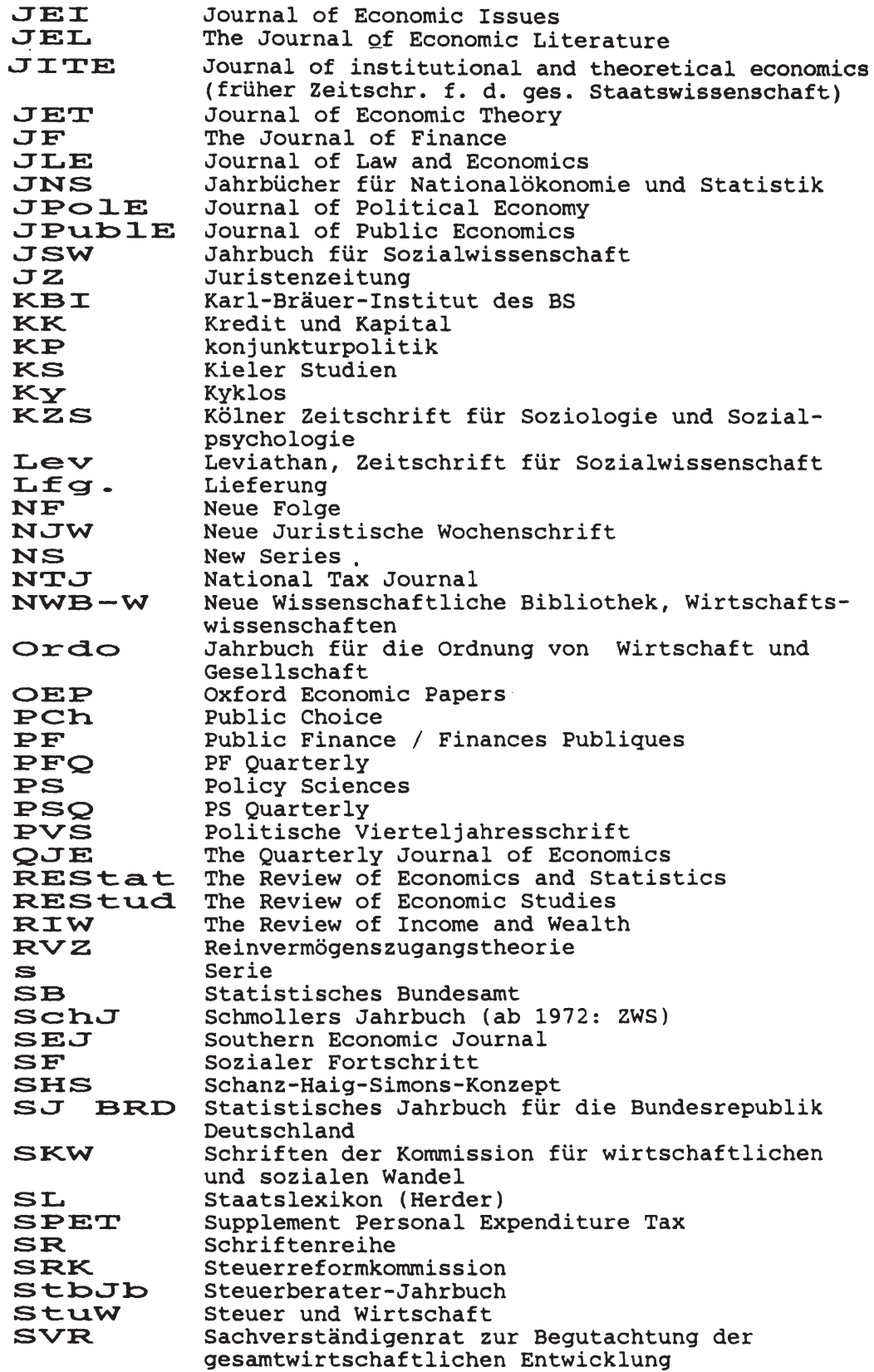




\begin{tabular}{|c|c|}
\hline szVs & $\begin{array}{l}\text { Schweizerische zeitschrift für Volkswirtschaft } \\
\text { und Statistik }\end{array}$ \\
\hline TEK & Transfer-Enquete-Kommission \\
\hline$V S$ & Volkswirtschaftliche schriften \\
\hline WB & $\begin{array}{l}\text { Wissenschaftlicher Beirat } \\
\text { Wirtschaftspolitische chronik, siehe auch ZWP }\end{array}$ \\
\hline WD & Wirtschaftsdienst \\
\hline wav & Wörterbuch der Volkswirtschaft \\
\hline wist & Wirtschaftswissenschaftliches studium \\
\hline wista & Wirtschaft und statistik \\
\hline Wisu & Das Wirtschaftsstudium \\
\hline WSI & $\begin{array}{l}\text { Mitteilungen des Wirtschafts- und Sozialwissen- } \\
\text { schaftlichen Instituts des Deutschen Gewerk- } \\
\text { schaftsbundes }\end{array}$ \\
\hline WuG & Wirtschaft und Gesellschaft \\
\hline$w W$ & Wirtschaftswoche \\
\hline WWA & Weltwirtschaftiches Archiv \\
\hline ZEbE & Zeitschrift für betriebswirtschaftliche Forschung \\
\hline ZEgK & Zeitschrift für das gesamte \\
\hline ZE & Zeitschrift für handelswissenschaftliche Forschung \\
\hline $\mathbf{Z} \pm \mathbf{N}$ & Zeitschrift für Nationalökonomie \\
\hline Zgs & $\begin{array}{l}\text { Zeitschrift für die gesamte staatswissenschaft, } \\
\text { siehe auch JITE }\end{array}$ \\
\hline ZRE & Zeitschrift für Rechtspolitik \\
\hline ZWP & Zeitschrift für Wirtschaft \\
\hline ZWS & Zeitschrift für Wirtschafts- \\
\hline SVS & Schriften des Vereins für So \\
\hline
\end{tabular}

\section{Zitierweise:}

Die Fundstelle ist der Jahreszahl, die auf den Namen des Verfassers folgt, $z u$ entnehmen. In der Zitierung "Jahr/Seite" wurde auf die Nennung "Band" bzw. "Teil" verzichtet. Bei mehreren Veröffentlichungen eines Verfassers oder Herausgebers im selben Jahr wurde dem Erscheinungsjahr ein (oder mehrere) Buchstaben angefügt. In derselben Schreibweise findet sich die Fundstelle auch im Literaturverzeichnis.

Die Beiträge im HdF der 3. Auflage und im HdWW sind mit den Erscheinungsjahren der jeweiligen Lieferungen aufgeführt, sofern sie vor dem Erscheinen des kompletten Bandes in die Untersuchung eingearbeitet wurden (die erste Fassung der vorliegenden Untersuchung wurde Ende 1982 abgeschlossen; danach erfolgte die Einarbeitung neu erschienener Literatur; AbschluB der Arbeiten im Juni 1993). 
Verzeichnis der Ubersichten und schaubilder im Text (kapitelweise numeriert)

3. 1 Analyseschema des Zusammenhangs zwischen Kapital. Ertrag, Einkommen und Vermögen

Seite

3. 2 Arten und Quellen des Zugangs an ökonomischen Größen 60

3. 3 Matrix-Darstellung enger und weiter Einkommensbegriffe

3 - 4 Grundschema der Transferbeziehung

$3 \cdot 5$

Kapital- und Vermögensarten und ihre Funktionen

$6 \cdot 1$

Problemkomplexe aus dem zusammenwirken von steuerlichen Begriffen, Systemen und Postulaten im Vermögensbereich

7. 1 Subtraktive Berechnungskonzepte für das steuerliche Einkommen

7. 2 system einer fortschreitenden Einengung der freien Verfügbarkeit über Einkommen und Vermögen

7 - 3 Nichterfassung wesentlicher zugänge und Bestände an ökonomischen Größen im deutschen Steuerrecht

7 - 4 Idealtypische temporale und personale Korrespondenzbeziehungen in der Transferbesteuerung

7. 5 Argumente für alternative Besteuerungen nach dem Korrespondenzprinzip

7. 6 Transferarten nach ihren Verpflichtungs- und Berechtigungsgrundlagen

7 . 7 Korrespondenzprinzip und Allgemeinheitspostulat in verschiedenen Transferarten

7 - 8 Auswirkungen des Nominalwertprinzips (NWP) bei Geldentwertung auf Bestände, Stromgrößen und Gruppenbeziehungen

8. 1 Einkunftsermittlungsmethoden und steuerliches Einkommen

8. 2 Wertermittlungsmethoden und steuerliches vermögen

10. I Die Realisierungs-Konzepte der LeistungsfähigkeitsBesteuerung

10. 2 Der Objektivierungs- und Personalisierungsbereich im System der Leistungsfähigkeits-Indikatoren und -Gestaltungen in der geltenden Einkommens- und Vermögensbesteuerung

10. 3 Der Objektivierungs - und Personalisierungsbereich in der persönlichen Ausgabensteuer nach der Methode der indirekten Konsumermittlung

10. 4 Schwerpunkte der allokativ-distributiven Problematik in alternativen Besteuerungs-Konzepten

10. 5 Ansatzpunkte allokativer und distributiver Entscheidungen im "kombinierten Einkommens-Ausgaben"-Konzept nach Andrews

10.6 Allokative und distributive Probleme in den Besteuerungs-Konzepten im Uberblick 
A. 1 Bestimmungsschema der Einkommensbegriffe

A. 2 Matrix-Darstellung der Teil- und Gesamtverfügungsgrößen nach Art und Quelle des Zugangs ökonomischer Größen

A. 3 Verfügungseinkommen versus Haushaltsbruttoeinkommen

640

A. 4 Kontinuum der Unternehmensbesteuerungs-Konzepte 
S 1 Problemstellung, Methodik und Abgrenzung

a) Die vorliegende Arbeit wurde geschrieben, weil zum einen das Thema einer Personal- wie auch einer Unternehmensbesteuerung immer aktuell ist, weil zum anderen es äuBerst reizvoll ist, in dieses weite Feld solche Grundzüge des Utberdenkens zu legen, die ordnen und Erkennen zugleich erlauben. Es scheint nämlich nur so, als seien jene Grundzüge in der Literatur mittlerweile längst gelegt.

Es galt, die umfangreiche Literatur zur Personalbesteuerung lückenlos und in einer solchen weise zu systematisieren, daß ihre zuordnung auf die der Steuertheorie und -politik zugrunde liegenden logischen Kategorien, ökonomischen Prinzipen, Zielen und Wirkungen erkennbar wird.

Im zuge der solchermaßen breit angelegten Untersuchung wurde ein Tatbestand offenkundig, der nicht vorherzusehen war: Die Uberlegungen zum Begrifflichen, d.h. zur Fassung der Bemessungsgrundlagen "Einkommen" und "Vermögen", erwiesen sich als so interessant, zahlreich und vielgestaltig, daß die Absicht, auch die Probleme der Freibetrags - und Tarifgestaltung in vergleichbar breiter und analytischer Weise zu bearbeiten, aufgegeben werden mußte. Dieser Verzicht bringt hier aber den Vorteil einer tiefen und in sich geschlossenen Darstellung mit sich, denn es ist zu vermuten, daß eine Theorie der Freibetrags- und Tarifgestalung mit ihrer vorwiegend politischen orientierung andere Bestimmungselemente wird berücksichtigen müssen als die hier vorgelegt Theorie der Einkommens- und Vermögensbegriffe.

Dennoch bleibt der innere Zusammenhang von Besteuerungsgrundlagen einerseits und Freibetrags- wie Tarifgestaltung andererseits unverkennbar, hergestellt nämlich im Postulat der Besteuerung nach der Leistungsfähigkeit. Inwieweit Einkommen und Vermögen die Grundlagen für dieses Postulat sein können, und zwar in wirtschaftstheoretischer wie in steuerlicher Sicht, ist die Darstellungsabsicht der vorliegenden Untersuchung, ist zugleich Ausdruck der Gliederung der Arbeit in den ersten beiden Teilen. Erst der dritte Teil problematisiert das Leistungsfähigkeitspostulat selbst. 
b) Fragt man nach den zielen der Steuerpolitik und nach den Wirkungen auf die ökonomischen Aktivitäten und Anpassungsreaktionen, der Menschen, die man mit den Personalsteuern - und unter diesen insbesondere mit der Einkommensteuer - erreichen kann bzw. verbinden muß, so entdeckt man zwei voneinander analytisch grundsätzlich zu trennende, nämlich die a 1 l $\circ \mathrm{k}$ a $\mathrm{t}$ v e $\mathrm{n}$ und die $d i s t r i b u t i v e n$. Mithin unterscheiden wir zunächst in vereinfachender Formulierung - den allokativen vom distributiven Bereich des Wirtschaftens und der Politik. Allokative und distributive Phänomene sind einerseits miteinander verknüpft und von einander abhängig, stehen andererseits auch im Gegensatz zueinander; im ersteren Fall meinen wir die Interdependenz-Beziehung, im letzteren die "trade-off"-Beziehung. Und beide, die Interdependenz- wie Gegensatzbeziehungen sind sowoh1 ein wirtschaftstheoretisches als auch ein steuerliches Problem. Alle Steuerwissenschaften ${ }^{1)}$ versuchen, diese Probleme bewuBt $z u$ machen.

Untersuchungsgegenstand der vorliegenden Arbeit ist die Bestimmung der Einkommens- und Vermögensbegriffe. Das Problematische der $s$ t e u r 1 i $c h$ e $n$ Begriffe wird dadurch herausgearbeitet, daB sie einerseits den wirtschaftstheoretischen gegenubergestellt werden, um die Abweichungen aufzeigen zu können, daB sie aber andererseits an drei grundlegenen Besteuerungspostulaten geprüft werden, an jenen nämlich, die steuerpolitisch für Einkommen und Vermögen als Richtgrößen wichtig sind. Das im Rhythmus

1) Darunter versteht man die Betriebswirtschaftliche steuerlehre, die Finanzwissenschaft, die steuerrechtswissenschaft und - so besonders G. Rose 1976 - die staats- und Verfassungslehre. Die interdisziplinäre Befruchtung scheint vorerst noch in den Anfängen $z u$ stehen. Erstaunlich ist, daB z.B. in der Betriebswirtschaftlichen steuerlehre und in der Steuerrechtslehre die gegenseitige Abhängigkeit und Ergänzungsnotwendigkeit klar gesehen, daB sie aber in der Finanzwissenschaft kaum so klar formuliert wird; eine Ausnahme macht hier G. Schmölders 1981b, S. $1371 \mathrm{ff}$. Als Indiz mag gelten, daB das Handbuch der Finanzwissenschaft sowohl der 2. als auch:3. Auflage und auch die renommierten Lehrbücher der Finanzwissenschaft das Stichwort "Steuerwissenschaften" nicht enthalten; hingegen ist es in den steuerrechtlichen Lehr- und Handbüchern sehr wohl ausgewiesen, siehe z.B. HwStR 2. Aufl.; Wacker, Steuerlexikon 1975, und K. Tipke 1991. - Siehe schließlich die Reihe "Steuerwissenschaft", hg. von Freericks, Friauf, Kirchhof u. Ruppe, die augenblicklich noch vorwiegend rechtswissenschaftlich besetzt ist. 
der 12 Kapitel stets wiederkehrende Thema ist die Interdependenzbeziehung zwischen Allokation und Distribution im zusammenhang mit den steuerlichen Begriffen Einkommen und Vermögen.

c) Für die Besteuerung wird das Phänomen "Leistung" dann maßgebend, wenn die personale steuerlast nach dem $L$ e $i s t$ u g $s$ f $\mathrm{h} i \mathrm{~g} \mathrm{k}$ e $\mathrm{i} \mathrm{t} \mathrm{p}$ r i n z i p verteilt werden soll (2. Kapitel). Der allokationspolitische Aspekt der Besteuerung nach der Leistungsfähigkeit kommt in der Schonung der Leistungsmotivation und -kraft sowie in der Beachtung der Dauerergiebigkeit der Steuerquelle (Einkommen- und Vermögensteuer) zum Ausdruck; der distributionspolitische Aspekt liegt in der den persönlichen Verhältnissen des Steuerpflichtigen angemessenen Beachtung der steuerentlastenden (Freibeträge) bzw. steuerbelastenden (Tarifprogressivität) Umstände begründet. DaB Steuerpolitik überhaupt auf Allokation und Distribution einwirken kann, liegt in der Funktion der Steuer begründet. Steuerfunktionen sind die der Besteuerung gesellschafts- und wirtschaftspolitisch zugedachten Aufgaben; die Steuer kann solche Aufgaben übernehmen, weil sie - unter rechtlichem Aspekt - elne Zwangsabgabe ohne den Anspruch auf eine spezielle Gegenleistung seitens des Staates ist und weil sie - unter ökonomischen Aspekt - einen Transfer von Werten aus der Verfügungsgewalt der Individuen in die des Kollektivs und damit letztlich eine EinkommenseinbuBe bei den Individuen bewirkt. Diese Einbuße setzt Signale für die allokativen und distributiven Entscheidungen des einzelnen. Aber fast ausnahmslos hat jede steuer innerhalb ihrer wirkungsfunktion einen EinfluB sowohl auf die Allokation als auch auf die Distribution, so daB es "Allokationssteuern" wie auch "Distributionssteuern" in nuce kaum geben kann. ${ }^{2)}$ Das ändert nichts daran, dab es analytisch notwendig ist, den allokativen vom distributiven wirkungsbereich zu trennen.

2) Gleichwohl können Distributionswirkungen in einer einzelnen Steuerart die Allokationswirkungen überwiegen und umgekehrt. Es besteht eine Abhängigkeit zwischen den beiden Steuerfunktionen derart, daB die Betonung der einen Funktion die Steuer um so weniger brauchbar macht für die Sicherung auch ihrer zweiten Funktion. Wird sie z.B. in erster Linie zur Sicherung der Finanzierungsaufgabe herangezogen, engt man damit ihre Verwendbarkeit für wirtschaftspolitische Zwecke ein (Mackscheidt/Steinhausen 1977, S. 125), da sie auf Dauerergiebigkeit angelegt sein müBte und allokative oder distributive Wirkungen unter gleichzeitiger Schonung der Steuerquelle nur bis $z u$ einem bestimmten Grade erzielen kann. 
Ihre distributive bzw. redistributive Funktion, also die Korrektur der marktlichen Verteilung, erfullt die Besteuerung nur insoweit, wie erstens die marktliche (primäre) Verteilung tatsăchlich aus leistungsentsprechender Entlohnung hervorgeht und zweitens die gesellschaftspolitischen Korrekturabsichten für die sekundäre Verteilung - orientiert an den herrschenden Gerechtigkeitsidealen - auch konkretisiert werden können. Entscheidend fur eine solche Beurteilung sind die Einkommens- und Vermoggensbegriffe, genauer: ist das Herausstellen des Gegensatzes zwischen den wirtschaftstheoretischen Begriffen einerseits und den steuerlichen andererseits.

d) Unsere Vorgehensweise beim Erarbeiten der $w$ i $r t$ $s c h$ a $t s t h$ e ore $t i s c h$ e $n$ Begriffe ist sowohl eine logisch-analytische als auch eine literarisch-kritische. Es läßt sich nachweisen, daß literarische Begriffsverwirrungen zwischen Ertrag und Einkommen einerseits wie auch zwischen Kapital und Vermögen andererseits darauf zurückzuführen sind, dab zwar die allokativ-distributive Interdependenz dieser okonomischen GröBen gesehen, nicht aber ihre analytische Trennungsnotwendigkeit erkannt wurde (3. Kapitel). Als die Kriterien der wirtschaftstheoretischen Einkommens- und Vermögensbegriffe stellen sich die "Zugangsregel", die "Verfügbarkeit" und die "Individualentscheidung" heraus. Die Reichweite einer solchen "begrifflichen" Theorie anhand des "Kriterien-Ansatzes" und thr Verhältnis $z u$ weiterreichenden Theorien wird im 4. Kapitel nachgewiesen.

e) Die Vorgehensweise beim Erarbeiten der s t e u e 1 i c h e $\mathrm{n}$ Einkommens - und Vermögensbegriffe ist sowohl eine gesetzes-empirische als auch eine normative. Unter dem ersteren Aspekt werden die steuergesetzlichen Einzelbestimmungen daraufhin untersucht, inwieweit sie mit den für die wirtschaftstheoretische Begriffsbestimmung als konstitutiv erachteten Kriterien vereinbar sind. Unter dem zweiten Aspekt wird vorgetragen, daB die steuerlichen Begriffe zwangsläufig von den wirtschaftstheoretischen in Inhalt u.Umfang abweichen, weil sie $n \circ r m a t i v$ gebildet sind: Die konstitutiven Ausgangspunkte der Begriffsbildung sind die Postulate der Allgemeinheit, der GleichmäBigkeit und der VerhältnismäBlgkeit (= Leistungsfähigkelt) der Besteuerung (6. Kapitel); 
die konstitutive Verwirklichung der Begriffe jedoch wird durch Einschränkungen der Postulate infolge der politischen Eingriffe (7. Kapitel) sowie der VerstöBe gegen sie (8. Kapitel) erreicht. Dabei wird das postulat der A $11 \mathrm{~g}$ e $\mathrm{e} i \mathrm{n} \mathrm{h}$ e $\mathrm{t}$ der Besteuerung als das für die Fassung des steuerlichen Einkommensund Vermögensbegriffs grundlegende angesehen, das notwendigerweise zur Erfüllung des Leistungsfähigkeitspostulats vorausgesetzt werden muB. Es hat, wie das GleichmäBigkeitspostulat, eine der Leistungsfähigkeits-Besteuerung vorgeschaltete, dienende Funktion. Die vollständige Konkretisierung des Leistungsfähigkeitspostulats zeigt sich über die Definition der Einkommensund Vermögensbegriffe hinaus in der Tarifproblematik und in der Frage der Besteuerungseinheiten (Individual-, Ehegatten- oder Haushaltsbesteuerung) .

f) Daß grundsätzlich die Probleme einer Bestimmung der B e m e s $s$ u g s g r u n d $l$ a $\mathrm{g} n$ und der Tarif- und Einheitenbestimmung $z u$ trennen sind, wird mit einer Lehre vom "Drei-Stufensystem" der leistungsfähigkeitsorientierten Besteuerung (5. Kapitel) begründet. Da die Tarif- und Einheiten-Bestimmung als Phänomene der "Personalisierung" bzw. "Individualisierung" aus dem Untersuchungsthema ausgegrenzt wurden, verbleibt als Untersuchungsgegenstand die " $\mathrm{b} j$ e $k t i \mathrm{v} i$ e $\mathrm{r}$ u $\mathrm{g}$ " der Leistungsfähigkeit, die in eine theoretisch gestaltete (6. Kapitel) und eine praktisch gestaltete (7. u. 8. Kapitel) gegliedert wird: Die praktisch gestaltete nimmt die bereits erwähnten Einschränkungen des Allgemeinheitspostulats und die VerstöBe gegen das GleichmäBigkeitspostulat auf. Der groBe Umfang, den die Untersuchung an dieser Stelle annimmt, erklärt sich aus der Notwendigkeit, dle Fülle der Einschränkungstatbestände und VerstöBe zu erfassen und ihnen eine angemessene systematik voranzustellen. Dies gilt insbesondere für das 7. Kapitel. Unter der theoretisch gestalteten Objektivierung wird die grundsätzliche Diskussion um die Indikatoren der Leistungsfähigkeit verarbeitet, um u.a. festzustellen, inwieweit die gesetzes-empirisch ermittelten objektivierungen der Indikatoren bereits eine Einschränkung der Leistungsfähigkeitsindikatoren festschreiben.

g) Weil sich im heute geltenden steversystem der Bundesrepublik Deutschland unterschiedlich motivierte Einschränkungen des Allgemeinheitspostulats und mannigfaltige verstöße gegen das 
GleichmäBigkeltspostulat häufen, hat sich ein steuerpolitisches und steuerbegriffliches spezifikum ergeben, das wir als eine "allokativ-distributive Mischbesteuerung" bezeichnen. Sie kann konstruktionsgemäB die mit ihr anvisierten steuerpolitischen $z$ i e $l$ e nie vollständig erreichen bzw. das eine ziel nur zu Lasten des anderen. Da unter dem Aspekt des Leistungsfähigkeitspostulats (und nur unter diesem!) in den Personalsteuern distributive ziele im Vordergrund stehen, wird im III. Teil geprüft, ob die formulierten Besteuerungskonzepte sämtlich dem distributiven $\mathrm{ziel}$ den gleichen Rang einräumen und inwieweit sie der Darstellung des allokativ-distributiven "trade-off" in der zielverwirklichung Raum geben.

h) Unter dem Zielaspekt ist auf eine Besonderheit einzugehen, die auch für das GleichmäBigkeltspostulat (8. Kapitel) eine Rolle spielt, nämlich auf die $G$ e $r$ e $c h t i g k$ e $i t$. Der Gesamtkomplex der "Gerechtigkeit in der Besteuerung" konnte ihm Rahmen der vorliegenden Untersuchung nur stellenweise intensiver bearbeitet werden. Soweit das GleichmäBigkeitspostulat unter die das steuerliche Einkommen und Vermögen konstituierenden Normen gerechnet wurde, ist es im wesentlichen als "Gleichbehandlung" und in Ubereinstimmung mit weiten Bereichen der Lehre als "horizontale" Gerechtigkeit aufgefaBt worden. Die vertikale Gerechtigkeit soll sich nach dieser Anschauung in einem gesellschaftlichen ProzeB finden lassen, im Verlaufe dessen man gesellschaftliche Konventionen über bestimmte Verteilungsziele und BelastungsmaBe vereinbart. Demnach wird das Leistungsfähigkeitspostulat erst in der politischen Entscheidung über BelastungsmaBe (Freibetrăge und Tarifprogressivität als PersonalisierungsmaBnahmen der Besteuerung) vollends konkret. Somit wurde das GleichmäBigkeitspostulat als ein die Objektivierungsversuche der Leistungsfähigkeits-Ind1katoren "begleitendes" Postulat aufgefaBt: Wie das Allgemeinheitspostulat ist es als eine Voraussetzung und Bedingung für das Leistungsfähigkeitspostulat verstanden worden. Diese Sichtweise des Problems ist auch für den III. Teil beibehalten worden: Als ziel der steuerpolitik wird nicht etwa angesehen, in einer Gesellschaft Gerechtigkeit herzustellen, sondern bei der Verwirklichung allokativer und distributiver Ziele die Einhaltung der Gerechtigkeitsbedingung zu gewährleisten. 
i) Das Spektrum der distributiven $B$ e $s$ e u e r u n g s k o n $z$ e $p t e$ beginnt bei jenen der Sollbesteuerung, die hier als "Possibilitäts"-Konzepte, als Besteuerung einer evtl. nur möglichen Leistungsfähigkeit, präsentiert werden und in denen demnach die allokationspolitisch motivierte Besteuerung dominiert (9. Kapitel). Demgegenüber basieren die "Realisierungs"-Konzepte auf den tatsächlich vorhandenen Leistungsfähigkeitsindikatoren; diese Konzepte werden einerseits nominalistisch, andererseits utilitaristisch begründet. Unter den "nominalistischen" (10. Kapitel) finden sich neben den Einkommen- und Vermögensteuer-Konzepten auch sämtliche Ausgabensteuer-Konzepte. Bei ihnen, die in den persönlichen Ausgaben den Leistungsfähigkeitsindikator sehen, stehen im allgemeinen wegen der steuerbefreiungen des sparens allokationspolitische Besteuerungsmotive stärker im Vordergrund als bei den Einkommensteuer-Konzepten. Die "utilitaristischen" Realisierungs -Konzepte, obwohl sie ein überwiegend distributiv verstandenes Besteuerungsinteresse vorweisen, greifen gleichwohl in der Bemessung ihrer Steueropfer im Kriterium des "Nutzens" $\mathrm{zu}$ einem AllokationsmaB par excellence. Dieser Widerspruch und die grundsätzlichen Realisierungsmöglichkeiten solcher Besteuerungskonzepte werden im 11. Kapitel diskutiert. So sind schlieblich die "Distributions"-Konzepte noch am striktesten mit dem Verteilungsziel verknüpft. Im 12. Kapitel wird dargestellt, wie sich die einzelnen Konzepte vom traditionellen Leistungsfähigkeitsprinzip lösen, wie sie das Verteilungsziel direkter in das Besteuerungskonzept aufnehmen und wie sie aber dazu letztlich bestimmter gesellschaftspolitischer Bedarfsnormen bedürfen. Das Problem der Bedarfsnormenfindung wird aber lediglich im Ansatz erwähnt, da seine konkrete Formulierung nur im zusammenhang mit "Personalisierungsmaßnahmen" möglich ist; die wurden aber hier ausgegrenzt. Verständlicherweise läuft ein solchermaßen strikt auf das Verteilungsziel ausgerichtetes Besteuerungskonzept Gefahr, allokativen Absichten und wirkungen nicht mehr den entsprechenden Raum zu gewähren und sie allenfalls noch als "allokative Nebeneffekte" der distributiven Absichten und wirkungen wahrzunehmen. Demgegenüber gehört es zum Anspruch insbesondere des "Verteilungs"-Konzepts, sämtliche redistributiven Aspekte aus einer finalisierten und integrierten Sozialpolitik zu berücksichtigen; jedoch auch hier gehören die konkreten Maßnahmen dieser "integrierten verteilungspolitik" nicht mehr in den hier gezogenen Darstellungsrahmen. 
j) Die allokativ-distributive Zielproblematik in den Personalsteuern ist durch eine $A s y \mathrm{~m}$ e $t r i$ e eigener Art gekennzeichnet, die sich aus dem steuerlichen Instrument ergibt. Verfolgt man das allokationspolitische Ziel, das Verhalten der Partner und Wettbewerber auf Märkten $\mathrm{zu}$ beeinflussen - und zwar durch Steuern ganz allgemein -, so kann das zunächst durch eine grundlegende Korrektur der Knappheitsrelationen bzw. der Umwelts1tuation geschehen, ferner durch Herstellung oder Aufrechterhaltung eines funktionierenden Wettbewerbs und schlieblich durch steuerliche Veränderung von Angebot und Nachfrage auf Gutterund Faktormärkten. Der Marktteilnehmer hat alle Möglichkeiten der Anpassungen an die neuen steuerlichen Bedingungen, sei es, durch Steuerausweichung dem Steuerzugriff $z u$ entgehen, sei es, durch steuerüberwälzung die zahllast von sich abzuwälzen. Vermeidet er durch steuerausweichung eine Gewinnschmälerung, wird uno actu das allokationspolitische $\mathrm{Ziel}$ erreicht. In jedem Falle aber ist die zielerreichung von der freiwilligen Anpassung abhängig. Ganz anders, wenn distributive ziele angestrebt werden. Hierfür kommen von vorn herein die Personalsteuern in Betracht, denen man weniger leicht ausweichen kann, die sich weniger leicht überwälzen lassen und deren Zielerreichungs-"Qualität" darin liegt, daB der Einkommensentzug auf keinerlei freiwillige loder erzwungene) "Mitwirkung" des Steuerpflichtigen angewiesen ist. Wo die Allokationspolitik qua Steuer nur einen Rahmen zieht, kann die Distributionspolitik qua steuer direkt zugreifen und Belastungspositionen verteilen.

Schon damit ist das Dilemma einer "zielvermischten" Einkommensteuer angedeutet, wie sie gegenwärtig in der Bundesrepublik erhoben wird: Sie enthält sowohl allokationspolitisch motivierte "Anpassungsaufforderungen" (in Form von einkunftsartbezogenen Freibeträgen und Vergünstigungen unterschiedlichster Art) als auch distributionspolitisch motivierte steuerentlastungen (Existenzminimum und persönliche Freibeträge) wie auch -belastungen (Progressionstarif). Wer die Vorteile der allokationspolitischen Vergünstigungen wahrnimmt, entgeht zugleich der distributionspolitisch motivierten Progressivităt. Andererseits ist die Erbschaftsteuer - in enger Verbindung mit dem Verteilungsiel und der persönlichen Leistungsfähigkeit begründet - auch auf das Allokationsziel ausgerichtet, denn gerade für das Funktionieren 
der Marktwirtschaftsordnung gilt die Gleichheit der Startchancen, die durch eine fuhlbare Erbschaftsteuer ja hergestellt werden soll (F. Neumark 1970, S. 22), als unerläBlich.

Es liegt demnach nicht im Leistungsfähigkeitsprinzip, sondern im Instrumentellen der Personalsteuern begründet, daB die hier vorgelegte Untersuchung auf die distributiven Besteuerungs-Konzepte zuläuft und die allokativen ziele und wirkungen als - allerdings beachtenswerte und keineswegs minderrangige - Probleme behandelt, die die distributiven ziele begleiten und oftmals beeinträchtigen.

k) Wenn der III. Teil unter den allokativ-distributiven zielaspekt gestellt wird, muB nun begründet werden, warum das $s t a-$ b i 1 is $i$ e r u g s z 1 e 1 aus der Untersuchung ausgeschlossen wird. Der wichtigste Grund liegt in dem bereits erwähnten allokativ-distributiven "trade off" des "efficiency versus equity" als der grundlegenden wirtschafts- und gesellschaftspolitischen Problematik.

Aber das Phänomen "Stabilisierung" ist nicht völlig aus dem allokativ-distributiven zielproblem verbannt, es wird hier nur als eigenständiges steuerpolitisches 2 iel nicht herausgestellt. Die Verknüpfung der Stabilisierung mit Allokation und Distribution läBt sich aus den Darlegungen von J. Werner (1971), Mackscheidt/ Steinhausen (1978, doch schon in der 1. Aufl. 1973), G. Blümle (1975) und H. Glersch (1977) wie folgt ablesen: Als das Allokationsziel par excellence darf das Produktionsziel angesehen werden. Solange die Produktionskapazitäten nicht voll ausgenutzt sind, stellen Maßnahmen zur Erreichung der Vollbeschäftigung gleichzeitig solche im Dienste der Produktionsausweitung dar (J. Werner S. 370), wenngleich dem Wachstumsziel durchaus elne eigenständige Aufgabe zukommt (J. Werner S. 371). Vollbeschaftigung und wirtschaftswachstum sind Aspekte des Produktionsziels (J. Werner S. 369). Uberdies ist Konjunkturpolitik immer zugleich Allokationspolitik, da jeder Konjunkturverlauf branchenstrukturelle Unterschiede aufweist (G. Fels 1978). Mackscheidt/Steinhausen (1978, s. 11) formulieren die These, "daB ein stabiler Verlauf fur elne wachsende wirtschaft und damit fur eine produktion und Vertellung der Guter in Berilcksichtigung des obonomischen Prinzips 
eine notwendige Voraussetzung ist. .... Wenn diese These belegt werden kann, ist die Ausgliederung des Stabilitätsziels als Gut sui generis aus dem Katalog aller sonstigen Allokations- und Verteilungsziele gerechtfertigt" (ähnlich auch Mackscheidt/Steinhausen 1973, S. 18). Bei Instabilität im Wirtschaftsablauf geraten die Allokations- und Verteilungsziele ständig in Gefahr, verfehlt $\mathrm{zu}$ werden.

Auch die Geldwertstabilität kann nach J. Werner (S. 373) nicht als ziel um seiner selbst willen verstanden werden, wenngleich ihre elgenständige Nennung legitim bleibe (S. 374); die Geldwertstabilität "stellt vielmehr ein Vorziel vor allem im Blick auf die produktionspolitische zielsetzung dar (S. 373).3) Eine mangelnde zielerreichung in der Geldwertstabilität ändert daneben aber auch die Einkommensverteilung in regressiver Weise (G. Blümle s. 9), und dies hat wiederum - als Ergebnis der allokativ-distributiven Interdependenz - eine "Verzerrung in der Allokation der Produktionskräfte" (H. Giersch S. 195) zur Folge. So lassen sich im Grunde genommen nur zwei zielkomplexe für das wirtschaftspolitische Handeln feststellen, das Produktionsziel und das Verteilungsziel (J. Werner S. 378). Insoweit hoffen wir, mit dem den Untersuchungsgegenstand ständig begleitenden Thema der allokativ-distributiven Interdependenz und des Gegensatzes "Allokation versus Distribution" die Problematik formuliert zu haben, die die Theorie der Personalsteuern bis in die steuerpolitischen Konzeptionen hinein kennzeichnet.

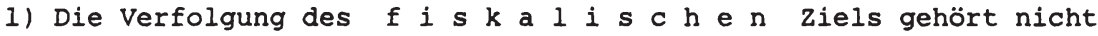
$\mathrm{zu}$ unsrem Untersuchungsgegenstand. Soweit diese Arbeit zu dem Ergebnis kommt, daß künftig breiter gefaßte Einkommens- und vermögensbegriffe die steuerliche Bemessungsgrundlage erweitern, kann das unter dem Aspekt der Aufkommensneutralität beurteilt werden. So ist also keineswegs zwingend zu folgern, die Verbreiterung der Bemessungsgrundlage würde eine Belastungsverschiebung von den indirekten $z u$ den direkten Steuern bedeuten. Denn in jedem Falle lie-

3) J. Werner 1971 , S. 374: "Angesichts einer oft zu isolierten Interpretation des $\mathrm{ziels}$ der Geldwertstabilität bleibt jedoch die grundsätzliche Feststellung bestehen, daB dieses Vorziel letztlich nur instrumentellen Charakter im Blick auf dahinter liegende Ziele hat." - Vgl. auch $\mathrm{H}$. Ohm 1972, S. 65 ff. mit seiner Differenzierung der Zielarten in Fundamentalziele und Vorziele (bzw. Zwischenziele) mit Instrumentalcharakter. 
Ben sich ja die Steuersätze der Personalsteuern senken, um eine Aufkommensneutralität zu erreichen.

m) Die breite Darlegung der Personalsteuerproblematik sollte nicht zu dem Fehlschlub verleiten, sie seien die gewichtigsten des steuersystems oder sollten es werden. Rückwirkungen von Problemen der Personalsteuern auf das $s t e u$ e $r$ y $s$ e $m$ sind also nicht Gegenstand der vorliegenden Untersuchung. Gleichwohl ist unbestritten, daß eine breitere Bemessungsgrundlage die Verfolgung des fiskalischen ziels erleichtert.

Auch wenn die Untersuchung $z u$ dem Ergebnis kommt, daß die logische und steuersystematische Trennung in eine Haushaltsbesteuerung (=Personalbesteuerung) einerseits und eine Unternehmensbesteuerung andererseits eine aus allokationspolitischen Gründen begrüBenswerte Schonung in der Unternehmensbesteuerung begünstigt, ist daraus nicht zu folgern, es sei der aus Gründen der Aufkommensneutralität erforderliche Belastungausgleich zwingend bei den Personalsteuern zu suchen. Der Ausgleich kann statt dessen ebenso gut ganz oder teilweise bei den indirekten Steuern gesucht werden, wodurch sich der positive Allokationseffekt ergibt, die Leistungsmotivation $\mathrm{zu}$ schonen. Wegen der hier erforderlichen eng begrenzten Thematik sind demnach steuersystematische Betrachtungen nur dort angestellt worden, wo sie den Zusammenhang unter den Personalsteuerarten betreffen.

Diese Beschränkung im Problemansatz ist um so eher gerechtfertigt, als vorliegend in erster Linie die Einkommens- und Vermögens$B$ e $g r i f f$ e untersucht werden. Wir sind uns dessen bewubt, daB in den Gesamtrahmen der "Theorie der Personalsteuern" neben solchen begrifflichen Fragen auch Probleme der Tarifgestaltung und der Bestimmung der Besteuerungseinheiten (Individuen bzw. Haushalte oder Ehepaare) gehören. Diese aber müssen einer gesonderten Untersuchung vorbehalten bleiben. Desgleichen sind die vorgenannten theoretischen Untersuchungen, die mit dem Leistungsfähigkeitspostulat verknüpft sind, aus steuersystematischen Gründen um eine Darstellung der Unternehmensbesteuerung zu ergänzen, die ja keineswegs demselben Steuerpostulat der Leistungsfähigkeit unterworden ist, sondern allenfalls einem solchen der "Ertragsfähigkeit". Auch dieser Problemkomplex bedarf einer gesonderten Behandlung. 
E $R \quad S \quad I \quad E$ R $T$ E I I

Die okonomischen Merkmale subjektiver steuexlicher leistungsfähigkeit in wirtschattstheoretischer sicht :

Grundiagen und Elemente einer normativen rheorie der personalsteuern

1. KAPITEI :

Die allokativ-distributiven Interdependenzen in der Besteuerung

s 2 Das steuerpolitische Grundproblem = Allokation versus Distribution

I. Die Begriffe Allokation und Distribution

1. "Produktions-Konsum-orientierte" und "dynamische" Allokation

2. Distribution und Redistribution

II. Der allokativ-distributive "trade-off"

1. Allokation und Distribution als die Grundprobleme des Wirtschaftens

2. Der Konflikt zwischen Allokation und Distribution

3. Die Asymmetrie in der allokativen und distributiven Steuerpolitik 
I. Die Klärung der Allokations- und Distributionsbegriffe ist die Voraussetzung zur Darstellung des gesellschaftspolitischen "trade-off" von "efficiency versus equity" in der Besteuerung.

1. Ein breit gefaßter und "dynamischer" Begriff der A 110 $k$ a $t i \circ n$ läßt sich aus dem Blickwinkel der Rationalität herleiten.

a) Allokation hat zwei Facetten: Zunächst ist die Ressourceneinsatz-optimierung auf die $P$ r $\circ d u k t i \circ n$ ausgerichtet und gehorcht einer "inneren Rationalität"1). Ihr Ziel ist die Erstellung eines größtmöglichen Gesamtprodukts, was bedingt, die Minimalkostenkombination $\mathrm{zu}$ verwirklichen, ein optimales Standortgefüge zu organisieren und die optimale Betriebsgröße zu finden. Daraus folgt, daß sowohl die staatliche allgemeine strukturpolitik als auch speziell die regionale und sektorale strukturpolitik allokationspolitischer Art sind. 2)

b) Zugleich unterliegt Aliokation auch der "äuBeren Rationalität", nämlich der Abstimmung auf die Bedürfnisstruktur der Menschen. Eine dergestalt vorgenommene Ausrichtung des Allokationsbegriffes auf den privaten $\mathrm{K} \circ \mathrm{n} \mathbf{s} \mathrm{m}$ nennen Musgrave-Musgrave-Kullmer (1984, S. 77) die effiziente Ressourcenverwendung bei bestmöglicher Befriedigung der Konsumentenbedürfnisse . Das Konsuminteresse kann als volkswirtschaftliches Allokationskriterium angesehen werden, da die "Lenkungsfunktion der Konsumentensouveränität ... eine der Prämissen des Pareto-Optimums dar(stellt)" (H. Minte 1978). Noch stärker betont E. Kantzenbach (1967, S. $15 \mathrm{ff.l}$ die Verbindung zwischen Konsum und Allokation, wenn er feststellt, daB das Prinzip der Konsumentensouveränität, als Steuerung der "Zusammensetzung des laufenden Angebots an Waren

1) H. Haller 1981, S. 221f.; unübersehbar gibt der Terminus "Innere" die Blickrichtung an, aus der das Problem gesehen wird, nämlich aus der Sicht des Betriebes als dem ort der Faktorkombination und der Leistungserstellung.

2) Für H. Giersch $(1960$, S. 160), der eine Differenzierung des Allokationsbegriffs nicht vornimmt und die Grundorganisation der Volkswirtschaft in den Allokationsbegriff einschlieBt, besteht ganz allgemein das Allokationsproblem darin, "den Prinzipien der optimalen Arbeitsteilung, der bestmöglichen Verteilung der Produktivkräte auf ihre alternativen Verwendungszwecke und der Optimalkombination der Faktoren Geltung $z u$ verschaffen". 
und Dienstleistungen nach den Käuferpräferenzen", als eine der Funktionen des Wettbewerbs in die moderne Wettbewerbstheorie integriert ist, denn "die Prämissen der Konsumentensouveränität sind zugleich die Prämissen der vollständigen Konkurrenz" (jedenfalls nach ihrem Idealverständnis im statischen, gleichgewichtsbezogenen Modell).

c) Diese begrifflichen Uberlegungen, die das Allokationsproblem als gleichermnaben effizienz- und marktorientiert beschreiben, erfassen das Produktionsziel aber nur "statisch", nämlich als ein Streben nach höchstem Produktionsergebnis bei einmal festgelegter Effizienzalternative mit der vorhandenen, voll ausgelasteten Faktorausstattung sowie bei einmal bekannten und unveränderten Konsumentenpräferenzen. Jedoch gehört zum Allokationsproblem auch die "d y n a m i s c h e" Sicht (J. Werner 1971, S. 369) einer Ausweitung des Bestandes an produktiven Ressourcen wie eine durch solches Wachstum bedingte Änderung in der Wirtschaftsstruktur und in der Umweltnutzung.

Allein G. Bombachs (1965, S. 766) Definition der Wachstumstheorie als "Theorie zweier Produktionsfaktoren" belegt die Zuordnung des $\mathrm{W}$ a $c h \mathbf{s}$ u $\mathrm{m} \mathbf{s}$ zum Allokationsproblem. Sofern Wachstum in der Zunahme des Bruttosozialprodukts gemessen (A. Stobbe 1975, S.369) und - auf den Kopf der Bevölkerung gerechnet - als Mehrung des Wohlstandes angesehen wird, präsentiert sich das Allokationsziel zugleich als Wachstumsziel (so J. Werner 1971, S. 370; vgl. auch G. Krause-Junk 1974 b, S. 35, der auf die instrumentelle Funktion der Allokation für die Wachstumszielsetzung eigens hinweist).

Insbesondere mit dem Wachstums- und Entwicklungsphänomen sind aber auch die dynamischen Ausprägungen des Strukturbegriffs verbunden, nämlich die wachstumsbedingten $s t r u k t u r a ̈ n d e-$ $\mathrm{r}$ u n g e $\mathrm{n}$, wie sie von H. Timm (1980, S. 159 ff.) verstanden werden. Ebenso sieht E. Sohmen (1976, S. 168 ff.) die "intertemporalen Effizienzbedingungen" als ein dynamisches Allokationsproblem, und zwar insbesondere die optimale Rate der Kapitalakku- 
mulation wie auch die optimale Art der Strukturänderung des vorhandenen Kapitalstocks. ${ }^{31}$

Eine weitere "dynamische" Dimension des Allokationsbegriffs, die zudem in engem Zusammenhang mit Wirtschaftswachstum und -entwicklung steht, drückt sich im EinfluB von ökonomischen $U \mathrm{~m}$ w e $1 \mathrm{t}$ $\mathrm{p} r \circ \mathrm{b} l \mathrm{e} \mathrm{m}$ e $\mathrm{n}$ auf die Allokation von Faktoren aus. Sowelt Wachstum und Wohlstandszunahme zusammengehen mit rasch zunehmendem technischem Fortschritt vermittels umweltbelastender Technologien, mit vermehrter und der ökologischen sowie ökonomischen zusammenhänge nicht achtender Ressourcenverwendung samt Rohstoffabbau sowie mit der wiederherstellung der durch produktion und Konsumtion geschädigten Umwelt, erfahrt die Faktorallokation eine Effizienzeinschränkung. ${ }^{4}$ )

d) Soweit in dieser Arbeit auf den Gegensatz zwischen allokativen und distributiven problemen abgestellt wird, ist stets dieser weite und dynamische Allokationsbegriff unterstellt. Wenn auf Details nicht eigens eingegangen wird, sollen auch die steuerlichen Allokationswirkungen bzw. die Distributionswirkungen "mit allokativen Effekten" in dieser Weise verstanden werden.

3) Die von Sohmen herausgestellten Kapitalprobleme sind die Konsequenz einer Beschränkung seiner Analyse auf Phänomene der intertemporalen Effizienz, die mit weniger Unsicherheit zu bestimmen sind als weitere Aspekte, die ebenfalls den dynamischen Aspekt der Allokation ausmachen, jedoch mit gröBerer Unsicherheit belastet sind: a) die Anderung der Konsumpräferenzen, b) der technische Fortschritt, c) die Entscheidungen der heute lebenden Generation, die zugleich die Lebensbedingungen fur die morgen lebende Generation festlegen, ohne deren Präferenzen zu kennen; ebenda, S. 168.

4) Im einzelnen hierzu: WB BMW 1979, S. 38 f., Ziff. 91; H. Giersch 1977, S. 343; Musgrave/Musgrave/Kullmer 1987. S. 276 f. - Ferner: K. - H. Hansmeyer, Produktion und Úmweltschutz, Stuttgart 1979; K. Zimmermann, Umweltpolitik und Verteilung, Kölner Habilitationsschrift, Typoskript 1982. 
2. Für die steuerliche Lastverteilung nach dem Leistungsfähigkeitspostulat (siehe SS $15 \mathrm{u} .18$ ) ist die Klärung der Begriffe Distribution und Redistribution, wie sie hier verwendet werden sollen, erforderlich.

a) Die Einkommens- und Vermoggensverteilung (D $i$ s $t$ i b u $t i \circ n$ ) wird nux personal gesehen; auch nach der Lehre von der funktionellen verteilung, deren Begriff der Produktionstheorie entstammt, fließen nämlich die Erträge letztlich den Besitzern dieser Faktoren als Einkommen zu.5) Gleichermaßen stellt die vermögensverteilung auf die personale verteilung ab (c. Folkers 1979, S. 272). Das geht schon allein aus den drei grundsätzlichen wegen hervor, auf denen Vermögen überhaupt gebildet werden kann: Sparen aus dem Nettoeinkommen, Erbschaft (Vermächtnis, Schenkung) ${ }^{6)}$ und Ubertragung seitens der offentlichen Hand sind personal gestaltet und nur personal denkbar. 7)

Beide Fragestellungen, nämlich die nach der Quelle der Einkommen (die funktionelle Verteilung) und die nach der Höhe und der Streuung der Einkommen und Vermögen (die personelle Verteilung), sind die notwendig zusammengehörenden Seiten eines Gesamtproblems, da sie im letzteren Fall die eigentlich distributive Seite der Verteilungsfrage, im ersteren aber ihre allokative seite ausdrücken: Die "funktionale Vertellung im engeren Sinne" zielt

5) "Insofern aber ist die Einkommensverteilung immer 'personell'. Die terminologische Unterscheidung von funktioneller und personeller Einkommensverteilung erweist sich daher als höchst unglücklich" (E. Preiser 1959, S. 622). G. Blilmle (1975, S. 11) weist darauf hin, daB die Trennung durch eine apologetische Komponente der Grenzproduktivitätstheorie bedingt zu sein scheint.

6) B. Molitor 1979, S. 286; siehe auch C. Folkers 1979, S. 27

7) Selbst das Vermögen der gesellschaftsrechtlichen Korporationen, wie etwa der juristischen Personen, gehört in letzter Konsequenz den natürlichen Personen (was auch für solche Korporationen gilt, die im Besitz der öffentlichen Hand, der Allgemeinheit also, stehen. In ökonomischer sicht leisten z.B. die juristischen Personen inre produktiven Dienste in Form von Vermögensnutzungen im Umfang der nicht verteilten Gewinne; siehe Haller, H., 1972, S. 12. 
im Rahmen der Preistheorie auf eine Erklärung der Faktorpreise ab (G. Blümle 1975, S. 10), wie das für die Güterpreise ganz analog im marktlichen ProzeB geschieht (siehe die allokativdistributive Interdependenz, $\S 3$ unten). Die exakte wirtschaftstheoretische Terminologie, die der Einsicht folgt, daB die funktionelle Verteilung ein Allokationsproblem ist, bezeichnet die Allokationsergebnisse auch nicht als Einkommen, sondern als Erträge der Faktoren. Die finanzwissenschaftliche und wohl auch die steuerrechtliche Terminologie haben sich teilweise dieser eindeutigen Festlegung angeschlossen: Einkommen können nur Personen (bzw. Personengruppen, wie Haushalte) empfangen.

Auf diese personale Seite des distributiven Bereichs der Wirtschaft sind die steuerwissenschaftlichen Betrachtungen abzustellen, wenn es darum geht, das Phänomen der Steuerlastverteilung auf die Personen am Einkommen und Vermögen festzumachen, wenn es darum geht, die Wirkungen der steuerpolitischen MaBnahmen auf das Einkommen und Vermögen festzustellen und wenn es schlieblich darum geht, die Umverteilungswirkungen durch Steuern und Transfers $z u$ ermitteln. Notwendigerweise kann der distributive Bereich nicht die offentlichen Güter enthalten, so sehr sie auch Verteilungswirkungen aufweisen mögen; erstens sind sie nur in Ausnahmefallen direkt personal zurechenbar und zweitens stehen sie weder mit der Personalsteuer noch mit den Personaltransfers in einem direkten zusammenhang.

b) Die Dominanz der personalen vor der funktionalen Verteilung kommt auch im Begriff der $R$ e $d i s t r i$ b $t i \circ n$ um Ausdruck, versteht man doch darunter die "Korrektur" 9) der markt-

8) Die funktionale Verteilung als "Theorie der Faktoranteile" ist hauptsächlich eine Theorie der effizienten Allokation, keine Theorie der distributiven Gerechtigkeit, denn "die Feststellung, die Faktorallokation solle auf einer effizienten Faktorpreisbildung beruhen", erfordert nicht, "daB die endgultige Einkommensverteilung der Individuen gleich den Ergebnissen der Verkäufe ihrer Faktorleistungen am Markt sein sollten"; Musgrave-Musgrave-Kullmer 1984, S. 105

9) G. Schmollders 1970 , S. 248; G. Krause-Junk 1981, S. 258: staat als "sozialer Korrektor". 
lichen (d.h. primären personalen) Einkommensverteilung in solcher Weise, daB nach bestimmten korrigierenden MaBnahmen sich als Ergebnis die Sekundärverteilung ${ }^{10)}$ im verfügbaren persönlichen Einkommen (= "Finaleinkommen") 11) zeigt. Notwendiges begriffliches Merkmal der staatlichen Redistribution ist, daB sie nur mithilfe der "Kombination"12) von Steuern u $\mathrm{n}$ d Transfers, genauer: von Personal-Steuern und Einkommenstransfers denkbar ist. Die Erhebung von Steuern auf das Einkommen allein nach einem progressiven Tarif ist noch keine Redistribution. Die Koppelung von budgetären Einnahme- und Ausgabepositionen, 13) der "Steuer-Transfer-Mechanismus (G. Krause-Junk 1977, S. 351), zielt auf eine Verfügbarkeitsgröße (siehe $\S \S 12$ u. 22) ab, die sich erst nach Kürzung um die persönlichen Steuern und nach Mehrung um die Personaltransfers

10) Sofern solche Sekundärverteilung durch staatliche MaBnahmen herbeigeführt wird, gehen sie zurück auf (1) Vorschriften für den privaten Einkommenstransfer, (2) staatlichen Einkommenstransfer selbst und (3) Eingriffe in den MarktprozeB, die bestimmte Anbieter oder Nachfrager begünstigen oder andere belasten; G. Schmitt-Rink 1978, S. 108.

11) Der Ausdruck "Finaleinkommen" findet sich bei K.-D. Grüske 1978, das definiert ist als die Differenz zwischen dem Primäreinkommen einerseits und dem Saldo zwischen staatlich in1tiierten Einkommensentzügen und Leistungen andererseits, s. 26 und $176 \mathrm{ff}$. Das Konzept läßt sich hier verwenden, auch wenn Grïske zur umverteilung die Realtransfers zählt, was wir nur für die direkt zurechenbaren zulassen. Andererseits verwendet ex Finaleinkommen und Sekundäreinkommen synonym, wohingegen andere Autoren zum Finaleinkommen erst nach allen sich an die UmverteilungsmaBnahmen anschlieBenden Anpassungsund Rückwirkungsprozessen gelangen.

12) So übereinstimmend und stellvertretend für viele: E. Liefmann-Keil 1961, S. 119; F. Neumark 1970, S. 218; B. Külp 1971 , S. 145 u. 163; H. Haller 1972, S. 226; Musgrave-Musgrave-Kullmer 1975a, S. 117; W. Albers 1978, S. 599; K. Schmidt 1978, S. 162; G.W. Brück 1981, S. 41 ff.; H. Bartmann 1981, S. 316; G. Krause-Junk 1981, S. 269 ("Umverte1lungskomponenten": Steuern und Sozialversicherungsbeiträge sind staatlich zugemessene Pflichten zur Leistungsabgabe, Transfers und Renten sind staatich zugemessene Rechte auf Leistungsempfang). - Wenn andererseits der SVR (Gutachten 1972/73, TZ 442)

feststellt, der staat sorge (1) durch die Progression für eine Umverteilung zwischen den hohen und niedrigen Einkommen, (2) durch das System der Sozialversicherung für eine Umverteilung zwischen Erwerbstätigen und den nicht mehr Erwerbstätigen und (3) durch bestimmte Transferzahlungen für einen Ausgleich der sozialen Härten, so geht der begriffsbestimmende Zusammenhang von Steuer + Transfers für die Umverteilung verloren.

13) Vgl. H.C. Recktenwald (1981, S. 406), der die "Umverteilung der Markteinkommen" als das Problem der "personalen Budgetinzidenz" interpretiert. 
ergibt. Diese Verfügungsgröße soll die steuerliche Leistungsfähigkeit repräsentieren. In dieser Untersuchung stellen wir daher auf einen Einkommensbegriff $a b$, der als ein Totaleinkommen und als "comprehensive tax base" sämtliche zugangselemente aus Einkünften aller Art, Quelle und Form, so auch aus persönlichen Transfers, einschließt und solchermaßen das Redistributionsproblem in seiner begriffsbildenden Eigenschaft (Steuer + Transfer) in sich aufnimmt.

II. Das Steuersystem - auch ein Teilsystem wie das der Personalsteuern - und die Wirtschaftsordnung eines Landes sind miteinander eng und wechselseitig verbunden. Wenn die Besteuerung bestimmte Wirkungen auf Faktorallokation, -kombination und -substitution, auf Gewinnhöhe, Einkommensentstehung, -verteilung und -verwendung ausubt und u.U. so weitgehend beeinfluBt, daB Konsum-, Spar- und Investitionsentscheidungen, Faktormobilität und Leistungsanreiz der Individuen gestört werden, so sind die grundlegenden Produktions - und Verteilungsprobleme einer Wirtschaftsgesellschaft berührt, sind Rückwirkungen auf die Wirtschaftsordnung nicht auszuschlieben.

1. Der Knappheit von Ressourcen ist zu danken, daB Steuerquellen nicht unerschöpflich flieBen, da die steuer einen Ressourcentransfer von der privaten Sphäre des Wirtschaftens in die öffentliche oder kollektive bewirkt. Vor diesem Hintergrund treten aus der Vielzahl ökonomischer Probleme zwei hervor, die schlechthin den Inhalt wirtschaftichen Handelns ausmachen und seine ziele bestimmen: Allokation und Distribution. Sie sind bereits von den Klassikern der ökonomischen Lehre als die Grundfragen ihrer "Political Economy" erkannt worden. So sah Adam Smith (1776, hier 1978) die Produktion und die Produktivität der Faktoren als die zentrale Problemstellung an. In Ergänzung dazu hat es David Ricardo (1817, hier 1923) als das Hauptproblem der Volkswirtschaftslehre bezeichnet, die Gesetze aufufinden, welche die Verteilung bestimmen. Nach einer Zeitspanne von fast zwei Jahrhunderten hat sich bis heute in der wirtschaftstheoretischen und 
finanzwissenschaftlichen Literatur die Bedeutung dieses Grundphänomens erhalten. Die beiden "H a u $t$ p r o b l e m e", die eine optimale Verwendung knapper Ressourcen aufwirft, sind "die Sicherung der Effizienz" (m.a.w. der Allokation, d.h. der Produktion) und "die sicherung des richtigen vertellungsstandes" (Musgrave/Musgrave/Kullmer 1984, S. 104). Sie werden als die "zentralen okonomischen Probleme" bzw. als "Dauerproblem der kapitalistischen Marktwirtschaften" (A. Stobbe 1975, S. 276 bzw. 306) bezeichnet, weil sie einige entscheldende Lösungen gesel1schaftspolitischer Fragen enthalten. Denn wer in unserer Wirtschaftsordnung über die produktion bzw. das Angebot von Gütern entscheidet und auch darüber, wie solche Entscheidungen koordiniert werden, das ist der wesentliche Inhalt des AllokationsProblems (A. Stobbe 1975, S. 276). Insofern nimmt das Allokationsproblem auch die Charakteristik unserer wirtschaftsordnung als eine aus Privatwirtschaft und offentlicher Wirtschaft "gemischte" rkonomie in sich auf. Und wie die Allokationsergebnisse auf Personen und Gruppen von Faktoranbietern und Bürgern verteilt werden, ob dabei ausschlieblich nach Gesichtspunkten des Marktprozesses verfahren wird oder ob (auch) politische Vorstellungen in der gesellschaftlichen Auseinandersetzung Gewicht erhalten, ist der wesentliche Inhalt des Verteilungsproblems. Als seine Lösung wird eine ständige Entwicklung in Richtung auf eine gleichmäBigere (nicht gleiche) Verteilung über die gesellschaftlichen Gruppen hin angestrebt, da für wirtschaftssysteme, deren allokative Grundstruktur im Marktwettbewerb gesehen wird, eine gewisse Ungleichverteilung als typisch angesehen und wohl auch als leistungsmotivierend verstanden wird.

2. Diskutiert wird oftmals, ob diese beiden Grundprobleme in Harmonie oder im $\mathrm{K} \circ \mathrm{n} f \mathrm{l} \mathrm{k} t$ zueinander stehen; nach Ansicht von A.M. OKUN ist das Verhältnis von Gerechtigkeit in der Vertellung zur Effizienz in der Produktion "our biggest socioeconomic tradeoff", 14) eine Gegensatzbeziehung, 15) die schwerwiegender und zugleich quälender sei als jene zwischen Unterbe-

14) 1975, S. 2; s.a. die Kritik an Okun durch M.F. Plattner 1979, S. $32 \mathrm{ff}$.

15) So wird sie auch als "Konkurrenz" zwischen beiden zielen bezeichnet: G. Krause-Junk 1974b, S. 35 . 
schäftigung und Inflation. 16) Diese Zielkonflikte sind "nahezu schicksalhaft vorgezeichnet", und die "allokationspolitischen Absichten stoBen auf verteilungspolitische Grenzen", die schwierig abzuschätzen sind (G. Krause-Junk 1981, S. 357). Nach ausfuhrlicher Diskussion aller Ziele des "magischen Vielecks" in der Wirtschaftspolitik und systematischer Analyse der Beziehungen zwischen diesen zielen kommt J. Werner (1971, S. 381) zu dem Ergebnis: "Wirtschaftspolitisches Handeln wird daher letztlich von produktionspolitischen und verteilungspolitischen zielsetzungen bestimmt." Auch G. Gäfgen (1975, S. 12 f. u. 16) kennzeichnet unter den vier Gruppen von Hauptzielen der Wirtschaftspolitik vorrangig die Produktions- und die Vertellungsiele als die alle wirtschaftlichen Aktivitäten einer Gesellschaft bestimmenden Richtwerte. G. Bombach (1978, S. 277) fragt, ob die "magische" Beziehung in dem alten Zieldreieck "Geldwerterhaltung-Vollbeschäftigung-Zahlungsbilanzausgleich" sich etwa heute ablösen lasse durch eine neue magische Dreierbeziehung "Effektivität-Egalităt-Vollbeschäftigung"; dabei kommt er ebenfalls zu der hier formulierten Polntierung, wenn er vermutet, daß ein Mehr an "Egalität heute" ein Weniger an "Wohlstand morgen" bedeuten könne. K.J. Arrow (1979, S. 4 f.), der die hier interessierende Fragestellung unter dem Aspekt des Wachstums angeht, ist hinsichtlich der Egalităt ebenso skeptisch, da sie elne EffizienzeinbuBe bedeutet; er erweitert unsere Pointierung des Problems um die Frage der "efficiency and equity over time", um das Problem der Vorteile und Belastungen künftiger Generationen einzufangen; er kommt $z u$ einer eher positiven Ein-

16) Oftmals wird der Gegensatz zwischen Equality und Efficiency auch formuliert als solcher zwischen Equity und Efficiency. Im Englischen bedeutet equality "Gleichheit", equity hingegen "Gerechtigkeit". Speziell in der deutschen finanzwissenschaftlichen Literatur, und hier insbesondere bei F. Neumark (1970, passim) wird aber Gleichheit (in der Verständnisweise von Gleichbehandlung gleicher Tatbestände) als eine von verschiedenen Ausprägungen der Gerechtigkeit aufgefaBt. Dle unterschiedliche Verwendung der Begriffe Effizienz und Effektivitat (die im Englischen als "efficiency" und "effectiveness" synonym verwendet werden und mit Leistungsfähigkeit, Tüchtigke1t, wirkende Ursächlichkeit oder Nutzleistung zu libersetzen sind) ist eine Spezialität der wissenschaftlichen Literatur im Englischen wie im Deutschen. Unter Effizienz versteht man das Abwägen zwischen mehreren ökonomischen und gesellschaftlichen zielen, unter Effektivität dagegen den Erfolg einer auf ein singuläres ziel gerichteten Handlung; vgl. O.L. Deniston, J.M. Rosenstock u.a. 1972, und Hansmeyer/Rúrup 1975, S. 66. 
schätzung der "redistribution in time", da sie mit einem Produktivitätszuwachs verbunden sei, solange nicht etwa eine völlige Egalität angestrebt werde.

3. In der Finanzwissenschaft hat die Pointierung des ökonomischen Grundproblems in der Beziehung "A 1 l $\circ k$ a $t i \circ n v$ e $s u s$ $D i s t r i b u t i \circ n "$ eine besondere Ausprägung erfahren. 17) Denn erstens fügt sie dem allgemeinen marktlichen Allokationsproblem effizienter Produktion privater Güter das spezielle nichtmarktliche des Angebots öffentlicher Güter hinzu, und zweitens untersucht sie die Möglichkeiten der Korrekturen marktlicher (primärer) Verteilungsergebnisse über den (sekundären) Weg steuerlicher Abschöpfung, sowohl in der Form der steuerliche Lastverteilung als auch auf dem Wege der Umverteilung.

Die besondere Ausprägung liegt mithin in einer Differenzierung sowohl des Allokations- als auch des Distributionsproblems. Wenn man allein die Steuerpolitik ins Auge faBt, ist auch hier die Orientierung an den Zielen der Allokation, Distribution und Stabilislerung üblich, doch deutlicher noch kommt die hervorgehobene Gegensatzbeziehung zwischen Allokation und Distribution $z$ um Ausdruck, wenn man das Besteuerungsproblem einmal auf die fiskalische Besteuerung konzentriert: Denn wird ein bestimmtes Steueraufkommen vorgegeben, läBt sich die steuer ja auf verschiedene Weise aufbringen: Es läBt sich die Verteilung der objektiven Steuerlast entweder mehr dem ziel der steuerlichen Gerechtigkeit (Steuerlastverteilung und Umverteilung folgen Gerechtigkeitsaspekten) oder mehr dem ziel der volkswirtschaftlichen Wohlfahrt, der Allokation also, unterstellen (G. Krause-Junk 1977, S. 332 ff.). Gerade die Steuerdiskussion der jüngeren Zeit läBt erkennen, daB die steuerliche Verteilungslehre mit ihrer Betonung des Äquiva-

17) Musgrave 1970a, S. 29: "The theory of public finance in its ability to pay tradition has been preoccupied with problems of distribution, while in its benefit tradition it has dealt primarily with issues of allocation." Detaillierter noch C.S. Shoup 1969, der in seinem Lehrbuch das gesamte Bündel der steuerlichen Instrumente anhand von "consensus criteria" und "conflict criteria" beurteilt und dabei durchgehend die "equity criteria" den "efficiency criteria" gegenüberstellt. AuBerst treffend für unser Problem bereits der Titel des Buches von F. Neumark (1970): "Grundsätze gerechter und ökonomisch rationaler Steuerpolitik". 
lenz-, Leistungsfähigkeits- und Umverteilungsprinzips ${ }^{18}$ ) eine gewisse Uberbetonung des Verteilungsziels erfahren hat (G. KrauseJunk 1977, S. 345 ff.). Dies ist auch insofern nicht uberraschend, als ja von der "Natur" des steuerlichen Eingriffs her die lastverteilenden und umverteilenden Instrumente direkter zupacken können als die "vorteilsgewährenden" Instrumente der allokativen Anreize und Belohnungen. Insofern liegt in der allokativ-distributiven Steuerpolitik eine vorgegebene "Asymmetrie" begründet. Demgegenüber stellen sowohl die "excess burden"-Diskussion als auch die "optimal taxation"-Konzepte auf eine Betonung des Allokationsproblems $a b$, nicht ohne jedoch in jüngerer zeit auch die wirkung der Personalsteuern $\mathrm{zu}$ diskutieren. Wie sich jedoch nachweisen läBt, geraten beide allokationspolitischen Problemansätze in einen Konflikt mit dem Verteilungsziel.

In der vorliegenden Untersuchung wird der trade off zwischen Allokation und Distribution zum ständig wiederkehrenden Thema. Dies gilt sowohl für die objektivierung der Leistungsfähigkeit (6. 8. Kapitel) als auch für die Personalsteuerkonzepte (Dritter Teil). Aus der begrifflichen steuerrechtlichen Fassung wie aus den steuerpolitischen Praktiken gelingt es uns abzuleiten, daB das steuerliche Einkommen ein "allokativ-distributiver Mischbegriff" ist. Da in unserem Steuersystem für groBe Gruppen von Einkommensbeziehern, nämlich für die Privaten, die Einzelunternehmer und die Personengesellschafter in ihrer Eigenschaft als Mitunternehmer, die Besteuerung der Einkommen als eine "integrale Unternehmens- und Haushaltsbesteuerung" praktiziert wird, kann man auch hier den allokativ-distributiven Mischcharakter von Teilen des Steuersystems deutlich ablesen. Schlieblich ist in der steuerlichen Behandlung des sparens, das ja gewissermaBen wegen seiner einkommenschaffenden und einkommensabhängigen Funktion und wegen seiner finanzierungs - und produktionswirtschaftlichen Funktion auf der "Nahtstelle" zwischen Distribution und Allokation liegt, die Interdependenz zwischen Allokation und Distribution $z u$ erkennen.

18) H. Haller 1973b u. 1981; K. Littmann 1970; F. Neumark 1970; K. Schmidt 1967 U. 1972 ; J.G. Head 1979. 
S 3 Die systematik der allokativaistributiven Interdependenz

I. Das Interdependenzproblem in den allokationsorientierten Theorien

II. Asymmetrische und wirkungsbedingte Interdependenzen

III. Inner-distributive Interdependenzen 32

IV. Zusammenfassung des 1. Kapitels 34

I. Da das Allokationsergebnis das Distributionsergebnis vorbestimmt und in einer Rückwirkung letzteres wiederum das erstere beeinflußt (G. Krause-Junk 1981, S. 259), spricht man von Interdependenz. Der Ausgangspunkt dieser. gegenseitigen Abhängigkeit liegt allerdings im Allokationsbereich: Das Distributionsergebnis und -problem ist eine unmittelbare Folge des für die Allokation grundlegenden Knappheitsphänomens. Weitere Interdependenzen lassen sich in der wirklichkeit und in theoretischen Darstellungen nicht mehr ohne die Heranziehung auch monetärer Größen darstellen. ${ }^{1)}$ Zunächst ist festzuhalten, daß - sollte das Allokationsproblem gelöst werden können - damit in keiner Weise das Verteilungsproblem ebenfalls gelöst ist, denn das Konkurrenzmodell, jenes "Referenzsystem für Allokationsentscheidungen", besitzt für Verteilungsfragen keinerlei Aussagekraft (E. Sohmen 1976 , S. 5f.).

Abgesehen davon, daB die praktische Allokationspolitik stets auch verteilungsprobleme - teils gewollt, teils ungewollt ${ }^{2}$ - hervorruft, ist hier insbesondere das Verhältnis von distributiven Problemen in Allokationstheorien von Interesse. Allgemein läßt sich sicher feststellen, daß die Verteilungsfragen - und damit auch die Verteilungswirkungen von Personalsteuern - sich in einem Theorieumfeld entwikkeln mußten, das sich ihnen gegenüber uninteressiert, wenn nicht gar

1) $\mathrm{DaB}$ in modernen Volkswirtschaften die Individuen Geldeinkommen beziehen, ist für das Verständnis des Distributionsproblems als aus der Knappheit der Ressourcen und Güter folgend ohne Interesse. Geldeinkommen wird erst im Hinblick auf die Entwicklung von Verkehrswirtschaften und Steuerstaaten (Inflation und Progression) problematisch.

2) Andel, N., 1992, S. 412ff.: Einfluß auf die Primärverteilung durch die öffentliche Hand als Arbeitgeber, Auftraggeber sowie durch Maßnahmen der Allokationspolitik. 
ablehnend verhielt ${ }^{3)}$.

Diese Feststellung, gewiB eine solche in groben zügen, ist keineswegs als eine Abqualifizierung der in erster Linie allokationsorientierten Theorien anzusehen. Vielmehr liegt hierin das Anerkenntnis, daß solche Theorien ein völlig anderes Erklärungsinteresse verfolgen. Dies ist in der Literatur eindeutig und oft belegt. Hier aber soll lediglich hervorgehoben werden, daß die stärker allokationsorientierten Theorien für die distributive Fragestellung die ungeeigneten Theorien sind.

a) Die Grenzproduktivitätstheorie mit ihrem güterwirtschaftlichen Leistungsbegriff erklärt sowohl in mikro- als auch in makroökonomischer Weise die Verteilung als Ergebnis des Marktund Preisprozesses, kommt dabei zu einer Gerechtigkeitsauffassung, die die Faktorentlohnung als leistungsgerecht definiert, gelangt darüberhinaus $z u$ einem optimalitätsverständnis, das sich darin zeigt, daß in dieser Faktorentlohnung die "Nutzenvorstellung" aller zum Ausdruck kommt. "4)

Es bleibt aber eine Diskrepanz zwischen den persönlichen Nutzenvorstellungen und der personalen Einkommensverteilung; insofern kann eine personale Einkommensverteilungstheorie von ihr nicht geleistet werden. Die den heutigen Gerechtigkeitsvorstellungen entsprechenden Verteilungs- und Umverteilungsmaßnahmen werden als Korrekturen der Blindheit des Marktes und seines mechanistischen Wirkens empfunden.

b) Auch die Wohlfahrtstheorie, die im sog. Pareto-optimum (V. Pareto 1927, S. 265) ihr Wohlfahrtskriterium formuliert hat, vernachlässigt die Frage der personalen Einkommensverteilung: Die Allokationsüberlegungen gehen von der einmal vorliegenden Verteilung aus, letztere wird weithin unproblematisiert ubernommen und nicht weiter hinterfragt; das relative optimum, das unter Ausschluß des Distributionsaspektes nur die Zweckmäßigkeit der Allo-

3) Hierzu G. Blümle 1975, S. 2-9 ausführlicher.

4) Solche nutzentheoretischen Vorstellungen haben sich bis in die Diskussion um die Besteuerung nach der Leistungsfähigkeit erhalten. 
kation konstatiert, kommt ohne interpersonelle Nutzenvergleiche aus. Der Katalog der Marginalbedingungen für das sozialökonomische Optimum (siehe H. Giersch 1960, S. 109 ff.) führt unter diesen keinerlei Distributionsbedingungen auf, sondern geht von der schon optimal vorhandenen Einkommensverteilung aus, um die Analyse der allokativen Bedingungen unter ceteris-paribus-Verhältnissen durchführen $\mathrm{zu}$ können. Das Problem suboptimaler Einkommensverteilung wird dann erst wieder in den sog. Theorien des "second best" (J.E. Meade 1955) bzw. des "Bestmöglichen" (H. Giersch 1959; 1960 , S. 125 ff.) zum Untersuchungsgegenstand gemacht.

c) Erst die Wachstumstheorie nimmt das grundsätzlich mit dem Allokationsziel konkurrierende Verteilungsziel deutlich in ihren Erklärungs zusammenhang auf, beläBt es aber zunächst im Hintergrund, wenngleich von Anfang an auch für die klassische Theorie mit ihrem zentralen Thema des Akkumulationsprozesses charakteristisch war, daB "die Analyse des wirtschaftlichen Wachstums untrennbar verbunden war mit einer Analyse der Entwicklung der Einkommensverteilung; Akkumulationstheorie und Distributionstheorie bildeten eine Einheit (P. Kalmbach 1972, S. 13). Wenn nun in neuerer Betrachtung "neoklassische und postkeynesianische Wachstumstheorie als zwei Theorien über den Zusammenhang von Wachstum und Verteilung" bezeichnet werden (P. Kalmbach 1972, S. $31 \mathrm{ff.}$ ), so soll damit $z$ um Ausdruck gebracht werden, daB mit verschiedenen Erklärungsansätzen versucht wird, den zusammenhang aufzuhellen, wobei die Theorien unterschiedliche verteilungstheoretische Ansätze enthalten: Die neoklassische Theorie baut ihre Erklärung auf dem Grenzproduktivitätsprinzip auf, die postkeynesianische auf dem Anpassungsmechanismus des Sparens an die Investitionen. ${ }^{5}$ )

5) Mit dieser Gegenüberstellung zweier Theorietypen ist das Gesamtproblem keineswegs vollständig erfaBt (P. Kalmbach 1972, S. 212), vielmehr wird versucht, die Interdependenz zwischen Allokation und Distribution auch auf dem Gebiete der ökonomischen Theorie beispielhaft $z u$ belegen, sei es, daB auf die beiden populärsten Richtungen der Wachstumstheorie abgehoben wird, die ihre Modellaussagen auf Annahmen über Produktionsfunktionen, Sparneigungen und technischem Fortschritt aufbauen, sei es, daB ergänzend auch auf ein Modell verwiesen wird, das weniger technische als vielmehr gesellschaftliche Machtverhältnisse zur Erklärung der Verteilungsfragen innerhalb des Wachstums heranzieht. So ist für E. Preiser (1970) die Profitrate auf lange Sicht festgelegt durch die gesellschaftlichen Machtverhältnisse, ausgedrückt im strukturellen Monopolgrad. 
d) Für die Finanztheorie ist heute die Interdependenz von Allokation und Distribution evident, gehört es doch zu ihren gesicherten Erkenntnissen, daß die allokationspolitisch motivierte Entscheidung zur Finanzierung der Staatsausgaben über steuern bzw. Anleihen je nach den Steuerarten und-tarifen sowie den zins- und Tilgungssteuern auch Verteilungswirkungen haben.

Es ist aber auf einen Unterschied zwischen einer "marktlichen" und einer "nichtmarktlichen" Interdependenz von Allokation und Distribution hinzuweisen, der den individuellen EntscheidungsprozeB bzw. den die Finanzpolitik kennzeichnenden kollektiven EinigungsprozeB berührt. Im marktlichen Allokations- und Einigungsverfahren fallen allokative und distributive Entscheidungen stets zusammen; distributive Vorgänge - so könnte man sagen - fördern geradezu die allokativen Entscheidungen (Mackscheidt/Steinhausen 1977, S. 38); in anderer Formulierung: alles Allokative zielt letztlich auf etwas Distributives, denn die Einkommenserzielung (und -maximierung) dient als Motiv und Antrieb zum Faktoreinsatz; wettbewerb ist kein unternehmerisches ziel, sondern lediglich eines von mehreren Mitteln, das ziel der Einkommensmaximierung zu erreichen (A. Stobbe 1983, S. 304). Demgegenüber können kollektive Entscheidungsprozesse und Distributionsverfahren die allokativen Entscheidungen eher behindern. Die Geschichte der steuerlichen Instrumente zur allokationspolitischen Förderung ist zugleich die Geschichte der politischen Auseinandersetzungen der verschiedenen Interessentengruppen untereinander und mit den Politikern, ist zugleich die Geschichte der allokativ-distributiven Konflikte und Zielverzichte. Dasselbe gilt umgekehrt für die Distributionspolitik. Die allokativ-distributive Interdependenz, die die wirtschaftlichen Geschehnisse kennzeichnet, hat für die Besteuerung eine herausragende Bedeutung deswegen, weil eines ihrer zentralen Instrumente, die Einkommensteuer, soweit sie zugleich Gewinnsteuer ist, in ein und demselben Besteuerungsakt unvermeidlicherweise sowohl auf die allokativen Entscheidungen als auch auf die distributive Lage der Wirtschaftenden einwirkt. Allokationspolitisch motivierte (und erfolgreiche) SteuermaBnahmen begünstigen oftmals zugleich die Einkommenslage der Unternehmer, 
was im Verhältnis $\mathrm{zu}$ den Nichtunternehmern $\mathrm{zu}$ Verteilungsunterschieden fuhrt. Das läBt sich als ein verteilungspolitischer zielverzicht definieren. SolchermaBen ist die Interdependenz $z w i s c h e n$ Allokation und Distribution ein Phänomen, das die Wirkungsmöglichkeiten der Personalsteuern, gemessen an ihren Zielen, in starkem MaBe einengt.

II. Nach diesem tberblick sei nunmehr das Interdependenzproblem s y $\mathrm{s}$ e m a $t$ i s $\mathrm{c}$ betrachtet.

a) Zunächst ergibt sich eine "As y m m e t r i e - B e z 1 e h u n g." Die Bildung der Einkommen und die interpersonelle Verteilung ist in der Marktwirtschaft "keln selbständiger Vorgang, sondern erfolgt ... im Zuge des Preisbildungsprozesses" (E. Preiser 1959, S. 620 f.) als eines Allokationsvorganges. Wenn auch die Einkommenserzielung oder -maximierung das ziel ist, so kann sie erst durch Faktorallokationen erreicht werden. Diese consecutio hat in der staatlichen Politik eine Entsprechung, nämlich in der Aufgabenhierarchie. Akzeptiert man die aus analytischen Gründen gewählte Musgrave'sche und Eintellung und unterscheidet die Staatsaufgaben typisierend in die Allokations-, die Distributions - und die Stabilisationsaufgabe; erkennt man ferner an, daB die Allokation vom sog. Ordnungsstaat und vom Fiskus zusammen wahrgenommen wird, die Distribution hingegen vom sog. Sozialstaat; ${ }^{6)}$ sieht man ferner, daB die Aufgaben des ordnenden Staates vorwiegend solche der Zuordnung von Eigentumsrechten, von Grundrechten der Vertragsfreiheit, der Abgabenhoheit sowie der Allozierung der Entscheidungsmacht sind, um für die private Güterbereitstellung Märkte einzurichten, die Bereitstellung öffentlicher Güter dagegen in staatliche Regie zu nehmen, so läBt sich folgern, daB der ordnende staat dem vertellenden staat "vorangeht"; dies ist zumindest historisch so gewesen, doch spricht dafür auch der Güterherstellungs-Güterverwendungs-Zusammenhang. 7)

6) Die Stabilisationsaufgabe wird von den traditionellen Elnteilungen der Aufgaben nicht erfaBt, sondern kommt neu hinzu, R.A. Musgrave 1969 , S. 3-32.

7) W. Engels (1979a) folgert sogar, daB der ordnende staat dem verteilenden "übergeordnet ist". 
Somit hängt die Distribution zeitlich, logisch und politisch von der Allokation ab. Daraus ist keinesfalls zu folgern, als wäre unter politischem Aspekt etwa stets das Allokationsiel dem distributiven vorzuziehen. Vielmehr liegt eine systematische Abhängigkeit vor. Eine Hierarchie der politischen ziele kann nicht von vorn herein für immer festgelegt werden. Wenn somit auch stets das Problem von Zweckkollisionen (K. Schmidt 1978, S. 135) präsent bleibt, so liegen in dieser systematischen Abhängigkeit der Distribution von der Allokation starke Restriktionen für die Distributionspolitik. Die "Asymmetrie" der allokativ-distributiven Politik hat hier ihren Grund.

b) Weiterhin besteht eine $R$ ü $c k$ b e $z$ i e h u $\mathrm{n} g$ von der Distribution auf die Allokation bzw. von der sekundär- auf die Primärverteilung. Den Einsatz der produktiven Faktoren machen die Faktorbesitzer davon abhängig, welche Entlohnung sie erzielen können. Jegliche Information, die das Individuum sowohl uber das Marktergebnis seines Faktoreinsatzes, aber auch über die nichtmarktlichen Korrekturen der Faktorentlohnung qua steuern, Steuervorteilen und Transfers (SVR 1982, TZ 255 u. 257: "Anreizstörungen" u. pos. Rückwirkungen) sowie über seine Einkommenslage im Rentenfalle erhält, kann seine Entscheidungen über den allokativen Faktoreinsatz beeinflussen; dies etwa dergestalt, daß sich der marktlich gering Entlohnte oder der hoch Besteuerte (man denke etwa an die Fixkostenbelastung durch Gewerbekapital- und Vermögensteuer) anderen Wirtschaftsbetätigungen $z$ uwendet und qua funktioneller Entlohnung seine personelle Einkommensposition $z$ verbessern trachtet; dies etwa auch dergestalt, daB sich jemand aus dem Erwerbsleben zurückzieht, sobald er sicher sein kann, daB seine Altersbezüge aus der Rentenversicherung sein Nettoeinkommen aus der Erwerbstätigkeit übersteigt. ${ }^{8)}$

8) F. Klanberg $(1981$, S. 7) fragt: "Wird nicht heute die Primärverteilung durch staatliche UmverteilungsmaBnahmen wesentlich mitbestimmt? Welchen EinfluB hat eine Sicherung gegen Arbeitslosigkeit auf das Lohnniveau? Wie wirken sich die Regelsätze der Sozialhilfe auf die untersten Lohngruppen aus? Ist die 'soziale Komponente', die in Tarifverhandlungen heute eine grobe Rolle spielt, überhaupt noch der Primäreinkommensverteilung zu-
zuordnen?" 
G. Krause-Junk (1981, S. 351f.) systematisiert die Interdependenzbeziehungen nach den Einwirkungen auf die Faktoren Arbeit und Kapital wie folgt ${ }^{9)}$ : Unter den abgabenwirtschaftlichen Einwirkungen auf die $A r b$ e $t s i o ̈ h n$ nennt er an erster stelle die Arbeitgeberbeiträge zu den verschiedenen Sparten der Sozialversicherung, die für die Unternehmen Lohnnebenkosten darstellen und in das Kalkül der Entlohnung eingehen. Seine überlegungen sind zu ergänzen: Daß auch der Arbeitgeberanteil in den alljährlichen Tarifrunden zwischen den Sozialpartnern mit berücksichtigt wird, ist eine Erweiterung der unter steuerlichem Aspekt aufgewiesenen Einflüsse ${ }^{10)}$. Daneben gibt es Einwirkungen auf die Primärverteilung, die zwar nicht vom staat direkt ausgehen, sich aber auf die durch ihn festgelegt Steuerprogression zurückführen lassen, wenn nämlich die Gewerkschaften unter Hinweis auf den nettolohnmindernden Effekt der Einkommensteuerprogression in Lohnverhandlungen etwaige steuertarifbedingte Mehrbelastungen vorwegnehmen und in Lohnvereinbarungen festschreiben. ${ }^{11)}$

Nichtmarktliche Verteilungsverfahren geben auch für den Einsatz des Faktors $\mathrm{K}$ a p i $t$ a 1 deutliche Signale über Steuern, Steuervorteile und Transfers (Prämien) für die Allokationsentscheidungen: Sparprämien, die degressive Abschreibung allgemein, aber besonders Sonder- und erhöhte Absetzungen (z.B. für den Wohnungsbau, aber auch für Umweltschutzgüter) lenken Sparströme

9) Aus seinem recht umfassenden Katalog von staatlichen Maßnahmen greifen wir hier nur die abgabenwirtschaftlichen heraus.

10) Nach E. Scheele (1979, S. 284) war ersichtlich beim damaligen Stand der Verteilungstheorie "die Wirkung der finanziellen Transaktionen des Staates auf die Primärverteilung völlig außer acht" geblieben.

11) Aus dem Gesichtswinkel des Gewerkschaftsverhaltens auf den "vollkommenen" Arbeitsmärkten wird dieses Verhalten gewöhnlich für unwahrscheinlich gehalten, weil sie bereits vorher als Lohnmaximierer aufgetreten seien; jedoch weisen Musgrave/Musgrave/Kullmer $(1977$, S. 50) darauf hin, daß in den letzten Jahren die Inflation sowohl die Lebenshaltung verteuert (dies ist die gewöhnliche orientierungsgröße der Gewerkschaften) als auch eine "kalte Progression" bewirkt und die Primärverteilung negativ beeinflußt; dieses Argument findet in Lohnverhandlungen immer häufiger Eingang; slehe 1988, S. $206 \mathrm{ff}$. 
wie Aktivitäten gezielt in bestimmte Sektoren und Regionen. ${ }^{12}$ ) Für die Finanzierung des Eigenkapitals, das grundsätzlich auf den beiden Wegen der Beschaffung über den Kapitalmarkt und der Elnbehaltung von Gewinnen möglich ist, sind - was die Gewinneinbehaltung betrifft - die Grenzen durch den Verteilungsstreit heute enger gezogen als in den 60er Jahren (SVR 1979, Ziff. 361). Darüber hinaus ist trotz der Erleichterung durch die Körperschaftsteuerreform die Eigenkapitalbildung immer noch teurer als die Fremdkapitalbeschaffung; da das vorwiegend an der Steuerbelastung liegt, ${ }^{13)}$ die Gesamtheit der das Kapital belastenden Steuern aber zur Finanzierung des Gesamthaushaltes (also nicht nur des Sozialhaushaltes) beltragen, kommt hier nur indirekt die Auswirkung der Verteilungspolitik $z$ um Vorschein.

Der Uberblick zeigt, daß die Interdependenz vielfältiger Art ist, daß sie aber auch zu allokativ-distributiven zielkonflikten füh$\operatorname{ren}^{14}$ ).

12) Insofern ist die sog. strukturelle "Verteilung" sowie die Verteilung der Einkommen auf nationale und internationale Regionen ihrem Inhalt nach ein Allokationsproblem, da sowohl Wirtschaftsbereiche wie -regionen die unter Effizienzerwägungen $z u$ wählenden Orte des Faktoreinsatzes sind. Diese allokative Bedeutung der strukturellen und regionalen Verteilung ist von der Finanzwissenschaft und der Steuerlehre stets in dieser Weise erkannt worden, man denke an steuerliche Vergünstigungen für die Landwirtschaft als Mittel der Agrar-, aber auch der Einkommenspolitik (siehe §§ 27, 28 unten), man denke an die Berlin- und zonenrandförderung sowle an internationale Doppelbesteuerungsabkommen $\mathrm{zur}$ Erreichung bzw. Behinderung der internationalen Faktorwanderung.

13) Die Aktie ist immer noch doppelt belastet durch die Vermögensteuer; ferner liegt die hohere Elgenkapitalbesteuerung begründet in der "Korperschaftsteuer auf die Vermögensteuer" sowie in der Gewerbesteuer nach dem Ertrag, der auch die Vermögensteuer und die Körperschaftsteuer auf die Vermögensteuer enthält.

Fn. 14 nächste seite. 
III. Innerhalb des distributiven Bereichs bestehen Interdependenzen zwischen $D i s t r i b u t i \circ n$ und $R$ e d $i s t i b u-$ $t i \circ n$, genauer: zwischen der Einkommensbesteuerung einerseits und den Transfers bzw. "Steuersubventionen" andererseits. Dabei sind Transfers und Steuersubventionen mit allokativer Zielsetzung $z$ u unterschelden von den Sozlaltransfers. Erstere, z.B. die Sparförderungs- und Wohnungsbauprämien, Sparerfreibeträge und Sonderausgaben usw., verfolgen allokative zielsetzungen, haben aber distributive Effekte und sind u.U. auch mit distributiven Bedingungen (z.B. in Form von Einkommensobergrenzen) ausgestattet, die dem verteilungspolitischen Nebenziel dienen. Eben deswegen werden sie in den distributiven Bereich aufgenommen. Die Interdependenz liegt darin, daB diese Transfers und Steuersubventionen nur dann gewährt werden, wenn das steuerlich definierte Einkommen eine bestimmte Höhe nicht überschreitet. Das Problem, das dabei entsteht, ist das in der Besteuerung bekannte "S c hwe 1 l e $n \mathrm{ph}$ ä $\mathrm{n} \circ \mathrm{m}$ e $\mathrm{n}$." Dieses ist in ein negatives und ein positives $z u$ unterscheiden. Das negative stellt sich ein, wenn nach Uberschreiten der steuer- und transfergesetzlich festgelegten Einkommensgrenze bestimmte Transfers bzw. Steuersubventionen nicht mehr bezogen bzw. in Anspruch genommen werden können. Nimmt im Zeitverlauf das steuerliche Einkommen $z u$, entsteht in der Gesamtwirkung durch den Fortfall der redistributiven Vergünstigungen ein Ausfall an Verfügungseinkommen. Ist der Ausfall entsprechend hoch, sind Rückwirkungen auf das Verhalten schon bei der Einkommenserzielung oder auch bei der steuerdeklaration nicht auszuschlieBen.

14) So stellt G. Krause-Junk (1981, S. 251) für die Verflechtung von Verteilungs- und allgemeiner Beschäftigungspolitik fest: "Steuererleichterungen oder direkte Investitionshilfen erscheinen formal oft als UmverteilungsmaBnahmen zugunsten der Bezieher höherer Einkommen und stoBen aus diesem Grunde ja auch regelmäBig auf (verteilungs-) politische Bedenken." K.E. Boulding (1981, S. 217) führt aus: "Die Geschichte der letzten hundert Jahre ist in der Tat ein bemerkenswertes Lehrstück dessen, was man politische Ironie nennen könnte, daB nämlich fast alle menschenfreundlichen MaBnahmen schmerzlich endeten, ... Ein groBer Teil des Unwissens, der $z u$ diesem politischen Ironie-Effekt geführt hat, ist Unwissen über das Zusammenwirken von Austauschwirtschaft und Transferökonomie." 
Das "positive" Schwellenphänomen beschreibt J. Giloy (1978, S. 83), der es auf die "zweigleisige" Politik staatlicher Förderung zurückführt, wie folgt: "Die Berücksichtigung der Bausparkassenbeiträge als Sonderausgaben vermindert die Bemessungsgrundlage ... und damit zugleich die BemessungsgröBe für das Anrecht auf Sparprämie. Ein Bausparer, der an sich zu hohe Einkünfte erzielt, um noch Sparprämie erreichen $z u$ können, drückt das $z u$ versteuernde Einkommen mit der Geltendmachtung von Bausparbeiträgen als Sonderausgaben" und kann dadurch in den Vorteil eines Transfers kommen. ${ }^{15)}$

Es ist allerdings für das Interdependenzproblem begrifflich $\mathrm{z} u$ bedenken, daB nur solche Transfers in Betracht kommen können, die ungeachtet der bestehenden "finanziellen" Beziehungen zwischen mehreren Transferarten und zwischen Transfers und persönlichen Einkommen ausschlieBlich das $\mathrm{v}$ e $\mathrm{r}$ h $\mathrm{l}$ t e $\mathrm{n}$ der Einkommensund Transferbezieher berühren, also die von den Transfers ausgehenden Anpassungsaktionen und -reaktionen im Einkommensbereich. Probleme finanzieller Beziehungen, wie sie z.B. in der Häufung von verschiedenen Transferarten bei ein und derselben Person auftreten, 16) müssen hier auBer Betracht bleiben. Ebenso müssen auBer Ansatz bleiben diejenigen Transferarten, die bei den Beziehern deswegen keinerlei Anpassungsreaktionen hervorrufen, weil sie entweder aus dem aktiven ErwerbsprozeB bereits ausgeschieden sind oder weil sie aus anderen Gründen kein Primäreinkommen beziehen.

Infolge solcher "inner-distributiver" Interdependenzen entsteht die Gefahr, daB die Distributions- und die Redistributionspolitik in ihren erklärten zielen konterkariert und daB die Besteue-

15) Siehe hierzu auch N. Andel 1979a, S. 344, Punkt 3: Unversteuerte Lohnersatzleistungen bzw. Transfers bewirken, daB bestimmte Einkommensgrenzen nicht überschritten werden.

16) Solche Fragen werden heute unter den Stichworten "finalisierte Sozialpolitik" und "integrierte soziale Sicherung" abgehandelt. Für den Totaleinkommensbegriff haben diese phänomene selbstverständlich ihre Gültigkeit, nicht jedoch für das hier erwähnte Anpassungsverhalten. 
rung wie die Transferpolitik immer unübersichtlicher wird. ${ }^{17)}$

Soweit also in der vorliegenden Untersuchung allokativ-distributive Beziehungen und Probleme angesprochen sind, kann davon ausgegangen werden, da $B$ die asymmetrischen und wirkungsbedingten Interdependenzen zwischen Allokation und Distribution stets mit bedacht werden und $\mathrm{da} B$ auch die inner-distributiven Interdependenzen zwischen Distribution und Redistribution zum Problemfeld gerechnet werden.

\section{Zusammentassung}

Wir fassen die Ausführungen des 1. Kapitels zu der allokativdistributiven Interdependenz in der Besteuerung wie folgt zusammen:

Die Grundfrage der Politischen ökonomie, das Interdependenzverhältnis zwischen Allokation und Distribution oder auch das Problem der "efficiency versus equity" machen wir zum Ausgangspunkt unserer theoretischen und praktischen Untersuchung. Dabei verwenden wir einen beiten und dynamischen Allokationsbegriff unter Einschluß aller Phänomene der Produktion, des Wachstums, der

17) Einige Sozialtransfer-Gesetze formulieren selbständige Einkommensgrenzen, wie z.B. für bestimmte Leistungen der Sozialhilfe, für die Ausbildungsförderung, für die Kriegsschadenrenten nach dem Lastenausgleich und für das Wohngeld; während bei den ersteren beiden ein Schwellenphänomen insofern nicht auftritt, als für eine bestimmte Einkommenszone abgestaffelte Leistungen gewährt werden, verzeichnet man in der Kriegsschadenrente jenseits einer bestimmten "Auffanggrenze" eine Einkommenskappung. Beim Wohngeld besteht ein Schwellenphänomen indirekt darin, daB nicht die Zahlung selbst, sondern der Anspruch auf Wohngeld vom Nichtüberschreiten eines bestimmten Einkommens-Höchstbetrages abhängt.

Andere Transfers bzw. Steuersubventionen, wie insbesondere die allokationspolitisch motivierten (Spar- und Wohnungsbauprämien), binden die Empfangsvoraussetzungen an die im EStG (§ 32I) genannte Grenze von 24.000 bzw. 48.000 DM. Nach Uberschreiten dieser Schwelle fällt die Vergünstigung fort, ohne daB eine Zone der härtenvermeidenden Ubergänge besteht. Möglicherweise liegt der Grund für die unterschiedliche Regelung in den beiden verschiedenen Transfergruppen in ihrer wirtschaftspolitischen Zielsetzung. In den Fällen dieser echten Schwellenphänomene sind ökonomische Anpassungsreaktionen im Bereich der Primäreinkommenserzielung denkbar (vgl. hierzu u.a. W. Albers 1974). 
Strukturentwicklung, der Ressourcen- und Umweltinanspruchnahme. Ferner verstehen wir unter Distribution sowohl die verteilung von Einkommen und Vermögen als auch die Verteilung der steuerlast und die Umverteilung unter Einschluß der Personaltransfers.

Wir konstatieren, daß die einzelnen Aspekte der Wirtschaftstheorie das Beziehungsverhältnis zwischen Allokation und Distribution unterschiedlich und nicht immer sehr deutlich reflektieren. Das ist in der Finanzwissenschaft traditionell anders, gehörte es doch zu ihrem Erklärungsgegenstand, daß die steuerlastverteilenden und umverteilenden Maßnahmen die subjektiven Entscheidungen im Allokationsbereich beeinflussen und bestimmte Verhaltensweisen vorprägen. Das ist nun hier insofern von besonderer Bedeutung, als das Verhältnis zwischen Allokation und Distribution durch eine bestimmte Asymmetrie gekennzeichnet ist. Diese zeigt sich nämlich darin, daß die Allokation der Distribution sowohl zeitlich als auch logisch vorangeht: Einkommen entsteht erst im Zuge der Produktion. Demnach steht jegliche steuerlastverteilung und Umverteilung unter dem Gebot, stets die optimalen Bedingungen für den Allokationsbereich garantieren $z u$ müssen. Das hat für die distributive Politik des Staates - gerade wenn sie dem Postulat der Besteuerung nach der Leistungsfähigkeit gehorchen soll - die Konsequenz, daB die Beachtung der "Dauerergiebigkeit der Steuerquelle" ein Gebot der Rationalität ist. Sinnfälliger läßt sich die Interdependenz zwischen allokations-und distributionspolitischen Normen nicht ausdrücken, als daß man klar herausstellt, daß das distributionspolitisch aufgefaßte steuerpostulat bereits einen starken allokativen Inhalt aufweist. 
Das Leistungstähigkeitspostulat als distributive steuerlastverteilungsnoxm

POIitisches Leistungstähigkeitspostulat und ókonomisches Leistungsprinzip

I. Das allokativ-distributive Dilemma des Leistungsfähigkeitspostulats

II. Das Leistungsprinzip als systemindifferente Produktionsregel und als systemtypische Verteilungsregel

III.Die ökonomischen Funktionen der Leistung

IV. Die Leistung im Besteuerungsproze $B$

I. Welche Bedeutung hat das Postulat der Besteuerung nach der Leistungsfähigkeit? Steuertheorie und -politik stimmen fast ausnahmslos in der Forderung überein, daß die Belastung des einzelnen mit Personalsteuern nach seiner Leistungsfähigkeit zu erfolgen habe. ${ }^{1)}$ Die Politik, für die normatives Denken und Handeln notwendig ist, bedient sich dieses Postulats allein schon wegen seiner "blendenden Faszinationskraft", läßt sich doch mit seiner Hilfe eine Art "Leistungsgerechtigkeit", unterstützt gar durch wissenschaftliche Absegnung, effektvoll vortragen, Für die Theorie hingegen dürfte heute gelten, daß sich über das Postulat zwar diskutieren, daß sich jedoch ein wissenschaftlicher Beweis seines Inhaltes nicht führen läßt. Die personale steuerlastverteilung folgt einer $\mathrm{n} \circ \mathrm{r} \mathrm{m} t \mathrm{i} \mathrm{v}$ e $\mathrm{n}$ Theorie der Besteuerung, die - wenn auch z.B. gegenüber der Wohlfahrtstheorie mit den Eigenschaften der Operabilität und Konsensfähigkeit ausgestattet

1) Wir sehen hier zunächst davon $a b, d a B$ das Postulat unterschiedlich fundiert und interpretiert werden kann, aber auch, daB vereinzelt seine Funktion gänzlich bestritten wird; hierzu siehe den 3. Teil dieser Untersuchungen. 
(W. Pfähler 1978) - ihr wesentliches Erklärungs - und Konkretisierungsanliegen an die Politik zurückgeben muB: Wie im 3 . Teil dieser Untersuchung dargelegt wird, führen die bisherigen Versuche, das Leistungsfähigkeitspostulat mithilfe von Nutzen- und opfertheorien zu bestimmten, nicht zum ziel; daher stehen Bemühungen im Vordergrund, es als eine Doktrin zu verstehen, die allein im politischen ProzeB konkretisiert werden kann. 2)

Für die Bedeutung dieses Postulats ist es nicht unwichtig, darauf hinzuweisen, daß es im Zuge politischer konkretisierung in ein zweifaches allokativ-distributives $D i l$ e $\mathrm{m} \mathrm{m}$ a gerät: Es will als eine distributive Norm die persönliche steuerlast so verteilen, daB der Leistungsfähigere gröBere Lastanteile trägt als der weniger Leistungsfähige, müBte aber zugleich anerkennen, daB bereits die MaßgröBe ihrer Lastzumessung, die persönliche Leistung, nicht korrekt ist; dies nicht allein wegen der zweideutigen MeB-, Zurechnungs- und Neutralitätsprobleme, sondern auch wegen der in $\$ 3$ nachgewiesenen Interdependenzen zwischen der Besteuerung und der Primäreinkommensverteilung. Ferner will es als eine distributive Norm die persönliche Steuerlast einerseits so niedrig bemessen, daB der ökonomisch Schwache geschont wird, andererseits so hoch ansetzen, daB der ökonomisch Stärkere jenes $M a B$ an Steuerlast mehr trägt, das auch noch die Finanzierung des Umverteilungsvolumens erlaubt, 3) müßte aber zugleich erkennen, daß bei einer ubergroßen Steueranspannung die ökonomische Reaktion der höher Besteuerten das Aufkommen und die Dauerergiebigkeit der steuer und damit das Distributionsziel gefährdet.

Dieser Konflikt bleibt unauflöslich, wird allein im politischen Kompromiß umgangen werden können.

II. Die Anwendung des Leistungsfähigkeitspostulats setzt aber voraus, daß definiert werden kann, was "Leistung" ist und welchen gesellschaftspolitischen Stellenwert sie im allokativ-distributiven Bezug eingeräumt erhalten soll. Denn einerseits wird unterstellt, Leistung sei korrekt meB- und zurechenbar und stets unbestrittener Ausdruck des marktlichen und wettbewerblichen Prozesses, ande-

2) $\mathrm{Zu}$ den Konkretisierungen dieser Norm siehe die $\$ \$ 34-17$.

3) Hier soll keineswegs bedenkenlos für die Umverteilung votiert werden, sondern davon ausgegangen werden, sie sei gesellschaftspolitisch erwünscht. 
rerseits werden bestimmte Leistungsnormen vorgegeben. In beiden Fällen darf man davon ausgehen, daß dem Prinzip Leistung ganz bestimmte gesellschaftliche Funktionen überantwortet werden.

Wenn nun eine Gesellschaft der individuell (bzw. kollektiv) erzielten Leistung besondere Funktionen zuerkennt, handelt sie nach dem "L e $i s t u n g s p r i z i p "$. In diesem läBt sich sowohl eine "Produktionsregel" als auch eine "Verteilungsregel" sehen. Die Produktionsregel rückt die allokativen, die Verteilungsregel die distributiven wirkungen der Leistung in den Vordergrund unserer Betrachtungen. Derselbe marktliche ProzeB, der die Produktionsregel mit Inhalt füllt, determiniert uno actu auch die Verteilungsregel. Da ein- und dasselbe Prinzip, nämlich das der Leistung, sowohl die Entstehung als auch die Verteilung des Sozialprodukts regelt, die Leistungsergebnisse aber je nach den persönlichen Voraussetzungen der Faktorverteilung sowie je nach der persönlichen Art und Intensität des Faktoreinsatzes unterschiedlich sind, bedeutet dies, dab das Sozialprodukt unterschiedlich verteilt wird. Dies ist eine wertfreie Feststellung.

a) Dabei darf nicht die $P$ r o d u k t i o n $\mathrm{r}$ e g e 1 als wirtschaftsordnungssignifikant bezeichnet werden, wohl aber die Verteilungsregel. Denn Leistung an sich, ob individuell und "privat" erbracht oder als "gesellschaftlich notwendig" bezeichnet und kollektiv verlangt, kennzeichnet bisher noch jede aller denkbaren gesellschaftlichen ordnungen. Das gilt auch für die nichtkapitalistischen Wirtschaftsordnungen. ${ }^{4)}$ Es ist gerade nicht die gesellschaftsorganisatorische Institution des Privateigentums an den Produktionsmitteln, sondern der Primat der Arbeit, der Leistung also, der in sozialistischen Marktwirtschaften und in zentral-administrativen Systemen die Verteilung in der "Aneignung des Produktes" regelt. So sehr sich also auch die marktlichen und nichtmarktlichen Allokationsmechanismen in den individualistischen

4) "Auch in einer Zentralverwaltungswirtschaft ist die zentrale Leitung gezwungen, den Leistungslohn als Anreizmittel zu verwenden, wobei sie sich sowohl der überproportionalen Lohnsteigerung sowie besonderer Prämien und Strafen bedient ..." $w$. Eucken 1968, S. 316. - K.P. Hensel 1964, S. 335: Betriebliche Planerfüllung, Akkordlohnprinzip, Soll-Leistungen, Prämien materieller und immaterieller Art, Aufrufe und Propaganda zur Planübererfüllung, Aufbau eines Verwaltungsapparates zur systemtypischen Leistungskontrolle. 
und kollektivistischen Gesellschaftssystemen grundsätzlich von einander unterscheiden, so einheitlich gilt in thnen die Regel der Anwendung von Gratifikationen (P. Bernholz 1975, S. 179 f.) und Sanktionen bei Beachtung bzw. Nichtachtung des (für die primäre Verteilung beanspruchten) Leistungsprinzips. 5)

b) Demgegenüber erfuhr und erfährt die $v$ e $r t$ e $i$ l u n g s $r$ e $g$ e $l$ in der geschichtlichen Entwicklung vom liberalen stat bis hin zum Wohlfahrtsstaat eine ständige Korrektur und wird damit wirtschaftsordnungssignifikant: Gilt die Leistungsgerechtigkeit für den Staat des'Liberalismus' noch als die naturgegebene Gerechtigkeitsregel schlechthin und damit als nicht weiter veränderungswürdig, so wird sie mit dem Entstehen des Interventionsstaats mehr und mehr als korrekturbedürftig angesehen, und zwar einerseits durch die Kritik am Leistungsprinzip selbst, andererseits durch die Entwicklung einer korrigierenden Sozial- und Verteilungspolitik mit ihrer Orientierung am Bedürfnisprinzip.

In den Wirtschaftssystemen mit sozialistischer Marktwirtschaft ivordem Jugoslawien) und mit zentralplanwirtschaftlicher Verwaltung (siehe alte sowjetunion und der DDR), gewinnt gerade das Verteilungssystem ordnungspolitische Qualität (H. Willgerodt 1973, s. 94).6) Auch in den sozialistischen Wirtschaftssystemen mit zentraladministrativer Planung ist das offizielle Hauptziel der Verteilungspolitik nicht etwa die Entlohnung nach den Bedürfnissen (die hat nur ergänzende Funktion), sondern nach der Arbeitsleistung. Die besondere Bedeutung des Leistungsprinzips zeigt sich in der Heraushebung von Ubererfüllung der Sollvorgaben, aber auch in den Sanktionen für ihre Untererfüllung, die ihren Niederschlag findet in der Aufteilung des Effektivlohns in den Tariflohn (der aus der Einstufung jedes Beschäftigten in die verschiedenen Lohngruppen folgt) einerseits und den Mehrleistungslohn, die Mehrlohnprämien und die Jahresendprämie andererseits (H. Leipold 1976, S. 67) .

5) H. Willgerodt 1973, S. 90: "Das Leistungsprinzip ist im Sowjetsystem schon allein deswegen unentbehrlich, weil das zentralgeleitete Wirtschaftssystem wegen seiner unrationellen Lenkungsmechanik unter notorischen Funktionsmängeln leidet und den dadurch entstehenden Rückstand an Produktivität durch erhöhten Leistungsanreiz, aber auch Leistungsdruck wettmachen muB."

6) Siehe hierzu insbesondere H. Leipold 1976, S. 64. 
c) Mithin dürte in allen Wirtschaftssystemen das Leistungsprinzip sowohl als Produktionsregel wie auch als Verteilungsregel verwendet werden, mit dem Unterschied freilich, daB im zentralen Planungssystem die Bewertung der Leistung zusammen mit der Allokationsentscheidung ausschlieblich politisch entschieden wird (K.P. Hensel 1972, passim), also über behördliche Instanzen erfolgt, die zwar die MaBstäbe betrleblicher Leistung zentral festlegen, selbst aber nicht in den AustauschprozeB zwischen Produzent und Nachfrager eingegliedert sind. Dagegen sind in marktwirtschaftlichen Ordnungen die zuständigkeiten zur Definition und Bewertung der Leistung dem jeweiligen Empfänger von Leistungen zugeordnet (H. Willgerodt 1973, S. 102), was bedeutet, daB in einem primären Schritt der private Wettbewerb über die Verteilung entscheldet, in einem sekundären der staat korrigierend eingreift. Dadurch haben die Preise eher die Chance, Ausdruck der Nachfragewünsche und der knapphelt zu sein, ohne daB sie generell, gleichzeitig und der politischen Absicht nach die Funktion der sekundären Verteilung in sich aufnehmen (den Agrarmarkt müBte man hier wohl ausnehmen, wie überhaupt jeden subventionspolitisch "gestörten" Markt).

Der Vergleich beider Wirtschaftssystemtypen legt offen, daB die Produktionsregel system- $i \mathrm{n} d i f \mathrm{e} r \mathrm{e} t$ von der Funktion des Leistungsprinzips bestimmt wird, effizlente Faktoreinsatzpositionen $z u$ finden und $z u$ maximalem Faktoreinsatzergebnis $z$ u fuhren; in beiden systemtypen gilt Lelstung als das einzige stimulanz für ökonomische Aktivitäten; für beide systemtypen gilt, daB die Erreichung des Allokations-ziels davon abhängt, inwieweit die Preisbildung auf den Märkten von politischer EinfluBnahme - sei es durch markterhaltende oder -anpassende subventionierung, sei es durch verbindliche staatliche Planung - geprägt ist (wobei wir uns der Tatsache erinnern, daB auch die zentraladministrativen systeme ohne Preise nicht auskommen).

Als Verteilungsregel allerdings welst das Leistungsprinzip s y s $t$ e $m$ t y $p 1 \mathrm{~s} h$ e Unterschiede auf, zwar nicht hinsichtlich der Funktion, Leistungsäquivalenzen und -zurechnungen $z u$ ermöglichen (hier stehen beide systemtypen vor identischen, nicht überzeugend $z$ u lösenden Problemen), doch bei der Bestlmmung der Einkommensskalenpositionen. In marktwirtschaftlichen systemen deter- 
miniert die Preisbildung allein die primäre Verteilung; weitere verteilungspolitische Aktivitäten sind der politischen Entscheidung überlassen und von der ökonomischen eindeutiger abgegrenzt als in planwirtschaftlichen systemen.

In letzteren dagegen ist mit der Produktionsregel im wesentlichen auch die Verteilungsregel verordnet, da die Preise im politischen Planungsverfahren festgelegt werden und zugleich die Verteilung grundlegend vorwegbestimmen sollen.

d) Für den Fortgang der Gedankenführung ist nun - auch angesichts des oben beschriebenen Dilemmas - besonders erheblich, herauszustellen, inwieweit sich das Leistungsfähigkeitspostulat auf die ökonomischen Funktionen und Erscheinungsformen von Leistung in marktwirtschaftlichen ordnungen verlassen kann. Sollten sich Probleme bei der Bemessung und Zurechnung von Leistung im marktlichen Entlohnungsproze $B$ ergeben, kann das nicht ohne Auswirkungen auf ein Postulat bleiben, das zwar die sekundäre Einkommensverteilung regeln will, dabei aber auf der im Marktprozeß sich ergebenden primären verteilung basiert.

III. Wir gehen davon aus, daß in ökonomischer Betrachtung vom L e $i s t u n g s p r i n z i p$, in steuerlicher vom $p \circ s t u$ 1 a $t$ der Besteuerung nach der $L$ e $i s t u g s$ f $a \mathrm{~h} i g$ $k$ e $i t$ gesprochen wird. Während ersteres die grundsätzliche ökonomische Aktivität des einzelnen allokativ reguliert und das Entlohnungsergebnis bereits determiniert, setzt letzteres an diesem Ergebnis an,greift mithin im distributiven Bereich an und erzielt gewollte oder ungewollte allokative Wirkungen über die Reaktionen der Besteuerten.

Das ökonomische Leistungsprinzip geht dem steuerlichen Leistungsfähigkeitspostulat logisch vor, ist in einem system rationaler Besteuerung demnach die vorgegebene Richtgröße. Die Funktionen des Prinzips und Postulats sind in einer idealen Betrachtung die folgenden:

Das Leistungsprinzip hat zwei allokative Aufgaben zu erfüllen, nämlich erstens, das Entgelt für den Faktoreinsatz zu gewährleisten; hier ist das Leistungsentgelt Stimulanz- und zugleich Sanktionskriterium. Leistung und Entgelt führen als zweite allokative 
Aufgabe zu Produktivitätsfortschritt und Wachstum.

Úber die Äquivalenz von Leistung und Entgelt regelt das Leistungsprinzip auch zwei distributive Aufgaben, nämlich erstens die Ausstattung des Leistenden mit Kaufkraft und zweitens die Bestimmung der Einkommens-Skalen-Position des Leistenden. Leistungsentgelte bestimmen die Primärverteilung der Einkommen und führen $\mathrm{zu}$ Einkommensunterschieden, die ihrer seits allokative Funktionen haben.

Diese Funktionen und Beziehungen lassen sich wie folgt darstellen:

Allokative Funktionen der Leistung

1. Äquivalenzfunktion zurechenbare Faktorentlohnung gilt als in übereinstimung befindlich mit dem zurechenbaren Faktoreinsatz

2. Produktivitätsfortschrittsund Wachstumsfunktion

Faktorentgelte beeinflussen bei Kostenüberdeckung als Stimulantien, bei Kostenunterdeckung als Sanktionen den weiteren Faktoreinsatz distributive Funktionen der Leistung

3. Kaufkraftfunktion Leistungsentgelt bedingt die Ausstattung des einzelnen mit ökonomischen Tauschmitteln

4. Einkommens-SkalierungsFunktion

Entgeltunterschiede beeinflussen qua Leistungsmotivation und Wettbewerb das Streben nach Erringen bestimmter EinkommensSkalen-Positionen

Für eine steuerliche Betrachtung sind damit bereits die Bedingungen rationaler Politik bestimmbar: Die Besteuerung nach dem Leistungsfähigkeitspostulat muß sich erstens darauf verlassen können, daß die Idealbedingungen für das Leistungsprinzip tatsächlich vorliegen; tun sie das nicht, enthalten alle steuerlichen Sekundärverteilungsmaßnahmen, die an die Primärverteilung anschließen, bereits den Keim der zielverfehlung. Wir könnten hier von einer "passiven" Verletzung des Leistungsfähigkeitspostulats sprechen. Die rationale Besteuerung muß zweitens, selbst wenn die Funktionen des Leistungsprinzips in idealer Weise verwirklicht sind, so vorgenommen werden, daß sie ihrerseits die Idealbedingungen des Leistungsprinzips durch negative Rückwirkungen nicht verletzen. Geschähe das aber, könnte man von einer "aktiven" verletzung des 
Postulats sprechen. Die Idealbeziehung zwischen Leistungsprinzip und Leistungsfähigkeitspostulat ist gewahrt, wenn weder aktive noch passive Postulatsverletzung vorliegt.

IV. Ist Leistung sowohl in ihrer materiell-ökonomischen als auch ihrer ideell-psychisch-sozialen Qualität die vermittelnde Einflußgröße zwischen Allokation und Distribution, so ist folgerichtig auch die $B$ e $s$ e $u$ e $r$ u $g$ auf diese allokativ-distributive Interdependenz abzustellen. Einerseits sind die produktions- und wachstumswirksamen Leistungskräfte zu schonen; andererseits sind die Leistungsergebnisse gerade dieser Kräfte zum Zwecke der Aufbringung der allgemeinen Finanzmittel des Staates so zu belasten, daß bei der Verteilung der Steueropfer die Leistungskräftigeren stärker in Anspruch genommen werden als die Leistungsschwächeren. Eine überbetonung der Leistungsschonung bringt die Gefahr, die steuerbelastende Norm zu verfehlen und umgekehrt. Soll dieser allokativ-distributive Konflikt gesellschaftspolitisch akzeptabel aufgelöst werden, muß sich die Besteuerung darauf verlassen können, daB erstens das Leistungsprinzip in idealer weise realisiert ist und zweitens das Leistungsergebnis nach der Besteuerung als leistungsmotivierendes Stimulanz erhalten bleibt.

Sowohl in positiver als auch in negativer Richtung ist also eine Beeinflussung des ökonomischen Leistungsprinzips durch die konkrete Gestaltung der Besteuerung in der folgenden Weise möglich:

Allokative Funktionen der Leistung:

1. Beeinflussung der Primärverteilung durch Belastung bzw. Entlastung bestimmter Faktorentlohnungen

2. Beeinflussung der Stimulanzbzw. Sanktionsfunktionen der Faktorentgelte, mitteloder langfristig
Distributive Funktionen der Leistung:

3. Beeinflussung der Kaufkraftausstattung durch Maßnahmen der Sekundärverteilung (Besteuerung und Transfers)

4. Beeinflussung der Kaufkraftunterschiede zwischen Einzelnen und Gruppen im Hinblick auf die Leistungsmotivationen (durch Steuern und Transfers)

Im folgenden soll untersucht werden, ob die ökonomischen Idealbedingungen des Leistungsprinzips in der Realität vorliegen. 


\section{S 5 Die Kritik der ojkonomischen Bedingungen des Leistungs- prinzips}

I. Funktionseinschränkungen im Marktmechanismus 44

II. Unvollständige marktliche Leistungsinhalte 46

III. Unlösbare Leistungszurechnung 47

I. Die Allokation über den Markt wird als ein vom Leistungs-Ergebnis bestimmter Mechanismus aufgefaBt. Auf dem Markt hat der Preis eine Doppelfunktion: Er soll die Produktionsfaktoren allozieren und zugleich deren Entlohnung, d.h. die funktionale verteilung (= Marktverteilung) herstellen. Herrscht Wettbewerb, tendiert dieser dahin, die Gewinne der Marktteilnehmer auf die gesamtwirtschaftlich durchschnittliche Rate zu drücken bzw. zu heben, weil das Leistungsergebnis "Gewinn" Nachahmer und damit weitere Wettbewerber auf den Markt lockt (A. Stobbe 1983, S.301 ff). Insoweit vermag tatsächlich das Leistungsprinzip die volkswirtschaftlichen Faktoreinsatzmöglichkeiten aufzuspüren und tendenziell auch Verteilungsunterschiede einzuebenen (die lediglich tendenzielle Einebnung gelingt aber vorwiegend unter den Wettbewerbern auf gleichen Gütermärkten, weniger eindeutig zwischen der Gruppe der Unternehmer einerseits und der der abhängig Beschäftigten andererseits auf den Faktormärkten). So sehr auch der marktliche Allokationsmechanismus von der Leistung her bestimmt ist, so sind dennoch marktliche Verteilung und "Leistungsverteilung" analytisch zu trennen. ") Denn die marktliche Verteilung läBt auch solche Preisentgelte $z u$, denen kein Faktorbeitrag gegenübersteht, läßt andererseits auch Faktorbeiträge unentgolten. Diese mit dem Begriff der "externen Effekte" bezeichneten Phänomene indizieren ein Versagen des Allokationssystems, in dem bestimmte Präferenzen der Beteiligten nicht zum Ausdruck kommen bzw. nicht wahrgenommen werden. Funktionsmängel des Allokationsmechanismus übertragen sich auf den Verteilungsmechanismus. Nicht alles, was als Leistung definiert werden mag,

1) Dies entnehmen wir auch einer Formulierung von G. Krause-Junk (1974b, S. 41), der feststellt, daB "Marktverteilung" und "Verteilung nach der Leistung" $n a h e z u$ synonyme, also nicht vollständig inhaltsgleiche Begriffe sind. 
findet marktlich seinen Ausdruck. Leistung und marktliches Leistungs-Ergebnis sind nicht vollständig deckungsgleich.

Verzerrungen im Allokationsmechanismus "Marktwettbewerb", die sich in der Unvollkommenheit der Märkte und in der Manipulationsmöglichkeit von Knappheiten zeigen, können zunächst den Allokationsmechanismus selbst, ${ }^{2)}$ daneben aber auch den der marktlichen Entlohnung in Mitleidenschaft ziehen.

Einen weiteren $A n l a B z$ vorsichtiger Beurteilung des Markmechanismus, korrekte Leistungs-Ergebnisse herstellen zu können, entnehmen wir der Kritik an der Grenzproduktivitätstheorie. ${ }^{3)}$ Denn auch wenn man anerkennt, da $B$ eine Marktwirtschaft bei der Ermittlung der Faktoreinkommen die Marktpreisbildung gelten lassen muB und sich demgemäB die systemimmanente Ausprägung des Leistungsprinzips als eine Relation "Leistung gleich Preis" ergibt, spielen Determinanten in die Bewertung des physischen "Grenzprodukts" hinein, die gänzlich auBerhalb des Bereichs der Leistung des Faktors liegen (J. Klaus 1972, S. 39). In der Marktpreisbildung kommen nämlich leistungsfremde Momente, wie Modeströmungen, Zufallsentdeckungen, konjunkturelle Schwankungen u.a. zum Ausdruck (E. Preiser 1953, S. 25 f.). 4)

2) WB BMW 1979, S. 17, Ziff. 38: "Nach dem 'Prinzip der Trennung der Aufgabenbereiche' ist dem Preismechanismus die marktwirtschaftliche Allokationsaufgabe zugewiesen. Für die Lösung dieser Aufgabe hat er sich als das uberlegene Instrument erwiesen. Wo hingegen Eingriffe in das Preissystem dazu benutzt wurden, um stabilitäts- oder verteilungspolitische ziele zu verfolgen, waren die Ergebnisse im Hinblick auf die unmittelbar angestrebten Ziele meist enttäuschend. Vor allem aber hat es sich gezeigt, das der Preismechanismus für andere als allokationspolitische Ziele immer mit EinbuBen an gesamtwirtschaftlicher Effizienz verbunden ist."

3) Diese hat für das Problem der marktlichen Verteilung insofern eine besondere Bedeutung, als gerade sie, nach manchen Schwerpunktsänderungen und ihrer zuletzt festen Verankerung im System der Neoklassik (vgl. G. Bombach 1959, passim) eine gesetzmäBige Verknüpfung zwischen marktlichem Leistungswettbewerb und Faktorentlohnung herausstellt. Was die Kritik an dieser Theorie - wie auch an jeder anderen, die gleiches versuchen wollte begründet erscheinen läBt, 'ist ihr mit gleichem Gewicht vertretener allokativer und distributiver Erklärungsanspruch.

4) Eine Theorie, die als eine eigenständige Verteilungstheorie die Faktorpreise gerade aus der Produktionsfunktion erklären will, sich aber entgegenhalten lassen muB, daB die individuelle Leistung in der Preisbildung nur eines unter mehreren Elementen ist, verfehlt ihren Erklärungsanspruch, F. Machlup 1963, S. 197). 
II. L e is $t$ ung $\mathrm{s}$ i h a $1 \mathrm{t} e$, die der Markt entlohnt oder eben nicht entlohnt, die der Mensch gleichwohl als ökonomische oder metaökonomische Leistungen erbringt, sind von unterschiedlichster "Qualität". Grundverschieden sind zunächst Leistungsbegriffe, die irgendeine Beteiligung an der Sozialproduktserzeugung ausdrücken, von solchen, die weder output- noch inputorientiert sind, sondern im Konsumverzicht oder in der Kapitalbereitstellung $z$ u erblicken sind und die damit das grundsätzliche Anbieten von Faktoren zur Sozialproduktserzeugung und die ökonomische Dispositionsentscheidung überhaupt betreffen. Ob die Kapitalbereitstellung bzw. die Bereitstellung von Arbeitskraft eine Leistung genannt werden kann, bestimmt sich nach gesamtwirtschaftlichen wie auch nach einzelwirtschaftlichen Gesichtspunkten. Die Entscheldung des Kapitalgebers, der Produktion sein Kapital zur Verfügung zu stellen, ist angesichts evtl. vorhandener materieller Unabhängigkeit und Sicherheit von anderer "Qualität" als die Entscheidung des Anbieters von Arbeitskraft, wenn dieser wegen materieller zwänge keine Dispositionsfreiheit hat (Gäfgen 1972, S. 29). Leistungsqualitäten werden auch von der "Mühe" bestimmt, die für eine Leistung aufzuwenden ist.5) so überaus diskutierenswert diese Leistungen aus der distributiven sicht auch sein mögen, sie werden für die Entlohnung auBer Ansatz bleiben müssen. Die metaökonomische Leistung wird wegen ihrer Qualifizierung als eine nichtunternehmerische Faktorreproduktion nicht vom Markt honoriert, sondern allenfalls im Rahmen der staatlichen Distributionspolitik unter Heranziehung des Bedarfsprinzips entgolten werden können (B. Külp 1971, S. 139). Insofern hilft auch die Kritik, die man an der Grenzproduktivität wegen ihres entpersönlichten und rein materiellen Leistungsbegriffes geübt hat, hier nicht weiter, so

5) F.A. v. Hayek (1971, S. 114-121) widmet dem Problem der Mühe unter dem Stichwort "Entlohnung nach Verdienst" einen Diskurs, wobei er unter Verdienst erstens einen objektiv feststellbaren, nicht auf moralischen Anschauungen gestützten Tatbestand sieht und zweitens einen weder vom Ergebnis noch vom Zufall her, sondern einen durch die Mühe und Plage qualifizierten Tatbestand. Das Entgelten nach individuellem Verdienst erscheint ihm nahezu unmöglich, da es objektive und vergleichbare Kriterien nicht geben kann. 
stichhaltig sie in sich ist. ${ }^{6)}$ DaB es dem Markt nicht gelingt, auch solche Leistungsinhalte in den Leistungsbegriff einzuschlieBen, wird man ihm nicht vorwerfen können. ${ }^{7)}$ Hier liegt - wenn uberhaupt ein solcher EinschluB möglich ist - die Domäne der Sekundärverteilungsmaßnahmen.

Aus diesem Grunde stellen wir in unserer Untersuchung hier und im folgenden stets auf die "Leistungs-Ergebnisse" ab, die sich im Bereich der primären Verteilung in den Einkommen ablesen lassen.

III. Die individuelle Zurechnung von Leistung wird in dem MaBe schwerer lösbar, wie Leistung zunehmend "kooperativ" in immer komplexer werdenden Mensch-Maschine-Verbundsystemen erstellt werden (G. Hartfiel 1977, S. 20). Daneben aber sind es gerade die Systeme der in Arbeitsteams (Werkstattfertigung) koopierierenden Menschen in den fortgeschrittenen Formen industrieller Arbeit, die eine orientierung an der individuellen Leistung erschweren. Fazit: Es läBt sich im modernen ArbeitsprozeB eben jenes Grenzprodukt der Grenzproduktivitätstheorie als isolierbarer Faktor-

6) Die Grenzproduktivitätstheorie erklärt nämlich die Verteilung allein aus den technischen Gegebenheiten der Produktionsfunktion und läBt dabei alle sonstigen sozialen, politischen und ökonomischen Bestimmungselemente der Verteilung auBer Betracht. Obwohl die Leistungsentlohnung des Faktoranbieters, z.B. des Arbeitenden, erklärt werden soll, macht diese Theorie allein das Verhalten des Faktornachfragers $z u$ ihrem Untersuchungsgegenstand. Ferner ist die Leistungsentlohnung am physischen Grenzprodukt, d.h. am "output" der Leistungserstellung orientiert und entbehrt somit eines jeden zusammenhangs mit dem, was der zu Entlohnende an Mühen, Gesundheit, Intellekt und Anteilnahme einsetzt. Jedoch vermag kein Unternehmer die Grenzprodukte, nach denen er seine Arbeitnehmer entlohnt, richtig abzuschätzen (E. Streibler 1981, S. 87).

7) Eine Ergänzung erfährt der ökonomische Leistungsbegriff durch H. Leibenstein (1976), der moderne psychologische Konzepte in die Mikroökonomie einschließen will. Hauptvariable seines Systems ist die "Anstrengung" (effort) in ihren breitesten psychischen Dimensionen. Seine x-efficiency factors (die Motivation, die Anstrengung usw.) sollen die Verbindung zwischen der ökonomischen und der Verhaltenswissenschaft herstellen. Er miBt ihnen eine solche Bedeutung bei, daB er immerhin ein Spannungsverhältnis zwischen "X-Efficiency versus Allocative Efficiency" als für die wirtschaftlichen Aktivitäten bezeichnend ansieht. Der Hinweis auf Leibenstein soll verdeutlichen, daB in der mikroökonomischen Theorie das übliche Leistungsschema als ergänzungsbedürftig angesehen wird. 
anteil nicht auffinden. 8) "Der Bereich, in dem das physische Grenzprodukt zugerechnet werden kann, verkleinert sich zusehends" 9). Die von der "Theory of the Firm" entfachte "Markt-Firma-Kontroverse ${ }^{10)}$ berücksichtigt ebenfalls eigens die technisch-organisatorischen Eigenheiten des Produktionsprozesses, daB nämlich die Produktionstechnologie Teamproduktion ist und daB der Beitrag des einzelnen Teammitglieds zum Gesamtprodukt, also sein "Grenzprodukt", nicht exakt ermittelt werden kann (L.C. Thurow 1975, S. 70 f., Fn. 2). Dies führt dazu, besondere leistungsspezifische Organisationen, Zentralisierungen und "Vergemeinschaftungen" in der Führung sowie im wirtschaftlichen Ergebnis $z u$ entwickeln. 11) Die Unlösbarkeit einer exakten Leistungszurechnung ist letztlich der Grund dafür, daß die "Preisgestaltung" der Faktorbeiträge in der politischen Auseinandersetzung erfolgt. 12 l

8) Neben diesem Einwand, der die Abgrenzung der Leistungsanteile arbeitender Menschen betrifft, wird der Begriff "Grenzprodukt" schon deshalb fragwürdig, weil sich bei gleicher Technik eine zusätzliche Kapitaleinheit wohl nur mit gleichzeitigem zusätzlichem Arbeitsaufwand einsetzen läBt (P. Sraffa 1968); mithin läbt sich die Aussage der Grenzproduktivitätstheorie, die Profitrate werde durch das Grenzprodukt des Kapitals bestimmt, der Lohnsatz hingegen durch das Grenzprodukt der Arbeit, und nur durch dieses, nicht aufrecht erhalten.

$9)$ So G. Blümle 1975, S. 121; und weiter: "Gehaltszahlungen an Angestellte können ebenso wie Lohnzahlungen an Arbeiter, die immer mehr Uberwachungsfunktionen wahrnehmen, nicht in Bezlehung zum physischen Grenzprodukt gesehen werden." Dasselbe gilt für Test-, Marktforschungs- und Leitungsaufgaben.

10) "Firma" verstanden als organisatorische und wirtschaftliche Aktionseinheit; "Kontroverse" verstanden als den Gegensatz zwischen der firmeninternen Entscheldungs-Koordination gegenüber der marktmäBigen Koordination, die dann Platz greift, wenn Wirtschaftssubjekte, die nicht in Firmen organisiert sind, Güter produzieren und verkaufen.

11) A. Alchian/H. Demsetz 1972, S. $777 \mathrm{ff}$. - Sie gehen zurück auf R.H. Coase 1937, S. 386 f.

12) In der Kritik an der Verteilungslehre wird diskutiert, ob der Einbau von "collective-bargaining"-Prozessen den Informationsund Realitätsgehalt der Theorie erhöhen kann, die ohnehin die Vorgänge auf dem Arbeitsmarkt nur unvollkommen erfaBt; zwar könne solchermaBen der EinfluB der Gewerkschaften auf die Lohnbildung berücksichtigt werden, doch müBten nach wie vor die Ausgangs-Lohnforderungen und -angebote theoretisch abgeleitet werden; demnach könne man in bargaining-Prozessen allenfalls die spezielle institutionelle Form der Marktlohnbildung erkennen; E. Scheele 1979, S. 283. 
s 6 Die distributionspolitische zielriohtung des Leistungsfähigkeitspostulats

I. Die unsichere Basis für die Sekundärverteilung 49

II. Freiheit versus Sicherheit in der Besteuerung 50

III. Das Leistungsfähigkeitspostulat als politisches Handlungsprinzip in personaler orientierung

IV. Zusammenfassung des 2. Kapitels

I. Die Kritik an den Realisierungsmöglichkeiten des ökonomischen Leistungsprinzips soll darlegen, daß für das Leistungsfähigkeitspostulat bereits von seinem Ansatzpunkt, nämlich von der Primärverteilung her, die Ralisierungschancen als eingeschränkt anzusehen sind. Sie sind dies insoweit, wie bereits das Leistungsprinzip sich nicht rein verwirklichen konnte. Dennoch wird damit das Leistungsfähigkeitspostulat der Besteuerung, so wie es allgemein verstanden wird, nicht vollends unbrauchbar. Immerhin liegt aber eine Präformierung vor, da die distributiven verzerrungen, die bereits die Primärverteilung enthalten kann, auf den Vorgang der Sekundärverteilung übertragen werden. Insofern ist es nur erstaunlich, wenn in der Finanzwissenschaft allgemein das Leistungsfähigkeitspostulat als "ability to pay-principle" verstanden wird: So wie der marktliche ProzeB mit all seinen Verzerrungen des ökonomischen Leistungsprinzips die Faktorentlohnung hergestellt hat, gilt diese "Zahlungsfähigkeit" als Ausdruck echter steuerlichen Leistungsfähigkeit. Ausgangspunkt der Besteuerung ist das tatsächlich erzielte Marktergebnis im Vertrauen auf sein unverfälschtes und personal exakt zurechenbares Zustandekommen. Diese Basis der Besteuerung mu $B$ nach allem aber als unsicher bezeichnet werden.

Insofern ist es nur konsequent, wenn in der jüngerern finanzwissenschaftlichen Diskussion das Postulat vom grundsätzlichen her in Frage gestellt und statt seiner gleich die Formulierung verteilungspolitischer Ziele verlangt wird (K. Littmann 1970). Diese Frage wird im Dritten Teil dieser Untersuchung aufgegriffen. 
Vorerst wird hier das allgemein übliche Verständnis des Postulats verwendet, das die soeben geschilderte Problematik nicht erkennt. Es soll uns aber die unsichere Basis des allgemein nicht hinterfragten Postulats immer präsent bleiben, die in den Mängeln der Primärverteilung liegt. Aber diese Arbeit will ja nicht das Problem des "gerechten Lohnes" lösen.

Es ist die folgende Abgrenzung vorzunehmen: Wie das Äquivalenz-, so ist auch das Leistungsfähigkeitspostulat mit einer Doppelfunktion verknüpft worden (F.K. Mann 1937, S. 105), nämlich mit der

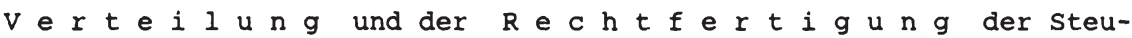
$\mathrm{er}^{1)}$. Letztere ist nicht unser Untersuchungsgegenstand. Demnach entfällt auch jegliches Eingehen auf das Verhältnis des Leistungsfähigkeitspostulat zum Áquivalenzprinzip und den bestehenden Gemeinsamkeiten und Unterschieden. Statt dessen interessiert hier das Postulat ausschließlich als jenes "Fundamentalprinzip", wie Haller (1981) es nennt, das die Verteiung einer finanzwirtschaftlich vorgegebenen Steuerlast regeln soll.

II. Die folgenden drei Phänome stehen in einem logisch-systematischen Zusammenhang: Erstens das verteilungspolitische Ziel, das aufgrund gesellschaftlich akzeptierter Gerechtigkeitskonventionen formuliert wird, zweitens das Prinzip, das mit Blick auf das $\mathrm{Ziel}$ die personale Verteilung der Steuerlast regeln soll, und drittens das Instrument steuer, das kraft ihm zugeordneter Funktionen eben jenes ziel verwirklichen soll und das daher prinzipiengerecht einzusetzen ist. Für den zusammenhang sorgt die $D \circ m i n a n z$ des $z$ i e 1 s : Ihm haben Prinzip und Instrument $z u$ dienen. Das Prinzip als allgemeingültige Handlungsnorm sorgt für die zielgerichtete Ausgestaltung des Instruments in Ubereinstimmung mit gesellschaftlich akzeptierten Grundwerten.

1) Der ständig zitierte Gegensatz zwischen dem Äquivalenz- und dem Leistungsfähigkeitsprinzip verdeckt im übrigen eine bestimmte Vielfältigkeit in den Steuerrechtferigungen; G.P. Ziemes (1980, S. $24 \mathrm{f.}$ ) ordnet ältere und neuere Ansätze anhand der multiplen Theorie des Haushalts von R.A. Musgrave. Auf die gleiche Weise ordnet b. Genser (1980, S. 12-31) die finanztheoretischen Steuerrechtfertigungen; nach Genser (S. 5, Fn. 3) umschließt die weitergefaßte Wortbedeutung von "Rechtfertigung" neben der Frage, ob überhaupt Steuern $z u$ erheben sind, auch die Frage nach der personalen Verteilung der Steuerlast. Dieser Auffassung folgen wir hier nicht. 
Wir problematisieren das ziel der $L$ a $s t v$ e $t$ e 1 l u n $g$, indem wir es in den Zusammenhang zwischen den Grundwerten F r e $i \mathrm{~h}$ e $i \mathrm{t}$ und $s i c h$ e $\mathrm{h}$ e $i t$ stellen: Die Besteuerung soll unter normativem Aspekt so erfolgen, daB für den Besteuerten sowohl die ökonomische Freiheit als auch die soziale Sicherheit in einem gegenseitig sich bedingenden (und auch begrenzenden!) Verhältnis möglich sind; zugleich soll die leistungsmotivierende Dauerergiebigkeit der steuer ${ }^{2)}$ als eine allokative und fiskalische Nebenbedingung gelten. ${ }^{3)}$ Die G e r e c h t i g $k$ e $i t$ taucht als ziel hier nicht auf, da sie als ein Grundwert gilt und als eine die Lastverteilung in horizontaler und vertikaler Weise begleitende Norm wirkt. Ziel der Besteuerung ist es nicht, Gerechtigkeit herzustellen, sondern die Lastverteilung in gerechter Weise vorzunehmen. Dieselbe "begleitende" Eigenschaft hat die Gerechtigkeit im übrigen auch, sofern allokative Ziele mit der Besteuerung verfolgt werden.

Fast unausweichlich geraten in der Besteuerung Freiheit und Sicherheit in einen Konflikt. రkonomisch bedeutet Freiheit für den Investor wie für den Konsumenten, daB er frei über die Einkommensund Gewinnerzielungs- wie auch -verwendungsmöglichkeiten sowie über den Vermögens- und Kapitaleinsatz disponieren kann. Jede Besteuerung schmälert diese individuelle Freiheit. Doch steht die Besteuerung in normativer sicht unter mehreren sie bestimmenden Anforderungen: Allokationspolitisch sollte - wenn man einmal alle Besteuerungsziele auBer Betracht läBt, die nicht in die allo-

2) Mit ökonomischer und zugleich freiheitlicher Politik ist notwendigerweise verbunden, auf die Motivierung $\mathrm{z}$ ur Leistung $\mathrm{Be}-$ dacht $z u$ nehmen. In den worten von F.K. Mann (1937, S. 95): "Sofern die Steuerwirtschaft keine vorübergehende Einrichtung ist, muB die Fähigkeit der Bürger zur steuerzahlung erhalten bleiben." Man darf folgern, daB die Motivation zur Leistung sich als ein systemstabilisierender Faktor erweist und daB sich aus der Uberspannung der Besteuerung bzw. aus dem Irrtum der Politiker über die Leistungskraft der Besteuerten dysfunktionale Konsequenzen ergeben.

3) Aus dem Gesichtswinkel der Systemstabilisierung geht die Besteuerungsnorm "Schonung der Steuerquellen" der Norm "Ausnutzen der Leistungskraft" vor, da sich nur ausnutzen läBt, was erhalten bleibt. Erhalten bleiben soll die Leistungsmotivation und -kraft generell. Sie hat eine gesamtwirtschaftliche Allokationsfunktion. Unterschiede in der Leistungskraft und im Leistungserfolg haben ebenfalls allokative Funktionen, da sie $\mathrm{zu}$ weiteren (auch besteuerbaren) Leistungen motivieren. 
kativ-distributive Problematik fallen ${ }^{4}$ - die Besteuerung nicht so weit getrieben werden, daB Demotivation und Leistungsverweigerung bel den Besteuerten wie auch bel jenen hervorgerufen würden, die in den GenuB der steuerfinanzierten Transfers kommen. Fiskalpolitisch muB aber die Besteuerung immerhin die gesellschaftspolitisch gewünschte Umverteilungs- und Sozialtransfermasse aufbringen. Distributionspolitisch gelten dieselben Motivations- und Leistungsargumente wie oben; die Besteuerung sollte nämlich nur ein solches MaB erreichen, daB die individuell $z u$ verantwortende und zu finanzierende Sicherung der Existenz und der Vorsorge bei den Besteuerten noch möglich bleibt, woraus folgt, daB diese Teile der Elnkommensverwendung unbesteuert bleiben. Doch selbst wenn solchermaBen die Bemessungsgrundlage zielentsprechend gestaltet wird, kann immerhin luber die progressivität des Tarifs die leistungshemmende Wirkung erreicht werden. Dies ist dann $z u$ erwarten, wenn die Politik der sozialen Sicherung ihr Sozialtransfer-Niveau nach oben verschiebt. Die Lösung dieses Konfliktes im Steuer-Transfer-System ist politisch zu finden. Das Leistungsfahigkeitspostulat kann nicht so verstanden werden, als diene es blind der Lastvertellung der Steuer und damit vorrangig dem Ziel der Finanzierung von UmverteilungsmaBnahmen, ohne auf die Belastungsfähigkelt des Besteuerten Bedacht zu nehmen. Die Abwägung zwischen beidem entscheidet uber die Interpretation des Leistungsfähigkeitspostulats .

III. Im Zusammenhang mit der Steuerlastverteilungsnorm nach der Leistungsfähigkeit verwenden wir die Termini Postulat, Grundsatz und Prinzip synonym. Unter den drei gültigen Interpretationsweisen von "P $r i n z i p "$ nämlich dem ontologischen Prinzip, 5$)$ dem Prinzip der Logik als einem "allgemeinen Satz" einer wissenschaftlichen Disziplin" und dem "praktischen" Prinzip (H. Delius $1958 \mathrm{a}, \mathrm{S} .71 \mathrm{f.l}$ als dem Prinzip der Moral, dem allgemein gultigen Grundsatz des Denkens und Handelns als einer Norm (kategorischer Imperativ) steht letzteres im Mittelpunkt unseres Interes-

4) Hierzu gehört vor allem das hier nicht problematisierte Stabilisierungsziel.

5) Man nennt dies auch das "Realprinzip" als den Seinsgrund der Dinge, der Ursache der realen Welt, A. Diemer 1958 , S. 232.

6) Dies sind die "Axiome" der Aussagenlogik, das den Aussagen

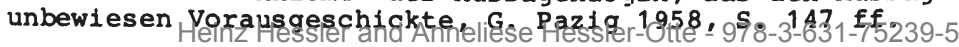


ses. Als Richtmaß für die Frage nach dem "richtigen Handeln" ist dieses prinzip aufs engste mit moralischen Werturteilen verbunden, so sehr auch Probleme der "Begründung" moralischer Forderungen wie auch des "Wesens" des moralischen Handelns dabei eine Rolle spielen (H. Delius 1958a, S. 74). Das "Prinzipielle" an der Besteuerung nach der Leistungsfähigkeit, das Modale nämlich, also die Frage, $w i$ e man in der Besteuerung "richtig" mit den Indikatoren der Leistungsfähigkeit umgeht, liegt letztlich darin, welchen Vorrang (oder Gleichrang) man den Grundwerten "Freiheit" und "Sicherheit" unter Wahrung der Gerechtigkeit einräumen will.

Zum Verhältnis von Leistungsfähigkeitspostulat und Gerechtigkeit folgen im 6. Kapitel detaillierte Darlegungen. Hier vorab nur soviel: Das Problem der Gerechtigkeit in der Besteuerung hat insofern eine hervorgehobene Position in der Finanzwissenschaft, als es gewissermaßen die vordem fast ausschließlich juristische steuerwissenschaft zur eigentlichen Finanzwissenschaft erhob. Dies geschah im 17. Jahrhundert und ist überdies mit den Namen Caspar Klock und später im 18. Jahrhundert mit Johann Heinrich Gottlob von Justi und Joseph von Sonnenfels verknüpft (D. Pohmer/G. Jurke 1984, S. 446f.). Gerechtigkeit aber drückt sich sowohl in den Fragen der Legitimität der Steuererhebung, der Rechtfertigung demnach, als auch in Fragen der Steuerlastverteilung aus. Gerechtigkeit ist die umfassendere Norm gegenüber der Norm der Lastverteilung. Man kann es auch so ausdrücken: Die Lastverteilungsnorm des Leistungsfähigkeitspostulats hat eine direkte, inhaltsgebende Verknüpfung mit der Gerechtigkeitsfrage, nicht aber mit der Rechtfertigungsfrage.

Schon aus der orientierung auf die individuelle Freiheit, soziale sicherheit und Gerechtigkeit geht hervor, daB das Leistungsfähigkeitsprinzip als steuerlastverteilungsnorm ausschlieblich person a 1 zu verstehen 1st. ${ }^{7}$ ) Dies ist auch historisch

7) Als "Pervertierung" (F. Neumark 1953 , S. 64) des Leistungsfähigke1tsgedankens mu $B$ es also verstanden werden, etwa eine höhere Leistungsfähigkeit der "Gesamtwirtschaft" anzustreben, was als ein allokatives ziel zu betrachten wäre. Auch die Leistungsfahigkeit einer Unternehmung als solcher ist eine Pervertierung, siehe hierzu unsere Darstellung in s 20.71-75239-5 
so entstanden. Die Orientierung des Prinzips auf die Person $\left.{ }^{8}\right)$ tritt uns in zweifacher Hinsicht vor Augen: Einerseits dadurch, daB die steuer dem Individuum eine seiner wirtschaftlichen Lage angepaBte persönliche steuertraglast zumiBt, andererseits dadurch, daB die Steuerpolitik auf die Relation der Einkommen und Vermögen $z$ wischen den Individuen Bedacht nimmt und die Last je nach den herrschenden Gerechtigkeitsvorstellungen unterschiedlich zuteilt. Folgerichtig wird unter den Indikatoren der Leistungsfähigkeit auch nur das persönliche Einkommen und das persönliche Vermögen verstanden. Einkommen und Vermögen sind die objektiven Merkmale subjektiver Leistungsfähigkeit.

\section{IV. zusammenfassung}

Die Ausführungen des 2. Kapitels fassen wir wie folgt zusammen: Besteht zwischen dem allokativen und dem distributiven Bereich des Wirtschaftens ein Interdependenzverhältnis, so zeigt auch der Begriff der Leistung, der ja einen wesentlichen Definitionsteil des Leistungsfähigkeitspostulats ausmacht, eine bivalente Eigenschaft, da er sowohl der allokativen als auch der distributiven Sphäre angehört. Denn das Leistungsprinzip ist einerseits eine (allokative) Produktionsregel, andererseits eine (distributive) Verteilungsregel. Eine faire und chancengleiche Ausgangslage unterstellt, soll Leistung kraft seiner stimulanzfunktion und seines Sanktionsmechanismus' den effektiven Faktoreinsatz sowie die Produktivitätszunahme ermöglichen. Ferner sollen Leistungsentgeltunterschiede die Einkommens-Skalen-Position der Individuen bestimmen und als Maßstab einer marktlichen Entlohnung gelten. Aber man kann sich in der ökonomischen wirklichkeit nicht immer bedenkenlos dem Leistungsprinzip überlassen. Der Marktmechanismus ist in seinen Funktionen eingeschränkt: Vollkommener Wettbewerb besteht

8) Weil wir uns auf die Definition von F. Neumark (1970, S. 135) stützen, sei diese in vollem Wortlaut wiedergegeben: "Der Grundsatz der Bemessung und Verteilung der Steuerlasten nach der individuellen Leistungsfähigkelt der Pflichtigen gebietet, die den einzelnen insgesamt zufallenden Steuerlasten so zu gestalten, daB diese unter Berücksichtigung aller für die Steverfähigkeitsindikatoren bedeutsamen persönlichen Momente das Verhältnis der individuellen Leistungsfähigkeit widerspiegeln und demgemäB die durch die Besteuerung bewirkten EinbuBen der einzelnen an ökonomisch-finanzieller Dispositionskraft als relativ gleich schwer anzusehen sind." 
nicht; individuelle Leistungsinhalte lassen sich nur unvollständig im ökonomischen Prozeß ausweisen und die Zurechnung der Leistungsergebnisse auf die Individuen ist exakt kaum möglich.

Das Dilemma einer Besteuerung nach der "Leistungsfähigkeit" die korrekter eine Besteuerung nach dem Leistungs-"Ergebnis" zu nennen wäre - liegt darin, daß sie in ihrer Lastverteilung auf einer Grundlage basiert, die unsicher ist. Diese eingeschränkte Anwendbarkeit des Steuerpostulats wäre dann besonders problematisch, wenn man von ihm erwartete, die Besteuerung so auszugestalten, daß individuelle Freiheit und soziale Sicherheit in einem gesellschaftlich vereinbarten Kompromißverhältnis zueinander realisiert werden: Verlangt die soziale Sicherung einerseits die steuerliche Schonung entsprechender Aufwendungen für die Existenz und Vorsorge (was zu Steuerminderaufkommen führt), andererseits einen gewissen Mindestbetrag an Transfervolumen (die nur bei einer deutlichen Steueranspannung finanzierbar ist), so verlangt die individuelle Freiheit die Erhaltung der Motivation zur Leistung und zur eigenverantwortlichen zukunftssicherung und damit eine bestimmte zurückhaltung im steuerzugriff. Beide Politiken sind demselben Prinzip überantwortet, nämlich dem Leistungsprinzip.

Wenn wir im Gange der Untersuchung das Leistungsfähigkeitspostulat erwähnen, wollen wir diese Diskrepanz zwischen Norm und Wirklichkeit nicht aus dem Auge verlieren.

Leistungsprinzip und Leistungsfähigkeitspostulat wurzeln im Allokativen wie im Distributiven. Deshalb betrachten wir die Interdependenz wie auch die analytisch-gedankliche Trennung beider Bereiche als die "Grundlagen" einer Theorie der Personalsteuern. 
Die Kritik der wirtschaftstheoretischen Bestimmungsversuche von Einkommen und vermögen

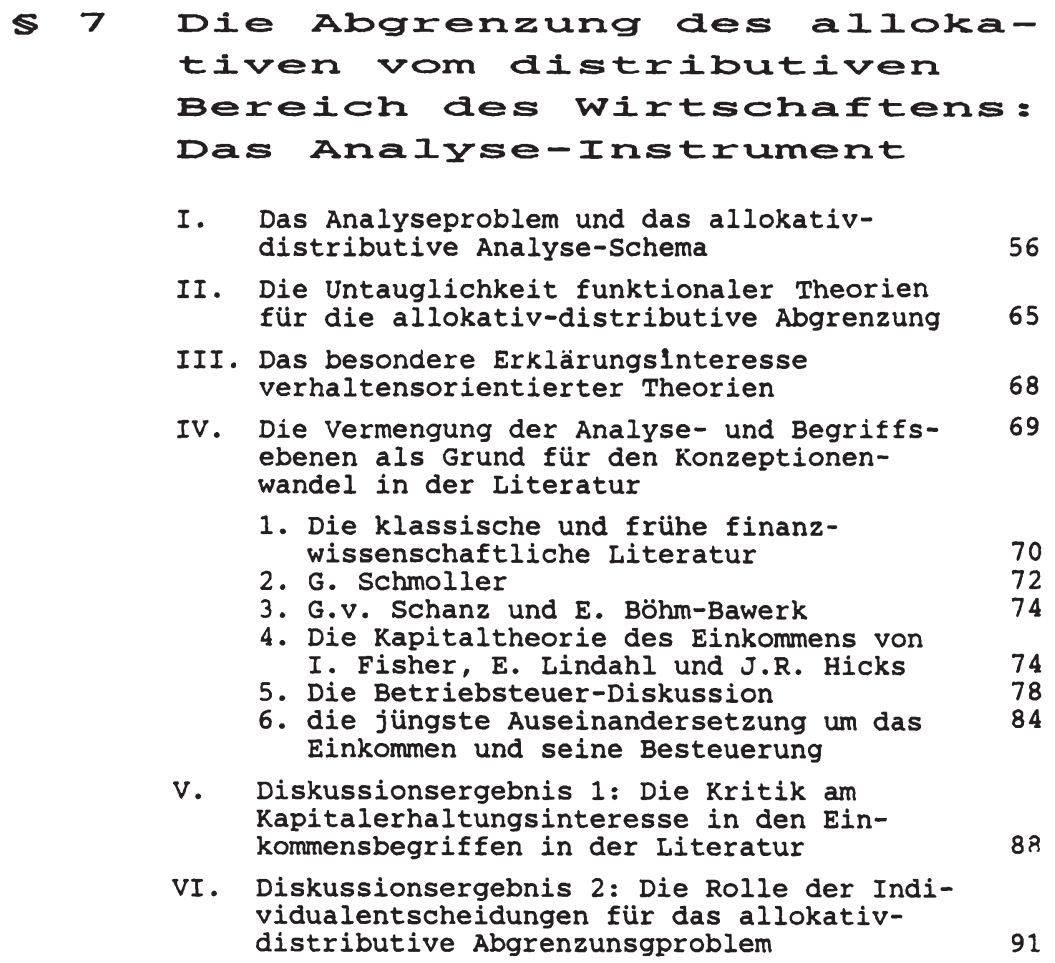

I. Einkommen und Vermögen wirtschaftstheoretisch zu bestimmen, muB als der unumgängliche Ausgangspunkt einer steuerlichen Begriffstheorie gelten. Die wirtschaftstheoretische Diskussion um den Einkommensbegriff läuft seit ihren Anfängen vorwiegend in die folgenden beiden Richtungen: Zum einen versucht man sich an der $I \mathrm{n} h$ a 1 t $s$ - Bestimmung des Einkommensbegriffs, zum anderen fordert man die Abgrenzung des Einkommens vom $K$ a $p$ t a 1 - Begriff (!). Im folgenden soll nachgewiesen werden, da $\beta$ 
sowohl die Inhalts- als auch die Abgrenzungsdiskussion von unzutreffenden Voraussetzungen ausgeht und demnach zu falschen Ergebnissen führen mußte. Diese haben leider die Diskussion des Einkommensbegriffs bis heute nachteilig beeinflußt und zu einer heillosen Verwirrung beigetragen. Das hatte außerdem seine nachteiligen Auswirkungen auch auf die Diskussion des steuerlichen Einkommensbegriffs.

Beide Theorien, die wirtschaftstheoretische und die steuerliche, sind strikt auseinanderzuhalten, da sie unterschiedliche Erklärungsinteressen verfolgen (F. Neumark 1961b, passim). Mithin werden sich Einkommens- und Vermögensdefinitionen danach unterscheiden, welches Interesse jeweils im Vordergrund steht: Die Erklärung der ökonomischen Zusammenhänge oder die Erklärung der für die Besteuerung maßgeblichen Leistungsfähigkeit.

Eine dritte Diskussionsrichtung befaßt sich mit den Funktionen, die Einkommen und Vermögen haben. Es zeigt sich aber, daß solche Theorien den begrifflichen Inhalt bereits voraussetzen und daB sie insbesondere $\mathrm{zu}$ erklären versuchen, wie die einzelnen mit Einkommen und Vermögen umgehen und welche Auswirkungen diese Verhaltensweisen auf ihre gesamten ökonomischen Aktivitäten und Positionen haben können (siehe unten III).

a) Der Versuch, Einkommen in Inhalt und Abgrenzung zu definieren, tritt uns besonders plastisch in einem Fragenkatalog von W. W. Hewett (1925, S. 9) entgegen, ist aber fast immer in ähnlicher Weise so formuliert worden. 1) Die Frage, "was gehört zum Einkommen?", läßt sich in der folgenden weise strukturieren:

(1) Der Geldbetrag, den man innerhalb eines zeitabschnitts erwirbt?

(2) Die Produktions- und Konsumgütermengen, die man damit kaufen kann? dies ist die Frage nach der $E r$ $z i$ e $l u n g$ von Erträgen und Einkommen einschließlich der ver $r$ u $B$ e r ung s e r l ös e für Kapital und Vermögen;

hier wird auf die $V$ e $r$ w e $n$ d u n g eines rein $m$ o $n$ e $t$ ä $r$ e $n$ Begriffes abgestellt;

1) So bei E.R.A. Seligman 1894; G.V. Schanz 1896; H.C. Simons 1938; G. Krause-Junk 1977; N. Andel 1979a; Musgrave-MusgraveKullmer 1980; R. Goode 1980, um einerseits zeitlich weit auseinanderliegende, andererseits englisch- und deutschsprachige Beiträge beispielhaft zu nennen. Der Katalog wurde von uns detaillierter gefaßt, als er in den genannten Beiträgen geboten wird, wurde auch anders systematisiert. 
(3) die Befriedigung, die man aus dem Verbrauch der Konsumgüter gewinnen kann?

(4) die Ersparnisse zu betrieblichen und privaten Zwecken, die in der Periode gebildet werden?

(5) das Nichtgeldeinkommen?

(6) die Erbschaften und Schenkungen?

(7) die Werterhöhungen des betrieblichen Kapitals und des privaten Vermögens?

(8) die Reserven in den Unternehmungen, die den Eigentümern gehören? dies sind $m$ e $t$ a 0 k $\circ \mathrm{n} \circ \mathrm{m} i$ $s \mathrm{c} h$ e Fragen, die allein für den $d i s t r i b u t i v$ e $n$ Bereich formuliert werden;

damit wäre dann die gesamte potentielle Geldbetragsverwendung begriffsbestimmend geworden;

d.s. alle Formen der Naturalentlohnungen, Nutzungen des (akkumulierten und erworbenen) Vermögens, auch des Humanvermögens und der Werterhöhungen des materiellen Vermögens ;

im Gegensatz zu den (distributiven) Nutzungen würden dann die Vermögensstämme selbst in den Einkommensbegriff aufgenommen;

eine solche Zurechnung beträfe wie bei (6) den Vermögensstamm, wäre aber vorläufig noch undifferenziert danach, ob auch nominelle oder nur reale, ob bereits realisierte oder noch nicht realisierte Werterhöhungen $z$ um Einkommen zählen sollen;

in diesem Fall wird, wie bei (1) (2) (4) (5) (7), der Bereich der a 1 l $\circ \mathrm{k}$ a $t \mathrm{i}$ e $\mathrm{n}$ (betrieblichen) Kapital- und Ertragswirtschaft in den persönlichen Einkommensbereich einbezogen.

Die Strukturierung verdeutlicht, daB drei Problemkreise mit den Definitionen berührt werden: Erstens der mögliche EinschluB auch metaökonomischer Phänomene; zweitens die versuchte Trennung des "Zugangsproblems.2) vom Bestandsproblem (namentlich für den distributiven Bereich ist der analytischen Trennung zwischen Einkommen und Vermögen einiger Raum gewidmet worden); drittens das (nicht wahrgenommene) allokativ-distributive Abgrenzungsproblem mit einer analytisch äuBerst unglücklichen Vermengung der beiden Sphären "Betrieb" (mit Kapitaleinsatz und Ertragswirtschaft) und "Haushalt" (mit Vermögensgrößen und Einkommenserzielung wie auch -verwendung).

2) Das Zugangsproblem ist für die begriffliche Theorie so grundsätzlich, daB wir ihm unten weitere Ausführungen widmen. 
Die Spannweite in der Fragestellung und die Heterogenität der einzelnen Tatbestände lassen schon vermuten, daB es äuBerst schwierig sein dürfte, auf diese Weise Einkommens- und Vermögensbegriffe $z u$ definieren, wenn theoretischen Ansprüchen der Eindeutigkeit und Konsistenz genügt werden soll.

b) Bevor in extenso auf Definitionsversuche in der Literatur eingegangen wird, soll ein A n a 1 y s e - S c h e m a entwickelt werden, das es erlaubt, verschiedene Einkommensbestandteile auszuweisen, sie den Phasen der Einkommenserzielung und -verwendung sowie dem Vermögensbereich zuzuordnen und schlieBlich die GröBen Kapital, Ertrag, Einkommen und Vermögen in einen allokativ-distributiven Zusammenhang $z u$ rücken (Schaubild 3.1). Mithin soll versucht werden, in ihm exakt jene probleme $\mathrm{zu}$ lokalisieren, die die bisherige Diskussion bestimmt haben, nämlich das Zugangs- und das Abgrenzungsproblem.

(1) Im weiteren Verlauf der Untersuchung wird von den zugehenden

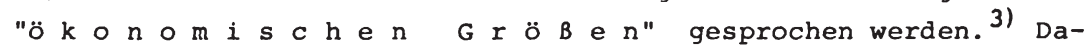
mit sollen erstens nichtökonomische "Einkommenskonzepte", wie etwa psychische Erlebnisse, ausgeschlossen werden; zweitens soll hervorgehoben werden, daB die Zugänge meBbar sind.

(2) In Ubereinstimmung mit vielen Einkommensdefinitionen wird vom $\mathrm{Z}$ u g a $\mathrm{n} g$ an ökonomischen GröBen gesprochen. Der Ausdruck "ZufluB" wird vermieden, um MiBverständnisse als GeldzufluB und Verwechslungen mit der Quellentheorie zu vermeiden, die ein Fließen aus ständig zur Verfügung stehenden Quellen zu ihrem Definitionsbestandteil für Einkommen macht. "Erwerb" oder "Erzielung" ökonomischer Größen würde zuviel Absicht im Einkommenszugang oder zuviel Rationalität ausdrücken; demgegenüber umschlieBt "zugang" auch den Zufall im Eintreffen ökonomischer GröBen wie auch deren Wertzuwachs ("Accretion Approach") .

Inhaltlich speist sich der Zugang sowohl aus Erträgen und Einkünften wie auch aus Vermögensanfall (Erbschaften, Schenkungen, Glücksgewinn, Kapitalauszahlungen). Personal meint zugang den ort des Eintreffens und zusammentreffens von ökonomischen GröBen

3.) Siehe die Verwendung dieses Terminus bei F. Klanberg 1981, S. 13. - Siehe ferner die Interpretation der "ökonomischen Güter" bzw. "GröBen" als Einkommen und Vermögen bei G. KrauseJunk 1981 , S. 260. 
Schaubild 3.1: Analyse-Schema des Zusammenhangs zwischen Kapital, Ertrag, Einkommen und Vermögen ${ }^{\star}$

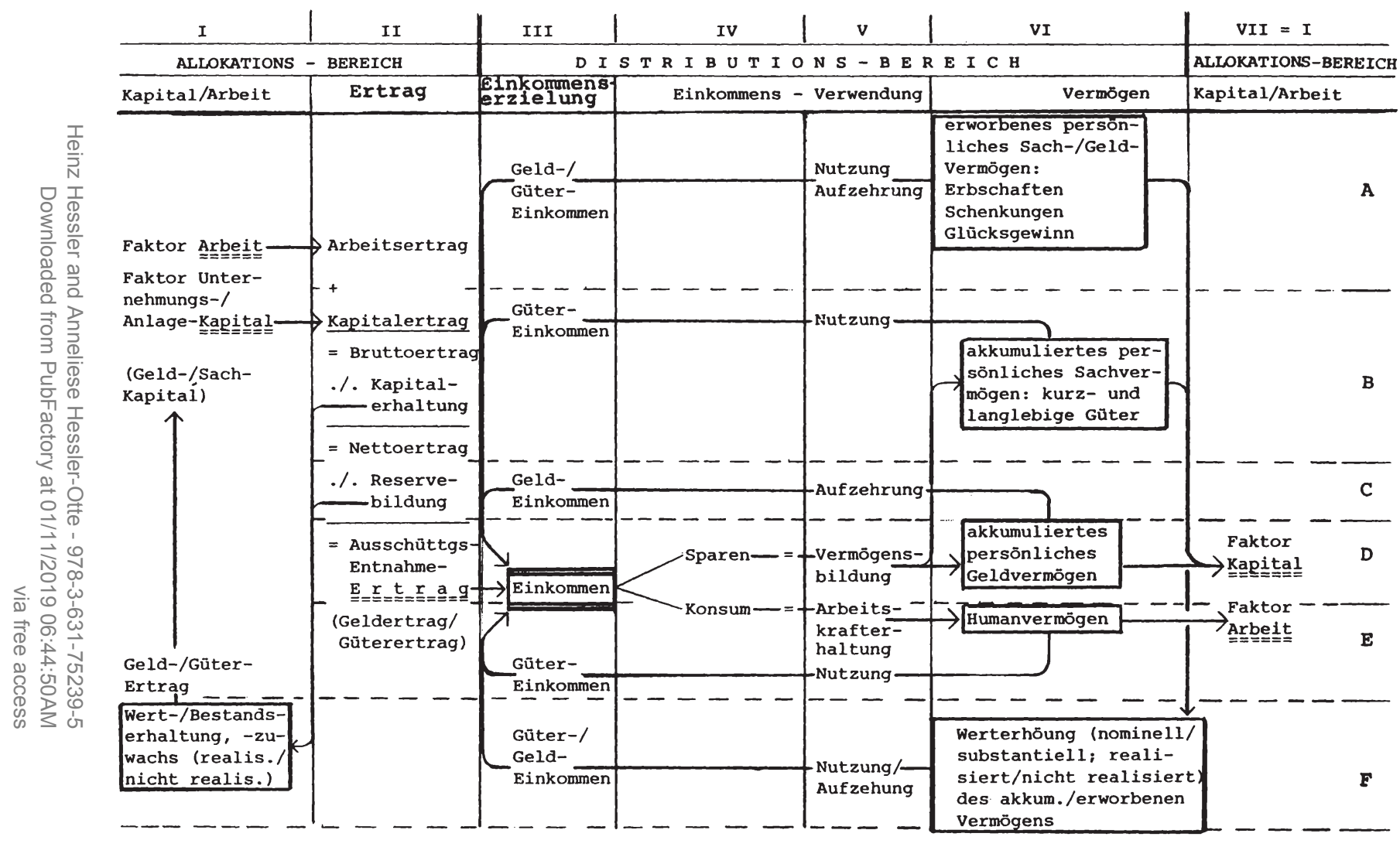


*) Bemerkungen zum 6-Phasen-Analyseschema

- Die in der Kopfzeile ausgewiesenen Phasen I bis VI (Phase VII ist identisch mit Phase I) folgen einem logischen Schema ökonomischer Entscheidungen, beginnend mit dem Faktoreinsatz, endend mit neuerlichem Faktoreinsatz nach allen Vorgängen der Einkommenserzielung und -verwendung sowie Bestandshaltung und -nutzung;

- die in der letzten Spalte ausgewiesenen Zeilenbezeichnungen A bis F benennen die verschiedenen Geld-, Güter- und Vermögensgrößen und Verwendungsarten

- die Zwecke der Schema-Darstellung sind die folgenden:

-- Darstellung, daB grundsätzlich die Begriffe Einkommen und Ertrag wie auch die Begriffe Vermögen und Kapital verschiedene Tatbestãnde des Wirtschaftens benennen, daB sie aber in einem ökonomischen und zeitlichen Zusammenhang stehen;

-- Zuweisung dieser Begriffe zu den Bereichen der Allokation und Distribution (I/II U. III-VI);

-- Nachweis, daß die Kreislaufphase der Einkommenserzielung wie auch das Halten des Vermögensbestandes sowohl allokative wie auch distributive Relevanz haben (II/III u. VI/VII);

-- Darstellung, daß mit Vermögensbestandsgrößen - soweit sie nicht allokativem Einsatz zugeführt werden - je nach der Vermögensverwendung (Nutzung oder Aufzehrung) verschiedene Arten von Einkommen verbunden sind, nămlich Geld- und Gütereinkommen (III/A bis C und E, F).

- Verschiedene GröBen und Einflüsse sind im Schema nicht nachgewiesen:

-- Das Schema enthält nur ökonomische, keine meta-ökonomischen Größen und Einflüsse, wie etwa die psychische Größe der Bedūrfnisbefriedigung aus Güter-, Geld-Einkommen und Vermögen;

-- das Schema enthält unter den ökonomischen Größen und Einflüssen nur die entscheidenden und direkt einkommensbeeinflussenden, vernachlässigt also unter dem Verwendungs- und Vermögensaspekt etwa die Vorsorge- und Kreditfähigkeitsprobleme (VI/B und D), die indirekt oder zeit-verzögert einkommenschaffend bzw. ertragschaffend wirken können.

-- das Schema vernachlässigt im allokativen Bereich die vielfältigen weiteren Kürzungen eines Bruttoertrages zur sonstigen Aufwandsgestaltung auBer denen der Kapitalerhaltung und-reservierung, da dies der Zielsetzung der Analyse direkt entspricht.

-- das Schema vernachlãssigt im distributiven Bereich die Transfers folgender Art: die offentlichen Transfers sind nicht enthalten; die privaten nur hinsichtlich der mit Vermögen verbundenen, die laufenden Geldtransfers (Unterstūtzungen, Sachleistungen) sind nicht aufgewiesen; siehe hierzu Ubersicht 3.2 und 3.4. 
bei einer Person. Insofern ist Zugang für das Einkommen der Definitionsbestandteil, die logisch und institutionell eindeutige Flxierung; und: sowohl geldliche wie güterliche zugangsarten, periodische und aperiodische Zugangsformen und Zugänge aus jedweder Quelle sind denkbar. ${ }^{4)}$

Bezugspunkt des Zugangs ist das Feld III/D des Schemas, das die einkommensbeziehende "Institution" (Person bzw. Haushalt) grafisch lokalisiert. 5) An diesem ort kommen die Bestandteile des Einkommens zusammen, hier exakt ist die "Nahtstelle" zwischen dem allokativen und dem distributiven Bereich des Wirtschaftens.

In der Literatur ist der Inhalt der Einkommens- und Vermögensdefinitionen weithin durch die "Zugangsregel" geprägt. Diese wird nicht ausschlieblich monetär, sondern weithin auch güterwirtschaftlich verstanden. Ein ausschlieBlich monetär aufgefaBtes Einkommen würde nicht sämtliche zugehenden VerfügungsgröBen (Rechte, Werte, Nutzungen etc.) repräsentieren und wäre $\mathrm{zu}$ eng begriffen. Monetärer Zugang ist eine Geldeinnahme sowohl aus dem Ertragsbereich (D/II-III) als auch aus dem distributiven Bereich in Form von Aufzehrungen des akkumulierten und/oder erworbenen Vermögens samt seiner realisierten Wertzuwächse (III/A, C, u. F).

Güterwirtschaftlicher Zugang stammt sowohl aus der naturalen Entlohnung der Ertragssphäre (D/II-III) als auch aus der Nutzung akkumulierten und/oder erworbenen Vermögens einschlieblich seiner nicht-realisierten Wertzuwächse (III/A, B, E u. F). Allerdings besteht bei den güterwirtschaftlichen Zugängen stets das Problem des adäquaten Ausdrucks in Geld. Der gemeinsame Nominator Geld drückt mithin das geld-güterwirtschaftliche Totaleinkommen aus.

Die zugangsregel legt ferner offen, daß Einkommen nicht ausschließlich aus den sog. produktiven Leistungsbeiträgen im allokativen Bereich, sondern auch aus dem distributiven Bereich des privaten vermögens stammt.

4) Demgegenüber würde "Zuwachs" eher eine Wertsteigerung als einen gegenständlichen Zugang ausdrücken.

5) F. Neumark 1947, S. 36: "Das einzig Verbindende zwischen den verschiedenen Einkünften, die sich zu 'Einkommen' zusammenschlieben, liegt in der Person ihres Beziehers". - G. Wöhe 1978, S. 78: "Vom Ertrag unterscheidet sich das Einkommen dadurch, daB letzteres stets auf ein subjekt, ersterer auf ein objekt bezogen ist. ... Der Ertrag des Betriebes wird erst dann zum Einkommen, wenn er einem Wirtschaftssubjekt zuflieBt." 
In diesem sinne läßt sich von der "Zugangsregel" des Einkommens als einer Regel sprechen, die weder bereichs- noch quellenspezifisch zu verstehen ist

Ihren literarischen Ausdruck findet diese Regel normativ im Allgemeinheitspostulat (siehe $\S 22$ ) und in dem, was man heute das "SHS"-Konzept (Schanz-Haig-Simons-Konzept) nennt. Gerade H.C. Simons hat dieses Konzept seit seiner Personal Income Taxation (1938) - basierend auf einer "political philosophy", die w. Hettich (1979, S. 2) eine "severely libertarian" nennt - mit solcher Uberzeugungskraft vertreten, daB sich das Paradebeispiel heutiger steuertheoretischer,-politischer und -reformerischer Argumentation, der "Report of the Royal Commission on Taxation" Kanadas (Carter Report, Ottawa 1966) in seinem normativen Konzept der "comprehensive tax base" (siehe auch die moderne Steuerdiskussion in den USA seit 1977) stets auf Simons beruft.

(3) Unter dem Abgrenzungsproblem verstehen wir die grundsätzliche Scheidung des allokativen vom distributiven Bereich des Wirtschaftens. Diese Trennung ist als analytisches Vorgehen, also instrumentell zu verstehen, da nicht behauptet werden soll, es wäre in der Wirklichkeit immer eine reinliche Trennung der Bereiche des Wirtschaftens anzutreffen. E. Schuster (1961, S. 56) kommt in seiner "institutionellen" Begriffsfassung für Einkommen $2 u$ der folgenden Unterscheidung der Wirtschaftsbereiche: "Einkünfte die im Betrieb verbleiben und über die vom Betrieb her verfügt wird, ... sind nicht Einkommen. Die Selbstfinanzierung des Betriebs aus seinen Einkünften ist daher nicht dem Einkommen seiner Betriebsinhaber zuzurechnen." Dieselbe klare Diktion geht aus der Darstellung von G. Wöhe hervor: "Wird der Reinertrag eines Betriebes, der sich bilanzmäßig als Gewinn zeigt, nicht in voller Höhe an die Eigentümer ... ausgeschüttet, so stellt z.B. der zum zweck der Selbstfinanzierung zurückbehaltene Teil des Gewinns kein Einkommen dar, denn er ist keinem Wirtschaftssubjekt zugeflossen, sondern ist eine ... Kapitalbildung" (1978, S. 79).

So auch F. Neumark (1970, S. 133), der diesen Aspekt im Rahmen seiner Untersuchung einer Unternehmensbesteuerung (die er als Besteuerung der Kapitalgesellschaften diskutiert) wie folgt berücksichtigt: Für die Besteuerung der Kapitalgesellschaften kommen "(in gewisser Weise analog wie bei den natürlichen Personen) Einkommen und Vermögen in Frage, doch würde man bei körperschaftHeinz Hessler and Anneliese Hessler-Otte - 978-3-631-75239-5 
steuerpflichtigen Personen besser von 'Gewinn' ... bzw. 'Ertrag' sprechen."

Das Schema 3.1 zeigt demnach im Bezugsfeld D/II-III, daB erstens "Ertrag" eine allokative Größe, "Einkommen" hingegen eine distributive Größe ist, Ertrag also niemals mit Einkommen gleichgesetzt werden kann. Es zeigt zweitens, daß die Phase der Einkommenserzielung den Ubergang vom allokativen in den distributiven Bereich markiert, wie das übrigens in sämtlichen Kreislaufschemata zum Ausdruck kommt: Die Einkommenserzielung bzw. -entstehung nimmt ihren Ausgangspunkt in den Produktionswirtschaften und endet bei den Haushaltswirtschaften, wo Erträge, die entnommen oder ausgeschüttet wurden, zu Einkommen werden. Vorgänge, die den Ertrag mehren oder mindern, sind im allokativen Bereich lokalisiert (Kapitalerhaltung, Reservebildung); sie sind keine Vorgänge der Einkommensveränderung im distributiven Bereich.

Einkommen ist, was seine personale Höhe und seine interpersonale Verteilung betrifft, seine konsumtive Verwendung (Konsumquote) und seine sparverwendung (Ausstattung mit persönlichem vermögen) angeht, eine distributive GröBe, ist allerdings hinsichtlich seiner Entstehung in Art und Höhe allokativ vorbestimmt. Uber die Verwendung ist Einkommen zugleich abermals mit dem allokativen Bereich verbunden, sofern die regenerierte Arbeitskraft und die Akkumulation von Humanvermögen als Arbeitsfaktor produktiv eingesetzt werden und sofern privates Vermögen in Form von Kapital dem produktionswirtschaftlichen Einsatz zugeführt wird. Die Verwendung des Vermögens $z$ um produktiven Einsatz ist eine Verwendungsm $\check{g} \mathrm{~g} i \mathrm{c} \mathrm{h}$ e $i \mathrm{t}$ von Einkommen, nicht hingegen eine Notwendigkeit. Die allokative Funktion, die Einkommen erfüllen kann, macht deswegen Einkommen noch nicht $z$ u einem allokativen Begriff. Aus diesen Gründen ist eine strikte Trennung der allokativen und distributiven Bereiche bei den Definitionsversuchen für Einkommen unabdingbar. Schon jetzt läBt sich festhalten, daB Abgrenzungsversuche zwischen "Einkommen und Kapital" die Betrachtungsebenen in logisch nicht zulässiger Weise vermengen und begriffliche Verwirrung stiften. 6) Kapital und Vermögen gleichzusetzen, würde den Unterschied verwischen, den sie hinsichtlich ihrer allokativen bzw. distributiven Funktionen für den wirtschaftenden Menschen haben. 7) Die allokative Funktion des ("Produktions")- 
Kapitals zeigt sich in seinem Einsatz als Faktor der Le1stungserstellung und Ertragserzielung, mithin in seiner betrieblichen oder unternehmerischen Funktion. Demgegenüber liegt die distributive Funktion des Vermögens u.a. darin, dem einzelnen Sicherheit für seine gegenwärtige und zukünftige Existenz zu bieten, sei es dadurch, daB er es nutzt, sel es dadurch, daB er es verwertet oder überträgt (C. Folkers 1979, S. 267 f.), ihm darüber hinaus die Möglichkeit der Einkommens- und Konsumsteigerung zu gewähren (H. J. Krupp 1975, S. 27).

II. Es läbt sich nun danach fragen, wie die Einkommenstheorie sich selbst definiert und wie sie den Unterschied zwischen funktioneller und personeller Verteilung verarbeitet. Wir erinnern daran, das die Fragen der $f$ u $\mathrm{n} t \mathrm{i} \circ \mathrm{n}$ e $\mathrm{l} l$ e $\mathrm{n}$ Vertellung a $11 \circ k$ a $t i v e$ Probleme, jene der personellen Verteilung hingegen distributive Probleme sind.

a) Ein historischer Rückblick macht offenkundig, daß über weite Abschnitte der Theoriegeschichte hinweg in der "Einkommenstheorie" das allokative Denken überwiegt. Soweit sie ausschlieblich funktionelle Theorie ist, kann das auch nicht uberraschen. In seinem Uberblick über die Einkommenstheorie seit dem Merkantilismus legt $w$. Hofmann (1965) dar, daB Einkommenstheorie weithin allokativ definiert wurde. Das gilt mit sicherheit für die vorklassik und wohl auch für die Klassik selbst, ${ }^{8}$ ) ja in Grenzen

6 ) $\mathrm{DaB}$ eine terminologische sauberkeit notwendig ist wird heute nicht bestritten; beispielhaft für diese Notwendigkeit ist z.B. die Abgrenzung zwischen Kapital und Vermögen, die das Kapital der Produktions-, Ertrags oder Erwerbssphäre zuweist, das Vermögen hingegen dem persönlichen Bereich; siehe hierzu G. Weisser 1961, S. 163 f.; W. Ehrlicher 1956 u. 1964; H. Peter 1956, S. 489 f., A. Stobbe 1976, S. 273; E. Schuster 1961, S. 56; G. Wöhe 1988, S. 108; G. Heidinger 1982, S. 268.

7 ) Für eine terminologische Sauberkeit spricht sich z.B. auch F. Neumark (1970, S. 133) aus, wenn er feststellt, daB im Berelch der persönlichen Besteuerung von Einkommen und Vermögen, im Bereich der Körperschaftsteuerpflicht dagegen von Kapital und Gewinn zu reden sei; diese im Zusammenhang mit der Besteuerung gemachte Unterscheidung darf man wohl auch für seine Vorstellungen zur Theorie des Einkommens und seines Begriffes unterstellen. - Siehe hierzu im übrigen $\S 11$ und Ubersicht 3.6 - G. Heidinger (1982, S. 268) trennt die Besteuerung streng nach "Wirtschaftssphären".

Fn. 8 nächste Seite 
sogar für die sozialreformerischen Theorien, 9 ) erst recht aber für die Marx'sche Lehre, denn der Ertrag der Faktoren (Faktoreigner) kann mit dem Einkommen der sozialen Klassen gleichgesetzt werden. ${ }^{10)}$ Die Grenznutzentheorie - so subjektivistisch sie sich gibt - und die Grenzproduktivitätstheorie - sie erst recht wegen ihrer objektivistischen Ausrichtung - knüpfen beide an die $\mathrm{F} a \mathrm{k} t \circ \mathrm{r}$ e $\mathrm{n}$ des Produktionsprozesses an und offenbaren solchermaßen a $11 \circ \mathrm{k}$ a $\mathrm{i} v$ e $s$ Denken.11) Sogar in den Verteilungskampftheorien ("Macht oder ökonomisches Gesetz"?), in denen sozioökonomische Gruppen um Verteilungspositionen streiten und in denen nicht die ökonomischen Argumente im Vordergrund erwartet werden, kehren bestimmte Monopol- und oligopolanalogien wieder einschlieblich ihrer preis - und damit allokationstheoretischen Implikationen. 12)

8) Die Klassik "hat mit ihrer Einkommenslehre die anhebende Erwerbsgesellschaft als eine nach rein ökonomischen Merkmalen sich gliedernde verstanden und den Kontrast der groBen sozialen Gruppen auf die Verschiedenartigkeit ihrer Einkommen zurückgeführt." W. Hofmann 1965, S. 51.

9) Hier unterscheiden sich die späten Sozialreformer von den frühen dadurch, daB sie nicht die produktions-, sondern die Verteilungsverhältnisse ändern wollen, womit sie Grundlagen schaffen für die heutige Sozialpolitik; W. Hofmann 1965, S. 96. Immerhin wird aber auch hier ein allokatives tbergewicht insoweit deutlich, als sich ihre Kritik auf die Grundrente und den Kapitalgewinn konzentriert.

10) Die Lehre vom Mehrwert, die die Produktions- mit der Einkommenslehre integrieren will und die zugleich als das "gemeinsame Substrat von Grundrente und Profit" (W. Hofmann 1965, S. 126) gelten kann, muB, gerade weil sie dergestalt eine modellhafte Zweiklassengesellschaft der Arbeiter und Unternehmer (Kapitalisten) schafft, als eine Einkommensvertellungshypothese gesehen werden, die vorwiegend Fragen der funktionalen Verteilung lösen will, mithin im $A l l \circ k$ a $t i v e n$ befangen bleibt.

11) Auch die Grenznutzentheorie richtet $1 \mathrm{hr}$ Augenmerk hauptsächlich auf die Produktionsfaktoren und erklärt deren Preisbildung $\mathrm{zu}$ einem Unterfall der allgemeinen Preistheorie (W. Hofmann 1965, S. 162). Das ist allokatives Vorgehen par excellence. Zugleich liegt im gesamten Zuge der weiteren Ausbildung grenznutzentheoretischer Gedanken eine Tendenz zum రkonomismus, der auch die Grenzproduktivitätstheorie kennzeichnet. Das kommt darin zum Ausdruck, daB das Grenzproduktivitätsprinzip letztlich sogar von den Theoretikern als "Grundtheorem der reinen $p \circ i$ i $t$ s c h e $n$ Okonomie" (W. Hofmann 1965, S. 188 ; Hervorhebung $\mathrm{HDH}$ ) bezeichnet wurde.

12) "Die Theorie des Monopolpreises ist ja zugleich die Theorie des Monopolgewinns. Vollends der Lohntheorie ist es zugefallen, zu prüfen, wie einerseits die neue Nachfragemacht überlegener Unternehmungen .... und andererseits ie Gegenmacht der sich entfaltenden Massengewerkscahften ... auch das Eingreifen des

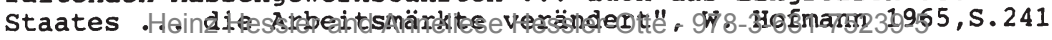


b) Für die Gegenwart kommt W. Hofmann (1965, S. 16) zu dem folgenden Urteil: Heute "kann von einer selbständigen Einkommenstheorie eigentlich nicht mehr gesprochen werden. Als Lehre von den Einzeleinkommen ist sie seit langem zu einem Anwendungsfall der Preistheorie geworden. Als Lehre von den großen gesellschaftlichen Einkommensproportionen und deren Bewegung hat sie sich mit der Theorie des volkswirtschaftlichen Gesamtprozesses verbunden. So gehört die Einkommenslehre heute im ganzen zu den vernachlässigten Gebieten auch der ökonomischen Literatur."

Dieses Urteil ist, was seine letzten Passagen betrifft, so nicht aufrecht zu erhalten, da einerseits die theoretische Auseinandersetzung gerade mit Themen der personalen Einkommensverteilung äuBerst intensiv geworden ist, da andererseits die "Einbindung der Einkommenstheorie in den volkswirtschaftlichen Gesamtprozeß" erstens nicht belegen kann, daß das Gebiet an Bedeutung verloren hätte und zweitens allenfalls darlegt, daß es sich hierbei um Fragen der makroökonomischen zusammenhänge, und innerhalb dieser um die Funktion von Faktoreinkommen handelt. Dennoch entnehmen wir den überlegungen Hofmanns, daß die frühe Entwicklung der Einkommenstheorie weithin von der allokativen Fragestellung einer funktionalen Einkommensverteilung geprägt war. Sie kann für das uns hier interessierende Problem der Einkommensdefinition nichts hergeben, da die Theorie als distributive damals weithin nicht aufgefaßt und entwickelt wurde.

c) Dasselbe Verdikt, daß nämlich bestimmte Theorien den Frageansatz unsererUntersuchung nicht erreichen, trifft ganz grundsätzlich für jene Versuche $z u$, persönliches Einkommen aus der volkswirtschaftlichen Wertschöpfung zu definieren. Die Wertschöpfung einer Volkswirtschaft zu bestimmen, ist ein makroökonomischer vorgang. Die Wertschöpfung ist überdies ein aus dem Einsatz von Produktionsfaktoren resultierendes, unter wahrung der Substanz und der Ertragsfähigkeit der Produktivkräfte errechnetes Produktionsergebnis. Sie berücksichtigt das allokative Problem der Kapitalerhaltung; die in der Wertschöpfungsrechnung verwendeten Begriffe "Abschreibungen" und "Subventionen" sind ausschlieBlich solche aus dem allokativen Bereich. Das aus dem Produktionsergebnis abgeleitete Volkseinkommen der Verteilungsrechnung enthält nur produktionswirtschaftliche und marktliche Elemente, keine nichtmarktlichen und keine Transfereinkommen. Insofern ist volskeinkommen eben nicht Individualeinkommen. Wie aus dem weiteren Darlegungen zum umfassen- 
den Individualeinkommensbegriff noch hervorgehen wird, kann das Volkseinkommen für den dem distributiven Bereich des Wirtschaftens angehörenden Begriff des Individualeinkommens keine Bedeutung haben. Ersteres ist, weil von vorn herein zu eng definiert, für unseren Frageansatz ungeeignet. Unser Einkommensbegriff ist ein mikroökonomischer, nicht auf die gesamtwirtschaftliche Wertschöpfung, sondern auf die summe aller einzelwirtschaftlichen Einkommenszugänge gerichtet, ohne die Erfordernisse der Rapital- und Faktorerhaltung. Er muß ein mikroökonomischer Begriff sein, denn nur dieser kann orientierungs- und vergleichsgröße für die konstruktion einer steuerlichen Bemessungsgrundlage sein. Besteuert wird im system der Personalsteuern nicht die volkswirtschaft, sondern das Einkommen und Vermögen des einzelnen.13)

III. Unser Untersuchungsinteresse ist aber weiterhin auch gegenüber solchen Theorien abzugrenzen, die beabsichtigen, bestimmte verhaltensweisen der Einkommensinhaber zu erklären. In diesem zusammenhang wird analysiert, wann jeweils der Konsum nicht dem Einkommen entspricht und warum es zu Ersparnissen kommt (vgl. E.-M. Claassen 1980, S. 23ff.). Die Motive, auf die man dabei stößt, daß also der intertemporale Konsum egalisiert werden soll, daß etwa ein permanenter Vermögensbestand konstruiert werden soll oder da $\beta$ die Existenz des Zinssatzes für die Abweichung zwischen Konsum und Einkommen ursächlich sein kann, liegen sämtlich im Bereich der verhaltensweisen angesichts eines bereits $d$ e $f$ i n $i$ e $t$ e $n$ (gegenwärtigen oder künftigen) Einkommens. Nicht die Definition von Einkommen ist - legitimerweise - der Erklärungsgegenstand dieser Theorien, sondern die Anpassungsweisen der einzelnen $i \mathrm{~m} B$ e $s$ i $t$ $z$ e des Einkommens. Mag es sich um das "fundamentale psychologische Gesetz" von J.M. Keynes (1936, S. 96) handeln oder um seine Widerlegung durch S. Kuznets (1946) und Goldsmith (1955/56), in beiden Fällen geht es um den Einfluß eines als gegeben oder steigend angenommenen Einkommens auf die Konsum- bzw. Sparhöhe. Ähnlich ist es mit der "absoluten Einkommenshypothese" von A. Smithies (1945) und mit der "relativen Einkommenshypothese" von J. Duesenberry (1949): Sie beruhen auf Annahmen über Konsumentenentscheidungen und darauf basierenden (kurz- und/oder langfristigen) Kon-

13) Denn es werden, bleibt man beim Begriff "Wertschöpfung", konsequenterweise die steuern darauf, also "Wertschöpfungsteuern", als sog. Objekt- oder Realsteuern, nicht als Personalsteuern bezeichnet, siehe A. Oberhauser 1983, S. 439.

Heinz Hessler and Anneliese Hessler-Otte - 978-3-631-75239-5 
sumfunktionen. Selbst die Theorie des "permanenten Einkommens" von M. Friedman (1957), die statt des tatsächlichen registrierten Einkommens das durchschnittlich erwartete in ihren Erklärungszusammenhang rückt, richtet sich auf das Konsumentenverhalten (Nutzenmaximierung).

Auch die Ausweitung socher Theorien über das Einkommen berücksichtigen nicht jene Aspekte, die uns in dieser Arbeit leiten. Wenn M. Friedman (1956 und 1959) ein umfassendes Gesamtvermögen konzipiert, das alle Quellen des Einkommens und alle konsumierbaren Dienste einschließt, so behandelt er den auch uns interessierenden Aspekt der Einzelelemente des Einkommens, richtet seinen Blick jedoch auf das ziel der wahlhandlungen in der Vermögensanlage und im Konsum ${ }^{14)}$. Solche Theorien berücksichtigen somit zwar auch die Elemente des Einkommens, nicht aber die Kriterien, die diese Elemente zu "Einkommen" machen. Als Kriterien aber, wie sie unten detailliert vorgestellt werden, gehören sie zum Bestandteil eines wirtschaftstheoretischen Einkommensbegriffs; ein so definiertes Einkommen mag sogar als voraussetzung aller verhaltensorientierten Einkommenstheorien angesehen werden.

IV. Die Definitionsversuche zum wirtschaftstheoretischen Individual-Einkommensbegriff sind zunächst danach $z u$ beurteilen, wie sie das a l l o k a $t i v-d i s t r i b u t i v e$ $\mathrm{A} b \mathrm{~g} r \mathrm{e} z \mathrm{u} \mathrm{ng}$ - Problem lösen. Kennzeichnend für die ältere wie jüngere literarische Auseinandersetzung mit dem Einkommensbegriff ist einerseits ein verblüffender, wenngleich nicht immer wahrgenommener Wechsel des Betrachtungsstandpunktes vieler Autoren, andererseits bezeichnenderweise ein - angesichts des einmal vorhandenen klaren Ausgangspunktes erstaunliches - Hin und Her im Ausweis der allokativ-distributiven Zusammenhänge zwischen Einkommen und Gewinn sowie zwischen Vermögen und Kapital.

14) Dieselbe Charakterisierung dürfte auf die "portfolio selection" von J. Tobin (1958 und 1961) zutreffen: Die Diversifikation zwischen ertraglosen undertragbringenden Vermögensgegenständen bzw. Einkommenselementen hat ihren Sinn in einer realistischen Fundierung der Liquiditätspräferenzen und damit in einer Wahlhandlungstheorie, nicht aber in der Definition dessen, was als Gegenstand des Wahlaktes gilt, also dessen, wann eine ökonomische Größe "Einkommen" ist. 
Definitorische und analytische Abweichungen lassen sich in fünf Epochen feststellen: die Vermengung allokativ-distributiver Abgrenzung in der frühen Literatur (1.); die klare Trennung der allokativ-distributiven Problematik bei Schmoller (2.), sowie Schanz und Böhm-Bawerk (3.); die Dominanz des allokativen Kapitalerhaltungsinteresses in der Kapitaltheorie des Einkommens bei Fisher, Lindahl und Hicks (4.); die Zurückgewinnung der allokativ-distributiven Abgrenzungsklarheit in der Betriebsteuer-Diskussion (5.) und der Rückfall in die Dominanz des Allokativen in der jüngsten Auseinandersetzung um Einkommen und Einkommensbesteuerung in der letzten Epoche.

1. Eine sehr tiefgehende Analyse zu unserem Problem sowie einen umfassenden tuberblick über die frühen Versuche, Einkommen zu definieren, gewinnen wir aus dem Aufsatz von G. Schmoller (1863, S. 186). Er bietet eine sehr instruktive Geschichte der Irrungen und Wirrungen der "Rein-Einkommens-Theorie" früher und zeitgenössischer Literatur, wobei er sich weithin ausdrücklich auf die kritische Darstellung von Bernhardi (Versuch einer Kritik der Gründe, die für grosses und kleines Grundeigenthum angeführt werden, 1849 ) stützt (dies gilt besonders für die Kritik Bernhardis an A. Smith und D. Ricardo).

a) Der Bogen der Schmollerschen Darstellung spannt sich von der Physiokratie über die Klassik (A. Smith, D. Ricardo, J.B. Say; J.St. Mill nur am Rande), Sismondi bis hin zu den deutschen Finanzwissenschaftlern Umpfenbach, Rau, Lotz, Schäffle, Hermann (besonders), Roscher, v. Mangold, L.v. Stein, Lotz, Jakob, Biersack, um die wichtigsten zu nennen.

b) Hier werden wesentliche Gedanken der "maintaining-capitalintact-Diskussion" vorweggenommen, die unter (3.) wieder aufgegriffen und diskutiert wird. Die Schmollersche Darstellung zeigt, daB das analytische Erfordernis einer allokativ-distributiven Problemabgrenzung in der Diskussion um Einkommen und Kapital nicht wahrgenommen wird.

c) Die Schmollersche Darstellung zeigt ferner, in welchem Maße der Einkommensbegriff von den Autoren "verwendungsorientiert" verstanden wird.

d) Teilweise attestiert Schmoller den von ihm kritisierten Autoren eine theoretische Einseitigkeit. 
e) Fast alle frühen Autoren gehen ihren Definitionsversuch von der gesamtwirtschaftlichen seite her an, die wir teilweise heute als den Ansatz der funktionalen Einkommensverteilung sehen würden. Kennzeichnend ist die immer wiederkehrende Vermengung der gesamtmit der einzelwirtschaftlichen Betrachtung. Wieder und wieder wird eine Beziehung zwischen Individual- und Nationaleinkommen gesucht, als sei letzteres der Fundus für die "Vermehrung der Bevölkerung, einer Erweiterung des Lebensgenusses und einer fortschreitenden Kapitalbildung" (Schmoller, S. 23).

f) Die kritischen Darstellungen Schmollers seien im folgenden kurz referiert:

f1) Die Ausführungen der Merkantilisten zum Einkommensbegriff sind unklar (S. 2). Der Irrtum der Physiokraten liegt darin, allein den Reinertrag aus der landwirtschaftlichen produktion zu reklamieren und ferner als Einkommen nur das $z u$ verstehen, was aus dem Blickwinkel des Unternehmers als Uberschuß gilt.

f2) Ausgehend vom Einkommensverständnis der Physiokraten mit ihrer Betonung der Kapitalerhaltung begreift $\mathrm{S}$. Smith als das "reine" Einkommen den "freien tberrest nach Abzug der Kosten, welche die Erhaltung zuerst ihres festen, sodann ihres umlaufenden Kapitals erfordert" (Schmoller, S. 3; unberücksichtigt soll hier bleiben, daß A. Smith auch die "nützlichen Kenntnisse und Fähigkeiten, welche die Einwohner oder Mitglieder der Gesellschaft sich angeeignet haben", zum fixen Kapital rechnet). Da Smith weiterhin zum umlaufenden Kapital auch Geld, Lebensmittel, Stoffe und fertige Arbeit rechnet, nennt Schmoller das einen "schiefen Kapitalbegriff" (S. 5). Uberdies läßt sich feststellen, daß Smith zu diesem Begirff nur gelangen kann, weil er von einer gesamtwirtschaftschaftlichen Einkommens- und Kapitalvorstellung ausgeht.

Einseitig ist der Einkommensbegriff insofern, als er allein aus dem Tauschverkehr sich ergibt (S. 6); "im Ganzen bleibt Grundrente und Kapitalgewinn das alleinige reine Einkommen" (S. 8).

f3) D. Ricardo seinerseits, als "Wigh und Kapitalist, entschlossener Vertreter des gewerblichen Bürgertums, des 'moneyest interest' im Parliament", erscheinen nur Grundrente und Kapitalgewinnst als die wahren kapitalbildenden Uberschüsse, als das reine Einkommen der Nation. Von hier ist es dann nicht mehr weit bis zu der Forderung nach der "Erhaltung der Stände", die von dem rei- 
nen Einkommen leben (S. 11). Auch dieser Lehre attestiert Schmoller Einseitigkeit.

f4) Erst Sismondi kommt zu einer modern anmutenden detaillierten Aufzählung von Einkommenselementen: Land- und Kapitalrente, Industriegewinnste, Arbeitslöhne und Bezüge aller staats- und Privatdiener; aber auch er verbleibt bei der bisher herrschenden allgemeinen Vorstellung, daB alle Mittel zur Aufrechterhaltung des Kapitalstocks nicht Einkommen sein können. Immerhin bemerkt Schmoller bei Sismondi einen wesentlichen Tatbestand, daß nämlich Einkommen nicht für die Nation, sondern für die Person festzuste1len sei (S. 15).

f5) "In wahrhaft ergreifender Weise hat aber erst Hermann, der grösste unter den älteren deutschen koryphäen unserer Wissenschaft, die Einkommenslehre umgestaltet" (Schmoller, S. 19). Aber es handelt sich um einen Einkommensbegriff, der von seiner Verwendungsseite her definiert ist (was von Schmoller nicht kritisiert wird), auf eine eigenartige Weise mit dem Vermögen verknüpft (was wiederum uns brennend interessieren muß): Einkommen ist ihm "die Summe von wirthschaftlichen Gütern, die ein Subjekt in einer gewissen zeit zur Befriedigung seiner Bedürfnisse ohne Schmälerung seines Vermögens verwenden kann", wozu allerdings auch die "ohne Tausch verbrauchten oder genossenen" ... "Früchte" (der Arbeit und) "des Vermögens gehören" (S. 19). Und Hermann stellt auch in Frage, daB überhaupt nur ein "tberschuß", also die Differenz zwischen Roh-Einkommen und den Aufwendungen zur Existenzsicherung, als Einkommen angesehen werden soll (S. 21). Roscher und v. Mangold haben die Hermannsche Lehre "adoptirt" ( $\mathrm{s}$. 22). Diese "absolute Sicherung" des Existenzminimums ist bei den meisten deutschen Finanzwissenschaftlern wiederzufinden (S. 30ff.).

g) Wir können Folgendes aus der Schilderung der Schmollerschen Zusammenfassung festhalten: Auch hier ist festzustellen, daß die Theorie einer begrifflichen Fassung dessen, was wirtschaftstheoretisch Einkommen sein soll, unvermittelt in das hinubergleitet, was $s t e u$ e 1 i $c h$ unter Einkommen verstanden werden soll. Das gilt für alle Autoren, die er kritisch würdigt.

2. Bevor auf die Ansätze von G.v. Schanz und E.v. Böhm-Bawerk eingegangen wird, sei die Auffassung von G.v. S c h $\mathrm{m} \circ 1 \mathrm{l}$ e $\mathrm{r}$ selbst in kürze referiert. 
Bemerkenswert ist, daß für ihn, wenn er auf die Besteuerung als Verteilungspolitik zu sprechen kommt (S. 34), "die wichtigste Garantie aber für die Erhaltung desselben" (er meint: des Kapitals) "... in dem wirthschaftlichen Sinn, in dem sittlichen Geist, in der ganzen Lebens- und Kulturrichtung eines Volkes, in dem Umstand, dass ein Land überhaupt ökonomisch, politisch und moralisch vorwärts schreite" liegt. Wenn man den Stellenwert der späteren "maintaining-capital-intact"-Diskussion der Kapitaltheoretiker erkennen will, wird man diese Abstützung der Schmollerschen Theorie auf metaökonomische Urteile und Normen mitbedenken müssen. Auch bei Schmoller nun stellen wir fest, daß bei allen Theoretikern, die er kritisiert, der Definitionsversuch des Einkommens unvermittelt in die Beschreibung des steuerlichen Einkommens hinübergleitet. Schmoller selbst macht aber die bedeutsame Feststellung (S. 36), daß "statt des tuberschusses das Einkommen als solches zur Grundlage der Steuerlehre" zu machen sei; "über die positive Größe und Höhe der Steuersumme des Einzelnen ist damit noch nichts gesagt". Und noch deutlicher (S. 54): Es ist im Einkommen ein Generalnenner zu finden, "wenigstens annähernd einen Geldausdruck zu finden für alle die verschiedenen Bestandteile und Arten, für die mannigfaltigen Quellen und Erscheinungsformen dessen, was wir die Totalität des Einkommens heißen. Diess ist die nothwendige Bedingung jedes Maasstabes; denn wie soll man messen ohne diese Möglichkeit? Wie soll man ohne einen festen, allgemein durchgreifenden Anhaltspunkt die verschiedenen Erscheinungen des Lebens in ihrem Verhältnis zu einander richtig würdigen? Ohne diesen Generalnenner kein Maassstab, ohne Maassstab keine Gerechtigkeit." Dies ist in einem sehr frühen Diskussionsstadium in nuce das Beispiel für die Totaleinkommensdefinition, gegeben im Jahre 1863, aber seitdem immer wieder theoretisch und politisch aufgegeben. Es münden dann die weiteren Ausführungen Schmollers - nach umfänglicher Fundierung auf staatsphilosophischen Grundanschauungen in eine Lehre von den Steuerbegründungen und -verteilungen, die die Einkommenstheorie weit hinter sich läßt.

Es findet sich just hier auch der Rückgriff Schmollers (S. 54) auf ein Zitat von Schäffle, der später D. Schneider $(1986$, S.231) zu der Bemerkung veranlaßt die sog. "finanzwissenschaftliche Sicht" (hier bezieht er sich auf J. Hackmann, 1983, dies aber im Zusammenhang mit nichtrealisierten vermögenswertsteigerungen) sei "wissenschaftstheoretisch lediglich durch wiederholung haar- 
sträubender zitierfehler zustande gekommen". Schneider kritisiert als zitierfehler an Schmoller, Schäffle habe niemals, wie Schmoller behaupte, dem Einkommen lediglich "buchhalterische Existenz" zugeschrieben. Ein zitierfehler liegt vor, doch der zusammenhang ist zu beachten: Schmoller will ausdrücken, daß jegliche Einkommensdefinition "buchhalterisch" bleibe, weil es kaum gelingt, es in seiner Totalität zu erfassen; wir interpretieren: Was faßbar ist, ist allenfalls das (zufällig) Aufgeschriebene. 3. G.v. S C h a n $\mathrm{z}$ und E.v. B ö $\mathrm{h} \mathrm{m}-\mathrm{B}$ a $\mathrm{w}$ e $\mathrm{r}$ k betonten klar die analytische Trennung zwischen dem Kapital- und GewinnBereich einerseits und dem Vermögens- und Einkommensbereich andererseits: Einkommen gehört nicht in die Gewinnkategorie (Schanz 1896); Abschreibungen - die ja der Kapitalerhaltung dienen - werden ausschlieBlich in den Allokationsbereich verwiesen (Böhm-Bawerk 1921), sie sind "Nutzleistungen" des Kapitals (1921, S. 360 f.). Der Reingewinn, der "Reinzins", ergibt sich als Abzug der Abschreibungen (der "Abnützungsquote") vom "Capitalwert" (S. 366, 368). Böhm-Bawerk grenzt diese Größen eindeutig vom distributiven Einkommensbereich ab (S. $378 \mathrm{f.)}$.

Auch K. W i c k s e I I kommt in seiner schrift von 1893, in der er sich in anderem Zusammenhang sehr kritisch mit Böhm-Bawerk auseinandersetzt, in dem uns hier interessierenden Punkt zu demselben Ergebnis: "Vom volkswirtschaftlichen Standpunkte aus sind die Unterhaltungsmittel, sobald sie in den Besitz der Arbeiter getreten sind, überhaupt nicht mehr Produktionsmittel und nicht mehr Kapital" $(1893 / 1969$, S. 77$)$.

4. Gerade I. F i s h e r, dem eine vertiefte Auseinandersetzung mit dem Einkommensbegriff und dem Kapitalbegriff $z u$ danken ist, trug unglücklicherweise durch die Verklammerung von Einkommen und Kapital sowie durch den Aufweis eines "theoretischen" Zusammenhanges zwischen ihnen dazu bei, daB bis auf den heutigen Tag versucht wird, Einkommen seiner Höhe nach aus der Funktion des Kapitals abzuleiten und zu "beweisen". Vermutlich war es das Bemühen, zwischen abstrakter Theorie und praktizierter Wirtschaftsrechnung $z u$ vermitteln und eine "künstliche" Brücke $z u$ schlagen zwischen einem buchhalterischen und einem "psychischen Einkommenskonzept" (S. H. Frankel 1969, S. 99), die Fisher die "rationale Gestaltung der Begriffe Kapital und Einkommen" (Erich Schneider 
1961, S. 742) dergestalt suchen lieB, daB er den Einkommensbegriff als vom Kapitalbegriff abhängig und auch wiederum auf ihn orientiert definierte: Ist Kapital der "Wert einer gegebenen Menge von Gütern", so ist demgegenüber Einkommen der "Wert einer gegebenen Menge von Nutzleistungen" (I. Fisher 1906 und 1928) 15); ist das konkrete Kapital in den "commodities" zu sehen, so das Einkommen in den "services" als der abstrakten Nutzung des Kapitals. Damit ist ein künstlicher zusammenhang zwischen Kapital und Einkommen, also zwischen dem allokativen und distributiven Bereich hergestellt. Der Gedankengang ist folgender: Aus Kapital flieBt Einkommen; Kapital muB erhalten werden; Doppelzählungen sind aus dem Einkommen zu eliminieren, d.h. Abschreibungen und Sparen (beide dienen der Kapitalbildung und -erhaltung, die wieder zu künftigem Einkommen führen), scheiden aus dem Einkommensbegriff aus; Einkommen ist somit der "net benefit from capital".

Schon H.C. Simons klassifiziert aber die Auffassung Fishers vom Einkommen als eine "Ertrags-Konzeption" (1938, S. 43), also als im allokativen Bereich befangene Definition, und R.H. Parker (Parker/Harcourt 1969, S. 8) vermutet, daB Fisher das Einkommen im Grunde nur deswegen durch den Kapitalterminus definiert, um das Sparen aus dem Einkommen ausschlieBen zu können, weil er einen konsumorientierten Einkommensbegriff postulieren möchte. ${ }^{161}$ Die Definition Fishers läBt das Einkommen als eine GröBe im distributiven Bereich nicht gelten; selbst das Sparen wird nur allokativ gesehen, ist in keiner Weise mit dem distributiven Phänomen der privaten Vermögensbildung und -ausstattung verbunden. Das aus "rationalen" Gründen vorgegebene Ziel der Kapitalerhaltung präformiert den Einkommensbegriff; eine distributive GröBe muB dann zwangsläufig durch allokative Elemente definiert werden.

Dieses Befangensein im Allokativen ist gleichermaBen kennzeichnend für die Hayek-Pigou-Hicks-Diskussion um das Phänomen des "ma $i n t a i n i n g \quad c a p i t a l$ i $n t a c t$, die in den Jahren 1941/42 in der Zeitschrift Economica ausgetragen wurde.

15) In dem deutschen Text Fishers von 1928 entspricht der Ausdruck "Nutzleistungen" exakt dem von Böhm-Bawerk gefundenen Terminus der "Nutzleistungen des Kapitals" für die Abschreibungen.

16) Als Nebeneffekt ergibt sich, daB Fishers Einkommensbegriff prozeBgebunden, d.h. nur als Ergebnis einer ökonomischen Aktivität denkbar ist. 
Die Auseinandersetzung entzündete sich am Abschreibungs- (Wertminderungs-)Begriff in seiner Bemessungsbasis und seinem Inhalt. Das allokativ motivierte Erklärungsinteresse des "maintaining" muB zur Bestimmung der distributiven Größe "Einkommen" herhalten.

Entscheldend ist, daB mithilfe dieser der Kapitalerhaltung dienenden AllokationsgröBen das Einkommen definiert werden soll. Nach Pigou ergibt sich nämlich das "net income" aus dem gross investment minus depreciation plus consumption (1941, S. 271). Weitere seiner Gleichungen ${ }^{17)}$ lassen erkennen, daB er erstens mit makroökonomischen GröBen arbeitet ${ }^{18}$ ) und daB er zweitens das net income als eine ErtragsgröBe definiert hat. Somit sind seine Darlegungen, obwohl sie das Einkommen erklären wollen, nur für den allokativen Bereich relevant. ${ }^{19)}$

Deutlicher aber wird das Phänomen der Vermengung der allokativen und der distributiven Betrachtungsebenen bei Hayek, der nach seinen tberlegungen zum "maintaining capital intact" qua Abschreibungen übergangslos auf das net income und die direct taxation $z$ u sprechen kommt (1941, S. 277). Das Interesse am net income begründet er mit der Notwendigkeit, ein "profitable investment" feststellen zu können (S. 278). Auch hier wird also das Einkommen in seiner Höhe durch die der Kapltalerhaltung dienende AbschreibungsgröBe bestimmt; hier dient ferner das Nettoeinkommen nur zur Untermauerung des Erklärungsinteresses an der allokativen GröBe "profitable investment". Treffend ist die Kritik von N. Kaldor

17) "net income = gross income minus depreciation", dies kann nur als eine Gleichsetzung von Ertrag mit Einkommen verstanden werden. - "net investment = gross investment minus depreciation"; aus der weiteren Definition "net investment = net income minus consumption" muB gefolgert werden, daB sparen und Investition gleichgesetzt wird, eine rein makroökonomische Betrachtung.

18) H.C. Simons kann nachweisen (1938, S. 46 f.), daB uberhaupt sich die Denkweise der Kapitalerhaltung aus dem gesamtwirtschaftlichen Elnkommensverständnis herleiten läBt.

19) Nicht ohne Grund wird diese Ansicht als "Kapitaltheorie des Einkommens" bezeichnet. 
(1955, S. 66 f.), der Hayek vorwirft, daB er sich der zu einfachen Methode bediene, die Kapitalerhaltung zu definieren als "maintenance of income": 'We cannot first define income as what is left after maintaining capital intact and then define the latter as what is left required to maintaining income intact, without getting involved in circular reasoning".

Wie I. Fisher sieht auch J. R. Hicks die Notwendigkeit einer strikten Trennung zwischen Einkommen und Kapital, doch anders als jener betont er die Unabhängigkeit des Einkommens von einer im Materiellen vorgefundenen Einkommensquelle. Anders auch als Pigou und Hayek ist ihm das Einkommen nicht ein Netto-Konzept zur Aufrechterhaltung der Quelle, nicht ein Problem des maintaining capital intact (1942, S. 176 ff.). Hicks löst den Einkommensbegriff aus einer zweifachen Verbundenheit: Weder geht Einkommen nur aus einer produktiven Tätigkeit noch nur aus einer Kapitalquelle hervor. ${ }^{20)}$ Vielmehr wird bei Hicks deutlich, daB die Einkommensdefinition von einem ganz speziellen erkenntnisleitenden Interesse bestimmt wird, das in der vorhersagbarkeit des Verhaltens der Einkommensbezieher im dynamischen Prozeß liegt. 21) Dennoch stellt auch Hicks seine Ausführungen zum Einkommensbegriff vorwiegend $a b$ auf die Bemessung der Abschreibungen (1942, S. 177); auch er vermengt die allokativen ("investment", "depreciation") und die distributiven ("income", "consumption") Elemente und argumentiert mit makroökonomischen GröBen ("Net Social Income = Consumption + Net Investment"). Zumindest aber hat er das allokativ-distributive Abgrenzungsproblem, so wie es in der vorliegenden Untersuchung gefabt ist, wohl erahnt, wenn er nämlich einen Realertrag vom Realeinkommen unterscheidet, und ersteren als jenen Ertrag versteht, der aus dem in seiner Substanz zu erhaltenden Kapital entsteht, letzteres als das Ein-

20) allerdings um den Preis, $d a B$ bei ihm nunmehr das Kapital nur noch als der kapitalisierte wert einer bestimmten $\mathrm{Zu}$ kunftserwartung auftaucht, und daB das Einkommen das "standard stream equivalent" dieser Erwartungen ist.

21) Das "Eigenartige" der Hicks'schen Einkommenstheorie liegt darin, daB er im Grunde nachzuweisen versucht, für die "dynamische" Theorie sei der Einkommensbegriff überflüssig, da eine solche Theorie nicht von den historischen GröBen (ex post) ausgehen müsse, sondern von ErwartungsgröBen; diese aber lieben sich als Einkommenskonzept nicht messen. Im übrigen siehe die Kritik N. Kaldors an den Hicks'schen ErwartungsgröBen, Kaldor 1955, S. $77 \mathrm{ff}$. 
kommen der realen Kaufkrafterhaltung auffaBt (S. 176). Doch gelangt er $\mathrm{zu}$ dieser Unterscheidung nicht etwa aus Gründen einer exakten Allokations-Distributions-Abgrenzung, sondern aus einem ganz anderen Blickwinkel: Sein Interesse ist - im Sinne einer Zeitdynamik - der Gegenwarts-Zukunfts-Gegensatz; so wird das Kapital mit dem Blick auf die Zukunftserträge (einschlieBlich der Abnutzungsprobleme) erklärt, das Einkommen hingegen mit Blick auf die Gegenwart und den möglichen Gegenwartskonsum. Demnach löst die von ihm geforderte strikte Trennung des Einkommens vom Kapital nicht unser Definitionsproblem, sondern ein Hicks'sches Zeit- und Verhaltensvorhersageproblem.

Das Ergebnis der Hayek-Pigou-Hicks-Diskussion bringt für uns lediglich eine Vermengung der allokativen und distributiven Betrachtungsebenen und Begriffe sowie den Versuch, eine distributive GröBe mithilfe allokativer Begriffselemente $z u$ definieren. Seit der durch $v$. Schanz und Böhm-Bawerk bezogenen klaren Ausgangsposition hat die Diskussion über Fisher und Hayek-PigouHicks mithin keinen Fortschritt in Richtung der Einkommensdefinition gebracht.

5. Zumindest die Chance $z u$ einem solchen Fortschritt stellte sich 1949 mit der $B$ e $t r i$ e b s $t$ e u e r - D isk us s i n ein, ${ }^{22)}$ seit nämlich der "BetriebsteuerausschuB" die bereits bestehende Literatur gewürdigt, die Vorteile und wirkungen einer Betriebsteuer begründet und Alternativ-Gesetzentwürfe formuliert hatte. ${ }^{23)}$ Es ergab sich das interessante Phänomen, daB Autoren, die nicht in erster Linie zur Lösung von Einkommensdefinitions-

22) Erwähnung verdient, daB bereits 1924 der Deutsche Juristentag dem Gesetzgeber die rechtsformunabhängige Unternehmensbesteuerung anempfohlen hatte, siehe Becker/Lion 1925, S. 429 f. u. 544. Im gleichen Jahr schlug F. Findeisen (1924) seine "Unternehmensteuer" vor. W. Flume $(1971,1972,1974$ und 1975) propagiert bei grundsätzlicher Anerkennung des Betriebsteuergedankens als steuerpolitischen Kompromi B eine objektivierte Unternehmensbesteuerung von Ertrag und Vermögen, die er in das Verhältnis von Körperschafts- zu Einkommensbesteuerung integrieren will. Siehe auch K. Tipke 1980c, S. 1080, und Chr. Flämig 1981, S. 160, aber auch - zur Frage der "Leistungsfähigkeit" in der Unternehmensbesteuerung D. Schneider 1975b, K. Schredelseker 1975, E. Schipporeit 1979 und G. Heidinger 1982.- Weitere Literatur zur "Leistungsfähigkeit von Unternehmungen" siehe unten $\$ 21$

$23)$ Veröffentlicht in StuW, 26. Jg. 1949, Sonderheft "Betriebsteuer", Sp. 929-1068. 
fragen angetreten waren, die Grundlagen schufen, eine solche Definition $z u$ ermöglichen, und zwar dadurch, daB sie in aller Klarheit die im allokativen Bereich $z u$ erhebende Betriebsteuer trennten von der im distributiven Bereich $\mathrm{zu}$ erhebenden Einkommensteuer. Wenn schon die Steuerarten klar voneinander getrennt werden sollten, so auch die ihnen zugrundeliegenden Bemessungsgrundlagen "Gewinn" und "Einkommen". Mit dieser Erkenntnislage war man wieder bei v. Schanz und Böhm-Bawerk. Aber trotzdem wurde unser Abgrenzungsproblem nicht mit allen Konsequenzen gesehen; da man in erster Linie an Steuerproblemen interessiert war, hat man auch infolge der Einwendungen gerade gegen die Praktikabilität und Steuersystematik der Betriebsteuer weitere Uberlegungen zum Einkommensbegriff nicht angestellt.

Was sich aber aus dem Konzept der Betriebsteuer klar ergibt, ist die mit ihm versuchte Abgrenzung des allokativ-betrieblichen Bereichs vom distributiv-privaten, ferner die MaBgeblichkeit einer rein allokativ motivierten Besteuerung in eben jenem betrieblichen Bereich. ${ }^{24}$ Eine solche Abgrenzung ist nicht sämtlichen Konzepten einer "Unternehmensbesteuerung" zu eigen.

Grundsätzlich kann eine neben der persönlichen Besteuerung existierende selbständige unternehmensbesteuerung nur in 2 Versionen durchgeführt werden: ${ }^{25}$ ) entweder basierend auf den ordnungsstrukturen des Zivilrechts oder basierend auf den organisationsvorstellungen des Wirtschaftslebens, auf dem sozioökonomischen Tatbestand, daB die Wirtschaftenden sich Unternehmensorganisationen schaffen, die sie ungeachtet der rechtlichen ordnungsstrukturen zur Erreichung ihrer ökonomischen ziele (Ertrags-/Gewinnerzielung) einsetzen. Aus der ersten Version folgt eine ungelöste allokativdistributive Abgrenzung wie auch eine steuerliche Ungleichbehandlung; denn entweder hat die Unternehmung keine eigene Rechtspersönlichkeit, dann werden das Unternehmen und sein Inhaber als identisch betrachtet und die Unternehmensgewinne als persönliche Inhabereinkommen definiert; oder die Unternehmung hat eine eigene

24) So auch H. Schulte 1967, S. 41: Die Betriebsteuer kann nur eine "Realsteuer" sein, und zwar in dem Sinn, daB die persönlichen Verhältnisse des Steuerpflichtigen unberücksichtigt bleiben.

25) Steuerreformkommission 1971, TZ IV 40-43; 94-98. 
Rechtspersönlichkeit (z.B. als Kapłtalgesellschaft), dann wird der Unternehmergewinn erst bei der Ausschüttung an den Inhaber (Anteilseigner) zu Einkommen.

Werden die Unternehmensgewinne in persönliche Einkommen umdefiniert (der Fall der Unternehmen ohne eigene Rechtspersönlichkeit) und steuerlich wie andere Einkommen progressiv belastet, ergeben sich ganz andere Verhaltensweisen (und Uberwälzungsmöglichkeiten) als im anderen Fall. Allokativ motivierte, auf den Gewinn ausgerichtete Steuererleichterungen und -belastungen haben im ersten Fall ihre unmittelbaren Auswirkungen auf den distributiven Bereich.

Demgegenüber folgt aus der zweiten Version (der Betriebsbesteuerung) - da die individuellen Wirtschaftsplaner ihre Unternehmung als Instrument, als Objekt, als Ertragsquelle betrachten - die steuerliche Behandlung als Objekt der Ertrags- bzw. Gewinnbesteuerung. Dies ist ein rein allokativer Vorgang. DaB mit der Betriebsbesteuerung nicht sämtliche steuerlichen Belastungen enden müssen, sondern daB sich eine distributive Besteuerung anschlieBen kann, ${ }^{26}$ ) ist ein Umstand, der ja gerade die grundsätzliche Trennung zwischen allokativer und distributiver sphäre und Besteuerung als sinnvoll und zielrational erscheinen läBt. 27) Die mögliche Anrechnung der Betriebsteuer auf die persönliche Einkommensteuer macht den Ubergang der GröBe "Ertrag" in den distributiven Bereich besonders sinnfällig; die Anrechenbarkeit dient der "Vermeidung der Gleichsetzung von Gewinn und Einkommen" (c. Boettcher 1960 , S. 144). 28)

26) Mit oder ohne Anrechnung der "Allokationssteuer" auf die "Distributionssteuer"; siehe auch das Anrechnungsverfahren in der Körperschaftsteuer.

27 ) Die Anwendung der Einkommensteuer auf den Betriebsgewinn verfälscht den Grundgedanken eines modernen Steuersystems; in der historischen Entwicklung ist eine fast überall geübte "Gleichsetzung des gewerblichen Gewinns mit dem (aus ihm abgeleiteten) Einkommen" festzustellen, G. Schmölders 1949a, Sp. $976 \mathrm{f}$.

28) DaB das geltende Anrechnungsverfahren in der Körperschaftsteuer schlieblich die thesaurierten Gewinne mit einer eigenständigen und endgültigen Körperschaftsteuer belegt, ist unter dem Aspekt der Kapitalbesteuerung ein allokatives Problem, belegt aber auch wiederum die Trennung in die allokativen und distributiven Bereiche. - Schlieblich wurde ja auch die Abschaffung der Mehrfachbelastungen von Ausschüttungen allokativ begründet, nämlich mit der Förderung der Finanzierung und der Kapitalbbildanger and Anneliese Hessler-Otte - 978-3-631-75239-5 
Ziele, Bemessungsgrundlage und steuersystematische Position lassen erkennen, daB die Betriebsteuer als eine "A 1 l $\circ \mathrm{k}$ a $t i \circ n s$ s $t$ e e $r "$ par excellence gedacht war:

- sie beabsichtigt die steuerliche Schonung und Förderung der betrieblichen Kapitalbildung (BetriebsteuerausschuB 1949, Sp. 935); die betriebliche Ertragsverwendung wird als Voraussetzung der Einkommensentstehung gesehen (Sp. 941), nicht als Definition,

- alle Rechtsformen für gewerbliche Unternehmen werden gleich behandelt (Sp. 943), da die Gewinnbesteuerung ausschlieBlich nach der Ertragskraft ohne Verfälschung der Wettbewerbslage der Betriebe vorgenommen wird;

- Bemessungsgrundlage ist nur, was nach betriebswirtschaftlicher Auffassung als Gewinn gelten kann (C. Boettcher 1949, Sp. 951); die Gewinnermittlungsvorschriften sollten in erster Linie auf die Erfolgsrechnung abstellen (C. Boettcher 1949, Sp. 965), die die objektive Ertragskraft des Betriebes zum Ausdruck bringt (G. Schmölders 1949a, Sp. 973);

- steuersystematisch ist die Betriebsteuer keine Personal-, sondern eine Realsteuer (Friedrich Klein 1949, Sp. 1004), ungeachtet dessen, ob sie auf die persönliche Einkommensteuer angerechnet wird 29) oder nicht. Der proportionale steuersatz, der für die Betriebsteuer gelten sollte, unterstreicht den allokativen Charakter dieser Ertragsteuerart. Zugleich entspricht die relativ geringe Höhe des Steuersatzes der Steuerneutralitätsforderung im Sinne einer möglichst geringen allokativen Beeinflussung.

Erstaunlich ist, daB die Steuerreformkommission 1971 die Einwendungen gegen die Betriebsteuer als solche bezeichnet, die in der praktischen Anwendung liegen, dann aber erklärt, die gesonderte Besteuerung der betrieblichen Gewinne gegenüber den anderen Einkunftsarten würde eine Aushöhlung des $E$ i $\mathrm{n} \mathrm{k} \circ \mathrm{m}$ e n s begriffes bedeuten (TZ IV 98). Ferner kritisiert sie, die persön-

29) Wird sie aber angerechnet, hat das positive Allokationswirkungen auf dem Kapitalmarkt, da dort die Risikokapitalbildung erleichtert wird. 
liche Leistungsfähigkeit wäre hinsichtlich der gewerblichen Einkünfte nicht ausreichend berücksichtigt.

Beide Einwendungen, das Aushöhlungs- und das Leistungsfähigkeitsargument liegen auf verschiedenen Ebenen: das erste Argument ist steuersystematischer Natur, das zweite begrifflich-theoretischer. Tatsächlich erführen die gewerblichen Einkünfte durch eine Betriebsteuer eine Sonderbehandlung, sofern nicht gesichert wäre, daB sämtliche Vorgänge im allokativen Bereich, also alle Einkunftsarten ähnlich vorab proportional besteuert würden; der BetriebsteuerausschuB hat sich mit diesem Argument aus der Steuersystematik und der Gleichbehandlung nicht auseinandergesetzt.

Jedoch führt die Betriebsteuer keineswegs zur Aushöhlung des Einkommensbegriffs, da es sich nicht um einen Vorgang im distributiven Bereich handelt. Auch wenn die nach der Betriebsteuer verbleibende "RestgröBe" des Einkommens, die der Einkommensteuer unterworfen werden kann, geringer ist als vorher, handelt es sich nicht um eine Aushöhlung des Einkommensbegriffs, sondern um eine solche der steuer. Dies ist tatsächlich mit jeder Ertragsteuer verbunden. Die festzustellende Ungleichbehandlung der Einkunftsarten geschieht nur im allokativen Bereich. ${ }^{30}$ ) Was hier hervorzuheben ist, ist lediglich der Umstand, daB im Betriebsteuervorschlag das allokativ-distributive Abgrenzungsproblem zum Ausdruck kommt; seine offenlegung allerdings haben die Autoren nicht nachhaltig genug betont, und die steuerreformkommission 1971 hat das problem vollends verschüttet. ${ }^{31)}$ Das läßt sich insbesondere mit

30) Zuzugeben ist, daB sich die Betriebsteuervorschläge auf die Vermeidung von Belastungsnachteilen und Wettbewerbsverzerrungen im Bereich der gewerblichen Einkünfte konzentrieren; dort aber sah der AusschuB diese Nachteile besonders ausgeprägt.

31) W. Flume 1972, S. 52, zur Ansicht der Steuerreformkommission, es handele sich bei der Betriebsteuer um einen Rückschritt in der Rechtsentwicklung: "Es geht aber bei der Bestriebsteuer gar nicht darum, daB der Betriebsgewinn als Einkommen des Steuerpflichtigen einer besonderen Schedulenbesteuerung unterworfen wird. Vielmehr wird der Betriebsgewinn abgesehen von dem Unternehmerlohn gar nicht dem Unternehmer als sein persönliches Einkommen, sondern dem Betrieb oder Unternehmen zugerechnet. Bei Personalgesellschaften wäre deshalb die Betriebsgewinnsteuer auch nicht eine Steuer der einzelnen Gesellschafter, sondern eine solche der Gesellschaft. ... Diese Wertung des Unternehmensgewinns ... scheint mir ganz und gar kein 'Rückschritt in der Rechtsentwicklung' $z u$ bedeuten. Im Gegenteil

(Forts. siehe folgende Seite) 
dem von ihr benutzten Leistungsfähigkeitsargument belegen, mit dem sie unterstellt, nicht die wirtschaftliche und personale Gesamtsituation des einzelnen wirtschaftenden sei der Indikator der Leistungsfähigkeit, sondern allein schon die Höhe der gewerblichen Einkünfte bzw. der Einkünfte schlechthin. Dies würde bedeuten, Leistungsfähigkeit mit Erträgen aus Einkunftsarten, Quellen oder Objekten gleichzusetzen, eine steuertheoretisch wie -politisch nicht akzeptable Vorstellung. Auch die jüngere Diskussion um die Unternehmensbesteuerung ist weithin von dem Bestreben geprägt, der Unternehmung eine Leistungsfähigkeit, also ein ausschlieBlich personales Attribut, zuzuschreiben (siehe $\$ 20$ ); sie muB sich daher denselben Einwand gefallen lassen. Da auch sie Ertragsfähigkeit und Leistungsfähigkeit nicht auseinanderhält, vermengt sie die allokativen und distributiven probleme und kann an die Vorarbeiten der älteren Betriebsteuerdiskussion nicht anknüpfen.

Eine Ausnahme in der jüngeren Diskussion machen aber $B$. KnobbeKeuk $^{32}$ ), w.Flume ${ }^{33)}$ unà G.Heidinger (1982), die strikt betonen, daß die Leistungsfähigkeit auf die Unternehmens- bzw. Betriebsbesteuerung nicht übertragbar ist. Insbesondere w. Flume spricht dem Leistungsfähigkeitsprinzip die Rolle zu, zwischen der Unternehmensteuer und der Besteuerung der Privaten die Trennlinie legen zu können: "Nur für die Besteuerung des Privaten ist es sinnvoll, die Besteuerung nach der persönlichen Leistungsfähigkeit auszurichten." 34) Was den Beitrag Flumes in unserem Zusammenhang bedeutsam macht, ist die in ihm ausgedrückte allokativ-distributive Abgrenzung $z$ wischen dem privaten und dem unternehmerischen Bereich als einer Voraussetzung für die Bestimmung des Einkommens: Man müsse nämlich realisieren, "daB Unternehmensvermögen und Unternehmensgewinn als steuertatbestand etwas grundsätzlich anderes sind als $z$ ur privaten Nutzung oder VeräuBerung verfügbares Privat-

Forts. Fn. 31:

dürte die Verselbständigung des Unternehmens für die Besteuerung des Gewinns wie die des Vermögens gesellschaftspolitisch und damit auch rechtspolitisch gerade dem zuge der zeit entsprechen."

32) Vortrag auf der Arbeitssitzung der Steuerrechtlichen Abteilung des 53. Deutschen Juristentages am 17./18.9. 1980 in Berlin; Chr. Fiämig berichtet darüber, siehe 1981, S. $164 \mathrm{f}$., so auch uber das Referat von B. Knobbe-Keuk.

33) 1971, S. $692 \mathrm{ff.;} 1972$, S. $31 \mathrm{ff.;} 1974$, S. $53 \mathrm{ff.;} 1975$.

34) 1974 , S. 68 unter Hinweis auf Sonderausgaben, außergewöhnliche Belastungen, Familienstand und Progression. 
vermögen oder zur privaten Nutzung verfügbares Privateinkommen" (1975; 1972, S. 40).

6. Die $j$ ü $\mathrm{n} g \mathrm{~s} e \quad \mathrm{D} i \mathrm{~s}$ u $s \mathrm{~s} i \circ \mathrm{n}$ um den Einkommensbegriff ${ }^{35)}$ zeigt zwei Charakteristika: Zum einen wird die seit I. Fisher ubliche Vermengung allokativer und distributiver Begriffselemente und Betrachtungsebenen - "unbelastet" von der Betriebsteuerdiskussion - fortgesetzt, zum anderen wird versucht, dem Einkommensbegriff dadurch beizukommen, daB man seine $\mathrm{V}$ e $r$ w e n d u n g zum "kritischen" Punkt der Inhaltsbestimmung und zugleich zum kritischen Punkt der Abgrenzung gegenüber dem $\mathrm{K}$ a p $i t$ a 1 macht. Schon allein diese Art des Vorgehens macht deutlich, daB man bei der Fischer'schen Fragestellung wieder angelangt ist.

Für das ersterwähnte Charakteristikum steht R. H. Parker (1969, S. 6 ff. u. passim), der zwar den Begriff "money income" benutzt, ihn aber als eine allokative GröBe im Bereich des "business enterprise" versteht. Auch sein Begriff des "real income" enthält neben dem distributiven "consumption"-Element das allokative des Wertzuwachses aller "capital assets". Abgrenzungsprobleme kann er solchermaßen nicht lösen, wenngleich zuzugeben ist, daß das auch nicht in seinem Erklärungsinteresse liegt. Zumindest aber darf festgestellt werden, daB eine Abgrenzungsnotwendigkeit uberhaupt nicht gesehen wird. Nach wie vor handelt es sich, wie J.G. Head (1979a, S. 222) feststellt, um die bekannte "troublesome capital-income- distinction" (die überdies noch der Grund ist für so viel "complexity, inequity and ineffiency in existing income taxes").

Ganz anders bei D. Schneider (1981). Er zielt zwar mitten in das Problem, wenn er fragt, ob die Kapitalerhaltung notwendiger Inhalt eines wirtschaftstheoretischen Einkommensbegriffes ist, verfällt aber der "Verlockung" des traditionellen Begriffsgegensatzes:

35) Man kann allerdings nicht umhin, festzustellen, daB sie gegenüber früher an Intensität verloren hat; weithin wird sie eher im Zusammenhang mit steuersystematischen oder mit steuertariffragen "miterledigt" und kommt solchermaBen nicht zu der uns hier interessierenden Vertiefung einer allokativ-distributiven Abgrenzung. 
es geht ihm wie I. Fisher um die Trennung von Einkommen und Kapital. Die Notwendigkeit einer allokativ-distributiven Abgrenzung deutet er dadurch an, daB er sagt, das zu erhaltende Kapital sei die "Voraussetzung für das Vorliegen von Einkommen" (S. 149).36) Richtig erscheint uns daran, daB die Entscheidung für die Kapitalerhaltung zeitlich (und nach der Logik der Ertragserwirtschaftung und Einkommenserzielung im WirtschaftsprozeB) einer Einkommensfeststellung vorangeht. Sie vollzieht sich im allokativen Bereich. Akzeptabel ist auch, wenn für die Entscheidung $z$ ur Kapitalerhaltung die Verwendungsfrage mit Blick auf den Zeithorizont gestellt wird: Welche Güterverwendung will ich heute, welche Güterreservierung plane ich für morgen? (S. 137). Aber unrichtig erscheint uns, daB die $k$ a $p i t$ a $l$ - Erhaltung die $\mathrm{E} i \mathrm{n}$ k $\circ \mathrm{m}$ e $\mathrm{n} s$ - Definition determinieren soll. Denn die sehr $z$ u recht in den Vordergrund gestellte Entscheidungsund Planungsfrage ist für den allokativen und für den distributiven Bereich jeweils getrennt zum Problem $z u$ erheben. Dann aber lautet die Frage nicht, wie bei Schneider (S. 160), wie der erzielte EinnahmenüberschuB aufzuteilen sei in erstens das "konsumierbare Einkommen" und zweitens in "einen Betrag, der notwendig ist, um das Kapital zu erhalten", sondern sie lautet: Wie ist der $E r t r a g$ der Unternehmung aufuteilen, um einerseits das Kapital zu erhalten, um andererseits durch Ausschüttungen bzw. Entnahmen dem Unternehmer privates Einkommen zu ermöglichen? ${ }^{371}$ Und im distributiven oder Haushaltsbereich lautet die Frage: Wie ist das Einkommen $\mathrm{z} u$ verwenden, um einerseits den Konsum, andererseits die Vermögensbildung $\mathrm{zu}$ alimentieren?

36) ferner S. 159: Was als "zu erhaltendes Kapital" anzusehen ist, ist eine Frage, die zu entscheiden ist, "ehe Einkommen vorliegt". Zumindest begrifflich etas genauer ist Schneider $1978 \mathrm{~b}, \mathrm{~S} .36$, wenn er für den Einkommensbegriff nicht die Erhaltung des Kapitals, sondern des "Vermögens" verlangt. $\mathrm{DaB}$ jede Art der Erhaltungsnotwendigkeit für welche GröBe auch immer eine Einengung des Einkommensbegriffs mit sich bringt, werden wir an anderer stelle beleuchten. Auf begriffliche Ungenauigkeiten stöBt man dann aber auf S. 87, wo betriebliche Erträge mit Einkommen gleichgesetzt werden.

37) Wohl aus diesem Grunde sind bei N. Andel (1979a, S. 360) die verschiedenen Kapital- und Kapitalerhaltungsdefinitionen nicht direkt begriffsbestimmend für das Einkommen sondern haben "entsprechende $R$ ü $c k w i r k$ u $g$ e $n$ auf die Einkommensdefinition"; Hervorhebung durch HDH. 
Die Verwendungsfrage zum Kriterium zu machen, kann durchaus das Entscheidungsproblem verdeutlichen, nur müssen die Verwendungen der richtigen Größen gegenübergestellt werden. Die Reservierung von Abschreibungen zur Kapitalerhaltung sind keine Einkommens-, sondern Ertragsverwendungen.

So hat Schneider mit der "Trennung von Einkommen und Kapital" ein traditionelles Problem erneut aufgeworfen, es aber für die klare allokativ-distributive Abgrenzung an einer korrekten Begriffsverwendung fehlen lassen. Das aber ist nicht das Wesentliche seines Beitrags. Das Wesentliche liegt vielmehr in der Betonung der $E \mathrm{n} t \mathrm{~s} \mathrm{c}$ e $\mathrm{i} d \mathrm{u} \mathrm{n}$ e $\mathrm{n}$. Hiermit geht er auf Feststellungen zurück, die bereits Böhm-Bawerk getroffen hatte. Diesem Gedanken soll nachgegangen werden, sobald das Fazit aus den bisherigen Diskussionsbeiträgen gezogen ist.

Für die Begriffsdiskussion nach 1981 läßt sich das Folgende feststellen. Erstens bleibt es bei den Versuchen, Einkommen von der Verwendungsseite her zu definieren; zweitens überwiegt das Interesse am Allokativen, d.h. die behauptete Notwendigkeit der Kapitalerhaltung; drittens wird die Ansicht, Einkommen sei als Totaleinkommen zu definieren, nur vereinzelt vertreten.

Für die letztere Auffassung steht J. Hackmann (1982 und 1986). Seine Untersuchungen sind zwar primär auf den steuerlichen Einkommensbegriff abgestellt, doch auch für unser theoretisches Problem von Wert: Einkommen ist ein Zugang an ökonomischer Verfügungsmacht (1986, S. 664), es muß einer Person zugehen (S. 667), es muß sich um tatsächlich entstandenes, nicht nur um potentielles handeln (S. 664), lediglich psychisches "Einkommen" ist auszuschließen (S. 673), Transfers und Erbschaften sind einzuschließen (S. 672), Freizeit hingegen nicht (passim).

Ein Streitpunkt ergibt sich aus der auch von Hackmann erhobenen Forderung, auch die nicht realisierten Wrtsteigerungen würden das Einkommen erhöhen (S. 664. 673. 692). Diesem Standpunkt widerspricht D. Schneider vehement (1986; die Auseinandersetzung zwischen Hackmann und Schneider wurde zuletzt im Finanzarchiv geführt.

An der Gegenmeinung von D. Schneider interessiert uns hier nicht die (von ihm behauptete und von Hackmann negierte) Allokations- 
wirkung der Besteuerung von nichtrealisierten Wertsteigerungen, sondern allein das, was zum Einkommensbegriff ausgeführt wird. Und hier kommen beide zuvor erwähnten Diskussionstopics zum Vorschein, nämlich die "Konsumseite" des Einkommens und die Kapitalerhaltung. Einkommen ist nach Schneider (1990, S. 36) "der Betrag, der entnommen (konsumiert) werden kann, ohne das Reinvermögen am Ende der Abrechnungsperiode gegenüber dem Reinvermögen zu Beginn der Abrechnungsperiode zu verringern."

Was die Konsum-, also die Verwendungsseite des Einkommens angeht, trifft sich Schneiders Meinung mit der von J. Mitschke (1985), der das Einkommen in seine Verwendungsbestandteile zerlegt und es (samt seiner Besteuerung) von der Verwendungsseite her definiert (s. 33). Dies muß er konsequenterweise so tun, da er ohnehin die Besteuerung in diesem Sinne reformieren will (in diesem zusammenhang sollte erwähnt werden, daß generell die "persönliche Ausgabensteuer" wieder etwas stärker als früher propagiert wird (M. Rose) und eben deshalb die Diskussion sich weniger mit dem Einkommensbegriff befaßt.

Was wir die "Dominanz des Allokativen" in den Einkommensdefinitionen nennen, findet sich bei Schneider ebenso. Einkommen ist ihm zunächst eine Folge der "Tauschwirtschaft" (1986, S. 228). Einkommen verbleibt dem einzelnen (Arbeitsentgelt beziehenden Beschäftigten und dem Unternehmer) "nach dem Abzug seiner Ausgaben" (auf den Beschaffungsmärkten) "von den Einnahmen". Es handelt sich also um Zugänge an Dispositionskraft in dem Bereich, den wir den "produktionswirtschaftlichen" nennen. Transfereinkommen kommen bei schneider nicht vor (dies mag daran liegen, daB er die Diskussion unter dem Vorzeichen der Allokationseffizienz führt. Daß es sich evlt. aus steuerlichen Gründen empfehlen mag, die der Kapitalerhaltung $z u$ widmenden Beträge aus der Bemessungsgrundlage zu eliminieren, ist für die einkommenstheoretischen $\mathrm{Be}-$ trachtungen nicht relevant.

Daß Schneider überdies in diesem Zusammenhang einen rein monetären Einkommensbegriff verwendet (Einkommen = "Zahlungsmittelüberschuß", S. 229), läßt vermuten, daß Naturaleinkommen nicht in das Einkommen aufgenommen werden sollen. Demgegenüber hält Mitschke das "imputed income" für relevant, wenn nach der Leistungsfähigkeit besteuert werden soll; er möchte lediglich klargestellt wissen, daß er Naturaleinkommen und häusliche Dienste 
als Einkommensbestandteile nicht von der Ersparnisseite des Haushaltes, sondern vom Geldwert her bewertet wissen möchte (1985, S. 168). Da sein Erklärungsinteresse im Sinne der von ihm angestrebten Reform der Besteuerung auch im Bereich des Vermögens liegt, kommt er zu der Feststellung, Einkommen enthalte Geldvermögensänderungen plus Sachvermögensänderungen (S. 119); Einkommen ist "auf der Vermögensebene angesiedelt" (S. 120).

Für die jüngste Phase der literarishen Auseinandersetzung läßt sich also festhalten, daß sie das uns interessierende Thema nicht in aller Breite und Tiefe erfaßt (mit der ausdrücklichen Ausnahme $J$. Hackmanns) und da $\beta$ aus der Geschichte bekannte Einseitigkeiten und wirrungen nicht vermieden worden sind. Die 1988 erschienene Arbeit von $D$. Pohmer befaßt sich mit dem Leistungsfähigkeitsprinzip; sie ist an anderer stelle zu würdigen.

V. Die kritische würdigung der literarischen Diskussion zeigt erstens, daB für die allokativ-distributive Abgrenzung der Begriffe das eingangs vorgestellte Analyseschema des Zusammenhangs zwischen Kapital und Ertrag einerseits sowie zwischen Einkommen und Vermögen andererseits wie auch schlieBlich grundsätzlich zwischen der Allokation und der Distribution als Beurteilungsgrundlage verwendet werden kann (Ubersicht 3.1). Die Würdigung zeigt zweitens, daB die zur exakten Bestimmung des Einkommensbegriffes erforderliche Abgrenzung selten beachtet wurde. Sie zeigt drittens, daB die Definitionsversuche nahezu ausnahmslos auf die GröBe $\mathrm{K}$ a $\mathrm{p}$ i $t$ a 1 fixiert sind; tatsächlich scheint hier der theoretische, um nicht zu sagen, der "ideologische"38) Fixpunkt zu liegen, der Punkt des hauptsächlichen, wenn nicht gar ausschlieblichen Erklärungsinteresses. Dies gilt nicht nur für die theoretischen, sondern auch für steuerliche Definitionen des Einkommens. ${ }^{39)}$ Man fragt sich, warum nicht auch

38) $\mathrm{Zu}$ den "ideologisch-wirtschaftlichen Motivationen" der Lehren von E.R.A. Seligman und I. Fisher siehe F. Neumark 1947 , S. 47, und seinen Hinweis auf frühere Arbeiten; siehe auch P. Wueller 1938 Teil II, S. 580, der solche Einkommensdefinitionen eher für normativ als analytisch hält.

39 ) Siehe z.B. auch Meade Committee 1978, S. 30, wo die Abhängigkeit des Einkommens vom Kapital postuliert wird, obwohl deutlich wird, daB nur der Ertrag gemeint sein kann. 
der Faktor Arbeit dasselbe Erhaltungsinteresse gefunden hat und ist verwundert ob des "materialistischen" Gehaltes solcher Anschauungen. Wegen des Interesses an der Erhaltung des Kapitals wird insbesondere die $\mathrm{V}$ e $r$ w e $n$ d $u n g$ des Einkommens und nicht so sehr das, was es insgesamt (also unter dem Aspekt auch der Erzielung) für das Individuum ausmacht, in den Vordergrund gerückt. So sehr aber der Blick auf die Verwendung einer Ertragsoder EinkommensgröBe den Blick schärft für das Planerische und Rationale in diesem Vorgang, so einseitig wäre es, eine Definition allein an der Verwendung festmachen $z u$ wollen. 40 )

Durchaus richtig gesehen wird in der Diskussion, daB Kapital Erträge abwirft und $d a B$ erst aus letzteren Einkommen werden kann; was nicht Ertrag geworden ist, kann nicht zu Einkommen werden. 41) Dies sind die üblichen Vorgänge in der wirtschaftlichen Realität, was nicht bedeutet, daß Erträge ausschließlich aus Kapital stammen. Aber die Formulierung einer Abhängigkeit des Einkommens vom Kapital, die gedankliche Verkettung von Realvorgängen, darf nicht zu dem SchluB führen, es lieBe sich vom Kapital her unmittelbar eine Aussage für das Einkommen treffen oder umgekehrt. Denn um hier weiter folgern $z u$ können, ist zunächst eine Unterscheidung $\mathrm{zu}$ treffen $\mathrm{zwischen}$ eben jenen realen Abläufen in der Wirtschaft mit der von ihnen begründeten Abhängigkeit des Einkommens vom Ertrag einerseits und den logischen Vorgängen der Begriffsbildung andererseits.

Was die realen Abläufe betrifft, so determiniert eben nicht - wie in der Diskussion behauptet wird - die Einkommensverwendung die Kapitalerhaltung, sondern die Ertragsverwendung tut das.

40) F. Neumark 1947, S. 47: für die Bestimmung des Einkommenscharakters von Einkünften ist die Art ihrer Verwendung ein "sekundäres Problem"; "Will man dle steuerliche Leistungsfähigkeit der Individuen treffen, so kann dabei offensichtlich die aktuelle Einkommensverwendung keine Rolle spielen." Wenn auch die Bemerkungen Neumarks in erster Linie steuerlicher Art sind, so ist seine Trennung der Verwendung von der Herkunft des Einkommens doch unter systematischem Aspekt eine grundsätzliche.

$41)$ Unterschlagen wird von jenen Einkommenstheorien, die ein Einkommen nur aus produktiven Quellen zulassen, da $B$ durchaus das, was Einkommen ist, nicht immer zuvor Ertrag gewesen ist; die Ertrags-Einkommens-Relation ist nicht einfach umkehrbar, da es auch nichtproduktive Einkommen gibt. 
Und was endlich die Logik der Begriffsbestimmung betrifft, so ist folgendes zu sagen: Hier ist kein Urteil über sinn oder Nichtsinn der Rapitalerhaltung zu fällen, sondern darüber, ob verwendung jemals - sei es die über den Ertrag, sei es die über Einkommen - zum notwendigen Definitionsbestandteil gehört. Das ist keineswegs so. An der Verwendung des Einkommens kann allenfalls abgelesen werden, welche Funktionen es erfüllt, nicht aber, was seinen qualitativen und quantitativen Inhalt ausmacht; wird dennoch der Begriff an der Verwendung festgemacht, so ist der Bereich, in dem die Verwendung stattfindet, exakt $\mathrm{zu}$ bestimmen und abzugrenzen: die Einkommensverwendung findet im Bereich der Distribution statt, nicht in jenem der Allokation und Kapitalerhaltung. Wer auBerdem innerhalb des distributiven Bereichs nur die konsumtive Verwendung des Einkommens zum Definitionsbestandteil macht, argumentiert - wie z.B. I. Fisher und D. Schneider (1978b, S. 36) - insofern einseitig, als er die Sparverwendung übersieht oder sie ausschlieblich allokativ (zur Kapitalerhaltung) interpretiert und der privaten Vermögensbildung keine distributive Rolle in der Einkommensverwendung zuerkennt.

Die starke Fixierung auf das Kapital und auf die Kapitalerhaltung hat dazu geführt, daß Abschreibungen und Reservebildungen zu Einkommensverwendungen definiert wurden. Sie sind es nicht, es sind vielmehr Ertragsverwendungen. Sie gehören dem allokativen Bereich des Wirtschaftens an, wie auch das Kapital selbst eine allokative GröBe ist, und zwar nach volkswirtschaftlicher ${ }^{42)}$ wie auch nach betriebswirtschaftlicher (K. Hax 1960, S. 102) Theorie. Selbst wenn man Kapital im "gesellschaftswirtschaftlichen" Sinne definiert (H. Peter 1956, S. 489) als eine besondere Erscheinungsform der kapitalistischen Wirtschaft, bleibt seine allokative $\mathrm{Zu}-$ ordnung unübersehbar und eindeutig. Was also F.W. Wagner (1976b, S. 232) unter Rückgriff auf I. Fisher, J.R. Hicks, N. Kaldor und D. Schneider den "kapitaltheoretischen Gewinn" und im gleichen

42) Die wichtigste Funktion des Kapitals ist nach Böhm-Bawerk (1921, S. 41) die, als Produktionsfaktor $z u$ dienen und einen Produktionsertrag abzuwerfen; an dieser produktionswirtschaftlichen Einordnung hat sich bis heute nichts geändert (siehe z.B. E. Helmstädter 1991, S. 95, 111, 170 ff., 191ff.; nach wie vor wird Kapital als der Bestand an dauerhaften produktionsmitteln definiert (siehe z.B. A. Stobbe 1962, S. 184 ff. und 1975, S. 160). 
Atemzuge die "kapitaltheoretische Einkommenskonzeption" nennt, kann eher zur Verwirrung als zur Klärung der theoretischen Begriffe und Beziehungen beitragen. ${ }^{43}$ )

VI. An die allokativ-distributive Kapital-Vermögens-Abgrenzung schliebt sich die Frage an, ob zur Bestimmung des Begriffes "Ertrag" zwangsläufig die Kapitalerhaltung gehört und ob zur Definition des "Einkommens" die Vermögenserhaltung notwendig ist. M. a. W.: Ist das Interesse an der Erhaltung von "BestandsgröBen" ein Definitionsbestandteil und die conditio sine qua non von "StromgröBen"? Diese Frage wurde oben bereits mit dem Hervorheben des Verwendungsproblems eingeleitet.

Es ergibt sich weder Ertrag noch Einkommen aus der "theoretisch bewiesenen" Notwendigkeit und Zwangsläufigkeit zur (nominellen oder substanziellen) Bestandserhaltung. Vielmehr ist die Verwendung des Ertrages zur Kapitalerhaltung und die Verwendung des Einkommens zur Vermögenserhaltung eindeutig abhängig von den $E \mathrm{n} t \mathrm{~s} \mathrm{c} h \mathrm{e} i \mathrm{~d} u \mathrm{n} g$ e $\mathrm{n}$ der in den jeweiligen Bereichen Berechtigten. So ist die Erhaltung des Kapitals nicht zwingend für das Vorliegen von Ertrag, also kein $D$ e $f i n i t i \circ n s$ bestandteil. Sie ist allenfalls das Ergebnis einer Entscheidung für die auf längere Sicht zu sichernde Ertragsfähigkeit, also ein $D i s p o s i t i \circ n s$ bestandteil. Ebenso ist die Verwendung des Einkommens (entweder zum Konsum oder zum Sparen) nicht ein Definitionsbestandteil, sondern entscheidungsabhängig. Alle Versuche, Ertrag und Einkommen durch Bestandserhaltung zu definieren, müssen ebenso fehl gehen wie Versuche, Einkommen durch lediglich eine einzige Entscheidungsrichtung, z.B. für den Konsum, $z$ u bestimmen.

Die Entscheidungsabhängigkeit des Erhaltungsinteresses ist beispielsweise bereits in der Kapitaltheorie von Böhm-Bawerk erkannt: Kapitalerhaltung und Reservebildung sind eine Frage des "Willens" (1921, S. 113) und der "Entscheidung" angesichts einer Wahl (S. 109 u. 118 f.) zwischen mehreren Möglichkeiten. Dies gilt auch für die Kapitalbildung und Strukturierung, wenn nämlich

43) Siehe auch die Kritik von P.H. Wueller (1938, S. $90 \mathrm{ff.}$ ) an der Verwendung des "preservation-of-source-criterion", das ebenso wie bei F.B.W. Hermann (1832, passim) auch bei G. v. Schmoller (1863, S. $52 \mathrm{ff.})$ auftaucht. 
die Entscheidung zwischen Konsum und Sparen zu treffen ist. 44) Persönliche Motivation, Vorliebe und die Entscheidungsfreiheit sind also für die Verwendung des Ertrags und des Einkommens zur Bestandserhaltung bzw. -auflösung die bestimmenden Elemente, und nicht etwa das rationale Interesse an der Kapitalerhaltung und der weiteren Ertragssicherung allein.

Nach L. v. Mises (1940, S. 450 ff.) wird Kapital nur erklärbar aus dem EinfluB der Zeit auf menschliche Entscheidungen und Handlungen. Nach seiner "praxeologischen" Anschauung ist die Entscheidung zur Einkommensverwendung - aber auch zur Kapitalschonung - ein Ausdruck des Handelns: es ist nicht die vorgegebene "Funktion" des Einkommens, Kapital zu schaffen, sondern die Entscheidung, Einkommen so oder anders zu verwenden, so oder anders über es zu verfügen. Einkommen und vermögen sind nach Mises "praxeologische Kategorien" (S. 353). Einkommen zieht Entscheidungen nach sich, und zwar "vernüntige" Entscheidungen, wie wir den Ausführungen von J.R. Hicks (1946, S. 172) entnehmen können. 45)

D. Schneider (1981) nimmt sowohl den Böhm-Bawerkschen Entscheidungsgedanken als auch den Mises'schen Zeltgedanken auf. Er geht davon aus, daB der wirtschaftende Mensch ein Interesse an der Erhaltung von BestandsgröBen haben muB, weil die Unsicherheit über den Zeitverlauf bis zu seinem Lebensende ihn dazu veranlasse. Nur wenn die Handlungszeitspanne gleich der Planungszeit-

44) Man kann sich andererseits auch für Kapitalauflösung entscheiden: Wenn ein Volk "sein ganzes Jahreseinkommen (bei Böhm-Bawerk: "Produktionsertrag", HDH) in GenuBmittelform verzehren will und verzehrt", ... "ist alsdann für eine Capitalvermehrung keine Produktivkraft disponibel, es wird nur der Beharrungszustand erreicht" (S. $123 \mathrm{f}$.$) .$

Was die Leute zum Sparen und zum produktiven Einsatz des Ersparten veranlaBt, sind "die treibenden, wirksamen Kräfte" (Böhm-Bawerk 1921, S. 134), neben der Intensität der Bedürfnisse vor allem die individuellen Wertschätzungen (S. $140 \mathrm{f}$. ).

45) Die zentrale Bedeutung des Einkommenskonzepts ist es, als eine Art Wächter des "Vernunftverhaltens" (prudent conduct) $z u$ fungieren, um den Elnkommensbeziehern genau jenen Betrag anzuzeigen, den sie konsumieren können, ohne sich selbst ärmer zu machen. Aber sie können sich eben auch entschelden, sich ärmer $z$ u machen. - Es sollte uns hier nicht stören, daB Hicks diese Funktion nur einem solchen Einkommen zubilligt, das einem statischen Konzept im Sinne eines "standard stream" entspricht; unter einem dynamischen Aspekt aber werde der Einkommensbegriff unbrauchbar, S. $176 \mathrm{ff}$. 
spanne eines Entscheidenden sei, der einzelne also bis an sein Lebensende mit Sicherheit planen könne, vermöge er seine Entscheidungen über die Verwendung von ökonomischen Größen (Konsum oder Investition) "ohne Zuhilfenahme der Vorstellung von $\mathrm{zu}$ erhaltendem Endkapital am Planungshorizont, und das heibt: ohne eine Trennung von Einkommen und Kapital, festzulegen" (S. 141). Das Wesentliche ist die Anerkennung der Rolle von Entscheidungen für (wir ergänzen: aber auch gegen!) die Erhaltung von BestandsgröBen. Dabei dient ihm das Zeitphänomen als ein Motiv für die Erhaltungsentscheidung. Wir haben jetzt lediglich anzufügen, daB die Erhaltungsentscheidung dann aber sowohl im allokativen als auch im distributiven Bereich gefällt werden muB.

Wenn solchermaßen der Ertrag in der allokativen Sphäre sich erst nach einer Entscheidung für die Kapitalerhaltung ergeben soll, wenn außerdem erst die Entscheidung über die Weitergabe des verbleibenden Ertrags an den Inhaber bzw. Anteilseigner des Unternehmens den zugang an ökonomischen Größen bei ihm zu Einkommen macht, so ist zwar dieses um die kapitalerhaltende Verwendung des Ertrages nunmehr geringer, doch ist die Kapitalerhaltung damit nicht zum zwingenden Definitionsbestandteil des Einkommens geworden. Sie ist lediglich eine Aufforderung $z u$ "vernünftigem" Verhalten angesichts des zeit- und Unsicherheitsphänomens. Als Ergebnis wäre festzuhalten, daB gerade die Rolle der ökonomischen Entscheidungen die Berechtigung und auch die Notwendigkeit einer allokativ-distributiven Abgrenzung des Einkommens von den Ertrags- und Kapitalbegriffen deutlich $z$ u demonstrieren vermag.

46) Auch im Steuerrecht ist die Rolle der "Willenshandlung" des Steuerpflichtigen (K. Tipke 1979a,S. 202) zur Abgrenzung zwischen der betrieblichen und der privaten sphäre bekannt; für die zuordnung einer Handlung und eines Wirtschaftsgutes entweder $z$ um allokativen oder $z$ um distributiven Bereich ist der Wille des einzelnen entscheidend. K. Tipke (1979a,S. 199) betont, daB zunächst nicht die Kausalität, sondern die Finalität einer Handlung, also das Motiv des Handelnden, für die Zuordnung ausschlaggebend ist, und daB das auch von der Rechtsprechung im Prinzip stets anerkannt worden sei; allerdings stehe der groBzügigen Anwendung dieses Grundsatzes im unternehmerischen Bereich die auffälig engherzige Praxis im privaten Bereich gegenüber. 
58 Das Problem der Inhalts- una

Umfangsbestimmung des

Einkommens

I. Vorbemerkung: Zur Zweckmäßigkeit von Begriffs"Konzeptionen"

II. Die "Zugangsregel" und die Periodisierung der Zugänge an ökonomischen Größen

III. Geld- und güterliche Zugangsarten und das allokativ-distributive Zugangsquellenproblem. überblick über die Systematik der Einkommenselemente

IV. Der "produktionswirtschaftliche" Einkommensbegriff

1. Die Dominanz des Alloktiven in der Quellentheorie

2. Die Dominanz des Allokativen bei I. Fisher, E. Lindahl und N. Kaldor

3. Die Dominanz der Makroökonomik bei F. Neumark

V. Der "vermögeneinschließende" Einkommensbegriff

1. Heterogener Vermögenseinschluß

2. Vermögenswertzuwachs-Einkommen (capital gains)

3. Zurechnungs-Einkommen (imputed income)

VI. Der "transfereinschließende" Einkommensbegriff

1. Die allgemeine Charakterisierung des Begriffs

2. Ein Grundschema der Versorgungssicherung als Ansatz für die Beurteilung der Einkommensqualität von Transfers

3. Die Klassifikation der Transfers und ihre Einkommensqualität

I. Im Gegensatz zur Abgrenzungsthematik, die die distributive Eigenschaft und Funktion ${ }^{1)}$ des Einkommens ausweist, bestimmt nunmehr die Inhaltsthematik, was Einkommen dem Gegenstande nach ist. 2)

Begriffe werden mit Blick auf ihre ZweckmäBigkeit gefaBt. ${ }^{31}$ Sowohl der wirtschaftstheoretische als auch der steuerliche Ein-

1) DaB das Einkommen in der primären und sekundären Verteilungspolitik auch allokative Effekte hat, ist unbestritten, ändert jedoch nichts an seiner primär distributiven Funktion.

2) Im Steuergesetz heiBt daher der Inhalt des Besteuerungsgutes auch der Steuer-"Gegenstand".

Fn. 3 siehe folgende Seite 
kommensbegriff wird im allgemeinen dabei in eine bestimmte K $\circ \mathrm{n} z$ e $\mathrm{p} i \circ \mathrm{n}$ eingebettet. ${ }^{4)}$ So sehr auch die logische Verknüpfung des Einkommensbegriffs mit dem Konzeptionsgedanken akzeptiert werden muB, so soll vorerst davon ausgegangen werden, daB für die Entwicklung des wirtschaftstheoretischen Einkommensinhaltes das Besteuerungsziel ohne Belang bleiben muB. Dennoch läBt sich auch in den von O. Ebnet (1978, S. 42 ff.) aufgezählten Konzepten im Kern der Anklang an wirtschaftstheoretische Konzeptionen erkennen. Verfolgen wir den konzeptionellen Gedanken, so liegt in seinem "Nutzenkonzept" der Versuch, Einkommenselemente im Sinne einer ökonomischen Interpretation gleichnamig zu machen, d.h. auf ihre Eigenschaft festzulegen, dem Individuum Nutzen zu stiften (daB Ebnet mit diesen Versuchen kritisch verfährt, interessiert an dieser Stelle erst in zweiter Hinsicht). Demgegenüber geht das "Wertkonzept", das dem Reinvermögenszugangskonzept von Schanz, Simons und Haig entspricht, auf die Feststellung der "Totalität" des Einkommens aus, die auch im wirtschaftstheoretischen Einkommensbegriff einen hohen Stellenwert hat. Schlieblich ist das "Konsumstromkonzept" bereits prima facie - wenn es auch von ernst $z u$ nehmenden Autoren vertreten wurde - als eine äuBerste Einengung des Einkommensbegriffs $\mathrm{zu}$ erkennen und hat überdies den Nachteil, die Einkommensqualität an seiner Verwendung, nicht an seinem Zugang, festmachen $\mathrm{zu}$ wollen. Wenn somit auch die genannten drei Konzepte des Einkommens erstens steuerlicher Betrachtung dienen sollen und zweitens auf unterschiedlichen AnalyseEbenen liegen, so machen wir sie dennoch zum Ausgangspunkt unserer wirtschaftstheoretischen Betrachtungen, indem wir auf die Unterschiede im Erklärungsinteresse hinweisen. Das Konzeptionelle an einem für die Wirtschaftstheorie geeigneten ("passenden" nach Sarrazin, s.o.) Einkommensbegriff sehen wir hauptsächlich in der

Fn. 3:

"Wie Begriffe überhaupt, so kann auch der Einkommensbegriff niemals 'falsch' oder 'richtig', sondern höchstens passend oder unpassend sein. Ist er passend, so ist er das Resultat einer vernünftig begründeten Konvention;" Th. Sarrazin 1976, S. 430.

4) Unten wird dargelegt, $d a B z u$ diesem Begriff stets das Programmatische, die Ausrichtung auf ein (Analyse- oder Handlungs-) Ziel gehört. Insoweit erscheint es konsequent, wenn $z \cdot B$. O. Ebnet (1978, S. $42 \mathrm{ff.})$ als die "Grundformen steuerlicher Einkommensbegriffe vom "Nutzenkonzept", vom "Konsumstromkonzept" und vom "Wertkonzept" des Einkommens spricht. 
Totalität ${ }^{5)}$ der Erfassung aller zugehenden ökonomischen Größen, in der Emanzipation von der "Verwendung" dieser GröBen und in der Eignung dieses so bestimmten Einkommens für die Zwecke der verteilungstheoretischen wie der verteilungspolitischen und umverteilungspolitischen Belastungs-/Entlastungsanalysen. Demgegenüber liegen die konzeptionellen Motivationen steuerpolitischer Art in der verteilungs- und unverteilungspolitischen Leistungsfähigkeitsnorm. Das Konzeptionelle des wirtschaftstheoretischen Einkommensbegriffs ist also nicht politisch, sondern analytisch bestimmt. In die Analysekonzeption hat sich der so $z u$ findende Einkommensbegriff einzufügen.

II. Als das wesentliche Merkmal der Einkommensdefinition hat sich aus der würdigung der Literatur jenes herausgestellt, das wir als die " $\mathrm{Z}$ u g a $\mathrm{g} s \mathrm{r}$ e $\mathrm{g} \mathrm{l}$ " bezeichnet haben. Schon die Wahl dieses Terminus drückt aus, daB für das Einkommen keinesfalls die "Verwendungsweise" von ökonomischen Gütern begriffsbestimmend sein kann.6)

a) Einkommensdefinitionen in der Literatur, mögen sie monetär oder güterlich bestimmt sein, mögen sie lediglich produktionswirtschaftliche Quellen gelten lassen oder auch transferielle, mögen sie schlieblich den periodischen ZufluB ständig strömender Quellen oder - umfassender - den Vergleich von Vermögensbeständen $\mathrm{zu}$ ihrem Inhalt machen, Einkommensdefinitionen enthalten als conditio sine qua non den "Zugang" ökonomischer GröBen. Zunächst wird diese Regel -. "Regel" verstanden als "causa" für jedes Einkommen -

5) Der Aspekt der $T \circ t$ a $l$ i $t$ ä $t$ vereint das Nutzen- und das Wertkonzept, schlieBt das Konsumstromkonzept aus; der Aspekt der $M$ e $B$ b a $r$ e $i t$ vereint Wert- und Konsumstromkonzept, schlieBt aber das Nutzenkonzept aus; der Aspekt der Einkommens - $R$ e a $l i s i$ e $r$ u $g$ vereint das Nutzenund Konsumstromkonzept zur Gänze, das Wertkonzept nur teilweise (nicht die unrealisierten Wertzuwächse), schliebt aber Einkommenskonzepte, die auf das Potential zur Leistung abstellen und die 0 . Ebnet nicht erwähnt, völlig aus. Vgl. hierzu unsere Systematik der Besteuerungskonzeptionen im 3. Teil.

6) Siehe hierzu F. Neumark 1947, S. 47 f. und H. Haller 1971 S. 54: "daB die Nichteinbeziehung von Einkommensteilen, auf deren konsumtive Nutzung man ... verzichtet hat, in das besteuerte Einkommen nicht angemessen erscheint, ... daB es also richtig ist, das gesamte Einkommen heranzuziehen, gleichgültig, wie es verwendet wird." - Diese für die Besteuerung anerkannte Regel soll auch für den wirtschaftstheoretischen Einkommensbegriff gelten dürfen. 
institutionell, genauer: personell gesehen; Einkommen geht immer einer Person bzw. einem Haushalt zu (E. Schuster 1961, S. 54). Dies gilt sowohl für die wirtschaftstheoretischen als auch für die steuerlichen Definitionen, und unter den letzteren gleichermaBen für die älteren und jüngeren Autoren und Interpreten der Reinvermögenszugangstheorie ${ }^{7)}$ wie auch für die vertreter der Quellentheorie. ${ }^{8)}$ Personeller Zugang bedeutet nicht, auch etwa eine juristische Person als Zugangsadressaten zuzulassen, denn es wäre ein Irrtum, eine juristische Person mit der physischen gleichzustellen. Sowohl Einkommen wie auch Vermögen gehen nur natürlichen Personen (Haushalten) $z u$, und das "Vermögen" einer juristischen Person ist ökonomisch gesehen nur ein abgeleitetes, kein orıginäres (K. Tiepelmann 1963, S. 46); denn im system der qualitativen Kreislaufzusammenhänge sind die juristischen Personen - abgesehen von völlig verselbständigten Vermögen, wie Stiftungen - nur zwischen die Produktionseinheiten (Unternehmen) und Haushalte (natürlichen Personen) geschaltet; hinter den juristischen stehen immer natürliche Personen, denen letztlich die Einkommen zufließen und die Vermögen gehören (H. Haller 1972, S. 10; G. Wöhe 1988, S. 109 f.; C. Folkers 1979, S. 266).

b) Personaler Zugang bedeutet als "ad-personam-Regel" schlieblich auch, daB Einkommen wie Vermögen zuallererst e i n z e l-

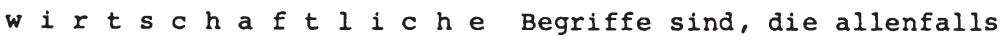
summarisch sich $z$ u gesamtwirtschaftlichen darstellen lassen. 9) Es kann in quantitativer Hinsicht der personale Einkommensbegriff nicht aus MakrogröBen abgeleitet werden. ${ }^{10)}$ Der Begriff eines

7) G. v. Schanz 1896, Brauckner 1921, B. Moll 1924 und 1930, Pistorius 1929, C.C. Plehn 1924 u. 1931, J. Popitz 1926, G. Strutz 1927/29, R.M. Haig 1959, H.C. Simons 1938, R. Goode 1976, 1977 u. 1980, J.C. Head 1972 u. 1979, Royal Commission (Carter Report) 1966, D. Schneider 1971, 1979a u. 1981, J. Mitschke 1976, M.S. Feldstein $1976 \mathrm{~b}$.

8) G. Cohn 1885 u. 1889 , A. Wagner 1892, F. Jul. Neumann 1887 u. 1896, E. v. Philippovich 1926, A. Schäffle 1895/97, E.R.A. Seligman 1919.

9) G. v. Schmoller sagt hierzu: "Nach unserer Ansicht gehört der Einkommensbegriff aber überhaupt streng genommen nur der Einzelwirtschaft an, der Volkswirtschaft nur in bildlicher analoger Ausdehnung" (1863, S. 78).

10) Hier ließen sich allenfalls näherungsweise die funktionalen Einkommen und Verteilungsverhältnisse darstellen. So weist z.B. H.C. Simons (1938, S. 46) darauf hin, daB die Entwicklung des personalen Einkommens aus der MakrogröBe Volkseinkommen die Geschenke, Wertzuwächse usw. aus dem Einkommen (und auch aus der steuerbemessungsbasis) ausschlieBen würden. 
"social income" ist im Sinne der Anwendung des Zugangsprinzips nicht brauchbar, da bestimmte Teile des individuellen Einkommens, wie die Nutzung der Wohnung im eigenen Hause, des Mobiliars usw. (das imputierte "Realeinkommen"), nicht an einer anderen stelle des Wertschöpfungskreislaufs als Output (I. Fishers "outgo") erscheinen. Der Rückgriff auf Makrobegriffe gesamtwirtschaftlicher Einkommensgrößen leistet für die Einkommensdefinition nichts und wird der von ad-personam-Regel somit ausgeschlossen. ${ }^{11)}$

c) Diese einkommenstheoretischen Qualitäten der Zugangsregel, die sich auf das personale Element im Zugang der ökonomischen GröBen konzentrieren, haben - worauf noch einzugehen sein wird ihre Konsequenzen für die $s$ e $u$ e $r$ l i $c$ h e $n$ Betrachtungen: Bekanntlich wird diskutiert, ob eine Größe, die bereits der Besteuerung unterlegen hat, abermals besteuert werden dürfe, wenn sie einer anderen Person zugeht (der Fall der Schenkungen und Erbschaften) oder derselben Person "erneut zugeht" (der Fall, da $B$ aus bereits versteuertem Einkommen Ersparnisse gebildet wurden und die Zinszugänge der Einkommensteuer unterworfen werden). Löst man den Blick von der ökonomischen GröBe und dem auf ihr liegenden Steuerbetrag und läBt die Regel des "Zugangs" dieser Größen gelten, so rückt die Person in den Betrachtungsmittelpunkt; ${ }^{121}$ ihr ist zum Zeitpunkt eines jeden zugangs auch Leistungsfähigkeit zugegangen. Mithilfe dieser Regel läBt sich dann die alte Streitfrage der sog. "doppelten" Belastung lösen: Mag auch das ererbte Vermögen bereits mit der Einkommen- und Vermö-

11) In seiner Analyse der Definitionen der Literatur kommt H.C. Simons (1938, S. $43 \mathrm{ff.}) \mathrm{zu}$ insgesamt vier unterschiedlichen Verständnisweisen von Einkommen: (1) dem "income from things"; (2) den "gains from transactions"; (3) dem "social" bzw. "national income" und (4) dem "personal income". Es läBt sich aber nachweisen, daB die ersten drei Versionen des Einkommensbegriffes eindeutig der Ertragssphäre des Wirtschaftens angehören, dem Allokationsbereich: sei es, daB sie als Marktwerte der Nutzungen $z u$ gelten haben mit "aquisite implication" (1); sei es, $d a B$ es sich um "trading profits" handelt (2); oder sei es, daB gerade das social income eng mit der Produktionssphäre verbunden ist (3). Nur das personal income gehorcht insofern der Zugangsregel, als der Person die "property rights" im Simons'schen Sinne zugehen, von der Person gehalten werden; und es ist im Sinne Simons' insofern ein distributiver Begriff, als nur die Person Entscheidungen über Konsumakte aus dem Einkommen trifft (S. 46).

12) In diesem Sinne argumentiert auch A. Oberhauser (1979, S. $491 \mathrm{f.l}$, wenn er den Erbanfall als Zugang von Einkommen und als Erhöhung der Leistungsfähigkeit darstellt-3-631-75239-5 
gensteuer des Erblassers belastet sein, für den Erben, dem es zugeht, drückt es Leistungsfähigkeit aus. Will man nach dem Leistungsfähigkeitsprinzip besteuern, hebt das die Problematik der Doppelbelastung auf. Das Leistungsfähigkeitsprinzip wird dann höher eingeschätzt als etwa andere vorher bestehende Prinzipien; es schlieBt sich an die einkommenstheoretisch entwickelte Zugangsregel an. 131

d) Von der Zugangsregel her ist die $\mathrm{p}$ e $\mathrm{r}$ i o d e $\mathrm{n}$ b e $\mathrm{z}$ o $g$ e $n h e i t$ des Einkommens kein Definitionserfordernis. Denn der Zugang an ökonomischen GröBen läBt sich sowohl für eine bestimmte Zeitspanne als auch jeweils von Fall zu Fall feststellen. Jedoch sind alle Einkommensdefinitionen in der Literatur streng mit der Periode verknüpft, sowohl die wirtschaftstheoretischen als auch die steuerlichen, ${ }^{14)}$ obwohl sich eine steuerliche Leistungsfähigkeit auch aperiodisch feststellen lieBe. Der Grund für die Periodisierung des Einkommens liegt in der MeB- und V e r g l e i c h b a r k e i t (H. J. Krupp 1975, s. 12): Verteilungstheorie, Verteilungspolitik, Steuertheorie und Steuerpolitik sind in einem solchen MaBe auf Vergleichbarkeit von ökonomischen Größen zwischen Individuen und Zeitspannen angelegt, daB die Einkommensdefinitionen dieses Erklärungsinteresse internalisiert haben.

Schlieblich aber beginnt gerade mit der Festlegung von Perioden zum Zwecke der Beurteilung und Durchführung der Wirtschafts- und Steuerpolitik das eigentliche Problem. Sowohl die geplanten allokativen als auch die distributiven $\mathrm{Ziele}$ verlangen eine Periodenbildung. Unterschiedliche Periodenlängen lassen die $z$ u vergleichenden ökonomischen GröBen unterschiedlich erscheinen. Einkommen ist nicht gleich Einkommen, wenn z.B. Jahres- und Lebenszeiteinkommen miteinander verglichen werden. Ob es nun gelingt, eine "sinnvolle Periodenlänge" (G. Krause-Junk 1981, S. 264) zu

13) In diesem Sinne jüngstens etwa N. Andel 1979a, S. 340 u. 356 sowie auch R.A. Musgrave 1981, S. 31 mit der Kritik an dem nicht angebrachten Argument der Doppelbesteuerung, das seit J. St. Mill und I. Fisher vorgebracht wird.

14) Selbst die Reinvermögenszugangstheorie ist auf Periodizität angelegt, da sich andernfalls ein Vermögensvergleich nicht anstellen lieBe. - Demgegenüber formulierte die Quellentheorie eine besondere Version der Periodizität im Sinne einer ständigen Wiederkehr von Einkünften. Den periodischen bzw. aperiodischen zugang nennen wir die zugangsweise oder -form. Heinz Hessler and Anneliese Hessler-Otte - 978-3-631-75239-5 
finden oder nicht, die Jahresperiode ist - wie jede andere auch immer eine "Konvention" (F. Neumark 1961b, S. 48). 15)

Dennoch muB die Aufnahme der Periodenbezogenheit in den Einkommensbegriff als definitorisch korrekt und unausweichlich bezeichnet werden, soll der Begriff uberhaupt "Sinn" haben und in der Realităt angewendet werden können. Die Unschärfen, die dabei auftreten, sind dann jeweils deutlich $\mathrm{zu}$ machen.

III. In ihrer Funktion als Instrument des Erkenntnisvorgangs ist die Zugangsregel "offen" und zugleich "blind": Offen hinsichtlich ihres Umfangs, d.h. für alle Zugangsarten, -quellen und -formen; einkommenstheoretisch ist die Regel auf die $T \circ t$ a $l i t a t$ des Einkommens angelegt. Blind ist sie hinsichtlich aller etwa aus steuerlichen Erwägungen für erforderlich gehaltener Einengungen eben dieser Totalität; was aus steuerpolitischen Gründen an Begründungen für die Begriffseinengung gegeben wird, hat für die einkommenstheoretische Definition kelne Bedeutung. Steuerlich mag ein anderer Totalitătsbegriff sinnvoll sein.

a) In der Literatur wird der Inhalt des theoretischen Einkommensbegriffes geprägt sowohl von der A $r t$ des zugangs, also von seinem geld- und güterlichen Ausdruck, als auch von der $Q$ u e I I e des zugangs, d.h. der geld- und guterliche zugang bestimmt sich danach, ob er aus dem unternehmerischen Ertragsbereich, aus dem privaten Vermögensbereich oder/und aus dem Bereich der laufenden (öffentlichen und/oder privaten) Transfers herrührt.

Die unterschiedich engen oder breiten Einkommensdefinitionen in der Literatur überspannen diese verschiedenen Bereiche von der (monetären) Faktorentlohnung bis hin zu den öffentlichen Realtransfers in Form der öffentlichen Güter. Sie unterschelden sich z.B. danach, ob innerhalb des allokativen Quellenbereichs der nicht ausgeschütete Gewinn dem Anteilseigner oder Inhaber

15) Der Postulat- oder Normcharakter der Periodenbildung wird nicht zuletzt aus der Schanz-Gärtner-Kontroverse deutlich, siehe Finanzarchiv 1896 (S. 1 ff.) bis 1898 (hier bes. S. 515 ff. U. 530 ff.). 
des Unternehmens als Einkommen zugerechnet werden soll oder nicht, ob die capital gains zum Einkommen zählen oder nicht; andererselts nehmen sie - innerhalb des distributiven Quellenbereichs - tellweise den Zugang privaten Vermögens in den Einkommensbegriff auf, teilweise nicht (siehe den Unterschied zwischen der Reinvermögenszugangs- und der Quellentheorie); innerhalb desselben Bereichs werden mitunter auch die häuslichen Dienste und die Freizeit zum Einkommen gerechnet; nur äuBerst selten - wenn man sich dem Bereich der Transfers zuwendet - wird den öffentlichen Gütern Einkommensqualität zugeschrieben.

b) Für die Inhaltsbestimmung wird nun namentlich die $M$ e $B$ b a $r$ $k$ e $i t$ des Zugangs an ökonomischen GröBen bedeutsam. Zum Problem wird sie unter den geldlichen Zugangsarten allenfalls dann, wenn Vermögen $\mathrm{zu}$ bewerten ist. GröBere Bedeutung erhält sie für die güterlichen Zugänge; Schwierigkeiten werden weniger im Bereich der naturalen Entlohnung und der Kapitalwertsteigerungen $\mathrm{zu}$ erwarten sein als vielmehr bei den Nutzungen des privaten Sachvermögens und bei einigen privaten Realtransfers. Als unüberwindlich dürften die MeBprobleme gelten bei den Nutzungen des Humanvermögens (häusliche Dienste und Freizeit), bei privaten Erziehungs- und Unterrichtsdiensten sowie insbesondere bei den öffentlichen Gütern. Sonderfälle nicht $z u$ leistender MeBbarkeit sind auch alle jene Einkommensbegriffe, die auf psychischen GröBen basieren, wie das "psychic income" von D.B. Marsh (1943, S. 519) mit seinen "satisfactions" aus den "income in kind", wie das "enjoyment income" von I. Fisher ${ }^{16)}$ als dem "ultimate income" und schlieblich das aus der Freizeit $z$ u erzielende Bedürfnisbefriedigungseinkommen von H. Haller ${ }^{17)}$ und Musgrave/Musgrave (1980, S. 347). Der jüngste Ansatz, die reine oder doch überwiegende GeldgröBensummierung des Einkommens $z u$ überwinden und $z u$ einem Totaleinkommensbegriff vorzustoBen, der auch Possibilitätselemente enthält, stammt von Atkinson/stiglitz (1980, s. 260 u. 566); sie definieren ein "full income", das neben den monetären zugängen auch ein bloB mögliches Einkommen enthält, das die Freizeit

16) Zur Beurteilung dieses psychischen Einkommens siehe S.H. Frankel 1969, S. $95 \mathrm{ff}$. auf der Basis der Uberarbeitung der Fisher'schen Beiträge aus 1906 und 1907 in Fisher 1930.

17) Haller, H., 1971, S. 44 ff. U. 62 ff.; 1977, S.225; 1981, s.46 ff. Siehe unten im Dritten Teil: "Potentialorientierung". 
erlaubt. ${ }^{18)}$ H.C. Simons aber stellte schon vier Jahrzehnte vorher fest, daB der EinschluB häuslicher Dienste und Freizeit-"Einkommen" Normierungsprobleme aufwirft und $\mathrm{zu}$ unüberschaubaren Verteilungsunterschieden und -interpretationen AnlaB gibt, so daB er seine Betrachtungen folgendermaBen abschlieBt: "The problem is clearly hopeless" (1938, S. 52). Auch K.E. Bouldings "psychic capital" (1950, S. 139 ff.) gehört wie die oben erwähnten zu den Phänomenen, die hier nicht weiter vertieft werden können. Vielmehr soll der Interpretation jener Größen nachgegangen werden, die oben als annäherend meBbar bezeichnet wurden. So steht denn auch der geldliche Zugang bei allen Autoren als ein Mindestinhalt des Einkommens auBer Frage und die güterlichen Zugänge sind insoweit Einkommen, als der zugehende Nutzen in Geld ausgedrückt werden kann. ${ }^{19)}$ Auf der Basis dieses Mindestinhaltes lassen sich sukzessiv weitere zugangsarten in den Einkommensbegriff aufnehmen bis hin $z u$ einem mithilfe von Näherungsverfahren (Bewertungen!) gerade noch meBbaren Totaleinkommen.

c) Innerhalb dieser Spannweite sind nun bestimmte $s t r u k-$ $t u r i$ e $r$ u g e $n$ auszumachen, die $z u$ unterschiedlichen und unterschiedlich begründeten Einkommensbegriffen führen (siehe auch Schaubild 3.3). Zur Würdigung dieser Begriffe in der Literatur bedarf es folgender Vorbemerkungen:

- Verwendungsarten, soweit sie nach der Auffassung mancher Autoren den Einkommensbegriff determinieren, bleiben hier auBer Betracht, da sie schon im Rahmen der allokativ-distributiven Abgrenzung behandelt wurden, hier nur Quellen und Arten des Zugangs zu referieren sind;

18) Wie im 3. Teil dargestellt wird, wirft das ein SollgröBenNormierungsproblem auf; zudem entsteht die Notwendigkeit, sich mit einem Verteilungsproblem besonderer Art auseinanderzusetzen: möglicherweise ist zu entscheiden, ob die "Armsten" oder die "Reichsten" die meiste oder gerade die wenigste Freizeit haben. Im übrigen zielen Atkinson/Stiglitz mit ihrem Ansatz wohl weniger auf einen korrekten Einkommensbegriff als vielmehr darauf, $z u$ belegen, daB der rein monetäre Einkommensbegriff die steuerliche Leistungsfähigkeit nicht ausdrücken könne; das aber ist Steuertheorie, und deshalb hier noch nicht darzustellen.

19) Für die frühen Autoren stehen Böhm-Bawerk und Fisher; E. v. Böhm-Bawerk (1921): nicht allein Einnahmen (S. 367), sondern auch Nutzen aus Sachgütern flieBen $z u$, und zwar als Abgabe von "Nutzleistungen" (S. 360). - I. Fisher (1928, S. 23): Geldausdruck von "Güternutzen". 
- der von manchen Autoren ${ }^{201}$ verwendete Begriff des "Realeinkommens" bzw. der "realen Bestandteile des Einkommens" hat nichts $\mathrm{zu}$ tun mit der Kaufkraft des Einkommens, sondern mit dem güterlichen Ausdruck des Einkommens bzw. mit seiner güterlichen Verwendung;

- "Gütereinkommen" ist nicht gleich der güterwirtschaftlichen Auffassung des Einkommens, denn letztere interpretlert auch das Geldeinkommen güterwirtschaftlich im Sinne einer Verwendung;21)

- steuerliche Einkommensbegriffe stehen hier vorerst nicht zur Diskussion; wenn diese die Kürzung des Totaleinkommens um Werbungskostenbeträge usw. verlangen, so ist das steuerliche argumentiert, nicht einkommens- und wirtschaftstheoretisch.

Die Einkommensbegriffe der Literatur zwischen der relativ engen Auffassung der Quellentheorie und der weitest denkbaren eines Totaleinkommens, das die gesamte "material welfare" eines Menschen ausdrückt, 22 ) unterscheiden sich danach,

- ob sie eine marktliche und produktionswirtschaftliche Herkunft (Quelle) des Zugangs als einkommensqualifizierendes Merkmal verlangen oder nicht (IV);

- ob sie das Vermögen einschlieBen oder nicht, wobei oftmals die allokativ-distributive Unterscheidung zwischen Kapital und Vermögen auBer acht gelassen wird (V); jedoch: immerhin einige

20) I. Fishers Realeinkommen z.B. drückt die Verwendung des Einkommens $\mathrm{zu}$ Konsumzwecken aus $(1930,5.5)$; Hallers Realeinkommensbestandteile sind dagegen güterlicher Art, wie die naturale Entlohnunq, die häuslichen Dienste und die Freizeit, 1981. S. $46 f f$.

21) Eine in diesem Sinne güterwirtschaftliche Interpretation des Einkommens ist die von B. Weiss $(1878$, S. $687 \mathrm{f.})$, der darunter regelmäBig anfallende Ausgaben für Güterkäufe zur Bedürfnisbefriedigung versteht; ähnlich argumentieren auch $\mathrm{E}$. Sax (1887, S. 364) und P. Mombert (1916). Die Einkommenskonzepte des "disposition type" nach P. H. Wueller (1938, S. $97 \mathrm{f.}$ ) sind dadurch gekennzeichnet, daB das Einkommen durch die Verwendung oder durch Ausgaben definiert wird; der entsprechende Begriff des Einkommens nach dem "accrual type" ist durch $\mathrm{Zu-}$ fluB (inflow, incomings) definiert. Einkommen als Ausgaben definierte auch erstmals F.J. Neumann (1889), allerdings unter Ablehnung des Erfordernisses eines regelmäBig wiederkehrenden Zuflusses; solche "Ausgaben-" oder "Ausgangs-Konzepte" sind nicht $z u$ verwechseln mit den Konzepten der Ausgabensteuer!

22) Pigou, A.C., 1951, S. 288: "When we speak loosely of 'material welfare', in the sense of a man's income or possessions, that ... may be a means to welfare, but it certainly is not identical with or a part of it." 
Sonderprobleme innerhalb des Vermögenskomplexes ergeben sich insofern, als die "Imputierung" von Vermögensnutzungen und die Kapital- und Vermögenswertsteigerungen ("capital gains") $\mathrm{zu}$ unterschiedlichen Einkommensbegriffen führen (V 2, V 3);

- ob sie Transfereinkommen einschlieBen oder nicht; der produktionswirtschaftlich determinierte Einkommensbegriff vermag das ex definitione nicht, da er kein derivates Einkommen zuläBt (VI).

d) Die in Ubersicht 3.2 entwickelte $s$ y $\mathrm{s}$ e $\mathrm{m}$ a $t \mathrm{k}$ d e s $\mathrm{z}$ u g a n g s p r b 1 e m s stellt eine Einteilung dar, anhand der die Definitionsversuche in der Literatur hinsichtlich Art und Quellen des Einkommens geprüft werden können. Die Analyse ergibt, daB von keiner Theorie sämtliche zugangsarten und -quellen jemals erfaBt werden, ja entsprechend dem Erklärungsinteresse der Theorie auch nicht erfaBt werden sollen.

Die Ubersicht ist auf einen vollständigen Nachweis aller Einkommensquellen und -arten angelegt. Sie ist hinsichtlich ihrer Brauchbarkeit mit zwei Systematiken zum Einkommensbegriff zu yergleichen, nämlich mit jenen, die z. B. von W. Albers (1979a, S. 197-201) und von N. Andel (1979a, S. 337-355) vorgelegt worden sind. 23)

Die ausführliche Besprechung der Ubersicht 3.2 mit der Abgrenzung ihrer Aggregate wurde, da sie für den Fortgang der Gedankenführung hier nicht vonnöten ist, in den Anhang unter "Exkurs I" verwiesen.

Anhand des Schemas der "Arten und Quellen des Zugangs ökonomischer Größen" sind wir nunmehr in der Lage, eine theoretische Beurteilungsbasis zu formulieren, in der drei Typen von Einkommens-

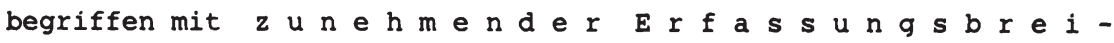
t e vorkommen. Der dritte Typus repräsentiert das Ideal des umfassenden, des totalen Einkommens, der "comprehensive tax base". (Fortsetzung des Textes auf Seite 102)

23) Siehe auch W. Albers 1957, S. 56-99. Diese Systematiken können stellvertretend für andere herangezogen werden. Wir gehen davon aus, das gerade Beiträge in Handbüchern und Handworterbüchern, in denen umfängliche Beschreibungen und Problematisierungen weitgehend vermieden werden, um so besser geeignet sind, die $s$ y $s$ e $m$ a $t i k$ der Begriffe und Beziehungen hervorzuheben. Es soll aber nicht übersehen werden, daB die Beiträge von Albers und Andel in erster Linie unter dem Aspekt der Besteuerung nach der Leistungsfähigkeit entwickelt wurden, was ihr Erklärungsinteresse gegenubber dem unsrigen lelcht verändert. 
Ubersicht 3.2: Arten und Quellen des Zugangs an ökonomischen Größen

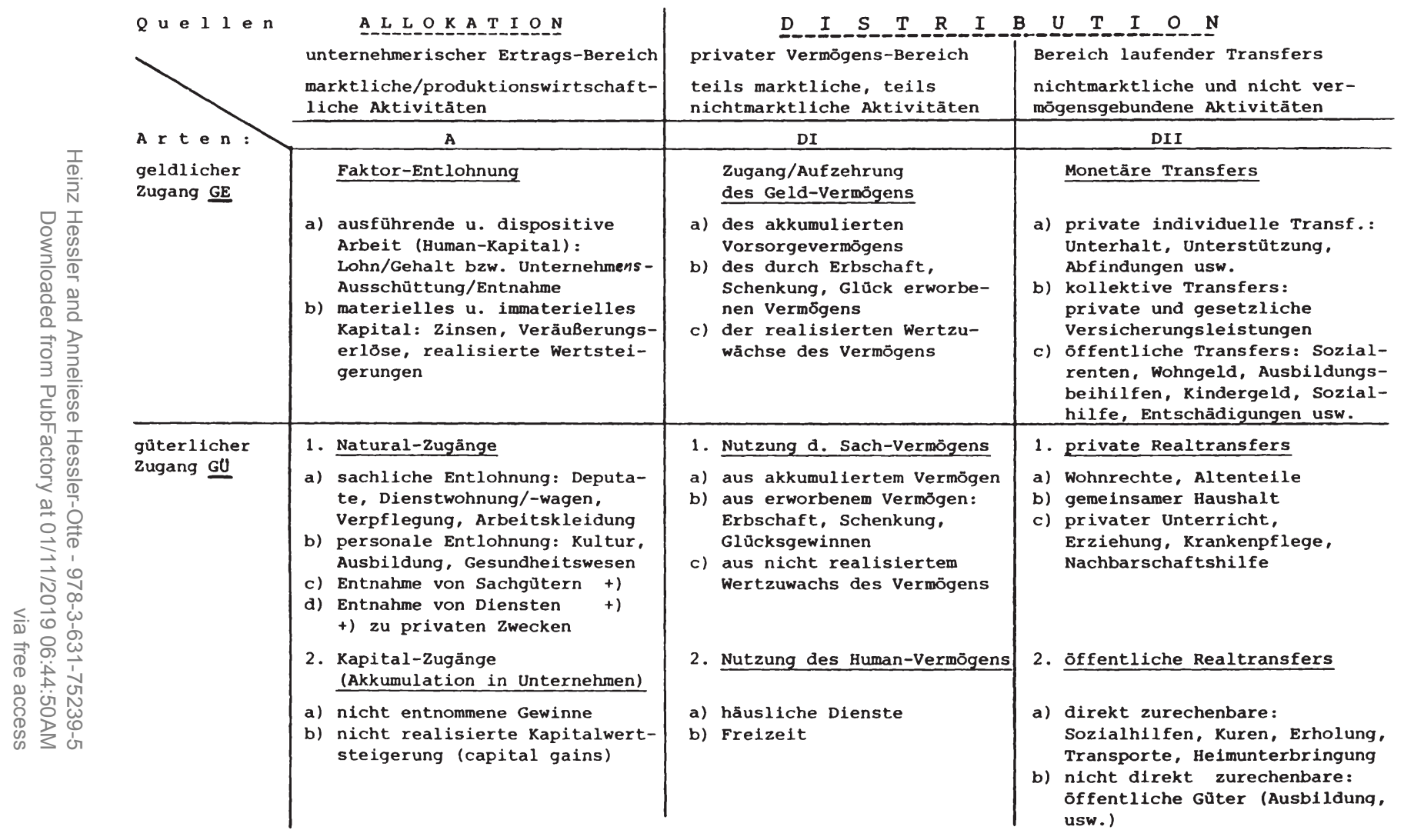




\section{Anmerkungen zur Ubersicht 3.2:}

- Weitere Erlāuterungen siehe "Exkurs I" im Anhang;

- Die Ubersicht stellt eine Systematisierung der Quellen des Einkommens und seines Geld- und Güterausdrucks dar, und zwar als ein modellhaftes "Maximalangebot"; nicht alle Positionen kehren in den Definitionen der Literatur wieder. Die Ubersicht kann als Ergānzung zum Schaubild 3.1 gelesen werden, wo auf den detaillierten Ausweis des Distributionsbereichs zugunsten der Zusammenhănge mit dem Allokationsbereich verzichtet wurde;

- die übliche Aufteilung des Einkommens in das "originäre" und das "derivative" lāBt sich in diesem Schema eindeutig nur für das erstere wiederfinden (originăr = allokative Herkunft); das derivative würde den gesamten Bereich "Distribution II" umfassen, zusätzlich noch aus Distribution I die Erbschaften usw.

- Abgrenzungskriterium zwischen den Bereichen Distribution I und Distribution II ist das private Vermögen:

-- soweit dieses privat gehalten, genutzt oder verzehrt wird, ohne daB Entgelt zugeht, liegt eine nichtmarktliche Aktivität vor;

-- soweit allerdings privates Vermögen allokativ eingesetzt wird und Entgelt zugeht, liegt marktliche Aktivitat vor;

- der Transferbereich ist als ein solcher aufgefaBt, der nicht auf Vermógen abstellt; das ist allerdings eine Interpretationssache, denn es läßt sich auch vertreten, Ansprüche gegen die privaten und gesetzlichen Versicherungen als Vermögensbestand auszuweisen.

- Legende: Zum Aufsuchen der Einkommensbestandteile wird folgende Spalten- und Zeilen-Bennennung verwendet:

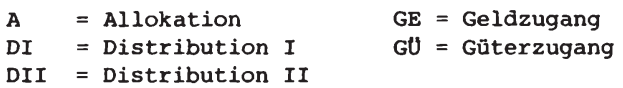

Beispiel: der Einkommensbegriff von $I$. Fisher:

"GE: A (ab); GU: A (1, 2a), DI (1, sofern marktlich)"; das bedeutet im Klartext:

"Das Einkommen besteht aus dem Geldeinkommen der Faktorentlohnung sowie aus dem Gütereinkommen, und hier aus der gesamten Naturalentlohnung, enthält jedoch nicht die capital gains; ferner umfaBt es - sofern marktliche Aktivitäten vorliegen - die Nutzungen des Sachvermögens. Transfers enthält das Fisher'sche Einkommen nicht."

-- siehe die Matrix-Darstellung verschiedener Einkommensbegriffe im Schaubild 3.3. 
Schaubild 3.3: Matrix-Darstellung enger und weiter Einkommensbegriffe

1. Der auf den "produktiven Aktivitäten" beruhende Einkommensbegriff von I. Fisher

\begin{tabular}{|c|c|c|c|}
\hline & A & DI & DII \\
\hline \multirow{3}{*}{ GE } & a & a & a \\
\hline & $b$ & $b$ & $b$ \\
\hline & & C & c \\
\hline \multirow{5}{*}{ GUt } & $1 \mathrm{a}$ & YIsts & $1 \mathrm{a}$ \\
\hline & $1 \mathrm{~b}$ & 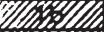 & $1 \mathrm{~b}$ \\
\hline & $1 c$ & IIISOIIIA. & $1 c$ \\
\hline & $2 a$ & $2 a$ & $2 a$ \\
\hline & $2 b$ & $2 b$ & $2 b$ \\
\hline
\end{tabular}

Die Schraffur im Vermögensbereich bedeutet: sofern produktiv eingesetzt

2. Der auf dem Vermögensvergleich beruhende Einkommensbegriff der Reinvermögenszugangstheorie

\begin{tabular}{c|c|c|c|} 
& $A$ & $D I$ & $D I I$ \\
\hline \multirow{3}{*}{$G E$} & $a$ & $a$ & $a$ \\
\cline { 2 - 4 } & $b$ & $b$ & $b$ \\
\hline \multirow{5}{*}{$G U$} & $c$ & $c$ \\
\hline \multirow{4}{*}{$1 a$} & $1 a$ & $1 a$ \\
\cline { 2 - 4 } & $1 b$ & $1 b$ & $1 b$ \\
\cline { 2 - 4 } & $1 c$ & $1 c$ & $1 c$ \\
\cline { 2 - 4 } & $2 a$ & $2 a$ & $2 a$ \\
\hline & $2 b$ & $2 b$ & $2 b$ \\
\hline
\end{tabular}

säntliche Realtransfers und die Nutzung des Humanvermögens bleiben ausgeschlossen

3. Der auf der "property rights-Regel" und der "Geldsummenregel" beruhende Einkommensbegriff von H.C. Simons (ähnlich auch von R.M. Haig)

\begin{tabular}{c|c|c|c|} 
& $A$ & $D I$ & $D I I$ \\
\hline \multirow{4}{*}{$G E$} & $a$ & $a$ & $a$ \\
\cline { 2 - 4 } & $b$ & $b$ & $b$ \\
\cline { 2 - 4 } & & $c$ & $c$ \\
\hline \multirow{4}{*}{$G U$} & $1 a$ & $1 a$ & $1 a$ \\
\cline { 2 - 4 } & $1 b$ & $1 b$ & $1 b$ \\
\cline { 2 - 4 } & $1 c$ & $1 c$ & $1 c$ \\
\cline { 2 - 4 } & $2 a$ & $2 a$ & $2 a$ \\
\hline & $2 b$ & $2 b$ & $2 b$ \\
\hline
\end{tabular}

nur was nicht meBbar und nicht zurechenbar ist, bleibt ausgeschlossen

Siehe auch die weiteren Matrix-Darstellungen in der Ubersicht A.2 zu den unterschiedlichen Verfügungsbereichen der Teil-Einkommensbegriffe. 
(1) Der "produktionswirtschaftliche" Einkommensbegriff, dessen Zugangsquellen allein im allokativen Bereich liegen;

(2) der "vermögeneinschließende" Einkommensbegriff, der in seiner gegenüber (1) erweiterten Fassung allokative Quellen einschließt, hingegen nicht mehr als Bedingung enthält, daß die Zugangsquellen ausschließlich produktionswirtschaftliche sein müßten;

(3) der "transfereinschließende" Einkommensbegriff, der den vermögenseinschließenden inkorporiert und insoweit der umfassendste ist.

Die kritische Beurteilung der Literatur wird jedoch ergeben, da $B$ vermögen- und transfereinschließende Begriffe unterschiedlicher Breite vorgetragen werden.

IV. $P r \circ d u k t i \circ n s w i r t s c h$ a $t$ t 1 i $c h$ e Argumente werden nicht nur in der alten Quellentheorie, sondern auch in neueren Theorien vorgetragen.

1. Das Postulat der ausschlieBlich produktionswirtschaftlichen Herkunft des zugangs an ökonomischen GröBen ist typisch für jene Einkommenstheorien, die man als $Q$ u e $l$ l e $n t h$ e $\mathrm{r} i \mathrm{e}$ 24) bezeichnet. Für sie gilt, was schon H.L. Biersack (1850, S. 146) feststellt und danach von vielen Autoren ${ }^{25)}$ - allerdings in einem engen Zusammenhang mit der Besteuerungsabsicht - anerkannt wurde: Alle jene Einkünfte sind steuerbare Einkünfte, die aus dem Einsatz der Produktivkräfte des einzelnen abgeleitet sind. Diese produktionswirtschaftlich orientierten Einkommensbegriffe ergaben sich aus dem Interesse, die Quellen der ökonomischen Wertschopfung wegen der Dauerhaftigkeit der Steuerquellen erhalten $\mathrm{zu}$ wollen.

24) B. Fuisting 1902, S. 110: Einkommen 1st die "Gesamtheit der Sachgüter, welche in einer bestimmten Periode ... dem Einzelnen als Erträge (! HDH) dauernder Quellen der Gütererzeugung zur Bestreltung der persönlichen Bedürfnisse für sich und für die auf den Bezug ihres Lebensunterhaltes von $1 \mathrm{hm}$ gesetzlich angewiesenen Personen ... zur Verfügung stehen."

25) A. Held 1872; W. Vocke 1894; W. Lexis 1906; W.G.F. Roscher 1922; W. Lotz 1931. - Mit der prod.wirtsch. Zugangsart hängt die periodische zugangsweise eng zusammen, ist aber nicht identisch, denn auch "windfall gains" sind prod.wirtschaftliche. 
Die Quellentheorie läßt sich auch als ein Theorieansatz vom Reinertrag ${ }^{26)}$ der einzelnen Produktionsfaktoren formulieren (Reinertragslehre), wonach nur die regelmäBigen und betriebsgewöhnlichen Einnahmen zum Rohertrag führen, von dem die betriebsgewöhnlichen und zur Erzielung der Erträge notwendigen Ausgaben abgezogen werden. D. Schneider (1978b, S. $46 \mathrm{ff.}$ ) betrachtet die Aufzählung der sieben Einkunftsarten des deutschen Einkommensteuerrechts als Ausfluß dieser Lehre. Er hebt für die Quellentheorie drei Merkmale hervor 27): Das "Trennungsprinzip", wonach die Früchte vom Vermögensstamm getrennt zu betrachten sind und das die Periodizität der Früchte begründet; das "Nettoprinzip", wonach die Aufwendungen zum Gewinnen der Früchte nicht zu den Früchten zählen; das "Ermittlungsprinzip", welches als das der Quellentheorie angemessene Verfahren die Einnahmen-Ausgaben-überschußermittlung verlangt, denn ein Vermögensvergleichsverfahren würde Wertminderungen und -erhöhungen ertragswirksam machen.

Der auf diese Weise ermittelte Einnahmenüberschuß soll also erstens nur produktionswirtschaftliche Ergebnisse erfassen und zweitens den "Vermögens"stamm erhalten, weshalb VeräuBerungsgewinne aus dem Vermögen nicht $z u$ den Einnahmen, Verluste aus dem Vermögen nicht $z u$ den Ausgaben gerechnet werden. Sowohl die Bestandserhaltung wie auch die conditio sine qua non produktionswirtschaftlicher Aktivitäten darf man als "D o m i n a n z d e s A 110 $k$ a $t i v e n "$ in dieser Lehre bezeichnen. Die Einkommensquellen der Quellentheorie sind definitionsgemäB "Ertrags"-Quellen, was abermals den allokativen Gehalt dieser Theorie unterstreicht. $\left.{ }^{28}\right)$

26) Siehe die oben wiedergegebene Definition von B. Fuisting: "Erträge" aus ... der Güter-"Erzeugung".

27) Dies allerdings an einer anderen Stelle: 1981, S. 149

28) Streng genommen sind auch die Einkunftsarten des deutschen Einkommensteuergesetzes Faktorertragsarten, was zumindest der "Summe der Einkünfte" (§2, Abs. 3 EStG) allokativen Gehalt verleiht. Da eine allgemeine Einkommensdefinition fehlt, muB man also im Aufbau dieser Norm die Wirksamkeit der alten Quellentheorie vermuten. 
Die Quellentheorie formuliert als Einkommen nur, was meBbar ist. Gleichwohl werden auch meßbare Größen nicht vollständig erfaßt, soweit sie nämlich einerseits aperiodisch anfallen und andererseits aus dem Vermögenssektor fließen. Man kann sagen: Das Konzept der MeBbarkeit sowie die Dominanz des Allokativen geht somit $z u$ Lasten der Vollständigkeit. Mit dem Hervorheben der auf die praktischen Belange abgestellten Kriterien sowie mit der Auslassung von Teilen der Wertschöpfungsquellen erweist sich mithin die Quellentheorie als eine steuerliche, nicht aber als eine wirtschaftstheoretische Einkommenstheorie.

2. Dennoch hat es nicht an Versuchen gefehlt, den produktionswirtschaftlichen Einkommensbegriff, der sich ja nicht nur auf die Quellentheorie zurückführen läBt, theoretisch abzuleiten. Ein eigentlich wirtschaftstheoretischer Gehalt des produktionswirtschaftlichen Einkommensbegriffs wurde durch I. Fisher (1906, 1907 und 1930) und - darauf aufbauend - durch E. Lindahl (1933) zu formulieren versucht.

a) Nach I. Fisher (1930, S. 4 ff.) sind Quellen des Einkommens nur die Geldeinkünfte und die Nutzleistungen von Gütern. ${ }^{29)} \mathrm{Da}$ zugleich immer eine ökonomische Aktivität vorliegen muB, um von Einkommen sprechen $z u$ können, scheiden für die Geldeinkünfte distributive Quellen wie Erbschaften und Transfer aus. Die Einkünfte aus Nutzleistungen, die ebenfalls aus dem allokativen Bereich stammen, ${ }^{30)}$ können aus demselben Grunde die nichtmarktliche Nutzung des Sach- und des Humanvermögens nicht enthalten. Aber trotz dem Erfordernis der produktionswirtschaftlichen Herkunft scheiden nach Fisher aus den Nutzleistungen der Kapital-

29) Fisher nennt es das "money income" (welches aber nur dann als solches $z u$ bezeichnen ist, wenn es $\mathrm{zu}$ nichtinvestiven Zwecken ausgegeben werden soll, S. 9) und "income derived from capital goods" (als ein "flow of services", S. 13). Diese Formulierung läBt den SchluB $z u$, daB die Elnkommensquelle ausschlieblich im allokativen Bereich liegt.

30) Wir dürfen folgern, daB Nutzungen des privaten Sachvermögens (siehe Ubersicht 3.2: GU DI 1), soweit es produktionswirtschaftlichem Einsatz zugefuhrt wird, als allokative Quelle gilt. 
güter die capital gains aus, da sie lediglich als Kapitalisierungen des zukunftseinkommens zu gelten haben (S. 24). 31) wir erkennen bei Fisher einen relativ engen Einkommensbegriff, der erstens auf die produktionswirtschaftliche Herkunft der zugänge fixiert ist und zweitens unter diesen nur die realisierten zugänge enthält. Die Betonung der Realisierung von Kapitalwertsteigerungen kehrt später aus den Gründen einer korrekten kaufmännischen Abrechnung wieder bei D. Schneider (1981, S. 147). Auch hier ist wieder das Interesse an der Kapitalerhaltung so dominant, daB nur realisierte Wertsteigerungen Einkommen sein können, und daB Allokationselemente $z$ ur Auffüllung eines distributiven Begriffes verwendet werden.

b) Dieselbe $\mathrm{D} \circ \mathrm{m}$ i n a z d e s A 1 lok a $\mathrm{t}$ i v e n stellen wir bei E. Lindahl (1933, S. $404 \mathrm{f.l}$ fest. Auch er läBt nur die produktionswirtschaftliche Herkunft gelten (S. 405), gemindert um produktionsbedingte Abzüge, wie Abschreibungen und Wertminderungen (S. 406); capital gains und losses bleiben ausgeschlossen: "Income as produce is defined analogously to the concept of production. Net income becomes identifiable with the net value which the owners of the factors of production receive as remuneration for their contributions to the productive process" (S. 404).32)

c) Uberraschenderweise erfährt die Uberbetonung des Allokativen in den Einkommensdefinitionen gerade durch einen Kritiker der Einkommensteuer und Befürworter der Ausgabensteuer, nämlich durch N. Kaldor, eine interessante, jedoch klar aus der Besteuerungsabsicht hervorgehende Ergänzung: In seinem Bestreben, die ökonomische Rolle des Sparens hervorzuheben, votiert er für die produktionswirtschaftliche Herkunft des Einkommens und konstatiert eine Interessensharmonie zwischen der Feststellung einer "taxable

31) Hier wird das Bemühen Fisher's deutlich, den Einkommensbegriff in Ubereinstimmung mit den Regeln des "bookkeeping" (S. 18) zu fassen, die eine Aktivierung nicht realisierter Kapitalwertsteigerungen nicht zulassen.

32) DaB Lindahl im übrigen in seiner allokativen Betonung des Einkommens über Fisher hinausgeht und dem Kapital eine solche Rolle zumiBt, daB er Einkommen schlieblich als zins definiert, soll hier nicht weiter vertieft werden; $z$ ur Kritik hieran siehe $\mathrm{N}$. Kaldor 1955, S. $58 \mathrm{ff}$. 
capacity", die auf der Dauerhaftigkeit der Einkommensquelle basiert, einerseits, und der Definition des Einkommens andererseits, das nur aus dem ProduktionsprozeB hervorgeht; der ProduktionsprozeB aber ist wesentlich vom Sparen und seiner produktionswirtschaftlichen Motivation abhängig (1955, S. 68 ff.). Die rein allokative Interpretation des Einkommens zeigt sich schlieblich in seiner Feststellung: "Capital and income are thus two different ways of expressing the same things, not two different things." 33) Es mag an der geistigen Verwandtschaft der Befüworter der Ausgabensteuer liegen, daB auch $D$. Schneider (wie Kaldor ein Vertreter der Ausgabensteuer) als Einkommen nur das gelten läBt, was eine Person durch ihre "Unternehmungstätigkeit" "erwirtschaftet". 34)

3. Etwas anders verläuft eine Argumentationsrichtung, die - ähnlich wie die Quellentheorie - die produktionswirtschaftliche Herkunft des Einkommens mithilfe der $m$ a k r ö k $\circ$ n $\mathrm{s} c \mathrm{~h}$ e $\mathrm{n}$ Zusammenhänge und Begriffe $\mathrm{zu}$ begründen versucht. Die Grundvorstellung, die F. Neumark hierzu entwickelt, ist folgende: Wenn auch ein Interesse daran besteht, den Einkommensbegriff möglichst weit $z u$ fassen, so sind dennoch nicht alle Einnahmen Einkommen, sondern nur jene, die zwei "Kriterien" einer "allgemeinen Einkommenstheorie" gehorchen. Gelten muB erstens, daB die Einkommensbezieher "an der Bildung des Sozialprodukts" teilnehmen und zweitens, daB eben diese Sozialproduktselemente einen "echten (effektiven) Zuwachs an ökonomischer Verfügungskraft des Empfängers bewirken" (1961b, S. 32). Schon aus dem ersten Grunde sind Transfers keine Einkommensbestandteile; in dieser Hinsicht verwendet Neumark das schon seit I. Fisher bekannte Argument der Vermeidung "irreführenden Doppelzählung" im Sozialprodukt (S. 32). Nicht was dem einzelnen an ökonomischen GröBen zugeht, was also aus seiner individuellen sicht seine ökonomische Verfügungskraft erhöht, soll Einkommen sein, sondern nur diejenige ökonomische

33) Ungeachtet seines Bemühens um eine Einkommensdefinition stellt Kaldor dann fest (S. $70 \mathrm{ff.}$ ), daB Einkommen sich korrekt gar nicht definieren lasse; dies ist u.a. der AnlaB, eine Ausgabensteuer zu fordern.

34) Aus den weiteren Ausführungen Schneiders sowie aus dem Kontext geht allerdings hervor, daB er nicht einen theoretischen, sondern einen steuerlichen Einkommensbegriff bestimmt, da er auf die Zwecke der Definition der Leistungsfähigkeit abstellt. 
Größe, die ihre erweiterte Dispositionsfähigkeit fïr den einzelnen aus der makroökonomisch zu verstehenden sozialproduktserstellung herleiten kann. Konsequenterweise schließt Neumark sämtliche Naturaleinkünfte aus dem Einkommensbegriff aus, die nicht über den Markt laufen (S. 36). Er läBt aber für bestimmte Untersuchungen auch einen "weiteren" Einkommensbegriff zu, der Naturalentlohnungen und Eigenverbrauch enthält, wie auch "konventionellerweise" den "Mietwert des Wohnens im Eigenheim" (S. 37).35) Kennzeichnend für die produktionswirtschaftlichen Einkommensbegriffe ist mithin $z$ um einen ein dominierendes Interesse an allokativen Problemen und elne Verwendung allokativer Begriffe, zum anderen die Argumentation mit makroökonomischen GröBen, dies alles in einem Bereich des Wirtschaftens, der seiner ökonomischen Struktureigenschaft nach ein einzelwirtschaftlicher, der nach den hier auftretenden wirkungen ein distributiver ist. So hat denn schon G. v. Schanz (1896) auch den EinschluB von Transfers in den Einkommensbegriff mit dem Hinweis gefordert, daB alle möglichen Quellen die "selbständige wirtschaftliche Kraft" einer Person bestimmen und ihre dispositiven Mittel darstellen (S. 5). Es hat nicht an dem Versuch gefehlt, selbst Transfers mit dem Erfordernis der produktionswirtschaftlichen Tätigkeit in Ubereinstimmung zu bringen; so will F.W. Gärtner (1898) in der Annahme einer Erbschaft schon eine ökonomische Tätigkeit sehen. Tatsächlich greift auch H.C. Simons diesen Gedanken auf und verlangt den EinschluB von Erbschaften und Schenkungen in den Einkommensbegriff, da sich nie prüfen lasse, inwieweit ihnen eine Art von Gegenleistung zugrundeliegt (1938, S. 56 f.). Aber er stellt grundsatzlich in Frage, ob sich überhaupt je eine scharfe Trennlinie zwischen ökonomischer und nichtökonomischer Tätigkeit ziehen lasse (S. $51 \mathrm{f.}$ ). Als wesentlicher Einwand gegen den produktionswirtschaftlichen Einkommensbegriff und gegen quellentheoretische Interpretationen läBt sich jedoch aus seinen Darlegungen entnehmen, daB mit hier unangebrachten makroökonomischen Volkseinkommensbegriffen und der Vorstellung einer gesamtwirtschaftlichen Wertschöpfung gearbeitet wird (s. $47 \mathrm{ff}$ ). Demgegenüber ist das persönliche Einkommen nach dem auf die Einzelperson ab-

35) Weitere Uberlegungen, etwa der AusschluB der Betriebsausgaben und Werbungskosten, unternehmerischer windfall gains and losses lassen erkennen, daB Neumark den Einkommensbegriff auch mit allokativen Begriffen diskutiert wissen will, S. 33, $45 \mathrm{f}$. 
gestellten Zugangsprinzip zu beurteilen; es hat - in den Worten von simons - zu tun mit "possessions and exercise of rights", nicht mit "production and predation" (s. 48).36) Für die Zwecke der personalen Einkommensdefinition eignen sich makroökonomische Begriffe nicht (W. Albers 1979a, S. 197 f.; s. auch $\S 8$ II).

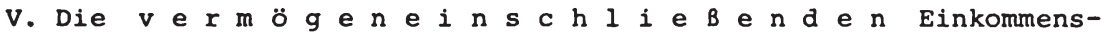
definitionen können nun keineswegs für sich in Anspruch nehmen, die Präponderanz allokativen Denkens im distributiven Bereich überwunden $z u$ haben. Es zeigt sich, daB sie heterogen sind insofern, als sie erstens nicht ausnahmslos auf die Verbindung zur produktionswirtschaftlichen Aktivität verzichten, als sie zweitens teilweise auch im Denken der Kapitalerhaltung wurzeln.

1. Auf den letzten Punkt ist zuerst einzugehen: Die auf F.B.W. v. Hermann ${ }^{37)}$ fußende Schanz'sche Reinvermögenszugangstheorie löst sich - im Gegensatz zur Quellentheorie - völlig von der produktionswirtschaftlichen Tätigkeit als einem einkommensqualifizierenden Merkmal und zählt jeglichen zugang an ökonomischen GröBen, sogar Transfereinkünfte, aber insbesondere das Vermögensmehr (= gegenständlicher Vermögensanfall und $\mathrm{Zufallsgewinne)}$ zum Einkommen; ${ }^{38}$ ) aber sie tut dies - wie die Quellentheorie auch - nur insoweit, wie die Zugänge uber den Erhalt des zu Beginn des Vermögensvergleichs bestehenden Kapitalstocks hinausgehen. Das bedeutet: Die Reinvermögenszugangstheorie, die stets als die breitest mögliche Einkommensdefinition angesehen wird, ist es dennoch nicht, da sie die allokativen Ertragsverwendungselemente der Kapitalerhaltung aus der Basis ausgrenzt.

36) Das bezieht sich auf Theoretiker, die das Einkommen produktionswirtschaftlich interpretieren und in der Nichtberücksichtigung der für die Produktion notwendıgen Kapitalerhaltung eine Plünderung ("predation") erblicken.

37) 1832 , S. 297 : bereits v. Hermann formuliert, daB Einkommen die Erhaltung des Vermögensstamms voraussetzt.

38) G. v. Schanz 1896, S. 24: "Wir rechnen also zum Einkommen alle Reinerträge und Nutzungen, geldwerte Leistungen Dritter, alle Geschenke, Erbschaften, Legate, Lotteriegewinne, Versicherungskapitalien, Versicherungsrenten, Konjunkturgewinne jeglicher Art, wir rechnen ab alle schuldzinsen und vermögensyerlustę" 
Schlieblich - was die Năhe des vermögensbezogenen Einkommensbegriffes $z$ ur produktionswirtschaftlichen Tätigkeit betrifft - ist auBer auf Musgrave/Musgrave auch auf $F$. Neumark $z u$ verweisen; er hält den Einkommensbegriff der Reinvermögenszugangstheorie dem der Quellentheorie für überlegen, möchte jedoch nicht auf einen strengen Bezug der Einkommensentstehung zur Produktion von Gütern verzichten, wie oben im einzelnen ausgeführt wurde (1961b, S. 32 u. 30). Konsequenterweise müssen dann Vermögenszugänge aus Erbschaften und Schenkungen, da sie vom Erben nicht produktionswirtschaftlich erworben wurden, aus dem Einkommensbegriff ausscheiden (so auch Neumark 1947, S. 44 f.; vgl. hierzu auch Ubersicht 3.2 oben, Spalte DI). Realisierte Vermögenswertzuwächse sind daraufhin zu unterscheiden, ob sie zufällig entstanden sind oder der Bildung des Volkseinkommens entstammen; nur letztere sind nach Neumark Einkommen (1947, S. 45). Dieselben Uberlegungen sind für die Nutzungen des Sachvermögens anzustellen; der entscheidende Punkt liegt hier bei den nicht realisierten Vermögenswertsteigerungen. Die Tatsache, daB Neumark diese generell aus dem Einkommensbegriff ausschliest (1947, S. 44), wenn sie auch produktionswirtschaftliche entstanden sein sollten, ${ }^{39}$ ) ist uns AnlaB, das Problem des Einschlusses solcher "capital gains" grundsätzlicher $\mathrm{zu}$ betrachten ${ }^{40)}$ und die Frage des "imputierten" (zugerechneten) Einkommens gleich anzuschlieben.

2. a) Vorauszuschicken ist, daB die "c a p i t a $l$ g a $i \mathrm{n} s "$ im Zusammenhang mit dem Einkommen nur problematisch werden können, wenn man einen Einkommensbegriff formuliert, der als zugänge nicht nur produktionswirtschaftliche, sondern auch vermögensbezogene umfaBt; denn nur dieser kann Wertzuwächse definitorisch in sich aufnehmen. Vorauszuschicken ist ferner, daB im strengen

39) Diesmal liegt der AusschluB nicht in der produktionswirtschaftlichen Tätigkeit begründet, sondern darin, daB hier eine effektive Erhöhung der wirtschaftlichen Verfügungsmacht fehle.

40) Es wird sich zeigen, daB die von M. Lion (1928, S. 287 f.) getroffene Unterscheidung in die Reinvermögens - $z$ u $w$ a $c h s-$ Theorie (der Lehre vom nichtrealisierten Vermögensmehr) und die Reinvermögens - $\mathrm{z}$ u g a n g s - Theorie (der Schanz'schen Lehre vom realisierten Vermögensmehr) sowie schlieblich auch das von $1 \mathrm{hm}$ formulierte "Imparitätsprinzip" von klassifikatorischem Nutzen ist. 
Wortsinn eine Unterscheidung zwischen Kapital- und Vermögenswert$\mathrm{zuwächsen} \mathrm{zu}$ treffen ist; denn nur soweit ausdrücklich klargestellt wird, unter capital gains den distributiven Begriff des Vermögenswertzuwachses verstehen $z u$ wollen, gehört dieses Thema ubberhaupt in den Einkommenszusammenhang. Gewöhnlich aber fehlt es an dieser ausdrücklichen Unterscheidung, und "capital gains" steht für das allgemeine Problem der Vermögenswertzuwächse. Vorauszuschicken ist schlieblich, daB die capital gains zum Problem erst dadurch werden, daB man $z$ wischen geldlichen und güterlichen zugängen unterscheidet und damit die $r$ e a $l$ is $i$ e $r$ e $n$ von den $n i c h t r$ e $l i s i$ e $r$ e $n$ Wertsteigerungen trennt. ${ }^{41)}$ Nur wer sich entscheidet, die durch Wertzuwachs des Kapitals und anderswie entstandenen Unternehmensreserven als Einkommen $\mathrm{zu}$ bezeichnen, 42 ) hat sich damit auseinanderzusetzen, wem und wie es zuzurechnen 1st; für denjenigen aber, der die Unternehmensreserven als eine allokative GröBe erkennt, entsteht ein Einkommensproblem in Verbindung mit den capital gains nicht.

41) Siehe tbersicht 3.2: GE DI c im Gegensatz zu GU DI 1c: während realisierte Wertzuwächse (sie sind ja ldentisch mit "VeräuBerungserlösen") fraglos zum Einkommen gerechnet werden. - es sei denn, man differenzierte nach der produktionswirtschaftlichen Auffassung zwischen dem Wertzuwachs durch ökonomische Tätigkeit und jenem durch Glück, Zufall und Nichtstun und bezeichnete nur das erstere als Einkommen - , entsteht das Problem erst bei den nichtrealisierten Wertzuwächsen. Das ausschlieBlich im allokativen Denken wurzelnde Imparitätsprinzip, das aus Gründen des Gläubigerschutzes und der kaufmännischen Risikopolitik in Bewertung und Bilanzierung die nichtrealisierten Verluste und Wertminderungen immer, die nichtrealisierte Gewinne und Wertsteigerungen dagegen niemals in den Unternehmensertrag hineinrechnet, wird steuerrechtlich als allgemein geltendes Einkommens-DefinitionsPrinzip postuliert; der Fehler, seine allokative Funktion auch für den distributiven Bereich zur Geltung zu bringen, wird lelder stets wiederholt und nie als ein solcher erkannt.

42) Wenn R. Goode (1964, S. 189) feststellt, daB es in einer modernen Wirtschaft unmöglich sei, zwischen $c$ a $p$ i a 1 gains und anderen Einkommen aus $p r \circ p$ e $t y$ (Hervorhebung HDH; property = Besitz bzw. Vermögen) elne klare Unterscheidung $\mathrm{zu}$ treffen, so mag das auf die realen Verhältnisse zutreffen, so mag das ferner auch für die steuerliche Behandlung dieser Realität von Bedeutung sein, für die analytische Unterscheldung hingegen zwischen dem allokativen Kapitalbereich und dem distributiven Vermogensberelch und damit für die systematische Einordnung der c.g. kann das nicht ausschlaggebend sein. 
AuBerdem ist die Einkommenseigenschaft strikt zu trennen von der steuerlichen Behandlung der capital gains; wenn sie auch gewöhnlich aperiodisch anfallen (sie ähneln in vielem den "windfall gains") und dann von einer progressiven steuer erfabt werden, so kann das Interesse, eine solche überproportionale Belastung vermeiden $z u$ wollen, niemals der Grund dafür sein, die Einkommensqualität $\mathrm{zu}$ verneinen. Die Steuervermeidungs- oder -entlastungsstrategie ist nämlich ein Folgeproblem, kein Definitionsproblem.

Auf der Basis dieser Klarstellungen läBt sich angesichts der Meinungsvielfalt in der Literatur zunächst eine Gemeinsamkeit erkennen, die im Gebrauch des "C a p i $t$ a 1 gains" - Begriffes als $E$ i n k $\circ \mathrm{m}$ e n s - Beqriff liegt. Wir schlieBen uns - wenn auch widerstrebend - diesen Usancen an und verstehen unter capital gains (fürderhin c.g.) ganz allgemein "Vermögenswertzuwächse" ${ }^{43)}$. Den Terminus c.g. vermeiden wir dann, wenn die Gefahr der Unklarheit auftaucht.44) Wir verstehen unter Vermögenswertzuwächsen "Erhöhungen des Wertes von Vermögensteilen", "soweit sie die Aufwendungen des Steuerpflichtigen nach dem Erwerb übersteigen" (N. Andel 1979a, S. 346). Dabei liegt weder ein ZufluB von Einnahmen noch das Fälligwerden einer Forderung vor (W. Albers 1979a, s. 197).

b) Die Unterschiede, die hinsichtlich der Einkommensqualität der c.g. in der Literatur nachzuweisen sind, lassen sich anhand des Erfordernisses einer produktionswirtschaftlichen Tätigkelt, anhand der Verfügungsmacht und auch der Zugangsregel markieren. Zwel grundsätzlich verschiedene Postitionen werden eingenommen: ${ }^{45}$

43) Siehe F. Neumarks Ubersetzung des c.g.-Begriffs als "Zuwachsgewinneinkommen" (1947, S. 44); siehe ferner seine Klassifikation der c.g. als einen Teil der "Vermögenserträgnisse" bzw. der "fundierten Einkünfte", 1970, S. 197.

44) Die Gefahr, die allokativen Merkmale der c.g. mit den distributiven der Vermögenswertzuwächse in einen Topf zu werfen, entsteht z.B. dadurch, daB Musgrave/Musgrave c.g. definieren als "gains which result from the sale of assets other than those held in ordinary conduct of business", 1980, S. 349; diese Abgrenzung der c.g. von den "operating profits" gilt aber ausschlieblich für den betrieblichen Ertragsbereich, erfaBt nicht die Vorgänge im privaten, im Einkommensbereich.

45) Wir erwähnen nur am Rande die frühere Auffassung von F. Neumark (1947, S. $44 \mathrm{ff}$. und $1961 \mathrm{~b}, \mathrm{~S} .42 \mathrm{f.l}$, da sie immerhin

(Forts. siehe folgende Seite) 
Zunächst die rückhaltlose Ablehnung der c.g. als Einkommen durch die Quellentheoretiker und durch I. Fisher; dies aufgrund des Erfordernisses, Einkommen solle aus produktionswirtschaftlicher Tätigkeit hervorgehen. Die Auffassung ist konsequent, weil kein vermögenseinschließender Einkommensbegriff verwendet wird und es den c.g. an der periodischen wiederkehr aus ständig fließenden Quellen gebricht.

c) Die Gegenposition betrachtet c.g., insbesondere auch nichtrealisierte, eindeutig als Einkommen; sie wurde schon früh von G. v. Schanz, R.M. Haig und H.C. Simons eingenommen. Bel Schanz ergibt sich das klar aus dem Konzept des Vermögenszugangs; die anderen Autoren benutzen zur Begründung der Einkommenseigenschaft neben der Zugangsregel das Institut der Verfügungsmacht. In lebhafter Auseinandersetzung mit den Quellentheoretikern und I. Fisher entwickelt Simons, aufbauend auf der Schanz'schen Theorie und auf der Haig'schen Einkommenskonzeption, den modernen "Accretion Approach", der nahezu von allen Theoretikern heute übernommen ist. Einkommen hat nach Simons (1938, S. $49 \mathrm{f.l}$ ) mit $\mathrm{R}$ e c h $t$ e $n$ zu tun; die Feststellung des Einkommens beruht auf dem Wert der "porperty rights", über die eine Person verfügt. ${ }^{46)}$ Die conditio sine qua non des Einkommens ist "gain" i.s. v. Zunahme bzw. Zugänge 47 ) einschlieblich der "windfall gains or losses".

Forts. Fn. 45:

geeignet ist, die Bedeutung der zweiten unten wiedergebenen Position $\mathrm{zu}$ unterstreichen, als er die Einkommenseigenschaft der nicht realisierten Wertzuwächse ablehnte, weil sie eine nur potentielle Verfügungsmacht darstellen würden und weil zufällig-einmalige Wertzuwächse oftmals nicht das Ergebnis einer Beteiligung an der Bildung des Sozialprodukts seien. Unter dem Eindruck der von Neumark weitgehend als zutreffend anerkannten Kritik an dieser Auffassung (W. Albers 1957, S. $78 \mathrm{f.})$ hat er später $(1970$, S. 136) seine Meinung revidiert und die c.g. als "prinzipiell ordentliche Einkommenselemente" akzeptiert. Es sei aber darauf hingewiesen, daB gerade in der amerikanischen betriebswirtschaftlichen Literatur der Gedanke, daB zufällig-einmalige Einkünfte nicht dem vorhersehbar-planerischen Verhalten des Kaufmanns und Planers entsprächen, so stark ist, daB windfall gains keinesfalls in den Betriebsertrag aufzunehmen seien, siehe S.H. Frankel 1969, S. 101 f.; siehe D. Solomons 1969, S. $109 \mathrm{f}$.

46) S. 49: "... the personal income has to do with rights ... Its calculation implies estimate ... of the amount by which the value of a person's store of property rights would have increased ..."

47) gain to someone, measured according to objective market standards. 
Der Zugang an ökonomischen Größen ist zugleich ein "accretion" an Verfügungsmacht ( $R$. Goode $1977, S .11), 48$ ) bzw. In den Worten von Musgrave/Musgrave $(1980, \mathrm{~s}$. 351) ein "accretion to wealth", der schon unter dem Gerechtigkeitsaspekt Einkommen sein muB (so auch Musgrave 1981, S. 35), gleich, ob es sich um realisierten oder nichtrealisierten Vermögenswertzuwachs handelt. "Die Begriffe 'realisiert' und 'nichtrealisiert' beinhalten eine Unterscheidung, die nur auf äuBerlichen formalen Kriterien und Buchführungsregeln beruhen. Sie sollten deshalb für den Einkommensbegriff keine Rolle spielen" (w. Albers 1957, S. 79).

Die Zugangsregel macht es notwendig, vom engen Konzept eines "cash income", das mit den realisierten vermögenswerten verbunden ist, abzugehen. Zugang an ökonomischen GröBen ist eine erhöhte Dispositionsfähigkeit, und nichtrealisierte Wertzuwächse stellen in jedem Falle eine "erhöhte Dispositionsfähigkeit" dar.49l Es ist die freie Entscheidung des Investors, Wertzuwächse in nichtrealisierter Form zu halten (Musgrave/Musgrave $1980, \mathrm{~s} .351) ; 50$ ) objektiv mögliche Realisierung unterstellt, bedarf es nur der Bereitwilligkeit zur Realisierung (A. Oberhauser 1980, S. 669). 51) Somit sind die nichtrealisierten c.g. mithilfe der Zugangsregel verläBlich als Einkommensbestandteil zu definieren. Ob und wie sie $z u$ be-

48) Er lehnt sich dabei an das Konzept von R.M. Haig (1921) an und macht zugleich deutlich, daB das Argument der "Doppelzählung" der c.g., das Fisher anführt, nicht trägt. Auch c.g. sind aus der Sicht der Person immer Zugänge, für jede Person jeweils neue $\mathrm{Z}$ ugänge an Verfügungsmacht, auch wenn diese $\mathrm{Zu}-$ gänge vorher schon anderen Personen zugegangen waren.

49) O. Ebnet 1978, S. 57 f. - N. Andel 1979a, S. 348 f.

$50)$ S. 346: "Wether or not a realization occurs is a matter of portfolio choice for the investor and should not affect income as measured for purposes of taxation."

"As measured": Es entsteht dabei ein MeBproblem. Aber das ist eine andere Frage. Soweit der Wert der "Nichtrealisierung" weder am Markt festgestellt noch geschätzt werden kann, verursacht die personale Zuordnung Probleme, auch der Besteuerung.

51) Ob allerdings in der Realität in jedem Einzelfall, wie $A$. Oberhauser vermutet $(1980, S .667)$, für alle Wertveränderungen ein Marktpreis festzustellen sein wird, kann bezweifelt werden angesichts der verschiedenen Ursachen für diese Wertzuwächse; gerade staatliche BodenaufschluBmaBnahmen, die neben der Knappheit, dem technischen Fortschritt und der Ertragssteigerung die Wertzuwächse hervorrufen können, müssen nicht unbedingt $\mathrm{zu}$ neuen Bewertungen am Markt führen. Aluer liegt uberhaupt eine Wertsteigerung vor, wenn niemand sie feststellen kann? 
steuern sind, ist keine Frage der Einkommensdefinition im wirtschaftstheoretischen Sinne.

3. I m p $\mathrm{t} i$ e $r$ u $\mathrm{g}$ bedeutet die personale Zurechnung nichtgeldlicher ökonomischer GröBen, die man als Einkommenselement betrachtet (Zurechnungseinkommen = imputed income). ${ }^{52}$ ) Die Imputierung soll nach wirtschaftstheoretischem und steuerlichem Anspruch die Totalerfassung des Einkommens gewährleisten.

a) Einer Würdigung der literarischen Auffassung vom Inhalt des Zurechnungseinkommens ist b e $g$ $i f f i c h$ vorauszuschicken, daB Imputierungen "Ökonomische" GröBen sind und daB somit jeglicher Rückgriff auf psychische Erlebnisvorgänge (Bedurfnisbefriedigung, satisfactions), die mit ihnen verbunden werden können, unnötig und verwirrend ist. Ferner: Imputiert werden nur $g$ id $t$ e $r$ I $c h$ e Zugänge, deren Zurechnung es aber erfordert, daB sie in Geld ausgedrückt, also objektiviert werden können.

Ein fataler Irrtum wäre es, Imputierungen - und hier insbesondere die Nutzen aus Vermögen - mit Einkommensverwendung gleichzusetzen. Imputiert wird der zugang an fiktivem Einkommen aus jenem Vermögensbestand, dessen Bilden - etwa aus Einkommensverwendung, aber auch aus Erbschaftsanfall - in Vorperioden stattfand (z.B. die selbstgenutzte Wohnung im eigenen Haus oder die Nutzung langlebiger Konsumgüter).

Zunächst ist $\mathrm{zu}$ erkennen, daB die imputierten Einkommenselemente sowohl betrieblichen als auch privaten Quellen entstammen; soweit letztere in Rede stehen, können grundsätzlich sowohl die Nutzungen des (Sach- und Human-) Vermögens als auch die Realtransfers in Betracht kommen (Ubersicht 3.2: GU DI und DII), doch haben in der

52) "Imputed income" ist nach der Definition von D.B. Marsh (1943, S. 514) "noncash income or income in kind", which "arises outside the ordinary processes of the market". 
literarischen Diskussion die Vermögensnutzungen stets im Vordergrund des Imputierungsproblems gestanden. Wenn also als die markanten Beispiele imputierter Einkommen einerseits der Selbstverbrauch, andererseits die Vermögensnutzungen genannt werden, so ist daran zweierlei bemerkenswert: Erstens der AusschluB der Realtransfers; zweitens die Anerkennung einer grundsätzlichen Trennung in allokative und distributive Quellen, da der Selbstverbrauch an Gütern und Diensten als ein naturaler Zugang aus dem betrieblichen Bereich (Ubersicht 3.2: GU A 1), die Vermögensnutzung hingegen als ein zugang aus dem privaten Bereich (Ubersicht 3.2: GU DI 1 u. 2) anzusehen ist.

So unterscheiden sich die Natural-zugänge aus dem allokativen Bereich vorderhand danach, ob sie sachliche bzw. personale Entlohnungen (Schema 3.2: GU A 1.a u.b) oder sachliche bzw. personale Entnahmen (Schema 3.2: GU A 1. c u. d) sind. Bekannte Imputierungen sind die Sachentnahmen, also der Eigenverbrauch in der Landwirtschaft und im Einzelhandel; weniger bekannt ist der nicht seltene Fall der "Entnahmen" von personalen Diensten aus dem Betrieb zu persönlichen Zwecken, obwohl er einen nicht geringen Einkommensbestandteil ausmachen kann (Inanspruchnahme von Planungs-, Bau- und gärtnerischen Leistungen des Betriebspersonals für die privaten Zwecke der Geschäftsleitung). Ähnlich liegen die Verhältnisse in der Entlohnung; über der rein sachlichen geraten die nicht minder bedeutsamen personalen zugangsarten wie betriebliche Ausbildungs- und Gesundheitsdienste in Vergessenheit. Mögen sie auch den Beschäftigten des Unternehmens in gleichem MaBe zukommen, so sind doch zwischenbetrieblich Unterschiede in der Entlohnung festzustellen.

Die nichtmarktlichen Nutzleistungen des Vermögens unterteilen sich in solche des Sach- und solche des Human-Vermögens. Soweit die Sachvermögensnutzung in Rede steht, ist zunächst der güterwirtschaftliche Vorgang des Wertzuwachses (capital gains; siehe Ubersicht 3.2: GU DI 1c) hier auszuscheiden, denn es geht um die Nutzung des Vermögens, nicht um den Wertzugang. Ferner ist zu unterscheiden, ob das selbst akkumulierte und das durch Erbschaften oder Schenkungen erworbene Vermögen (Ubersicht 3.2: GU DI 1. a 
u. b) aus kurzlebigem Gebrauchs- (bzw. Konsum-) oder langlebigem Versorgungs-Vermögen besteht. Während letzteres vorwiegend in Form von selbstbewohntem Haus- und Wohnungsvermögen genutzt wird und hinsichtlich der Auswahl und Abgrenzung keine Schwierigkeiten auftreten, ist elne gewisse Willkür (F. Neumark 1947, S. 44) bei der zurechnung von Nutzungen aus Konsumvermögen nicht auszuschlieBen. ${ }^{53}$ )

Schließlich die Zeiten für häusliche Dienste, Muße und Erholung: In der Literatur werden sie als "reale" Einkommenselemente diskutiert, ohne die Herkunft dieses zugangs zu thematisieren. Sie werden nicht als Nutzungen des Human-Vermögens ausgewiesen; es bleibt aber kein anderer Weg als dieser (Ubersicht 3.2: GU DI 2), da diese Zeiten weder allokativ eingesetzt (es wären dann keine freien und häuslichen zeiten mehr, sondern Arbeitszeiten) noch geldich bzw. güterlich entlohnt werden. Vielmehr handelt es sich bei diesen zugängen um eine private, distributive Zugangsquelle güterlicher Art aus vermögensnutzung ${ }^{54)}$.

b) Der Vergleich der Argumente für oder gegen den EinschluB des imputed income in den wirtschaftstheoretischen Einkommensbegriff ergibt zunächst, daB ein völliger AusschluB jeglicher Imputierung nicht vertreten wird;55) ein rein geldlicher Einkommensbegriff wird angesichts der Verfügungsmacht oder auch der psychischen GröBen, die mit Gütereinkommenselementen verbunden sind, als zu eng empfunden. Da ferner eine allokativ-distributive Ein-

53) Die Frage ist nämlich, wann ein Gebrauchsvermögensgegenstand konsumtiver Aufwand und wann er Vermögen ist, dessen Nutzung nur zeitanteilig als Einkommenselement zuzurechnen ist. Auch die Abgrenzung der Dauerhaftigkeit durch enumerative Aufzählung, die D.B. Marsh findet (1943, S. 521), bleibt willkürlich: Automobile, Möbel, elektrische Geräte u.ä.

54) Soweit aber ihre Einkommensqualität bejaht wird, stehen die Befürworter erstens vor dem Problem der MeBbarkeit, und zwe1tens vor dem Problem, die Umwandlung privater zeit in allokative Faktorzeit normativ festlegen zu müssen, um Beziehungen $z$ um Monetären und zur Bewertung der fiktiven Entlohnung herstellen zu können. Näheres zum Normativen im 3. Teil unter den "Possibilitätskonzepten" der Besteuerung nach der Leistungsfähigkeit.

55) Dies gilt nicht für die steuerlichen tberlegungen, siehe unten. 
ordnung und vollständige Katalogisierung aller Imputierungsquellen nicht vorgenommen wird, werden mitunter die Entnahmeformen zum Paradigma der naturalen Zugänge gemacht. Soweit nun aber die Vermögensnutzungen in Rede stehen, sind hier die Auffassungen äuBerst heterogen, sowohl hinsichtlich der Sachvermögensnutzung mit der üblichen Einteilung in die Nutzung des Wohnungsvermögens und des Gebrauchsvermögens als auch hinsichtlich der Humanvermögensnutzung mit häuslichen Diensten und Freizeit. Auffassungsunterschiede hängen hier mit dem zugrundeliegenden Begriffskonzept zusammen und führen im wesentlichen zu zwei Möglichkeiten der Aufnahme von imputierten Einkommenselementen in den Einkommensbegriff: erstens die völlige, zweitens die nur teilweise EinschlieBung.

c) So begründen beispielsweise D.B. Marsh (1943, S. 514 f.) und H. Haller (1971, S. 42 f.) die lückenlose EinschlieBung a 1 e r güterwirtschaftlichen Zugänge, wie sie auch aus den dauerhaften Gebrauchsgegenständen (Marsh) und den häuslichen Diensten und der Freizeit (Haller) hervorgehen, mit psychologischen Argumenten: Generalnenner für alle Einkommenselemente sind die "satisfactions" (Marsh) bzw. die "Bedürfnisbefriedigung" (Haller), die ihnen anhaften. Damit qualifizieren sie den Generalnenner als nichtmarktlich und haben sich mit dem Problem der MeBbarkeit solcher metaökonomischen GröBen auseinanderzusetzen. Demgegenüber benutzen Musgrave/Musgrave (1980, S. 346) für die Begründung eines völligen Einschlusses das theoretische "accretion"-Konzept: Aus der Definition des zugangs (accretion) als "Nettowertzuwachs plus Konsum" (dies entspricht insoweit dem Konzept des Reinvermögenszugangs) ergebe sich selbst der EinschluB der häuslichen Dienste und der Freizeit als eine "pure logic of accretion" (S. 347). 56)

d) Nach dem Reinvermögenszugangskonzept gehen auch R.M. Haig (1921, S. 7) und H.C. Simons vor (1938, S. 50), doch führt ihre Forderung, daB sich alles Einkommen letztlich in Geld ausdrücken muB, 57) zu

56.) Wobel sie allerdings nicht versäumen $z$ u bemerken, daB mit Rücksicht auf Besteuerungskonzepte andere Positionen vertreten werden können.

57) Nach Haig ist das Einkommen der "m $\circ \mathrm{n}$ e $y$ v a 1 u e of the net accretion to one's economic power between two points of time"; nach Simons' Definition (S. 50) ist das persönliche Einkommen die "a $1 \mathrm{~g} e \mathrm{~b} \mathrm{r}$ a $\mathrm{c} s \mathrm{um}$ of (1) the ma r (Forts. siehe folgende seite) 
einer Einschränkung in der völligen güterwirtschaftlichen Interpretation des Einkommens: Das güterwirtschaftliche Denken verwirre, da für die Definition des Einkommens etn Generalnenner zu formulieren ist, der alle Bestandteile gleichnamig machen könne (Simons, S. 51). Die conditio sine qua non des Einkommens, der Zuwachs ("gain"), müsse sich $m$ e s $s$ e $n$ lassen "according to objective market standards" (Simons).

So ist es auch die MeBbarkeit, die F. Neumark (1947, S. 43 und 1961b, S. 40) zur Begründung anführt, daB nicht sämtliche imputierbaren Einkommenselemente in den Einkommensbegriff einzuschlieBen sind. Das Erfordernis der MeBbarkeit und auch das der ökonomischen und $m a r k t i c h$ e $n$ Aktivität verhindern die Anerkennung des psychischen Generalnenners der satisfactions und Bedürfnisbefriedigung. Die genannten Erfordernisse würden z.B. nicht von sämtlichen Dienstleistungen und auch nicht von Nutzungen dauerhafter Gebrauchsgüter (wie des Mobiliars usw.) erfullt. Die zurechnung des Gebrauchsnutzens aus dauerhaften Konsumgütern sei jedoch nicht $z$ u realisieren und zudem in der Auswahl willkurlich. 58)

e) Uns scheint, daB mit dem Haig-Simons-Konzept der theoretisch korrekte Ansatz gefunden wurde, der mit der zugangsregel vereinbar ist; die Beschränkung auf marktliche zugangsquellen ist zu eng; wohingegen die MeBbarkeit notwendige Bedingung ist. Doch ähnlich wie bei den capital gains zeigt sich auch hier, daB die Frage einer theoretischen Fundierung des Zugangs, soll sie $z u$ einem haltbaren wirtschaftstheoretischen Einkommensbegriff führen, von sämtlichen steuerlichen und -politischen Aspekten freizuhalten ist.

Forts. Fn. 57:

$k$ e $t \quad v$ a $l$ u e of rights exercised in consumption and (2) the change in the val u e of the store of property rights between the beginning and the end of the period in question." Hervorhebungen $\mathrm{HDH}$.

58) Wenn Neumark für die zuzurechnenden Nutzen aus Dienstleistungen $(1947$, S. 43) das Erfordernis formuliert, sie seien nur insoweit Einkommen, wie "für sie infolge marktmäBiger Verwertung effektive Entgelte gezahlt werden", so kann das nur im Sinne eines Vergleichs gemeint sein; denn wenn für Dienstleistungen der gemeinten Art (des Selbstrasierens, der Eigengärtnerei, der Freizeit) tatsächlich Entgelte gezahlt werden, bedarf es keiner Imputierung. 


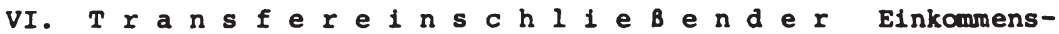
begriff bedeutet nicht zwingend Totaleinkommensbegriff, da auch der ihm vorangehende vermögenseinschllebende Elnkommensbegriff wie dargestellt - unterschiedlich weit gefaBt werden kann, je nachdem, ob man capital gains und die verschiedenen Imputierungstatbestände elnbegrelft oder nicht. Wie erinnerlich, zeigt ja bereits das dem Totaleinkommen zugrunde liegende Reinvermogenszugangskonzept verschieden weite Ausprägungen: Nach Schanz enthält es zwar Transfers, nicht jedoch zur Kapitalerhaltung verwendete Betrăge; nach Haig/Simons werden gerade letztere sowle auch Transfers in den Zugang elnbezogen; nach Musgrave/Musgrave sollen nun aber die Transfers wiederum nicht im Einkommensbegriff enthalten sein, hingegen Human-Vermögens-Nutzungen doch, die wiederum bei simons wegen des nicht gewährleisteten Geldausdrucks ausgeschlossen bleiben.

1. Den transfereinschließenden Einkommensbegriff zeichnet aus, da $B$ er die produktionswirtschaftlichen und vermögensgebundenen $\mathrm{zu}-$ gangsquellen (Ubbersicht 3.2: $A+D I+D I I$ ) einschließt, ohne jedoch deren teilweise nicht haltbare "theoretische" Rechtfertigung zu übernehmen. Seine Charakterisierung liegt in folgendem: Erstens in der völligen Abkehr von der "Dominanz des Allokativen", denn weder sind die produktionswirtschaftlichen Quellen für ihn allein maßgebend noch schließlich auch die "Zwänge" zur Kapitalerhaltung; zweitens in der tbernahme des Reinvermögenszugangskonzeptes, was das Interesse an der Totalerfassung des Einkommens offenbart; und drittens vermeidet er den Rückgriff auf psychische Größen und Nutzenvorstellungen angesichts der unbestrittenen Einsicht, daß sie (vorerst?) nicht meßbar sind.

Dennoch sind auch transfereinschließende Einkommensbegriffe unterschiedlich weit denkbar, wenn sie einerseits nur die monetären Transfers einbegreifen (Ubers. 3.2: GE DII 1 u. 2a) 59), andererseits zusätzlich die güterlichen und realen, und nur ausnahmsweise die öffentlichen Güter.

59) ES kann die eindeutige, aber nicht überraschende Feststellung getroffen werden, daB in erster Linie solche Autoren die Transfereinschliebung in den Einkommensbegriff diskutieren, die die steuerlichen Probleme dieses Vorgehens untersuchen; es kann nicht ausgeschlossen werden, daB ihr Urteil über die steuerlichen Wirkungen und die steuersystematischen Bezüge dieser erwelterten Bemessungsgrundlage die Einkommensqualität von Transfers mitbeeinfluBt. 
Dabei herrscht uber die Einkommensqualität der Transfers - zumindest der monetären - Einigkeit, denn sie sind neben den steuern die Komponenten der Umverteilung von $\mathrm{E} i \mathrm{n} \mathrm{k} \circ \mathrm{m} \mathrm{m} n$ (G. Krause-Junk 1981, S. 269; W. Albers 1977c, S. 863). DaB Transfers oftmals die einzige Einkunftsart sind, über die eine Person verfügt, daB Transfers zum Ausgleich des Einkommensausfalls oder zur Auffüllung des nicht ausreichenden Leistungseinkommens ( $W$. Albers 1977c, S. 895) gewährt werden, daB sie - sowelt nicht qualitative Merkmale wie Arbeitslosigkeit oder Invalidität eine Rolle spielen - eine direkte "Einkommensabhängigkeit" (W. Albers 1977c, S. $881 \mathrm{f.l}$ aufweisen und daB sie schlieblich auch dynamisiert werden, all dies spricht für ihre Einkommensqualität. ${ }^{60}$ )

2. Es ist darzustellen, welche Transferarten Einkommen sind. GemäB der Transfer-Enquete-Kommission (TEK 1979, TZ 65; TEK 1981, S. 22, TZ 3$)$ sind Transfers dadurch definiert, daß kein unmittelbarer "Bezug zu einer auf die Erzielung eines Einkommens gerichteten produktiven Tätigkeit" vorliegt ${ }^{61)}$. Wenn daher Transfers nicht Faktorentgelte sind 62), können Vermögensteile, die Erträge abwerfen, nicht Transfers sein. WErden aber Vermögen und Erträge auf Dritte übertragen, sind sie bei diesen Transfers. Der Verzehr oder die Veräußerung des Vermögens spielt sich in der Vermögenssphäre des Verfügenden $a b$, ist kein Transfer. Nach der zugangsregel sind nur jene ökonomischen Größen Einkommen, die über die Vermögensumschichtung hinausgehen (Erträge); Transfers liegen nur vor, wenn sie nicht Gegenleistungen sind (somit scheiden Vermögenserträge, obwohl Einkommen, als Transfers aus; vgl. das Korrespondenzprinzip in $\$ 23$ III 3 ).

60) Wenn dennoch W. Albers (1977c, S. 906 ff.; 1979a, S. 199 f.; $1979 \mathrm{~b}, \mathrm{~S} .304 \mathrm{ff.)}$ die Besteuerung dieser Transfereinkommen nicht befürwortet, obwohl er den Grundsatz zitiert, jedes Einkommen sei - ob beim Transfergeber oder beim Transferempfänger - einmal zu besteuern, so will er damit dem Steuergesetzgeber die Freiheit erhalten, unterschiedliche Ziele zu verfolgen (1977c, S. 907).

61) TEK 1981, TZ 3: Transfers sind alle "Einkommen oder einkommensähnliche Leistungen, die nicht Faktoreinkommen, und das heibt Entgelt für die Nutzung von Produktionsfaktoren sind."

62) Allerdings sind hinsichtlich dieses "abgeleiteten" Einkommens auch Unterschiede in den Auffassungen möglich; so betont E. Schuster (1961, S. 59) den Unterschied zwischen Renten aus der Sozialversicherung und jenen aus der Sozialhilfe (die aus den allgemeinen öffentlichen Haushaltsmitteln aufgebracht werden) 
a) Der Gesamtüberblick soll, um die besondere Existenz- und Vorsorgesicherungsfunktion von Transfers darzustellen, ergänzt werden durch eine Grundüberlegung zur Versorgungssicherung allgemein. In dieser Grundüberlegung kann nämlich das 0 r g a $n$ i sations s chema der Transferbezie$\mathrm{h} u \mathrm{n} g$ e $\mathrm{n}$ erblickt werden. So ist es korrekt, etwa nicht nur die staatlichen personalen Transfers, sondern auch die zwischen den Privaten organisierten nichtgegenleistungsabhängigen Leistungen als Transfers $z u$ bezeichnen. Denn ganz generell ergeben sich zwischen Einzelnen und Gruppen Transferbeziehungen aus organisatorischen Regelungen der verschiedensten Art, handele es sich dabei nun um staatliche distributive und redistributive Politik, mit gewollten oder ungewollten Folgen, handele es sich um kollektive MaBnahmen mit und ohne staatliche Beteiligung oder um rein private und individuelle MaBnahmen. Soweit mit ihnen Umschichtungen der individuellen Einkommen verbunden sind, haben sie in jedem Falle Auswirkungen auf die Sicherung der Existenz und Vorsorge. Die Grundüberlegungen zur Vorsorgesicherung sind also darauf abgestellt, auch die spezielleren Transferleistungen aufzunehmen und ihren systematischen Platz auszuweisen. Die in Ubersicht 3.4 vorgelegte Systematik der monetären und realen Transfers reflektiert dieses Organisationsschema der Transferbeziehungen und erlaubt es, die Transferleistungen als individuelle, kollektive und offentliche $\mathrm{zu}$ klassifizieren. ${ }^{63}$ )

Grundsätzlich ist die Existenz- und Vorsorgesicherung für das Individuum entweder eigen- oder fremdverantwortlich, d.h. frei oder gesetzlich erzwungen organisierbar. Handelt der einzelne e $i$ $g e n v e r a n t w \circ r t l i c h$, so entscheidet er selbst, ob und wie er sich sichert; eine staatliche Einwirkung auf das ob und wie seiner sicherung unterbleibt, weil Fähigkeit und willigkeit vorausgesetzt wird. Das wie der sicherung ist entweder individuell oder kollektiv möglich.

(1) I $\mathrm{n}$ d i v i d u e 11 e sicherung ist einerseits das freiwillige sparen in Form von selbst geschaffenem und selbst verwal-

63) Die Grundüberlegungen lehnen sich vorwiegend an H. Giersch 1960 , S. 83 ff.; E. Liefmann-Keil 1961, S. 32 f., 45-46 u. 213-226; N. Andel 1970, 1979a u. 1979b; W. Albers 1979b,

S. $304 \mathrm{f} ;$ D. Brümmerhoff 1979, S. 220, G.W. Brülck 1981,

S. $70 \mathrm{ff}$. und K.Mackscheldt 1983 an. 
Ubersicht 3.4: Grundschema der Transferbeziehungen

\begin{tabular}{|c|c|c|c|}
\hline \multirow[b]{2}{*}{$\begin{array}{l}\text { Organisation der } \\
\text { Transferbeziehung }\end{array}$} & \multirow[b]{2}{*}{ Mittelaufbringung } & \multicolumn{2}{|c|}{ Transferleistungsarten (Mittelverwendung) } \\
\hline & & $\begin{array}{l}\text { Monetäre Transfers } \\
\text { (Ubers. } 3.2: \mathrm{DII} / \mathrm{GE} \text { ) }\end{array}$ & $\begin{array}{l}\text { Realtransfers } \\
\text { (Ubers. } 3.2: \mathrm{DII} / \mathrm{GU} 1+2\end{array}$ \\
\hline $\begin{array}{l}\text { eigenverantwortlich - } \\
\text { individuell } \\
\text { Einkommens-Umschichtung: } \\
\quad \text { interpersonal + } \\
\text { intertemporal }\end{array}$ & $\begin{array}{l}\text { aus privatem Einkommen: } \\
\text { nach individueller Lei- } \\
\text { stungsfähigkeit, nach } \\
\text { rechtl. u. sittl. Ver- } \\
\text { pflichtung u. evtl. ge- } \\
\text { richtlichem Urteil }\end{array}$ & $\begin{array}{l}\text { individuelle: } \\
\text { Unterhalt } \\
\text { Unterstützungen } \\
\text { Abfindungen usw. }\end{array}$ & $\begin{array}{l}\text { private: } \\
\text { Wohnrechte, Altenteile, ge- } \\
\text { meins. Haushalt, Geschenke, } \\
\text { priv. Unterricht u. Kranken- } \\
\text { pflege, Nachbarschaftshilfe } \\
\text { usw. }\end{array}$ \\
\hline $\begin{array}{l}\text { eigenverantwortlich - } \\
\text { kollektiv } \\
\text { Einkommens-Umschichtung: } \\
\text { interpersonal }+ \\
\text { intertemporal } \\
\text { innerhalb best. Gruppen }\end{array}$ & $\begin{array}{l}\text { aus privatem Einkommen: } \\
\text { "strenge Äquivalenz" = } \\
\text { die Beitragsleistung } \\
\text { bestimmt die Transfer- } \\
\text { leistung }\end{array}$ & $\begin{array}{l}\text { kollektíve: } \\
\text { Leistungen aus priv. Ver- } \\
\text { sicherungen: Krankenhaus- } \\
\text { tagegeld, Renten aus Un- } \\
\text { fall-, Lebens-, Kapital- } \\
\text { vers., Kapitalauszahlung } \\
\text { u. Schadensregulierung aus } \\
\text { Versicherungen usw. }\end{array}$ & $\begin{array}{l}\text { Realleistungen } \\
\text { siehe unten } \\
\text { i }\end{array}$ \\
\hline $\begin{array}{l}\text { fremdverantwortlich - } \\
\text { kollekteiv mit__Aquivalenz } \\
\text { Einkommens-Umschichtung: } \\
\text { intergenerativ + } \\
\text { intertemporal } \\
\text { 2w. best. Gruppen } \\
\text { und allen Steuer- } \\
\text { pflichtigen }\end{array}$ & $\begin{array}{l}\text { a) aus priv. Einkommen: } \\
\text { "strenge Aquivalenz" = } \\
\text { kein SteuerzuschuB } \\
\text { b) teils aus priv. Ein- } \\
\text { kommen, teils aus offent- } \\
\text { lichen Haushalten: "ge- } \\
\text { milderte Aquivalenz" = } \\
\text { Beitrag nach Aquivalenz, } \\
\text { steuer nach Leistungsfa- } \\
\text { higkeit, Transferleistung } \\
\text { nach Bedürftigkeit }\end{array}$ & $\begin{array}{l}\text { kollekttive: } \\
\text { Leistungen aus gesetzlichen } \\
\text { Versicherungen: Krankengeld, } \\
\text { Arbeitslosengeld, Unfall- } \\
\text { rente, Altersrente usw. }\end{array}$ & $\begin{array}{l}\text { kollektive: } \\
\text { stat. u. ambul. Heilbehand- } \\
\text { lung, Heilmittel, Kuren, Ex- } \\
\text { holung, Transporte, Heim- u. } \\
\text { Sanatoriumsunterbringung } \\
\\
\mid \\
\end{array}$ \\
\hline $\begin{array}{l}\text { fremdverantwortlich - } \\
\text { kollektiv_ohne_Aquivalenz-_.enz } \\
\text { Einkommens-Umschichtung: } \\
\text { interpersonal zw. } \\
\text { allen Steuexpflichti- } \\
\text { gen u. best. Gruppen }\end{array}$ & $\begin{array}{l}\text { aus offentl. Haushalten: } \\
\text { Steueraufkommen nach der } \\
\text { Leistungsfähigkeit, } \\
\text { Transferleistungen nach } \\
\text { der Bedürftigkeit }\end{array}$ & $\begin{array}{l}\text { offentliche (staatliche u. } \\
\text { kommunale): } \\
\text { Sozialrenten, Wohn-, Kinder- } \\
\text { geld, Ausblldungsbeihilfe, } \\
\text { Entschädigungen, sonstige } \\
\text { Sozialhilfeleistungen }\end{array}$ & $\begin{array}{l}\text { öffentlliche: } \downarrow \\
\text { Realleistungen siehe oben } \\
\text { Sozialhilfeleistungen } \\
\text { (auBer den obigen) } \\
\text { offentliche Güter }\end{array}$ \\
\hline
\end{tabular}


tetem Vermögen für die eigene Person, ist andererseits auch Sicherung der Familie bzw. der kleinen Solidargemeinschaft. "64) Soweit die Einkommensumschichtung rein "intrapersonal" verbleibt, solange also die person, die heute die Einkommensverwendung "Nichtkonsum" für die morgige Einkommensmehrung bei sich selbst verfügt, führt dieser Vorgang nicht zu Transfers. Anders bei der Sicherung der Familie oder der Solidargemeinschaft; hier liegt eine interpersonale Einkommensumschichtung vor, die zu Transfers monetärer Art (wie Unterhalt, Unterstützungen, Abfindungen usw.) führt oder reale Transfers (wie Wohnrechte, gemeinsamer Haushalt, privater Krankenpflege usw.) bewirkt (nicht jeder Realtransfer ist eine Einkommensumschichtung).

Bereits die erste Untergliederung der eigenverantwortlichen Sicherung in eine intrapersonale und eine interpersonale füht $z$ ur Ausgrenzung des Sparens aus dem Transferbereich; alle weiteren individuellen Sicherungsformen sind nur noch interpersonal denkbar und daher mit Transferbeziehungen notwendig verbunden. Soweit aber keine Transferbeziehungen vorliegen, sind Umfang und Höhe der Sicherung von der eigenen Entscheidung abhängig; ein Risikoausgleich vollzieht sich allein durch das eigene Vermögen. ${ }^{65}$

(2) Die eigenverantwortlich - $\mathrm{k} \circ \mathrm{l} 1 \mathrm{e} \mathrm{k} t \mathrm{i}$ e Sicherung ist das Eingehen von Transferbeziehungen bzw. Vermögensakkumulationsverpflichtungen in privaten Versicherungs- und Spargesellschaften sowie in freiwilligen Gemeinschaften. Sie begründen Geldforderungsrechte gegenüber dem selbständigen Gesellschafts- bzw. Gemeinschaftsvermögen oder begründen Ansprüche auf monetäre oder ma-

64) Selbst dies kann als kollektive Form der Sicherung angesehen werden; so definiert W. Engels 1979b, S. 22: "Die Familie ist bis heute ein Versicherungsverein"; das kollektive Element läge in der zukunftssicherung durch die Kindereinkommen. Sofern aber - wie wir meinen - zum Kollektiv auch die Teilnahme an der Finanzierung gehört, und sei sie auch nach bestimmten Merkmalen gestaffelt, wäre die Familie mit nur einem Sparer bzw. Beitragszahler, d.h. mit nur einem einkommenerzielenden Finanzier, kein Kollektiv.

65) Das Individualvermögen deckt die Risiken ab, die zwischenzeitlich durch Einkommensausfall auftreten können. Insofern handelt es sich um eine intertemporale Sicherung. Transfers sind aber mit interpersonaler Sicherung verbunden. 
terielle Leistungen. Den Umfang dieser Art eigenverantwortlicher Sicherung (Alters-, Krankheits-, Vermögenssicherung usw.) bestimmt der einzelne selbst; die Höhe der sicherung hängt direkt vom individuellen Einkommen und seiner steigerung im Zeitverlauf $a b$. Eine Ungleichheit in der Zukunftssicherung zwischen den Individuen ist dann der Reflex einer ungleichen Primäreinkommensverteilung oder einer ungleichen Risikoabdeckungswilligkeit.

Auch hier ist $z u$ unterscheiden, ob die Sicherung der Existenz und Vorsorge in Form von Vermögensakkumulation organisiert wurde oder nicht; im letzteren Fall liegt nicht ein Anspruch auf Auszahlung eines Vermögensbetrages vor, sondern die Garantie eines gegenseitigen Eintretens der Solidargemeinschaftsmitglieder bei Einkommensausfällen. Nur in diesem letzteren Fall handelt es sich unbestritten um Transfers, die man einander gewährt. Im ersteren Fall, der Vermögensakkumulation, kann ein Transfer nur dann vorliegen, wenn eine Vermögensauszahlung erfolgt, der keine entsprechende Ansparung samt $\mathrm{Zins}$ und Zinseszins zugrunde liegt.

Die individuell-kollektive Sicherung bedeutet eine intertempora$1 e^{67)}$ und zugleich eine interpersonale ${ }^{68)}$ Einkommens- und Vermö-

66) Erlebt jemand den Ablauf der auf seine Lebens- und Beitragszeit berechneten Versicherungszeit, d.h. erhält er keine vorzeitige Auszahlung des vertraglich ausbedungenen Vermögens, empfängt er auch keinen Transfer, sondern erhält lediglich seine Sparsumme samt $Z$ insen zurück.

67) Im Rahmen der kollektiven Vorsorge ist im Gegensatz zur individuellen eine intertemporale Umschichtung nur aus der einzelwirtschaftlichen sicht möglich, nicht aber aus der gesamtwirtschaftlichen. Ganz gleich, ob die kollektive Vorsorge freiwillig oder zwangsweise geschieht, stets wird gesamtwirtschaftlich die alte Generation durch die jeweils erwerbstätigen unterhalten, z.B. in der Alterssicherung nach dem Umlageverfahren; die erwerbstäige verzichtet zugunsten der alten Generation auf einen Teil der von ihr erstellten Wertschöpfung. Denn die gesamte Bevölkerung muB ihren Lebensunterhalt - abgesehen von der Nutzung dauerhafter Güter - aus dem Sozialprodukt der jeweiligen Periode bestreiten; hierzu W. Albers 1979b, S. $304 \mathrm{f}$.

68) Die Einkommensverwendung, die die Person $A$ zum Zwecke der Sicherung trifft und die seine Verfügungssumme mindert, entspricht dem Einkommenszugang bei der Person B. Auf diese Weise ergeben sich qruppenmäBiqe Verschiebungen des Einkommens z.B. von Gesunden $z u$ Kranken, von Arbeitenden $z u$ Nichtarbeitenden usw. Inwieweit die Verschiebungen einkommensnivellierend wirken, ist eine Tatfrage. 
gensverschiebung. Das Risiko liegt hier nicht mehr im intertemporalen Bereich, ${ }^{68 a)}$ da zum Augenblick der ersten Beitragszahlung (bzw. ab dem Augenblick der Mitgliedschaft in der Solidargemeinschaft) die Ansprüche auf Risikoausgleich bereits entstanden sind. Vielmehr liegt hier der Risikoausgleich im interpersonalen Bereich. ${ }^{68 \mathrm{~b})}$ Inwieweit dieses durch Transferleistungen abgedeckt ist, entscheidet sich danach, ob ein Vorgang in der Vermögenssphäre abläuft oder nicht. Die Fälle der eigenverantwortlich-kollektiven Sicherung rufen also nur Transferleistungen hervor, soweit nicht sicherung durch Vermögensakkumulation geschieht.

b) Ganz anders die f $r e m d v$ e $r$ a $t$ wor $t i c h$ e Sicherung. Erstens ist sie in praxi bisher nur kollektiv organisiert. Zweitens unterscheidet sie sich von der eigenverantwortlichen dadurch, daß sie auf keinerlei Individualvermögen basiert. ${ }^{69}$ Demnach können grundsätzlich immer Transferbeziehungen entstehen. Drittens: Das $\mathrm{Ob}$ und Wie der fremdverantwortlichen Sicherung, also der "sozialen Sicherung" liegt nicht mehr in der Entscheidung des einzelnen, sondern beim Staat. Die Entscheider gehen davon aus, da $B$ die Sicherungswilligkeit, die Sicherungsfähigkeit oder beides beim einzelnen nicht vorliegen. Das ob und wie der Sicherung wird uno actu organisiert, wobei dem Rechtsanspruch auf Leistung aus dem Sozialverband eine Pflichtmitgliedschaft samt einer Beitragspflicht gegenübersteht.

(1) Fremdverantwortlich-kollektive Sicherung läBt sich danach organisieren, ob eine $\AA \mathrm{q} u \mathrm{i}$ a $l$ e $\mathrm{n} z$ zwischen Beitrag und Lelstung - völlig oder nur annähernd - gelten soll oder nicht. Dort, wo Steuerzuschủsse in das system der sozialen sicherung einfließen, ist die strenge Aquivalenz, nach der die Beitragslei-

68a)wie das noch bei der intrapersonalen Einkommensumschichtung (s.o.) der Fall war. Dort konnte im Zeitverlauf bei Einkommensausfall die Notwendigkeit entstehen, auf das eigene Sparvermögen zurückzugreifen und es aufzehren zu müssen.

$68 \mathrm{~b}$ )eben weil eine Einkommensverschiebung von den durch Beiträge Belasteten an die durch Transfers Begünstigten stattindet.

69) Nach dem vor 1957 geltenden alten Deckungsstockverfahren in der Alterssicherung konnte man noch in der persönlichen Anwartschaft auf einen Teil des Deckungsstocks eine Art von Individualvermögen erblicken. 
stung die Transferleistung bestimmt, nicht mehr gegeben. ${ }^{70}$ Derselbe Fall liegt vor, wenn die Beiträge nach sozialen (Einkommens - und Familien-) Merkmalen bemessen sind. Dies ist das Kennzeichen der Zweige des Sozialversicherungssystems. Es ist zu unterschelden von jener sozialen Sicherung, die völlig aus allgemeinen Steuermitteln finanziert wird, wo also das Aquivalenzprinzip nicht gelten kann; hier handelt es sich un die Sozialtransfers der offentlichen Hand (des Staates und der Gemeinden): Sozialrenten, Sozialhilfeleistungen usw. monetärer und realer Art.

Transferbeziehungen in dem hier beschriebenen Kontext lassen sich allgemein beschreiben als ein Strukturbild der $\mathrm{Zu}$ - und Abgänge von రkonomischen Größen $z$ wischen denen, die die finanziellen Mittel für die monetären und realen Leistungen aufbringen und jenen, für die sie verwendet werden. Die im zusammenhang mit diesen Bezlehungen organisierten Einkommensumschichtungen entstehen nun im System der "fremdverantwortlich-kollektiven Sicherung mit Aquivalenz" in differenzierter Weise; und zwar differenziert insoweit, wie den nach sozialen Merkmalen gestaffelten Beiträgen die zudem durch Steuerzuschüsse aus den öffentlichen Haushalten im Gesamtniveau niedrig gehalten sind - ein generell undifferenzierter Leistungsanspruch gegenübersteht, der von der Beitragshöhe, also von der Gegenleistung, unabhängig ist, sich aber nach individuellen Bedürfnissen richten kann (wie z.B. in der Heilbehandlung, in der Sozialhilfe für Kranke usw.). Soweit Steuerzuschüsse existieren, gilt also das strenge Aquivalenz- wie auch das "Versicherungsprinzip" nicht, sondern es wird ein eher "gemildertes Aquivalenzprinzip" angewendet, das allenfalls die Beitragsaufbringung betrifft, die steuerfinanzierung und die Transferleistungen hingegen nicht.

(2) Wird aber der Aquivalenzgedanke aufgegeben, wie das im System der sozialen Sicherung aus Mitteln der öffentlichen Haushalte der Fall ist, so liegen, da auf jeglichen Eigenbeitrag der $\mathrm{Zu}$ wendungsempfänger verzichtet wird, "undifferenzierte" Transfers vor: nicht differenziert nach irgendwelchen Arten der Mittelaufbringung, wenngleich sehr wohl abgestellt auf die verschiedenen Bedürfnisse der zuwendungsempfänger.

70) Hierbei ist allerdings zu berücksichtigen, daB die Zuschüsse teilweise deswegen gegeben werden, weil die Sozialversicherungen auch versicherungsfremde Aufgaben für den Staat übernehmen. 
In allen Fällen der Einkommensumschichtung handelt es sich um interpersonellen Einkommensausgleich ${ }^{71}$ ) in Verbindung mit einem intergenerativen; das heutige Umlageverfahren ${ }^{72}$ ) erlaubt einen unmittelbaren generativen Einkommensausgleich und zugleich einen intertemporalen insoweit, als die Versorgungseinkommen dynamisiert werden.

3. Die Organisation der Transferbeziehungen und die Darstellung der Mittelaufbringung konnten in unserem Untersuchungsrahmen nur insoweit aufgezeigt werden, als sie für die Klassifizierung der Transferleistungsarten, also der Mittelverwendung erforderlich sind. Letztere sollen daraufhin geprüft werden, inwieweit sie bei den Transferempfängern Einkommen sind (vgl. Übers. 3.4).

Es werden die üblichen finanzwissenschaftlichen Begriffe benutzt, derer sich auch die Transfer-Enquete-Kommission bedient. $\mathrm{Zu}$ Transfers zählen unter dem Einkommensaspekt nur solche an Haushalte. Allein die "direkten" Transfers als übertragungen, die das Einkommen unmittelbar erhöhen ${ }^{73)}$, finden Beachtung. Die Termini "positive" und "negative" Transfers machen nur Sinn für staatliche Transfers, im Hinblick auf das Sozialbudget. Hier gelten für die Einkommensdefinition nur die positiven als die monetären übertragungen vom staat auf die Haushalte ${ }^{74}$ ). Somit werden hier unter den Transferbegriff ausschließlich die "expliziten" gefaßt, wohingegen

71) in Richtung Einkommens-Nivellierung, ohne sie jedoch erreichen zu wollen; der Wirkungsverlauf dieser Inzidenz ist äuBerst kompliziert; er verläuft $z$ wischen den verschiedensten Gruppen, nicht nur zwischen den unmittelbar von den Transfers Begünstigten und Betroffenen, sondern - bei steuerlicher ZuschuBfinanzierung - auch zwischen den Besteuerten und Nichtbesteuerten, zwischen Arbeitnehmern und Selbständiqen, zwischen Eltern und Kinderlosen.

72) Das ältere Kapitaldeckungsstockverfahren wurde mit der Rentenreform von 1957 grundsätzlich aufgegeben und - wenn man die Ubergangsform des Abschnittsdeckungsverfahrens mit in Betracht zieht - erst $1969 \mathrm{mit}$ dem Ubergang $z$ um reinen Umlageverfahren vollends verlassen; G.W. Brück 1981 , S. $70 \mathrm{ff}$.

73) Die direkten Transfers sind in der Nomenklatur der TEK 1981 , $\mathrm{S} .22 \mathrm{f}$. unter den monetären Transfers jene Leistungen des Staates, die auch die "expliziten" Transfers genannt werden und sich auf die folgenden Leistungsbereiche erstrecken: Alter und Hinterbliebene, Gesundheit, Beschäftigung, Familie, Wohnung, Sparforderung, Folgen politischer Ereignisse usw.

74) Zum Staatssektor werden hier auch die staatlich mitfinanzierten Solidargemeinschaften der Sozialversicherungen gezahlt. "Positiv" ist aus der Sicht des Anspruchsberechtigten eine Leistung des staates (Renten, Pensionen, Arbeitslosenunterstützung, Wohngeld, Sparprämie u.a.l 
die "impliziten" als "steuervergünstigungen" und Vergünstigungen bei realen Transfers (z.B. Wohnungsbau) gelten. ${ }^{75}$ )

Monetäre Transfers haben unbestritten Einkommensqualität. Die Einkommensqualität der Realtransfers beurteilt man am besten nach der verfügbarke1t. ${ }^{76)}$ Dies soll wie folgt geschehen:

(1) Grundsätzlich gilt auch für Transfers: Was einer Person an ökonomischen GröBen zugeht, ist Einkommen. Zu diesem Einkommen gehören neben den gewöhnlich "Transfers" genannten Leistungen der öffentlichen Hände und der Kollektivverbände auch die privaten Einkommensubertragungen .

(2) So wie die aus dem Einkommen zu zahlenden Steuern und Beiträge zur Finanzierung der öffentlichen und kollektiven Transfers Einkommens-"Verwendung" sind, sind es auch die privaten Einkommensübertragungen. Diese dürfen nicht etwa vom Einkommen der Transferleister saldiert werden, so da $B$ deren Einkommen begrifflich als vermindert erschiene. DaB die Transferleistung bei dem Empfänger nochmals als Einkommen auftaucht, ist die Konsequenz aus dem personalen Einkommens-"Zugangskonzept", ein etwa an dieser Stelle vorgebrachtes "Doppelzählungsargument" solcher Ein-

75) Obwohl ein Zusammenhang erkannt wird zwischen Transfers und Steuervergünstigungen (z.B. zwischen der Wohnungsbauprämie einerseits und dem Sonderausgabenabzug der Bausparaufwendungen andererseits, zwischen dem Kindergeld einerseits und den Kinderfreibeträgen andererseits), bleibt auf diese Weise der nichtmonetäre und implizite Anteil der Transfers aus dem wirtschaftstheoretischen Einkommensbegriff ausgeschlossen.

76) In seinem Minderheitsvotum zum Gutachten der TEK 1981 sagt W. Albers auf S. 81: Die vorgenommene Abgrenzung der Realtransfers ist nicht aussagefähig. Einzelnen Personen zuzurechnende Leistungen können nicht deshalb Realtransfers sein, nur weil sie nicht in Geld gewährt werden. Auch Kollektivgüter werden zu den Realtransfers gezählt, obwohl es an einem bestimmten Empfänger fehlt. "Aus diesen Unterschieden ergibt sich, daB die erste Gruppe von Leistungen zum Einkommen der Empfänger gehört, während die zweite Gruppe ... nicht Bestandteil ... (des) Einkommens" der NutznieBer dieser Leistungen ist. Somit ist für Albers die Zurechenbarkeit begriffsentscheidend, ein Faktum, das wir - wie unten in $\$ 11$ noch dargelegt wird als die Voraussetzung der Verfügbarkeit bezeichnen. - W. Albers $1982 \mathrm{a}$, S. 23ff.: "zeitliche Verschiebung der Verfügbarkeit der übertragenen Einkommensteile". 
kommensbestandteile wäre ein Argument aus der makroökonomischen Gesamt- und Simultanbetrachtung, die hier nicht angestellt werden darf. Schon die ökonomische Konsequenz, daB Transfers letztlich Einkommens-Umschichtungen bewirken, verdeutlicht, daB auf seiten der Transferleister auch Einkommen vorlegen haben muB. ${ }^{77)}$ Begriffsbestimmend für Einkommen ist nicht die Verwendung von ökonomischen GröBen, sondern deren Zugang; dies gilt für Transferleister wie -empfänger. Konsequenterweise mulssen dann neben den Arbeitnehmeranteilen auch die Arbeitgeberanteile an den Beiträgen zur sozialen Sicherung $z u$ den individuellen Einkommen der Arbeitnehmer gezählt werden .

(3) Was nun den Transferempfängern an individuellen, kollektiven und öffentlichen Transfers zugeht, ist insowelt Einkommen, als der zugang verfügbar und meBbar ist. Für die monetären Transfers gilt das unbestritten mit der einen Ausnahme jedoch, das der monetäre Zugang kein VermögensrückfluB sein darf; ist er dies aber, liegt kein Transfer vor sondern eine Vermögensumschichtung.

(4) Legt man für die Realtransfers die Kriterien der Verfügbarkeit und der MeBbarkeit des zugangs an, so ergeben sich von vorn herein bestimmte unbestrittene Konsequenzen.

(4a) In erster Linie betreffen diese die öffentlichen Realtransfers, und zwar jene, die nicht direkt den einzelnen zurechenbar sind, wie die öffentlichen Güter. Sie sind keine Einkommen. Die Sozialhilfeleistungen der öffentlichen Hand und die Realleistungen der Kollektive sind zwar direkt zurechenbar, doch nicht in jedem Falle so verfügbar wie Einkommen, namentlich das monetäre.

(4b) Die Einkommensqualität der direkt zurechenbaren Realtransfers ${ }^{78)}$ muB man zunächst einmal in direktem zusammenhang mit den Formen der Realentlohnung ${ }^{79)}$ sehen; man darf sie des weiteren

77, Konsequent verlangt man deshalb, so z.B. auch N. Andel (1970, s. 329), für die $s$ t e u e r $l$ i $c h$ e Behandlung des Problems, sämtliche Sicherungs-Beiträge aus dem zu versteuernden Einkommen zu leisten.

78) Z.B. die stationäre und ambulante Heilbehandlung, Heilmittel (Medikamente, Prothesen usw.), Kur- und Erholungsaufenthalte, Sanatoriumsbehandlung, Alters- und Pflegeheimunterbringung, Kindergärten und horte usw.

Fn. 79 siehe folgende seite 
nicht in eine unmittelbare Nachbarschaft mit der Bedürftigkeit bringen, denn daß die Transferempfänger der konkreten Leistungen bedürtig sind, heißt nicht, daß sie aus dem Aspekt der Einkommens (verteilungs) situation immer zu den Bedürftigen zählen. Für die Frage der wirtschaftstheoretischen Einkommenseigenschaft ist überhaupt die Bedürftigkeitsfrage nicht von Belang, sondern die Frage der Verfügbarkeit. Das bedeutet also schlieBlich, daB nur über die Verfügbarkeit der einzelnen Realleistung $z u$ entscheiden ist ohne Ansehung der Person in ihrer Verteilungssituation; dies bereitet gerade bei Transfers einige Denkschwierigkeiten. ${ }^{80}$ )

Die Verfügbarkeit vieler Realtransfers, soweit sie direkt zurechenbar sind, gleicht in vielem den Realentlohnungsformen; wie diese sind sie zwar nicht in jeder Weise frei verfügbar (z.B. auf dem Markt veräußerbar), doch wie diese ersparen sie die Bereitstellung sonst notwendig gewordener monetärer Einkommensteile. Dienen die Realentlohnungen weithin der Wiederherstellung oder Bereitstellung der Arbeitskraft und des Humanvermögens, so dienen die Realtransfers weithin der Wiederherstellung der Gesundheit, also ebenfalls der Wiederherstellung und Aufrechterhaltung des Humanvermögens. Da dies zu erhalten in die Zuständigkeit des Individuums fällt, 81 ) sind Realtransfers, deren verfügbarkeit für ebendiese Zwecke vorliegt, Individualeinkommen.

Fn. 79 :

Deputate, Dienstwohnung, Dienstwagen, Verpflegung, Arbeitskleidung, betriebliches Gesundheits-, Sozial- und Kulturwesen, die Sachgüterentnahme in Form von Konsumgütern, Baustoffen, Werkzeugen, die Entnahme von Dienstleistungen aus dem Betrieb zu privaten Zwecken (Bau- und Gartenarbeiten usw.), siehe Ubersicht 3.2 .

80) Man ist nämlich allzusehr gewohnt, die Frage der Transfers sofort mit steuerlichen Problemen $\mathrm{zu}$ verknüpfen. Steuerlich aber, wenn tatsächlich unter verteilungs- und belastungspolitischem Aspekt Bedürftigkeitsfragen $z u$ lösen sind, kann man die Einkommenseigenschaft bestimmter Realtransfers so lösen, wie sie den politischen zielen entsprechen.

81) Unbestritten liegt trotz der individuellen zuständigkeit auch ein Interesse der Solidargemeinschaft an der Erhaltung des Humanvermögens vor, und zwar aus gesamt- und sozialwirtschaftlichen Gründen. Dennoch sind alle sozialpolitischen MaBnahmen dazu angetan, die Individualzuständigkeit zu unterstützen, nicht $z u$ ersetzen. Wäre es anders, hätten wir ein völliq anderes Sozialsystem vor uns mit der Konsequenz staatlicher Anordnungen über Gesundheits-, Bildungs-, AusbildungsmaBnahmen und -aufwendungen usw. uber die Individualentscheidungen hinweg. 
(4c) Grenzfälle der Einkommensqualität von Realtransfers treten im Bereich der privaten Transferleistungen auf, weil hier oft die MeBbarkeit der Leistungen schwierig oder unmöglich sein dürfte, wie z.B. bei der Nachbarschaftshilfe (auBer z.B. den Bauleistungen). Wo die MeBbarkeit grundsätzlich möglich wäre, könnte es aber an der Feststellbarkeit und Kontrolle scheitern, wie z.B. bei der privaten Unterrichtung, der privaten Krankenpflege und dem gemeinsamen Haushalt. Hier dürfte allgemein kein Raum sein für eine Qualifizierung als Einkommen. Altenteile und Wohnrechte lassen sich grundsätzlich wohl berechnen, doch können Zweifel bestehen, ob nicht eher Vermögenseinkommen vorliegen; zumeist werden ja Ubergabeverträge abgeschlossen, aus denen sich folgern läBt, daB das $z u$ gewährende Altenteil und Wohnrecht eine Art Gegenleistung für die Ubergabe auf den Nachkommen sein soll. Auch wenn ein Altenteil oder Wohnrecht als eine Art vorweggenommenen Erbes interpretiert würde, wäre der Zusammenhang mit dem Vermögen unübersehbar. Hier dürfte dann nur ein über den Vermögenswert hinausgehender Anteil als individueller Realtransfer anzusehen sein.

VII. Fazit : Die Darstellung der zugangsarten und -quellen zeigt, daB der lehrbüchüblich herausgestellte Gegensatz "Quellentheorie versus Reinvermögenszugangstheorie" nicht den gesamten Problemumfang des Einkommens veranschaulichen kann; die angesprochenen allokativ-distributiven Abgrenzungs- und Inhaltsprobleme vermag er nicht auszudrücken. DaB beide Einkommenstheorien eine gewichtige allokative Gemeinsamkeit in der hineindefinierten "Kapitalerhaltungsaxiomatik" aufweisen, wird von der so dargestellten Dichotomie verschleiert. DaB schlieblich das Schanz-Haig-SimonsKonzept eine totale, auch die Transfers einschlieBende Erfassung des Einkommens beabsichtigt, kommt in der Benennung einer der beiden Theorie als "Rein - V e r m ö g e n s - Zugang" nicht deutlich zum Ausdruck. Die literarische Diskussion um das Einkommen läuft statt dessen allenfalls an diesem Gegensatz thematisch "entlang" und läBt sich möglicherweise in der hier vorgeschlagenen Weise in allokativ motivierte und in distributiv motivierte Konzepte prägnanter einteilen, wobei letztere sich durch den bloben Vermögens- bzw. durch den zusätzlichen TransfereinschluB unterscheiden. 
59 zeitbeziehungen und Ent scheiaungsabhängigkeiten als Abgrenzungskriterien zwischen Einkommen und vexmögen

I. Der Versuch einer Trennung in Strom- und Bestandsgrößen sowie die Rolle der zeit in der ökonomik

II. Der Versuch einer Periodisierung des Zugangs und der verwendung

III. Die Rolle der individuellen Entscheidungen für die Abgrenzung von Einkommen und Vermögen

I. Da in der Besteuerung Einkommen und Vermögen als d i e Indikatoren der Leistungsfähigkeit gelten, wird hier versucht, den Inhalt dieser Begriffe wirtschaftstheoretisch zu bestimmen.

a) Die Abgrenzung des Vermögens vom Einkommen wird im allgemeinen mit den Begriffen der Kreislauftheorie und mit der zeitbeziehung vorgenommen:

Einkommen als eine Strom- oder Flußgröße entstehe im Leistungskreislauf der wirtschaftlichen Wertschöpfung, Vermögen stehe als eine Bestandsgröße außerhalb dieses Kreislaufs; Einkommen entstehe in der laufenden Periode, Vermögen sei bereits vorhanden, sei die in den Vorperioden akkumulierte Ersparnis. ${ }^{1}$ ' In diesen Definitionen sind sowohl die Termini der (Bestands-bzw. FluB-) GröBen als auch der Periode vereinigt. Daran hat sich bis heute nicht viel geändert, wenngleich die Kriterien des Definiendum deutlicher ausgesprochen werden: Entscheldend für die Existenz von Vermögen sei nach G. Krause-Junk (1981, s. 260) die "Verfügungsmacht", die jemand in einer "Periode" innehat; "die Verfügungsmacht mag er bereits am Stichtag des Periodenbeginns besessen haben, oder sie mag ihm erst in der laufenden Periode zugefallen sein. Im er-

1) In den Worten von I. Fisher (1906): Capital (dasselbe kann in unserer Terminologie für das Vermögen angenommen werden) ist der "stock of wealth, existing at a given instant"; income ist der "flow of benefits from wealth through a period of time". 
steren FAll würde man sie als Vermögen, im zweiten Fall als Einkommen bezeichnen".

Die Gegenüberstellung von Vermögen und Einkonmen wird letztlich dadurch pointiert, daß man das Vermögen als eine "statische", das Einkommen als eine "dynamische" GröBe kennzeichnet.2) Einkommen sei ein "Begriff aus einer einperiodischen (statischen) Wirtschaftstheorie", der die "mehrperiodische (dynamische)" gegenüberzustellen sei (D. Schneider 1979a, S. 47).

b) Doch sollte - was ihre Abgrenzungs- und Erklärungskraft betrifft - die strikte Unterscheidung in FluB- und BestandsgröBen skeptisch beurteilt werden, da z.B. die weithin akzeptierte Reinvermögenszugangstheorie versucht, Einkommen als zugang von $\mathrm{V}$ e $\mathrm{r}$ m ö $\mathrm{g}$ e $\mathrm{n}$ zu interpretieren, also die Unterscheidung aufzuheben. Daraus wäre zu folgern, daB Einkommen und Vermögen inhaltlich identisch sind. Deutlich sagt B. Moll (1924, S. 99):

"Vermögens- und Einkommensbegriff entspringen der gleichen wurzel wirtschaftlichen Könnens, dem Vermögensbegriff im weitesten sinne". Mit derselben Entschiedenheit führt jüngstens w. Stützel (1979, S. 45) aus, es sei geboten, davon auszugehen, "daB 'Einkommen' einerseits und 'Vermögen' andererseits ökonomisch nicht anderes sind als verschiedene Ausdrucksformen zur Benennung und Quantifizierung letztlich absolut identischer Sachverhalte." Akzeptiert man dies, so erscheint tatsächlich die Gegenüberstellung von Bestands- und stromgröBen als eine lediglich didaktische, die aber nichts erklärt (O. Weinberger 1956 , S. 486 f.). Analog dem Zugangskonzept der Reinvermögenszugangstheorie definiert H.C. Simons (1938, S. 49 f.) das Einkommen als den gesamten $B$ e $s$ t a $n$ d an "property rights" und hebt dadurch die Grenze zwischen Einkommen und Vermögen auf. Gemessen werden in jedem Fall nur Bestände, und auch Einkommen ist letztlich der Unterschied zwischen Beständen. 3)

2) F. Neumark 1947, S. 36; E. d'Albergo 1953, S. $30 f$.

3) In Wahrheit wird ja auch beim Einkommen nicht die "Strömung" gemessen, sondern es werden verschiedene zugänge bzw. Veränderungen des Zugangs zwischen 2 Zeitpunkten einer Periode gemessen; eine echte Strömungsmessung wäre u.E. die Messung der Intensität von DurchfluBmedien, die Geschwindigkeit des Durchflusses, die Dichte und die Gleichförmigkeit des Mediums. 
Auch die Autoren, die sich direkt - also ohne den "Umweg" über wirtschaftstheoretische Definitionsversuche - den Indikatoren der Leistungsfähigkeitsbesteuerung zuwenden, machen mitunter kaum eine "folgenschwere" Unterscheidung zwischen Einkommen und Vermögen. Wird nach F.K. Mann (1937, S. 258) den Worten E. Pfeiffers zufolge der Begriff des Vermögens weit genug gefaBt, so daB er "also auch die persönlichen Eigenschaften und vornehmlich die Erwerbsfähigkeit mitumschlieBt, stehen vermögen und Einkommen in so enger Wechselwirkung, daB es fast gleichgültig erscheint, ob das Einkommen oder das Vermögen als SteuermaBstab gewählt wird." Der entscheidende Unterschied allerdings $z$ ur Simons'schen Definition liegt in der weiteren Fassung des Vermögens, die der von B. Moll entspricht, liegt also letztlich im Inhalt dessen, was als Bestand $\mathrm{zu}$ gelten hat, und das ist der $U \mathrm{~m} f \mathrm{f} g \mathrm{de} \mathrm{r}$ e r $f$ ü $g$ u $g s m$ a $c h t$. Der Versuch, Einkommen als Differenz zwischen Vermögenszugängen $z$ u definierer, also einen Bestandsvergleich anzustellen, gelingt dann, wenn man Vermögen mit Verfügungsmacht identifiziert. Wenn die Verfügungsmacht bei simons von geringerem Umfang erscheint als bei anderen Theoretikern, so liegt das einzig und allein an dem von ihm aufgestellter Erfordernis, es müsse die Verfügungsmacht in Geld ausgedrückt werden können; ansonsten läBt sich auch hier kein Einwand gegen die Identität von vermögen und Einkommen als verfügungsmacht erheben.

Wenn in dieser Arbeit dennoch die Begriffe Bestands- und StromgröBen verwendet werden, so geschieht das in dem BewuBtsein, daB sie allenfalls ökonomische Phänomene, deren Existenz wahrzunehmen ist, "benennen", nicht jedoch definieren. Das Gegensatzpaar leistet also lediglich den Dienst einer leichteren Verständigung über Aussagegegenstände, nicht jedoch den einer theoretischen Abgrenzung. 4 i

4) C. Gräff widmet den definitorischen Problemen profunde Ausführungen (Strom- und Bestandsgrößen in makroökonomischen Vermögensmarktmodellen. Studien zur Wirtschafts- und Finanzwissenschaft, Band 4, Bergisch Gladbach 1991). Wenngleich dies in einer makroökonomischen Analyse geschieht, so ist dennoch für unseren mikroökonomischen Ansatz sein Hinweis auf die Ausführungen von G.W. Harrison (Stocks and Flows, in: Eatwell, J. u. a. (Hrsg.), The New Palgrave 4, S. 506-509) wichtig: Die Strom-Bestands-Analyse zur Beschreibung des individuellen verhaltens, somit auch der individuellen Entscheidungen 
c) Strom- und Bestandsgrößen werden gewöhnlich unter Hinweis auf ihren "Zeitbezug" von einander abgegrenzt. Dies betonen u. a. insbesondere I. Fisher (1906 und 1912), A. Marshall (Principles of Economics, 8. Aufl., London 1920) und P. N. Rosenstein-Rodan (The Role of Time in Economic Theory, Economica 1/1934, S. 77-97). Der entscheidende Aspekt, ob als zeitbezug ein zeitpunkt oder eine Zeitspanne gewählt wird, ist heute Bestandteil eines jeden Lehrbuches.

Die Kritik, die sich in der Folgezeit an den makroökonomischen Folgerungen aus diesem Ansatz ergeben hat, ist unser Erklärungsgegenstand nicht. Vielmehr verfolgen wir hier die mikroökonomische Spur, denn es läßt sich neben der makroökonomischen Analyse mit ihren dimensionalen Aspekten (C. Gräff, 1991, S.2 und passim) auch die mikroökonomische Analyse mit den verhaltenstheoretischen Aspekten durchführen (G.W. Harrison 1987). In der mikroökonomischen Sicht aber spielen die individuellen Entscheidungen (für oder gegen den Konsum, für oder gegen das Sparen) eine große Rolle.

II. Bei weiterer Prüfung, ob sich Vermögen sinnvoll vom Einkommen abgrenzen läBt, bleiben wir beim Kriterium der von KrauseJunk (s.o.) und auch von F. Neumark (1947, s. 36) postulierten $p$ e $r i \circ$ e $n$ b e $z \circ g$ e $n$ e $i t$ und stellen - da dies als identisch bezeichnet wird - auf den Unterschied zwischen dem dynamischen Einkommen und dem statischen Vermögen ab. $\left.{ }^{4}\right)_{\text {Allerdings }}$ müssen wir fragen: Was bitte ist das $D$ y $n$ a $\mathrm{m} s \mathrm{ch}$ e am Einkommen? Etwa, daB es innerhalb jeder Periode auch einmal unregelmäBig fliebt? Oder daB es zwar regelmäBig fliebt, jedoch gegenüber der Vorperiode vielleicht unterschiedlich hoch ist? Und was ist das Statische am Vermögen angesichts der Geldentwertung? Vermutlich ist das einzig $s t$ a $t i s ~ c h$ am Vermögen das sich durch wirtschaftliche Aktivitäten nicht automatisch

4a) F. Neumark 1947, S. 36: Einkommen ist der "Zuwachs an ökonomischer Verfügungsmacht... w $\ddot{a} h r$ e $n d$ e $i n$ e s b e $s t i m m$ e $n$ e i t $r$ a u m s "; "Mit anderen Worten: Einkommen ist etwas essentiell $\mathrm{D}$ y $\mathrm{n}$ a $\mathrm{m} i \mathrm{~s} c \mathrm{~h}$ e $\mathrm{s}$, Vermögen etwas $s t a t i s c h$ e $s$." Hervorhebungen des ersten Zitattells durch Neumark selbst, des zweiten durch $\mathrm{HDH}$. - Wir meinen, nicht Einkommen und 'Vermögen an sich, allenfalis thr zugang in der zeit kann etwas Dynamisches haben. 
Verändernde, der Rechtszustand: Vermögen ist der Gesamtbestand an Werten, der einer Person in jedem Augenblick - bis $z$ u der von ihm gewollten und veranlabten Zustandsveränderung - zusteht. ${ }^{5}$ ) Ist bei der Geldentwertung nur die nominelle oder gar die substantielle Erhaltung des Vermögens eine Bedingung des Statischen? Wieviele Perioden müssen in den zur Feststellung der Bestandserhaltung notwendigen Vergleich eingehen, um vom Statischen $z u$ reden, eine oder mehrere; und wenn mehrere: Wieviele?

Es dürfte deutlich geworden sein, daB für die statisch-dynamische Betrachtung allein das Zeitproblem, die konventionell akzeptierte Periodisierung von Zugängen ökonomischer GröBen ausschlaggebend ist. Ohne diese Periodisierung der zeit hat der Gegensatz von Statik und Dynamik keinen Sinn. ${ }^{6}$ ) Wenn dies aber so ist: Auch Vermögen ändert seinen wert u.U. täglich, wäre somit eine dynamische GröBe; auch Einkommen lieBe sich im Vergleich zwischen zwei Betrachtungszeitpunkten u.U. als unverändert in der Höhe und gleichbleibend zuflieBend feststellen, sofern man auch die zwischen den Zeitpunkten liegenden zugänge mitbetrachtet. Regelmäßiger zugang und gleiche Höhe der ökonomischen Größen können eine Inhaltsbestimmung von "Dynamik" und damit eine Abgrenzung des Vermögens vom Einkommen folglich nicht beschreiben.

$\mathrm{DaB}$ andererseits die Abgrenzungsaufgabe durch eine Periodisierung der $\mathrm{v}$ e $\mathrm{r}$ w e $\mathrm{n}$ d u $\mathrm{n} g$ der zugänge ebensowenig geleistet werden kann, sollen drei Beispiele demonstrieren:

Jemand erbt eine ökonomische GröBe von 1 Millionen Geldeinheiten. Ist der Zugang Einkommen oder Vermögen? Falls die Antwort ${ }^{7)}$ auf

5) Siehe die Vermögensdefinition von E. Grossmann 1956, S. 526 : "Gesamtheit der einer Person privatrechtlich zustehenden Sachen und Rechte"; siehe hierzu ferner H. Laufenburger 1956, S. 462, der im Gegensatz zum ökonomischen Begriff des Kapitals das Vermögen als einen Rechtsbegriff bezeichnet; siehe auch H. Fecher 1979, S. 466, der Vermögen als die summe der bewertbaren Güter und Rechte versteht, die im Eigentum einer Person stehen.

6) Ein Zeitaspekt, und zwar der einer Periodisierung des Zeitablaufs in Vergangenheits-, Gegenwarts- und Zukunftsabschnitte liegt auch der "dynamischen Theorie" des Einkommens von J.R. Hicks $(1946$, S. $179 \mathrm{f.})$ zugrunde, etwa in der Gegenúberstellung von historischen und Erwartungswerten.

7) Für H. Haller 1978, S. 237, fällt die Antwort auf diese Frage mit der Entscheidung über die Verwendung; wer nicht konsumiert,

(Forts. siehe folgende seite) 
Vermögen fällt: Was macht die Erbschaft zum Vermögen, die $\mathrm{H}$ ö $\mathrm{h}$ e des zuflusses, die A p e $\mathrm{i}$ o d i z $\mathrm{i}$ ä $t$ des $\mathrm{zu}-$ flusses oder der Umstand, daB der Erbe sich nicht $O$ k $\circ$ n o $\mathrm{m} i \mathrm{~s} \mathrm{c} h$ betätigt hat und insofern "Unverdientes" erwarb? Alle drei Definitionen sind möglich, um Vermögen $z u$ beschreiben; sie sind nicht widerlegbar, haben aber den Nachteil, daB sie auch nicht begründbar sind. Jetzt gebe der Erbe sein Geld $s$ f aus: Konsumiert er Einkommen oder Vermögen? Oder er gebe es erst nach ein oder zwei Jahren aus: Ist es Konsum oder Vermögensverzehr (bzw. -auflösung)? Die Periodisierung der Verwendungsseite soll aus dem zweiten Beispiel noch deutlicher hervorgehen:

Jemandem geht monatlich regelmäBig eine ökonomische GröBe in Höhe von 1000 Geldeinheiten $z u$ : VergröBert er damit sein Vermögen oder erhält er Einkommen? Dies müBte ohne Blick auf die Höhe oder die Verwendung $\mathrm{zu}$ entscheiden sein, kann aber nur in Richtung "Einkommen" entschieden werden, wenn man dem Periodizitätsdenken anhängt. Er gibt es nun entweder sofort oder erst nach einem Jahr aus: Ist es Konsum oder Vermögensverzehr? Wenn er aber überhaupt nichts ausgibt sondern alles spart: Ist der monatliche Zugang Einkommen oder Vermögen? Oder macht erst die Verwendungsentscheidung das Geld zu Vermögen? Das dritte Beispiel für die Unlösbarkeit der Abgrenzung durch die Periodisierung der zeit entrehmen wir I. Fisher: ${ }^{8)}$ Der Kurswert eines Wertpapiers steige zwischen den Zeitpunkten zweier Kuponabtrennung. Nach Fisher ist diese Wertsteigerung nicht Einkommen sondern Kapitalzuwachs; nur wenn der Kupon abgetrennt werde, verschaffe er Einkommen. Werde der Kupon wieder in ein anderes Wertpapier investiert, liege aber kein Einkommen vor, vielmehr bleibe es ein Kapitalzuwachs.

Forts. Fn. 7 :

hält Vermögen: "Da das zugegangene Vermögen ... auch konsumtiv genutzt ... werden kann, wäre seine Konservierung als neuer sparakt $z u$ interpretieren."

8) 1930 , S. 24 f. unter der Uberschrift "Capital Gain not Income"; er benutzt dieses Beispiel allerdings zur Demonstration der Beziehungen zwischen Kapital und Einkommen.

9) Fisher: "If the coupon thus given off is reinvested in another bond, that event is outgo, and offsets simultaneous income realized from the first bond." - en Darlegungen von F. Neumark 1961b, S. 33, können wir entnehmen, daB es sich hierbei nicht um sog. Umschichtungen der Kapital- bzw. Vermögensstruktur handelt, also nicht um sog. "unwirksame Einkiunfte", da Kapitalgewinne vorliegen. 
Trotz der zwischen Kuponabtrennung und Reinvestition gelegenen Einkommensrealislerung (Fisher: "income realized") ist nach Fisher der gesamte "Simultanakt" keine Einkommensrealisierung. Die endgultige Verwendung des Kupons entscheidet uber Einkommensoder Wertstelgerungsqualität des zugangs. Tatsalchlich handelt es sich 1m ersten Fall (der nicht erfolgten Wiederanlage des Kupons) um eine realisierte Wertstelgerung. Aber wir haben $z u$ fragen: Ist es nicht im Fall der Wiederanlage - wenn auch nur fur einen logischen Augenblick - realisiertes Einkommen, das da wieder ausgegeben wird (Fisher: "outgo")? Und was, wenn der kuponerlos nicht sofort wieder investiert wird, sondern erst nach einer oder mehreren "Perioden"? Wie lange darf die zeit zwischen Kuponerlos und Reinvestition andauern, um der Wertrealisierung die Qualităt von "Einkommen" zuschreiben $z u$ können oder um diese Qualităt wieder "vernichten" zu mussen? Wie man sieht, tritt hier zum Problem der Wertzuwachsrealisierung das der Zeitdauer hinzu. Beide sollen für die Einkommensdefinition ausschlaggebend sein.

Aus allen drei Beispielen läBt sich folgern, daB ungeachtet der Art und Quelle des zugangs weder das Zeitmoment lalso die Bestimmung der Periodenlänge) noch die Verwendung elne eindeutige $\mathrm{Ab}-$ grenzung des Einkommens vom Vermögen erlauben.

III. Vielmehr ist die $E n t s c h$ e $i d u n g$ das einzige Kriterium der Abgrenzung zwischen Einkommen und Vermögen, und zwar in der Phase der $\mathrm{V}$ e $\mathrm{r}$ w $\mathrm{n}$ d u $\mathrm{n}$ des Zugegangenen:

a) Nicht die Art und die Quelle des zugangs, nicht seine töhe und seine Periodizität, sondern Entscheidungen des Wirtschaftenden, und zwar darüber, einen zugang an ökonomischen Größen nicht etwa zu konsumieren, sondern der Risikovorsorge, dem sparen zur späteren Erhöhung des Lebensstandards usw. zu widmen, also die verwendungsentscheidung, macht den zugang einer ökonomischen Größe zum persönlichen Vermögen. Die verwendungsentscheidung ist die conditio sine qua non des Vermögensbegriffs. Erst wenn diese Entscheidung gefallen ist, hat es sinn, von "Bestandsgrößen" im Gegensatz zu Stromgrößen zu sprechen; das Begriffsgegensatzpaar erklärt nicht das zustandekommen von Vermögen, sondern bezeichnet einen "nachentscheidlichen" zustand ökonomischer Größen. 
b) Statt der Unterscheidung zwischen Strom- und BestandsgröBen, statt der Periodisierung im Zugang ökonomischer GröBen rückt nunmehr die persönliche Entscheidung in die maßgebliche Posititon $\operatorname{der} B$ egriff $\mathrm{s} a \mathrm{~b} g \mathrm{r}$ e $z \mathrm{u} n \mathrm{~g}$. Damit tritt die Gefahr auf, daB die Abgrenzung zwischen Vermögen und Einkommen dem AuBenstehenden unscharf erscheint, ihm objektiv nicht möglich wird. Dennoch kann in ökonomischen Begriffs-Theorien an den Entscheidungen der Wirtschaftenden nicht vorbeigegangen werden, denn erstens hängen von den Entscheidungen ihre ökonomischen Aktivitäten $a b$, und zweitens sind Entscheidungen und ihr zustandekommen Kennzeichen ökonomischer systeme. Entscheidungen über die Verwendung ökonomischer GröBen lassen sich aber ermitteln, wohingegen die Unterscheidung in Strom- und BestandsgröBen nichts erklärt und jede Abgrenzung des Vermögens vom Einkommen etwa durch die Art, Höhe oder Periodizität des Zugangs willkürlich ist. Die "Willkür" des Wirtschafters und Entscheiders ist demgegenüber immerhin ökonomisch begründet im Planungshorizont und in den Funktionen, die das Vermögen ihm leisten soll.

c) Vom wirtschaftstheoretischen Argumentieren dagegen völlig zu trennen ist die Frage, wie das Vermögen $s t$ e $u$ e $r$ i c h $z u$ behandeln ist. Hier sollte unterschieden werden zwischen der Steuerpolitik und der Steuertheorie und ihren jeweiligen Lösungen. Erstere beschäftigt sich - soweit unser Problem betroffen ist - mit der allokativ-distributiven Abgrenzung, also mit der Abgrenzung der Erwerbssphäre von der Privatsphäre. Diese Abgrenzung ist für das Einkommensteuerrecht "fundamental" (K. Tipke 199:, S.244). sowohl hinsichtlich der Vorgänge im Ertrags-/Aufwands-/Einkommens-/Ausgabenbereich als auch hinsichtlich der Tatbestände im Kapital-/Vermögensbereich. Die Steuerpolitik kann durchaus in Beweisnot darüber geraten, welcher sphäre ein Vorgang oder Tatbestand zuzuordnen ist. Doch auch das Steuerrecht verläBt sich bei der Abgrenzung des Betriebs- vom Privatvermögen neben der objektiv feststellbaren Eigenart des Betriebes und bestimmten tatsächlichen Nutzungen des Vermögens auf die persönliche Entscheidung des steuerpflichtigen, nämlich auf den "Widmungsakt", feststellbar im Ausweis der entsprechenden Vorgänge und Tatbestände in Buchführung und Bilanz; für diese individuelle widmung ist maBgeblich, ob das Vermögen "im konkreten Fall betrieblichen oder privaten Zwecken dient" (K. Tipke 1981, S. 233). Die entsprechende 
Entscheidung für den tatsächlichen zweckhaften Einsatz des Vermögens trifft das Individuum. Nur von seinem Standpunkt und Beurtellungsspielraum aus ist $\mathrm{zu}$ sagen, welcher sphäre das Vermögen dienlich ist, der betrieblichen oder der privaten. 10)

Eine eher steuertheoretische und -systematische Frage ist es, in Anerkennung dessen, daB sich aus der wirtschaftstheoretischen sicht Vermögen vom Einkommen nur qua Entscheidung abgrenzen läBt, Vermögen dennoch zur Bemessungsgrundlage für eine gesonderte Vermögensteuer $z u$ erklären. Wenn die wirtschaftstheoretischen Uberlegungen ergeben, daB eine Abgrenzung zwischen Einkommen und Vermögen eben von einem Phänomen abhängt, das schwierig $z u$ greifen und nur selten eindeutig nachprüfbar $\mathrm{zu}$ machen ist, da die tbergänge fliebend werden können, bleibt für die Steuertheorie nur die folgende Alternative: Entweder sie zieht die Konsequenz daraus und verzichtet auf den Versuch, eine zusätzliche Vermögensteuer theoretisch zu begründen, oder sie nimmt den Vorwurf der willkürlichen, dem ökonomischen Geschehen aufoktroyierten Abgrenzung in Kauf und baut ihre Besteuerung nach der "Leistungsfähigkeit" auf diesem Vorgehen auf. Sie hat dann allerdings die Beweislast dafür, wann jeweils beim einzelnen zusätzliche Leistungsfähigkeit wegen des Vermögensbesitzes vorliegt, die nicht bereits im zugang begründet ist.

Für die weitere wirtschaftstheoretische Analyse aber können wir von dem folgenden Ergebnis ausgehen: Entscheidend ist im Inhalt des Einkommens- und Vermögensbegriffs die individuelle Verfügung. Erhält jemand in der Zugangsphase ökonomischer Größen Verfügungsmacht, ist das Einkommen; verfügt er über den zugang in der oben beschriebenen Weise, macht er das Einkommen zu Vermögen.

10) So auch sinngemäB Tipke, der dort, wo das Steuerrecht noch objektive Beurteilungskriterien verlangt, nachdrücklich die Anerkennung der $p$ e r sön $\mathrm{l} i \mathrm{ch}-\mathrm{i} \mathrm{n} d \mathrm{i}$ v $\mathrm{i}$ d u e l1 e $n$ Motive fordert: nach Tipke kommt es nicht darauf an, ob die Anschaffung oder Nutzung eines Vermögensgegenstandes für den Betrieb objektiv notwendig oder zweckmäBig ist; daraus, daB es auf die Motivation des Steuerpflichtigen, auf den von $i \mathrm{hm}$ verfolgten $\mathrm{zweck}$ ankommt, ergibt sich, daB Erwerbshandlungen nicht nur solche sind, die objektiv der Erwerbstätigkeit dienen, sondern auch solche, die ihr vom Standpunkt des Handelnden aus dienen; der Handelnde hat einen Beurteilungsspielraum. Auf die betriebliche/berufliche Notwendigkeit, Ublichkeit oder ZweckmäBigkeit der Handlung kommt es nicht an; so fast wörtlich 1991, S. 246 ("subjektivfinale Ursachen" der "Abgrenzung der Erwerbssphäre zur Privatsphäre"). 
10 Das Problem der Inhaltsund Umfangsbestimmung des Vermogens

I. Vermögen als Gesamtgröße

II. Die Trennung zwischen Eigentum und Verfügungsgewalt

III. Die Vermögensfunktionen als begriffsbestimmende Merkmale

IV. Bewertbarkeit und verfügbarkeit als begriffsbestimmende Werkmale

v. Zusammenfassung des 3. Kapitels

I. Wie der Einkommensbegriff, so geht auch der wirtschaftstheoretische Vermögensbegriff - ungeachtet dessen, da $B$ ein allgemein anerkannter Begriff nicht existiert - auf die $G$ e $s$ a $m$ e r f a s $s$ u g aller Tatbestände aus, gleich, welche Vermögensarten diese Tatbestände repräsentieren. Die Absicht der Totalerfassung, die allgmein ${ }^{1)}$ und steuerrechtlich"l mit dem Begriff der "Gesamtheit" von Gütern verbunden wird, kommt auch in ökonomischen Definitionen zum Ausdruck. So verstehen z.B. E. Blumenstein (1926, S. 172) das Vermögen als "Gesamtheit der ... Sachen und Rechte", G. Weisser (1961, S. 163) Vermögen als die "Gesamtheit der ... Güter einer Person oder Personengruppe"; nach C. Folkers (1979 ,S. 266) bilden "Teilgesamtheiten" des Vermögens die "Vermögensgesamtheit", und D. Schneider (1978b, S. 35) benennt als Indikator für Leistungsfähigkeit des "Gesamtvermögen". 3)

1) Bürgerlich-rechtlich ist Vermögen die Summe der einer Person zustehenden geldwerten Güter ohne Abzug der Schulden; Vermögensgüter werden mit dem Rechtsinstitut des Eigentums verbunden.

2) GemäB $\S 4$ vStG ist die Bemessungsgrundlage das "Gesamtvermögen"; nach K. Tipke (1991, S. 470) kommt es bei der Vermögensteuer darauf an, "das Steuergut möglichst voll zu erfassen und nicht Vermögensteile, die ebenfalls Ertrags- und Leistungsfähigkeit verkörpern, definitorisch auszuklammern; andererseits müssen Scheinobjekte eliminiert werden."

3) Vom Gesamtvermögen geht auch die amerikanische und die englische Literatur aus, stellvertretend für diese siehe Musgrave/Musgrave 1980, S. $489 \mathrm{ff} .$, und C.T. Sandford 1971b, S. $177 \mathrm{ff}$. 
II. Wenn auch manche der ökonomischen Vermögensdefinitonen mit den rechtswissenschaftlichen insoweit einig gehen, als sie Vermögen mit Eigentum verknüpfen, ${ }^{4)}$ so liegt in wirtschaftlicher Betrachtung gerade im "Besitzmoment" (B. Fux 1927, S. 140) das Wesentliche der personalen Zurechnung und des Umfangs an Vermögen; denn es stellt, wie C. Folkers (1979, S. 266) darlegt, das Eigentum nur eine von mehreren Grundlagen einer "Verfügung" über Vermögen dar. Der Tenor aber liegt auf dem $v$ e $r$ fi $g$ e $n^{5 l}$ bzw. auf der $\mathrm{V}$ e I $\mathrm{f} \ddot{\mathrm{u}} \mathrm{g} \mathrm{n} \mathrm{g} \mathrm{s} \mathrm{m} \mathrm{ch} t ;{ }^{6)}$ das Bestehen von Verfügungsmacht indiziert die begriffliche Bindung des Vermögens an eine Person, ${ }^{7}$ ) jedoch muB der Verfügende nicht der Eigentümer sein. ${ }^{8)}$ Es muB nur eine Person existieren, der Vermögen zuzuordnen und zuzurechnen ist. Im Zusammenhang mit den Personalsteuern ist das allerdings allein die natürliche Person, nicht die juristische. Mit dem Abstellen auf die Verfügungsmacht läßt

4) E. Blumenstein (1926, S. 172): "... privatrechtlich zustehende Sachen und Rechte ...": G. Weisser (1961, S. 163): "für die Dauer gehören"; K.A.Herrmann $(1961$, S. 149): "im Eigentum einer ... Person". Nach R. Herzog (1975, Sp. $514 \mathrm{ff.})$ ist Verfügen ein Bestandteil der Eigentumsdefinition: durch das gesetzte Recht des Eigentums erhält der Mensch das Recht, "über einzelne Sachen oder sonstige Güter seiner Umwelt unter AusschluB aller anderer Menschen $z u$ verfügen"; der Eigentumsbegriff erstreckt sich "auf alle vermögenswerten Rechte". Siehe ferner W. Steinberg 1981a, S. 1535. - $\mathrm{Zu}$ beachten ist auch, daB Vermögen als "Substrat der Verteilungspolitik" stets mit dem Eigentum verbunden sein muB: Es muB einer Person "auf Dauer gehören", so B. Molitor 1979, S. 283.

5) K. Diehl 1933, S. 707 : Vermögen als "Inbegriff von Gütern, die einer Person zu ihrer freien Verfügung stehen." - H. Haller 1978, passim. - Auch H. Fecher (1979, S. 468) trennt zwischen Eigentum und Verfügung. - Siehe auch B. Molitor 1979, S. 285 .

6) D. Schneider $(1978 \mathrm{~b}$, S. 35) setzt Verfügungsgewalt mit wirtschaftlichem Eigentum gleich.

7) Da sowohl natürliche wie juristische Personen Eigentum haben können (anders das Einkommen, das nur physische Personen haben können), unterscheidet die Finanzwissenschaft zwischen der "Vermögensteuer" und der "persönlichen allgemeinen Vermögensteuer", siehe H. Fecher 1979, S. $453 \mathrm{ff}$; entsprechend ist der Vermögensbegriff gebildet.

8) Siehe unsere Ausführungen in $\$ 20$ III zum "wirtschaftlichen Eigentum" des Besitzers und Verfügers von bzw. über Vermögen. 
sich ökonomisch gesehen der breitest mögliche Totalvermögensbegriff verwirklichen.

So ist für den wirtschaftstheoretischen Vermögensbegriff davon auszugehen, daB eine Totalerfassung der Gegenstände bezweckt ist. రffentliche Güter können nicht zum Vermögen der Privaten gehören, weil sie ihnen nicht zurechenbar sind und nicht in jemandes Verfügungsmacht stehen; private Ansprüche auf Renten aus der Sozialversicherung sind zwar zurechenbar, jedoch - ungeachtet des Elgenttums an diesen Ansprüchen - nicht individuell vollständig in die persönliche Verfügungsmacht gegeben, sind weder veräuBerbar, beleihbar noch verpfändbar.

III. Nach unseren obigen Ausführungen zur Abgrenzung zwischen Einkommen und Vermögen kommt es auf die subjektive Entscheidung des Wirtschaftenden an, ob er eine ökonomische GröBe als Vermögen ansieht. Doch gibt es objektive Anhaltspunkte dafür, welche GröBen Vermögen sein können? H. Fecher vermutet, daB es für den operationalen wirtschaftlichen Vermögensbegriff wesentlich darauf ankommt, "wie" jemand 9) "über Wirtschaftsgüter disponiert und welche wirtschaftlichen $\mathrm{ziele}$ er mit ihnen ... verfolgen kann". 10) Wir setzen diesen Gedankengang fort und formulieren: MaBgeblich für die wirtschaftlichen Ziele und für die Dispositionen des Verfügenden sind die $F$ u $n k t \circ n$ e $n$ des Vermögens. Eine ökonomische GröBe für eine Zeitspanne nicht $z u$ konsumieren, sondern $\mathrm{zu}$ konservieren, sie als Vermögen einzuplanen, entscheidet der Verfügende anhand der Funktionen, die Vermögen hat und die allein das Vermögen haben kann. Das gilt analog auch für den Entscheider im unternehmerischen Bereich, der Kapital wegen der ihm anhaftenden Funktionen in den Produktions- und ExpansionsprozeB einsetzt.

9) Fecher geht hier vom Eigentümer aus.

10) Anstelle der Auslassung "..." steht bei Fecher: "nach Meinung des Gesetzgebers "; er bezieht das auf die Bewertungsregeln, die verhindern sollen, daB der Verfügende willkürlich gewählte Werte in seine Vermögensbilanz einsetzt (S. 470). Diese Einschränkung erscheint uns steuerlich intendiert, weshalb wir ihr für einen wirtschaftstheoretischen Begriff keine Bedeutung beilegen.

Siehe zu den Funktionen des Vermögens auch Hedtkamp 1988, S.328. 
Die ökonomisch-sozialen ${ }^{11)}$ Funktionen des Vermögens sind sämtlich zeitorientiert; Vermögen überbrückt die Vergangenheits-GegenwartsZukunfts-zeitspanne. Zwischen dem Erinnerungshorizont und dem Erwartungshorizont hat der Wirtschaftende gelernt loder vertraut er darauf), daB Vermögen ihm die physische und kulturelle Existenz sichert (= Sicherungsfunktion des Vermögens) ${ }^{12)}$, daB Vermögen in Zeiten vorubergehender Not und im Alter den Einkommensausfall wett macht (Vorsorgefunktion), daB es ihm sogar kraft der Erträge, die Vermögen abwirft oder kraft der Erlöse, die es bei der Veräußerung erzielt, eine Hebung des Lebensstandards ermöglicht (Lebensstandardfunktion) ${ }^{13}$ ), daB es ihm letztlich eine Unabhängigkeit vermittelt in der Entscheidung über seinen Arbeitseinsatz ${ }^{14)}$ und über seine Freizeit, und daB auch die Kreditfähigkeit, ${ }^{15}$ ) die Vermögen

11) AuBerökonomische Funktionen, wie etwa die psychische der "Bedürfnisbefriedigung" und des "Ansehens", des "Prestiges" und der nichtökonomischen "Macht" bleiben hier auBer Betracht. Ansonsten betont A. Stobbe (1989, S. 343) ausdrücklich, daB Vermögen für seinen Inhaber "mehrere Funktionen" habe, ökonomische wie auBerökonomische. Siehe bes. H. Haller 1981, S. 47 f.

12) Die sicherheit, die vermögen bietet, betonen auch (und begründen damit zugleich eine besondere Leistungsfähigkeit, die zur Erhebung einer Vermögensteuer neben der Einkommensteuer berechtige) F.R. Mann 1928b, S. 610 f., W. Bickel 1960, s. 266; H. Haller (1978, S. 227 f.) nennt die Funktion der Versorgungssicherheit (1971, S. 42: "Versorgungspotential"). - Nach W. Albers (1960 , S. 21) gewährt Vermögen einen "Rückhalt".

13) Eine solche Funktion, wiewohl nicht so bezeichnet, läBt sich aber - zugleich mit der Sicherheitsfunktion - mit der in der Finanzwissenschaft diskutierten Fundustheorie verbinden; diese basiert auf Ertragsfähigkeit des Vermögens und der Zuverlässigkeit des Ertrages; beides dient sowohl der Existenzsicherung als auch der Lebensstandardverbesserung (hierzu H. Fecher 1979, S. 473). Vgl. auch das Argument des zusätzlichen Einkommens der Vermögenden bei F. Neumark 1961d, S. 393. In der Literatur findet sich auch die Bezelchnung "Einkommensfunktion" des Vermögens; wir gehen hier davon aus, daB diese Funktion aufzuspalten ist in die Vorsorge- und die Lebensstandardfunktion, da das aus Vermögen entspringende zusätzliche Einkommen gerade diesen Vorsorge- und Konsumsteigerungszielen dient.

14) E. Preiser (1964, S. 237) sieht im Vermögensbesitz eine hohe Elastizität des Arbeitsangebots; K. Tiepelmann (1963, S. 40) spricht allgemein von einer Steigerung der wirtschaftlichen Aktivität, die das Vermögen erlaubt; sofern man bei $\mathrm{W}$. Bickel $(1960$, S. $266 \mathrm{f.})$ das Gewicht auf die von ihm so genannten "Voraussetzungen" legt, die Vermögen für die "unternehmerische" Betätigung haben kann, ist dem beizupflichten; ansonsten gehört die unternehmerische Betätigung als Folge von Kapitaleinsatz nicht $z u$ den "Vermögens"-Funktionen.

15) So W. Bickel 1960, S. 266; ferner H. Haller 1978, S. 227 ff. 
ihm gibt, diese Unabhängigkeit16) steigert (Unabhängigkeitsund Kreditfunktion). Diese Funktionen 17) hat sowohl das in der Vergangenheit gebildete oder geerbte als auch das in der Gegenwart und zukunft zu bildende Vermögen. Im Hinblick auf die Funktionen werden auch die sparmotive erklärbar, die ihrerseits sämtlich ohne das zeitmoment nicht denkbar sind. $\mathrm{zu}$ den Funktionen des Kapitals im Allokationsbereich und des Vermögens im Distributionsbereich siehe übersicht 3.5 samt der Legende; s.a. $\$ 13.18$ )

Die auf den entfernteren Zeithorizont zielenden Funktionen (Vorsorgefunktion; in Grenzen auch die Unabhängigkeitsfunktion) sind an solche Gegenstände gebunden, die entweder eine eher längerfristig intendierte Bindung (Investierung) erfordern (wie z.B. die Wertpapiere, Nutzungsverpflichtungen, dauerhafte Gebrauchsgüter, Grundstücke und Gebäude) oder die eine längerfristige Bildungsphase benötigten (wie das Humanvermögen in Form des Ausbildungs- und Erfahrungsstandes). Analog verhält es sich mit dem Kapital. Diese Funktionen kann das Vermögen einzig und allein

16) Nach H. Haller (1978, S. 227 f.) erhöht die Unabhängigkeit den wirtschaftlichen Entscheidungsspielraum und somit auch das Potential an Freizeit und Kredit.

17) C. Folkers (1979 ,S. 267 f.) nennt vier Funktionen, die wir aber, wie darzustellen sein wird, überwiegend als "Eigenschaften" bezeichnen, wohingegen H. Fecher (1979, S. 470) zwei fundamentale Funktionen kennt, die Funktion der Einkommenserzielung und die der Erwartungswertrealisierung in der Vermögensanlage; D. Schneider (1978b, S. 35) wiederum gibt dem Konsumvermögen die Funktion der Bedürfnisbefriedigung, dem Nichtkonsumvermögen die Funktion der Einkommenserzielung. Mithin muB die Funktionenbetrachtung als äuBerst heterogen erkannt werden.

18) Ubersicht 3.5 stellt eine Systematisierung an Kapital- und Vermögensgütern jeglicher Art dar, ohne daB behauptet werden soll, irgendeines der gängigen einzelwirtschaftlichen Rechenwerke der Praxis sei in ihr repräsentiert. Die Systematik enthält die Vermögensgegenstände ohne Ansehung ihrer Herkunft und ohne Rücksicht darauf, ob sie geldliche oder güterliche Erträge abwerfen. Die Vermögensgegenstände sind nach dem vermuteten Grad ihrer Bindungsfristen und Mobilisierungsmöglichkeiten angeordnet; dieser kann auch Anhaltspunkte für den Wertausdruck der Gegenstände geben, wenn man in der Anordnung zugleich den vermuteten Grad der Verwertbarkeit erblicken will und einen funktionierenden Kapitalmarkt für Vermögen unterstellt. Die Ubersicht macht deutlich, daB nicht alle Funktionen von sämtlichen Vermögensgegenständen gleichermaßen erfüllt werden können; so ist auBerdem $z u$ beachten, daB Geldbestände nur insoweit Vermögensfunktionen erfüllen können, wie sie nicht lediglich der Liquiditätsvorsorge dienen. 
Ubersicht 3.5: Kapital-u.Vermögensarten und ihre Funktionen (Legende siehe folgende Seite)

GELD:

+ FORDERUNGEN:

+ BEWEGLICHE SACHEN :

+ UNBEWEG-

LICHE SACHEN:
1. Kassenbestand

Bestānde an Forderungen und Finanzanlagen (teilw. betriebliches Umlaufvermögen)

aus dem Finanzbereich:

2. Geldmarktpapiere, Gut haben bei Kreditinstituten, Schecks, Wechsel

3. Wertpapiere (Aktien, Obligationen)

4. Beteiligungen

5. Ausleihungen

aus dem Leistungsbereich:

6. Warenlieferungen, Lieferantenkredite

7. Dienstleistungen

8. geleistete Anzahlungen

aus dem Verpflichtungsbereich:

9. Rechte auf (einmal. u. wiederkehrende) Nutzungen u. Leistungen (einschl. Versicherungsansprüche d. Nichtunternehmer)

10. aktivische Rechnungsabgrenzungsposten

Bestãnde an Betriebskapital (teils Umlauf-, teils Anlage-Verm.) und Konsumvermögen

aus dem produktionswirtschaftlichen Bereich:

11. Halb- und Fertigfabrikate

12. Roh-, Hilfs- und Betriebsstoffe

Kap.- Verm.Funktionen

13. Maschinen und maschinelle Anlagen

14. Geschäftsausstattung

15. Anlagen im Bau

\begin{tabular}{l|l}
\hline$P$ & $S$ \\
\hline
\end{tabular}

aus dem haushaltswirtschaftlichen Bereich:

16. dauerhafte Konsumgüter (PKW, Möbel, Schmuck, Sammlungen, Elektrogerăte, usw.)

17. nicht dauerhafte Konsumgüter

Bestānde an betrieblichem Anlagekapital und Privatvermōgen

18. Grundstücke und Gebãude

19. Bodenschätze-Abbaurechte p

P

PRA

VI

LU


Erklärung der Symbole in Ubersicht 3.5

$\mathrm{X}=$ indifferent, ka keiner einzelnen Funktion unmittelbar zuzuordnen.

Funktionen des Kapitals:

$\mathrm{P}=$ Produktionsfunktion; Aufrechterhaltung der produktionswirtschaftlichen Betätigung des Unternehmens in kurzer bis mittelfristiger sicht.

$\mathrm{R}=\mathrm{Risikofunktion;} \mathrm{Aufrechterhaltung} \mathrm{der} \mathrm{Existenz} \mathrm{des} \mathrm{Unter-}$ nehmens in mittelfristiger bis langfristiger sicht; Grundlage der Kreditfähigkeit des Unternehmens.

$A=$ Ausdehnungs- oder Expansionsfunktion; produktionswirtschaftliche und marktliche Betriebserweiterung sowie finanzwirtschaftliche Expansion.

$E=$ Einflußfunktion; Einflußnahme (bzw. Beherrschung)auf die Allokationsentscheidungen in anderen Unternehmen zum $\mathrm{Zwecke}$ der Ressourcensicherung, der Produktion, des Absatzes, der Ertragslage usw.

Funktionen des Vermögens:

$S$ = Sicherungsfunktion; Sicherstellung des Existenzniveaus des einzelnen, Sicherstellung der kurz- bis mittelfristigen Versorgung.

$\mathrm{V}$ = Vorsorgefunktion; Sicherstellung der mittel- bis langfristigen Versorgung, insbesondere der sicherung in $\mathrm{N} c t-$ und Krankheitsfällen und der Alterssicherung.

$L=$ Lebensstandard (erhöhungs) funktion; Verbesserung der Versorgung in Gegenwart und Zukunft kraft der Vermögenserträge sowie der Vermögensnutzung und -auflösung.

$U=$ Unabhängigkeitsfunktion und Kreditfähigkeitsfunktion; vermittelt Entscheidungsfreiheit im Einsatz des Faktors Arbeit sowie in der Disponibilität über Vermögenseinsatz und -umschichtung. 
wegen bestimmter "E $i \mathrm{~g}$ e $n \mathrm{~s}$ h a $\mathrm{f} e \mathrm{e}$ ", 19) die es hat, ausüben. Vermögen hat $z$ unächst die Eigenschaft, daB es überhaupt als Substanz existent ist und insoweit sich "verwerten" läBt durch Nutzung, durch Umwandlung in andere Anlageformen sowie

19) Mit der Unterscheidung zwischen $\mathrm{E}$ i g e $\mathrm{n} s \mathrm{c}$ a $\mathrm{f} t$ und $\mathrm{F} u n k t i \circ \mathrm{n}$ des vermögens (es gibt ihn auch in der steuerliteratur, vgl. Hessler, H.D. 1976, S. 2-5, 10) befinden wir uns allerdings in einem Gegensatz $\mathrm{zu}$ Teilen der Lehrmeinung. H. Fecher z.B. schreibt in Ubereinstimmung mit den "zeitgenössischen Lehrmeinungen" (1979, S. 470) dem Vermögen "zwei fundamentale einzelwirtschaftliche Aufgaben" (er nennt sie auch "Funktionen") zu: erstens, "fundiertes Einkommen zu erzielen" (also Erträge), zweitens, "einen bestimmten Erwartungswert bezüglich der Realisierung von zielen zu erreichen, die einen Wechsel der Anlageformen im Laufe der Zeit bedingen" Genau die beiden von Fecher Funktionen genannten Topics nennen wir aber "Eigenschaften" des Vermögens: Kraft der Eigenschaften des Vermögens aus Substanz und Erträgen werden erst Funktionen möglich. Auf S. 469 allerdings nennt Fecher eine Funktion ("Hauptaufgabe") des Vermögens: die "Existenzsicherung" bzw. die Erhöhung der "Realisierungschancen von individuelien Wirtschaftsplänen". Auf S. 469 u. 477 hingegen spricht er ausdrücklich von "Eigenschaften" des Vermögens (hier des Arbeitsvermögens). An wiederum anderer stelle (S. 475) nennt er u.a. die durch Vermögen ermöglichte Versorgungssicherung, die zusätzliche Freizeit und Arbeitszeit sowie die Kreditbasis "Leistungen" des Vermögens. - Auch drei der Funktionen von C. Folkers (1979 ,S. 267 f.), nämlich die "Nutzungsfunktion" (die monetären und realen Erträge aus Vermögen), die "Verwertungsfunktion" (die Transformation und Fungibilität des V.) und die "Ubertragungsfunktion" (der Transfer des V. auf andere Personen) bezeichnen wir als Eigenschaften des Vermögens, die das Vermögen auch dann haben würde, wenn es dem Verfügenden nicht die Dienste einer Existenzsicherung, einer Sicherung der künftigen Versorgung usw. leisten würde. Lediglich Folkers' "Machtfunktion" als ein "zentrales Phänomen der Verfügung über Vermögen" nennen wir eine Funktion in unserem Sinne, die der Unabhängigkeitsfunktion verwandt ist und - sofern sie sich auf den allokativen Bereich bezieht - der Einflubfunktion in unserem Sinne (nach Folkers: "Einwirkungsmöglichkeiten") entspricht (nach unserem Verständnis sind allerdings allokative Funktionen des Kapitals $z u$ trennen von den distributiven Funktionen des Vermögens, so daB die Einwirkung auf die Entscheidungen der "Manager" - Folkers - nicht eine Funktion des Vermögens sein kann). - Siehe bes. \$ 12 I c. 
durch Auflösung bzw. VeräuBerung. Zweitens hat Vermögen die Eigenschaft, daB es sich marktlich als Produktionsfaktor einsetzen läBt und demnach Ertragskraft besitzt. Beide Eigenschaften bilden keineswegs die Voraussetzungen für den Vermögensbegriff, etwa insoweit, als sie notwendig zusammenwirken müBten, um von vermögen sprechen zu können. ${ }^{20)}$ Eigenschaften, insbesondere aber die für die zweckbezogenen Entscheidungen und Verfügungen maBgeblichen Funktionen des Vermögens machen die "Bedeutung", den "Inhalt" des Vermögens - B e g $r$ i f $s$ aus, wohingegen der "Umfang" des Begriffs ${ }^{21)}$ durch die Gesamtmenge aller jener Gegenstände, die den Begriff vollständig $z u$ beschreiben in der Lage sind und dieselbe Bedeutung haben, bestimnt wird.

Zum wirtschaftstheoretischen Totalbegriff des Vermögens zählen somit alle jene Gegenstände, die dem Verfügenden wenigstens eine der zeitorientierten Funktionen leisten. Das in Ubersicht 3.5 nach Zeile 23 ausgewiesene Roh-Vermögen ist zunächst ein individualistischer und wegen der Entscheidungsabhängigkeit auch voluntaristischer Vermögensbegriff, der nunmehr, im Hinblick auf seine Verwendung im ökonomischen und rechenhaften Bereich in einem zweiten Schritt der Begriffsbestimmung noch $\mathrm{zu}$ objektivieren ist. Die Abhängigkeit des Vermögensbegriffs von der Entscheidung des Individuums und die unterschiedlichen Funktionen, die einerseits das Kapital, andererseits das Vermögen haben, lassen zugleich die allokativ-distributive Abgrenzungsproblematik auch in Ubersicht 3.5 hervortreten. In dem folgenden zweiten Bestimmungsschritt des Vermögensbegriffs wird auf die allokativen Funktionen des Kapitals nicht mehr eingegangen. ${ }^{22}$ )

20) H. Fecher 1979, S. 469: "Für keine Vermögensart, die unter den traditionellen Vermögensbegriff subsumiert zu werden pflegt, bildet die Höhe der Verzinsung ein begriffliches Element."

21) Zum Unterschied von Inhalt und Umfang eines Begriffs siehe H. Seiffert $1975 a$, S. 42 , sowie unsere Ausführungen in $\S 12$ VI: "Die analytische Einkommens- und Vermögensdefinition und das Verhältnis der Begriffstheorie $\mathrm{zu}$ weitergehenden Theorien".

22) Der als "Brutto-Kapital" ausgewiesene Begriff in Ubersicht 3.5 ist keineswegs der Kapitalbegriff aus der Bilanzlehre; auch die Unternehmungen stellen ja "Vermögensübersichten" auf, die allokativ orientiert bewertete Gegenstände enthalten. Symboli(Forts. siehe folgende Seite) 
IV. Sowohl die steuerlichen als auch die ökonomischen Vermögensdefinitionen sprechen von bewerteten oder doch zumindest von b e w e $r$ b a $r$ e $n$ Gütern. ${ }^{23)}$ Erst der Totalumfang des Vermögensbegriffs bei gleichzeitigem Geldausdruck wäre dem "einheitlichen, modernen Vermögensbegriff" von B. Moll (1911, S. 87) adäquat. Aus dem Geldausdruckserfordernis geht zweierlei hervor, nämlich erstens, daB das so präsentierte Vermögen (wie das Einkommen auch) einen summenbegriff darstellt, und zweitens, daB es notwendig ist, aus dem Vermögen, das ja als "ökonomische" GröBe verstanden werden will, all jene Gegenstände auszugrenzen, die nicht bewertbar sind. Die begrifflich-praktische Notwendigkeit des Zurechenbaren und die aus dem Funktionen-Konzept folgende logisch-begriffliche Notwendigkeit der Totalität liegen miteinander im Konflikt. Dieser ist zugunsten des ersteren Erfordernisses $\mathrm{zu}$ entscheiden, denn sowohl das volkswirtschaftliche Rechenwerk (siehe A. Stobbe 1989, S. 44,57 u. passim) als auch die verteilungstheoretischen Vergleichsanalysen verlangen die Rechenhaftigkeit des Vermögensbegriffs. Dort, wo Vermögensgüter keinen Preis am Markte haben, sondern ihr Wert erst nach bestimmten Rechenoperationen festgelegt werden muB, stellt sich das eigentliche "Bewertungs"-problem ein. ${ }^{24}$ )

Ungeachtet der möglicherweise immer vorhandenen Funktionen sind einige Vermögensgüter allein wegen der fehlenden Bewertbarkeit,

Forts. Fn. 22:

siert der bilanzielle Begriff die finanzielle Investierung und zudem eine NettogröBe, so ist der hier ausgewiesene Betrag eln bewerteter, nichtfiktiver und nichtfinanzieller, von dem überdies alle Wertminderungen bereits abgezogen sind. Ferner handelt es sich um eine BruttogröBe; sie ist insofern auch nicht etwa mit Elgenkapital gleichzusetzen. Der Betrag ist vielmehr die gröBtmögliche summe der Wirtschaftsgüter, die unter volkswirtschaftlichem Aspekt Kapital in breitestem Verständnis sind und demnach Kapitalfunktionen haben.

23) w. Lotz 1931, s. 525: "... Geldwert ..."; G. Weisser 1961, S. 163: "... in Geld schätzbaren Güter ...", "d.h. es ist nicht gefordert, daB sie tatsächlich so geschätzt" werden; R. Liefmann (nach H. Fecher 1979, S. 466): "Geldveranschlagung aller Güter"; D. Schnelder 1978b, S. 35: "Geldausdruck".

24) auf diesen wird erst im zusammenhang mit der steuerlichen Problematik des Vermöqensbegriffs eingegangen werden, siehe $\$ \$ 19,24$ und insbes. 27.

24a)Hedtkamp (1988, S. 339) hält die Verfügbarkeit über Human capital für gegeben, soweit es auf dem Arbeitsmarkt angeboten wird; als Vermögen werde es von den einzelnen angesehen, weil Ausbildung als Investition gilt. 
andere zusätzlich oder einzig wegen nicht vorhandener personaler $\mathrm{V}$ e $\mathrm{r} f \mathrm{u} \mathrm{g} b$ a $\mathrm{r}$ e $i \mathrm{t}$ auszugrenzen; so könnten gewi $\mathrm{B}$ Ansprüche an die Sozialversicherungsträger bewertet werden, doch sind sie nicht verfügbar; andererseits sind die Gegenstände des öffentlichen Vermögens weder für den einzelnen verfügbar noch in der Mehrzahl der Fälle bewertbar. Gegenstände, die völlig "abgewertet" sind (etwa nicht dauerhafte Konsumgüter, nicht einbringbare Forderungen) sind ökonomisch keine Güter mehr. Güter, die weder nutzbar noch beleihbar noch $z u$ veräuBern sind, lassen sich nicht bewerten. $24 a$ )

Daraus folgt, daB vom Grundsätzlichen her heurteilt sowohl Konsumgüter als auch Humanvermögen (im Sinne des Arbeitsvermögens und des geistigen Eigentums) zwar zunächst zum Kreis der Vermögensgüter $\mathrm{zu} z$ ählen sind 25) - wie überhaupt "intangibles",26) -, daß sich aber ihre Ausgrenzung nach der Bewertbarkeit und Verfügbarkeit richtet. ${ }^{27)}$

Auch für das Arbeitsvermögen, das grundsätzlich die Funktionen der Existenzsicherung, der Vorsorgeoewährleistung sowie der Lebensstandarderhöhung erfüllen kann, ${ }^{28}$ ) sind die beiden Eigenschaften der "Substanz" und der "Ertragskraft" $z u$ würdigen: Soweit es Erträge abwirft, lieBe sich eine Bewertung wohl durchführen, wenn auch unter rigorosen Annahmen bei der Berechnung der Lebenszeiteinkommen und der Verzinsung. Was aber die Substanz des Arbeitsvermögens betrifft, so ist es unter dem allokativen Aspekt des Einsatzes als Produktionsfaktor allenfalls verfügbar, nicht jedoch

25) So z.B. auch H. Fecher 1979, S. $467 \mathrm{ff.}$, und B. Molitor 1979, S. 283; ferner Hedtkamp 1988, S. 339.

26) Musgrave/Musgrave 1980, S. 489: "Intangible as well as tangible and nonearning as well as earning assets should be included." Angesichts dieser $z$ unächst breiten Formulierung überrascht es allerdings, unter dem Immateriellen (intangibles) auf S. $490 \mathrm{f}$. als Beispiele nur die "private claims" und die "claims against government" zu finden.

27) Vgl. C.T. Sandford, 1971b, S. 177, der diskutiert, inwieweit "the capitalized value of future earnings" in den Vermögensbegriff einzuschließen ist.

28) DaB die "Unabhängigkeitsfunktion" vom Arbeitsvermögen nicht erfüllt wird, braucht unter Hinweis auf die Arbeitslosigkeit auch hochqualifizierter Fachkräfte nicht eigens bewiesen $\mathrm{zu}$ werden. Anders als die Sachvermögensbesitzer können die Arbeitsvermögensbesitzer weder ihr Vermögen aufzehren noch beleihen oder veräuBern.

Fn. 24a) siehe vorige seite. 
unter dem distributiven Aspekt. Hier ist nämlich entscheidend, ob und inwieweit der einzelne über dieses sein Vermögen Verfügungsgewalt hat, $d . h$. ob er es grundsätzlich wie Sachvermögen auch verzehren, beleihen oder veräuBern - evtl. übertragen kann. Die Diskussion hat sich hier an der Ubertragbarkeit ent$z$ ündet, die an die Stelle der zweifellos nicht vorhandenen Veraủerbarkeit des Arbeitsvermögens getreten ist.

Die tbertragbarkeit des Arbeitsvermögens wird unter dem Hinweis auf die auch beim Sachvermögen übliche Unterscheidung zwischen dem rechtlichen und dem wirtschaftlichen Eigentum für möglich gehalten: Nicht das mit der Person unlösbar verbundene rechtliche Eigentum am Arbeitsvermögen, sondern das wirtschaftliche lasse sich auf andere Personen übertragen, so daB das Arbeitsvermögen nunmehr, weil übertragbar, ein selbständiger Vermögensgegenstand sei, mithin zum Gesamtvermögen zähle. ${ }^{29)}$

Bei einer solchen Argumentation wird jedoch übersehen, daB zwar die Verfügungsgewalt übertragen wird, aber nicht jene über das Arbeits - V e r m ö g e $\mathrm{n}$, sondern die Verfügungsgewalt über den produktionswirtschaftlichen Einsatz des $F$ a $k$ t $r s$ "Arbeit" nach Ort, Zeit und Intensität. Der nunmehr Berechtigte verfügt über eine - evtl. berechenbar zu machende - ökonomische GröBe im Rahmen seines Unternehmens, nicht im Rahmen der privaten Sphäre; er verfügt über ein $K$ a $p i t$ a 1 - Gut. Konsequenterweise müBte dieses ihm auch wirtschaftlich zugerechnet werden (mit allen Auswirkungen auf die Vermögens- bzw. Kapitalbesteuerung). Wird die . Verfügbarkeit anstelle des Eigentums zum Kriterium für Vermögen und den Vermögensbegriff gemacht, so ist Arbeitsvermögen zwar rechenbar,aber nicht dem Unternehmer zurechenbar, da es - distributiv betrachtet - an der personalen vermögensspezifischen Verfügungsgewalt fehlt, da vielmehr - allokativ betrachtet - allenfalls

$29)$ H. Fecher (1979, S. 468) setzt insoweit das Arbeitsvermögen mit dem Sachvermögen gleich und "erweitert" (S. 469) solchermaßen zunächst den traditionellen Vermögensbegriff, scheint dann aber unter Hinweis auf die Existenzsicherungsfunktion und auf die Unabhängigkeitsfunktion (die er als nicht vollständig vorhanden ansieht) sowie unter Hinweis auf die "Eigenschaft" (sic! S. 469 u. 477) des Vermögens, innerhalb des Anlageportefeuilles nur in bestimmten Grenzen austauschbar $z u$ sein, den Vermögenscharakter der Arbeitskraft zu verneinen; auch unter dem Aspekt der Besteuerung nach der Leistungsfähigkeit lehnt er später die Besteuerung des Arbeitsvermögens ab, S. 477 . 
eine kapitalspezifische Verfügungsgewalt besteht, die aber nicht mehr unter dem distributiven Aspekt zugerechnet werden kann.

Der zweite Schritt der Bestimmung des persönlichen Vermögensbegriffs endet demnach mit einer Ausgrenzung jener Gegenstände aus dem Totalumfang, die nicht bewertbar und/oder nicht verfügbar sind. Vermögen ist somit wirtschaftstheoretisch die summe der Werte solcher ökonomischer Größen (Güter/Gegenstände), über die eine Person Verfügungsgewalt hat und die ihr nach ihrer individuellen Entscheidung persönlich präferierte Vermögensfunktionen leisten.

\section{V. zusammentassung:}

V. Wir fassen die Ergebnisse des 3. Kapitels wie folgt zusammen: Die Definitionen des Einkommens in der Literatur stellen teilweise recht eindeutig auf die Verfügungsgewalt oder die Verfügungsmacht ab: Liegt Verfügbarkeit vor, soll grundsätzlich von Einkommen gesprochen werden können. Weithin sind aber die Einkommensdefinitionen von steuerlichen Interessen geprägt, die wirtschaftstheoretisch jedoch keine Rolle zu spielen haben. Aus der Verfürbarkeit und der Trennung in das wirtschaftstheoretische und das steuerliche Erkenntnisinteresse gilt es, die Konsequenzen zu ziehen. Es kann sowohl über Einkommen aus der produktionswirtschaftlichen Betätigung als auch aus Vermögenszugang wie -nutzung sowie schließlich aus den Transfers "verfügt" werden. Wirtschaftstheoretisch ergibt sich die Notwendigkeit, als Einkommen ein Totaleinkommen zu definieren, das frei zu halten ist von der zweckmäBigkeit oder UnzweckmäBigkeit seiner totalen steuerlichen Erfassung und Belastung. Doch weder die enge Quellentheorie noch die breite Reinvermögenszugangstheorie postulieren ein lückenloses Totaleinkommen, weil sie im Kapitalerhaltungsinteresse befangen sind. Unbestritten ist die Reinvermögenszugangstheorie die theoretisch geschlossenere, doch sie bleibt in erster Linie eine steuerliche Theorie. Mit ihr aber wird ein wesentliches konzept der wirtschaftstheoretischen Fragestellung eröffnet, wenngleich sich nunmehr die Notwendigkeit einstellt, zu definieren, was vermögen ist und wie es $z u$ bewerten ist. 
Auch hier ergibt die Analyse der Literatur keine in jedem Falle eindeutige Aussage. Weder der Rückgriff auf Statik- und Dynamikvorstellungen noch die Periodisierung des Zugangs an ökonomischen Größen bzw. ihre Verwendung erlauben, das Einkommen vom Vermögen begrifflich abzugrenzen. Wesentlich mit dem Vermögensbegriff verbunden ist aber das zeitphänomen, und zwar fungiert Vermögen als Zeitüberbrückung in der Lebensführung. Elnerseits hat der Wirtschaftende aus der Erfahrung u. Erinnerung heraus geiernt, andererseits erwartet er für die zukunft, daß Vermögen ihm bestimmte Funktionen erfüllt, nämlich die der sicherung der gegenwärtigen Existenz, der Vorsorge, der Aufrechterhaltung und Steigerung des Lebensstandards sowie der Unabhängigkeit und Kreditfähigkeit. Für die theoretisch wie steuerlich wichtige Abgrenzung zwischen Einkommen und Vermögen stellt sich nun die Entscheidung des einzelnen heraus: Vermögen ist jene ökonomische Größe im distributiven Bereich des Wirtschaftens, die jemand kraft der ihm zustehenden Verfügungsmacht entscheidet, nicht zu konsumieren. Diese Verwendungsentscheidung trifft er mit Blick auf die ökonomisch-sozialen Funktionen, die ihm das vermögen erfüllt. Wirtschaftstheoretisch folgt auch für das Vermögen wie für das Einkommen das Totalkonzept. Der Uberblick über die Definitionen in der Literatur sowie die Geltung des Totalkonzeptes sind die wesentlichen Vorarbeiten für die Erarbeitung eines eigenen "Kriterien-Ansatzes" zur begrifflichen Bestimmung von Einiommen lund Vermögen in wirtschaftstheoretischer sicht. 
4. Kapite1=

Der "Kriterien"-Ansatz einer begrifflichen Theorie fir Einkommen und vermógen

S 11 Die "Verfigbarkeit" ökonomischer Größen als das begriffsbildende Kriterium

I. Vorbemerkung: Kennzeichen und Reichweite des Ansatzes

II. Voraussetzungen der Verfügbarkeit

1. Wirtschaftliches und rechtliches Verfügen

2. Rechenbarkeit und personale Zuordnung

III. Die personalen Elemente der Verfüg-

barkeit: Verfügungsmacht

1. Institutionen der Verfügungsmacht: Individuen und Haushalte

2. Inhalte der Verfügungsmacht

3. Umfang der Verfügungsmacht und Ziel der Verfügungen

IV. Die gegenständlichen Elemente der

Verfügbarkeit: Verfügen über Totalgrößer. 171

1. Das "Quellenphänomen" 171

2. Die "Brutto-Erfassung" 174

3. Die "Zurechnung" 176

4. Der Wertzuwachs 177

$\because$ Ergebnis: Rationalität und Theorie-

1. "Fazit 1": Der Kriterien-Ansatz als Konzept der Rationalität: Verfügbarkeit, Entscheidung und Zugangsregel

2. "Fazit 2": Die analytische Einkommensund Vermögensdefinitionen sowie das Verhältnis der Begriffstheorie zu weltergehenden Theorien.

I. Der Kriterien-Ansatz für die wirtschaftstheoretischen Definitionen geht davon aus, die Kriterien für Einkommen und Vermögen unbeeinfluBt von den Absichten der Besteuerung $z u$ finden. Es gilt, die $w i t s c h$ a $t s t h$ e $t$ e $t i s c h e$ Begriffsbestimmung von der steuerlichen zu trennen. ${ }^{1)}$ Nur die steuerlichen

1) F. Neumark 1961b, S. $34 \mathrm{f} .:$ "Es versteht sich, daB wie jeder andere so auch der Begriff des Einkommens nach logischen und ZweckmäBigkeitsgesichtspunkten $\mathrm{zu}$ bilden ist und daB schon im Hinblick auf die Verschiedenartigkeit der Bedürfnisse, denen sie dienen sollen, die individualwirtschaftlichen, volkswirtschaftlichen und fiskalischen Einkommensbegriffe nicht identisch sein kwinzentessler and Anneliese Hessler-Otte- 978-3-631-75239-5 
Einkommens - und Vermögensbegriffe können als die Indikatoren der Leistungsfähigkeit gelten, da die Besteuerung nach der Leistungsfähigkeit eine "Handlungsnorm" und kein Erkenntnisprinzip ist.

Der wirtschaftstheoretische Begriff soll inhaltlich und umfangsmäBig beschreiben, was als ein Ergebnis aktiver u $n$ d passiver Teilnahme am Wirtschaften bei einem Individuum oder einem privaten Haushalt in ökonomischen GröBen vorzufinden ist, bevor die MaBnahmen der verteilenden und umverteilenden steuerpolitik einsetzen, um Einkommen und Vermögen nach den politischen zielvorstellungen $\mathrm{zu}$ verändern. ${ }^{2)}$

Die Reichweite einer Theorie vom Begriff ist - sachlich begrüdet begrenzt; Ansätze zu Theorien etwa, die aus der Ausstattung mit Einkommen und Vermögen Hypothesen über das Verhalten der wirtschaftenden (Konsum-, Spar-, Investitionsverhalten) entwickeln und daran sich knüpfende allokative und distributive wirkungen aufzeigen wollen, gehen über das hier gewählte Erklärungsziel hinaus. Gesucht wird ein theoretischer Ansatz, der zu erklären und abzugrenzen erlaubt, was Umfang und Inhalt von Einkommen und Vermögen einer Person ist, der für wirtschafts-theoretisch-analytische Zwecke brauchbar ist und dadurch für die finanzwissenschaftlichen Absichten als Ausgangs- und Beurteilungspunkt gelten kann (siehe \$7III).

Als in diesem Sinne verwendbar wird hier ein "Kriterien-Ansatz" entwickelt. Kriterium ist verstanden als Merkmal im Sinne von "unterscheidendem Kennzeichen". Die Unterscheidung des Einkommens vom Extrag, des Vermögens vom Kapital ist oben anhand der Abgrenzung des allokativen Bereichs der రkonomie vom distributiven vorgenommen worden; die Unterscheidung des Einkommens vom Vermögen wurde an der Verwendungsentscheidung des wirtschaftenden festgemacht. Vorliegend sind $\mathrm{zu}$ unterscheiden:

- die $z$ u r e c h e n b a r e $\mathrm{n}$ von den nicht zurechenbaren Gegenständen,

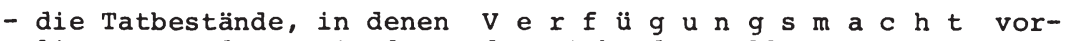
liegt, von denen, in denen das nicht der Fall ist,

2) Wir erinnern uns daran, daB aber die "vorsteuerliche" Einkommens- und Vermögenssituation beim einzelnen wegen der Interdependenzen $z$ wischen dem privaten und öffentlichen Sektor der Wirtschaft hereitss präfomientefitstssler-Otte - 978-3-631-75239-5 
- die Institutionen, in denen Verfügungs - $\mathrm{E} n \mathrm{t} \mathrm{s} \mathrm{c}$ h e i d u n $g$ e $n$ im distributiven Bereich getroffen werden von jenen, die im allokativen Bereich angesiedelt sind, und

- die $\quad \mathrm{g}$ e $g$ e $n s t \ddot{a} n d e$, über die verfügt werden kann von solchen, über die nicht verfügt werden kann.

Wenn hier die Bestimmung des Einkommens- und Vermögensbegriffes nach einem Rriterien-Ansatz erfolgt, so findet dieses Vorgehen in der Literatur, wie sich ergeben hat, vielfache stütze und teilweise auch eine ähnliche Benennung; z.B. entwickelt F. Neumark (1961b, S. 32 und passim) zu der Frage, was den Inhalt des Einkommens bestimme, zwei "Kriterien", nämlich die Teilnahme der Bezieher von Einkommen an der Bildung des Sozialprodukts und zusätzlich - soweit das erste Kriterium zutrifft - das Vorliegen eines effektiven $\mathrm{Z}$ uwachses an ökonomischer Verfügungsmacht des Empfängers von Einkommen. Wir glauben begründet $z u$ haben, daB das erste Kriterium nicht gelten kann, greifen aber das zweite Kriterium auf und folgen dem Gedanken, daB methodisch eine Formulierung von Kriterien für eine Inhaltsbestimmung die korrekte Vorgehensweise ist. Dies um so lieber, als das auch rechtswissenschaftlichen Erfordernissen der Einkommens- und Vermögensdefinition entspricht.

Kriterien sollen der intersubjektiven überprüfbarkeit zugänglich sein, weshalb der kriterienansatz nicht auf unmeßbare "Qualitäten" der Faktoren und Verfügungsgegenstände sowie bloßer "Möglichkeiten" ausgerichtet ist, sondern an dem meßbaren $\mathrm{E} r \mathrm{~g}$ e b $\mathrm{n} s$ des zugangs ökonomischer Größen.

Was die wissenschaftstheoretische $M$ e $t h \circ d i k$ der Verwendung von Kriterien im Definitionszusammenhang angeht, so folgen wir T.S. Kuhn (1978) wie auch H. Seiffert (1975a). Nach Kuhn (S. 330 ff. u. $345 \mathrm{ff.l}$ müssen zur eindeutigen Beurteilung spezifischer Situationen und Begriffe mindestens zwei unabhängige Kriterien vorhanden sein, die sich miteinander verbinden lassen. Ebenfalls verlangt Seiffert (S. 33) für eine Definition das Vorhandensein zweier (bereits bekannter) Termini, um den noch unbekannten beschreiben zu können. Im Zusammenhang mit der "intersubjektiven Uberprüfbarkeit" ist die verwendung von Kriterien das typische wissenschaftliche und theoretische Vorgehen (H. Seiffert 1975a, S. 188f.). Ein "Satz von Kriterien" identifiziert und definiert soinit einen Ausdruck bzw. Terminus und liefert die "seine Anwendung regelnden notwendigen und hinreichenden Bedingungen" (Kuhn 1978, S. 
Kriterien der Einkommens- und Vermögensbegriffe sind:

- die "Verfügbarkeit" über ökonomische Größen als conditio sine qua non;

- die "Zurechenbarkeit" als Voraussetzung für die Verfügbarkeit und

- die "Konsumorientierung" als beschreibendes, nicht als begriffsbestimmendes (eher als ein begriffserklärendes) Element der Definition.

II. Das Problem der $V$ e $r$ f $u g$ b $r k$ e $i t$ ist unter den folgenden drei Aspekten $\mathrm{zu}$ sehen: Sie hat erstens zur Voraussetzung, daß die ökonomischen Größen, über die rechtlich verfügt werden darf und wirtschaftlich verfügt werden soll, rechenbar sind und sich einer Person zuordnen lassen; es ist zweitens $\mathrm{zu}$ klären, welche Institution, der einzelne bzw. der Privathaushalt oder der Betrieb bzw. die Unternehmung, verfügt (III); schlieblich ist drittens der Gegenstand, über den verfügt wird, als der Inhalt der Verfügbarkeit $\mathrm{zu}$ beschreiben (IV).

1. Verfügbarkeit richtet sich auf Verfügen über ökonomische GröBen - ist demnach an Verfügungsobjekten orientiert - und setzt deren Rechenhaftigkeit wie auch zuordnung auf die verfügende Person voraus. Verfügen ist $0 \mathrm{k} \circ \mathrm{n} \circ \mathrm{m} i \mathrm{~s} \mathrm{c}$ e $\mathrm{s} n \mathrm{~d} \quad \mathrm{e} c \mathrm{~h} t$ 1 i $c h$ e $s$ Verfügen gleichermaBen. Verfügen muB innerhalb des gesellschaftlichen systems geordnet und ausgeübt werden; in einem dezentralen gemischtwirtschaftlichen system mit privateigentum am Konsumtiv- und Produktivvermögen lassen sich grundsätzlich einerseits Verfügungen treffen über die eigene Person und thre ökonomischen Leistungen wie andererseits über Sachvermögen aus dem Gedanken des Eigentums im wirtschaftlichen und rechtlichen sinne. ${ }^{3)}$ Unter die erstere Verfügungsart hat man auch Verfügungen $z u$ zäh-

3) So C. Folkers 1979, S. 266, der hinsichtlich des Sachvermögens noch weiter spezifiziert: Verfügungen über Sachvermögen aus juristischem Eigentum ohne einen (vollen) Anspruch im wirtschaftlichen Sinn; Verfügungen über Sachvermögen im fremden, nicht zuletzt öffentlichen Eigentum aufgrund unterschiedlicher Nutzungsrechte und schlieblich Verfügungen über Forderungen oder forderungswerte Rechte. 
len über das Einkommen; so läBt sich schlieblich folgern, daB die für die literarischen Einkommensdefinitionen oben als konstitutiv erkannte "Zugangsregel"4) in ihrem rechtlichen und wirtschaftlichen Umfang von "Verfügungen" erfaBt wird. In dem hier in Rede stehenden $\mathrm{Z} u$ ammenhang ist ökonomisches Verfügen "Entscheidungen treffen" über die Erzielung und Verwendung von Einkommen, über die Bildung und Verwendung von Vermögen. ${ }^{5)}$ Rechtlich ist die Verfügung ein in das Belieben des einzelnen gestelltes (im Hinblick auf den Tatbestand einseitiges, zudem vom sog. Verpflichtungsgeschäft abstrahiertes) Rechtsgeschäft, 6) das unmittelbar auf Sachen und Rechte einwirkt, also z.B. als Ubertragung eines Gegenstandes, als Belastung eines Grundstücks, als Veränderung eines Rechts in seinem Inhalt usw. 7) Diese privatrechtliche E1genschaft der Verfügung hat eine verfassungsrechtliche Entsprechung: "Die freie Disposition des eigenen Lebensstandards ist Teil der freien Entfaltung der Persönlichkeit." ${ }^{8}$ ) Sie betrifft

4) Als "Zugangsregel" hatten wir die in den Definitionen zum Ausdruck kommenden Erfordernisse bezeichnet, daB es sich beim Einkommen (1) um eine ö $\mathrm{k} \circ \mathrm{n} \circ \mathrm{m} \mathrm{i} \mathrm{s} \mathrm{che} \mathrm{G} \mathrm{r} \ddot{\mathrm{B}} \mathrm{B}$ e handelt und $d a B$ diese (2) einer $P$ e $r$ s o $n$ zugeht; Interpretationsunterschiede waren allerdings hinsichtlich der Art und der Quelle des Zugangs in den Definitionen enthalten. $\ddot{y} 9$ II.

5) Siehe die breiten Verfügungsbegriffe im Carter Report 1966, vol. 1, "discretionary economic power" und "comprehensive tax base" (S. 5 u. 9 f.; vol. 3, S. 32 ff.). - Siehe ferner W.W. Hewett 1925, S. 22 f. ("available for disposition"); K. Diehl 1933, S. 707 ("zur freien Verfügung"); F. Neumark 1947 ("ökonomische Verfügungsmacht"); G. Weisser 1961, S. 163 ("groBe" und "geringe Verfügungsmacht"); C. Folkers 1979, S. 266 ("verfügen können"), G.Heidinger (1982,s.269, wirtsch.Verfügbarkeit).

6) "Unter Verfügung ist dabei jedes Rechtsgeschäft zu verstehen, durch das der Berechtigte entweder die Rechtszuständigkeit oder den Rechtsinhalt oder beides ändert", K. Larenz, Lehrbuch des Schuldrechts, Bd. I: Allgemeiner Teil, 13. A. München 1982, S. 518.

7) రkonomisch allerdings hat die Verfügung auch bestimmte Eigenschaften, die eine Tathandlung (einen Realakt) auszeichnet, in der Bedeutung, etwas mit einem Gegenstand, mit dem man rechtlich alles nach Belieben tun darf, tatsächlich auch $z u$ können, d.h. praktisch nicht gehindert $z u$ sein, gegenständlich dazu in der Lage zu sein; so kann man Gegenstände verbinden, verarbeiten, vermischen (die Rechtsfolgen einmal beiseite gelassen), jedoch über öffentliche Güter nicht nach Belieben verfügen, sie allenfalls in Anspruch nehmen. Das ökonomische Verfügen über private Güter gleicht einem Realakt.

8) G.B. Krause-AblaB 1971, S. 207; er leitet die freie Disposition aus Art. 2 Abs. 1 GG ab. 
Einkommen und Vermögen: das Einkommen hinsichtlich sämtlicher Bestandteile wie der Sacheinkommen, der VeräuBerungserlöse, der Transfers (nicht jedoch hinsichtlich der Sollerträge 9), das Vermögen auch hinsichtlich der Vermögenswertsteigerungen, da hier frele Disposition in jedem Falle möglich ist. Sie besteht uneingeschränkt, soweit Einkommen und Vermögen rechtmäBig erlangt wurden und soweit vertragliche Abmachungen nicht entgegenstehen. Sie besteht weiterhin nur dann ohne Einschränkung, wenn nicht gesetzliche bzw. hoheitliche Regelungen entgegenstehen. ${ }^{10)}$ An solchen Regelungen, insbesondere auch an denen der Steuererhebung, findet die freie Verfügbarkeit des Einkommens und Vermögens ihre Grenze. 11)

2. $z$ u $\circ \mathrm{r}$ d $\mathrm{n} n \mathrm{~g}$ bzw. $\mathrm{z}$ u $\mathrm{r}$ e $\mathrm{chn} \mathrm{n} \mathrm{n} g$ bedeutet rechtlich die Festlegung, in wessen Verfügungs- und Herrschaftsmacht der Zugang an ökonomischen Größen fällt. Man kann das den "a d $\mathrm{p}$ e $\mathrm{r}$ s $\mathrm{n}$ a $\mathrm{m}$ - I $\mathrm{n} \mathrm{h}$ a $1 \mathrm{t}$ " des Zugangs nennen. రkonomisch hat die Zuordnung des Einkommens bzw. Vermögens außer dem "ad personam-Inhalt" auch noch die Bedeutung der Zurechenbarkeit, der $R$ e $c h$ e $n h$ a $f t i g$ e $i t$ ökonomischer GröBen. Das $\mathrm{guzu}$ ordnende muB demnach in einem allgemeinen Nominator, in Geld auszudrücken sein. ${ }^{12)}$ zum Kreis der zuzuordnenden ökonomischen GröBen

9) Denn hierbei handelt es sich um zukunftserträge, J. Mitschke 1976, S. 164; sie sind gegenwärtig nicht erzielt und nicht verfügbar.

10) Es existiert schon allein aus rechtlichen Gründen ein Unterschied in der freien Verfügung zwischen Gewinn- und Lohneinkunftsbeziehern. Dem letzteren steht eine um die Steuer geringere Dispositionsmasse zur Verfügung. "In Höhe des Lohnsteuerabzugs ( $\$ 38$ Abs. 1 Satz 1 EStG) wird dem Lohnsteuerpflichtigen seine gegen den Arbeitgeber bestehende Lohnforderung durch den Abzug entzogen. Es steht dem Lohnsteuerpflichtigen nicht frei, die Lohnsteuer aus anderem Vermögensgegenstand zu erbringen. Damit wird in das Eigentum des Lohnsteuerpflichtigen eingegriffen", G.B. Krause-AblaB 1971, S. 200.

11) "Die Verfügungsmacht erscheint der heutigen Rechtslehre als normaler Bestandteil jedes Vermögensrechts, der dem Berechtigten immer dann zukommt, wenn er ihm nicht ausnahmsweise ... entzogen ist", K. Larenz, Lehrbuch des Schuldrechts, Bd. I: Allgemeiner Teil, 13. A., München 1982, S. 518.

12) So die Einkommensdefinitionen nach dem Reinvermögenszugangskonzept von Schanz, Haig, Simons und sämtliche neueren; so insbe-

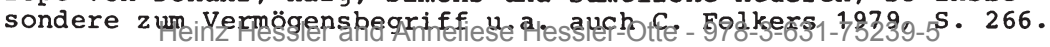


gehört neben dem Geldeinkommen und dem in Geldeinheiten ausgedrückten Vermögen alles, was einer Bewertung in Geld zugänglich ist. ${ }^{13)}$ Der Geldausdruck ist die notwendige Bedingung der Zurechnung, da nach unserer Eingangsdefinition für ökonomische GröBen (siehe $\S 8$ ) metaökonomische GröBen auszuschließen sind. Für die Verfügbarkeit ist die Zuordnung der rechenbaren GröBen die Voraussetzung; da der Einkommensbegriff eine numerische GröBe ist, kann nicht Einkommen sein, was sich nicht in Geld ausdrücken läBt, so unbestritten auch das Nichtberechenbare als ein ökonomisches "Potential" angesehen werden kann.

III. Im Rahmen dieser rechtlichen und wirtschaftlichen "Objektivierung" ist die sozialökonomische Interpretation der Verfügbarkeit zu konkretisieren, sind ihre persönlichen Elemente darzustellen. Diese zeigen sich einerseits darin, daB eine Person durch Einkommen und Vermögen $v$ e $r$ ü $g$ u $n g s m a c h t$ gewinnt; andererseits wird über ökonomische GröBen auch in nicht-personalen $I n s t i t u t i \circ n$ e $n$ (Betrieben) verfügt, so daB $z u$ prüfen ist, ob auch diesen Verfügungsmacht über Einkommen und Vermögen zuzuschreiben ist.

1. Zum institutionellen Problem, ob also die hier relevanten Entscheidungen und Verfügungen über Einkommen und vermögen nur von der $\mathrm{E} i \mathrm{n} z$ e 1 person bzw. vom $\mathrm{p}$ i $\mathrm{i}$ a $t$ e $\mathrm{n}$ $\mathrm{H}$ a $\mathrm{u} \mathrm{s} \mathrm{h} \mathrm{a} 1 \mathrm{t}$ oder auch in Unternehmungen getroffen werden, greifen wir auf unsere Unterscheidung des allokativen und des distributiven Bereiches der ökonomie zurück (siehe \$7) und stellen hinsichtlich des charakters der in den beiden Institutionen zu treffenden Entscheidungen und Verfügungen fest: Nur natürliche Personen können Einkommen und Vermögen haben.14) "Wenn der Begriff Einkommen eindeutig sein soll, kann er nur angewendet werden auf Einkünfte über die ein ... Mensch verfügt" (E.Schuster 1961, S.54, siehe unsere Ausführung in $\$ 11$ ) Das schließt Verfügungen

13) Siehe Schaubild 3.1 über das Gesamtbild der Geld- und Gütereinkommen; S. R.M. Haig 1959, S. 59; S.a. G.v. Schanz 1896 (Nutzungen und Leistungen Dritter.

14) G. Wöhe 1988, S.109: "Ein Betrieb kann also niemals ein Einkommen erzielen, sondern ... stets nur einen Ertrag. Der Betrieb ist kein Subjekt, sondern ein Objekt, mit dem sein Eigentümer ein bestimmtes ziel verfolgt." 
Im Rahmen der Unternehmungen aus dem Einkommens- und Vermögensbegriff aus. Es gilt das Konzept der "Personenbezogenheit" (C. Folkers 1979, S. 268) als die entscheidende BezugsgröBe für distributive Phänomene.15) Die Unternehmung fungiert als Transformationsinstitution von Kapital in Einkommen; die dort $z u$ treffenden Verflugungen sind Transformationsverfügungen, nicht verfügungen über Einkommen und Vermögen.

2. In der Verfügbarkeit über ökonomische Größen zeigt sich die "ökonomisch-finanzielle"16) Dispositionskraft17) des einzelnen. Die von ihm ausübbare $V$ e $r$ f die gesamte "ökonomische Position des Menschen" (G. KrauseJunk 1981 , S. 260 und 1977, S. 338). Verfügungsmacht verschafft Entscheidungsfreiheit (R. Goode 1980, S. 52), ja ist sogar die Voraussetzung der personalen Existenz (G. Krause-Junk 1981 , S. 260 f.). Für R.M. Haig ist die "p o w e $r$ to satisfy" nahezu das "Fundament" des ökonomischen Prinzips. Die den Umfang des Einkommens kennzeichnenden Fragen, ob z.B. Gratisaktien, ob unvertellte Gewinne und ob nichtrealisierte Vermögenswertsteigerungen Einkommen sind, beantwortet er danach, ob der Empfang eines solchen Gegenstandes die ökonomische kraft so weit gesteigert hat, $d a b$ der Empfänger über Güter und Dienste verfügen kann ("to command"). 18) Auch Weisbrod/Hansen schlieBen sich dieser Interpretation des Einkommens als einem Begriff, der seinen Inhalt aus der "Verfügung" bestimmt, vollständig an ${ }^{19}$ ).

Was Simons als "the right to command prices" bezeichnet, sind

15) Carter Report 1966, vol. 1, S. 5: "The family ... should be recognized as the basic taxpaying unit in the system".

16) F. Neumark 1970, S. 136; G.B. Krause-AblaB 1971, S. 207; F. Neumark 1947, S. 36: "Verfügungsmacht".

17) G.v. Schanz 1896, S. 5: "Wir wollen wissen, welche selbständige wirtschaftliche Kraft eine Person ... darstellt, ... welche Mittel sie ... zu ihrer Disposition hat."

18) R.M. Haig 1959 , S. 59ff., insbes. S. 62; "income is defined in terms of power to satisfy economic wants".

19) B.A. Welsbrod, W.L. Hansen 1968, S. 1315: "A (consumer) unit's (das ist entweder ein Individuum, eine Familie oder ein Haushalt, siehe S. 1316) economic well-beeing or economic position should be thought of as a function of the flow of services over which it has command." 
"property rights" im Sinne von Verfügungsgewalt 20 ) aus dem Eigentumsrecht, begrenzt auf das meBbare persornliche Einkommen, ${ }^{2}$ ) bemessen in Mäiktpreisen. Da in diesen Zusammenhang auch das Vermogen gehort, erklärt sich aus dem property rights-Ansatz bel simons auch dessen Totaleinkommenskonzept im Sinne des Einkommensbegriffes von G. v. Schanz.

3. Eine allokativ-distributive Bereichsabgrenzung dieser Art berücksichtigt ausschlieBlich den organisatorischen Rahmen des Institutionenproblems, berücksichtigt nicht in vollem AusmaBe die Figur des Entscheiders, also das personale Element des Institutionenproblems. Diese personale Seite, also die Verfügungsmacht, braucht nicht deckungsgleich zu sein mit der organisatorischen. Daher schlagen wir zur vollständigen inhaltlichen Auffüllung des Institutionenphänomens vor, die Verfügungsmacht sowohl sachlichorganisatorisch als auch personell-zielbezogen zu definieren, sie durch eine Berücksichtigung sowohl des Umfangs als auch des ziels, auf das sich die Verfügung richtet, zu differenzieren.

Der $U$ m $f$ a $n g$ der Verfügungsmacht im allokativen Bereich wird bestimmt durch die Unternehmereigenschaft. Entscheidungen und Verfügungen, die jemand als Unternehmer - in welcher Form der Einzeloder Mitunternehmereigenschaft auch immer - trifft, berühren die Einkommens- und Privatvermögenssphäre mittelbar, als Entscheidungen in der Vorstufe. Aber es läBt sich die Unterscheidung, ob eine Verfügung die unternehmerische oder die private sphäre betrifft, nur mit Blick auf das Verfügungs - $z$ i e l treffen, mit Blick also auf das vom Entscheider Gewollte. Wird in einer Unternehmung

20, Zum Unterschied zwischen Verfügungsmacht und Verfügbarkeit: letztere ist eine Eigenschaft, die einem Gegenstand (Sache, Recht) anhaftet, jedoch subjektorientiert ist; demgegenüber ist Verfügungsgewalt und Verfügungsmacht eine (tatsächliche oder rechtliche) Qualität, die einer Person gegeben ist, siehe J. Hackmann 1979, S. 32.

2 1) Insoweit property rights bei simons nicht im sinne von materiellen Gütern $z u$ verstehen sind sondern als "increase of power", als "greater freedom", als "security", als "prestige" und nicht zuletzt als "respectability", soll eine Darstellung unter dem SHS-Konzept unten gegeben werden. "The relation between income (yield) and value, in the case of capital goods, is by no means a one-way relation", $S .94$. 
der Rechtsform der Einzelunternehmung entschieden, den Gewinn zu entnehmen, so hat diese Entscheidung die allokative Funktion der "Nichtinvestition" sowie die distributive, den Gewinn privater Verwendung zuzufuhren. Wird in einer Unternehmung in der Rechtsform der Kapitalgesellschaft eine Entscheidung zur Gewinnausschüttung getroffen, gilt dasselbe. Hier mag das ziel der Entscheidung sogar noch von der Aussicht mitbestimmt worden sein, die Ausschüttung (unter allokativem, hier unter finanzierungspolitischem Aspekt) wieder zurückholen zu können. Jedoch bleibt die verwendung völlig der Entscheidung des Anteilseigners überlassen, der sie konsumtiv verwenden mag. Läßt man die abgrenzungs-determinierende Rolle des Verfügungsziels gelten, so folgt, daB Ertragsteile, die in der Unternehmung verbleiben - und dies gilt ungeachtet $z$ unächst alier Rechtsformen -, niemals Einkommen der Einzel-, Mitunternehmer und Anteilseigner sein können. Letztere mögen mit dem Ertrag im Betrieb "Ansprüche" oder "Anwartschaften" auf Einkommen erworben haben, doch das macht den Ertrag nicht zum Einkommen. Aus der ökonomischen sicht ist allein das $\mathrm{H}$ a $\mathrm{n}$ d $\mathrm{l}$ u n $\mathrm{g}$ s $z$ i e 1 als allokativ-distributives Abgrenzungsmerkmal analytisch einwandfrei.

Dagegen bleiben Entscheidungen jener Personen, die zwar Eigentumer oder Miteigentümer von Unternehmen, nicht jedoch Unternehmer oder Mitunternehmer sind (also z.B. Aktionäre oder GmbH-Gesellschafter), von vorn herein Verfügungen mit allokativer Reichweite. Ihr Verfügungsziel, so sehr es qua Divendenden- oder KapitalrückzahlungsbeschluB auch ihre private Einkommens- und Vermögenslage berührt, ist in erster Linie das einer rentierlichen Kapitalanlage bzw. das einer wirtschaftlichen EinfluBnahme, also ein allokatives; es ist begrenzt durch den Rechtsrahmen für diese Art der Entscheidung, der sich vorwiegend auf den Gewinnverwendungsbeschluß erstreckt. Distributive Verfügungsgewalt erhalten sie erst mit dem übergang ihrer Ertrags- und Rapitalanteile in den Privatbereich. Verfügungen über diese Anteile sind dann solche der Einkommensverwendung.

Die vorgeschlagene Erweiterung in Richtung auf das VerfügungsZiel konkretisiert sich als die Entscheidung, Geldbeträge und in Geld bewertbare Gegenstände für eine private Verwendung zu reservieren. Damit hat in diesem Bereich die Individualentscheidung der Unternehmer und Mitunternehmer dieselbe Rolle, die wir thr für die Abgrenzung im distributiven Bereich zwischen Einkommen

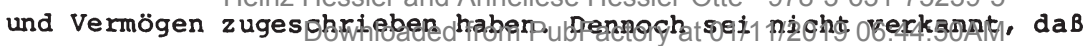


für den Fall der Kapitalakkumulation in Einzelunternehmen der Nachweis seiner rein allokativen Zweckbestimmung schwierig sein kann. Da auch distributiv motiviertes Sparen sich in der betrieblichen Akkumulation "verstecken" läBt, die über das reine "betriebsnotwendige Kapital" hinausgeht, könnte die Individualentscheidung für praktische, d.h. statistische und steuerpolitische Zwecke unbrauchbar werden. Aber es wäre theoretisch nicht korrekt, die gesamte betriebliche Kapitalakkumulation in Einzelunternehmen entweder ausschlieblich dem allokativen oder ausschlieblich dem distributiven Bereich zuzurechnen. Beides wäre eine Konvention zur Bewältigung der praktischen Anwendungsprobleme. ${ }^{22}$ )

IV. Schlieblich ist das Kriterium der "Verfügbarkeit "unter dem Aspekt des $G$ e $g$ e $n s t a n d e s$ prüfen, über den verfügt werden kann. Die mit keinerlei Einschränkung versehene Verfügbarkeit meint das Verfügen über eine "TotalgröBe:" Die Totalität - in der Besteuerung zur vollständigen Erfassung der Leistungsfähigkeit erforderlich ${ }^{23}$ ) - hat begriffstheoretisch die Funktion, für den Verfügungsgegenstand die Bedingungen einer umfassenden Beschreibung festzulegen. Vier Problemkreise sind mit dieser Funktion verbunden: das Quellenphänomen, die Bruttoerfassung, die Imputierung von Einkommen und der Wertzuwachs des Vermögens.

1. Die Geltung der Totalitätsregel verlangt $z$ unächst die Lösung des "Q u e l l e $n \mathrm{p} h \ddot{a} \mathrm{n} \circ \mathrm{m}$ e $\mathrm{s}$ ", d.h. sle verlangt, von der Herkunftsbetrachtung der ökonomischen GröBen abzugehen. Da das Verfügbarkeitskriterium gelten soll, kann über alles, was als Verfügungsgegenstand existiert, verfügt werden, ungeachtet seiner Herkunft. Einen in diesem Sinne breiten Verfügungsbegriff formuliert auch der Carter Report 1966; wenn auch in erster Linie auf

22) Siehe \$20 II 2. und die dort gegebene stellungnahme $z$ un sog. "Desertionsargument".

23) Der Unterschied zwischen der Totalität in der Besteuerung und der Totalität auf dem wirtschaftstheoretischem Gebiet liegt darin, daB es dort als ein Handlungsprinzip, hier als ein Erkenntnisprinzip auftritt. Um diesen Funktionenunterschied auch terminologisch deutlich $\mathrm{zu}$ machen, wird hier von Totalitäts"Rege1" gesprephenessler and Anneliese Hessler-Otte - 978-3-631-75239-5 
die Besteuerung ausgerichtet, vermag er dennoch in seinen theoretischen Passagen Grundlagen für unser Problem zu liefern. Die uns hier interessierende Totalität in der Verfügung formuliert er als "discretionary economic power" (vol. 3, S. 5) und als "power to command goods and services for personal use (nicht konsum!), wether the power is exercised or not" (s. 22.u.32).24)

a) Aus diesem Verständnis der Totalitätsregel folgt zunächst unmittelbar die Ablehnung jener RegelmäBigkeit für den zugang von ökonomischen GröBen, den noch die alte Quellentheorie zu ihrer Bedingung für Einkommen machte.

b) Das Kriterium der Verfügbarkeit verlangt weiter die Nichtbeachtung dessen, ob der Verfügungsgegenstand einer produktionswirtschaftlichen Tätigkeit des einzelnen bzw. dem marktlichen Tausch entstammt oder nicht. Die Einbeziehung nur derjenigen Gegenstände, die aus einer aktiven Wirtschaftstätigkeit gewonnen wurden, würde die Basis der Verfügbarkeit logisch unzulässigerweise einengen, da auch uber Erbschaften oder Wertsteigerungen, die jemand passiv hinnimmt, sowie über Wertschöpfungsergebnisse, die jemandem "unverdienterweise" zufallen, obwohl andere Individuen oder das Kollektiv sie erbracht haben, sehr wohl einen $\mathrm{Zu}-$ gang belm Empfänger darstellen, über den dieser verfügen kann. Auch über Nutzungen, die jemand unter Umgehung des marktlichen Prozesses zieht, kann er verfügen. E. Schuster (1961, S. 53) spricht von "direkter und indirekter Beteiligung des Menschen am WirtschaftsprozeB", die bei ihm zu Einkommen führen kann, und diese Beteiligung ist keineswegs nur die aktive produktionswirtschaftliche. 25 )

24) Erst im Hinblick auf die Absichten der Besteuerung kommt der Carter Report dann zur Festlegung von Einschränkungen dieses Totalbegriffs: Die Totalgrößen müssen "frei" verfügbar sein für den Steuerpflichtigen, und sie sind es z.B. nicht, soweit sie lebensnotwendig sind (S. $32 ; \mathrm{s} . \mathrm{a}$. unten $\$ \$ 21 \mathrm{ff.}$ ).

25) Carter Report 1966, vol. 3, s. 14: "A dollar gained through the sale of a share, bond or piece of real property bestowes exactly the same economic power as a dollar gained through employment or operating a business." 
c) Nach der Totalitätsregel sind auch Vermögens- und Transfereinkünfte $z$ um Verfügungsgegenstand $z u$ zählen, sofern nur tatsächlich über sie verfügt werden kann. Ob es sich dabei aber um ursprüngliche (primäre) oder um abgeleitete (sekundäre) Einkünfte handelt, ist für die Verfügbarkeit unerheblich. Es entscheidet allein der Zugang ökonomischer GröBen bei der Person. Für einige Sonderfälle von individuell organisierten Transfers entspricht der Zugangsregel ein Abgang von Einkommensteilen, wenn nämlich jemand privat und direkt einem anderen zuwendungen gewährt. Der Zuwender verfügt den Abgang von ökonomischen GröBen, somit zählt auch dieser "durchlaufende Posten" zu seinem Einkommen. Ursprünglich war ihm ja die GesamtgröBe zugegangen. Auf seiten des Empfängers steht die Einkomensqualität der Transfers auBer Frage, da auch hier ein $\mathrm{Zu}-$ gang vorliegt, über den er verfügen kann. Dies verdeutlicht, daB für die personale Einkommensbestimmung nach der Zugangsregel jegliches gesamtwirtschaftliche "Doppelzählargument" fehl gehen muB. Der privat veranlaBte Transfer ist Einkommen bei beiden Personen; daB in der gesamtwirtschaftlichen sicht der Transfer zweimal als Einkommen auftaucht, ist insofern unerheblich, als hier das Einkommen $j e r$ e $r o n$, also individuell $z u$ definieren ist. Verfügt wird ja individuell, nicht gesamtwirtschaftlich.

d) Ferner kann die Art des Faktors, des Faktoreinsatzes und des Faktorertrags aus Gründen der Totalitätsregel ebenfalls keine Rolle spielen. Auch die sog. "windfall gains" und "losses" gehören zum Ertrag, werder Einkommen ungeachtet der Planbarkeit oder auch nur der Vorhersehbarkeit ihres Zugehens (F. Neumark 1961b, S. $44 \mathrm{f.l}$. Verfügbar ist das Einkommen in jedem Fall, stamme es aus Kapital- oder Arbeitseinsatz oder auch aus dem Einsatz des Humanvermögens. Die Quellenbetrachtung ist auch innerhalb einer Faktorart unerheblich, denn z.B. kann Lohn sowohl aus betrieblichem Faktoreinsatz wie auch aus betrieblicher Kapitalauflösung finanziert worden sein; ebenso kann eine geldliche zuwendung an eine Person sowohl aus einem Einkommen als auch aus Vermögensauflösung herrühren; eine Altersrente kann Ubertragung von Einkommen aus Einkommen sein, kann aber auch aus den Erträgen eigener Ersparnisse stammen wie schlieblich auch als Form der nachträglichen Einkünte aus der Mitwirkung am WirtschaftsprozeB gedeutet werden (E. Schuster 1961, S. 55). 
e) Letztlich ist für die Verfügbarkeit auch die Qualität der Faktoren unerheblich: Arbeitsqualität, Arbeitsplatzsicherheit, ja auch sektorale oder regionale Quellen der Arbeitslöhne müssen als unbeachtlich gelten für die Verfügbarkeit über die Einkünfte.

Als Regel der Totalität gilt, daB die Einkünfte und Vermögensarten unabhängig von jeglicher Quellenbetrachtung am personalen Ort des Zusammenwirkens und der Gesamtverfügung (W. Albers 1979a, S. 199) zu erfassen sind.

2. Aus dem Kriterium der Verfügbarkeit folgt notwendig, das Einkommen $b r u t t \circ z u$ erfassen, d.h. keine Einengung des Verfügungsgegenstandes durch Verwendungsverfügung zuzulassen. Verfügbar ist der ungeschmälerte Brutto-Zugang an ökonomischen GröBen, mögen auch die Verwendungsverfügungen, die zur Schmälerung führen, noch so rationale allokative und beachtenswerte distributive Motive haben.

a) Allokativ motivierte Ausnahmen von der Brutto-Erfassung verlangen die quellentheorie und die Reinvermögenszugangstheorie: Ihnen zufolge sollen Verwendungsverfügungen, die der Kapitalerhaltung dienen, nicht zum Einkommen gerechnet werden. Mag dies unter steuerpolitischem Aspekt bedenkenswert sein, unter begriffstheoretischem ist es das nicht. Denn die der Kapitalerhaltung dienenden Ertragsbestandteile sind sehr wohl verfügbar, nämlich ebendazu; aber sie sind auch für andere Zwecke verfügbar. M.a.W.: Verfügbarkeit likegt vor ungeachtet des ziels der Verwendung.

b) Ausnahmen vom Grundsatz der Bruttoerfassung werden überdies auch im distributiven Bereich gefordert und zwar zumeist in Verbindung mit der Besteuerung. Hier sind zwei Argumentationsrichtungen zu erkennen: Einerseits wird generell die Freistellung der Sparakte von der Besteuerung des Einkommens diskutiert, andererseits wird die Ausnahme ganz bestimmter Verwendungszielrichtungen des Nichtkonsums von der Besteuerung erwogen. Die generelle steuerbefreiung des sparens wird oftmals damit $z u$ begründen 
versucht, daB man erstens auf die üblicherweise besteuerten $E$ r $t r \ddot{a} g e$ des gesparten vermögens hinweist (und insoweit zu dem Argument der zweifachbelastung kommt, wenn schon die sparbildung nur aus versteuertem Einkommen geschehen kann) und daB man ferner daran erinnert, die Ersparnisse würden bei der Auflosung wie jeder andere Konsum auch den Mehrwert- und Verbrauchsteuern unterliegen. Dern ersteren Hinweis ist entgegenzuhalten, daB nichtertragabwerfendes Sparen dann der Einkommensbesteuerung entgehen würde und $d a b$ diese Beträge allein von indirekten steuern dann erfaBt würden, wenn entspart würde. Dies aber hieBe, nicht angefallene Einkommensteuer gegen $z u$ entrichtende Mehrwert- und Verbrauchsteuern aufrechnen $z u$ wollen. Korrekt wäre allenfalls, die Einkommensteuer beim Entsparen nachzuholen, ein steuertechnisch schwieriges Unterfangen. Aber das ist in diesem Zusammenhang nicht das entscheidende Gegenargument. Vielmehr würde der AusschluB des Sparens doch bedeuten, daB man aus rein steuerlicher Argumentation elnen verengten Einkommensbegriff definieren mochte. Dies kann theoret1sch nicht durchschlagen; abgesehen davon, daB Sparen auch weithin nur ein zeitlich verschobener Konsum ist, ist ja die Sparentscheidung eine Verfügung über eine Gesamteinkommensgrobe. Gespart wird in Ansehung des Gesamtzugangs und in Ansehung beider Verwendungsarten dieses Zugangs, nämlich des Konsums und des Nichtkonsums. Aus dem Blickwinkel der Verfugbarkeit - und verfügbar ist mit Blick auf die Verwendung immer das gesamte Einkommen - gehört das Sparen mit in den Einkommensbegriff hinein (E. Schuster 1961, S. 55 unter H1nwe1s auf die ungeschmalerte Verfügung uber das Gesamtelnkommen). DaB dem Finanzpolitiker unter dem rein steuerlichen Aspekt eine Freistellung des Sparens von der Einkommensteuer angebracht erscheint, ja evtl. als allokativ und distributiv geradezu notwendig erscheint, darf die theoretische Begriffsprägung nicht determinieren.

c) Nicht anders nimmt es sich aus mit der zweiten Argumentationsrichtung, die ganz bestimmte Verwendungsrichtungen von der Besteuerung freistellen und demnach auch aus dem Einkommensbegriff 
ausscheiden will. Sie werden begründet mit der eingeschränkten oder kaum vorhandenen Verfügungsmacht über Einkommensteile, die der Sicherung der Existenz und der Vorsorge dienen müssen. Hier können wir F. Neumark (1961b, S. 31) folgen, der dies steuerlich zwar für geboten erkennt, wenn es gelte, die Leistungsfähigkeit festzustellen, der daraus aber keineswegs schließen möchte, solche Beträge würden wirtschaftstheoretisch ebenfalls nicht $z$ um Einkommen $z u$ rechnen sein. Dennoch ist auch begriffstheoretisch jüngst die Ansicht vertreten worden, Einkommen sei als Netto-Vermögenszunahme zu definieren (K. E. Boulding 1981, S. 211). U.E. ist dies aber ein ausschlieblich steuerliches Problem. Hier allerdings hat das Argument der nicht vorhandenen oder eingeschränkten Verfügbarkeit über gewisse Einkommensbestandtelle Gewicht.

3. Die $\mathrm{z} u \mathrm{r}$ e $\mathrm{h} n \mathrm{n} \mathrm{g}$ oder I m p t $\mathrm{i}$ e $\mathrm{r}$ n g "realer" geldwerter Vorteile und Nutzungen als Einkommen setzt voraus, daB sie objektiv rechenbar gemacht werden können, dab ferner eine Verfügungsmacht in der Person, der ste zuzurechnen sind, vorliegt. Daraus folgt, daB von vorn herein die Freizeit, die von vielen Autoren als Einkommensbestandteil zumindest nicht ausgeschlossen wird, und die öffentlichen Güter in einem Totalkonzept des Einkommens keinen Platz finden können. Ebensowenig ist aus denselben Gründen eine Verfügbarkeit über das Humanvermögen möglich; zwar ist es in der Phase seiner Bildung insofern disponibel, als es quantitativ und qualitativ (J. Mitschke 1976, S. $91 \mathrm{f.}$ ) und auch im Hinblick auf die Intensltät, den ort und die zeit seines Einsatzes variiert werden kann, doch ist es indisponibel insoweit, als seine Quelle (H. Fecher 1979) nicht veräußert werden kann.26)

26) J. Hackmann (1972, S. 170 f.) unterscheidet zwischen "persönlicher" und "ökonomischer" Verfügungsmacht; was nicht übertragbar ist, gehöre nicht zur ökonomischen Verfügungsmacht; erst die Leistung (z.B. aus dem Humanvermögen), die ein Vermögen erbringt, würden zur ökonomischen Verfügungsmacht gehören. K.E. Boulding (1981, S. 212) allerdings betont die Verfügungsmöglichkeit über die Leistungen aus diesem Vermogen; dies allerdings würden wir dann als Verfügen über Einkommen bezeichnen. 
Wenn aber Rechenhaftigkeit und Verfügungsmacht gegeben sind, wie z.B. bei den güterwirtschaftlichen Zugängen, sind diese $z$ um Totaleinkommen bzw. -vermögen $z$ u rechnen: So beispielsweise die eigengenutzte wohnung im eigenen Hause, eigengenutzte sonstige langlebige Güter, die mietfreie Betriebswohnung, das privat genutzte Dienstfahrzeug, ferner der gesamte Umfang betrieblich gestellter Sachleistungen und Leistungen aus Sozialeinrichtungen (wie Arbeitskleidung, Kantinenessen, Kultur- und Sportmöglichkeiten, Kindergärten, Ausbildung und Deputate, J. Giloy 1978, S. 72) . Diese Art der Totalerfassung dient sowohl einkommenstheoretischen Erfordernissen als auch den Absichten der steuerlichen Gleichbehandlung.

4. Letztlich gelten für die $w$ e $r t z u$ ä $c h s e$, seien sie nur nominelle oder gar reale, seien sie bereits realisiert worden oder noch nicht, die Erfordernisse der Rechenbarkeit und Verfügbarkeit gleichermaBen. Unabhängig von den Problemen steuerpolitischer Praktikabilität gilt: Uber bloB nominelle wertzuwächse kann verfügt werden; sie sind auch rechenbar und daher wirtschaftstheoretisch Einkommen. Jedoch als Indikatoren der Leistungsfähigkeit für die Besteuerung scheiden sie aus, da keine steigerung der realen Kaufkraft vorliegt (A. Oberhauser 1980, S. 668; siehe auch § 25).

Uber realisierte Wertzuwächse und deren Geldesvorteil kann, was Rechenbarkeit und Verfügbarkeit angeht, kein Zweifel bestehen. $\mathrm{Ob}$ sich demgegenüber die nicht realisierten Wertzuwächse bewerten lassen, ist eine Tatfrage; soweit dies aber gelingt, läbt sich auch über sie in jedem Falle verfügen, es bedarf dazu nur der Bereitwilligkeit,27) aber stets liegt "erhöhte Dispositionsfähigkeit" vor. 28 )

27) A. Oberhauser 1980 , S. 669 ; verzichtet der Verfügungsberechtigte auf die Realisierung, präferiert er offensichtlich diese Vermögensanlage. Insofern liegt hier auch eine unter steuerlichem Aspekt relevante höhere Leistungsfähigkeit vor.

28) N. Andel 1979a, S. 348 f.; auch steuerlich ist der Wertzuwachs Einkommen. 
Selbst uber die nicht realisierten und zugleich nicht bewertbaren Zuwächse kann selbstverständlich verfügt werden, allerdings mit der begriffstheoretischen Folgerung, daB sie wegen des erfüllten Verfügbarkeitskriteriums $z$ um Totalvermögen $z$ ählen, wegen der unerfülten Rechenbarkeitsvoraussetzung jedoch nicht. Das Erfordernis logischer Konsistenz eliminiert mithin nicht bewertbare Vermögenswertsteigerungen (deren Wert ja ohnehin nur "erahnt" werden könnte), obgleich verfügbar, aus dem Totaleinkommen.

Gerade das Problem der Wertzuwächse und der Nichtrealisation wird zum Testfall des Verfügungskriteriums: Unter der Voraussetzung der objektiv möglichen Rechenbarkeit entscheidet die Verfügbarkeit über die Vermögensqualität der Wertzuwächse. Ist dies einmal akzeptiert, können handelsrechtliche und auch steuerrechtliche Gründe durchaus dazu führen, die Vermögensqualität zu verneinen. So kennt das Aktienrecht wegen des hier vorrangigen Gläubigerschutzes das sog. Imparitätsprinzip, nach dem noch nicht eingetretene Verluste zwar vorweggenommen werden, nicht realisierte Gewinne jedoch nicht. DaB diesem Grundsatz des Gläubigerschutzes nun nicht etwa alle Steuerpflichtigen, sondern nur jene unterworfen werden, die als buchführende Kaufleute einen Vermögensvergleich zur Gewinnfeststellung machen, ist ein bemerkenswertes Spezifikum des Einkommensteuerrechts. Nicht in jedem Falle dient nämlich die Emanzipation vom theoretischen Vermögens- bzw. Einkommensbegriff der vollständigen Erfassung der Leistungsfähigkeit und der gleichmäBigen Besteuerung (siehe hierzu §§ 26 u. 27.).

V. Wir kommen, was das Kriterium der Verfügbarkeit, ihre Voraussetzung sowie die personalen und gegenständlichen Elemente der Verfügbarkeit betrifft, $z u$ den folgenden $E r g$ e $\mathrm{n}$ i s $s$ e $n$ in Rationalität und Inhalt der Theorie:

1. "F a z $i t$ ": Der Kriterien-Ansatz darf mit seinem Abstellen auf die Verfügbarkeit, die EntscheidungsmaBgeblichkeit und die Zugangsregel als ein $r$ a $i \circ \mathrm{n}$ a $l$ e Konzept gelten.

a) Sinn und Zweck des hier beschrlebenen Kriterien-Ansatzes ist es, einen theoretischen Einkommensbegriff $z u$ formulieren. Das heute 
allgemein akzeptierte Reinvermögenszugangs- bzw. Schanz-HaigSimons-Konzept wird übernommen und daraufhin geprüft, welche kennzeichnenden Merkmale es aufweist für die Bestimmung des Einkommensbegriffs, und welche Merkmale den entwickelten Kriterien widersprechen. Die Auseinandersetzung gerade seitens Haigs und Simons' mit dem Schanz'schen Ansatz belegen einen solchen widerspruch, ohne daB er bis heute deutlich genug markiert wurde; erst die zusammenfassung der literarischen Diskussion konnte zeigen, daB er mit der allokativ-distributiven Abgrenzungsfrage identisch ist.

Als das den diskutierten Einkommensbegriffen gemeinsame Merkmal stellt sich die $v$ e $r$ f ü $g$ b a $r k$ e $t$ heraus, ausgesprochen bei G. v. Schanz in der "selbständigen wirtschaftlichen Kraft", die eine "Person zu ihrer Disposition" hat (1896, S. 5); verfügt werden kann über alles, "was einer Person zugeht" (S. 17).

Ausdruck der Verfügbarkeit ist bei F. Neumark (1947, passim; 1961b passim) die "ökonomisch-finanzielle Dispositionskraft", ist bei R.M. Haig (1921) die "economic power" bzw. die "power to satisfy"; verfügen kann eine Person über den "net accretion between two points of time". 29) Verfügbarkeit ist schlieblich bei H.C. Simons enthalten in seinem Begriff der "rights"; und das Reinvermögenszugangskonzept ist niedergelegt in der Summationsregel für das persönliche Einkommen als der Addition von "consumption" während der Periode und dem Unterschied von "wealth" zu Ende und $\mathrm{zu}$ Beginn der Periode. ${ }^{30}$ ) Die Formulierung der Verfügbar-

29) 1921, S. 7; zur Erinnerung hier nochmals die vollständige Definition: "... the increase or accretion in one's power to satisfy his wants in a given period insofar as that power consists of (a) money itself, or (b) anything susceptible of valuation in terms of money." "Income is the money value of the net accretion to one's economic power between two points of time;" S. 7.

Da die Verfügungsmacht nicht an die Verausgabung gebunden ist, sondern savings und consumption gleichermaBen enthält, handelt es sich hier um ein Konzept des $z$ u g a $n g s$ von Einkommen.

30) 1938 , S. 50; zur Erinnerung auch hier die vollständige Definition: "Personal income may be defined as the algebraic sum of (1) the market value of rights exercised in consumption and (2) the change in the value for the store of property rights between the beginning and the end of the period in question." "The sine qua non of income is gain ..." (S. 50). 
barkeit als ein Kriterium für Einkommen soll das Essentielle der genannten Definitionen herausstellen, soll zugleich den Bezugspunkt für Interpretationen festlegen; in diesem Sinne gelingt es auch, Widersprüche im Reinvermögenszugangskonzept offenzulegen, die darin bestehen, daB Beträge zur Kapitalerhaltung, über die durchaus verfügt werden kann, nicht zum Einkommen gerechnet werden. ${ }^{31)}$ Dabei ist Verfügbarke1t, obwohl die Rechenbarkeit und zuordnung der ökonomischen Größen zu ihrer Voraussetzung gehört, im wesentlichen ein qualitatives Merkmal; denn ein vollständiger quantitativer Geldausdruck aller Gütereinkommenselemente (z.B. imputed income) wird sich nie herstellen lassen (Simons 1938, S. 48). Die "Qualität" des Kriteriums zeigt sich im Wirksamwerden zweier Regeln, die den Inhalt der Verfügbarkeit bestimmen, nämlich der Entscheidungsregel und der Zugangsregel.

b) Unter der Wirkung der $E \mathrm{n} t \mathrm{~s} \mathrm{c}$ e $i \mathrm{~d} u \mathrm{n} g \mathrm{~s}$ e g e 1 soll verstanden werden, daB sich einerseits die allokativ-distributive Abgrenzung ökonomischer GröBen, andererselts die Trennung des Einkommens vom Vermögen nur mithilfe von individuellen Entscheidungen treffen läBt:

- Es hat sich gezeigt, daB sowohl die Quellen- wie auch die Reinvermögenszugangstheorie von der "Dominanz des Allokativen" geprägt ist, daB das "maintaining capital intact-Denken" - obwohl auf die Einkommensdefinition ausgerichtet - ausschlieBlich im Allokativen verankert ist. Kapitalerhaltung und -bildung ist aber eine Frage der Entscheidung, nicht der Einkommensdefinition;

- es hat sich ferner herausgestellt, daB die Einkommensqualität der nicht entnommenen Gewinne und auch der Unternehmensreserven von Entscheidungen abhängt, nämlich dann, wenn die Entscheider Einzel- oder Mit-Unternehmer bzw. Selbständige sind und ihre betrieblichen von ihren privaten Sphären abgegrenzt werden sollen; hier werden die Verfügungsziele der Entscheidungen relevant;

- es hat sich schlieblich gezeigt, daB auch innerhalb des distributiven Bereichs die Abgrenzung des Einkommens vom Vermögen

31) So bei Schanz, so auch in der Quellentheorie, in "produktionswirtschaftlichen" Theorien und bei I. Fisher. 
nur mithilfe der Individuellen Entscheidung gelingt, die mit dem Blick auf die Vermögensfunktionen sowie den Planungs- und Zeithorizont getroffen werden (Existenzsicherung, Vorsorge, Lebensstandarderhöhung und Unabhängigkeit).

c) Die Wirkung der $\mathrm{z}$ u g a n g s $\mathrm{e} g$ e 1 für die Verfügbarkeit liegt in folgendem:

- erstens ist die Regel eine "a $d$ p e $r$ s o n a m - R e g e l", was zweierlei bedeutet: (a) Elnkommen und Vermögen geht nur physischen Personen $z u$, nicht aber unternehmerischen Institutionen; (b) jedweder zugang an die Personen ist für diese Einkommen, unabhängig davon, ob es sich um primäres oder sekundäres handelt, d.h. ungeachtet dessen, von wem es erwirtschaftet oder sonst wie erzielt wurde;

- zweitens ist die Regel eine "M e B r e g e l", da der Zugang keine metaökonomischen, sondern nur meBbare ökonomische Größen enthält, solche aber aus jeder (geldlichen und güterlichen) Art und aus jedweder Quelle; diese offenheit der Regel für alle denkbaren meBbaren Einkommensquellen berührt sich eng mit dem Gegenstandselement der Regel, denn:

- drittens ist die zugangsregel eine "T 0 t a 1 - R e g e I" : (a) wenn die Quelle des zugangs kein Indikator fur die Einkommensqualität einer ökonomischen GröBe ist, so ist es unerheblich, ob der zugang aus einer produktionswirtschaftlichen Aktivität, ja überhaupt aus dem wie immer gearteten Einsatz der Faktoren hervorgeht; es ist vielmehr notwendig, dann darüber hinaus auch die aus Vermögenszugang und -nutzung sowie aus Transfers stammenden zugangsquellen in das Einkommen einzuschlieBen; über Zugänge aus allen diesen Quellen kann verfügt werden;

(b) die Total-Regel verlangt, daB die sog. zugerechneten Einkommen (das imputed income) und die realisierten wie auch die nicht realisierten Vermögenswertzuwächse grundsätzlich zum Einkommen gezahlt werden; hier ist die Begründung erstens die persönliche Verfügungsmacht, die in Bezug auf diese Einkommenselemente vorliegen muB, und zweitens das Erfordernis der Rechenbarkeit; durfen beide Erfordernisse als gegeben unterstellt werden, ist auch der nichtrealisierte Vermögenswertzuwachs Einkom- 
men, da es zur Realisierung lediglich einer Bereitwilligkeit zur Verfügungsentscheidung bedarf. Auch die Nichtrealisierung ist eine Entscheidung, und der Vermögenswert gehört zum TotalZugang.

2. "F a $z$ i $t$ 2": Schlieblich ergibt sich unter Verwendung der Funktionen, die die Kriterien für das theoretisch-methodische und definitorische vorgehen haben, ein weiteres Fazit ${ }^{32}$.

a) Für die Definition der Begriffe haben wir den folgenden analytischen weg zurückgelegt:

(1) Als "Definiendum", d.h. als vorerst noch unbekannter Terminus der Definition, gilt das Einkommen. Es wird determiniert durch die bereits bekannten Termini "Verfügbarkeit", "Rechenbarkeit" und "personale Zuordnung", also durch die Kriterien als "Definiens" 33 ).

Bei dieser Art des Vorgehens, Definitionskriterien vorzuführen, stellt die "ad-personam-Regel" eine im Vorfeld des Begrifflichen allgemein geltende Grundregel dar, da sowohl das Definiendum als auch die Elemente des Definiens nur im personalen Bereich aufgesucht werden sollen; gleichermaBen sollen auch nur ökonomische GröBen personal zugeordnet werden, immerhin aber solche nicht willkürlich begrenzten AusmaBes (TotalgröBen). Damit ist zugleich Inhalt (Bedeutung) und Umfang des Einkommens festgelegt: Der I $\mathrm{n} h$ a $1 \mathrm{t}$ ist definiert durch die Kriterien; als $U \mathrm{~m}$ f a $\mathrm{ng}$ des Einkommens gilt die Gesamtmenge aller jener Phänomene, die dieselbe Bedeutung haben, d.h. alle Elemente des Totaleinkommens. ${ }^{34}$ ) Nur soweit eine Identität von Inhalt und Umfang des Einkommens vorliegt, soll von Einkommen gesprochen werden. Wird der Inhalt durch die Kriterien beschrieben, so geht der Umfang aus Ubersicht 3.2 (geld- und güterliche Arten des Einkom-

32) Was im folgenden zum Begriffsanalytischen des Einkommens ausgefuhrt wird, gilt analog auch für das Vermögen.

33) H. Selffert 1975a, S. 33: eine Definition ist die Gleichsetzung eines bisher noch unbekannten Terminus mit einer Kombination bereits bekannter Termini.

34) H. Seiffert 1975a, S. 37-42: zur vollständigen Fassung des Begriffs gehört die Austauschbarkeit beider Seiten der Definition bei Erhaltung ihrer Bedeutung; Begriff ist die Bedeutung des Terminus; die Bedeutung wird ausdrücklich vereinbart. 
mens; entlohnungs-, vermögen- und transfereinschlieBende Quellen des Einkommens) hervor. Ähnliches gilt hinsichtlich des Vermögens von der Ubersicht 3.6 (Kapital- und Vermögensarten der Einzelwirtschaften).

(2) Die Aufgabe, sowohl die inhaltsbestimmenden Kriterien als auch die umfangsbestimmenden Elemente des Einkommens und Vermögens näher zu bestimmen, zu konkretisieren, in der Realität handhabbar zu machen, haben wir einigen " $R$ e g e $I \mathrm{n}$ " übertragen. In unserem Zusammenhang verstehen wir Regeln weder als Grundsatz oder Prinzip, noch als Regel der mathematischen Logik, Vielmehr hat für uns "Regel" die Bedeutung der Notwendigkeit und des verfahrens, Denkabläufe und Begriffe zu charakterisieren, ihre speziellen definitionsbestimmenden Merkmale hervorzuheben.

Wenn wir Regeln für okonomische Begriffsbildungen formulieren, kommt es uns gerade darauf an, darzulegen, dab diese Regeln eine Verbindung zwischen logischer Konsistenz, Entscheidungsrationalität und praktischer orientierung herstellen. Dieser Absicht dient das Herausstellen von begrifflichen Merkmalen, Kennzeichen, Charakteristika, die einen theoretisch konstruierten Begriff im Hinblick auf seine praktische Anwendung auszeichnen. In diesem Sinne verbindet das Verständnis von Regel die "Logik der Eigenschaftsbeschreibung" 35) mit dem Verfahren von Denkabläufen bel der Begriffsbildung. ${ }^{36)}$

35) W. Leinfelner 1965, S. 38 f. "Die Logik, die der Elgenschaftsbeschreibung zugrunde liegt, ist die (niedere) Prädikatenlogik", und zwar wird sie hier in ihrer "ontologisch-deskriptiven" (bzw. "Ontologisch-semantischen", auch "nominalistischen") Art benotigt.

36) In diesem Verstädnis von "Regel" stutzen wir uns ferner auf T.S. Kuhn 1978, S. 433 ff., der im Zusammenhang mit dem Problem der Auswahl zwischen konkurrierenden Theorien "Rege In" in die Nahe der Kriterien und Begriffe ruckt, ferner auch in die Nahe von Denk- und Entscheidungsablaufen. - Siehe auch die sog. Entscheidungslogik im Gegensatz zur Entscheidungstheorie. - Wenn ferner K.R. Popper (1966, S. $189 \mathrm{ff}$. U. $339 \mathrm{ff}$.$) von$ den "methodologischen Regeln" der Akzeptanz von Hypothesen, der Prüfung also, inwieweit sich Hypothesen "bewähren" können, spricht, so ist darin ebenfalls die Bedeutung der "Regel" für begriffilche Logik und Stringenz der Denkabläufe ausgedrückt. 
Erfullbarkeit und Konsistenz müssen vorliegen, wenn wir behaupten, daB die Zugangs- (ad-personam-) Regel, die Geldausdrucksregel (als praktischer Ausdruck der personalen zurechenbarkeit von రkonomischen GröBen, die 1hrerseits die Voraussetzung des Verfügbarkeitskriteriums ist), die Totalitätsregel und schließlich die Entscheidungsregel für die Einkommens- und Vermögensbegriffe bestimmend sein sollen. 37 )

(3) Unter EinschluB der Kriterien und der Regeln lautet die Einkommensdefinition in einer ersten, formalen Annaherung ${ }^{38}$ ) wie folgt:

"Einkommen ist der elner Person (bzw. einem privaten Haushalt) zuzuordnende rechenbare und durch sie verfügbare zugang einer ¿konomischen Totalgroße."

FaBt man diese theoretisch-abstrakte Formulierung nunmehr für die wirklichkeitsnahen Entscheidungs- und Handiungssituationen konkretanschaulich und ersetzt demzufolge den Gesamtausdruck "Okonomische TotalgröBe" durch ihre Einzelelemente; berücksichtigt ferner, $\mathrm{daB}$ wegen der unumgänglichen Rechenhaftigkeit des Wirtschaftens diese Elemente in Geld auszudrücken (und $z u$ bewerten) sind und daB der Zugang aus MeB- und Vergleichsgründen konventionellerweise in der Jahresperiode erfaBt wird; beachtet schlieblich, daB sämtliche Zugänge in die Verfügungsmacht von Wirtschaftenden fallen, die ihre Entscheidungen im allokativen Gewinn- und Kapi-

37) Wir werden feststellen, daB gerade im Hinblick auf die Praktikabilität der steuerlichen Politik vor allem die Totalitätsund die Erhaltungsregel (s.u.) eine andere Interpretation erfahren bzw. ausschlieblich für steuerzwecke formuliert werden. Auch dort dient aber die Formulierung von "Regeln" der Konkretisierung von Begriffen.

38) $\mathrm{Zu}$ einer solchen theoretisch-abstrakten Definition gelangt man durch die Anwendung eines Systems von Reduktionssatzen; was im einzelnen auf diese knappe Formel reduziert wurde, geht aus den Punkten 2a bis 2c hervor. - C.G. Hempel 1974, S. 34: "... Systeme von Reduktionssätzen vereinigen auf merkwurdige Weise die Funktion der Begriffsbildung und der Theoriebildung." 
talbereich trennen von jenen im distributiven Einkommens- und Vermögensbereich, so lauten die endgültigen Formulierungen der Definitionen für Einkommen und Vermögen wie folgt:

\begin{abstract}
"Einkommen ist die Gesamtheit der einer Person (bzw. einem privaten Haushalt) zuzuordnenden, rechenbaren und durch sie verfügbaren jährlichen zugangsgröBen an marktlichen Leistungsund VermögensveräuBerungs-Entgelten, an zugerechneten nichtmarktlichen Entgelten und Vermögensnutzungen, an monetären und realen, privaten und öffentlichen Transfers sowle an gegenständlichem und wertmäBigem Vermögensmehr."
\end{abstract}

Aus der Zugangsregel folgt, daB die Verwendung der Zugänge unbeachtlich ist. Ferner folgt, daB die (gegenständliche) Vermögensumschichtung nicht Einkommen sein kann. Sie bleibt, was sie war: Vermögen (s bestand) :

"Vermögen ist die Gesamtheit der einer Person zuzuordnenden, rechenbaren und durch sie verfügbaren zugangsgrößen aus vorherigen Perioden und der laufenden Periode, die eine Person (ein Haushalt) entscheidet, nicht zu konsumieren".

b) Das Ergebnis unserer Darlegungen über die Verfügbarkeit und die zurechenbarkeit als begriffsbildende Kriterien ist der Endpunkt einer Vorgehensweise, die wir als eine "b e g r i f f s $t h$ e $\circ$ e $t i s c h e "$ bezeichnen wollen. Zwar finden sich Begriffe "stets in einem Netz von Gesetzen, Theorien und Erwartungen, aus dem sie nicht für Definitionszwecke völlig herausgelöst werden können" (T.S. Kuhn 1978, S. 346), doch ist eine Begriffs-

39) Dies läBt sich treffend mit elner launigen Marginalie in R.A. Musgraves Aufsatz "Der gegenwärtige Stand der Theorie der Besteuerung" (1981, S. 29) illustrieren: "Das Triumvirat Schanz, Haig und Simons, etwas deprimiert darüber, daB die Zeitläufe ihnen nicht günstig sind, aber voll dex Hoffnung auf bessere Tage", thront in der "Mittelloge" unterhalb des "Steuer-olymp", in dem A. Smith, D. Ricardo, J.St. Mill, A. Wagner und A.C. Pigou residieren.

40) H. Seiffert 1975b, S. 2: analytisch = "in Bestandteile auflösend".

41) H.-J. Krupp 1968, S. 139: "Nur institutionelle oder Verhaltensgleichungen vermehren den empirischen Gehalt einer Theorie " (Hervorhebung durcis HDH). 
theorie stets eine Theorie mit begrenzter Reichweite. ${ }^{39}$ ) Es ist der Zweck zu beachten, der mit ihr verfolgt werden soll: Klarstellung, hervorgehend aus logischen Zusammenhängen zwischen den für die Begriffsfassung notwendigen Teilelementen einerseits sowie aus der Beobachtung von realen Verfügungs- und Entscheidungspositionen und -situationen andererseits. Als Theorie mit begrenzter Reichweite ist also das Kriterien-Konzept keine Theorie im Sinne eines "geschlossenen Aussagenzusammenhanges mit empirischem Gehalt" (siehe W. Stegmüllers "statement view" von Theorien; 1973, S. 41 f.; 1975, S. 51 f.), wenngleich sich an ihren Ergebnissen die empirisch vorzufindenden steuerlichen Einkommens- und Vermögensbegriffe beurteilen lassen. Die hier entwickelte Begriffstheorie - notwendigerweise eine analytische ${ }^{40)}$ Theorie - liefert den Ausgangspunkt für (ökonomische und politische) Theorien, die auf andere Felder der Erkenntnis und der Lebensgestaltung hinausgehen, die aber nicht mehr unser Thema sind. Den Ausgangspunkt für solche Entscheidungs- und Verhaltenstheorien ${ }^{41)}$ liefert die Begriffstheorie insofern, als Einkommen der "Ausdruck der wirtschaftlichen Wirkungsmöglichkeiten des Menschen" (E. Schuster 1961, S. 54) ist, als Einkommen die Ausgangs- und ZielgröBe der Entscheidungen und des Verhaltens der Empfänger und Verwender von Einkommen sowie der Besteuerten ist in Bezug auf Konsum, Investition sowie auf Geld, Kapital- und Vermögensdispositionen. Neben solchen mikroökonomischen Theorien stehen die speziell steuerlichen; auch für sie gilt, daB die Begriffstheorie des Einkommens zwar die in der Wirklichkeit oft anzutreffende heterogene Zusammensetzung des steuerlichen Einkommensbegriffs aufdeckt und insofern für die Eignung des Einkommens zu distributionspolitischen und leistungsfähigkeitsorientierten Zwecken der Besteuerung die Beurteilungsbasis legt, daB aber steuerüberwälzungen und -wirkungen nicht zum Erklärungsinhalt einer Begriffstheorie gehören, ebensowenig wie solche unmittelbar aus dem heterogenen steuerlichen Einkommensbegriff hervorgehenden sozioökonomischen Phänomene, die zu der Bezeichnung der Einkommensteuer als einer "Klassensteuer"42) geführt haben.

39) 40) 41)

diese Fußnoten befinden sich auf der vorigen Seite.

42) G. Schmölders 1960 sowie Schmölders/Hansmeyer 1980, S. 80, unter Hinweis auf P. Schimke 1940, K. Bräuer 1927, und E. Becker 1940, S. 231 . 
Die "Konsum-orientierung als begriffserklärendes Kriterium
I. Die "Konsum-Determinierung" des Einkom- mens als wirtschaftstheoretisches Scheinproblem

II. Die "Konsum-Orientierung" als "schwaches" Kriterium der Begriffsfindung

III. Zusammenfassung des Ersten Teils

I. Wie sich ergeben hat, ist das Verfügungsziel insofern für die Einkommensdefinition relevant, als mit seiner Hilfe darüber entschieden werden kann, ob eine ökonomische GröBe jenem Bereich, in dem überhaupt nur Einkommen entstehen kann, zuzuweisen ist, also dem Distributionsbereich: Ob ein Ertrag Einkommen werden soll, entscheidet sich mit dem Verfügungsziel "Ausschüttung" bzw. "Entnahme"; ob ein Wertgegenstand Kapital oder Vermögen sein soll, entscheidet der Wirtschaftenden nach seinen ökonomischen Plänen und Verwendungsabsichten hinsichtlich dieses Gegenstandes.

a) Mithin ist das $\quad \mathrm{V}$ e fü $g$ u $\mathrm{n} \mathrm{s} z \mathrm{i}$ e $\mathrm{l}$ im Zusammenhang mit der Einkommensdefinition ausschlieblich für $A$ b g r e $n$ z u n g s p o b 1 e me relevant, nicht jedoch zur Inhaltsbestimmung. Denn das Kriterium der Verfügbarkeit, das der Verfügung und dem Verfügungsziel logisch vorangeht, ist nicht einseitig zu interpretieren, ist weder allein auf die Erzielung bzw. Bildung noch allein auf die Verwendung von Einkommen und Vermögen abzustellen. Nach P.H. Wueller (1938, S. 98) lassen sich nämlich Einkommensbegriffe vom "accrual type" und solche vom "disposition type" unterscheiden, woraus hervorgeht, daB sowohl Erzielung als auch Verwendung begriffsbildend sein können. ${ }^{1)}$ Dennoch ist angesichts anderer Auffassungen $z u$ prüfen, ob $z$ ur vollständigen Definition von Einkommen die Einbeziehung des Verfügungsziels, also die Verwendung, notwendig ist.

1) Die Ambivalenz der Einkommensbegriffsbestimmung $z$. B. für die Reinvermögenszugangstheorie und damit für das Schanz-HaigSimons-Konzept drücken Brown/Bulow (1977, S. 243) wie folgt aus: "It should be noted that the Haig-Simons definition of income is one based on the $u s e$ of income and is identically equal to one based on the s o u r c e of income"; Hervorhebungen dort. Unter "use" verstehen sie Konsum u n d Sparen, unter "Source" Löhne, Zinsen, Renten, Profit, Transfer und Gewinn bzw. Verlust. 
b) In der Iiteratur wird oftmals das Verfügungsziel "Konsum" zum notwendigen Begriffsinhalt gemacht. Wir nennen dies die Versuche, den Einkommensbegriff mit der "K $\circ \mathrm{n} s \mathrm{u}-\mathrm{D}$ e $t$ e $r \mathrm{~m}$ i $i$ e $r$ u $\mathrm{g}$ " $\mathrm{zu}$ beladen.

Zunächst muB die Interpretation I. Fishers (1906, S. 34 ff.), Einkommen sei ein Vorrat von Gütern, über den das Individuum im Laufe der zeit sukzessiv verfügen könne, klar als konsumdeterminiert erkannt werden: Einkommen besteht in den Geldausgaben für den Konsum; nicht konsumlertes Geld gehört nicht zum Einkommen (Sparen). 2) Nach der Auffassung von M. Feldstein (1976b, S. 86) ist überdies der gesamte Haig-Simons-Ansatz eindeutig konsumbestimmt. ${ }^{3}$ )

E. d'Albergo (1953) versteht unter Einkommen nur das, was "in dem betreffenden Zeitraum auch konsumiert werden kann" (S. 31) und verbindet daher mit Einkommen auch nur die "reale Verfügbarkeit" (S. 33). Keinen Zweifel hat auch R. Goode (1980) an der Gleichsetzung von Einkommen und "power to consume". ") E. Schuster ist nicht eindeutig festzulegen, da er teils von der Verfügung "als Konsument", teils von der Verwendung für Verbrauch und Sparen spricht, ${ }^{5)}$ wohingegen D. Schneider (1979a, S. 47) Einkommen als das "In Konsumausgaben verwirklichte Einkommen" definiert und damit wohl die Auffassung aller Befürworter einer persönlichen Ausgabensteuer wiedergibt. ${ }^{6)}$

2) Siehe die Klassifizierung der Auffassung von Fisher als sog. "Konsumstromkonzept" des Einkommens bei O. Ebnet 1978, S. 47 ff.

3) Wir können dem keineswegs zustimmen, denn der erste Teil der Simons'schen Definition ("the market value of rights exercised in consumption") soll lediglich den im zweiten Definitionsteil ausgesprochenen Vermögensvergleich, der Einkommen darstellt, ergänzen um die bereits konsumierten Einkommensteile, die ja sonst von der Definition des Vermögensvergleichs nicht erfaBt würden; sonst bliebe die Definition unvollständiq.

4) S. 51: "Income is the accreation to power to consume. It consists of a person's (a) actual consumption, (b) plus or minus any increase or decrease in the value of his power to consume in the future as measured by his net worth."

5) 1961, S. 54: der Einkommensbegriff ist nur eindeutig, wenn er auf Einkünfte angewendet wird, uber die jemand "als Konsument verfügt"; S. 55: "die Tatsache, daB Verbrauch und Sparen ... nicht scharf gegeneinander abzugrenzen sind, ist eine Begründung dafür, daB der Einkommensbegriff nicht auf die Einkünfte, die im engeren Sinne verbraucht werden, beschränkt werden kann".

6) $1978 \mathrm{~b}$, S. $36 \mathrm{f} .:$ "Zweck dieses Einkommensbegriffs ist es, einen 'Konsumfonds' für die Periode $z u$ bezelchnen." Ferner 1981, S. 147: "Nur jener Tell der zugeflossenen Einnahmen zählt zum

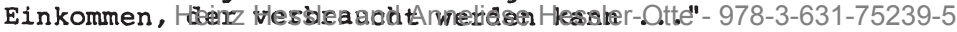


c) Die Konsumdeterminiertheit des Einkommens scheint weithin als ein Problem nicht $z u$ bestehen, da andere Autoren sie nicht weiter hinterfragen, sondern sich allenfalls dazu äuBern, inwieweit denn auch das $\mathrm{V}$ e $\mathrm{r} \mathrm{m}$ ö $\mathrm{g}$ e $\mathrm{n}$ konsumdeterminiert sei.

Was das Vermögen angeht, so eröffnet sich der Zugang $z$ um Problem seiner Konsumbestimmtheit über das Verfügungsziel "Sparen". Für die meisten Menschen führt nur die bewuBte Entscheldung für den Konsumverzicht zum Vermögen (lassen wir einmal Erbschaften, Schenkungen, Vermögensbildung durch Ertragsakkumilation und widerrechtliche Inbesitznahme beiseite).

Sparen wird nämlich dann mit Konsumverschiebung in die zukunft gleichgesetzt (E. Schuster 1961, S. 55). "Letztlich gibt auch der Sparer seinen Anspruch an das Sozialprodukt nicht auf, ja seine Einkommensverwendungsentscheidung ist zugleich eine bestimmte Disposition über das Sozialprodukt" (Krause-Junk 1977, S. 341). Die Nichtaufgabe des Anspruchs kann nur als nachzuholender Konsum verstanden werden. Soll sie aber als späterer Investitionswunsch interpretiert werden, so verlagert sich das Problem abermals nur zeitlich, nicht sachlich.

Dieser gesamtwirtschaftlichen Interpretation schlieBt sich die einzelwirtschaftliche nahtlos an: Sparen ist Verzicht auf gegenwärtige Bedürfnisbefriedigung, ist zeitlich verschobener Konsum. 7) Die mikroökonomische Sicht des Problems erschliebt uns die Motive des Sparens und der Vermögensbildung, die nicht unabhängig von den Funktionen, die das Vermögen für den einzelnen hat, gesehen werden können. Uber die Berücksichtigung der Motive zur Konsumverschiebung läßt sich nun direkt die ökonomische GröBe "Vermögen" mit der Konsumdeterminierung verbinden: Gespart wird dann in diesem Zusammenhang aus dem Motiv des Strebens nach Sicherheit.

Eine direkte gedankliche Verbindung zwischen Vermögen und Konsum wird nicht von allen Autoren bejaht. Den striktesten Zusammenhang formuliert $\mathrm{H}$. Haller. Zunächst ist nach Haller (1971, S. 53 f.) Vermögensbildung und -haltung ein Ausdruck des "Besitzbedürfnisses", dann auch des "Einkommenssteigerungsbedürfnisses"

7) H. Fecher 1979, S. 478 ; H. Haller 1971 , S. 53 ff.; D. Schneider 1971, S. 369, und 1979a, S. 29 u. 49; E. Schuster 1961, S. 56 . 
und des "Vorsorgebedürfnisses". Alle diese Bedürfnisse sind ihm in letzter Konsequenz Ausdruck der Versorgungssicherheit: "Vermögen gibt ... schon dadurch zusätzliche 'Versorgungssicherheit', daB man es aufzehren kann" (H. Haller 1977, S. 226). Mithin dürfen wir folgern, daB für ihn das Vermögen konsumdeterminiert ist. Aber es darf nicht übersehen werden, daB die Funktionen des Vermögens nach Haller die der Bedürfnisbefriedigung sind; sofern man den Generalnenner der Vermögensfunktionen vọ vorn herein in solchen psychischen Kategorien sucht, ergibt sich zuletzt die zurückführung aller Funktionen auf eine einzige fast unausweichlich.

Anders die Analysen von D. Schneider und H. Fecher. ${ }^{8)}$ Nach D. Schneider dient das Vermögen der Erweiterung des Entscheidungsund Handlungsspielraums, der Erweiterung der kreditfähigkeit und zuletzt der Sicherung des künftigen Konsums (1979a, S. 49, und 1971, S. 369). H. Fecher sieht die Hauptaufgaben des persönlichen Vermögens $z$ um einen in der Erhöhung der Realisierungschancen von individuellen Wirtschaftsplänen, zum anderen in der Existenzsicherung (1979, S. 469). Beide Positionen lassen sich mühelos vereinigen, sofern man anerkannt, daB Schneiders Erweiterung der Kreditfähigkeit entweder der Entscheidung und Handlung in der wirtschaftlichen Planung und Betätigung dient oder der Existenzsicherung. Dann ist sowohl bei Schneider als auch bei Fecher die Funktion des Vermögens eine zweifache, nämlich die der höheren Realisierung von Wirtschaftsplänen und die der Sicherung. Damit ist klar herausgestellt, daB Vermögen im Grunde zwei Funktionen hat, nämlich die allokative der Realisierung von Wirtschaftsplänen und -aktivitäten, und die distributive der Sicherung von Existenz und Lebensstandard. Sparen liegt auf der "Nahtstelle" zwischen Allokation und Distribution und hat allokative wie auch distributive Funktionen. Demgegenüber ist die Hallersche Konsumdeterminiertheit des Vermögens ausschlieblich der distributiven Funktion des Vermögens unterworfen (1981, s. 47ff.) ${ }^{9}$ ).

8) Auch die von H.-J. Krupp, 1975, S. 27, aufgeführten Vermögensfunktionen müssen in diesem zusammenhang erwähnt werden.

9) H.-J. Krupp, 1975, S. 27, nennt die folgenden Funktionen des Vermögens (von uns teilweise zusammengefaBt und beziffert): (1) Sicherung der Stetigkeit des Einkommensstroms; (2) Vergrößerung des Einkommensstroms und der Konsummöglichkeiten; (3) Ermöglichung zu selbständiger Erwerbstätigkeit und (4) Erringung von Verfügungsmacht im ProduktionsprozeB. Wir würden die ersten beiden Funktionen als distributive, die letzten beiden als allokative bezeichnen. 
Die Vermögensfunktionen nach C. Folkers (1979, S. 267 f.) erschlieben sich nicht von vorn herein diesem allokativ-distributiven Wirkungsschema, da sie nicht auf die Fernziele der ökonomischen Betätigung, wie Existenzsicherung und Planrealisierung ausgerichtet sind, sondern eher einen Nah-Ziel-Charakter aufweisen. Seine Vermögensfunktionen sind die der Nutzung, der Verwertung, der Macht und der Ubertragung. Noch am ehesten kann die Machtfunktion des Vermögens als eine allokative verstanden werden; Macht ist jenes "zentrale Phänomen" einer Verfügung, die jenseits des des eigenen Vermögens fremde Vermögenseinheiten und andere Personen und auch gesamtwirtschaftliche Vorgänge beeinfluBt (S. 268) . Ferner kann noch am ehesten die Ubertragungsfunktion als eine distributive verstanden werden, da sie mit ihrer Möglichkeit, Vermögen unter Lebenden oder von Todes wegen auf andere Personen $z u$ übertragen, für "die Verteilungsfrage von äuBerster Bedeutung" ist (S. 268). Andererseits sind sowohl die Nutzungsfunktion als auch die Verwertungsfunktion des Vermögens gemischten allokativdistributiven Inhalts. Die erstere erfaBt die Möglichkeit $\mathrm{zu}$ monetären Erträgen sowie zu realen Erträgen aus der Verwendung von Vermögen "zu Konsum- bzw. Produktionszwecken" (S. 267). Letztere ermöglicht die Transformation eines Vermögensobjekts "in andere ökonomisch bewertete GröBen" (S. 268); das können andere Vermögensobjekte sein, doch enthält die Verwertungsfunktion letztlich "die Voraussetzung für eine individuelle zeitliche Konsumverschiebung und eine Absicherung gegen Risiken" (S. 268). Diese Formulierung scheint für eine distributive Auslegung $z u$ sprechen, doch ist Risikoabsicherung auch allokativ denkbar.

d) Ganz gleich, ob man auf die ziele oder die Funktionen abstellt, es erscheint nicht angängig, dem Vermögen wie auch dem Einkommen ausnahms los eine Konsumbestimmtheit zuzuschreiben. Nur unter Vernachlässigung des zeitmomentes könnte das geschehen, indem man auch dem allokativ eingesetzten Vermögen quasi nach Ablauf aller Produktionsvorgänge und "Liquidationen" einen distributiven "Sinn" unterstellt. Selbst wenn man dies für plausibel hielte, würde man doch wesentliche Funktionen des Vermögens in der "vordistributiven" Zwischenzeit übersehen. Aus diesem Grunde ist es auch nicht hilfreich, wenn R. Goode (1980, S. 51) seine Einkommensdefinition auf eine "power to consume" abstellt, die sich auBer im aktuellen Konsum auch in jenem Konsum repräsentiere, den das Nettovermögen einer Person erlaube. 
Wir stehen nicht an, die Konsum-Determinierung von Einkommen und Vermögen als wirtschaftstheoretisches $\mathrm{s}$ ch e i n p r b l e m aufzudecken. Daß sie auch heute noch vertreten wird, erstaunt angesichts der bereits früh erfolgten klarstellungen. In ihnen wird von einer generellen Verwendungsorientierung des Einkommens ausgegangen, die als Verfügungsziele sowohl das Konsumieren als auch das Sparen benennt und somit ganz allgemein auf die Bedürfnisbefriedigung abstellt. So spricht H.C. Simons (1938, S. 98) davon, daß Einkommen ein "Maß" ist, das Konsum und Sparen gleichzeitig zulasse; so schreibt R.M. Haig (1959, S. 59) dem Einkommen die Funktion zu, dem Individuum zu einer "power to satisfy his wants" $z$ verhelfen. Einkommen ist immer nur ein Potential zum Konsum ${ }^{10}$ ) (so auch 0. Ebnet 1978 , S. 33).

II. Es stellt sich also heraus, daß die Einbeziehung des Verfügungsziels in den Einkommensbegriff falsch, jedoch in den Vermogensbegriff anlablich der $B 1$ i u $\mathrm{n} g$ von Vermogen notwendig ist, anlablich der $v$ e $r$ w $n d u n g$ des vermogens aber nur dann nicht $2 u$ Irrtümern fürt, wenn das ziel fur alle verwendungsarten offen formuliert ist: Eine okonomische GroBe, uber die jemand volle Verfugungsgewalt hat, bleibt nicht etwa allein deswegen auBerhalb seines Einkommens oder Vermogens, weil er sie nicht dem Konsum zufüren will. ${ }^{11)}$ Dennoch leistet mit Blick auf die Bedeutung dieser Begriffe für das Verteilungsproblem die gedankliche Verbindung zum Konsum den Dienst elner anschaulichen Beschreibung. Gegenuber dem strengen kriterium der Konsumdeterminierung könnte man also allenfalls das $\mathrm{s} c \mathrm{~h}$ w $\mathrm{ch} \mathrm{e}^{12}$ ) Kri-

10) und auch K.E. Boulding stellt (1981) darauf ab, daß Einkommen nur das sein könne, was "ohne Vermögensveränderung" verbraucht werden könnte (S. 211).

11) N. Kaldor 1955, S. 56 f.: "... it is evident that income and consumption ... do not refer to the same thing, but to two different things; and if we reserve the term income for consumption we should still need another term for what would otherwise be called income; and we should still be left with the problem of how to define the latter."

12) Die Unterscheidung in strenge und schwache Kriterien ist in der రkonomie nicht unbekannt, vgl. in der Wohlstandsökonomlk das strenge paretianische Kriterium des Optimums und seine Ersetzung durch "schwache" Kriterien, die durch die Implikation normativer Prämissen ermöglicht wird; hierzu Weber/Jochimsen 1965 , S. 354. 


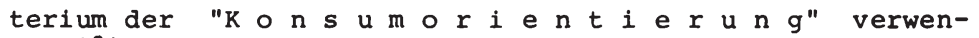
den. ${ }^{131}$

Orientierung auf den Konsum heiBt nicht, Einkommen und Vermögen durch den Konsum $\mathrm{zu}$ definieren, wie das die Determinierung durch den Konsum versucht. Schon H.C. Simons (1938, S. 89 f.) hatte die Zeitpräferenztheorie von I. Fisher (1906 u. 1930) kritisiert, die den DiskontlerungsprozeB als eine wahl zwischen gegenwärtigen und zukünftigen Konsumgütern versteht, als ob alles Sparen immer nur eine Umverteilung des Konsums über die Zeit wäre. Die Kritik Simon' ' richtet sich darauf, daB nicht das gesamte ökonomische Verhalten allein durch Konsumwünsche motiviert sein kann. Und R.A. und P.B. Musgrave (1980, S. 245) sagen: "Economic activity is undertaken to $p$ e $r m 1 t$ consumption" (Hervorhebung durch $\mathrm{HDH}$ ). Deshalb ist auch die Gleichsetzung von vermögen und Einkommen mit ökonomischer verfüqungs- $M$ a $C h t$ und KaufKraf $t$ (A. Oberhauser 1980, s. $667 \mathrm{f}$.) wohl eher als eine orientierung auf den Konsum denn als eine Bestimmung durch inn anzusehen.

Orientierung auf den Konsum heiBt in Rechnung stellen, daB tendenziell wesentliche Teile des Einkommens dem Konsum und der konsumtiven Verwendung des Zwecksparens gewidmet werden, heiBt berücksichtigen, daB unter Verteilungsgesichtspunkten einkommensklassenspezifisch hohe Konsumquoten am Einkommen bestehen und daB in diesen Einkommensklassen die Vermögensbestände vorwiegend in Form des Existenzsicherungsvermögens gehalten werden, die überwiegend späterem Konsum zugeführt werden ${ }^{14)}$.

Konsumorientierung als beschreibendes Kriterium für den Einkommensund Vermögensbegriff bedeutet mithin die Aufnahme von typischen

13) F.W. Wagner 1976b, S. 231: Der Einkommensbegriff ist an den Konsumpräferenzen "orientiert"; Einkommen ist ein "konsumfähiger" Betraọ. Die Position Wagners ist nicht völlig eindeutig, da er erstens die Vermögenserhaltung postuliert und zweitens auf die Konsum-Determinierung seitens Fishers, Hicks' und Schneiders rekurriert, S. 232 .

14) Insofern heibt Konsumorientlerung auch erkennen, daB insbesondere die Besteuerung letztlich darauf aus ist, das Verfügungseinkommen in ein Konsumeinkommen $2 u$ transformieren; siehe hierzu die in $\$ 13$ gemachten Ausführungen $z$ um Kaufkrafteinkommen und 2 um Konsumeinkommen. Auch das schwache Kriterium der konsumorlentierung leistet mithin ebenso wie das starke der Verfügbarkeit eine Vorarbeit für die Aufgabe der Leistungs fahigkeitsindikation. 
sozio-ökonomischen Verhaltensweisen breiter Schichten in den theoretischen Definitionszusammenhang. Und so liegt es durchaus im $\mathrm{zu}-$ ge unserer Argumentationsweise, wenn der Sachverständigenrat (SVR 1982, TZ 254) den Einkommensbegriff mit "Konsumchancen" in Verbindung bringt.

\section{Zusammenfassung des Ersten Teils:}

Für das $z$ i e $l$ unserer Untersuchung, die in der Personalbesteuerung maßgeblichen ökonomischen Merkmale subjektiver Leistungsfähigkeit zu formulieren und ihre Probleme zu diskutieren, waren im ersten Teil der Arbeit die wirtschafts- $t h$ e $\circ$ e $t$ i s c h e $n$ Grundlagen darzulegen. Hierzu gehört erstens die Erkenntnis, daß der a $1 \mathrm{l} \circ \mathrm{k}$ a $\mathrm{ti} \mathrm{v}$ e Bereich des Wirtschaftens analytischer-

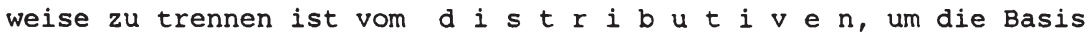
für die Bestimmung der Einkommens- und Vermögensbegriffe $z u$ legen. Die sind allein im distributiven Bereich aufusuchen. Ferner war darzustellen, daß für alle steuerlichen ziele und Maßnahmen eine allokativ-distributive Interdependenz besteht und da $\beta$ daneben die gesamtgesellschaftliche Situation durch die allokativ-distributive "trade off"-Beziehung gekennzeichnet ist. Damit sind schon für die späteren steuertheoretischen Ableitungen Markierungspunkte festgelegt.

$\mathrm{Zu}$ den Grundlagen gehört weiterhin, aufzuzeigen, daß auch das die Personalbesteuerung bestimmende $L$ e $i s t u n g$ f $k$ e $i t s p r i n z i p$ als ein Lastverteilungsprinzip nur in dieser allokativ-distributiven Interdependenz wirksam werden kann und daB seine Anwendbarkeit bestimmten Beschränkungen unterliegt, die in der Anknüpfung an das marktliche Leistungsergebnis gründet.

Als Indikatoren steuerlicher Leistungsfähigkeit gelten gemeinhin $\mathrm{E} i \mathrm{n} \mathrm{k} \circ \mathrm{m} \mathrm{m} \mathrm{n}$ und $\mathrm{V}$ e $\mathrm{r} \mathrm{m}$ ö $\mathrm{g}$ e $\mathrm{n}$. Zu der Klarstellung eines für den distributiven Bereich einsetzbaren Steuerlastverteilungsprinzips tritt demnach das Erfordernis hinzu, wirtschaftstheoretische Einkommens- und Vermögensbegriffe zu entwickeln. Diese sind dem ziel der Untersuchung entsprechend mikroökonomische Begriffe. Analysen der Literatur und eigene überlegungen führen da$\mathrm{zu}$, als die begriffsbildenden Kriterien die "Zugangsregel", die "Entscheidungsregel" und die "verfügbarkeitsregel" zu erkennen. 
Für die Verweisung in den Exkurs spricht ferner, daß manche Ergebnisse des Vergleichs zwischen dem wirtschaftstheoretischen, dem steuerlichen und dem in der Statistik verwendeten Einkommensbegriff Ihre Anwending mündet - hinsichtlich Inhalt und Umfang unausweichlich - in "Totaldefinitionen" für Einkommen und Vermögen.

An diesen wirtschaftstheoretischen Begriffen sind im zweiten Teil der Untersuchung die $s$ e $u$ e $r l i c h$ e $n$ zu messen; anhand der Abweichungen vom Totalitätskonzept sind die steuerlich praktizierten Einkommens- und Vermögens-Begriffsfassungen $\mathrm{zu}$ beurteilen.

$\$ 13$ Das "Verfigungseinkommen" im spektrum der Individualeinkommensbegriffe. -

Ein Uberblick

Nachdem Verfügbarkeit als die conditio sine qua non des Einkommensbegriffs erkannt wurde, läge es nahe, den solchermaBen entwickelten Begriff in eine EinkommensgröBe umzuformulieren und in ein spektrum praktikabler, additiv und subtraktiv ermittelter Individualeinkommensbegriffe einzuordnen. Angesichts des aufgeworfenen Problems einer Gleichsetzung von Einkommen und Konsum wäre es reizvoll, zu prüfen, was tatsächlich "Konsumeinkommen" sein könnte und in welchem Verhältnis dieses zum totalen "Verfügungseinkommen" steht.

Wenn eine solche Analyse als "E $x \mathrm{k}$ u $\mathrm{r}$ II" in den Anhang verwiesen wird, so u.a. deshalb, weil die Entwicklung dieser Einkommensbegriffe nur sinnvoll ist, wenn auch das steuerliche Einkommen dabei berücksichtigt wird, das aber hier noch nicht thematisiert wurde. Das steuerliche Einkommen wird teilweise erst verständlich, wenn die Ausführungen des 7. Kapitels verarbeitet wurden. Ist dies aber geschehen, läBt sich erkennen, in welchem Maße das Kriterium der Verfügbarkeit und das Verfügungseinkommen als eine Vorarbeit zur Bestimmung und Kritik der Leistungsfähigkeitsindikatoren angesehen werden können. 
teilweise außerhalb des hier unmittelbar zu verfolgendenden Analysefortgangs liegen. So notwendig also der Exkurs für die vollständige Behandlung des Problems ist, kann er dennoch an dieser stelle, da der Ubergang von der wirtschaftstheoretischen zur steuerlichen Einkommens- und Vermögensbegriffe $\mathrm{zu}$ leisten ist, ohne Bedenken vorerst übergangen werden.

Immerhin soviel vorab: Es werden dort verschiedene mikroökonomische Einkommensbegriffe eingeführt: Verfügungseinkommen, Bedarfseinkommen, Kaufkrafteinkommen und Konsumeinkommen. Interessant ist nun, daß der weiteste aller dieser Begriffe, der des Verfügungseinkommens, inhaltlich auch seitens der amtlichen statistik in Richtung auf das wirtschaftstheoretische Totaleinkommen interpretiert wird, nämlich durch die Summierung der folgenden Einkommensarten ${ }^{1)}$ :

- Lohn

- Gehalt

- Gratifikationen

- Unternehmereinkommen

- Arbeitslosengeld /-hilfe

- Sozialhilfe

- Rente

- Pensionen

- Kindergeld

- Wohngeld

- eigenes Vermögen

- Vorschüsse
- Vermietung, Verpachtung

- Zinsen

- Altenteil

- BAFÖG

- Stipendien

- Alimentationszahlungen

- private Unterstuitzungen

- Sachbezüge (Naturalbezüge, Deputate)

- Zuschüsse zum vermögenswirksamen Sparen

- vom Arbeitgeber getragener Anteil an einer Werkswohnungsmiete u. ä.

Man erkennt, daß hierbei neben dem produktionswirtschaftlichen Einkommen sowohl der geldlichen als auch der güterlichen Art alle weiteren Formen des transfereinschließenden und vermögenseinschließenden Zugangs erfaßt werden. Steuerliches Einkommen wird erst in einem zweiten Schritt definiert werden können.

Es ist aber bei der Gegenüberstellung der wirtschaftlichen und steuerlichen Einkommensbegriffe im Exkurs II $z u$ beachten, daß der steuerliche Einkommensbegriff auf die z.zt. in der Bundesrepublik Deutschland übliche Rechtsanwendung abstellt und die in den $\$ \$ 17$ bis 27 erarbeitete Kritik an dieser Rechtsanwendung nicht in allen Einzelheiten wiederholt.

1) Statistisches Bundesamt 1992, S. 11 (Einkommens- und Verbrauchsstichprobe 1990); die im Exkurs zugrundegelegte Quelle für die Struktur der Einkommensbegriffe beruht auf einer Publikation des Bundesamtes von 1977; danach erschienene $(1988,1990)$ enthalten keine wesentlichen Angaben zur Einkommensbegriffsstruktur. 


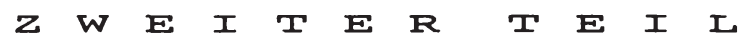

Die ökonomischen Merkmale subjektiver Leistungsfähigkeit in steuerlicher sicht:

Theorie und Politik einer objektivierung der Leistungsfähigkeit

5. Kapite1:

Das Dreistufen-system der $1 e i-$ stungsfähigkeitsorientierten Besteuerung

$\mathbf{S}$

14 Die "Objektivierung" als

die Wahl von Indikatoren

der Leistungsfähigkeit

I. Die Objektivierung innerhalb einer mehrstufigen Konkretisierung der Leistungsfähigkeitsnorm

1. Die dreistufige Normenkonkretisierung aus finanzwissenschaftlicher sicht

2. Die zweistufige Konkretisierung aus steuerlicher Sicht zum Vergleich

II. Die Objektivierung als ein Problem der Indikatorenauswahl und -konkretisierung 203

III. Die objektivierung als ein Problem der Steuersystematik

I. Es ist beklagt worden (so z.B. von D. Schneider 1978b, S. 39 u. 1979c, s. 38), daB im $f i n$ a $n$ w i s $s$ e $s c h$ a $t$ 1 i $c h$ e $n$ Schrifttum allzu selten deutlich unterschieden würde zwischen der "Theorie der Leistungsfähigkeit" als Begründung für die Wahl der Steuerbemessungsgrundlage und damit zugleich für die Wahl der Steuer - A $r$ e $n$ und der "Theorie der Leistungsfähigkeit" als Begründung für den Verlauf der steuerbelastung, also des $T$ a $r i f s$. Sollte Schneider recht haben, so liegt das daran, daß die beispielgebende systematik und Terminologie F. Neumarks $(1947$, S. 83) möglicherweise heute in den 
Hintergrund getreten ist. Neumark unterscheidet nämlich bei der Analyse der Leistungsfähigkeit in eine qualitative und eine quantitative Differenzierung. Erstere erstreckt sich sowohl auf eine Differenzierung nach bestimmten, die Leistungsfähigkeit ausdrükkenden Steuergegenständen wie Einkommen, Vermögensbestand und Vermögenszugang (Erbschaft und Schenkung), als auch auf die Differenzierung innerhalb der jeweiligen Einzelsteuer, etwa nach Einkunftsarten oder -quellen (Einkommensteuer als "Schedulensteuer", als "Summensteuer"). Diese qualitative Differenzierung nennt Neumark die "D $\mathrm{i} f \mathrm{e} r$ e $n t i$ a $i \circ \mathrm{n}$ ". Demgegenüber ist die quantitative Differenzierung der Leistungsfähigkeit auf die Bestimmung der Steuerbemessungsgrundlage und des Steuermaßes abgestellt; Neumark nennt sie die "D i f e r e n z i e r u $\mathrm{n} g$ ".

Aus dieser Zweistufung des Differenzierungsbemühens läBt sich der Versuch herauslesen, die vorerst noch unbestimmte Leistungsfähigkeitsnorm inhaltlich auszufüllen, ihren Sinn 7.u konkretisieren, und zwar in einem analytisch schrittweisen Vorgehen. So soll die Differentiation zunächst einmal festlegen, welches überhaupt die Indikatoren der Leistungsfähigkeit sind: Einkommen, Vermögen, und möglicherweise die aus Einkommen und Vermögen $\mathrm{zu}$ bestreitenden Ausgaben. Konkreter dann läBt sich danach der steuerliche $\mathrm{Zu}-$ griff auf die persönlichen wirtschaftlichen Verhältnisse und die Belastbarkeit des Zensiten abstellen, wenn im Zuge der quantitativen Differenzierung persönliche Freibeträge und der (progressive) Tarif eingerichtet werden.

1. Basierend auf Systematik und Terminologie Neumarks wird in dieser Arbeit die steuerliche Instrumentierung. (d.h. die Bestimmung der steuerlichen Basis, der Bemessungsgrundlage und des Tarifs) so präsentiert, daß das Bemühen erkennbar wird, das Leistungsfähigkeitspostulat "von stufe zu stufe" mehr und mehr zu k $\circ \mathrm{nkret}$ i s i e r e n; daß die Absicht deutlich wird, die qualitative und quantitative Differenzierung als eine steuerliche "Instrumentierungsleistung" analytischer Art zu kennzeichnen, die "zunehmend leistungsfähigkeits-orientiert" ausgestaltet ist. Es ergab sich aus einem solchen Versuch die Entwicklung einer $d r e i s t$ u $i g$ e $n$ Instrumentierung, nämlich in Form 
der "Objektivierung", der "Personalisierung" und der "Individualisierung". Das Systematische dieser Instrumentierungsleistungen liegt sowohl im Aufzeigen ihrer jeweiligen Beziehungen zueinander als auch im Ausweis ihrer gemeinsamen Zielausrichtung begründet. Im Hinblick auf das steuerpolitische ziel, die persönliche Leistungsfähigkeit $z u$ erfassen und danach die steuerlast $z$ uzumessen, sind alle Maßnahmen, die dazu dienen, die Grundlagen der persönlichen Besteuerung $z u$ ermitteln - also die Indikatoren und die Tarifverläufe festzulegen -, Instrumentierungsleistungen. Die Beschreibung solcher Instrumentierungen ist als ein Auswahlund ordnungsproblem, somit als ein theoretisch-analytisches Vorgehen zu sehen.

2. Zu fragen ist, ob eine dreistufige Normenkonkretisierung dem Problem angemessen ist. Im Gegensatz dazu hat D. Birk ${ }^{1 /}$ in jüngerer zeit die $s t e u e r r e c h t s w i s s e n s c h a f t-$ $I$ i $c h$ e Literatur um den Vorschlag bereichert, eine zunehmende Konkretisierung des Leistungsfähigkeitsprinzips dadurch zu erreichen, $d a B$ er eine $z$ w $i s t$ u $i g$ e "Abfolge von Wertungen" einführt. Er unterscheidet zwischen "Primärableitungen" mit der Formulierung von "Grundwerten" und "Sekundärableitungen" mit der Formulierung von "Einzelwertungen". Die Grundwertungen liegen nahe am Gerechtigkeitspostulat und legen die Basis für die Sekundärableitungen. Letztere sollen die Grundwerte detaillieren und auf diese Weise die rechtliche steuergestaltung konkretisieren. Um diese steuerrechtliche Absicht mit unserer finanzwissenschaftlichen vergleichen $z u$ können, ist eine Gegenüberstellung

1) Seine Arbeit "Das Leistungsfähigkeitsprinzip als Maßstab der Steuernormen. Ein Beitrag zu den Grundfragen des Verhältnisses Steuerrecht und Verfassungsrecht" (Habilitationsschrift München) wurde 1981 als Typoskript mit dem erstmals verliehenen "AlbertHensel-Preis" ausgezeichnet; Birk hatte uns seinerzeit freundlicherweise sein Typoskript noch vor Drucklegung zur Auswertung zur Vefügung gestellt, wofür ihm an dieser Stelle nochmals ausdrücklich gedankt sein soll. Mittlerweile sit die Schrift längst publiziert in der Reihe "Steuerwissenschaft" als Band 13. Wir beziehen uns im folgenden auf $\mathrm{S} .52 \mathrm{ff}$. dieser publikation. Im übrigen siehe die Besprechung durch $\mathrm{K}$. H. Friauf in StuW 58 . (11.) Jg. 1981, Nr. 4, S. 392.

Ein besonderes Merkmal der Arbeit ist, daB Birk neben den Steuern auch die staatlichen Transferleistungen mit dem Leistungsfähigkeitsprinzip verknüpft und solchermaßen zu einem einheitlichen Verteilungsprinzip kommen will. Hierauf aber werden wir erst an späterer Stelle eingehen. 
der zweistufigen mit der dreistufigen Normenkonkretisierung erforderlich.

a) Zu den Primärableitungen rechnet Birk in einem ersten Fragenkreis die Entscheidung darüber, welches wirtschaftliche Potential als MeBgröBe der Leistungsfähigkeit dienen und damit die Grundlage der Besteuerung sein soll. Dies betrifft die Steuerarten. Der zweite Fragenkreis umschlieBt die Probleme der ökonomischen BezugsgröBen innerhalb der ausgewählten Steuerarten (z.B. der Einkommensteuer) und erfordert eine Entscheidung dem Grundsatz nach, was Einkommen sein soll (die Definition des Rechtsbegriffs selbst wäre eine Sekundärableitung); hierher gehören etwa Fragen nach der Einrichtung eines Existenzminimums überhaupt, nach dem Prinzip der Soll- oder der Ist-Leistungsfähigkeit, nach der Auswahl der Leistungsfähigkeitsindikatoren, nach der Anwendung bestimmter Besteuerungsprinzipien wie des Netto-Prinzips und des Nominalwertprinzips zur Ermittlung der "objektiven Leistungsfähigkeit" und schlieblich nach Berücksichtigung der relevanten "notwendigen" oder "fakultativen" Elemente in den persönlichen Verhältnissen der Steuerpflichtigen. Der dritte Fragenkreis umschliebt die grundsätzliche Entscheidung für einen proportionalen oder progressiven Tarif (nicht die des konkreten Tarifverlaufs).

b) Zu den Sekundärableitungen rechnet Birk die Festlegung der konkreten rechtlichen Fassung des Einkommensbegriffs (Reinvermögenszugangs-, Quellenbegriff oder eine Kombination von beiden), die konkrete Bemessung des steuerfreien Existenzminimums, die Staffelung der Leistungsfähigkeit nach Familienstand und Kinderzahl und letztlich die tatsächliche Gestaltung des progressiven Tarifverlaufs.

c) Um Gemeinsamkeiten und Gegensätzlichkeiten mit einer finanzwissenschaftlichen Betrachtung des Konkretisierungsproblems $\mathrm{zu}$ demonstrieren, sei die folgende Gegenuberstellung gewählt, die in verkürzter Form und stellenweise veränderter Relhenfolge die Birk'sche Einteilung $z$ um Ausgangspunkt wählt und ihr die von uns präferierten Objektivierungs-, Personalisierungs- und Individualisierungsbegriffe gegenüberstellt: 


\section{steuerrechtliche Zweistufung}

I. Primärableitungen

(1) wirtschaftliche Potentiale und Steuerarten

(2) ökonomische Bezugs größen :

a) Ist-/Soll-LF

b) objektive LF (Netto-Prinzip/ Nominalwert-Pr.)

c) Indikatorenauswahl

d) Existenzminimum grundsätzlich

e) pers. Verhältnisse

(3) proport. od. progress. Tarif grundsätzlich

II. Sekundärableitungen

(1) Existenzminimum konkret

(2) Tarifverlauf konkret

(3) Einkommensbegriff konkret

(4) Staffelung der LF nach Familienstand finanzwissenschaftliche Dreistufung

I. Objektivierung, $§ 17-27$ (Steuerbasis)

II. Personalisierung, § 15 (Steuerbemessungs grundlage u. -tarif)

\section{Objektivierung}

III. Individualisierung, \$ 16 (Steuerdestinatar, Besteuerungseinheit)

Sinnvollerweise gehen die steuerrechtlichen wie die finanzwissenschaftlichen Konkretisierungsbemühungen vom "wirtschaftlichen Potential" bzw. vom realen wirtschaftlichen Ergebnis la)oder - in der Ausdrucksweise von F. Neumark - von der "matière imposable" 2) aus; es zeigt sich aber, daB das finanzwissenschaftliche Bemühen, die Leistungsfähigkeit in den verschiedenen Indikatoren $z u$ konkretisieren und $z u$ objektivieren, den Birk'schen ersten Fragenkreis, Teile des zweiten und sogar einen Teil der Sekundärableitungen mit erfaBt. Denn sowohl die grundsätzlichen Entscheidungen über die "ökonomischen BezugsgröBen" als auch die konkrete rechtliche Fassung des Einkommensbegriffs sind analytische Maßnahmen, um die

1a) Im Dritten Teil legen wir dar, daß in der ökonomik die Unterscheidung zwischen der bloßen Möglichkeit zu einer Leistung und der tatsächlich realisierten Leistung außerordentlich wichtig ist.

2 ) Der "matiére imposable" entspricht $K$. Tipkes "Besteuerungsgut" (1991, S. 131), die grundsätzlich besteuerbaren Vorgänge oder Zustände. 
Leistungs- und steuerliche Belastungsfähigkeit zunächst einmal objektiv festzulegen. Alle Entscheidungen und MaBnahmen der o b j e k $t$ i $i$ e $r$ u $g$ beziehen sich auf die $s t e u$ e $r$ b a s is ("comprehensive tax base"); auf die steuerbasis richten sich alle Vorgänge der EinschlieBung von Indikatoren (umfassender Einkommensbegriff) und der Einschränkungen in der Verfügbarkeit ( $\S 18,21-27$ ). Die Frage der Indikatorenauswahl, die Birk dem zweiten Fragenkreis zuordnet, gehört nach finanzwissenschaftlichem Verständnis unmittelbar in die Ausgangsfrage nach der "matière imposable" und hat zudem steuersystematische Konsequenzen.

Demgegenüber ist selbst die Grundsatzentscheidung über die Einrichtung eines steuerfreien Existenzminimums erstens von dem Problem der konkreten Tarifgestaltung nicht völlig zu trennen und zweitens ein Problem der Personalisierung (der "subjektiven Leistungsfähigkeit"), und zwar insofern, als sie - wie auch die Berücksichtigung der "persönlichen" Verhältnisse in der Belastbarkeit - auf die Person abstellt; auch die Entscheidung für einen progressiven Tarif und die Gestaltung der gleichförmigen, verzögerten oder beschleunigten Progressivität im einzelnen ist allein mit Blick auf die Leistungsfähigkeit von Personen und Haushalten sinnvoll. Nach unserem Verständnis sind die MaBnahmen zur Bestimmung der $B$ e m e $s$ u n g s g $r$ u d l a g e durch Abzug von Freibeträgen wie auch die Anwendung des $T$ a $r i f s$ auf eben diese Bemessungsgrundlage solche der $\mathrm{P}$ e $\mathrm{s}$ o n a 1 i s i e $r$ u $\mathrm{n}$.

Schlieblich sehen wir in der Staffelung der Leistungsfähigkeit und der steuerbelastung nach dem Familienstand ein so grundsätzliches Problem, daB wir ihr den Stellenwert einer dritten und gleichwertigen Konkretisierungsstufung zuerkannt haben. Dies erhellt schon allein aus der Tatsache, daB z.B. zur Frage der Ehegattenbesteuerung bzw. Haushaltsbesteuerung das Bundesverfassungsgericht sich äuBern muBte. In der Finanz- wie auch in der Steuerrechtswissenschaft wird seit langem diskutiert, ob nicht das Ehegattensplitting nur ein Teilproblem lösen (bzw. eben nicht lösen) kann und ob es konsequenterweise durch ein Familiensplittung ergänzt oder durch die Individualbesteuerung völlig abgelöst und durch ein umfassendes System von steuerlichen Abzugsregelungen 
(von der Bemessungsgrundlage bzw. Steuerschuld) erweitert werden muB. Ob nur der aktiv im WirtschaftsprozeB Tätige ein Einkommen hat oder ob das von ihm erworbene Einkommen auch zum Teil den von ihm abhängigen Familienangehörigen als deren originäres Einkommen zugerechnet werden soll, ist eine Frage, die uber das rein రkonomische hinausgeht und originär rechtliche Vorstellungen bzw. Fiktionen berührt. Wenn diese MaBnahmen als I n d i $\mathrm{v}$ i d u a $\mathrm{l}$ i s $i$ e $\mathrm{r}$ u g bezeichnet werden, so deshalb, weil auch die Haushalt- und Ehegattenbesteuerung an der Grundvorstellung der Individualbesteuerung, so wie sie sich aus der "ad personam-Regel" des Einkommenszugangs logisch ergibt, gemessen werden müssen. Familien- und Ehegattenbesteuerung sind dann als Abweichungen von der Individualisierung $z u$ diskutieren.

II. $0 \mathrm{~b} j \mathrm{e} k \mathrm{t} \mathrm{v} i \mathrm{e} \mathrm{r} \mathrm{n} \mathrm{g}$ der Leistungsfähigkeit, also die Bestimmung der Steuerbasis, ist sowohl ein Problem der Entscheidung über die Indikatoren der Leistungsfähigkeit schlechthin und damit der Auswahl von Steuerarten aus dem Gesamtsystem, als auch ein Problem der genauen Bestimmung dessen, wie innerhalb einer Einzelsteuer der Steuertatbestand qualitativ und quantitativ zu definieren ist. Ein solcher Tatbestand ist objektiv, d.h. unabhängig von den Präferenzen, Erwartungen und Verwendungsdispositionen des einzelnen, festzustellen. ${ }^{3)}$ Grundsätzlich können nur bei den Personalsteuern die eine steuerliche Leistungsfähigkeit bestimmenden Faktoren umfassend und direkt berücksichtigt werden (F. Neumark 1979 , S. 318).

a) Das Problem der Objektivierung besteht also in dem Auffinden von Faktoren der individuellen Leistungsfähigkeit überhaupt. Als solche sind sie die "subjektbezogenen" (Neumark 1979 ebda). Subjektbezogen bedeutet, daB die Erfassung und die zurechenbarkeit eines Steuerobjektes bei einer bestimmten Person möglich ist, daB mit der Bestimmung dieser Person der steuerpflichtige und der Zahllastpflichtige ermittelt wird. ${ }^{4)}$

3) Siehe das "Objektivitätspostulat" bei o. Ebnet 1978, S. 35. 4 ) Als "Subjektivierung" bezeichnet F. Neumark (1951, S. 68) den Vorgang, der den Subjektsteuern arteigen, der den objekt(Forts. siehe folgende Seite) 
Nur eine Person bzw. ein Steuersubjekt kann leistungsfähig sein (siehe $\$ 20$ ), da nur einer Person (bzw. der "Haushaltsinstitution" im Wirtschaftskreislauf), nicht aber Gegenständen (wie Betrieben oder Grundstücken, d.h. den Produktionswirtschafts-Institutionen im Wirtschaftskreislauf) Einkommen und Erbschaften zuflieBen können, und da in letzter Konsequenz nur die Person Bestände an Vermögen hält und Konsum-Ausgaben tätigt.

Als Leistungsfähigkeitsindikatoren können, wenn auch mit unterschiedlich behaupteter Eignung, folgende gelten: das Einkommen, das Vermögen (in der Form des selbst gesparten oder des geerbten bzw. des als Geschenk erhaltenen Vermögens) und der Verbrauch bzw. die Ausgaben. Demnach werden als Personalsteuern bezeichnet: $:^{5}$ )

- die Einkommensteuer, ${ }^{6}$ )

- die Einkommensdifferenzsteuer, 71

- die persönliche allgemeine Ausgabensteuer, ${ }^{8)}$

- die persönliche allgemeine Vermögensteuer und

- die Erbschaft- und Schenkungsteuer.

Forts. Fn. 4 :

steuern fremd ist. Wir haben in diesem Zusammenhang stets $z u$ beachten, daB die Objektivierung innerhalb der Personalsteuern begrifflich und unausweichlich auch mit der personalen Zuordnung des Besteuerungsgegenstandes (Einkommen, Vermögen) verbunden ist; dies wäre als die "Subjektivierung" zu bezeichnen, als die Zuordnung der objektivierten Leistungsfähigkeitsindikatoren $z u$ einem Steuersubjekt ( $\$ 11$ : Der "ad personam"-Inhalt der "Zugangsregel".

$5)$ In der neuesten Einteilung des Handbuches der Finanzwissenschaft, 3. Auf1., Bd. II, Tübingen 1979, S. 317 ff. Hervorzuheben ist, daB die hier getroffene Aufzählung und Gruppierung sich von der Neumark'schen Einteilung in seinem zitierten Uberblick unterscheidet: (1) Einkommensteuern; (2) Einkommensdifferenzsteuern; (3) Vermögensteuern (hier unterscheidet Neumark in die "periodisch-nominalen" (denen er die aus dem Ertrag $\mathrm{zu}$ zahlende Vermögensteuer zurechnet) und in die "einmalig-realen" Vermögensteuern (zu denen er die sog. Vermögensabgaben und die NachlaBsteuern rechnet, letztere nur cum grano salis); sog. periodisch-reale, d.h. laufende, aber aus der Substanz $\mathrm{zu}$ zahlende Vermögensteuern, kennt seine Einteilung nicht; (4) Vermögenszuwachssteuern (zu denen in erster Linie die Erbanfallsteuer zählt, aber auch andere, sofern sie den Gesamtbetrag des Zuwachses einschlieBlich der Berücksichtigung von persönlichen Momenten enthalten); (5) persönliche Ausgabesteuern. F. Neumark 1979 , S. 320 f.

Fn. 6,7 und 8 siehe folgende seite 
b) Die Indikatoren der Leistungsfähigkeit "Einkommen", "Vermögen" und "Ausgaben" qualitativ und quantitativ $\mathrm{zu}$ bestimmen, ist eine Instrumentierungsleistung, die innerhalb der Einzelsteuergesetze zu vollziehen ist. 9) Sie besteht zunächst in einer Qualifizierung der Ströme (Einkommen, Ausgaben) und Bestände (Vermögen) ihrem Inhalt und Steuergegenstand nach sowie in der sachlichen Ein- und Ausgrenzungen (Befreiungen) bestimmter Bestandteile.

Dieser Objektivierungsschritt umfaBt ferner die Periodisierung der Einnahmen und Ausgabenströme sowie die Bewertung aller Bestände. Insgesamt dienen die Qualifizierungs-, Periodisierungsund BewertungsmaBnahmen dazu, das jeweilige Besteuerungsgut so zu bestimmen, $d a B$ es unter Leistungsfähigkeitsaspekt dem einzel-

Fn. 6:

Also nicht die Körperschaftsteuer, die oftmals fälschlicherweise als Einkommensteuer der juristischen Personen bezeichnet worden war. Nach dem nunmehr in Band II des o.a. Handbuchs vorgelegten System wurde sie zwischen den Personal- und den Ertragsteuern lokalisiert, wohin sie auch gehört. Vermutlich wegen dieser Unterscheidung war die Einkommensteuer noch 1975 in der Vorankündigung von den Herausgebern des Handbuches als "persönliche allgemeine" avisiert worden, doch hätten sich dann Schwierigkeiten ergeben, die auch von Einzelunternehmern zu zahlende "Gewinnsteuer" in "persönliche" Einkommensteuern $\mathrm{zu}$ inkorporieren.

Fn. 7:

Eine von der Einkommensteuer gesonderte Steuer auf jenen Teil des Einkommens, der eine zeitlich gesetzte Norm ("Mehreinkommensteuer") oder eine qualitativ gesetzte Norm ("Ubergewinnsteuer") überschreitet; nicht hierzu zählt die angelsächsische "excess profits tax", da sie von Unternehmen erhoben wird (so F. Neumark 1979 , S. 320), jedoch gehört hierher die persönliche "Kriegsgewinnsteuer" (E. Willms 1979, S. 404, rechnet auch Ubergewinnsteuern, die von z.B. Mineralöl-Konzernen gezahlt werden könnten, hierzu). Auf Einkommensdifferenzsteuern wird von uns nicht eingegangen.

Fn. 8 :

Die "spendings tax" in einem Entwurf an den FinanzausschuB des amerikanischen Senat aus dem Jahre 1942, siehe A.G. Buehler 1950, S. $8 \mathrm{ff}$.; ferner die "expenditure tax" von N. Kaldor 1955; hierzu R. Peffekoven 1979a, S. 417 ff.; P. Zumstein 1977, wie auch J. Mitschke 1976 u. 1980b sowie D. Schneider 1971 u. 1979 a.

9) So stellt K. Tipke für die Einkommensbesteuerung fest, daB es einem logischen Aufbau des Einkommensteuergesetzes entspräche, $\mathrm{z}$ unächst die objektive Leistungsfähigkeit einer natürlichen Person als Träger der Leistungsfähigkeit zu erfassen (1991, S. 197), grob schematisiert als "summe der Bezüge ./. Summe der Erwerbsabzüge = Summe der Einkünfte". 
nen $z$ urechenbar gemacht wird. Diese zurechnung ad personam läBt sich als "Subjektivierung" bezeichnen, die einen wichtigen Zwischenschritt darstellt von der Objektivierung hin zur Personalisierung.

III. Schon allein um die "Reichweite" des Differentiationsproblems anzudeuten, ist der steuersystematische Bezug kurz aufzuzeigen. Das Problem liegt im Verhältnis der Einkommens- zur Vermögensbesteuerung. Würde eine Einkommensteuer so ausgestaltet, daB sie sämtliche subjekt- und personalsteuerlichen Tatbestände und Gegenstände, wie Einkommen aus Arbeit und Kapital, aus Vermögen, Erbschaften und Schenkungen enthielte, dann erfaBte sie das Gesamtspektrum dessen, was sich an ökonomischen Werteströmen überhaupt einem Subjekt direkt zuordnen läBt; eine solche umfassende Einkommensteuer inkorporierte neben der engeren Einkommensteuer auch die Vermögen- sowie Erbschaft- und Schenkungssteuer. Rein technisch ließe sich die Objektivierung in einer einzigen Personalsteuer konzentrieren. ${ }^{10)}$ Dem stehen aber im wesentlichen Belastungsprobleme gegenüber, die sich aus dem aperiodischen Anfall von Vermögenszugängen in Verbindung mit dem progressiven Tarif ergeben. ${ }^{11)}$ Aus diesem Grund wird der objektivierung der Leistungsfähigkeit in verschiedenen Einzelsteuern der Vorzug gegeben.

Würden die personalen Zugänge an Einkommen und Vermögen (durch Erbschaften, Schenkungen u.a.) allein mit einer Einkommensteuer belegt, ergäbe sich daraus eine unvollständige Erfassung der Leistungsfähigkeit: Eine "einheitliche" Einkommensteuer, die die Erträge der Vermögensteuer mit erfaBt und keine gesonderte Vermögensteuer neben sich kennt, ist nach F. Neumark (1979, S. 327) ungeeignet, jenes spezifische Merkmal der steuerlichen Leistungsfähigkeit $z$ u erfassen, das im Vermögens - B e s i t $z$ als sol-

10) Hierzu N. Andel 1979a, S. 337-355, der die Gesamterfassung der Entgelte für Marktleistungen, der zugerechneten Einkünfte, der persönlichen Transfers, der Wertzuwächse und auch der Erbschaften und Schenkungen diskutiert.

11) Siehe das Plädoyer für eine getrennte Besteuerung bei A. Oberhauser 1979, S. 493. 
chem liegt, ohne Rücksicht auf dessen Ertrag. ${ }^{12)}$ Dieses Moment nat sogar einige Befürworter der Ausgabensteuer dazu bewogen, das Vermögen neben den Ausgaben ergänzend $z u$ besteuern (so D. Schneider und J. Mitschke, siehe 3. Teil), nachdem auch N. Kaldor (1980, Comments) zugeben mußte, daß mit der Ausgabensteuer der "geizige Reiche" kaum ausreichend steuerlich zu treffen wäre.

S 15 Die "personalisierung" als steuerlastzuweisung an unterschiedlich leistungstähige personen

I. Ziel und Maßnahmen der Personalisierung 207

II. Das allokativ-distributive Problem: Der "progressionsdeterminierte" Einkommensbegriff

Wenn auch entsprechend der getroffenen thematischen Abgrenzung die Personalisierungs- und Individualisierungsprobleme hier nicht detailliert $\mathrm{zu}$ behandeln sind, sollen dennoch einige $\mathrm{G} r \mathrm{u} n \mathrm{~d}$ $\mathrm{p} r \circ \mathrm{b} l \mathrm{e} \mathrm{m}$ e insoweit vorgetragen werden, wie sie auf den Einkommens- und vermögensbegriff Einfluß haben.

I. Die Personalisierung ist nach der objektivierung der nächste Konkretisierungsschritt in dem Bestreben, die Leistungsfähigkeit möglichst genau in den persönlichen verhältnissen des Steuerpflichtigen zu entdecken. Sie will zweierlei erreichen: Zum einen, die steuertraglast i $\mathrm{n} d \mathrm{i}$ i d u e $1 \mathrm{l}$ so zumessen, wie das nach den gesellschaftlich akzeptierten Gerechtigkeitskonventionen mit seiner persönlichen wirtschaftlichen Leistungsfähigkeit $\mathrm{zu}$ vereinbaren ist; $\mathrm{zum}$ anderen, die Steuerlasten im $i \mathrm{n} t \mathrm{e} \mathrm{r}$ i n d i v i d u e 1 l e $n$ Vergleich so verteilen, wie es den gesellschaftspolitischen Distributionszielen entspricht. So verhilft die Personalisierung dem Grundsatz der VerhältnismäBigkeit der Besteuerung und solchermaBen auch der Konvention einer "vertikalen" Gerechtigkeit zur Geltung.

12) Allerdings ergeben sich - wie an anderer Stelle darzulegen ist - aus der Besteuerung allein des Bestandes weitere Probleme, die mit der Besteuerung des Sparens und der Vermögensakkumulation zusammenhängen. 
a) Die Konkretisierung aller die individuelle Leistungsfähigkeit berührenden Umstände, nämlich einerseits die Anpassung der Steuerbemessungsgrundlage an die unterschiedliche Belastung infolge der Existenz- und Vorsorgesicherung und weiterer (tatsächlicher und sittlicher) Verpflichtungen, andererseits das Anlegen des (bei Personalsteuern typischerweise progressiven) Tarifs an diese so personalisierte Bemessungsgrundlage nennt F. Neumark expressis verbis die "Persona $\mathrm{l}$ i s $i$ e $r$ u $\mathrm{g}$ ". "1) Die typischen Mittel der $s t e u$ e $r$ b e e s $s$ u g g r u n d1 a $g$ e $n$-Differenzierung sind die personengebundenen Freibeträge und Abzugsposten, wohingegen sich die $t$ a $r$ i men in der Einrichtung eines Grundfreibetrages, ${ }^{2)}$ dem Festlegen des (verzögerten, gleichförmigen bzw. beschleunigten) Progressivitätsmaßes, eines unteren Plafons bzw. eines durchgehenden Tarifverlaufs und $z$ uletzt eines oberen Plafonds ausdrücken.

b) Die Differenzierung der Bemessungsgrundlage (vgl. auch $\S 43$ IV) soll zum einen die Existenzsicherung des einzelnen gewährleisten, $z$ um anderen der persönlichen Lage des Steuerpflichtigen durch den steuerlichen Abzug eines gewissen "Mehrbedarfs" Rechnung tragen. Die $\mathrm{Ex}$ is te $\mathrm{nz}$ s $i \mathrm{c}$ e $\mathrm{r}$ u $\mathrm{g}$ als steuerliche Freistellung jener Aufwendungen, die einen minimalen Lebensstandard $w$. Schreiber 1959, S. $211 \mathrm{ff.}$ ) erlauben würden, wird steuertechnisch heute durch die Einräumung eines "Grundfreibetrags" im Tarif gewährleistet, ohne daB jedoch anerkannt worden wäre, daB diese Existenzsicherung für jedes Familienmitglied vonnöten ist. Neben dem Grundfreibetrag sind jedoch weitere existenzsichernde Abzugsmöglichkeiten im Einkommensteuerrecht enthalten, vorwiegend in den Vorschriften über die "auBergewöhnlichen Belastungen". Zugleich kann - in Abweichung von der geltenden Regelung - nicht übersehen werden, daB bestimmte Aufwendungen, die erst den Erwerb von Einkommen möglich machen (die also die Voraussetzung für

1) 1979 , S. 326 u. 322; ders. 1970, S. 170: "Echte Personalisierung" durch persönliche Freibeträge und progressiven Tarif. Abweichend davon versteht 0 . Ebnet (1978, S. 34) unter dem "Personalitätspostulat" die Tatsache, daB Einkommen eine personenbezogene GröBe ist; wir haben dies als die "ad personamRegel" des Zugangs an ökonomischen Größen bezeichnet.

2) Sofern man nicht den Grundfreibetrag als einen das Existenzminimum sichernden Freibetrag in die Abzugsregelung aufnimmt. 
eigenes Einkommen sind), den Charakter von Ausgaben der Existenzsicherung haben. ${ }^{3)}$ Ist die Existenzsicherung als Ermöglichung des Uberlebens ein humanitäres Problem, so ist die sicherung des Einkommenserwerbs eln rationales, da der sich selbst erhaltende und sichernde Mensch nicht auf die humanitäre Einstellung der Mitmenschen angewiesen sein soll. Eine so weit gehende steuerliche Schonung aller existenzsichernden Aufwendungen hat entsprechend zur Folge, daB die Bildung von Sicherungs- und Vorsorge-Vermögen möglich wird und daB in diesem Umfang spätere Transfers, die die Gemeinschaft aufzubringen hätten, entfallen können. Bestimmte Aufwendungen, die als "Werbungskosten" bezelchnet werden und in den Bereich des Einkommenserwerbs fallen, haben eine existenzsichernde Eigenschaft. ${ }^{4)}$

Als "M e h r b e d a r f" wird hier von uns ein solcher Bedarf bezeichnet, der oberhalb des (fremdbestimmten) Bedarfs fur die Existenzsicherung, aber unterhalb des (selbstbestimmten) Bedarfs für die freie Einkommensverwendung liegt und zwei Gruppen von Aufwendungen enthält: (1) den "V $\circ$ r s o r g e b e d a r f" mit einem nicht ganz so hohen Fremdbestimmungs- und Zwangscharakter wie der Existenzsicherungsbedarf; er unfaBt das sparen für die Uberbrückung von Einkommensausfällen im Krankheits- und Katastrophenfall, das Alters- und das Ausbildungssparen (die Mehrzahl dieser Aufwendungen wird einkommensteuerrechtlich von den "Sonderausgaben" repräsentiert); ${ }^{5)}$ (2) den "V e r p f 1 i c ht u n g s b e d a r f" ; dieser der freien Verfügung schon erheblich näher stehende Bedarf umfaBt Aufwendungen, denen sich der steuerpflichtige aus tatsächlichen, rechtlichen oder sittlichen Gründen nicht entziehen kann. ${ }^{6)}$ wer aus schätzenswerten, jedoch freiwilligen

3) So auch G.B. Krause-AblaB 1971, S. 206 u. 211: Mindesteigenbedarf = Mindestbedurfnisbefriedigung + Aufwendungen für die Einkommensquelle.

4) Vgl. jedoch die Kritik von F. Neumark (1947, S. 49): "Produktionskosten der Arbeitskraft" sollten nicht in Abzug gebracht werden düren.

5) So die Beitrăge $z u$ den verschiedenen Versicherungen, die Aufwendungen für die Aus- und Welterbildung, für die auswärtige Unterbringung von Rindern in der Berufsausbildung, auch wenn letztere vom geltenden Gesetz unter die "außergewöhnlichen Belastungen" subsumiert werden.

6) Auch wenn diese Beschreibung den qualitativen Erfordernissen der auBergewöhnlichen Belastungen ( $\$ 33 \mathrm{EStG}$ ) entspricht, sollte

(Forts. siehe folgende seite) 
Gründen Gemeinschaften und Zwecke, die ihm oder der Gesellschaft nützen, unterstützt, kann den Zwangscharakter solcher Verfügungen nicht dartun. Sind gleichwohl solche Aufwendungen gesellschaftspolitisch gewünscht, böte sich hier statt des Abzugs von der steuerbemessungsgrundlage der Abzug von der Steuerschuld an, um wenigstens hinsichtlich dieser Art von Aufwendungen die Diskussion um die Abzugsfähigkeit mit ihren negativen distributiven Effekten zu entschärfen. Was auBerhalb der Diskussion stehen sollte, nämlich die Abzugsfähigkeit der existenzsichernden und wohl auch der vorsorgesichernden Aufwendungen von der Bemessungsgrundlage, das muB nicht zwingend auch für sämtliche Aufwendungen des Verpflichtungsbedarfs gelten.

II. Das weitere, für unsere grundlegenden Betrachtungen wesentliche Problem liegt darin, daB sich aus dem zusammenspiel von Freibetrags- und Progressionsregelung das Phänomen des "p $r$ o g r e s $s \circ n s d e t e r m i n i$ e $t$ e $n$ E i n k m $m e n s$ b g r i f $\mathrm{f} "$ mit seinen distributiven und allokativon Problemen ergibt (vgl. G. Schmölders 1950a, S. 122f): Schaffung von Aufwand und die Umkehr von Ursache und Wirkung. Die Steuer bestimmt die Leistungskraft; unter dem Druck der Progression muß die Entstehung von Gewinn möglichst vermieden werden; die Progression determiniert die "Wahl" des Einkommens (S.F. Franke 1983)

a) Unter diesem Phänomen soll verstanden werden, daB im Hinblick auf die $z u$ erwartende progressive Belastung distributions- und allokationspolitisch motivierte Abzugsregelungen vom Steuerpolitiker eingerichtet und vom steuerpflichtigen wahrgenommen werden, die das $z u$ versteuernde Einkommen kürzen und die Steuerbelastung mindern. Das distributive Problem entsteht dadurch, daB der Progressionsvermeidungsvorteil mit zunehmendem Einkommen wächst und daB für Einzel- und Personenunternehmungen wie auch für Freiberufler die allokative Ertragsbesteuerung als private Personalbesteuerung durchgeführt wird (allokativ-distributive Mischbesteuerung, siehe $\$ 20$ ). Eine Begrenzung der progessions-

Forts. Fn. 6:

doch nicht stören, daB die meisten der von uns unter diese Gruppe eingereihten Aufwendungen vom Gesetz als Sonderausgaben behandelt werden ( $\$ 10 \mathrm{EStG}$ ): Unterhaltsleistungen, andere Leistungen und Lasten, Zahlungen an Religionsgemeinschaften, politische Partelen, spenden für wissenschaftliche, gemein-

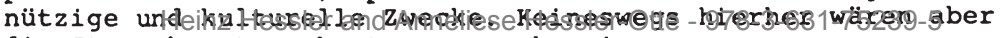

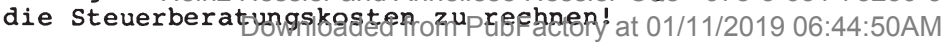


bedingten Vorteile sieht man allgemein in der Beschränkung der Abzugsfähigkeit: Sie soll nicht von der Bemessungsgrundlage, sondern von der Steuerschuld vorgenommen werden dürfen.

Ohne daB auf Einzelheiten eingegangen werden kann, soll hervorgehoben werden, daB sich die Ausnutzung der Abzugsregelung im distributiven Bereich, soweit sie die Unternehmensbesteuerung betrifft, nur eingrenzen lieBe, wenn man eine allokative Betriebsbesteuerung strikt von einer distributiven privaten Einkommensbesteuerung trennen würde. Soweit aber eine einkommensklassenspezifische Ausnutzung der Abzugsregelung in der privaten Einkommensteuer zur Diskussion steht, müBte hier streng unterschieden werden zwischen dem Abzug all der Beträge, die frei verfügbar sind und solcher, die es nicht sind (siehe $\S 21$ ). Liegt freie Verfügbarkeit vor, läBt sich in der Tat die Abzugsfähigkeit von der Steuerschuld statt von der Bemessungsgrundlage diskutieren. Liegt sie nicht vor, wie bei den Aufwendungen der Existenz- und Vorsorgesicherung, insbesondere auch bei den die Existenz sichernden Kinderfreibeträgen, 7) sollte ihre Abzugsfähigkeit von der Bemessungsgrundlage auBer Diskussion stehen, da in dieser Höhe steuerliche Leistungsfähigkeit nicht vorliegen kann. Es ist erstaunlich, in welchem MaBe die wissenschaftliche und Laiendiskussion diese einfachen ökonomischen Tatbestände vermengt und somit $\mathrm{zu}$ eindeutig politisch und interessensdeterminierten Forderungen kommt. So ist bisher noch nicht objektiv bewiesen worden, warum nur dem Verdiener, nicht aber jeder Person in einem Haushalt der existenzsichernde Grundfreibetrag zusteht.

Mit einer Trennung der Bereiche des Wirtschaftens in die allokative und die distributive Sphäre sowie mit einer Berücksichtigung der "freien" Verfügbarkeit über ökonomische GröBen im Sinne einer leistungsfähigkeitsorientieren Besteuerung lieBe sich das Phänomen des "progressionsdeterminierten Einkommensbegriffs" unvoreingenommen analysieren. 8) 9)

7 ) D. Birk (1983, S. 173) weist darauf hin, daB die Problematik des Fortfalls der Kinderfreibeträge nicht im Bereich des Art. 6 GG (Schutz von Ehe und Familie), sondern des Art. 3 GG (Gleichheitssatz) angesiedelt ist.

Pn. 8 siehe folgende Seite.

Fn. 9 siehe folgende Seite. 
b) Grundlegende tarifliche Fragen sind auch in der Vermögensbesteuerung auszumachen. Die $\mathrm{V}$ e $\mathrm{m}$ ö $\mathrm{g}$ e $\mathrm{s} t$ e $\mathrm{u}$ e $r$ hat im Feld der Personalisierung eine Sonderstellung inne, weil erstens mit der Berücksichtigung der persönlichen Lebensumstände elne Besteuerung der juristischen Personen nicht begrüdet werden kann und insoweit hier politische Wertungen noch viel unmittelbarer als anderswo zum Vorschein kommen (H. Fecher 1979, S. 463), weil zweltens der in der Bundesrepublik Deutschland angewendete proportionale Tarif im strengen Sinne dem Leistungsfahigkeitsprinzip und der Absicht einer Personalsteuer zuwiderläuft (F. Neumark 1979 , S. 328); dies kann auch dadurch nicht gehellt werden, daB wegen der Freibetrăge der Tarif faktisch indirekt progressiv ist.

Die Berücksichtigung der Leistungsfähigkeit in der $E \times b$ $s$ c $h$ a $t$ s $t$ e u e $r$ hat zwei Aspekte, einen Progressionsund einen Steuerklassen-Aspekt: daB mit einem höheren Vermögenszugang eine höhere ökonomische Leistungsfähigkeit verbunden ist, erfaBt der Tarif in "vertikaler" Weise innerhalb jeder Verwandtschafts- (und damit Steuer-) Klasse durch progressiv steigende Steuersätze. DaB aber die Steuersätze bel identischer Vermögenshöhe "horizontal" von Steuerklasse zu Steuerklasse ebenfalls steigen (fälschlicherweise oft als "doppelte" Progression bezeichnet, obwohl es sich hier um nach Verwandtschaftsgraden unterschiedene Steuerklassen handelt), ist mit höherer Leistungsfähigkeit nicht $z u$ erklären. In diesem Zusammenhang ist $z u$ vermerken, $d a B$ in der distributionspolitischen Entscheidung, ob denn der einzelne oder die Familie als die leistungsfahige und $z u$ besteuernde Insti-

Fn. 8 :

Instruktives Beispiel für die Analyse der Belastungswirkungen durch den "progressionsdeterminierten Einkommensbegriff" ist die Diskussion im National Tax Journal des letzten Dezenniums, die sich sowohl auf die distributiven probleme (Freibeträge, Progression, effektiver steuersatz angesichts unterschiedilch breiter tax base) erstreckt als auch auf die allokativen Wirkungen (mit distributiven Effekten) sowie die distributiven Wirkungen (mit allokativen Effekten).

Fn. 9:

D. Pohmer 1988, befaßt sich mit dem Prinzip der Besteuerung nach der Leistungsfähigkeit im weiteren sinne (S. 138ff.) betont aber, daß das Prinzip allein noch keine Tarifaussage erlaube, S. 137. 
tution gilt, das wesentliche Problem für die Erbschaftsbesteuerung und die damit zusammenhängende Personalisierung zu sehen ist ( $A$. Oberhauser 1979, S. 493; siehe anschließend).

516 Die "Individualisierung"
als steuerlastzuweisung
an die zahl inrer Träger
I. $\begin{array}{ll}\text { Die objektivierende und personalisier- } \\ \text { ende Seite der Individualisierung }\end{array}$
II. $\begin{array}{ll}\text { Heterogene Individualisierung in den } \\ \text { Personalsteuerarten }\end{array}$
III. Die Problematik der Individualisierung 213

I. Auch für die Individualisierung sind nur einige Grundprobleme vorzutragen, soweit sie die Einkommens- und Vermögensbegriffe berühren.

a) Individualisierung der Steuerlast ist wie die Personalisierung eine politische und $w$ e $r$ e $n d e$ Entscheidung. MaBgeblich sind für sie die Postulate der Gleichbehandlung und der VerhältnismäBigkeit (Leistungsfähigkeit). Der Grundsatz der GleichmäBigkeit enthält nach F. Neumark (1970, S. 100 f.) das Bestreben, "die Bemessungsgrundlage der Einkommensteuer ... zu individualisieren". Vollständige Gleichbehandlung und VerhältnismäBigkeit kann nur zwischen Einzelpersonen erreicht werden, da Haushalte in den allerseltensten Fällen in ihrer alters-, bedarfs- und einkommensspezifischen Struktur vergleichbar sind. Nach K. Tipke (1991, S. 194) regelt das "Individualprinzip" der Besteuerung die Zuordnung und Zurechnung von Einkommen und Vermögen und ist solchermaBen der notwendige Inhalt des Leistungsfahigkeitsprinzips (siehe auch J. Becker 1970).

b) Die Individualisierung hat sowohl eine objektivierende als auch eine personalisierende Seite. Die erstere betrifft die Bemessungs- 
grundlage; hier bedeutet Individualisierung, den Indikator der Leistungsfähigkeit allein dem Individuum zuzurechnen, nicht etwa einer Mehrheit von Personen in einem Haushalt. Einkommen und Vermögen wird demjenigen zugerechnet, der es erzielt bzw. besitzt. Daraus folgt das Verbot einer Zusammenrechnung von Einkommensund Vermögensbeträgen aller in einem Haushalt zusammenlebenden Personen. Die personalisierende Seite der Individualisierung tritt mit der Tarifanwendung ins Blickfeld; sie hăngt mit der Progression zusammen: Würden - wie in einer "Haushaltsbesteuerung" die Einkommen und Vermögen aller Personen zusammengerechnet, ergäbe sich gegenüber einer Individualbesteuerung eine höhere steuerlast; würde das allein von einer Person erzielte Einkommen auf alle Personen des Haushalts aufgeteilt, ergäbe sich eine niedrigere Steuerlast. Da solchermaBen die Belastungsprobleme erst mit der Anwendung des Tarifs ins Blickfeld kommen, da ferner auch für das Individuum die familiären und haushaltswirtschaftlichen Verhältnisse steuerlastmindernd wirken, da schlieblich das "Problematische" der Individualisierung stets vor dem Hintergrund einer Entscheidung für die Ehegatten- oder die Haushaltsbesteuerung diskutiert wird, ist in der vorliegenden Untersuchung die Individualisierung als ein Sonderfall der $p$ e $r$ o n a $l$ is $i$ e $r \mathrm{n} g$ behandelt und eingeordnet:

Schema der Instrumentierungen in der Personalbesteuerung

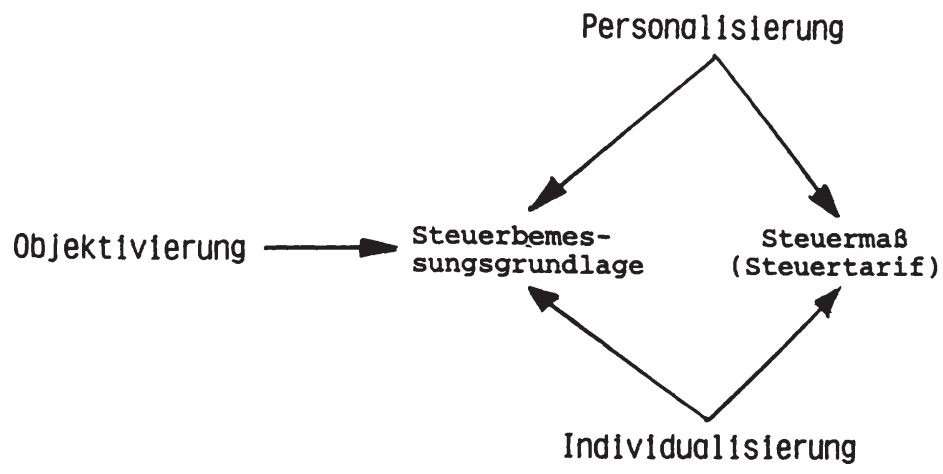


II. Das Problem der Individualisierung entzündet sich also an den steuerpolitisch ebenfalls möglichen Konzepten der Ehegattenund der Haushaltsbesteuerung. Dies gilt jedoch nicht für alle Personalsteuerarten mit derselben Intensität.

a) Sie ist bisher nur für das Einkommensteuerrecht - und hier in Verbindung mit dem splittingverfahren - problematisch geworden. Da seit dem 17.1.1957 die Haushaltsbesteuerung in der Bundesrepublik als verfassungswidrig gilt, ist in der Einkommensteuer als "einheitliche" Besteuerung nur noch die Ehegattenbesteuerung vorgesehen und als sog. Zusammenveranlagung (gem. § 26 EStG) wählbar anstatt der Einzelveranlagung.

b) In den anderen Personalsteuern ist die Individualisierung kein Thema. Das $\mathrm{v}$ e $\mathrm{r} m$ ö $\mathrm{g}$ e $\mathrm{n} \mathrm{s}$ e u e $\mathrm{r} g \mathrm{e}$ e $\mathrm{t} z$ verlangt zwingend die zusammenveranlagung von Ehegatten mit ihren unter 18 Jahren alten Kindern ( $\$ 14 \mathrm{VStG}$ ), erlaubt aber auch eine vollständige innerfamiliäre Berücksichtigung aller individuell exakt identischen Freibeträge (DM 70.000 je Person, gleich, ob Ehegatten oder Kinder, $\S 6$ vStG) mit dem Vorteil der Kompensation. Auch wer kein Vermögen hat, kann innerhalb des Familienverbandes seinen persönlichen Freibetrag steuermindernd zur wirkung bringen. Demgegenüber kennt die $E r$ b $s h$ a f $t-u n d \quad s c h$ e n $k$ u $n g$ s $\mathrm{e}$ e $r$ keine zusammenveranlagung, weder eine fakultative noch eine obligatorische. Der Erwerber als Individuum ist sowohl Steuerschuldner ( $\$ 20$ ErbschStG) als auch zur Anzeige des Erwerbs ( $\$ 30$ ErbschstG) und zur Abgabe der Steuererklärung verpflichtet ( $\$ 31$ ErbschstG) .

Die unterschiedliche Regelung der Veranlagung in der Vermögenund der Erbschaftsteuer ist mit Blick auf den jeweiligen Tarif zu beurteilen: die zusammenveranlagung bei der vermögensteuer führt zu keinerlei zusätzlichen Belastungen der addierten Vermögen, da ein proportionaler Tarif zugrundeliegt. Dagegen würde ein Progressionseffekt in der Belastung bei der Erbschaftsteuer auftreten, wenn die familiär erworbenen NachlaBvermögen addiert werden müBten. Mit der Aufgabe der Haushaltsbesteuerung in der 
Einkommensteuer ist auch dieser Progressionseffekt verschwunden. Allerdings sind im Zusammenhang mit der Personalisierung im Splittingverfahren des Tarifs nun andere Probleme aufgetreten, die den Gegensatz "Individualbesteuerung" versus "Ehegattenbesteuerung" erneut zur Diskussion stellen.

III. Wenn die Individualisierung problematisiert wird, sind Entscheidungskriterien dafür $\mathrm{z} u$ suchen, welches die personale $\mathrm{Be}-$ steuerungseinhelt, der zu Besteuernde, sein soll: die Einzelperson oder die Lebensgemeinschaft (Haushalt bzw. Familie oder Ehepaar).

a) Unter dem Aspekt des GleichmäBigkeitspostulats ist die Zusammenfassung sämtlicher Einkommen der Haushaltsmitglieder $z u$ einem Haushalts-Gesamteinkommen auszuschlieBen. Denn eine solche "Haushaltsbesteuerung" ergibt eine EinkommensgröBe, die bei Anwendung des progressiven Tarifs $z u$ einer steuerbelastung führt, die über der Belastung des Individualeinkommens liegt.

b) So bleibt nur die Möglichkeit, eine geringere Belastung als die Individualbesteuerung in Erwägung $z u$ ziehen. Dazu ist es zwingend, vom GleichmäBigkeitspostulat abzurücken. Das Entscheidungskriterium fur diese Politik wird im allgemeinen im Gedanken des $s c h u t z e s \quad v \circ n$ E h e und Familie nach Art. 6 Abs. 1 GG gesehen. Die Minderbelastung läBt sich grundsätzlich auf zwei Wegen herstellen: Entweder man führt für jede einzelne Person des Haushalts, auch soweit sie kein eigenes Einkommen erzielen (Ehepartner, Kinder), Steuerfreibeträge ein, die den Bedarf an Existenzsicherung und notwendiger Vorsorge decken; diese Beträge subtrahiert man vom Einkommen des (alleinigen) Einkommensbeziehers; danach wird der Progressionstarif angewendet; wir nennen dies die "F r e 1 b e $t$ a g $s$ oder B e m e s sung s g r und 1 a ge $n-V$ a 1 a $n t e "$ des steuerlichen Familienschutzes. Oder man teilt das individuell erzielte Einkommen auf die Mitglieder der Personenmehrheit auf (Ehepartner oder Gesamtfamilie) und wendet je Person den Progressionstarif an; wir nennen dies die "T a $r i f-V$ a $r i$ a $t e "$ des steuerlichen Familienschutzes. Eine Ausprägung dieser Variante ist das Splitting (Ehegatten- bzw. Familiensplitting). 
c) Wir übergehen das Problem, in welcher Höhe denn nun der steuerliche Schutz und die Minderbelastung anzusetzen ist, ${ }^{1)}$ und wenden uns lediglich kurz der augenblicklichen Diskussion um den Progressionsvorteil des splitting $z$. Je nach der Höhe der Freibeträge in der Bemessungsgrundlagen-Variante des Familienschutzes und je nach dem Ausma $B$ der Progression kann gelten, daB der steuersparende Effekt der Tarif-Variante gröBer ist als der der FreibetragsVariante. Die gegenwärtige Diskussion um die Abschaffung oder Begrenzung des splittingvorteils ubersieht häufig, daB der Steuergesetzgeber, als er in Reaktion auf das Bundesverfassungsgerichtsurteil von 1957 das Splitting einführte, keineswegs gezwungen war, den Familienschutzgedanken allein durch diese Variante $z u$ verwirklichen. Die Freibetrags-Variante kann denselben Schutz gewähren ohne den distributiven Nachteil des splittingvorteils für die höheren Einkommensschichten.

Es läBt sich zeigen, daB der Schutzgedanke auch ohne Verletzung des Grundsatzes der I $n d i v i d u$ a $l$ b e $s t$ e $u$ e $r$ u $g$ in die Tat umgesetzt werden kann. Die Individualbesteuerung richtet sich in erster Linie auf die Bemessungsgrundlage. ${ }^{2}$ Das splitting verletzt den Individualitätsgrundsatz; es beruht auf einer der ökonomischen Wirklichkeit widersprechenden Fiktion: Einem Ehegatten wird Einkommen oder ein Teil des Einkommens zugerechnet, das bzw. den er nicht erzielt hat. Die Einkommensteuer erfaBt aber "Einkommen", nicht die "Gesamtlebenslage" einer Familie. Hingegen berücksichtigt sie eben diese Lebenslage durch die Anerkennung des Abzugs der persönlichen und familienbedingten Belastungen. Die Einkommensteuer geht - läBt man einmal das ihr nachträglich "verordnete" und systemwidrige splittingverfahren beiseite - in ihrer ursprünglichen zielrichtung nicht so weit, ein Einkommen, das jemand erzielt hat, einer anderen Person zu-

1) Die Frage ist: Was sollen die Ehegatten, bei einem Verdiener oder bei zwei Einkommensbeziehern, weniger an Steuern tragen müssen als zwei ledige Verdiener? Siehe hierzu J. Hackmann 1973 , s. 498 ff.

2) Selbst in der Zusammenveranlagung von Ehegatten bleiben die zusammengerechneten Einkünfte solche der einzelnen Ehegatten, und ihre Erfassung erfolgt aus dem Gedanken der Individualbesteuerung. Gemeinsam ist allenfalls die Bewirtschaftung und die Entscheidung uber die Verwendung $\mathrm{zu}$ Spar-, Investitionsund Konsumzwecken, niemals jedoch ihre Erzielung; K. Tipke 1991, S. 194 und $226 f$. 
zurechnen. Wenn heute die Ausdehnung des Ehegattensplitting auch auf die sog. Halbfamilien diskutiert wird, so möchten wir dies als einen Irrweg bezeichnen. ${ }^{3)}$ Wenn auBerdem die Beschneidung des Splittingvortells durch die Einführung von Einkommensgrenzen diskutiert wird, so kommt man dadurch zwar einem distributiven ziel ein wenig näher, jedoch auf einem Irrweg. Denn wollte man den Splittingvorteil nur für bestimmte höhere Einkommen abschaffen, hätte man zwar Ungleichbehandlungen abgebaut, doch auch dies nur teilweise und nur durch die Preisgabe des Individualprinzips in der Besteuerung. Überdies ließe sich die "kritische" Einkommensobergrenze nur mit weitaus mehr Willkür festlegen als es bei der Bestimmung des Tarifs in der Einkommensteuer ohnehin unvermeidlich ist.

3) Genau so systemwidrig wäre das Familiensplitting. Konsequent wäre die Freibetrags-Variante, da sie einkommensklassenspezifische progressionsbedingte Steuerentlastungsvorteile vermeidet. Zwar wird durch die Einführung des Kindergeldes anstatt der Kinderfreibeträge eine "Gleichbehandlung" erreicht, doch läge die Einführung von ausrelchend hoch bemessenen KinderGrundfreibeträgen im Zuge der leistungsfähigkeitsorientierten Einkommens besteuerung. 
6. Kapite1 =

Theoretisch gestaltete objektivierung:

Die Leistungstähigkeitsindikatoren als sachliche und personale Bedingungen fir die Besteuerung

S 17 Die steuerpostulate als die begriffsbestimmenden Faktoren des steuerlichen Einkommens und Vermögens

I. Die Interpretationsunterschiede in den Steuerwissenschaften

1. Zielorientierung des Leistungsfähigkeitsprinzips in der Finanzwissenschaft

2. Bedeutung und Konkretisierung des Leistungsfähigkeitsprinzips in der Steuerrechtswissenschaft

3. Das Verhältnis des Allgemeinheitsund des GleichmäBigkeitspostulats zum Leistungsfähigkeitspostulat aus finanzwissenschaftlicher sicht

4. Das Verhältnis der Steuerpostulate untereinander aus steuerwissenschaftlicher sicht

II. Die begriffs- und systemprägende Kraft der Steuerpostulate und ihrer verletzungen

III. Fragen theoretischer und praktischer Konkretisierung der Leistungsfähigkeit als Untersuchungskonzept

I. $O b$ und wie jemand $z u$ besteuern ist, definieren die steuerwissenschaften übereinstimmend aus dem Prinzip der Besteuerung nach der Leistungsfähigkeit. Daneben haben das Allgemeinheits- und das Gleichnäßigkeitspostulat für die Besteuerung Bedeutung. Die Situation, in der sich die Steuerwissenschaften hier wiederfinden, läßt sich durch drei Phänomene kennzeichnen: Erstens werden die steuerpostulate allgemein akzeptiert und in einer normativen Steuertheorie erfaßt; zweitens weichen die steuergesetzlich formulierten Einkommens- und Vermögensbegriffe ${ }^{1 l}$ erheblich von den 
wirtschaftstheoretisch entwickelten $a b$; und drittens ist die situation der Steuerwissenschaften durch den Umstand markiert, daB die in den Steuergesetzen tatsächlich vorzufindenden Begriffe und Regeln zur Erfassung der Tatbestände eben jenen Steuernormen oftmals auffällig widersprechen. Die Brisanz dieses Widerspruchsproblems sieht man unmittelbar ein. Demgegenüber würde man in der zuvor genannten Normenakzeptanz Problematisches nicht von vorn herein vermuten; doch dieser Eindruck täuscht. Zwar stimmen die Lehrmeinungen annähernd darin überein, was inhaltlich unter dem Allgemeinheitspostulat und dem GleichmäBigkeitspostulat $z$ u verstehen ist, doch bestehen abweichende Auffassungen darüber, in welchem Verhältnis eben diese Postulate zum Leistungsfahigkeitspostulat stehen. Selbstverständlich setzen sowohl die Finanzwissenschaft als auch die steuerrechtswissenschaft hier ihre eigenen Akzente.

1. Dem Leistungsfähigkeitspostulat wird in der Finanzwissenschaft eine recht differenzierte zielorientlerung zugeschrieben, die von einer ausschlieblich fiskalisch bestimmten uber eine allokativfiskalische und eine allokativ-distributive bis hin $z$ u einer klar distributiven orientierung reicht. Wir versuchen zu begründen, warum wir die distributive orientierung des Leistungsfähigkeitspostulats für allein sinnvoll halten.

a) K. Littmann (1970, S. 125), der das Leistungsfähigkeitspostulat verabschiedet wissen möchte zugunsten einer "ökonomisch-gesellschaftlich orientierten Steuerpolitik" (S. 126), sieht die Besteuerung nach der Leistungsfähigkeit im "Getto fiskalischer Zwecksetzungen". Nach Littmann hat die Entwicklung der Theorie um dieses Prinzip dafür gesorgt, daB die diskriminierenden Wirkungen, die die Besteuerung hervorruft, hinter diesem angeblich wissenschaftlich beweisbaren Prinzip verborgen gehalten werden; demgegenüber sollte aber gerade eine aneutrale Wirkung der Besteuerung im offenen Konflikt der Interessen ausgetragen werden

1) Die kontroversen Auffassungen konzentrieren sich auf den Einkommensbegriff; der Vermögensbegriff steht weniger im Blickpunkt. Wenig Interesse hat bisher der Ausgabenbegriff als Indikator für Leistungsfähigkeit auf sich ziehen können. 
(S. 127). Die Besteuerungsziele, die man mithilfe des Prinzips verfolgen möchte, sieht Littmann als distributive, doch das Prinzip selbst, so wie es präsentiert wird, sieht er als rein f $i s k$ a $l i s c h$ e $s$, das keinen Bezug $z$ ur gesellschaftspolitischen Kontroverse der Gegenwart mehr habe.

b) Für K. Schmidt (1978, S. 135) ist demgegenüber die Frage der "individuellen Steuerzumessung ein Teilproblem der gesamtwirtschaftlichen A I l $1 \circ$ a $t i \circ \mathrm{n} "$; nach $\mathrm{K}$. Schmidt (1972, s. 208) ist das fiskalische $\mathrm{ziel}$ aus dem vorrangig allokativen abgeleitet. Da auch die Allokationsentscheidung eine politische sei, hebe sich der behauptete Gegensatz zwischen fiskalisch und gesellschaftlich orientierter Steuerpolitik auf. Indessen verbindet K. Schmidt (1978, S. 141) das Leistungsfähigkeitsprinzip mit der distributiven Gerechtigkeit (s. 137 u. 142), sieht diese aber dennoch als ein Problem der Allokation. ${ }^{2)}$ somit ist für $k$. Schmidt das Leistungsfähigkeitspostulat eindeutig in den fiskalisch-allokativen Bereich verwiesen, während er im Distributionsbereich ohne das postulat auskommt.

c) Dagegen hat für G. Krause-Junk (1977, S. $338 \mathrm{ff.}$ ) das fragliche Postulat sowohl eine a $110 \mathrm{k}$ a $t i v e^{3)}$ als auch eine d $i s t r i b$ u $t$ i e Bedeutung; nicht nur, daB man es "einfach auch als plausible Interpretation eines allgemein geteilten Gerechtigkeitsempfindens" verstehen kann (S. 338), es kann auch direkt der Herstellung der Verteilungsgerechtigkeit dienen. Selbst dann bleibt für das Leistungsfähigkeitsziel noch Raum, "wenn das fiskalische ziel fallen sollte" (S. 353). Die Gerechtigkeitsfrage ist aber für Krause-Junk im Gegensatz zu K. Schmidt ein Problem der Distribution, nicht der Allokation.

2) Distributive Probleme sind für $K$. Schmidt lediglich solche der unverteilung (1978, S. 160 f.) einschl. der Transfers, der negativen Einkommensteuer und der Progression, also nicht der Steuerlastverteilung.

3) G. Krause-Junk (1977) widerspricht aber Schmidt insofern, als er das fiskalische und das allokative $\mathrm{Ziel}$ in einem nur losen Zusammenhang sehen will (S. 352) und unterstützt Littmanns pointierte Gegenüberstellung (S. 353), will nur dessen einseitige Orientierung des Prinzips am fiskalischen ziel nicht bestätigen. 
d) Um hier kritisch stellung nehmen zu können, müssen wir auf Bekanntes zurückgreifen: Wirkungen, die primär allokativer Art sind, können sekundär auch distributive Effekte haben und ungekehrt. Genau so verhält es sich mit dem Einsatz der wirtschaftspolitischen Instrumente in einem Wirkungsbereich und mit dem Ansatz theoretischer Analyseinstrumente in einem Analysebereich: Wenn man das Leistungsfähigkeitspostulat im Bereich der Distribution ansiedelt und mit Gerechtigkeitsvorstellungen in Verbindung bringt, so schlieBt das nicht aus, daB Allokationsprobleme auftreten.

Schmidt bleibt mit seiner Zuordnung des Leistungsfähigkeitsprinzips zum allokativen Bereich insofern konsequent, als die nutzentheoretische Interpretation dieses Prinzips es als ein Entscheidungsmodell wohlfahrtstheoretisch-allokativer Provenienz ausweist. Nutzentheorie ist Allokationstheorie. Soweit er das Prinzip jedoch - wie mehrfach überzeugend geschehen ${ }^{4}$ - eben wegen der inkonsistenten Prämissen kritisiert und soweit er es dennoch grundsätzlich erhalten wissen will als ein Rahmenkonzept zur Ausrichtung an Globalzielen, insbesondere als warnung vor $r$ e g r e s $\mathrm{i} v$ e $r$ Gesamtbelastung sowie als Mahnung zur Beachtung der Familienverhältnisse bei der Besteuerung ( $R$. Schmidt 1967, s. $385 \mathrm{ff}$. und 1978, S. 150), ist seine rein allokative zuordnung nicht überzeugend. Für K. Schmidt mag der Gedankengang der folgende sein:

Zunächst muB die Steuerlast, die der Finanzierung der staatsausgaben und damit der Verwirklichung allokativer Grundentscheidungen dient (Versorgung durch private und öffentliche Güter), verteilt werden; dies ist das Verteilungsproblem, resultierend aus der Allokation. Danach ist gemäB politisch vereinbarter Absicht eine Umverteilung durchzuführen. Jedoch wird damit das Prinzip, nach dem die steuerlast verteilt wird, kein allokatives. Das Leistungsfähigkeitsprinzip reicht insoweit in den allokativen Bereich, als die personale Steuerlast erstens aus einer Allokations- und Finanzierungsentscheidung herrührt und als sie zweitens

4) K. Schmidt 1966, S. 22 ff. u. 41 ff.; 1972, passim; 1978, S. $141 \mathrm{ff} .$, insbes. S. $145 \mathrm{ff}$. 
in ihrer Auswirkung allokative Effekte (incentives und disincentives) hervorrufen kann. Drittens veranlabt die engere oder breitere Erfassung der Indikatoren, auf denen Leistungsfähigkeit beruht (Einkommen, Ausgaben, Vermögen), allokative Wirkungen (mit distrubutiven Effekten) und verursacht somit Probleme der horizontalen Gerechtigkeit (Gleichbehandlung, Allgemeinheit und GleichmäBigkeit der Besteuerung). Jedoch gehört das Prinzip entsprechend der Neumark'schen Analyse (1970, S. $121 \mathrm{ff.}$ ) wegen seiner orientierung an der vertikalen Gerechtigkeit und wegen der mit unterschiedlicher individueller Leistungsfähigkeit begründeten Personalisierungsmaßnahmen in der praktischen steuerpolitik (durch Freibeträge und Tarifverlauf) in den $d i s t r i b u-$ $t i v$ e $n$ Bereich.

Die Finanzwissenschaft hat sich lange Zeit der Neigung hingegeben, das Prinzip ökonomisch und vor allem theoretisch erklären $\mathrm{zu}$ wollen, weil sie als ökonomische Disziplin bemüht war, auf die hinter dem Geldeinkommen liegenden, das Kauf- und Zahlungsverhalten motivierenden psychischen Phänomene, auf "Bedürfnisse" und "Bedürfnisbefriedigung" zurückzugehen; sie wollte die hier liegenden Divergenzen im Befriedigungspotential zwischen den Personen als Unterschiede in der Leistungsfähigkeit erklären. Die Ausweglosigkeit, in die die Finanzwissenschaft dabei geriet, hat ihre Ursache darin, daB psychische Bedürfnisunterschiede nicht meBbar und damit zwischen verschiedenen Personen nicht vergleichbar sind. Heute ist in der Finanzwissenschaft die Tendenz festzustellen, das Prinzip vollends von den nutzentheoretischen Interpretationen $\mathrm{zu}$ lösen. Statt dessen werden die Probleme der Bemessungsgrundlagen- und Tarifgestaltung in den Mittelpunkt gerückt. Dabei wird zunehmend klarer, daB sowohl die Abzugsmöglichkeiten von der Bemessungsgrundlage als auch die Progressivität des Tarifs allokations- und distributionspolitisch bestimmt werden, daB hierbei gerade die Korrekturmöglichkeiten an der Bemessungsgrundlage eine groBe Anziehungskraft auf die Politiker ausüben und $\mathrm{daB}$ eine solche praxis zumeist jeglicher theoretischer Grundlage entbehrt.

2. Die Steuerrechtswissenschaft kann eine politische Problemstellung nur in begrenztem Maße aufnehmen, woraus sich grundlegende Unterschiede in ihren Aussagen zum Leistungsfähigkeitsprinzip 
ergeben $^{6)}$. Man beachte, daß sich aber auch die Finanzwissenschaft mit den rechtlichen Problemen auseinandersetzt, siehe hierzu $D$. Pohmer 1988, der das Verhältnis zu den Normen des Grundgesetzes diskutiert, S. $141 \mathrm{ff}$.

Die Steuerrechtswissenschaft hat ihre eigenen Schwierigkeiten mit dem Leistungsfahigkeitspostulat. Sie liegen nicht zuletzt auch darin, unterscheiden $z u$ müssen zwischen dem Postulat als einer obersten Leitlinie für rechtliches Werten und Beurteilen einerseits und der notwendigen Konkretislerung dieser Leitlinie für aktuelle steuerpolitische Handlungsanweisungen andererseits.

a) Das Leistungsfähigkeitsprinzip ist ein steuerspezifisches Prinzip (Tipke 1991, S. 25); als Ausdruck steuerlicher Gerechtigkeit stellt es "materiale Rechtsstaatlichkeit" her (S. 47; ähnlich Walz 1980, S. 155). Gerechtigkeit wird hauptsächlich verbürgt durch Gleichbehandlung (Tipke S. 49). Der Gleichheitssatz nach Art. 3 GG "wird erfüllt durch ... gleichmäßige Besterung nach der Leistungsfähigkeit"(Tipke 1991, S. 51). Höchstwahrscheinlich in Anlehnung an Haller (1981) nennt Tipke (1991, S. 57) dieses Rechstprinzip ein "Fundamentalprinzip", well es die "rechtsethischen Wertvorstellungen" trägt. "Das Leistungsfähigkeitsprinzip ist für die steuerwirtschaft von derselben zentralen Bedeutung wie die Privatautonomie für die rechtliche ordnung des Waren- und Dienstleistungsverkehrs. Bürgerliche Freiheit im liberalen Verständnis und Besteuerung nach der Leistungsfähigkeit sind aufeinander bezogene Grundprinzipien oder Grundentscheidungen für die wirtschaftsrechtliche Ordnung" (W.R. Walz 1980, s. 158).7)

6) Dennoch wäre es vorteilhaft, wenn sie sich um die Rezeption auch der jüngeren finanzwissenschaftlichen Diskussion bemühte; denn dann könnte nicht mehr behauptet werden, der streit würde nicht so sehr um das Leistungsfähigkeitsprinzip selbst geführt wie vielmehr um seine Anknüpfungspunkte und deren ErfaBbarkeit; s. H.H. Mösbauer 1975, S. 685; ausgerechnet die Nutzentheorie hält Mösbauer für "zutreffend", S. 685, Fn. 141. - Eine äuBerst gelungene Rezeption hingegen bietet die Arbeit von D. Birk 1983

7) Wir stimmen mit W.R. Walz (1980, S. 158) darin uberein, das "Leistungsfähigkeitsprinzip als ordnungspolitische Grundentscheidung" $z$ u bezeichnen, melden jedoch Zweifel an, wenn er es zugleich (S. 155) als einen "marktwirtschaftlichen Gerech(Forts. siehe folgende Seite) 
b) Angesichts der hervorgehobenen rechtlichen und gesellschaftspolitischen Stellung des Prinzips gewinnen alle Bemuhungen an Bedeutung, dieses Prinzip rechtlich zu konkretisieren. Die ständige Berufung auf das Prinzip selbst, der Hinweis auf seine Verankerung in den sozialen Strukturen und auf die zu internalisierenden Gerechtigkeitsvorstellungen (R.W. Walz 1980 , S. 156) sowie auch die Hinweise darauf, daB das Leistungsfähigkeitsprinzip in den verschiedenen steuergesetzen unterschiedlich ausgeprägt sei, können nicht als Konkretisierungen angesehen werden. ${ }^{8}$ Ein DifferenzierungsmaBstab kann aus der Verankerung eines einheitlichen, "von den Steuerbürgern mitvollziehbaren materiellen Gerechtigkeitsprinzips" (W.R. Walz 1980 , S. 157) nicht direkt hervorgehen. Möglicherweise liegt die unterschiedliche Wirksamkeit,

Forts. Fn. 7 von S. 250

tigkeitsgrundsatz" kennzeichnet. Die Besteuerung als solche mag sich durchaus im Einklang mit der Wirtschaftsordnung und der Marktwirtschaft befinden; doch die Verteilung der Steuerlast auf die Individuen nach irgendwelchen Gerechtigkeitsoder Leistungsfähigkeitsvorstellungen ist als eine politisch gewollte "Sekundärverteilung" gerade nicht die marktliche Verteilung; insofern ist die Wortverbindung zwischen Markt und Gerechtigkeit in jedem Falle unangebracht.

8) Den Satz von W.R. Walz (1980, S. 155) "Die Leistungsfähigkeit als Prinzip materieller Gleichheit hat ihre bleibende Bedeutung darin, daB sie dem Rechtsanwender DifferenzierungsmaBstäbe an die Hand gibt, die von der Mehrheit der Rechtsgenossen - dem 'biliig und gerecht denkenden Steuerschuldner' intuitiv als gerecht empfunden werden" möchten wir in dieser Form keineswegs akzeptieren. Zwar enthält der Rekurs auf die in der Bevölkerung vorhandene Rechtsüberzeugung und -empfindung ein erfahrungswissenschaftliches Element; doch dies ist in dieser Form $z u$ wenig konkret für die Rechtsanwendung. Ferner dürfte sich Widerspruch erheben, die Leistungsfähigkeit als "materielle G I e $i \mathrm{ch} \mathrm{h}$ e $i$ t" lalso nicht als blob formelle) $\mathrm{zu}$ interpretieren, da doch je nach ökonomischer Ausstattung die Steuerlast ungleich verteilt werden soll (wie sonst wollte der Rechtswissenschaftler den Progressionstarif rechtfertigen?). Letztlich aber können aus einem Prinzip kelne DifferenzierungsmaBstäbe für konkretes Handeln im Einzelfall hervorgehen, wenn es in der ublichen unverbindlichen Form präsentiert wird.

Demgegenüber betont Tipke (1991, S. 59) die Notwendigkeit und Möglichkeit der Ronkretisierung des Leistungsfähigkeitsprinzips: Es ist durch subprinzipien wie prinzip der Individualbesteuerung, Prinzip der Gleichwertigkeit der Einkunftsarten, Realisationsprinzip, objektives Nettoprinzip usw. konkretisiert worden. Allerdings folgen wir Tipke nicht in dem Bemuihen, auch in der Umsatzsteuer und Körperschaft(gewinn)st. Konkretisierungen des Prinzips zu sehen; hier zeigt sich das "zahlungswirtschaftliche" verständnis des Prinzips (ability to pay) bei Tipke (S. 57). 
die die రkonomen und die Juristen sich von einem formulierten Prinzip jeweils erwarten, darin begründet, daB Juristen eher auf die realitätsgestaltende Kraft von Normen vertrauen, wohingegen die ökonomen von vorn herein den nur begrenzten Einfluß der Prinzipien auf den realen Lebenslauf berücksichtigen und den Ronflikt sowie die zu findende Kompromißlösung als einen gangbaren Weg akzeptieren.

Aber gerät nunmehr auch die Steuerrechtswissenschaft bei ihrem Bemühen, das Leistungsfähigkeitsprinzip rechtlich konkret $z u$ machen, ins "fiskalische Getto" à la K. Littmann? Denn nach K. Tipke (1991, S. 20) liegt der Hauptzweck der Steuerrechtsnormen in der Einnahmenbeschaffung, und gerade hierfür sei das Leistungsfähigkeitsprinzip (mit seinem Gerechtigkeitsinhalt) das "sachgerechte Prinzip". 9) Anders formuliert: Im Kreise der Steuerrechtsnormen ${ }^{101}$ seien die meisten "Finanzzwecknormen"; diese seien fiskalisch motiviert und gerade dazu am Leistungsfähigkeitsprinzip orientiert.

Bei den weiteren Konkretisierungsbemühungen stoBen wir auf das Signum der "ability to pay": Die Rechtswissenschaft versteht soweit sie nicht bei lediglich "formelhaften Wendungen" bleibt und eine inhaltliche Konkretisierung von der Finanzwissenschaft erwartet ${ }^{11)}$ - die Besteuerung nach der Leistungsfähigkeit z.T. rein zahlungstechnisch als "ability to pay" und ubernimmt damit eine finanzwissenschaftliche Interpretation, versteht Leistungsfähigkeit als die "Fähigkeit, Steuern zahlen zu können" (Tipke 1991, S. 57). Danach dient das Leistungsfähigkeitsprinzip der "Verwirklichung" einex fiskalischen Zielsetzung" (H.H. Mösbauer 1975,

9) Tipke, K., 1981, S. 22: Sachgerecht ist ein Prinzip, wenn es dem Zweck der Norm entspricht, die das Prinzip konzipieren soll; das Prinzip soll die Norm bestimmen, die Norm soll auf dem Prinzip beruhen. S. 24 : Durchbrechungen des Leistungsfähigkeitsprinzips bedürfen der Rechtfertigung durch ein anderes sachgerechtes Prinzip.

10) Es gibt nach K. Tipke 1991, S. 19ff., drei Normengruppen: die Finanzzweck-, die Sozialzweck- und die Vereinfachungszwecknormen, letztere mit besonderen Eigenschaften, S. 19.

11) Siehe hierzu D. Birk 1983, S. 52 u. 62f., der diese Fragen genauer untersucht. 
s. 684). 12) Was Leistungsfähigkeit seinem Inhalt nach ist, wird danach klar und einfach monetär festgestellt; Leistungsfähigkeit drückt sich in der Höhe des Einkommens (und des Vermögens) aus: "Je höher die Bemessungsgrundlage der Leistungsfähigkeit ist, desto höher muB die steuer sein (K. Tipke 1981, S. 25). 13) Ungeachtet dessen, ob die Finanzwissenschaft mit der Interpretation der Leistungsfähigkeit als ability to pay so ganz glücklich sein darf, soll hier vorerst festgehalten werden, daB auch dadurch eine Konkretisierung des Prinzips nicht gelingen kann. Denn das konkretisierte prinzip sollte ja schon etwas verbindlichere Handlungsanweisungen an den Steuergesetzgeber aussprechen als die, bei der Steuerzumessung auf die individuellen wirtschaftlichen Verhältnisse und Umstände des einzelnen Bedacht zu nehmen, oder den mehr Steuern zahlen zu lassen, der mehr Einkommen bzw. Vermögen habe, oder solche Steuerpflichtige, deren Verhältnisse ungleich sind, auch ungleich zu besteuern. Diese "leeren" (dennoch nicht sinnentleerten)Formeln können nur im ProzeB der politischen Gestaltung und Auseinandersetzung mit Inhalt gefüllt werden. Hier werden dann die Bemessungsgrundlagen in numerisch klare Größen gefaBt, Freibeträge in Geldeinheiten beziffert und SteuermaBe in Beträgen oder Vom-Hundert-Sätzen festgesetzt. Das Prinzip kann hierbei Anhaltspunkte liefern, Warnzeichen setzen und $z$ um Uberdenken von Gerechtigkeitsvorstellungen mahnen.

12) Allerdings widerspricht sich Mösbauer selbst, wenn er auf S. 685 in Fn. 145 sagt: "Das Leistungsfähigkeitsprinzip dient ausschlieBlich der gerechten individuell-proportionalen Lastenverteilung." Was die proportionale Lastenverteilung bedeutet, wird nicht erläutert, läBt sich aber insofern nicht belegen, als mit dem Leistungsfähigkeitsprinzip immer schon auch die individuell-progressive Lastenverteilung verknüpft wurde.

13) Siehe aber D. Birk 1983, S. 59 ff., der aus der steucrrcchts.wissenschaft].ichen Sicht die Möglichkeiten einer Konkretisierung des Leistungsfähigkeitsprinzips untersucht. und sich mit den von Tipke 1981 geäuBerten Auffassunqen auseinandersetzt. Nach ausführlichen methodologischen Rlärungen kommt er zu der folgenden Beschreibung seines Denkweges: Was ist das Wesentliche bei der Verteilung von Steuern? Ist dieses 'Wesentliche' freigelegt, offnet sich der Weg, den Verteilungsgegenstand $z u$ definieren. Hat man hier eine Festlegung getroffen, kann nach der verfassungsrechtlichen Prägung der Verteilungsregel gesucht werden." Es geht ihm also um die Beziehung des Prinzips zur Verfassung, um die verfassungsrechtliche Interpretation. 
3. LäBt sich also die Funktion des Leistungsfahigkeitsprinzips allein im distrivutiven Bereich aufsuchen, so ist nunmehr innerhalb dieses Bereichs nach dem Verhältnis $z u$ fragen, das zwischen den Postulaten der Allgemeinheit, der GleichmäBigkeit und der Leistungsfähigkeit besteht (vgl. auch unten \$ 25 IV).

a) Auch hier kennt die Finanzwissenschaft Auffassungsunterschiede. F. Neumark $(1970,1988)$ und Musgrave/Musgrave $(1980, \mathrm{~S}$. 242 ff. u. 250) sehen die Allgemeinheits- und GleichmäBigkeitspostulate als Vorbedingungen des Leistungsfähigkeitspostulats, die die formale (bzw. horizontale) Gerechtigkeit herstellen, wohingegen die materiale (bzw. vertikale) Gerechtigkeit sich gerade erst in der Besteuerung nach der Leistungsfähigkeit erweist, die ja auch die Besteuerung nach der "VerhältnismäBigkeit" genannt wird. Dies ist einleuchtend, weil die praktischen Konkretisierungen der ersten beiden postulate sich ausschließlich auf die objektivierte steuerbasis erstreckt, während die Besteuerung nach der Leistungsfähigkeit sich in der individuell unterschiedlichen Anwendung von personengebundenen Freibeträgen und in der individuell unterschiedlichen Anwendung des entsprechenden SteuermaBes ausdrückt. Freibetrags- und Tarifanwendung aber sind SteuermaBnahmen der Personalislerung (und Individualisierung, s. S\$ 14-16) und als solche auf die persönlichen "Verhältnisse" des Steuerpflichtigen abgestellt. Demgegenüber sorgen die Allgemeinheits- und GleichmäBigkeitspostulate, jedenfalls soweit sie die Steuergegenstände Einkommen und Vermögen determinieren, für eine Erfassung und Behandlung in "objektiver", d.h. hier in gegenstandsbezogener Sicht; siehe jedoch Mitschke 1985, S.136 ${ }^{13 \mathrm{a}}$ ).

b) Ganz anders G. Krause-Junk (1977, S. 338 ff.), der mit dem Leistungsfähigkeitsprinzip beide Aspekte der Gerechtigkeit, also die formale und die materiale, verwirklichen will. Beide Gerechtigkeitsaspekte, den horizontalen wie den vertikalen, betrachtet er als Probleme der "Gleichbehandlung". 14) Entsprechend

13a) Die das Leistungsfähigkeitsprinzip"ergänzenden Prinzipien sind ethisch-soziale wie Allgemeinheit und GleichmäBigkeit".

14) Beide können mit bestimmten Indikatoren der steuerlichen Leistungsfähigkeit besetzt werden: Für die horizon $t$ a $l$ e Gleichbehandlung sind bestimmend (a) die aus der ökonomischen Betätigung hervorgehende Leistungsfähigkeit (nach der die Steuerlast zu verteilen ist); (b) die Anerkennung von politisch bestimmten Minimalstandards, die auf der (Forts. siehe folgende seite) 
werden die steuerlichen Maßnahmen eingesetzt, um die Gleichbehandlung zu gewährleisten ${ }^{15)}$. Möglicherweise liegt der KrauseJunk'schen Nomenklatur das Denken in den traditionellen Opferkonzepten zugrunde: Die Opfer hatten bekanntermaBen stets "gleich" zu sein. Wie aber auch immer, die Gleichheit kann nur als Prinzip gelten, nicht als Belastung; denn: Gilt für alle zu Besteuernden mit unterschiedlicher Leistungsfähigkeit das "gleiche" (marginale oder absolute) Opfer ${ }^{16)}$ an NutzeneinbuBe, so ist dennoch die EinbuBe an ökonomischer Dispositionskraft und Einkommen ungleich. Der terminologischen Klarheit wegen sollte auf die "vertikale Gleichbehandlung" verzichtet werden. Irrtumsfrei ist die Terminologie dann, wenn unter Gleichbehandlung nur die GleichmäBigkeit der Besteuerung, also die "horizontale" bzw. formale Gerechtigkeit verstanden wird. Die vertikale bzw. materiale Gerechtigkeit zeichnete sich dann durch eine bewuBte, auf die jeweilige, individuell unterschiedliche Leistungsfähigkeit abgestellte Ungleichbehandlung aus.

c) Nach allem gehen wir in dieser Untersuchung hinsichtlich der Besteuerungspostulate von dem folgenden Verhältnis der Steuerpostulate untereinander aus: Die Postulate der Allgemeinheit und der GleichmäBigkeit der Besteuerung sind die Voraussetzungen, die Grundfragen und die ständig geltenden Begleitbedingungen für die Besteuerung nach der Leistungsfähigkeit. Will das letztere Postulat eine politisch gewollte Ungleichbehandlung der einzelnen nach dem Verhältnis ihrer ökonomisch ungleichen Lagen durchsetzen und solchermaBen durch persönliche Abzüge von der Steuerbemessungsgrundlage und durch Tarifgestaltung eine "vertikale"

Forts. Fn. 14:

Bedarfsgerechtigtkeit beruhen (und die die Umverteilung bestimmen); für die $v$ e $r i k$ a $l$ e Gleichbehandlung gelten (c) die Bestimmung des Belastungsmaßes (ob Opferkonzept oder Einkommen, bleibt offen) und (d) die Festlegung der Mehrbelastung des Leistungsfähigeren, wobei die Interpretation vertikaler Gleichbehandlung dem politischen ProzeB überlassen bleibt.

15) Die Auswahl der Steuerarten, die Bestimmung der Einkunftsarten, die sachlichen steuerbefreiungen und die Festlegung der Einkunftsermittlungsmethoden bestimmen die horizon $t$ a $l$ e Gleichbehandlung; Tarifanwendung und Kinderfreibeträge garantieren die $v$ e $r i k$ a $l$ e Gleichbehandlung, S. $344 \mathrm{f}$.

16) Dies wäre also die vertikale Gleichbehandlung, die den Leistungsfähigeren an dasselbe opferkonzept bindet wie den weniger Leistungsf fïhi gemer and Anneliese Hessler-Otte - 978-3-631-75239-5 
Gerechtigkeit verwirklichen, so sind Allgemeinheit und Gleichmässigkeit darauf gerichtet, umfassende Leistungsfähigkeits-Indikatoren $\mathrm{zu}$ finden (die Objektivierungsleistung der Besteuerungskunst), daraus eine breit angelegte, keine persönlichen und allenfalls nur wenige objektiven Ausnahmen von der Steuer zulassende Bemessungsgrundlage $z u$ schaffen (ebenfalls eine Objektivierungsleistung) und durch die Gleichbehandlung dieser Bemessungsgrundlage - sowohl hinsichtlich aller ihrer konkreten Einzelbestandteile wie auch ihrer rechnerischen Gesamtheit - bei allen Steuerpflichtigen eine "horizontale" Gerechtigkeit herzustellen; Personen in gleichen oder gleichartigen ökonomischen und steuerlichen Verhältnissen sollen gleich behandelt werden, woraus folgt, daB ungleich behandelt werden soll, wer gegenüber anderen ungleiche Verhältnisse aufweist (vgl. F. Neumark 1970, S. 75 u. 120). Selbstverständich schwingt zumindest eine implizite Vorstellung von Leistungsfähigkeit immer schon mit, wenn man die Allgemeinheit und die GleichmäBigkeit der Besteuerung festlegt (F.W. Wagner 1976b, S. 233). Was aber letztlich unter steuerlicher Leistungsfähigkeit verstanden wird, wird politisch bestimmt und ist dem రkonomen weithin vorgegeben; er kann helfen, eine steuerpolitische Richtlinie $\mathrm{zu}$ formulieren; ${ }^{17)}$ keineswegs steht ihm die Festlegung der Normen $\mathrm{zu}$. ${ }^{18)}$

4. DaB alle drei Postulate innerlich zusammenhängen, wird von den Steuerwissenschaften gleichermaBen erkannt, doch gibt es in der Charakterisierung des Zusammenhangs Unterschiede: Die Finanzwissenschaft formuliert die drei Postulate jeweils gesondert und mit ihren Eigenbedeutungen, wobei Allgemeinheit und GleichmäBigkeit eine der Leistungsfähigkeit dienende Funktion haben, die GleichmäBigkeit jedoch weiter gefabt ist als die Allgemeinheit. ${ }^{19)}$ Demgegenüber subordiniert das steuerrecht den Grundsatz der GleichmäBigkeit direkt unter den der Leistungsfähigkeit und schliebt den Grundsatz der Allgemeinheit in den der GleichmäBigkeit mit

17) C.S. Shoup 1970, S. 250: "We clearly need some concept of income defined in a manner that satisfies the society's intuitive test for horizontal equity."

18) U.K. Hicks 1968, S. 117: "This question cannot be settled objectively, so that the interpretation of the principle must remain a matter of policy."

19) Denn VerstöBe gegen das Postulat der Allgemeinheit schlieBen zwangsläufig VerstöBe gegen das der GleichmäBigkeit ein, doch kann letzteres auch verletzt sein, ohne daB ersteres

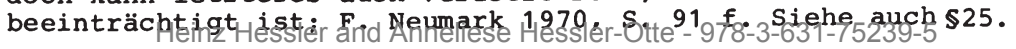


ein; 20) auch das Steuerrecht versteht den Grundsatz der Gleichmäßigkeit als weiter gefaßt denn jenen der Allgemeinheit. Die Charakterisierungsunterschiede im zusammenhang zwischen den Steuerpostulaten führen jedoch $z u$ keinerlei folgenschwerem Dissens zwischen den Sparten der Steuerwissenschaften: GleichermaBen sind in beiden Richtungen der Steuerwissenschaften ${ }^{21)}$ die Grundsätze der Allgemeinheit wie der GleichmäBigkeit sowohl auf personale wie auf sachliche Elemente ausgerichtet. ${ }^{22}$ ) Einigkeit besteht auch zwischen den beiden Richtungen darin, daB das wesentliche Paradigma der GleichmäBigkeit der Besteuerung in der "Gleichbehandlung" der Tatbestände und Personen liegt, wobei die Steuerrechtswissenschaft naturgemäB dieses Problem vor dem Hintergrund des Gleichheitssatzes der Verfassung diskutiert, die Finanzwissenschaft eher allgemeine, wohl auch philosophische Vorstellungen horizontaler und vertikaler Gerechtigkeit 23). Demgegenüber betont die Rechtswissenschaft eher die "formale Gleichheit"24).

20) K. Tipke 1981, S. 29 u. 140; ferner ders. 1981a, S. 52: "Gleichbehandlung heiBt ins Steuerliche übertragen: GleichmäBigkeit der Besteuerung"; "GleichmäBigkeit der Besteuerung versteht sich zunächst als Allgemeinheit der Besteuerung."

K. Tipke 1981, S. 29: GleichmäBigkeit der Besteuerung erschöpft sich nicht in Allgemeinheit der Besteuerung; zu ihr gehört auch die "Gleichbehandlung der allgemein erfaBten Steuerpflichtigen im einzelnen." Siehe auch ders. 1981a, S. 53.

21) Das steuerrecht steht hier stellvertretend auch für die Betriebswirtschaftliche steuerlehre; gleichwohl ist zu bemerken, daB in der Betriebswirtschaftlichen Steuerlehre der Grundsatz der Allgemeinheit viel seltener problematisiert wird als in der steuerrechtswissenschaft.

22) Das personale Element liegt in der Besteuerung a $11 \mathrm{e} \mathrm{r}$ Personen wie auch in der Beachtung ihrer gleichen oder ungleichen persönlichen Verhältnisse; das sachliche Element liegt z.B. darin, daB die Einräumung eines Existenzminimumfreibetrages nicht als Versto $B$ gegen die Allgemeinheit verstanden wird (F. Neumark 1970, S. 80; K. Tipke 1981, S. 24 : die "Leistungsfähigkeit beginnt erst jenseits des Existenzminimums"; weiterhin liegt das sachliche Element im GleichmäBigkeitspostulat darin, daB sich die geforderte Gleichbehandlung auf den gesamten Besteuerungstatbestand und die Steuerbemessungsgrundlage erstreckt, also im einzelnen auf die Einkunftsarten, die Zurechnungen, Vergünstigungen, Ermittlungsmethoden, persönlichen Abzüge und steuersätze.

$23)$ Fast überflüssig zu erwähnen, daß selbstverständlich die Rechtswissenschaft hierin auf der Rechtsphilosophie gründet; betont werden soll, daB die Finanzwissenschaft in dieser Frage nicht in jedem Fall die Kompatibilität mit der Verfassung diskutiert, wozu sie sich auch nicht berufen fühlen dürfte. 
II. Wichtig für unsere Betrachtungen zur Theorie und Politik der steuerlichen Einkommens- und Vermögensdefinitionen ist vor allem, daB unbeabsichtigte VerstöBe gegen die Allgemeinheits- und GleichmäBigkeitspostulate wie auch politisch gewollte Ausnahmen von ihnen die steuerbemessungsgrundlage, die die Grundsätze ja in gröBtmöglicher Breite herstellen sollen, schmälern. Schon die Ausnahmen vom Allgemeinheitspostulat, die die Finanzwissenschaft aus gesamtwirtschafts-, aus sozial-, kultur- und gesundheitspolitischen sowie aus steuertechnischen Gründen zulassen will, beleuchten, welche Möglichkeiten einer Einengung der Bemessungsgrundlage eröffnet werden. H. Laufenburger (1956, S. 461) sah noch eine Ausweitung der Bemessungsgrundlage für seine Epoche. Blickt man hingegen auf das Instrumentenarsenal des steuer- und Interventionsstaates, so wird man nicht bestätigt finden, daB - trotz seines Interesses an hohem Fiskalaufkommen, das überdies zunehmend durch die Progression bereitgestellt wird - die steuerliche Bemessungsgrundlage sich ständig erweitere. Allerdings betreffen die hier zu nennenden Interventionsmabnahmen und Regellosigkeiten zumeist Verstöße gegen das GleichmäBigkeitspostulat. 25) Erst recht zeigt sich keine Erhohung des Allgemeinheitsgrades für das $z u$ versteuernde Einkommen, wenn man es dem wirtschaftstheoretisch entwickelten Einkommen gegenüberstellt; denn das Einkommen der heutigen steuerlichen Rechtsanwendung ist "befreit" von vielen Zurechnungseinkommensteilen, von fast allen Transfereinkommensbestandteilen sowie von Vermögenszugängen wie generell den Erbschaften und z.T. den privaten VermögensveräuBerungserlösen wie auch den meisten Vermögenswertzuwächsen (siehe Exkurs II).

Nach allem stellt sich das Verhältnis zwischen den Termini "steuerliches Einkommen", "steuerliches Vermögen" und "Steuerbemessungsgrundlage" sowie das $\mathrm{zu}$ den Besteuerungsgrundsätzen wie folgt dar:

24) K. Tipke 1981a: GleichmäBigkeit der Besteuerung ist Gleichbehandlung (S. 52); diese ist ein "wesentlicher Gerechtigkeitsfaktor" (S. 24). "Gleichheit hat generellen Charakter, sie verlangt Allgemeinheit der Rechtssätze"; Gleichheit verlangt nach einer konsequenten und tatsächlichen Anwendung von sachgerechten Regeln, Prinzipien oder Grundsätzen. Formale Gleichheit 1st die "Gerechtigkeit als Gleichheit der Rechtsanwendung" (S. 42 f.).

$25)$ siehe hierzu K. Tipke 1981a, S. 65-97; F. Neumark 1970, S. 95-116. (im Ubrigen siehe \$\$ 18-27) 
a) Die grundlegende weite oder enge Fassung und die (mehr oder weniger gelungene) Durchsetzung des Allgemeinheitspostulats determinieren steuerliches Einkommen und Vermögen als Ausgangsgrössen dafür, wa $s$ überhaupt besteuerbar sein soll. Bereits in der Grundentscheidung, wie weit die steuerlichen Begriffe von den wirtschaftstheoretischen abweichen sollen, ob etwa das Einkommen neben den Markteinkommenselementen sämtliche Zurechnungs-, Transfer- und Vermögenszugänge enthalten soll oder nicht, wird der erste Schritt in Richtung einer Einengung der AusgangsgröBe getan.

(1) Dieser Schritt bringt zwei Probleme: Erstens entsteht das Problem der Indikatoren-Auswahl für die Besteuerung nach der Leistungsfähigkeit, denn wenn der steuerliche Einkommensbegriff enger gefabt wird als der wirtschaftstheoretische, wird zumeist im Interesse einer Gesamterfassung der Leistungsfähigkeit zumindest ein weiterer Indikator, nämlich das Vermögen, herangezogen. Zweitens indiziert das Indikatorenproblem ein Mehrsteuerphänomen, denn nun muB versucht werden, je Indikator die ihm angemessene Steuerart zu finden. Aus der Beziehung dieser Steuerarten untereinander und aus ihrer Abstimmung auf die ihnen vorgegebenen allokativen und distributiven $\mathrm{ziele}$ ergeben sich steuersystematische Probleme.

(2) Ein zweiter Schritt in Richtung Ausgangsgrößeneinengung liegt in VerstoBen gegen das nummehr auf einer schmaleren Basis geltende Allgemeinheitspostulat, sofern aus gesamtwirtschafts-, sozialund kulturpolitischen Gründen Ausnahmen zugelassen werden sollen. So werden steuerliches Einkommen und Vermögen immer mehr $\mathrm{zu}$ allokations- und distributionspolitisch präformierten GröBen, die nicht von theoretischen Sätzen und Kriterien, sondern von gesellschaftspolitischen Einflüssen und Entscheidungen bestimmt sind.

b) W $i$ e diese Steuergegenstände im einzelnen in den steuerrechtlichen Regelungen (gleich oder ungleich) behandelt werden, bestimmt sich nach der Fassung des GleichmäBigkeitspostulats sowie nach den VerstöBen. Die Gleichbehandlung von Steuerpflichti- 
gen hat zwei Aspekte, erstens die Vergleichbarkeit ihrer persönlichen sozialen Verhältnisse, zweitens die Vergleichbarkeit der von ihnen realisierten steuerlichen Einkommen und Vermögen. Nur der zweite Aspekt wird unmittelbar wirksam für die Einkommensund Vermögensbegriffe der Besteuerung. VerstöBe gegen die Gleichbehandlung können $z u$ einer Einengung des steuerlichen Begriffs führen, diesmal aber nicht $z u$ einer generell, sondern $z u$ einer gruppenspezifisch wirksamen. Das hat eindeutig noch nichts unmittelbar mit Leistungsfähigkeit $z u$ tun, die ja "Individualgerechtigkeit" herstellen will. Vielmehr führen unterschiedliche steuerrechtliche Regelungen für verschiedene Einkunfts- und Vermögensarten $\mathrm{zu}$ Ungleichbehandlungen von Gruppen: Von Unternehmern und Nichtunternehmern; Landwirten, Gewerbetreibenden und Freiberuflern; Beziehern von Miet-bzw. Pachteinkünften und von Kapitaleinkünften usw. (K. Tipke 1981a, S. 67). 26) Soweit dieses Phänomen der "Gruppengerechtigkeit" (K. Tipke, ebd.) zugleich mit einer unterschiedlichen Behandlung von Einkommensklassen einhergeht, könnte man von "Klassensteuer" (G. Schmölders 1960 , Sp. 79) sprechen.

c) Sowohl die qualitative Auswahl als auch die quantitative Bestimmung der Indikatoren - wenngleich sie nicht die persönlichen Abzüge und Freibeträge und nicht die Festlegung der Tarife betreffen und somit keine Personalisierungsmaßnahmen sind - werden bereits mit Blick auf das Ziel der leistungsfähigkeitsorientierten Erfassung vorgenommen. Hier ist eine Rückbeziehung zum Allgemeinheitspostulat zu konstatieren: So kann z.B. alles, was unter dem Aspekt der Besteuerung nach der Leistungsfähigkeit dem einzelnen an Steuertraglast nicht zugemutet werden soll (und sofern es steuerpolitisch oder -technisch "untunlich" erscheint, dafür eigens persönliche Freibeträge oder Tarifvergünstigungen einzurichten), bereits als "Nichteinkommen" definiert werden. Ein groBer Teil der Steuerbefreiungstatbestände in den $\S \S 3-3 b$ EStG

26) Einkunftsartbezogene Freibeträge und Befreiungen sind $z u$ den "ObjektivierungsmaBnahmen" zu zählen, da sie die Bemessungsgrundlage verändern; soweit die für die obigen Gruppen geltenden Regelungen die Steuersätze berühren, sind das Maßnahmen, die zur "Personalisierung" zählen und unmittelbar die Leistungsfähigkeit betreffen. 
ist so $z u$ werten. Auch das Leistungsfähigkeitsprinzip und die mit ihm verbundenen Gerechtigkeitsvorstellungen präformieren das Allgemeinheitspostulat. Somit bleibt festzuhalten, daB sämtliche drei Besteuerungspostulate den Umfang der Steuergegenstände determinieren und dadurch "begriffswirksam" werden.

d) Gerechtigkeitsvorstellungen, Besteuerungspostulate und auf ihnen gründende Auswahl- und Bemessungsvorgänge münden schlieBlich in die Konstruktion der "Steuerbemessungsgrundlage". Als eine auf vielfältige Weise allokations- und distributionspolitisch eingeengte MaßgröBe werden steuerliches Einkommen und Vermögen zur individuellen steuerbemessungsgrundlage durch die Einführung weiterer, nun auf die persönlichen wirtschaftlichen und sozialen Verhältnisse abgestellten Minderungen der Ausgangsgrössen (Abzüge).

Doch schon bevor solche Personalisierungsvorgänge einsetzen, läBt sich ein bezeichnendes Urteil über die Steuergegenstände und auch über die steuerbemessungsgrundlage fällen: Die Beziehungen und Wechselbeziehungen zwischen den Besteuerungspostulaten, die mit politischen Absichten begründeten Ausnahmen von ihnen sowie die VerstöBe gegen die konsistente Durchführung der Postulate machen bereits die steuergegenstände, letztlich erst recht die steuerbemessungsgrundlage, zu einem allokativ-distributiven Mischbegriff, der, sofern man ihn aus allokationspolitischen Motiven verändert, neben den (gewollten und ungewollten) Allokationswirkungen auch distributive Effekte zeitigt, und umgekehrt: Sofern man mit seiner Hilfe distributive Ziele erreichen will, führt das auch zu allokativen Nebeneffekten. Ein steuerlicher Einkommensbegriff z.B., der auf die Produktionswirtschaften und deren allokationswirtschaftliche Aktivitäten ebenso angewendet wird wie auf Haushaltswirtschaften und deren distributionswirtschaftliche Betätigungen, kann bei z.B. distributionspolitisch motivierter Veränderung und Besteuerung nicht $z u$ allokationsneutralen Folgen führen; umgekehrt haben dann allokationspolitisch motivierte Beeinflussungen des Unternehmergewinns unausweichlich auch Einkommenswirkungen, die nicht den verteilungspolitischen Zielen entsprechen müssen. Dieser zielkonflikt ist in einem steu- 
erlichen Einkommensbegriff, der die (allokative) Unternehmenssphäre nicht von der (distributiven) Haushaltssphäre zu trennen vermag, konstruktiv angelegt. Der steuerliche Einkommensbegriff hat sich von den Rationalitätskriterien der Begriffstheorie gelöst und muB eigenen Kriterien, nummehr denen einer politischen und/oder sozialen Theorie, gehorchen. Inwieweit ihm das gelingen könnte oder nicht, läBt sich an den Abwelchungen von den Besteuerungspostulaten ablesen. Schon der Exkurs in die vermuteten wirkungen läBt erkennen, daB ein allokativ-distributiver Mischbegriff dem Konsistenzgebot auch einer politischen Theorie nicht wird gehorchen können.

e) Doch selbst wenn eine allokativ-distributive Trennung der Sphären sich steuerpolitisch durchsetzen lieBe, etwa dergestalt, daB man für den Allokationsberelch den Kapital- bzw. Ertragsbegriff reservierte, für den Distributionsbereich ausschlieblich den Vermögens- bzw. Einkommensbegriff, so würde auch letzterer unter steuerlichem Aspekt stets ein originär politischer Begriff sein, mit Inhalt gefüllt ausschlieblich aus der verteilungspolitischen Sicht, d.h. aus der Sicht der Leistungsfähigkeit. Um einen solchen Einkommensbegriff von dem wirtschaftstheoretischen abzuheben, liebe sich formulieren: Der mikroökonomische Einkommensbegriff der Wirtschaftstheorie ist ohne Ansehung der Besteuerung nach der Leistungsfähigkeit $\mathrm{zu}$ bestimmen, doch die Besteuerung nach der Leistungsfähigkeit gelingt nur in Ansehung erstens eines Einkommensbegriffs überhaupt (wenn nicht zusätzlich in Ansehung eines Vermögensbegriffs oder - alternativ - eines Ausgabenbegriffes), gelingt uberdies nur zweitens mithilfe eines politisch definierten Einkommensbegriffes. Zu vermuten ist, daB auch bei der Wahl eines begriffsrational gebildeten Leistungsfähigkeitsindikators einer letztlich anzustrebenden zielrationalen Besteuerung keine allzu günstigen Perspektiven eröffnet werden können: Der immerhin theoretisch denkbare Fall, daß nach der Leistungsfähigkeit besteuert wird, und zwar mithilfe eines theoretisch abgeleiteten Einkommensbegriffs, auf den die persönlichen Abzüge und der Progressionstarif angewendet werden, ist nach den bisherigen Erfahrungen vermutlich politisch nicht durchsetzbar, denn allzu verfestigt sind die Verfahren, Steuerpolitik mithilfe der Einengung des Einkommensbegriffs zu treiben. 
III. Steuerliche Leistungsfähigkeit wird vernünftigerweise auf die wirtschaftliche als ihrem einzigen Fundament bezogen bleiben müssen. Sie kann auf verschiedene Weise interpretiert werden. Wird sie definiert als die Fähigkeit, Steuern zahlen zu können (ein steueropfer tragen zu können), handelt es sich um eine auf konkreten ökonomischen Größen basierende, zahlungstechnische Interpretation der Leistungsfähigkeit (ability to pay). Wird sie dagegen aufgefaßt als die Fähigkeit, die Bedürfnisbefriedigung eines Menschen ausdrücken zu können, so ist sie zwar der allgemeiner verstandenen wirtschaftlichen Leistungsfähigkeit konzeptionell näher gekommen, hat sich aber zugleich von realen ökonomischen Größen entfernt und psychischen Beziehungen und Zuständen zugewendet.

Sofern nun die Finanzwissenschaft sich nicht auf dem bisher wenig fruchtbaren Weg bewegen will, die Bedürnisbefriedigungsinterpretation des Leistungsfähigkeitsprinzips opfer- und nutzentheoretisch zu fundieren, liegt es nahe, die Voraussetzungen der "ability-topay"-Auffassung näher $z u$ analysieren und sich den politischen und realen ökonomischen Bezügen, Größen und wertungen zuzuwenden. Dies kann zunächst geschehen mit einer vertieften Diskussion aller sachlichen und personalen Voraussetzungen für die Besteuerung nach der Leistungsfähigkeit (s. 6. Kapitel), dies kann ferner geschehen mithilfe eines Konzeptes, die Allgemeinheit (und damit auch die Leistungsfähigkeit) der Besteuerung an der "freien Verfügbarkeit" ökonomischer Größen auszurichten oder zu messen (7. Kapitel).

Der Aufbau des 6. Kapitels geht davon aus, daB die Leistungsfähigkeit schrittweise zu konkretisieren ist. Da die spezifischen Probleme des Leistungsfähigkeitspostulats in den Personalisierungen und in der Individualisierung der Leistungsfähigkeit liegen, diese aber nicht zum engeren Thema des steuerlichen "Einkommensbegriffs" gehören, sollen hier nur die Voraussetzungen für die Leistungsfähigkeit geprüft werden, also die Frage, w a s überhaupt Leistungsfähigkeit indiziert, und ferner die Frage, w e $r$ denn grundsätzlich leistungsfähig sein kann. Zu diesem Indikatorproblem sei vorab festgehalten, daB die Fragen der verfügungsmacht, der Verfügbarkeit und der Zurechenbarkeit für den Indikator "persönliche Ausgaben" unproblematisch erscheinen, da sie nicht andere sind als bei Einkommen und Vermögen; deshalb konzentrieren sich unsere Ausführungen auf die letzteren Begriffe. 
Die im 7. Kapitel zu leistende Ausrichtung der Leistungsfähigkeit und des Allgemeinheitspostulats auf die freie Verfügbarkeit kann der Finanzwissenschaft nicht schwer fallen, da sie die individuelle Leistungsfähigkeit als "ökonomisch-finanzielle Dispositionskraft" ( F. Neumark 1970, S. 135) interpretiert und solchermaßen anerkannt, daß das Einkommen insoweit keine Leistungsfähigkeit verkörpert, als es - etwa als familiäres Existenzminimum nicht disponibel ist und es demnach im sinne des Leistungsfähigkeitsprinzips konsequent (ist), die Einkommensteuer nur nach dem disponiblen Einkommen $z u$ bemessen (K. Tipke 1991, S. 210). Steuerrecht wie Finanzwissenschaft haben seit je akzeptiert, daB diese Disponibilität politisch bestimmt und eingegrenzt ist (D. Birk 1983, S. 23ff. u. $43 \mathrm{ff.}$ ). Mit dem Konzept der "freien Verfügbarkeit" als dem Versuch, für die Indikatoren der Leistungsfähigkeit ein Konkretisierungskonzept $\mathrm{zu}$ entwickeln, könnte eine Annäherung der verschiedenen Disziplinen der steuerwissenschaften erreicht werden.

S 18 Das Leistungsfähigkeitspostulat und seine erste sachliche Bedingung:

Der Indikator "steuerliches Einkommen"

I. Der "steuertechnische" Einkommensbegriff 238

II. Der "zweiseitige" Einkommensbegriff 241

III. Der "personale" Einkommensbegriff 243

1. Der "ad-personam-Zugang" an

Leistungsfähigkeit 243

2. Die personale Zuordnung der Einkünte 247

IV. Der "zweckbezogene" Einkommensbegriff 248

V. Der "zieloffene" Einkommensbegriff 252

I. Da ein genereller $s t$ e e $r$ e $c h n i s ~ c h$ einheitlicher Einkommensbegriff, der die drei Postulate der Allgemelnheit, der GleichmäBigkeit und der VerhältnismäBigkeit der Besteuerung in sich verwirklichen könnte, im Einkommensteuergesetz "fehlt" (G. Schmölders 1960 , Sp. 75 ff.), konnte die im Zuge der interventionistischen Steuerpolitik liegende Kasuistik der Tatbestandsbeschreibung dazu führen, dab die Einkommensteuer "ein Bündel von 
Sondersteuern" wurde (G. Schmolders, 1960 , Sp. 81). Je umfassender und genereller "Einkommen" gesetzlich festgeschrieben würde, desto geringer würde die Gefahr beabsichtigten und unbeabsichtigten AusschlieBens von Einkommenselementen aus dem Kreis der steuerpflichtigen Tatbestände, desto günstiger wären in der Rechtsprechung die Moglichkeiten einer zweckentsprechenden Auslegung in Zweifelsfällen. ") Ein allgemein gefaBter Einkommensbegriff würde überdies im Hinblick auf die Einmaligkeit oder Periodizität von Zugängen von praktischem Vorteil sein, weil er die "kasuistische Entscheidung erübrigt, ob nicht regelmäßige Einkünfte in Verbindung mit einer bestimmten Berufstätigkeit anfallen und daher steuerpflichtig sind oder mit den einzelnen steuerpflichtigen Einkunftsarten nichts $\mathrm{zu}$ tun haben und deshalb steuerfrei bleiben" (W. Albers 1957, S. 67). Deshalb auch hielt es F. Neumark (1947, S. 37) für "wünschenswert, wenn jedes Einkommensteuergesetz zunächst eine allgemeine Definition des fiskalischen Einkommensbegriffs gäbe, um dann etwa fortzufahren: ' Zum Einkommen gehören insbesondere diejenigen Einkünfte, die unter eine der folgenden Einkunftskategorien fallen ...'. Auf diese Weise würde ein fester Maßstab für die interpretative Bestimmung des Einkommenscharakters von Einnahmen geschaffen, die keine ausdrückliche Erwähnung im Gesetzestext gefunden haben." Die Wünschbarkeit einer solchen "allgemeinen Richtlinie"2) unterstreicht ebenfalls der WD (Organische Steuerreform 1953, S. 25). Sie brächte unter technischem. Aspekt einen Auslegungshinweis, der die Breite des Steuerzugriffs nicht allein aus dem fiskalischen Blickwinkel, sondern auch aus dem der Besteuerung nach der Leistungsfähigkeit gewährleisten würde. Bei der Fassung der Generalklausel sollte einerseits auf die angestrebte Totalität der Erfassung der Leistungsfähigkeit, andererseits auf die Praktikabilität der Steuertechnik Bedacht genommen werden.

Wenn somit eine Generalklausel nicht besteht, so bedeutet das nicht, daß die Steuerrechtswissenschaft ohne ein generelles Theo-

1) WB BMF 1953, S. 24: "Der formale Einkommensbegriff des deutschen steuerrechts ... vermag einerseits $z u$ gewissen bedenklichen Aus legungen $z u$ führen, ... während er andererseits ... es der Verwaltung und Rechtsprechung erschwert, strittige Grenzfälle zu entscheiden ..."

2) Vgl. das Einkommensteuerrecht der USA, das in Sec. 61a I.R.C. definiert: "Exept as otherwise provided in this subtitle, gross income means all income from whatever source derived, including (but not limited to) the following items:-jíc"." 
riefundament auskommt. Zumindest sieht Tipke (1991, S. 159ff.) diese Fundierung in der "Markteinkommenstheorie" von $W$. Roscher 1918). Sie soll in kurzen Zügen geschildert werden.

Als Einkommen definiert Roscher solche Einnahmen, die "aus einer wirtschaftlichen Tätigkeit" herrühren (S: 438, \$144); das ist eine planmäßige Tätigkeit,um den Bedarf an "äußeren Gütern" (zur Bedürfnisbefriedigung hergestellte oder erhaltene) zu decken (S.5), bei Geltung des ökonomischen Prinzips (S. 25). "Rohes" Einkommen sind für Roscher sämtliche Güter, die die Wirtschaft neu produziert (S. 439, \$ 145); "reines" Einkommen ist derjenige Teil hiervon, der nach Abzug der Produktionskosten übrig bleibt, der also verzehrt werden kann, ohne das Stammvermögen zu schmälern. "Freies" Einkommen ist derjenige Teil des reinen, welcher nach Befriedigung der unentbehrlichen Bedürfnisse des Produzenten noch verfügbar ist. Man muß hinzufügen, daß nach Roscher (1901, S. 399, \$72) auch die "Werthabnahme oder -zunahme" aller Vermögensgegenstände zum Einkommen zählt.

nach allem handelt es sich um einen Begriff, der sehr stark in der produktionswirtschaftlichen sphäre wurzelt, verwendungsorientiert ist, das Interesse an der Kapitalerhaltung deutlich formuliert und durch die Aufnahme der Wertveränderung eine bestimmte Breite erreicht. Dennoch ist er nach unseren Ausführungen in den \$\$ 7-12 in hohem Maßre der theoretischen Kritik ausgesetzt.

Von diesem Begriff sagt nun Tipke (1991, S. 159), er habe sich in der Praxis durchgesetzt, da der Steuergesetzgeber von 1925 die Reinvermögenszugangstheorie von Schanz verworfen habe. Die Anwendung des steuergesetzlichen Einkommensbegriffes sei eine "Konkretisierung" des Einkommens in Richtung "Makteinkommen".

Auf den ersten Blick aber ist zu erkennen, daß dieser Begriff keine privaten Zuwendungen, keine private Wertschöpfung (das sieht auch Tipke, s. 159) und keine öffentlichen Transfers erfassen kann. Dennoch hat er nach Tipke (S. 202f.) "fundamentale Bedeutung für das Wesen der Einkommensteuer als Element einer freiheitlich organisierten Marktwirtschaft", da als Einkommen "alle Einkünfte aus einer Erwerbstätigkeit, die mit Gewinn-/Ubberschußabsicht erwirtschaftet worden sind" definiert werden.

Der Einkommensbegriff unseres Steuergesetzes ist ein technischer; es bestehen jedoch Zweifel, ob selbst bei diesem stark verkürztem Anspruch an einen Begriff die obige Theorie fundamental sein kann. 
II. Will man allokative und distributive Ziele vermittels steuerpolitischer Abzugsregelungen durchsetzen, kommt man nicht umhin $z u$ akzeptieren, daB das steuerliche Einkommen ein "z w e i $s$ e $i$ t $i \mathrm{~g}$ e $r$ " Begriff ist: Das Einkommen hat nämlich eine Erzielungs - und eine Verwendungsseite; auf beide Seiten richten sich aber die Individualentscheidungen, somit werden auch beide Seiten - da ja die Steuerpolitik die Individualentscheidungen beeinflussen will - notwendigerweise und absichtlich von der steuerpolitik betroffen. Soll ein bestimmtes Verhalten des Wirtschaftenden aus allokations- oder distributionspolitischen Motiven in eine bestimmte Richtung gedrängt werden, so müsssen - als die Ansatzstellen der Politik - seine Verfügungen über die Einkommenserzielung $\mathrm{u} n \mathrm{~d}$-verwendung beeinfluBt werden. Für den einzelnen wird die Entscheidung, in diesem oder jenem Wirtschaftssektor, in dieser oder jener Region usw. sein Einkommen nicht oder gerade doch $z u$ e $r z i$ e $l$ e $n$, von der Steuerpolitik und ihren Anreizen bzw. Sanktionen genau so beeinflubt wie seine Entscheidung, das Einkommen für diesen oder jenen Konsum- bzw. Sparzweck nicht oder gerade doch $z u$ v e $r$ w e $n$ d e $n$. Oftmals hat sogar der einzelne über seine Verwendungsverfügungen eine größere Entscheidungsfreiheit als über seine Erzielungsverfügungen. Man wird nicht folgern dürfen, eine Ausrichtung der Politik an der Verwendung des Einkommens mache die Einkommensteuer "systemwidrig". Man könnte sogar sagen, daB gerade eine steuerpolitik, die sich auf die Verhaltensbeeinflussung der Einkommensverwendung richtet, das Prinzip der Totalerfassung des Einkommens und der Leistungsfähigkeit viel eher verwirklicht als eine erzielungsgerichtete, da sie es vermeidet, bestimmte Einkommenserzielungsquellen $z u$ diskriminieren und $z u$ ihrem Versiegen $A n l a B z u$ geben. U.E. ist die Definition des $s$ e $u$ e $r l i c h$ e $n$ Einkommens sowohl von der Erzielungs- als auch von der Verwendungsseite ${ }^{3)}$ her erlaubt bzw. erforderlich, sofern sie erreicht, was sie bezweckt: das zu besteuernde Einkommen nach dem belastungspolitischen ziel festzulegen. Allerdings gibt sie damit ihren Anspruch auf, eine theoretisch geschlossene Einkommensdefinition erreichen zu wollen. Den Anspruch würde sie allerdings auch verlieren - sofern sie ihn je erhoben hat -, wollte sie bestimmte Einkunftsquellen und -arten als nicht besteuerbar ausklammern. Somit ist die Einbeziehung der Einkommensverwendung in den Begriff des steuerlichen Einkommens

Fn. 3) auf der folgenden Seite 
auch unter rationalem Aspekt nicht zu kritisieren, denn nach welcher Rationalität wird denn verlangt, die Leistungsfähigkeit nur von der Erzielungsseite $z u$ beschreiben? Im Distributionsbereich ist die Trennung zwischen Erzielung und Verwendung aber nicht begriffsbegründend. ${ }^{4}$ Es wäre jedoch theoretisch verfehlt, die Einkommensverwendung in den steuerlichen Einkommensbegriff dergestalt hineinzunehmen, daB etwa die Kapitalerhaltung qua steuerliche Abschreibungen und sonstige Abzugsposten das Einkommen und damit die Steuerbemessungsgrundlage schmälern dürfte. Das hieBe nämlich, die Fehler aus der "maintaining capital intact-Diskussion" (s. oben $\S 8$ III u. IV sowie $\S 12$ V) zu perpetuieren. Kapitalerhaltung spielt sich im allokativen Bereich ab und schmälert den Ertrag bzw. Gewinn, nicht das Einkommen. Wenn dennoch in einem Steuergesetz - wie etwa dem bundesrepublikanischen - diese Tatbestände miteinander vermengt werden, so zeigt sich darin, daß man es vorgezogen hat, die persönliche und die unternehmerische Besteuerung in ein und demselben Steuergesetz $\mathrm{zu}$ regeln und solchermaBen einen allokativ-distributiven Gewinn-/ Einkommensbegriff als Mischbegriff $\mathrm{zu}$ creieren.

Einkommen als ein Phänomen der steuergesetzlichen Realität ist nicht identisch mit Leistungsfähigkeit; Einkommen "indiziert"

3) K. Tipke (1.991, S. 21C) bezeichnet den Abzug von (existenziell notwendigen) $\mathrm{A}$ u $\mathrm{s} \mathrm{g}$ a b e $\mathrm{n}$ (also die Einkommensverwendung) als steuergerecht, wenn auch hier unter dem Aspekt des $\mathrm{Ab}-$ zugs von der Bemessungsgrundlage und vor dem Hintergrund des Progressionseffektes. Aber er korrigiert solchermaßen immerhin den Gesamtbetrag der erzielten Einkünfte um die Verwendungsgröße "Ausgaben". 1981, S. 150: Obwohl der Einkommensbegriff als Indikator steuerlicher Leistungsfähigkeit "zunächst umfassend und einheitlich erscheinen mag, ist er es nicht. Man kann ihn nur ausmessen, wenn man das ganze Gesetz mit seinen Detailregelungen einbezieht. Tut man das, so ergibt sich, daB wesentliche Teile des Einkommens definitorisch aus dem Einkommensbegriff ausgeklammert sind, namentlich durch ... Nichterfassen von Einkünften des privaten Bereichs." - Damit scheint Tipke seine Auffassung von 1971 (S. 8: Der Einkommensbegriff sei zu rügen, weil er mit Sonderausgaben und auBergewöhnlichen Belastungen definitorisch verklammert sei) aufgegeben $\mathrm{zu}$ haben.

4) Wie aus den $\S \S 3-10$ erinnerlich, ist innerhalb des distributiven Bereichs des Wirtschaftens und seiner Begriffe für den wirtschaftstheoretischen Einkommensbegriff die Verwendung einer ökonomischen GröBe nicht begriffsbestimmend; sie ist es aber sehr wohl für die Abgrenzung des Einkommens vom Vermögen. 
Leistungsfähigkeit, so wie andere Indikatoren ebenfalls Leistungsfähigkeit indizieren können. Die wissenschaftliche Theorie des ökonomischen Einkommens ist logisch gebildet, die "Theorie" der Leistungsfähigkeit hingegen politisch. Leistungsfähigkeit ist als eine Richt- und MaBgröBe in ein Besteuerungsprinzip aufgenommen worden. Aus dem Verhältnis zwischen Steuerprinzip und Verteilungsziel folgt: Das Prinzip als allgemeingültige praktische Handlungsregel sorgt für die zielgerichtete Ausgestaltung des Instruments "Einkommensteuer". Wie das Ziel, beruht auch das Prinzip auf Urteilen und Werten. Das Leistungsfähigkeitsprinzip bedient sich der GröBe des "steuerlichen Einkommens" (ebenso wie der Bemessungsgrundlage und des Tarifs); solchermaBen miBt die prinzipiengerecht und personalisiert ausgestaltete Einkommensteuer den einzelnen wirtschaftenden individuell und interpersonell unterschiedliche Traglasten $z u$. Ist für den ökonomischen Einkommensbegriff die Verfügbarkeit als solche die conditio sine qua non der Begriffsbildung, so ist für den steuerlichen Einkommensbegriff vorwiegend die teils ökonomisch bedingte, doch vorwiegend politisch bestimmte $f$ e $i$ e Verfügbarkeit entscheidend. Sie bestimmt den Begriffsinhalt dieser $p \circ 1$ i $t$ i $s \mathrm{c} h$ e $n$ Größe (\$ $21 \mathrm{ff.}$ ). Freie oder nicht freie verfügbarkeit 1 äßt sich aber in der gebotenen Breite nur beschreiben, wenn auch die verwendung des Einkommens einbezogen wird.

III. Für den steuerlichen Aspekt der $\mathrm{z} u \mathrm{~g}$ a $\mathrm{n} g \mathrm{~s}$ e g e l gilt: Rechenhaftigkeit und Periodeneinteilung müssen vorliegen, soll eine Bemessungsgrundlage überhaupt gegeben sein. Dagegen werden die beiden weiteren Erfordernisse, die "ad-personam-Regel" und die "zugangstotalität" (s. unten) aus steuerlicher sicht kontrovers diskutiert. Sie erfahren überdies auch in der praktischen Ausgestaltung veränderungen.

1. Was die "a $d-p$ e $s \circ n$ a $m$ - R e g e l" angeht, so hat sie gerade für die Besteuerung nach der Leistungsfähigkeit eine besondere Konsequenz: Der ad-personam-zugang an ökonomischen Größen ist zugleich die "Subjektivierung", mithin ein ad-personam-zugang an Leistungsfähigkeit. 
a) Daraus folgt steuertheoretisch5) auch die Forderung nach einem transfer- und vermögenseinschließenden Einkommensbegriff.6) Läßt man den erst in zweiter Linie interessierenden Progressionseffekt beiseite und betrachtet nur das Problem des zugangs an Leistungsfähigkeit, so vermittelt er ungeachtet seiner Quellen (erarbeitet, ererbt oder auf Wertzuwachs basierend) eine erhöhte Dispositionskraft und Verfügbarkeit. 7) Der Zugang ist ausschlieblich personal zu sehen. Die Personalsteuern setzen bei der Person an und erfassen deren Leistungsfähigkeit aus jedweder Quelle und ungeachtet dessen, welchen Einschränkungen und Vorbelastungen wirtschaftlicher und steuerlicher Art der den Zugang begrüdende Tatbestand vorher unterlegen hat. Man kann auch sagen: Gilt die Zugangsregel mit ihrem ad personam-Zugang auch steuerlich, so ist jede Person für die Personalsteuern eine $\mathrm{n} e \mathrm{u} e$ Person ex ovo. Das hat dann die Konsequenz, daB etwa vorher gezahlte Steuern, z.B. die Einkommen- oder die Vermögensteuer des Erblassers, für den neuerlichen (leistungsfähigkeitsdeterminierten) Besteuerungs-

6) So sieht das auch der Vorschlag der Carter Commission 1966, Vol. III, S. $465 \mathrm{ff.,} \mathrm{der} \mathrm{die} \mathrm{Vermögenstransfers} \mathrm{dem} \mathrm{Einkom-}$ men zuschlagen und im Rahmen der Einkommensteuer besteuern will, exakt gemä $B$ der Reinvermögenszugangstheorie.

5) DaB steuerpolitisch von dieser Konsequenz abgewichen wird, soll die theoretischen Uberlegungen nicht stören, denn die Argumente für eine gesonderte Erbschaft- und Schenkungsteuer werden angesichts des diskontinuierlich anfallenden Erbund Schenkungsfalles vorwiegend auf den progressiven Belastungseffekt gestützt, der die Einbeziehung der Erbschaftsteuer in die Einkommensteuer verbiete. Diese Argumente werden also erstens nicht aus dem objektivierungsbereich der Leistungsfähigkeit, sondern aus dem Personalisierungsbereich hergeleitet; sie sind zweitens mit steuersystematischen und ordnungspolitischen Problemen und Vorstellungen verknüpft, die mit begrifflichen Uberlegungen nichts $\mathrm{zu}$ tun haben.

7) N. Andel 1979a, S. 348 f. - A. Oberhauser 1980, S. 669. Beide bejahen die höhere Dispositionsfähigkeit und Leistungsfähigkeit für den Fall des Wertzuwachses, was rein einkommensbegrifflich - würde ein vermögenseinschlieBender Einkommensbegriff verwendet - auch für jeden anderen Verfügungszugang gelten müBte.

8) H. Haller 1978, S. 236: "Der Z u g a n g des Erbes wird als Entstehung einer Leistungsfähigkeit $s$ u $i \quad g$ e $n$ e $r i s$ interpretiert", was sich auch in der Freibetrags- und Tarifgestaltung ausdrücke; Hervorhebung HDH. Wir wollen allerdings nicht verkennen, daB Haller stets mit dem Zugang an "Bedürfnisbefriedigungspotential" argumentiert, wohingegen wir den Zugang an Vermögensgegenständen bzw. Einkommenselementen meinen. 
akt unerheblich sind. 9) Für den Erben ist wegen der höheren Leistungsfähigkeit eine auf ihn abgestellte Steuer (Einkommen-, Erbschaft- oder Vermögensteuer) also "erstmalig". Er ist ein neues Steuersubjekt "ex ovo"; er ist leistungsfähig unabhängig von der Leistungsfähigkeit des Erblassers. In strenger Anwendung hat die ad personam-Regel des zugangs darüber hinaus eine innerpersonale steuerliche Konsequenz dergestalt, daB mit ihr auch die Besteuerung von Einkünften aus dem selbst-gebildeten Vermögen begründet werden kann; ${ }^{11}$ überall dort, wo - ungeachtet der Zugangsquellen - erhöhte Leistungsfähigkeit bei einer Person sich einstellt, entfallen Argumente einer irgendwie gearteten "Doppelbelastung". 12)

9) Aus diesem Grunde widersprechen wir auch der Auffassung von A. Oberhauser in $1979 \mathrm{a}, \mathrm{S} .492 \mathrm{ff}$., die im übrigen nicht mit seiner eigenen Meinung in 1980, S. 669 hinsichtlich der für die Leistungsfähigkeit ausschlaggebenden höheren Dispositionsfähigkeit übereinstimmt. Wenn er in der Erbschaftsteuer des Erben und der Einkommensteuer des Erblassers eine Doppelerfassung desselben Vermögens sieht (weil der Erblasser sein Vermögen nur aus versteuertem Einkommen bilden konnte), so übersieht oberhauser entweder die Regel, daB ja die Leistungsfähigkeit einer $P$ e $r$ s o n erfaBt werden soll oder er unterstellt, daB immer die Leistungsfähigkeit einer Familie die korrekte Art der Besteuerung nach der Leistungsfähigkeit sei.

10) Man sieht, daß das Zugangsprinzip ohne die moralisierende Begründung der Erbschaftsteuer auskommt, die mit der "Mühe- bzw. Opferlosigkeit" des Vermögenserwerbs seitens des Erben argumentiert und solchermaßen das Werturteil des nur unter Mühen, Plage und Opfern Erworbenen als eines wahren Lebenswertes nicht einmal $\mathrm{zu}$ verbergen sich bemüht.

11) Aus diesem Grunde widersprechen wir auch H. Fecher (1979, S. 478 u. 479 !), der bei gleichzeitiger Existenz von Einkommen-, Umsatz- und Vermögensteuer in jedem Spar- und Vermögensbildungsakt (den er im übrigen stets mit einer Konsumverschiebung gleichsetzt) eine Doppelbelastung erblickt; nicht jeder Sparakt ist uneingeschränkt eine Konsumverschiebung; liegt tatsächlich eine solche vor, wie etwa beim Zwecksparen für langlebige Gebrauchsgüter, dann läBt sich mit Fecher (ebda.) von einer "Doppelbelastung" sprechen. Denn dann kommt es zu einer Diskriminierung derer, die zum Zwecksparen gezwungen sind, gegenüber jenen, die langlebige Güter leicht aus dem laufenden Einkommen anschaffen können; diese zahlen dann keine Vermögensteuer.

Zwecksparen auf Gebrauchsgüter führt nicht zu erhöhter Leistungsfähigkeit; würde dieses Vermögen besteuert, würde das $\mathrm{zu}$ einer Doppelbelastung führen.

12) Man sieht, daB die zugangsregel von jeglicher Schattierung einer "Fundustheorie" frei ist und sich auf die fragwürdig (Forts. siehe folgende Seite) 
b) Für die reale Steuerpolitik hierzulande gilt demgegenüber zweierlei: Erstens wird die leistungsfähigkeitsorientierte ad personam-Regel dem Grunde nach insofern anerkannt, als die in der Theorie angeführten Doppelbelastungsargumente keinerlei Gewicht erhalten haben: Erbschaften und Schenkungen werden ungeachtet der vorherigen Einkommensbesteuerung des Erblassers beim Erben besteuert; auch der Ertrag des aus versteuertem Einkommen gebildeten Vermögens unterliegt der Besteuerung. Doch zweitens gilt die wirtschaftstheoretische Zugangsregel in der dort begründeten Breite steuerlich nicht: Selbst die zweifellos einer Person zugehenden Transfereinkommens- und Imputierungseinkommensbestandteile zählen nicht sämtlich zum steuerlichen Einkommen; ferner ist der vermögenseinschlieBende Einkommensbegriff nur für die Gewinnermittlung nach dem Vermögensbestandsvergleich vorgesehen. Beides wirft Probleme der Gleichbehandlung und GleichmäBigkeit der Besteuerung auf, im ersten Fall zwischen Gruppen von Einkommensbeziehern, im letzteren zwischen den Einkunftsarten, was in einigen Fällen ebenfalls zu Gruppenungleichheiten führt (s. §§ 25 ff.).

Die Anerkennung der Zugangsregel dem $G r u n d e$ nach, bei einem gleichzeitigem Zurückweisen der Regel ihrer $G$ e 1 t u n g s b $r$ e $i$ t e nach, führt $z u$ den folgenden steuersystematischen Unverträglichkeiten: Die Erhebung einer Vermögensteuer neben der Einkommensteuer belastet die Vermögenserträge zweifach; ${ }^{13)}$ ebenfalls wird der Erbanfall im Jahr des Zugangs sowohl durch die Erbschaftsteuer als auch durch die vermögensteuer zweimal belastet. ${ }^{14}$

Forts. Fn. 12: gewordene allgemein geltende Unterstellung der Vermögenseinkommen als den auf jeden Fall sicheren Einkommen gegenüber denen aus Arbeitseinsatz nicht einzulassen braucht.

13.) Man beachte: Dieses Doppelbelastungsargument ist nicht identisch mit dem oben als unerheblich für die Leistungsfähigkeitsbesteuerung bezeichneten; die beiden Tatbestände der Doppelbelastung unterscheiden sich sowohl personell als auch zeitlich. Die obige Belastung des Erbes durch die ESt des Erblassers und Erbschst des Erben ist keine Doppelbelastung im Sinne der personalen Besteuerung; bei der hier vorliegenden steuersystematischen Unverträglichkeit ist $n$ i $c h t$ zu kritisieren, $\mathrm{daB} \ddot{\mathrm{u}} \mathrm{b}$ e $\mathrm{r} h \mathrm{a} u \mathrm{p} t$ Vermögenserträge steuerlich erfaBt werden (obwohl sie aus versteuert gebildetem Einkommen stammen können), sondern daB sie durch $z w$ e $i$ Steuern derselben Person, also zweimal erfaBt werden.

Fn. 14 siehe folgende Seite 
2. Steuerrechtlich wird die ad personam-Regel einerseits als subjektive steuerpflicht, andererseits als subjektive zurechnung von Einkünften gesehen. Die erste Frage ist sowohl eine personale als auch eine sachliche $\mathrm{z}$ u $\circ \mathrm{r} \mathrm{d} \mathrm{n} \mathrm{n} \mathrm{g}$ von Einkünften, denn Voraussetzung für die unbeschränkte steuerpflicht ist der Wohnsitz, der gewöhnliche Aufenthalt oder der Schwerpunkt des Lebensund Interessenkreises im Inland. Die GröBe des steuerlichen Einkommens sowie deren personale zuordnung bestimmt sich solchermaBen aus einer "territorialen" Sicht des Zugangs, nicht aus einer ökonomischen oder belastungspolitischen.

రkonomisch determiniert ist demgegenüber die subjektive Zurechnung von Einkünften. Wie sich aus $\S 2$ Abs. I Satz 1 i.V.m. $\S 1$ Abs. I Satz 1 und Abs. II EStG ergibt, sind die Einkünfte bzw. Bezüge "natürlichen $\mathrm{P}$ e $\mathrm{r}$ s $\circ \mathrm{n}$ e $\mathrm{n}$ " bzw. "Staatsangehörigen" zuzurechnen; welche Personen allerdings die Einkünfte "erzielen", bestimmt sich danach, wer sie erwirtschaftet. Letztlich gilt: Demjenigen, der eine Einkunftsquelle "nutzt", indem er Leistungen erbringt, also entweder arbeitet oder Vermögen einsetzt, werden die Bezüge zugerechnet, wobei nicht entscheidend ist, wem die Bezüge unmittelbar zuflieBen. 15) MaBgebend ist das Erwirtschaften.16) Es ist aber damit keineswegs die Einkommensqualität selbst beschrieben, wie das für die o.g. produktionswirtschaftlichen Einkommensdefinitionen gilt, die als Einkommen nur bezeichneten, was der produktionswirtschaftlichen Tätigkeit entspringt; hier geht es nur um die Entscheidung, we $r$ im Zweifelsfalle der Einkommensbezieher ist. Immerhin läBt sich daraus folgern, daB auch steuerlich die ökonomische ad personam-Regel gilt.

Fn. 14 :

Auch hier gilt die Kritik nicht der Erbschaftsteuer als solcher oder etwa der Besteuerung dieses Leistungsfähigkeitsindikators überhaupt, sondern der Erfassung durch $z$ w $e$ i Steuerarten bei derselben Person.

15) Tipke 1981, S. 190: "Zurechnung und Zufluß sind zu unterscheiden." 1991, S. 226: Allgemeine Zurechnungsreqel: Die Einkünfte sind der Person zuzurechnen, die sie "erzielt", \$2EStG. 1991 , S. 295: "Bilanzieren muß den vermögensgegenstand derjenige, dem er zuzurechnen ist. Siehe auch die "zuordnung" S. 205 u. 248 der Einkunftsarten nach "zu- und Abflußprinzip".

16) Die Zurechnung bestimmt sich ausnahmsweise nach dem "ZufluB" im Erbfall, K. Tipke 1991, S. 232; eine Ausnahme vom Prinzip des "Erwirtschaftens" gilt für das Ehegattensplitting (K. Tipke 1981, S. 194), bei dem unterstellt wird, der gering verdienende Partner habe einen Teil der Einkünfte seines Partners "erwirtschaftet". Siehe unsere Kritik daran in $\$ 16$. 
Die zurechnung berührt unmittelbar die wirtschaftliche Leistungsfăhigkeit, denn durch sie wird festgelegt, wer Steuerschuldner ist. Schon allein die Existenz des "wirtschaftlichen Eigentums", die das Steuerrecht zuläBt, beweist, daB die Zurechnung zwar grundsätzlich frei gestaltbar, ${ }^{17,)}$ daB sie aber zur Feststellung der Leistungsfähigkeit unabdingbar ist. Somit gilt auch für die zuordnung der Indikatoren die ganz spezielle sichtweise der steuerlichen ad personam-Regel: Die "Objektbindung" der Leistungsfähigkeit an einerseits die Arbeitskraft, an andererseits den Vermögenseinsatz will nicht aussagen, w a $s$ uberhaupt mit Leistungsfähigkeit $z u$ bezeichnen ist, sondern $w$ e $r$ sie besitzt. Die tatsächliche Herrschaftsausübung ist im wesentlichen ein Problem des "Verfügens". 18) Auch die Frage des Verfügens, für die wirtschaftstheoretische Einkommensdefinition die conditio sine qua non, ist steuerlich zunächst eine solche der personalen $\mathrm{Zu}-$ rechnung.

IV. Der Einkommensbegriff ist auf dreifache Weise "z w e c k $\mathrm{b}$ e $\mathrm{z} \circ \mathrm{g}$ e $\mathrm{n} "$ : Zum einen hat Einkommen den Zweck, dem Individuum in Form geldlichen und güterlichen zugangs die Verfügung über jene Ressourcen $z u$ verschaffen, die es zur sicherung seiner Existenz jetzt und in zukunft, die es als Belohnung für seine Aktivitäten und die es - über solche ökonomische Planverwirklichung hinaus - auch für die metaökonomische Lebensgestaltung und gesellschaftliche Positionsbestimmung haben will; dies sei der "Individualzweck" des Einkommens. ${ }^{19)}$ Zum anderen hat Einkommen den

17) E. Littmann 1978, § 2, Rd.-Nr. 93; sie muB allerdings ernsthaft, eindeutig und inhaltlich auch so vollzogen sein (Rd.Nr. 94); dann ist der wirtschaftliche Eigentümer zur steuer heranzuziehen.

18) Die Herrschaftsausübung des wirtschaftlichen Eigentümers hat so zu sein, daB er den Eigentümer von der Einwirkung auf das Wirtschaftsgut ausschlieBen kann. Es ist dies nach E. Littmann (1978, § 2, Rd.-Nr. 94 u. 102) eine Frage des Innenverhältnisses: der wirtschaftliche Eigentümer muB "verfügen" können wie ein Eigentümer, muB frei schalten und walten können und dies auch tun.

19) Ein solcher Zweck des Einkommens wird in der Literatur nicht eigens formuliert; wenn E. Schuster (1961, S. 54) feststellt, daB das Einkommen "die Lebens- und wirkungsmöglichkeiten des einzelnen Menschen" bestimmt, so ist das in dieser Allgemeinheit nur der Ausgangspunkt einer Individualzweckformulierung

(Forts. siehe folgende Seite) 
Zweck, dem steuererhebenden Staat als MaBgröBe zu dienen, wenn er das in Aussicht genommene Steueraufkommen auf jene Individuen verteilen will, die nach seiner Vorstellung ökonomisch in der Lage sind, Steuerlasten zu tragen und die nach seiner Vorstellung darüber hinaus in der Lage sind, auch umverteilende Einkommenseinbußen hinzunehmen. Dies sei der "Steuerzweck" des Einkommens genannt.20) Er steht im Dienste der steuerpolitischen zwecke (ziele).

Verständlicherweise sind die individuellen und die steuerlichen Zwecke des Einkommens einander entgegengerichtet, ohne daB sich jedoch der eine unter vollständigem Verzicht auf die Durchsetzung des anderen verwirklichen lieBe. So wie heute die Lebensgestaltung des einzelnen ohne einen großen Teil des kollektiv bereitgestellten (und daher auch kollektiv finanzierten) Angebots an öffentlichen Gütern kaum möglich ist, so kann auch der staat die Steuer nicht losgelöst vom Individualzweck des Einkommens erheben. Man pflegt diese Zusammenhänge mit dem Postulat nach "Beachtung der Dauerergiebigkeit" von Steuern $z u$ untermauern. Der staat ist in der Setzung des Umfangs seiner MaßgröBe "steuerliches Einkommen" nur so frei, wie ihm einerseits der Individualzweck des Einkommens, andererseits die gesellschaftliche Akzeptanz bzw. Verweigerung seiner politischen ziele Grenzen angeben, bis zu denen er die Besteuerung äußerstenfalls treiben kann. In diesen politischen zielen, denen der steuerzweck dient, liegt die dritte zweckbezogenheit; hier handelt es sich nummehr um eine "zweckbezogene

Forts. Fn. 19:

des Einkommens. Etwas genauer läBt sich der Zweck aus der Theorie der personalen Einkommensverteilung herleiten: Wenn hier von "Leistungs"- und "Bedürfnisgerechtigkeit" gesprochen wird, unter der die Einkommensverteilung $z$ u beurteilen sei, so sind damit die Zwecke des Einkommens als die Existenzsicherung und die Entlohnung für den Faktoreinsatz bereits vorausgesetzt. Diese Individualzwecke des Einkommens heben wir hier lediglich hervor.

20) Die Bezeichnung "Sozialzweck" ginge zu weit, denn dann wäre der Zweck des Einkommens aus der wirtschafts- und sozialpolitischen Gesamtbetrachtung heraus gesehen. Der Steuerzweck des Einkommens ist so breit nicht gedacht; er ist - wenn auch ein politischer - so doch ein Zweck der MaBstabsfindung. 
Selbständigkeit"21) des Einkommensbegriffs insoweit, als er für die $z$ i e l e d e $r \quad B$ e $t$ e u e $r$ u g verwendet wird. Von hier aus wird der steuerliche Einkommensbegriff definiert. Um den Unterschied zwischen der theoretisch gedachten und der politisch praktizierten zielbezogenen Selbständigkeit des Steuerbegriffs deutlich zu machen, sei folgendes festgestellt: Der Steuerbegriff ist grundsätzlich so gestaltbar, daß er für politische ziele eingesetzt werden kann. Ist er für politische ziele einsetzbar, so bleibt er dennoch vom Begrifflichen her für das gesamte politische Zielbündel generell "offen". Insofern besteht zwischen dem "zielbezogenen" und dem "zieloffenen" Steuerbegriff kein Gegensatz. Vielmehr stellt sich das Verhältnis zwischen beiden als das des besonderen zum allgemeinen dar.

Für die politische Zweckbestimmung aber gehen wir nun von der folgenden Hypothese aus: Innerhalb eines weiten Rahmens bestimmt der Staat die Grenzen der Besteuerung vorwiegend nach den steuerpolitischen zielen; will sagen: Ist der Individualzweck des Einkommens auch nur halbwegs gewährleistet und sind die Belohnungen des Individuums für seine ökonomischen Aktivitäten annäherend akzeptabel für es, so nutzt der Staat die Möglichkeiten zu einer weiteren oder engeren Definition des steuerlichen Einkommens vorwiegend im Sinne seiner interventionistischen Steuerpolitik; d.h. der Steuerzweck des Einkommens ergibt sich für den staat aus der beabsichtigten Steuerpolitik. SolchermaBen reflektiert der steuerliche Einkommensbegriff die verhaltensbeeinflussenden Absichten. Die Geschichte der interventionsausdehnenden staatstätigkeit mag als ein Beleg dafür dienen.

Zu fragen ist, ob die "zweckbezogene Selbständigkeit" des Einkommensbegriffs Segen oder Fluch für die steuerpolitik ist. Die Bedeutung des steuerlichen Einkommens erhöhte sich mit dem Rollenwandel, den man der Steuerpolitik um die Mitte des 19. Jahrhunderts zuschrieb. In einer Zeit, da das öffentliche Finanzsystem längst vom "Anteilsystem" zum "Kontrollsystem" - etwa um die Epoche nach dem 1. Weltkrieg - gewandelt worden war (F.K. Mann 1937, S. 341),

21) Man sollte vielleicht diesen von N. Andel (1979a, S. 334) benutzten Begriff in "zielbezogene" statt zweckbezogene Selbständigkeit umbenennen, damit der Unterschied zwischen dem Steuerzweck des Einkommens und Besteuerungsziel des Staates deutlicher hervortritt. 
wurde die Steuerpolitik zur "Vollstreckerin des allgemeinen politischen Willens" (ders., S. 344). Wenn F.K. Mann (1937, S. 354) den Einkommensbegriff einen "Kunstbegriff" nennt, so nicht etwa deswegen, weil das steuerliche Einkommen "nicht mit logischem Zwang aus volkswirtschaftlichen Obersätzen abgeleitet" werden kann, sondern weil es mit zahlreichen Ausnahmen und Sonderregelungen durchsetzt wurde. Generell wird nämlich die Abweichung des steuerlichen vom wirtschaftstheoretischen Einkommen mit der ZweckmäBigkeit, der die steuerpolitik unterliegt (J. Popitz) 22), d.h. mit den "spezifisch finanzpolitischen Bedürfnissen und Vorstellungen" (F. Neumark) ${ }^{23}$ ) begründet. Sind im Extrem die Zwecke beliebig setzbar, wird man ohne Bedenken G. Myrdal (1963, S. 161) zustimmen, wenn er feststellt: Der finanztheoretische Einkommensbegriff "kann mit beliebigem Inhalt und den jeweils gewünschten Folgerungen verwendet werden"; "das Wort bekommt ganz einfach den Inhalt, den man ihm gibt". 24) Auch wenn man der völligen Beliebigkeit in den Zwecksetzungen nicht zustimmt, wird man konzedieren, daB der steuerliche Einkommensbegriff dennoch grundsatzlich die "Auswahl" (R. Goode 1977, S. 2) der Zwecke erlaubt. Als eine "politische Zielgröße" (W. Albers 1979a, S. 191) hat der steuerliche Einkommensbegriff eine "zweckbezogene Selbständigkeit", die nach N. Andel (1979a, S. 334) sogar notwendig ist. 25)

22) 1926, S. 418: Für die praktische Gestaltung ist ein starres Festhalten an einem theoretisch an sich richtigen Einkommensbegriff nicht möglich; vielmehr muB "im einzelnen untersucht werden, wie sich zweckmäBig der Umfang des Einkommens umschreiben läBt".

23) $1961 \mathrm{~b}, \mathrm{~S} .31$; ob ein Begriff $\mathrm{zu}$ weit oder $\mathrm{zu}$ eng sei, beantworte sich danach, wie zweckmäBig er gebildet sei.

24) Myrdal analysiert den Einkommensbegriff nicht im einzelnen, sondern kritisiert die Brauchbarkeit des Leistungsfähigkeitsprinzips (S. $157 \mathrm{ff.})$ für die Besteuerung des Einkommens und für die Begründung der Progression. Von Bedeutung ist hier sein Hinweis, daB man durch eine Änderung des Einkommensbegriffs nach Belieben den konkreten politischen Inhalt der Steuerprinzipien verändere, durch die man ja die Steuer in Beziehung zum Einkommen gesetzt habe.

25) Allerdings erscheint die Zwecksetzung bei $N$. Andel eingeschränkt, S. 334: "Sieht man den Zweck der Einkommensteuer darin, öffentlichen Finanzierungsbedarf auf der Grundlage der Leistungsfähigkeit zu decken, .... ist die Definition so zu wählen, daB diese beiden Aspekte möglichst genau erfaBt werden." - In dieser Formulierung scheint als variable ZielgröBe einzig die Ausgabenfinanzierung zugelassen zu sein, wobei das, was individuell-belastungspolitisch Einkommen sein soll, als verteilungspolitische Bedingung auftritt. 
V. Es läge nun nahe, in die einen " $z i$ e $l$ o f $f$ e $n$ e $n$ " Einkommensbegriff prägende "steuertechnische Generalklausel" (s. I) eben diese Besteuerungszwecke aufzunehmen. Das bringt jedoch Probleme mit sich, da die steuerzwecke verschiedene sind und auf unterschiedlichen Ebenen liegen. Würde das fiskalische Ziel präferiert, müBten vom allokativen und vom distributiven ziel - sofern sie mittels des Instruments der Abzüge vom Einkommen bzw. von der Steuerbemessungsgrundlage durchgesetzt werden sollen - Abstriche vorgenommen werden. Soll als Nebenbedingung zum fiskalischen ziel die Vertellung der Steuerlast nach der Leistungsfähigkeit hinzutreten - der gewöhnliche, in Theorie und Politik postulierte Fall der Besteuerung -, fallen bei Aufkommensneutralität die Abstriche am allokativen ziel um so gröBer aus, je strikter die Lastverteilungsregel angewendet wird; denn die Verteilung der steuerlast nach der persönlichen Leistungsfähigkeit enthält distributive Zielelemente: Nicht nur hinsichtlich des Existenzminimums wird übereinstimmend jegliche Leistungsfähigkeit verneint, sondern auch hinsichtlich weiterer nicht oder eingeschränkt disponibler Einkommensteile (hiërüber kann aber keineswegs immer Ubereinstimmung zwischen den politischen Entscheidern erwartet werden).

DaB ein allokatives ziel oder zielbündel bzw. daB distributive Ziele von vornherein in der Generalklausel festgeschrieben würden, wäre mit Rücksicht auf den gesellschaftlichen Abstimmungsund KompromiBfindungsproze $B$ kaum ohne Reibungen durchzusetzen, wäre auch aus theoretischer sicht nicht zu begründen, da die Präferenz der ziele von situation zu situation wechselt. zudem wïrde dies die Hintanstellung des fiskalischen ziels bedeuten, die im Bedarfsfall nur durch ständiges Verändern der Freibetragsregelungen und des Progressionsmaßes zu korrigieren wäre.

Soll das steuerliche Einkommen offen und umfassend definiert werden, harmoniert das zwar mit dem fiskalischen ziel, konfligiert hingegen mit allokativen und distributiven zielen dann, wenn etwa das Fiskalziel nur geringe allokativ bzw. distributiv motivierte Ab$z$ lige vom Elnkommen erlauben würde. Und dennoch erscheint ein zieloffener $s t$ e u e $11 \mathrm{c}$ h e r Elnkommensbegriff als der noch am ehesten gangbare weg 26), da erstens sich damit der steuerliche Einkommensbegriff dem wirtschaftstheoretischen annähert (was im-

26) auf der fplgendessl Seitte Anneliese Hessler-Otte - 978-3-631-75239-5 
merhin kein systematischer Fehler ist, sondern allen bisherigen theoretischen tberlegungen entgegenkommt und als der Sinn der Generalklausel angesehen werden darf); da zweitens damit zumindest die Grundbedingung - aber auch nicht mehr! - für ein maximales Fiskalaufkommen gelegt wäre (von dem aber jederzeit qua Grundfreibetragsausdehnung und Progressionsverlaufsänderung abgewichen werden könnte); und da sich drittens die allokativen resp. die distributiven Zwecke immer noch durch ein System von Abzügen vom Einkommen bzw. von der Bemessungsgrundlage verwirklichen lieBen. Der zieloffene steuerliche Einkommensbegriff überantwortet mehr Tatbestände der offen diskutierten gesellschaftspolitischen Entscheidung und bietet die breitest mögliche Anwendungsbasis für die Politik. Wäre auch der steuerliche Einkommensbegriff wie der wirtschaftstheoretische auf Vollständigkeit angelegt, lieBen sich steuerpolitisch dieselben ziele anstreben, die wirtschafts- und finanzpolitisch als wünschbar erscheinen.

Ist solchermaßen der Vollständigkeitsgehalt des Einkommens an den mit ihm bezweckten steuerpolitischen zielen gemessen, so muB nunmehr ergänzend beurteilt werden, inwieweit der g e s e $t z$ I i c h gefabte Einkommensbegriff - auch oder gerade wenn ihm eine Generalklausel nicht vorangestellt wurde - einen zieloffenen und umfassenden Zugriff auf das Besteuerungsgut erlaubt und dergestalt sowohl GleichmäBigkeit als auch Leistungsfähigkeit der Besteuerung bereits vom Ansatz her in den Griff bekommt. Das geltende deutsche Einkommensteuergesetz führt statt einer umfassenden allgemeinen Einkommensdefinition die bekannten sieben Einkunftsarten auf. Es ist theoretisch unbefriedigend, aus der Kasuistik des Gesetzeswortlautes schlieben zu müssen, was allgemein als Einkommen gemeint sein könnte. Wenn K. Tipke (1991, S. 2021 feststellt, "was durch die sieben Einkunftsarten nicht erfaBt ist, fällt in den / rechtsfreien Raum", dann sind damit solche Einkommenselemente gemeint, die der Gesetzgeber (planmäBig oder planwidrig) bewuBt nicht erfaBt hat Ergebnis: Die ideale Vorstellung eines generellen und zieloffenen Einkommensbegriffs bleibt die Maßgröße der Kritik am gesetzlich festgeschriebenen Einkommensbegriff.

26) Das würde es erfordern, vom Gedanken der "Kapitalerhaltung" in den Begriffen der älteren Theorien (siehe oben in II und \$\$ 7 und 11) abzurücken. 
519 Das Leistungstähigkeitspostulat und seine zweite sachliche Bedingung:

Der Indikator "steuerliches Vermögen"

I. Vorbemerkung: Die Mehrschichtigkeit des Indikatorproblems

II. Der "steuertechnisch-einheitliche" Vermögensbegriff

1. Die steuertechnische "Eklektik"

2 . Die bewertungsbedingte Uneinheitlichkeit: Verfahrenskomplizierung und zielabhängige BelastungsniveauUnterschiede

3. Der allokativ-distributive mischcharakter

III. Der "personale" Vermögensbegriff

1. Die Zurechnung des Vermögens an nichtnatürliche Personen

2. Die Zurechnung nach der Vorstellung des wirtschaftichen Eigentums

IV. Der "zweckbezogene" Vermögensbegriff 272

1. Der "Individualzweck" des Vermögens 272

2. Der "Steuerzweck" des Vermögens 273

3. Der "zielbezogene" Vermögensbegsiff 278

I. Den wirtschaftstheoretischen Vermögensbegriff hatten wir oben wie folgt entwickelt (\$\$ 9 u. 10) :

- Vermögen ist jene ökonomische GröBe im distributiven Bereich des Wirtschaftens, die jemand - woher sie ihm auch immer zugegangen ist - kraft der ihm zustehenden Verfügungsmacht e $n t$ scheidet, nicht $z$ u k o nsumieren.

- Diese Entscheidung über die ZugangsgröBen - $\mathrm{V}$ e $r$ w e n d u n g trifft stets nur eine natürliche Person und zwar ausschlieblich im Hinblick auf die ökonomisch-sozialen $F$ u $n t i \circ n$ e , die ihr das Vermögen erfüllen kann.

- Damit nicht etwa auch nur eine einzige der denkbaren Zugangsentscheldungen willkürlich von der wirtschaftstheoretischen Begriffsfindung ausgeschlossen bleibt, erfordert es ein solcher 
vermögenstheoretischer Ansatz, in die Bestimmung des Vermögensbegriffs das $\mathrm{T} \circ \mathrm{t}$ a $l \mathrm{v}$ e $r \mathrm{~m}$ ö $\mathrm{g} \mathrm{n}$ als die gröBtmögliche $\mathrm{S} u \mathrm{~m}$ e jene Vermögensgegenstände aufzunehmen, über die eine Person Verfügungsgewalt hat und die zugleich - da nur die Verfügungsgewalt über "ökonomische" GröBen begrifflich erfaBbar ist - im Generalnenner $G$ e $l d$ b e w e $r$ t b a $r$ sind. Ist dieser allgemeine theoretische Vermögensbegriff auch als steuerlicher $\mathrm{zu}$ verwenden? Auch hier gilt: Die Bestimung des steuerlichen Vermögensbegriffs entscheidet sich nach politischen Erwägungen, insbesondere denen der steuerlichen Belastungspolitik. Als die eine solche Belastung normativ prägenden Besteuerungsgrundsätze gelten auch hier die Postulate der Leistungsfähigkeit, der Allgemeinheit und der GleichmäBigkeit.

a) Gegenüber dem Einkommensindikator zeichnet sich jedoch das Problem des Vermögensindikators durch eine $M$ e $h$ r s $\mathrm{c} i \mathrm{ch}-$ $t i g k$ e $i t$ aus: Erstens tritt $z u$ der Darstellung der Charakteristika, die die Eigenart des Vermögens belegen (s. \$ 10), das Problem der Bewertung hinzu, das beim Einkommen nicht im Vordergrund steht, das aber gerade für den Vermögensbegriff die "qualitative" Seite des Phänomens ausmacht (K. Tiepelmann 1963, S. 45) und notwendigerweise mit dem quantitativen Begriffsumfang verbunden ist. Zweitens ist ein enger Zusammenhang festzustellen zwischen der wahl des die Leistungsfähigkeit anzeigenden Einkommensbegriffs und der Heranziehung des zusätzlichen Indikators "Vermögen"; wählt man nämlich statt des engeren "produktionswirtschaftlichen" Einkommensbegriffs den weiteren "vermögenseinschliessenden", so ist damit bereits die Existenz und die Berechtigung des Vermögens als Indikator implizit mitentschieden!' zugleich sind dadurch, weil nunmehr eine Vermögensteuer in den Bereich des steuerpolitisch Möglichen oder gar Notwendigen tritt, steuersystematische Beziehungen hergestellt. Solche steuersystematischen Beziehungen stellen nun die dritte Ebene der Mehrschichtigkeit dar, auf der drei Problemvarianten auftreten, nämlich das zusam-

1) Soweit in den vermögeneinschließenden Einkommensbegriff imputierte Vermögenseinkommenselemente aufgenommen sind, ist die Bewertungsnotwendigkeit dieser Vermögensarten ein Problem des Vermögens. Soweit in den steuerlichen Einkommensbegriff Vermögensvergleiche eingehen - s. unten $\$ 26$-, ist die Bewertung ebenfalls ein Problem des Vermögens. 
mentreffen zweier Indikatoren (Einkommen und Vermögen), ${ }^{2)}$ das zusammentreffen verschiedener (und verschieden besteuerter) Vermögensarten ${ }^{3 /}$ und die gleichzeitige Besteuerung des "Vermögens" verschiedener Steuersubjekte, nämlich der Privaten und der Unternehmen. ${ }^{4}$ )

b) Diese Komplexität des Problems wird in Ubersicht 6.1 abgebildet. Die Ubersicht enthält Beziehungsfelder (F: I, II, III, A und $B)$ sowie Beziehungen ( $Z$ : $a, b, c$, usw.). Sie soll deutlich machen, daB dem steuerlichen Vermögensbegriff verschiedene Charakteristika zugeordnet sind (F: I, Z: a), daB die steuerliche Realisierung und Nichtrealisierung des Allgemeinheitspostulats den Umfang des steuerlichen Vermögens determinieren (F:I; Z:b), daB die Vermögensartenerfassung und -bewertung von der Beachtung bzw. Nichtbeachtung des GleichmäBigkeitspostulats bestimmt werden (F: I/B; $Z: C)$ und $d a B$ sich daraus der gesamte bewertete vermögensumfang ergibt $(\mathrm{z}: \mathrm{d}+\mathrm{b})$. Mithin zeigt die Ubersicht in ihrer ersten Ebene der vermögensteuerlichen Mehrschichtigkeit, daB für das steuerliche Vermögen die Steuerpostulate sowohl umfangs- als auch wertmäBig begriffsbestimmende Einflüsse haben.

c) Die tbersicht zeigt auf ihrer zweiten Mehrschichtigkeitsebene, daB bereits die Wahl des Einkommensbegriffs den Wertausdruck des Gesamtvermögens teilweise vorbestimmt (F: II/A; Z: f). Hier wird auch erkennbar (F: II A), daB das vermögeneinschlieBende Einkommen die Vermögenserträge des produktionswirtschaftlichen Einkommens mit erfaBt ( $(\mathrm{Z}: \mathrm{e}), \mathrm{zusätzlich}$ noch die Vermögensbestandsveränderungen, und $d a B$ nur dieser Einkommensbegriff den Vermögensbegriff determiniert. Dies zeigt nun, daB durch die Heranziehung welchen wirtschaftstheoretischen Einkommensbegriffs

2) Problemvariante 1: Besteuerung desselben Vermögensertrags durch die Einkommen- plus Vermögensteuer.

3) Problemvariante 2: Besteuerung desselben Vermögensgegenstandes durch Vermögen- plus Gewerbekapital- plus Grund- plus Erbschaftsteuer.

4) Problemvariante 3: Zweifachbesteuerung durch Vermögensteuer auf Betriebsvermögen bei der Kapitalgesellschaft plus Vermögensteuer auf den Anteilsbesitz an dieser Gesellschaft beim privaten Anleger. 
Ubersicht 6.1: Problemkomplexe aus dem Zusammenwirken von steuerlichen Begriffen (I U. II), Systemen (III) und Postulaten (A u. B) im Vermögensbereich

$\begin{aligned} & F= \begin{array}{c}\text { Beziehungsfelder } \\ \left(A, B, I . I . .^{\circ} \text { III }\right)\end{array} \\ & z=\text { Beziehungen }(a, b)\end{aligned}$

I. steuerliches Vermögen

allg. Merkmale für den Begriff:

- "zweckbezogen".

- "zieloffen"

- "einheitlich"

- personale Zuordnung

- Verfügbarkeit

a)
A

Allgemeinheit (Totalerfassung) 10

- Ausschlūsse: (Human-, Freizeitmetabk. Vermōgen)

- Einschlüsse:

o Verm. d. Zurechnungseinkommens

o verm. d. VerãuBerungse inkommens

- Vermögen der Unternehmungen b)

Gesamtvermögens-

bewertung

$$
\text { T }
$$

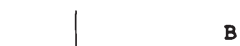

GleichmäBigkeit (Gieichbehandlung) Vermögensartenerfassung

- im Privatbereich

- im Untern.-bereich

- zwischen Priv. - u. Unternehmensbereich

f)

II. steuerliches Einkommen

f)

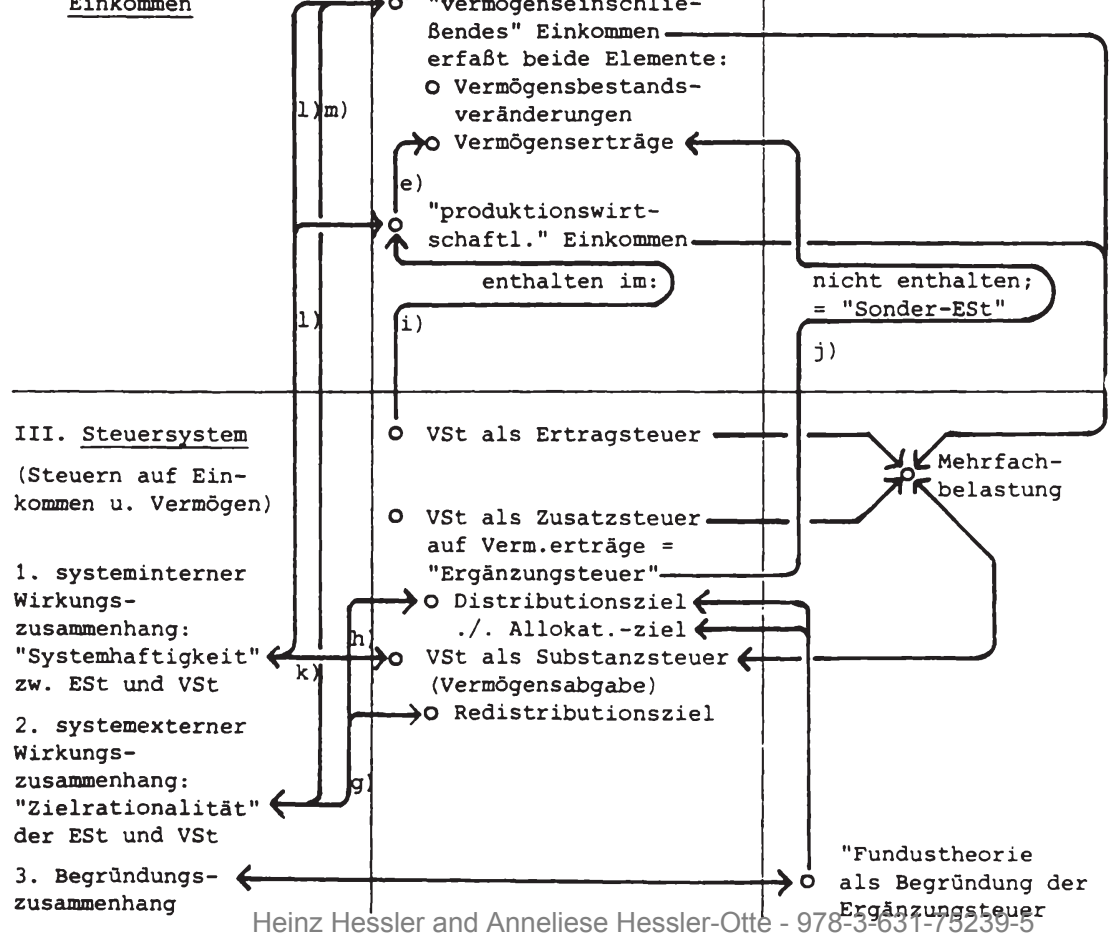


auch immer das steuerpolitische Bedürfnis nach Erfassung der

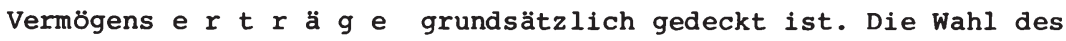
weiteren Einkommensbegriffes würde aber zugleich ein Votum für das Vermögen als Leistungsfähigkeitsindikator implizieren, da er den Vermögensbestandsvergleich am Ende und am Anfang einer wirtschaftsperiode voraussetzt. ${ }^{5}$ )

d) Alle weiteren Beziehungen, nämlich die steuersystematischen, liegen auf der dritten Ebene der Mehrschichtigkeit. Zunächst werden die einzelnen Steuerarten (Ertrag-, zusatz- u. Substanzsteuer) unter dem Aspekt des Allgemeinheitspostulats gewürdigt (F: III A); dies dient der Totalerfassung der Leistungsfähigkeit. Ferner sind die Probleme der Mehrfachbelastung und Besteuerung sog. "fundierter" Einkommen als Probleme der (fehlenden) Gleichbehandlung gesehen, weil nicht sämtliche Vermögensarten von ihnen gleichermaBen betroffen sind (F: III B). Steuersystematische Fragen - obwohl sie in aller Breite nicht zu dem hier gewählten Untersuchungsgegenstand gehören - werden hier nur in Einzelpunkten aufgegriffen, soweit sie nämlich mit der Leistungsfähigkeit und mit distributiven Zielen der Besteuerung zusammenhängen. ${ }^{6)}$

Präferiert man das Distributionsziel zu Lasten des Allokationsziels, hat man die Zielrationalität der Vermögensteuer in ihrer Form als zusatz- oder Ergänzungssteuer zu prüfen (F: III2.; $z$ : g). Verfolgt man darüber hinaus das Redistributionsziel, hat man sich - neben der allgemeinen Vermögensteuer - insbesondere mit der Zielrationalität der Vermögensteuer als substanzsteuer auseinanderzusetzen (F: III 2.; Z: h). Beziehungen zum Allgemeinheitspo-

5) Das bedeutet vorerst aber noch keineswegs, die Bestände an Vermögen auch gesondert $\mathrm{zu}$ besteuern; das bedeutet bisher lediglich, daB das Vermögen als Indikator insoweit gilt, als die Leistungsfähigkeit in der $\AA \mathrm{n} d$ e $r$ u $\mathrm{n} g$ von körperlichen und wertmäBigen Beständen erblickt wird.

6) So kann die Fundustheorie in der Bedeutung als eine "Begründung" für eine Zusatzertragsteuer im Grunde genommen nur im steuersystematischen Zusammenhang gewürdigt werden; jedoch berücksichtigt sie unter dem steuersystematischen Aspekt der "Zielrationalität" einen bestimmten Teil des Zielspektrums, nämlich das Redistributionsziel, nicht. - In Feld III ist die Erbschaft- und Schenkungsteuer nicht eigens ausgewiesen, da sie auf das Vermögen erhoben wird und dieses im schema bereits lokalisiert ist. 
stulat und zum Vermögensbegriff ergeben sich insofern, als die Vermögenertragsteuer bereits sowohl in der steuer auf das produktionswirtschaftliche wie auch auf das vermögeneinschlieBende Einkommen enthalten ist und dem Allgemeinheitspostulat bereits genügt (F: III $A ; Z:$ i). Demgegenüber bedeutet eine Ergänzungsoder Zusatzsteuer auf Vermögenserträge immer eine "Sondereinkommensteuer" (j), wobei man aber davon ausgeht, daß die Vermögenserträge eine über die Einkommensqualität aus dem Faktor Arbeit hinausgehende Leistungsfähigkeit indizieren (Fundustheorie). 7) Erhebt man neben der Einkommensteuer und neben der laufenden Vermögenertragsteuer noch eine Vermögensbestandsteuer unabhängig vom Ertrag, unterstellt man eine besondere Leistungsfähigkeit kraft der $0 . g$. Vermögensfunktionen $(\S 10)$, mit der vermuteten redistributiven wirkung, $\left.{ }^{8}\right)$ da eine Vermögensbestandssteuer nicht aus dem Ertrag entrichtet wird (Substanzsteuer).

Gegenüber diesem systemexternen Wirkungszusammenhang besteht der interne, der die "Systemhaftigkeit der Einkommensteuer und Vermögensteuer" beschreibt. Systemrein wäre eine Wirkungsabgrenzung nur, wenn entweder eine Einkommensteuer, die die Vermögenserträge neben anderen Einkommens-Elementen erfaBt und mit versteuert, neben einer reinen Vermögensbestandssteuer existierte oder neben dieser Kombination eine ausdrückliche Vermögensertrags-Zusatzsteuer bestünde (nur im letzteren Fall käme es zur Mehrfachbelastung der Erträge). Damit wären zugleich die systemhaften Beziehungen zum Einkommens- und Vermögensbegriff aufgewiesen: Die Besteuerung der Erträge ließe sich mit dem produktionswirtschaft-

7) Im Grunde ein verblüffendes Ergebnis, denn daraus dürfte hervorgehen, daB die Fundustheorie nicht zur Begründung einer persönlichen, sondern einer sachlichen, objektgebundenen "Leistungsfähigkeit" herangezogen wird: Die Tatsache allein, daB Vermögenserträge dem Empfänger zugehen, und nicht etwa, daB diese Vermögenserträge im Rahmen des Gesamtzugangs an Einkommenselementen seine Leistungsfähigkeit erhöhen, dient der Fundustheorie als Begründung für eine zusätzliche Besteuerung der Erträge aus Vermögen. Wenn aber die Leistungsfähigkeit als ein persönlicher Gesamtzustand betrachtet wird, kann eine Zusatzsteuer auf Vermögenserträge allenfalls mit einer Fundustheorie begründet werden, die sich selbst als eine allokative versteht.

8) Sie tritt tatsächlich nur dann ein, wenn auf der Ausgabenseite des öffentlichen Haushalts entsprechende Posten erscheinen. 
lichen wie auch mit dem vermögeneinschlieBenden Einkommen herstellen (F: III 1.; Z: 1), die Besteuerung der Vermögenssubstanz mit dem Vermögensbegriff (F: III 1.; $\mathrm{Z}: \mathrm{k}$ ).

e) Die steuersystematischen Zusammenhänge führen uns hinsichtlich des Begriffsproblems $\mathrm{zu}$ folgenden Ergebnissen:

(1) Die Besteuerung von Vermögenserträgen verlangt keine Definition des steuerlichen Vermögens als BestandsgröBe, sofern der enge produktionswirtschaftliche Einkommensbegriff als steuerliches Einkommen gilt (i). Sollen unabhängig von der wahl des engeren oder weiteren Einkommensbegriffs die Vermögenserträge zusätzlich besteuert werden, erfordert die "Zielrationalität der Einkommenund Vermögensteuer" mit Blick auf die Wirkungen eine Abwägung zwischen dem Allokations- und dem Distributionsziel: Präferiert man die allokativ motivierte zusätzliche Besteuerung von Vermögenserträgen ungeachtet der individuellen Gesamt-Leistungsfähigkeitssituation des Steuerpflichtigen, so genügt die schlichte Definition dessen, was als Vermögensertrag zu gelten hat; ${ }^{9}$ ) schon allein das zugehen von Erträgen bei einem Steuerpflichtigen, der ansonsten keinerlei weitere Einkünfte hat, würde bei einer Allokationssteuer die steuerpflicht auslösen. Präferiert man dagegen eine distributiv motivierte Sondersteuer auf Vermögenserträge, so muB die Definition der Erträge von der individuellen GesamtLeistungsfähigkeit des Steuerpflichtigen abhängig gemacht werden; die Sondersteuer dürfte nicht alleln vom Zugang der Erträge als solchen abhängen, sondern davon, ob eine als Norm angesetzte Gesamteinkommensgrenze aus Arbeits- und Vermögenserträgen überschritten wird (j). 10)

(2) Die Wahl des weiteren, des vermögeneinschlieBenden Einkommensbegriffs erfordert die Definition von VermögensbestandsgröBen. Sollen zugleich diese Bestände auch gesondert besteuert werden, erfordert die innere Systemhaftigkeit zwischen Einkommen- und Vermögensteuer eine solche Definition des Vermögensbestandes und

$9)$ mit der tarifpolitischen Konsequenz eines proportionalen Steuersatzes

10) mit der tarifpolitischen Konsequenz einer Einbeziehung in die Progression oder einer gesonderten Progression (mit oder ohne Anrechnung auf die Einkommensteuer) 
damit des gesetzlichen steuergegenstandes, daB eine zusätzliche Besteuerung der Vermögenserträge ausgeschlossen bleibt, um "systemintern" die Wirkung der Mehrfachbelastung auszuschlieBen und eine reine Bestandsbesteuerung $z$ u erreichen (I). Allerdings wirkt eine reine Bestandsbesteuerung als "Substanzsteuer", was die bewubte setzung, zumindest aber die Inkaufnahme des Redistributionsziels voraussetzt und solchermaBen zur zielrationalität in der Formulierung des Steuergegenstandes zwingt (m).

(3) DaB die gegenwärtig in der Bundesrepublikt erhobene Steuer auf das "Gesamtvermögen" bzw. das "Inlandsvermögen" ( $\$ 4$ VStG) einheitlich, d.h. als "Vermögensteuer" erhoben wird, sollte nicht den Blick dafür verstellen, daB sie sowohl eine zusatzertragsteuer als auch eine Bestandsteuer ist, über deren Substanzsteuerqualität allein das zufällige Ausbleiben von Erträgen, nicht aber die gewollte redistributive Steuerpolitik entscheidet. Die Frage, ob nur die Erträge oder auch die Bestände besteuert werden sollen, ist also nicht qua Entscheidung gelöst worden, sondern beantwortet sich gewissermaBen unter dem Aspekt des "dolus eventualis": Sollten Vermögenserträge ausbleiben, wird die Vermögensteuer nolens volens zur Substanzsteuer, und die redistributive Wirkung ergibt sich keineswegs als situationsangemessene Folge einer Rationalentscheidung.

II. Was steuerlich Vermögen ist, bestimmt sich teleologisch ( $K$. Tlepelmann 1963, S. 45); die Absicht liegt darin, nach der Leistungsfähigkeit $z \mathrm{u}$ besteuern, und als Indikator dient das Vermögen in Umfang und Wert. Die Norm des Allgemeinheitspostulats richtet sich auf die Erfassung des Gesamtvermögens, die Norm des GleichmäBigkeitspostulats auf die Gleichbehandlung der verschiedenen Vermögensarten in der Erfassung und vor allem in der Bewertung. Wo letzteres nicht erreicht wird, kann auch der wert des Gesamtvermögens nur ein unvollständiger Ausdruck der Totalerfassung und damit der Leistungsfähigkeit sein. Den Zugang $z$ um Problem der Totalerfassung eröffnen wir uns mit einer Prüfung jener Charakteristika, die zur Bestimmung des steuerlichen Einkommensbegriffs bereits oben entwickelt wurden. ${ }^{11}$

11) Dies ist verkürzt dargestellt der Inhalt der Felder I A/B in Ubersicht 6.1 . 
1. Vermögen wird im gegenwärtigen Steuersystem einerseits in der Vermögensbesteuerung (der periodischen Vermögensteuer und der aperiodischen Erbschaft- und Schenkungsteuer sowie evtl. einer Vermögensabgabe), andererseits im Zuge des Vermögensvergleichs in der Einkommensbesteuerung herangezogen. Das sind zwei grundverschiedene Vermögensbesteuerungsweisen; denn in der letzteren dient Vermögen der Gewinnfeststellung und damit der Besteuerung einer stromgröBe, in der ersteren dient es der Besteuerung einer BestandsgröBe. Die Gewinnbesteuerung ist eine allokative Besteuerung, da betrieblicher Gewinn erst durch die Ausschüttung bzw. Entnahme Einkommen wird. Die Vermögensteuer dagegen ist eine Besteuerung, die im betrieblichen Bereich die Ertragsfähigkeit, im persönlichen Bereich die Leistungsfähigkeit "ergänzend" erfassen soll. Die Vermögensteuer ist also teils eine allokative, teils eine distributive Besteuerung.

Diese divergierenden Besteuerungsabsichten bestimmen die $\mathrm{E}$ i $\mathrm{n}$ -

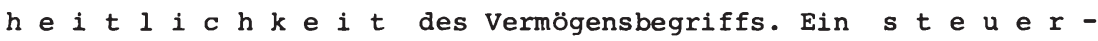
$t e c h n i s c h$ einheitlicher Vermögensbegriff ist in den Gesetzen nicht $z \mathrm{u}$ finden: Weder das Vermögensteuergesetz, das Erbschaft- und Schenkungsteuergesetz noch das Bewertungsgesetz definieren allgemein, was steuerlich Vermögen sein soll. Auch das Einkommensteuergesetz enthält keine Legaldefinition, obwohl es doch in $\S 4$ seiner allgemeinen Gewinnvorschrift auf den Vermögensvergleich abstellt. Weil nur allgemeine Hinweise und allenfalls Anhaltspunkte gegeben werden, sind Begriffsverwirrungen und dogmatische Unklarheiten (K. Tipke 1979a, S. 197) unvermeidlich. Bei Vorhandensein einer Legaldefinition würde sich die chance für eine Totalerfassung des Vermögens, aber auch für eine Gleichbehandlung der Vermögensarten in der Bewertung erhöhen. ${ }^{12}$ ) In der geltenden Fassung kennt das Erbschaft- und Schenkungsteuergesetz lediglich in $\S 12$ die Verweisung auf das Bewertungsgesetz ganz allgemein, kennt das Vermögensteuergesetz in $\S 4$ das Institut des "Gesamtvermögens", ohne $z u$ erklären, was das ist, verweist aber zur näheren Bestimmung ebenfalls auf das Bewertungsgesetz. Dieses jedoch zeigt anstelle einer allgemeinen Definition seiner-

12) Musgrave/Musgrave 1980, S. 489: "Similar to the case of the income tax, the base should be defined globally, so as to give equal treatment to all components of net worth." 
seits in $\S 18$ eine Aufzählung bestimmter Vermögensarten und kommt in $\S 114$ Abs. $2 \mathrm{zu}$ der erstaunlichen Feststellung, daB zum Gesamtvermögen alles das "nicht" gehört, was nach irgendwelchen Vorschriften andernorts ausdrücklich von der Vermögensteuer "befreit" ist. Es fehlt also nicht nur an einer allgemeinen gegenständlichen Vermögensdefinition, sondern es wird negativ definiert, und zudem werden in die - hier aber nur wertmäBig vorgestellte - Gesamtvermögensvorschrift Befreiungstatbestände aus anderen Steuergesetzen aufgenommen. Auf diese Weise wird, ähnlich wie in der Einkommensteuer, die mögliche breite Fassung eines Besteuerungstatbestandes von vornherein um steuerpolitisch motivierte Ausgrenzungen eingeengt, so akzeptabel die Ausgrenzung im Bewertungsgesetz selbst auch sein mag. In der steuertechnischen würdigung handelt es sich also um ein Zusammenspiel von positiv-enumerierenden und negativ-eliminierenden Rechtsvorschriften, deren gemeinsames Kennzeichen die $E \mathrm{k} l$ e $\mathrm{k} t \mathrm{i}$ ist. Die enumerierende Eklektik grenzt z.B. Hausrat völlig aus dem Vermögensbegriff aus, obwohl sich darin erhebliche Werte ansammeln können, die auch Wertsteigerungen erfahren und Vermögensfunktionen erfüllen ( $\$ 10$ III unserer Untersuchung). 131

2. Wie bereits erwähnt, sind die mit den Bewertungsgrundsätzen verfolgten Absichten und selbst auch die Bewertungsmaßstäbe so unterschiedlich, daß "zwei Bewertungssysteme nebeneinander" (G. Wöhe 1992,S.464f.) in unserem Steuerecht bestehen.

a) Das erste System kennzeichnet die Absicht der periodengerechten Gewinnfeststellung mithilfe des Vermögensvergleichs nach dem Einkommensteuerrecht. Diese Methode zeichnet aus, daB sie erstens

13) Der steuerlichen Erfassung des Hausrats könnte entgegengehalten werden, dab sie hohen Verwaltungsaufwand erfordere; dieser aber entsteht für andere Fälle des "sonstigen Vermögens" ohnehin, wenn nämlich nach $\S 110$ BewG Nrn. 9-12 alle Möbel in möbliert vermieteten Wohnungen, alle Wert- und Schmuckgegenstände, Kunstgegenstände und Sammlungen erfaBt werden müssen, die bestimmte Wertgrenzen übersteigen.

14) Das Problem der Gleichbehandlung im allokativen Bereich.

15) Das Problem des Hinüberziehens von allokativ motivierten Regelungen in den distributiven Bereich; auf beides wird in $\$ 27$ II genauer eingegangen.

16) dem Schutz jener Gesellschafter, "die keinen Einfluß auf die Geschäftsführung und die Gestaltung des Rechnungswesens haben", Wöhe, G., 1978, S. 403. 
nicht von allen Unternehmern angewandet werden muB ${ }^{14}$ ) und daB sie zweitens eine Methode der Unternehmensbesteuerung ist, demgemäB mit allokativen GröBen operiert, die dennoch für die distributiven Belange der Feststellung des persönlichen Einkommens die Ausgangslage herstellt. ${ }^{15)}$

Ihren auf der kaufmännischen Vorsicht beruhenden allgemeinen "gewinnsteuerlichen" Bewertungsgrundsätzen, nämlich der (nominellen) Kapitalerhaltung, dem Gläubigerschutz und dem Gesellschafterschutz, ${ }^{16)}$ dienen alle jenen Bewertungsmaßstäbe, die für eine vergleichbare steuerliche Belastung des Gewinns bestimmte Höchst-, Mindest- und Zwischenwerte für Wirtschaftsgüter vorschreiben bzw. zulassen: Anschaffungs- ode Herstellungskosten, Teilwert, Imparitäts-, Realisations- und Niederstwertprinzip.

Repräsentieren diese einzelnen Werte und Besteuerungsregeln noch im wesentlichen einzelwirtschaftliches und kaufmännisches Denken, so gilt das nicht mehr für die Sonderabschreibungen. 17) Der nach dem Einkommensteuerrecht bewertete Vermögensbestand, der qua Vermögensvergleich die objektive Ertragsfähigkeit der Einzelwirtschaften repräsentieren soll, ist solchermaBen durch die Möglichkeiten zur Bildung stiller und steuerfreier Rücklagen, degressiver und Sonderabschreibungen, Bewertungs- und Periodisierungsfreiheiten differenziert und modifiziert, daB er weder einzelwirtschaftlich das korrekte Allokationsergebnis, noch zwischenbetrieblich eine Gleichbehandlung in der steuerbelastung gewährleistet. Je nach den in Anspruch genommenen Bewertungsfreiheiten kann von einem dem Vermögensvergleich zugrundeliegenden "einheitlichen" Vermögensbegriff nicht gesprochen werden. Einheitlichkeit liegt auch insofern nicht vor, als nicht alle Unternehmer gezwungen sind, ihre Ertragsfähigkeit qua Vermögensvergleich nachzuweisen. Was also als Ertrag aus dem allokativen in den distributiven Bereich eingeht und dort Einkommen ist, wurde berelts nach unterschiedlichen Gewinnfeststellungsmethoden differenziert. Es muB aber wohl betont werden, daB die Forderung nach einer Elnheitlich-

Fußnoten 14 bis 16 auf der vorigen Seite

17) Sie dienen nicht der Erfassung eingetretener Wertminderungen, sondern der Durchsetzung nichtfiskalischer, insbesondere allokationspolitischer, strukturpolitischer, stabilisierungspolitischer und weiterer (umweltschutz-, wohnungspolitischer) Ziele (§§ 7a bis $7 f$ EStG; s.a. G. Wöhe 1y92. S $464 \mathrm{E.}$ ). 
keit der Vermögensfeststellung im Rahmen des vermögeneinschlieBenden Einkommensbegriffs von anderer Qualität ist als die nach der Einheitlichkeit im Rahmen der Vermögenserfassung für die Bestandsbesteuerung.

b) Gegenüber der unternehmensertrags- und bilanzorientierten, also letztlich auch "verhaltensspezifischen" Vermögensbewertung erfolgt die Bewertung der unternehmerischen und privaten Bestände an Vermögen mithilfe der Vermögensaufstellung "vermögensartenspezifisch". Ihre BewertungsmaBstäbe legt das Bewertungsgesetz fest; dabei handelt es sich um Versuche, Gegenwartswerte festzustellen, und zwar solche Werte, die auf die speziellen Eigenheiten und auf die besondere und unterschiedliche Ertragskraft der Vermögensarten Bedacht nehmen. Unter diesem Aspekt ist die Frage nach der Einheitlichkeit des Vermögensbegriffes zu stellen.

Prinzipiell findet der gemeine Wert nur bei Gütern Anwendung, bei denen normalerweise Veräußerungspreise zur Bewertung nicht vorliegen, so daB besondere Schätzverfahren zur Bestimmung des gemeinen Wertes entwickelt werden muBten.$^{18)}$ Die Anwendung dieses WertmaBstabes, der wegen seiner Verknüpfung mit dem objektiven Marktgeschehen die Chance $z$ ur Präsentation eines "einheitlichen" Zustandekommens im Prinzip wohl hätte, ist sehr stark begrenzt. "Die Geschichte des gemeinen Wertes als Rechtsnorm ist die Geschichte seines wechselnden Begriffsinhaltes"19) und seines immer mehr eingeschränkten Anwendungsbereichs.

Auch der Teilwert strebt die Realisierung elnes "objektiv feststellbaren Marktpreises" an (G. Wobe 1992,S.175ff), ist aber ausschlieblich für Güter des Betriebsvermögens reserviert, was die Chance für seine "einheitliche" Anwendung schon von der Absicht her schmallert.

18) G. Wöhe 1992, S. 487f. Ferner: Der gemeine Wert findet nur noch Anwendung bei der Bewertung von Grundstücken (außer dem land- und forstwirtschaftlich genutzten Grundbesitz), Mineralgewinnungsrechten, Wertpapieren und Anteilen an Kapitalgesellschaften.

19) K.-H. Hansmeyer 1981, S. 733, und weiter: "Wertansätze in H8he eines Nutzungswertes, eines Ertragswertes und schlieblich eines Verkehrswertes haben einander abgewechselt, immer mit der Absicht, den 'eigentlichen' Wert des Bewertungsgegenstandes $z$ u erfassen", unter Hinweis auf K. Vogel 1979, S. 28-33. 
Die Frage nach der Einheitlichkeit des Vermögensbegriffes und seines Wertmaßstabes läuft letztlich auf die Eignung der "Einheitsbewertung" $\mathrm{zu}$ und hier insbesondere auf den Maßstab des Ertragswertes. Ihrem Namen zum Trotz erfolgt die Einheitsbewertung nicht für alle Vermögensarten einheitlich, sondern artenspezifisch. Die Kritik an diesem Verfahren richtet sich wegen der angestrebten verwaltungstechnischen Vernünftigkeit ("Verfahrensökonomie") und bewertungstechnischen Funktionalität nicht dagegen, daß für die einheitswertabhängigen Steuern überhaupt ein solches Verfahren einheitlich gelten soll, sondern gegen die Bewertungsvorgänge und -unterschiede in bzw. zwischen den jeweiligen vermögensartenspezifischen verfahren. Nicht $d$ a $\beta$ die vermögensarten, die ja stets eine unterschiedliche Ertragsfähigkeit haben, auch unterschiedlich verfahrenstechnisch behandelt werden, sondern $w i$ e es geschieht und nach welchen allokativen und distributiven Grundüberlegungen jeweils vorgegangen wird, ist der Gegenstand der Kritik. Die beklagte vorgehensweise i $\mathrm{n}$ e $\mathrm{r}$ h a $1 \mathrm{~b}$ der vermögensarten betrifft ihre Rompoliziertheit, 20) die $\mathbf{z}$ i $\mathrm{s}$ c $\mathrm{h}$ e $\mathrm{n}$

den Vermögensarten betrifft den vermögensumfang und damit zugleich das unterschiedliche Belastungsniveau, wobei die Kompliziertheit vielfältige Möglichkeiten bietet, über allokativ und distributiv entsprechend angesetzte Faktoren und Einzelelemente gewissermaBen "versteckt" die Niveaufrage der steuerlich unterschiedlichen Belastung zu "lösen". Für die Einheitsbewertung des Grundvermögens ist die fehlende Gegenwartsnähe, die sie ja in Ermangelung eines gemeinen Wertes herstellen sollte, der Hauptkritikpunkt; die fehlende Gegenwartsnähe drückt sich generell in einem zu niedrigen Niveau der Einheitswerte aus. Für die Land- und Forstwirtschaft dürfen dahinter einkommenspolitische, für das Grundvermögen der Privaten eher wohnungspolitische Motive vermutet werden.

3. Die Kompliziertheit der Einheitsbewertung steht also im Widerspruch zu der angestrebten "Verfahrensökonomie", wohingegen die gesetzlich herbeigeführten Niveauunterschiede zum Problem der - teils distributiv motivierten - Allokationsverzerrungen für den Kapitaleinsatz führen. "Manipulationen" an der Bemessungsgrundlage erwecken den Anschein, als würde man den Vermögensarten eine unter-

20) K.-H. Hansmeyer 1981, S. 734. - Ähnlich Pelka 1975, S. 206 u. $209 \mathrm{ff}$. - Siehe auch K. Tipke 1991, S. 465f.; G. Wöhe 1992, passim; siehe unsere Ausführungen in SS 26 und 27 
schiedliche "Leistungsfähigkeit" imputieren. ${ }^{21)}$ Leistungsfähigkeit läbt sich aber in der Vermögensbesteuerung nur im Vermögen als einem Gesamtausdruck, also in der Summe aller Wertausdrücke der Vermögensarten (nicht aber des Kapitals!), steuerlich erfassen.

Ein steuertechnisch einheitlicher Vermögensbegriff ist also, dies macht die Bewertungsverfahrenstechnik klar, in praxi nicht anzutreffen; unterschiedlich bewertete Vermögensarten, dies machen die Niveauunterschiede klar, sind unterschiedliche Vermögen. Normativ beurteilt kann die Forderung nach Einheitlichkeit nur als ein Appell an einheitlich durchzusetzende Grundprinzipien der Bewertung verstanden werden. Diese wären verwirklicht, wenn die Bewertungsverfahren für alle Vermögensarten zu gegenwartsnahen Werten führen und ertragsbedingte Wertunterschiede $\mathbf{z w i s c h e n}$ den Vermögensarten weder einebnen noch überdehnen würden. Mit Blick auf die Besteuerung nach der Leistungsfähigkeit wäre Einheitlichkeit des Vermögensbegriffs erreicht, wenn der Besteuerung ein monetärer Gesamtbegriff unterlegt wird, der in einer Gesamtvermögensteuer ("wealth tax") die Quellen der Leistungsfähigkeit in allen Vermögensarten aufspürt und zusammenfaBt ("comprehensive tax", Musgrave/Musgrave 1980, S. 469 f.l. Einheitlichkeit des Vermögensbegriffs wäre überdies dann erreicht, wenn in beiden Bewertungssystemen, dem einkommensteuerlichen und dem vermögensteuerlichen, dieselben Vermögensbegriffe verwendet würden, ungeachtet des Umstandes, daB die Zielrichtung der Gewinnbesteuerung entsprechende Korrekturen erfordert, die eine periodenangemessene Besteuerung erlauben.

Die Einheitlichkeit des Vermögensbegriffs leidet letztlich darunter, daB eine "Vermögensbesteuerung" nicht nur für die "Distributionsinstitution" Privathaushalt, sondern vor allem auch für die "Allokationsinstitution" Unternehmung durchgeführt wird. Nicht allein die o.e. eliminierende Eklektik des steuertechnischen Vermögensbegriffs, sondern vor allem die bewertungsverfahrensbedingten Ungleichheiten, Kompliziertheiten und Niveauunter-

21) F. Neumark (1970, S. 168) kann eine Differentiation innerhalb der Vermögensteuer nach den Vermögensarten keineswegs befürworten, da den einzelnen Vermögensarten eine etwa unterschiedliche Leistungsfähigkeit "nicht imputiert werden" kann. 
schiede in der Belastung wären weitgehend vermieden, wenn nur die persönlichen Vermögen besteuert würden und die Besteuerung einheitlich unter das Prinzip der Lelstungsfähigkeit gestellt würde. Die steuertechnischen Probleme der Erfassung des "Betriebsvermögens" entfielen. Auch die Besteuerungsziele würden dann eindeutig hervortreten, weil dadurch besonders deutlich würde, daB die allokativen Zwecken dienenden Unternehmenskapitalien von der Besteuerung ausgenommen sein sollen; wollte man dennoch evtl. wegen des fiskalischen Interesses am Steueraufkommen auch das Unternehmenskapital besteuern, müBte man schon klar begründen, warum man den produktionswirtschaftlichen Faktoreinsatz künstlich verteuern will. 22) Dies mag in gewissen situationen angebracht sein, lieBe sich aber besser durch eine wirkliche Ertragsteuer als durch eine steuer erreichen, die u.U. Fixkostencharakter hat und so das eben noch gesetzte Allokationsziel selbst in Frage stellt.

III. Den Vermögensbegriff der Vermögensteuer als einen $p$ e $r$ s o n a l e n zu bezeichnen, kann als "doppelbödige" Feststellung gelten. Denn erstens sind nach dem Gesetz nicht nur "private" Personen mit ihrem Vermögen in der privaten sphäre steuerpflichtig, sondern auch solche mit ihrem Kapital in der betrieblichen Sphäre, also die Unternehmer im breitesten ökonomischen Sinne; zweitens sind daneben die "Körperschaften, Personenvereini-

22) Ein Gerechtigkeits- oder Gleichbehandlungsinteresse kann nicht vorliegen, da private und unternehmerische "Vermögen" unterschiedlichen Zwecken und Funktionen dienen. So könnte man nicht etwa argumentieren, das allokativen Zwecken und Funktionen dienende Unternehmenskapital müsse aus Gerechtigkeitsgründen "gleich behandelt" werden wie das den distributiven Zwecken dienende private Vermögen, wenn dieses aus Gründen der Leistungsfähigkeit besteuert werden soll. Die Besteuerung des Kapitals mag ihre Gründe haben, nur sind es keineswegs solche der "Gerechtigkeit". $\mathrm{Zu}$ den "rationalen" Gründen einer Kapitalbesteuerung siehe z.B. M. Rose 1979, S. 313: die Anregung $z$ um Ubergang $z u$ einem arbeitsintensiveren Produktionsverfahren, sofern das gesamtwirtschaftich uberhaupt als sinnvoll angesehen wird. - Im übrigen siehe unsere Darstellung in $\$ 22$. 
gungen und Vermögensmassen", deren Entscheidungszentrum nicht die Person, sondern die "Geschäftsleitung" oder der "Sitz" (§ 1 Abs. 1 Nr. 2 VStG) ist, also im wesentlichen die "juristischen Personen", vermögensteuerpflichtig. Nur über das Rechtsinstitut der"juristischen Person" lieBe sich behaupten, der Vermögensbegriff dieser Steuer sei ein personaler. Unbestritten ist, daB die Vermögensteuer in dieser Form sowohl eine Personen- als auch eine Unternehmenssteuer, daß also der vermögensbegriff ökonomisch ein personaler wie auch ein "nichtpersonaler" ist. 23) Das "Doppelbödige" liegt zum einen darin, daB eben nicht nur natürliche Personen steuerpflichtig sind, und zum anderen darin, daB der steuergegenstand der allokativen wie auch der distributiven Sphäre angehört.

Vor diesem Hintergrund sind zwei Probleme der a d p e $r s$ $\mathrm{n}$ a $\mathrm{m}-\mathrm{R}$ e $\mathrm{g}$ e 1 in der Besteuerung des Vermögens $\mathrm{zu}$ unterscheiden, nämlich erstens die Frage, wie sich die Zuordnung des Vermögens - ungeachtet der rechtlichen Regelung - auch auf nichtnatürliche Personen ökonomisch begründen lieBe, und zweitens, welcher Person - sei es die natürliche, sei es die juristische rechtlich das vermögen zuzuordnen ist, wenn die Herrschaftsausübung über den Vermögensgegenstand nicht mit den Eigentumverhältnissen zusammenfällt.

1. Ökonomisch ist die zuordnung von Vermögensgegenständen an die nichtnatürliche Person kaum zu begründen. In seiner qualitativen Betrachtung der Kreislaufzusammenhänge zwischen der öffentlichen Finanzwirtschaft und der Volkswirtschaft legt H. Haller (1972, S. $10 \mathrm{ff.l}$ diesen Tatbestand wie folgt dar: Zwischen die Produktionswirtschaften und die Haushalte, die produktive Dienste gegen Entgelt austauschen, sind vielfach "juristische Personen" geschaltet, "die sowohl als Empfänger von Residualeinkommen als auch als Eigentümer von Vermögen in Erscheinung treten." Abgesehen von völlig verselbständigten stiftungen "stehen hinter ihnen als vermö-

23) Konsequenterweise müBte die steuer auf die betrieblichen Gegenstände eine "Kapitalsteuer" genannt werden; die nach dem VStG erhobene Steuer zeichnet aus, dab sie beide steuerformen erhebt, und zwar in ein und demselben Gesetz simultan, und demzufolge, da betriebliches Kapital wegen der Eigentumsverhältnisse letztlich Privaten zuzurechnen ist, dieses zweimal bestevert. 
gensmäBige Träger wieder natürliche Personen (Haushalte)". ${ }^{24}$ ) Erst bei ihrer Auflösung zwar gehen Ertrag und Kapitalbestände der juristischen Person in Form von Einkommen und Vermögensbeständen an die vermögensmäBig beteiligten natürlichen Personen über, doch kann man für das Gesamtbild der volkswirtschaftlichen Wertschöpfung und -verteilung folgern: Die juristischen Personen sind nur die in eine bestimmte Rechtsform gekleideten Durchgangsstationen für ökonomische Werte, eingeschaltet in die wertströme, die in Wahrheit zwischen den Haushalts- und den produktionswirtschaften bestehen. Juristische Personen liefern zwar, wie die Haushalte selbst, produktive Dienste (Vermögensnutzungen im Umfang der nicht verteilten Gewinne) an die Produktionswirtschaften; sie erhalten andererseits einen Wertzuwachs in Höhe ihres Ertrages; letztlich aber sind es die Haushalte, die durch ihre vermögensmäBige Beteiligung an den juristischen Personen diese Vermögensnutzungen $z$ ur Verfügung stellen, und die mit den verteilten Gewinnen entgolten werden (G. Wöhe 1978, S. 113).

Insoweit ist also "das Vermögen einer juristischen Person ... ökonomisch gesehen nur ein abgeleitetes, nichtoriginäres" (K. Tiepelmann 1963, S. 46). Dieser Gedanke läBt sich aus der eigentumsbezogenen Systematik auf die allokativ-distributiven Beziehungen ganz allgemein übertragen: "Wirtschaftlich betrachtet kann ein Betrieb ebensowenig Eigentümer eines Vermögens sein, wie er ein Einkommen erzielen kann" (Steinberg/wöhe 1981, S. 1550). Auch das allokativ (zu Ertragserzielungszwecken) eingesetzte Kapital in der Unternehmung ist als Vermögen originär privates. ${ }^{25)}$ Die steuer-

24) So auch der Carter Report 1966, Vol. 3, S. 31 ff.: Hinter dem Betriebsvermögen stehen Privatpersonen. So auch F. Neumark 1970, S. 131: "Die 'eigene Rechtspersönlichkeit' mag dem Juristen imponieren - für den Nationalökonomen ist von gröBerer Bedeutung, daB hinter einer "personne morale' stets 'personnes physiques' stehen, die früher oder später, in dieser oder jener Gestalt an den Gewinnen (freilich auch den Verlusten) der Gesellschaft partizipieren." - So auch D. Schneider 1990, S. 159

25) Aus diesem Grunde ist eine "die Kapitalgesellschaften treffende Vermögensteuer ... vom wirtschaftlichen Standpunkt aus ebenso wie die Körperschaftsteuer als Ertragsteuer anzusehen" (Steinberg/Wöhe 1981, S. 1550). - Musgrave/Musgrave, 1980, S. 472: "First of all the tax should be imposed on individuals only, with business property being umputed to its owners"; S. 489: "Hence it should be imposed on individuals and not on corporations." 
politik aber, die sich von solchen grundlegenden Zusammenhängen des Wirtschaftens "emanziplert", hat die allokativ-distributive Problematik nicht erkannt oder bewubt im sinne einer falsch verstandenen "Gleichbehandlung" von Kapital und Vermögen ubersehen.

2. Demgegenüber ist das zweite ad personam-Problem eindeutig im Sinne einer okonomischen Betrachtungsweise ${ }^{26)}$ gelöst worden. Statt der MaBgeblichkeit der zivilrechtlichen Berechtigung gilt bei der zurechnung des Vermogens an die Person die "wirtschaftliche zurechnung", "denn Im Steuerrecht geht es darum, die Indikatoren

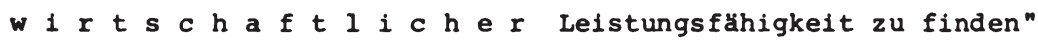
(K. Tipke 1981, S. 111; Hervorhebung dort). Es existiert das Rechtsinstitut des "wirtschaftlichen Eigentums" als eine spezifische Regelung im Sinne des ad personam-zugangs von Leistungsfähigkeit. Nach $\S 39$ AO sind wirtschaftsgüter zwar grundsätzlich dem Eigentümer zuzurechnen, doch extscheidet die wirtschaftliche Betatigung bzw. die tatsächliche Herrschaftsausübung über das wirtschaftsgut. Entsprechend dieser Grundregel stellen die Vorschriften in den $\S \S 34 \mathrm{Abs}$. IV-VII und 94 Abs. I Bewg auf den "wirtschaftlichen Eigentümer" ab; ihm sind die Gegenstände zuzurechnen.

Die steuerrechtliche Regelung steht hier im Einklang mit unseren wirtschaftlichen Uberlegungen zur Zugangsregel (\$8II). Ein Zugang an ökonomischen Größen drückt Leistungsfähigkeit aus (H. Haller 1978, S. 236).

Die grundsätzliche Trennbarkeit zwischen dem Eigentümer einerseits und dem Vermögensnutzer bzw. Verfüger über das Vermögen andererseirs kann man auch für das "Humanvermögen" prüfen. Das "Arbeitsvermögen" ist in diesem Sinne zunächst möglicherweise als Vermögen in der wirtschaftstheoretischen Sicht anzusehen (H. Fecher 1979, S. 468), doch wäre es dem Verfüger zuzurechnen. Streit kann kaum darüber entstehen, wer über die Arbeitskraft im modernen ProduktionsprozeB wirklich "verfügt", der anordnungsberechtigte Arbeitgehor oder der "Eigentümer" der Arbeitskraft, der Arbeitsleistende.

26) Als wirtschaftliche Betrachtungsweise gilt die am wirtschaftlichen Gesetzeszweck orientierte Auslegung der Steuergesetze. Tipke (1991), S. 20: Für die Auslegung der "Fiskalzwecknormen" kommt hier das Leistungsfähigkeitsprinzip in Betracht; S. 107: "Die wirtschaftliche Betrachtungsweise dient der gleichmäBigen Erfassung der wirtschaftlichen Leistungsfähigkeit ...". 
Es hieße die Institution des wirtschaftlichen Eigentums überfrachten, wollte man sie auf das Arbeitsvermögen ausdehnen ${ }^{27}$ ) und wollte man eine Trennung zwischen seinem Eigentümer und Verfüger postulieren.

IV. Auch der steuerliche Vermögensbegriff ist " $z w$ e c k b e $z$ o$g$ e $n "$. Dies sei zunächst aus der distributiven Sicht der Besteuerung begründet:

1. Wenn wir analog den einkommensteuerlichen Uberlegungen den Individualzweck, den Steuerzweck und die Zielbezogenheit des Vermögens unterscheiden, so liegt der $I \mathrm{n} d \mathrm{i} i \mathrm{~d}$ a $1 \mathrm{z}$ w e c $k$ des Vermögens in den ökonomischen ${ }^{28}$ ) Funktionen, die es für den einzelnen hat (s. \$ 10): (1) in der das Existenzminimum sowie eine darüberhinausgehende "normale" Gegenwarts-Lebensführung grundsätzlich gewährenden "Sicherungsfunktion", (2) in der den zukunftsbedarf sichernden "Vorsorgefunktion", (3) in der einen höheren Lebensstandard erlaubenden "Lebensstandard(steigerungs) funktion" und (4) in der den Arbeitseinsatz freier gestaltenden und die Kreditfähigkeit erweiternden "Unabhängigkeitsfunktion". Teils gründen diese Funktionen sich auf die Eigenschaft des Vermögens, ertragreich zu sein, teils gründen sie sich auf die Eigenschaft seines bloBen Bestehens und seiner Dauerhaftigkeit über eine Zeitspanne hin. Daraus entsteht steuerpolitisch das Problem, die auf Vermögen basierende Leistungsfähigkeit sowohl am tatsächlich erzielten Ertrag als auch am Wert seines bloBen Bestandes messen zu müssen, sofern man sowohl im Ertrag als auch im Bestand eine Indikation für Leistungsfähigkeit sieht. Denn erhöbe man lediglich eine Vermögensertragsteuer, fänden jene Vermögensfunktionen keinen Eingang in das Besteuerungskonzept, die auf dem Bestand beruhen; erhöbe man statt dessen eine "reine" Vermögensbestandsteuer, gingen die auf dem Ertrag beruhenden Funktionen verloren.

27) Siehe hierzu unsere Kritik an der Verfügbarkeit des Arbeitsvermögens in $\$ 10$, wo wir die "Nicht-Vermögens-Eingenschaft" der Arbeitskraft begründen, weil u.a. Nichtverfügbarkeit vorliegt.

28) Metaökonomische Funktionen sollen für die Besteuerung wegen ihrer nicht möglichen interpersonellen Vergleichbarkeit ausgeschlossen bleiben. 
Die Ertragsbesteuerung lieBe sich aber im Rahmen der Einkommensteuer durchführen, es sei denn, man hielte die Erträge aus Vermögen gegenüber denen aus Arbeit für besonders leistungsfähigkeitsinduziert und daher "ergänzend" besteuerungswürdig und -notwendig. Die Bestandsbesteuerung dagegen muB neben der Ertrags(und evtl. Einkommens-) besteuerung durchgeführt werden und erfordert die zusätzlichen steuerpolitischen Entscheidungen, wie der Bestand bewertet wird, ab welcher Höhe er zusätzliche Leistungsfähigkeit indizieren soll und ob mit wachsendem Vermögensbestand und -wert evtl. eine überproportionale Leistungsfähigkeit unterstellt werden soll, was eine weitere Entscheidung über die Progressivität des Vermögensteuertarifs verlangt.

Fazit: Betrachtet man - was vermögenstheoretisch und begrifflich geboten erscheint - den steuerlichen Vermögensbegriff als vom Individualzweck des Vermögens determiniert ${ }^{29)}$ und will man dies steuerpolitisch zum Ausdruck bringen, werden steuersystematische Eezüge offensichtlich und steuersystematische Probleme wachgerufen; ferner münden die weiteren MaBnahmen der leistungsfähigkeitsorientierten Besteuerung, also der Personalisierungen durch Freibetrags- und Tarifgestaltung, in einen Zusammenhang mit der Einkommensbesteuerung.

2. Dem Individualzweck des Vermögens steht der $s t$ e u e $r$ $\mathrm{z}$ w e c h gegenüber; er ist darauf ausgerichtet, im vermögen eine Maßgröße zu erblicken für die Verteilung der steuerlast.

a) $\mathrm{Zu}$ diesem Grundgedanken tritt aber ein korrigierendes, den Steuerzugriff hemmendes Moment hinzu. nämlich das auf die Dauerergiebigkeit des Steueraufkommens, auf die Erhaltung der "Steuerkraft"

29) Das Funktionsdenken erscheint in der literarischen Diskussion wie auch in der steuerrechtlichen Gestaltung durchaus anerkannt, jedoch mit einem Ubergewicht im distributiven Bereich durch die Anerkennung der Vermögensfunktionen; erstaunlicherweise aber fehlt in der "Vermögensbesteuerung" des unternehmerischen Kapitals eine solche Beachtung der Kapitalfunktionen; denn von den vier in $\$ 10$ III genannten Funktionen ("Produktions-, Risiko-, Ausdehnungs- und EinfluBfunktion") sind $z$ umindest die ersten drei solcher Art, daB ihre steuerpolitische Anerkennung eine Zurückhaltung in der Steuerbelastung, wenn nicht gar eine völlige Abstinenz verlangen würden. Jedoch das geschieht keineswegs: Der Steuersatz liegt hier höher als der auf persönliches vermögen. 
(B. Moll 1930, S. 364) sowie zugleich auf die Erhaltung der Individual-Funktionen des Vermögens angelegte Prinzip der "steuerlichen Schonung des Vermögens". Diese (auch auf die steuerliche Schonung des Kapitals ausdehnbare) Maxime ist ein politisches Prinzip und keineswegs ein theoretischer Definitionsbestandteil für den Vermögensbegriff.

Der Schonungsgedanke wird aus der gesamtwirtschaftlichen Sicht wie auch aus der sozioökonomischen Sicht begründet; beide Argumente laufen dabei letztlich in eine einzelwirtschaftliche Begründung zusammen. Denn würde einerseits das Vermögen steuerlich nicht geschont, würde das auch die Vermögens- und Kapitalneubildung und damit die Grundlage der Produktion und des Wachstums (B. Molitor 1979, S. 295) und schlieblich auch die "Grundlage der Konsumtion" (B. Moll 1930, S. 364) zerstören. Andererseits sorgt Vermögensbildung für eine Befriedung unter den sozialen Schichten (B. Molitor 1979, S. 285) und verschafft dem einzelnen soziale Sicherheit. Wird also der vermögensbestand und die Vermögensbildung letztlich aus einzelwirtschaftlicher sicht als positiv und systemstabilisierend angesehen, so wird dennoch ein steuerpolitischer Interessengegensatz offenkundig; denn die gesamtwirtschaftlich und sozioökonomisch motivierte Schonung des Vermögens muB nicht von vorn herein eine $v$ ö 1 l $\mathrm{i}$ e Schonung des privaten Vermögens bedeuten (A. Wagner 1890, S. 318), da ja Vermögen Indikator der steuerlichen Leistungsfähigkeit und somit SteuermaBstab ist. Zwei Denkrichtungen sind es hier, die eine "eingeschränkte Schutzwürdigkeit" des Privatvermögens zum Ausdruck bringen.

b) Die erstere propagiert eine Trennung des Vermögensbestandes in ein solches Vermögen, das selbst "erarbeitet" wurde und daher steuerlich zu schonen sei, und in ein solches, das ohne Mühe und Arbeit erworben (z.B. ererbt oder per zufall gewonnen) wurde und demnach steuerlich $z u$ belasten sei. Doch abgesehen von dem leicht moralisierenden Beigeschmack dieser Argumentation, die den Wert des unter Mühen Erarbeiteten über alle anderen Lebenswerte erhebt und der Vermögensteuer den Geruch einer "Neidsteuer" gibt, ist ein solcher Trennungsversuch einerseits nicht immer exakt durchfürbar, ${ }^{30}$ ) andererseits im Hinblick auf das von uns hervorgeho- 
bene "Zugangsprinzip" im Rahmen der Leistungsfähigkeitsbesteuerung theoretisch nicht einwandfrei. Ohne Rücksicht auf die Quellen des zugangs, so hatten.wir gefolgert, ist Vermögen und Einkommen aus Vermögen Ausdruck der Leistungsfähigkeit. Die teilweise steuerliche Schutzwürdigkeit des Vermögens kann also mit der geforderten Trennung des Vermögens in die beiden Herkunftsquellen nicht begründet werden.

c) Anders verhält es sich mit der zweiten Denkrichtung, die wirkungsmäBig zwischen einer Ertragsteuer und einer substanzsteuer unterscheidet. Sie geht davon aus, daß der vermögensertrag vom Vermögensstamm oder -kern zu trennen ist. Die steuerliche schonung des vermögensstamms wie auch die des Kapitalstocks ist eine "wirtschaftliche Selbstverständlichkeit" (F. Neumark 1965, S. 25); eine Steuer, die den Vermögensstamm schont, "muB aus dem Einkommen gezahlt werden" (B. Moll 1930, S. 364). Für den Vermögensstamm gelten in noch höherem MaBe die Auswirkungen jeglicher Vermögensbesteuerung, die in der Beeinträchtigung einer Vermögens neubildung mit ihren allokativ nachteiligen Folgen liegen, so daB unter "normalen" Umständen, wenn etwa Umverteilungsziele nicht vorrangig sind, die substanzbesteuerung der ökonomischen ratio widerspricht. Demnach dürfte die Vermögensertragsteuer den "Normalfall" darstellen, sofern man unter steuersystematischem Aspekt eine Ergänzungsteuer auf die Vermögenseinkünfte überhaupt als normal ansehen will.

Wo nun die Grenze der Ertragsbesteuerung uberschritten und die Substanzbesteuerung erreicht wird, versucht B. Gemper (1971, S. $187 \mathrm{ff}$.) vor dem Hintergrund der Beurteilung der Tautscher'schen "Grenzen der Besteuerung"31) darzulegen mit seiner auf die "Er tragsfähigkeit" des vermögens abgestellten Einteilung des vermö-

30 ) B. Moll z.B. erwägt, daß selbst erarbeitetes Vermögen u.u. dadurch gebildet worden sein könnte, daB im Zeitverlauf der Akkumulation unzureichend besteuert wurde; dann aber sei die Trennung in das erarbeitete und arbeitslos erworbene vermögen sinnlos (1930, S. 367). Wir fügen hier an, daß das Urteil über die Sinnlosigkeit der Trennung auch mitbeeinfluBt wurde durch die Wertvorstellung, die in dem Wort "unzureichend" $z$ um Ausdruck kommt.

31) B. Gemper kritisiert zu recht, daB A. Tautscher (1954) diese Grenzen letztlich in der Liquidisierung von Vermögensgegenständen sieht, da dies nicht Ausdruck der Leistungsfähigkeit des Steuerpflichtigen sein kann (sondern eine Eigenschaft des Vermögens). 
gens (S. 191): Grundsätzlich sei nämlich nicht jeder Ertrag auch besteuerbar; zunächst scheide das nicht ertragsfähige Vermögen ohnehin aus der Besteuerung aus; was danach besteuerbar bleibe, unterscheide sich darin, ob es zwar ertragsfähig, tatsächlich aber nicht ertragsbringend sei oder wirklich Erträge erziele. Werde ersteres besteuert, könne zwar diese Sollsteuer zur Aktivität der Vermögensbesitzer anregen, sei aber mit einem abzulehnenden Eingriff in ihre Dispositionsautonomie verbunden; bei erzwungener Mobilität des Vermögens drohe ein Substanzverlust. Angesichts dessen bliebe allein die Möglichkeit der Istbesteuerung auf die effektiv erzielten Vermögenserträge.

Wir entnehmen den Gemper'schen Darlegungen, daB eine Sollsteuer nicht in jedem Falle eine substanzsteuer ist. Dem ist zuzustimmen: Sie ist es nur dann, wenn sie beim Verfüger keine ökonomischen Aktivitäten zur Ertragserzielung anregen kann, wenn eine VermögensveräuBerung die Quelle der Steuerzahlung wird und solchermaBen ein Substanzverlust eintritt. In der Terminologie von Gemper aringt eine solche Steuer bereits in die "innere Vermögensertragssphäre"32) ein. Diese aber gehöre zur Substanzerhaltung und solle nicht besteuert werden. Da nun die innere Ertragssphäre, in die auch die Aufwendungen zur Erhaltung der Substanz gehören, je nach Vermögensart unterschiedlich ist und nie von vorn herein fix angegeben werden kann, folgt aus der Gemper'schen Forderung eine auf den tatsächlichen Istertrag abgestellte Vermögensbesteuerung. Dies ist im Grunde eine Ablehnung der Potentialorientierung der Vermögensteuer (S. 189), eine Verengung des breiteren Ansatzes der Besteuerung nach der Leistunqsfähigkeit und damit auch des Steuerzwecks des Vermögens. ${ }^{33)}$ Sie kann allerdings den Vorzug für sich in Anspruch nehmen, die völlige Eindeutigkeit der LeistungsFähigkeits-Indikation erreichen zu können, da erzielte Erträge meßbar, Potentiale jedoch der Auslegung fähig sind. Widerspruch

32) Nach B. Gemper (1971, S. 191, Fn. 24) soll der Besteuerung nur die "äuBere" Vermögensertragssphäre zugänglich sein; sie ist mit dem Nettoertrag des Vermögens gleichgesetzt

33) Vgl. demgegenüber die Ansicht F. Neumarks (1961f, S. 408) über die Funktionen der Vermögensteuer: Ihre Hauptfunktion sei die Höherbelastung der fundierten Einkommen, ihre Nebenfunktion sel die Erfassung solcher Vermögensteile, die keinen Ertrag erbringen bzw. deren Ertrag einkommensteuerfrei bleibt. Vgl. auch ders. 1970, S. $137 \mathrm{f}$. 
erhebt sich aber bei der Nichtbesteuerung jener Vermögenserträge, die zur Erhaltung des Vermögensstammes als notwendig erachtet werden: Denn soll der Vermögensbestand auch nach der Vermögensbesteuerung erhalten bleiben, muB es dem Verfüger zwar grundsätzlich möglich sein, die Steuer aus dem Ertrag aufzubringen; doch sofern ihn eine Sollsteuer zur ertraglichen Anlage seines Vermögens veranlaßt hat, ist ja ebendiese Bedingung gewahrt: Der Ertrag des Vermögens hat dann ausgereicht, sowohl die "privat induzierten" Aufwendungen zur Vermögenserhaltung als auch die "öffentlich induzierten" Steueraufwendungen zu decken. Nur dann sei gewährleistet, daß die Vermögenssteuer, was z.B. auch W. Gerloff (1926, S. 453) fordert, letztlich aus dem Einkommen fliebt.

Doch wann gilt der Vermögensbestand als ungeschmälert? Wenn wir die Definition, die A. Stobbe (1976, S. 273) für den Kapitalstock trifft, auf den Vermögensstamm übertragen, so dürfte der "zu Beginn einer Periode vorhandene Bestand" an Vermögensgegenständen auch am Ende der Besteuerungsperiode infolge von SteuermaBnahmen nicht abgenommen haben. B. Gemper (1971, S. 118 f. u. 122) verlangt nun, auch solche Einkünfte von der Besteuerung auszunehmen, die zur VergröBerung ( $z$ um Wachstum) des Vermögensstocks bestimmt sind. Das ist in dieser allgemeinen Aussage nicht hinzunehmen. würde doch dadurch in der Interessenabwägung zwischen dem Steuerzweck des Vermögens und der Kapitalneubildung (P. Mombert 1916, S. 10) zugunsten des letzteren Interesses vorwegentschieden. 34) Vermögensneubildung ist - so wïnschenswert sie gesamtwirtschaftlich sein mag - nicht Substanzerhaltung. Vielmehr dürfte jeweils eine situationsabhängige zielabwägung erforderlich werden. Diese könnte etwa darin liegen, entscheiden zu müssen, ob einer Vermögenserhaltung oder -neubildung der Vorrang gegeben werden sollte vor der Vermögensumverteilung; dann läge ein Allokationsziel (zweifellos mit bestimmten distributiven Effekten) im Konflikt mit einem Distributionsziel (das seinerseits nunmehr allokative Effekte haben könnte). So führen uns diese den steuerzweck des Vermögens abschließenden Darlegungen direkt zur "Zielbezogenhelt des steuerlichen Vermögensbegriffs" als der dritten Erscheinungsform der hier $\mathrm{zu}$ behandelnden "Zweckbezogenheit" des Vermögens.

34) Probleme der Bewertung, die zweifellos bei dem Urteil, wann der Bestand als erhalten zu gelten hat. mitwirken 
3. Die $z i$ e $l$ b e $z \circ g$ e $n h$ e $i t$ des steuerlichen Vermögensbegriffes zeigt sich auf zweifache Weise, nämlich zum einen im Distributionsziel "Steuerlastverteilung", zum anderen im Distributionsziel "Vermögenspolitik" mit steuerlichen Maßnahmen. Einerseits ist die personale Ausstattung der Gesellschaftsmitglieder mit Vermögen ein Indikator für die Leistungsfähigkeit, und der Einsatz des steuerlichen Instruentes dient der Aufbringung der allgemeinen Dekkungsmittel unter Schonung solcher Vermögens-Mindestbestände, die für den einzelnen wie auch für die Geselllschaft individuelle und soziale Funktionen haben.

Gegenüber dieser eher "passivischen" Politik läBt sich die zielgerechte Ausstattung der Gesellschaftsmitglieder mit Vermögen auch "aktivisch" sowohl durch das Setzen von steuerlichen Bedingungen für die Vermögensbildung qua Beteiligung am Vermögenszuwachs als auch durch die direkte Umverteilung des Vermögens herstellen bzw. verändern (B. Molitor 1979, S. 282).

a) Aber die gesellschaftliche Akzeptanz, auf die das Ziel der Vermögensbesteuerung wie auch der steuerlichen Vermögenspolitik angewiesen ist, wird letztlich von der sozialen Befriedung bestimmt, die mit der Vermögensausstattung erreicht wird (B. Molitor 1979, S. 285). Wenn überhaupt, dann werden hier die gesellschaftspolitischen ziele einer chancengleichheit in den startbedingungen und in den allgemeinen Gerechtigkeitsvorstellungen deutlich. Und da ist es bemerkenswert, daß trotz der oftmals festgestellten Ungleichheit in der personalen Vermögensausstattung, 35$)$ trotz der von allen politischen Instanzen stets erhobenen Forderung nach mehr Chancengleichheit und höherer Vermögensausstattung gerade für die unteren Einkommensschichten steuerpolitisch und vermögenspolitisch eine äuBerst starke Zurückhaltung geübt wird. ${ }^{36)}$ Weder wäre das derzeitige Aufkommen an persönlicher Vermögensteuer noch an Erbschaft- und Schenkungsteuer geeignet, eine spürbare Vermögensumverteilung $z u$ finanzieren noch ver-

35) Vgl. hierzu, trotz berechtigter Skepsis wegen mancher Informationslücken, die Ergebnisse der Einkommens- und Verbrauchsstichproben, besonders von 1969; vgl. dazu C. Folkers 1979 ,S. $269 \mathrm{ff}$. stellvertretend für viele. Für die Us-amerikanischen Verhältnisse siehe Musgrave/Musgrave 1980, S. $474 \mathrm{f}$. mit dem Fazit (S. 473): "... there is ample evidence that the distribution of wealth among wealth holders is substantially more unequal than that of income ..."

Fußnote 36 auf der folgenden seite 
teilt man tatsächlich um. Zugleich läßt man erstaunlicherweise unter "rigorosem" Festhalten am traditionellen nominalistischen "Mark gleich Mark-Prinzip" ${ }^{37)}$ angesichts der fortschreitenden Geldentwertung einen Kaufkraftschwund des Vermögens zu und sorgt im gleichen Atemzuge durch die steuerlichen Bewertungsvorschriften für eine deutliche Ungleichbehandlung zwischen verschiedenen Vermögensarten. Dieselbe Gesellschaft, die die Möglichkeit hat, kraft der Unterscheidung zwischen dem allokativen und distributiven Bereich des Wirtschaftens $z u$ erkennen, daB eine am $\mathrm{ziel}$ der Leistungsfähigkeit orientierte Vermögensbesteuerung nur im persönlichen Bereich überhaupt sinnvoll ist, im unternehmerischen Bereich dagegen die Allokationsbedingungen verzerrt und den Faktoreinsatz künstlich verteuert, vermag dennoch nicht, die Vermögensteuer für Unternehmen abzuschaffen, sondern erhöht vielmehr noch den für diese geltenden Steuersatz im Vergleich zur personalen Besteuerung. Das wird mit Gerechtigkeitsargumenten begründet. Diese aber dürfen zwischen dem allokativen und dem distributiven Bereich nicht hin- und hergeschoben werden. Gerechtigkeitsargumente im distributiven Bereich unterscheiden sich von denen im allokativen Bereich. Man kann sie nicht "miteinander" vergleichen, sondern nur "gegeneinander" abwägen. Gerechtigkeitsargumente im ausschlieBlich allokativen Bereich können nur solche der auf die wettbewerbsneutrale Besteuerung gerichteten Argumente der Gleichbehandlung zwischen den Unternehmen, den Kapitaleinsätzen, der Finanzierungsweisen usw. sein. Demnach verbieten sich Vergleiche zwischen der Besteuerung des Kapitals und der Besteuerung des Vermögens. Wird es für richtig gehalten, das Vermögen zu besteuern, zieht das keineswegs zwangsläufig - und schon garnicht aus "Gerechtigkeitserwägungen" - die Besteuerung des Kapitals nach sich. Aber die Besteuerung des unternehmerischen Kapitals als "Pendent" zur Besteuerung des privaten Vermögens dürfte als gesellschaftspolitische Beschwichtigungspolitik kaum zu umgehen sein.

36) Diese Feststellung trifft nicht so sehr die Zahl der Aktivitäten (vgl. hierzu die Ubersicht in B. Molitor 1979, S. 297 ff.) als vielmehr die Ergebnisse solcher Strategien, die sich in den Statistiken (s..die o.a. EVS 1969) niederschlagen oder besser eben nicht niederschlagen, wenn man sie anhand des formulierten $\mathrm{Ziels}$ beurteilt.

37) Vgl. hierzu das Gutachten der Deutschen Bundesbank vom 22 . Sept. 1977 für das Bundesverfassungsgericht: Berücksichtigung der Geldentwertung bei der Besteuerung von Einkünften

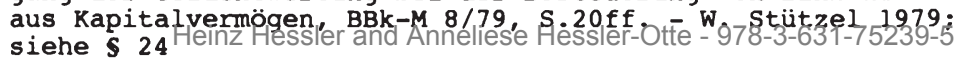


Dieselbe Gesellschaft, die es trotz des auBerst geringen steueraufkommens aus der Erbschaft- und Schenkungsteuer nicht wagen wurde, gerade wegen der Rücksichtnahme auf die Gerechtigkeitsgefuhle in der Bevolkerung diese steuer wegen ihrer momentan bezwelfelbaren vertellungspolitischen Effizienz etwa vollig abzuschaffen, kann sich dennoch nicht entschlieben, diese steuer fühlbar zu erhohen oder gar fur die Vermogensumverteilung zu reservieren. Die einzig echte substanzielle vermorgensabgabe der jungeren steuergeschichte in der Bundesrepublik, die "Vermögensabgabe" nach dem Lastenausgleichsgesetz von 1952 (s. Art. 106 I Nr. 5 GG), wurde steuerrechtlich so gestaltet, daB ihre Entrichtung wie eine laufende Vermögensteuer wirkte: ${ }^{38}$ ) sie war in vierteljährlichen Teilbeträgen uber 30 Jahre hinweg bis zum 31.3.1979 zu entrichten und konnte als Sonderausgabe vom Einkommen abgezogen werden. (W. Steinberg 1981b, S. 1540f. . Dergestalt wurde ein rigoroser Eingriff in die vorhandene Vermögensverteilungsstruktur zwar vermieden, zugleich aber auch elne sofortige Neustrukturierung des vermögensbesitzes mit den distributiv positiven Wirkungen ${ }^{39}$ ) unterbunden.

b) Was die Zielbezogenheit des Vermögensbegriffs betrifft, so läbt sich nun fragen, ob von einem zieloffenen oder eher von einem zielbegrenzten Begriff zu sprechen ist. Zieloffen ist ein steuerlicher Vermögensbegriff dann, wenn er so formuliert ist, daB er grundsätzlich für alle zlele der Besteuerungspolitik einsetzbar ist. Das ist aber hier nicht vollends der Fall: Der steuerliche Vermögensbegriff ist nämlich im Gegensatz zum Einkommensbegriff für politische ziele nicht ähnlich geeignet, ist also

38) K.H. Frlauf, 1977, S. 63: "Die Entstehungsgeschichte der Vorschrift ... (Art. 106 I Nr. $5 \mathrm{HDH}$ ) belegt eindeutig, daB das Grundgesetz die elnmaligen Vermogensabgaben allein im Zusammenhang mit der Bewaltigung der Kriegsfolgenproblematik sieht und sie keinesfalls als permanent verfügares instrument einer Vermögensumverteilung ohne Rücksicht auf die Anforderungen des Art. 14 GG zuläbt."

39) Wegen der uberaus langen Zeitdauer der Mittelaufbringung und der Mittelvergabe haben die Mittel $\mathrm{zu}$ einem groBen Teil ihre Berechtigten erst sehr spät erreicht oder überhaupt nicht, weil sie inzwischen gestorben waren. - H. Fecher $(1979, \mathrm{~S}$. $462 \mathrm{f.}$ ) sieht daher in der VA nach dem LAG eine laufende Vermögensteuer, die keinesfalls die Vermögenssubstanz angriff; "allein durch Verrentung der Abgabeschuld erreichte der Gesetzgeber die Schonung der der Abgabepflicht unterliegenden Vermögen." 
nur "begre nzt zi e lof $\mathrm{f}$ e $\mathrm{n} "$. So scheidet er z.B. für die Stabilisierungspolitik weithin aus, so kann er ferner für allokationspolitische Zwecke nur über den Umweg der Distributionspolitik eingesetzt werden; denn in erster Linie ist für die staatliche Politik das Vermögen der Privaten eine MaBgröBe der Besteuerung nach der Leistungsfähigkeit, ist zugleich auch eine OrientierungsgröBe für die direkte Vermögensumverteilung wie auch für die (indirekte) Vermögenspolitik mit steuerlichen Mitteln. Erst in zweiter Linie ergeben sich über die Vermögensbildung und personale vermögensausstattung positive Allokationseffekte durch das Einsetzen von Vermögen als Kapitalfaktor im Produktionsprozeß. Allokative Politik ist mithin durch Besteuerung des privaten Vermögens nur indirekt möglich.

Neben solchen Begrenzungen in der grundsätzlichen zielrichtung sind aber im wesentlichen zwei weitere auszumachen, die zwar in der Handhabung der Vermögensbesteuerung liegen, jedoch Auswirkungen auf die Zielverwirklichungsgrade haben: Es besteht zunächst ein nicht auflösbarer widerspruch zwischen den durch eine Vermögensumverteilung $z u$ erreichenden $z i e l e n$ einer sozialen Befriedung einerseits und der Eigentums- und Erbrechtsgarantie andererselts; dieser Widerspruch ist geeignet, die Umverteilungsmasse gering $z u$ halten, d.h. den Umfang des steuerlichen Vermögensbegriffes $\mathrm{zu}$ begrenzen (\$ 21). Ferner existiert ein ebensolcher Widerspruch zwischen der Eigentumsgarantie und den steuerlichen Bewertungsvorschriften für die Vermögensgegenstände, weil eine Bewertung, die trotz offensichtlicher inflationsbedingter Geldentwertung das Nominalwertprinzip verbindlich vorschreibt, die Eigentumsgarantie, aber auch die Vermögensverteilungspolitik, letztlich ad absurdum führt (\$24).

c) Sieht man sich vor der Aufgabe, die Rolle des Vermögens in der Steuerpolitik zielbezogen zu würdigen, so kann man angesichts der Erfahrungen, der herrschenden Wirtschaftsordnung, der Mentalität der Wirtschaftenden und der geltenden Verfassung der Bundesrepublik die folgenden Hypothesen formulieren:

(1) Die Haltung der Politiker gegenüber dem Vermögen ist "ambivalent"; zum einen gilt ihnen das vermögen als sakrosankt und schützenswert, was psychische und ordnungspolitische Gründe hat, $\mathrm{z}$ um anderen verhalten sie sich ihm gegenüber angesichts der Geld- 
entwertung gleichgültig und überlassen es hinsichtlich der Bewertungsvorschriften schutzlos den Gruppeninteressen. Psychisch dürfte doch im allgemeinen ein intensives Streben nach Eigentum das Wirtschaftsverhalten und die Motivationsstruktur der Wirtschaftenden kennzeichnen; weithin ist das Eigentumserlebnis an ganz spezielle Vermögensformen (z.B. Sach- und insbes. Wohnungseigentum) gebunden; eine Abschaffung des Eigentums, wohl auch schon der enteignungsähnliche Eingriff dürfte auf "massive psychische Widerstände" (Molitor 1979, S. 295) in der Bevölkerung treffen. Ordnungspolitisch gilt, daB (als eine Fortsetzung der Rolle des Bürgertums in der historischen Entwicklung) das Eigentum die heutige "gesellschaftliche und politische Grundlage" (Maunz 1980, RdNr. 1) bildet; die Eigentumsgarantie hat Verfassungsrang. Eigentum und Erbrecht werden verstanden als ein "Grundpfeiler der gesamten Wirtschaftsverfassung", in der "eigentumsfeindliche Wirtschaftssysteme" nicht möglich sind. (KdNr.4) Doch inwieweit eine in das Eigentum eingreifende Umverteilung der Eigentumsgarantie zuwiderläuft, wird unterschiedlich beurteilt. Einerseits wird gesagt, die ordnungspolitische Komponente der Eigentumsgarantie könne schon nach der alten liberalen Konzeption nur dann voll wirken, wenn die Masse des Volksvermögens nicht allzu ungleich verteilt sei; in diesem Sinne setze sie sogar eine Umschichtung voraus, die allerdings ihrerseits in Konflikt mit der individualrechtlichen Eigentumsgarantie geraten könne (Maunz 1980, Art. 14, RdNr. 9). 40) Andererseits stellt B. Molitor (1979, S. 295) fest, daB einer Vermögensumverteilung die "Hürde der verfassungsgetragenen Eigentumsgarantie" geradezu entgegenstehe; diese Garantie lasse sich "weder der Rechtsfigur der verwaltungsmäBigen Enteignung oder der 'Sozialisierung' sub-

40) Maunz ebda: Uber die Sozialbindung des Eigentums hinaus "ist rechtspolitisch $z u$ fordern, daB der staat auf Grund des Sozialstaatsprinzips zur Vermögensbildung bei den wirtschaftlich schwächeren Schichten der Bevölkerung beiträgt."

41) K.H. Friauf 1977, S. 59, kritisch zur Entscheidung des Bundesverfassungsgerichtes (DStZB 75, 352), eine Verfassungsbeschwerde nicht anzunehmen und statt dessen auf einen BilligkeitserlaB zu verweisen. Tatsächlich kann es durch eine Kumulation von ESt u. VSt $\mathrm{zu}$ einer Belastung kommen, die $100 \%$ des Vermögensertrags überschreitet. Dies ist bisher durch das BVG nicht als ein solcher Eingriff in die Substanz angesehen worden, daB etwa Art. 14 GG verletzt worden wäre. Friauf aber hält eine verfassungsgerichtliche Neubesinnung über das Ver-

(Forts. siehe folgende seite) 
sumieren, noch als sozialstaatliche Eigentumsbindung begründen." Die Rechtsprechung allerdings vermag bei einer in die substanz eingreifenden Steuer vorerst noch keinen Vorsto B gegen die Eigentumsgarantie des Grundgesetzes zu erkennen. ${ }^{41)} \mathrm{Da}$ solchermaBen keine einheitliche Auslegung der Eigentumsgarantie möglich ist, auBerdem auch der Inhalt des Sozialstaatsprinzips, aus dem nicht nur steuerliche, sondern auch transferielle und damit unverteilende Maßnahmen abgeleitet werden, im einzelnen umstritten ist, läBt sich die ambivalente Einstellung der Politiker zum Vermögen nicht durch Verweise auf wissenschaftliche Meinungen und Ergebnisse auflösen. Auf unabsehbare zeit wird daher die ambivalente Haltung den steuerlichen Inhalt des Vermögens und den Umgang mit ihm bestimmen.

(2) Die Ambivalenz und die bisher fehlenden Erfahrungen mit einer Vermögensumverteilung qua echter Vermögensabgabe dürften der Grund dafür sein, daB angesichts der beiden grundsätzlichen Ansatzpunkte der Verteilungspolitik, nämlich einerseits der Umverteilung des gegebenen Vermögensbestandes, andererseits der Beteiligung an den periodischen Vermögenszuwächsen, der Nachdruck der Verteilungspolitik auf der letzteren Variante liegt, sofern sie "schichtenspezifisch vorgeht" und dadurch - unter der Voraussetzung einer hinreichenden Motivation zur Vermögensbildung und -haltung - "mit einer positiven Verteilungswirkung verbunden ist" ( $B$. Molitor 1979, S. 283). Ergänzt wird diese schrittweise Vermögensverteilungspolitik durch die relativ eingeengten Möglichkeiten

41) Fn. 41 beginnt auf der vorigen Seite.

hältnis von Steuergesetzgebung zur Eigentumsgarantie für "dringend notwendig", 1975a, S. 361. - Siehe auch E. Benda 1973, S. $49 \mathrm{ff}$. - Den Darlegungen von Friauf $(1977$, S. 64) läBt sich entnehmen, daB das BVG selbst nicht so recht wei $B$, ob nun die VSt eine Ertrag- oder eine Substanzsteuer sein soll; er urteilt abschlieBend: "Die Annahme eines der Vermögensteuer latent innewohnenden verfassungsrechtlich legitimierten gemeinen substanzsteuerelements läBt sich daher nicht aufrechterhalten."

42) K. Tipke 1981, S. 25: "Die Staatsrechtslehre hat sich hauptsächlich mit den aus liberalem Gedankengut entstandenen Freiheitsrechten ... befaBt, mit der Sicherung des Bürgers gegen die Staatsgewalt ...; sie hat das Sozialstaatsprinzip, das allen ein menschwürdiges Dasein sichern will, überhaupt dem sozialen Fortschritt, dem sozialen Ausgleich dienen soll, aber relativ vernachlässigt. Das gilt zumal auch für die Grundrechtsliteratur $z$ um Steuerrecht. - Diese Einseitigkeit verleitet zu der Vorstellung, der Rechtsstaat des Grundgesetzes sei primär eine schutzburg der beati possidentes. ..." 
der Erbschaftsbesteuerung, ${ }^{43}$ denn elnerseits gilt das Erbrecht als Ausdruck der Eigentumsgarantie, andererseits ist das Aufkommen dieser Steuer für Umverteilungszwecke zu gering. Die Möglichkeiten $\mathrm{zu}$ einer vermögensverteilenden Steuerpolitik erscheinen aber darüber hinaus noch äuBerst begrenzt, denn man darf nicht ubersehen, daB auch der Vermögensbegriff selbst ambivalent ist: Einerseits ist Vermögen ein allokativ-distributiver Anreiz für den Leistungswillen zum wirtschaftlichen Erfolg, den es - eine entsprechende allokativ-distributive Zielsetzung durch den Staat vorausgesetzt - durch allokative und distributive MaBnahmen zu erhalten und $\mathrm{zu}$ mehren gilt; andererseits ist Vermögen Ausdruck des bereits erzielten Leistungserfolges wie auch des privaten (Erb- und Schenkungs-) Transferergebnisses, das als durch staatliche distributive Politik steuerlich belastbar gilt. Diese allokativ-distributive Doppelrolle des Vermögens grenzt die steuerpolitischen Möglichkeiten ein. Trotz dieser "Begriffsambivalenz", die ja ähnlich auch das Einkommen kennzeichnet, dürfte gerade wegen der "Haltungsambivalenz" der Politiker der steuerliche Vermögensbegriff und seine zielorientierte Gestaltung nicht entfernt dasselbe interventionistische Interesse auf sich ziehen wie der Einkommensbegriff.

43) "Nicht darin, daB uberhaupt vererbt werden kann, sondern in den GröBenunterschieden der Begünstlgung beim einzelnen Erben liegt verteilungspolitisch das Problem", B. Molitor 1979, S. 286; verteilungspolitisch kommt es darauf an, "daB die Erbschaftsteuer einen Druck zur Vermögensaufteilung ausübt und die bei groBen Erbschaften anfallenden Budgetmittel in den unteren Vermögensklassen möglichst wieder dem privaten Vermögensstock zuwachsen" (ders., ebda.), sel es durch eine beschleunigte Progression, sei es (so B. Molitor 1979, S. 286) durch Begrenzung auf Höchstbeträge. 
S 20 Das Leistungsfähigkeitspostulat und seine personale Bedingung = Der Leistungsträger "Individuum" / Personalbesteuerung versus unternehmenbesteuerung

I. Die Ertragsfähigkeit als Steuerfähigkeit der Unternehmung

II. Die Unternehmensbesteuerung als allokative Besteuerung

III. Problemschwerpunkte der Unternehmensbesteuerung aus personalsteuerlicher sicht

IV. Zusammenfassung des 5. und 6. Kapitels

I. Wir knüpfen an die in $\$ 11$ gemachten Ausführungen zu den verschiedenartigen Entscheidungen in den allokativen und distributiven sphären des Wirtschaftens an. die fundamentale Gültigkeit dieser Unterscheidung läßt sich gerade anhand der Unternehmensbesteuerung deutlich demonstrieren. In den Steuerwissenschaften - wenngleich weniger in der Finanzwissenschaft - ist umstritten, ob nur die Individuen oder auch Unternehmen eine wirtschaftliche und steuerliche "Leistungsfähigkeit" haben. In der Diskussion um die Leistungsfähigkeit der Unternehmen wird zwar der Terminus "Ertragsfähigkeit" selten benutzt, dürfte sich aber als die Grundlage der steuerfähigkeit von Unternehmungen, als der einzig sinnvolle und logische Teminus erweisen. "Unternehmensbesteuerung" umschliebt mehr als nur die Besteuerung der juristischen Personen und reicht demnach über die Körperschaftsbesteuerung hinaus. ${ }^{1)}$ Der Begriff Unternehmensbesteuerung wird hier nicht so breitgefaBt verstanden, daB er alle von einer Unternehmung $z u$ zahlenden Steuerarten umfaBt, ${ }^{2}$ sondern

1) Die Argumente für und gegen eine zuordnung von. Leistungsfähigkeit auch an die Unternehmen lassen sich zwar recht gut aus der Diskussion um die Rechtfertigung der Körperschaftsteuer herleiten, doch muB man sich davor hüten, daB man nicht in die Argumentation der "besonders hohen" Leistungsfähigkeit, die Körperschaften, insbesondere die juristischen Personen, angeblich gegenüber den Einzelunternehmen haben, gerät; denn diese Argumente laufen auf die Rechtfertigung der Körperschaftsteuer hinaus und sind mit jenen des breiter ansetzenden Problems der Leistungsfähigkeit "von Unternehmen an sich" nicht vollständig deckungsgleich.

2) Siehe hierzu etwa K. Schmidt 1963, S. 35: Körperschaftsteuer, Gewerbesteuer und Umsatzsteuer. - Doch lieBen sich, wenn schon die Unternehmung als der Zahlungsort für überwälzbare Steuern (s.o. die Umsatzsteuer) gesehen wird, auch die speziellen Steuern auf die Produktions- und Absatzgüter dazuzählen. 
lediglich jene, die im Rahmen dieser Untersuchung thematisiert wurden, nämlich Gewinnsteuern und die Vermögensteuer. Auch diese Steuern jedoch werden nur insoweit diskutiert, als sie mit der angeblichen Leistungsfähigkeit in Verbindung gebracht werden.

II. In $\$ 7$ hatten wir die Notwendigkeit einer wirtschaftstheoretischen scheidung des allokativen vom distributiven Bereich des Wirtschaftens mit der unterschiedlichen zielsetzung und Funktion der ökonomischen GröBen Ertrag und Kapital (samt Reservebildung und Kapitalerhalten) einerseits sowie Einkommen und Vermögen (samt Sparen und Entsparen) andererseits begründet. Demnach erscheint es nicht korrekt, das politische Postulat der Besteuerung nach der Leistungsfähigkeit, das sich auf die ökonomischen GröBen der privaten sphäre bezieht, in die unternehmerische sphäre mit ihren Faktor-Effizienz-, Finanzierungs-, Wettbewerbs- und weiteren allokativen Entscheidungsproblemen $z u$ übertragen. ${ }^{3)}$ Das Interesse an der Kapitalerhaltung, das wir für den wirtschaftstheoretischen Einkommensbegriff als nicht relevant erachtet hatten, gewinnt hier in der Besteuerung zwar bedeutung, jedoch nur für eine a 1 $1 \circ k$ a $t i v$ motivierte, "objektivierte Unternehmensteuer" 4 ).

Es ist "höchst zweifelhaft, ob sich eine an einem firmenbezogenen Unternehmensbegriff orientierte substantielle Kapitalerhaltung mit der Vorstellung persönlicher steuerlicher Leistungsfähigkeit vereinbaren läßt". 5) Unternehmensvermögen und -gewinn sind als steuertatbestände etwas grundsätzlich anderes als Privatvermögen und -einkommen ${ }^{6)}$. Möglicherweise liegt Irrationalität vor: Vielleicht

3) Carter Report 1966, vol. 3, S. 31: "intermediaries cannot have discretionary economic power - the residual power to command goods and services for personal use."

$4)$ W. Flume 1975 und weiter: es wäre "sachgerecht, ... den Unternehmensertrag, soweit er dem Unternehmen verbleibt, also nicht zum Privateinkommen ... wird, nicht einer Personalsteuer, sondern einer Realsteuer .... $\mathrm{zu}$ unterwerfen" in Form einer "objektivierten Unternehmensteuer" einheitlich auf Ertrag aus Eigen- und Fremdkapital. Da dieses grundsätzliche Umdenken $z$. zt. nicht zu erwarten sei, sei der Steuersatz auf den betrieblichen Gewinn so zu fixieren, daB er die betriebliche Kapitalbildung ermögliche und induziere.

5) F.W. Wagner $1976 \mathrm{~b}$, S. 232 und weiter: solchermaBen würde die Erhaltung der Leistungsfähigkeit der Betriebe zur "Nebenbedingung der Besteuerung nach der Leistungsfähigkeit" der Individuen gemacht.

6) W. Flume 1975 und 1972, S. 40. - G. Schmölders 1953, S. 17. D. Schneider 1990 S. 159: "Institutionen können kein eigenes

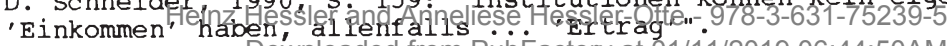


wegen der Emotionen, die eine gedankliche Verbindung von "GroBkapital" und "Millionengewinnen" mit Unternehmungen schlechthin hervorruft, ist die Leistungsfähigkeit mit der Unternehmensbesteuerung in eine direkte Verbindung gebracht worden. Aber eine gröBere Leistungsfähigkeit drücken Millionengewinne nur aus, "wenn sie einer oder wenigen Personen zuflieBen. Dann sind diese Personen besonders leistungsfähig, nicht aber die Betriebe" (G. Wöhe 1988, S. 197). Die Betriebsteuerdiskussion hat in ihren Anfängen deutlich gemacht, daB eine Unternehmensbesteuerung sich nicht mit dem Leistungsfähigkeitsargument begründen läBt (s. $\S 8$ III). Besonders plastisch geht das auch aus der Begründung für die "Unternehmungsteuer" von K. Schmidt (1963, S. 51) hervor: Die Unternehmung zieht Vorteile aus Kollektivleistungen, die solchermaßen als "vierter oder fünfter Produktionsfaktor" zum Produktionsergebnis beitragen; das ist allenfalls ein Ausdruck des Aqquivalenzdenkens, hat keinesfalls etwas mit Leistungsfähigkeit zu tun. 7)

Nach K. Tipke (1981, S. 232) ist die Abgrenzung der Erwerbssphäre von der Privatsphäre für das Einkommensteuerrecht "fundamental"; so dürfe z.B. das Vorliegen eines betrieblichen Ertrages oder eines Verlustes nicht die Gesellschafter oder Einzelunternehmer treffen, sondern die Unternehmung, dürfe also nicht in die Privatsphäre hineinreichen (K. Tipke 1981a, S. $100 \mathrm{f.}$ ). Bei inhaltlich weitgehender Gleichsetzung der betrieblichen sphäre mit dem allokativen Bereich des Wirtschaftens wie auch der privaten sphäre mit dem distributiven Bereich möchten wir diese Abgrenzungsnotwendigkeit $z u$ einer generellen für die gesamte Besteuerung machen und formulieren, daB sie "fundamental" für die Besteuerung insgesamt ist.

Eindeutig ließen sich dann so bekannte Postulate wie die Rechtsform-, Wettbewerbs- und Finanzierungsneutralität der Besteuerung der Allokationsbesteuerung zuweisen. Genau so eindeutig ließe sich dann erkennen, daß die Unternehmen nach einer "sachgerechten" Leistungsfähigkeit (H. H. Mösbauer 1975, S. 686), d.h. nach ihrer Ertragsfähigkeit zu besteuern wären. ${ }^{8)}$

7 ) Siehe hierzu insbes. die generelle Kritik bei K. Schmidt (1963, $\mathrm{S} .49 \mathrm{f.l}$ an den Ubertragungsversuchen der Leistungsfähigkeit auf Unternehmungen; "die Leistungsfähigkeitstheorie lerweist sich) nicht als zwingende Rechtfertigung der Unternehmungssteuer" (S. 50). Siehe jüngstens auch G. Heidinger 1982, S.270. Fußnote 8 auf der folgenden seite. 
E. Schipporeit hat versucht (1979 u. 1980) nachzuweisen, daß die Unternehmung eine "steuerliche Leistungsfähigkeit" "an sich" habe wie die Person. Man übersehe, "daß die Unternehmung selbst durch Kombination persönlicher und sachlicher Mittel ein Ergebnis erwirtschaftet" (1980, S. 190). Der Tatbestand der Kombination von Faktoren ist nicht zu bezweifeln, doch aus dem Umstand, daß ein Unternehmen wegen des dort entstandenen Ertrages auch besteuert werden kann - ebenfalls nicht zu bezweifeln - , folgt nicht zwingend, daß dies nun nach dem (distributinspolitisch besetzten) Leistungsfähigkeitspostulat erfolgen muß.

E. Schipporeit sagt selbst, $d a B$ wegen der Ablehnung einer nutzentheoretischen Interpretation des Leistungsfähigkeitsprinzips auf den "E $r$ t $\mathrm{a} \mathrm{g"} \mathrm{(1980,} \mathrm{S.} \mathrm{196)} \mathrm{als} \mathrm{Anknüpfungspunkt} \mathrm{einer} \mathrm{Be-}$ steuerung $z$ u rekurrieren sei, und das ist tatsächlich eine betrieblich-allokative GröBe, die keine distributive Besteuerung erlaubt. 9) Dies ist mehr als eine bloBe Differenzierung in der Terminologie, weil mit der Anwendung des Leistungsfähigkeitspostulats auf betriebliche Gewinne steuerpolitische probleme beruhrt sind: Im allokativen Bereich gilt die Forderung nach Allokationsneutralität der Besteuerung; der von Schipporeit vorgeschlagene Progressionstarif auf den betrieblichen Gewinn (S. 197 f.) kann diese Neutralität nicht haben, ist z.B. im wesentlichen nicht wettbewerbsneutral, beeinflußt die Betriebsgrößenentscheidung und die

8) Der Terminus der "sachgerechten Leistungsfähigkeit" ist allenfalls im Gegeneinander $\mathrm{zu}$ einer "personengerechten Leistungsfähigkeit" akzeptabel; Mösbauer, ebda: "Die Koppelung von sachgerechter und personengerechter Besteuerung nach der Leistungsfähigkeit scheint der Gefahr einseitiger Manipulierbarkeit besonders hinsichtlich der Besteuerung der Unternehmen wirksamer entgegenzuwirken."

9 ) Der Heraushebung der betrieblichen Ertragsfähigkeit kann auch nicht der Vorwurf gemacht werden, sie würde sich gegen die Zuerkennung jeglicher Steuerfähigkeit immunisieren, wie das E. Schipporeit tut. Wenn wir nur die von Schipporeit verwendete Terminologie ändern, befindet er sich mit der von uns in \& 7 entwickelten Analyse- und Abgrenzungsproblematik in Ubereinstimmung; E. Schipporeit 1980, S. 196: "VerläBt (der Gewinn) die Unternehmung, ... so erlischt auch ihre" - statt "Leistungsfähigkeit" wäre nun zu sagen - Ertragsfähigkeit; und weiter: es "werden alle ihre Gewinne ... zu Einkommen der Eigner" (S. 197). Völlig richtig gesehen; und wir ergänzen in unserer Terminologie: der Gewinn verläBt den unternehmerischen Allokationsbereich, wird im Distributionsbereich des Wirtschaftens zu persönlichem Einkommen und erst dort dem Leistungsfähigkeitspostulat unterworfen. 
Kapitalbildung. Die allokationsneutrale Wirkung stellt sich aber auch ohne einen Progressionstarif ein, wenn die für das Leistungsfähigkeitspostulat begriffsnotwendigen Personalisierungselemente (wie die persönlichen Abzüge von der Bemessungsgrundlage) auch den Betriebsgewinn schmälen sollen.

III. Soweit die Unternehmensbesteuerung das hier zu behandelnde personalsteuerliche Thema berüht, haben wir drei Problemschwerpunkte ausgemacht:

Der erstes ist ein rein ökonomischer und betrifft die allokativen Entscheidungen in Unternehmungen. Entscheidungs- und Organisationsanalogien mit dem privaten Bereich als Begründungen für die parallele Anwendung des Leistungsfähigkeitspostulats heranzuziehen, muß fehl gehen.

Der zweite ist ein rein steuerlicher: Das Problem liegt darin, im Gegensatz zur persönlichen Belastbarkeit die Effektivität in der Erreichung von Unternehmenszielen in der Besteuerung von Ertrag und Kapital zu berücksichtigen. Die Besteuerung des Gewinns bzw. Ertrags hat allokative Auswirkungen auf dsa Investitionsverhalten, die Wettbewerbspositionen usw., die mit den Auswirkungen der Haushaltsbesteuerung nicht entfernt vergleichbar und daher strikt von dieser $z u$ trennen sind. Bereits der steuerpolitische Ansatzpunkt der leistungsfähigkeitsorientierten Besteuerung der Haushalte ist wegen seiner Nähe zum Gerechtigkeitspostulat grundverschieden von dem einer allokativ motivierten Besteuerung im Unternehmensbereich, in dem nicht Gerechtigkeitsgesichtspunkte der vertikalen Richtung zwischen unterschiedlich leistungsfähigen Personen sondern allenfalls Gesichtspunkte der horizontalen Gleichbehandlung eine Rolle spielen.

Steuersystematisch - und die ist der dritte Problemschwerpunkt ist von Interesse, daß die Analyse der in der Literatur diskutierten und tatsächlich angewendeten Formen der Unternehmensbesteuerung eine "mehrschichtige Asymmetrie" offenlegt, die sich auf steuerarten, Rechtsformen und ökonomische Betätigungen bezieht. überdies zeigt sich, daß es sowohl objektivierte als auch personalisierte Konzepte der Unternehmensbesteuerung gibt.

Obwohl es aus Gründen der Vollständigkeit in der Problembearbeitung vonnöten ist, diese Schwerpunkte sämtlich aus der personaisteuerlichen sicht zu beurteilen, ist dennoch ihre ausfürliche 
Darstellung an dieser Stelle, da von der theoretisch gestalteten zur praktisch gestalteten objektivierung der Leistungsfähigkeit überzugehen ist, nicht erforderlich. Wir haben daher, ohne den thematischen Zusammenhang aufgegeben zu haben, die detaillierte Bearbeitung der genannten Problemschwerpunkte einer Unternehmensbesteuerung als "Exkurs III" in den Anhang zu dieser Arbeit verwiesen.

IV. Unsere Ausführungen zum "Drei-Stufen-System" der Leistungsfähigkeitsbesteuerung (5. Kapitel) und der theoretisch gestalteten Objektivierung der Leistungsfähigkeit (6. Kapitel) fassen wir wie folgt zusammen: Der Inhalt der steuerlichen Einkommens- und Vermögensbegriffe wird von den Postulaten der Allgemeinheit und der Gleichmäßigkeit der Besteuerung und der Besteuerung nach der Leistungsfähigkeit geprägt bzw. von den Verstößen dagegen. Die Postulate berühren sich mit Gerechtigkeitsvorstellungen. Das Allgemeinheits- und das Gerechtigkeitspostulat als die Voraussetzungen des Leistungsfähigkeitspostulats haben die Aufgaben, die Indikatoren der Leistungsfähigkeit $\mathrm{zu}$ "objektivieren" und dadurch die "horizontale" Gerechtigkeit zu verwirklichen. Der Herstellung der "vertikalen" Gerechtigkeit dient endlich das Postulat der Leistungsfähigkeit, das sich in den verschiedenen, hier nur angedeuteten Maßnahmen der "Personalisierung" unả der "Inäividualisierung" konkretisiert.

Das Ideal eines einheitlichen unả umfassenden Elnkommensbegriffs hat sich in den Steuergesetzen nicht verwirklichen lassen. Die Aufspaltung in die verschiedenen Einkunftsarten zeigt, daß man in Steuertheorie und -praxis der analytischen Trennung in den allokativen und distributiven Bereich mit der Unterscheidung von betrieblichen Erträgen und persönlichen Einkommen keinerlei Wert beimiBt. Was aber als ein Fehler der theoretischen Einkommensdefinition anzusehen ist, nämlich die Bindung des Begriffs an die Verwendungsseite des Einkommens, stellt sich für die politische Begriffsbiläung geradezu als die notwendige Bedingung heraus. Denn man will doch die Verhaltensweisen der Steuerpflichtigen im Sinne wirtschaftspolitischer ziele von beiden Seiten des Einkommens her beeinflussen. Somit ist der steuerliche Einkommensbegriff "zweiseitig". Uberdies ist er "zweckbezogen", denn er erfüllt sowohl den "Individualzweck" als auch den "Steuerzweck". Der steuerliche 
Einkommensbegriff ist aber nicht einheitlich: Obwohl vom Grundsatz her nun in der steuerlichen Definition die wirtschaftstheoretisch entwickelte "ad-personam-Regel" anerkannt ist und damit die notwendige Bedingung für einen "Totalbegriff" gesetzt wurde, wird sie durch die "Zerklüftung" in die Einkunftsarten wieder aufgehoben. Ähnlich verhält es sich beim vermögen, wenn auch die hier entstehenden probleme ungleich vielschichtiger sind. Bei einer Besteuerung des Vermögens kommen die probleme der Bewertung ins Blickfeld. Mit der Definition des Einkommens auf der Basis des Vermögensvergleichs spielen Vermögensprobleme auch in die Einkommensdefinition hinein. Ferner entstehen Probleme der Steuersystematik, weil nämlich mit der steuerpolitischen Entscheidung für eine Vermögensteuer neben der Einkommensteuer je nach der steuertechnischen Ausgestaltung zwei Vermögensbewertungssysteme nebeneinander bestehen, weil darüberhinaus Vermögenserträge durch die Einkommensteuer und die Vermögensteuer zweifach belastet sind, weil es sogar zu einer Sollbesteuerung kommen kann, weil im Jahr des Erbanfalls das Vermögen durch die Erbschaftsteuer und durch die Vermögensteuer zweifach belastet wird und weil schlieblich je nach der Rechtsform des Vermögenshalters eine zweifachbelastung bei den mittelbaren und unmittelbaren Haltern des Vermögens stattfindet (die ertragsteuerlichen Belastungen sind hierbei auBer Betracht gelassen). Damit ist auch der steuerliche Vermögensbegriff wie der Einkommensbegriff kein rein personaler mehr; zwar berücksichtigt er - wie der wirtschaftstheoretische Vermögensbegriff - die Verfügungsmacht im sog. "wirtschaftlichen Eigentum", doch wird Vermögen auch juristischen Personen zugerechnet. Die allokativ-distributive Abgrenzung der wirtschaftlichen Sphären wird nicht eingehalten.

Schlieblich offenbart sich unter politischem Aspekt in der Belastung des Vermögens durch die Vermögen- und Erbṣchaftsteuer die allokativ-distributive Interdependenz: Einerseits hat Vermögen, das dem einzelnen die Funktionen der Existenzsicherung, Vorsorge, Lebensstandardsteigerung (bzw. -erhaltung) sowie der Unabhängigkeit und Kreditfähigkeit erfüllt, einen "Individualzweck" und ist damit Indikator der Leistungsfähigkeit; andererseits kann der Staat den "Steuerzweck" des Vermögens nicht so weit ausnutzen, daß die allokations- und ordnungspolitische Funktion des Vermögens in Gefahr gerät (Eigentumsgarantie, Substanzbesteuerung, Geldentwertung). 
So zeigt sich in der Belastung des Vermögens durch Vermögen- und Erbschaftsteuer eine gewisse Ineffektivität bzw. Unentschiedenheit in der Besteuerung im Hinblick auf das Besteuerungsziel: Es ist nicht zu erkennen, ob lediglich ein - wenn auch bescheidenes Steueraufkommen geplant ist (fiskalisches ziel wird präferiert) oder ob entsprechend mancher Rechtfertigungstheorie eine Vermögensumverteilung gewollt ist (das distributive ziel wird präferiert). Die allokativ-distributive Interdependenz und die Ambivalenz der Politiker gegenüber dem Vermögen und der Vermögensbesteuerung legen es nahe, dem steuerlichen Vermögensbegriff das Signum eines "begrenzt zieloffenen" Begriffs zu geben. Deutlicher aber kann nicht demonstriert werden, daB die steuerlichen Begriffe politisch geprägte Begriffe sind.

Als Fazit der theoretischen Analysen im 5. und 6. Kapitel stellt sich heraus, daß für die Einkommens- und Vermögensbegriffe die Steuerpostulate maßgeblich sind, daß unter diesen insbesondere das Allgemeinheitspostulat eine hervorgehobene Bedeutung hat (Totalbegriff), daß die Analyse dieses postulats dazu dient, die Vollständigkeit bzw. Unvollständigkeit der objektivierung der persönlichen Leistungsfähigkeit offenkundig $\mathrm{zu}$ machen und daß letztlich an der steuergesetzlichen Fassung der Einkommens- und Vermögensbegriffe abgelesen werden kann, inwieweit es an der Grundvoraussetzung für die Anwendung des Leistungsfähigkeitspostulats, nämlich an der analytisch exakten Trennung des allokativen und distributiven Bereichs fehlt. Einkommens- und Vermögensbegriffe, die auch für die Besteuerung unternehmerischer Erträge und Gewinne herhalten müssen, können keine Indikatoren der $\mathrm{p}$ e r s ö n 1 i c h e $\mathrm{n}$. Leistungsfähigkeit, keine Indikatoren der steuertragfähigkeit sein. 
7. KAPITEI =

Praktisch gestaltete objektivierung $I:$ Die Einschräkungen des Allgemeinheitspostulats

521 Das Allgemeinheitspostulat und seine erste sachliche Einschränkung : Die "Ausgrenzungen" aus aer "freien" Verfigbarkeit. -

Die Gesamtproblematik

I. Die allokativ-distributive Abgrenzung der Verfügungsbereiche

1. Die Totalverfügbarkeit als Ausdruck der Leistungsfähigkeit

2. Das Nettoprinzip und die Objektivierung der Leistungsfähigkeit

3. Kapitalerhaltende Steuerbefreiungen und zwischenperiodischer Verlustausgleich als rein allokative Vorgänge

II. Ist-versus Soll-Leistungsfähigkeit und das Allgemeinheitspostulat

1. Ist-Leistungsfähigkeit und Totalität der Besteuerung

2. Das Realisationsprinzip im Bereich der persönlichen Leistungsfähigkeit

III. "Freie" Verfügbarkeit und Totalitätsprinzip: Die Konkretisierung der objektiven Leistungsfähigkeit

1. Die distributiv vorbestimmte Totalverfügbarkeit

2. Additive und subtraktive Methoden zur Einengung der Totalverfügungsgröße 306

3. "Comprehensive Tax Base" versus "Adjusted Gross Income"

4. Eine entscheidungs - und ratiobezogene Systematik der Einengungs-Tatbestände für die freie Verfügbarkeit

IV. Die "Ausgrenzungen" als Maßnahmen einer politisch bestimmten Verfügbarkeit

1. Nichterfassungs- bzw. Befreiungs-Tatbestände in der Einkommensbesteuerung

2. Nichterfassungs- bzw. Befreiungs-Tatbestände in der vermögensbesteuerung

3. Allgemeine allokativ-distributive Beur-

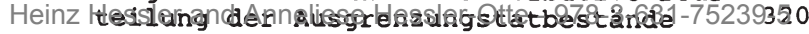
Downloaded from PubFactory at 01/11/2019 06:44:50AM 
I. Um darzustellen, welche Rolle die "f r e i e V e r f ü g b a $r k$ e $i$ t" für die Besteuerung spielt, beziehen wir uns auf die Voraussetzungen und Inhalte, die die Verfügbarkeit über ökonomische Größen wirtschaftstheoretisch hat (s. $\$ 11$ V) und knüpfen an das in $\$ 17$ herausgesteilte Verhältnis zwischen dem Allgemeinheits- und dem Leistungsfähigkeitspostulat an.

1. Das Allgemeinheitspostulat hat eine personale Seite insoweit, als es die steuerliche Erfassung aller Einkommensbezieher und damit deren Gleichbehandlung verlangt, wie auch eine sachliche Seite (F. Neumark 1970, S. 75), wonach alle ökonomischen GröBen zu erfassen sind, die einer Person zugehen. Die Absicht der personal-sachlichen Gesamterfassung wird als das steuerliche "T 0 t a 1 i t ät s p i n z i p" bezelchnet (Tipke 1991, s. 191) x).

Für unsere Darstellung einer Konkretisierung des steuerlichen Einkommens- und Vermögensbegriffs hat nur der sachliche Aspekt des Totalitätsprinzips Bedeutung, aber auch dieser nicht in voller Breite; denn die Totalerfassung der Erträge im allokativen Verfügungsbereich der Unternehmenswirtschaft ist zunächst kein Einkommensproblem. Die Totalerfassung ruft aber insbesondere dann distributive hervor, wenn Unternehmensgewinne wie Einkommen behandelt werden, wie das für die Besteuerung der Einzelunternehmen und Personengesellschaften hierzulande typisch ist. Die wesentlichen distributiven Effekte liegen darin, daß Ertragsteile als Einkommen progressiv besteuert werden und daß infolge des hierdurch angestiegenen Fiskalaufkommens niedrigere spitzensteuersätze möglich werden. Die allokativen Folgewirkungen einer progressiven Gewinnbesteuerung könnten in einer niedrigeren Rücklagenbildung und Kapitalausstattung der Unternehmen liegen.

Zur vermeidung allokativ nachteiliger Effekte im Zusammenhang mit dem Allgemenheitspostulat ist es geboten, zwar die Einkommen total, d.h. "ohne Lücken" gleichmäßig zu erfassen, doch nicht Größen als "Einkommenselemente zu behandeln, die es nicht sind" (N. Andel 1979a, S. 334). Die sachliche Seite des Allgemeinheitspostulats soll

x) zu unterscheiden vom "Universalitätsprinzip", siehe Lang, J., Die Bemessungsgrundlage der Einkommensteuer, Köln 1981/88, S. $167 \mathrm{ff}$. 
die "comprehensive tax base" unter Einschluß sämtlicher zugangsquellen erfassen (Musgrave/Musgrave 1980, S. 243 f. u. 345 ff.); insofern führt sie zu einem Einkommen als "Summenbegriff" (F. Neumark 1947, S. 29). Das aber verlangt, daß die Einkunftsarten Arbeit und Kapital nicht unterschiedlich besteuert werden dürfen, daB auch die Herkunft dieser Einkommen aus verschiedenen Wirtschaftssektoren, -regionen usw. keine Rolle spielen darf und daB schlieblich nur auf eine solche Erfassung aller Einkommenselemente "in a global total" sinnvollerweise der Progressionstarif anzuwenden ist (Musgrave/Musgrave 1980, S. 344). Insofern "muB" der steuerliche Einkommensbegriff das Totaleinkommen sein (K. Tipke 1972, S. 215 f.). Da die Totalerfassung ungeachtet auch threr allokativen Vorteile vor allem im Dienste des distributiven Zieles steht, weil nur in der Gesamtsumme an ökonomischen Größen die individuelle ökonomische Leistungsfähigkeit sich überhaupt ausdrücken kann, ist eine vorherige Abgrenzung aller rein allokativen Größen begrifflich zwingend.

2. Die abzugrenzenden AllokationsgröBen interessieren hier nur insoweit, wie sie mit dem Einkommensbegriff verbunden sind. Ein solcher zusammenhang wird in der betriebswirtschaftlichen und rechtswissenschaftlichen Steuerlehre über das "N e $t$ t o p r i n $z$ i p" hergestellt, das ganz bestimmte Ausnahmen von der Totalerfassung begründen soll. Wenn nun aber abgeleitet wird, dieses Prinzip sei der "Ausfluß des Leistungsfähigkeitsprinzips" (K. Tipke 1991, S. 59), so ist zunächst einmal eine gerade in der Steuerrechtslehre getroffene Unterscheidung $\mathrm{zu}$ beachten: Danach fordert das "objektive" Nettoprinzip, das Totaleinkomen um die sog. "Erwerbsabzüge" zu kürzen (Betriebsausgaben, Werbungskosten); das "subjektive" Nettoprinzip verlangt, "persönliche" Abzugsposten, wie Sonderausgaben, auBergewöhnliche Belastungsausgaben, Alters- und Haushaltsfreibeträge usw. als "private Abzüge" zu berücksichtigen. ${ }^{1)}$ so unbestritten die jeweiligen $\mathrm{Ab}-$ zugsnotwendigkeit auch sein mag, so liegen beide Arten ein- und desselben Prinzips doch in völlig verschiedenen Bereichen des Wirtschaftens und vor allem auch des Besteuerungsvorganges: Das objektive Nettoprinzip soll dort wirksam werden, wo von Einkommen

1) R.Tipke 1991, S. 197, 203, 258, 375ff.;464; ders. 1980b, S. 290 . 
überhaupt noch nicht gesprochen werden kann, nämlich im betrieblich-beruflichen Bereich (Betriebsausgaben, 2) Werbungskosten!). 3) Demgegenüber erstreckt sich das subjektive Nettoprinzip tatsächlich auf das (zu versteuernde) Einkommen. Nur diese "privaten Abzüge" sind als "Personalisierungsgrößen" mit dem Leistungsfähigkeitsprinzip in Verbindung $z u$ bringen. Wenn gesagt wird, die Erwerbsaufwendungen müBten aus dem "Einkommensbegriff" ausscheiden, so werden die verschiedenen Ebenen der Analyse, die Bereiche der Allokation und der Distribution, miteinander vermengt (s. hierzu $\S 10$, III) und nicht kompatible Begriffe verwendet. Die Postulierung des Nettoprinzips, dessen a $l \mathrm{l} \circ \mathrm{k}$ a $t \mathrm{i}$ e seite $\mathrm{K}$. Tipke herausstellt, wenn er ihm die Funktion einer "Pflege der Einkunftsquelle" (1979a, S. 194) zuschreibt, entspricht nicht der allokativdistributiven Abgrenzung bei der Analyse des $\mathrm{E} i \mathrm{n}$ k $0 \mathrm{~m}$ m n s begriffs. Mit seinen Erwerbs- und auch mit seinen privaten Abzügen liegt es außerhalb jenes Bereichs, in dem der Begriff

2) Eine detaillierte Ubersicht uber allokative Abzugsposten im EStG gibt J. Giloy 1978, S. 79 f., obwohl auch er sie unter dem Titel des Einkommensbegriffs aufführt.

3) Terminologisch exakt spricht Tipke hier von dem "objektiven Nettoprinzip (1991, s. 203) bzw. vom "Erwerbs-Nettoprinzips" (1981, S. 151), wobei aber mit Erwerb sowohl der betriebliche als auch der berufliche Bereich erfaBt wird; "Berufszweck" ist aber weitgespannter als allein der Bereich der Freiberufler, denn auch der Lohnabhängige verfolgt einen Berufszweck. Wir melden jedoch Bedenken an, wenn Tipke sagt (1980b, S. 290), es gäbe keinen Wertungsunterschied zwischen den Erwerbsaufwendungen und den privaten Aufwendungen, da sie alle notwendigerweise die Leistungsfähigkeit mindern würden. Denn erstere fallen - wie wir meinen - im allokativen Bereich an; Betriebsausgaben werden getätigt, noch bevor ein Gewinn (und erst recht ein Einkommen) festgestellt werden kann. Von diesen Erwerbsabzügen sagt Tipke an anderer Stelle (1991, S. 197), sie seien überhaupt nicht disponibel für den steuerpflichtıgen Nun, disponibel sind sie schon, jedoch mögen sie aus anderen beachtenswerten Gründen vom Gewinn und von der Besteuerung ausgenommen werden. - Rückhaltlos zustimmen müssen wir aber der von Tipke herausgestellten ökonomisch-inhaltlichen Identität von Betriebsausgaben und Werbungskosten $(1981$, S. 237 ff. u. 269; 1979, S. $194 \mathrm{ff.l}$, da beide vom Privatbereich abzugrenzen seien. Damit bestätigt Tipke indirekt, daB beide Aufwandgruppen dem allokativen Bereich zuzurechnen sind; K. Tipke 1979, S. 196: "Man sollte daher besser einheitlich von "Berufsausgaben" sprechen und den Begriff "Betriebsausgaben" (ebenso wie den der Werbungskosten) aufgeben. Das empfiehlt sich auch deshalb, weil die Einkommensteuer keine Betriebssteuer, sondern eine Personensteuer ist und weil auch das Betreiben eines Unternehmens ein Beruf ist." 
des steuerlichen Einkommens objektiviert und konkretisiert werden soll: Erwerbsabzüge mindern den Ertrag, private Abzüge sind dagegen Subjektivierungsmaßnahmen und mindern das Einkommen. ${ }^{4)}$

3. Ohne daB sie unter den Betriebsausgabenabzug fallen, sollen auch die beiden folgenden steuerlichen Regelungen eine Einschränkung des Totalitätsprinzips bewirken, haben aber aus den Gründen der o.e. analytisch notwendigen Trennung zwischen dem allokativen und distributiven Bereich keine unmittelbare Auswirkung auf die Bestimmung des steuerlichen Einkommens: Es handelt sich um die $s t$ e $u$ e $r$ b e $\mathrm{r}$ e $i$ u $g$ für Gewinne aus der VeräuBerung bestimmter Anlagegüter ( $\S \S 6 \mathrm{~b}$ u. $6 \mathrm{c}$ EStG) sowie um den " $z$ w $i$ -

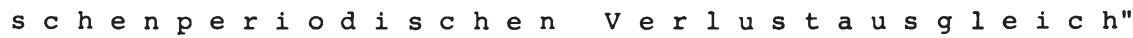
(N. Andel 1979a, S. 368), also den Verlustvor- und -rücktrag; ${ }^{5)}$ analog zu diesem "Verlustabzug" ( $\$ 10 d$ EStG) ist der Schuldenabzug bei der Besteuerung des Vermögens ( $\S 4$ VStG u. $\S 118$ BewG) zu sehen. Ist die Steuerbefreiung eine allokationspolitisch motivierte sachliche Verminderung der Bemessungsgrundlage für die Besteuerung betrieblicher Erträge, so hat der Verlustabzug als eine zeitliche Ausgleichsregel seinen Grund in der Periodizität der Steuer, also in einer steuertechnischen Regelung. ${ }^{6)}$ DaB sich beide

4) Völlig anders versteht D. Schneider (1978b, S. 38) die Begriffe "objektive" und "subjektive" Leistungsfähigkeit, da er damit zwei unterschiedlich weite Einkommensbegriffe (nach Schneider "Betrachtungsweisen") assoziiert; mit der objektiven Leistungsfähigkeit verbindet er den "Zuwachs an Verfügungsmacht"; bei genauerer Prüfung handelt es sich dabei in unserer Terminologie um den produktionswirtschaftlichen Einkommensbegriff, ergänzt um Teile des vermögeneinschließenden (einige Imputierungen); die subjektive Leistungsfähigkeit wird durch den $\mathrm{Ab}-$ zug der "persönlichen Abzüge" hergestellt; jedoch solle der Steuergegenstand nicht dieses subjektive, sondern das "volle wirtschaftliche Einkommen" sein (S. 40), um den "Progressionseffekt" der persönlichen Abzüge auszuschalten.

5) Nicht hierher gehören der horizontale Verlustausgleich innerhalb der Einkunftsarten und der vertikale Verlustausgleich zwischen den Einkunftsarten, denn diese Regelungen beziehen sich tatsächlich auf die Ermittlung des Einkommens in seinem "Summencharakter". Nach Andel (1979a, S. 367) sind dies die Fälle des "innerperiodischen Verlustausgleichs".

6) K. Tipke 1991, S.206 - F. Neumark 1947, S. 29 sowie ders., $1961 \mathrm{~b}$, S. 48: Die Definition der Einkommen (und der Erträge) als Zugänge innerhalb einer Jahreszeitspanne "ist nur eine Sache der Konvention". Tipke spricht von der Utberperiodidischen Berücksichtigung des verlustabzugs (S. 206). 
Einschränkungstatbestände des Totalitätsprinzips ausschlieBlich in der allokativen Sphäre abspielen und mit den Einkommen nichts zu tun haben, wird oftmals übersehen. 7) Jedoch geben beide, wenn sie auch als allokative $z u$ kennzeichnen sind, AnlaB zu Uberlegungen für den distributiven Verfügungsbereich:

Zunächst besteht das allokationspolitische Motiv, das der Steuerbefreiung bestimmter Erträge ${ }^{8)}$ zugrundeliegt, im Interesse an der Kapitalerhaltung ${ }^{9)}$ sowie an der EinfluBnahme auf die sektorale und strukturelle Entwicklung. Dies gilt im übrigen auch für den Betriebsausgabenabzug und für den Abzug der Abschreibungen. Schon E.R.A. Seligman (1931, S. 14) hatte festgestellt, daB eine Bruttobesteuerung zur Bevorzugung von "Raubbau", zur Benachteiligung der kapitalintensiven produktion führt und die Vermögenssubstanz angreift. 10 )

7) So verlangt F. Neumark (1947, S. 29 ; Hervorhebungen dort) die Zulassung des Verlustabzugs, um das "R e $i \mathrm{n}$ e $i \mathrm{n}$ $\mathrm{k} \circ \mathrm{m} \mathrm{m} \mathrm{e} \mathrm{n}$ zu besteuern. Für den Verlustausgleich innerhalb und zwischen den Einkunftsarten wäre das korrekt, nicht aber für den Verlustabzug; diesen aber hält Neumark "theoretisch" für ein "selbstverständliches Prinzip der Einkommensbesteuerung".

8) DaB gerade die ZweckmäBigkeit der $\S 6$ b-Regelung im EStG auch kritisch beurteilt werden kann, sei am Rande vermerkt; siehe hierzu D. Schneider 1978c.

9 ) Eine Besteuerung der Verluste (wie auch der unrealisierten Gewinne) wird zur realen Vermögensbesteuerung (D. Schneider 1978 b, S. 57 u. 60 . - Siehe hierzu auch F.W. Wagner 1976a, S. $230 \mathrm{ff}$. Soweit Wagner an der Kapitalerhaltung im Steuerrecht kritisiert, daB sie eine Gleichbehandlung nicht gewährleiste, sei ergänzt: Nur wenn man den gegenwärtigen Zustand des Nebeneinander von (allokativ determinierter) Gewinnfeststellungsmethode und (eher distributiv determinierter) UberschuBfeststellungsmethode beibehält, hat Wagner recht. Würde man aber die Unternehmens- von der Haushaltsbesteuerung trennen, würde sich das Problem der Gleichbehandlung reduzieren auf die Gleichbehandlung zwischen Unternehmen.

10) LäBt man dieses allokativ-betriebliche Argument ausschlieBlich für das Sachkapital gelten, so zeigt sich darin ein "materialistisches" Denken, denn den gleichen Anspruch auf Schonung und Erhaltung in seiner Substanz kann man für den Produktionsfaktor Arbeit erheben. Strebt man eine Gleichbehandlung an, wären "abschreibungsähnliche" Regelungen etwa durch Abzüge für den Fortbildungsaufwand konsequent, doch ohne da $B$ eine Begrenzung auf Höchstbeträge $\mathrm{zu}$ begründen wäre. Keineswegs aber gehören hierher die Abzüge für das Existenzminimum und einen darüber hinausgehenden Mehrbedarf, denn diese fallen als PersonalisierunqsmaBnahmen in den distributiven Bereich. 
Ubertrüge man den Erhaltungsgedanken nunmehr auf den distributivpersonalen Bereich, ergäbe sich daraus die konsequente Forderung nach Erhaltung des Humanvermögens (soweit es nicht dem produktionswirtschaftlichen Einsatz dient) und des privaten Sachvermögens (etwa zur Erhaltung der mit ihm verbundenen Vermögensfunktionen. Aber eine solche "Gleichbehandlung" ist keineswegs zwingend geboten. Aus demselben Grunde ist die Ubernahme des Verlustabzugsgedankens aus der Unternehmensbesteuerung in die Personalbesteuerung nicht zwingend, ist überdies bei kontraktgebundenen Einkommen auch unnötig., Die "Kontinuität des Wirtschaftsprozesses" (F. Neumark 1961b, S. 48), die zur Begründung für den zwischenperiodischen Verlustausgleich in Anspruch genommen wird und die dazu führt, daB der staat qua Verlustabzug am Risiko der Investitionen des privaten Sektors beteiligt wird (F. Neumark 1970, S. 324) - gewissermaBen als Preis für positive Wachstumseffekte -, kann zwar für den distributiven Bereich ebenso vorgebracht werden, nicht aber als Konsequenz aus einem allokativ-distributiven Gleichbehandlungsgebot. Man kann nämlich in der Allokationspolitik durchaus andere wirtschafts- und gesellschaftspolitische ziele verfolgen als in der Distributionspolitik. ${ }^{11}$

II. Wird die steuerliche Leistungsfähigkeit in I $s t$ - oder in $S \circ 11 \mathrm{~g} r$ ö $B$ e $\mathrm{n}$ gemessen? ${ }^{121}$

1. Nahezu überwiegend wird gefordert, die leistungsfähigkeitsorientierte Besteuerung im I $\mathrm{s}-\mathrm{E} i \mathrm{n} \mathrm{k} \circ \mathrm{m} \mathrm{m} \mathrm{n}$ auszudrücken, 13) und zwar im Einkommen als dem "wirklichen Reineinkommen", 14) also nicht im Einkommen als nur eịnem Leistungsfähigkeits-Potential. ${ }^{15}$ ) Das erzielte Isteinkommen wird dabei di-

11) Doch ein den Verlustabzugsregelungen analoges Verfahren im distributiven Bereich, etwa in Form einer mehrperiodischen Durchschnittsbesteuerung, kann mit der Progessionswirkung des Einkommensteuertarifs begründet werden. Eine solche Begründung läge dann im distributiven Bereich selbst und ergäbe sich nicht aus einer Ubernahme allokativer Argumente. Sie läge darin, daB sich in der Lebenseinkommensbetrachtung zeitlich unqleich anfallende Einkommenshöhen und damit ungleiche Leistungsfähigkeiten ausgleichen würden.

Fußnoten 12) bis 15) auf der folgenden seite. 
rekt mit der Leistungsfähigkeit in Beziehung gebracht. Es könnte der Eindruck entstehen, als sei das Soll-Einkommen wegen seines Potentialcharakters der weitere Begriff und daher besser geeignet, das "Totaleinkommen" auszudrücken. Doch dieser Eindruck täuscht. Die extern vorgebenen Sollwerte können durchaus hinter den effektiv erreichten Istergebnissen zurückbleiben. Die Sollbesteuerung ist in einem völlig anderen ordnungspolitischen Denken angesiedelt als die Istbesteuerung. In der ersteren kommen vorwiegend allokative Absichten zum Vorschein, nämlich eine steuerliche "Belohnung der Tüchtigen" und "Bestrafung der Faulen", die Tendenz, die "Rendite des Unternehmens, unabhängig von seiner steuerlichen Belastung zu steigern", und zwar durch die steuerpolitisch angeregte "Aktivität und Leistungsfähigkeit der Unternehmer" (G. Schmölders 1981a, S. 1205). 16) so ist der Einkommensbegriff der Sollbesteuerung nicht zwangsläufig umfassender, aber die "T $0 t$ a $l i t$ a $t$ " des Steuerzugriffs ist intensiver, zeigt einen hoheren Grad an interventionistischer Motivation ${ }^{17}$ ) und uberindividuell verordneter Leistungsfiktion.

12) Das Gegensatzpaar "Soll-Ist-Leistungsfähigkeit" formuliert die steuerpolitische Grundauffassung, das Gegensatzpaar "Soll-Ist-Besteuerung" deren steuertechnische Umsetzung bzw. Ausnahmeregelung. K. Tipke 1981, s. 24: die "reelle" (Ist-) Leistungsfähigkeit" und die "potentielle (Soll-) Leistungsfähigkeit; D. Birk 1983, S. 55 u. 147: "Ist-" und "Soll-Leistungsfähigkeit".

13) D. Birk 1991, passim; K. Tipke 1980b, S. 295, und 1981, S. 24; F. Neumark 1970, S. 165. - Anders jedoch K.H. Ossenbühl 1972, S. 86, der auf die Soll-Leistungsfähigkeit abstellen will; anders auch wohl H. Haller, in dessen Bedürfnisbefriedigungskonzept Potentialelemente stecken, was die Verbindung zwischen dem erzielten Einkommen und der daraus möglichen Bedürfnisbefriedigung betrifft, siehe 1981, s. $46 \mathrm{ff}$.

14) F. Neumark 1970, S. 165: die Sollbesteuerung berücksichtigt "statt der wirklichen individuellen die muBmaBliche potentielle Leistungsfähigkeit".

15) K. Tipke 1980b, S. 295: "Die Einkommensteuer sollte sich grundsätzlich nur am Ist-Einkommen orientieren und die 'Leistungsmühsal' nicht berücksichtigen."

16) Zur Literatur der Sollbesteuerung siehe insbes. W. Andreae 1927, 1928 und 1930 mit seiner "universalistischen Steuerlehre" und "neuen Staatswirtschaftslehre", der "Erhohung der Leistungsfähigkeit des Gesamtkörpers der Volkswirtschaft" und der "Bildung eines Kapitals höherer ordnung" als es das reine privatwirtschaftliche Kapital sein kann. Im Interesse dieser ziele stehe die Sollbesteuerung.

17) F.K. Mann 1937, S. 357, mit seiner Kritik an W. Andreae und dessen Befürwortung der Sollsteuer. 
Der Einkomensbegriff der subjektiv-individuellen Ist-Leistungsfahigkeit folgt aus der selbstbestimmten einzelwirtschaftlichen Planung und Wirtschaftsaktivitat. Er ist deren Leistungsergebnis, eine gemessene, bewertete und individuell zugerechnete 8konomische GroBe, versehen mit dem Kriterium der Verfügbarkeit durch die einzelne Person. Jegliche bloBe "Möglichkeit" zur Leistung, jegliches etwa nur angenommene "Potential" $z$ ur Leistung ist mit der Ist-Le1stungsfahigkelt nicht vereinbar. Steuerliche Leistungsfähigkelt ist mit der Ist-Leistungsfahigkeit identisch und verlangt den Begriff des Ist-Einkommens.

2. Die Unterscheidung zwischen effektiver und potentieller Leistungsfähigkelt wird besonders anhand des "R e a 11 s a t 1 on s p i n i p s" deutlich. Dieses verbietet, nichtrealisierte Gewinne, so auch nichtrealisierte Vermögenswertzuwächse, auszuweisen.18) Es ist zwar nicht aus dem Ertrags-oder Leistungsfähigkeitsgedanken, sondern aus dem Vorsichtsmotiv ${ }^{19}$ ) heraus entwickelt wordẹn, hat aber - da es über den Vermögensvergleich $^{201}$ den steuerlichen Gewinn bestimmt - eine Elnwirkung von der Ertragsfähigkeit uber den "ausschüttungsfähigen Gewinn" auf das personale Einkommen und auf die individuelle Leistungsfähigkeit. Die eher ordnungs- und allokationspolitischen Motive, unternehmerische Haftungssubstanz $z$ erhalten und überhöhte Gewinnausschüttungen und -entnahmen auszuschlieBen, haben ihre distributiven Effekte, die darin liegen, daB das Einkommen geringer erscheint und Vermögenssubstanz erhalten bleibt.

Der Realisierungsgedanke hat zwel Aspekte, nämlich den Privatvermögens- und den Betriebsvermögens- (exakt: Betriebskapital-) Aspekt; wenngleich das eigentliche Realisierungs-"Prinzip" nur mit dem Betriebsvermögen in Verbindung $z u$ bringen ist, ist der Realisie-

18) Das Realisationsverbot gilt nicht für drohende Verluste, denn die werden antizipiert, = "Imparitätsprinzip".

19) H.Bleg 1981 , S. 1107; K. Tipke 1991; S. 153f, 309

20) Das Realisationsprinzip wird grundsätzlich nur im Zusammenhang mit VermögensveräuBerungen - seien sie Geldforderungen, seien sie Sachvermögen - wirksam; K. Tipke 1981, S. 227: "Der Gewinn tritt bilanziell als der zu Geld gewordene Mehrwert gegenüber dem bisherigen Buchvermögen in Erscheinung." 
rungsgedanke in der breiteren Fassung als "die einkommensteuerliche Relevanz von VeräuBerungsvorgängen" (G. Rose 1977a, S. 75) $\mathrm{zu}$ bezeichnen. In dieser Fassung hat der Gedanke ganz allgemein den Bezug zur Leistungsfähigkeit. Es ist nun sehr interessant, das hierzulande praktizierte Einkommensteuerrecht daraufhin $\mathrm{zu}$ untersuchen, wie es betriebliche und private Realisierungen besteuert. Aus der theoretischen und distributiven Sicht darf man doch davon ausgehen, daB Vermögensrealisierungen die (private) Leistungsfähigkeit erhöhen. Im betrieblichen Bereich könnte man ebenfalls aus theoretischen Erwägungen - eine erhöhte Ertragsfähigkeit verneinen, um durch solche allokativ motivierte steuerschonung die Rapitalerhaltung zu gewährleisten. Doch in praxi ist die entgegengesetzte Handhabung anzutreffen: Es sind nämlich "... nur solche Vermögenswertänderungen steuerlich beachtenswert, die ein Betriebsvermögen betreffen. ... VeräuBerungserfolge im ertragbringenden ... und im ertraglosen Privatvermögen ... bleiben ... grundsätzlich einkommensteuerlich auBer Betracht" (G. Rose 1982a. S. 76). 21)

III. Ist für die wirtschaftstheoretische Einkommensdefinition die Verfügbarkeit als solche die conditio sine qua non, so ist es für den steuerlichen Einkommensbegriff nunmehr die "f $r$ e $1 e^{\text {" Ver- }}$ fügbarkeit. Sie determiniert den Inhalt der politisch bestimmten GröBe "steuerliches Einkommen". Wir entnehmen die Vorstellung einer "freien" Verfügbarkeit den Gedanken von A. Wagner. ${ }^{22)}$ Wenn nach N. Andel (1979a, S. 337) fü den steuerlichen Einkommensbegriff kennzeichnend ist, daB "okonomische Dispositionsfähigkeit" im Sinne von "Verfügungsmacht uber Güter und Dienstleistungen" vorliegen muB, so ist damit zunächst gefordert, daB auch das

21) "Von dem Grundsatz, daB nur VerăuBerungserfolge im Betriebsvermögen einkommensteuerlich beachtlich sind, gibt es aber zwei Ausnahmen: Die VerăuBerung gewisser Teile sog. wesentlicher Beteiligungen an Kapitalgesellschaften und die Verauberung von wirtschaftsgitern im Rahmen eines Spekulationsgeschäftes ... sind hinsichtlich des eintretenden Erfolges auch dann einkommensteuerlich beachtlich, wenn es sich dabel um Gegenstände des Privatvermogens handelt." G. Rose 1977a, S. 76 .

22) Wagner formulierte die Theorie vom progressiven Wachstum des "freien Einkommens", das Im Gegensatz stehe zum "gebundenen", welches der Befriedigung der existenziellen Bedurfnisse diene, 1880 , S. 357 f. 
steuerliche Einkommen vom wirtschaftstheoretischen Definitionsmerkmal der Verfügbarkeit als solcher her $z u$ begreifen ist, so ist darüber hinaus auch ausgedrückt, daB eine steuerliche Leistungsfähigkeit nur durch die "Okonomische" Dispositionsfahigkeit $\mathrm{zu}$ konkretisieren ist. Wir interpretieren diese "bkonomische" Dispositionsfähigkeit im Sinne der "frelen" Verfugbarkeit. vollig freie Verfügbarkeit uber Einkommen und Vermoggen ist nur dann vorhanden, wenn auf den einzelnen kein Zwang zu existenzsichernder und vorsorgender Verwendung einwirkt; liegt aber solcher Zwang vor, ist die rkonomische Entscheidung nicht mehr frei (zum Phänomen des "Zwangs" s.a. Ph. Herder-Dorneich 1982). Mit der freien Verfügbarkeit ${ }^{23}$ läßt sich die Frage aufwerfen, ob man nur einige Elemente der wirtschaftstheoretischen Einkommens- und vermögensbegriffe in die steuerlichen Begriffsfassungen übernimmt. Die freie Verfügbarkeit führt damit nämlich zu einer $v$ e $r$ e $n$ $g$ u $\mathrm{n} g$ des Totalitätsprinzips, so z.B. in den objektiven Befreiungen und im innerperiodischen verlustausgleich bzw. im Schuldenabzug vom Rohvermögen bis hin $z u$ besonderen Einengungen der $\mathrm{Be}-$ messungsgrundlage aus verteilungspolitischer Motivation (wie sie sich z.B. in der steuerlichen Freistellung des Existenzminimums zeigt.

1. Die nach dem steuerlichen Totalitätsprinzip zu ermittelnde Verfügungsgröße ist von geringerem Umfang als sie sich nach der wirtschaftstheoretischen Ubberlegung ergibt. Keineswegs ist aus der Verfügbarkeit von Wirtschaftsgütern und ökonomischen GröBen allein bereits auf eine steuerliche Leistungsfähigkeit zu schließen, ${ }^{24}$ ) soweit sie sich auf zugangsgrößen bezieht. Die Leistungsfähigkeit des einzelnen zeigt sich nämlich auch in seinen persönlichen Lebensverhältnissen. Diese bestimmen nun interessanterweise nicht nur die steuerlichen Abzugsbeträge im Zusammenhang mit PersonalisierungsmaBnahmen (personenbezogene Abzüge und Freibeträge), sondern in einem gewissen Umfang bereits den Zugangsaspekt selbst, also die objektivierte VerfügungsgröBe in ihrem Allgemeinheitsverständnis. Für beide Bereiche aber, nämlich für die objektivierung wie für die Personalisierung, ist die "Freiheit" der Verfügbarkeit $\mathrm{zu}$ untersuchen.

23) Carter Report 1966, Vol. 3, P. 5: "discretionary economic power" zur Konkretisierung der "ability to pay".

24) F.K. Mann 1928b, S. 609; B. Fux 1927, S. 139 
Freie Verfügbarkeit ist hier nicht gleichbedeutend mit Freiheit und Beliebigkeit in der Selbstbestimmung und Verfügung über Konsum und Investition ganz allgemein, sondern freie Verfügbarkeit uber die ökonomischen GröBen Einkommen und Vermögen meint die Freiheit vom Zwang zur Existenzerhaltung, auch die Freiheit von Zwängen anderer Art und evtl. minderen Drucks. Die freie Verfügbarkeit besteht insoweit nicht, wie erstens - im Bereich des $\mathrm{Zu}$ gangs - keine "ökonomisch-finanzielle Dispositionskraft" (F. Neumark 1970, S. 135) entsteht, wie zweitens - im Bereich der Verwendung - "Fremdbestimmung" gegeben ist. ${ }^{25)}$

a) Im Gegensatz zur wirtschaftstheoretischen Einkommensdefinition, die allein von der Zugangsregel (accretion approach) ausgeht, ist steuerlich nicht jeder Zugang eo ipso Einkommen. Er muB vielmehr einer Belastbarkeitsregel gehorchen. Diese ist an der freien Verfügbarkeit des zugangs $\mathrm{zu}$ orientieren. Die Belastbarkeit ist aus der dist $r i b u t i \circ n s p o l i t i s c h$ e $n$ sicht zu messen an der ökonomischen Gesamtposition des einzelnen, d.h. daran, ob der Zugang einen vorher zwangsläufig erfolgten "Abgang" an ökonomisch-finanzleller Dispositionskraft lediglich ausgeglichen hat. In diesem Fall ist wegen der nur wiederhergestellten Ausgangslage ein belastbares und somit steuerliches Einkommen nicht festzustellen. ${ }^{26)}$ Beispiele für die Zwangsläufigkeit, die Unfreiwilligkeit des "Abgangs" an ökonomischer Dispositionskraft lassen sich im Bereich der Transfereinkommen finden: Hat der einzelne eine Beeinträchtigung seiner persönlichen Leistungskraft durch Verlust seiner körperlichen oder geistigen Unversehrtheit hinnehmen müssen (Unfallschaden, Krankheitsfolgen: Verlust eines Korperteils, Verlust der Geisteskräfte), so ist eine in geldli-

25) Vgl. hierzu N. Andel 1979a, S. 334, der darauf hinweist, daB die Leistungsfähigkeit sowohl im Zuwachs an ökonomischer Dispositionskraft als auch in solchen Faktoren zum Ausdruck kommt, die den individuellen Bedarf bestimmen. - Wir weisen den Ausdruck der Dispositionskraft dem Zugangsbereich ökonomischer Größen zu, also dem Objektivierungsbereich, hingegen die Bedarfsfaktoren dem Verwendungsbereich; die Bedarfsfaktoren werden im Rahmen der PersonalisierungsmaBnahmen in Form von Abzugs- und Freibeträgen berücksichtigt.

26) Des weiteren gilt: analog ist im Vermögensbereich immer dann kein Zugang an Verfügbarkeit gegeben, wenn es sich lediglich um eine Vermögensumschichtung handelt; dem Zugang an Vermögen in der einen Form entspricht ein Abgang in der anderen. 
cher oder gliterlicher Form zugewendete Unterstützung bis zur (fiktiv nur $z u$ messenden) Höhe dieses Verlustes an Human-Vermögen kein (steuerlich belastbares) Einkommen oder Vermögen. Wenn andererseits eine Berechnung solcher Ausgleichszuwendungen wegen objektiver Unmöglichkeit scheitert, kann schon aus diesem Grunde eine Zurechnung von Einkommen nicht in Betracht kommen. Aus diesen Gründen also wird ein groBer Teil der als private und öffentliche Realtransfers in Ubersicht 3.2 (siehe $\$ 8$ ) aufgezählten zugangsquellen unter belastungspolitischem Aspekt nicht Einkommen sein können. Soweit diese Zugangsbeträge lediglich dazu dienen, die Existenz $\mathrm{zu}$ sichern und die - im Vergleich $\mathrm{zu}$ anderen Individuen "normale" - Ausgangslage wiederherzustellen, sind sie nicht Einkommen und Vermögen, sind sie kein Ausdruck der ökonomisch-finanziellen Dispositionskraft unter steuerlichem Gesichtspunkt. Bezüglich dieser zugänge besteht keine "freie " Verfügbarkeit.

b) Dieselben steuer- und belastungspolitischen Grundüberlegungen gelten für bestimmte Verwendungsarten der Verfügungsgrößen, soweit sie mit der Existenz- und Vorsorgesicherung zusammenhängen. Die steuerpolitische Zulassung bestimmter Abzugs- und Freibeträge im Rahmen der PersonalisierungsmaBnahmen basiert darauf, daB hinsichtlich dieser "Vorausverfügungen" über Einkommen entweder überhaupt kein oder ein sehr geringer Freiheitsgrad vorliegt: keine "freie" Disponibilität für die Aufwendungen zur Existenzsicherung der eigenen Person und der Abhängigen, stark verminderte Disponibilität für die Vorsorge-Aufwendungen und eine schon erhöhte Disponibilität für Aufwendungen aus rechtlichen und sittlichen verpflichtungen. 27) Im AusmaB dieser Vorausverfügungen ist Einkommen steuerlich nicht disponibel und kann demnach keine Leistungsfähigkeit indizieren; vorausverfügtes Einkommen ist nur "logisch" Ein-

27) Die Konsequenz aus diesen Grundüberlegungen wäre, die Einkommensverwendungen für die sog. "Sonderausgaben" und "auBergewöhnlichen Belastungen" neu zu organisieren und nach dem Grad der Verfügungsfreiheit $z u$ ordnen; in diesem Sinne würde man für den Existenzsicherungsbedarf einerseits und den sog. "Mehrbedarf" andererseits, der sowohl den Vorsorge- als auch den Verpflichtungsbedarf umfaBt, eine unterschiedlich hohe Abzugsfähigkeit konstruieren können bzw. eine Abzugsfähigkeit teils von der Steuerbemessungsbasis (so für den Existenzsicherungsbedarf, evtl. auch für den Vorsorgebedarf), teils von der Steuerschuld, um den Progressions-Entlastungseffekt $\mathrm{zu}$ vermeiden (so etwa für den Verpflichtungsbedarf, wie die Unterstützung von Parteien, Vereinen usw.); s. oben $\$ 15$. 
kommen, nicht steuerlich. ${ }^{28)}$ Die Besteuerung bestimmt, was politisch Einkommen sein soll; dadurch, daB sie auf die "freie" Verfügbarkeit abstellt, gibt die Steuerpolitik dem Einkommen einen realitätskongruenten und handlungskonformen Inhalt; "konform" bezogen auf das ziel einer Verwirklichung von ökonomischer Freiheit im Verbunde mit sozialer Sicherheit. Ein solcher Einkommensbegriff reflektiert die gesellschaftspolitischen Wertungen und enthält nun möglicherweise Zielwidersprüche und Unvereinbarkeiten, weil der gesellschaftliche KompromiB sich nicht nach den Kriterien der Logik richtet.

2. Die dem steuerlichen Totalitätsprinzip gemäBe VerfügungsgröBe läbt sich $m$ e $t h \circ d i s c h$ grundsätzlich a d d $i t i v$ oder $s$ u $b r a k t i v$ entwickeln. Ob man aber additiv oder subtraktiv vorgeht, in jedem Fall postuliert man als Bezugspunkt für die Berechnung des steuerlichen Einkommens eine Brutto-AusgangsgröBe. Diese ist das maximal individuell zurechenbare Einkommen, das zwar grundsätzlich besteuerbar ist, jedoch im zuge einer schrittweisen Verminderung zur tatsächlich besteuerten Bemessungsgrundlage durch eine Reihe bestimmter "Ausgrenzungen" und "Elngrenzungen"29) zunehmend verengt wird. Dafür werden die verschiedensten steuersystematischen wie auch allokations- und distributionspolitischen Motivationen angegeben. 30 !

Die additive Methode würde direkt von den Indikatoren ausgehen, die man unter dem steuer- und belastungspolitischen Aspekt mit der persönlichen Leistungsfähigkeit verbindet. Die Addition der Einkommenselemente zur Brutto-AusgangsgröBe verliefe dann etwa - in Anlehnung an N. Andel (1979a, S. 336 ff.) - wie folgt:

28) Das Phänomen des Zwangs erhält seine konsequente steuertechnische Ergänzung durch das Prüfungsverfahren: Die Verpflichtungen müssen als solche anerkannt werden.

29.) Zum Vergleich siehe das Konzept des AGI (= Adjusted Gross Income) bei Musgrave/Musgrave 1980 , S. 343 ff. mit seinen "exclusions" (capital gains, dividends, pensions, social insurances), die wir Ausgrenzungen nennen, und seinen "deductions", die wir zu den Abzügen der PersonalisierungsmaBnahmen zählen (Sonderausgaben, auBergewöhnliche Belastungen usw.).

Fußnote 30) auf der folgenden seite. 
Bruttoentgelte für Marktleistungen (nominale und naturale)

+ zugerechnete Einkünfte (imputed income)

+ Lohnersatzleistungen und Unterstützungszahlungen (Transfers)

+ Vermögenswertzuwächse (realisierte und nicht-realisierte)

+ Glücksspielgewinne

+ Erbschaften und Geschenke (sofern nicht in eigenen Steuerarten erfaBt).

Diese Vorgehensweise bringt es mit sich, daB bestimmte Einkommenselemente, die durchaus das theoretische Einkommenserfordernis erfüllen, jedoch unter politischem Aspekt nicht erfaBt werden sollen, in der maximalen BruttoausgangsgröBe gar nicht erst erscheinen.

3. Verfährt nan nun subtraktiv, liegt der Ausgangspunkt der Berechnung im wirtschaftstheoretischen Totaleinkommen nach der $\mathrm{Zu}$ gangsregel ( $\$$ ) und dem Gesamtverfügungskriterium ( $\$ 11$ ). Dieses Totaleinkommen ist in der subtraktiven Berechnungsweise bereits die Brutto-AusgangsgröBe für die Besteuerung. Von ihr aus gewinnt man im Zuge fortschreitender Einengungen schlieblich das steuerliche Einkommen. Stets ist dieses ein im Hinblick auf die Leistungsfähigkeit und Belastungsfähigkeit des einzelnen vermindertes wirtschaftstheoretisches Einkommen.

30) Diese Ein- und Ausgrenzungen von der ButtoausgangsgröBe weichen $a b$ von den "Abzügen" bei $N$. Andel und W. Albers. Andel (1979a, S. $355 \mathrm{ff.}$ u. $370 \mathrm{ff.l}$ nennt hier die "Berücksichtigung der Einkunfterzielungskosten", die wir dem beruflich-allokativen Bereich zugewiesen haben, und die "ausgabenbezogenen Abzüge", die wir zu den persönlich-distributiven rechnen. Albers (1979a, S. $202 \mathrm{ff.}$ ) entwickelt ein System der "Einengung der Steuerbemessungsgrundlage durch Abzüge", das aus "steuersystematischen", "sozialpolitisch motivierten" und "wirtschaftspolitisch motivierten" Abzügen besteht. Letztere würden wir, da sie der Wachstumsförderung, der Verbesserung der regionalen, sektoralen und wettbewerblichen Wirtschaftsstruktur sowie des effektiven Einsatzes der Produktionsfaktoren dienen sollen, dem Allokationsbereich zuordnen, ebenso wie manche der von Albers als "steuersystematische Abzüge" bezeichneten (wie Betriebsausgaben, Werbungskosten, Abschreibungen und auch Bewertungsfreiheiten im Rahmen der Aktivierungspflicht). Generell ist $\mathrm{zu}$ den sowohl seitens Andels als auch Albers' vorgestellten "Abzügen" zu sagen, daB sie sich teils auf allokative Vorgänge, teils auf PersonalisierungsmaBnahmen erstrekken und nicht auf den hier $z u$ prüfenden Einkommensbegriff. Diesen aber betrachten wir unter dem Aspekt der den Umfang festlegenden "Ein-" und "Ausgrenzungen". 
In der englischsprachigen Literatur wird das Problem der Brutto-Ausgangsgröße bei Rückgriff auf das "ability to pay principle" unter der Bezeichnung der "comprehensive tax base" 31) bzw. "comprehensive income tax" behandelt. 32) Zwei ihrer subtraktiven Verfahren werden im folgenden einander gegenübergestellt, nämlich einerseits das von der kanadischen Royal Commission on Taxation (Carter Report 1966) empfohlene Verfahren der "C $\circ \mathrm{m}$ p r e h e n s i ve T a $x$ B a s e" (СTB-Konzept), an das sich auch der Report des Meade Committee 1978 für GroBbritannien anschlieBt, andererseits das in den USA praktizierte Verfahren des "A d jus $t$ ed $\mathrm{g}$ r $\mathrm{s} s$ I $\mathrm{n} c \circ \mathrm{m}$ " (AGI-Konzept; Ubbers. 7.1).

Die Brutto-AusgangsgröBe im СТВ-Konzept entspricht mit ihrer Definition der "discretionary economic power" (Carter 1966, vol. 3, s. 5) noch am ehesten - auch in der Terminologie - jenem in $\$ 11$ entwickelten Verfügbarkeitskonzept für einen wirtschaftstheoretischen Einkommensbegriff. Als Vorläufer dieser steuerlichen Einkommens-TotalgröBe kann unschwer H.C. Simons erkannt werden, der den Gedanken des Reinvermögenszugangs von G. v. Schanz aufgreift. Der Unterschied zwischen Simons (übrigens auch R.M. Haig) und Schanz liegt in dem Erfordernis der Kapitalerhaltung: Während Schanz für den steuerlichen Einkommensbegriff die Notwendigkeit der Kapitalerhaltung postuliert, ${ }^{33)}$ rückt simons auch für den steuerlichen Einkommensbegriff von dieser Einschränkung ab. ${ }^{34)}$ Auch das Meade Committee (1978, S. 127) will "the accretion of economic spending power" besteuern, ohne daB diese "opportunities" durch Kapitaler-

31) Vollständigkeitshalber ist hier festzuhalten, daB auch für die Ausgabensteuerkonzepte das Erfordernis der "comprehensive tax base" gilt: D.F. Bradford 1980, S. $75 \mathrm{f}$.; die consumption ist hier so umfassend zu definieren, daB sie sowohl "cash purchases" als auch den Konsumstrom in seiner "imputed form" enthält, siehe Musgrave/Musgrave 1980, S. 244 u. 457.

32) Für die USA: R. Goode 1962, 1976, 1977 u. 1980; Musgrave/ Shoup 1966; Parker/Harcourt 1969; J.A. Pechman 1977 u. 1980; Musgrave/Musgrave 1980 (insbes. S. $234 \mathrm{ff}$ u. S. $345 \mathrm{ff.}$ ); Atkinson/Stiglitz 1980, S. 261 u. $566 \mathrm{f}$. und - als frühen Aus gangspunkt für die heutige Diskussion - R.M. Haig 1921 und H.C. Simons 1938 (unter Rückgriff auf G. v. Schanz 1896). Für Kanada: Carter Report 1966.

Für GroBbritannien: C.T. Sandford 1971a, 1971b; Meade Committee 1978 (dieser Report orientiert sich sehr stark am Carter Report, betont jedoch stärker als dieser die Probleme der Anpassung der Besteuerung an die Geldentwertung).

Fußnoten 33) und 34) auf der folgenden seite. 
Ubersicht 7.1: Subtraktive Berechnungskonzepte für das steuerliche Einkommen

A G I - Kon z e p $t$ ("Adjusted Gross Income")
C T B $-K \circ n z$ e $p t$ ("Comprehensive Tax Base")

1. B r u $t o-A u s g a n g s g r o ̈ B e$ :

"GROSS INCOME"

(total accretion to a person's wealth: net worth + comsumption)

"GROSS GAIN"

(a person's total discretionary economic power)

Summe der Zugänge aus allen Einkommensquellen, -arten und formen

2. . E 1 nkunftserzi e l ungskos ten: (Betriebsausgaben/Werbungskosten)

COSTS of EARNING INCOME (certain work-related expenses)
EXPENDITURES in the expectation of ACQUIRING A NET GAIN

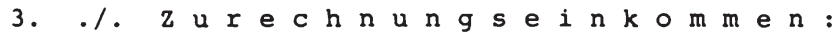

IMPUTED INCOME (sämtliche)
IMPUTED INCOME (sämtliche)

4. . n icht $r$ e a 1 is $i$ e $r t e$ $\mathrm{V}$ e $r \mathrm{~m}$ ö $\mathrm{g} n \mathrm{~s}$ e $r$ t $\mathrm{u}$ w ä $c h \mathrm{~s}$ :

UNREALIZED CAPITAL

GAINS

(sämtliche)
UNREALIZED CAPITAL GAINS (sämtliche; jedoch: constructive realization"
5. .1. B e f r e i u n g e n :

\section{EXCLUSIONS}

(certain forms of cash income: Interst, dividends, pensions, social insurance, life insurance)

\section{EXCLUSIONS}

(äuBerst wenige, auslaufend)

6. $=N$ e $t$ to-Endgr öB e der 0 b jek $t i-$ $v i$ e $u$ n $g$ :

N E T I N C O M E $=A G I=$ "cash income concept"
$N$ E $T$ G I N = "reformulated and modified CTBconcept"

Nachrichtlich: a) "net income" bzw. "net gain" definiert in nominal terms (Nominalwertprinzip)

b) Verlustausgleich ist anzuwenden 
haltungsregeln eingeschränkt werden sollten. ${ }^{35)}$ Der Carter Report (1966, S. 54) formuliert als Ausgangspunkt der CTB den GesamtReinvermögenszugang à la simons (= konsumierter und nicht konsumierter Vermögenszugang), stellt ausdrücklich auf die Verfügbarkeit $a b, 36)$ definiert dann unter dem postulat der "ability to pay" die Notwendigkeit, die CTB umzuformulieren und zu modifizieren, um den "net gain" als Ausdruck einer freien ${ }^{37)}$ Verfügbarkeit $\mathrm{zu}$ erhalten.

Auch der Ausgangspunkt des AGI-Konzepts mit seiner "total accretion" ist auf das Schanz-Haig-Simons-Konzept gegründet ${ }^{38)}$ und gleich weit gefaBt wie das СТВ-Konzept. Als ein "cash income concept" ist auch dieses letztlich auf die freie Verfügbarkeit, die die Grundlage der Besteuerung sein soll, ausgerichtet. Beide Konzepte sind als Versuch $z u$ werten, eine breit gefaßte Ausgangsbasis, die (1) alle zugangsquellen, (2) alle monetären und güterlichen Zugangsarten und (3) alle periodischen und aperiodischen Zugangsweisen umschließt, durch eine schrittweise verengung der Basis in Form von Abzügen (1) für Aufwendungen und (2) für Zugangselemente zu überfüh-

33) G. v. Schanz 1896, S. 5: Die Person solle ihre Dispositionen über finanzielle Mittel treffen, "ohne daB sie ihr eigenes Vermögen verzehrt oder fremde Mittel (Schulden) hinzunimmt" .

34) Simons 1938, S. 50: "Personal income may be defined as the algebraic sum of (1) the market value of rights exercised in consumption and (2) the change in the value of the store of property rights between the beginning and the end of the period in question."

35) Wenngleich das Meade Committee ausdrücklich auf die Funktion eines perfekten Kapitalmarktes eingeht und den EinfluB der Inflation auf die Bewertung des Kapitals und Vermögens herausstellt.

36) 1966, S. 5: Die "discretionary economic power" ist "the product of the tax unit's $t \circ t$ a 1 economic power and the fraction of the total economic power $a v a i l a b l e$ for discretionary use of the unit"; Hervorhebungen HDH. "Total economic power" wird dann definiert als "the power to command goods and services for the personal use (also nicht nur für den Konsum!), wether the power is e $x$ e r c i s e d or not." Hervorhebung HDH. Siehe auch S. 22 f. und 35.

37) Die freie Verfügbarkeit folgt aus der Definition auf S. 32 : "... total power... less the power $n$ e $c$ e s $s$ a $r i$ y exercised to maintain the appropriate standard of living of the unit relative to other units." Hervorhebung $\mathrm{HDH}$.

38) Musgrave/Musgrave 1980, s. 243 ff., s. 336. - Atkinson/ Stiglitz 1980, S. 261 u. 566 f. 
ren in die Besteuerungsgröße der $f r$ e $i$ e $n$ Verfügbarkeit. Diese Besteuerungsgröße ist das " $\mathrm{N}$ e $t$ I n c o m e " bzw. der " $\mathrm{N}$ e $\mathrm{t}$ a $\mathrm{i} \mathrm{n} "$.

Bei identischen Brutto- Ausgangsgrößen ergibt der Vergleich, daß zwar erstens beide verfahren (AGI und CTB) in den ersten drei verminderungsschritten dieser Bruttoausgangsgröße ein nahezu identisches Vorgehen kennen, daB aber zweitens die Inhalte der NettoEndgröße beider Verfahrensweisen, die Leistungsfähigkeit $\mathrm{zu}$ objektivieren und zu konkretisieren, sich hauptsächlich in den Befreiungen (Exclusions) unterscheiden. Während das AGI-Konzept eine stattliche Anzahl von Befreiungstatbeständen nennt (ähnlich wie das im deutschen steuerrecht der Fall ist), läBt das CTB-Konzept nur äuBerst wenige $z u$, die auBerdem nach einer Ubergangsfrist auslaufen sollen. Das Unerwartete an diesem Vergleich eines theoretisch konzipierten mit einem praktizierten Verfahren liegt darin, daß sie weder in den "Einkunftserzielungskosten" ("costs of earning income" bzw. "expenditures in the expectation of acquiring a net gain") noch den Zurechnungseinkommen ("imputed income") und nicht-realisierten vermögenswertzuwächsen ("unrealized capital gains") große Unterschiede - wenn uberhaupt irgendwelche - aufweisen. ${ }^{39)}$

Per saldo aber kommen sie wegen ihrer Abzüge für die Zurechnungseinkommen und nicht realisierten vermögenswertzuwächse zu doch erheblichen Abwelchungen vom wirtschaftstheoretischen Verfügungskonzept.

39) Der einzige Unterschied liegt bei den "unrealized capital gains", die der Carter-Vorschlag anläBlich des Todes, der Schenkung und der Emigration als eine "constructive realization" besteuern will, vol.3, S. 51. Eine ähnliche Denkweise kann man in der deutschen Erbschaftsteuerregelung für bestimmte Stiftungen und Vereine erblicken, die alle 30 Jahre besteuert werden, gleichsam als Folge eines "fiktiven Erbgangs". Dieses Vorgehen schlägt A. Oberhauser (1980, S. 673) auch für die Erfassung der nichtrealisierten Bodenwertzuwächse vor, u.a. auch, um die Sperreffekte zu mildern: "hypothetische Realisierung". - Siehe auch N. Andel 1979a, S. 349. - Ebenso das Meade committee (1978, S. 129) befürwortet eine "deemed realization" on occasion of gift, death or emigration. 
4. Ausgehend von derselben breiten Basis der СТВ soll nunmehr die freie Verfügbarkeit in einer $s y s t e m$ a $t i k$ (tbersicht 7.2) präsentiert werden, die nicht wie die oben geschilderte das Erreichen der objektivierten Besteuerungsgrundlage als eine Abfolge von Abzugsvorgängen darstellt, sondern die erstens den Inhalt der freien Verfügbarkeit sowohl des Einkommens als auch des Vermögens simultan ausweist und zweitens eine Einteilung bietet, die zunächst die $p \circ I i t i s c h$ bestimmte Verfügbarkeit, danach die $r$ a $t i \circ \mathrm{n}$ a $l$ bestimmte Verfügbarkeit über Einkommen und Vermögen abbildet. Dies wird erreicht durch den getrennten Ausweis eines Katalogs von $A$ u $s$ r e $n z$ u $g s t$ a $t$ b e $t a ̈ n d$ e $n$ und eines Katalogs von $E$ i $n g$ e $n z u n g t$ a $t$ b e $s$ t ä $n-$ d e $n$. Die Ausgrenzungen beziehen sich $z$ unächst auf solche Verfügungselemente, die man unter steuersystematischem Aspekt von Sondersteuern erfassen lassen will, daneben auf das system der Zugangselemente des produktionswirtschaftlichen, vermögeneinschlieBenden und transfereinschlieBenden Einkommens. Mit Hilfe der Ausgrenzungen aus dem theoretisch möglichen Gesamtumfang der Verfügbarkeit sollen also alle jene Verfügungselemente ausgeschieden werden, die man unter steuersystematischem wie auch steuerpolitischem Aspekt gar nicht erst gewillt ist, als "matière imposable", als Besteuerungsgut in Erscheinung treten $\mathrm{zu}$ lassen. Demnach vollziehen sich die politischen "Begriffs-Entscheldungen" über steuerliches Einkommen und Vermögen wie folgt:

- Entscheidung, den Vermögensbestand mit der Vermögensteuer, den Vermögenszugang mit der Erbschaft- und Schenkungsteuer zu erfassen;

- Entscheidung, nicht alle Elemente des produktionswirtschaftlichen Einkommensbegriffs, wie bestimmte Markteinkommen und $\mathrm{Zu}-$ rechnungseinkommen (z.B. betriebl. Naturalentlohnungen) mit der Einkommensteuer zu erfassen (\$ 22 I);

- Entscheidung, nicht alle Elemente des vermögeneinschlieBenden Einkommensbegriffs, wie bestimmte Vermögensnutzungen und realisierte bzw. nicht realisierte Vermögenswertsteigerungen, mit der Einkommensteuer $z u$ erfassen (\$ 22 II);

- Entscheidung, nicht alle Elemente des transfereinschlieBenden Einkommensbegriffs, wie bestimmte Sozialversicherungsrenten und private Realtransfers, mit der Einkommensteuer zu erfassen (\$ 22 III).

Durch die Auswahl unter den Zugangsarten sowie durch ein ganzes Bündel von "objektiven Befreiungen" erfährt somit der "quellenun- 
Ubersicht 7.2: System einer fortschreitenden Einengung der freien Verfügbarkeit über Einkommen und Vermögen

I. Brutto-Ausgangsgröße:

Gesamtverfügbarkeit über "Einkommens-Zugang + Vermögens-Bestand"

II. I. A u s g $r$ e $n z$ u g e $n$ :

1. steuersystematische Ausgrenzung von Tatbeständen, für die Sondersteuern erhoben werden

a) Bestand an Vermögen

b) Zugang an Vermōgen aus Erbschaften und Schenkungen

2. Ausgrenzungen aus dem Vermögen

c) Teilausgrenzungen durch Freibeträge und Freigrenzen

d) Gesamtausgrenzungen durch Befreiungen

3. Ausgrenzungen aus dem produktionswirtschaftlichen Einkommensbegriff

e) geldiche Faktorentlohnung

f) güterliche (naturale) Faktorentlohnung

4. Ausgrenzungen aus dem vermōgenseinschließenden Einkommensbegriff

g) Geldvermögen (realisierte Vermögenswertzuwächse als VerãuBerungserlōse; "realized capital gains")

h) Sachvermögen (nichtrealisierte Vermögenswertzuwächse, c.g.; Zurechnungseinkommen durch Vermögensnutzung, "imputed income")

5. Ausgrenzungen aus dem transfereinschlieBenden Einkommensbegriff

i) monetäre Individualtransfers

j) monetäre Kollektivtransfers

k) monetäre offentliche Transfers

1) private Realtransfers

m) offentliche Realtransfers

III. = ZwischengrōBe der steuerlichen Verfügbarkeit

IV.. . E i n g e n z u n e n :

6. Eingrenzung auf das verfügbare Geld- und Sachvermögen: Eliminierung des Humanvermögens

7. Eingrenzung auf das verfügbare Netto-Einkommen: Innerperiodischer Verlustausgleich

8. Eingrenzung auf das verfügbare Netto-Vermögen: Schuldenabzug vom Rohvermögen

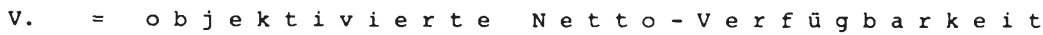
in Nominalwerten vor der Anwendung der PersonalisierungsmaBnahmen (persōnliche Abzüge und Freibetrãge) 
abhängige" und "zugangsoffene" wirtschaftstheoretische Verfügungsbereich seine erste deutliche Einschränkung. Die so definierte Verfügungs-Zwischengröße ist die Basis für die "Eingrenzungen" auf den personalen Verfügungsbereich; ihre Bestimmung ist der erste schritt in der steuerpolitisch motivierten Verengung des Totalitätsprinzips mit Blick auf das, was $k$ o $\mathrm{k} r$ e $t$ unter der Leistungsfähigkeit verstanden werden soll.

Der folgende Schritt der "Eingrenzungen" besteht in der Herstellung einer VerfügungsgröBe, deren Umfang nunmehr ökonomisch begründet wird, und auf die die weiteren "sozialpolitisch" bzw. belastungspolitisch motivierten "Abzüge" aller Personalisierungsmaßnahmen angewendet werden kann. Die Eingrenzungen auf den personalen Verfügungsbereich folgen der Vorstellung einer "freien" Verfügbarkeit über ökonomische GröBen insoweit rational, als

- nicht verfügbare und rechenbar zu machende GröBen aus dem Verfügungsumfang auszuscheiden sind; dies führt im Vermögensbereich zur Eliminierung des Humanvermögens (\$ 23 II);

- Verluste im Einkommensbereich nicht nur keine Verfügbarkeit indizieren, sondern die Summe der verfügbaren Zugänge schmälern; dies führt $\mathrm{zum}$ (innerperiodischen) horizontalen und vertikalen Verlustausgleich (\$23 I);

- Schulden im Vermögensbereich aus denselben Gründen die Verfügbarkeit einengen; dies führt zum Schuldenabzug (\$23 III).

Die "freie" Verfügbarkeit wird solchermaBen auf den Umfang einer wertmäBig konkretisierten und finanziell saldierten Verfügbarkeit eingegrenzt. Sie ist vorerst in Nominalwerten ausgedrückt; inwieweit die freie Verfügbarkeit jedoch durch die Anwendung des Realwertprinzips inhaltlich korrekt beschrieben werden kann, wird erst in $\$ 24$ problematisiert. Die Darstellung der subjektiven Verfügbarkeit als AusfluB der PersonalisierungsmaBnahmen gehört nicht mehr in den hier gewählten Untersuchungsrahmen.

IV. Im $d e u t s c h e n$ E $e^{n} k \circ m m e n s t e u e r-$ $r$ e $c h t$ ist nicht ein Totaleinkommensbegriff verwirklicht, der dem wirtschaftstheoretisch umfassenden entspräche. Die 
theoretische "Zugangsregel" und das Theorie-Kriterium der "Verfügbarkeit" (siehe $\$ 11$ ) sind steuerlich nicht verwirklicht.

1. In welcher Weise statt dessen der personale Verfügungsbereich teils durch "stumme" Nichterfassung, teils durch ausgesprochene Befreiungen politisch bestimmt ist, zeigt ein Blick auf den Katalog der "objektiven Befreiungen" nach dem $E \mathrm{i} n \mathrm{k} \circ \mathrm{m}$ e $\mathrm{n}-$ s t e u e r e c h t (vgl. auch F. Neumark 1970, s. 95 f.).

a) Allein schon der enge produktionswirtschaftliche Einkommensbegriff ist in den steuerlichen nur mit beträchtlichen Lücken übernommen worden. Die folgenden Tatbestände im distributiven Bereich - vgl. hierzu die Gruppierung in Ubersicht 3.2 - werden nicht besteuert

(1) im Bereich der geldlichen Faktorentlohnung:

- bestimmte Einnahmen aus dem Arbeitsverhältnis (gem. § 3 Nrn. ....EStG), wie Abfindungen (9.), Ubergangsgelder (10.), Heirats - und Geburtsbeihilfen (15.), Bergmannsprämien (46.), Trinkgelder (51.), besondere Zuwendungen (52.), Zahlungen aus Stillegungs- und RationalisierungsmaBnahmen (60.), Arbeitgeberanteile zu den Sozialversicherungsbeiträgen (62.), Lohnzuschläge für Sonntags-, Feiertags- und Nachtarbeit ( $\S 3$ b ESG) und die Bezüge der Diplomaten (§ $3 \mathrm{Nr} .29$ EStG);

- bestimmte Zinseinnahmen (\$ 3 Nrn. 21, 54);

(2) im Bereich der naturalen Faktorentlohnung:

- Geldwert der Dienstkleidung der Bundeswehr und des Bundesgrenzschutzes, der Polizei, Feuerwehr und Kriminalpolizei (§ $3 \mathrm{Nr} .4 \mathrm{a}$ EStG);

- Geldwert der freien ärztlichen Behandlung, Krankenhauspflege sowie Kur- und Heilmittel der 0.g. Personen, ihrer Ehefrauen und unterhaltsberechtigten Kinder ( $\$ 3 \mathrm{Nr} .4 \mathrm{~d}$ EStG);

- Geldwert der Werkswohnungen, soweit die Differenz zur tatsächlichen Miete unter DM 40 liegt;

- Geldwert der Mahlzeiten im Betrieb, soweit er unter DM 1,50 täglich liegt;

- bestimmte geldwerte Leistungen werden steuerlich nicht als Einkommen erkannt, wie betriebliche Kultur-, Sport-, Ausbildungs- und Gesundheitsleistungen, und somit auch nicht "befreit". 
b) Aber auch der vermögeneinschlieBende Einkommensbegriff hat steuerlich nicht vollständig Geltung gewonnen, da nicht sämtliche Zugänge in Form von Nutzung bzw. Aufzehrung des Geld- und Sachvermögens Einkommensqualität erhalten. So werden z.B. nicht als Einkommen erfaBt

(1) im Bereich des Geldvermögens:

- der Glücksgewinn,

- der Erbanfall,

- bestimmte Geldzugänge aus realisierten Wertzuwächsen, z.B. aus GrundstücksveräuBerungserlösen jenseits der 2-Jahresgrenze und aus WertpapierveräuBerungserlösen jenseits der 6-Monatsgrenze;

- bestimmte VeräuBerungserlöse (Freibetrag von 20.000 DM für die VeräuBerung der Anteile an einer Kapitalgesellschaft, $\S 17$ III EStG;

(2) Im Bereich des Sachvermögens:

- die geldwerte Nutzung der Vermögensgegenstände mit Ausnahme des Wohnens im eigenen Haus;

- die geldwerte Nutzung aus einem nicht realisierten Vermögenswertzuwachs wie etwa eine gestiegene Beleihungsgrenze von Grundstücken und Wertpapieren;

- der nicht realisierte Vermögenswertzuwachs selbst, insbesondere der bei Grundstücken (mit Ausnahme der Kurswertsteigerung bei Wertpapieren, die zum Jahresende allerdings im Rahmen der Vermögensbestandsbesteuerung erfaBt wird);

- der Erbanfall.

c) Vollends der transfereinschlieBende Einkommensbegriff ist steuerlich nahezu ohne Anerkennung geblieben, sieht man einmal von der grundsätzlichen Besteuerung der wiederkehrenden Bezüge (Unterhaltsbezüge, Renten, Beamtenpensionen, freiwillige Zuwendungen sowie der realen Wohnrechte und Altenteile, \$ 22 EStG) ab. So werden z.B. nicht als Einkommen erfaßt

(1) im Bereich der privaten monetären Individual-Transfers:

- Stipendien ( $\$ 3$ Nrn. 42/44;); Ausgaben des Arbeitgebers für die Zukunftssicherung des Arbeitnehmers (Nr. 62.);

- Unterstützungen privater Art, die z.B. in den Bereich der Unterhaltszahlungen nach $\S 33$ a EStG fallen und eine bestimmte Höhe nicht errelchen;

(2) im Bereich der privaten und gesetzlichen monetären KollektivTransfers :

- Leistungen aus der Kranken-, Unfall- und Rentenversicherung (§ 3 Nrn. 1a u. 1c EStG);

- Mutterschaftsgeld (\$3. Nr. 1d EStG):

Heinz Hessler and Anneliese Hessler-Ótte - 978-3-631-75239-5 
- Arbeitslosen-, Kurzarbeiter- und Schlechtwettergeld (§ $3 \mathrm{Nr} .2$ EStG);

- Kapitalabfindungen aus der Rentenversicherung ( $\$ 3 \mathrm{Nr} .3$ EStG) ;

(3) im Bereich der monetären öffentlichen Transfers:

- Arbeitslosenhilfe, Leistungen nach dem Arbeltsförderungsgesetz ( $\$ 3 \mathrm{Nr} .2$ EStG) ;

- Leistungen an Wehrdienst-, Zivildienst- und Kriegsbeschädigte und deren Hinterbliebene ( $\$ 3 \mathrm{Nr} .6$ EStG);

- öffentliche Stipendien ( $\$ 3 \mathrm{Nr} .44$ EStG);

- Leistungen nach dem Lastenausgleichsgesetz (§ $3 \mathrm{Nr} .7$ EStG), Wiedergutmachungs leistungen ( $\$ 3 \mathrm{Nr}$. 8 EStG), Kriegsgefangenenentschädigungen ( $\$ 3 \mathrm{Nr} .19 \mathrm{EStG})$;

- Kindergeld ( $\$ 3 \mathrm{Nr} .24$ EStG), Leistungen nach den Unterhaltssicherungsgesetz ( $\$ 3 \mathrm{Nr} .48 \mathrm{EStG}$ ), Wohngeld ( $\$ 3 \mathrm{Nr}$. 58 EStG), Leistungen nach dem Entwicklungshelfergesetz ( $\S 3 \mathrm{Nr} .61 \mathrm{EStG})$; Mutterschaftsgeld ( $3 \mathrm{Nr} .1 \mathrm{~d}$ EStG) ;

(4) im Bereich der privaten Realtransfers:

- Vorteile aus der gemeinsamen Haushaltsführung und kleine Geschenke werden nicht erfaBt;

- Vorteile aus privater Erziehung, Unterrichtung, Krankenpflege und Nachbarschaftshilfe werden nicht erfaßt;

(5) im Bereich der öffentlichen Realtransfers:

- Sachleistungen aus der gesetzlichen Rentenversicherung sind steuerfrei ( $\S 3 \mathrm{Nr}$. 1b EStG);

- die Vorteile aus Sozialhilfen, Kurverfahren, Erholungsurlauben, Transporten, Heimunterbringung usw. werden nicht erfaBt.

2. Auch in der $v$ e $r \mathrm{~m}$ ög e $\mathrm{n} s$ b e $\mathrm{s} t$ e u e $r u n g$, in der nach dem Allgemeinheitspostulat alle Vermögensarten, -teile und -erwerbe $z u$ erfassen sind, verengt ein Katalog von objektiven Befreiungen den personalen Verfügungsbereich. Um in den Umfang der Ausgrenzungen nur solche Tatbestände aufzunehmen, die den personalen Vermögensbegriff berühren, sind Abgrenzung vonnöten; diese betreffen solche des privaten Vermögens gegenüber dem betrieblichen, solche der objektiven Befreiungen und vermögensartbezogenen Freibeträge gegenüber den PersonalisierungsmaBnahmen und die Abgrenzung der natürlichen Personen gegenüber bestimmten anderen steuersubjekten. 
a) Ausgrenzungen aus dem Vermögensumfang des Betriebsvermögens gehören nicht zum Untersuchungsgegenstand, da sie in den allokativen Bereich fallen.

b) Demgegenüber fallen die persönlichen Freibeträge ( $\$ 6$ VStG und $\S \S 16,17$ ErbStG) zwar in den distributiven Bereich, gehören aber $\mathrm{zu}$ den PersonalisierungsmaBnahmen und haben somit keine Auswirkung auf den Vermögensbegriff.

c) Das Vermögensteuergesetz kennt im Gegensatz zum Einkommen- und zum Erbschaftsteuergesetz subjektive Steuerbefreiungen, so daB auch die Vermögensgegenstände dieser befreiten Steuersubjekte nicht zum steuerlichen Vermögen zählen können. Die Befreiungsgründe nach $\S 3$ VStG sind aber weder distributionspolitisch motiviert noch haben sie Auswirkungen auf den persönlichen Vermögensbegriff.

d) Somit gehört zum Untersuchungsgegenstand ausschlieBlich jenes Privatvermögen, das - sei es Bestand oder Erwerb - im Steuerrecht als das "sonstige Vermögen" ( $\$ 18$ BewG) bezeichnet wird. Doch gibt es Vorschriften, die zwar den Vermögensumfang einengen, die ihren Grund jedoch in steuertechnischen Vereinfachungsabsichten, nicht in allokations- oder distributionspolitischen Motiven haben dürften. ${ }^{40)}$ Mit allen diesen Abrundungen und Freibeträgen sind und werden z.T. auch technische Erfassungsprobleme umgangen.

e) Die folgenden Ausschlüsse sind unter dem Aspekt des Totalitätsprinzips nunmehr als echte Lücken in der Erfassung des personalen Vermögens anzusehen:

(1) Teilausschlüsse durch Einrichten von Freibeträgen und Freigrenzen (nach $\S 110$ I und II BewG bzw. \$13 ErbStG): 41)

- Freibetrag von 10.000 DM für den Wert der Kapitalforderungen jeder Art; der Spareinlagen, Bankguthaben und Zahlungsmittel; der Aktien oder Anteilsscheine, Kuxe, Geschäftsanteile, Gesellschaftseinlagen und Guthaben bei Genossenschaften; die Inhaber dieser Vermögensbestände dürfen nicht Unternehmer sein;

40) Hierher gehören Abrundungen von Geldbeträgen, Freigrenzen für Schmuckgegenstände, kleinere Geldvermögen und bestimmte Erwerbsvorgänge minderer Bedeutung.

41) Die Teilbefreiung für Werte, deren Erhaltung im öffentlichen Interesse liegt, wird nicht zu den Ausschlüssen aus dem persönlichen Vermögen gezählt. 
- Freibetrag von 10.000 DM für Lebens-, Kapital- und Rentenversicherungen (nicht Versicherungen aus dem Arbeits-oder Dienstverhältnis u.a.);

- Freibetrag von 4800 DM für Ansprüche auf Renten aus wiederkehrenden Nutzungen oder Leistungen (§ $111 \mathrm{Nr}$. 9 BewG);

- Freibeträge nach ErbStg für Hausrat von 40.000 bis 10.000 DM je nach Verwandtschaftsgrad;

- Freigrenze 1t. VStG in Höhe von 20.000 DM für Kunstgegenstände und Sammlungen, Freibeträge von 40.000 bis 10.000 DM nach ErbStG je nach Verwandtschaftsgrad;

- Freigrenze von 10.000 DM für Wirtschaftsgüter der land- und forstwirtschaftlichen und gewerblichen Betriebe, sofern sie auBer Funktion sind;

- Freigrenze von 10.000 DM für Wirtschaftsgüter in ständig vermieteten möblierten Wohnungen;

- Freigrenze von 10.000 DM für Schmuck- und Edelmetallgegenstände und bestimmte Luxusgegenstände.

(2) Gesamtausschlüsse (j 111 BewG), die jedoch in den meisten Fällen kein beleih- und veräußerbares Vermögen darstellen:

- Ansprüche an Witwen-, Waisen- und Pensionskassen sowie Ansprüche auf Renten aus früheren Arbeits- und Dienstverhältnissen; ferner Rentenversicherungen, die mit Rücksicht auf ein Arbeits- oder Dienstverhältnis abgeschlossen worden sind und solche, bei denen die Ansprüche erst fällig werden, wenn der Berechtigte das 60 . Lebensjahr vollendet hat oder erwerbsunfähig ist (§ 110 I Nr. 6 a u. b BewG);

- Ansprüche aus der Sozial-, Arbeitslosen- und einer Krankenund Unfallversicherung;

- fällige Ansprüche auf Renten aus Rentenversicherungen, wenn der versicherungsnehmer das 60 . Lebensjahr vollendet hat oder voraussichtlich für mindestens drei Jahre erwerbsunfähig ist;

- Ansprüche auf gesetzliche Versorgungsbezüge;

- weitere Ansprüche (aus dem Lastenausgleich, dem Kriegsfolgengesetz, den Entschädigungsgesetzen und Wiedergutmachungsgesetzen (VStG und ErbStG);

- Ansprüche auf Renten aus der Unterhaltspflicht, aus Entschädigungen usw.

(3) Gesamtausschlüsse verfügbaren Vermögens ( $§ 111$ EewG, \} 1 3 ErbStG):

- Ansprüche auf Kapitalabfindung;

- der gesamte Hausrat nach VStG;

- Erfindungen und Urheberrechte, soweit es sich um eigene Erfindungen, Ansprüche auf Vergütungen für eigene Diensterfindungen und eigene Urheberrechte sowie Originale urheberrechtlich geschützter Werke handelt;

- Grundbesitz, Kunstgegenstände und Sammlungen, sofern die Erhaltung im öffentlichen Interesse liegt und der Denkmalspflege unterstellt werden bzw. sofern sie der Allgemeinheit z ugäng li chlegemalebslewerdemneriash Hesblst-Qtte - 978-3-631-75239-5 
- Schuldbefreiung sowie Zuwendungen unter Lebenden aus Gründen des Unterhalts oder der Ausbildung, ErbstG;

- zuwendungen an bestehende Gesellschaften und Gemeinschaften, ErbStG;

- Vermögenserwerb durch Gebrechliche lohne nennenswertes eigenes Vermögen) in bestimmten Grenzen, ErbStG.

3. Die $k r i t i s c h e$ w ü $r$ d $i g u n g$ der Lücken in der Einkommens - und in der Vermögensbesteuerung offenbart $z$ unächst ein gewisses uni sono und Schwergewicht der Steuerschonung in den Tra n $\mathrm{s}$ e r s (s. Ubersicht 7.3: c), und hier insbesondere im Berelch der öffentlichen Transfers: Sozialtransfers und Versicherungs leistungen werden elnkommensteuerlich ebensowenig erfaBt wie vermögensteuerlich die Ansprüche auf gesetzliche Renten und Versorgungsbezüge. Ein ähnliches Gewicht hat die steuerliche Schonung im Bereich der privaten Transfers; hier werden einkommensteuerlich die zugänge in Form von Unterstützungs - und Versicherungsleistungen nicht erfaBt, hier bestehen vermögensteuerlich Freibeträge für private Lebens-, Kapital- und Rentenversicherungen. AuBerdem existiert im Bereich der "privaten Transfers qua Erbschaften" eine Reihe von unterhaltsorientierten Vermögenserwerben, die steuerbefreit ist. Im Transferbereich ist also das Allgemeinheitspostulat auBerordentlich stark durchbrochen.

Geringere Bedeutung ${ }^{42}$ für die Verletzung des Totalitätsprinzips dürften dagegen die Erfassungslücken im $\mathrm{V}$ e $\mathrm{m}$ ö $\mathrm{g}$ e $\mathrm{n}$ haben (Ubersicht 7.3: b); hier bestehen sie insbesondere in der Einkommensbesteuerung: die Glücksgewinne und die nicht realisierten Vermögenswertsteigerungen werden überhaupt nicht, die VeräuBerungserlöse nur in Grenzen erfaBt. Allerdings hängen die Lücken in diesem Bereich mit steuersystematischen "Vorwegentscheldungen" zusammen, da die Vermögenszugänge qua Erbschaft und Schenkung von einer eigenen steuer erfabt werden, bestimmte Vermögenswertzuwächse von der Vermögensteuer. Soweit aber die Vermögensteuer eine Bestandssteuer ist, wird möglicherweise die Nichterfassung des Hausrats eine bedeutende Lücke darstellen. Wie ubberhaupt gerade hier im Vermögensbereich begriffstheoretisch die ansonsten

42) N. Andel (1979a, S. 346) weist die hohe quantitative Bedeutung nicht insgesamt für die "Erhöhung des Wertes von Vermögensteilen", sondern nur für die "Kapitalgewinne" nach. 
Ubersicht 7.3: Nichterfassung wesentlicher Zugänge und Bestände an ökonomischen GröBen im deutschen Steuerrecht

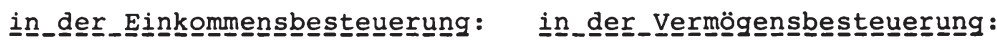

a) produktionswirtschaftlicher Bereich

- Sozialversicherungsanteile der Arbeitgeber

- bestimmte Lohnanteile und -zuschläge

- Zins- u. Pachteinnahmen u. VeräuBerungserlöse

b) Vermögensbereich

- Glücksgewinne

- Vermögensveräußerungserlöse jenseits bestimmter Fristen

- nicht realisierte Vermögenswertsteigerungen

c) Transferbereich

- private Unterstützungen

- private Versicherungsleistungen

- öffentliche reale und monetäre Sozialtransfers

- reale und monetäre Transfers der Sozialversicherungen
- Freibeträge für Kapitalforderungen $u$. Wertpapiere (VSt)

- FB für Wirtschaftsgüter in möblierten Wohnungen (VSt)

- eigene Erfindungen und Urheberrechte (VSt)

- Freibeträge für Kunstgegenstände, Luxusgegenstände, Schmuck u. Edelmetallgegenstände (VSt und Erbst)

- Hausrat (nach VSt völlig frei, nach Erbst in Grenzen)

- Freibeträge für private Versicherungen (VSt)

- Freibeträge für Renten und wiederkehrende Leistungen (VSt)

- Ansprüche auf gesetzliche Renten und Versorgungsbezüge (VSt) + )

- Ansprüche aus best. Entschädigungsgesetzen (ErbSt) + )

- Erwerb von Vermögen durch Gebrechliche in best. Grenzen und ohne großes eigenes Vermögen (ErbSt)

- Schuldbefreiung sowie Zuwendungen aus Gründen des Unterhalts oder der Ausbildung (Erbst)

- Zuwendungen an best. Gesellschaften und Gemeinschaften (Erbst)

+ Ein Anspruch ist nicht in jedem Fall ein verfügbares Vermögen. 
als modern geltende "Reinvermögenszugangstheorie" sich am allerwenigsten durchsetzen konnte, was die private sphäre angeht.

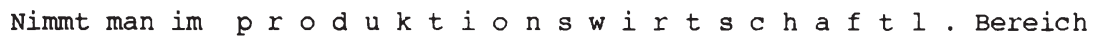
7.3 a zunächst die Nichterfassung der sozialversicherungsanteile aus, so bestehen wesentliche Erfassungslücken in der Einkommensteuerfreiheit für bestimmte private $\mathrm{Zins-}$ und Pachteinnahmen sowie für private VeräuBerungserlöse, nicht zuletzt auch für bestimmte Naturalentlohnungsformen. Vermögensteuerliche Lücken sind in den Freibeträgen für Kapitalforderungen und Wertpapiere zu sehen.

Die Sozialversicherungsanteile der Arbeitgeber werfen ein besonderes Problem insofern auf, als man sie wie einen Lohn, der nicht ausgezahlt wurde, ansehen kann. Nur in diesem Falle wäre ihre Nichterfassung ein Versto $B$ gegen das Totalitätsprinzip in der Einkommensbesteuerung. ${ }^{43}$ )

Vorausgesetzt, daB die steuertechnische Erfassungsmöglichkeit und die Erfassungskosten nicht entgegenstehen, sind Nichterfassung und Befreiungen grundsätzlich VerstöBe gegen das Allgemeinheitspostulat und gegen die mit ihm beabsichtigte Normierung des Totalbegriffes in der Einkommens- und Vermögensbesteuerung. Das Ideal einer "comprehensive tax base", das jenseits der wirtschaftstheoretischen Analysen gerade auch als steuertheoretische Vorstellung formuliert wurde, hat sich bisher nicht durchsetzen lassen. Die steuerpolitische Entscheidung für die Ausgrenzung der o.g. Zugangselemente ist dahingehend $\mathrm{zu}$ interpretieren, da $B$ im Bereich der Faktorentlohnung die allokationspolitischen Motive (mit ihren distributiven Effekten selbstverständlich) überwiegen, daB im Vermögensbereich teils steuersystematische und steuerrechtliche Gründe, teils steuertechnische Erfordernisse ausschlaggebend sind und $\mathrm{da} B$ im Transferbereich des Einkommens die distributionspolitischen Absichten vorherrschen.

Die VerstöBe gegen das Allgemeinheitspostulat gelten als nicht zielkonform, weil eine nicht zustande gebrachte "comprehensive tax base" die fiskalische Basis für verteilungs- und umverteilungspolitische Maßnahmen schmälert, und zwar durch die "tax erosion" 44) und die dadurch möglich gewordene Umgehung der Pro-

43) diese Steuerbefreiung ist als Personalisierungsmaßnahme für die Einkommensbegriffsbestimmung ohne Bedeutung

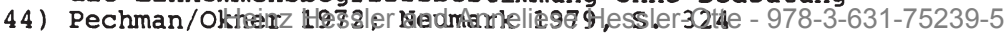


gression. Eine solche Schmälerung der Steuerbasis ist das Ergebnis gesellschaftspolitischer Entscheidungen. Mit ihren Auswirkungen auf die Höhe des Grenzsteuersatzes und den Verlauf der Progression sind bestimmte allokative und distributive Wirkungen bereits vorprogrammiert; diese Entscheidungen stehen zumeist mit den Anforderungen der Rationalität der Finanzpolitik im Widerspruch: Mit dem gesamten Katalog der Befreiungstatbestände der $\S \S 3$ - 3b EStG werden bestimmte Geld-, Natural- und Transfereinkommen sowie Vermögenszugänge aus der möglichen zurechenbaren Zugangs -Summe der $\mathrm{zu}$ besteuernden Personen ausgegrenzt, so da $B$ sie gar nicht erst besteuerbar werden; mit diesem Betrag wird der Einkommensbezieher überhaupt nicht steuerpflichtig. Es sind nach $W$. Albers (1974, S. 82) "nicht erfaßte steuerfrei gebliebene Einkommensteile". Noch bevor uberhaupt die individuelle Leistungsfähigkeit, die ökonomische Dispositionskraft über Geldbeträge, als Information in die Entscheidung der Steuerpolitiker eingehen kann, werden durch die Einengungspraxis bestimmte allokations- und distributionspolitische Akzente gesetzt. Soweit tatsächlich bestimmte, bisher befreite Tatbestände als steuerlich zu schonende gelten können, sollten sie nicht als Befreiungen formuliert werden, sondern als offen ausgewiesene Abzüge für Entlastungen oder Aufwendungen allokations- und distributionspolitischer Art erscheinen. Dies allein schon, um den Deklarations- und Informationsgrad bei allen Beteiligten $z u$ erhöhen und die steuerlichen Entlastungen diskutierbar und kontrollierbar $z u$ machen.

$45)$ "Notwendige" Schonungstatbestände dieser Art - die gesellschaftspolitische Akzeptanz vorderhand einmal unterstellt könnten sein:

- allokationspolitisch motivierte: Sparerfreibeträge ;

Lohnzuschläge für Sonntags-, Feiertags- und Nachtarbeit; Ehrensold;

- distributionspolitisch motivierte (im Zweifel bleiben diese ohnehin unter der Besteuerungsgrenze für das Extistenzminimum) :

Stipendien;

Wiedergutmachungs-, Schadensersatzleistungen; Sonderaufwendungen für Heirat, Geburt usw. (diese können besser bei den auBergewöhnlichen Belastungen erfaßt werden und gelten dann für alle Steuerpflichtigen; in Form der Befreiungen jetzt bedeuten sie eine Bevorzugung der Arbeitnehmer).

Dieser Katalog ist nicht vollständig, sondern ist orientiert an den $z$. $z t$. geltenden Befreiungen. 
Im Gegensatz zu einem möglichen einheitlichen, vollständigen und integrativen Besteuerungsverfahren, das sämtliche Geldeinkünfte (einschlieblich der Arbeitgeberanteile zur Sozialversicherung), Sozialtransfers und -versicherungsrenten zur Grundlage einer Entscheidung über die Besteuer b a $\mathrm{r}$ e $i \mathrm{t}$ macht, ungeachtet dessen, ob sie dann auch in voller Höhe steuerlich b e $l$ a $s t$ e $t$ und $z$ ur steuer $p f I i c h t$ führen werden, qualifiziert sich das praktizierte Besteuerungsverfahren als ein lediglich partielles und einkunftsdifferenzierendes. Die objektivierung bleibt unvollständig. Somit ist die Besteuerung hierzulande durch recht groBe "Einkommens-Deklarations-Differenzen" (W. Albers 1974 ) gekennzeichnet. ${ }^{46)}$

Sofern man einmal von den rein erhebungstechnischen Lücken absieht, die sich in gewissen Grenzen schlieben lassen, ${ }^{47}$ weisen die Gründe ${ }^{48}$ ) doch vorwiegend in den politischen und mentalen Bereich; teils wird eine allzu perfekte Datenerhebung vermieden,

$46)$ J. Mitschke weist darauf hin, daB es Ausnahmen von der objektiven Steuerpflicht gibt, "die zufolge ungenügender Erhellung des anvisierten Steuerobjekts ... in Befreiungskatalogen erst gar nicht in Erscheinung treten"; 1976, S. 25. - Zur Verteilung der "Einkommens-Deklarations-Differenzen" auf die verschiedenen Erinkommensklassen siehe W. Albers 1979b, S. 310: "Es ist erstaunlich, wie wenig Anstrengungen unternommen wurden, um die auch steuerpolitisch wichtige Frage nach den Ursachen der Nichterfassung aufzuklären; denn immerhin handelt es sich um ein Viertel des Sozialprodukts." M.a.W.: Vorerst gilt wegen fehlender Statistiken, daB die Verteilungswirkungen der steuerfrei bleibenden Einkommensbestandteile nicht $z u$ beurteilen sind. - Zur makro-ökonomischen Schätzung der Einkommens-Deklarations-Differenzen siehe W. Albers 1974 und Musgrave/Musgrave/Kullmer 1975b, S. $81 \mathrm{ff.:}$ Die Differenzen, die neben den Hinterziehungen zur Hauptsache in den steuerbefreiungen begründet liegen, werden für die Bundesrepublik Deutschland im Jahr 1968 auf Werte zwischen 26,4 \& und 31,0 \& des Volkseinkommens geschätzt.

47) Siehe hierzu W. Albers S. 99, 101, 103 f.(1974).

48) Als Gründe für ihre Nichterfassung kommen in Betracht ( $w$. Albers 1974 , S. 107):

- Furcht vor politischen Widerständen einfluBreicher Gruppen (Landwirte, Haus- und Grundbesitzer),

- technische Schwierigkeiten bei der Erfassung der Einkünfte (Schwarzarbeit, Nebeneinkünfte von Lohnsteuerpflichtigen, Geschäfte "ohne Rechnung"),

- mangelnde Informationen über den tatsächlichen Umfang der nicht deklarierten Einkommensteile,

- Einstellung der Politiker und Administratoren, die geprägt ist von der Maxime, daB - so, wie alte Steuern gute steuern sind - alte Privilegien unantastbare Privilegien sind und ihre Abschaffung nur unnötige politische Widerstände hervorruft. 
teils wird überdeutlich, daB der moderne Sozialstaat der Interventionsstaat in nuce ist. Hier liegen somit auch eher die einengenden Bedingungen als die aktiven Möglichkeiten für eine steuerpolitik:

(1) ist $z u$ erkennen, $d a B$ eine umfassende Information uber das Verfügungseinkommen nicht angestrebt ist; damit ist einer integrierten Finanz- und Sozialpolitik von vornherein der Boden entzogen; ${ }^{49}$

(2) ist $z u$ erkennen, daB bestimmte Einkommensteile die Besteuerungsbasis schmälern, obwohl sie keinen eindeutigen Bezug zur sozialen Lage der Empfänger haben, sondern eher allokationspolitisch motiviert sind, dies aber nicht offen ausweisen. ${ }^{50)}$

Nichterfassungstatbestände und Befreiungsregelungen machen das politische Handeln undurchschaubarer und weniger leicht kontrollierbar, als es durch offene Transfers in Form von Staatsausgaben sein könnte. Diese Wirkungen sind distributionspolitisch um so schwerwiegender, ${ }^{51}$ ) als im Transferbereich die Nichterfassung der die Leistungsfähigkeit indizierenden Tatbestände eine in die steuerpolitik "integrierte" (M. Pfaff 1978a) und stärker "final orientierte Sozialpolitik" (W. Albers 1976) unmöglich macht. ${ }^{52}$ ) Gerade die Verzahnung zwischen diesen beiden Politikbereichen verdeutlicht die Eigenschaft der steuerlichen Einkommens- und Vermögensbegriffe als eminent "politischer" Begriffe.

49) Hierher gehört die Steuerfreistellung bestimmter Einkommensteile aus distributionspolitisch motivierten Absichten, wie die Nrn. in $\S 3$ EStG)

50) Hierher gehören die folgenden Steuerfreistellungen (§3EStG,Nr.)

- Abfindungen, Ubergangsgelder, Aufwandsentschädigungen und Prämien $(9 ., 10 ., 12 ., 13 ., 16 ., 18,, 46 ., 50$ u. 51$)$,

- freiwillige soziale Leistungen der Unternehmen (15.),

- Einkünfte aus bestimmten Tätigkeiten, einschlieBlich hoheitlicher Tätigkeit, aus Ehrensold und aus bestimmten Zinsen $(25, \ldots 53 ., 54 \ldots 64 \ldots 66,62 \ldots, 29 \ldots 61 ; \S \S 3 a, 3 b$.

51) "... exclusion is undesirable because it undermines the equity of the income tax. Moreover, tax exemption is an inefficient means of supporting state and local government borrowing"; Musgrave/Musgrave 1980, S. 348 .

52) Vgl. auch WB BMW 1979, S. 14, Ziff. 32: Das Nebeneinander von mehreren Arten von Sozialleistungen führt nicht allein dazu, "daB diese sich in manchen Fällen unangemessen kumulieren, sondern haben auch die Folge, daB andere sozial Bedürftige nur unzureichend versorgt werden. Daher wäre ein vereinfachtes und vereinheitlichtes Transfersystem, das AusmaB, Richtung und Wirkungen der Umverteilungsvorgänge besser überschaubar macht, dem bestehenden System vorzuziehen."

Heinz Hessler and Anneliese Hessler-Otte - 978-3-631-75239-5 
522 Die Einzelproblematiken der besonderen Ausgrenzungstatbestände "zurechnungseinkommen". "Wertzuwachseinkommen" und Transfereinkom$m \in n \cdots$

I. Heterogene Besteuerungskonzepte und Erfassungslücken: Die Zurechnungseinkommen

1. Abgrenzungskriterien

2. Enge und weite Begriffsfassungen

3. Verfahrensmängel und Erfassungslücken

4. Allokativ-distributive Beurteilung

II. Allokativ-distributiver zielkonflikt und Nichterfassung: Die nichtrealisierten Vermögenswertzuwachseinkommen

1. Allokative und distributive Argumente für die Einkommenseigenschaft der Wertzuwächse

2. Die kontroverse Regelung im deutschen Steuerrecht und ihre Beurteilung

III. Politisch gewollte Verletzung des Allgemeinheitspostulats: Die Transfereinkommen

1. Das Ergebnis der wirtschaftstheoretischen Analyse im Uberblick

2. Der Versuch zur Inthronisierung eines "öffentlichen Lastverteilungsprinzips" für ein incegriertes Steuer-TransferSystem

3. Die Rolle des Korrespondenzprinzips für das steuerliche Einkommen

4. Die Beurteilung der praktizierten Transferbesteuerung anhand des Korrespondenzprinzips und des Allgemeinheitspostulats

I. Fur die allokativ-distributive Beurteilung der politisch bestimmten Verfügbarkeit über das Einkommen spieien drei Verfügbarkeitstatbestände eine wichtige Rolle: Die zurechnungseinkommen (imputed income), die nichtrealisierten Vermögenswertzuwächse (capital gains) und bestimmte Transfereinkommenselemente ${ }^{1)}$.

1. Das " $\mathrm{z}$ u $\mathrm{e} c \mathrm{~h} \mathrm{n} \mathrm{u} \mathrm{g}$ s $\mathrm{e} \mathrm{n} \mathrm{k} \circ \mathrm{mm}$ e $\mathrm{n}$ " wird ausschließlich güterwirtschaftlich verstanden (income in kind) ${ }^{2}$ ). Weit aus-

1) Soweit die wirtschaftstheoretische Einkommensqualität dieser zugangselemente zu untersuchen war, ist das in den \$\$ 8 (IV-VI) und 11 geschehen; hier sind nunmehr jene Argumente zu prüfen, die diesen Zugangselementen aus der s t e u e r l i c h e n Sicht die Einkommenseigenschaft $\mathrm{zu}$ - oder absprechen wollen.

2) Unter diesem Aspekt braucht also nicht problematisiert $z u$ wer-

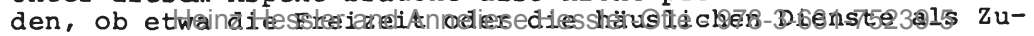

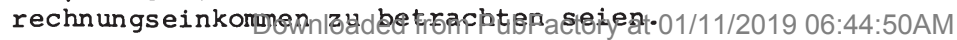


gelegt umfaBt es vier Bestandteile und taucht somit in allen drei Bereichen der Einkommensquellen auf: Erstens der Zugang an Naturalentlohnungen und güterlichen Vorteilen aus dem produktionswirtschaftlichen Bereich, zweitens der Zugang an nichtmonetären Nutzungen des Vermögens, drittens der zugang an nichtrealisierten Wertzuwächsen des vermögens und viertens der zugang an Realtransfers (Verfügbarkeit unterstellt). Eine solche weite Fassung des zurechnungseinkommens, die definitorisch ausschließlich auf die guiterliche Eigenschaft des zugangs abstellt, ist aber nicht die übliche. Definiert man demgegenüber das zurechnungseinkommen mithin nur - was mitunter unausgesprochen geschieht - vom vermögensbereich her, enthält es immer noch zwei Bestandteile, nämlich die Nutzung und den Wertzuwachs. Die engste Definition des Zurechnungseinkommens erreicht man erst mit dem AusschluB des Wertzuwachses; als Zurechnungseinkommen (imputed income) gilt dann, was einer Person an tatsächlicher nichtmonetärer Nutzung aus Vermögen zugeht. Nicht lediglich die mögliche (evtl. aus dem gestiegenen Wert eines nur im Besitz gehaltenen, ansonsten tatsächlich nicht genutzten Vermögens), nicht die aus der Nutzung flieBende "Bedürfnisbefriedigung", sondern der tatsächliche und rechenhafte Vorteilszugang ist zurechnungseinkommen.

In der Literatur findet sich keine eindeutige Festlegung auf diese $D$ e $f$ i $i t i o n s k$ i $t$ e $r i e n$; vielmehr wird $z$. T. enumerativ der Zugang sowohl aus unbaren Entlohnungs- und Entnahmeformen als auch aus Vermögensnutzungen als zurechnungseinkommen erwähnt. Zugänge in Form von Realtransfers werden durchweg nicht $\mathrm{zu}$ den zurechnungseinkommen gezählt. Teils wird ein Abgrenzungskriterium - explizit oder implizit - benutzt, teils wird darauf verzichtet. Soweit aber eines verwendet wird, führt es zu verschieden weiten Konzepten des Zurechnungseinkommens:

So nennt W. Albers (1979a,S.197) "Naturaleinkünfte und Zurechnung von geldwerten Vorteilen aus der Nutzung von Vermögen" in einem Atemzuge und stellt als Kriterium auf den Vorteilszugang ab. ${ }^{31}$

3) Uberdies nennt er unter den 5 Fällen von naturalen Vorteilen vier aus der distributiven Sphäre, die definitionsgemäB tatsächlich Einkommen sein können (drei entstammen dem produktionswirtschaftlichen, einer dem Vermögensbereich: Naturalentlohnung, Güterentnahme zum Eigenverbrauch, Wertschöpfung durch häusliche Arbeit; "Verzinsung" des selbstgenutzten Vermögens), führt aber (Forts. siehe folgende Seite) 
N. Andel (1979a, S. $339 \mathrm{f.})$ sucht das Abgrenzungskriterium nicht im Zugangsbereich, sondern im Verwendungsbereich auf, als "Selbstkonsum" von "Leistungen des Steuerpflichtigen an sich selbst oder an seine Familienangehörigen". Die als Konsum bezeichnete "Nutzung" ist hier stets mit einem Vermögensgegenstand verbunden (wenn man die von ihm hier erwähnte "Freizeit" als Nutzung des Human-Vermögens interpretieren würde) und schliebt daher den $\mathrm{zu}-$ gang an unbaren Entlohnungsvorteilen aus dem Begriff der Zurechnungseinkommen aus. Diese erfaBt er vielmehr als "Bruttonaturalentgelte für Marktleistungen" in einer eigenen Kategorie (Werkswohnungen, Kantinenessen, Deputate, privat genutzte Geschäftswagen); sie sind eindeutig in die zugangssphäre, nicht in die Nutzungs- und Verwendungssphäre verwiesen. Andels Einteilung entspricht der eingangs dargestellten klaren Abgrenzung anhand der zugangsquellen und ist wegen ihrer orientierung am Vermögen eine äuBerst enge Definition des Zurechnungseinkommens. ${ }^{4}$

Demgegenüber ist für Musgrave/Musgrave (1980, S. 346) das Abgrenzungskriterium eben jene verwendungsorientierte Formel des AGIKonzeptes: "net worth plus consumption"; gemäB ihrer Orientierung sowohl am Vermögen als auch am - hier breiter als bei Andel aufgefabten - Konsum zählen sie zum imputed income sowohl die Vermögensnutzungen als auch die unbaren Entlohnungen (income in kind). 5) Bei der in dieser Breite auf den Konsum gestützten Defition überrascht, daB im imputed income nicht die Realtransfers enthalten sind, zumal Musgrave/Musgrave an gleicher stelle empfehlen, in das Gesamteinkommen nach der "net wealth plus consumption"Formel auch die gesamten Transfereinkommen aufzunehmen, und zwar entgegen dem AGI-Konzept.

Forts. Fn. 3:

auch "die Verwendung von im eigenen Betrieb hergestellten Gütern zur Produktion im gleichen Betrieb" als Einkommen auf, obwohl sie klar im allokativen Bereich und damit in der Ertragssphäre verbleiben und das persönliche Einkommen nicht berühren.

4) Auch der Carter Report (1966, vol. 1, S. 12 und vol. 3, s.43 ff.) trennt in "benefits in kind" und "imputed income"; er empfiehlt die Besteuerung der ersteren, hingegen die Befreiung der letzteren.

5) Aus diesem Grunde kritisieren sie am AGI-Konzept, daB es weder die "imputed rent" aus den "owner-occupied houses" noch die Vorteile der Entnahme von Feldfrüchten aus landwirtschaftlichen Betrieben und auch nicht die Vorteile aus der Nutzung von Dienstwagen $z u$ privaten $\mathrm{Zwecken}$ und die Arbeitgeber-Sozialaufwendungen enthält. 
D. Schneider dagegen (1978b, S. $44 \mathrm{f.})$ läßt als Zurechnungseinkommen ausschließlich Einkommen aus dem produktionswirtschaftlichen Sektor gelten, da die Einkommensteuer nicht "Bedürfnisbefriedigungen" erfasse, sondern "Erwerbstätigkeiten"; die Nutzungsbesteuerung sei vergleichbar der Besteuerung persönlicher Konsumausgaben, weshalb die Eigenerzeugung und der Selbstverbrauch in der Landwirtschaft sowie die Selbstnutzung von Unternehmungsmitteln (z.B. PKW) für den privaten Zweck zwar Einkommen seien, nicht aber die "Selbstnutzung von Haushaltsmitteln" (Nutzung des Einfamilienhauses, der Gebrauchsgüter). Aufgrund der nicht weiter hinterfragten "Absicht" der Einkommensteuer, ob sie erklärtermaßen und unbestritten stets nur die Erwerbstätigkeiten erfassen wolle, gelangt Schneider zu einem eindeutigen Abgrenzungskriterium; mit der distributionspolitischen Konsequenz allerdings, den Kreis der zuzurechnenden Imputierungstatbestände sehr stark einzugrenzen.

2. Auch soweit Abgrenzungskriterien nicht eigens formuliert werden, bleiben Realtransfers und Vermögenswertzuwächse als Imputierungsfälle schlicht auBer Betracht, erscheint das Zurechnungseinkommen als eine Mischung von nichtmonetären Zugängen aus dem produktionswirtschaftlichen und Vermögensbereich.

Selbst in diesem nunmehr engeren Rahmen sind unterschiedliche Auffassungen festzustellen: Sollen unbare Entlohnungen und Vermögensnutzungen stets, niemals oder nur teilweise dem Einkommen zugerechnet werden?

Die Meinungen reichen von dem einen Extrem des völligen Ausschlusses jeglicher Imputierungen aus dem steuerlichen Einkommen über verschieden weite Teilausschlüsse bis $z u$ dem anderen Extrem des totalen Einschlusses. Konsequenterweise ergeben sich dadurch unterschiedliche Distributionswirkungen mit allokativen Effekten.

Das AGI-Konzept schlieBt jegliche Imputierungen, sowohl der Naturalentlohnung als auch der Vermögensnutzung und des Selbstverbrauchs eigenerzeugter Güter und Dienste aus dem steuerlichen Einkommen aus. Der Carter Report, der die "benefits in kind"6) vom

6) 1966, vol. 3, S. 44: Sie hängen zumeist mit einem Beschäftigungsverhältnis zusammen oder mit einem Geschäftsbetrieb: Benutzen eines Kraftfahrzeuges oder Wohnhauses, Gewährung einer

(Forts. siehe folgende seite) 
"imputed income"7) unterscheidet, will erstere aus Gründen der GleichmäBigkeit der Besteuerung umfassend in das steuerliche Einkommen aufnehmen, ${ }^{8)}$ will letztere jedoch wegen der großen Bewertungsschwierigkeiten unbesteuert lassen; dies soll auch gelten für die ersparte Miete des vom Eigentümer genutzten Hauses (vol. 3, s. 47). SolchermaBen wird aber - wie noch zu zeigen ist - im letzteren Falle ausgerechnet das bereits für die "incomes in kind" bemühte GleichmäBigkeitspostulat verletzt.

Die deutsche Steuerreformkommission (SRK) 1971 bezieht $z u$ den Naturalentlohnungen eine aus dem Arbeitsverhältnis und der Fürsorgepflicht des Arbeitgebers begründete, hingegen zum Mietwert der eigengenutzten Wohnung im eigenen Hause eine mehrschichtig begründete Position. Die generell bzw. in Grenzen bestehende Steuerfreiheit von Aufwendungen des Arbeitgebers, die überwiegend im eigenen Interesse geschehen ${ }^{9}$ ) oder bestimmte Annehmlichkeiten für den Arbeitnehmer darstellen, ${ }^{10)}$ will sie erhalten oder auch ausgeweitet wissen. Beim Mietwert der eigenen Wohnung schlägt sie im Gegensatz zum geltenden Recht einen völligen Verzicht vor, weil sie den Gesichtspunkten, daB sich das Wohnen in der Konsumsphäre abspiele und den Wohnungseigentümern keine Einnahmen zuflössen (!), daB der Verzicht auf die Erzielung von Einnahmen in keinem anderen Fall besteuert würde und daB der Verzicht auf eine steuerliche Erfassung eine Vereinfachung bedeuten würde, eine gröBere Bedeutung beimiBt als jenen Argumenten, die für eine Besteuerung sprechen. 11 )

Forts. Fn. 6 :

Lebensversicherung oder Pensionsbeihilfe, Verpflegungs- und Wohnzuschüsse, Warenrabatte oder zinsfreie Darlehen.

7) Vermögensnutzungen und Selbstverbrauch eigenerzeugter Güter und Dienste

8) Bei weitgehender steuerfreiheit der "non cash benefits" fänden es die Beschäftigten attraktiv, Geldeinkommen durch diese $z u$ substituieren, 1966, vol. 1, S. 12; siehe auch Musgrave/Musgrave 1980, S. 346 .

9) Aufwendungen für gestellte Arbeitskleidung, für die Berufsfortbildung, für die Gesundheitsvorsorge sollen nicht zum Arbeitslohn gehören, S. 93 f., TZ 129.

10) Hygiene-Einrichtungen, Sport- und Freizeitanlagen, Betriebskindergärten, Getränke- und GenuBmittel, Uberlassung von Theaterkarten, S. 94, TZ 130; schlieBlich auch freie Mahlzeiten im Betrieb (S. 99, Tz $146 \mathrm{ff}$. ).

Fn. 11 siehe folgende Seite 
Gegenüber solchen eher im Pragmatischen begründeten Besteuerungskonzeptionen nimmt sich die Position E. Kellenbergers (1957, S. 303) anders aus, der neben der Nutzung des selbstbewohnten eigenen Haus auch jede Nutzung von Gebrauchsgütern (wie Hausrat und Kunstgegenständen) zum Einkommen rechnet.

Während also im allgemeinen Bedenken gegen den EinschluB des imputed income in das steuerliche Einkommen aus theoretischer sicht heute nicht vorgetragen werden, ${ }^{12}$ ) scheitert er einfach an der praktisch-rechnerischen Verwirklichung. Und so ergeben sich allein aus Praktikabilitäts - und Gleichbehandlungserwägungen bestimmte steuerpolitische "Mittelpositionen", nach denen - so sehr man auch die Besteuerung der Nutzung von Gebrauchsgütern (Auto, Hausrat) grundsätzlich wünscht - die Besteuerung beschränkt wird auf die Nutzung der Wohnung (N. Andel 1979a, S. 340) und Teile der entnommenen bzw. selbst produzierten Güter und Dienstleistungen. 13)

Fn. 11 :

S. 118, TZ 217; allerdings soll Voraussetzung für die steuerbefreiung sein, daB sich die Wohnung im Privatvermögen befindet. Für Wohnungen dagegen im Betriebsvermögen soll es bei der jetzt angewendeten Besteuerung bleiben (S. 121, TZ 226). Den Widerspruch nimmt die Kommission in Kauf, "weil er nur durch eine Einschränkung des Einnahmebegriffes ausgeräumt werden könnte ...".

12) Vgl. jedoch früher F. Neumark (1961b, S. 39f.), eine Totalerfassung sei nicht möglich, aber gerade aus theoretischen Gründen sei ein "alles oder nichts" zu fordern; da ein "alles" nicht in Betracht käme, müsse es beim "nichts" bleiben. -

Diese rigorose Einstelluna aibt er 1970 (S. 133) auf, bezeichnet vielmehr die Nichteinbeziehung der imputed incomes als Versto $B$ gegen die GleichmäBigkeit der Besteuerung und die Kritik an der Nichterfassung des landwirtschaftlichen Eigenverbrauchs als rechtens; darüber hinaus ist nach Neumark gerade die Nichtbesteuerung des Wohnens im eigenen Haus das "Hauptbeispiel" der "nicht nur theoretisch interessanten, sondern ... auch praktisch bedeutsamen" VerstöBe gegen das GleichmäBigkeitspostulats.

13) Nach N. Andel, 1979a, S. 341, ist es erwünscht, sicherzustellen, daB bei selbst produzierten und im privaten Haushalt verbrauchten Produkten zumindest die bezogenen Zwischenprodukte bzw. entlohnte fremde Arbeitskraft nicht als Betriebsausgabe, sondern als steuerpflichtige Einnahmen behandelt werden. 
3. Nach dem in $\$ 11$ entwickelten Verfügbarkeitskonzept wäre als Zurechnungseinkommen jedweder unbare zugang an ökonomischen GröBen aus jeglicher Quelle anzusehen, sofern nur tatsächliche Verfügbarkeit über diesen Zugang beim einzelnen vorliegt und sofern er auch rechenbar gemacht werden kann. Ein solcher Zugang wäre in das steuerliche Einkommen einzuschlieBen. Verfahrensmängel in der Bewertung sprechen nicht gegen das Verfügbarkeitskonzept, sondern gegen das Bewertungsverfahren.13a) Erst wenn die Bewertung auf übergroBe Schwierigkeiten stöBt oder unmöglich ist, müBte um schiere Willkür auszuschlieBen - der "kompromiBhaltige VerstoB" gegen die Totalitäts - und GleichmäBigkeitspostulate hingenommen werden. Abweichungen von dieser Regel offenbaren den politischen Gehalt der steuerlichen Einkommensbestimmung.

Die Regelung des zurechnungseinkommens im $d$ e $u t s h$ e $n$ $s t$ e u e r e c h $t$ enthält beides, $v$ e $r$ f $h r$ e $n s-$ $m$ ä $\mathrm{n} g \mathrm{e} l$ und $\mathrm{E} f \mathrm{f} s \mathrm{~s} \mathrm{n} \mathrm{g} l$ ü $\mathrm{c} k \mathrm{e} \mathrm{n}$. So müssen grundsätzlich die Naturalentgelte gemäB $\S 8$ EStG erfaBt und zu Marktpreisen bzw. zu bestimmten Werten nach einer Regierungsverordnung bewertet werden. Doch der Katalog der Befreiungen in $\S 3$ EStG begünstigt gerade manche Naturalentgelte (Getränke, GenuBmittel, Deputate und Sachbezüge), sofern sie nicht überhaupt als Aufwand behandelt werden und als Entgelte gar nicht in Erscheinung treten (N. Andel 1979a, S. 339). 14) Die Entnahmen aus dem Betrieb zum Selbstverbrauch werden grundsätzlich nach $\S 4$ I EStG

13a)Siehe den Hinweis auf die "skandalc̈ise, der Gleichmäßigkeit der Besteuerung Hohn sprechende" Einheitsbewertung für die landund forstwirtschaftlichen Betriebe bei N. Andel (1979a, S. 343 ) unter Verweis auf R. Fecht, Kritische Untersuchung der Einkommensbesteuerung der deutschen, französischen, US-amerikansichen und britischen Landwirtschaft, Berlin 1970. S. $53 \mathrm{ff.}$

14) E. Hamer (1982) hat einen umfangreichen Katalog all jener Tatbestände $z$ usammengetragen, die nicht eigens von der Einkommensteuer befreit werden muBten, aber dennoch die vielfältigen Formen der "Selbstbedienung" aus öffentlichen Kassen demonstrieren und ihren Beziehern unversteuertes Naturaleinkommen verschaffen: Stromlieferung unter Normalpreis an EVU-Mitarbeiter; kostenlose Bahnfahrten der Bundesbahnmitarbeiter; preisvergünstigte Flugscheine der halbstaatlichen Lufthansa; Zahlung von Sitzungsgeldern an Mandatsträger, die in ihrer Dienstzeit und in Ausübung ihrer Dienstpflicht tätıg werden; Gewährung von Bürodiensten an Parlamentarier und Bürgermeister ohne Berechnung; Freikarten für Mandatsträger; Gestellung offentlicher und verbilligter Wohnungen an Hochbezahlte usw. 
versteuert, doch kennt man hier weitgehende Pauschalierungen, die u. U. zu Entnahmen unter Marktwert führen können.

Bis 1986 wurde - ganz im Gegensatz zu den AGI- und CTB-Konzepten die Wohnungsnutzung im eigenen Haus zum steuerlichen Einkommen gerechnet, und zwar getrennt für den Nutzwert der Wohnung im eigenen Haus ( $\S 21$ II EStG), für den Nutzwert der selbstgenutzten Wohnung im eigenen Einfamilienhaus oder der Eigentumswohnung ( $\$ 21 \mathrm{a}$ EStG) und für den Mietwert der eigenen Wohnung des Inhabers eines landwirtschaftlichen Betriebes ( $\$ 13 \mathrm{a}$ III Nr. $4 \mathrm{u}$. VII EStG). 15)

4. Die Regelung der Zurechnungseinkommen im deutschen Steuerrecht

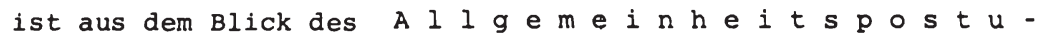
1 a $t s$ zu beurteilen:Sie folgt zunächst einem relativ engen Konzept, da sowohl nichtrealisierte Vermögenswertzuwächse als auch Realtransfers nicht $z u$ den Imputierungen gezählt werden. Sie folgt darüber hinaus einem "verengt-asymmetrischen" Konzept insofern, als sowohl die Naturalentlohnung und güterliche Vorteilsgewährung wie auch die nichtmonetäre Vermögensnutzung grundsätzlich als $\mathrm{zu}$ rechnungseinkommen gesehen, aber nur teilweise verwirklicht werden; denn einerseits wird die Erfassung der Naturalentlohnung und der Güterentnahme $z u$ privaten Zwecken von zahlreichen Befreiungsvorschriften durchlöchert, andererseits entstehen durch die pauschale Berechnung der Nutzungswerte des Wohnens im eigenen Hause, durch den Ansatz veralteter Einheitswerte und durch den erlaubten Schuldenabzug Unterbewertungen und auch Ungleichbehandlungen unter den Eigentümern und Mietern.

Allokative Wirkungen sind in erster Linie im Bereich der Entlohnungen denkbar, und zwar als Wettbewerbsvorteile für jene Betriebe, die mit anderen um knappe Arbeitskräfte konkurrieren und in Form von Naturalentlohnungen und Vorteilsgewährungen die Lohnhöhen der Konkurrenten überspielen können.

15) § 21 II EStGverlangte den Ansatz der Marktmiete für vergleichbare objekte. $\S 21$ a EStG fingierte den Nutzwert auf 1 \& des Einheitswertes, der auf $140 \%$ der Einheitswerte von 1964 festgesetzt ist und in dieser Höhe längst unter den Marktwerten liegt; die Schuldzinsen sind bis zu dem Betrag absetzbar, der sich als Nutzwert ergibt. Nach $\S 13$ a war das $1 / 18$ des Einheitswertes des Wohnteils des landwirtschaftlichen Betriebes anzusetzen; auch hier sind Ungleichbehandlungen in der Bewertung ublich. 
Im Vordergrund jedoch stehen die distributiven Wirkungen. Rechnet man weder die nichtrealisierten Vermögenswertzuwächse noch die Realtransfers $\mathrm{zu}$ den Imputierungen, so ergeben sich die distributiven Wirkungen durch eine Nichterfassung der Vermögensnutzung bzw. durch ihre nur teilweise Erfassung. LäBt man die Nichterfassung von Gebrauchsgüternutzung (Hausrat, Kraftfahrzeuge, Kunstgegenstände) einmal wegen der Bewertungsprobleme auBer Betracht, so entzündet sich die Diskussion um die distributiven Wirkungen stets an der Erfassung der Wohnungsnutzen im eigenen Haus.

In klarer Kenntnis der Ungleichbehandlung von Mietern und Eigentümern fordern Carter Report und Meade Committee dessenungeachtet, eine "imputed rent" nicht zu erfassen, und zwar ausschlieblich wegen der Bewertungsprobleme: Eben weil die Bewertung Unzulänglichkeiten aufweise, führe sie zu Diskriminierungen. ${ }^{16)}$ Ubersehen wird hier U.E., daB die Ungleichbehandlung zwischen den

16) $\mathrm{DaB}$ aus theoretischen Gründen alles für eine Einbeziehung der imputed rent in die Besteuerung spricht, läBt sich ausgerechnet aus eben jenen Beispielen folgern, die Carter und Meade geben. C a r t e r s(Report 1966, vol. 3, S. 47) Vergleich zwischen zwei Vermögensanlageformen durch verschiedene Investoren (isoliert betrachtet):

$\mathrm{S} \mathrm{m} i \mathrm{t} h$ (Mieter) legt Vermögen in Wertpapieren verzinslich an, versteuert den monetären Ertrag, kann jedoch seine Mietzahlung - sie möge die Höhe des $\mathrm{Zinsertrages} \mathrm{nach} \mathrm{Z}$ inssteuern erreichen - nicht steuerlich absetzen, da sie die private Lebensführung betrifft. Obwohl sein "Nettoergebnis" (Wertpapierertrag ./. Miete) gleich Null ist, zahlt er Steuern.

B $r \circ \mathrm{w} n$ (Eigentümer) investiert ein gleich hohes Vermögen in seine eigengenutzte Wohnung, erzielt keinen Zins in bar, zahlt aber auch keine Miete. Sein "Nettoergebnis" ist ebenfalls gleich Null. Würde seine imputed rent nicht besteuert, wäre er bei gleicher Leistungsfähigkeit im Vorteil gegenüber Smith (die Diskriminierung des Smith würde noch kumuliert, könnte Brown seine Hypothekenzinsen steuerlich absetzen).

M e a d e s(1978, S. 214) Vergleich zwischen zwei untereinander kombinierten Anlageformen :

$S \mathrm{~m} i \mathrm{t} \mathrm{h}$ (Mieter) investiert in Wertpapiere und erhält $\mathrm{Zin-}$ sen; er zahlt Miete an Brown.

$B \mathrm{r} \circ \mathrm{w} \mathrm{n}$ investiert in ein Haus, vermietet an Smith und erhält Miete. Beide $z$ ahlen Steuern auf ihre Erträge. Nun tauschen Smith und Brown das Haus gegen die Wertpapiere. Brown als Wertpapiereigentümer zahlt nach wie vor Steuern, doch Smith nicht mehr, sofern seine "imputed rent" kein Einkommen ist, obwohl sie beide gleich leistungsfähig sind.

Carter und Meade geben hier Beispiele für die Ungleichbehandlung der Mieter- und Eigentümergruppen. Der allokative Vorteil der Wohnraumerstellung wird erkauft mit dem distributiven Nachteil der Ungleichbehandlung. 
Gruppen der "owners" und "renters" eine andere ist als jene innerhalb der Eigentümergruppe. Die Verfahrensmängel der Bewertung, so sehr sie zu einer Ungleichbehandlung der Eigentümer führen mögen, sind aber zumindest nicht geeignet, eine Verringerung der Steuerbelastungsdifferenz zwischen Eigentümern und Mietern $z u$ verhindern. Aus diesem Grunde ist - sofern man der Vermeidung einer Ungleichbehandlung $z$ w i $s$ h e $n$ den Gruppen einen Vorrang einräumt - der Regelung im deutschen Steuerrecht der Vorzug zu geben, zumal sich die Ungleichbehandlung i $\mathrm{n} n$ e $\mathrm{h}$ a $\mathrm{l}$ b der Eigentümergruppe mildern lieBe, wenn man die Bewertungsverfahren verbessern würde. Dies aber erscheint nicht ausgeschlossen.

II. Der AusschluB der $n i c h t r$ e 1 i s i e $r$ e $n$ v e r möge ns we r $\mathrm{z}$ u wä $c h s e^{17)}$ ist möglicherweise der am stärksten umstrittene Punkt in der Diskussion um den Inhalt des steuerlichen Einkommens. ${ }^{18)}$ Die Geister scheiden sich an der Frage, ob es aus allokations- und/oder distributionspolitischen Gründen sinnvoll ist, ein steuerliches "Realisationsprinzip" einzuführen. ${ }^{19)}$ Soweit die Folgen einer Besteuerung nur der realisierten Vermögenswertzuwächse negativ beurteilt werden, wird sogar ein

17.) Zur Definition und zur Verwendung des capital gains-Begriffes siehe $\$ 9 \mathrm{~V}$.

18) "Perhaps the most important and controversial issue in income definition", Musgrave/Musgrave 1980, S. 349. - Nach Auffassung von A. Oberhauser dagegen $(1980$, S. 666) steht in Deutschland möglicherweise eher die Bodenwertzuwachssteuer im Vordergrund. Siehe hierzu auch K.-H. Hansmeyer 1974, S. $134 \mathrm{f}$. mit der Darstellung des Verhältnisses der Bodenwertzuwachssteuer zum Planungswertausgleich für die Bodennutzung, siehe ferner WB BMF 1976 , S. $78 \mathrm{ff}$. u. $109 \mathrm{ff}$.

19) Während das Realisationsprinzip für die Lösung des Zugangsproblems (Erhöhung der ökonomisch-finanziellen Dispositionskraft) reklamiert wird, betrifft das Realwertprinzip die Bewertung dieses Zugangs; gleichwohl haben beide Prinzipien insofern Berührungspunkte, als darüber diskutiert wird, ob bei einer AuBerachtlassung des Realwertprinzips die Leistungsfähigkeit infolge realisierten Vermögenswertzuwachses wegen des Kaufkraftschwundes evtl. nur scheinbar realisiert ist (Steuerreformkommission 1971, S. 68: WB BMF 1976, S. 86 ff.) Siehe hierzu $\$ 23$ unten.

Siehe hierzu im übrigen die zwischen Hackmann und D. Schneider im Finanzarchiv (Bd. 44, 1946) gefühte Auseinandersetzung, in der es darum geht, ob die Besteuerung der nichtrealisierten Wertzuwächse zu allokativen Nachteilen führt oder nicht. 
"erweiterter Realisationsbegriff" diskutiert, der - bei voller Integration der Einkommen- und Vermogensteuer und Fehlen einer Erbschaft- und Schenkungsteuer - jede Art einer Ubertragung von Verfügungsmacht als Realisierung definiert. ${ }^{20)}$

1. Gerade die Diskussion um die Ausgrenzung der nicht-realisierten Vermögenswertzuwächse (= capital gains $=$ c.g. $)$ ist ein Paradigma für den a $110 k$ a $t i v-d i s t r i b u t i v e n$ z 1 e $l k \circ n$ f 1 i $t$. . $^{2}$ ) Je nachdem, ob man den distributiven Argumenten mehr Gewicht verleiht und im Halten der wertgestiegenen Vermögensgegenstände einen Indikator der Leistungsfähigkeit sieht oder ob man eher den allokationspolitischen Gegenargumenten zuneigt und wegen der Bewertungs - und Liquiditätsprobleme die nichtrealisierten Vermögenswertzuwächse aus dem Einkommen ausgrenzen möchte, definiert man einen weiteren bzw. engeren steuerlichen Einkommensbegriff. Dabei wird aber selbst von den Befürwortern des engeren Begriffs überwiegend anerkannt, daB zunächst die c.g. Leistungsfähigkeit indizieren. Oftmals zeigt sich aber, daB die Trennung in die allokative und distributive Problematik nicht beachtet wird. Zunächst behandeln wir das c.g.-Problem aus der sicht des Einkommens.

a) Der EinschluB der c.g. In das steuerliche $\mathrm{E} i \mathrm{n} k \circ \mathrm{m} \mathrm{m}$ ist Ausdruck der gestiegenen $L$ e $i s t u n g$ f $\mathrm{a} h \dot{h}$ $k$ e $i t .^{22)}$ Er ist insoweit eine Konsequenz des Postulats der Totalerfassung (WB BMF 1976, S. 118). Für die durch c.g. bewirkte erhöhte Dispositionsfähigkeit spielen die Gründe der Werterhöhung ebensowenig eine Rolle $e^{23)}$ wie die Besitzdauer und die - evtl. un-

20) Carter Report 1966, vol. 3, S. 50 ff. u. passim; WB BMF 1976, S. 78. - Siehe auch oben die CTB- und AGI-Konzepte in $\S 22$, Abschnitt III.

$21)$ Siehe hierzu allgemein Aktkinson/stiglitz 1980, S. 567, mit einer ausführlichen Zielabwägung.

22) Steuerreformkommission (SRK) 1971, S. 68. - WB BMF 1976, S. 14. - N. Andel 1979a, S. 346. - So eindeutig zugestanden werden muB, daB die Bodenwertzuwächse spezifische Probleme mit sich bringen, die im Bereich der Bodenpolitik nicht mit allokativen Problemen der c.g. direkt zu vergleichen sind, so eindeutig ist auch aus dem Gutachten des WB BMF 1976, S. $73 \mathrm{ff}$. u. $78 \mathrm{ff}$. $z u$ folgern, daB eine Zunahme der Leistungsfähigkeit vorliegt.

Fn. 23 siehe folgende Seite 
terschiedliche - Wertsteigerungsrate. C.g. steigern die ökonomische "Verfügungsmacht"24) im Sinne einer "economic power" (Carter Report 1966, vol. 3, S. 50), 25) da sie eine "Erhohung der Eigentumsrechte einer Person" darstellen, 26) über die man selbst dann verfügen kann, wenn sie noch nicht realisiert sind. 27) (A. Oberhauser 1980, S. 668). Eine Transformation dieser Rechte in andere ökonomische Rechte ist grundsätzlich möglich 10 . Ebnet 1978 , S. 58), man muB nur dazu bereit sein (A. Oberhauser 1980 , S. 668). Das Halten der im Wert gestiegenen Vermögensgegenstände angesichts der Wahl zwischen verschiedenen Anlagemöglichkeiten ist eine freie Entscheidung und damit Ausdruck der freien Verfügbarkeit (N. Andel 1979a, S. 348).

Das im Steuerrecht verankerte Realisationsprinzip müBte im Sinne einer Totalerfassung der Leistungsfähigkeit allerdings aufgegeben werden, mit dem Vorteil, daB sich auch die Schwierigkeiten vermeiden lieBen, "die sich aus der zusammengeballten Besteuerung stiller Reserven im Zeitpunkt ihrer Auflösung ergeben" (Steuerreformkommission (SRK) 1971, S. 68) und zu dem stets beklagten "lock in-Effekt" führen. ${ }^{28)}$ Besteuert man die nichtrealisierten Vermögenswertzuwächse nicht, kann jemand laufend reicher werden, ohne daB er je steuerpflichtige Einkünfte erzielte (W. Albers

Fn. 23:

N. Andel 1979a, S. 348; selbst wenn eine Zinssatzsenkung der Grund für den Wertzuwachs eines Wertpapieres war, liegt wegen der Verschlechterung bei allen neuen Anlagemöglichkeiten ein relativ zu ihnen höherer Wert vor, auch wenn das Papier nicht verkauft wird.

24) WB BMF 1976, S. 118. - A. Oberhauser 1980, s. 668.

25) Bei Beleihungen $z$ um Marktwert werden die Wertsteigerungen eines Vermögensgegenstandes ungeachtet seiner Nichtrealisierung berücksichtigt. Nichtrealisierte "Gewinne" sind eben deswegen nicht etwa "fiktive", sondern können genau so "real" sein wie realisierte.

26) So - basierend auf H.C. Simons (1938) - O. Ebnet 1978, S. 58.

27) Insoweit ist auch die Auffassung von D. Schneider (1978b, S. 55) zurückzuweisen, nur der "ZufluB von Geld oder Gütern" erhöhe die Verfügungsmacht; vielmehr kann auch über erhöhte Bestände, die keinen ZufluB darstellen, verfügt werden.

28) Was aber nach der Meinung des WB BMF 1976, S. 14, allenfalls nur sehr langfristig durchzusetzen wäre. zum "lock-inEffekt" siehe unter b) 
1957, S. 70 f.). 29) Die Bedenken gegen eine steuerliche Freistellung der c.g. werden durch empirische Befunde verstärkt, von denen man weithin annimmt, sie würden höchstwahrscheinlich auch für die Bundesrepublik Deutschland gelten. ${ }^{301}$ Allerdings müBte, da die nominellen und im Rahmen des allgemeinen Preisanstiegs liegenden Wertzuwächse keine Erhöhung der Leistungsfähigkeit darstellen, nur der reale Wertzuwachs in den Einkommensbegriff aufgenommen werden (A. Oberhauser 1980, S. 668). ${ }^{31}$ ) In dieser Form kann er dann auch dem progressiven Einkommensteuertarif unterworfen werden, da die dadurch steigende Grenzsteuerbelastung aus verteilungspolitischen Gründen durchaus erwünscht sein kann, sich aber auch qua Durchschnittsbesteuerung mildern läBt (A. Oberhauser 1980, S. 672).

All diese distributiven Argumente werden letztlich durch eines vervollständigt, das den Ubergang $\mathrm{zu}$ einer eher allokativen Betrachtung bildet: Bei einer steuerfreiheit der c.g. entsteht die Tendenz zur Steuervermeidung (Musgrave/Musgrave 1980, S. 350), da es für den Steuerzahler, der ansonsten nur Einkommen $z u$ versteuern hat, verlockend wird, "income gains" (bzw. "capital income" in Form von Gewinn, Dividenden, Zinsen) durch c.g. zu substituieren (Carter Report 1966, Vol. 1, s. 13 f.).

b) Auch aus a $1 \mathrm{l} \circ \mathrm{k}$ a $\mathrm{t} i \mathrm{v}$ e $\mathrm{n}$ Gründen ist die Besteuerung der c.g. befürwortet. Denn die Ausgrenzung der c.g. aus dem steu-

29) Ferner: Wenn von zwei Personen, die Aktien derselben Gesellschaft besitzen, deren Börsenkurse steigen, die eine ihre Aktien veräuBert, die andere nicht, ist niemand von beiden reicher geworden; würden nur die realisierten Gewinne besteuert, widerspräche das der Besteuerung nach der Leistungsfähigkeit; Albers, ebda.

30) Bei kleinen und mittleren Einkommen ist der Anteil der Wert$z$ uwächse am gesamten Periodenzuwachs der wirtschaftlichen Verfügungsmacht in der Regel weitaus niedriger als bei hohen Einkommen. Eine Ausgrenzung der Wertzuwächse aus der Einkommensdefinition des Steuerrechts bedeutet somit eine Ungleichbehandlung wie auch eine Verletzung der vertikalen Steuergerechtigkeit. So der WB MBF 1976, S. 19. - Auch N. Andel (1979a, S. 346) und A. Oberhauser $(1980, \mathrm{~S} .670 \mathrm{f}$.) weisen auf die sehr ungleicher Verteilung der c.g. hin, die mit steigendem Einkommen relativ an Bedeutung gewännen.

31 ) Auch N. Andel, 1979a, S. 348 f., hält dies als Tatsachenfeststellung für richtig, lehnt aber eine Steuerfreiheit als Inflationsausgleich dann $a b$, wenn man ansonsten generell am Nominalwertprinzip festhält. - Siehe auch O. Ebnet 1978, S. 58, der Wertzuwächse nur bei "konstantem Preisniveau" definiert. 
erlichen Einkommensbegriff führt $\mathrm{zu}$ einer verminderten Mobilität von Vermögensgegenständen ("lock-in effect"). 32) Die Probleme, die aber sowohl in der distributionspolitisch wie auch in der allokationspolitisch motivierten Erfassung entstehen, sind neben denen der Liquidität solche der Bewertung. Für jedes Vermögensobjekt muB ein vergleichbarer Gegenstand und ein vergleichbarer Realisierungsvorgang gefunden werden. Ist das geschehen, ist dieser Preis ein Datum, nicht nur für die tatsächlichen Tauschvorgänge, sondern auch für die Bewertung der nicht getauschten Bestände. Allerdings wird dabei Vollkommenheit der Märkte gefordert. Soweit sie aber nicht vorliegt, ist dies ein volkswirtschaftliches und wirtschaftspolitisches, kein originär steuerliches Problem. Denn auch die Erträge aus tatsächlichen Tauschakten und die Einkommen aus tatsächlichen Erwerbsvorgängen werden ja unabhängig davon besteuert, wie vollkommen oder unvollkommen die

32) Diese Wirkung hängt auf folgende Weise mit dem Liquiditätsund dem Bewertungsproblem zusammen:

Wird nur die Realisierung besteuert, entsteht die Tendenz, den Steuertatbestand nicht $\mathrm{zu}$ verwirklichen (WB BMF 1976, S. 20), also Wertzuwächse nicht $z$ u realisieren und der "Steuerstrafe" auf den "Wechsel in der Investierung" $z$ u entgehen (R. Goode 1980, S. 64). Zwar ergeben sich so keine Liquiditäts - und Bewertungsschwierigkeiten, doch kann die verhinderte Faktorwanderung wie auch insbesondere die Bodenimmobilität allokativ nachteilig sein. Zweifel an dem Sinn des Realisationsprinzips werden verstärkt (WB BMF 1976, S. 21). Werden dagegen Nichtrealisierungen (c.g.) besteuert, ist zwar das Immobilisierungsproblem vermieden, nicht dagegen das Liquiditäts- und Bewertungsproblem. Zwar lassen sich Liquiditätsengpässe grundsätzlich lösen, doch wo Verkäufe im ganzen oder in Teilen nicht möglich sind und die Kreditaufnahme versagt, werden SondermaBnahmen nötig, entweder durch distributionspolitisch motivierte Freibeträge, steuerstundungen usw. (WB BMF 1976, S. 20 u. 38/39) oder durch die besonderen Besteuerungsformen der nur in gröBeren Zeitabständen oder nur am Lebensende erhobenen Steuern (N. Andel 1979a, S. 350). Andererseits hat der liquiditätsbedingte Realisierungsdruck den allokativen Vorteil, daB die Steuerpflichtigen - insbesondere bei einer permanenten Wertzuwachsbesteuerung - laufend gezwungen sind, $z u$ überprüfen, ob ihre Allokationsentscheidungen optimal sind (WB BMF 1976, S. 21). Denn die Besteuerung auf der Basis des Realisationsprinzips kann die Individualentscheidungen über Halten oder VeräuBern von Anlagen stören (J. R. Green/E. Sheshinski 1978, S. $1143 \mathrm{ff.}$ ). Insbesondere in der Bodenpolitik geht es darum, die effiziente Nutzung herbeizuführen und der spekulativen Verminderung des Angebots entgegenzuwirken (A. Oberhauser 1980, S. 670). "Eine allgemeine Erfassung der Wertzuwächse würde die Attraktivität von Grundstücken als Anlageobjekte wegen der hier relativ gröBeren Bedeutung der Wertzuwächse reduzieren und dadurch das Angebot erhöhen" (N. Andel 1979a, S. 351). 
Güter- und Faktormärkte gewesen sind: Wenn eine Ubernachfrage $z u$ höheren Tauschwerten führt, werden diese "Uber"-Erträge bzw. -Einkommen besteuert, ohne daB steuerlich auf eine hypothetische Vollkommenheitssituation zurückgerechnet würde. Es gilt die IstBesteuerung. So wäre es verfehlt, in der Bewertung von Wertpapierbeständen etwa mit dem Hinweis zu argumentieren, ein hypothetisches "Uberangebot" (Verkaufsabsichten) an Wertpapieren würden den sich so ergebenden Kurswert gegenüber dem für die Bestandsbewertung angesetzten abnorm absinken lassen. Wenn behauptet wird, der sich aus einzelnen Tauschakten ergebende Kurswert am Stichtag sei demzufolge für die ruhenden Bestände $z u$ hoch angesetzt, so ist dem entgegenzuhalten, $\mathrm{daB}$ es sich erstens bei dem Stichtagswert um einen tatsächlichen Wert handelt (Ist-Besteuerung), der nach dem Gesetz der Unterschiedslosigkeit für alle noch vorzunehmenden und noch nicht vollzogenen Tauschakte vorerst ein Datum ist, wohingegen jeder andere wert ein hypothetischer wäre (SollBesteuerung); daB es zweitens völlig unrealistisch wäre, anzunehmen, das Hinzutreten eines weiteren Verkäufers würde diesen Kurswert nennenswert senken können und daß es ebenso unrealistisch wäre, anzunehmen, sämtliche Wertpapierbesitzer würden sich zur selben Börsenstunde zum Verkauf des nämlichen Papiers entschließen.

Allenfalls das stichtagsprinzip kann für die Bewertung der Bestände in Zweifel gezogen und durch ein Durchschnittsprinzip ersetzt werden. Dies aber ist eine Frage der Bewertungstechnik, nicht der Einkommenseigenschaft von nichtrealisierten Vermögenswertzuwächsen. Es ist theoretisch nicht zulässig, Bewertungsschwierigkeiten sogar uber die Einkommensqualifizierung entschelden zu lassen. Nur wo die Bewertung völlig unmöglich ist und demnach die zurechnung ad personam von vorn herein nicht gelingt, kann von Einkommensqualifizierung dann nicht gesprochen werden.

Letztlich ist festzustellen, daß die fehlende Trennung des allokativen vom distributiven Bereich die Unvereinbarkeit der unterschiedlichen Standpunkte in der Einkommenseigenschaft von nichtrealisierten Vermögenswertzuwächsen verstärkt. Für die Unternehmungen kann die Besteuerung der nichtrealisierten Wertzuwächse (des Kapitals!) Probleme der Liquiditat und der langfristigen Existenz aufwerfen, die sich bel langfristiger Investierung 
nicht durch sofortige Realisierung der Wertzuwächse lösen lassen. Dieser Tatbestand macht aber nur deutlich, daB solche Probleme erstens mit der steigenden Steuersatzhöhe verschärft werden, weshalb sich in diesem Bereich der Erträge und des Kapitals die Progression verbietet; er macht zweitens deutlich, daB in diesem Bereich nicht mit den Vorstellungen der persönlichen Leistungsfähigkeit argumentiert werden kann, weshalb aus allokationspolitischen Erwägungen die steuerliche Behandlung der Kapitalwertzuwächse durchaus nach dem Realisationsprinzip organisiert werden kann.

Nunmehr - statt der Ertragsprobleme - zurück zu den tatsächlichen Einkommens problemen.

c) $\mathrm{k} \circ \mathrm{n} f \mathrm{l} i \mathrm{k}$ e mit dem distributiven ziel entstehen bei der Frage, ob der Realisierungsaruck politisch als zumutbar angesehen werden soll. Das problem liegt auf $z$ wei verschiedenen Ebenen. Zunächst kann man - ausgehend von der Tatsache, daB über das genaue AusmaB der nachteiligen Wirkung der Mobilitätshemmung keine genauen Kenntnisse bestehen - in der Zielabwägung eine EffizienzeinbuBe als preis für die zielerreichung in der Verteilungspolltik in gewissem Umfange hinnehmen, wie das sonst auch geschieht (N. Andel 1979a, S. 351). 33) Aber selbst wenn man aus eben diesen Gründen insbesondere für die Bewohner von Eigenheimen Freibeträge einrichten würde, ergäbe sich ein Verteilungsproblem innerhalb der Gruppe der Wohnungsnutzer: Die solchermaBen begünstigten Elgentümer von Einfamilienhäusern "würden gegenüber denjenigen, die später ein Einfamilienhaus erwerben, sowie gegenüber bloBen Mletern begünstigt" (WB BMF 1976, S. 20).

Um die allokativ nachteiligen Mobilitätshemmnisse ${ }^{341} \mathrm{zu}$ vermeiden, sind grundsätzlich drei Wege möglich (N. Andel 1979a, S. 351),

33) So weist der WB BMF 1976, S. 39, darauf hin, daB gegen eine Begünstigung durch Steuerbefreiungen eingewendet werden kann, die Haus - und Wohnungseigentümer würden in Zeiten steigender Bodenpreise häufig weit "uber ihre Verhältnisse" leben, was Fehlallokationen nur dann ausschliebe, wenn der Verkauf erzwungen werde. Aber dagegen ist seiner Melnung nach vorzubringen, daB absichtlich die Deckung des Wohnbedarfs in gewissen Grenzen von den Marktbedingungen gelöst sei.

34) Der tatsächliche Nachweis der Immobilitat steht vor der Schwierigkeit, die den "lock-in Effekt" hervorrufenden Steuerwirkungen von jenen $z u$ trennen, die aufgrund der allgemeinen Geldentwertung ebenfalls Immobliltät bestimmter Anlagegüter hervorrufen. 
nämlich die Steuerfreiheit der c.g. bzw. ihrer Realisierungen mit eindeutiger Verletzung des Verteilungsziels, die permanente Besteuerung der c.g. in Ubereinstimmung mit dem Verteilungsziel, doch mit den Schwierigkeiten einer ständigen Bewertung samt hohem Verwaltungsaufwand, letztlich die sog. "constructive realization" nach dem "Comprehensive Tax Base-Konzept" (Carter Report 1966, vol. 3) bzw. die "hypothetische Realisierung" (A. Oberhauser 1980, S. 673). Sie ist der KompromiB im allokativ-distributiven Konflikt, weil sie den sperreffekt mildert, den steuertechnischen Bewertungsaufwand in Grenzen hält und die Liquidität der Besteuerten schont durch ein Verteilen der Steuerbelastung auf mehrere Zahljahre. ${ }^{35)}$ Für die hypothetische Realisierung spricht, daB nach einer allzulangen Reihe von Jahren erhebliche steuertechnische Bewertungsprobleme bestehen ${ }^{36)}$ und daB eine $z u$ vorsichtige Bewertung $z u$ Unterbewertungen führen, die das Verteilungs ziel in Frage stellen und nach(N. Andel 1979a, S. 350) in der Einkommensteuer keinen Platz haben. Nach Andel (a.a.O., S. 349) sei zwar mit einer befriedigenden Exaktheit in der Bewertung kaum $z u$ rechnen, aber es sei eine perfekte Lösung auch gar nicht erforderlich, solange die Mängel der Bewertung "geringer bleiben als diejenigen, die mit der völligen Steuerbefreiung verbunden sind". Letztlich aber bleiben die Empfehlungen der Wissenschaftler und Beratergruppen äuBerst unterschiedlich, wobei - zumindest in

35) Hierbei ist eine gewisse Spannweite möglich, die von einem Besteuerungsturnus alle 5 - 6 Jahre bis zu 30 Jahren reicht; $z u-$ mindest soll einmal je Lebenszeit, wenn mit einem Sperreffekt nicht mehr zu rechnen ist, besteuert werden: Im Erbfall, bei der Schenkung oder anläBlich der Emigration. Sowohl der Carter Report 1966, vol. 3, S. 52, als auch das Meade Committee 1978, S. 143, empfehlen an dieser Stelle, auch die c.g. in den Unternehmen $\mathrm{zu}$ besteuern, um das steuerindizierte "Sparen im Unternehmen" $z$ u verhindern. Wir haben oben dazu ausgeführt, daB die Besteuerung von c.g. im Unternehmen aus bestimmten Gründen für sinnvoll gehalten werden kann, daB jedoch eine sog. "Gleichbehandlung" der unternehmerischen Erträge und der persönlichen Einkommen aus Gründen der Konsistenz unserer allokativ-distributiven Bereichsabgrenzung nicht in Betracht kommen kann.

36) Nach W. Albers 1979a, S. 197 f. geht allein schon aus der Einheitsbewertung hervor, daB bisher die dort gefundenen Werte kaum überzeugend waren, daB im Privatbereich häufig die für die Wertsteigerungsermittlung notwendigen Anschaffungspreise nicht mehr festzustellen sind und daB sich Abgrenzungsnotwendigkeiten für die werterhöhenden Aufwendungen ergeben, die ja eliminiert werden müssen. 
der anglo-amerikanischen Literatur - die zwar nicht einmütige, doch vorherrschende Meinung vertreten wird, die Besteuerung der c.g. sei nicht praktikabel (so R. Goode 1980, S. 64). 37)

2. Dennoch ist die Nichterfassung der c.g. "eine der bedenklichsten Lücken nicht zuletzt des deutschen steuersystems", "namentlich dann, wenn dieses im übrigen angeblich nach sozialen Kriterien gestaltet ist" (F. Neumark 1970, S. $338 \mathrm{f.l).} \mathrm{Die} \mathrm{Lücke} \mathrm{er-}$ gibt sich aber eindeutig daraus, daB ein mit dem Belastungsziel konsistenter Einkommensbegriff nicht formuliert wurde. Das führt dann $z u$ den äußerst kontroversen Regelungen im gegenwärtigen d e u t s c h e $n$ s t e u e r e c h $t$. Aufgrund des in ihm festgeschriebenen Realisationsprinzips gilt folgendes: (1) Realisierte Vermögenswert- bzw. Gewinnzuwächse werden im privaten Bereich nicht als Einkommen definiert, von einigen Ausnahmen ${ }^{36}$ ) abgesehen, obwohl eine höhere Disponibilität der ökonomischen GröBen vorliegt, was im Grunde ja auch durch die Ausnahmen indirekt bestätigt wird. (2) Demgegenüber werden realisierte Vermögenswertbzw. Gewinnzuwächse im betrieblichen Bereich sehr wohl als Erträge (und sogar Einkommen!) definiert, doch hier gelten ebenfalls in Höhe der verschiedenen Freibeträge (für land- und forstwirt-

37) Der Carter Report 1966, vol. 3, S. 50, empfiehlt, obwohl er die Bewertungs- und Liquiditätsprobleme für lösbar hält, die Nichtbesteuerung der c.g., d.h. nur die Besteuerung der Realisationen; zugleich spricht er sich für den KompromiB der "constructed realization" aus. Die deutsche SRK 1971 (allerdings in ihren äuBerst knappen Bemerkungen auf S. 68/69) spricht sich ebenfalls gegen eine Besteuerung der c.g. aus wg. der Rücksichtnahme auf die EWG (wo eine Absicht der Besteuerung von c.g. nicht festzustellen seil und wg. der Notwendigkeit, auch Vermögenswertminderungen berücksichtigen und von den normalen Abnutzungen abgrenzen $z u$ müssen. Ihr Hinweis allerdings, daB die c.g. von der Vermögen- und der Grundsteuer im Prinzip erfaBt würden, vermag eine Lösung des Einkommensbegriffes nicht $z u$ bringen, ist allenfalls ein steuersystematisches Argument. - Der WB BMF 1976, S. 124, lehnt eine Ausdehnung der Einkommensteuerpflicht auf unrealisierte Bodenwertgewinne im Rahmen des gegenwärtigen Einkommensteuerrechts ab, "weil steuersystematisch insbesondere die einseitige Durchbrechung des Realisationsprinzips nicht zu vertreten ist". - Der WB BMF 1967 hatte sich seinerzeit mit dem Problem der c.g. nicht befaBt.

38) Spekulationsgewinne werden nach $\S 22$ EStG normal besteuert, es gibt jedoch "Steuervermeidungsfristen" für Wertpapiere und Grunds tücke. 
schaftliche und gewerbliche Betrlebe wie für Freiberufler) ${ }^{39}$ ) einige Ausnahmen; die allokationspolitisch nicht sinnvolle Grundsatzregelung wird dadurch z.T. korrigiert, wenngleich nicht auf Grund der Einsicht in die Ratio oder in das system, sondern der Gruppeneinflüsse. (3) Nicht realisierte Vermögenswert- bzw. Gewinnzuwächse werden sowohl im privaten wie im betrieblichen Bereich nicht als Einkommen bzw. Gewinn erkannt. ${ }^{40)}$ Im betrieblichen Berelch ist dies allokativ sinnvoll, was insoweit den Ausnahmeregelungen für die realisierten Vermögenswertzuwächse entspricht. Im privaten Bereich ist das distributiv gesehen ohne Sinn, da erhohte Dispositionskraft und damit Leistungsfähigkeit vorliegt.

Die Würdigung der Argumente gegen eine Besteuerung der c.g. vermittelt den Eindruck, als würde die Ausgrenzung der c.g. aus dem Einkommensbegriff nicht ohne Blick auf die als nachteilig empfundenen Wirkungen der Einkommensteuerprogression geschehen. Doch das Definitionsproblem des steuerlichen Einkommens ist grundsätzlich zu trennen vom "full taxation"-Problem (N. Andel 1979a, S. 350 u. 392 f.). Ein höherer Grenzsteuersatz für c.g. kann zunächst einmal distributionspolitisch gewollt sein; überdies lassen sich differenzierte Steuersätze einführen, wenn man Liquiditätsschwierigkeiten beheben und evtl. Notverkäufe vermeiden will. Vor allem aber sollte das Tarifargument nicht dazu herhalten, das Einkommensbegriffsproblem $z u$ "lösen", also die c.g. aus dem Begriff "herauszudefinieren". DaB die steuergesetzliche Regelung, realisierte Kapitalwertzuwächse (im betrieblichen Bereich) grundsätzlich $z u$ besteuern, realisierte Vermögenswertzuwächse (im privaten Bereich) dagegen grundsätzlich $\mathrm{n} i \mathrm{cht}$ - und dasselbe gilt

39) Steuerfrei bleiben nach $\S \S 6 \mathrm{~b}$ u. 6c EStG die VeräuBerungsgewinne bei bestimmten Anlagegütern sowie Grund und Boden samt Gebäuden; Freibeträge bzw. Freigrenzen sowie halbe Steuersätze gelten für bestimmte realisierte Wertzuwächse in der Land- und Forstwirtschaft ( $\S 14 \mathrm{u}$. 14a EStG), für Gewerbebetriebe ( $\$ 16 \mathrm{EStG})$, für Anteile an Kapitalgesellschaften bei wesentlicher Beteiligung ( $\$ 17$ EStG) und fur Freiberufler (§ 18 III EStG).

40) Nur für die Vermögensbesteuerung gilt, daB Aktien und Wertpapiere zum Börsenkurswert am Stichtag bewertet werden, auch wenn sie nicht veräuBert wurden. Die Wertfortschreibung des Einheitswerts nach $\S \S 22$ u. 79 BewG ist nach Auffassung von A. Oberhauser $(1980$, S. 670) nicht eine Besteuerung des Wertzuwachses, sondern des höheren Bestandes. 
für die Nichterfassung privater nichtrealisierter Wertzuwächse -, nicht als ein Widerspruch innerhalb eines auf distributive ziele angelegten Steuersystems erkannt wird, bedarf einer besonderen Erklärung: Das Nichterkennen- oder Nichtlösenwollen dieses Widerspruchs hängt damit zusammen, daB die Abgrenzungsnotwendigkeit zwischen dem allokativ-betrieblichen und dem distributiv-privaten Bereich des Wirtschaftens nicht gesehen oder in ihrer Bedeutung verkannt wird. ${ }^{41)}$

Eine Beurteilung der steuerlichen Ausgrenzung von nichtrealisierten Vermögenswertzuwächsen aus der Sicht des oben entwickelten Verfügungsansatzes stellt sich wie folgt dar:

(1) Ausgangspunkt ist die Zugangsregel und das Verfügbarkeitskriterium. Die Zugangsregel wurde "offen" formuliert und führt somit zum steuerlichen Totalitätskonzept, zur Erfassung aller zugänge an ökonomischen Größen aus allen Quellen, die steuerliche Leistungsfähigkeit anzeigen. Dies erfordert den Einschluß der c.g.; wie nachgewiesenen, liegt auch bei c.g. Verfügbarkeit vor.

(2) Bereits in die Zugangsregel und in das Verfügbarkeitskriterium eingeschlossen ist die "ad-personam-Regel", aus der folgt, daB nur c.g. im personalen Bereich in den steuerlichen Einkommensbegriff einzuschlieBen sind. Will man dennoch auch betrieblich entstehende c.g. besteuern, bedarf das einer eigenen allokationspolitischen Entscheidung, kann das nicht mit "Gleichbehand-

41) N. Andel (1979a, S.347) argumentiert zum "lock-in-Effekt" bezüglich der vermuteten wirkungen aus dem Blickwinkel der progressiven Einkommensteuer: "Allokationspolitisch wäre die Steuerfreiheit von Wertzuwächsen unproblematisch, wenn man davon ausgehen könnte, daB dadurch der Umfang der Aktivitäten, die (in besonderem MaBe) mit solchen Wertzuwächsen verbunden sind, unbeeinfluBt bliebe." Das aber sei nicht $\mathrm{zu}$ erwarten, "wenn man bedenkt, das Steuerfreiheit bei einem marginalen Einkommensteuersatz von 50 \& einem (auf die Wert$z$ uwächse bezogenen) Bruttosubventionssatz von $100 \%$, bei einem marginalen Einkommensteuersatz von 80 \& einem Bruttosubventionssatz von 400 o entspricht." Das ist nun exakt unser Problem: Die Argumentation Andels erhält ihr besonderes Gewicht dadurch, daB auch im betrieblichen Bereich anfallende Allokationsaktivitäten von der progressiven Einkommensteuer, nicht aber von einer "allokationsneutralen" proportionalen Unternehmensteuer getroffen werden. 
lung̣sargumenten" begründet werden. Dies aber ist eine Besteuerung von "c a p i t a l" - gains im Ertragsbereich.

(3) Probleme wirft die Rechenbarkeitsvoraussetzung des Einkommensbegriffs auf: Nur solche c.g. können in den steuerlichen Einkommensbegriff eingeschlossen werden, die bewertbar sind. Bewertungsprobleme umfassen sowohl die Festlegung eines Maßstabs (Vergleichspreise) als auch die gegenständliche Erfaßbarkeit und Kontrollierbarkeit der Zugänge an ökonomischen Größen (z.B. Schmuck, Edelsteine, Sammlungen, Antiquitäten u.a.), genauer: ihrer Wertzuwächse.

(3a) Ein erster Ansatz zur Erleichterung der Bewertungsaufgaben wäre die Aufstellung eines Katalogs von Gütern, die annäherend und gleichmäBig über die Mitglieder einer modernen Industriegesel1schaft verteilt sind, weil deren Nichterfassung dann nur minimale Verteilungsunterschiede hervorriefe bei einer gleichzeitig vermiedenen steuertechnischen und verwaltungsmäBigen Ineffizienz durch Fortfall der Erfassung, der Kontrolle und der Bewertung.

(3b) Um den Bewertungsaufwand in Grenzen $\mathrm{zu}$ halten und um sich zugleich dennoch nicht des Vorteils zu begeben, der in einer annähernd permanenten Besteuerung der c.g. und der dadurch gemilderten Sperreffekte liegt, empfiehlt es sich, die Besteuerung auf wenige Termine $z u$ begrenzen. Sinnvollerweise geschieht dies solange einheitswertabhängige steuern weiterhin erhoben werden in Ubereinstimmung mit dem Bewertungsgesetz. ${ }^{42}$ )

(4) Inwieweit Liquiditäts - und Bewertungsproblemen Rechnung getragen wird, inwieweit evtl. Rigorositäten und (unvermeidbare) Willkürlichkeiten in die Bewertungsregeln eingehen, hängt letztlich mit den Zielen zusammen, die man mit der Einkommensteuer verfolgt. Eine Bevorzugung des Verteilungszieles läßt erwarten, daß der Einkommensbegriff in Richtung auf die Totalerfassung - evtl. unter Inkaufnahme unexakter Bewertungen - ausgestaltet wird; wie mehrfach betont, ist das steuerliche Einkommen eine politische GröBe.

42) Nach § 21 BewG ist z.B. die Hauptfeststellung für den Grundbesitz in Zeitabständen von 6 Jahren vorgesehen. Da sich das in der Vergangenheit lediglich als ein frommer wunsch herausgestellt hat, erwiese sich ein Zehnjahresabstand als eher wahrscheinlich. Das aber erhöht den Sperreffekt wieder. Unter diesem Aspekt erscheinen Durchschnittsbesteuerungen zwischen den Hauptfeststellungszeitpunkten sinnvoll, mit Neufeststellungen bei Wertminderungen auf Betreiben des Steuerpflichtigen. 
III. Während in $\$ 8$ die Einkommenseigenschaft der $T$ ra $n$ s f e r s geklärt wurde, geht es vorliegend um die Einfügung der Transfers in das Konzept der Besteuerung nach der Leistungsfähigkeit.

1. Einleitend seien die Analyse- und Abgrenzungsergebnisse zur Einkommenseigenschaft der Transfers in $w i r t s$ a $f t s-$ $t h$ e $\circ \mathrm{r}$ e $\mathrm{i} s \mathrm{ch}$ e $\mathrm{r}$ Betrachtung zusammengestellt (siehe \$ 8 VI):

(1) Grundsätzlich ist $z u$ unterscheiden zwischen Transfers aus Vermögen (individuellem oder kollektivem) und Transfers aus der laufenden Wertschöpfung (des Individuums oder des Kollektivs). Gemeinsam ist allen Transfers die fehlende Gegenleistung, so da $B$ Erträge aus Vermögen für den Vermögenseigner keine Transfers sein können.

(2) Vermögen, das der einzelne in Vorperioden akkumuliert (gespart oder geerbt) hat, kann nicht bei ihm zu Einkommen in Form von Transfers führen, da kein Zugang in der laufenden Periode vorliegt; sofern er das Vermögen verrentet, handelt es sich - mit Ausnahme etwaiger Vermögenserträge - um eine Vermögensumschichtung, aber selbst unter EinschluB der Erträge niemals um Transfers.

(3) Privat akkumuliertes Vermögen, das auf Dritte übertragen wird (einmalig oder laufend), führt bei diesen zu Transfers in Form von Ubertragungseinkommen, weil hier ein zugang vorliegt.

(4) Der Einkommenszugang des Vermögenseigners, der weder Vermögensumschichtung noch Transfer ist, setzt sich zusammen aus dem Ertrag (bei laufender Verrentung "Ertragsanteil" genannt) und dem "Vermögensmehr" in Form von Wertsteigerungen oder Mehrauszahlungen gegenüber dem Vermögen, das durch eigene Akkumulation aufgebracht wurde. 431

(5) Ubertragungseinkommen entstehen aus privaten wie auch aus öffentlichen Ubertragungen; begriffsentscheidend ist die Zurechen-

43) So treten in Lebensversicherungen sog. Umverteilungsgewinne auf bei den überdurchschnittlich lang Lebenden, N. Andel 1979a, S. 338; Umverteilungsverluste müssen dann abgezogen werden. 
barkeit, die Verfügbarkeit und die fehlende Gegenleistung. ${ }^{4}$ )

(6) Aufgrund der Unterscheidung in die individuell-eigenverantwortlich organisierte Zukunftssicherung und die kollektive (die sowohl eigen- als auch fremdverantwortlich organisiert sein kann), sowie aufgrund der Trennung in die "intrapersonale", in die "interpersonale" wie auch in die "intertemporale" zukunftssicherung und intratemporale Einkommensubertragung ergibt sich folgendes:

- die individuell-eigenverantwortliche zukunftssicherung führt als ein zwar intertemporaler, aber intrapersonaler Vorgang nicht $z u$ Transfers (es sei denn, der einzelne versorgt und sichert die Zukunft seiner Familie als einziger Einkommensbezieher und -verwender; dann erhalten die Mitglieder Transfers);

- in der kollektiv-eigenverantwortlich organisierten Zukunftssicherung kommt es $\mathrm{zu}$ Transfers insoweit, als tbertragungseinkommen entsteht, das über das selbst akkumulierte Vermögen hinausgeht;

- in der kollektiv-fremdverantwortlich organisierten zukunftssicherung (im allgemeinen die Zweige der gesetzlichen Sozialversicherungen) kommt es wegen des Umlageverfahrens, das für eine private Vermögensbildung keinen Raum läBt, dem Grundsatz nach in der Tendenz überwiegend zu Transfers (es gilt die "gemilderte Äquivalenz"). Dagegen sind die Sozialhilfen und Sozialrenten aus den staatlichen und kommunalen Haushalten ausschlieblich Transfers.45)

(7) Nur die bestimmten Personen direkt zugehenden öffentlichen und privaten Ubertragungseinkommen sind Transfers, und unter den offentlichen nur die positiven und expliziten. Dies gilt ungeachtet

$44)$ So fehlt bei den Beamtenpensionen die Eigenleistung deshalb, weil der Erwerb der Anwartschaft nicht als Einkommen versteuert wird, WB BMF 1967, S. 22. - Wenn die TEK 1981 auf S. 13 definiert, Transfers seien "alle monetären und realen Einkommensübertragungen ...., die vom staat $z u$ den privaten Haushalten und von diesen zum staat flieBen", so sind die Transfers zwischen Privaten ausgeklammert; ihr Begriff der "positiven Transfers" ist für unsere Untersuchung hier zu weit gefaBt, da er wie die Pensionen die gesamten Renten (als "abgeleitete Erwerbseinkommen") einschlieBt und dabel die (nichttransferiellen) Ertragsanteile nicht unterscheidet.

45) Die gesetzliche Sozialversicherung enthält realiter sowohl Elemente einer rein individuellen Anspruchs (vermögens-) Bildung als auch eines echten Transfers. Mit Blick auf die Zuschüsse aus Steuermitteln sieht D. Brummerhoff $(1979, \mathrm{~S} .220)$ sie als Teil des "Steuer-Transfer-Systems"; W. Albers (1979a, S. 199) $z$ ählt $z u$ den "Kombinationen von interpersonellen und intertemporalen Ubertragungen" in erster Linie Leistungen der Arbeitgeber für die zukunftssicherung ihrer Arbeitnehmer. 
der Quellen und der Motive der Ubertragung. Hinsichtlich der Realtransfers ist sowohl die MeBbarkeit als auch die Verfügbarkeit die Voraussetzung für die Transfereigenschaft. ${ }^{46)}$

Ausgehend von diesen wirtschaftstheoretischen Analyseergebnissen ist $z u$ prüfen, inwieweit die zugehenden Transfers aufgrund der der Allgemeinheit der Besteuerung $z$ um steuerlichen Einkommen $z$ ählen.

2. Die Einbettung eines sehr groBen Teils der Transfereinkommen, nämlich der Sozialversicherungsrenten und der Sozialhilfeleistungen, in den "Steuer-Transfer-Zusammenhang" kann AnlaB sein, auch für die staatlichen Transferleistungen die Gültigkeit des "Leistungsfähigkeitsprinzips" $z$ u untersuchen. So konzipiert die TEK 1981 (S. 13 f.) einen "Gesamtansatz des Transfersystems", wonach als Transfers "alle monetären und realen Elnkommensübertragungen $z u$ verstehen" seien, "die vom Staat zu den privaten Haushalten und von diesen zum staat flieBen"; die Verteilungssituation des einzelnen wird vor allem durch das zusammentreffen von positiven und negativen (Steuern und Sozialabgaben) Transfers beschrieben, das ihn entweder zum "Nettoempfänger" oder zum "Nettozahler" macht. ${ }^{47)}$ Doch die Gültigkeit des Leistungsfähigkeitsprinzips auch für die transferielle seite des staatshandelns untersucht erst D. Birk (1981). Dabei folgt aus der Anwendung des Leistungsfähigkeitsprinzips nicht allein die Forderung nach dem EinschluB

46) Es gibt Ubertragungseinkommen und Ubertragungsvermögen. Erstere stehen bei der Besteuerung der Transfers im Mittelpunkt der Betrachtung. Jedoch ist das Kriterium der Verfügbarkeit unter dem hier interessierenden Aspekt der Besteuerung nach der Leistungsfähigkeit auch für das Vermögen zu beachten. Hinsichtlich der Renteneinkommen liegt in Höhe der Geldzugänge Verfügbarkeit und auch Leistungsfähigkeit zweifellos vor. Als Vermögen könnte allenfalls das Rentenstammrecht gelten, und zwar als ein Forderungsvermögen. Es ist aber nicht übertragbar und nur z.T. vererbbar (sofern nicht neuestens ein ureigener Anspruch des Ehepartners auf das Stammrecht gesehen wird). Insofern ist die Verfügbarkeit der Ansprüche aus der Rentenversicherung nicht gegeben, zumal sie auch nicht jederzeit kapitalisierbar und verwertbar sind, vgl. Gutachten BBk-M 8/1979.

47) Unter diesem Aspekt entwickelt die TEK 1981, S. 123 ff. ihre Vorschläge für eine "geschlossene Verteilungsrechnung"; siehe auch die TEK 1979 (Zwischenbericht) TZ 65 und TEK 1981, S. $22, \mathrm{TZ} 3$. 
in das steuerliche Einkommen, sondern weitergehend die Gestaltung der Transfers in ihrer Höhe und in ihrer "vertikalen" Gerechtigkeitsvorstellung nach dem Sozialstaatsprinzip (Birk 1983, S. 139 ff.). Birk prüft die Eignung des Leistungsfähigkeitsprinzips für das gesamte Transferverhältnis, das er wegen der auf einander $z u$ beziehenden Be- und Entlastungen im Steuer- und Transfersystem als ein "zweiseitiges" bezeichnet (S. 118). 48) Die steuerliche Belastung und die soziale Entlastung saldiere sich zur "öffentlichen Last" (S. 102, 119); das Leistungsfähigkeitsprinzip sei demnach als ein $v$ e $r$ e $i l$ u g s p r inzip de $r$ ö $f$ e $n t l i c h$ e $n$ L a $t$ zu entwickeln, das steuerlastverteilungsprinzip als ein Subprinzip (S. 120). Daraus folge für den EinschluB der Transfers in den steuerlichen Einkommensbegriff, daB sie wie verdiente Markteinkommen der steuerlichen Lastverteilungsregel unterlägen. ${ }^{49}$ )

Dies bedeutet also zweierlei: zum einen sollen die Transfers selbst nach einem irgendwie gearteten Leistungsfähigkeitsprinzip zugemessen werden, sollen sie Eingang in das steuerliche Einkommen finden und dort entsprechend dem Steuerlastverteilungsprinzip integrativ mit allen anderen Einkommensteilen belastet werden. Nicht die exakte Gestaltung der Steuerlast und der Transfers in vertikaler Hinsicht soll hier weiterverfolgt werden, sondern allein die Auswirkungen des die steuern und Transfers umschlieBenden einheitlichen Verteilungsprinzips auf den Einkommensbegriff.

48) Unter Bezug auf A. Wagner (1891, S. 1 ff.) muB nach Birk dort, wo soziales Nehmen (Steuer) nicht möglich ist, soziales Geben Platz greifen, wenn insgesamt ein sozialer Zweck erfüllt werden soll. "Soziale Besteuerung und soziale Transferleistungen sind Bestandteile eines sozialen Transferverhältnisses, welches AusfluB der sozialen Finanz- und steuerpolitik ist und in seiner Gesamtheit von der Verteilungsregel erfaBt wird", S. 103.

49) D. Birk formuliert entsprechend seinem Untersuchungsthema seine Kritik in erster Linie verfassungsrechtlich, 1983, $\mathrm{S}$. $120 \mathrm{f}$.: Nicht mehr nur der Bürger bestimme in Eigenverantwortung, wie leistungsfähig er sein wolle, sondern auch der Staat; dieser mache seine Sozialleistungen, die der steuerlichen Bemessungsgrundlage zugerechnet würden, neben Einkommen und Vermögen zu Anknüpfungsmerkmalen der steuerlichen Lastentscheidung. Dadurch seien die dem Freiheitsbereich des Bürgers zugerechneten Anknüpfungsmerkmale entwertet; der Bürger verliere die seinen Freiheitsrechten zugeordnete Entscheidungsbefugnis über den Gegenstand, der Anknüpfungsmerkmal einer Lastenverteilungsregel sei. 
Das Problem der einheitlich-prinzipiellen Ausrichtung des SteuerTransfer-Systems muß als äuBerst schwierig bezeichnet werden. ${ }^{0}$ ) Nicht daB überhaupt Wertentscheidungen getroffen werden müssen, ist das Problem, sondern daB sie in so unterschiedlich historisch gewachsenen staatlichen Leistungszweigen einheitlich gefunden werden sollen, erscheint als die schwierige Aufgabe.

Wie auch immer sie getroffen werden, wertentscheidungen würden in jedem Falle in die Freiheit der Steuer- und Transferbürger eingreifen. Ginge man von solchen wertentscheidungen im Gesamtsystem aus, müBte der Gesetzgeber grundlegende Vorstellungen darüber entwickeln, in welchem Verhältnis MindestversorgungsgröBen zur Besteuerungsuntergrenze zu stehen hätten. Zumindest drei Wertentscheidungen wären zu treffen, um eine integrierte Steuer- und Sozialpolitik zu betreiben, wenn das transfereinschlieBende Einkommen der Indikator der Leistungsfähigkeit sein soll: Eine untere Versorgungsschwelle wäre festzulegen, unterhalb derer nicht nur keine steuern erhoben, sondern bis zu der Sozialtransfers gewährt würden. Zugleich müBte diese Schwelle in die allgemeine Transferpolitik inkorporiert werden, falls die "Verteilungsregel der öffentlichen Last" auch für die Sozialversicherungsrenten gelten soll. Ferner wäre zu bestimmen, bis $z u$ welcher Höhe überhaupt Transfers $z u z a h l e n$ sind (volle oder nur teilweise schlieBung der sog. "Armutslücke"). ${ }^{51)}$ Letztlich

50) Ein Blick auf die verschiedenen Bemessungsgrundlagen der Transfers zeigt, daB die unterschiedlichsten Einkommensdefinitionen verwendet werden, je nachdem, ob es sich um Leistungen nach dem Bundessozialhilfegesetz, nach dem Wohngeldgesetz, nach dem Arbeitsförderungsgesetz, Wohnungsbauprämiengesetz, Bundesausbildungsförderungsgesetz, Vermögensbildungsgesetz usw. handelt; siehe hierzu J. Giloy 1978, S. 41 ff. und 51 ff.

51) Vgl. hierzu die Entscheidungsinhalte im Konzept der "negativen Einkommensteuer": "Nach W. Albers (1977c, S. 937) können zwei Zielsetzungen verfolgt werden. Einmal das der Existenzsicherung der Staatsbürger; hier soll die negative ESt die bestehenden Transfers ergänzen, wenn sie zu niedrig sind (subsidiäre Aufgabe). Zum anderen soll sie als Instrument eines allgemeinen Umverteilungsziels, in das alle Bürger einzubeziehen seien, das differenzierte system der sozialen sicherheit ersetzen durch eine Art Staatsbürgerrente; hier geht die Umverteilungsabsicht über die steuerfreiheit des Existenzminimums weit hinaus. Den letzteren Aspekt stellt I. Metze (1982, S. 790) allein heraus, weist aber auf die begrenzte Möglichkeit dieser Zielerfüllung hin: Danach kann die negative ESt nur die sog. "Umverteilungstransfers" ersetzen, wie Sozialhilfe, Arbeitslosenhilfe usw.; die daneben bestehende Vielgestaltigkeit der "Versicherungstransfers bleibe erhalten, da sie auf erworbenen Ansprüchen

(Forts. siehe folgende Seite) 
wäre das SteuermaB auf dieses integrierte Einkommen festzusetzen, dessen Höhe nicht zuletzt mit Rücksicht auf die nunmehr breitere Bemessungsgrundlage $\mathrm{zu}$ bestimmen wäre (Aufkommensneutralität als ziel vorausgesetzt). Transfers würden somit wie Markteinkommen besteuert, die Kumulationswirkungen von Markteinkommen plus Transfereinkommen, aber auch von Transfereinkommen untereinander, würden solchermaBen steuerbedingt tendenziell ausgeglichen, würden - auch wenn die Häufung erhalten bliebe - zum Ausdruck der Leistungsfähigkeit gemacht. ${ }^{52}$ ) Zudem verhinderte die Totalerfassung unter EinschluB der Transfers, daB Verteilungsrelationen vor und nach der Besteuerung bzw. dem Transferzugang völlig auf den Kopf gestellt werden.

Das $\mathrm{Z}$ i e $\mathrm{l}$ einer integrierten Steuer- und Sozialpolitik erscheint somit als sinnvoll. Aber ist deshalb ein einheitliches Verteilungs - P r i n $z$ i p für so unterschiedliche Vorgänge angebracht? Ist es nicht vielmehr so, daB im Bereich der SozialTransfers das Bedürftigkeitsprinzip zu gelten hat, wie Immer seine konkrete Gestaltung aussehen mag? Und ergibt sich eine "Leistungsfähigkeit" für jene, die Transfers erhalten, nicht erst n a c h dem Zugang aller ökonomischen GröBen, sprich Einkommenselemente, $z u$ denen auch die Transfers gehören? Dies ist unser Haupteinwand gegen die Funktionstüchtigkeit eines allgemeingültigen Verteilungsprinzips: Für so diametral einander entgegengesetzte staatliche Handlungsweisen wie das (steuerliche) Nehmen und das (transferielle) Geben kann es kein einheitliches Handlungsprinzip geben, auch wenn das ziel der Handlungen darin besteht, einen Mindestkonsens $z u$ finden über die Verteilungsposition und Lebenslagen derer, die von Transfers und Steuern erreicht bzw. getroffen werden. So mag das gemeinsame ziel für die steuer- und Transferpolitik darin bestehen, den steuerbürger erst ab einem

Forts. Fn. 51 :

beruhe (Sozialversicherungsrenten, Krankengeld der ges. Krankenversicherung usw.).

52) Soweit argumentiert wird, die Höhe der Transferleistungen sei mit Rücksicht auf ihre steuerfreiheit bemessen worden, kann dem nicht gefolgt werden: selbst wenn die Festsetzung der Höhe von Transfers nicht dem Leistungsfähigkeitskonzept folgt, so ist ihre Bemessung die eine Sache, die Festsetzung des SteuermaBes die andere. N. Andel (1979a, S. 344) macht deutlich, daB der Ausweis der BruttogröBen dem Konzept der Leistungsfähigkeit entspricht; der korrekte Weg ist demnach die Erhöhung der Transfers bei ihrer vollen Besteuerung. 
bestimmten Existenzsicherungsbetrag $\mathrm{zu}$ besteuern, den Transferburger bis zu diesem Betrag zu unterstützen. Der Sinn der Gemeinsamkeit liegt darin, daB beide unterhalb dieses Betrages keine Entscheidungsfreiheit, keine ökonomische Dispositionsfähigkeit haben, da sie dem zwang zur Existenzsicherung unterliegen. Der Steuerbürger - mag er auch ein relativ hohes Einkommen haben - wird erst oberhalb des Existenzsicherungsbetrages überhaupt leistungsfähig (i.S.v. "steuertragfähig"), der Transferbürger dagegen ist unterhalb der Mindesttransfers "bedürtig". Das staatliche Handlungsprinzip im Existenzsicherungsbereich ist für den Steuerbürger auf die steuerliche Schonung, auf das Nichteingreifen, für den Transferbürger aber auf das aktive, teilnehmende Elngreifen ausgerichtet. Erst soweit steuer- wie Transferburqer über ökonomische GröBen jenseits des Existenzsicherungsbetrages verfligen - ersterer kraft elgenen Leistungseinkomnens belspielswelse, letzteter möglicherweise infolge einer Kumulation von Transfers - , setzt für beide die Leistungsfähigkeit ein. Das Leistungsfähigkeltsprinzip auch als ein Prinzlp für die Belastbarkelt der öffentlichen Haushalte $\mathrm{zu}$ verstehen, hieße übersehen, daß die "öffentliche" Last nicht mit der privaten vergleichbar ist. Beide Lasten können demnach nicht ein und demselben Belastungsprinzip unterworfen werden.

Mithin ist das Leistungsfähigkeitsprinzip ausschlieblich ein Steuerlastverteilungsprinzip. Was aber den Wert der Diskussion um ein vermeintlich einheitliches "öffentliches Lastverteilungsprinzip" ausmacht, ist der DenkanstoB, Transfers in das steuerliche Totaleinkommen einzuschließen. Mögen sie nämlich aufgrund einer Beitrags-Leistungs-Äquivalenz oder aufgrund des Bedürftigkeitsprinzips gewährt werden, in ihrer Kumulierung - evtl. zusammen mit Leistungseinkommen - zeigen sie jenseits der Bedurftigkeits- und Existenzslcherungsgrenze in jedem Fall steuerliche Leistungsfähigkeit an.

3. Das Allgemeinheitspostulat soll mit Blick auf die Leistungsfä.higkeit sowohl die Nicht- als auch die Doppelerfassung ausschlieBen. Die Gefahr der Nichterfassung ist bei den offentlichen Sozial- 
transfers gegeben, die der Doppelerfassung bei den privaten und den Sozialversicherungstransfers, soweit hier dem Transferempfang eine Sparleistung des Empfängers vorausgeht, die aus bereits versteuertem Einkommen aufgebracht wurde.

a) Daraus ergeben sich die Probleme für die Besteuerung oder Nichtbesteuerung der späteren Transfers: Diese können GröBen-Umschichtungen ${ }^{53)}$ und Erträge enthalten; nur die letzteren zählen $z$ um Einkommen. ${ }^{54)}$ Um die Nicht- und Doppelerfassungsprobleme auszuschlieBen, hat man das "Kor $r$ e $\mathrm{p} \circ \mathrm{n}$ d e $\mathrm{z} p \mathrm{r}$ i $\mathrm{i} p$ " formuliert. 55) Dieses verlangt vom steuergesetzgeber, daB er eine belastungspolitische Abhängigkeit beachtet zwischen der Steuerbefreiung der nicht-konsumtiven Einkommensverwendung in der Gegenwart und der Besteuerung des Einkommenszugangs in der Zukunft und auch zwischen der Steuerbefreiung einer Einkommensverwendung bei der verpflichteten Person und der Besteuerung des Einkommenszugangs bei der berechtigten. Korrespondenzbeziehungen sind also temporaler und personaler Art; sie sind aber sachlich eingegrenzt auf den nichtbetrieblichen Bereich.

53) F. Neumark (1961b, S. 33) nennt die "Umschichtung der Vermögensstruktur" die "unwirksamen Einkünfte". Es ist aber zu beachten, daB die Vermögenstruktur vielgestaltig sein kann (Sach-, Geld- und Forderungsvermögen) und daB Vermögensumschichtungen zwar Korrespondenzfälle darstellen, aber nicht die einzigen; wie unten ausgeführt wird, sind auch Einkommensumschichtungen als Korrespondenzfälle denkbar.

$54)$ N. Andel (1979a, S. 338): "Leibrenten, die aus Ansprüchen herrühren, die mittels aus versteuertem Einkommen geleisteter Zahlungen erworben wurden, stellen in Höhe des Kapitalrückflusses lediglich Aktivtausch dar. Nur der darüber hinausgehende sog. Ertragsanteil ... hat den Charakter steuerpflichtiger Bruttoeinnahmen."

55) Das Korrespondenzprinzip geht aus den folgenden Ausführungen von N. Andel (1979a, S. 338) hervor: "Ungeachtet der Auffassung, daB KapitalrückfluB kein Einkommen im Sinne der Erhöhung der Dispositionskraft darstellt, ist eine steuerliche Erfassung des gesamten Rentenbetrages $z u$ rechtfertigen, ja zu fordern, wenn die gezahlten Beiträge, die den Anspruch begründeten, steuerfrei waren." - H. Weise 1979, S. 417: "Das Prinzip besagt, daB Teile des Leistungseinkommens, wie z.B. Vorsorgeaufwendungen ... die der Verfügbarkeit des Steuerpflichtigen (zeitweilig) entzogen sind ..., bei späterem effektivem ZufluB 'nachzuversteuern' sind. Nach demselben Prinzip muB auch Einkommen, das aus einer steuerbefreit gebildeten 'Quelle' flieBt, ... zur steuer herangezogen werden." Slehe auch W. Schmähl 1981a, S. 265: Zwel Varlanten der Besteuerung: Vorsorgeaufwendungen in der Erwerbsphase steuerfre1, und daraus fließende Alterselnkinfte voll besteuert (Variante I)

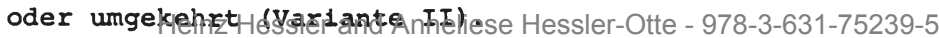


Es soll an dieser Stelle dem Korrespondenzprinzip nicht so weit nachgegangen werden, daB etwa auch die VerstöBe gegen das Gleichbehandlungspostulat für alle Transfers aufgezeigt werden. ${ }^{56)}$ Insofern sind auch keineswegs die Fälle von Belastungsdifferenzierungen durch Freibeträge und tarifäre Maßnahmen aufzuspüren. Vielmehr soll anhand der im folgenden gegebenen Einteilung. die nicht die üblichen Gliederungen der Transfers ersetzen kann, ${ }^{57)}$ eine Beurteilung versucht werden, inwieweit das Korrespondenzprinzip geeignet ist, die Einkommensqualität der Transfers $z u$ klären (Ubersicht 7.4).

Der hier verwendete $T$ r a $n$ f e $r$ b e g $r$ if ist nicht der breite finanzwissenschaftliche, ${ }^{57 a)}$ sondern der der TEK 1979 und 1981, wie er oben definiert wurde als das einer Person aus öffentlichen und privaten Quellen zugehende Ubertragungseinkommen (s. W. Albers 1977c passim). Transfers werden entweder aus dem laufenden Einkommen von Personen (bzw. aus dem laufenden Jahresergebnis von Betrieben) oder aus dem Vermögen finanziert. Ubersicht 7.4 demonstriert diese "typenreine" Trennung von einkommens- und vermögensgebundenen Transfers. ${ }^{58)}$ Zugleich wird, wie das üblich ist, in die intra- und interpersonalen wie auch in die intra- und intertemporalen Transfers unterschieden. ${ }^{59}$ ) während die einkommensge-

56) Siehe hierzu insbes. D. Brümmerhoff 1979, S. $219 \mathrm{ff}$, und N. Andel 1970; ferner D. Pohmer 1988, S. 143 u. $150 f$.

57) Siehe hierzu insbes. SRK 1971, S. 154; G. Rose 1982a, S. 90 ff. u. 235; H. Beisse 1981, S. 1077, und B. Dreyer/W. Oberborbeck 1981 , S. 217 ff.

57a)dieser enthält u.a. Schuldenzins- und Schuldentilgungsausgaben, wobei dieser weite Begriff nicht auf ungeteilte zustimmung stößt.

58) Die Trennung basiert auf der grundlegenden Unterscheidung der Transfers in solche aus dem vermögen und solche aus der laufenden Wertschöpfung, siehe die theoretischen Ausführungen in $\$ 8$ III und tbersicht 3.2 .

59) Siehe auch w. Albers 1977c, S. 907, der unter verzicht auf die Trennung $z$ wischen vermögensgebundenen und vermögensungebundenen Transfers zu der folgenden Einteilung kommt:

"1. intertemporaler Transfer ohne personellen Wechsel (Alterssicherung)"; wir nennen diesen den intertemporal-intrapersonalen Transfer, Spalte 4 in Ubersicht 7.4);

"2. interpersoneller Transfer in der gleichen Periode (Unterhaltungszahlung)"; dieser Transfer ist bei uns der intratemporal-interpersonale, Spalte 1 in Ubersicht 7.4 ;

" 3 . interpersoneller und gleichzeitig intertemporaler Transfer (Arbeitgeberleistungen zur Zukunftssicherung ihrer Arbeitneh-

(Forts. siehe folgende Seite) 
Ubersicht 7.4: Idealtypische temporale und personale Korrespondenzbeziehungen in der Transferbesteuerung

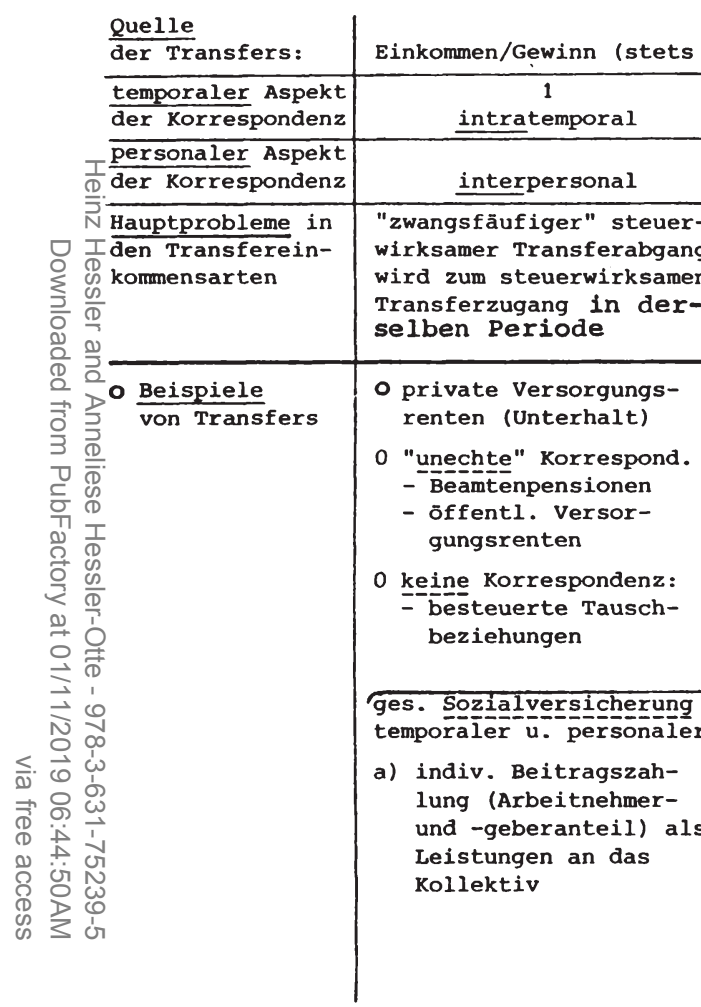

Sach- / Geld- / Forderungs-

Kapital/Vermögen (stets intertemporale Transfers

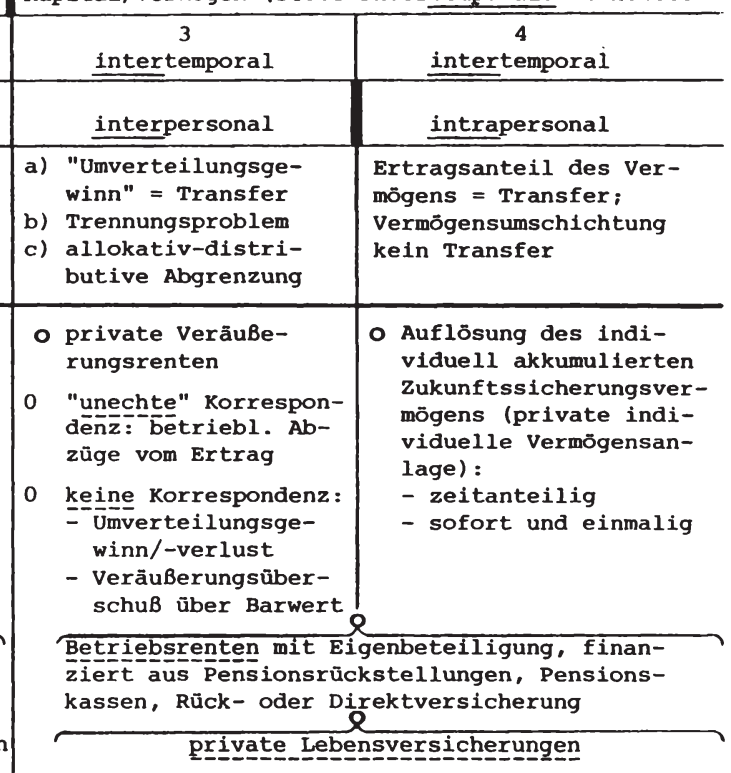

a) mit "Umverteilungs- b) ohne "Umverteilungsgewinnen": die Zukunftsleistung entspricht der kollekt. Vermögensakkumulation gewinne": die $\mathrm{Zu-}$ kunftsleistung entspricht der individ. Vermögensakkumulation lungsgewinn/-ver Umverteilungen $\mathbf{z w}$. Gruppen u. Generationen tragungseinkormen;

kungen

- durch Eigenbeitrag auf Zukunftssichesonales Konzept Betriebspension gesetzl. Sozialver qua Umlageverfahren =

b) Anspruchserwerb auf indiv. Sicherung durch Kollektivleistunge

Lebenszeit-Umvertei- 
bundenen Transfers "typenrein" ausschlieblich interpersonal denkbar sind, können die vermögensgebundenen Transfers sowohl interpersonal als auch intrapersonal ablaufen. Vermögensgebundene Transfers sind aber immer zugleich auch intertemporale, da zwischen der Vermögensbildung durch das Sparen und der Auslösung durch die Verrentung eine Zeitspanne vergeht. Diese fehlt bel der Finanzierung der Transfers aus dem laufenden Einkommen bzw. Gewinn, weshalb sie als intratemporale Einkommensubertragungen gelten.

Will man sich dagegen einen Transfer vorstellen, der aus dem Einkommen finanziert wird, und zwar aus dem verschiedener Personen, und der zugleich trotz fehlender Bindung an Vermögen intertemporal möglich sein soll, so ist das nur denkbar als ein temporalpersonales Mischkonzept: Durch Eigenbeiträge in der Gegenwart erwirbt der Zahler Ansprüche auf künftige tbertragungen aus dem Einkommen anderer Personen; das Intrapersonale liegt in den eigenen Konsumverzichts- (= Beitragszahlung = "Spar") Verfügungen, das Interpersonale in den "Ubertragungs"-Einkommen, das Intertemporale in dem aus heutigen Beiträgen finanzierten "Zukunfts"-Einkommen und das Intratemporale in dem in der Gegenwart bzw. Zukunft jeweils ablaufenden "Generationenausgleich", in dem die Beiträge der aktiven Generation korrespondieren mit dem Rentenempfang der inaktiven Generation. Der generative Lastenausgleich selbst verläuft also intratemporal-interpersonal, wohingegen der durch Eigenbeiträge erworbene Anspruch auf die Leistungen anderer eine intrapersonal-intertemporale Beziehung herstellt. Prototyp dieser "typenunreinen" Transfers ist die gesetzliche Sozialversicherung mit dem Umlageverfahren. ${ }^{601}$

Forts. Fn.59:

mer)"; Transfers solcher Art haben wir sowohl in spalte 2 als auch in spalte 3 ausgewiesen, da sie einmal ohne, elnmal mit Vermögensbindung auftreten können; die von Albers gemeinten Betriebspensionen sind mit Vermögenakkumulation (innerhalb des Betriebes oder auBerhalb bei Rück- oder Direktversicherungen) verknüpft.

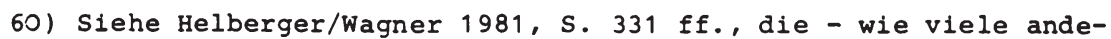
re Autoren - für die gesetzliche Sozialversicherung eine Querschnittsbetrachtung und eine Lebenszeitbetrachtung unterscheiden (s. z.B. auch W. Schmähl 1977b); die Querschnittsbetrachtung untersucht die "intergenerationale Umverteilung" von Aktiven $z u$ Rentnern, die Umverteilungen innerhalb der zahlenden und empfangenden Gruppen sowie die Umverteilung von den

(Forts. siehe folgende Seite) 
Die Einordnung der verschiedenen tatsächlichen Transferbeziehungen in die $I d e a l t y p i k$ d e $r \quad k \circ r$ e $p \circ n-$ $\mathrm{d}$ e $\mathrm{n} z$ e $\mathrm{n}$ (Ubersicht 7.4) zeigt, daB sich in manchen Transfers die intra- und intertemporalen sowie die intra- und interpersonalen Elemente mischen. Da die heutige gesetzliche Sozialversicherung das Deckungsstockverfahren nicht mehr kennt, kann sie nicht als sach-, geld- oder forderungsvermögensgebundener Transfer eingeordnet werden. Da das Umlageverfahren Teile des gegenwärtig erwirtschafteten Einkommens auf die Rentner überträgt, handelt es sich insoweit um eine intratemporale Korrespondenzbeziehung. So sind auch mit den einzelnen Transfers oft mehrere steuerliche probleme zugleich verbunden. ${ }^{61)}$ Als die wesentlichen Probleme können

Forts. Fn. 60 : Nichtmitgliedern der GRV zu den Mitgliedern qua StaatszuschuB; wir nennen das die interpersonalen Transfers, die intratemporal ablaufen. In der Lebenszeitbetrachtung unterscheiden sie die "echte" interpersonale Umverteilung der Lebenseinkommen (sie kann nur zugleich auch eine intertemporale sein) von der intertemporalen; daneben gibt es den "Risikoausgleich", der nach unserer Auffassung sowohl intrapersonal wie intertemporal möglich ist. - Somit glauben wir, die intergenerativen Beziehungen mit unserem Schema der vier grundlegenden Transferbeziehungen "intrapersonal", "interpersonal", "intratemporal" und "intertemporal" vollständig erfaBt zu haben.

6I) Als ein Beispiel für die Bündelung der verschiedensten Probleme kann die gesetzliche Sozialversicherung gelten. Der Anspruchswerwerb und das Umlageverfahren weisen sie zunächst als ein Konzept aus, in dem die individuelle Beitragszahlung und der Anspruch auf spätere Sicherung durch das Kollektiv miteinander korrespondieren, jedoch nicht der Höhe zwischen Beitrag und Rente nach, sondern dem Grunde nach; durch die Dynamisierung der Rente hat sich die Höhe der Beitragszahlung von der Rentenhöhe gelöst. Zudem ist im Beitrag der Arbeitgeberanteil enthalten, der die Höhe eigener Beiträge beeinfluBt. Ferner sind über die Umverteilungsgewinne und -verluste hinaus, die mit der Lebenserwartung (so auch bei den privaten Lebensversicherungen) verknüpft sind, weitere Umverteilungsprobleme gegeben (N. Andel 1970, S. 339):

(a) "innerhalb des Kreises der Versicherten gleichen Alters durch von den Prinzipien privater Lebensversicherungen abweichende sozialpolitisch motivierte Beitrags- oder Leistungsstaffelungen" (gleicher Beitragsatz für Ledige und Verheiratete, obwohl die Leistung an die witwe eines verstorbenen Beitragszahlers weitergeht) ;

(b) "zwischen Versicherten und steuerzahlern gleichen Alters durch Zuschüsse aus allgemeinen Haushaltsmitteln";

(c) "zwischen den Generationen durch eine Politik der für die einzelnen Altersjahrgänge betriebenen systematischen Differenzierung zwischen dem Wert der jeweiligen Beiträge einschl. des Anteils an den laufenden Zuschüssen aus den allgemeinen Haushaltsmitteln und dem Wert der zuflieBenden Renten" (dynamische Anpassung der Renten). 
die in den Spalten der Ubersicht 7.4 ausgewiesenen gelten, nämlich zunächst das "A b g a n g $s$ - Z u g a n g - P r o b l e m", das vorwiegend die interpersonal-intertemporalen Korrespondenzen (Spalte 1) kennzeichnet, ferner das Problem der "a $110 \mathrm{k}$ a $t i v-d i s t r i b u t i v e n$ A b g r e nzung" (Spalte 3: interpersonal-intertemporale Korrespondenzen), das dann entsteht, wenn den Verpflichtungen im betrieblichen Bereich, die dort Betriebsausgaben oder Werbungskosten sind, Transferzugänge im privaten Bereich gegenüberstehen, die hier als Einkommen versteuert werden. Ein weiteres Problem ist das der " $\mathrm{m} s \mathrm{~s} i \mathrm{c} h \mathrm{t} u \mathrm{n}$ " zwischen Transfers und Vermögen (bzw. zwischen Transfers und Beitragssparen für die gesetzliche Sozialversicherung), das in erster Linie in den intrapersonal-intertemporalen Korrespondenzen auftaucht (Spalte 4). Eine besondere Problematik stellen die "U m verte $\mathrm{i} l \mathrm{l}$ ng $\mathrm{s} g$ e $\mathrm{w}$ i n e bzw. -verluste" dar (Spalte 2 und 3); sie entstehen durch ein Abweichen der individuell erreichten Lebenszeit gegenüber der für die Versicherungsbeiträge errechneten durchschnittlichen Lebenserwartung nach oben bzw. unten. Im Bereich der privaten Lebensversicherungen sind sie mit Vermögensumverteilungen verbunden (N. Andel 1970), doch sind sie auch im Bereich der nicht an Vermögen gebundenen Sozialversicherungen denkbar. Denn diese Versicherungsform, die zwar weithin am Prinzip der Aquivalenz von Beiträgen und Leistungen ausgerichtet ist (Helberger/wagner 1981, s. 331), enthält spezielle "Ubertragungsmechanismen" insbesondere in Form der Mitgliedschaft samt Beitragspflicht sowie der Beitragsbemessungsgrenze ( $\mathrm{Ph}$. HerderDorneich 1981a, S. 405 ff.), die trotz der Äquivalenz zu Umverteilungen führen, zu gruppenspezifischen Begünstigungen sowohl bei der Beitragszahlung als auch beim Leistungsbezug (Helberger/Wagner 1981, S. 339).

Wenn das Korrespondenzprinzip mit "Vermögensumschichtung" in Verbindung gebracht wird, so ist das richtig, aber unvollständig; richtig insofern, als Vermögensumschichtungen tatsächlich echte Korrespondenzfälle sind; unvollständig insofern, als auch Einkommensteile umgeschichtet werden können, nämlich jene gesparten bzw. nicht konsumierten Einkommensteile, die entweder in solche Anlageformen investiert wurden, die Vermögensfunktionen (s. § 11) erfüllen (Vorsorgetransfers) oder die bei dem Transferempfänger zur Existenzsicherung benötigt werden (Existenzsicherungstransfers). 
Zu den Vorsorgetransfers würde z.B. die Einkommensverwendung für die Sozialversicherungsbeiträge gehören, zu den Existenzsicherungstransfers die Einkommensverwendung zur Unterstützung von bedürftigen Personen. Statt Vermögensumschichtung wäre der Terminus "Umschichtung von VerfügungsgröBen" angebracht, bzw. die Kurzform "Verfügungsumschichtung". Die Bedingung für die steuerentlastende bzw. -belastende Wirkung, die einerseits temporal, andererseits personal eintritt, ist jedoch stets die nichtkonsumtive Einkommensbzw. Vermoggensverwendung: Soll die Einkommensminderung heute (bel den intrapersonalen Vorsorgetransfers) bzw. beim Transfergeber (bei den interpersonalen Existenzsicherungstransfers) eintreten, muB die Einkommensverwendung entweder Sparcharakter oder Unterstützungscharakter haben und solchermaBen zu einer Einkommensmehrung morgen bzw. beim Transfernehmer fuhren.

So läBt sich das Vorliegen von Korrespondenzen wie folgt definieren: Bezogen auf die personale Seite korrespondiert der nichtkonsumtive Abgang an VerfügungsgröBen (Einkommen bzw. Vermögen) bei der einen Person mit dem entsprechenden zugang bei der anderen; bezogen auf die temporale seite korrespondiert der nichtkonsumtive Abgang an Verfügungsgrößen in der Gegenwart mit dem entsprechenden Zugang bei derselben Person in der zukunft.

b) Im Zusammenhang mit den $z$ e $i t g i$ e $i c h$ ablaufenden und dem Versorgungsziel dienenden $E$ i $\mathrm{n} \mathrm{k} \circ \mathrm{m}$ e $\mathrm{n}-\mathrm{U}$ b e r t $r$ a g u $n$ g e $n$ liegt die Korrespondenzbeziehung darin, da $B$ dem Zugang bei der empfangenden Person ein Abgang bei der gewährenden Person oder dem gewăhrenden Kollektiv (Betrieb oder öffentlicher Haushalt) entspricht. Da das Korrespondenzprinzip ein steuerliches Prinzip ist; das einerseits den Abgang entlastet, andererseits den zugang belastet, da es ferner nur auf Transfers angewendet wird, gelten die Fälle einer echten (zeitgleichen und zwischen-personalen) Korrespondenz somit die dem Versorgungsziel dienenden und aus dem laufenden Gewinn bzw. Einkommen finanzierten Betriebsrenten (-pensionen) bzw. privaten Unterhaltszahlungen. Betriebsrenten werfen im Gegensatz $\mathrm{zu}$ den letzteren besondere Fragen der "Umverteilungsgewinne" und "-verluste" sowie der allokativdistributiven Abgrenzung auf, die erst später zusammen mit den Lebensversicherungen $z u$ erörtern sind. Die Einkommensverfügungen $z u$ Unterhaltszwecken, die auf seiten der empfangenden Person ein Uber- 
tragungseinkommen ist, ist für die leistende Person zunächst daraufhin zu untersuchen, ob bei ihr trotz der Abgangsverfügung steuerliches Einkommen vorliegt. Wirtschaftstheoretisch ist dieses Problem bereits gelöst, da sämtliche Einkommensteile, auch die verwendeten, nach der ad-personam-Regel des zugangs und nach dem Verfügbarkeitskriterium Einkommen sind, so daB es hier keine "durchlaufenden Posten" geben kann. Was der Geber transferiert, ist für ihn Einkommen, muB es logisch vorher gewesen sein.

Demgegenüber stellt die steuerliche Lösung des Problems auf die Leistungsfähigkeit ab, die entweder beim Geber oder beim Nehmer vermutet werden kann. Dem Korrespondenzprinzip, das ja als steuertechnische Regelung die Doppelerfassung für den Fall ausschlieBen will, daB der Transfer beim Nehmer als steuerliches Einkommen gelten soll, beim Geber dagegen nicht, geht die steuerpolitische Entscheidung voraus, bei welcher Person die Leistungsfähigkeit anzunehmen ist. W. Albers (1979a, S. 199) möchte die Entscheidung anhand der Bedürfnisbefriedigung treffen: Weil das Ubertragungseinkommen besser an die Bedürfnisbefriedigungsmöglichkeiten des Transferempfängers angepaBt werden könne, solle der Transfer vom Einkommen des Gebers steuerlich abgezogen werden. Aber eine solche Entscheidung anhand der Bedürfnisbefriedigung ist nur dann eindeutig, wenn man Bedürfnisbefriedigung mit Konsum gleichsetzt. Sobald man aber den Gedanken zuläBt, daB auch das Geben Bedürfnisbefriedigung, diesmal seelischer Art, verschafft, ergibt sich keine eindeutige Zurechnungsregel.

VerläBt man die metaökonomische Betrachtung, bietet sich die ökonomische Dispositionsfähigkeit, die freie Verfügbarkeit als $\mathrm{Zu}-$ rechnungsregel an. $\mathrm{Zu}$ prüfen ist sie vorerst beim Geber, bei dem zuallernächst Einkommen vermutet werden darf. Kann er frei verfügen, ist das Einkommen auch bei ihm $\mathrm{zu}$ lokalisieren und $\mathrm{zu}$ besteuern. Liegt dagegen ein Verwendungszwang als sittliche oder rechtliche Verpflichtung vor, wäre nach der Korrespondenzregel nunmehr das Einkommen beim Empfänger zu lokalisieren. Ob hier die Transfers allerdings auch $\mathrm{zu}$ besteuern sind, entscheidet sich danach, ob sie zusammen mit anderen $1 \mathrm{hm}$ zugehenden Einkommenselementen unterhalb oder oberhalb eines gesellschaftspolitisch akzeptierten Existenzsicherungsbetrages liegen. ${ }^{62)}$ Nur soweit das Ge-

Fn. 62 siehe folgende Seite 
samteinkommen diesen übersteigt, kann es frei verfügbar sein, Leistungsfähigkeit indizieren und besteuert werden. Das Korrespondenzprinzip leistet anhand der freien Verfügbarkeit mithin zunächst die Funktion der Einkommenslokalisierung, bestimmt also, wo das Einkommen $z u$ besteuern ist; es leistet ferner Beihilfe zur Lösung der Frage, ab welcher $\mathrm{H}$ ö h e das Einkommen $\mathrm{zu}$ besteuern ist. LäBt man das Kriterium der freien Verfügbarkeit gelten, führt demnach das Korrespondenzprinzip nicht in jedem Fall, in dem beim Geber Steuerfreiheit gewährt wird, zwingend $z$ ur korrespondierenden tatsächlichen Besteuerung beim Nehmer. Andererseits - immer die Freiheit in der Verfügung beim Geber als die kritische GröBe im Auge behaltend - können Transfers, die der Geber freiwillig und ohne Zwang gewährt und die deshalb bei ihm steuerbares Einkommen sind, sehr wohl auch beim Empfänger, da sie ihm zugehen und verfügbar sind, steuerbares Einkommen sein, nämlich dann, wenn sie zusammen mit den anderen Einkommenselementen die Existenzsicherung übersteigen und insoweit freie Verfügbarkeit ausdrücken. Das Korrespondenzprinzip läBt sich also nicht mechanisch anwenden, sondern bedarf stets der sinngebenden Interpretation durch eine Prüfung der freien Verfügbarkeit. Als ein Handlungsprinzip fordert es lediglich auf, die freie Verfügbarkeit korrespondierend sowohl beim Geber als auch beim Nehmer zu prüfen. ${ }^{63)}$ Keineswegs darf daraus gefolgert werden,

Fn. 62 :

Zur gesellschaftspolitischen Akzeptanz gehört auch die mit dem Zwang verbundene Prüfung, ob die Verpflichtung zu einem Transfer als den $\mathrm{Zielen}$ der Belastungspolitik angemessen gelten kann; diese ist allein schon deswegen notwendig, um willkürliche Verlagerungen der Einkunftsquellen nach dem Prinzip der Individualbesteuerung auszuschlieBen und um ein Ausweichen vor der Progression zu verhindern; siehe hierzu W. Albers 1977c, S. 908; K. Tipke 1991, S. 194; H. Weise 1979, S. $397 \mathrm{ff}$. u. $417 \mathrm{ff}$.

63) W. Albers (1979a, S. 199) und G. Krause-Junk (1981, S. 263) treffen aus dem Blickwinkel des Totaleinkommenskonzepts eben diese Entscheidung nach der Freiwilligkeit, mit der ein Leistender an einen Empfänger Transfers bewirkt: Weil dem Leistenden bei gesetzlich erzwungenen Transfers weder materiell noch psychisch ein Vorteil entstehe, könnten sie ihm innerhalb des Reinvermögenszugangskonzepts auch nicht als Einkommen zugerechnet werden. Hier wird also die Einkommenseigenschaft an die Vorteilsverschaffung gebunden, und die ist jedenfalls beim Geber nicht vorhanden. "Derartige Zahlungen haben also in einem vernünftigen ökonomischen Einkommensbegriff nichts zu suchen" (G. Krause-Junk, ebda.). Wir deuten das "vernünftige ökonomische" als eine Orientierung des Einkommensbegriffs an der Verfügungskraft. 
daB etwa die steuerliche Leistungsfähigkeit entweder beim Geber o d e $r$ beim Nehmer liegt; sie kann - entsprechend der "freien" Verfügbarkeit - auch bei beiden oder bei niemandem liegen.

c) Bei den $z$ e $i t v$ e $s$ e $t$ z ablaufenden und aus $v$ e $r$ $m$ ö $\mathrm{g}$ e $\mathrm{n}$ gespeisten "Transfers einer Person an sich selbst" (Spalte 4 in Ubersicht 7.4) handelt es sich um eine Korrespondenzbeziehung zwischen Einkommenszugängen derart, daB ein künftiger Zugang (Verrentung des Vermögens) nur möglich ist aufgrund der zweckgebundenen Verwendung eines gegenwärtigen Einkommenszugangs (individuelles Vorsorgesparen, kollektives privates Versicherungssparen). Somit soll nach dem Korrespondenzprinzip eine integrierte Besteuerung aller mit der Zukunftssicherung zusammenhängenden Beitragsabgaben einerseits und Rentenleistungen andererseits gefunden werden. Die "korrespondierende" Gestaltung soll für die Fälle gelten, daB man sich steuerpoltisch $n i c h t$ dafür entscheiden will, entweder nur die heutige Beitragsabgabe zu besteuern (exakt: sie nicht von der Steuer $z u$ befreien; dann aber soll die spätere Rentenzahlung insgesamt und völlig steuerfrei bleiben) oder umgekehrt nur den späteren Empfang der gesamten Rente einschlieBlich aller Kapital- und Ertragsanteile $z$ u besteuern (wobei die vorherige Vermögensakkumulation durch Sparen unbesteuert bleibt). Das Korrespondenzprinzip folgt hier dem Grundsatz, daB der Zugang an ökonomischer Verfügungskraft, da er Leistungsfähigkeit ausdrückt, zumindest einmal, aber auch nicht mehr als einmal, steuerlich erfabt wird; man kann dies als das Prinzip der "Einmal-Besteuerung" des Einkommens bei der gleichen Person bezeichnen (A. Albers 1977C, S. 906; H. Weise 1979, S. 398). 63a) Uber diese zeitlich korrespondierende grundsätzliche Besteuerung der Vermögensakkumulation hinaus ist es geboten, auch den zinsertrag des durch das Beitragssparen gebildeten Vermögens, also den in der späteren Rentenzahlung enthaltenen Ertragsanteil zu besteuern, da er einen Zugang an ökonomischer Dispositionskraft darstellt. Die Besteuerung des Ertrags hat jedoch mit dem Inhalt des Korrespondenzprinzips ebensowenig $z u$ tun wie wenn man etwa das Beitragssparen nicht von der steuer befreien und $z u-$

Fußnote $63 a$ auf der folgenden seite 
sätzlich noch die Rente besteuern wollen; denn im Fall der Ertragsbesteuerung folgt die Steuererhebung aus dem Allgemeinheitspostulat, wohingegen die kumulative Besteuerun sowohl des Beitrag-Sparens als auch der Rente auf eine Besteuerung der Vermögensumschichtung, d.h. auf eine doppelte Erfassung des Lebenseinkommens (D. Brümmerhoff 1979, S. 219) hinausliefe. 64 )

Das intertemporale, intrapersonale und vermögensgebundene Korrespondenzprinzip setzt also einen Einkommensbegriff voraus, der nach der zugangsregel konzipiert ist und die vermögensumschichtung nicht zum Einkommen rechnent, weil die Verfügbarkeit hierüber in der Besteuerungsperiode bereits vorhanden war. Zinserträge hingegen sind ein Neuzugang an Verfügbarkeit; sie sind unter dem Aspekt der Leistungsfähigkeit als steuerliches Einkommen zu erfassen, doch folgt das aus dem Allgemeinheitspostulat, nicht aus dem Korrespondenzprinzip. Letzteres ist nicht auf die Totalerfassung hin konzipiert, sondern auf die Erfassungsalternativen hin: Nach dem Korrespondenzprinzip müssen sich die steuerlichen Befreiungen der Sparbeiträge $h$ e $u t$ e (Vermögensakkumulation) und die steuerliche Erfassung der Rentenzahlungen $s$ p ä $t$ e $r$ (Vermögensauflösung) entsprechen; dieselbe Entsprechung ist gegeben, wenn das Sparen nicht von der Steuer befreit wird, die Rentenzahlung aber dann später auch nicht besteuert wird. 65 )

63a) Das Prinzip der Einmal-Besteuerung auf mehrere Personen auszudehnen, würde der "ad-personam-Regel" und damit dem Leistungsfähigkeitspostulat zuwiderlaufen, siehe $\$ 11$.

64) Diese Trennung zwischen dem Korrespondenzprinzip und dem Allgemeinheitspostulat soll eingeführt werden, weil sich mit ihr darstellen läßt, daß trotz Verwirklichung des Korrespondenzprinzips das Allgemeinheitspostulat verletzt sein kann, daß aber eine verletzung des Korrespondenzprinzips zugleich auch stets das Allgemeinheitspostulat verletzt.

65) Wir widersperechen also hier der Auffassung von D. Brümmerhoff (1979, S. 220), der es als Konsequenz des Korrespondenzprinzips bezeichnet, bei einer steuerbefreiung der Beiträge zur Alterssicherung den späteren Kapitalrückfluß $\mathrm{p} l \mathrm{u} s$ den Zinserträgen $\mathrm{zu}$ besteuern. Diese Konsequenz vermögen wir a 1 l e $i \mathrm{n}$ aus dem Korrespondenzprinzip nicht zu ziehen. Wenn D. Brümmerhoff (1979, S. 220, Fn. 10) feststellt, daB die SRK 1971 den Zinsnateil außer acht gelassen habe, so kann (Fortsetzung folgende Seite) 
Gleichwohl gehört der "Kapitalrückfluß" plus zinsen zum Inhalt der Transfers, und eine Besteuerung der gesamten Transfers wïrde beide Bestandteile erfassen. Somit entspricht die Gesamterfassung der gleichzeltigen Geltung von Korrespondenzprinzip plus Totalitätspostulat.

Welcher Einkommensbegriff der hier ausgewiesenen intertemporären Korrespondenz nunmehr für die Besteuerung präferiert werden sollte, ob der einer sofortigen Besteuerung des Totaleinkommens ohne Abzug des Beitragsparens - sie sei "B e i t r a g s b e $s t$ e u e r u n g" genannt - oder der einer späteren integrierten Besteuerung der Renten, vermehrt um ihre Ertragsantelle sie sei "R e $n t$ e $n$ b e $s$ e u e $r$ u g" genannt (s. Ubersicht 7.5) - entscheidet sich nach den Argumenten, die fur beide Besteuerungsalternativen vorgebracht werden können.66) Wenn man ausschließlich vom wirtschaftstheoretischen Einkommensbegriff her argumentiert, müBte gelten, daB die Art der Einkommensverwendung (Sparen) keinen EinfluB auf den Einkommensbegriff haben darf, 67) so daB das Einkommen im Augenblick seines Zugangs zu besteuern wăre, das Beitragssparen also nicht abgezogen werden dürfte. Jedoch soll es ja gerade nach dem Korrespondenzprinzip erlaubt sein, einen "zeitversetzten" Einkommensbegriff dann zu postulieren, wenn Argumente der steuertechnischen Erfassungserleichterung sowie der

Forts. Fn. 65 :

das keine Kritik an einem etwa falschen Verständnis des Korrespondenzprinzips auf seiten der SRK sein; wenn aber die SRK (TZ 239) trotz Steuerbefreiung der Versicherungsbeiträge auch die späteren Sozialversicherungsrentenbezüge nicht besteuern will, so verstöBt sie insofern gegen das Leistungsfähigkeitspostulat, als sie das Korrespondenzprinzip hier nicht gelten lassen will; die Nichterfassung des Ertragsanteils wäre dann ein weiterer Versto $B$ gegen das Leistungsfähigkeitspostulat, und zwar wegen der Nichtbeachtung des Allgemeinheitspostulats, das Totalerfassung gebietet.

66) Die Hervorhebung dieser beiden Alternativen ist ganz auf das Korrespondenzprinzip ausgerichtet; vgl. jedoch die von N. Andel, 1970 , S. $334 \mathrm{ff}$. behandelten fünf Besteuerungsalternativen und ihre einkommensteuer-systematische Beurteilung. - Vgl. auch die Modelle der SRK 1971, S. 145, TZn $345 \mathrm{ff.;}$ Modell I: "Die volle Besteuerung der Altersbezlige nach Einordnung in die Einkunftsart, der sie am nächsten stehen"; Modell II: "die auf die Erträge oder den Ertragsantell aus dem Vorsorgevermögen beschränkte Erfassung und Besteuerung".

$67)$ F. Neumark 1947, S. 47 f.; N. Andel 1970, S. 329 f.; D. Brümmerhoff 1979, S. 219. 
Ubersicht 7.5: Argumente für alternative Besteuerungen nach dem Korrespondenzprinzip

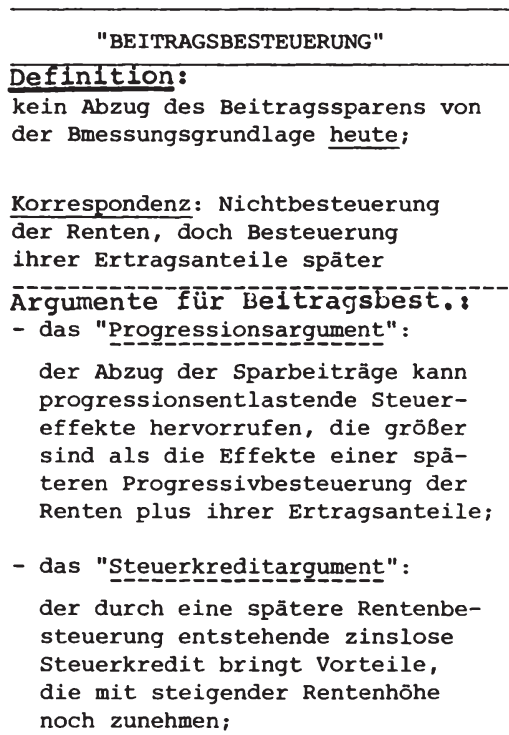

- das "Verfügbarkeitsargument": soweit Beitragssparen keinem Zwang unterliegt, spricht die "freie" Verfügbarkeit zur privaten Vermögensanlage und zum Versicherungssparen für die Beitragsbesteuerung;

Argumente für Rentenbest.:

- das "Fiskalargument":

die Belastung der öffentlichen Haushalte durch den beitragsbedingten Steuerausfall wird durch Zuschüsse an die gesetzlichen Rentenversicherungsträger noch erhōht; die Rentenbest. würde die Belastung mildern;

- das "Schockargument" : bei einer Beitragsbesteuerung müBte, sobald der in der Rente enthaltene steuerfreie VermögensrückfluB erreicht ist, ein plötzlicher Ubergang zur vollen Besteuerung der Rente einsetzen; finanzpsychologisch erscheint dieser Belastungsschock nicht wünschenswert.

Heinz Hessler and Anneliese Hessler-Otte - 978-3-631-75239-5
"RENTENBESTEUERUNG"

DefInIEIOn:

Einbeziehung der Renten und ihrer Ertragsanteile in die Bemessungsgrundlage später;

Korrespondenz: Abzug der Sparbeitrăge von der Bemessungsgrundlage heute

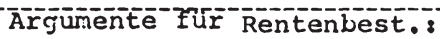

- das "Kumulationsargument":

nur eine Gesamtbesteuerung kann die Hãufung von Transfers, auch mit anderen Einkünften, als Leistungsfähigkeitsbesteuerung angemessen erfassen;

- das "Integrationsargument" : die Unmöglichkeit einer exakten und die Willkūrlichkeit einer schematischen Ertragsanteilsberechnung sprechen für eine integrierte Besteuerung von Renten und Erträgen;

- das "Zwangsargument":

soweit Beitragssparen unter gesetzlichem, ökonomischem oder sittlichem Zwang erfolgt, liegt keine "freie" Verfügbarkeit vor; sie ist erst beim Renten- und Ertragszugang gegeben und zu besteuern;

- das "Anreizargument" :

die allokativ und distributiv gūnstigen Wirkungen des Sparens sprechen für seine steuerliche $\mathrm{Ab}-$ zugsfăhigkeit in der Gegenwart;

- das "Lawinenargument":

die Steuerbefreiung der Transfers kann "zirkulăre" Rückwirkungen auf Steuervergünstigungs- und Transferansprüche hervorrufen, sofern diese nicht an das Brutto-, sondern an das (um Befreiungen verminderte) zu versteuernde Einkommen gebunden sind; dadurch kommen Steuerpflichtige in eine evtl. distributionspolitisch unerwünschte günstige Nettoposition; 
fiskalischen Wirkung, insbesondere aber der Verfügbarkeit und der allokativen und distributiven Wirkungen dafür sprechen. Die Argumente für die Rentenbesteuerung überwiegen nicht nur der Zahl, sondern vor allem ihrem Gewicht nach.

Für die $B$ e $i t r$ a $g$ s b e $s$ t e u e r u n g können aus distributionspolitischer sicht das "Progressionsargument"68) und das "Steuerkreditargument"69) ins Feld geführt werden; ihnen stehen jedoch die ebenfalls distributionspolitisch zu verstehenden " $\mathrm{Ku}$ mulations"- , "Lawinen"-69a) und (teilweise) "Anreizargumente"70)

68) Die Progressionswirkung liegt in der Abzugsfähigkeit der Sparbeiträge von der Bemessungsgrundlage begründet. Die Abzugsfähigkeit selbst dürfte, soweit es sich um Zwangsbeiträge und solche für die notwendige zukunftsvorsorge handelt, nicht mit dem Argument abgewehrt werden können, daB die Bezieher höherer Einkommen den gröBeren Spareffekt realisieren. Im Bereich der nicht frei verfügbaren Einkommen ist sie "nur das Spiegelbild der mit steigendem marginalem Steuersatz wachsenden tberbelastung, die sich im Falle einer vollen Besteuerung ergeben würde" (N. Andel 1970, S. 331). Unbestritten führt überdies in einem progressiven Tarifsystem die intertemporale Verschiebung der Steuerbelastung zunächst $\mathrm{zu}$ einem "Progressionsverlust" für den Fiskus (H. Weise 1979, S. 397, 417 u. 419); derselbe ist festzustellen, wenn das Leistungseinkommen auf 2 Personen aufgeteilt wird und der spareffekt bei dem höher versteuertem Transfergeber den $z$ usätzlichen Belastungseffekt beim Nehmer übersteigt (W. Albers 1977c, S. 908). Jedoch kann erstens das Argument der AufkommenseinbuBe nicht durchschlagen, wenn es um die Erfassung der korrekten Verfügbarkeit und Leistungsfähigkeit geht; zweitens läBt sich die fiskalische Belastung in einem teilweisen AusmaB mildern, wenn man an die "Rentenbesteuerung" der kumulierten Transfers denkt. Der Verzicht auf die Rentenbesteuerung würde bedeuten, daB die "Vorsorge $z u$ einem beträchtlichen Teil $z u$ Lasten des allgemeinen Haushalts ginge, und zwar über das MaB hinaus, das sich bereits durch die Steuerbefreiung der Beiträge ergibt" (N. Andel 1979a, S. 343). In gewisser Weise können also das "Lawinenargument" und das "Fiskalargument" dem Progressionsargument entgegengehalten werden.

69) Zu den zeitlichen Unterschieden, die eine Steuerbelastung mit sich bringt, wenn einerseits die Renten, andererseits die Beiträge und Ertragsanteile besteuert würden, siehe D. Brümmerhoff 1979, S. 220;

die Unterschiede führt er auf die Tarifprogressivität, die zeitpräferenz, die zinssatzentwicklung und die zeitreihen der Beitrags- und Rentenzahlung zurick.

69a) die Argumentation hierzu findet sich bei N. Andel 1979a, S. 344, ohne daB er die Verantwortung für diesen Terminus trägt; dieser soll das unausweichliche Anwachsen steuerbedingter Transfervorteile ausdrücken;

Fn. 70 siehe folgende Seite 
sowie das aus finanzpsychologischer Sicht beachtliche "Schockargument" (vgl. N. Andel 1970, S. 340) entgegen. Sie haben das gröBere Gewicht. Ubergeht man einmal das "Fiskalargument" $71 i$ und das "Integrationsargument", 72$)$ so liegt die für unsere Betrachtung Interessierende Problematik in dem Gegensatz zwischen dem "Verfügbarkeitsargument" und dem "Zwangsargument".

Das Verfügbarkeitsargument bringt noch am ehesten zum Ausdruck, $\mathrm{daB}$ eine freie Verfügbarkeit insbesondere mit der privaten Vermögensanlage und mit dem Versicherungssparen verbunden ist und da $B$ eine Besteuerung dieser intertemporal-intrapersonalen Transfers auf der konzeptionell klaren Trennung zwischen Vermögensumschichtung und Ertragsanteil aufbaut. Besteuert man nämlich den Vermögensrückfluß (also $z$ u einem späteren Zeitpunkt), handelt es sich "gewissermaBen um eine Verschiebung der Steuerpflicht auf den Zeitpunkt, in dem über das Einkommen verfügt werden kann"; diese Art der Besteuerung ist zugleich "einkommensteuersystematisch richtiger" (N. Andel 1970, S. 333). Doch die theoretisch-begriffliche Trennung in Vermögensumschichtung und Ertragsantell wird schon dann fragwürdig, wenn im privaten Versicherungssystem "Umverteilungsgewinne" bzw. "-verluste" ${ }^{73}$ ) auftauchen (siehe auch die Ein-

Fn. 70:

die distributiv erwünschten Wirkungen des Anreizes zum Sparen liegen in den Funktionen des privaten Vermögens begründet ( $s$. hierzu $\$ 10$ oben); siehe im ubrigen $z$ u den distributiven und allokativen Wirkungen D. Brümmerhoff 1979, S. 211, re. Sp.

71) Auch dieses findet sich - dem Inhalt nach - weitgehend bei N. Andel 1979a, S. 343 .

72) Das Integrationsargument ist nicht ohne Gewicht und trägt zur begrifflichen Klärung des Transfereinkommens und der Ertragsanteile bei. So stellt N. Andel $(1970, \mathrm{~S}$. $334 \mathrm{ff.})$ folgendes fest: mithilfe einer schematischen Berechnung der Ertragsanteile in den Renten läßt sich niemals eine exakte Zurechnung auf die Personeneinkommen erreichen, da die individuellen Lebensjahre und folglich auch die Jahre der Rentenzahlung streuen. Legt man die Sterbewahrscheinlichkeiten zugrunde, bekommt die Gesamtheit der Rentner also nur im Durchschnitt ihre verzinsten Investitionen in die Alterssicherung zurück; Personen mit unterdurchschnittlicher Lebensdauer erhalten ihre Investitionen nicht steuerfrel zurück und erleiden "Umverteilungsverluste"; Personen mit überdurchschnittlicher Lebensdauer erhalten mehr als ihre Investitionen steuerfrei ersetzt und genieBen "Umverteilungsgewinne".

73) N. Andel 1970, S. 333 ff.; W. Albers 1979a, S. 200. 
ordnung in tbersicht 7.4, Spalten 3 u. 4). Eine Beitragsbesteuerung wäre in diesem Fall nur für solche Personen leistungsfähigkeitsangemessen, deren Lebenszeit sich exakt mit der versicherungstechnischen Durchschnittslebenszeit deckt. Somit verliert der Einkommensbegriff der Beitragsbesteuerung viel von seiner Attraktivität. Es kommt hinzu, daB sich die theoretisch-begriffliche Trennung zwischen Vermögensumschichtung und Ertragsantell einer Rente mit dem Integrationsargument stöBt, wonach sie praktisch gar nicht exakt durchführbar ist.

Bringen wir jetzt das Zwangsargument ins Spiel: Eine freie Verfügbarkeit liegt erst dann vor, wenn angesichts des zwangsweisen Beitragssparens die Renteneinkommen einschlieblich ihrer Ertragsanteile den einzelnen Personen zugehen (w. Albers 1977c, S. 908), so daB sich schon aus dieser begrifflich-theoretischen Sicht der Einkommensbegriff der Rentenbesteuerung empfiehlt. Insbesondere gilt dies für die Sozialversicherungsrenten, deren Beiträge zwangsweise - als Quasisteuern ${ }^{74}$ ) erhoben werden. Eine Beitragsbesteuerung kann als "Steuer auf eine Steuer" interpretiert werden, die mit dem Leistungsfähigkeltspostulat nicht mehr im Einklang stünde (D. Brümmerhoff 1979, S. 220). Auch aus praktisch-belastungspolitischen Gründen ist demnach die Rentenbesteuerung $z u$ präferieren.

Da nun die private Lebensversicherung sowohl intra- wie interpersonaler Transfer ist und sich demnach eine ausschliebliche Besteuerung allein des Ertragsanteils nicht herstellen läBt, da die Sozialversicherung ebenfalls ein intra- wie interpersonaler Transfer ${ }^{75)}$ und uberdies wegen des Umlageverfahrens nicht vermögensge-

74) WB BMF 1967, S. 28: Sozialversicherungsbeiträge als "Quasisteuern"; Beiträge zur freiwilligen Weiterversicherung als "Quasizwangsbeiträge". H. Weise 1979, S. $398 \mathrm{ff.:}$ "zwecksteuerähnliche Zwangsumlage" in ein- und derselben Finanzperiode. - N. Andel 1970, S. 329 f. - G. Hedtkamp 1980, passim.

75) Im Vergleich mit den privaten Lebensversicherungen kommt es hier erst recht $\mathrm{zu}$ Umverteilungsgewinnen und-verlusten; sie sind hier nicht das Ergebnis der versicherungstechnischen Zwangsläufigkeiten, sondern der sozlalpolitischen Absicht. Werden Rentenzahlungen, die durch das Umlageverfahren finanziert sind, als nachträgliche Faktoreinkommen, d.h. als "zeitliche Verschiebung der Verfügung über Einkommen" (E. Schuster 1961, S. 59) oder auch als "Lohnersatzleistungen" (N. Andel 1979a, S. 343) definiert, steht eher die Vorstellung eines intrapersonalen Transfers (mit interpersonalem Einschlag) im Vordergrund. 
bunden ist ${ }^{76}$ ) (siehe auch die Einordnung in übersicht 7.4), und da schließlich der übergang vom gesetzlichen Versicherungszwang zur notwendigen privaten Vorsorge fließend ist (D. Brümmerhoff 1979, S. 221), weil auch die private Vorsorge einige Elemente des Zwangs enthält ${ }^{77)}$, sprechen aus der sicht einer Anwendung des Allgemeinheitspostulats sowie aus der Sicht einer Geltung des Korrespondenzprinzips letztlich alle Argumente für die politik der "R e $n t e n b$ e $t$ e $u$ e $r u n g "$, also für den $A b z u g$ der $\mathrm{S} p$ a $r$ - Beiträge von der Bemessungsgrundlge $h$ e $u t e$ und für eine vollständige Einbeziehung der Renten samt ihren Ertragsanteilen in die Bemessungsgrundlage $s$ p ä $t$ e $r$ (K. Littmann 1980, $s$. 19f., jedenfalls für die gesetzliche Sozialversicherung).

d) Nicht alle Fälle, in denen sich einerseits die steuerliche Entlastung eines zum Transfer Verpflichteten, andererseits die Steuerpflicht eines $z$ um Transferempfang Berechtigten sachlich verbunden gegenüberstehen, sind Korrespondenzbeziehungen. Demnach wird vorliegend zwischen fehlenden, unechten und echten Korrespondenzen unterschieden, wobei nur die letzteren vom Korrespondenzprinzip erfaBt werden können. Es 1st nicht der Sinn dieses Prinzips, steuefpolitische Anreize z.B. zum Sparen oder zur Altersicherung zu geben, sondern elnen steuerlich korrekten Elnkomensbegriff iu fassen. So kann auch nicht argumentiert werden, die Besteuerung der Alterseinkünfte wïrde den Sinn der Steuerfreiheit des sparens in der Erwerbsphase wieder aufheben, wle das bel $W$. Schnahl geschieht (1981a, S. 269).

76) Zwar arbeiten die umlagefinanzierten Sozialversicherungsrenten ohne Kapitalansammlung, doch "wird ihnen beim Beginn der Rentenlaufzeit ein fiktiver Kapitalwert zugeordnet, dessen ebenfalls fiktive Tilgung uber die nach der durchschnittlichen Lebenserwartung voraussehbare Laufzeit der Rente verteilt wird" (H.H. Rupp U.a. 1970, S. 17); aber das ist keine tatsächliche Bindung an ein Vermögen. Daher läBt sich auch das Verfahren, nur den Ertragsteil zu besteuern, "nicht auf Sozialversicherungsrenten ubertragen", denn es bestehen keine "betragsmäBig feststehenden Ansprüche auf Rente aufgrund der früheren Beiträge (D. Brümmerhoff 1979, S. $224 \mathrm{f}$. ). Daher hält auch $W$. Albers $(1979 a, S .200)$ das Verfahren, die auf das Kapital entfallenden zinsen als Ertragsanteil besteuern zu wollen, für fragwürdig, s.a. W. Albers 1977c, S. 909. S. a. H. Weise 1979, S. $422 \mathrm{ff}$. sowie die weiteren Ausführungen unten.

77) Siehe die Zwănge der Existenzsicherung und der Zukunftsvorsorge aus rechtlichen, 8konomischen oder sittlichen Gründen. So auch K. Tipke 1991. S. 363-366. 
Welche Anteile des personalen Gesamteinkommens nach dem Allgemeinheitspostulat, welche nach dem Korrespondenzprinzip zu besteuern sind, ergibt sich aus der nachstehenden skizze.

Das Gesamteinkommen setzt sich zusammen aus :

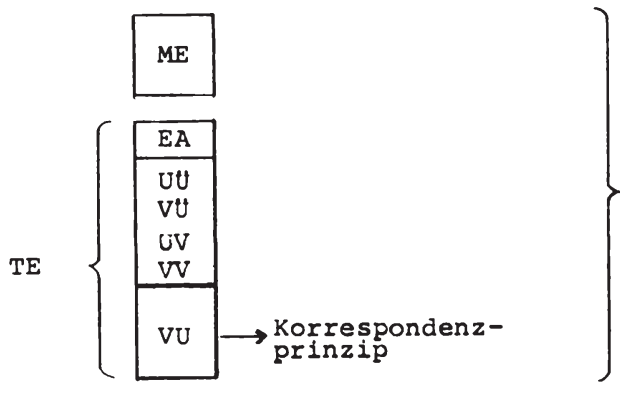

Seine Besteuerung/Nichtbesteuerung folgt aus dem:

Allgemeinheitspostulat

\footnotetext{
Abkürzungen :

$\mathrm{ME}=$ Markteinkommen

$\mathrm{TE}=$ Transfereinkommen

$E A=$ Ertragsanteil

$U U$ = Umverteilungsüberschu $B$

$v t=$ VeräuBerungsüberschu $\beta$

$U V$ = Umverteilungsverlust

$\mathrm{VV}=$ Veräußerungsverlust

$\mathrm{VU}=$ Verfügungsumsch1chtung
}

Der umfassende Grundsatz ist der der Allgemeinheit der Besteuerung, wohingegen das Korrespondenzprinzip als ein personal-temporales besteuerungstechnisches Prinzip allein auf die Verfügungsumschichtung abgestellt ist. Demnach kann ihm nicht das gesamte Transfereinkommen unterworfen werden, wie oben bereits begründet wurde.

d 1) K e i n e r l e i Korrespondenz liegt vor bei den Markteinkommen, selbst wenn mitunter versucht wird, hier die Auswirkung 77 a) des Korrespondenzprinzips $z u$ entdecken. Auch wenn bestimmte Einkommensverwendungen in einem sachlichen Zusammenhang stehen mit bestimmten Einkommenserzielungen, folgt dennoch die Begründung, die man für diese Vorgänge steuerlich formulieren mag, nicht dem Korrespondenzprinzip. Denkt man z.B. an die Mietausgabe, die von der einen Person aus bereits versteuertem Einkommen zu leisten ist, und an die für eben diese wohnung erzielte Mieteinnahme bei

77a) So hält D. Pohmer (1988, S. 144) Tipkes Mietbeispiel (siehe Fn. 78 auf der folgenden Seite) für ein Mißverständnis. 
einer anderen Person, so kann die Regel, "was der Geber steuerlich abziehen darf, muB der Nehmer versteuern" (das zeitgleiche Interpersonenverhältnis) hier nicht gelten, weil es sich nicht um dem versorgungsziel dienende Transfers handelt.78) Das Korrespondenzprinzip hängt immer in der personalen Beziehung mit Freiheit bzw. Unfreiheit in der Verfügung über ökonomische Größen bei Transferverpflichtungen und -berechtigungen oder - soweit Vermögen involviert ist - mit der Nichteinkommenseigenschaft von Vermögensumschichtungen zusammen. Die wirtschaftlichen Tauschund Leistungsbeziehungen, Miet- und Kaufpreise lassen sich hier nicht unterbringen.

Daneben gibt es Einkommensbestandteile, für die - obwohl sie zum Transfereinkommen zählen - das Korrespondenzprinzip ebenfalls nicht gelten kann. Renten aus Alters- und Lebensversicherungen, mögen sie auf betrieblich oder privat akkumuliertem Vermögen beruhen, erbringen für den Berechtigten einen über die aus eigenen Sparbeiträgen ${ }^{79)}$ finanzierte Vermögensumschichtung hinausgehenden Ertragsanteil sowle für die uberdurchschnittlich lang Lebenden einen Umverteilungsgewinn. Auch die Renten aus der VeräuBerung von Wirtschaftsgütern enthalten diese beiden Bestandteile, wie selbstverständlich auch Kapitallebensversicherungen, die in einer summe ausgezahlt werden. ${ }^{80)}$ Alle Transferzugangsbestandteile, die uber die reine Vermögensumschichtung hinausgehen, unterliegen nicht der Besteuerung nach dem Korrespondenzprinzip. ${ }^{81}$ ) Wenngleich

78) Wenn K. Tipke sagt, das Korrespondenzprinzip sei eine "Gedankenverwirrung" (1980b, S. 291), so meint er diesen Fall, daB A von B ein privates Grundstück mietet; A kann die gezahlte Miete nicht abziehen, gleichwohl muB B die erhaltene Miete versteuern. Hier können die unterschiedlichen Besteuerungsregelungen nicht miteinander korrespondieren. Wenn auch der private Darlehensnehmer die gezahlten zinsen nicht abziehen darf, muB sie dennoch der Darlehensgeber versteuern, siehe K. Tipke $1980 \mathrm{~b}$. Tipke hält das Korrespondenzprinzip aus grundsätzlichen Gründen für verfehlt, aber vor allem läbt es sich nicht verallgemeinern.

79) Soweit Betriebspensionen ohne eigenen Sparbeitrag des Arbeitnehmers aufgebaut werden, kann man in diesen "Arbeitgeberantellen" einen zweckverwendeten Lohn erblicken; analog ist die Betrachtungswelse für den Arbeltgeberantell am Sozialversicherungsbeitrag als "Lohnbestandteil", siehe W. Albers 1977c, S.905.

80) Zu recht kritisiert $W$. Albers (1977c, S. 909), daB in diesem Versicherungsformen der Ertragsanteli nicht eigens berechnet und versteuert wird.

Fn. 81 siehe folgende Seite 
sie vom Allgemeinheitspostulat erfaßt werden, liegt bel ihnen - wie bei den Markteinkommen - keine Korrespondenz vor.

d2) Als "u n e c h t e" Korrespondenz bezeichnen wir Fälle, die zwar Transfers sind, bei denen aber die transfergewährende Institution nicht besteuert wird oder nicht der Einkommensbesteuerung natürlicher Personen unterliegt, so daB sich eine steuerliche Korrespondenzbeziehung nicht herstellen läBt. Zunächst trifft dies $z u$ für die Versorgungsrenten aus öffentlichen Haushalten (Kriegsopfer-, Lastenausgleichs-, Wiedergutmachungsrenten u.ä. Sozialrenten) wie auch für die Beamtenpensionen. Eine echte Korrespondenz läge vor, wenn der Geber steuerbefreic, der Nehmer also korrespondierend zu besteuern wäre. Der staatliche Haushalt ist aber keine Institution, die wegen der Verlagerung in der Verfügungsgewalt über Einkommen Steuern zahlt, die also auch nicht befreit werden kann. \&2)

Anders liegen die Verhältnisse bei den betrieblichen VeräuBerungsund Versorgungsrenten. ${ }^{83}$ ) Eine im vordergründigen Wortsinn korrespondierende Besteuerung zeigt sich hier insofern, als der Verpflichtete seine Betriebsausgaben und Werbungskosten steuerlich vom Gewinn abziehen darf, wohingegen der Berechtigte die Ertrags- bzw. UberschuBteile als nachträgliche Betriebseinnahmen bzw. Einkommen versteuern muB. ${ }^{84)}$ Auch hier werden konsequen-

Fn. 81 :

Wegen der Mischung aus intrapersonaler (eigenerbrachter) und interpersonaler (fremderbrachter) Vermögensakkumulation lassen sich die Zukunftssicherungen aus Betriebs- und Lebensversicherungen in Ubersicht 7.4 nur auf der Trennungslinie zwischen Spalte 3 und 4 lokalisieren.

82) Da überdies die Beamtenpensionen nach $\S 19$ II EStG steuerbegünstigt und die Versorgungsrenten nach $\S 3$ Nrn. 6-8 EStG steuerbefreit sind, betrifft das Allgemeinheitspostulat, nicht das Korrespondenzprinzip.

83) Vgl. hierzu die Ausführungen von G. Rose 1982a, S. 90 ff. sowie die Ubersicht auf S. 235 .

84) Siehe auch $\mathrm{w}$. Albers 1977c, S. $907 \mathrm{f} .$, der $z u$ dieser betrieblich-privaten Beziehung zustimmend feststellt, daB die Transfers auf der betrieblichen seite gewinnmindernd abgezogen werden, daB sie aber beim Empfänger von der Steuerpflicht ausgenommen seien. Uns interessiert hier nicht, daB gleichwohl grundsätzlich die Steuerpflicht besteht, daB nur in der Wirkung wegen des Versorgungsfreibetrages nach $\S 19$ II EStG und wegen des Steuergrundfreibetrages die Transfers praktisch steuerfrei bleiben; uns interessiert hier allein, daB eine betrieblich-private "Abzugs-Zurechnungs-Beziehung" hergestellt,

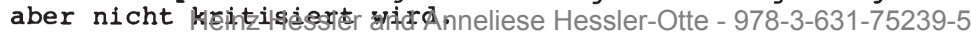


terwelse reine Vermögensumschichtungen nicht erfaBt. Jedoch unterliegen diese betrieblichen Verrentungsfälle nicht dem Korrespondenzprinzip, da der Abzug einerseits sowle der zugang andererseits in Bereiche des Wirtschaftens fallen, zwischen denen keine Korrespondenz in der Besteuerung des $\mathrm{E} i \mathrm{n} \mathrm{k} \circ \mathrm{m} \mathrm{m} \mathrm{n}$ je entstehen kann: Der Abzug des zum Transfer Verpflichteten wirkt sich gewinnmindernd in der Sphäre des betrieblichen Ertrags aus, der zugang und die Steuerpflicht in der privaten des Einkommens. Das Korrespondenzprinzip nun verlangt die zeitlich oder personal korrespondierende steuerliche Regelung allein in der Einkommenssphäre. ${ }^{85)}$ Da sich hier die steuerentlastung des Verpflichteten und die steuerbelastung des Berechtigten nur scheinbar entsprechen, betrachten wir diese Fälle ebenfalls als "unechte" Korrespondenz.

d 3) E c h t e Korrespondenz liegt mithin in den folgenden idealtypischen Transferfällen vor:

(a) Im Bereich der einkommens- bzw. gewinngebundenen Transfers:

- die privaten und intratemporalen Versorgungstransfers, z . B. In Form der Unterstutzungszahlungen aus dem laufenden Einkommen (Ubersicht $7.4 \mathrm{Sp} .1$ ); hier korrespondieren interpersonal der steuerliche entlastete Abgang mit dem zu belastenden Zugang. Erfolgt der Abgang "zwangsläufig" im Sinne einer anerkannten Verpflichtung, umfaBt der Transferinhalt sowie auch der Korrespondenzinhalt die gesamte Zuwendung; 85) in dieser Hohe entsteht beim Empfänger grundsätzlich eine Verfügbarkeit, uber deren Besteuerung aber seine persönliche Belastbarkeit entscheidet;

- die gewinnfinanzierten betrieblichen Versorgungsrenten, jedoch nur insoweit, wie der steuerpflichtige Empfänger die Finanzierung durch Eigenbeträge, die für ihn einen steuerbefreiten Abgang darstellten, vollständig selbst aufgebracht hat. Wegen des durch eigene Einkommensabgänge erworbenen Anspruchs auf die Zukunftsversorgung ist dieser Transfer nur intertemporal denkbar (Ubersicht $7.4 \mathrm{Sp} .2$ ). Bei einer Rente ohne jegliche Eigenleistung liegt unechte Kor espondenz vor. Wurde der Empfänger an der Finanzierung lediglich beteiligt, handelt es sich um ein intra-/interpersonales Mischkonzept, vergleichbar der gesetzlichen Sozialversicherung. Der Transferinhalt betrieblicher Versorgungsrenten besteht im gesamten Rentenzugang, doch der korrespondierenden Besteuerung unterliegt nur die Vermögensumschichtung;

(b) im Bereich der vermögensgebundenen Transfers:

- der interpersonale Transfer aus einer VeräuBerung von Wirtschaftsgüter (Ubersicht $7.4 \mathrm{Sp}$. 3). Transferinhalt ist der gesamte Rentenzugang, Korrespondenzinhalt jedoch nur der Anschaffungswert in Höhe des Barwerts aller veräuBerten Vermögensgegenstände ; 
- die intrapersonale zeitanteilige oder einmalige Auflosung des privat akkumulierten Vermogens (Ubersicht $7.4 \mathrm{Sp}$. 4), 2. B. durch Aufzehrung des Geldvermögensbestandes oder durch Nutzung des Sachvermögens. Transferinhalt ist der gesamte Geld-bzw. Nutzungszugang, Korrespondenzinhalt nur der Anschaffungswert ohne Wertsteigerung und Erträge.

(c) Die das Korrespondenzprinzip kennzeichnende Problematik laBt sich jedoch insbesondere in den Mischkonzepten der Transfers wiederfinden, und zwar

- sowohl im Bereich der einkommensgebundenen Transfers in der gesetzlichen Sozialversicherung (analog auch die gewinnfinanzierte Betriebspension mit Eigenbeteiligung (Ubersicht 7.4 Sp. 1/2);

- als auch im Bereich der vermogensgebundenen Transfers in der privaten Lebensversicherung (analog auch die Betriebspensionen aus besonderen Fonds (Ubersicht $7.4 \mathrm{Sp} .3 / 4$ ).

An diesen intra-/intertemporalen bzw. intra-/interpersonalen Mischkonzepten läBt sich wegen der Abhängigkeit der Zukunftssicherung von den laufenden Gegenwartssparbeiträgen in der Aufbauphase des Anspruchs bzw. Vermögens sehr gut die echte Korrespondenz einer sich entsprechenden Steuerent- und -belastung des Spar-Entspar-Vorgangs unter Ausklammerung der Umschichtungen demonstrieren. Im Bereich der vermögensgebundenen Transfers zeigt sie sich als eine Korrespondenz zwischen den Akkumulationsbeträgen in der Aufbauphase und dem ratierlichen Transferzugang in der späteren Abbauphase des Vermögens (Vermögensumschichtung) . Im Bereich der einkommensgebundenen Sozialversicherungstransfers ist sie als Korrespondenz zwischen dem Aufbau des Sicherungsanspruchs und dem laufenden Transferzugang im Altersfall zu entdecken ("Anspruchs-Leistungs-Umschichtung"). 86 )

85) Wenn K. Tipke (1981a, S. 86) sagt, das Korrespondenzprinzip vermische die individuelle Leistungsfahigkelt (von Geber und Nehmer des Transfers), so ist das für diesen Fall der Unterstützungszahlungen nicht zutreffend, da es ja gerade die Le1stungsfahigkeit von zwei Personen, die unterschiedlich hohe Einkommen beziehen, berücksichtigen will. Wir widersprechen also entschieden der Feststellung von $\mathrm{K}$. Tipke (ebda), das Korrespondenzprinzip sei"mit dem Leistungsfähigkeitsprinzip nicht verelnbar". Dieser Fall der Transfers unterscheidet sich nämlich vollig von dem oben dargestellten Fall der "fehlenden Korrespondenz zwischen Mietzahler und Mieteinnehmer; dort liegt in der Tat keinerlei Leistungsfahigkeitsbetrachtung vor.

86) Siehe den auf zahlungen abgestellten Korrespondenzbegriff bei N. Andel 1979a, S. 338 und H. Weise 1979, S. 417. 
Die echte Korrespondenz muB bei einer "Rentenbesteuerung" (siehe oben Punkt c) angesichts der Steuerfreiheit für Sparbeiträge $z u$ einer zusätzlichen Besteuerung der Umverteilungs- bzw. VeräuBerungsgewinne führen (bzw. zu einer Entlastung für Umverteilungsoder VeräuBerungsverluste); bei einer "Beitragsbesteuerung" (die die spätere Umschichtung steuerfrei läBt) muß der Umververteilungsbzw. der VeräuBerungsüberschuB zusammen mit dem Ertragsanteil besteuert werden. Beides foljt aber aus dem Allgemeinheitspostulat, nicht aus dem Korrespondenzprinzip.

4. Unter dem Aspekt des so beschriebenen Zusammenwirkens zwischen dem Allgemeinheitspostulat und dem Korrespondenzprinzip soll im folgenden die steuerliche $P r$ a $x$ s $d$ e $r$ T $r$ a $n$ f e $r-$ b e s $t$ e u e $r$ u $\mathrm{g}$ hierzulande daraufhin b e u $r$ e $i \mathrm{l}$ werden, welchen Einkommensbegriff sie unterlegt. ${ }^{871}$

a) Die steuerrechtliche Regelung des Korrespondenzprinzips ${ }^{88}$ ) stellt sich dar als eine gegenseltige Abhängigkeit des steuerabzugs der "Sonderausgaben" nach $\S 10$ I EStG. Dlese Abhängigkelt zwischen den Vorsorgeaufwendungen für die Alterssicherung und den Alterseinküften, soweit diese Leibrenten sind, ist aber von der Steuerrechtssetzung nicht als ein systematisches Ergebnis hergestellt worden, obwohl Aufwendungen und spätere Elnkünte sachlich verknüpft sind und korrespondieren, ist diese Korrespondenz steuerrechtlich nicht ausformuliert worden. Die geltende steuerrechtliche Regelung wird in der Ubersicht 7.6 verdeutlicht. Wegen der Darstellung der Geber-Nehmer-Beziehung bzw. der

87) Es sei wiederholt, daB die Beurteilung sich nicht auf alle Probleme der steuerlichen Belastung generell und ihrer UngleichmäBigkeiten erstreckt, sondern auf den Umfang und den Inhalt des Einkommensbegriffs. Zum Problem der Unqleichbehandlung siehe u.a. K. Tipke 1991, S.225, 235 u. 329 sowie ders., 1981a passim. Siehe auch H. Weise 1979, S. $429 \mathrm{ff}$. mit Berechnungsbeispielen.

88) K. Tipke 1991, S. 363 verbindet mit dem Korrespondenzprinzip - im Gegensatz zu den in Übersicht 7.6 dargestellten Fällen ausschließlich die Beziehung zwischen \$\$ $10 \mathrm{I} \mathrm{Nr}$. 1a und 12 $\mathrm{Nr} .2$ (Nichtabzugsfähigkeit von bestimmten zuwendungen) einerseits und $\$ 22 \mathrm{Nr} .1$ S. 2 EStG andererseits.

Nach Tipke erfaßt also das Korrespondenzprinzip ausschließlich die Geber-Nehmer-Beziehung zweier Personen, nicht aber den Spar-Entspar-Zusammenhang bei ein und derselben Person. 
Ubersicht 7.6: Transferarten nach ihren Verpflichtungs- und Berechtigungsgrundlagen

\begin{tabular}{|c|c|c|c|}
\hline $\begin{array}{l}\text { Auswahl aus den Transfers } \\
\text { der Existenz- und Zukunfts- } \\
\text { sicherung }\end{array}$ & $\begin{array}{l}\text { Abzugsfähig- } \\
\text { keit beim } \\
\text { Geber/Sparer } \\
\text { nach EStG }\end{array}$ & $\begin{array}{l}\text { Befreiung } \\
\text { bzw. Steuer- } \\
\text { pflicht bzw. } \\
\text { Vergunstigung } \\
\text { beim Nehmer } \\
\text { nach EStG }\end{array}$ & $\begin{array}{l}\text { Korrespon- } \\
\text { denz }\end{array}$ \\
\hline $\begin{array}{l}\text { I. staatliche Leistungs- } \\
\text { gesetze: } \\
\text { (1) Versorgungsrente }\end{array}$ & - & $\S 3 \mathrm{Nr} \cdot 6-8$ & \multirow{5}{*}{ unechte } \\
\hline $\begin{array}{l}\text { II. vertragliche Regelungen } \\
\text { a) offentl.-rechtl. } \\
\text { Dienstverhältnis: } \\
\text { (2) Beamtenpension }\end{array}$ & - & $\S 19$ I Nr. 2 & \\
\hline $\begin{array}{l}\text { b) privat-rechtl. } \\
\text { Arbeitsverhältnis: } \\
\begin{array}{r}\text { (3) Betriebsrente } \\
\text { (4) ges. Sozial- } \\
\text { vers.-rente } \\
\text { (= Leibrente) }\end{array}\end{array}$ & $\begin{array}{l}(\S \S 4,4 b-d) \\
\S 10 I \\
N r \cdot 2 . a)\end{array}$ & $\begin{array}{l}\S 19 I \mathrm{Nr} \cdot 2 \\
\S 22 \\
\mathrm{Nr} \cdot 1 . \mathrm{a})\end{array}$ & \\
\hline $\begin{array}{l}\text { c) privat-rechtl. } \\
\text { Versicherungsvertrag } \\
\text { (5) Leibrente }\end{array}$ & $\begin{array}{l}\S 10 \mathrm{I} \\
\mathrm{Nr} \cdot 1 \mathrm{a} .\end{array}$ & $\begin{array}{l}\S 22 \\
\mathrm{Nr} \cdot 1 \cdot \mathrm{a})\end{array}$ & \\
\hline $\begin{array}{l}\text { III. Unterhaltsverpflichtung } \\
\text { (6) zwischen ge- } \\
\text { schiedenen oder } \\
\text { dauernd getrennt } \\
\text { lebenden Ehe- } \\
\text { gatten }\end{array}$ & $\begin{array}{l}\text { S } 10 \mathrm{I} \\
\mathrm{Nr} .1 .\end{array}$ & $\begin{array}{l}\S 22 \\
\mathrm{Nr} .1 \mathrm{a} .\end{array}$ & \\
\hline
\end{tabular}

+) Zum Problem der Auswahl siehe die Bemerkungen in Fn. 89).

Versorgungsrenten stehen hier stellvertretend für jene Transfers, die keinen strengen Rentencharakter haben (wie Bafog-Leistungen, Mutterschaftsgeld, Wohngeld usw.). Sie alle zeichnet aus, (a) daB sie Leistungen des Staates ohne einen Eigenbeltrag des Empfängers sind, (b) daB deswegen auch das Korrespondenzprinzip nicht berührt ist und daB sich auch für die zeit vor oder nach dem Transferbezug eine "Steuerbeitrags-Leistungsbezug-Korrespondenz" nicht herstellen läBt; denn die Transferleistungen sollen ja gerade ohne Gegenleistung erbracht werden; Steuern aber sind Abgaben ohne spezielle Gegenleistungsanspruch.

Fortsetzung Fn. 88 :

Nach unserer Auffassung jedoch läBt die rechtliche Konstruktion der in Ubersicht 7.6 ausgewiesenen Zusammenhänge zwischen $\$ 10$ und $\$ 22$ EStG auch eine zeitliche Inhaltsgebung des Korrespondenzprinzjps zu. 
Sparer-Entsparer-Beziehung sind nur jene Transfers ausgewählt, die eine solche Beziehung repräsentieren ${ }^{89}$.

b) Die Beurteilung ist auf zwei Arten vorzunehmen, nämlich zum einen danach, ob das $\mathrm{k} \circ \mathrm{r}$ e $\mathrm{s}$ p $\mathrm{nd}$ e $\mathrm{nz}$ r i n z i verletzt wurde, zum anderen danach, ob das A 1 l g e m e i n $h$ e $i t s p o s t u l$ a $t$ gar nicht oder nur unvollständig verwirklicht wurde. Zunächst aber ergibt ein Uberblick (siehe Ubersicht 7.7), daB VerstöBe gegen das Korrespondenzprinzip zugleich immer auch VerstöBe gegen das Allgemeinheitspostulat sind, daB aber umgekehrt das Korrespondenzprinzip durchaus verwirklicht worden sein kann und gleichwohl das Allgemeinheitspostulat nicht. Ferner zeigt ein erster Uberblick, daB in keinem der hier ausgewählten Transferfälle das Allgemeinheitspostulat vollständig verwirklicht worden ist, daB m.a.w. in der Transferbesteuerung ein äuBerst eingeschränkter steuerlicher Einkommensbegriff verwendet wird. Teils liegt dies daran, daB die Transferzugänge (einmalige oder laufende) beim Empfänger von der steuer befreit sind, teils daran, daB sie - trotz der grundsätzlich gegebenen Steuerpflicht entweder wegen Nichtüberschreitens der Freibeträge bzw. tariflichen Grundfreibeträge praktisch steuerfrei bleiben oder wegen des zu niedrig angesetzten Ertragsanteils in $\S 22$ EStG nicht vollständig erfaBt werden.

b 1) Unter den Tatbestand der Verletzung des $\mathrm{K} \circ \mathrm{r} \mathrm{r}$ e $\mathrm{p} \circ \mathrm{n}$ d e n z p r i n i p s fällt zunächst eine Besonderheit, die mit der Vermögensumschichtung innerhalb jener zeit zusammenhängt, die bei Leibrenten als die durchschnittliche Lebenserwartung bezeichnet wird. Auf diese zeit ist normalerweise die Vermögensumschichtung berechnet. ${ }^{90}$ ) wird diese Zeit überschritten, erhält

$89)$ Aus dem Katalog der Sozialtransfers ist daher nur die öffentliche Versorgungsrente erwähnt. Eine vollständige und systematische Ubersicht über die Leistungen der Transfer- und Sozialpolitik ist nicht angestrebt. Ziel der Darstellung ist vielmehr, an Beispielen deutlich zu machen, wie Korrespondenzprinzip und Allgemeinheitspostulat zusammenwirken und eine Begründung liefern können für das Konzept der "Rentenbesteuerung" bzw. - bezieht man grundsätzlich auch jene Transfers ein, die keine Renteneigenschaft haben - für das Konzept der "Transferbesteuerung".

$90)$ Das Problem entsteht bei Zeitrenten nicht, weil diese im Gegensatz zu Leibrenten, die versicherungsmathematisch errechnet werden, ihrerseits finanzmathematisch errechnet werden, bei denen also die zeitspanne der Rente vorher exakt feststeht. 
Ubersicht 7.7: Korrespondenzprinzip und Allgemeinheitspostulat in verschiedenen Transferarten

(Transferarten (1) bis (6) siehe Ubersicht 7.6 )

\begin{tabular}{|c|c|c|c|c|c|}
\hline \multicolumn{2}{|c|}{$\begin{array}{l}\text { Abzugsfāhigkeit } \\
\text { beim T-Geber } \\
\text { bzw. Sparer oder } \\
\text { Beitragszahler }\end{array}$} & $\begin{array}{l}\text { Steuer- } \\
\text { freiheit }\end{array}$ & $\begin{array}{l}\text { Steuer- } \\
\text { pflicht }\end{array}$ & $\begin{array}{l}\text { Steuerver- } \\
\text { günstigung }\end{array}$ & $\begin{array}{l}\text { Korrespondenz- } \\
\text { prinzip +) } \\
\text { Allgemeinheits- } \\
\text { postulat +) }\end{array}$ \\
\hline (1) & nicht möglich & völlige & & & $\begin{array}{l}\mathrm{K} \text { nicht } \\
\text { berührt (b1) } \\
\text { A verletzt (b2a) }\end{array}$ \\
\hline (2) & $\begin{array}{l}\text { kein } \\
\text { Eigenbeitrag }\end{array}$ & $\begin{array}{l}\text { der Kapital- } \\
\text { abfindung } \\
\text { gem. } \$ 3 \mathrm{Nr} \text {. } \\
3 \text { EStG }\end{array}$ & ja, doch $\longrightarrow$ & $\begin{array}{l}\oint 19 \text { II EStG } \\
\text { Versorgungs- } \\
\text { freibetrag } \\
408, \mathrm{max} . \\
4.800 \mathrm{DM} / \mathrm{J} .\end{array}$ & $\begin{array}{l}\text { K nicht } \\
\text { berührt (b1) } \\
\text { A verletzt (b2b) }\end{array}$ \\
\hline (3) & $\begin{array}{l}\text { a) beim Ar- } \\
\text { beitgeber: } \\
\text { Betriebsaus- } \\
\text { gabe } \\
\text { b) beim Ar- } \\
\text { beitnehmer: } \\
\text { kein Eigen- } \\
\text { beitrag } \\
\text { ublich }\end{array}$ & --- & ja, doch- & $\begin{array}{l}\text { § } 19 \text { II EStG } \\
\text { Versorgungs- } \\
\text { freibetrag } \\
40 \& \text { max. } \\
4.800 \mathrm{DM} / \mathrm{J} .\end{array}$ & $\begin{array}{ll}\text { K nicht } & \\
\text { berührt } & \text { (b1) } \\
\text { A verletzt } & \text { (b2b) }\end{array}$ \\
\hline (4) & $\begin{array}{l}\text { a) beim Ar- } \\
\text { beitgeber: } \\
\text { Betriebsausg. }\end{array}$ & $\begin{array}{l}\S 3 \mathrm{Nr} \cdot 62 \\
\text { EStG }\end{array}$ & & & $\mid \begin{array}{ll}K \text { verletzt } & \text { (b1) } \\
\text { A verletzt } & \text { (b2c) } \\
& \text { (b2d) }\end{array}$ \\
\hline & $\begin{array}{l}\text { b) beim Ar- } \\
\text { beitnehmer: } \\
\text { Eigenbeitrag } \\
\text { als Sonderaus- } \\
\text { gaben in be- } \\
\text { grenztem Um- } \\
\text { fang gem. } \\
\S 10 \text { III EStG }\end{array}$ & $\begin{array}{l}\text { der Kapital- } \\
\text { abfindung } \\
\text { gem. } \$ 3 \\
\text { Nr. } 3 \text { EStG }\end{array}$ & $\begin{array}{l}\text { des Ertrags- } \\
\text { anteils }\end{array}$ & $\begin{array}{l}\text { keine Be- } \\
\text { steuerung: } \\
\text { a) der steu- } \\
\text { erbefreiten } \\
\text { Eigenbei- } \\
\text { tragsaus- } \\
\text { zahlung, } \\
\text { b) der Um- } \\
\text { verteilungs- } \\
\text { gewinne }\end{array}$ & $\begin{array}{ll}K \text { verletzt } & \text { (b1) } \\
\text { A verletzt } & \text { (b2c) } \\
& \text { (b2d) }\end{array}$ \\
\hline (5) & $\begin{array}{l}\text { des Ertrags- } \\
\text { anteils }\end{array}$ & --- & $\begin{array}{l}\text { des Ertrags- } \\
\text { anteils }\end{array}$ & $\begin{array}{l}\text { keine Be- } \\
\text { steuerung } \\
\text { d. Umvertei- } \\
\text { lungs- bzw. } \\
\text { VeräuBer.- } \\
\text { gewinne }\end{array}$ & $\begin{array}{ll}\text { K verwirklicht } \\
& \text { (b1) } \\
\text { A verletzt } & \text { (b2c) } \\
& \text { (b2d) }\end{array}$ \\
\hline (6) & $\begin{array}{l}\text { Aufwendungen } \\
\text { als Unter- } \\
\text { haltsleistg. } \\
\text { bis max. } \\
27.000 \mathrm{DM} / \mathrm{Jahr}\end{array}$ & --- & $\begin{array}{l}\text { Einkünfte } \\
\text { als Unter- } \\
\text { haltslei- } \\
\text { stung }\end{array}$ & & $\begin{array}{ll}\text { K verwirklicht } & \\
\text { (b1) } \\
\text { A verletzt } & \text { (b2e) }\end{array}$ \\
\hline
\end{tabular}

+) Unter den hier angegebenen Gliederungspositionen findet sich im Text die Beurteilung zum Korrespondenzprinzip und Allgemeinheitspostulat

Heinz Hessler and Anneliese Hessler-Otte - 978-3-631-75239-5 
der überdurchschnittlich lang lebende Transferempfänger den

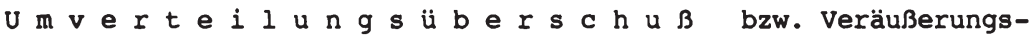
gewinn; die Besteuerung dieses Gewinns unterliegt nicht dem Korrespondenzprinzip, da nur Vermögensakkumulation mit -auflösung bzw. -rückzahlung korrespondiert. Erreicht aber der Rentenbezugsberechtigte die durchschnittliche Lebenszeit nicht, bleibt auch die Vermögensumschichtung unvollendet. Steuerliche Ent- und Belastungen können nicht mehr korrespondieren. Im Gegensatz zu den Umvertellungsgewinnen unterfallen aber die Umverteilungsverluste dem Korrespondenzprinzip. Es mübten danach Steuern erstattet werden, wenn vorher eine "Beitragsbesteuerung" durchgeführt wurde; denn dann wäre die Vermögensakkumulation $\mathrm{zu}$ hoch besteuert worden. 91) Umgekehrt aber, wenn zum Zeitpunkt des vorzeitigen Todes eine "Rentenbesteuerung" läuft, wäre in Höhe des Umverteilungsverlustes ein Steuerausfall für den Fiskus eingetreten, da die mit der Rentenbesteuerung korrespondierende Beitragsbefreiung im Vertrauen darauf gewährt wurde, daB der Rentenberechtigte die unterstellte Lebenszeit erreicht, daB die Vermögensumschichtung vollendet wird und $d a B$ während dieser zeit die volle Rentenhöhe hätte besteuert werden können. In diesem Fall müBten sogar steuern nachgezahlt werden. Diese Besonderheit des Korrespondenzprinzips ist nicht nur bei den vermögensgebundenen Transfers festzustellen. 921 Im allgemeinen wird eine gesonderte Berechnung solcher Steuernachzahlungen und -erstattungen nicht vorgenommen, ebensowenig wie bei den unter das Allgemeinheitspostulats fallenden Umverteilungsgewinnen.

Unter den Transferarten in Ubersicht 7.7 sind daher solche Verletzungen des Korrespondenzprinzips nicht eigens aufgeführt. Hier ist eine Prinzipsverletzung ausschlieblich in der gesetzlichen Sozialversicherung festzustellen. In den ersten drei Transferarten

91 ) Es wäre eine Steuer auf Einkommen erhoben worden, über das eine endgültige Verfügungsgewalt nie erlangt worden ist, weder vor noch nach dem vorzeitigen Todesfall.

92 ) Wenn auch hier das Phänomen des "Verlustes" am deutlichsten wird; dennoch sind auch bei der Berechnung der Beitragshöhe in der Sozialversicherung solche Verluste denkbar, wenn nämlich die Summe der Rentenzahlungen die summe der Beitrags$z$ ahlungen unterschreitet (UmvertellungsunterschuB). Allerdings findet hier keine vermögensumschichtung statt. Dennoch fallen diese Unterschuisse in den Bereich der Geltung des Rorrespondenzprinzips, wie oben gezeigt wurde. 
ist das Korrespondenzprinzip nicht beruhrt. In Transferart (6) entspricht der Unterhaltsaufwand exakt den Unterhaltseinkünften (wobei die Höhe des Abzugs- bzw. Zurechnungsbetrages aus anderen Gründen kritisierenswert erscheinen mag und wobei die Gesamterfassung aus dem Blickwinkel des Allgemeinheitspostulats zu beurteilen ist). In Transferart (5) entsprechen sowohl der Abzug als auch die Steuerpflicht beiderseits dem Ertragsanteil; daB dieser aber seiner Höhe nach in $\S 22 \mathrm{Nr}$. 1.a) EStG zu niedrig festgesetzt wurde, ist eine Kritik aus der Sicht des Allgemeinheitspostulats. Auch soweit die Beurteilung der Besteuerung oder Nichtbesteuerung von Sozialversicherungsrenten unter dem Aspekt der Hobe des in ihnen enthaltenen Ertragsanteils vorgenommen wird, ist sie mit Blick auf das Allgemeinheitspostulat $z u$ sehen; eine tiefergehende Kritik verlangt dagegen, daB in die Besteuerung einer nach dem Umlageverfahren arbeitenden Versicherung das Denken in Ertragsanteilen, das ja auf vermögensumschichtungen beruht, gar nicht eingeführt werden dürfe.

Das Korrespondenzprinzip bezieht sich allein auf die $U \mathrm{~m}-$ $\mathrm{s} c \mathrm{~h} i \mathrm{c} h \mathrm{t} u \mathrm{n} g$ : Der ökonomische Inhalt des Prinzips verlangt, daß die Verfügungsgröße entweder bei ihrer Akkumulation im zuge der Einkommensverwendung $\circ$ d e $r$ später bei ihrer verrentung im Zuge des Transferzugangs versteuert wird, daß aber der steuerliche Zugriff dem Prinzip der "Einmal-Besteuerung" des Einkommens bei derselben person folgt.

Unabhängig von der Höhe des Ertragsanteils liegt die Korrespondenz in der gegenwärtigen Beitragszahlung und dem späteren Transferempfang. Bei der Sozialversicherung wird nun weder die Beitragsaufbringung vollständig besteuert noch der Rentenzugang uberhaupt. Die Verletzung des Korrespondenzprinzips hat sowohl auf der Beitrags- wie auch auf der Transferseite einen zweifachen Aspekt.

Die Beitrăge werden gröBtenteils aus unversteuertem Einkommen entrichtet, was nach dem Korrespondenzprinzip die volle Besteuerung der Rente nach sich ziehen müBte. "GröBtenteils" bedeutet: Es besteht zwar für die Abzugsfähigkeit der Arbeitnehmeranteile an den Beiträgen die Umfangsbegrenzung der Sonderausgaben nach $\S 10$ III EStG, doch reichen erstens die maximalen Abzugsbeträge nicht aus, 
um die Höchstbeiträge eines Ledigen auszugleichen; 93 ' zweitens werden die Arbeitgeberanteile, die als Lohnbestandteile angesehen werden können, 94 ) dem Arbeitnehmer nicht als Einkommen zugerechnet. Sie sind im Gegenteil ausdrücklich gemäB $\S 3 \mathrm{Nr} .62$ EStG von der Steuer befreit. 95) Die Steuerfreiheit des Beitrags stellt sich dadurch höher, als sie durch § 10 III EStG - trotz der nicht ausreichenden Maximalbeträge - ausgewiesen wird. 96) Da sich der Rentenanspruch sowohl aus dem Arbeitnehmer- als auch aus dem Arbeitgeberanteil aufbaut, ist das Korrespondenzprinzip - bei Steuerfreiheit der Renten - zweifach verletzt: Einerseits wegen der Steuerbefreiung der Arbeitnehmeranteile, andererseits wegen der Nichtzurechnung der Arbeitgeberanteile zum Einkommen des Arbeitnehmers.

Auch beim Empfang der Sozialversicherungsrenten ist eine zweifache Verletzung des Korrespondenzprinzips zu konstatieren. Zunächst sind - wie bei den Beamtenpensionen auch - die in einer summe ausgezahlten Kapitalabfindungen gemäB $\S 3 \mathrm{Nr}$. 3 EStG steuerfrei; als Einkommen gilt offenbar nur, was "in kleinen Raten" ökonomische Verfügungsmacht verschafft. Ferner ist zwar der Zugang der Rente grundsätzlich nach $\S 22 \mathrm{Nr}$. 1.a) EStG steuerpflichtig, jedoch wegen der Qualifizierung als "Leibrente" nur mit ihrem Ertragsanteil; daher ergibt sich in der Wirkung eine steuerfreiheit. Diese "Wirkung" beruht auf einem Zusammenspiel (a) des tariflichen Grundfreibetrags mit (b) verschiedenen Freibeträgen und (c) dem zu niedrig bemessenen Ertragsanteil nach der folgenden Berechnung: 97 )

93) DaB sie nicht vollständig von der steuer entlastet werden, könnte man fast als ein Korrektiv zur unterlassenen Rentenbesteuerung auffassen, wenn nicht die unübersehbare systemlosigkeit dieser Regelung dem entgegenstünde.

94) Wird er das nicht, müBte angenommen werden, daB in dieser Höhe der Beitragszahler keinen Rentenanspruch erworben hat, daB er in dieser Höhe in den GenuB eines Umverteilungsuberschusses gelangt, der nach dem Allgemeinheitspostulat $\mathrm{zu}$ versteuern wäre.

95) Ginge man davon aus, daB nur befreit werden kann, was grundsätzlich pflichtig ist, liegt streng genommen in der Befreiung das Anerkenntnis der Einkommenseigenschaft der Arbeiteranteile.

96) Die Steuerfreiheit für Arbeitgeberanteile als "Betriebsausgaben" im Rahmen der unternehmerischen Tätigkeit berührt nicht das Korrespondenzprinzip, siehe oben 3. dl).

Fn. 97 siehe folgende seite 
A. Freibeträge gem. EStG in DM

EStG 1990

\begin{tabular}{rrrrr}
\multicolumn{1}{c}{ EStG } & 1990 & & EStG Vor & 1990 \\
\cline { 1 - 2 } I & II & & I & \multicolumn{1}{c}{ II } \\
5.559 & 11.339 & & 4.752 & 9.504 \\
200 & 400 & & 200 & 400 \\
108 & 216 & & 270 & 540 \\
- & - & & 300 & 600 \\
- & - & & 720 & $\frac{1.440}{12.484}$
\end{tabular}

B. Steuerfreier Ertragsanteil

(\$ $22 \mathrm{Nr}$. 1.a); 65 Jahre (*)

Annahme: Summe $A=$ Ertrags-

anteil; dann ergeben sich:

c. steuerfreie Jahresrenten von

29.885

59.775

26.008

52.016

D. steuerfreie Monatsrenten von

2.490

4.981

2.167

4.334

$I$ = Verwitwete ab dem 65. Lebensjahr

$I I=$ zusammenveranlagte Ehepaare ab dem 65. Lebensjahr

$(*)=$ vordem $20 \%$; neuerdings angehoben auf $24 \%$. "Die Bemessungsgrundlage wird seit der Anhebung der Ertragsanteile bei hohen Renten u.U. nicht mehr ganz aufgezehrt, so daß eine steuerbelastung entsteht", Tipke 1991, S. 371.

Soweit die Rentenhöhen (und bei Ehepaaren dürfte dies überwiegend so sein) unter den genannten Beträgen liegen, ergibt sich in der Wirkung praktisch eine Steuerbefreiung der gesamten Rentenbezüge aus der Sozialversicherung. Damit ist angesichts der steuerbefreiten Beiträge das Korrespondenzprinzip verletzt.

Die Beurteilung, welcher Einkommensbegriff aus der Verletzung des Korrespondenzprinzips hervorgeht, erfordert eine offenlegung, welche Art der Transferbesteuerung man präferiert. Befürwortet man die "Rentenbesteuerung", so liegt die Verletzung des Prinziops im zu niedrig ausgewiesenen Einkommen während der Phase des Transfer- und

97) zum Grundsätzlichen und zu älteren Berechnungen siehe SRK 1971, S. 143, T2 338; ferner M. Meyer 1977, S. 207; H. Weise 1979, S. 429f.; D. Brümerhoff 1979, S. 255; K. Tipke 1981, S. 203. Tipke (1991, S. 370f.) führt zur unterschiedlichen Besteuerung der Alterseinkuinfte aus: "Die Befreiung des Kapitalanteils ist deshalb nicht gerechtfertigt, weil die Beiträge zur Sozialversicherung nicht versteuert werden."... Es wäre "konsequent, die gesamte Rente (Ertrags- und Kapitalanteil) zu versteuern (soweit durch die Rente nicht Krankheits- oder Unfallkosten abgegolten werden)." ... "Da die Höhe der Sozialversicherungsrenten begrenzt ist, sind faktisch nur die spitzenrenten nicht steuerfrei." 
Verfugungszugangs, läuft demnach dem Leistungsfähigkeitsprinzip zuwider. zieht man statt dessen die "Beitragsbesteuerung" vor, wäre die steuerbefreiung der Transfers (ohne Befreiung der Umverteilungsiberschisse und Ertragsanteile!) systemkonform, jedoch ist dann wegen der verletzung des Prinzips das steuerliche Einkommen in der Aufbauphase des Anspruchserwerbs, so wie die heutige steuerrechtliche Regelung ist, $z u$ niedrig ausgewiesen. Würde man die Steuerbefreiung der Beiträge beseitigen, hätte man zwar dem Korrespondenzprinzip genügt, jedoch nicht dem Leistungsfähigkeitspostulat, nach welchem ein Einkommen, das nicht um die Zwangsbeiträge vermindert ist, als $\mathrm{zu}$ hoch gelten müBte. Für beide Besteuerungsarten aber ist noch zu prüfen, inwieweit darüber hinaus auch die Verletzung des Allgemeinheitspostulats zu steuerlichen Einkommensbegriffen führt, die als zu gering gelten müssen.

b 2) Die Verletzung des A $1 \mathrm{lg}$ e $\mathrm{m}$ e $\mathrm{n}$ h e $i \mathrm{t} \mathrm{p} \circ \mathrm{s} t \mathrm{u}$ 1 a $t s$ ist in allen aufgefuhrten Transferarten auszumachen. Sie hat - von den Einflüssen des nicht verwirklichten Korrespondenzprinzips abgesehen - ihre Ursachen erstens in dem völligen AusschluB von Versorgungsrenten aus der steuerpflicht (a), zweitens in der Einrichtung des Versorgungsfreibetrags (b), drittens in der unzureichenden Erfassung der Umverteilungsüberschüsse und Veräußerungsgewinne (c) und viertens in der unzureichenden steuerlichen Erfassung der Ertragsanteile (d).

(a) Unter dem Aspekt der Besteuerung nach der Leistungsfähigkeit ist die völlige steuerbefrelung der $V$ e $r$ s $r g$ u g $s$ e $n-$ $t$ e $n$ nicht $z u$ rechtfertigen. Denn es ist nicht einzusehen, daB bei gleich hohen Einkommen das eine nur deshalb kein steuerliches sein soll, weil es das Etikett "Transfereinkommen aus offentlicher "Versorgungsrente" trägt.98) Dies würde nämlich bedeuten, das Allmeinheitspostulat nach der Quelle des Tranferzugangs zu differenzieren, ein widerspruch in sich.

98) Mit der Einbeziehung der Versorgungsrenten in die grundsätzliche Steuerpflicht ist ja noch nichts über die endgultige Belastbarkeit entschieden; denn soweit keine freie Verfügbarkelt uber den Transferzugang vorliegt, wird er auch steuerlich nicht belastet, da das dem Leistungsfähigkeitspostulat zuwiderliefe. 
(b) Die Einrichtung eines Freibetrags für $v$ e r s o r g u n g s $\mathrm{b}$ e $\mathrm{z} \ddot{\mathrm{u}} \mathrm{g} e$ aus früheren Dienstverhältnissen (Beamten- und Betriebspensionen) wird mit der nur partiellen Besteuerung der sozialversicherungsrenten (s.0.) begründet ${ }^{99)}$. Der Versorgungsfreibetrag nach $\$ 19$ II EStG beläuft sich auf $40 \%$ der Versorgungsbezüge höchstens jedoch auf $4.800 \mathrm{DM} / \mathrm{Jahr}$; ab dem Veranlagungsjahr 1993 beträgt er höchstens $6.000 \mathrm{DM} / \mathrm{Jahr}$. Bis zur Höhe von 15.000 $\mathrm{DM} / J a h r$ also werden Versorgungsbezüge ab 1993 linear entlastet ${ }^{100)}$.

Beispiel:

Bezieht ein 65-jähriger Lediger

Versorgungsbezüge in Höhe von jährlich

$9.962 \mathrm{DM}$

und kürzt sie um $40 \%$, also um

$-3.985 \mathrm{DM}$,

so verbleiben zunächst

$5.977 \mathrm{DM}$.

Zieht er dann davon die oben als A errechnete

Summe aller sonstigen Freibeträge in Höhe von

$a b$, so verbleibt ein zu versteuernder Betrag von

$-\underline{-5.977 \mathrm{DM}}$

$0 \mathrm{DM}$.

Es zeigt sich, daß für den Bezieher von Beamtens- und Betriebspensionen die Steuerbelastung erst oberhalb von 9.962 DM/Jahr einsetzt. Im Gegnsatz dazu muB ein lediger aktiver Arbeitsnehmer unter den sonst gleichen Verhältnissen (also bei Ansatz nur der Freibetragspauschalen) bereits ein Einkommen oberhalb 5.977 DM/ Jahr versteuern ${ }^{101)}$.

Betrachtet man diese Entlastungen im zusammenhang mit der genrellen Vergünstigung bei Altersbezügen, insbesondere einschlieBlich des immer noch geltenden Altersentlastungsbetrages nach \$24a EStG, so versteht man Tipkes Kritik an dieser Besteuerung (1991,S.370ff.).

99) Dem Allgemeinheitspostulat hätte entsprochen, den Systemfehler bei den Sozialversicherungsrenten zu beheben; statt dessen wurde durch den Versorgungsfreibetrag ein weiter hinzugefügt, der nun seinerseits abermals einen systemfehler nach sich zog, nämlich den Altersentlastungsbetrag nach $\$ 24 a$ EStG (N. Andel $1979 a$, S. 345).

100) Vgl. hierzu D. Brümmerhoff 1979, S. 225, der darauf hinweist, daß die Entlastung mit zunehmenden Bezügen degressiv wirkt.

101) Sie das Berechnungsbeipiel bei N. Andel 1979a, S. 345.

102) Anstatt weitere Verstöße gegen das Allgemeinheitspostulat in die Besteuerung einzubauen, um dadurch gleichsam "Gleichbehandlung" herzustellen, wäre es besser, sämtliche Entlastungen abzuschaffen (W. Albers 1977c, S. 910; N. Andel 1979a, S. 344 ; D. Brümmerhoff 1979, S. $226 f$. 
(c) Sind Umverteilungsüberschüsse und/oder Veräußerungsgewinne in den Rentenbezügen enthalten, müßten sie - da sie vom Korrespondenzprinzip und der vermögensumschichtung nicht erfaßt werden - nach dem Allgemeinheitspostulat besteuert werden. Das würde bei $L$ e i b $r$ e $n t e n$ in jedem einzelnen Besteuerungsfall eine eigene, auf die Lebenszeit des Transferempfängers abgestellte Berechnung erfordern. Von dem Zeitpunkt an, da solche Gewinne anfallen, würde die Steuer auf die Rente erhöht werden müssen, sofern die Vermögensumschichtung steuerfrei war. ${ }^{103)}$ Nicht zuletzt mit Rücksicht darauf, daB sich im Durchschnitt der Fälle die Umverteilungsverluste, bei denen evtl. ein Steuererstattungsanspruch entstanden ist, $103 a)$ und die Fälle der Umverteilungsgewinne, bei denen eine Steuernachforderung entsteht, möglicherweise ausgleichen, zumindest aber mit Rücksicht auf die erheblichen Verwaltungsmehrarbeiten, die zudem noch nicht einmal unbedingt einen Gewinn an steuergerechtigkeit mit sicherheit erbringen, kann man es als einen "vernünftigen KompromiB $\mathrm{zwischen} \mathrm{Steuergerechtigkeit} \mathrm{und} \mathrm{administrati-}$ ven Erfordernissen" (N. Andel 1979a, S. 345) erachten, Umverteilungsgewinne nicht $\mathrm{zu}$ besteuern. ${ }^{104)}$ Unter diesem Aspekt kann die Verletzung des Allgemeinheitspostulats hingenommen werden.

(d) Die deutlichste Kritik hat die Besteuerung der Ertragsanteile von Renten auf sich gezogen. Diese Besteuerungsregelung gilt für alle Leibrenten; da man auch die $s$ o $z$ a $l$ v e r s 1 $c h$ e $r$ u g $r$ e $n$ e $n$ hierzu zählt, sind auch deren "Ertragsanteile" unter dem Aspekt des Allgemeinheitspostulats $z u$ würdigen. Dennoch müBten die Sozialversicherungsrenten, da streng genommen eine fiktive Errechnung von Ertragsanteilen bei ihnen keinen Sinn macht, aus dem Gesichtswinkel der Allgemeinheit der Besteuerung ähnlich gewürdigt werden, wie die öffentlichen Versorgungsrenten: Die Sozialversicherungsrenten sollten gänzlich unter die Steuerpflicht fallen. Erstaunlich ist aber, dab die

103) So im Fall der "Rentenbesteuerung"; wurde dagegen eine "Beitragsbesteuerung" durchgeführt, müBte ab Eintreten der Gewinne eine Steuer darauf neu eingeführt werden.

103a)Man beachte, daß dies ein Fall der Verletzung des Rorrespondenzprinzips ist.

1.04) So auch H.H. Rupp u.a. 1970, S. 15, u. D. Brümmerhoff 1979, S. 224 . 
grundsätzliche Kritik an der zu niedrigen Bemessung der Ertragsanteile von Renten gemäB $\S 22 \mathrm{Nr}$. 1.a) EStG just dann immer wieder auftaucht, wenn die spezielle Besteuerung der Sozialversicherungsrenten zur Diskussion steht. Statt nun rundweg die Besteuerung dieser Transfers in toto $\mathrm{zu}$ fordern, wird häufig vorwiegend auf die zu niedrig bemessenen Ertragsanteile verwiesen. Streng genommen ist das der "Versuch am untauglichen objekt".

Die Untauglichkeit des objektes kann durch nichts besser verdeutlicht werden als durch das die Sozialversicherung kennzeichnende Umlageverfahren. Wenn auch behauptet wird, mit den Beiträgen würde ein "Rentenstammrecht" aufgebaut, für das die steuerlichen Regeln der Vermögensumschichtungen in Anspruch $\mathrm{zu}$ nehmen seien (H. Weise 1979, S. 422), so handelt es sich dennoch lediglich um den Aufbau von Ansprüchen, nicht von Vermögen. Die Berechnung von Ertragsanteilen ist aber zugeschnitten auf die Hingabe von aus versteuertem Einkommen gebildeten "Vermögen" (N. Andel 1979a, s. $344 \mathrm{f.l} .105)$

Die schematische Festlegung der Ertragsanteile in $\S 22 \mathrm{Nr}$. 1.a) EStG berücksichtigt nicht, ob und inwieweit die Rente vom Bezieher selbst finanziert wurde (K. Tipke 1981, S. 183). Von hier aus betrachtet muB auch der Aufbau des Rentenstammrechts, das als erworbenes Vermögen gelten soll, fragwürdig erscheinen, da in den Beiträgen die nicht selbst aufgebrachten Arbeitgeberanteile enthalten sind ( $\mathrm{H}$. Weise 1979, S. 422). Aber selbst ein Zusammenhang zwischen dem eigenen Beitrag und der absoluten Rentenhöhe besteht nicht (W. Albers 1977c, S. 909). "Der Wert der künftigen Rentenleistung kann nicht wie bei privaten Renten kalkuliert werden. Er hängt u.a. von der künftigen Einkommensentwicklung und vom Familienstatus der Versicherten ab" (D. Brümmerhoff 1979, S. 225). Gerade die Dynamisierung der Rente ist der gröBte Widerspruch $z u$ der in $\S 22$ EStG unterstellten gleichbleibenden Höhe der wiederkehrenden Leistung (N. Andel 1979a, S. 345). 106)

\footnotetext{
105) "So ist hier eine Regelung beibehalten worden, die auf die nach dem Kapitaldeckungsverfahren arbeitenden privaten Lebensversicherungen zugeschnitten ist, auf Transferzahlungen im Rahmen der gesetzlichen Rentenversicherungen aber nicht paBt" (W. Albers 1977c, S. 909).
}

106) Die SRK 1971, S. 149, TZ 363, ist hier anderer Ansicht: "Gegen die Einbeziehung der Renten aus der gesetzlichen Renten-

(Forts. siehe folgende Seite) 
Daneben bestehen aber erhebliche Elnwände gegen die Berechnung der Ertragsanteile von Renten überhaupt, unabhängig von der falschen Ubertragung auf die Sozlalversicherungsrenten. 107)

Dem Allgemeinheitspostulat würde es entsprechen, wenn die Ertragsantelle erstens in der richtigen Höhe und $\mathrm{zweitens}$ individuell exakt ermittelt würden. Statt dessen pauschaliert die in $\S 22$ EStG ausgewiesene Tabelle in zwelfach grober Weise, ${ }^{108)}$ da sie von einer gleichmäBigen Verteilung der Kapitalwerte auf die voraussicht11che Laufzeit der Rente ausgeht: Mit zunehmendem Lebensalter sinken die in der Tabelle ausgewiesenen Ertragsanteile. ${ }^{109)}$ sie müBten

Forts. Fn. 106:

versicherung kann auch nicht eingewandt werden, daB die Altersbezüge den Wert des mit den Beiträgen erworbenen Rentenstammrechts nebst der angefallenen Erträge infolge der Dynamisierung der Renten weit übersteige, da $\S 22$ Ziff. 1.al EStG nicht auf das Rentenstammrecht, sondern nur auf den allein rechnerisch erheblichen Posten des Rentenkapitalwerts abstellt. Der Anwendung des $\S 22$ Ziff.1.a) EStG steht es daher nicht entgegen, daB rein rechnerisch nur ein geringer Teil der Rentenlast auf den vom Arbeitnehmer und seinem Arbeitgeber angesparten Beiträgen beruht ..." Dem kann zumindest entgegengehalten werden, daB nichts gespart und demnach kein Rentenkapitalwert gebildet wurde.

107) Abgesehen davon, daß der $\mathrm{für}$ die in $\$ 22$ EStG ausgewiesenen Ertragsanteile unterstellte zinssatz von 5,58 (1982) zu niedrig ist, weil er unterhalb des langfristigen Marktzinses liegt (D. Brümmerhoff 1979, S.224; N. Andel 1979 a, S.345), ist auch die zugrundeliegende sterbetafel von 1949/51 für männliche Personen bis 1981 unrealistisch, weil sich das durchschnittliche Lebensalter erhöht hat (D. Brümmerhoff 1979, S.224; 1982 gilt sterbetafel 1972) und weil sie nicht nach Geschlechtern differenziert (N. Andel 1979 a, S.345). Aber auch unabhängig davon sind die Ertragsanteile nicht korrekt ermittelt.

108) Gutachten der Treuarbeit 1976, S. 81. - H. Weise 1979, S. 423. Liegt z.B. bei Beginn der Rente das vollendete Lebensjahr des Rentenberechtigten

bei 0 - 2 Jahren, ist der Ertragsanteil 648

liegt es bei 55 Jahren, " " " 298

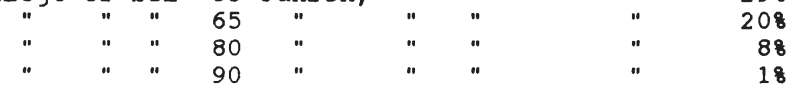

109) W. Albers 1977c, S. 909: "Offenbar geht man davon aus, daB bei Rentenbeginn eine bestimmte Kapitalsumme angesammelt sein muB und $d a B$ diese sich auf die Dauer der gesamten Rentenzahlung unter Einbeziehung der zwischenzeitlich anfallenden $Z$ insen gleichmäBig verteilt. Dabei sind die zuwachsenden zinsen und der $\mathrm{Zinsanteil} \mathrm{umso} \mathrm{gröBer,} \mathrm{je} \mathrm{länger} \mathrm{die} \mathrm{zeit} \mathrm{1st,} \mathrm{auf} \mathrm{die}$ die Auszahlung des Kapitals sich verteilt. Das ist aber weitgehend eine Illusion; denn wenn jemand mit 25 Jahren ein Transfereinkommen erhält, hat er bel weitem nicht den dem Kapitalwert der Rente entsprechenden Betrag 'angespart'". 
aber mit zunehmendem Alter stelgen und die Kapitalanteile müBten abnehmen. 110) tberdies berücksichtigt der Ertragsanteil nur die Kapitalerträge, die während des Rentenbezugs erwirtschaftet werden, läBt dagegen jene aus der Ansparzeit auBer Betracht (SRK 1971, S. 150, TZ 371). Wenn auch aus den Gründen der Verwaltungsökonomie die Individualpauschalisierung, also das Abgehen von der exakten Berechnung für jeden Einzelfall, hinzunehmen 1st, so muB in der falschen Berechnung des Ertragsantells über die Lebenszeit hin ein grober Versto $B$ gegen das Allgemeinheitspostulat gesehen werden, der dazu führt, daB das steuerliche Elnkommen $z u$ niedrig ausgewiesen wird.

(e) Mit Blick auf die $U n t$ e $r$ a 1 t s a $f$ we $n d u n-$ $g$ e $n$ bzw. -einkünfte, bei denen das Korrespondenzprinzip ja verwirklicht ist, muB das Allgemelnheitspostulat insoweit als verletzt gelten, als die $1 \mathrm{~m}$ Gesetz festgeschriebene Höhe von 27.000 DM DM/Jahr überschritten wird. Zahlt ein steuerpflichtiger über diesen Betrag hinaus, ist seln Einkommen um jenen Tell $z u$ hoch, den die Verfügungsumschichtung diese Grenze ubbersteigt; auf der anderen Seite ist das Einkommen des Empfängers um eben diesen übersteigenden Betrag zu niedrig (inwiewelt dieses Einkommen steuerlich belastet wird, ist - wie mehrfach dargelegt - eine zweite Frage). Unübersehbar 1st, daB sich auf seiten des Zahlungsverpflichteten die Leistungsfähigkeit verringert, auf seiten des Berechtigten grundsätzlich erhöht.111)

C) Angesichts der Verletzungen des Korrespondenzprinzips und des Allgemeinheitspostulats sind die stellungnahmen der $R$ e $f \circ r m-$ $\mathrm{k} \circ \mathrm{mm} i \mathrm{~s} 1 \circ \mathrm{n}$ e $\mathrm{n}$ von Interesse. Den engsten Einkommensbegriff postuliert die SRK 1971 (S. 122 f.). Obwohl sie einen "engen Sachzusammenhang" zwischen den "Lebensvorsorgeaufwendungen und den späteren Altersbezügen" nicht übersieht, obwohl sie die Auswirkungen der Prinzipsverletzung auch unter dem Gleichbehandlungsaspekt erkennt, obwohl sie zugibt, daB der Sachzusammenhang für eine "Gesamtkonzeption" nicht unbeachtet bleiben

110) W. Albers 1977c, S. 909. - N. Andel 1979a, S. 345. Tipke/Lang 1991, S. 371 (Tabelle zu $\$ 22$ EStG i.d.F.v. 22.12.1981, BGBI. I 81, 1523, 1538 .

111) Tipke/Lang 1991, S. 383: ..."ist eine Begrenzung auf 27000DM nicht gerechtfertigt, wenn ein Rechtstitel über einen höheren Betrag vorliegt." 
darf (Tz 239, 346 u. 365), lehnt sie das Korrespondenzprinzip als eine in das Gesetz aufunehmende Regel ab; allerdings macht der Hinweis auf die "steuersystematischen", die "weitgehend außerfiskalischen, insbesondere sozialpolitischen" Gesichtspunkte die Gründe dieser Ablehnung nicht klar. 112) Auch wenn die SRK 1971 sich intensiv mit der Differenzierung der Vorsorge nach ihren Arten befaBt (TZ $241 \mathrm{ff.}$ ) und Reformmodelle entwickelt (TZ $254 \mathrm{ff.}$ ), fällt auf, daB die Ablehnung des Korrespondenzprinzips, die doch gerade in den Sozialversicherungen $z u$ deutlichen Vertellungsvorteilen für die dort Versicherten führt, "sozialpolitisch" begründet wird. 113)

Die Verletzung des Allgemeinheitspostulats möchte die SRK 1971 nicht beseitigen - sofern sie sie uberhaupt als solche sieht: Sie lehnt die volle Besteuerung der Altersbezüge (Altersleibrenten, Sozialversicherungsrenten, Beamten- und Betriebspensionen, Renten- und Kapitallebensversicherung; Modell I, S. 145, TZn $347 \mathrm{ff.l}$ ab, und zwar aus sozialen, politischen und praktischen Gründen. ${ }^{14}$ ) Stattdessen propagiert sie "die auf die Erträge oder

112) Siehe hierzu die Kritik an der SRK 1971 von H. Weise 1979, S. $419 \mathrm{ff}$.

113) Unklar bleibt auch folgender Satz, nachdem zuvor die Ablehnung des Korrespondenzprinzips ausgesprochen, glelchwohl aber die unterschiedliche Behandlung in einigen Transferarten dargestellt wurde: "Der Umfang der Steuerpflicht eines jeden Bürgers soll grundsätzlich aus den bei ihm feststellbaren Merkmalen bestimmt werden und von der konkreten steuerlichen Beurteilung korrespondierender MaBnahmen bei Dritten unabhängig sein." Dies betrifft die Besteuerung nach der persönlichen Leistungsfähigkeit und ist - wie wir glauben deutlich gemacht $\mathrm{zu}$ haben - das interpersonale Korrespondenzverhältnis, das nicht mit dem intrapersonalen verwechselt werden sollte; wenn auch interpersonal im Geber-NehmerVerhältnis die Besteuerung auf die jeweils vorhandene oder eingeschränkte Verfügungsfreiheit abzustellen und insoweit der Auffassung der SRK zuzustimmen ist, so kann die kategorische Ablehnung des gesamten Korrespondenzprinzips auf keinen Fall für die intrapersonale Korrespondenz akzeptiert werden, da es sich dabei um den Vorgang der Vermögensumschichtung und Anspruchs-Leistungs-Umschichtung handelt. Möglicherweise erklärt sich die Einstellung der SRK 1971 damit, die innerpersonale und die zwischenpersonale Korrespondenz nicht auseinander gehalten $\mathrm{zu}$ haben; so ist nämlich auch in TZ 239 von der ersteren, in $\mathrm{TZ} 240$ aber von der letzteren die Rede, ohne daB der Unterschied eigens hervorgehoben wird.

114) Erstaunlich, daB sie dies in $\mathrm{T} Z 358 \mathrm{mit}$ dem Hinweis auf die nur äuBerst geringe Rentenhöhe tut, als ob dies ein theoretisch befriedigender Grund sein könnte, als ob nicht erst im zweiten Schritt einer Belastungsfähigkeitsprüfung über das Steuerma $\beta$ entschieden werden könnte. 
den Ertragsanteil aus dem Versorgungsvermögen beschränkte Erfassung und Besteuerung" (Modell II, TZn 345 u. 362 ff.) und will die auf Vermögen basierenden wie auch die Sozialversicherungsrenten gleich behandeln: Sie sollen nach der Tabelle in $\S 22$ EStG besteuert werden, allerdings dem gegenwärtigen mittleren ZinsfuB und den gestiegenen Lebenserwartungen angepaBt. Während bei den Sozialversicherungsrenten die Ablehnung sowohl des Korrespondenzprinzips als auch der Totalerfassung der Rentenzahlung damit gerechtfertigt wird, daB sich die relative Einkommensposition des Rentners beim Ubergang ins Rentenalter erheblich verschlechtere (TZ $364 \mathrm{f.}$, wird die offensichtlich sehr niedrige Besteuerung der Renten- und Kapitallebensversicherungen nach $\$ 22$ EStG damit begründet, daB diese - anders als die Sozialrenten - nicht dynamisiert seien und daB sie dadurch einen Ausgleich für "einen gewissen Geldwertschwund" erhielten. 115) Dies würde zugleich eine steuerliche Gleichbehandlung von Sozialversicherungsrenten und Lebensversicherungsrenten bedeuten. ${ }^{116)}$ zusammenfassend läBt sich festhalten, daB die SRK 1971 die Verletzungen des Korrespondenzprinzips überhaupt nicht, und die Verletzungen des Allgemeinheitspostulats nur in äuBerst bescheidenem Umfang beseitigen will. 117) Insofern geht sie von einem relativ engen steuerlichen Einkommensbegriff aus.

Der Carter Report mit seinem "Comprehensive Tax Base-Konzept", 18) ganz im Gegensatz zum "Adjusted Gross Income-Konzept" der USA, 119) verlangt dagegen einen vollständigen EinschluB der Transfers in den steuerlichen Einkommensbegriff. Dieselbe Position bezieht der

115) Der ansonsten dem Steuerrecht fremde Geldwerterhaltungsgedanke - es gilt das Nominalwertprinzip - soll hier also ausnahmsweise für bestimmte Transfereinkünfte gelten.

$116)$ Wenn aber beide Transferarten von demselben $z u$ niedrigen Ertragsanteil profitieren, die Sozialversicherungsrenten daneben noch von der Nichtgeltung des Korrespondenzprinzips, kann das keine Gleichbehancilung sein.

117) Dem Grundsatz nach hält sie auch die Besteuerung der Beamtenpensionen, so wie sie seinerzeit geregelt war, für systemgerecht und mit der Gleichbehandlung für vereinbar, TZ 366 f., 382 .

118) 1966, vol. 3, S. 5; siehe auch unsere Ausführungen in $\$ 21$ III 3 .

119) Musgrave/Musgrave 1980, S. 243 ff. u. 336; S. 347 : "there is no good reason for this exclusion" of transfer receipts from government from AGI. 
WB BMF 1967 hinsichtlich des Allgemeinheitspostulats, verlangt daneben ausdrücklich die Anerkennung des Korrespondenzprinzips. ${ }^{120}$ ) D. Brümmerhoff (1979, S. 226) legt dar, daß eine solche Lösung die Abschaffung der Begünstigungen nach $\S 19$ II und $\S 22 \mathrm{Nr} .1$ EStG bedeuten würde, da es nicht zu rechtfertigen sei, nach Berufsgruppen Altersvergünstigungen $\mathrm{zu}$ differenzieren. ${ }^{121}$

Nachdem auch im politischen Raum stellenweise gefordert wird, die Besteuerung der Renten $z u$ überdenken, ${ }^{122)}$ da das Bundesverfassungsgericht in seinem Urteil vom 26.3.1980 dem Gesetzgeber aufgegeben hat, bis 1984 die Neuordnung der Rentenbesteuerung zu regeln, bleibt abzuwarten, inwieweit dann dem Allgemeinheitspostulat Geltung in dem hier vertretenen Sinne verschafft werden wird. Denn diese Aufgabe wurde auch von der Steuerreform 1986/90 nicht gelöst. Änderungsvorschläge liegen mittlerweile vor $\left.{ }^{123}\right)$. R. Tipke 1991, S. 373: "Im Bundesministerium der Finanzen bewegt sich aber ersichtlich noch nichts, so daß weitere verfasungsbeschwerden erforderlich werden."

120) SR BMF H.9, S.22 f.: "Bei Renten und Pensionen hat der Grundsatz zu gelten, daß die Rückzahlung früher versteuerter angesparter Einkommensteile in der Periode der Renten$z$ ahlung steuerfrei bleibt, während alle anderen Rentenzahlungen und Pensionszahlungen (auch die aus den Zinserträgen stammenden Teile) der Einkommensbesteuerung $\mathrm{zu}$ unterwerfen sind. Daraus ergibt sich, daB Pensionszahlungen aller Art in voller Höhe besteuert werden müssen, weil beim Pensionsempfänger der Erwerb der Anwartschaft nicht als Einkommen besteuert wird. Das gleiche gilt für die Renten aus der Sozialversicherung ...., well die Beträge zur gesetzlichen Pflichtversicherung ... in voller Höhe als Sonderausgaben abzugsfähig sind ... Ebenso sind die Leistungen der Lebensversicherungen, soweit die Prämienzahlungen bisher als Sonderausgaben steuerfrei waren, voll in die Besteuerung einzubeziehen."

121) In seinen Ergänzungen zum Reformvorschlag des WB BMF 1967 kommt Brümmerhoff $\mathrm{zu}$ einer Konsequenz, die einerseits das Korrespondenzprinzip bestätigt, andererseits insbesondere die zugangsregel in dem von uns vertretenen Sinne stützt: Neben den Arbeitnehmerbeiträgen zur Sozialversicherung sollen auch die Arbeitgeberbeiträge in voller Höhe $z$ um Einkommen rechnen (1979, S. 226): "Dies ist für eine vergleichbare Behandlung verschiedener Vorsorgeformen wichtig. Beiträge sollten aber auch z.B. als Sonderausgaben voll bei der Ermittlung des steuerpflichtigen Einkommens abzugsfähig sein." - Siehe auch H. Weise 1979, S. 429.

122) Siehe hierzu insbes. J.W. Gaddum 1978, ferner die "Hamburger Denkschrift 1978" und den vergleichenden Artikel von H.D. Hessler 1978 .

123) Kommission "Alterssicherungssysteme"; WB BdF Heft 38,1986 Heinz Hessler and Anneliese Hessler-Otte - 978-3-631-75239-5 
523 Das Allgemeinheitspostulat und seine zweite sachliche Einschränkung = Die "Eingrenzung" auf den "freien" Vertigungsbereich

I. Die "saldierte" Verfügbarkeit des Einkommens: Innerperiodischer Verlustausgleich

II. Die "güterliche" Verfügbarkeit des Rohvermögens: Nichterfassung des Human-Vermögens

III. Die "finanzielle" Verfügbarkeit des Reinvermögens: Notwendigkeit des Schuldenabzugs

I. Vergegenwärtigt man sich den umfangreichen Katalog der Steuerbefreiungen im Bereich der Faktorentlohnung sowie des Vermögenszugangs und -bestandes, die Nichterfassung bestimmter zurechnungseinkommen, Wertzuwachseinkommen und vor allem der Transfereinkommen (s. $\$ 21$ IV), so zeigt sich, daB die Ausgrenzungen aus der freien Verfügbarkeit in erster Linie politisch bestimmt sind. Demgegenüber dürften die nunmehr darzustellenden "Eingrenzungen" auf den Untersuchungsgegenstand "freier Verfügungsberelch" eher $r$ a $t i \circ$ a $l$ e $r$ Art sein, zumal einerseits sich der Besteuerungsgegenstand selbst einer freien Verfügbarkeit widersetzt (so das Human-Vermögen), andererseits sowohl das Einkommen als auch das Vermögen steuerlich als "Summenbegriffe" aufgefaBt werden und "negative zugänge" (="Abgänge") das Einkommen, Schulden das Vermögen mindern. Der solchermaBen eingegrenzte Verfügungsgegenstand ergibt sich aus der Logik des Allgemeinheitspostulats zum Zwecke der Besteuerung nach der Leistungsfähigkeit: Schulden, "Abgänge" und nicht disponibles Vermögen können keine Leistungsfähigkeit anzeigen, sind daher aus der Besteuerung auszuschlieben.

a) Die "s a $l$ d $i$ e $r t e "$ Verfügbarkeit des Einkommens ergibt

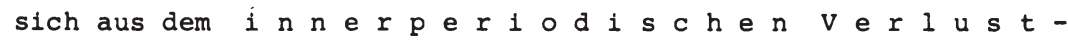
a u s g l e i c h (N. Andel 1979a, s. $367 \mathrm{ff.}$ ), sel es ein interner (order horizontaler) Verlustausgleich innerhalb derselben Einkunftsart, sei es ein externer (oder vertikaler) Verlustausgleich zwischen den Einkunftsarten (G. Rose 1977a, S. 47 u. 64 ff.). 1)

1) Wir erinnern uns, daB der zwischenperiodische Verlustausgleich (oder "Verlustabzug" als Vor- oder Rücktrag) ein rein allokatives Verfahren ist und dementsprechend in $S 2: I \mathrm{~s}$. ausgegrenzt wurde. Die hier genieinten "Abgänge" 1.S.v. Nichtzugängen sind distribueinveresar.and Anneliese Hessler-Otte - 978-3-631-75239-5 
Der innerperlodische Verlustausgleich folgt unmittelbar aus dem Totalitätskonzept der Einkommensbesteuerung (F. Neumark 1947, S. 29). Er ist die Ergänzung zu der Absicht, den "Gesamtnettozuwachs an ökonomischer Dispositionsfähigkeit" zu erfassen (N. Andel 1979a, S. 367). Nur unter der Voraussetzung allerdings, daB auch sämtliche Verfügungszugänge ausnahmslos $z u$ den gleichen Bedingungen - also ohne Steuerbegünstigungen - erfaBt wurden, kann der Verlustausgleich uneingeschränkt gelten. ${ }^{2)}$ Konsequenterweise können Einkunftsarten, die nicht steuerlich erfaBt werden bzw. befreit sind, auch nicht zu verlusten führen. ${ }^{3)}$ Wenn steuerlich die Verluste aus der sog. Liebhaberei nicht ausgleichsfähig sind, so allein deswegen, weil vorher, in der Phase der Entstehung von Liebhaberei-Einkünften, bereits gegen das Allgemeinheitspostulat verstoBen wurde. ${ }^{4)}$ Insoweit kann man jetzt nicht von elner Beschränkung oder Nichtgeltung der Verlustausgleichsregel sprechen; sie ist logisch von vorn herein gar nicht anwendbar.

Konsequent wäre folgendes: Wenn die Zugangsregel in dem von uns oben definierten Sinn für die Bestimmung des steuerlichen Einkommens gälte und demnach die Quelle des Einkommens unerheblich für die Einkommenseigenschaft des zugangs wäre, so könnte auch die Verlustausgleichsregel uneingeschränkt gelten und brauchte nicht für die Abgrenzung von "e $c h t$ e $n$ " $E i n k$ ü $n$ f $t$ e gegenüber "u $n$ e c h t e n" (Liebhabereien) herzuhalten. Die Aufzählung der Liebhabereien wird immer ein Element der Willkür enthalten, insbesondere wenn man auf die "längere sicht" abstellt, die angeblich die "echten" Einkünfte und die in ihnen zu erzielenden Gewinne oder Uberschüsse auszeichnet. ${ }^{5)}$

2) $\mathrm{zu}$ der Möglichkeit, daß Verluste aus steuerbegünstigten Einkunftsarten auf das Gesamteinkommen übertragen werden und dieses entgegen der Gesamterfassungsabsicht mindern, siehe N. Andel 1979a, S. 368.

3) Insofern ist es also inkonsequent, den privaten Konsum als den vom Prinzip des Verlustausgleichs nicht gedeckten Tatbestand aufzufassen, da Konsum begrifflich nicht Einkommenszugang sein kann.

4) "Einkünfte werden nur angenommen, wenn das wirtschaftliche ziel dahin geht, auf längere sicht Gewinn oder Überschuß zu erzielen. Trifft das nicht zu, so liegt sogenannte Liebhaberei (Hobby) vor", K. Tipke 1981, S. 148. 1991, S. 220 u. 333f. Der Liebhaber ist Konsument.

Fn. 5 siehe folgende seite 
So läBt sich festhalten: Ist steuerlich das Allgemeinheitspostulat verwirklicht, ist die Verlustausgleichsregel uneingeschränkt anwendbar als die logische Konsequenz aus dem genannten Postulat. Das sich daraus ergebende Einkommen ist das einer "saldierten" Verfügbarkeit. Soweit in der Steuerpraxis heute eine vollständige Saldierung der Uberschüsse (Gewinne) mit den Verlusten"steuerlich nicht zugelassen ist, wurde vorher bereits das Allgemeinheitspostulat verletzt.

b) Eine weitere Auswirkung der Verlustausgleichsregel hängt mit der Gestaltung von Abzugsbeträgen zusammen. Die Verlustausgleichsregel kann dann allokative und distributive Konsequenzen haben, die sich weder wirtschafts- noch gesellschaftspolitisch ungeteilter Zustimmung erfreuen. Wenn nämlich die sog. Verlustzuweisungen der Abschreibungsgesellschaften steuerfinanzierte Kapitalanlagen 5 a) gerade den oberen Einkommensschichten anbieten und ihnen solchermaßen eine höhere Vermögensbildung auf Kosten der Allgemeinheit erlauben (Jahrmarkt/Bareis 1981, S. 32), so wird dies zwar durch die Verlustausgleichsregel erst möglich; dennoch sind die negativen Allokations - und Distributionswirkungen nicht der Regel anzulasten, sondern der Abschreibungs-, Bewertungs-, Rücklagen- und sonstigen steuerlichen Politik. Die Verlustausgleichsregel ist mit Blick auf den Einkommensbegriff zweckrational, wirkt gleich-

Fn. 5 :

Dasselbe Willkürelement ist in der Argumentation des Carter Report 1966, vol.3, S. 42, zu erkennen, wenn es dort heiBt: "The presumption must be that the owner is obtaining personal satisfaction from operating the business and that the losses of the business are therefore disguised personal living expenses." - Wie stellt man Befriedigungen verläBlich fest?

5a)Die verschiedenen Maßnahmen sind: (1) das Schaffen von Verlusten aus Gewerbebetrieb durch Abschreibungen, Bewertungsabschläge, steuerfreie Rücklagen, Nichtaktivierungen, Anlauf- und Vorlaufkosten; (2) das Schaffen von Verlusten aus Vermietung und Verpachtung durch vorweggenommene Werbungskosten und erhöhte $\mathrm{Ab}-$ schreibungen. Die Verluste entstehen aber auch durch Konkurse der Abschreibungsgesellschaften; letztere führen dann zu Freibeträgen für die "Betriebsaufgabe", \$ 26 III U. IV EStG, 30.000 DM; siehe hierzu Jahrmarkt/Bareis 1981, S. 31ff. 
sam "blind" gegenuber den Wirkungen und ist vor einer nachteiligen Ausnutzung durch die $p \circ 1$ i $t i s \mathrm{ch}$ initilerte "V e r l u $s$ w 1 r $t s c h$ a $t$ " nicht gefeit.

II. Das Kriterium der freien Verfügbarkeit richtet sich auch auf das $V$ e $r \mathrm{~m}$ o $\mathrm{g}$ e $\mathrm{n}$.

a) Ob über sämtliche Vermögensgegenstände (Sachen und Rechte) frei verfügt werden kann, läßt sich anhand der übersicht 3.6 ("Kapital- und Vermögensarten und ihre Funktionen ...") beurteilen. Im ersten Angang der Fragestellung erscheinen alle jene Gegenstände des Rohvermögens als frei verfügbar, die eine der dort genannten Vermögensfunktionen erfüllen. Doch dieser Kreis von Gegenständen ist $z u$ weit gefaBt, denn bereits in der wirtschaftstheoretischen Betrachtungsweise hatte das $\mathrm{H}$ u m a n v e r m ö $g$ e $n$ wegen nicht vorliegender Verfügbarkeit ausgeschieden werden muissen. So 1st es auch in steuerlicher Betrachtung. Zwar hat das "human capital" dieselbe Funktion wie das Sachkapital, wie Investitionen generell, nämlich zukunftserträge abzuwerfen, 6) doch sind sie durch zwei Phänomene unterschieden, durch die MeBbarkeit und die Verfügbarkeit. Die MeBbarkeit des Humanvermögens wird nicht grundsätzlich für unmöglich gehalten, nur gilt sie gegenüber der des Sachkapitals als viel unsicherer. ${ }^{71}$ Und so ist es auch nicht eigentlich in erster Linie das Bewertungsproblem, das zum AusschluB des Human- und Arbeitsvermögens aus dem steuerlichen Vermögensbegriff führt, sondern die fehlende $V$ e $r$ f ù $g$ b a r k e $i$ t (H. Fecher 1979, s. 468). 8) Der Kapitalwert der

6) T.W. Schultz (Hrsg.) 1962: Investment in Human Beings; C.T. Sandford 1971b, S. 185: "potential future earning power".

7) C.T. Sandford $(1971 \mathrm{~b}$, S. 185) führt als Gründe die ungewisse Lebensarbeitszeit und die Risiken der Gesundheit an; dem wäre $z u$ entgegnen, daB bei Langzeitinvestitionen in Sachkapital die Ertrags- und die politischen Risiken ähnlich unübersehbar sind. Doch sind im allgemeinen die Bindungsfristen der Sachinvestitionen kürzer als eine Lebensarbeitszeit, und daher kann man dem Argument beitreten.

8) Man könnte nun darüber streiten, ob die Tatsache, daB für Humanvermögen kein Markt besteht, die Bewertung oder die Verfügbarkeit unmöglich macht. Genauso lieBe sich diskutieren, ob es letztlich sittliche Fragen sind, die ein Zustandekommen des Marktes und damit des Wertes und der tbertragbarkeit des Humanvermögens verhindern; siehe hierzu u.a. O. Ebnet 1978, S. 57 f. 
Zukunftserträge des Humanvermögens ist weder beleibar noch übertragbar (C.T. Sandfort 1971b, S. 185).

b) Soweit Argumente gegen die Besteuerung des Humanvermögens vorgetragen werden, die in der $p \circ t$ e $n t i$ a $l \circ r i$ e $t i e-$ $r$ u $n g$ der Besteuerung begründet liegen, 9 ) erstrecken sie sich in erster Linie darauf, daB tatsächliche Leistungsergebnisse aus dem Humanvermögen erst in der Zukunft anfallen können. Die "intertemporale Allokation", die "Einkommenserwerbskapazität" des Humanvermögens (H. Luckenbach 1979 S. 316 f.) sind notwendigerweise - wie beim Sachkapital auch - mit dem Zeitfaktor verknüpft. Eine bloße Möglichkeit kann nicht Einkommen sein (O. Ebnet 1978, S. 57). Diese zeit- und potentialergumentation milßte nun aber auch gegen eine Kapitalbesteuerung gerichtet werden. C.T. Sandfort (1971b, S. 185) meint: Selbst wenn es gelänge, die Zukunftserträge des Humanvermögens $z$ u messen, könnte man sie nur messen in enger Bindung an die aktuellen Erträge; das aber brächte die Gefahr, daB schlicht die Basis der Einkommensteuer dupliziert würde mit allen negativen Folgen für das Arbeitsangebot. Dieses Argument gilt aber ebenso für die Besteuerung der Zukunftserträge des Kapitals und weist dann in dieser Allgemeinheit auf ein generelles Problem der Steuersystematik hin, nämlich auf die Kumulation von zwei Ertragsteuern. ${ }^{10)}$ Den Widersinn der Potentialbesteuerung weiB H. Fecher (1979, S. 477) überzeugend damit zu belegen, daB sie die "absurde" Konsequenz haben würde, dann auch Arbeitslose $z u$ besteuern: deren Humanvermögen liegt zwar momentan brach, ist aber immerhin vorhanden. Von hier aus ist es dann nicht weit, einzusehen, daB auch die Freizeit, wie das Arbeitsvermögen ein Potential, nicht besteuerbar ist. ${ }^{11)}$

9) Sie werden allerdings nicht immer als probleme der "faculty" oder Potentialbesteuerung ausgewiesen, sondern eher als MeBbarkeits - oder auch als Steuersystemprobleme.

10) Das Sandford'sche Argument, Humanvermögen hütte Vorteile für die Gesellschaft insgesamt und dürfe daher nicht besteuert werden, halten wir weithin ebenfalls auf das Sachkapital für übertragbar.

12) Während die meisten Autoren die englische Bezeichnung "net worth tax" oder "net wealth tax" so verstehen, daB das "Netto" den Abzug der Schulden von der Summe des Rohvermögens ausdrücken soll (so u.a. Musgrave/Musgrave 1980, S. 472 u. 489), betont C.S. Shoup (1969, S. 358), im "net" liege der AusschluB des human capital als einer bloBen "Fähigkeit" aus dem Kreise der im Besitz gehaltenen Vermögensteile. 
c) In dem allokativ-distributiven Konflikt, der darin liegt, daB eine Potentialbesteuerung allokative Anreizwirkungen auf das Humanvermögen haben könnte, daB aber zugleich belastungspolitische Nachteile gerade bei denen auftreten, die mangels ausreichender Allokationsmöglichkeiten ihr Humanvermögen gar nicht anbieten und einsetzen können, haben sich die $s t e u$ e $g$ e $s$ e $t z$ e ganz allgemein dafür entschieden, das Humanvermögen nicht zum steuerlichen Vermögen $z u$ zählen. Mit dem Allgemeinheitspostulat ist durchaus im Einklang, daB die Verfügbarkeit über das Rohvermögen mithin nur auf die tatsächlich verfügbaren Gegenstände eingegrenzt und solchermaBen " $g$ ü $t$ e $r$ i c h-g e g e $n s t a ̈ n d ~ l i c h "$ verstanden wird.

III. Ist nun das um das Humanvermögen verminderte Rohvermögen insgesamt die maBgebliche GröBe für die distributiven Ziele der steuerpolitik oder ist die Verfügbarkeit über diese GröBe abermals eingeschränkt?

a) Unter steuerlichem Gesichtspunkt ist jetzt das Kriterium der Verfügbarkeit nicht mehr an die Gegenstände des Vermögens, sondern an seinen w e $r$ t $\ddot{a} B$ i g e $n$ Gesamtausdruck anzulegen. Denn maBgeblich für die Belastbarkeit des Vermögensbesitzes soll seine "freie" Verfügungsmöglichkeit über sein Gesamtvermögen sein. Nunmehr, da das körperlich verfügbare Vermögen im Rohvermögen seinen summenmäBigen Ausdruck gefunden hat, liegen weitere Einschränkungen der Verfügbarkeit ebenfalls im WertmäBigen, im Finanziellen. Daraus läBt sich folgern, daB als finanziell lastfrei verfügbar und demnach steuerlich belastbar nur jene summe gelten kann, die eine $f$ i n a z i e l l e $V$ e $r$ f d.h. die um Schulden und Verpflichtungen des Vermögensbesitzes vermindert ist. Die leistungsfähigkeitsorientierte Vermögensteuer wäre danach als eine steuer auf das Reinvermögen ("net worth tax") zu gestalten.

b) Dies wird auch weithin so gehandhabt bzw. in der Diskussion so verlangt. So läBt z.B. die Vermögensteuer der Bundesrepublik den S c h u l d e n a b z u g grundsätzlich zu (§ 4 IVStG i.v.m. \$ 118I BewG), begrenzt ihn allerdings dem Grunde nach auf solche, 
die mit den besteuerten Wirtschaftsgütern in einem wirtschaftlichen Zusammenhang stehen ( $\$ 118$ II BewG), begrenzt ihn in Ausnahmefällen auch der Höhe nach (§ 118 III BewG). Wie erwähnt, kommt in der englischen Bezeichnung "net worth tax" der Schuldenabzug bereits zweifelsfrei zum Ausdruck.

c) Jedoch ist die zulässigkeit oder auch Notwendigkeit des Schuldenabzugs durchaus diskussionswürdig, wenn man bei der Vermögensbesteuerung entweder die allokativen oder die distributiven ziele in den Vordergrund rückt. Daraus können sich $B$ e $g$ r $n z$ u $n-$ $\mathrm{g}$ e $\mathrm{n}$ des Schuldenabzugs nach der Schuldenart, nach der Schuldenhöhe oder nach dem Schuldenzweck ergeben (H. Fecher 1979, S. 462). Eher $a l l \circ k$ a $t i v$ motiviert erscheint z. B. ein AusschluB des Schuldabzugs für Konsumkredite. ${ }^{12}$ ) In der sachlichen Bindung des Schuldenabzugs an die besteuerten Vermögensgüter kommen in geringem Maße ebenfalls allokationspolitische Motive zum Vorschein, und zwar insofern, als zu den besteuerten Vermögensgegenständen keine Konsumgüter gehören und somit der Bestand an solchen Gütern auch nicht die Basis für den Schuldenabzug erweitern kann. Wollte man das Verbot des Schuldenabzugs etwa mit dem Argument begründen, daB im Wirtschaftsleben immer mithilfe des $B r u t t$. - Vermögens $\operatorname{der} E$ i n $f$ I $B$ auf andere ivirtschaftseinheiten ausgeübt würde, so folgen wir diesem Argument nicht, weil den EinfluB unter Kontrolle zu nehmen nicht die Aufgabe der Steuerpolitik sein kann, sondern die der ordnungspolitik.

Begrenzungen in der Schuldenhöhe können stabilisierungspolitische, aber auch dis $t r i b u t i \circ n s p \circ 1$ i $t i s c h e$ Gründe haben; letztere deshalb, weil mit der schuldenbegrenzung - wie

1 ) Dies allerdings würde eine Kontrolle der Kreditverwendung nötig machen, die letztlich bis zur politischen Willkür führen kann (F. Neumark 1970, S. 168).

Neumark sagt $z$ um Konsumkredit, daB eine Verdammung wegen der Verleitung $z u$ "Verschwendung und MiBbrauch" nicht angebracht sei, da ihm persönliche Notlagen vorausgehen könnten (S. 167) und daB - hätte der Steuerpflichtige Teile seines Vermögens veräuBert statt sie zu beleihen - das steuerpflichtige Nettovermögen genau so hoch wäre wie mit Schuldenabzug (S. 168). 
uberhaupt mit dem Verbot des Schuldenabzugs - immer die Gefahr des Substanzverlustes verbunden ist (der seinerseits selbstredend auch allokativ nachteilig sein kann). Kein substanzverlust tritt ein, wenn die Vermögensteuer als echte Ertragsteuer ausgestaltet ist und der Zinsaufwand für Schulden vom Ertrag abzugsfähig ist. Jedoch ist mit einem Substanzverlust dann zu rechnen, wenn die Vermögensteuer - sei sie eine Ertrag- oder Bestandssteuer - den Nettoertrag übersteigt bzw. auf das Rohvermögen erhoben wird und gleichzeitig die schulden eine solche Höhe ausmachen, daß ihr zinsaufwand den Ertrag ubersteigt. Hierfür kann nicht von vorn herein ein bestimmtes Rohvermögens-Schulden-Verhältnis angegeben werden.

H. Fecher (1979, S. 462) weist darauf hin, daB auch der umgekehrte Vorgang denkbar und praktisch wird, nämlich die Substanzakkumulation, und zwar dann, wenn fiktive Vermögenswerte geringer sind als der Schuldenabzug. ${ }^{13)}$ Auch dies hat distributive Effekte.

Aus distributiven Gründen könnte aber auch der Schuldenabzug grundsätzlich und generell bestritten werden, weil im Rahmen der zeitpunktbezogenen Besteuerung der Steuerpflichtige absichtlich eine kurzfristige Schuldaufnahme zum Jahresende "organisieren" könnte, um den Vermögenswert künstlich zu senken; um dem abzuhelfen, würde es sich empfehlen, die Vermögensbestandsdauer mit der schuldenbestandsdauer $\mathrm{zu}$ vergleichen und nur den zeitgleichen Schuldenabzug zuzulassen.

d) Man wird nach allem folgern dürfen, daß der Schuldenabzug sich zunächst logisch-rational, dann aber auch politisch zwingend ergibt, wenn man das distributive ziel der Besteuerung nach der Leistungsfähigkeit voranstellt und Leistungsfähigkeit mit Dispositionskraft und Verfügbarkeit des Vermögens gleichsetzt. Ausdruck der Leistungsfähigkeit, d.h. der "freien" Verfügbarkeit ist nur die

13) Nach H. Fecher wies der Gutachterausschuß Vermögensteuerschätzung nach, daß das land- und forstwirtschaftliche Vermögen in der Bundesrepublik in den Jahren 1953 bis 1963 bei Konstanz der Fläche, die nach den Wertansätzen des Jahres 1935 bewertet wurde, und bei einer gleichzeitigen zunahme der zum jeweiligen Wert berücksichtigten Verschuldung laufend abnahm. Siehe IFOInstitut für Wirtschaftsforschung (Hrsg.), Das künftige Vermögensteueraufkommen in der Bundesrepublik Deutschland, Studien zur Finanzpolitik, Heft 9, München 1967, S. 7. 
f i n a n $\mathrm{i}$ e 1 l e Verfügbarkeit und Disponibilität frei von Lasten; sie erfordert den Schuldenabzug. Die Notwendigkeit des Schuldenabzugs folgt auch daraus, daB ein mit Schulden belastetes Vermögen bei seinen sämtlichen Funktionen ${ }^{14}$ ) an Wirkungskraft einbüBt. Bedingung für den Schuldenabzug ist aber vor allem eine Kongruenz in den Bestandszeiten von Vermögen und Schulden ${ }^{151}$ sowie eine korrekte und tagesnahe Bewertung beider "Bilanzseiten" nach denselben Maßstäben.

524 Das Allgemeinheitspostulat und seine dritte sachliche Einschränkung = Das "Nominalwertprinzip" als Begrenzung der "realen" verfigbarkeit

I. Kaufkraftzusammenhänge zwischen Ertrag, Einkommen und vermögen 402

II. Nominalwertprinzip und Kaufkrafterhaltung

III. Nominalwertprinzip und Steuerbelastung 408

IV. Allokativ-distributive Beurteilung des Nominalwertprinzips in seinem Einfluß auf den Einkommens- und VermögensUmfang

v. Das "Niveauproblem" der Geldentwertung und die realwirtschaftliche Verfügbarkeit

VI. Zusammenfassung des 7. Kapitels

Bei der Frage, welches Phänomen nunmehr eine freie Verfügbarkeit und die Geltung des Allgemeinheitspostulats beeinflussen kann, stoßen wir auf die $B$ e we r $t$ u $n g$. Dieses Problem kann erst jetzt, da die finanzielle verfügbarkeit definiert ist, eingefuhrt

14) Rückzahlungsverpflichtungen und Schulden beeinträchtigen die Funktionen der Sicherung der Existenz, der Vorsorge, der Lebensstandardsteigerung und der Unabhängigkeit samt Kreditwürdigkelt. Ohne den Schuldenabzug würde ein nominelles Vermögen ausgewiesen, das $z u$ hoch ist und die von $1 \mathrm{hm}$ repräsentierten Funktionen in dieser Höhe nicht aufweist. - Vgl. \$ 10. Fußnote 15) auf der folgenden seite. 
werden, weil es beide Seiten der "Bilanz", die Aktiva und die Passiva, betrifft. Es steht-hier nicht die Bewertung positiver und negativer Vermögensgegenstände zur Diskussion, sondern allein die Grundfrage der Bewertung angesichts der $G$ e $l$ d e $n t w$ e $r$ $t \mathrm{u} \mathrm{n} \mathrm{g}$. Ein schwindender Geldwert mindert zwar nicht die Verfügungssumme, aber doch deren Gegenwert, beeinträchtigt damit wesentliche Allokations- und DistributionsgröBen und verengt zugleich den Inhalt der finanziellen Verfügbarkeit, das substrat der ökonomischen Dispositionskraft.

Referiert werden hier nur die steuerlichen Probleme, und diese nur in Verbindung mit dem Allgemeinheits- und dem Leistungsfähigkeitspostulat. Diese Probleme sind hier in erster Linie solche des Einkommens- und Vermögensbegriffs, nicht solche des Tarifs. Es wird keine lückenlose Sammlung von Argumenten für oder gegen das Nominalwert- und Realwertprinzip angestrebt, sondern der Nachweis ihrer Auswirkungen auf die genannten Begriffe sowie der Nachweis der hinter den Prinzipien stehenden steuerpolitischen ziele.

I. Zunächst sei festgestellt, daß innerhalb des Distributiven die Geldentwertungsprobleme sowohl das Vermögen als auch das Einkommen $^{1)}$ und solchermaßen den Zusammenhang zwischen Einkommen und vermögen beleuchten ${ }^{2}$ ). Denn wenn eine (inflationäre) Geldentwertung als (längerdauernde) Verringerung der "realen Kaufkraft" einer Geldeinheit definiert wird ${ }^{3}$, wirkt sich diese sowohl für jede

15) Zur Zeitenkongruenz führt M. Rose $(1979$, S. 314 f.) aus, daB die Vermögensteuer mit dem Nachteil behaftet sei, den Abzug von Schulden vom Zeitpunkt ihrer Entstehung an zu gewähren, wohingegen es doch rational wäre, "daB Schulden nur im Zeitraum ihrer Tilgung abzugsfähig sind". Dieser Kongruenzaspekt ist von dem unseren deswegen verschieden, weil Rose die Vermögensbesteuerung unter dem Aspekt der Nachfrageregulierung der privaten Haushalte beurteilt und solchermaBen zu einer anderen Rationalitätsforderung kommt. Wir stellen dagegen auf die Verfügbarkeit $a b$, und die ist zum Zeitpunkt der Schuldaufnahme vermindert.

1) Siehe hierzu R.A. Musgrave 1981, S. 34, der die Notwendigkeit einer Korrektur von Geldwertminderungen sowohl bei den Lohnund Kapitaleinkünften als auch bei Vermögens- und Kapitalbeständen betont.

2) Auf den steuersystematischen Zusammenhang, der insbesondere durch das Nominalwertprinzip offensichtlich gemacht wird, weisen N. Andel (1979a, S. 361) und W. Stützel (1979, S. $48 \mathrm{ff}$. u. $52 \mathrm{f.l}$ hin: Uber $\mathrm{zu}$ niedrig bemessene Abschreibungsbeträge, die "keine real berechnete Wiederbeschaffung" der im Produk(Fortsetzung auf der folgenden Seite) 
Art von Einkommen als auch beim Vermögen, seiner Nutzung und seiner VeräuBerung aus: Der Gegenwert geldentwerteter Einkommen und Vermögen ist geringer als vorher. Ein "vermögenseinschlieBender Einkommensbegriff" wie auch der Vermögensbestandsvergleich ist generell von der Bewertungsproblematik abhängig (w. Albers 1979a, S. 192) und somit auch von der Geldentwertung; sie bestimmen seinen Umfang. ${ }^{4)}$ Den Umfang des steuerlichen Einkommens bestimmt aber als Vorbedingung bereits auch schon die Kapitalbewertung bzw. die durch Geldentwertung beeinfluBte Kapitalwerterhaltung. Demnach ist die Bewertungs- und Geldentwertungsfrage ein allokativ-distributives Interdependenzproblem. Es sei an die "maintaining capital intact-Diskussion" ( $\$ 7$ III) erinnert, die ergab, daB zwar Kapital- wie Vermögenserhaltung kein Erfordernis des wirtschaftstheoretischen Einkommens- und Vermögensbegriffs ist, daB dennoch aus steuerpolitischen Gründen, die auch die ordnungspolitischen reflektieren, die Vermögens- und Kapitalerhaltung erwünscht sein kann, mit der Folge, daB durch die Zulassung von Inflationierungsgrößen der Einkommens- und Vermögensumfang gegenüber den wirtschaftstheoretischen Begriffen eingegrenzt wird. Im allokativen Bereich des Betriebes liegt in den um die Inflationsrate erhöhten Erträgen keine erhöhte Ertragsfähigkeit, sondern ein "illu-

(Fortsetzung Fn. 2)

tionsprozeB abgenutzten Kapitalgüter erlaubt, wird "real betrachtet .... aus der Einkommensteuer teilweise eine Vermögensteuer (Andel). "Weil unser Steuerrecht trotz Geldentwertung zur Messung von Vermögensänderungen das Nominalprinzip beibehalten hat, ist die steuerlast für diejenigen Steuerzahler, deren Einkünfte durch Vergleich zwischen Jahresanfangs- und -endvermögen bestimmt werden, in der Weise umverteilt worden, daB unter den Komponenten der Leistungsfähigkeit ... die durch ... Realerträge erzielte 'Ist-Leistung' im Gewicht etwas verringert, und dafür die ... (im Vermögen repräsentierte) 'potentielle Leistung' im Gewicht etwas erhöht wurde (Stützel S. 53).

3) Gemessen als reziproker Wert der Veränderung des allgemeinen Preisniveaus, wobei als MaBstab für letzteres der vom Statistischen Bundesamt berechnete Preisindex für die Lebenshaltung gilt; so in Ubereinstimmung mit der Lehrbuchliteratur auch die Deutsche Bundesbank in ihrem Gutachten vom 22. Sept. 1977 für das Bundesverfassungsgericht "Berücksichtigung der Geldentwertung bei der Besteuerung von Kapitalvermögen", Monatsbericht $8 / 1979$, S. 21 .

4) Das gesamte Schanz-Haig-Simons-Konzept steht und fällt mit Bewertungsproblemen. D. Schneider kritisiert an der Reinvermögenszugangstheorie, daB allerdings G.v. Schanz den Grundsatz der Kapitalerhaltung in die Besteuerung aufnahm, ohne genau anzugeben, wie sie zu messen sei. 
sionärer Kapitalgewinn"5) vor, und für den distributiven Bereich der Haushalte läßt sich folgern, daß in Höhe der Inflationsrate keine erhöhte Verfügbarkeit erwirkt wird ${ }^{6)}$, die daher nicht zu besteuern ist. ${ }^{7)}$

Wăhrend im distributiven Berelch die Nichtberücksichtigung der Geldentwertung für Einkommen und Vermögen eine nur nominale Erhöhung der Kaufkraft und damit eine um die Geldentwertungsrate nur vorgetäuschte Leistungsfähigkeit herbeiführt, ist im allokativen Bereich die vorgetäuschte Ertragsfähigkeit die Ursache für die nicht gelungene Kapital- bzw. Substanzerhaltung. Da, wie dargestellt (\$7), nur das aus dem betrieblichen Berelch zugehende Einkommen $z$ u persönlichem Einkommen werden kann, was vorher tatsächlich Ertrag gewesen ist, hat die Geldentwertung für den allokativen Berelch ihre mittelbare Auswirkung auf den distributiven.

II. Angesichts dieser für die Besteuerung nach der Leistungsfähigkeit bedeutsamen Zusammenhänge fragt man, welche Entscheidungsregeln zu finden sind, um vorgetäuschte Ertrags- und Leistungsfähigkeiten auszuschließen. An Bewertungsregeln kennt man grundsätzlich zwei: Entweder hält man an der einmal getroffenen Bewertung unverrückbar fest und läßt den auf diese weise gefundenen nominalen Geldausdruck für Vermögen und Einkommen, für Kapital und Ertrag auch dann gelten, wenn der Geldwert sich geändert hat, $\circ \mathrm{b}$ w $\circ \mathrm{h} l$ man die Folgen dieser Änderung kennt; dann handelt man nach dem

5) Musgrave/Musgrave/Kullmer 1975b, S. 73, wenn auch unter Vermengung der Begriffe: "Ein Anstieg des Geldwertes eines Vermögens, der gerade dem Anstieg des Preisniveaus entspricht, ist ein illusionärer Kapitalgewinn und darf deshalb nicht als Einkommen betrachtet werden ...". SVR 1982. TZ 307: Der "real überhöhte Anspruch des Staates an das Produktionsergebnis" ist zu senken.

6) N. Andel 1979a, S. 348: Wertzuwächse durch steigendes Preisniveau repräsentieren "keinen realen zugang an wirtschaftlicher Dispositionsfähigkeit". - A. Oberhauser 1980, S. 668: "Nominelle Wertzuwächse, die sich im Rahmen des allgemeinen Preisanstiegs bewegen, stellen keine Erhöhung der Leistungsfähigkeit des Steuerpflichtigen dar. Die reale Kaufkraft ihrer Vermögen steigt nicht."

7) Musgrave/Musgrave 1980, S. 346: "If income is to serve as a measure of ability to pay, it should be defined in real terms. An increase in money income which is matched by a rise in prices does not constitute a gain in real income." S. 389: "Since taxable capacity or accretion should be measured in real terms, such gains should not be taxed. 
"N $\circ \mathrm{m}$ i a $l$ we $r$ t p r $\mathrm{nz} i \mathrm{p} "$. Oder man paBt den Geldausdruck ökonomischer GröBen der in wirklichkeit eingetretenen Geldwertänderung an, w e $i$ l man die Folgen kennt, die eine Nichtberücksichtigung der Geldwertänderung für alle Beteiligten hat; in diesem Fall handelt man nach dem "R e a $l$ w e $r t-$ p r i n z i p".

Was heiBt in einer dynamischen Wirtschaft mit ökonomischem und sozialem, mit technischem und rechtlichem Wandel, zugleich aber mit Preisschwankungen und Inflation 8) nun "Erhaltung", und welche ökonomischen GröBen sollen als erhaltenswert gelten? Die Literatur - wohl unter dem EinfluB der dominanten Werterfassungsund Wertkorrekturprobleme gerade im unternehmerischen Bereich 9) kennt das Erhaltungsproblem vorwiegend unter der Bezeichnung "reale" oder "substantielle Kapitalerhaltung". 10) Aber erhaltungsbedürftig ist angesichts des Geldwertschwundes nicht nur Kapital und Vermögen, sondern auch das Einkommen. 11) Umfassender wäre also das Problem mit $k$ a u $k r$ a $t$ e $r$ h $l$ t u n $g$ beschrieben; denn sowohl Kapital wie Ertrag, Vermögen wie Einkommen repräsentieren Kaufkraft, wenn auch auf verschiedenen Märkten. $\mathrm{Ob}$ nun Bestands- oder StromgröBen geldentwertet sind, sie weisen in jedem Falle eine verminderte Kaufkraft auf; ${ }^{12}$ ) so kommt in der

8) Zur Gesamtsicht dieser Phänomene und ihrer Reflexion besonders aus der betriebswirtschaftlichen Sicht siehe D. Schneider $1978 \mathrm{~b}, \mathrm{~S} .71 \mathrm{ff}$.

9) Als Beleg diene die seit F. Schmidt 1921: "Die organische Bilanz im Rahmen der Wirtschaft"; 1929: "Die organische Tageswertbilanz") und im AnschluB an die damalige wirtschaftskrise erschienene umfangreiche betriebswirtschaftliche Literatur über die Kapital- und Substanzerhaltung im Kalkulations- und Bilanzwesen.

10) Stellvertretend für viele: K. Hax 1957: Die Substanzerhaltung der Betriebe.

11) F.W. Wagner (1976b, S. 236) weiB durch ein Berechnungsbeispiel $\mathrm{zu}$ belegen, daB die Beschränkung der Geldwerterhaltung auf den Besitz zu groBen Belastungsunterschieden gegenüber Beziehern von laufenden Einkünften aus Arbeit führt.

12) H. Haller 1971, S. 44: "Das Geldeinkommen selbst ist auch nur der quantifizierte Ausdruck für die Summe der mit seiner Hilfe beschaffbaren Güter und Dienste. Das Geldeinkommen läBt die GröBe dieser Summe nur erkennen in Verbindung mit dem jeweiligen Preisniveau. Bei Anderung des Preisniveaus bedeutet das gleiche Geldeinkommen jeweils etwas anderes." 
"Kaufkrafterhaltung" im Gegensatz zu Kapitalerhaltung deutlicher zum Ausdruck, daß die Geldentwertung in gleichem Maße wie ein allokatives auch ein distributives Problem ist, das heute sogar eher unter distributiven Aspekten diskutiert wird als unter allokativen. ${ }^{13)}$

Die Merkmale der Kaufkrafterhaltung sind: ${ }^{14}$ )

- die "Totalitätsregel": Alle ökonomischen Größen, die Kaufkraft repräsentieren, sind $\mathrm{zu}$ erfassen; im distributiven Bereich $\mathrm{zäh-}$ len $z u$ den Stromgrößen alle Elemente des vermögen- und transfereinschließenden Einkommensbegriffs, $z u$ den Bestandsgrößen alle verfügbaren Vermögenselemente nach Schuldenabzug;

- die "Geldausdrucksregel": Gemeinsamer Generalnenner für die ökonomischen GröBen ist der Ausdruck ihres Wertes in Geld; bei Bestands- und WertzuwachsgröBen erfordert das eine Bewertung, die gegenwartsnah und für die verschiedenen Kapital- und Vermögensarten gleichartig ( $d . h$. vergleichbar) ist;

- die "Vergleichsregel": Um Erhaltung bzw. Verlust der Kaufkraft feststellen zu können, müssen erstens die bewerteten Größen periodisiert werden; so sind Bestandsgrößen auf zwei Vergleichszeitpunkte, Stromgrößen auf die Zeitspanne zwischen diesen Vergleichszeitpunkten zu beziehen; zweitens ist die Vergleichsgröße "allgemeines Preisniveau" $z u$ denselben beiden Vergleichszeitpunkten heranzuziehen;

- die "Erhaltungsregel 1": Der Geldwert der Strom- und Bestandsgrößen darf sich infolge einer allgemeinen Preisniveauänderung (-erhöhung oder -senkung) innerhalb der Vergleichsperiode weder positiv noch negativ verändert haben: daraus folgt, daß die Kaufkrafterhaltung nur nach dem "Realwertprinzip" gelingen kann, nicht aber nach dem Nominalwertprinzip;

- die "Erhaltungsregel 2" betrifft speziell die realen Bestandsgrößen und setzt die Erhaltungsregel 1 voraus: Die bewerteten Bestände dürfen in der Vergleichsperiode keine Verminderung ihrer zu Beginn des Vergleichs festgestellten Mengenstruktur

13) Siehe BBk M 8/1979 (Gutachten für das Bundesverfassungsgericht).

14) Zu den "Regeln" für die Begriffsbestimmung, für die Hervorhebung von Merkmalen, wie auch zu ihrer Abgrenzung gegenüber den "Kriterien" siehe unsere Ausführungen in $\$ 11 \mathrm{VI}$. 
erfahren haben, die über die technische und wirtschaftliche Abnutzung und/oder Vernichtung sowie über die diesen Vorgängen entsprechende zeitanteilige Wert- oder Totalabschreibung usw. hinausgeht; soweit aber eine Abnutzung und/oder Vernichtung eingetreten sind, müssen sie, um den realen Bestandswert wieder zu repräsentieren, durch eine kaufkraftwertgleiche Zufuhr von Beständen wieder aufgefüllt werden, und zwar in Form von gegenständlichem Ersatz bzw. in Form von finanziellen Gegenposten (akkumulierte Abschreibungen $z$ ur Ersatzbeschaffung der am Periodenende fehlenden Bestandswerte). 15)

In diesen "Regeln" der Kaufkrafterhaltung ist der Geldvermögensbegriff, der in der Geldentwertungsdiskussion im Mittelpunkt steht, weit gefaBt und entspricht dem oben entwickelten steuerlichen Vermögensbegriff. Im Gegensatz zur Abgrenzung, die die Deutsche Bundesbank in ihrem Gutachten für das BVG getroffen hat, ${ }^{(0)}$ enthält Geldvermögen hier alles Geld, das der Steuerpflichtige nicht $z u$ konsumieren entschieden hat. ${ }^{17)}$ In der Pointierung "nominelle versus reale" Erhaltung der Kaufkraft ist ein Gegensatzpaar gewählt, das möglicherweise betriebswirtschaftlichen Notwendigkeiten nicht völlig entspricht; so differenziert D. Schneider die Formen der Erhaltung in die "Ertragswerterhaltung", die "nominelle" und die "reale" Kapitalerhaltung sowie in

15) Die Erhaltungsregel 2 gilt somit - was die Abschreibungen betrifft - für den produktionswirtschaftlichen Kapital- und Ertragsbereich (Substanzerhaltung) und ansonsten - was den gegenständlichen Ersatz der Bestände betrifft - auch für den privaten Vermögensbereich. Im übrigen ist ja bei Kapital und Vermögen zwischen Sach- und GeldgröBen zu unterscheiden, wobei wegen der im $\mathrm{Z} u g e$ von Geldentwertungen steigenden Preise für Sachgüter die Erhaltungsregeln für letztere im allgemeinen nicht relevant sind. Vielmehr gilt die Kaufkrafterhaltung in erster Linie für Geldkapital und -vermögen; und bezüglich dieser GeldgröBen wird das Erfordernis ihrer realen Werterhaltung bereits von der Erhaltungsregel 1 erfaBt.

16) BBk-M 8/1979, S. 21: die Bundesbank hat lediglich die Kaufkrafterhaltung jener Geldforderungen untersucht, die verzinsliche Ersparnisse darstellen; das Geldvermögen der Kassenhaltung bleibt ausgeschlossen, ebenso wie die Sichteinlagen bei Kreditinstituten, selbstverständlich auch Aktien und andere Beteiligungsrechte.

17) Siehe unsere vermögenstheoretische Definition in \$\$ 10 und 19 mit dem Abstellen auf Entscheidungen. 
die "Substanzerhaltung". 18) Unbestritten aber ist, daB bei Geltung des NWP sowohl die Geldwerterhaltung als auch die Substanzerhaltung in den Betrieben nicht gelingt; mit der Inflationsrate nimmt die relative Belastung durch die Substanzsteuern $\mathrm{zu}$ (G. Rose 1975, S. 319). 19) Für die hier verfolgten Zwecke einer Darstellung unterschiedlicher Wirkung der beiden Bewertungsprinzipien auf die steuerlichen Einkommens- und Vermögensbegriffe reicht die gewählte Pointierung "Nominalwertprinzip versus Realwertprinzip" völlig aus.

III. Um die Auswirkungen des $s t e u$ e $r$ e $c h t$ i $c^{h}$ geltenden Nominalwertprinzips auf den steuerlichen Einkommens- und Vermögensbegriff darstellen zu können, gehen wir von einer Art "Grundformel" für das steuerliche Einkommen aus, die den Vermögensbegriff einschließt und auf dem Vermögensvergleich beruht: Einkommen wird definiert als "Reinvermögenszuwachs + Konsum". 20)

18) Nach D. Schneider (1978b) ist das engste Kapitalerhaltungskonzept das der nominellen, zu verwirklichen nur in einer für heute nicht typischen stationären Wirtschaft ohne Inflation, aber zugleich für den heutigen Steuerrechtszustand kennzeichnend (S. 77). Ohne auf weitere Konzepte Schneiders einzugehen, war uns doch seine gesamtwirtschaftlich orientierte "Kaufkrafterhaltung" des Kapitels - in Verbindung mit der Kaufkrafterhaltung des Geldvermögens 1t. Bundesbank (BBk-M 8/1979) - die entscheidende Anregung zur Wahl des Terminus "Kaufkrafterhaltung" als Oberbegriff für die Geldwertstabilität bei strom- und BestandsgröBen.

19) Die relative Belastung ist nach G. Rose der Anteil der Substanzsteuern an dem nach der Scheingewinnausschaltung und nach der Ertragsbelastung verbliebenen realen Gewinn. Der EinfluB der Geldentwertung auf die Substanzbesteuerung liegt darin, daB die Bemessungsgrundlage nominell erhöht wird, wenn auch beim Anlagevermögen mit einer zeitlichen Verzögerung, S. $317 \mathrm{f}$.

20) Diese Grundformel findet sich in der gesamten steuerwissenschaftlichen und ökonomischen Literatur, selbst in jener, die statt der Einkommensbesteuerung eine Ausgabenbesteuerung propagiert. Die Grundformel drückt, unabhängig vom einkommenoder ausgabensteuerlichen Ansatzpunkt, die überhaupt als besteuerbar angesehene Basis der leistungsfähigkeitsorientierten Summe aller ökonomischen GröBen aus. Allerdings begegnet die korrekte Interpretation der Schwierigkeit, die "KonsumgröBe" inhaltlich genau zu treffen: in ihr müBten alle Vermögenserträge und Einkommenstransfers enthalten sein, um einen umfassenden Einkommensbegriff $z$ u erhalten; der andere Weg wäre, die Vermögenserträge sowie Transfereinkommen auf Vermögenswerte

(Forts. siehe folgende Seite) 
Orientiert an der für Unternehmungen geltenden Gewinnfeststellungsmethode, 21) nimmt die Grundformel die folgende Gestalt an (w. Stützel 1979, S. 43):

Nominalwert des Reinvermögens am Jahresende

./. Nominalwert des Reinvermögens am Jahresanfang

+ Netto-Entnahmen

= Einkommen (Gewinn).

Diese Formel ist das Ergebnis aus der Anwendung des steuerrechtlichen Nominalwertprinzips, die w. Stützel (1979, S. 42) den "Nominalismus $\mathrm{Nr} .7$ " nennt: Die steuerliche Leistungsfähigkeit wird gemessen durch das Einkommen in Mark, auch wenn sich der Wert der Mark ändert (= Nominalismus in der steuerlichen Einkommensdefinition)". Es soll selbst dann von Vermögenszuwachs gesprochen werden, wenn auch nur der Nominalwert eines Vermögens am Jahresende höher ist als am Jahresanfang, m.a.W. wenn wegen zwischenzeitlicher Geldentwertung der Realwert des Endvermögens kleiner ist als der Realwert des Anfangsvermögens (W. Stützel 1979 , S. 76 f.). Nach dem Nominalwertprinzip ist Einkommen das, "was über die Rückgewinnung des eingesetzten nominal fixierten Kapitalbetrags hinausgeht" (N. Andel 1979a, S. 360).22) Von wenigen Ausnahmen ${ }^{23}$ ) abgesehen ist das Nominalwertprinzip die Grundkonstruktion in der steuerrechtlichen Bewertung.

Bei dieser Sachlage sind die Einkommens- und Vermögensbegriffe, d.h. der Umfang dieser GröBen, um die Geldentwertungsrate zu hoch.

Forts. Fn. 20:

umzurechnen und im Reinvermögen zu repräsentieren. Insofern ist die Grundformel eine zu stark betriebene Vereinfachung der Besteuerungsbasis. Vgl. unsere Kritik oben, $\$ 21$ III 3 .

21) Vgl. die Gewinndefinition in $\S 4$ I S. 1 EStG; siehe auch G. Rose 1977a, S. 51, und das dort entwickelte Schema.

22) Dies ist streng genommen der Ertrag der Unternehmung; wie bereits mehrfach betont, ist das "unternehmerische Einkommen" ein Ertrag, der persönliches Einkommen werden kann. Gleichwohl trifft der hier zum Ausdruck gebrachte Nominalismus sowohl für den Ertrag als auch für das Einkommen $z u$.

23) Ausnahmen von dem sonst geltenden Nominalwertprinzip in der Besteuerung und in der Handelsbilanz sind: die Rücklage für Preissteigerungen ( $\S 51 \mathrm{Abs} .1 \mathrm{Nr}$. 2b EStG i.V.m. $\S 74$ EStDV); der Importwarenabschlag ( $\$ 51$ Abs. 1 Nr. $2 \mathrm{~m}$ EStG i.V.m. $\S 80$ EStDV); die Ubertragung stiller Reserven ( $\S \S 6 \mathrm{~b}, 6 \mathrm{c}$ EStG) und die vorratsbewertung nach der lifo-Methode ( $\$ 40$ Abs. 4 Nr. 2 HGB; § 155 Abs. 1, S. 3 AktG). Diese Bestimmungen können die Geldentwertung teilweise ausgleichen, s. K. Tipke 1991, S. 284 
"Wer sonach die Formel 'Mark gleich Mark' gebraucht, will damit entweder ein bisher utopisches währungspolitisches Ziel ansprechen oder er sagt die Unwahrheit" (R. Nöll von der Nahmer 1980). Die Nichtaufgabe des $N W P^{24)}$ hat Folgen für die Belastung.

IV. Die $A$ u $\mathbf{s}$ w $\mathbf{r}$ u $\mathrm{n}$ g $\mathrm{n}$ des Nominalwertprinzips auf die steuerlich "erhaltenswerten" ökonomischen Größen sind allokativer wie distributiver Art; sie berühren dort die $E r t r a g s$ a -

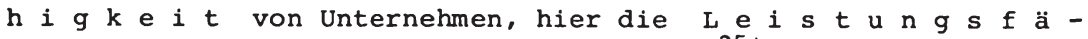
$\mathrm{h} i \mathrm{~g} \mathrm{k}$ e $\mathrm{t}$ von Personen und Haushalten. ${ }^{25}$ ) In Ubersicht 7.8 ist der Versuch unternommen, diese Wirkungen zu systematisieren und ihre hauptsächlichen hervorzuheben.

a) Auswirkungen sind sowohl bei den BestandsgröBen (Kapital und Vermögen) als auch bei den Stromgrößen (Ertrag und Einkommen) festzustellen. Ubersicht 7.8 stellt synoptisch dar, daB die Auswirkungen auf jene ökonomischen Größen, deren Kaufkraft von der Geldentwertung betroffen wird, danach $z u$ unterscheiden sind, w e $r$ über $w$ e $l \mathrm{c} h$ e Art von Bestands- und StromgröBen verfügt; entsprechend dem (unternehmerischen oder privaten) Verfüger und entsprechend der Art der (sachlichen und monetären) Bestandsund Stromgrößen sind vier Kategorien (A bis D) gebildet: die Sachwertbesitzer A und B, die Geldwertbesitzer und Geldstromverfüger $C$ und D. Sowohl Unternehmer wie Nichtunternehmer verfügen über (sachliches) Produktionskapital (A) als auch über monetäre Bestände und Ströme, also über Geld, Finanzinvestitionen, Forderungen aus diesen (z.B. Zinsen) u.ä. (C), aber nicht nur über positive, sondern auch über negative Bestände und Ströme (D), wie verbindlichkeiten, Zins- und Tilgungszahlungen. Private Haushalte und Personen verfügen über Sachvermögen (B) und ebenfalls über monetäre Bestands- und Stromgrößen wie Geld- und Forderungsbestände, aber auch über kontraktbestimmte Einkommen wie Zinsen, Löhne, Renten und über gesetzliche Transfers (C); auch sie können Schuldner aus Kontrakten und demnach $z u$ Zins- und Tilgungszahlungen verpflichtet sein (D).

24) K. Tipke 1981, S. 229: "M.E. verstößt die Eliminierung bloß nomineller Vermögenswertsteigerungen ... durch Ansatz eines entsprechenden Passivpostens nicht gegen das Nominalprinzip. Sie trägt hingegen dem Leistungsfähigkeitsprinzip ... Rechnung".

25) Gegenstand der Beurteilung ist hier $n i c h t$ die UngleichmäBigkeit der Besteuerung zwischen Unternehmen und Haushalten

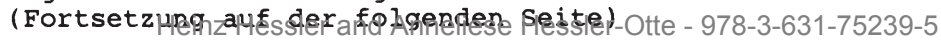


Ubersicht 7.8: Auswirkungen des Nominalwertprinzips (NWP) bei Geldentwertung auf Bestände, StromgröBen und Gruppenbeziehungen

Verfügungen über Sachen

A. Netto-

B. Netto-

Sachkapital Sachvermögen

Verfügungen über Geld

\begin{tabular}{l|l} 
C. positive & D. negative
\end{tabular} Netto-Geldkapital-/Netto-GeldvermögensBestände und Geldstrōme

I. Auswirkungen auf die inner-institutionelle, bereichsorientierte "Ertragsfăhigkeit" bzw. "Leistungsfähigkeit":

\begin{tabular}{|c|c|c|}
\hline $\begin{array}{l}\text { Produktions- } \\
\text { Kapital }\end{array}$ & $\begin{array}{l}\text { Forderungen aus } \\
\text { Nichtsachbestand } \\
\text { u. Kontrakt-Ein- } \\
\text { kommen (Zinsen/ } \\
\text { Lōhne/Renten) }\end{array}$ & $\begin{array}{l}\text { Verbindlichkeiten } \\
\text { bzw. Schulden so- } \\
\text { wie die Zahlungen } \\
\text { daraus }\end{array}$ \\
\hline 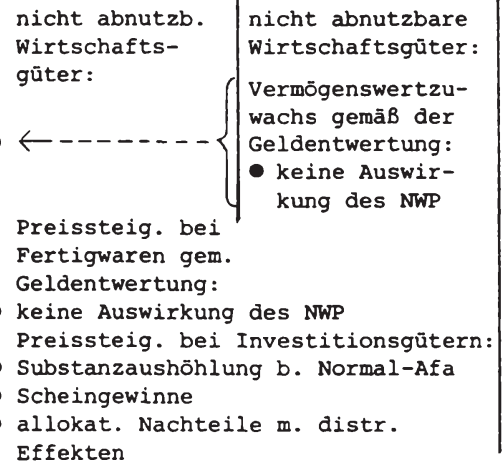 & $\begin{array}{l}\text { a) Kontrakteink. } \\
\text { steigen gemāB d. } \\
\text { Geldentwertung: } \\
\text { - keine Auswir- } \\
\text { kung des NwP } \\
\text { b) Geldentwertung } \\
\text { hōher als Kon- } \\
\text { trakteinkommen: } \\
\text { - Scheinertrags- } \\
\text { fähigkeit } \\
\text { Scheinlei- } \\
\text { stungsfähigkeit } \\
\text { allok./distr. } \\
\text { Nachteile mit } \\
\text { d./a. Effekten }\end{array}$ & $\begin{array}{l}\text { a) Zinsen steigen } \\
\text { gemäB der } \\
\text { Geldentwertung: } \\
\text { - keine Auswir- } \\
\text { kung des NwP } \\
\text { b) Zinsen konst. } \\
\text { trotz Geldentw.: } \\
\text { erhöhte Ertrags- } \\
\text { fähigkeit } \\
\text { erhöhe Lei- } \\
\text { stungsfähigkeit } \\
\text { allok. Vorteile } \\
\text { m. distr. Effekt. } \\
\text { distr. Vorteile } \\
\text { m. allok. Effekt. }\end{array}$ \\
\hline
\end{tabular}

II. Auswirkungen auf die zwischen-institutionellen, gruppenorientierten "Vorteils-Nachteils-Beziehungen":

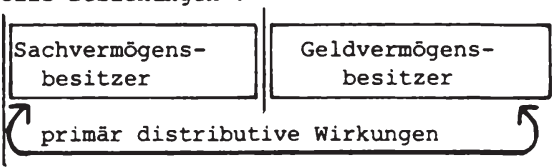

a) Mobilitätsunterschiede/Kleinsparerproblem/Flucht in die Sachwerte"
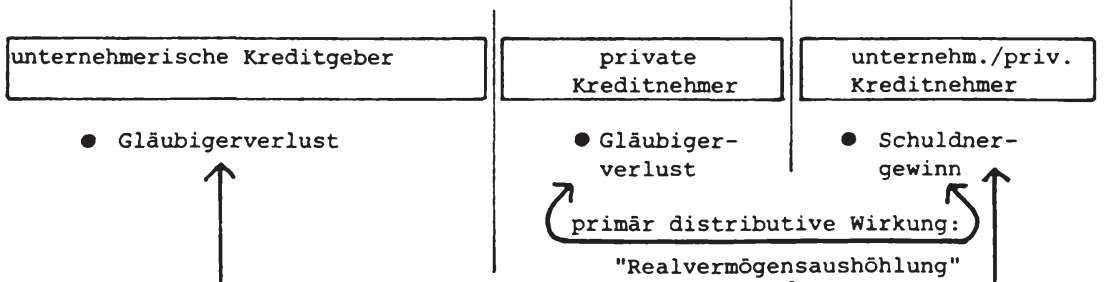

b) "Glaubiger-schuldner-Beziehung

primär allokative Wirkung: "Realkapitalaushöhlung" 
Diese Einteilung reflektiert nicht einfach ein UnternehmerNichtunternehmer-Schema, sondern stellt darauf ab, wer jeweils über welche ökonomischen GröBen verfügt; so können Unternehmer wie Private über kontraktbestimmte Erträge bzw. Einkommen verfügen, so können Unternehmer wie Private sowohl Gläubiger als auch Schuldner von Geldbeständen und Zahlungen sein. Ubersteigt mithin z.B. die Geldentwertung die Kontrakterträge bzw. - einkommen (Fall C I b), führt das Festhalten am Nominalwertprinzip sowohl zu einer nur vorgetäuschten Ertrags- wie auch einer nur scheinbaren Leistungsfähigkeit. Die Schein-Ertragsfähigkeit hat allokative Nachteile ${ }^{26}$ ) (siehe auch Fall A I c), und zwar in der Form des Ausweises von Scheingewinnen und Substanzaushöhlungen; diese wiederum führen $z u$ distributiven Effekten, wenn auf Grund dieser nur scheinbar positiven Ergebnisse (1nterpersonell unterschiedliche) Einkommensausschüttungen bzw. -entnahmen veranlaBt werden (die einzelnen Wirkungen sind der Ubersicht $7.8 \mathrm{zu}$ entnehmen). Entsprechend kommt es bei nur nominell erhöhten Kontrakteinkommen direkt zum Ausweis einer Schein-Leistungsfähigkelt mit allokativen Effekten dann, wenn die Vermögensbildung darunter leidet und sparkapital der Produktionswirtschaft nicht mehr angeboten werden kann.

b) Die Auswirkungen sind als "inner-institutionelle" (wie die in I geschilderten) $\mathrm{zu}$ trennen von jenen, die wegen der Beziehungen zwischen den Personengruppen der Sach (bzw. Geld-)Vermögenshalter (Fall II 1) wie auch zwischen den Gruppen der Gläubiger und Schuldner (Fall II 2) als "zwischen-institutionelle" Vorteils-Nachteils-Beziehungen (II) ausgewiesen sind. Diese Vorteils-Nachteilsbeziehungen stellen sich zum einen als distributive dar (a), hängen zum anderen mit der Gläubiger-Schuldner-Beziehung zusammen (b) und offenbaren hier sowohl distributive als auch allokative Wirkungen. Was hier thematisch interessiert, ist nicht die Entstehung solcher Auswirkungen durch das Nominalwert-

26) Wв BMW 1975, S. 4 f.: "Da die steuerlich zulässigen Abschreibungen auch bei langlebigen Anlagegütern stets nur von den durch den InflationsprozeB überholten nominalen Anschaffungswerten vorgenommen werden dürfen, werden Schelngewinne ausgewiesen und versteuert"; bei stelgenden Wiederbeschaffungspreisen entstehen also reale Wertverluste.

Fortsetzung Fn. 25: durch das Nominalwertprinzip darzustellen; eine vergleichende Betrachtung zwischen Unternehmens- und Haushaltsbesteuerung ist

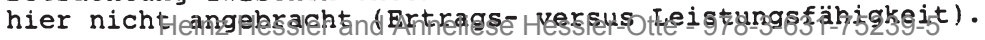


prinzip ganz allgemein, sondern die Auswirkung durch die Geltung des Nominalwertprinzips für die steuerliche Bewertung.

(1) In der Beurteilung des Nominalwertprinzips für die Besteuerung gehen wir zunächst so vor, daB wir den Fall B I mit dem in B II a kombinieren. Hier heben wir vorerst solche Vermögensgegenstände (Grundstücke, Sammlungen, Kunstwerke, Edelmetalle usw.) hervor, deren Preissteigerung die Geldentwertung ausgleicht oder übersteigt; weil diese Güter nicht in den ProduktionsprozeB eingeführt und dort abgenutzt werden, liegt das Problem hier erstens darin, daB - was allerdings selten vorkommt - die Steuerbelastung die Realwertsteigerung zunichte macht oder in eine Realvermögensaushöhlung verkehrt, zweltens darin, daB für viele Wirtschaftssubjekte die Haltung von Sachvermögen überhaupt, und zudem von solchem Sachvermögen, das eine Realwertsteigerung erfährt und infolge der Geldentwertung nicht verliert, oftmals gar nicht möglich ist, und daB ihnen die Flexibilität abgeht, in Reaktion auf die zins-, Steuersatz- und Geldentwertungsratenvariation mal in Sachvermögen, mal in Geldvermögen $z u$ investieren und ihre Bestände entsprechend schnell umzuschichten. Variables Anlageverhalten, "Absicherung des Zinsänderungsrisikos" und "Umsteigen" von "Kurzzu Langläufern" (BBk-M 8/1979, S. 25) sind Reaktionsweisen, die von vielen Vermögensbesitzern, insbesondere von den Kleinsparern, wohl kaum $\mathrm{zu}$ erwarten sind.

Erst recht haben sie keine Möglichkeit, ein Sachvermögen dieser Art in Produktivkapital umzuwandeln, welches angesichts der Preissteigerungen bei Fertigwaren deswegen unter den nachteiligen Folgen des Nominalwertprinzips nicht leldet, weil für Marktleistungen, die an keinerlei längerfristigen Kontrakte gebunden sind, grundsätzlich preisliche Anpassungen möglich sind (Fall A I a, der deshalb mit Fall B I vergleichbar ist). Diese Besitzer halten ihr Vermögen vorwiegend als Geldvermögen in der Form von sparbüchern oder Forderungen an Kreditinstitute, Versicherungen, Bausparkassen usw. Das $d i s t r i b u t i v e$ problem aufgrund des geltenden NWP läBt sich also mit der Relation "Sachvermögensbesitzer versus Geldvermögensbesitzer" beschreiben und mit den Stichworten "Mobi $l i t a ̈ t s u n t$ e $r$ s hi e d e" der Vermögenshalter, "F 1 u c h $t$ i $n$ d $i s$ a $h w$ e $t e "$ und "K l e i n s a r e r p r o b l e m" bezeichnen (Fall B/C 
II ). Hier, in der Gruppe der Kleinsparer und der Halter von früher begebenen festverzinslichen Wertpapieren, kumuliert das allgemeine Geldvermögensproblem mit dem steuerlichen und oft auch mit einem sozialen: Von der Benachteiligung der Geldvermögensbesitzer gegenüber den Sachvermögensbesitzern sind sie besonders betroffen; "die Inflationsverluste der Geldvermögensbesitzer werden als Folge des geltenden Steuerrechts zusätzlich dadurch vergröBert, daB auch derjenige Teil der Nominalerträge, der nur den Wertverfall des Forderungsbetrages ausgleicht, von den Einkünften nicht abgesetzt werden darf" (WB BMW 1975, S. 3); die in Gelddispositionen relativ immobilen Kleinsparer halten ihr Vermögen vorwiegend in Spareinlagen, bei denen der Zusammenhang zwischen Zins und Geldentwertungsrate wesentlich weniger ausgeprägt ist als bei anderen, zinsreagibleren Sparformen: "für die relativ geldnahen Spareinlagen mit gesetzlicher Kündigungsfrist ist daher der Zins (der sog. Spareckzins) traditionell niedrig und wird nur wenig verändert. Der Ertrag dieser Spareinlagen bleibt seit 1971 durchweg hinter der laufenden Geldentwertungsrate zurück" (Gutachten der Bundesbank, siehe BBk-M 8/1979, S. 24). Wie gering die Chancen einer Lösung dieses distributiven Problems selbst von der Deutschen Bundesbank eingeschätzt werden, kann man daran ablesen, daB ihr erstens die "relativ niedrige Nominalverzinsung" dieser Einlagen als ein Preis für den "hohen Liquiditätsgrad" ökonomisch "gerechtfertigt erscheint" (ebda), daB sie darüber hinaus erkennen läBt (S. 23-26), daB das Risiko des Geldwertverlustes allein der Sparer selbst trägt und daB er dem Risiko nur durch eine geschickte Anlagenwahl entgehen kann. 27)

(2) SchlieBlich vereinigt die "Gläubiger-Schuldner-Beziehung" (Fall II b) sowohl auf der Gläubiger- als auch auf der Schuldnerseite Unternehmer mit Nichtunternehmern samt den gleichgerichteten Folgen ihrer Kreditbeziehungen: ${ }^{28}$ ) Sowohl der Unternehmer wie der

27) Zumindest konnte er das in der Vergangenheit, was der Bundesbank schlieblich der ausschlaggebende Grund dafür war, ein Abgehen vom Nominalwertprinzip in ihrem Gutachten nicht $\mathrm{zu}$ befürworten.

28) N. Andel 1979a, S. 362: "Das ökonomisch gleiche Problem (der Gefahr einer inflationären Realkapitalaushöhlung, HDH) taucht z.B. bei Krediten auf", nicht nur im Abschreibungsbereich; "der Kreditgeber erhält als Tilgung nicht mehr den ursprünglich hingegebenen Realwert zurück. Bei realer Betrachtung entstehen Gläubigerverluste und Schuldnergewinne." 
Private kommt in den Vorteil des Schuldnergewinns wie auch in den Nachteil des Gläubigerverlustes. Jedoch sind die Gläubigerverluste des Privaten als "Realvermögensaushöhlung" primär distributiver Art, die Gläubigerverluste des Unternehmers als "Realkapitalaushöhlung" primär allokativer Art. Diese Wirkungen werden nun über die inflationär bedingte Kaufkraftentwertung der Bestände und Ströme hinaus dadurch noch gesteigert, das die steuerliche Bewertung und Ertrags- bzw. Einkommensberechnung keinerlei Gläubigerverluste und Scheingewinne berücksichtigt; weder kann der Gläubiger die bloB inflationär bedingte Bestandswerterhöhung steuerlich absetzen bzw. die kaufkraftentwerteten Geldströme steuerlich nach unten korrigieren, noch wird der schuldner gezwungen, seine inflationär bedingt $\mathrm{zu}$ hoch ausgewiesenen schulden nach unten $z u$ korrigieren, um danach einen real höheren Vermögensbestand auszuweisen und $z u$ versteuern bzw. seine real geringerwertigen $\mathrm{Zins-}$ und Tilgungsverpflichtungen steuerlich entsprechend zu korrigieren. ${ }^{29)}$ Die Geltung des NWP ist durch eine eindeutige "B e we r t u g s - A s y m e t r i e" gekennzeichnet, die die Kapital- und Vermögensaushöhlungen noch verstärkt.

Die "Verteilung" der Lasten aus der Aushöhlun von Realbeständen und Realströmen hat einen "zwischen-institutionellen" wie auch einen "inner-institutionellen" Aspekt: Der erstere zeigt sich darin, ob die Gruppe der Unternehmer insgesamt gegenüber der der Nichtunternehmer die Gläubigerposition innehat, ob also die Nichtunternehmer als Gewinner aus der Realbestandswertverschiebung hervorgehen. Der inner-institutionelle Aspekt erfordert eine Differenzierung dahingehend, ob die Unternehmer selbst als Gläubiger und zugleich als schuldner sich gegenüberstehen; sollten sich die divergierenden Positionen $\mathrm{zu}$ Null ausgleichen, sind dennoch innerhalb der Gruppe der Unternehmer allokative Verschiebungslasten in der Realkapitalaushöhlung mit evtl. wettbewerbsbeeinflussenden

29) R.A. Musgrave (1981, S. 34) verlangt daher, die Zinseinkünfte des Gläubigers sollten nur als reale besteuert werden, wobei zwar die Nominalverzinsung erfabt, die Geldentwertung jedoch als negative Einkünfte abgezogen werden; analog sei beim Schuldner dessen "Inflationsgewinn" seinen Einkünften zuzuschlagen (die Korrektur wird also von der Seite der Bemessungsgrundlage her angegangen, nicht von der Tarifseite her). Siehe auch N. Andel (1979a, S. 349), der bei Aufhebung des NWP eine steuerlich gleichmäBige Behandlung von Kapital-, Schuldnergewinnen und Gläubigerverlusten verlangt. 
Auswirkungen entstanden; Analoges gilt für die Verschiebungslasten einer Realvermögensaushöhlung und ihre distributiven Folgen bei den Privaten. ${ }^{30}$ )

c) In der Gesamtbeurteilung führt also das Nominalwertprinzip inner-institutionell wie zwischen-institutionell zu einer Verkettung von allokativen und distributiven Nachteilen : Die ScheinErtragsfähigkeit ist unausweichlich verknüpft mit der Schein-Leistungsfähigkeit. Das Nominalwertprinzip definiert die Bestandsund StromgröBen bei den Anspruchs- und Verfügungsberechtigten $\mathrm{zu}$ hoch, bei den -verpflichteten zu niedrig. Mag letzteres für den Schuldner auch ein Ertrags- und Einkommensvorteil sein, so kann diese Lastverschiebung keineswegs etwa "gesamtwirtschaftlich" in einer utility-disutility-Betrachtung zu Null summiert werden. Denn die Norm des Leistungsfähigkeitsprinzips - sofern sie als der gesellschaftlich akzeptierte Besteuerungsgrundsatz gilt kann nicht lediglich als ein "Durchschnitt", sondern nur im jeweiligen Einzelfall, also je Person verwirklicht werden. Ferner haben distributive Verzerrungen allokative Folgewirkungen: $\mathrm{Zu}$ geringe Nettoeinkommen und -vermögen beeinträchtigen die Sparbildung und das Kapitalangebot. Auch die Bevorzugung des Sachkapitals (-vermögens) vor dem Geldkapital (-vermögen), so vorteilhaft sie sich für die oberen Einkommensschichten ausnimmt, ist zunächst einmal - distributiv gesehen - eine gruppenspezifische Geldwertstrategie, die ihre Privilegien eben nur wegen der unterschiedlichen Mobilität im Anlageverhalten $z u$ verteilen vermag; aber daneben hat sie auch allokative Nachteile, da die Flucht in die Sachwerte von den Sachwertinteressierten zumeist ohne Rücksicht auf die tatsächlich realisierbare Investitionsrentabilität betrieben wird.

V. Das Nominalwertprinzip, obgleich lediglich ein "technisches", ein Bewertungsprinzip 31 , wird von seinen Befürwortern mit einer Regel des geordneten gesellschaftlichen zusammenlebens gleichge-

30) Diese auf dem Nominalwertprinzip beruhenden allokativen und distributiven wirkungen sollten aber nicht verwechselt werden mit den ganz generell entstehenden Auswirkungen jener ertragsteuerlichen Regelungen, die die zulässigkeit von $\mathrm{Ab}-$ $z$ ügen des $\mathrm{Z}$ insaufwandes vom Gewinn bzw. vom Einkommen betreffen, siehe WB BMW 1975, S. 4

31) auf der folgenden Seite 
setzt 32 ), zumindest aber als eine "elementare Rechtsnorm" und als "einer der tragenden Grundsätze des geltenden Steuerrechts" gesehen (WB BMF 1976, S. 89 f.). Ja es wird sogar grundsätzlich für das Funktionieren der "marktwirtschaftlichen ordnung" in Anspruch genommen, das es "kompromiblos beizubehalten" gelte (WB BMF 1967, s. $18 \mathrm{f.}$ ). 33)

a) Nun ist zunächst die seinerzeitige Inthronisierung des Nominalwertprinzips und seine inhaltliche Formulierung gewiB eine

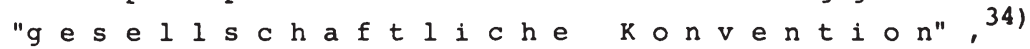

31) K. Tipke 1981, s. 228: "kein Verfassungsprinzip, normkonz1pierendes Prinzip", sondern eines der sich am "Nennwert orientierenden Geldrechnung" für die Handels- und Steuerbilanz.

32) $\mathrm{Zu}$ dieser Interpretation und der mit ihr verbundenen Verwechslung von prinzipien nehmen insbesondere $W$. Stützel und $D$. Schneider Stellung, ersterer im Rahmen einer detaillierten Ubersicht über die verschiedenen Interpretationsweisen von "Nominalismus" (1979, S. $27 \mathrm{ff} . \mathrm{u} .74 \mathrm{ff.})$, letzterer eher aus dem Blickwinkel der Kapitalerhaltung und seiner Bedeutung für das Einkommen und den Gewinn $(1978 \mathrm{~b}, \mathrm{~s} .77 \mathrm{ff} . \mathrm{u}$. $95 \mathrm{ff.;} 1981$, S. $159 \mathrm{f.l}$. Danach ist streng $\mathrm{zu}$ unterscheiden zwischen dem "Mark-gleich-Mark-Prinzip" (Nominalismus) als einer Regel des geordneten Zusammenlebens, als Pflicht zur Vertraqstreue eben wegen der Vertragsfreiheit (Stützel);

Völlig unabhängig davon existiert ein Nominalismus in der steuerlichen Einkommensdefinition (Stützel), dem Rechtssatz einerseits zur Berechnung von Einkommen und zur Erhaltung von Kapital und Vermögen, andererseits auch zur Berechnung des Steueranteils daran (Schneider). "Ein Verzicht auf Nominalismus in diesem Sinne einer 'nominellen' VermögenszuwachsDefinition stünde nicht im Widerspruch zu jenem Nominalismus, der einen Eckpfeiler unserer gesamten freiheitlichen Rechtsund Wirtschaftsordnung darstellt" (Stützel S. 77). Wenn also behauptet wird, jede Abweichung von der nominellen Kapitalerhaltung verstoBe gegen den Grundsatz "Mark-gleich-Mark" und damit gegen die Einheitlichkeit der Rechtsordnung, so werden zwei völlig unterschiedliche Probleme miteinander vermengt (Schneider).

33) Der WB im Gutachten zur Reform der direkten Steuern: "Es ist nochmals mit Nachdruck zu betonen, daß die ungerechten Folgen einer schleichenden Inflation nicht mit steuerlichen MaBnahmen beseitigt werden können, da dies immer nur ein Kurieren an einzelnen Symptomen bedeutet. Es ist vielmehr $\mathrm{zu}$ fordern, daB das tbel von der Wurzel aus angegangen wird, d.h. daB die Geldwertstabilität mit allen Mitteln gesichert wird" (S. 19).

34) Es kam in die Besteuerung durch die Reinvermögenszugangstheorie von Schanz, der seine "theoretischen Konstrukte Einkommen und Kapital, ohne genau zu sagen, wie sie zu messen seien, gedankenlos auf gleichklingende Namen der kaufmännischen Buchfuhrung" ubbertrug; so D. Schneider 1981, S. 160. 
für die nicht einmal steuerrechtlich die Inhaltsformulierung so eindeutig ist, wie sie sich gibt. ${ }^{35 !}$ Entscheidend für die Beurteilung seiner Funktion aber ist eine gegenwärtige ökonomische Fragestellung: Eine absolute Geldwertstabilität, die allein das Nominalwertprinzip rechtfertigen würde, hat sich als reale Politik in der jüngeren Vergangenheit nicht durchsetzen lassen. Die kategorische Feststellung des Primats der Geldwertstabilisierungspolitik, die der WB BMF noch 1967 formulierte, stöBt - so wünschenswert die Geldwertstabilität ist - angesichts der tatsächlichen Verhältnisse ins Leere; das Festhalten an der Primatsforderung wäre Ausdruck eines Wunsches trotz der gleichzeitigen politischen Unmöglichkeit, ihn zu erfüllen.

b) Entscheidend wird nunmehr die Frage, ob angesichts der dargelegten allokativen und distributiven Nachteile das Nominalwertprinzip unter allen Umständen aufrecht erhalten werden soll. Hier$\mathrm{zu}$ sagt der WB BMF 1976 , s. $86 \mathrm{f} .{ }^{36)}$ daB die Geltung des Nominaloder Realwertprinzips von den $z i$ e $l$ e $n$ abhänge, die sowohl allokativer als auch distributiver Art sein können. 37) Von hier aus wandert das Problem einer "prinzipiellen" Besteuerung in eine neue Dimension, die nämlich die Besteuerung abhängig machen will von einer $" N i v$ e u f $r$ a $g e "$ : Sofern die Geldentwertung ein wie auch immer angesetztes, jedoch politisch nicht mehr tolerierbares Niveau überschreitet, soll das Nominalwertprinzip auf-

35) Tipke scheint 1991 seine ursprüngliche Haltung zur Rorrektur der Geldentwertung aufgegeben zu haben. Obwohl rein nominelle Vermögenswertsteigerungen bei Veräußerungen verfälschende "Scheingewinne" bewirken, spricht er sich gegen eine inflationsbereinigte Geldrechnung aus (S. 204). "Mithin kann im Interesse der steuergleichheit auf das Nominalwertprinzip nicht verzichtet werden, so daß die verfälschung der Nominalwertrechnung durch die Inflation zu den kaum $z u$ lösenden Problemen einer... Best. nach der Leistungsfähigkeit gehört."

36) Keineswegs soll übersehen werden, da $B$ diese Ausführungen im Zusammenhang mit den Problemen einer Bodenwertzuwachsbesteuerung gemacht werden, weswegen der Beirat manche seiner eher allgemeinen Ableitungen relativiert.

37) S. 86: "... können bei der Eigenart von Wertänderungen am ruhenden Vermögen dennoch Bedenken gegenüber einer ausschlieBlich auf dem Nominalwertprinzip beruhenden steuer geltend gemacht werden." - S. 87: "Sowohl der Grundsatz steuerlicher Leistungsfähigkeit als auch der Grundsatz steuerlicher Gleichbehandlung lassen daher bei fühlbarer Geldentwertung die Abkehr vom Nominalwertprinzip ... als ratsam erscheinen." 
gegeben werden. Von der Uberschreitung dieses Niveaus an werden die distributiven und allokativen Nachteile als so gewichtig angesehen, daB man ein "grundsätzliches Prinzip" auBer Kraft setzen will. Dies ist erstens ein ökonomisches Argument; dies ist zweitens ein politisches Argument; und dies ist drittens das Eingeständnis, daB es sich beim Nominalwertprinzip im Kern doch um ein "technisches", ein Bewertungsprinzip handelt, dessen ZweckmäBigkeit sich in bestimmten realen wirtschaftssituationen beweisen muB, und das aufgegeben werden soll, wenn es seine Zwecke, nämlich die "realwirtschaftliche Verfügbarkeit von Einkommen und Vermögen" als ein Bemessungsgrundlagenproblem $z$ u repräsentieren und in den Zusammenhang mit dem Leistungsfähigkeitspostulat $\mathrm{zu}$ stellen, nicht mehr erfüllen kann.

Sowohl der WB BMW 197538) als auch der WB BMF 197639) wie schlieBlich die Deutsche Bundesbank (BBk-M 8/1979) erkennen in der Niveaufrage das entscheidende Moment für die Geltung des Nominalwertprinzips. Die Deutsche Bundesbank belegt in ihrem erwähnten Gutachten, $d a B$ und in welchem AusmaB eine Geldentwertung in den letzten Jahren stattgefunden hat (S. 22-25). Zunächst setzt sie die Grenze, von der ab überhaupt von Geldwertminderung gesprochen werden könne, auf maximal $2 \&$ an, jenseits der "freilich ... eindeutig eine Verringerung der Kaufkraft des Geldes auf der Verbraucherebene festzustellen" sei. ${ }^{40}$ ) Die Grenze wurde in den Jahren von 1966 bis 1976 eindeutig und auch langanhaltend überschritten, mit einem Mittelwert von 4,2 \& im Jahr (BBk-M 8/ 1979, S. 21). Für das Festhalten am Nominalwertprinzip trotz der über 2 \& liegenden Geldentwertung führt die Bundesbank im wesentlichen drei Gründe an: erstens seien die Preissteigerungen nicht ausschlieblich auf inflatorische Ursachen "im üblichen Sinne" $z u-$

38 ) "Die ... zu prüfende Milderung der unbeabsichtigten Umverteilungs- und Allokationswirkungen des Steuersystems im InflationsprozeB ist eine Aufgabe, welche ... zwangsläufig um so dringender (wird), je weiter sich das Preisniveau von dem Niveau entfernt, das bei Inkrafttreten der steuergesetze bestanden hat" (WB BMW 1975, S. 12).

39) auf S. 89 folgt: "Solange der längerfristige Geldwertschwund jährlich nicht mehr als 2 oder 3 v.H. beträgt, wird es sich empfehlen, das Nominalwertprinzip nicht aufzugeben. Erreicht er dagegen $z . B$. eine Höhe von $10 \mathrm{v} . \mathrm{H}$. oder mehr, läBt sich die Besteuerung nach dem Nominalwertprinzip gerade im Falle von Vermögenswertzuwächsen kaum noch rechtfertigen ..."

$40)$ BBk-M 1968, Nr. 3, S. 3ff., ein früheres Gutachten für den Bundesf inanzhpf Hessler and Anneliese Hessler-Otte - 978-3-631-75239-5 
rückzuführen (S. 21), zweitens stünden den Geldvermögensverlusten der Haushalte auch Realwertgewinne bei den Schulden gegenüber, und drittens sei der Realzins am Kapitalmarkt zwischen 1955 und 1977 nie gleich Null, d.h. der reale Kapitalzins sei immer positiv gewesen (S. 23). 4l) Daraus läBt sich nun folgern, daB für die Bundesbank der EinfluB der Inflation als ein Problem erst dann auftaucht, wenn die Inflationsrate höher ist als die Nominalverzinsung. Leistungsfähigkeitseinbußen liegen für sie nicht etwa dann vor, wenn die Geldentwertung einen Teil des nominalen Einkommens aufzehrt; solange überhaupt noch ein positiver Nominalzins festzustellen ist, drückt er für sie in voller Höhe Leistungsfähigkeit aus. 42 ) 43)

c) Wie man sieht, kann die Niveaufrage danach beurteilt werden, ob man lediglich die Geldentwertungsrate isoliert würdigt oder gegen die Verzinsung der Kapitalerträge s a 1 d $i$ e $r$; letzteres kann nur für Einkünfte aus Kapital bzw. Vermögen gelten. Man wird die Frage, ob "beträchtliche Inflationsraten" das

41) Wir haben $z u$ berücksichtigen, daB die Bundesbank ihr Gutachten auf die "Berücksichtigung der Geldentwertung bei der Besteuerung von Einkünften aus Kapitalvermögen" abzustellen hatte, das also eine Begutachtung der Geldentwertung bei sämtlichen Markteinkünften und Vermögensbeständen nicht zu ihrem Prüfungsauftrag gehörte.

42) Zum methodischen Vorgehen der Bundesbank: Hinsichtlich der Realwerte der vermögen und schulden argumentiert sie gesamtwirtschaftlich, nicht einzelwirtschaftlich; die Geldvermögen der Haushalte werden mit den Schulden insgesamt und pauschal saldiert, wodurch sich das AusmaB des "Gläubiger-Schuldner-Gegensatzes" vermindert und nicht mehr als ein einzelwirtschaftliches Problem darstellen läBt. Dies billigen wir nicht.

43) Zur Charakteristik des methodischen Vorgehens der Bundesbank gehört auch das Folgende. Sie bezieht die steuerlichen Sparerfreibeträge und die 800 DM-Freigrenze für Nebeneinkünfte (zu denen auch Kapitalerträge gehören) in ihre Betrachtungen ein und kommt $\mathrm{zu}$ dem Ergebnis, daB davon vor allem die unteren Einkommen profitieren (S. 28); auBerdem trete die Problematik des Nominalwertprinzips "bei weitem nicht bei sämtlichen Kapitaleinkünften" auf; "da davon auszugehen ist, daB der Anteil der Geldvermögenseinkünfte mit $z$ unehmendem Gesamteinkommen wächst, sind von den daraus resultierenden Folgen vor allem die Bezieher höherer und hoher Einkommen betroffen." Das ist nun aber nicht zwingend, denn man kann die Auffassung vertreten, daß die Sparerfreibeträqe sowie die Freigrenze für Nebeneinkünfte von Anfang an nicht als ein Inflationsausgleich gedacht, sondern gesellschaftspolitisch, also vermögensbildend, motiviert sind. Dann aber ist der Bundesbank nicht zuzustimmen. 
Nominalwertprinzip "fragwürdig" machen (N. Andel 1979a, S. 361), zunächst politisch entscheiden müssen - dies unterstreicht abermals die politische Funktion der Leistungsfähigkeitsindikatoren -, dies aber für alle Einkunftsarten gleichmäBig; danach ergäbe sich für die Nichtvermögenseinkünfte der volle Deflator, aber für vermögenseinkünfte der um die positiven zinsen saldierte Deflator. Hingegen den saldierten Deflator nun auch für die Nichtvermögenseinkünfte heranzuziehen, erschiene nicht sachgerecht. Eine Gleichbehandlung in der realwirtschaftlichen Verfügbarkeit von Einkommen und Vermögen lieBe sich dadurch nicht erreichen. Somit verändert die Anwendung des Nominalwertprinzips wie auch evtl. seine Korrekturweise den Inhalt der Indikatoren der Leistungsfähigkeit in Abhängigkeit von der (politisch beurteilten und $\mathrm{zu}$ lösenden) Niveaufrage der Geldentwertung.

d) Im Gegensatz zur "güterlichen" und zur "finanziellen" Verfügbarkeit hat die "realwirtschaftliche" keinen Eingang in die $s t e u e r g e s e t z$ e gefunden. ${ }^{441}$ sie wird also solange nicht als verwirklicht anzusehen sein, wie inflatorische Einflüsse auf die Bestands- und StromgröBen zugelassen werden. Die "freie" Disponibilität über diese ökonomischen Größen muB als rein nominal angesehen werden, und die Besteuerung nach der Leistungsfähigkeit ist somit bereits im Bereich der Indikatoren, d.h. im Bereich der "Objektivierung", durch den EinfluB der Geldentwertung beeinträchtigt. ${ }^{451}$

\section{VI. zusammentassung:}

Die Ergebnisse des 7. Kapitels fassen wir wie folgt zusammen: Soll auch für die Besteuerung ein umfassender Einkommens- und Vermögensbegriff gelten, so muß bei allem Interesse an einer breitesten Steuerbasis die objektivierte Leistungsfähigkeit auf IstgröBen, nicht auf Sollgrößen basieren. Nur Istgrößen sind tatsächlıch verfügbar, seien sie als Entlohnungen, Vermögensnutzungen oder Transfers geldlich oder natural zugegangen, seien sie als Vermö-

44 ) Siehe hierzu unsere Ausführungen in $\$ 19$ II (Der "steuertechnisch-eiheitliche" Vermögensbegriff).

45) Dies gilt bereits ohne die Berücksichtigung der Ungleichbehandlung zwischen den einzelnen Vermögensarten durch die steuerliche Bewertung, siehe \$\$ 25-27. 
genszugang bereits realisiert oder noch nicht. Allerdings ist für die belastungspolitischen Absichten davon auszugehen, daß der einzelne in seiner Verfügung "frei" von den Zwängen der Existenzsicherung und vorsorge ist. Diese Freiheit in der verfügung wird teils politisch definiert, teils ergibt sie sich aber auch aus der Logik des wirtgchaftens.

Um den denkbar weitesten Ansatz für die steuerliche Begriffsprägung zu finden, von dem aus zu entscheiden ist, welche Einkommensund Vermögensteile als nicht disponibel und steuerlich belastbar aus der Bemessungsgrundlage auszugrenzen sind, ist es erforderlich, ein System der Totalverfügbarkeit sowie ihrer Ausgrenzungen zu entwerfen. Wir geben gegenüber der additiven Methode der subtraktiven den Vorzug und haben zu diesem zweck zwei Konzepte aus der Literatur in die Form einer Subtraktionsübersicht gegossen und synoptisch präsentiert $(\$ 22$ III). Sowohl das praktizierte amerikanische Adjusted Gross Income-Konzept als auch das kanadische Reformkonzept der Comprehensive Tax Base demonstrieren ein überraschendes Ergebnis, das der deutschen Besteuerungspraxis $(\$ 22$ IV) ähnlich 1st: Es fällt auf, daß drei Gruppen von verfügbaren ökonomischen Größen aus der Gesamtverfügungsbasis eliminiert werden, nämlich die Zurechnungseinkommen ("imputed income"), die Vermögenswertzuwachseinkommen ("capital gains") und - dies aber nicht Im kanadischen Konzept - groBe Teile der Transfereinkommen. Als Problemüberblick läßt sich also festhalten, daß als wesentlicher Versto $B$ gegen das Allgemeinheitspostulat quantitativ bedeutsame Einkommensteile aus der freien Verfügbarkeit ausgegrenzt werden. Dies hat nur zum geringsten Tell steuersystematische Gründe (so wird in der Bundesrepublik ein breiter Vermögenszugang nicht als Einkommen realisiert, weil neben der Einkommensteuer gesonderte Vermögen- und Erbschaftsteuern erhoben werden). Zum überwiegenden Teil sind für die Ausgrenzungen aber allgemeine politische und insbesondere sozialpolitische Gründe maßgeblich. Teils werden bestimmte zugänge an Verfügbarkeit expressis verbis von der steuer befreit, teils aber werden sie auch garnicht erst zur Kenntnis gebracht und genommen. Die im Anschluß an die synoptisch dargestellten Konzepte von uns entwickelte Entscheidungssystematik soll dies zum Ausdruck bringen. In verschiedenen steuerpolitischen Entscheidungsschritten wird festgelegt, inwieweit steuersystematische, wirtschafts- und sozialpolitische Motivationen dazu führen, von einer breiten Steuerbasis abzurücken. 
Die Analyse der mit den besonderen Ausgrenzungstatbeständen verbundenen Problematik ( $\$ 23$ ) bringt zunächst hinsichtlich des Zurechnungseinkommens ans Licht, daB diese selten anhand von eindeutigen Abgrenzungskriterien dargestellt werden und daß äuBerst heterogene Besteuerungskonzepte vertreten werden. Verfahrensmängel und Erfassungslücken kennzeichnen die bundesdeutsche Besteuerung.

In der Nichterfassung der unrealisierten Vermögenswertzuwachseinkommen wird ein ständiger allokativ-distributiver zielkonflikt sichtbar. Obwohl nachgewiesenermaßen Verfügbarkeit und somit Leistungsfähigkeit vorhanden ist, obwohl sogar die Nichterfassung allokative Nachteile bringt ("lock in-Effekt"), ist die Nichterfassung üblich und wird zudem allzu sehr aus der betrieblichen und bilanziellen sicht (Realisierungsprinzip) begründet. Eine klare Trennung jedoch des allokativen Bereichs vom distributiven würde erkennen lassen, daß Kapitalwertzuwächse im Unternehmen etwas völlig anderes sind als Vermögenswertzuwachseinkommen im privaten Bereich, und daB jene durchaus nicht (und erst recht nicht progressiv) besteuert werden müßten wie private. Allerdings bestehen Bewertungsprobleme, doch nicht nur an dieser Stelle des Steuersystems; darüberhinaus müBten sie auf dem Wege kompromiBhaltiger Näherungsverfahren zu lösen sein.

Die weitaus schwerwiegendere Problematik liegt im Bereich der Transfereinkommen. Ein exstes Problem entsteht in der Sphäre der Transfergewährung, also noch vor der Besteuerung. Wir haben dieses problem aufgegriffen, weil aus steuerrechtlicher sicht jüngst vorgeschlagen wurde, auch für die Transfergewährung das Leistungsfähigkeitspostulat anzuwenden. Wir haben nachzuweisen versucht, daß die Gewährung ein völlig anderes Prinzip, nämlich das Bedarfsprinzip verlangt und daß das Leistungsfähigkeitspostulat als eine Steuerlastverteilungsregel in dieser Transferphase noch nicht anwendbar ist.

Der bedeutsamste Teil unserer Ausführungen im Transferbereich ist dem "Korrespondenzprinzip" gewidmet. Anhand einer intensiven Diskussion konnte erstens deutlich gemacht werden, daB die AuBerachtlassung dieses Prinzips eine bedeutende Einengung des Einkommensbegriffs und damit eine steuerliche Begünstigung bestimmter Gruppen herbeiführt, daB also das Allgemeinheitspostulat immer dann 
nicht verwirklicht werden kann, wenn gegen das Korrespondenzprinzip verstoßen wird. Zweitens konnte veranschaulicht werden, daß die richtige Anwendung des Korrespondenzprinzips zu unterschiedlich welten bzw. engen Einkommensbegriffen in verschiedenen Lebensphasen des Steuerpflichtigen fuhrt: Zum einen ist in der Beitragsphase, während der der Aktive seine Transferansprüche aufbaut, das steuerliche Elnkommen dann geringer als in der Rentenphase, wenn die Beiträge steuerlich abzugsfähig, die Renteneinkommen dagegen später zu versteuern sind; wir nennen dies die "Rentenbesteuerung". Zum anderen ist in der Beitragsphase das steuerliche Einkommen dann weiter, wenn die späteren Renten unbesteuert bleiben sollen, dann aber korrespondierend die Beitragszahlung nicht befreit werden kann; wir nennen dies die "Beitragsbesteuerung". Zahl und Gewicht der Argumente zu beiden Besteuerungsweisen sprechen eindeutig für die Rentenbesteuerung. Voraussetzung allerdings ist die richtige Anwendung des Korrespondenzprinzips. Uber seinen Sinn und seine Wirkungsweise herrschen stellenweise Unklarheiten, sodaß umfängliche Darlegungen erforderlich waren, die Fälle einer "echten" Korrespondenz von den unechten zu trennen.

Gegenüber diesen politisch bestimmten Verstößen und Postulatsverletzungen ist eine zweite sachliche Einschränkung des Allgemeinheitspostulats eher rationaler Art. Hierbei handelt es sich - wie wir sie zur Unterscheidung von der ersten bezeichnet haben - um "Eingrenzungen" auf den freien Verfügungsbereich ( $§ 24)$. Im Gegensatz zum zwischenperiodischen Verlustausgleich (Vor- und Rücktrag), der als ein allokativer Vorgang gekennzeichnet wurde, folgt der innerperiodische Verlustausgleich zwischen den Einkunftsarten der logischen Regel des Einkommenskonzeptes als einer Summe der Einkünfte. Verfügbar ist somit nur eine saldierte ökonomische Größe. Gleichermaßen ist das Vermögen erst nach dem Schuldenabzug, also als "finanzielle" Verfügbarkeit Indikator der LeistungsFähigkeit, selbstredend unter Nichtansatz des Human-Vermögens. Gegen die Einbeziehung des Human-Vermögens in das Gesamtvermögen sprechen Bewertungs- und Gerechtigkeitsaspekte.

Problematischer ist schon die dritte sachliche Elnschränkung des Allgemeinheitspostulats durch die Anwendung des Nominalwertprinzips angesichts einer spürbaren Geldentwertung: Eine freie Verfügbarkeit über eine um die Geldentwertungsrate erhöhte TotalHeinz Hessler and Anneliese Hessler-Otte - 978-3-631-75239-5 
einkommens- und -vermögensgröße ist nur vorgetăuscht, gemessen an der Kaufkraft ist die frele Verfügbarkeit in Hohe der Geldentwertungsrate begrenzt. Die Leistungsfähigkeit wird nominell zu hoch ausgewiesen, denn in Hohe der Geldentwertungsrate ist sie nicht vorhanden. Aus dem Gesichtswinkel einer tatsächlichen fre1en Verfügbarkeit dürfte die Geldentwertungsrate nicht auch noch besteuert werden.

Obwohl die negativen Allokations- und Distributionswirkungen unübersehbar sind, die das Festhalten am Niminalwertprinzip mit sich bringt (und die noch dadurch erhöht werden, daß eine Korrektur auf seiten der Schulden nicht erfolgt) und obwohl gewichtige Stimmen für die Aufgabe dieses Prinzips sprechen, ist es bis heute nlcht zu erschüttern. Dadurch mündet das Problem letztlich, wie die jüngste Diskussion und das Gutachten der Bundesbank vom August 1979 klar belegen kann, in eine "Niveaufrage": Erst wenn die Inflationsrate höher ist als die Nominalverzinsung, entsteht überhaupt der EinfluB der Inflation auf die Kaufkraft als ein Problem. Doch das widerspricht dem Verfügungskonzept und dem Leistungsfahigkeltspostulat. Allokationsnachtelle entstehen in Form der Substanz- Lnd Ertragsaushöhlung, evtl. mit distributiven Folgen; D1stributionsnachtelle liegen hauptsächlich in der Realvermögensaushöhlung sowie in den Mobilitätshemmissen und den Spar- und Anlagegewohnheiten der unteren Einkommensschichten ( $\$ 24$ IV U.V).

Die Einschränkungen des Allgemeinheitspostulats in der hier gebotenen Einteilung zu präsentieren hat den Sinn, den unterschiedlichen Charakter und die Motivationen der drei Arten von Einschränkungen hervorzuheben. Ist die "Eingrenzung" auf den wirklich freien Verfügungsbereich (\$ 23) noch ökonomisch und rational gerechtfertigt, so sind es die anderen beiden nicht mehr. Die "Ausgrenzungen" ( $\$ \$ 21$ und 22) sind - wo nicht die Kompliziertheit der Materie oder die historisch lange tbung und Verfahrensverfestigung als Begründungen angeführt werden können - insbesondere auf aktive politische Einflüsse zurückzuführen, die oftmals zu Gruppenvorteilen führen. Die Begrenzung der freien Verfügbarkeit durch das Festhalten am Nominalwertprinzip letztlich (\$ 24) kann angesichts der genau bekannten Folgen wohl eher mit Trägheit, mit bewußtem Treibenlassen oder dem "Vertrauen" erklärt werden, es wïrden sich die allokativen und distributiven Nachteile schon irgendwo und irgendwie unmerklich "im Unendlichen verteilen". 
Solchermaßen aber determinieren die sachlichen Einschränkungen des Allgemeinheitspostulats ökonomische Größen (nämlich Einkommen und Vermögen), die - wären sie als Gesamtverfügungsgrößen rational definiert - die Chance hätten, Beurteilungsmaßstäbe für die allokative und distributive Besteuerungspolitik zu sein. So aber bleibt nur die Möglichkeit, anhand des wirtschaftstheoretisch bestimmten Einkommens- und Vermögensbegriffes im Sinne einer Gesamtverfügungsgröße stets auf die Verletzungen des Allgemeinheitspostulats hinzuweisen. Die Ausgrenzungen sind mit dem Sinn des Leistungsfähigkeitspostulats nicht zu vereinbaren, da sie die breitest mögliche Erfassung der Indikatoren verhindern. Allzuoft wird nämlich übersehen, daß ja mit der Erfassung noch keineswegs über die tatsächliche steuerliche Belastung der Indikatoren vorwegentschieden ist. Zudem gerät mit jeder Ausgrenzung gleichzeitig das Gleichmäßlgkeitspostulat in Gefahr. 
8. KapiteI:

Praktisch gestaltete objektivierung II = Die Verstöße gegen das Gleichmäßigkeitspostulat

\section{s 25 Die steuerliche "Gleich- behandlung" als Inhalt des Gleichmäßigkeitspostulats}

I. Begriffe, allokativ-distributive Abgrenzung und steuersystematische Voraussetzungen

II. GleichmäBigkeitspostulat und Gerechtigkeit

III. Verteilungsgerechtigkeit und Gleichbehandlung

IV. Gleichmäßigkeitspostulat, Allgemeinheitspostulat sowie die steuerliche und soziale Wirklichkeit

I. Für die begrifflichen Uberlegungen zum steuerlichen Einkommen und Vermögen sind nicht sämtliche GleichmäBigkeitsprobleme von Bedeutung. So scheiden gemä $B$ dem Untersuchungsziel zunächst Fragen der ungleichmäBigen "Belastung", weil tarifabhängig, hier aus.

a) Es werden nur solche Fragen aufgegriffen, die zu einer UngleichmäBigkeit zwischen den Personen bzw. Gruppen dadurch führen, daB die objektiven $G r$ ö $B$ e $n$ Einkommen und Vermögen $u n t$ e r $s c h i e d l i c h$ e $r m i t t e l t$ (d.h. erfaBt und bewertet) werden. Auch mit der Untersuchung der GleichmäBigkeit bleiben wir also im Rahmen der Analyse von $O b j$ e $k t i v i$ e

u n g s - Tatbeständen der Leistungsfähigkeit.

b) Des weiteren sind die rein a $l$ lok a $t i v e n$ von den d i s $t r i$ b $u t i v$ e $n$ Fragen $z u$ trennen. Wird ein Kapitalbetrag anders besteuert als ein gleich groBes Vermögen, oder werden betriebliche Erträge anders besteuert als gleich hohe (nichtbetriebliche) Einkommen, so liegt allein darin keine UngleichmäBigkeit der Besteuerung unter dem Aspekt der "Leistungsfahigkeit", weil sich der allokative und der distributive Bereich

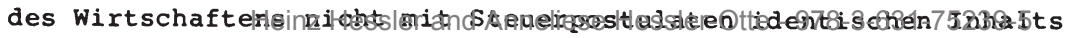


erfassen, well sich betriebliche GröBen und Entscheidungen nicht mit privaten "gleichsetzen" lassen. Demnach liegen in beiden Berelchen die "glelchen Umstände" oder "Verhältnisse", unter denen die Besteuerung nach dem GleichmäBigkeitspostulat ja beurteilt werden, eben nicht vor. Da die allokativen GröBen Kapital und Ertrag andere Funktionen haben als die distributiven GröBen Vermögen und Einkommen, kann auch ihre Besteuerung unterschiedlichen MaBstäben und zielen unterworfen werden (siehe $\$ 10$ ).

c) Daher müssen auch die $B$ e w e $r$ t u n g $s$ a $B s$ t ä b e fur Kapital und Vermögen zwar "manipulationsfrei" 1a), doch nicht zwingend identisch sein. Für ihre Identität mag manches sprechen, doch liegt bei Nichtidentität kein Verstoß gegen das GleichmäBigkeitspostulat vor, soweit dieses dafür in Anspruch genommen wird, das Leistungsfähigkeitspostulat einzuleiten und zu gewährleisten. Daraus folgt, daB streng genommen nicht einmal das Nominalwertprinzip oder das Realwertprinzip im allokativen wie im distributiven Bereich gleichermaßen angewendet werden müssen. ${ }^{1)}$

d) Auch der festgestellte "D u a 1 i $s \mathrm{~m}$ u s" in der Methode der Gewinn-bzw. UberschuBermittlung ist keine Verletzung des GleichmäBigkeitspostulats. So kann streng genommen nicht beklagt werden, es entstünden den Unternehmern dadurch Nachteile, daB die Nichtunternehmer ihre VeräuBerungsgewinne nicht in ihr Einkommen aufzunehmen brauchten. ${ }^{2)}$ Unbestritten ist der Einkommensbe-

1a) Schneider 1978b), S. 31:"Der Grundsatz der Manipulationsfreiheit besagt, daß Bewertungswahlrechte und eigenes Ermessen bei der Bewertung mit GleichmäBigkeit der Besteuerung unvereinbar sind." Das von Schneider dann verwendete Beispiel halten wir allerdings nicht für illustrativ, weil die allokativ-distributive Abgrenzung nicht beachtet wird.

1) Auf das Argument der Ungleichbehandlung von Unternehmern und Arbeitnehmern angesichts von Preisstelgerungen geht D. Schneider (1981, S. 159) ein: Das Argument der Ungleichbehandlung sei unbegründet, well sowohl historisch wie theoretisch bis zum Ende des 19. Jahrhunderts das Kapital immer als eine erhaltenswerte Substanz aufgefaBt wurde; jede Art der Kapitalerhaltung müsse ökonomisch begründert werden. - Wenn daraus gefolgert werden soll, daB die Besteuerung von Unternehmern und Nichtunternehmern aus allokationspolitischen Gründen unterschiedlich sein darf, so stimmen wir dem zu. Im übrigen siehe $\S 8$ : unsere Kritik an der Folgerung Schneiders, der Einkommensbegriff erfordere die Kapitalerhaltung.

Fn. 2 siehe folgende seite 
griff des geltenden Rechts "zerklüftet" (K. Tipke 1981, S. 150 ff.), doch liegt dies an der zusammenfassung ungleicher (allokativer) Ertrags- mit (distributiven) Einkommenselementen $z u$ einem allokativdistributiven "Einkommens - Mischbegriff". Würden die rein allokativen GröBen des Gewinns oder Ertrags getrennt erfaBt von den rein distributiven des Einkommens, und würden sie nicht zusammen einer "einheitlichen" Einkommensteuer unterworfen, entstünde das Problem der unterschiedlichen Gewinn- bzw. UberschuB-Feststellungsmethoden uberhaupt nicht. Wir vermögen daher D. Schneider (1978b, S. 99) nicht zuzustimmen, wenn er sagt, GleichmäBigkeit der Besteuerung erfordere "eine einzige Methode der Einkommensermittlung". 3)

e) Umgekehrt kann auch nicht beklagt werden, daB den privaten E1nkommensbeziehern und Einkommensteuerpflichtigen die unternehmerischen Vorteile der Periodenabgrenzung und Periodenertragsverlagerung, der Bewertungsfreihelten, der grobzügigeren Gestaltung der Betriebsausgaben gegenuber den Werbungskosten nicht $z u$ Gebote stehen. So unerwünscht diese $G$ e $s$ a 1 t u n g f $r$ e i h e i $t$ e $n$ im allokativen Bereich und im Wettbewerb der Ertragserzielenden untereinander auch sein mögen, so wenig liegt hier eine Ungleichbehandlung von Gewinnen und Uberschussen vor (vgl. aber F. Neumark 1970, S. 102). Anders, wenn das "Gestaltungsprivileg" (Schmölders/Hansmeyer 1980, S. 81) dazu führt, daB sich die Grenzlinie zwischen dem betrieblichen und dem privaten Bereich verwischt und private Aufwendungen zu steuerabzugsfahigen betrieblichen undefiniert werden.

Jeglicher allokationspolitisch motivierten Besteuerung stunde es durchaus frei, an die summe der Betriebseinnahmen andere MaBstabe anzulegen als an die Summe der Einkommenselemente, etwa bestimmte Erfordernisse der Periodizität, der Herkunft aus bestimm-

Fn. 2 :

In $1981 \mathrm{a}, \mathrm{S} .72$ weist $\mathrm{K}$. Tipke auf den Dualismus der Einkünfteermittlung und die dadurch entstehende Ungerechtigkeit in der Besteuerung hin, anhand des Beispiels der VeräuBerung eines Betriebsgrundstückes gegenüber der VeräuBerung eines Privatgrundstückes.

3) Zustimmen würden wir allerdings, wenn er mit "Einkommensermittlung" tatsächlich die Feststellung nur des persönlichen Einkommens, nicht auch des betrieblichen Gewinns meinte. Auch der Gewinn sollte einheitlich ernictelt werden. 
ten sektoralen oder regionalen ökonomischen Aktivitäten $z u$ verlangen. Auch wenn der interperiodische Verlustausgleich, der gewöhnlich mit betrieblichen zielen der Substanz- und Unternehmenserhaltung begründet wird, in der Einkommensbesteuerung nicht entsprechend angewendet wird, liegt darin kein Versto $B$ gegen das GleichmäBigkeitspostulat.

f) Aus Gründen dieser allokativ-distributiven Themenabgrenzung bleiben mithin die zahlreichen a $110 \mathrm{k} t 10 \mathrm{n} s-\mathrm{p} \circ 1 \mathrm{i}$ $t i s c h$ motivierten Veränderungen der Bemessungsgrundlage der Einkommensteuer auBerhalb unserer Betrachtung. ${ }^{4}$ ) Dennoch ist aber in besonderem MaBe hervorzuheben, daB sie den Einkommensumfang für die natürlichen Personen (Unternehmer, Mitunternehmer, Freiberufler usw.) verändern und solchermaBen einen Unterschied im Einkommen gegenüber den "Nichtunternehmern" hervorrufen. Diese Ungleichbehandlung ist sehr wohl unser Problemgegenstand. Aus der Darstellung von Wöhe $(1988$, S 109,193f) kann man zwei Seiten des GleichmäBigkeitspostulats herauslesen: Erstens die Besteuerung im Verhältnis der Unternehmer untereinander und zweitens die Besteuerung im Verhältnis der Unternehmer zu Nichtunternehmern. Das erstere Verhältnis ist als ein allokatives und wettbewerbliches nur insoweit unser Thema, als es das zweite Verhältnis determiniert. Das aber ist der Fall. Im zweiten Verhältnis darf die Besteuerung wegen unterschiedlicher ziele durchaus abweichend gestaltet werden, doch dann darf das erstere Verhältnis das zweite nicht beeinflussen. Weil dies aber dennoch geschieht, wird die UngleichmäBigkeit der Besteuerung zwischen den Unternehmern $z u$ unserem Problem.

g) Die analytische Abgrenzung und Problemklärung ist demnach durch zwei notwendige Feststellungen $z u$ ergänzen: Erstens können bei aller Trennung in die allokativen und distributiven Probleme i $\mathrm{n} n$ e $\mathrm{r}$ a $1 \mathrm{~b}$ der jeweiligen Bereiche UngleichmäBigkeiten

4) Solche bestehen z.B. in der Einrichtung der einkunftsartbezogenen Freibeträge, in den Regelungen für erhöhte Abschreibungen oder Sonderabschreibungen, in den Beschränkungen des Verlustausgleichs und -abzuges für bestimmte Einkunftsarten, in den Steuervergünstigungen für bestimmte Einkunftsarten sowie in den zahlreichen Steuervergünstigungen in Förderungsgesetzen. Sie fallen nicht in die Thematik der mit der Einkommensbesteuerung verfolgten Distributionspolitik. 
in der Besteuerung entstehen, und zweitens kann gerade dadurch, daB für bestimmte Personen die $E$ r $t$ a $g s$ - Besteuerung als $\mathrm{E} i \mathrm{n} \mathrm{k} \circ \mathrm{m} \mathrm{m} \mathrm{n} \mathrm{s}$ - Besteuerung durchgeführt wird - wie das im hierzulande geltenden steuerrecht der Fall ist*) - und daB solchermaBen Regelungen, die aus allokationspolitischen Gründen in der Ertragsbesteuerung angebracht sein können, in die Einkommensbesteuerung hineinwandern, wo sie aber anderen Einkommensteuerpflichtigen nicht $z u$ Gebote stehen, eine UngleichmäBigkeit der Besteuerung entstehen. Beide Arten von Verletzungen des GleichmäBigkeitspostulats sind der Gegenstand der vorliegenden Untersuchung, wobei jedoch Probleme, die ausschlieblich allokativer Art sind und keine Auswirkung auf den distributiven Bereich haben, wiederum ausgeschlossen bleiben.

Dies sind also die $s t$ e $u$ e $s$ y $t$ e $m$ a $t i s c h$ e $n$ Voraussetzungen, unter denen die Analyse der Gleichbehandlung abläuft. Dieser Tatbestand läBt sich auch so formulieren: Die Systemkonstruktion der gegenwärtigen Besteuerung produziert eine "allokationsdeterminierte distributive Ungleichbehandlung". UngleichmäBigkeit der Besteuerung läge also vor, wenn innerhalb des distributiven (privaten) Bereichs etwa Vermögensgegenstände gleichen Wertes unterschiedlich besteuert oder Vermögensgegenstände mit vergleichbaren Funktionen ungleich bewertet würden, wenn ferner Einkommenszugänge in Ansehung ihrer Quellen teils erfaBt, teils nicht erfaBt würden. UngleichmäBigkeit der Besteuerung läge ebenfalls vor, wenn Einzelunternehmer und Personengesellschafter ihre betrieblichen Erträge derselben Art von Einkommensteuer unterwerfen wie Nichtunternehmer und dabei Gestaltungsvorteile wahrnehmen, die jene nicht haben. ${ }^{\star *}$ )

Das GleichmäBigkeitspostulat, das im Rahmen unserer begrifflichen Uberlegungen zum steuerlichen Einkommen und Vermögen eine formale Gleichbehandlung der steuergegenstände verlangt, kann mithin nur jeweils für solche Tatbestände gelten, die einander in ihrem

*) denn es gelten ja der Gewinnbegriff und die Gewinnermittlungsverfahren für die Körperschaften wie für die natürlichen Personen gleichermaßen.

**) auf der anderen Seite können sie Progressionsvorteile haben, die dem körperschaftsteuerpflichtigen Unternehmen nicht zu Gebote stehen, vgl. H.D. Hessler 1976, S. 123. 


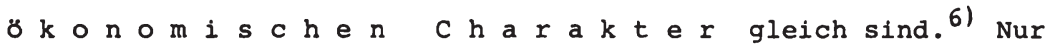
well die geltende deutsche steuergesetzgebung slch daruber hinwegsetzt, ist in die steuerwissenschaft die Vorstellung eingedrungen, das GlelchmäBigkeltspostulat sei in einer solch absoluten Form gültig und $z$ u rechtfertigen, ${ }^{6)}$ daB von diesen ökonomischen Unterschieden völlig abgesehen werden dürfe. 7)

II. Das GleichmäBigkeitspostulat steht wie das Allgemeinheitspostulat in engem Zusammenhang mit dem Leistungsfähigkeitspostulat, da es inhaltsbestimmende Merkmale enthält, von denen das eine auf die formale GleichmäBigkeit ( $=G 1$ e $i c h$ b e ha $n d i$ u g ), das andere auf die materiale GleichmäBigkeit hinausgeht und nicht nur eine gleiche steuerliche Behandlung der sachlichen Bemessungsgrundlagen verlangt, sondern eine gleichmäBige Würdigung der persönlichen Belastungen (= Leistungsfähigkeit). Diese Verbindung zwischen beiden Postulaten kommt schon in der Formulierung des ersten Besteuerungsgrundsatzes von Adam Smith ${ }^{8}$ ) zum Ausdruck.

5) Das private Einkommen des einzelnen oder des Haushalts ist dem Ertrag des Unternehmens nicht gleich. Siehe hierzu auch unsere Ausführungen zur Unternehmensbesteuerung in $\mathbb{\$} 20$.

6) Vgl. K. Tipke 1981a, S. 67, der Arbeitnehmer- und Unternehmereinkommen gleichsetzt: "Wenn ein Arbeitnehmer ein Einkommen von 100.000 DM bezieht und ein Unternehmer ein (vergleichbares) Einkommen von $80.000 \mathrm{DM}$, so steht fest, daB dieser Unternehmer nicht so leistungsfähig ist wie der Arbeitnehmer." Diesen Vergleich lieBen wir gelten, falls es sich um vergleichbare persönliche Einkommen handelte und nicht um Einkommen auf der einen, und um Unternehmererträge auf der anderen Seite.

7) Diese Feststellunq ailt für die Finanzwissenschaft wie für das Steuerrecht, gleichermaßen aber auch für die Betriebswirtschaftliche Steuerlehre; G. Wöhe (1988,S.619ff) ist zuzustimmen, wenn er die Bedingungen der Nichtverletzung des Postulats für den betrieblichen Bereich festlegt; es ist ihm aber nicht zuzustimmen, wenn er verlangt, nach dem GleichmäBigkeitspostulat müsse der Bezleher der Gewinneinkunftsarten die gleiche Feststellungsmethode anwenden wie der Bezieher der anderen Einkunftsarten. Sie $k$ a $n$ allenfalls die gleiche sein!

8) 1776; in der tbersetzung von H.C. Recktenwald, 1978, heiBt es auf S. 703: "Die Bürger eines jeden Landes sollten eigentlich zur Finanzierung der öffentlichen Aufgaben soweit als möglich im Verhältnis $z u$ ihren Fähigkeiten beisteuern, was bedeutet, daB sich ihr Beitrag nach dem Einkommen richten sollte, das sie jeweils unter dem Schutz des Staates erzielen." "In der Be- oder MiBachtung besteht das, was Gleichheit oder Ungleichheit in der Besteuerung genannt wird." - Wenn auch F.K. Mann

(1937, S. 147) eine etwas andere Ausdrucksform wählt, so stellt

(Forts. siehe folgende Seite) 
Halten wir uns an F. Neumark, 9$)$ so treten ebenfalls beide Aspekte der GlelchmäBigkeit hervor, nämlich die Glelchbehandlung sowie die würdigung der gleichen oder gleichartigen steuerlich relevanten Verhältnisse. Dies ist ein wesentliches Charakteristikum der Steuerwissenschaften: Die Forderung nach (rechtlicher) Gleichbehandlung ${ }^{10)}$ wie die enge Bindung an die Leistungsfähigkeit ${ }^{11)}$ und Belastbarkeit ${ }^{12}$ l des Steuerpflichtigen.

Sowohl die Gleichbehandlung der sachlichen Bemessungsgrundlagen als auch die persönlich gleichmäBige Steuerlastverteilung nach der

Forts. Fn. 8 :

jedoch auch er die enge Beziehung zum "Fähigkeitstheorem" (S. 148) her und hebt hervor, daB Smith damit kein Gerechtigkeits-, sondern ein GlelchmäBlgkeitsproblem lösen wollte ("equality", nicht "equity") . - F. Neumark dagegen (1970, S. 126) stellt den Grundsatz von A. Smith in die Nahe der Gerechtigkeit, bleibt aber in diesem Punkt recht unverbindlich: "Bekanntlich hat ja schon Adam Smith darauf abzielende Bemerkungen gemacht." In seinen weiteren Aus führungen rekurriert dann Neumark nicht mehr auf Adam Smith.

9) 1970, S. 120: "GemäB dem Grundsatz der GleichmäBigkelt der Besteuerung sind Personen, soweit sie $\mathrm{zu}$ irgendeiner Steuer herangezogen werden und sich in gleichen oder gleichartigen steuerlich relevanten Verhältnissen befinden, in bezug auf die betreffende steuer gleich $\mathrm{zu}$ behandeln; als logische Konsequenz daraus ergibt sich das Prinzip der steuerlichen Ungleichbehandlung von Personen in ungleichen Verhältnissen."

10) Tipke 1991, S. 50: "Gleichheit ist - dadurch unterscheidet sie sich von der Identität, immer relativ. Der Satz, daß Gleiches gleich $z u$ behandeln ist, meint nicht Identisches, sondern relativ Gleiches." "Gleichbehandlung setzt Prinzipien voraus, die das verlangt die materiale Gleichheit - sachgerecht sein müssen; sie müssen überdies konsequent verwirklicht werden." S.51: "Inkonsequenz ist das Messen mit zweierlei Maß, ist systembruch und verletzt den Gleichheitssatz."

11) Horizontale und vertikale Gleichbehandlung sind für $\mathrm{K}$. Schmidt (1978, S. 142) direkt mit dem Leistungsfähigkeitsprinzip verbunden. - D. Schneider (1990, S. 37t) sieht hinter dem Wunsch nach GleichmäBigkeit der Besteuerung die Forderung nach unterschiedsloser Besteuerung "gleicher steuerlicher Leistungsfähigkeit" bzw. "gleicher wirtschaftlicher Sachverhalte" (siehe auch 1978 b, S. 23).

12) G. Schmölders $(1981 \mathrm{C}, \mathrm{S}$. 691) versteht das GleichmäBigkeitspostulat als Verbot von Privilegien (dies wäre nach u.A. eher ein Gebot des Allgemeinheitspostulats), sieht ebenfalls eine enge Verbindung der GleichmäBigkeit zur Leistungsfähigkeit und hebt insbesondere hervor, daB heute GlelchmäBigkeit mit dem Steuerbelastungsgefühl verknüpft ist: Nach Möglichkeit solle die Besteuerung bei den Staatsbürgern das Gefuhl einer gleichen steuerlichen Belastung hervorrufen. 
Leistungsfähigkeit sind Ausdruck der steuerlichen $\mathrm{G}$ e $\mathrm{r}$ e c $\mathrm{h}$ $t i \mathrm{~g} \mathrm{k} i \mathrm{t}$. Diese beiden Ausprägungen der Gerechtigkeit begegnen uns in der bekannten Unterscheidung zwischen "formaler" oder "horizontaler" Gerechtigkeit einerseits und "materialer" oder "vertikaler" Gerechtigkeit andererseits. Formale Gerechtigkeit zielt auf das Einhalten (nicht auf das Finden und Begründen) von Normen. Sie bedeutet die Gleichbehandlung aller Gesellschaftsmitglieder in gleichen gesellschaftlichen und ökonomischen Lagen, bedeutet WillkürausschluB und Diskriminierungsverbot. Sie schlieBt das Gebot ein, auch bei Verwirklichung der vertikalen Gerechtigkeit innerhalb der gesellschaftlich beschlossenen Ungleichbehandlungsfälle die identisch Ungleichen ausnahmslos gleich $\mathrm{zu}$ behandeln. 13)

13) Der Terminus der "formalen" Gerechtigkeit vermag die hierin enthaltenen Probleme der Gleichbehandlung, der Gleichheit aller vor dem Gesetz und der Gleichberechtigung in ihrer Bedeutung nur unvollständig wiederzugeben; die Formulierung läBt die hier erfaBten Probleme gegenüber denen der materialen Gerechtigkeit als von minderem Rang erscheinen. Treffender wäre, zwischen "rechtlicher" und "politischer" Gerechtigkeit $\mathrm{zu}$ unterscheiden. Insbesondere die "politische" brächte zum Ausdruck, daB der Inhalt der materialen Gerechtigkeit auf Gerechtigkeitsurteilen und -vorstellungen in politischen Entscheidungsprozessen beruht. Demgegenüber liebe sich die "rechtliche" Gerechtigkeit im Hinblick auf die demokratische und humanitäre Entwicklung der Gesellschaften - unter Anlehnung an K.R. Poppers Beschreibung der antiken Geschichte - auch als "humanitäre" oder besser noch als "demokratische" Gerechtigkeit formulieren. Dabei kommt dann auch zum Ausdruck - worauf F.A. v. Hayek $(1971$, S. 142) ausdrücklich hinweist -, daB Demokratie ein Mittel zur Sicherung der Gerechtigkeit selbst ist.

Der formale (rechtliche oder demokratische) Grundsatz ist von völlig anderer Qualität als der materiale (politische): Gesetze und Institutionen können trotz gleicher Anwendung ungerecht sein, d.h. den Gerechtigkeitsauffassungen widersprechen. "Die Gleichbehandlung gleicher Fälle ist keine hinreichende Begründung für inhaltliche Gerechtigkeit"; "die formale Gerechtigkeit ist Beachtung von Grundsätzen oder ... Gehorsam gegenüber dem System" (J. Rawls 1975, S. 79, unter Hinweis auf $\mathrm{Ch}$. Perelman). Formale Gerechtigke1t als Handlungsanweisung muB sich auf ein Handlungsziel beziehen, da sie für sich allein inhaltsleer ist (J. Werner 1979, S. 48). Demgegenüber ist die materiale Gerechtigkeit der eigentliche "Gegenstand" der Gerechtigkeit, der gesamte durch gesellschaftliche Konvention gefundene Inhalt der Gerechtigkeitsgrundsätze (J. Rawls 1975, S. 79).

Siehe im übrigen zur Bedeutung von "Gleichheit" und "Gerechtigkeit" in der Finanzwissenschaft w. Weber 1964, S. $180 \mathrm{ff}$. 
III. Wenn auch bereits oben (I) das Ziel selbst, also die Herstellung der materialen steuerlichen Gerechtigkeit als ein Untersuchungsobjekt aus dieser Arbeit ausgegrenzt wurde, soll dennoch die Verknüpfung zwischen der Handlungsmaxime und dem Handlungsziel verdeutlicht werden, weil nur so die Verbindung zwischen der Gleichbehandlung und dem Leistungsfähigkeitspostulat hergestellt werden kann.

a) In der Sozialökonomie ist materiale Gerechtigke1t die "V e r -

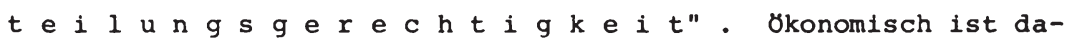
mit nicht die Herstellung eines "richtigen" Gesamtzustandes einer Gesellschaft (G. Gäfgen 1975, S. 24) ${ }^{14)}$, sondern die Verteilung der spezifisch ökonomischen GröBen Einkommen und vermögen gemeint. 15) రkonomische Verteilungsgerechtigkeit erfordert, da eine zeitlos gültige Verteilungsnorm nie gelten kann, die jeweils gegenwärtige Verteilungssituation aber zumeist als ungerecht empfunden wird (H. Bartmann 1981, S. 2 f., 13, 30 ff. U. 322), das Formulieren von inhaltlichen zeit- und zielbezogenen Verteilungskonventionen ${ }^{16)}$ und ZuteilungsmaBen. ${ }^{17)}$ Dle Konventionen können nun eher eine politisch ausgehandelte Unterschiedlichkeit der Verteilungssituation als "Gerechtigkeit" festlegen oder eine in bestimmten Grenzen (!) gehaltene materiale "Gleichheit" 18) formulieren. ${ }^{19}$ )

14) Als ein solcher gilt die Verteilung von Berufen, sozialer Stellung, Rang und Titel an die Gesellschaftsmitglieder, siehe W.A. Jöhr 1943, S. 41 ff.

15) Ferner umfaBt Verteilungsgerechtigkeit auch die Einkommensund Vermögenswirkungen, die durch die zustände und die Veränderungen der gesellschaftlichen struktur unmittelbar hervorgerufen werden, J. Werner 1979, S. 2 f.

16) Siehe die Gerechtigkeitsgrundsätze bei J. Rawls 1975, S. 81 ff.

17) Vgl. die Kriterien bei Musgrave-Musgrave-Kullmer 1990, S.100f. "Ausstattungskriterien, Utilitarismus-Kriterien, Gleichheitskriterien und Gemischte Kriterien" für Verteilungsgerechtigkeit.

18) Die Durchsetzung des "Egalitätsprinzips" (siehe B. Külp 1971, S. $140 \mathrm{f}$. mit der Abgrenzung zum Gleichheitsprinzip) ist insoweit nicht gerechtfertigt, als es den erwarteten Gerechtigkeitsvorstellungen der zumeist leistungswilligen Mehrheit der Gesellschaftsmitalieder hiesiger Demokratien zuwiderläuft. Eine Forderung nach materialer Gleichhelt berücksichtigt nicht die Unterschiede in der Intensität individueller Bedürfnisse. "Selbst gleiche Geldeinkommen (bedeuten) je nach Preissystem verschiedene Realeinkommen - und gleiche Naturalzuteilung je nach Bedürfnisstruktur unterschiedliche Versorgungsniveaus", G. Gäfgen 1975, S. 24. Siehe ferner Chr. Watrin 1982 .

Fn. 19 siehe folgendesseittend Anneliese Hessler-Otte-978-3-631-75239-5 
Als MaBgröBen der Verteilungsgerechtigkeit gelten "Leistung" und "Bedarf". Soll die persönliche steuerlast nach der Leistungsfähigkeit verteilt werden, bleibt auch für die steuerpolitik "Leistung" die maßgebliche Bezugsgröße (erst wenn jenseits der steuerlastvertellung auch Redistributionspolitik getrieben werden soll, kommt der Bedarf als weitere BezugsgröBe der Politik ins Blickfeld). Das bedeutet, daB die Steuerlastverteilung nach der Leistungsfahigkeit die individuelle Verteilungsposition, so wie sie durch Leistung und Entlohnung vorgegeben ist, von sich aus nicht verändert, sondern an sie anknüpft.

b) Innerhalb dieses Verteilungsrahmens werden die Allgemeinheitsund GleichmäBigkeitspostulate wirksam. Für das GleichmäBigkeitspostulat heiBt das zwelerlei: Sowelt die Steuerlast auf unterschiedlich leistungsfähige Personen verteilt werden soll, geschieht das nach den auf politischen Konventionen beruhenden Vorstellungen von der materialen (vertikalen) Gerechtigkeit; diese Problematik wurde von uns ausgegrenzt. ${ }^{20)}$ Soweit aber die die Leistungsfähigkeit ausdrückenden Indikatoren Einkommen und Vermögen "gerecht" zu erfassen sind, erfolgt das nach dem Gerechtigkeitsgrundsatz der $\mathrm{G} l$ e $i \mathrm{c} h \mathrm{~b}$ e $\mathrm{h}$ a $\mathrm{n}$ d $1 \mathrm{u} \mathrm{n} g$. Das Problem der GleichmäBigkeit der Besteuerung im Sinne der Besteuerung nach der Leistungsfähigkeit verengt sich auf das Problem der der "unterschiedslosen Besteuerung gleicher steuerlicher Bemessungsgrundlagen" (D. Schneider 1978b, S. 30). Die Gleichbehandlung in der Ermittlung der Steuerbemessungsgrundlage bedeutet, "daB gleiche Steuergegenstände bei allen Steuerpflichtigen in gleicher Höhe zu Steuerzahlungen führen (D. Schneider, a.a.o.).

IV. Es bleibt zu klären, in welchem Verhältnis die Steuerwissenschaften das Gleichmäßigkeitspostulat zum Leistungsfähigkeits-, und insgesondere zum Allgemeinheitspostulat sehen.

Fn. 19:

Dennoch wird wenigstens ein gewisser Grad an mehr materialer Gleichheit angestrebt, der sich als ein Verlangen nach "mehr GleichmäBigkeit in der Einkommens- und Vermögensverteilung" angesichts der vorherrschenden Asymmetrie formulieren läBt. E. Sohmen 1976, S. 440 .

20) Siehe oben unter $I$; es sei daran erinnert, daB auch das Allgemeinheltspostulat eine personale und eine sachliche Ausprägung hat, siehe $\$ 21$ l; erstere hatten wir ebenfalls aus der Untersuchung ausgegrenzt, um uns auf die sachlichen Fragen des Einkommens - und Vermögensbegriffs $z u$ konzentrieren.

21) folgende Seite.Hessler and Anneliese Hessler-Otte - 978-3-631-75239-5 


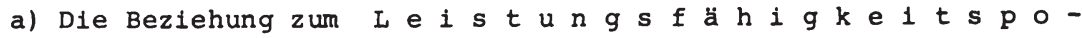
s $t$ u $l$ a $t$ drückt sich darin aus, daB die Gleichbehandlung von Steuerpflichtigen auf deren persönliche und familiăre Lebensumstände Rücksicht nimmt: Der Gesundheitszustand, die Unterhaltsverpflichtung gegenüber Angehörigen und anderen unterstützungsbedürftigen Personen, die besonderen Verpflichtungssituationen, Notlagen und Vorsorgenotwendigkeiten erfordern eine gleiche steuerliche Behandlung all jener, deren Verhältnisse gleich oder gleichartig sind. 22)

b) Gegenüber dieser auf die Belastung abgestellten Beziehung basiert die Verbindung zwischen dem GleichmäBigkeits- und dem A $1 \mathrm{lg}$ e m e $1 \mathrm{nh}$ e $i \mathrm{t} \mathrm{p} \circ \mathrm{s} t \mathrm{u} \mathrm{l} t$ in der gleichen bzw. ungleichen Behandlung der Bemessungsgrundlage. Der Aufforderungsgehalt des GleichmäBigkeitspostulats an den Steuerpolitiker geht über das Allgemeinheitspostulat hinaus, sobald der Bereich des Existenzminimums verlassen wird (F. Neumark 1970, S. 91): Trotz allgemeiner Besteuerung aller Steuerpflichtigen ist von Ungleichbehandlung dann $\mathrm{zu}$ reden, wenn - ungeachtet der Gleichheit aller persönlichen und familiären Lebensumstände z.B. ihre Einkunfts- oder Vermögensarten unterschjedlich besteuert werden (Unternehmer- versus Landwirtseinkünfte; Pensions- versus Renteneinkünfte). M.a.W.: Jeder VerstoB gegen das Allgemeinheitspostulat schlieBt zwangsläufig einen solchen gegen das Gleichmä-

21) Auch hier stimmen wir der Konsequenz aus diesem Postulat zu, nicht jedoch dem von Schneider gewählten Zahlenbeispiel, da es die allokativ-distributive Abgrenzung vermissen läBt: 60.000 DM Unternehmensgewinn sind nicht identisch mit 60.000 DM privaten Einkommens; sie drücken im ersteren Fall lediglich Ertragsfähigkeit, im letzteren aber Leistungsfähigkeit aus. Wohl aber sind 60.000 DM Gewerbeertrag vergleichbar mit 60.000 DM Ertrag aus landwirtschaftlicher oder freiberuflicher Tätigkeit.

22) Wenn F. Neumark (1970, S: 91) hierzu ausführt, das GleichmäBigkeitspostulat sei insofern "weiter" als das Allgemeinheitspostulat, als es auch dann verletzt sein könne, wenn die Allgemeinheit der Besteuerung voll gewahrt sei, so trifft das dann $z u$, wenn dem einzelnen eine Steuerlast zugemutet wird, die die besonderen Lebensumstände nicht berücksichtigt; der Aufforderungsgehalt des GleichmäBigkeitspostulats an den Steuerpolitiker geht also über den des Allgemeinheitspostulats hinaus. - K. Tipke (1981, S. 29) sagt: "GleichmäBigkeit der Besteuerung erschöpft sich nicht in Allgemeinheit der Besteuerung. $\mathrm{Zu}$ ihr qehört auch die Gleichbehandlung der allgemein erfaßten steuerpflichtigen $i \mathrm{~m}$ e $\mathrm{n} z$ e $\mathrm{l} n$ e n "; Hervorhebungen von $\mathrm{HDH}$. In 1991, S. 50 konkretisiert er das als "Sachgerechtigkeit". 
Bigkeitspostulat ein, doch ist umgekehrt die Verletzung des letzteren nicht immer zugleich eine Verletzung des ersteren.

c) Weil aber nur Personen über Einkommen verfügen können, haben Postulatsverletzungen der sachlichen Art fast ausnahmslos Verletzungen der personalen Art zur Folge: Wenn die Einkünfte von Personen teils nach der Methode des Einnahmen-WerbungskostenUberschusses, teils nach der Methode der Gewinnfeststellung (Betriebseinnahmen-Betriebsausgaben-Differenz) und teils nach der Methode der Durchschnittssatzbesteuerung festgestellt werden, so führt das unweigerlich über die personalen Ungleichbehandlungen hinaus auch zu einer "gruppenspezifischen" Besteuerung: Sie ist für verschiedene sozio-ökonomische Gruppen, wie z.B. die der Arbeitnehmer, Unternehmer und Landwirte, trotz gleich hoher Einkommen bzw. Vermögen, ungleichmäßig. ${ }^{23)}$ Kraft dieser UngleichmäBigkeit in der Besteuerung wird aus einer allgemeinen Einkommensteuer eine Art "Klassensteuer". 24) So wandern steuerliche Privilegien und Diskriminierungen, die durch die Befolgung der p e r s o n a 1 e $n$ Ausprägung des Allgemeinheitspostulats bereits gebannt schienen, durch steuerrechtliche Praktiken einer sachlich ungleichen Gestaltung der Bemessungsgrundlagen wieder in die Einkommensbesteuerung zurück. Diese "Umwegskonterkarierung" des Allgemeinheitspostulats zeigt, daB Verletzungen des GleichmäBigkeitspostulats den Charakter der Einkommensteuer nachhaltiger verändern können als Verletzungen des Allgemeinheitspostulats.

23) Nicht nur bei der Erfassung der Bemessungsgrundlagen, auch bei den Freibeträgen und der Tarifanwendung lassen sich gruppenspezifische Ungleichbehandlungen feststellen, so z.B. für die Gruppen der jungen und alten Steuerpflichtigen, für die Gruppen der Bezieher von Renten, Pensionen und anderen Alterseinkünften, letztlich auch für bestimmte Familienstandsgruppen wie die der Verheirateten, Getrenntlebenden und Geschiedenen; siehe K. Tipke 1980b, S. 287; "das Leistungsfähigkeitsprinzip ist nicht konsequent durchgeführt, wenn die steuerpflichtigen ohne Rücksicht auf ihre Leistungsfähigkeit z.B. eingeteilt werden in Unternehmer und Arbeitnehmer, Landwirte und andere Steuerpflichtige, alte und junge Steuerpflichtige ...", K. Tipke 1981, S. 31 .

24 ) Schmölders/Hansmeyer 1980, S. 80; R. Tipke 1981, S. 32: "Klassen"-Steuerrecht, W. Upmeier 1970. 
s 26 Die verstöße gegen die

Gleichbehandlung als die

Determinanten des steuer-

lichen Einkommensbegriffs

I. Vorbemerkungen

439

II. Die Einkunftsermittlungsmethoden als

"System der Ungleichbehandlungen"

441

1. Ausgangspunkt und Kriterien der Ungleichbehandlung

2. Geringe Ungleichbehandlung zwischen vollständigem und unvollständigem Vermögensvergleich

3. Fehlende Bilanzierung und fehlender interperiodischer Verlustausgleich im Betriebseinnahmen-Betriebsausgaben-ÜberschuB

4. Fehlende "Gestaltungsprivilegien" im Einnahmen-Werbungskosten-UjberschuB

5. Subventionsdurchsetzte Besteuerung des Sollertrags in der Durchschnittssatz-Besteuerung

III. Ungleiche Erfassung der Einkommenszugänge

1. Ungleichbehandlung in der Faktorentlohung

2. Ungleichbehandlung in der Vermögensnutzung und -veräußerung

3. Ungleichbehandlung der Transfers und Privilegierung der Alterseinkünfte

I. Für die hier allein interessierenden begrifflichen Betrachtungen stellt sich also die "G 1 e $i c h$ b e h a $n d i$ u g" als der wesentliche Inhalt des GleichmäBigkeitspostulats heraus. In der Bundesrepublik Deutschland folgt die GleichmäBigkeit der Besteuerung aus dem "Gleichheitssatz" in Artikel 3 des Grundgesetzes, und zwar personal ${ }^{1)}$ wie auch sachlich" als Privilegierungs-bzw. Diskriminierungsverbot. Interpretiert man die Gleichbehandlung personal als Gleichbehandlung der steuersubjekte, leuchtet sofort

Fn. 1 und 2 siehe folgende seite 
ein, daB sle in Rechtsstaaten politisch unabdingbar ist und daB heute Verletzungen dieses postulats prima facie nicht vorstellbar sind. Interpretiert man sie dagegen als Gleichbehandlung der Bemessungsgrundlagen Einkommen und Vermögen, lassen sich in der steuerwirklichkeit Verletzungen des Postulats nicht übersehen. Gleichwohl wird es unverdrossen als "Richtschnur für die Gestaltung von Steuerbemessungsgrundlagen" (D. Schneider 1978a, S. 13) formuliert. Daraus müBte sich notwendig ergeben, daB sämtliche Zugänge an Einkommen, aus welchen Quellen und welcher Art auch immer, gleich zu erfassen und $z u$ besteuern wären, unabhängig davon, welcher Person sie zugehen. Daraus müBte weiter zwingend folgen, daB sämtliche Vermögensgegenstände, welcher Art und welcher Ertragskraft auch immer, gleich $\mathrm{zu}$ erfassen, $\mathrm{zu}$ bewerten und $\mathrm{zu}$ besteuern wären, unabhängig davon, welcher Person sie zuzurechnen sind.

Soweit Steuerrecht und -politik V e r s t ö B e gegen diese Grundinhalte der sachlichen Gleichbehandlung zulassen oder sogar durchsetzen, de $t$ e $r \mathrm{~m} i \mathrm{n} i$ e $r$ e $n$ sie die steuerlichen Einkommens - und Vermögensbegriffe. ${ }^{3)}$ Mit dem Hinweis auf die systematik der Einkommenszugänge und Vermögensarten (siehe §§ 9 u. 11) sowie mit dem Rückgriff auf Inhalt und Gliederung dieser ökonomischen GröBen aus dem Gesichtswinkel des Allgemeinheitspostulats

Fn. 1 :

Maunz-Dürig-Herzog (1980, Rd.-Nr. 8 zu Art. 3 Abs. I) sprechen von der im traditionellen Gleichheitssatz mitgedachten "Allgemeinheit des Gesetzes", die sich auf seine Gültigkeit für jedermann ohne Ausnahme bezieht. - Siehe ferner K. Tipke 1991, S. $49 \mathrm{ff}$. und $196 \mathrm{ff}$.

Fn. 2:

F. Klein 1977, S. 2246 ff. - K. Tipke 1981, S. 152: "Die Differenzierungen" ... der Einkünfteermittlungs - und Steuererhebungsarten, der Pausch- und Freibeträge, Vergünstigungen usw. ... "sind zum Teil verdächt1g, dem Gleichheitssatz zu widersprechen." Ferner S. 207: "Tatsächlich verstöBt eine Einkünfteermittlung, die mit zweierlei MaB miBt, in Wirklichkeit zwei Einkommensbegriffe schafft, gegen den Gleichheitssatz."

3) Dabei sind wir uns der Tatsache bewuBt, daB dem strengen Inhalt des GleichmäBigkeitspostulats Pauschalierungen, selbst wenn sie aus Verwaltungsvereinfachungsgründen angebracht werden, zuwiderlaufen. Hier wird ein Spannungsverhältnis nicht $\mathrm{zu}$ vermeiden sein. Jedoch (so N. Andel, 1979a, S. 391): "Mit den Prinzipien der Einkommensbesteuerung ist es nur schwer vereinbar, wenn durch bewuBt aus anderen als Verwaltungsgründen differenzierte Pauschbeträge einzelne Einkunftsarten begünstigt werden." 
(siehe $\S 21$ IV u. 22) stellen wir die folgenden Gruppen von

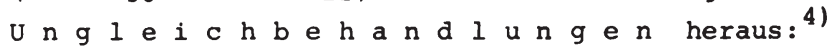

- Ungleiche Ermittlungsmethoden für verschiedene Einkunftsarten (II);

- ungleiche Erfassung verschiedener Einkommenszugänge (III);

- ungleiche Erfassung und Bewertung verschiedener Vermögensararten (siehe \$27).

II. Unter der bereits als wesentlich erkannten Voraussetzung, daB bestimmte $E r m i t t l u n g s m$ e $t h o$ d $n$ für den unternehmerischen Gewinn zugleich auch die Ermittlungsmethode des persönlichen Einkommens eben jener Unternehmer sind, liegt die Ursache für die $U \mathrm{ng} l$ e $i \mathrm{ch}$ b e $\mathrm{h}$ a $\mathrm{n}$ d 1 u $\mathrm{n} g$ der Einkommensbezieher darin, daB der Gewinn auf unterschiedliche Weise ermittelt wird. Dies vorausgeschickt gilt, was $D$. Schneider (1978b, S. 25) feststellt: Aufgrund der unterschiedlichen Ermittlungsmethoden sind numerisch gleich hohe Einkommen nicht gleich, weil sie unterschiedliche "Lebensstandards" erlauben. 5)

1. Numerisch gleich hohe Einkommen haben wegen der unterschiedlichen Einkunftsermittlungsmethoden verschieden hohe A u s ga ngs ni ve a us.6) Das zeigt sich in Ubersicht 8.1. In ihr sind - bei AuBerachtlassen der Schätzung - die wichtigsten Methoden, getrennt nach ihren Berechnungsarten, zusammen-

4) Da - wie erwähnt - Verletzungen des Allgemeinheitspostulats zwangsläufig solche des GleichmäBigkeitspostulas hervorrufen, werden erstere hier nicht wiederholt. Siehe $\S \S$ 21-24.

5) Mithin ist für die Ungleichheit der Einkommen nicht ausschlaggebend, $d a B$ es verschiedene Gewinnermittlungsmethoden gibt (wenngleich auch dies sich aus rein allokativen Gründen nicht rechtfertigen läBt (siehe D. Schneider 1978b, S. $172 \mathrm{ff.}$ ), sondern daB diese Methoden zugleich die der Einkommensermittlung sind, und zwar einzig und allein deswegen, weil die Ermittlung des im Allokationsberelch entstehenden Gewinns bzw. Ertrags nicht vom im Distributionsbereich entstehenden Einkommen getrennt wird.

6) Anders formuliert: gleiche Ausgangsniveaus würden wegen der unterschiedlichen Ermittlungsmethoden $z u$ ungleichen Einkommen führen. Zum Ausgangsniveau vgl. auch die "AusgangsgröBe" in $\S 21$ III.2. U. 3. sowie Ubersicht 7.1 . 
Ubersicht 8.1: Einkunftermittlungsmethoden und steuerliches Einkommen

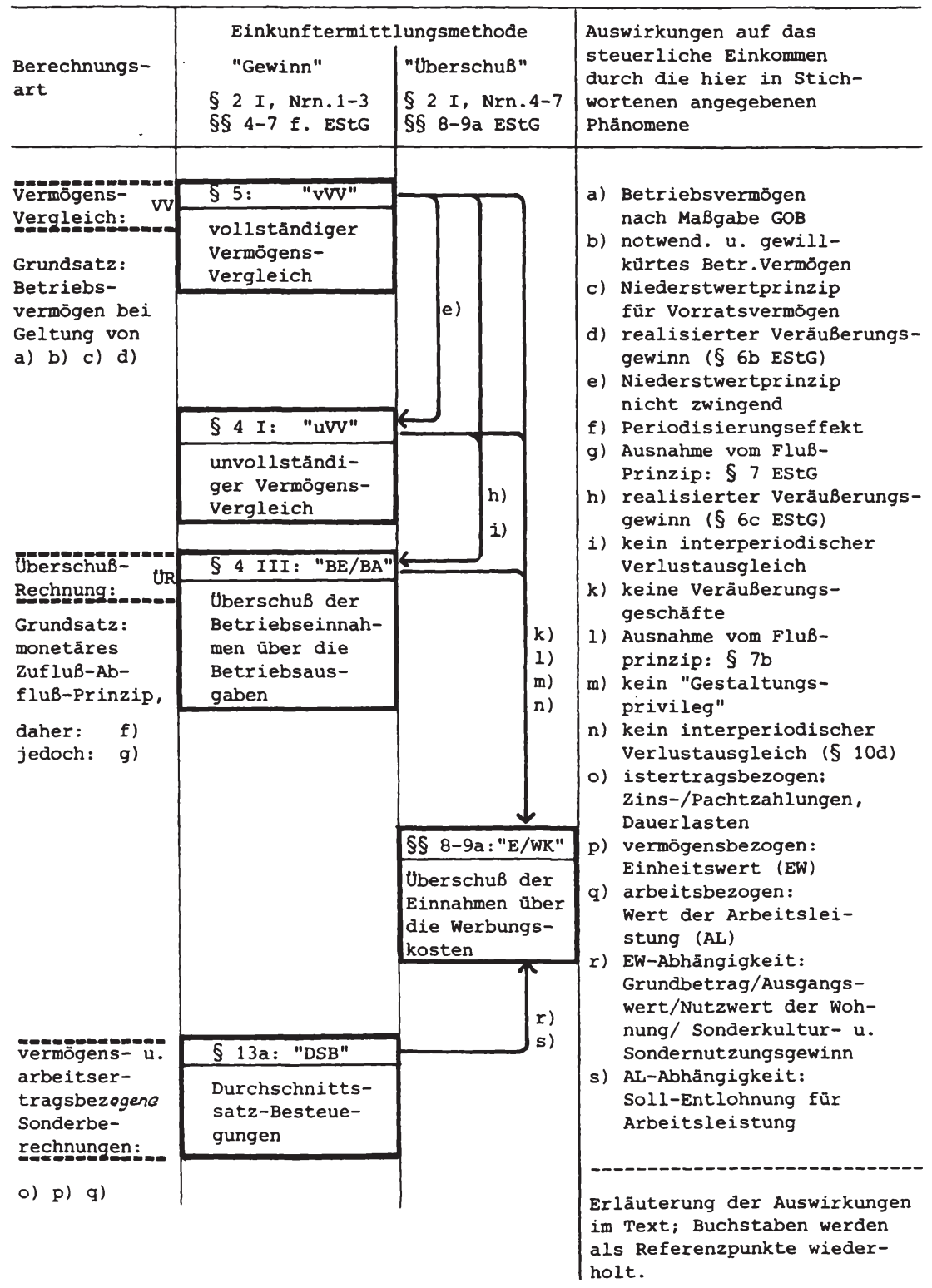


gestellt, um die in den Methoden enthaltenen Auswirkungen auf den steuerlichen Einkommensbegriff synoptisch ausdrücken $z u$ können. ${ }^{7)}$ In der rechten Randspalte sind lediglich die bedeutsamsten Auswirkungen aufgeführt. Es läBt sich - bezogen auf den hier als RichtgröBe fungierenden "UberschuB der Einnahmen über die Werbungskosten" - die methodenübergreifende Auswirkung feststellen, daB der vollständige Vermögensvergleich (vVV), der unvollständige Vermögensvergleich (uVV) sowie die UberschuBrechnung in Form des Uberschusses der Betriebseinnahmen über die Betriebsausgaben (BE/BA) und auch die Durchschnittsbesteuerung (DSB) sämtlich geringere EinkommensgröBen aufweisen als der UberschuB der Einnahmen über die Werbungskosten (E/WK).

Für die Darstellung der allokativ-distributiven Problematik haben wir zu unterscheiden zwischen einer a $110 \mathrm{k} t i \mathrm{v}$ e und einer distributiven $\mathrm{U} n \mathrm{~g} l$ e $\mathrm{i} c \mathrm{~h}$ b e $\mathrm{h}$ a $\mathrm{n}$ d $l \mathrm{u} n \mathrm{~g}$. Erstere liegt vor, wenn das finanzielle Ergebnis der wirtschaftlichen Betätigung von Unternehmen nach unterschiedlichen Methoden erfaBt und versteuert würde, d.h. wenn die unterschiedliche Besteuerung auch $\mathrm{zu}$ unterschiedlichen Steuerzahllasten führt, obwohl die Erträge gleich sind. Dies kann unter den steuersystematischen Voraussetzungen ${ }^{8)}$ ugleich eine $d i s t r i b$ u $t$ -

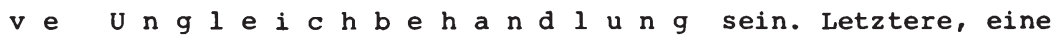
artenspezifische Ungleichbehandlung, liegt dann vor, wenn trotz gleichen Umfangs an Einkommenszugängen die einzelnen Zugangselemente personal unterschiedlich intensiv erfaBt und dadurch unterschiedliche steuertraglasten herbeigefüht werden, obwohl die

7) Die Kopfzeile weist eine Unterteilung nach den Einkunftsermittlungsmethoden aus und folgt der Gliederung von G. Rose, $1982 a$, S. 53, der sich streng an die Nomenklatur des Gesetzes hält; die linke Randspalte dagegen lehnt sich an die Einteilung von D. Schneider, $1978 \mathrm{~b}$, S. $103 \mathrm{f}$., an, Obwohl der Terminus "UberschuB" als Ermittlungsmethode nach $\S 4$ III auftaucht, handelt es sich hier um einen Gewinn, der lediglich nicht nach dem Ver ögenvergleich ermittelt wird, siehe G. Rose 1982a, S. 51. - Für die Einteilung und Beurteilung der Methoden und Berechnungsarten sind auBer den vorgenannten Quellen (siehe auch Schneider, S. 105) maßgeblich: G. Wöhe 1988 , S. $136 \mathrm{ff.}, 143 \mathrm{ff} . ; \mathrm{R}$. Tipke 1991, S. $236 \mathrm{ff}$.

Die Buchstaben der rechten Randspalte tauchen im Text als Referenzangaben für die Auswirkungen wieder auf.

8) Siehe \$25 J: die "allokationsdeterminierte distributive Unglei chbehandlung". 
persönlichen Verhältnisse des Steuerpflichtigen und die Leistungsfähigkeit gleich sind.

Hier zeigt sich nun, daB die verschiedenen Einkunftsermittlungsmethoden in erster Linie $z u$ einer distributiven Ungleichbehandlung führen, nur in einigen Fällen zu einer allokativen Ungleichbehandlung. Dies liegt daran, daB die bekannten Einkunftsermittlungsmethoden nicht an ökonomischen, sondern an den rechtlichen Vorschriften der Buchführungs- und Aufzeichnungspflicht (§§ 5 u. 4 III EStG; $\$$ 140-148 AO) ansetzen. Allokative Ungleichbehandlungen wirden dann nur festzustellen sein, wenn man die verschiedenen Gewinnermittlungsmethoden an der Effizienz des Faktoreinsatzes, am Wachstumsergebnis allgemein oder am Wachstum speziell in bestimmten Wirtschaftssektoren oder -regionen festmachen würde. Das aber ist nicht der Fall. § 5 EStG, den vorwiegend gewerbetreibende Unternehmer und Gesellschaften anwenden, gilt für jeden Gewerbebetrieb ungeachtet seines Wirtschaftszweiges oder Faktoreinsatzes. Dieselbe Feststellung ist für $\S 4$ I EStG zu treffen, nach dem vorwiegend Land- und Forstwirte und Freiberufler besteuert werden. Und wenn $\S 4$ III EStG in erster Linie Freiberufler, Kleingewerbetreibende und einige Land- und Forstwirte in Anspruch nehmen, folgt dasselbe: Freiberufler konkurrieren nicht mit Gewerbetreibenden und Landwirten, und soweit sie untereinander konkurrieren, ist dabei nicht der Unterschied in der Gewinnermittlungsmethode maBgeblich. ${ }^{9}$ ) Anders verhält es sich dagegen in der "subventionsdurchsetzten" Durchschnittssatzbesteuerung: Sie wird von Land- und Forstwirten präferiert und führt hier wegen ihres deutlich geringeren Einkommensumfangs $z u$ spürbaren Belastungsunterschieden und distributiven sowie allokativen Gruppenvorteilen. Anders verhält es sich auch bei den UberschuB-Einkunftsarten: Hier entstehen in erster Linie wegen des allgemein gröBeren Einkommens-Umfangs distributive Nachteile; allokative Nachteile entstehen kaum, da die private Vermietung und Verpachtung sowie die private Kapitalanlage in den seltensten Fällen mit der gewerblich betriebenen in Konkurrenz tritt. Soweit aber - von den in Form der Gesellschaften betriebenen Unternehmen abgesehen - die Gewinnermittlungen zu-

9) Ob allerdings die verschiedenen Ermittlungsmethoden alle erforderlich sind, ist eine zweite Frage. Siehe dazu unten den Punkt 2. 
gleich auch die Einkommensermittlungen sind, und die Einkunftsermittlungsmethoden $\mathrm{z} u$ unterschiedlich weiten Einkommensbegriffen führen, dürften in diesen Methodenunterschieden in erster Linie distributive Ungleichbehandlungen begründet sein.

2. Die Gegenüberstellung der Berechnungsarten $V$ e $r m$ ö g e $n s-$ ve $r g i$ e $i c h$ (Vv) und $U b$ e $r s h$ u $B$ e $c h n$ u $g$ (UR) macht zunächst den grundsätzlichen Unterschied deutlich: Die Bindung einerseits des Gewinns an die BestandsgröBe des Betriebsvermögens, ${ }^{10)}$ andererseits des Uberschusses an die Zahlungsströme. Daraus ergibt sich zwingend, daB für die UR sämtliche Bestandsund Bewertungsfragen " $a$ bis $d$ " gegenstandslos sind und daB dort, wo keine Vermögenswerte erfaBt werden, auch keine VeräuBerungsgewinne oder -verluste entstehen können (VV: d); UR: k). 11) Eine Sonderstellung nimmt hier die Methode "BE/BA" ein, weil es sich hier einesteils un eine unternehmerische und gewinnbringende Betätigung handelt, die nicht völlig ohne den Einsatz von Betriebsvermögen denkbar ist, dieser Gewinn anderenteils qua UR ermittelt werden soll. Daher wird fingiert, daB mit der veräuBerung von betrieblichem Vermögen Betriebseinnahmen entstehen (h).

Ein durchgehendes Gefälle im Einkommensumfang etwa ist zwischen den Methoden des VVV nach $\S 5$, des uVV nach $\S 4$ I und des BE/BA nach $\S 4$ III nicht wahrzunehmen. Ein solches ist auch zwischen dem $v$ V V und dem u V V nicht eindeutig auszumachen. Die streitige Frage, ${ }^{12}$ ) ob der $u v^{13)}$ in seinem aktivierungspflichti-

10) Zwar ist auch die Durchschnittsatzbesteuerung ( $\S 13 \mathrm{a}$ EStG) $\mathrm{zu}$ einem Anteil an Vermögen gebunden (Einheitswert), doch nicht ausschlieblich durch Vermögensbindung qualifiziert; daher wird sie als Sonderberechnung ausgewiesen, siehe die Indices o) und p) in Ubersicht 8.1

11) Die systemwidrige Ausnahme bilden die Spekulationsgeschäfte, die auch in den Einkommensbegriff der UR aufgenommen wurden. Unter dem Allgemeinheits - und Vollständigkeitsaspekt gehören sie zwar in das Einkommen, nicht aber aus dem Blickwinkel der UR.

12) Herrmann/Heuer 19.A. Anm. 4n zu $\$ 4$ EStG; nach G. Wöhe 1978, S. 334 sind die immateriellen Wirtschaftsgüter und die Rechnungsabgrenzungsposten nicht in das Betriebsvermögen aufzunehmen; D. Schneider $(1978 \mathrm{~b}, \mathrm{~S} .177)$ bestreitet dies $z$ u recht mit dem Hinweis, daB die bilanzfähigen Wirtschaftsgüter nach $\S 4$ I EStG definiert werden, der für alle Formen der Gewinnermittlung gilt; auch E. Littmann (1978, §§ 4, 5 Rd.-Nr. 5a)

Fn. 13 siehe folgende seite (Forts. siehe folgende Seite) 
gen Betriebsvermögen auch die immateriellen Wirtschaftsgüter (wie den erworbenen Firmenwert), transitorische Rechnungsabgrenzungsposten (wie Lohnvorauszahlungen) und bestimmte Aktiva ${ }^{14}$ ) $\mathrm{zu}$ enthalten hat, wird man wohl so beantworten müssen, daB zwischen den beiden Methoden des Vermögensvergleichs kein Unterschied im Betriebsvermögen bestehen soll. ${ }^{15)}$ Als demnach einzig gravierende Abwelchung gilt, daB Im uV das die Gegenstände des Vorratsvermögens betreffende $N i$ e d e $r$ s $t$ e $r$ t $r$ i $n i p$ nur f a k u 1 a $t i v$ (e) angewendet wird. ${ }^{16)}$ Somit läBt sich ein geringerer Einkommensumfang des uVV gegenüber dem vVV nur in dem MaBe unterstellen, wie die Steuerpflichtigen des uV sich in der Bilanzierung ihres Vorratsvermögens streng an das Niederstwertprinzip halten. Den sich daraus ergebenden Vorteil des uVV können in erster Linie buchfuhrungspflichtige und buchführende Land- und Forstwirte sowie die geringe $\mathrm{Zahl}$ solcher Gewerbetreibender wahrnehmen, die erlaubtermaBen keine Bücher führen. 17) Bedenkt man nun, daB ein groBer Teil der Land- und Forstwirte entweder den UberschuB nach § 4 III berechnet oder noch eher die Privilegierung der Durchschnittssatzbesteuerung nach $\S 13 \mathrm{a}$ wahrnimmt (s.u.), und

Forts. Fn. 12:

hält es für nicht vertretbar, das Betriebsvermögen für $\S 5$ und $\S 4$ I unterschiedlich zu fassen, da es sich beide Male um einen Vermögensvergleich handelt.

Fn. 13:

Das früher gewährte Privileg, Vermögen in Form von Grund und Boden auBer Ansatz zu lassen, wurde 1971 beseitigt, siehe $K$. Bierle 1981, S. 673; zu den vorteilhaften Auswirkungen dieses Privilegs auch nach der Beseitigung siehe G. Wöhe 1978, S. 337. - Gewilikürtes Betriebsvermögen kann angesetzt werden mit den gewinnerhöhenden Auswirkungen bei VeräuBerungen bzw. den gewinnsenkenden Wirkungen bei Wertminderungen; siehe G. Wöhe 1992 , S. 31f. und $252 \mathrm{ff}$.

14) Hierzu zählen als Aufwand berücksichtigte zölle und Verbrauchssteuern beim Vorratsvermögen sowie als Aufwand berücksichtigte Umsatzsteuer auf Anzahlungen.

15) Es wäre ja ansonsten die Bestimmung in $\S 11$ EStG ohne Sinn, die für die UR nach der "BE/BA"-Methode den Ansatz von Rechnungsabgrenzungsposten analog der Regelung des VV zuläBt.

16) Ein unter den Anschaffungs- oder Herstellungskosten liegender Teilwert braucht nicht angesetzt $\mathrm{zu}$ werden; nur dann dürfen die Anschaffungs- oder Herstellungskosten nicht ausgewiesen werden, wenn die Wirtschaftsgüter wertlos oder so gut wie wertlos geworden sind.

17) Für Freiberufler kommt der uVV nicht in Betracht, siehe $\mathrm{k}$. Bierle 1981, S. 675, und K. Tipke 1981, S. 209. 
daB die Mehrheit der Gewerbetreibenden nach $\S 5$ (vVV) bilanziert, so kann das AusmaB des Vorteils aus dem uW auf die Gesamtzahl der Steuerpflichtigen nur äuBerst gering sein. Individuell wie auch gruppenmäBig betrachtet hält sich demnach hier die distributive UngleichmäBigkeit in der persönlichen Einkommensbesteuerung, die durch die Anwendung unterschiedlicher Berechnungsmethoden im allokativen Bereich hervorgerufen werden könnte, in engen Grenzen.

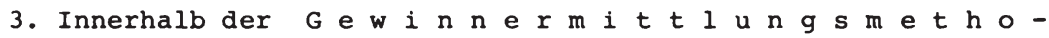
$\mathrm{d}$ e $\mathrm{n}$ ist jedoch der gröBere Unterschied im Einkommensumfang zwischen dem $\mathrm{V} V$ ( 55 und $\S 4$ I) und $\operatorname{der}$ "B E / B A" - M e $t h \circ d$ e festzustellen. Weil hier jegliche Vermögensbestandswerte in der Gewinnermittlung fehlen, findet die Gewinnermittlung der UR von vornherein - je nach dem Vermögen-Schulden-Verhältnis sowie dem AusmaB der angesetzten Wertberichtigungen, Rückstellungen und steuerfreien Rücklagen im VV - auf anderem Niveau statt. Die erwähnte Fiktion realisierter VermögensveräuBerungsgewinne für die "BE/BA"-Methode sorgt allerdings dafür, daB der Unterschied im Einkommensumfang zunächst nicht noch gröBer wird (d und $h$ ). 18)

a) Da für die UR grundsätzlich das Zahlungs- oder ZufluB-/AbfluBPrinzip gilt, entsteht gegenüber dem VV bei zeitversetztem Umsatz- und zahlungsakt ein "P e $r$ i o d i s i e r u n g s e f $f e k t "(f)^{19)}$ im Einkommensumfang. Mögen diese einkommensaus-

18) Sowohl für den VV als auch für die UR in Form der "BE/BA"Methode gilt, daB ein realisierter VeräuBerungsgewinn durch den steuerfreien Ubertrag auf bestimmte Ersatz-Anlagegüter neutralisiert werden kann; allerdings sind die Voraussetzungen des für den VV geltenden $\S 6 \mathrm{~b}$ andere als die des $\S 6 \mathrm{c}$, der auf die "BE/BA"-Methode anzuwenden ist.

19) K. Tipke 1981, S. 267: "periodische Verschiebungen"; G. Wöhe 1978, S. 331: "Kauft der Betrieb Waren, die er noch in derselben Periode umsetzt, wird die Forderung aber erst in der nächsten Periode bezahlt, so mindern bei der UberschuBrechnung die Anschaffungskosten der beschafften waren in der ersten Periode als Betriebsausgaben den Gewinn, während die Bezahlung der Forderung in der nächsten Periode den Gewinn erhöht." రkonomisch zusammengehörende Akte werden also durch die Organisation der UR auseinandergerissen und führen $\mathrm{zu}$ Schwankungen im Rechnungsergebnis; knüpfen daran dann noch Besteuerungsakte an, werden bei progressionstarifen diese Schwankungen ibermäßig betont. Wöhe 1992, S. 42ff. u. 49: eine periodenrichtige Erfolgsermittlung ist nicht möglich. 
dehnenden und -einschränkenden Effekte sich auch zwischenperiodisch ausgleichen, so entsteht in Verbindung mit dem Progressionstarif dennoch ein Belastungsunterschied. Gegenüber diesem nicht zu steuernden Effekt, der zudem auch durch eine schwankende Gewinnhöhe zwischen den Perioden hervorgerufen werden kann, entsteht im VV ebenfalls ein Periodisierungseffekt durch die bewuBte Bildung von stillen Reserven qua Unterbewertung von Vermögen oder Uberbewertung von Rückstellungen (G. Wöhe 1978, S. 309 f.). Auch hier führt der Progressionstarif bzw. eine schwankende Gewinnhöhe zu Belastungsunterschieden. Soweit nun der Periodisierungseffekt eine unmittelbare Folge aus der unternehmenspolitischen Entscheidung im Rahmen der Bilanz- und Bewertungspolitik ist, liegt hier ein Privileg für den Vermögensvergleich und damit ein mit dieser Gewinnfeststellungsmethode untrennbar verbundenes Ungleichbehandlungsproblem vor. Unterschiede beim "gewillkürten Betriebsvermögen" treten hinzu. 201

b) Anders dagegen verhält es sich mit der Regelung für die A b s c h r e $i$ b u $n g$ e $n$ im VV wie auch in der BE/BA-Methode. Vom strengen FluBprinzip wird nämlich insofern eine Ausnahme gemacht, als die Anschaffungs- und Herstellungskosten abnutzbarer Anlagegüter nicht Betriebsausgaben sind. Als Pendent dazu wird aber für die "BE/BA"-Methode derselbe Ansatz der nichtgeldlichen und somit "kalkulatorischen" Absetzungen für Abnutzungen oder Substanzverringerung nach $\S 7$ EStG zugelassen $(g)^{21)}$ wie für den VV. Das mindert den Einkommensumfang, woraus sich aber gegenüber dem vV kein Unterschied ergibt.

20) Das Interesse an der Einrichtung des gewillkürten Betriebsvermögens, das nur dem VV erlaubt ist, erklärt sich daraus, daB mithilfe von VeräuBerungsverlusten an diesem Vermögen oder mithilfe von Wertverlusten durch Tellwertabschreibungen auf dieses Vermögen Verluste aus der privaten Sphäre in die betriebliche verlagert werden können.

21) G. Wöhe 1978, S. 331 : "Diese Regelung soll verhindern, daB im Jahre der Anschaffung oder Herstellung von Anlagegütern starke Gewinnschwankungen oder sogar nicht vortragsfähige Verluste entstehen." Interessanterweise kennt auch die andere UR-art, der UberschuB der Einnahmen über die Werbungskosten in der Einkunftsart "Vermietung und. Verpachtung" diese Aus nahme vom FluBprinzip in der Zulassung der $7 b$-Abschreibung, obwohl dort die Frage der Anschaffungs- und Herstellungskosten gar nicht erst auftaucht. 
c) Wieder anders ist dagegen die weitere Regelung $\mathrm{zu}$ beurteilen, in der "BE/BA"-Methode keinen interperiodischen $V$ e $r 1$ u s $t$ a us g l e $i c h$ zuzulassen (i) 22$)$, wie das im ubrigen auch bei der "E/WK"-Methode der Fall ist. Vermutlich hält man den interperiodischen Verlustausgleich für überflüssig, well die sofortige Verbuchung von Anlagenanschaffungen $z u$ Lasten des Gewinns, der einen hohen Verlust hervorriefe, nicht erlaubt ist. Das mag in sich stimmig sein, doch ist der verlustausgleich beim vv, der demselben Aktivierungsgebot für Anlagengüter unterliegt, zugelassen. ${ }^{23)}$ G. Wöhe (1978, s. 328) hält das Fehlen des interperiodischen Verlustausgleichs für so gravierend, daB er darin - in Verbindung mit einer engeren Auslegung des Betriebsausgabenbegriffs für die "BE/BA"-Methode - geradezu den wesentlichen Grund dafür sieht, daB der Einkommensumfang zwischen dieser Methode und dem VV erheblich abweicht.

d) Die Auswirkungen der Regelungen f) bis i) auf den Einkommensumfang sind auch hier getrennt $z u$ analysieren, $z$ um einen für die Wirkungen innerhalb der "BE/BA"-Methode, zum anderen für jene im Verhältnis zum VV. Innerhalb von $B E / B A$ haben die gewinnmindernden Abschreibungsregelungen $(g)$ und die gewinnerhohenden VeräuBerungsgewinnregelungen (h) gegenläufige Tendenz. Somit wäre BE/BAintern kaum mit einer nennenswerten Ausdehnung des Einkommensumfangs $z u$ rechnen. Im Verhältnis $z u m ~ V V$ ist die VeräuBerungsgewinnerfassung kein Unterscheldungsmerkmal, da hier wie dort VeräuBerungsgewinne das Einkommen erweitern ( $d$ und $h$ ). Was aber im Verhältnis zum VV den Einkommensumfang in der "BE/BA"-Methode u.U. eindeutig erweitert, ist das verweigern des interperiodischen verlustausgleichs.

22) E. Littmann 1978, §§ 4,5 Rd.-Nr. 12a; G. Wöhe 1978, S. 329.

23) D. Schneider 1978b, S. 178, bezweifelt, ob der interperiodische Verlustausgleich bei der "BE/BA"-Methode tatsächlich nicht erlaubt 1st. Aber auf S. $179 \mathrm{gibt}$ er selbst ein Gegenbeispiel: "Werden die Anschaffungsausgaben sofort als Betrlebsausgaben verbucht, wirken sich die Anschaffungsausgaben oft nur $z$ um $k l$ e $i$ n e $n$ T e $i l$ gewinnmindernd aus." (Hervorhebung $\mathrm{HDH})$. Wie das, wenn der Verlustausgleich erlaubt 1st? Dann können nämlich solche "Anlagenanschaffungsverluste" $\mathrm{zu}$ einem groBen Teil verteilt werden, sofern sie selbstredend innerhalb der von $\S 10$ d EStG gezogenen Betrags- und Zeitgrenzen bleiben. 
Ob dagegen der $N i c h t a n s$ a $t z$ d e s B e $t$ r i e b s $v$ e $r \mathrm{~m}$ ö $g$ e $n s$ Im BE/BA $z u$ einer Erweiterung oder Verengung des Einkommensumfangs und damit $z$ ungleichbehandlungen zwischen beiden Gewinnermittlungsmethoden führt, hängt von verschiedenen Faktoren ab. Die Möglichkeit unterschiedlicher Vermögensbewertung und Gewinnverlagerung erschwert eine generelle Aussage. Es läBt sich aber sagen, daB der vv die gröBeren Chancen enthält, durch autonome unternehmerische Entscheidungen auf die EinkommensgröBe EinfluB zu nehmen. Hier ist die "BE/BA"-Methode im wesentlichen auf die $n i c h t$ e $n t s h$ e $i d u n g s$ e $i$ e "L e g a 1 i $t$ ä $t$ " angewiesen, die ihr eine freie Vermögensbewertungsund Rückstellungspolitik verwehrt. Von vornherein ist der Rahmen der Auslegung der "Betriebsausgaben" hier enger gezogen, da im VV auch Nichtgeldausgaben zur Bildung von steuerfreien Rücklagen führen können (G. Wöhe 1978 , S. 330). Auch in der Nichtzulassung von Rückstellungen liegt dann z.B. ein Ungleichbehandlungsnachteil, wenn infolge Schadensersatzverpflichtungen ein hoher drohender Verlust nicht qua vorheriger Rückstellung auf mehrere Jahre verteilt werden kann. ${ }^{24)}$ Demgegenüber verfügt der VV in Bilanzierung und Bewertung über einen relativ groBen $e n t s c h e i-$ d u n g a u $t \circ \mathrm{n} \circ \mathrm{m}$ e $\mathrm{n}$ Bereich. Eine niedrigere Bewertung der Vermögensgegenstände bzw. eine hohe Bewertung der Schulden mindert den Einkommensumfang. Ferner kann der Unternehmer qua VV immer dann durch die Inanspruchnahme von Bewertungsfreiheiten und die Bildung von steuerfreien Rücklagen seinen Einkommensumfang eingrenzen, wenn die staatliche Finanzplitik aus allokativen und/oder stabilisierungspolitischen Gründen dazu anreizt. Eine ähnliche Möglichkeit steht den BE/BA-Unternehmern nur über die Abschreibungsregelungen offen.

Nun liegt aber der Grund für die Ungleichbehandlung der Gewinneinkommen nicht in der Entscheidungsfreiheit selbst, sondern ausschlieblich darin, diese Entscheidungsfreiheit nur einem bestimmten Kreis von "Gewinnermittlern" einzuräumen. Einen eventuellen Nachteil des gröBeren Einkommensumfangs verspüren in erster Linie Freiberufler, ${ }^{25)}$ seltener schon Land- und Forstwirte und Kleinge-

24) D. Schneider 1978b, S. 179; G. Wöhe 1978, S. 329.

25) K. Bierle 1981, S. 675: "Seit der AO 1977 sind die Angehörigen der freien Berufe insoweit nicht mehr buchführungspflichtig, als sich die in $\S 141$ AO festgelegten Grenzen, deren

(Forts. slehe folgende Seite) 
werbetreibende, die nicht buchführungspflichtig sind und auch freiwillig keine Bücher, sondern lediglich bestimnte Aufzeichnungen führen. Es ist $\mathrm{zu}$ vermuten, daB sowohl individuell als auch gruppenmäBig die UngleichmäBigkeit der Besteuerung durch die Anwendung der "BE/BA"-Methode eine gröBere Bedeutung hat als die der "uVV"-Methode. Ein Rat, auf den VV überzugehen, falls die Ungleichheit der Einkommen $z$ u Belastungsnachteilen führt, beseitigt nicht die in der Methode selbst angelegte UngleichmäBigkeit. 26)

4. Welche Bedeutung die "E / W K" - Me $t h \circ d e$ hat, wird besonders deutlich, wenn man sich den Gesamtkatalog der UberschuBEinkunftsarten vor Augen führt und dann abzuschätzen versucht, welche Auswirkungen auf den Einkommens-Umfang sich aus den folgenden Regelungen ergeben können:

a) Zunächst werden VeräuBerungsgeschäfte nicht erfaBt VeräuBerungsgewinne und - verluste haben keinen EinfluB auf das Einkommen (k). Diese Regelung, die gegenüber dem VV und dem BE/BA einkommensbegrenzende Vorteile bietet, entfaltet ihre Wirkung nicht so sehr im Kreise der Bezieher von Arbeits- und Renteneinkünften, wo VermögensveräuBerungen seltener vorkommen, als vielmehr im Kreise der Bezieher von Einkünften aus Kapitalvermögen sowie Vermietung und Verpachtung. Deshalb ist für diese Anlegergruppen das VeräuBerungsgeschäft als steuerpflichtiges "spekulationsge-

Forts. Fn. 25:

Uberschreitung zur Buchführungspflicht führt, entgegen der Regelung in $\S 161$ AO a.F. nur noch auf gewerbliche Unternehmer und Land- und Forstwirte beziehen."

26) "Um GleichmäBigkeit der Besteuerung $z u$ wahren, müBte ein traditionelles Vorurteil verworfen werden: DaB die steuerliche Gewinnermittlung in irgendeinem sachlichen zusammenhang zur handelsrechtlichen Bilanzierung stehe .... Wer die steuerliche Einkunftsermittlung grundsätzlich auf der handelsrechtlichen Bilanzierung aufbaut, verstöBt absichtlich gegen die GleichmäBigkeit der Besteuerung. Nicht die Handelsbilanz darf das Rückgrat der Steuerbilanz sein, sondern die Forderung nach möglichst unterschiedsloser Berechnung der Einkünfte bei den einzelnen Ermittlungsmethoden: UberschuBrechnung und Vermögensvergleich" (D. Schneider 1978b, S. 175). - Im übrigen siehe zur Vermeidung von Diskriminierungen und Ungleichbehandlungen innerhalb der verschiedenen Einkunftsarten sowie der unterschiedlichen Besteuerung aus allokativen und distributiven Motiven F. Neumark 1961d, S. $394 \mathrm{ff}$. u. $399 \mathrm{ff}$. 
schät" definiert worden. Dennoch: Wer jenseits der in $\S 23$ festgelegten Spekulationsfristen VeräuBerungsgewinne erzielt, erhält sie steuerfrei, da sie den Einkommensumfang nicht berühren. Die Nichterfassung dieser Gewinne ist ein VerstoB gegen das Allgemeinheitspostulat und damit gegen das Leistungsfähigkeitspostulat (siehe auch K. Tipke 1981, s. 185 f.). 27)

b) Von einem einkommensmindernden Vorteil kann man bei der $7 \mathrm{~b}-\mathrm{Ab}-$ schreibung nicht sprechen (1); zwar mindert sie das Einkommen der Bezieher von Einkünften aus Vermietung und Verpachtung in der methodeninternen Betrachtung, doch ergibt sich gegenüber dem VV und dem BE/BA keine Bevorzugung, wenngleich im GeldzufluB-AbfluB-Konzept der UR diese Regelung ein Fremdkörper ist. Dies zeigt aber nur, daB bei einem Verzicht auf Sonderabschreibungsregeln und gleichwohl angestrebter Gleichbehandlung das monetäre FluBprinzip sich nur dann hätte "lupenrein" verwirklichen lassen, wenn die gesamte Geldausgabe im Zuge der Anschaffung des Mietobjektes in die Besteuerung aufgenommen worden wäre und dann $z u$ einem Verlust hätte führen dürfen. Doch ein interperiodischer Verlustausgleich (n) ist für die tberschuB-Einfkunftsarten ebenfalls nicht vorgesehen.

c) Im Versagen des interperiodischen Verlustausgleichs für die UberschuB-Einkunftsarten $(n)$ liegt wegen seiner einkommenserhöhenden Wirkungen gegenüber dem $\mathrm{VV}$ und dem $\mathrm{BE} / \mathrm{BA}$ der wesentliche Tatbestand der distributiven Ungleichbehandlung. Es wäre verfehlt, diesen Umstand allein aus dem Blickwinkel der kontraktbestimmten Arbeits- und Renteneinkommen beurteilen zu wollen, da hier Verluste im allgemeinen nicht entstehen können. Im Kapitalertrags-, Vermietungs- und spekulationsgeschäft dagegen können sehr wohl Verluste entstehen. Der Verlustausgleich als ein die Härten des

27) Die Ungleichbehandlung liegt jedoch, wie bereits dargestellt, nicht in der Befreiung als solcher, also nicht darin, daB VeräuBerungsgeschäfte im privaten Bereich unerfaBt bleiben, wohingegen sie im unternehmerischen Bereich zum steuerpflichtigen Tatbestand gerechnet werden. Die Ungleichbehandlung liegt vielmehr darin, daB für den Unternehmer die $\mathrm{G}$ e $w$ i n $\mathrm{n}$ Ermittlung zugleich auch die Methode der Ermittlung seines privaten $E \mathrm{i} \mathrm{n} \circ \mathrm{m} \mathrm{m} \mathrm{n}$ ist, dort aber die VeräuBerungsgewinne erfaBt. Für die Nichtunternehmer hat also die UR einen steuersystematisch bedingten einkommensmindernden Vorteil. 
Periodizitätsprinzips milderndes Prinzip der Steuergerechtigkeit (K. Tipke 1991, S. 206), das seine einkommensbegrenzenden und steuerlastsenkende Wirkungen vor allem vor dem Hintergrund eines Progressionstarifs entfaltet, sollte nicht nur dem Einkommen der Unternehmer zugute kommen dürfen.

d) Da die Einkünfte der UR definitionsgemä $B$ Vermögensbestände nicht enthalten, verfügen die Bezieher dieser Einkünfte auch nicht über die Möglichkeiten der einkommensbegrenzenden Bewertungsfreiheiten und der Gewinnverlagerungen (m). Es ist das Kennzeichen dieses steuerlichen "G e s t a l t u n g s p r i vi1 e g s", daB die mehr oder weniger freie Zurechnung von Aufwands- und ErtragsgröBen auf die Perioden mit ihren progressionsbedingten Auswirkungen auf die Belastung mit Steuern insbesondere mit den VV- und BE/BA-Methoden verknüpft sind und solchermaBen mit einem hohen Grad an Wahrscheinlichkeit insbesondere den höheren Einkommensklassen zu Gebote stehen (G. Krause-Junk 1981, s. 348$) .281$

e) Versucht man abschlieBend die Auswirkungen der steuerlichen Regelungen der "E/WK"-Methode auf die Einkommen $z u$ würdigen, so wird man alles in allem vermuten dürfen, daB der nach dieser Methode ermittelte Einkommensumfang weiter ist als bei den anderen Methoden. Uber alle UberschuB-Einkunftsarten betrachtet (nicht allein auf die Arbeits- und Renteneinkünfte abgestellt) kann gefolgert werden: VeräuBerungsgewinne, die bei Einkünften aus Vermietung und Verpachtung, aus Kapitalvermögen und aus spekulationsgeschäften (jenseits der gesetzlichen Fristen) das Einkommen nicht erhöhen können, weil sie nicht erfaBt werden (k), haben ihre Entsprechung darin, daB VeräuBerungsverluste das Einkommen nicht mindern können. Wenn also ein interperiodischer Verlustausgleich $(n)$, der auf solche Transaktionen zurückzuführen wäre, versagt wird, ist das akzeptabel. Dennoch verbleiben jene Verluste, die nicht aus dem VeräuBerungsgeschäft, sondern aus der Vermögens- und Kapitalanlage hervorgehen, ohne interperiodischen Ausgleich. Sie erhöhen das Einkommen nach der "E/WK"-Methode ebenso wie die fehlende Gestaltungsmöglichkeit (m). Wenn also bei

28) Zum "Gestaltungsprivileg" im Rahmen der Steuertechnik und internationaler Steuerprobleme siehe G. Schmölders 1965, S. 82 u. S. 269 f. 
für alle VV- und UR-Berechnungsarten gleich hohen Ausgangsbeträgen der Einkommensumfang der "E/WK"-Methode höher liegt oder - was auf dasselbe hinausläuft - wenn bei in allen Berechnungsarten gleichem Einkommensumfang die Ausgangsbeträge der "VV"- und der "BE/BA"-Methoden höher liegen als der der "E/WK"-Methode, so ist unter den mehrfach zitierten steuersystematischen Voraussetzungen der Tatbestand der distributiven Ungleichbehandlung erfüllt.

5. Die $D u r c h s c h n i t t s s a t z b$ es $t$ e u e r ung nach $\S 13 a$ EStG ("DSB") ist weder ein Vermögensvergleich noch eine UberschuBrechnung, sondern eine Methode der Sollertragsberechnung (N. Andel 1979a, S. 392). Die "längsten und kompliziertesten Vorschriften des EStG" (K. Tipke 1981, S. 266) enthalten neben Zahlungs-Istgrößen (o) zwei Gruppen von Durchschnittssatzgewinnen, die erstens die Bindung der Erträge sowohl an das Vermögen bzw. Kapital (p) als auch an die Arbeitskraft (q) zum Ausdruck bringen und zweitens den Sollertragscharakter des gesamten Rechenwerkes dadurch bestimmen, daB sie den Gewinn einerseits vom Einheitswert (r), 29) andererseits vom Wert der Arbeitsleistung abhängig machen. 30 )

a) Es handelt sich bei der "DSB" nicht um eine Schätzung, sondern um eine "typisierende" Gewinnermittlung ${ }^{31}$ ). Die solchermaßen entstehende allokative und distributive Ungleichbehandlung des Ein-

29) Siehe auch unsere Darstellung in $\$ 27$ II unten, mit der allokativ-distributiven Problematik.

30) Die Gesetzesvorschriften lassen sich unter Abänderung ihrer Reihenfolge nach dem unten wiedergegebenen Schema gruppieren,

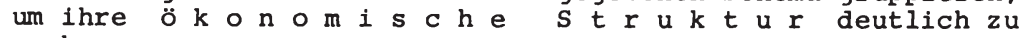
machen:

I. Der Durchschnittssatzgewinn ist die summe aus
a) Aufwendungen und Erträgen aus $\mathrm{z}$ a $\mathrm{h} l \mathrm{l} \mathrm{n} g \mathrm{e} \mathrm{n}$ : Pachten, Zinsen und dauernde Lasten;
b) Erträge aus der Ermittlung des $E$ in $\mathrm{h}$ e $i \mathrm{t} s \mathrm{w}$ e $t \mathrm{~s}$ s Grundbetrag, Nutzung der Wohnung, Ertragswert der Sonderkulturen,
c) Erträge aus der Ermittlung des Wertes der A r b e 1 t s - leistung (nach Soll- und Prozentsätzen).

II. Der $A$ u $s$ a $n g s$ e $r t$, der mit einem Sechstel bzw. Fünftel in den "Grundbetrag" eingeht, errechnet sich aus dem $E i n h$ e $t s w e r t v e r f a h r e n$ als summe der Vergleichswerte für sämtliche Nutzungen.

Fn. 31 folgende seite. 
kommens-Umfangs haben wir getrennt zu analysieren und einerseits für das Verhältnis der Landwirte untereinander (in dem Wettbewerbsverzerrungen entstehen ${ }^{32}$ ), andererseits für das verhältnis der Landwirte $z u$ den Nichtlandwirten, was auf einen Vergleich der "DSB" mit allen anderen Gewinn- und UberschuBermittlungsmethoden hinausläuft, ${ }^{33)}$ zu beurteilen.

b) Die allokative und distributive Ungleichbehandlung sowohl in individueller als auch in gruppenmäBiger Hinsicht steht und fällt mit der Koppelung an das Einheitswertverfahren. Die Kritik an diesem Verfahren ist $\mathrm{zu}$ häufig und $\mathrm{zu}$ profunde geliefert worden, als daB sie hier im einzelnen vorgetragen werden sollte (siehe $\$ 19$ II 2.); auf die entsprechende Literatur kann verwiesen werden. Für unsere Zwecke ist lediglich hervorzuheben, daB zum einen die im Einheitswertverfahren festgestellten, die Ertragsfähigkeit des landwirtschaftlichen Betriebes ausdrückenden "V e r g 1 e 1 c h s w e $r e^{\prime}$ äuBerst pauschal ermittelt und weitgehend undifferenziert auf die einzelnen Betriebe angewendet werden ${ }^{34}$ ) und daB die sich so ergebenden Werte den Marktwerten keineswegs entsprechen. Die Abweichung von den Marktwerten birgt neben dem $s t r u k-$ t u r p r $\circ$ b 1 e m, 35) das schlieblich dazu führt, dab zufäll1-

31) Carle/Felix 1981, S. 945: Die Durchschnittssätze gehen von normalen, in mehreren Jahren unter in etwa gleichbleibenden Verhältnissen bei einer vielzahl von Landwirten durchschnittlich erzielbaren Reinerlösen aus, so daB die Verhältnisse des Einzelfalls auBer acht bleiben.

32) Nicht alle Landwirte kommen in den Vorteil der DSB. Letztere gilt für nichtbuchführungspflichtige (s. \$ $141 \mathrm{AO}$ ) Land- und Forstwirte und nur dann, wenn sie nicht einen Antrag auf Gewinnermittlung nach $\S 4$ I oder $\S 4$ III EStG gestellt haben

33) Unmittelbarer Vorläufer des jetzt geltenden $\S 13 \mathrm{a}$ war $\S 13 \mathrm{a}$ i.d.F.v. 1974, der für verfassungswidrig gehalten wurde; K. Tipke 1981, S. 288: "Das FG sieht mit Recht den Gleichheitssatz sowohl im Verhältnis zu anderen Steuerpflichtigen als auch im Verhältnis der Landwirte untereinander als verletzt an."

34) Das nach $\S 37$ I Bewg formalisierte "vergleichende" verfahren vermag nur grob die natürlichen Ertragsbedingungen wie Bodenbeschaffenheit, Geländegestaltung, Anbau- und Nutzungsart (z.B. Ackerland, Obstland) und klimatische Verhältnisse zu berücksichtigen; das Ergebnis wird je nach den verschiedenen wirtschaftlichen Ertragsbedingungen (BetriebsgröBe, innere und äuBere Verkehrslage, gegendübliche Preis- und Lohnverhältnisse sowie Organisations form und Ausstattung des Betriebes) modifiziert; siehe K.-H. Hansmeyer 1981 , S. 730 .

35) Dieses liegt in der Kompliziertheit und der Unbestimmtheit des Vergleichswertverfahrens. Zur Kompliziertheit siehe die

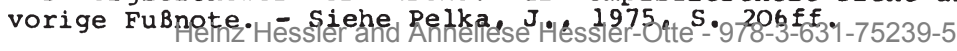


ge, unsystematische und damit nicht exakt begründbare Bewertungsergebnisse vorgezeichnet sind (K.-H. Hansmeyer 1981b, S. 734), vor allem ein $\mathrm{N} 1 \mathrm{v}$ e a $\mathrm{u}$ p $\mathrm{r}$ b $\mathrm{l}$ e $\mathrm{m}$. Dieses zeigt sich darin, daB die aufgrund der Vergleichswerte ermittelten Einheitswerte äuBerst niedrig sind. Im wesentlichen haben die Bodenschätzungen des Jahres 1934 zur Ermittlung der landwirtschaftlichen Vergleichszahlen noch heute ihre Gültigkeit. ${ }^{36)}$ Die auch heute als extrem niedrig zu bezeichnenden Einheitswerte ${ }^{37)}$ sind nun ihrerseits Grundlage für die "DSB" insofern, als sie in etwa jenem "Ausgangswert" entsprechen, der mit einem Fünftel bzw. Sechstel in den sog. Grundbetrag der "DSB" eingeht. ${ }^{38)}$ Dadurch ist auch der "Grundbetrag" sehr niedrig. Es kommt hinzu, daB der Wert der Arbeitsleistung des Betriebsinhabers und seiner mitarbeitenden Angehörigen $z$ u relativ niedrigen Soll-Entlohnungssätzen angesetzt werden. Der insgesamt sich so ergebende Durchschnittssatzgewinn fält demnach wesentlich geringer aus, als es nach korrekten Einzelaufzeichnungen der Fall wäre. Die allokativ-distributive Verknüpfung liegt hier darin, daB die Sollbesteuerung mit ihrer speziellen Begünstigung eines Wirtschaftszweiges zugleich zu einem Instrument der Einkommenspolitik wird.

c) Bei dieser Sachlage uberrascht es nicht, daß ein starker Trend der steuerpflichtigen dahin geht, in den Vorteil40) der "DSB" zu kommen.41) Für Nichtlandwirte und buchführende Landwirte gilt daher die "DSB" als "fundamentaler verstoß gegen den Grundsatz der Gleichmäßigkeit der Besteuerung" (N. Andel 1979a, S. 392;

36) 1964 wurde statt einer Neufestlegung der Bodenqualität nur eine groBe Uberprüfung der damaligen Ergebnisse durchgeführt. "Hinzu kommt, daB der Gesetzgeber die geschätzten Reinerträge zur Feststellung der Einheitswerte von 1964 bewuBt niedrig angesetzt hatte; auf Betreiben des Ernährungsausschusses des Deutschen Bundestages wurden die probeweise ermittelten Ertragswerte um mehr als die Hälfte reduziert, da solche Erträge in ihrer Höhe nicht nachhaltig erzielbar seien." K.-H. Hansmeyer 1981 , S. 734 .

$37)$ Bereits 1965, bei der Verabschiedung des neuen Bewertungsgesetzes, lagen sie bei nur etwa 135 \% der Einheitswerte von 1935; aufgrund von Schätzungen erreichen die Einheitswerte der Land- und Forstwirtschaft heute 1 bis $10 \%$ der Verkehrswerte. K. -H. Hansmeyer 1981, S. 734 .

$38)$ Siehe die Fußnote 30 oben; Analoges gilt für den Wohnungswert, der nach ähnlich "günstiger" Berechnungsweise ermittelt wird.

Fn. 40 und 41 auf der folgenden seite. 
Andel stellt seine Kritik aber insbesondere auf das Verhältnis zwischen der Landwirtschaft und anderen Wirtschaftsbereichen ab).

III. Das GleichmäBigkeitspostulat verlangt, sämtliche Zugangsarten ökonomischer GröBen gleich $z u$ behandeln. Im Rahmen der hier $\mathrm{zu}$ leistenden Analyse des steuerlichen Einkommensbegriffs bedeutet das, sämtliche Zugangsarten in den Einkommensumfang aufzunehmen, so daB die sachliche Gleichbehandlung auch eine personale nach sich zieht. Dann entsteht kein allokatives Problem mehr, sondern ausschlieblich ein distributives. Die u $\mathrm{n} g \mathrm{l} i \mathrm{ch}$ e Erfassung der $\mathrm{E} i \mathrm{n} \mathrm{k} \circ \mathrm{m} \mathrm{m} \mathrm{n} z \mathrm{u} \mathrm{g}$ ä $\mathrm{g}$ e wird als distributive Ungleichbehandlung dargestellt: Werden trotz Gleichheit in den persönlichen und familiären Verhältnissen die Einkommen ungleich erfaBt, liegt auBer dem VerstoB gegen des Allgemeinheitspostulat (einschlieblich des Korrespondenzprinzips) ein solcher gegen das Gleichbehandlungsgebot vor.

Im folgenden ist im wesentlichen lediglich ein grober Uberblick $z u$ geben über die Tatbestände der Verletzung des Gleichbehandlungsangebots, da die Problematik bereits in den Ausführungen zum Allgemeinheitspostulat (SS $21 \mathrm{u} .22$ ) sowie auch in den Ausführungen zur Methodik der Erfassung (\$ 25 III 1.) behandelt wurde. 42)

4.0) K. Tipke 1981, S. 266 u. 1981a, S. 81: "Bei der Anwendung des $\S 13 a$ EStG n. F. bleiben an der Obergrenze des Anwendungsbereichs ... Gewinnanteile von durchschnittlich uber 7.000 DM unerfaBt." - SRK 1971, S. 617, TZ 10: "Die Einheitswerte... liegen mehr oder weniger unter dem Verkehrswert vom Hauptfeststellungszeitpunkt, weil die übliche Verzinsung für den Bereich der Land- und Forstwirtschaft mit 5,5 v.H. zu hoch angenommen worden ist...".

41) Schätzungen schwanken, jedoch liegen die Werte einheitlich sehr hoch: K. Tipke (1991, S. 331f.) geht davon aus, daß ca. "drei Viertel aller landwirtschaftlichen Betriebe den Gewinn in Anknüpfung an den Einheitswert nach Durchschnittssätzen ermitteln dürfen." D. Schneider $(1978 \mathrm{~b}, \mathrm{~S} .183)$ ermittelt für einen etwas früheren Zeitpunkt: "Berücksichtigt man die Freibeträge und die sonstigen Bewertungsvergünstigen, so ist ersichtlich, wie gering Land- und Forstwirte besteuert werden. ... 87 aller Land- und Forstwirte ... ermitteln ihren Gewinn nach Durchschnittssätzen und zahlen deshalb im Durchschnitt nur zwischen 50 und 60 Mark Einkommensteuer jährlich!"

42) In der Gliederung der Tatbestände knüpfen wir an die übersicht 3.2 in $\$ 7$ an. 
1. Ungleichbehandlungen können auftreten im Zusammenhang mit der geldlichen und güterlichen $F$ a $k$ to $r$ e $t / \circ h$ u $\mathrm{h}$, wenn für bestimmte Gruppen von Beschäftigten oder Einkommensbezieher Entlohnungsformen und/oder -anteile nicht in den Einkommensumfang aufgenommen werden, sei es durch steuerbefreiungen expressis verbis oder durch "schweigende" Nichterfassung, sei es durch Unterschiede in der Methodik der Erfassung:

- Zins- und Pachteinnahmen,

- Arbeitgeberanteile zur Sozialversicherung,

- betriebliche Beihilfen (Geburt, Heirat),

- betriebliche Prämien und Trinkgelder,

- Deputate und Naturalentgelte,

- Dienstwohnung, Dienstwagen u.ä.,

- Betriebsverpflegung, Arbeitskleidung,

- betriebliche Kulturveranstaltungen, Gesundheitspflege und Ausbildung,

- Entnahme von Sachgütern und Dienstleistungen aus dem Betrieb,

- differierende EinkommensgröBen je nach der Methode der Einkommensermittlung (Gewinn, UberschuB oder Durchschnittssatzgewinn).

2. Auch im Zusammenhang mit dem Vermögen, sei es als Vermögensnutzung, sei es als VermögensveräuBerung, können Ungleichbehandlungen auftreten:

- Wenn die $V$ e $r m$ ög e $n s n u t z u n g$ in Form der eigengenutzten Wohnung im eigenen Hause als zurechnungseinkommen in den Einkommensbegriff aufgenommen wird, so erreicht man damit zweifellos eine Gleichbehandlung zwischen Haus (oder Wohnungs-)eigentümer und Mieter, jedoch bleibt eine Ungleichbehandlung zwischen den Eigentümern dann, wenn Bewertungseigentümlichkeiten im Hinblick auf die verschiedenen objekte bestehen;

- eine Ungleichbehandlung bei den $V$ e $r$ ä u B e $r$ u n g s e r 1 ö s e $n$ für Vermögen liegt dann vor, wenn private VeräuBerungsgeschäfte nicht, betriebliche hingegen - unter den oben in I angegebenen steuersystematischen Bedingungen - erfaBt werden. Desgleichen liegen Ungleichbehandlungen vor, wenn für die verschiedenen Einkunftsarten unterschiedliche Freibeträge vorgesehen sind.

3. Die wesentlichen Fälle der Ungleichbehandlung sind jedoch im T $r$ a n $\mathrm{s}$ e $\mathrm{r}$ b e $r$ e $i c h$ festzustellen. Hier haben wir $z u$ unterscheiden zwischen einer Ungleichbehandlung innerhalb des Krei- 
ses der verschiedenen Transfers generell und einer Privilegierung der Alterseinkünfte speziell. Erstere läuft auf eine Ungleichbehandlung der Transferbezieher untereinander hinaus, letztere auf eine solche zwischen Alters- und Aktiveneinkommensbeziehern.

a) Die Ungleichbehandlung der $\operatorname{tr}$ a $\mathrm{n}$ s $\mathrm{f}$ e $\mathrm{e} i \mathrm{n}$ ü $\mathrm{n}$ f $t$ e (siehe auch $\$ 22$ III 4.) zeigt sich auf mehrfache Weise:

- Versorgungsrenten aus den öffentlichen Haushalten sind gegenüber allen anderen Transferarten grundsätzlich und völlig steuerfrei; solange das mit dem allgemeinen Steuerfreibetrag im Einkommensteuertarif betraglich übereinstimmt, ist wegen fehlender Leistungsfähigkeit die steuerfreiheit dieser Transfers im Einkommensbegriff zu akzeptieren; jenseits dieses Betrages - über seine Höhe ließe sich streiten - jedoch beginnt die steuerliche Leistungsfähigkeit und die Ungleichbehandlung gegenüber anderen grundsätzlich besteuerbaren Einkünften.

- Einkünfte aus "wiederkehrenden Bezügen" (als Bezüge aufgrund von dauernden Lasten beim Geber) und zeitrenten werden voll versteuert, im Gegensatz zu Leibrenten und Pensionen, die wenn auch in sehr unterschiedlichem MaBe - geringer besteuert werden.

- Beamtenpensionen und Betriebspensionen werden - jenseits eines Versorgungsfreibetrages - versteuert, private Leibrenten und Sozialversicherungsrenten dagegen nur mit dem irreal niedrigen Ertragsanteil, der bei Sozialversicherungsrenten zur praktischen Steuerfreiheit in der überwiegenden Zahl der Fälle führt. Der Versuch, diese Ungleichbehandlung bei anderen Alterseinkünften durch die Einführung eines Altersentlastungsbetrages (§ $24 \mathrm{a}$ EStG) auszugleichen, kann nur teilweise zum Erfolg führen. ${ }^{43)}$

- Einkünfte aus wiederkehrenden Bezügen in Form von Unterhaltungsbezügen, die freiwillig oder aufgrund einer freiwillig begründeten Rechtspflicht oder einer gesetzlich unterhaltsberechtig-

43) Das Bundesverfassungsgericht hatte steuerliche Begünstigungen der Pensionäre gegenüber den Rentnern 1969/70 (BVerfG JZ 80, S. $566 \mathrm{ff.)}$ als seinerzeit noch für verfassungsmäßig angesehen; heute ist erwiesen, daß sie ein Ausmaß erreicht hat, welches unter dem Gesichtspunkt gleicher steuerlicher Lastenverteilung nicht gerechtfertigt werden kann; siehe hierzu K. Tipke 1991, S. 373 und D. Birk 1983, S. 177; Birk weist auch auf die umfangreiche rechtswissenschaftliche Diskussion im

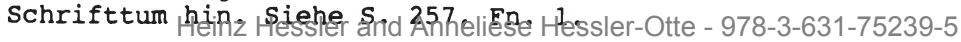


ten Person gewährt werden, werden dem Empfänger nicht zugerechnet ( $\$ 22 \mathrm{Nr} .1 \mathrm{~S} .2 \mathrm{EStG}$ ), obwohl hier Leistungsfähigkeit grundsätzlich vorliegen kann (siehe die obige Argumentation) und eine Ungleichbehandlung gegenüber solchen Einkommensempfängern vorliegt, die ein gleich hohes Einkommen aus anderen Quellen als der der rechtlichen oder der Unterhaltsverpflichtung beziehen. Nur Ehegatten, die geschieden oder dauernd getrennt leben, müssen den Bezug von Unterhalt bei bestimmten Bedingungen, und begrenzt auf $27.000 \mathrm{DM}$ versteuern (\$ $22 \mathrm{Nr}$. la i.v.m. S 10 I Nr. 1 EStG).

b) Die steuerliche Bevorzugung der A l t e r s e $i \mathrm{n}$ iu $\mathrm{n} f \mathrm{t} e$ gegenüber den Aktiveneinkünften liegt

- einerseits in der praktischen Steuerbefreiung der Sozialversicherungsrenten allgemein,

- andererseits in der Einrichtung eines besonderen Freibetrages für den Fall der Alterseinkünfte, der bei den Pensionen elnen Umfang von 40 \& der Bezüge ausmacht, höchstens jedoch DM 6.000 DM (§ 19 II EStG); bei Personen, deren Einkünfte nicht in Pensionen und Leibrenten bestehen, beträgt dieser Freibetrag (Altersentlastungsbetrag, $\S 24 a$ EStG) 40 o des Arbeltslohns, höchstens 3.720 DM. (Daneben erhielt bis 1990 der Steuerpflichtige ab dem 65. Lebensjahr den Altersfreibetrag nach $\S 32$ II EStG in Höhe von 720 DM. Ein objektiver Grund für diese "Aufstockung des Existenzminimums" (so sinngemäB K. Tipke 1981, s. 275) war nicht zu erkennen, da eine verminderte steuerliche Leistungsfähigkeit nur wegen Alters und trotz evtl. nicht verminderter Bezüge nicht angenommen werden kann (K. Tipke 1981, S. 203). 
s 27 Die verstöbe gegen die

Gleichbehandlung als die

Determinanten des steuer-

lichen Vermögensbegriffs

I. Die Wertermittlungsmethoden als ein

"System der Ungleichbehandlung" 461

II. Ungleiche Erfassung der Vermögensbestände

1. Grundfragen einer vermögensartspezifischen Ungleichbehandlung

2. Ungleichbehandlungen als Folge der Einheitsbewertung

466

Ungleichbehandlungen als Folge der zuordnung und des Schachtel"Privilegs"

481

III. Zusammenfassugnng des Zweiten Teils 482

I. Für die Besteuerung werden hierzulande zwei "Bewertungssysteme" nebeneinander angewendet (G. Wöhe 1978, S. 683 ; siehe \$ 19 II 2.). Ersteres bewertet Vermögen so, daB eine periodengerechte $\mathrm{E}$ i $\mathrm{n}$ $\mathrm{k} \circ \mathrm{m} \mathrm{m}$ e $\mathrm{s}$ - Ermittlung unter dem gleichzeitigen Aspekt der kaufmännischen Vorsicht und des Gläubigerschutzes möglich wird; es ist ausgerichtet auf die handelsrechtliche Bilanzierung und den steuerrechtlichen Vermögensvergleich. Das hier interessierende zweite System will den Bestand an Vermögen qua steuerlicher vermögensaufstellung erfassen und dient der $v$ e $r m$ ö g e $n s-B e-$ steuerung. Grundlage soll ein Gegenwartswert sein oder ihm möglich nahe kommen, um die Leistungsfähigkeit zu reprädentieren. Auch hier gilt, daß die persönliche Leistungsfähigkeit berührt ist, wenn unternehmrerisches Vermögen auch zu persönlicher Vermögensteuer führt. Dies ist im gegenwärtigen steuerecht der Fall. 1)

a) Das geltende Bewertungsrecht, das gegenwartsnahe Wertfeststellungen gewährleisten soll, teilt das Vermögen einer natürlichen Person und einer Unternehmung in vier $A, t$ e $n$ ein, ungeachtet $\operatorname{der} F$ u n t i n e n, die es sozialökonomisch haben kann (siehe $\$ 10$ ) und ungeachtet dessen etwa, daß auf die vermögensarten einheitliche Wertbegriffe oder Wertermittlungsmethoden anzuwenden wären. Wie tbersicht 8.2 zeigt, ist allenfalls das sog. "sonstige Vermögen" einheitlich auf den "Gemeinen Wert" bzw. auf

1) Damit ist keineswegs die Mehrfachbesteuerung gemeint, die die Antellseigner von Vermögen in Kapitalgesellschaften trifft, sondern der Fall, daB Einzelunternehmer ihr betriebliches Vermögen (Kapital) der persönlichen Vermögensteuer zu unterwerfen habenteinz Hessler and Anneliese Hessler-Otte - 978-3-631-75239-5 
eine seiner Unterarten festgelegt. Ansonsten werden für das Grundvermögen drei, für das Betriebsvermögen vier Wertbegriffe verwendet; lediglich das land- und forstwirtschaftliche Vermögen kommt mit einem Wertbegriff aus, der allerdings wegen der besonderen Verfahrensweise, kraft derer man $z$ u ihm gelangt, viel von seiner Uberzeugungskraft verliert.

b) Die Probleme allokativer und distributiver $\mathrm{U}$ n $\mathrm{g} l \mathrm{e} i \mathrm{c} \mathrm{h}$ $\mathrm{b}$ e $\mathrm{h}$ a $\mathrm{n} d \mathrm{l} \mathrm{u} \mathrm{g}$ (siehe die stichworte a bis $\mathrm{k}$ in der rechten Randspalte von Ubersicht 8.2), die bei der Bewertung entstehen, ergeben sich zum einen daraus, daB sich die zeitnahen Werte $\mathrm{n} i \mathrm{c} h \mathrm{t}$ direkt aus gegenwärtigem $\mathrm{M} \mathrm{a} \mathrm{k} \mathrm{g}$ e $\mathrm{s} \mathrm{h}$ e $\mathrm{h}$ e $\mathrm{n}$ ablesen lassen (Gemeiner Wert, Teilwert), zum anderen aus dem besonders konstruierten Einheitswertverfahren, im Zuge dessen sowohl der "Ertragswert" als auch der "Sachwert" oftmals so formalisiert werden, $d a B$ sie entweder einen $z$ e $t \mathrm{t}$ a $h$ e $n$ Wertausdruck des vermögens $v$ e $\mathrm{f}$ e $\mathrm{h} l$ e $\mathrm{n}$ (und auch $z \cdot T$. verfehlen sollen) oder wegen der Pauschalierungen eine $i \mathrm{n} t$ e $r$ -

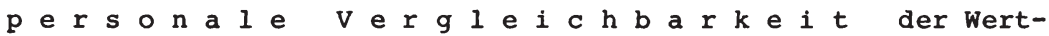
ansätze $n i c h t$ erlauben. Verfehlte Gegenwartsnähe und interpersonal unterschiedliche Werte für die gleichen Vermögensgegenstände aber widersprechen einerseits dem GleichmäBigkeitsprinzip der Besteuerung und dem Gebot der Gleichbehandlung, andererseits dem Prinzip der Besteuerung nach der Leistungsfähigkeit. Bewertungsverfahren, in die allokative und distributive zielvorstellungen hineinkonstruiert werden, determinieren solchermaBen den steuerlichen Vermögensbegriff, noch bevor darüber entschieden werden konnte, ob aus Gründen der persönlichen Leistungsfähigkeit eine besondere Schonung oder Belastung des Vermögens angebracht ist.

So führen Ungleichbehandlungen in der Bewertung der Vermögensbestände $\mathrm{zu}$ ungleichen steuerlichen Vermögensbegriffen. Ungleiche Vermögensbegriffe, die im zuge der Besteuerung auch ungleiche Belastungen hervorrufen, können die Allokationsentscheidungen stören und distributive Effekte hervorrufen. Werden die Vermögen in den verschiedenen wirtschaftszweigen unterschiedlich bewertet, kann sich in den Bewertungsergebnissen nicht mehr niederschlagen, inwieweit eine Investitionsentscheidung über den Einsatz in diesem oder einem anderen Wirtschaftszweig sinnvoll ist; die Allokationsergebnisse müssen - zumindest was die steuerliche Belastung 
Ubersicht 8.2: Wertermittlungsmethoden und steuerliches Vermögen

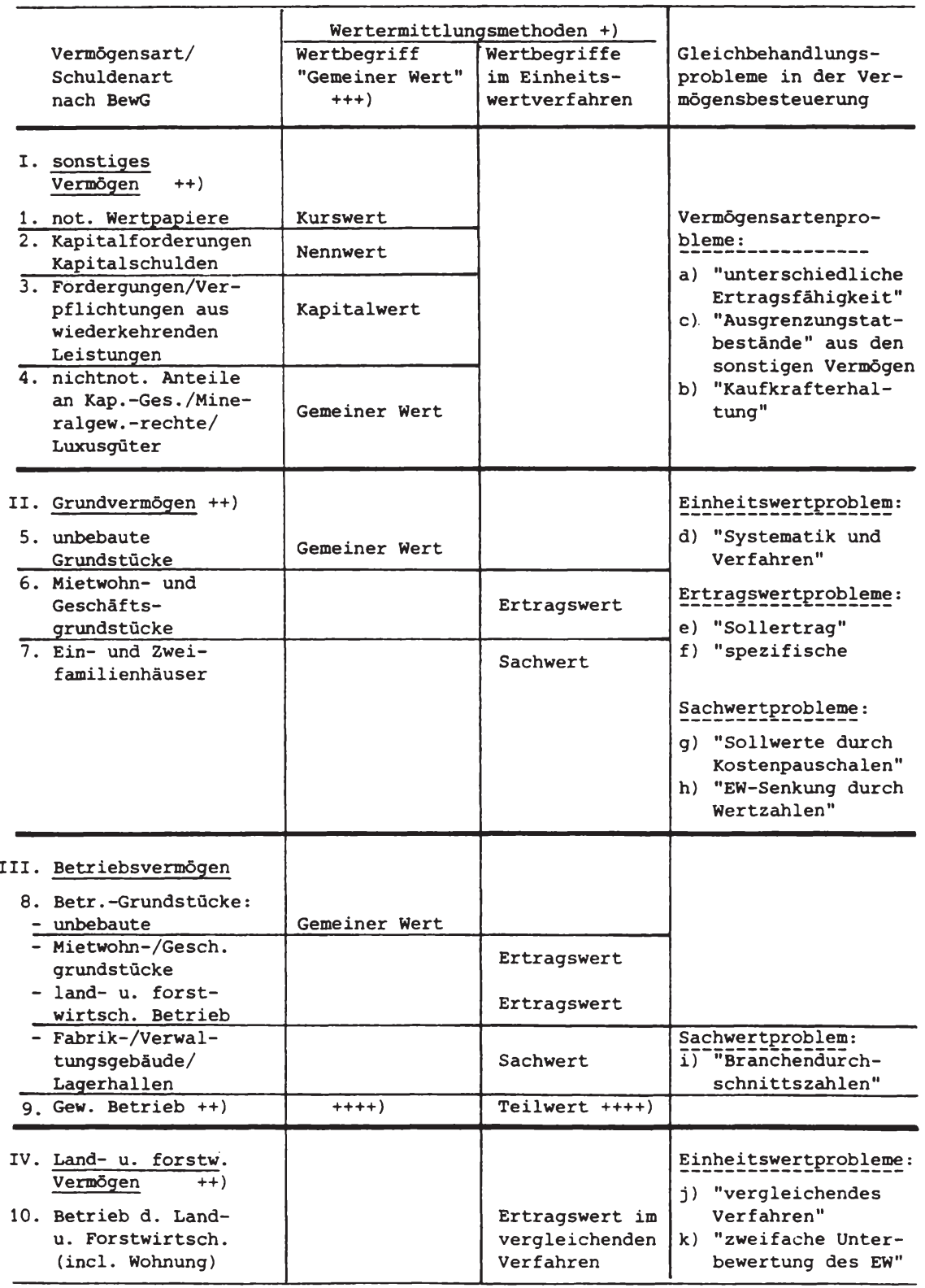


Legende zu Ubersicht 8.2:

+) Vorrangproblem für den Gemeinen Wert, den Teilwert und den Ertragswert:

Welches die zentralen Wertbegriffe des deutschen Bewertungsrechtes sind, wird in der Literatur unterschiedlich gesehen. Dies kann nicht verwundern, da das Bewertungsgesetz einleitend als "Bewertungsgrundsatz ( $(9)$ den Gemeinen Wert formuliert, danach sofort $(\S 10)$ den Teilwert für die Wirtschaftsgüter eines Unternehmens postuliert, ansonsten fast ausschlieBlich die Einheitsbewertung regelt. Demnach hălt sich G. Rose streng an das Gesetz, wenn er (1982b, S. 34) zwei für die Bewertung zentrale Werte feststellt: den Gemeinen Wert für die nichtbetrieblichen, den Tellwert für die betrieblichen Vermögensgegenstände. G. Wöhe (1978, S. 687) dagegen sagt: "Das Bewertungsgesetz verwendet folgende drei Wertmaßstäbe: den gemeinen Wert, den Teilwert und den Ertragswert." Dies ist ökonomisch argumentiert, da man der Meinung sein kann, daB sich sowohl im Gemeinen Wert (dem am Markt erzielbaren VerăuBerungspreis) als auch im Tellwert (sofern der tatsăchlich feststellbar sein sollte) ein solcher Wert dokumentiert, der die auf Dauer angelegte Ertragsfähigkeit eines Wirtschaft sgutes ausdrückt. Diesen ökonomischen Gedankengang stellt K. Tipke (1981, S. $353 \mathrm{f.)}$ so in den Mittelpunkt, daB er den Ertragswert überhaupt für den fundamentalen Wert hălt ("Das Prinzip der Bewertung kann in der Tat nicht dem Bewertungsgesetz selbst entnommen werden; es muß aus den Gesetzen über die einheitswertabhăngigen steuern ... abgeleitet werden. Vermögensteuer ... wollen die potentielle Ertragskraft von Vermögen besteuern. Die prinzipielle Anknüpfung an den gemeinen Wert (Verkehrswert) statt an den Ertragswert erstaunt daher."

Die Einteilung von K.-H. Hansmeyer (1981, S. 728) enthält sich der Gesetzeskritik, nimmt aber den ökonomischen Gedankengang auf, berücksichtigt jedoch, daB gerade der Ertragswert in ein Exmittlungsverfahren eingebunden wurde, das einen wesentlichen Teil des Bewertungsgesetzes ausmacht und das Bewertungsgesetz geradezu zu einem Gesetz des Einheitswertverfahrens macht: "Für die Bewertung .... kennt das Bewertungsgesetz zwei zentrale Wertbegriffe und ein Wertermittlungsverfahren: Den Begriff des 'gemeinen Wertes', ... den Begriff des 'Teilwerts' .... und das Verfahren der 'Einheitsbewertung'".

++ Inhalt der Vermögensarten:

a) das sonstige Vermögen kann auch Inhalt des Grund-, Betriebs- sowie des land- und forstwirtschaftlichen Vermögens sein;

b) zum Betriebsvermögen gehört auch das der Ausübung eines freien Berufes dienende Vermögen;

c) zu den Begriffen Grundvermögen, Grundbesitz und Grundstücke (s. K. Tipke 1981, S. 355; G. Rose 1982b, S. 61 f.): "Grundbesitz" ist der Oberbegriff; er umfaBt land- und forstwirtschaftliche Betriebe, Betriebsgrundstücke und Grundvermögen (= Privatgrundstücke). Zum "Grundvermögen" gehört nur solcher Grundbesitz, der weder land- und forstwirtschaftlicher Betrieb noch Betriebsgrundstück ist. Ein "Grundstück" ist entweder Betriebsgrundstück (und gehört dann als eine "wirtschaftliche Untereinheit" zum Betriebsvermögen) oder ein Privatgrundstück (und gehört dann in die wirtschaftliche Einheit des Grundvermögens).

+++ Inhalt und Anwendung des Gemeinen Wertes:

Der Gemeine Wert ist der objektiv am Markt erzielbare EinzelveräuBerungspreis. Für die wenigsten Güter ist er überhaupt feststellbar. Daher greift man zu Schätzverfahren. Für ganze Unternehmungen ist ein solcher EinzelveräuBerungspreis ungeeignet, weshalb man den Begriff des Teilwertes entwickelte.

Zur Entwicklung des Inhalts des Gemeinen Werts siehe K. Vogel 1979, S. 28 ff. Zur Rolle des Gemeinen Wertes aus ökonomischer Sicht siehe K.-H. Hansmeyer 1981 , S. 733 - allerdings mit vorwiegendem Bezug zur Grundsteuer. 
betrifft, die sich als eine Veränderung des Nettoertrages darstellt - nachteilig sein. Inwieweit gerade dieser Tatbestand mit distributionspolitischen zielen verbunden ist, zelgt das Einheitswertverfahren in der Landwirtschaft besonders deutlich. Man kann hier von allokativen Wirkungen (nachteiliger Art) mit distributiven Effekten (vorteilhafter Art, aber nur für die betroffene Gruppe der Landwirte) sprechen. Geht man umgekehrt von den distributionspolitischen Zielvorstellungen z.B. Im Wohnungsbau aus und konstatiert die steuersparende Wirkung der Unterbewertung des Grundvermögens für Hauselgentümer oder - tberwälzung unterstellt fur Mieter, so liegen die allokativ nachteiligen wirkungen in den für die Investitionspolitik nicht exakt wiedergegebenen Werten und Erträgen des Grundvermögens.

II. Steuerliche Ungleichbehandlungsprobleme ergeben sich nicht für jene Vermögensarten, die gleichermaBen gegenwartsnah bewertet werden. Dies ist bei solchen Vermögensgegenständen der Fall, deren Wert (Gemeiner Wert oder seine Unterarten) sich aufgrund marktlichen Austausches einstellt. ${ }^{2)}$ Die Möglichkeit zur steuerlichen Ungleichbehandlung taucht aber immer dann auf, wenn die Wertermittlung eigens konstruierten Verfahren (Einheitsbewertung) überantwortet wird. Dann kann es zur Ungleichbehandlung gegenüber den Vermögensarten aus der gegenwartsnahen Bewertung wie auch $\mathrm{zu}$ ungleichbehandlungen solcher Vermögensarten untereinander kommen, die jeweils eigenen Verfahren der Bewertung unterworfen werden.

2) Stellen sich unterschiedliche Werte aufgrund inflationärer Entwicklungen ein, ist das nicht auf die steuerlichen MaBnahmen zurückzuführen; allerdings soll - worauf unten noch hingewiesen werden wird - die steuerpolitik die inflationsbedingten Wertdifferenzen nicht noch unterstreichen oder ihre Einebnung unterschiedlich betreiben.

Fortsetzung der Legende zu Übersicht 8.2

$++++)$ Inhalt und Anwendung des Teilwerts:

Der Teilwert ist der Teil eines fiktiven GesamtveräuBerungswertes eines Betriebes bei dessen unterstellter Fortführung; G. Rose 1982b, S. 37: "anteiliger Betriebswert". Obwohl er - wie der Gemeine wert - einen objektiv feststellbaren Marktpreis realisieren will (G. Wöhe 1978, S. 443), widerspricht er dem Gemeinen Wert, weil er kein EinzelveräuBerungspreis ist und zudem von den individuellen Einschätzungen des Erwerbers eines Betriebes abhāngt. Weil ein solcher Wert in der Praxis kaum feststellbar ist und eine Fiktion bleiben muB (G. Wöhe 1978, S. 440 ff., insbes. S. 445), hilft sich die Praxis mit "Teilwertvermutungen" (G. Rose 1982b, S. 38). 
Dieses sind also die $v$ e $\mathrm{f}$ a $\mathrm{h}$ e $\mathrm{n} s-\mathrm{u} \mathrm{d}$ we $\mathrm{r} t$ -

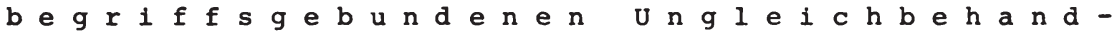
I u n g e $\mathrm{n}$ (siehe tbersicht 8.2: Punkte d bis k). Daneben spielen bestimmte steuerpolitische MaBnahmen, die sich direkt auf die Vermögensarten erstrecken, eine Rolle für die Ungleichbehandlung, sei es, daB man inflationäre Entwicklungen in der Bewertung nicht oder in einzelnen Vermögensarten unterschiedlich berücksichtigt, sei es, daB man versucht, je Vermögensart eigene "Ertragsfähigkeiten" zu postulieren, die eine unterschiedliche Belastung rechtfertigen würden (Ubersicht 8.2: Punkte a bis $c$ ). Diese Ungleichbehandlungen lassen sich als die $v$ e $r$ ö g e $n$ a $r t g$ e b u d e $\mathrm{n}$ e $\mathrm{n}$ bezeichnen. Sie sollen zuerst behandelt werden.

1. a) Ganz grundsätzlich muB zunächst entschieden werden, ob man

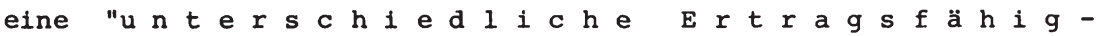
$k$ e $i t$ " von Vermögensarten (Ubersicht 8.2: a) bereits in der Bewertung bzw. erst in der Besteuerung berücksichtigen will, oder ob man überhaupt die Wertermittlung und -besteuerung völlig losgelöst von der etwa unterschledlichen Ertragsfähigkeit durchführen und allein auf den erzielten Ertrag bzw. das sich daraus ergebende Einkommen abstellen will. ${ }^{3)}$ Einen entschiedenen standpunkt nimmt K. Tipke" ${ }^{4)}$ ein: "Da die Ertragskraft land- und forstwirtschaftlichen Vermögens und Grundvermögens hinter der Ertragskraft von gewerblichem Vermögen zurückzubleiben pflegt, die Ertragswerte von den gemeinen Werten erheblich abweichen, ist es insoweit nicht nur zulässig, sondern geboten, Ertragswerte zu bestimmen, die hinter den gemeinen Werten zurückbleiben."

3) Dann würden Vermögensgegenstände mit höherer Ertragsfähigkeit (streng genommen sind es bereits höhere tatsächliche Erträge) $\mathrm{zu}$ höheren Einkommen führen und einen höheren Steuersatz auslösen.

4) 1981 , S. 354, mit dem Hinweis auf die gleiche Auffassung bei K. Vogel (1979, S. $28 \mathrm{ff.})$, jedoch auf die gegengesetzte bei J. Pelka (1975, S. 206, 209 ff.): Tipke fährt fort: "Da die Ertragskraft die Bemessungsgrundlage betrifft, nicht den Steuersatz, ist es folgerichtig (jedenfalls zulässig), unterschiedliche Ertragskraft durch unterschiedliche Bewertung (statt durch unterschiedliche Steuersätze) auszudrücken." 
Dem soll hier deutlich widersprochen werden; dies nicht nur, weil der gegenwartsnahe Gemeine Wert der allgemeine Bewertungsgrundsatz ist, ${ }^{5)}$ sondern aus ökonomischen Gründen: Da die einzelnen Vermögens- (und Kapital-)arten in einer Wirtschaft mit unterschiedlichen Erwartungshorizonten, Plänen und Märkten stets auch unterschiedlich hohe Erträge haben werden, geht es zunächst darum, diese Unterschiede steuerlich weder mutwillig einzuebnen noch zu vergröbern. Die Bewertungsverfahrenstechnik darf Unterschiede in der Ertragskraft des Kapitals und Vermögens nicht aufheben, soll

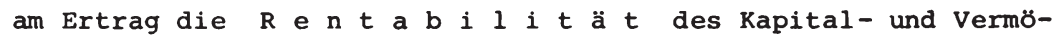
genseinsatzes noch abgelesen werden können. Dies ist ein a 1 $1 \circ k$ a $t i \circ \mathrm{n}$ theoretisches und -politisches $\mathrm{g} r \mathrm{u}$ d e r $f \circ r d e r n i s$ der Bewertung. Davon $z u$ trennen ist die weitere Frage der steuerlichen Belastung: Hier mögen allokationsund distributionspolitische ziele dazu veranlassen, mittels eines offen ausgewiesenen, nicht in die Bewertungstechnik eingearbeiteten Abschlags oder anhand von MeBzahlen die Bemessungsgrundlage zu kürzen, sofern nicht tarifäre MaBnahmen ergriffen werden. $A b-$ schläge und Steuersatzprivilegien hätten den Vorzug, daB sie die politischen Vorstellungen uber die personell unterschiedliche Leistungsfähigkeit unmittelbar zum Ausdruck brächten, wohingegen "Manipulationen" in den Bewertungsverfahren den Anschein erwecken, als würde man den Vermögensarten eine unterschiedliche "Leistungsfähigkeit" imputieren. ${ }^{6)}$

5) Siehe J. Pelka 1975, S. 209, unter Hinweis auf ein Urteil des BVerfG vom 7.5.1968 (BVerf GE 23,242, 256), das grundsätzlich bei einem Abweichen von diesem Grundsatz einen Versto $B$ gegen den Gleichheitssatz folgert.

6) So argumentiert F. Neumark $(1970$, S. 168), der keine Differentiation innerhalb der Vermögensteuer nach Vermögensarten zulassen will. - H. Fecher dagegen (1979, S. 477) scheint anderer Auffassung $z u$ sein, wenn er sagt: "Danach gilt, dab unterschiedliche Vermögensarten steuerlich verschieden behandelt werden müssen. Dies ist nicht, wie bisweilen behauptet, Folge der Verschiedenheit der auf die einzelnen Vermögensarten angewendeten Bewertungsmethoden." Wenn er meint, daB die andere "steuerliche Behandlung" sich auf etwas anderes erstrecken soll als auf die Wertermittlungsmethoden, wäre ihm zuzustimmen; es sollte auch nicht übersehen werden, daB Fecher seine Feststellung im Zusammenhang mit der Bewertung des Arbeitsvermögens trifft, die ja ganz besondere Probleme aufwirft. 
b) Ein weiteres "Vermögensartenproblem" liegt darin, daB sich die $K$ a u $\mathrm{f} k \mathrm{r}$ a $t$ in den Vermögensarten unterschiedlich stabil erhält. Steuerliche Maßnahmen zur Erhaltung der im Vermögen repräsentierten Kaufkraft (Ubersicht 8.2 : b) kennt die gegenwärtige Vermögensbesteuerung nicht, weder als Besteuerung der Vermögenssubstanz noch als Besteuerung des Vermögensertrags (siehe $\$ 24)$. Infolgedessen ist hier lediglich zu einer eher "indirekten" steuerlichen Ungleichbehandlung Stellung $z u$ nehmen. Grundsätzlich liebe sich eine Ungleichbehandlung in der Kaufkrafterhaltung durch den steuerlichen Ausgleich der Geldentwertung einerseits im Verhältnis von Unternehmern $z u$ Nichtunternehmern, andererseits im Verhältnis der Vermögensarten untereinander denken. Das erstere Problem stellt sich gegenwärtig nicht. ${ }^{7)}$

Demgegenüber läbt sich jedoch eine indirekte steuerliche Ungleichbehandlung im Verhältnis des Grundvermögens $\mathrm{zu}$ anderen Vermögensarten feststellen. So ist zwar die Steigerung der Verkehrswerte des Grundvermögens als Folge der Geldentwertung nicht steuerlich induziert, jedoch wird der Wertunterschied insoweit ein steuerliches Ungleichbehandlungsproblem, als das Einheitswertverfahren die Grundvermögenswerte künstlich niedrig hält. Andererseits werden inflationsbedingte Vermögenswertsteigerungen (wie im übrigen auch Scheingewinne und -überschüsse), die nicht einheitswertabhängig sind, in vollem MaBe besteuert. Dies gilt insbesondere für Geldvermögen und Aktien (R. Nöll v.d. Nahmer 1980). Dadurch gerät im Ergebnis das für die Besteuerung generell geltende Mark-gleichMark-Prinzip punktuell für das Grundvermögen auBer Kraft, und die allokativen Ausgangsbedingungen werden verfälscht.

7) Gleichwohl ist hier anzumerken, daB eine steuerliche Kaufkrafterhaltung im Unternehmensbereich notwendigerweise eine ebensolche im nichtunternehmerischen Bereich nach sich ziehen muB (G. Wöhe 1978, S. 405), da sowohl unternehmerisches wie privates Vermögen (und Einkommen) Kaufkraft repräsentiert, das weder aus allokativen noch aus distributiven Motiven unterschiedlich zu behandeln ist. Wollte man z.B. Kaufkraftkorrekturen nur für das unternehmerische Vermögen (etwa beim Vermögensvergleich, und zwar durch Substanzerhaltungsrücklagen oder durch Abschreibungen vom Wiederbeschaffungspreis) zulassen, käme das "nur solchen Einkunftsarten zugute, bei denen ein 'Vermögen' im materiellen Sinne vorhanden 1st"; Korrekturen würden die GleichmäBigkeit der Besteuerung noch mehr als gegenwärtig verletzen, F.W. Wagner $1976 \mathrm{~b}$, S. 234 . 
c) Vermögensartenspezifische Ungleichbehandlungen sind schlieblich denkbar, wenn es in einigen Vermögensarten $\mathrm{B}$ e $\mathrm{f}$ r e $1 \mathrm{u} \mathrm{n}$ $g$ e $n$ gibt, in anderen nicht. Von allokativen wirkungen wäre $z u$ sprechen, wenn einzelne Vermögensarten völlig, oder wenn innerhalb der Arten einige Wirtschaftszweige oder -regionen befreit wären. Distributiv motivierte Befreiungen von der Vermögensteuer sind dann Ungleichbehandlungen, wenn sie zu einer für den Steuerpflichtigen ungleichen Erfassung von Vermögensgegenständen fuhrt, die eine ungleiche steuertraglast angesichts gleicher, im Vermögensbestand repräsentierter Leistungsfählgkeit führt (Ubersicht 8.2: c). Allokativ motivierte Befreiungen kennt das deutsche Steuerrecht nicht; distributiv motivierte lieben sich gemäB \$ 21 IV (Teil- und Gesamtausschlússe aus dem Totalvermögen) unter dem Aspekt des Allgemeinheitspostulats lediglich für das "sonstige Vermögen" feststellen. Diese sind daraufhin zu prüfen, inwieweit sie dem Gleichbehandlungskriterium genügen. Allenfalls für den Hausrat ließe sich das elnigermaBen zweifelsfrei angeben, da dieser groBe Wertunterschiede zwischen den Besteuerten ausmachen kann, so daB zu vermuten ist, gerade die oberen Einkommensschichten könnten gröBere Werte der Besteuerung legal vorenthalten. ${ }^{8)}$

$\mathrm{Ob}$ in der Befreiung der mannigfaltigen Rentenansprüche von der Vermögensteuer Ungleichbehandlungen liegen, muB davon abhängig gemacht werden, inwieweit uberhaupt eine objektive Bewertbarkeit und zudem die persönliche verfügbarkeit vorliegen (siehe $\$ 10$ IV). Für die Sozialversicherungsrenten und die Ansprüche an Witwen-, Waisen- und anderen Kassen und für viele andere Ansprüche ist jedenfalls die Verfügbarkeit (mit dem ziel der Beleihung, VeräuBerung usw.) nicht gegeben, so daB der Vermögenscharakter $z u$ verneinen ist. Ungleichbehandlungen wären nur dann festzustellen, wenn ganz generell Gegenstände, deren ungleiche Besteuerung $z u$ prüfen ist, den gleichen Grad an Vermögenseigenschaft aufweisen.

8) Die Hausratbefreiung ist im Zusammenhang mit den Freigrenzen (in Höhe von DM 10.000) für Schmuck, Edelmetallgegenstände und bestimmte "Luxusgegenstände" zu sehen, wobei aber die letzteren ein Abgrenzungsproblem bergen (K. Tipke 1981, S. 361). Auch die Freigrenze (in Höhe von DM 20.000) für Kunstgegenstände und Sammiungen gehört in diesen zusammenhang, wobei glelchzeit1g zu erwähnen ist, daB auch das Erbschaftsteuergesetz einen Freibetrag für diese Gegenstände (in Höhe von DM 10.000 bis 40.000 je nach Verwandtschaftsgrad) enthält. 


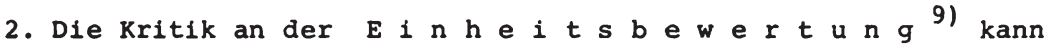
wie folgt systematisiert werden:

a) Zunächst ist festzustellen, daB die Einheitsbewertung, die für die Vermögensarten "land- und forstwirtschaftliches Vermögen", "Grundvermögen" und "Betriebsvermögen" durchzuführen ist, kraft ihrer inneren systematik und der verschlungenen Verfahrenswege nicht für alle Vermögensarten $\mathrm{zu}$ jenen gegenwartsnahen Werten kommt, die dem Bewertungsgrundsatz des Gemeinen Wertes entsprechen würden. So ist offensichtlich, daB Verkehrswerte in erster Linie für das "sonstige Vermögen" und aus dem Kreise der Einheitswert-Vermögensarten allenfalls für das Betriebsvermögen (nicht unbedingt für die bebauten Betriebsgrundstücke) erreicht werden. Es kommt hinzu, daB für die Einheitswerte des Grundvermögens und des land- und fortwirtschaftlichen Vermögens nicht nur zu geringe, sondern untereinander unterschiedlich niedrige Einheitswerte ermittelt werden, die überdies noch nicht einmal für alle einheitswertabhängigen Steuerarten gleichmäBig gelten. Diese Phänomene der allgemeinen und differenzierten Unterbewertung gegenüber anderen Vermögensarten nennen wir das "S y $s$ e $m-u n d$ Verfahrensproble m" der Einheitsbewertung (d).

Daneben stehen jene Phänomene der Ungleichbehandlung, die mit den im Einheitswertverfahren verwendeten Wertbegriffen zusammenhängen; dieses Problemfeld nennen wir die "W e $r$ b e g $r$ i f $f$ p $r \circ b l$ e $m a t i k "$ der Einheitsbewertung. In ihr unterscheiden wir Ertragswertprobleme (im Zusammenhang mit dem Grundvermögen; Ubersicht 8.2: e und f), Sachwertprobleme (im Zusammenhang mit dem Grund- und dem Betriebsvermögen; Ubersicht 8.2: $\mathrm{g}, \mathrm{h}$ und i) und die speziellen Einheitswertprobleme des land- und forstwirtschaftlichen Vermögens (Ubersicht 8.2: j und $k$ ).

b) Eine Ungleichbehandlung wird in der Einheitsbewertung immer in zweierlei Weise sichtbar; zum einen darin, daß für vergleichbare Vermögensarten unterschiedlich hohe Einheitswerte gefunden

9) Die Kritik ist hier nicht in den Einzelheiten nachzuvollziehen; siehe hierzu die $\$ \$ 19$ IT 2 . und 26 II 5 sowie die dort erwähnte Literatur. Vorliegend geht es uns um eine systematik der kritischen Argumente zur Einheitsbewertung und ihres Gehaltes an Ungleichbehandlung. 
werden (dies läBt sich als das "W e $r$ n $i v$ e a p r o b l e m" der Einheitsbewertung bezeichnen); zum anderen darin, daB die Verfahren - oftmals unvermeidlicherweise - so pauschal konstruiert sind, dab unterschiedliche Ertragsfähigkeiten (oder die Werte schlechthin) gleich behandelt werden (dies läBt sich das "we $r t p a u s c h$ a 1 i e r u n s p r o b 1 e m" der Einheitsbewertung nennen). Wie sich zeigen wird, haben wir es unter dem Stichwort "Systematik und Verfahren" (Ubersicht 8.2: d) ausschlieblich mit dem Wertniveauproblem $z u$ tun. Hier geht es nämlich um die schlichte Tatsache, daB die Einheitswerte in jedem Falle $\mathrm{zu}$ einer Abweichung vom Niveau des Gemeinen Werts (VeräuBerungspreises) führt. Demgegenüber enthalten die im Einheitswertverfahren verwendeten Wertbegriffe, also der Ertragswert, der Sachwert und der Vergleichswert (als ein besonderer Ertragswert) zumeist sowohl Niveau- als auch Pauschalierungsprobleme.

Die generelle Unterbewertung als $\mathrm{N} i \mathrm{v}$ e a $\mathrm{u}$ p $\mathrm{r}$ b $1 \mathrm{e} \mathrm{m}$ ruft in erster Linie a $1 \mathrm{l} \circ \mathrm{k}$ a $i \mathrm{v}$ nachteilige Wirkungen hervor, etwa mit Blick auf die bereits erwähnten Entscheidungsbedingungen für Investitionen und Vermögensanlagen in bestimmten Wirtschaftszweigen und Vermögensarten (Grundvermögen versus Betriebsvermögen; landwirtschaftliches Vermögen versus gewerbliches Betriebsvermögen usw.). Distributive Effekte entstehen für die von den Allokationsvorteilen betroffenen Gruppen unmittelbar.

So sind zunächst mit Allokationswirkungen die folgenden Tatbestände des Einheitswertverfahrens und der Wertbegriffsproblematik verbunden:

- das allgemeine Einheitswertniveauproblem (Ubersicht 8.2: d);

- die differenzierte Ungleichbehandlung im Grundvermögen und im land- und fortwirtschaftlichen vermögen durch das Sollertragsproblem (e);

- die gruppenspezifischen Subventionierungen im öffentlich geförderten Wohnungsbau (f);

- die einheitswertsenkende Wirkung der Anwendung von Wertzahlen im Sachwertverfahren des Grundvermögens (h);

- die einheitswertnivellierende Wirkung der Anwendung von Branchendurchschnittsverfahren für bestimmte Betriebsgrundstücke (i) und

- die einheitswertnivellierende Wirkung der Vergleichszahlen wegen der Nichtbeachtung betriebs-individueller Unterschiede im landund forstwirtschaftlichen Vermögen $(j)$. 
Ungleichbehandlungen infolge der $P$ a $u s c h$ a $l i$ e $\mathrm{u} n \mathrm{~g}$ e $\mathrm{n}$ dürften sich - mit Blick auf die sich im Ertrag bzw. Einkommen und im Vermogenswert zeigende ungleiche Leistungsfähigkeit bel dennoch gleicher Besteuerung - zunächst als ein d is $t r i$ b u $t$ i v e s Problem erweisen. Allokative Effekte entstehen dann im Gefolge der distributionspolitisch motivierten Entscheidungen.

So sind zunächst mit Distributionswirkungen die folgenden Tatbestände der Einheitsbewertung und der Wertbegriffsproblematik verbunden:

- die Sollerträge im Ertragswertverfahren bei Mietwohngrundstücken (Ubersicht 8.2: e);

- die Kostenpauschalierung beim Sachwertverfahren für Ein- und Zweifamilienhäuser $(\mathrm{g})$;

- die einheitswertsenkende Wirkung des Vergleichswertverfahrens (j) und der Nichtanwendung der pauschalen 40 ofigen Erhöhung der Einheitswerte $(\mathrm{k})$ in der Land- und Forstwirtschaft und

- die Ungleichbehandlung bestimmter Gruppen von Vermögensanlegern durch das Schachtelprivileg (3.).

c) Die Ungleichbehandlung, die das " $s$ y $t$ e $m$ - und $v$ e $r$ f a h r e n p r o b 1 e m" der Einheitsbewertung (tbersicht 8.2: d) mit sich bringt, liegt in der konstruktion und der fehlenden Anpassungsfähigkeit des Verfahrens selbst begründet. ${ }^{10}$ ) Wenn die Hauptfeststellungszeitpunkte keine gegenwartsnahen Werte erbringen und ihre Wiederholungsrhythmen für die vermögensarten unterschiedlich sind, liegt darin eine Ungleichbehandlung. ${ }^{11)}$ Wenn für die Einheitswertermittlung des Grundvermögens und der Betriebsgrundstücke generell von den Wertverhältnissen am 1.1 .1964 ausgegangen wird und - um Verwaltungsaufwand $\mathrm{zu}$ vermeiden - nach $\S 121 \mathrm{a}$ BewG heute ein pauschaler zuschlag von 40 \% auf die 64 er Elnheitswerte angesetzt wird, so ist damit eine Verzerrung der Werte für den Grundbesitz in dreifacher Hinsicht erreicht: ${ }^{12}$ )

10) Nicht nur die Verwaltungsaufwendigkeit, auch die Kompliziertheit der Bewertung spielen eine Rolle.

11) Für Gewerbebetriebe wird der Einheitswert alle drei Jahre festgestellt, für den Grundbesitz alle sechs Jahre. Die Zeitnähe der Werte kann im ersteren Fall gegeben sein, im letzteren Fall nicht mehr.

12) Eine vierte Verzerrung ist steuersystematischer Art: der pauschale Zuschlag von 40 o wird für die einheitswertabhängigen Steuerarten mit Ausnahme der Grundsteuer angesetzt; darin

(Forts. siehe folgende Seite) 
- trotz des Zuschlags von 40 \& auf die 64er Einheitswerte werden gegenwartsnahe Werte nicht erreicht; ${ }^{13}$ ) dies galt schon bei der Einführung des Zuschlags erstmals für das Jahr 1974 (J. Pelka 1975, S. 216);

- die land- und forstwirtschaftlichen Einheitswerte machen wegen des "vergleichenden Verfahrens" und der Nichterhebung des $\mathrm{Zu}$ schlags von $40 \%$ heute nur ungefähr 1 bis $10 \%$ der Verkehrswerte aus (K.-H. Hansmeyer 1981 , S. 734); dies bedeutet erstens ein enormes Abweichen von den Gegenwartswerten überhaupt und zweitens eine Ungleichbehandlung gegenüber den anderen Grundbesitzarten;

- die pauschale Anwendung eines Zuschlags auf die nichtlandwirtschaftlichen Grundbesitzarten widerspricht nicht nur dem Prinzip der Einzelbewertung, sondern berücksichtigt nicht, daB die Wertentwicklung innerhalb der Grundstücksarten unterschiedlich verläuft. ${ }^{13)}$

Das System- und Verfahrensproblem der Einheitsbewertung liegt also sowohl in der generellen als auch in der spezifischen "Unterbewertung" qua Wertermittlungsmethode und zuschlagsanwendung; es fuhrt $z u$ einer differenzierten Ungleichbehandlung im Grundbesitz und gegenüber anderen Vermögensarten (Wöhe 1988,S.406f.; 1992, S. 508) und ist damit "der schärfste verstoß gegen die Gleichmäßigkeit der Besteuerung" (D. Schneider 1978b, S. 206). Steuersystematisch verzerrende Auswirkungen werden dadurch erreicht, daB die Zuschlagsregelung nicht für sämtliche einheitswertabhängigen steuerarten angewendet wird und $d a B$ für die Land- und Forstwirtschaft wie auch für das Zurechnungseinkommen der Nutzer von Wohnungen im eigenen Hause die so gefundenen Einheitswerte von

Forts. Fn. 12:

liegt auBer einer steuersystematischen Uneinheltlichkeit eine Bevorzugung der Land- und Forstwirtschaft, die die in der Einkommens- und Vermögensbesteuerung erreichte noch zusätzlich in der Ertragsbesteuerung erweitert. Uberdies ist sowohl für die Land- und Forstwirtschaft als auch für die Nutzer der Wohnung im eigenen Hause der Einheitswert auch für die Einkommensbesteuerung maBgeblich.

13) Nach K. Tipke 1981, S. 363 (unter Hinweis auf Troll 1980/81 und 1978/79 sowie Strunk 1980, ferner Pelka 1975) betrugen schon 1977 die Einheitswerte + 40 \& Zuschlag je nach Grundstücksart nur noch $\mathrm{zwischen} 20$ und 42 \& des gemeinen Werts. In 1991, S. 465f. erwähnt er den "Gipfel der Falschbewertung" im Einigungsvertrag v. 31.8.1990 mit den Einheitswerten von 1935 ohne Indizierung.

Heinz Hessler and Anneliese Hessler-Otte - 978-3-631-75239-5 
der Vermögensbesteuerung in die Einkommensbesteuerung hinüberwirken und dort das steuerliche Einkommen senken (siehe \$\$ 22 I und 26 II 5.). Während hinter der Bevorzugung des Grundvermögens wohnungspolitische Absichten vermutet werden dürfen, sind es hinter der Bevorzugung des land- und fortwirtschaftlichen Vermögens wohl eher einkommenspolitische.

d) Ein "s $\circ 1$ e r t r a g s p 0 b 1 e m" (Ubersicht 8.2: e) ergibt sich zunächst bei der Ertragswertermittlung. Der Gesamtwert eines bebauten Grundstücks errechnet sich im wesentlichen aus dem Produkt von "Jahresrohmiete" und "Vervielfältiger". Wenn wir das Niveauproblem vom Pauschalierungsproblem unterscheiden, so liegt ersteres sowohl in der Jahresrohmiete als auch im Vervielfältiger. Bei der Miete geht der Gesetzgeber von der Kostenmiete aus. Diese ist für ein älteres Gebäude wegen der geringeren Anschaffungskosten erheblich niedriger als für ein neues; "folglich sind die aufgrund dieser Mieten berechneten Einheitswerte untereinander ungleich, ohne daB dies, etwa wegen des Alters der Gebäude, gerechtfertigt wäre" (J. Pelka 1975, S. 220). Wenn sich aufgrund dessen eine Anlagevorliebe für ältere Gebäude einstellen sollte, so liegt darin keine allokative, wohl aber eine distributive Wirkung. Auch die Vervielfältiger haben elne Niveauwirkung dadurch, daB sie äuBerst niedrig angesetzt sind. Nach Angaben J. Pelkas (1975, S. 221) belaufen sich die auf dieser Basis berechneten Einheitswerte zum 1.1 .1974 auf etwa $15 \%$ der Verkehrswerte. ${ }^{14)}$

Wie das Niveauproblem, so ist auch das Pauschallerungsproblem sowohl mit der Jahresrohmiete als auch mit den Vervielfältigern verknüpft. Die Pauschalierung stellt sich hier als ein Sollertragsproblem dar. Soweit für die Jahresrohmiete nicht das tatsächlich gezahlte Mietentgelt ( $\$ 78$ I BewG), sondern bei Eigennutzung, bei Nichtnutzung, bei unentgeltlicher tberlassung sowie bei Nachlässen von mehr als 20 \& die "übliche Miete" anhand von Mietspiegeln geschätzt wird, liegt darin eine Sollmiete.

14) In Verbindung mit dem Kostenmietenansatz und den zu niedrigen Vervielfältigern hält J. Pelka, im Gegensatz zu K. Tipke (1981, S. 356), die so gefundenen, zu niedrigen Einheitswerte für verfassungswidrig. Wir haben an anderer stelle dargelegt, daB wir die Begründung Tipkes aus ökonomischen Gründen nicht für überzeugend halten. 
Mietausfälle werden nicht berücksichtigt, so daB sich auch hierin der Sollcharakter zeigt (G. Wöhe 1988, S. 395). Wenn also Steuerpflichtige trotz tatsächlich geringerer Erträge behandelt werden wie jene, die Erträge in der gesetzlich unterstellten Höhe erreicht haben, werden sie im Hinblick auf ihre persönliche Leistungsfähigkeit (nicht im Hinblick auf die Ertragsfähigkeit des Vermögens!) ung̣leich behandelt. Sollmieten dürften bei dieser Konstellation nahezu ausschlieblich distributive Probleme aufwerfen und keine allokativen.

Ebenso weisen die Vervielfältiger Sollelemente auf, da sie pauschalierte Bewirtschaftungskosten und Bodenertragsanteile enthalten. ${ }^{15)}$ Sofern also die tatsächlichen Bewirtschaftungskosten und Bodenertragsanteile von den typisierten und festgeschriebenen ${ }^{16)}$ individuell abweichen und der "schematisierten Reinertragskapitalisierungsmethode" (G. Rose 1982b, S. 64) entsprechen, ergibt sich eine Sollertragsbesteuerung mit den oben beschriebenen Folgen der Ungleichbehandlung.

Eine Ungleichbehandlung liegt ferner im Festhalten bestimmter Jahresrohmieten, die über das für das Einheitswertverfahren typische Niveauproblem hinausgeht: In Art. 2 Abs. 1 Satz 2 BewAndG vom 13.8.1965 wird festgelegt, daB bei öffentlich geförderten Bauten auch nach der Mietfreigabe gem. $\S 15$ des Zweiten Bundesmietengesetzes von 1963 für die Einheitsbewertung weiterhin die preisgebundenen Jahresrohmieten anzusetzen sind. ${ }^{17)}$ Wir bezeichnen

15) D. Schneider 1978b, S. 189; J. Pelka 1975, S. 215. G. Wöhe 1992, S. 563, 564: statt eines "exakten Reinertragsverfahrens" ein "vereinfachtes pauschaliertes Verfahren".

16) Die Vervielfältiger sind in den Anlagen 3-8 zum BewG enthalten und verbindlich; sie sind nach Grundstücksart, Bauausführung, Baujahr und Einwohnerzahl der Belegenheitsgemeinde unterschieden; sie reichen von einem Wert in Höhe von 4,5 (für ein Mietwohngrundstück, Altbau vor dem 1.4.1924 in Holzfachwerk mit Lehmausfachung in einer Gemeinde über 500.000 Einwohner) bis $\mathrm{zu}$ einem Wert in Höhe von 13,5 (für ein Einfamilienhaus als Neubau zwischen dem 1.1.1935 und 20.6.1948 errichtet, in massiver Bauweise, in einer Gemeinde bis 2.000 Einwohner.

17) Nach K. Tipke (1981, S. 356) hat der BFH (BStBl. 78, 446) darin einen Versto $B$ gegen den Gleichheitssatz gesehen und das Bundesverfassungsgericht angerufen. 
dieses zementieren der Rohmiete als eine "spezifische subventionierung" (Übersicht 8.2: f). Subventionierung, weil die Bindung der Jahresrohmiete unmittelbar den Wohnungseigentümern zugute kommt, obwohl doch die Mietfreigabe die Mieter belastet und ein Anheben der Jahresrohmiete für die Vermögensbesteuerung der Vermieter erlaubt hätte. Sofern die Bindung der Jahresrohmiete aber eine allokationspolitisch sinnvolle Verbesserung der Investitionsbedingungen im Wohnungsbau initileren sollte, zeigt sich darin der Subventionscharakter der Maßnahme, zugleich aber auch seine "gruppenspezifische" Auswirkung auf die Vermögenssituation bestimmter Eigentümerkreise. Die Ungleichbehandlung liegt nicht im Kreise der Mleter, deren Miete angehoben wurde, sondern im Kreise der Vermieter. Vermieter, deren Einheitswerte durch die Bindung der Rohmiete niedriger gehalten werden, als das ohnehin schon geschieht, haben solchermaßen einen Vortell gegenüber jenen, deren Einheitswerte nicht die von öffentlich gefördertem Grundvermögen sind. ${ }^{18)}$

e) S a c hwe $r$ t p $\mathrm{r}$ b 1 e m e ergeben sich sowohl für das Grundvermögen als auch für das Betriebsvermögen, für letzteres insoweit, wie die "typischen" Betriebsgrundstücke (Fabrik-, Verwaltungsgebäude und Lagerhallen) berührt sind. Auch im Sachwertverfahren begegnen uns beide Varianten der Ungleichbehandlung, das Wert-Pauschalierungs-Problem und das Wert-Niveau-Problem.

Das Sachwertverfahren schreibt die getrennte Ermittlung für den Bodenwert, ${ }^{19)}$ den Gebäudewert und den Wert der AuBenanlagen vor. Die letzteren beiden werte folgen im wesentlichen glelcher Ermittlungsmethode. Vernachlässigt man hier überflüssige Verfahrensschritte, so zeigt sich das Pauschalierungs- wie auch das Niveauproblem in drei Punkten:

(1) es wird von den $d u r c h s c h n$ i t $t^{\prime} i c h$ e $n$ Anschaffungs- und Herstellungskosten des Jahres 1958 ausgegangen, die auf die Wertverhältnisse des Jahres 1964 (!) umgerechnet werden (§ 85 BewG);

18) In der Wirkung mag diese Subvention auch Transfercharakter haben, nämlich dann, wenn die Vermögensteuerentlastung $z u$ keinen allokativen Veränderungseffekten im Wohnungswesen führt, sondern ausschließlich die persönliche Vermögenssituation des Eigentümers verbessert.

19) Er wird wie für unbebaute Grundstücke ermittelt, also als Gemeiner Wert, allerdings anhand von Richtwerten. 
(2) der Gebäude - N $\circ \mathrm{r}$ m a 1 - Herstellungswert ist ein Durchschnittswert;

(3) die Wertminderung des $\S 86$ BewG wegen Alters des Gebäudes bestimmen sich nach der $g$ e $\mathrm{w}_{\mathrm{o}} \mathrm{h} l i \mathrm{c} h \mathrm{e} \mathrm{n}$ Lebensdauer (von Gebäuden gleicher Art und Nutzung).

Die Umrechnung auf die 1964 er Verhältnisse erfolgt pauschal durch Zuschläge in Höhe von 50 \& für Ein- und Zweifamilienhäuser, in Höhe von 35 \& für alle anderen Gebäude. ${ }^{20)}$ sie wirkt zwar tendenziell werterhöhend, errelcht jedoch heutige Verkehrswerte nicht. Wollte man die Anschaffungs- und Herstellungskosten "durchgăng 19 aktualisieren, so böte sich dafür ein Bauindex ... an. Das Bewertungsverfahren geht diesen einfachen Weg nicht" (K.-H. Hansmeyer 1981 , S. 735). Es will nicht einfach die Wertverhältnisse ubernehmen, sondern auch noch einen EinfluB auf die einzelnen Wertelemente und deren jeweilige Höhen durch Normierung - und sel sie noch so kompliziert - ausuben. Eine solche Postulierung von "Sollwerten durch Kostenpauschalen" (Ubersicht 8.2: g), selbst wenn sie in Richtung einer Annäherung an den Gemeinen wert wirkt, ist eine Ungleichbehandlung insofern, als Werte auBerhalb der Pauschalen ohne EinfluB bleiben. Steuerpflichtige, deren individuelle Gebäudeherstellungswerte oberhalb oder unterhalb des gesetzlichen "Normal"-Wertes liegen, werden einander gleichgestellt. ${ }^{21)}$

Die Anwendung von "Wertzahlen" ( $\$ 90$ BewG) ${ }^{22}$ ) auf den sog. Ausgangswert ( $\$ 83$ BewG: der Sachwert der Gebaude und AuBenanlagen und der Bodenwert) bezweckt die "Angleichung" an den Gemeinen Wert. Diese Anglelchung, ein ganz wesentlicher Schritt des Sachwertverfahrens, ist geelgnet, den Unterschied zwischen diesem Ver-

20) Siehe die Berechnungsbeispiele bei G. Rose 1982b, S. 67 f., G. Wöhe 1992, S. 556 und D. Schneider 1978b, S. 190.

21) J. Pelka (1975, S. 217) hält den Gemeinen Wert, den die Pauschalierungen anstreben, für den korrekten und objektiven: "Wenn ein Steuerpflichtiger aus Ungeschick oder anderen Gründen erhöhte Kosten aufgewendet hat, so wird dadurch der gemeine Wert seines Hauses nicht erhöht". Wir widersprechen mit dem Hinweis, daB das dem Prinzip der Indlvidualbesteuerung nicht gemäB ist. Wir fragen ferner: Wie verhält sich die Gewinnbesteuerung, wenn ein Steuerpflichtiger durch "Ungeschick" eine GewinneinbuBe herbeifuhrt oder durch "Geschick" eine Gewinnmehrung? Sie besteuert den individuellen Ist-Gewinn!

22) Die Wertzahlen liegen zwischen 85 und $50 \&$ des Ausgangswerts, je nach Zweckbestimmung des Grundstücks, nach Einsatz in einem bestimmten Wirtschaftszweig (Allokationsproblem!) und nach GemeindegröBe, festgelegt für die Hauptfeststellung vom 1.1 .1964 . 
fahren und dem Ertragswertverfahren wieder aufzuheben. Denn nunmehr wird der Sachwert pauschaliert um 15 bis $50 \%$ herabgesetzt und der Einheitswert gesenkt (Ubersicht 8.2: h). 23) Wenn wirklich hinter der Angleichung, wie Rössler/Troll/Langer (1981) vermuten, die Hypothese steckt, daß "erfahrungsgemäB ... der gemeine Wert eines Grundstücks im allgemeinen hinter dem Sachwert zurück (bleibt)",24) dann ist mit K.-H. Hansmeyer (1981, S. 735) zu bezweifeln, ob dies in inflationären Phasen realistisch ist. So ist durch die "Angleichung" jegliche Chance des Sachwertverfahrens, das Niveau- und Ungleichbehandlungsproblem in der Einheitsbewertung wenigstens zu einem Teil mildern zu können, vertan. 25)

Die pauschalierende Vorgehensweise, die ein weiteres Ungleichbehandlungsproblem mit sich bringt, zeigt sich insbesondere in der Anwendung der Wertzahlen auf Betriebsgrundstücke, weil hier sog. "Branchendurchschnittszahlen" angewendet werden (Ubersicht 8.2: i). Die durch Probebewertungen und Vergleiche mit Verkaufswerten gefundenen Wertzahlen wirken nivellierend. Zwar enthalten sie ein durchaus beachtenswertes allokatives Element: Ein Grundstück wird um so höher bewertet, je vielseitiger es verwendbar ist, je weniger es auf die Verwendung in nur einem Wirtschaftszweig spezlalisiert ist. Dennoch handelt es sich um eine Bewertung, die auf betriebsindividuelle Verhältnisse keine Rücksicht nimmt. Die Kritik G. Wöhes (1978, S. 729) an den gleichermaBen nivellierend wirkenden "Nutzungsziffern" des ehemaligen Weil'schen Verfahrens bleibt also erhalten: Es kann "zu einer ungleichmäBigen steuerlichen Belastung kommen, da die Besteuerung den tatsächlichen wirtschaftlichen Verhältnissen nicht genügend Rechnung trägt."26)

23) Wöhe 1988 , S. 415: dennoch brachte es bei der letzten Einheitswert-Hauptfeststeilung genauere und gleichmäBigere Bewertungsergebnisse als das Ertragswertverfahren.

"DaB der Gesetzgeber erst ein besonderes Sachwertverfahren anwendet, um dann durch Kürzungen möglichst doch wieder auf die Ergebnisse des sonst üblichen Einheitswertverfahrens $\mathrm{zu}$ kommen, kennzeichnet wieder einmal die tiefe Weisheit unserer Steuergesetzgebung" (D. Schneider 1978b, S. 190).

24) Dieser Satz enthält keine situationsbezogene Einschränkung!

25) J. Pelka (1975, S. 217) kommt $z$ u der Feststellung, daB die nach dem Sachwertverfahren ermittelten Grundstückseinheitswerte ebenso falsch sind wie die nach dem Ertragswertverfahren ermittelten; "sie sind rechtswidrig."

26) "Selbst in Zeiten höchster Konjunkturlage wird der Beschäftigungsgrad der einzelnen Betriebe eines Wirtschaftszweiges un-

(Forts. siehe folgende seite) 
f) Probleme der Ungleichbehandlung durch Pauschalierung und insbesondere durch eine äuBerst wirksame Niveausenkung ergeben sich gerade für das land- und fortstwirtschaftliche Vermögen. DaB das hier nach $\S 37-41$ Bewg anzuwendende "ve $r \mathrm{~g} l$ e $i \mathrm{ch}$ e $\mathrm{n} d \mathrm{e}$ $\mathrm{V}$ e r f a h $\mathrm{e} n$ " (Ubersicht 8.2: j) ganz generell zu extrem niedrigen Einheitswerten führt, wurde oben bereits im Rahmen der Gewinnermittlungsmethoden ausgeführt ( $\$ 26$ II 5: Durchschnittssatzbesteuerung). Für die Vermögensbesteuerung ist nunmehr festzustellen, daB nicht einmal für die nicht nach Durchschnittssätzen besteuerten Land- und Forstwirte der Ertragswert, der ja nach dem Bewertungsgrundsatz des $\S 36$ II BewG allgemein gelten und sich aus dem 18-fachen des Reinertrages ergeben soll, aus den betrieblichen Aufzeichnungen entnommen wird, was ja möglich wäre. Diesen einfachen weg geht das Gesetz nicht. ${ }^{27)}$ Es konstruiert vielmehr eben jenes "vergleichende Verfahren", das in "seiner Verworrenheit kaum mehr $\mathrm{zu}$ überbieten ist" (J. Pelka 1975, S. 210). Ungleichbehandlungen sind in ihm konstruktiv angelegt.

Zum Niveauproblem: Unterschiede in der Ertragsfähigkeit sollen durch Vergleichszahlen ausgedrückt werden, die dem Verhältnis der betriebsindividuellen Ertragsfähigkeit $z u$ der von sog. Hauptbewertungsstützpunkten entsprechen; aber die den Vergleichszahlen (§ 38 BewG) zugrundeliegenden Bodenschätzungen stammen aus dem Jahr 1934, wurden nie überprüft und gelten noch heute (J. Pelka 1975, S. 212 f.).

Ferner: Die Ertragswerte je Nutzungsart sind in $\S 40$ BewG festgeschrieben; doch die vom sog. Bewertungsbeirat ermittelten Hektarwerte wurden auf Vorschlag des Ernährungsausschusses des Bundestages vom Gesetzgeber um mehr als die Hälfte gekürzt (J. Pelka 1975, S. 214).28)

Forts. Fn. 26 : terschiedlich hoch sein, auch wenn im Durchschnitt sich eine Vollbeschäftigung für die betreffenden Branchen errechnet." G. Wöhe ebda.

27) J. Pelka 1975, S. 210: "Die deutsche Landwirtschaft hat es seit jeher verstanden, den Eindruck zu erwecken, als sei die Anfertigung von Aufzeichnungen etwas schier unmögliches."

28) D. Schneider 1978b, S. 187: "Der FinanzausschuB des Bundestages fragte damals die Bundesregierung, ob die Halbierung mit GleichmäBigkeit der Besteuerung $z u$ vereinbaren sei. Die Bundesregierung meinte, den Anforderungen des Gleichheitsgrundsatzes sei genügt, 'wenn die Motive einer Begünstigung ver- 
Zum Pauschalierungsproblem: Die betriebsindividuellen wirtschaftlichen Verhältnisse können sich seit der Bodenwertschätzung von 1934 zwischenbetrieblich völlig verändert haben, so daB die Nichtbeachtung etwa der Modernisierung durch die Ausdehnung des Maschinenparks eine Ungleichbehandlung bedeutet (G. Wöhe 1992, S. 606).

Ferner: Nicht die tatsächlichen betriebsindividuellen wirtschaftlichen Verhaltnisse werden ermittelt, sondern allenfalls die der Bewertungsstützpunkte ( $\S 39$ BewG); diese gehen in die ErtragsmeBzahlen ein, nicht die individuellen. ${ }^{29)}$ tberdies ist die Bodenqualität, wenn auch der wichtigste, so doch nur e 1 n Faktor, andere sind die Arbeitskraft und die maschinelle Ausstattung; diese finden keinen Ausdruck im vergleichenden Verfahren (G. Wöhe 1992, S. 607). Es handelt sich insowelt auch hier um eine Sollbesteuerung mit allen Nachtellen der Ungleichbehandlung zwischen dem Tüchtigen und weniger Tüchtigen, da nur der durchschnittlich erzielbare Ertrag zur Grundlage der Besteuerung gemacht wird.

Zu dem hier geschilderten Niveauproblem tritt hinzu, daB es in der Besteuerung der Land- und Forstwirtschaft zu einer "zweifachen Unterbewertung des Einheitswerts" (Ubersicht 8.2: k) kommt: Sorgt das "vergleichende Verfahren" ohnehin schon für elne markante Unterbewertung, so bleiben die landwirtschaftlichen Einheitswerte selbst im Rahmen der Vermögensbesteuerung (also nicht nur bel der Grundsteuer und anderen Steuerarten) von der in $\S 121 \mathrm{a}$ BewG vorgeschriebenen Erhöhung der 1964 er Elnheitswerte um pauschal $40 \%$ verschont. ${ }^{30}$ ) Mit der Bemessungsgrundlage hat sich auch

Forts. Fn. 28: nünftig, d.h. sachdienlich und nicht willkürlich seien. Dies treffe im vorllegenden Fall zu.' ... (Bundestagsdrucksache IV/3508 vom 20.5.1965, S. 4 / Schriftlicher Bericht des Finanzausschusses)" . Schneider fährt unter Hinwels auf den Gleichheitsartikel des GG fort: 'Alle Menschen sind vor dem Gesetz gleich' ... "heiBt doch nicht: Alle Landwirte seien in etwa gleicher Weise $\mathrm{zu}$ begünstigen ..."!

29) "Da der Steuerpflichtige aber keinen EinfluB darauf hat, welcher Vergleichsbetrieb herangezogen wird, ist der nach diesem Verfahren ermittelte Wert weitgehend zufällig", J. Pelka 1975, S. 220 .

"Für die Land- und Forstwirtschaft ... bleiben die Einheitswer-

30) te 1964 unverändert als Bemessungsgrundlage bestehen. Diese unterschiedliche Regelung ist notwendig, weil die Ertragsentwicklung der Landwirtschaft eine Indexierung nicht rechtfertigt." Bundestagsdrucksache VI/3418 vom 4.5.1972, S. $49 \mathrm{f}$. 
die Steuerreformkommission 1971 zwar ausführlich befaBt, aber wie D. Schneider (1978b, S. 207) vermutet - nicht unter dem Gleichbehandlungsaspekt, denn "sonst hätte sie nicht im wesentlichen für die Beibehaltung des gegenwärtigen Rechts sprechen können".

3. Letztlich ist Ungleichbehandlung noch mit der "z u o r d $n$ u $n g "$ von Vermögen an eine juristische Person gebunden. Problematisch wird die zuordnung beim Halten von Vermögen in Form von Anteilen an einer Kapitalgesellschaft. ${ }^{31)}$

a) Um die Zweifachbelastung mit Vermögensteuer im Bereich der Besitz-Verschachtelungen von Kapitalgesellschaften ${ }^{32)}$ untereinander auszuschalten, wurde das sog. S c h a c h t e l p r i vi 1 e g (§ 102 BewG) konstruiert. Dieses können nun nicht etwa sämtliche Steuerpflichtige in Anspruch nehmen, sondern nur jene, die bestimmte Voraussetzungen erfüllen. Die Ungleichbehandlung liegt nicht etwa in der Existenz des Schachtelprivilegs als solchem, denn dieses sorgt dafür, daB eine allokativ nachteilige Mehrfachbelastung mit Vermögensteuer ausgeschlossen bleibt. Vielmehr liegt die Ungleichbehandlung darin, daB die Inanspruchnahme des Privilegs von der Eigenschaft als korporative Institution, von der Beteiligung $\mathrm{zu}$ mindestens einem zehntel und von der mindestens 12 Monate währenden Beteiligung abhängig gemacht wird. Warum nur die "wesentlich beteiligten" nicht-privaten Steuerpflich. tigen von den allokativen Nachteilen verschont werden sollen, die anderen nicht, läBt sich sachlich nicht begründen (K. Tipke 1991 S 4621. Für die privilegierten Gesellschaften ergibt sich also gegenüber den nichtprivilegierten Personen und Unternehmer ein geringerer steuerlicher Vermögensumfang.

31) Ausgeschlossen aus unserer Betrachtung bleibt die Zweifachbelastung mit Vermögensteuer $z u m$ einen bei der Kapitalgesellschaft und $z$ um anderen beim privaten Anteilsinhaber; diese Form der Belastung hängt nicht mit dem Vermögensbegriff, sondern mit dem Steuersystem zusammen.

32) bzw. der ihnen nach $\S 102$ BewG gleichgestellten nichtprivaten Institutionen. 
b) Mit unserem Problem der $p$ e $s$ ö $n ~ l i c h$ e $n$ Besteuerung hängt das Schachtelprivileg insofern zusammen, als der Vermögensumfang der "hinter" der Beteiligung stehenden endgültigen privaten Vermögenshalter damit willkürlich qua Abzugsregel ${ }^{33}$ ) verringert wird, obwohl sich im tatsächlichen Vermögensbestand nichts ändert. Sie sind im Vorteil gegenüber jenen, die Vermögensanteile an einer Kapitalgesellschaft halten, die nicht privilegiert ist bzw. die Vermögen nicht in Form von Anteilen angelegt haben. Nicht auszuschlieBen ist, daB mit Rücksicht auf das steuersparende Privileg Beteiligungsentscheldungen getroffen werden, denen nicht in vollem AusmaB das rein ökonomisch sinnvolle Kalkül aus der Markt-, Produktions- und Kooperationssicht gegenübersteht (vgl. SRK 1971, S. 301, TZ 30). Das kann zu Allokationsnachteilen führen. Die distributive Ungleichbehandlung unter den letztendlichen Antellsbesitzern ist sachlich ebensowenig begründbar wie die gegenüber anderen Vermögensbesitzern. Die Herabsetzung der wesentlichen Beteiligung von 25 \& auf 10 \& (SRK 1971, S. 641, TZ 95 u. S. 651, T2135) konnte das Problem mildern, nicht aber beseitigen.

\section{III. zusammenfassung}

Die Ergebnisse des Zweiten Teils fassen wir jetzt wie folgt zusammen: Erweist es sich aus der theoretischen Sicht als notwendig, die Objektivierung der Leistungsfähigkeit auf die Steuerpostulate der Allgmeinheit und der GleichmäBigkeit zu gründen, so stellt sich die in der Realität praktizierte objektivierung weithin als ein Bündel von Verstößen gegen das Allgemeinheitspostulat (7. Kapitel) und als ein regelrechtes "System" von Verstößen gegen das GleichmäBigkeitspostulat (8. Kapitel) dar. Die Ungleichbehandlungen, die im 8. Kapitel dargestellt werden, gehen teilweise über die Verstöße gegen das Allgemeinheitspostulat hinaus. Somit werden letztere hier nicht wiederholt; sie sind in jedem Fall zugleich Verstöße gegen das Gleichheitspostulat. Ungleichbehandlungen, die ihren Ursprung in den tarifären Ungleichheiten haben, werden nach der gegebenen Themenabgrenzung hier nicht dargestellt, so daB sich

33) in der Ausdrucksweise des Gesetzes, S 102 I: "... so gehört die Beteiligung insoweit nicht zum Gewerbebetrieb, als sie..." 
unsere Analyse strikt auf die Einkommens- und Vermögensbegriffe konzentriert.

Zunächst heben wir einen steuersystematischen Zusammenhang zwischen den Methoden der Gewinnermittlung und jenen der Einkommensermittlung hervor, der Ausdruck der steuergesetzlich hergestellten allokativ-distributiven Interdependenz 1st: Ungleichbehandlungen in der allokativ-betrieblichen Sphäre, die zu ungleich großen Gewinnbegriffen führen, gelten für Einzelunternehmer, Mitunternehmer und Personengesellschaften zugleich auch als deren Einkommen; Ungleichbehandlungen übertragen sich demnach vom allokativen auf den distributiven Bereich, und zwar allein deswegen, weil die Systematik der Bemessungsgrundlagen-Feststellung die allokativ-distributive Trennung der so unterschiedlichen Größen wie Gewinn und Einkommen nicht beachtet. Wir nennen diesen Ubertragungseffekt "die allokationsdeterminierte distributive Ungleichbehandlung". zugleich legen wir dar, daß eine Gleichbehandlung nicht zwischen dem allokativen Bereich einerseits und dem distributiven andererseits gesucht werden darf, da die beiden Bereiche jeweils für sich hinsichtlich der in ihnen versammelten Tatbestände Gleichbehandlung zu organisieren haben. Das personale Einkommen im distributiven Bereich darf durchaus steuerlich anders belastet werden als der Ertrag im Unternehmen. Diese Auffassung welcht aber von der üblichen Lehrmeinung erheblich ab.

Was in Kapitel 8 erstmals versucht wird, ist die vollständige Systematisierung aller Ungleichbehandlungen, die durch die Ermittlungs- und Erfassungsverfahren entstehen, soweit sie Einflub haben auf die Breite des steuerlichen Einkommensbegriffs. Wir kommen dabei zu zwei Gruppen von Ungleichbehandlungen, erstens den ungleichen Ermittlungsmethoden für die verschiedenen Einkunftsarten, zweitens den ungleichen Erfassungsmethoden für die verschiedenen Einkommens-zugangsarten. Die wesentlichen Ergebnisse für den ersten Bereich sind nach einer detaillierten Abwägung aller Einflüsse der Ermittlungsmethoden auf den Einkommensbegriff die folgenden: Kraft des Ubertragungseffektes führt in der Betriebsausgaben-Betriebseinnahmen-tberschuBermittlung das Nichtbilanzieren und die Nichtanwendung des zwischenperiodischen Verlustausgleichs $z u$ einem steuerlichen Einkommensbegriff, der gegenüber dem des Vermögensvergleichs tendenziell weiter ist und höhere Belastungen ergibt. In der Einnahmen-Werbungskosten-UberschuBmethode andererseits sind 
es vor allem die fehlenden "Gestaltungsprivilegien", die zu einem weiteren Umfang des Einkommens gegenüber allen anderen AnlaB geben. Dabei ist aber $z u$ beachten, daB in dieser Gruppe der UberschuBeinkünfte sehr unterschledliche ökonomische Aktivitäten versammelt sind. Der Höhepunkt der Ungleichbehandlung aber wird in der Durchschnittssatzbesteuerung für die Landwirtschaft erreicht, die den engsten aller Einkommensbegriffe produziert. Dies zu erkennen wurde dadurch erleichtert, daß wir die überaus komplizierten Gesetzesvorschriften in eine ökonomisch orientierte Gliederung gebracht haben, aus der die einkommensmindernde gegenseitige Beeinflussung der Rechengrößen und Berechnungsschritte abzulesen ist.

In der zweiten Gruppe, der ungleichen Erfassung der Einkommens-zugänge, bleibt der Ubertragungseffekt ohne Einfluß; hier kommen wir mit der Darstellung der nunmehr ausschließlich im distributiven Bereich angesiedelten Ungleichbehandlung zu dem Ergebnis, daß zwar Ungleichbehandlungen in allen Zugangsarten auftreten, ihr Schwergewicht jedoch Im Transferbereich liegt: Teils völlig steuerfreie Transfers, teils voll besteuerte, teils nur teilweise besteuerte Renten bzw. Pensionen oder Alterseinkünfte.

Auch in der Vermögensbesteuerung wird die Ungleichbehandlung auf den übertragungseffekt zurückgeführt. Eine ungleiche Bewertung je nach Vermögensart und Bewertungsverfahren hat personalungleiche steuerliche Vermögensbegriffe zur Folge. Wir haben demnach unterschieden zwischen der "vermögensartgebundenen" und der "verfahrensund wertgebundenen" Ungleichbehandlung. Wirtschafts- und sozialpolitisch motivierte Begünstigungen für bestimmte Vermögensarten sollten nicht in den Bewertungsvorschriften "versteckt" werden, sondern als Korrekturen am Bewertungsergebnis offen ausgewiesen sein, weil sonst am Bewertungsergebnis nicht mehr abgelesen werden kann, ob die Investitionsentscheidung in eine bestimmte Vermögensart rational war. Allokative Fehlentscheidungen und distributive Ungleichbehandlungen stellen sich insbesondere dann ein, wenn die steuerpolitik dazu beiträgt, inflationsbedingte Unterschiede in der Substanz- und Kaufkrafterhaltung noch zu betonen (Grundvermögen).

Im Bereich der verfahrens- und wertbegriffsgebundenen Ungleichbehandlung haben wir es mit einer Fülle von Tatbeständen zu tun; diese hängen zumeist mit der Einheitsbewertung zusammen. Wir kommen 
hier zu der folgenden Systematisierung: Unter dem "System- und Verfahrensproblem" verstehen wir, daß entgegen dem Grundsatz von der allgemeinen Geltung des Gemeinen Wertes die Einheitsbewertung eine Annäherung an den Marktwert wohl gar nicht anstrebt und zudem auch ungleiche werte für die einheitswertabhängigen steuerarten postuliert. Dies widerspricht der Grundidee der zeitnahen Bewertung, der Vorstellung von der (allokativen) Gleichbehandlung der vermögensarten und der Einheitlichkeit im steuersystem.

Unter der Bezeichnung "Wertbegriffsproblematik" werden drei Problembereiche erfaßt, die auf die in der Einheitsbewertung verwendeten Wertbegriffe zurückgehen, nämlich auf den Ertragswert, den Sachwert und den Vergleichswert. Die mit diesen Werten und Verfahren zusammenhängenden Ungleichbehandlungen kennzeichnen wir einerseits als das "Niveauproblem", andererseits als das "Pauschalierungsproblem". Diese tauchen bei allen drei Wertbegriffen auf. Die Unterschiede in den Wertniveaus für einzelne Vermögensarten und auch die Pauschalierungen in Form von vorgegebenen Sollwerten weichen vom Grundsatz der Istbesteuerung bzw. vom GleichmäBigkeitspostulat ab. Soweit es sich um die Bewertung betrieblichen Vermögens handelt, sorgt der Ubertragungseffekt dafür, daB es auch zu einer distributiven Ungleichbehandlung kommt. In einer detaillierten Analyse der steuerlichen Bewertungsvorschriften ist es uns gelungen, die wesentlichen Ungleichbehandlungstatbestände zu erfassen und sie der hier vorgelegten Systematik der Probleme zuzuordnen. Das "System" der Ungleichbehandlungen scheint fast lückenlos zu sein. Dieses System führt zu einer Fülle von unterschiedlich weit gefaßten steuerlichen Vermögensbegriffen.

Die Erkenntnisse zun aliokativ-distributiven Abgrenzungsproblem und seine Wirksamkelt fur den steuerlichen Einkommens- und Vermügensbegriff, ferner die Erkenntnisse aus der Bedeutung der Allgemeinhelts- und Gerechtigkeitspostulate sowie auch der Verstöße gegen sle müssen auf den entscheldenden Punkt zugeführt werden: Dieser liegt in der Aussage über die Anwendbarkeit unserer Untersuchungsergebnisse auf steuersystematische zusammenhänge. Steuersysteme werden gemelnhein auch darauf analysiert, inwiewelt sich mit den in ihnen vorhandenen Steuerarten wirtschaftspolitische ziele verwirklichen lassen, zumindest wird danach gefragt, inwiewelt die spezielle Ausgestaltung der Steuerarten den präferierten zielen 
nicht entgegensteht. Und da haben die Analysen in ersten und zweiten Teil unserer Arbeit erceben, daB rein allokative ziele konfliktfrel noch am ehesten mit einer Besteuerung im allokativen Bereich des Wirtschaftens, mit einer Unternehmensbesteuerung also, zu vereinbaren sind. Unser Thema aber ist die Personalbesteuerung, d.h. die Besteuerung im distributiven Bereich. Es ist daher jetzt $z u$ untersuchen, welche Personalsteuerkonzepte für die Besteuerung im distributiven Bereich existieren, welche Einkommens- und Vermögensbegriffe sie verwenden, welche distributiven ziele sie thematisleren und auch, wie in ihnen unser Grundthema der allokativdistributiven Abgrenzung verarbeitet wird. Insbesondere aber ist darzulegen, wle die Konzepte dem Leistungsfähigkeitsprinzip folgen und welche theoretische oder politische Interpretation sie ihm unterlegen. 


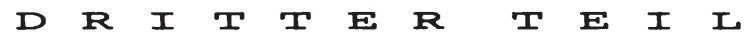

Steuerpolitik zwischen Lastverteilung und verteilungsziel:

Theorie-konzepte einer allokativaistributiven Besteuerung

528 tiberblick = Die systematik der personalsteuer-konzepte

I. Der Konzeptbegriff 487

II. Die Gruppierungsversuche in der Literatur 488

III. Eine neue Systematik für Theorie-Konzepte 489

I. In einer Theorie der Politik mit Personalsteuern - und das gilt sowohl für die Norm selbst (5. und 6. Kapitel) als auch für die Normverstöße (7. und 8. Kapitel) - steht immer die Vorstellung einer mit Gerechtigkeitsideen verbundenen $v$ e $r$ e $i$ i u n g im Vordergrund. Denken wir dabei an die Verteilung der steuerlast, ist unmittelbar das Leistungsfähigkeitspostulat angespriochen; es fungiert als Steuerlastverteilungsnorm (2. Kapitel): Die steuerlast soll analog der Verteilungsstruktur der Primäreinkommen verteilt werden. Legen wir dagegen in unserer Vorstellung von verteilung das Gewicht auf die Verteilung der $\mathrm{E} i \mathrm{n} \mathrm{k} \circ \mathrm{m} \mathrm{e} n$, so assoziieren wir, dab qua steuer eine bestimmte verteilungsstruktur der $\mathrm{s}$ e $\mathrm{k}$ u $\mathrm{n}$ d ä $\mathrm{r}$-Einkommen hergestellt werden soll.

Diese beiden grundsätzlichen Vorstellungen über die Besteuerung kehren nun in den theoretischen Konzepten darüber wieder, ob mithilfe der Personalsteuern nur die Steuerlast verteilt werden, die P r i m ä r - Einkommens-Struktur also der Fixpunkt der Lastverteilung bleiben soll, oder ob direkt die sekundäreinkommensstruktur verändert werden soll. Hierbei geht die Theorie der Personalbesteuerung davon aus, daB eine bestimmte gesellschaftspolitische Akzeptanz der sekundären Einkommensverteilung zum Fixpunkt der Verteilungspolitik wird. Wir erkennen in der Geltung dieser Fixpunkte unterschiedliche $T h e \circ r i e-k \circ n z e p t e$. Dabei verstehen wir "Konzept" als eine summe von theoretischen Aussagen, die auf ein ziel (z.B. Verteilung) ausgerichtet und anwendungsbezogen sind. 1 ) 
II. Die Aufzählung der distributiven Besteuerungs-Konzepte folgt in der $I i t$ e $r$ t $u r$ keinem ordnungsmuster, zu verschieden sind nämlich die Erklärungsinteressen und die in den Konzepten enthaltenen steuerrechtfertigungen. Soweit man überhaupt unterschiedliche konzepte präsentiert, werden diese - teils als "Denkrichtungen", teils als "Rechtfertigungen" bezeichnet - einfach enumerativ, wenn auch korrekt aufgezählt, ohne etwa nun konzeptverbindende oder -trennende Merkmale zu thematisieren und solchermaßen die Konzepte $z u$ vergleichen. So hebt J. Hackmann (1979, S. 28) grundsätzlich zwei Denkrichtungen hervor, die utilitaristische (der er Autoren wie H. Haller, D. Schneider, M.S. Feldstein und R.A. Musgrave zuweist) und die auf Verfügungsmacht und Einkommen abgestellte (deren Repräsentanten G. V. Schanz, H.C. Simons und R. Goode sind); eine Zwischenposition weist er R.M. Haig mit seinem Options- oder Chancen-Ansatz $z u$.

G.P. Ziemes (1980, S. 24 f.) stellt drei Gruppen nebeneinander: die Opferprinzipien, den "faculty"-Ansatz von E.R.A. Seligman und den sozialpolitischen Ansatz von A. Wagner. Diese Gruppierung wird nun von H.M. Groves (1969, S. $339 \mathrm{ff.}$ ) speziell im Bereich der politischen Ziele erweitert: Er nennt vier Gruppen von Ansätzen, nämlich erstens die klassischen des abnehmenden Grenznutzens aus den Opfertheorien, zweitens den Seligman-Ansatz ("faculty"), drittens den Verteilungsziel-Ansatz nach H.C. Simons und Taussig und viertens den sozialpolitischen Ansatz nach Wagner und Fagan. $\mathrm{Zu}$ den beiden letztgenannten weist Groves ausdrücklich darauf hin, daß sie als die politischen die wichtigeren Ansätze sind, da sie die Unzulänglichkelten der klassischen (opfer- und faculty-theoretischen) vermeiden; die bedeutsameren Auswirkungen der Besteuerung seien eher politischer als ökonomischer Natur (S. 345).

Fn. 1:

So etwa in dem Sinne, wie K. Lompe (1966, S. 57) das Popper' sche "piecemeal social engineering" ein "Konzept" nennt, so etwa auch in dem Sinne, wie G. Gäfgen (1975, VII A) von "wirtschaftspolitischen Konzeptionen" spricht: Realisierbare (also nicht nur ideale) ordnungsentwürfe stellen eine Verbindung her zwischen der ordnungszielvorstellung, der tatsächlichen historischen Lage und den faktischen Gestaltungsmöglichkeiten. 
Im Grunde werden in diesen Gruppierungen die inhaltlichen Unterschiede der konzepte durchaus gesehen, aber nicht ausformuliert. Uberdies wird z.B. das Schanz'sche Reinvermögenszugangs-Konzept teilweise gar nicht erwähnt, zumindest nicht mit dem Simons-, Haig- und Carter-Konzept in Verbindung gebracht, oder es wird H.C. Simons in die Nähe des Verteilungsziel-Ansatzes gerückt, dem er nur schwerlich zuzuordnen ist.

Auffällig ist dreierlei: Erstens sind konzeptionelle Dar- und Gegenüberstellungen selten; Gesamtdarstellungen finden sich nicht. Zweitens ist die zuordnung bestimmter Autoren $z u$ den vorgestellten Konzepten heterogen. Und drittens wird $z$ umeist die Ausgabensteuer in Verbindung mit der Leistungsfähigkeitsbesteuerung nur von solchen Autoren in eine konzeptionelle Gegenüberstellung aufgenommen, die selbst die Ausgabenbesteuerung auch befürworten. ${ }^{21}$

III. Für unseren eigenen systematisierungsvorschlag greifen wir zurück auf die grundsätzlichen Uberlegungen $z$ ur Leistungsfähigkeit und stellen zugleich die besondere Bedeutung des verteilungspolitischen $\mathrm{ziels}$ heraus; wir kommen $\mathrm{zu}$ folgenden Uberlegungen:

a) Erstens ist es möglich, das Lelstungsfähigkeitsprinzip auf die persönlichen $P \circ t$ e $n t i$ a $l$ e der Leistung, auf die Möglichkeiten zur Leistung ("Possibilität") auszurichten. Dies setzt voraus, daß die Merkmale der persönlichen Ausstattung mit psychophysischen Gaben, mit realen und monetären Gütern, mit den objektiv und subjektiv gegebenen Möglichkeiten des Einsatzes dieser Gaben und Güter zur Bildung eines Soll-zustandes für die erzielbaren Leistungsergebnisse zusammengefaBt werden. Die Steuerlast müBte nach dem Grad der erreichten Sollwerte verteilt und könnte besonders dorthin gelegt werden, wo die sollwerte verfehlt wurden. Abgesehen von den MeBproblemen, die ein solches Konzept verursacht, ${ }^{3)}$ würden ordnungspolitische Widerstände $z u$ erwarten sein: Besteuert wird, was einer leisten soll, nicit, was er geleistet hat.

2) So z.B. von N. Kaldor 1955, D. Schneider 1971, J. Mitschke 1976, W.D. Andrews 1980.

3) Es müBten nämlich die Faktoren der Begabung, der Mühe, des Antriebs, der Körperkraft, der Intelligenz usw. überhaupt in MeBwerte überführt werden können, und danach müBte ein Gesamt-

(Forts. siehe folgende seite) 
Der Grundwert der Freiheit würde dem der gröBeren Allokationseffizienz geopfert werden. Aus diesem Grunde sind bisher sollsteuern lediglich sehr vereinzelt und zwar nur dort praktiziert worden, wo erstens die MeBbarkeit bereits vorliegt und zweitens die Besteuerungsbasis nur einen sehr kleinen Teil der gesamten volkswirtschaftlichen Wertschöpfung ausmacht.

b) Es ist zweitens möglich, das Leistungsfähigkeitsprinzip auf das persönlich e $r z i$ e $l$ t e Leistungs - E r g e b n i s auszurichten. Damit wäre dem Norm-Charakter des Prinzips insoweit direkt entsprochen, als Normen vergleichbar sein müssen und in Geld ausgedrückte Normen dies fraglos sind. Die Entscheidungsgrößen sind also die Geldeinkommen und die Geldvermögen, oder allgemeiner: die in Geld ausgedrückte Dispositionskraft bzw. Kaufkraft. Geld indiziert die "ability to pay".

Dieser Gedanke kann nun grundsätzlich auf eine direkte oder auf eine indirekte Weise in der Lastverteilungsnorm zur Geltung kommen; direkt dann, wenn die Geld - E i $\mathrm{n} k \circ \mathrm{m}$ e $\mathrm{n}$ (einschlieBlich der Vermögen) oder die Geld - A u s g a b e $n$ (einschlieblich der Vermögen) zur Basis der Lastverteilung, d.h. zu den Indikatoren der steuerfähigkeit gemacht werden. Die indirekte Weise besteht darin, auf dem Umweg über die mit der Kaufkraft erreichte $B$ e $d$ ü $f \mathrm{n} i \mathrm{~s}$ e $f \mathrm{r} i \mathrm{e} i \mathrm{~g}$ u $\mathrm{g}$ und deren N u t z e n s $t$ i f $t$ u $g$ zu Lastverteilungskonzepten $z u$ gelangen. Insbesondere dieser Weg wurde von der Theorie beschritten und hat zur Konstruktion der Steuer als Nutzenopfer und zu den Vorstellungen einer Verteilung der opfer auf die Individuen als die einzige Form der steuerlastverteilung geführt.

c) Es ist drittens möglich, die distributive Besteuerungspolitik sowohl vom ihr fremden allokativ motivierten Sollsteuerdenken als auch vom Primat der Leistungserfolge, also vom Leistungsfähigkeitsprinzip überhaupt $z u$ lösen. Das erfordert, daB sie

Forts. Fn. 3:

indikator entwickelt werden können, der alle diese Einzelwerte und auch die der materiellen Ausstattung (Kapitalbestand, Wettbewerbsvorteile, Kreditmöglichkeiten usw.) gleichnamig macht, um Vergleiche anstellen zu können. 
e $i \mathrm{~g}$ e $\mathrm{n}$ M a Bs $t$ äb e verte i l ung pol i$t i s c h$ e $r$ A $t$ setzt, wie sie sich z.B. in bestimmten Bedarfsgrößen, wie dem Existenzminimum und dem "Mehrbedarf" zeigen, die nach verschiedenen Graden ökonomischer Notwendigkeit und persönlicher Entscheidungsfreiheit differenziert werden können. Sie verzichtet dabei auf die Versuche, die BedarfsgröBen und den Tarifverlauf in den Personalsteuern theoretisch bestimmen $\mathrm{zu}$ wollen, hält vielmehr ihren Handlungsspielraum offen für erforderliche politische Anpassungen ihrer MaBstabsgröBen. Allerdings lädt eine solche distributive Besteuerungspolitik ohne wirtschaftstheoretisches Fundament das politische Problem der Anfälligkeit für Gruppen- und Verbände-Einflüsse auf sich. Doch die Abhängigkeit von politischen Einflüssen besteht auch schon für die o.g. beiden Grundverständnisweisen des Leistungsfähigkeitsprinzips: Einerseits müssen ja die Sollwerte des "Fähigkeitskonzepts" ebenfalls im politischen ProzeB festgelegt werden, da sie sich theoretisch nicht "beweisen" lassen. Andererseits ist auch das "Ergebniskonzept" der Leistung letztlich ohne politischen Akt nicht zu praktizieren; denn steuerliches Einkommen läBt sich "theoretisch richtig" nicht bestimmen, bedarf der politischen Inhaltsgebung, und ebenso lassen sich die (linearen oder progressiven) Tarifverläufe der Personalsteuern nicht theoretisch begründen. Auch bei ihrer Festlegung waren und sind bisher stets politische Prozesse und die Einflüsse der Gruppen und Verbände wirksam.

d) In der hier vorgelegten Systematik der distributiven Besteuerungskonzepte unterscheiden wir die "Possibilitäts"-, die "Realisierungs"- und die "Distributions"-Konzepte, wobei die mittlere Gruppierung zwei Versionen aufweist, die sich durch die direkte bzw. indirekte Erfassung des Leistungserfolges unterscheiden: die direkte Erfassung richtet sich auf die meBbaren GröBen Einkommen, Vermögen und Ausgaben; dies sind die "Nominalismus"Konzepte. Die indirekte Erfassung des Leistungserfolges richtet sich auf die hinter diesen Indikatoren liegenden psychischen Phänomene der Bedürfnisbefriedigung, die stets - so auch hier als die "Utilitarismus"-Konzepte bezeichnet werden.

In der danach sich ergebenden Systematik der

- Possibilitätskonzepte,

- Nominalismus-Konzepte,

- Utilitarismus-Konzepte und

- Distributionskonzepte 
behandeln die ersten beiden Konzepte-Gruppen vorwiegend das Problem der Indikatoren der Leistungsfähigkeit, also die horizontale Gerechtigkeit (siehe auch $\mathrm{K}$. Schmidt 1978, S. 151), weniger das Tarifproblem. Die Gruppe, demnach die der Utilitarismus-Konzepte, behandelt demgegenüber das Leistungsfähigkeitsproblem eher als Frage der vertikalen Gerechtigkeit, ${ }^{4)}$ d.h. als die suche nach dem "gerechten" Tarifverlauf. Sie versuchen, diese Frage mit der Nutzentheorie zu lösen, wohingegen die Distributionskonzepte bedarfsgröBenorientiert und politisch ausgerichtet sind; sie versuchen von vorn herein, den Anschein zu vermeiden, als seien sie $f a ̈ h i g k e i t s$ - oder e rge b n isorientierte Konzepte der Leistung. In ihnen haben die Bemessungsgrundlagenund die Tarifverlaufsbestimmung dieselbe wichtige Bedeutung. In ihnen zeigt sich - mehr als in den anderen Konzepten - die Stellung der "Personalisierungsleistung" einer objektivierung der Besteuerung mit ihren politisch festgesetzten BedarfsgröBen.

In der Darstellung der Realisierungs-Konzepte werden wir uns der folgenden Vereinfachungsregel bedienen: Da diese Konzepte auf den realisierten Größen "Einkommen", "Ausgaben" und "Vermögen" basieren, nennen wir diese Leistungsfähigkeits-Indikatoren überall dort, wo wir sie summarisch zu bezeichnen wünschen, die "EAV"-GröBen.

4) Siehe hierzu Musgrave/Musgrave 1980, S. 242 u. 250, die das Indikatorenproblem als eine Frage der horizontalen, das Tarifproblem als eine Frage der vertikalen Gerechtigkeit behandeln. 
9. Kapite1:

Die "Possibilitäts"-Konzepte

\section{s 29 Die analytische Bedeutung des "seligman-Ansatzes"}

In Besteuerungskonzepten, die wir die "Possibilitäts"-Konzepte nennen und deren Bezeichnung wir von E.R.A. Seligman ableiten, werden die umfassendsten aller denkbaren Besteuerungsbasen formuliert, da sie neben den materiellen auch die psychischen und somit die äuBerstenfalls "möglichen" Leistungsfähigkeitsindikatoren heranziehen. Aber den Possibilitäts-Konzepten der Leistungsfähigkeit ist weniger eine praktisch-politische, sondern eher eine analytische Bedeutung zuzuschreiben. E.R.A. Seligman" unterscheidet in seinem "faculty"- bzw. "ability"-Ansatz (1) die "powers of production" (= power of income and property) and (2) deren "results". $\mathrm{Zu}$ den powers $\mathrm{zählt} \mathrm{er} \mathrm{zunächst} \mathrm{die} \mathrm{angeborenen}$ und erworbenen Fähigkeiten, ferner die Möglichkeiten, solche Fähigkeiten, die Macht bedeuten, zu gebrauchen, und schlieblich die Art und Weise, in der Macht tatsächlich gebraucht wird. Sein Ansatz enthält demnach sowohl die Faktoren der Fähigkeit und Macht selbst als auch die "capacity to make use of it". 2)

Der capacity-Begriff greift also uber den der (primären) powers hinaus und enthält auch jene (sekundären) Phänomene, die sich durch aktiven Einsatz der powers ergeben. Demnach ist in den beiden "elements of faculty" die Einkommens- und Vermögenssphäre (einschl. des human capital) der Person auf eine zweifache Weise ausgedrückt: $z$ um einen in der Erwerbs- (oder Produktions-), zum anderen in der Ausgaben- (oder Konsum-) Sphäre. ${ }^{3)}$

1) $1894, \mathrm{~S} .190 \mathrm{ff}$; income = periodical accretion; property = permanent accretion.

2) Es lieBe sich ergänzen: einschlieblich der Fähigkeit, Steuern $\mathrm{zu}$ überwälzen.

3) Vgl. zum Terminologischen auch die in den früheren britischen Kolonien in Neuengland erhobene "faculty tax" als einer steuer auf die persönlichen Fähigkeiten bzw. auf "Phantasiekapitalien" (Steuer auf das Humankapital), wie sie interpretiert wird von B. Moll, Zur Geschichte der englischen und amerikanischen Vermögenssteuern, München u.a. 1912, S. 43. 
Damit ist eine Grundlegung für das Problem der Indikatorenfindung bereits erreicht, die erst in der späteren Diskussion wieder stärker betont wird, nämlich die Indikatoren der persönlichen Leistungsfähigkeit sowohl in der Einkommensentstehung als auch in der Einkommensverwendung aufzusuchen. Der erste Fall ist die faculty theory in der "acquisition"-Version, der letzte die Theorie in der "consumption"-Version (Seligman, 1894, S. 191). Mit der Ausdehnung der faculty-Vorstellung auch auf die Nutzungsmöglichkeiten der Fähigkeitsergebnisse gelingt Seligman ein über das Einkommen hinausreichender Begriff insoweit, als er glaubt, damit ausdrücken zu können, daB "faculty" die zunahme an Macht und Dispositionsfähigkeit besser ausdrückt als lediglich das Einkommen selbst: "money makes money" (Seligman, S. 192). Hier sind Anklänge an die Fundustheorie festzustellen; zugleich hat die faculty theory auch $\mathrm{zu}$ theoretischen Versuchen einer breiten Einkommensdefinition angeregt. ${ }^{4)}$ AuBerdem macht nach seligman erst die Ausdehnung der faculty theory auf den Konsum, also auf den Bereich des "disposing of income", die Denkvorstellung von Last und Opfer möglich (S. 131), so daß der faculty-Ansatz das weitere, der sacrifice (Opfer-)-Ansatz das engere Konzept ist (S. 192).5) Der Seligman'sche Ansatz ist der Ausgangspunkt für manche modernen Ansätze, die wir als Potentialkonzepte bezeichnen und die bis in die jüngste Zeit hinein (H. Haller; Atkinson/Stiglitz 1980, s. 260 u. 566, $)^{6)}$ vorgetragen werden. Es ist aber kritisch zu fragen, ob allein das "Potential zur Leistung" ein Indikator der Steuerfähigkeit sein kann und ob die Trennung in die Bereiche der Einkommenserzielung und -verwendung einen analytischen Fortschritt bedeutet.

4) So z.B. bei R.M. Haig 1959, S. 59. - Ferner bei H.C. Simons 1938.

5) Beide Ansätze führen nach Seligman in vorsichtiger SchluBweise und Plausibilitätsannahme tendenziell zur Progression, S. 193.

6) Siehe den Begriff des "full income" bei Atkinson/Stiglitz 1980 , S. 261, der auch das blob "mögliche Einkommen" enthält, das Freizeit erlaubt. - Siehe ferner das potentialorientierte Konzept bei H. Haller 1981 unter EinschluB der Freizeit. 
II. Potential und Freizeit

IV. Sollbesteuerung und ihre ordnungspolitischen Implikationen

I. Potentiale sind der Inhalt der Possibilitätskonzepte. Stellt nun aber die Possibilität eher auf die "Möglichkeiten" zur Leistung $a b$, auf die offenheit für jede Art von Lestungsfaktoren $a b$, so soll mit Potential der Versuch ausgedrückt werden, allein die bloßen Möglichkeiten in einem ökonomisch beschreibbaren und umgrenzbaren Faktorvolumen genauer festzulegen.

a) R.M. Haig (1959, S. 59) trifft wie E.R.A. Seligman die Unterscheidung in $\mathrm{p} \circ \mathrm{t} \mathrm{e} \mathrm{n} i \mathrm{a} l$ und $\mathrm{R}$ a $\mathrm{l}$ i s $\mathrm{s}$ e u n $\mathrm{g}$. würde man nach Haig anstelle der Besteuerung anläBlich der tatsächlichen Bedürfnisbefriedigung schon dann besteuern, wenn jemand die Möglichkeit erhält, seine Wünsche $z u$ befriedigen, so würde das dem Grundsatz der von Haig hervorgebobenen Gerechtigkeit keinen Abbruch tun: Die Tatsache, daB sich jemand entschliebt, die Befriedigung seiner Bedürfnisse zu verschieben, sei kein ausreichender Grund, auch die Steuer zu verschieben. Für Haig dient also der Possibilitätsansatz der Bestimmung eines weitgefaBten Einkommensbegriffs unter dem Aspekt der Gleichbehandlung. ") Haig argumentiert potentialorientiert, wenn er sagt, daB Einkommen die "net accretion to one's economic p o w e r between two points of time" ist, aber er argumentiert zugleich nominalistisch, wenn er sagt: "Income is the $m \circ n$ e y value of the net accretion" (S. 59).2) Dieser letztere Umstand und das

1) Gerade die Gleichbehandlung aber ist ein Punkt der Kritik seitens M.S. Feldsteins $(1976 \mathrm{~b}$, S. 87): "Even with identical utility functions, the Haig-Simons tax will violate the principle of horizontal equity when individuals differ in ability if there is more than one type of ability".

2) In anderen Worten: Einkommen ist nach Haig "the increase or accretion in one's power to satisfy his wants in a given period in so far as that power consists of (a) money itself, or, (b) anything susceptible of valuation in terms of money". -

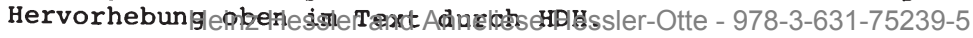


Abstellen der Einkommensbemessung auf die beiden Zeitpunkte veranlassen uns, die Position Haigs unter die Realisierungskonzepte einzureihen, zumal die in diesem Zusammenhang auftauchende Reinvermögenszugangstheorie dort ihren richtigen Platz hat. ${ }^{3)}$ Die Potentialorientierung Haigs richtet sich im Gegensatz zu der Seligmans auf den Zeitpunkt, nämlich auf den der Erlangung jener "power to satisfy" anstelle der tatsächlichen Bedürfnisbefriedigung.

b) Mit dem Abstellen auf die $B$ e $d$ ü $r$ f $i s$ b e $r i$ e d i $\mathrm{g}$ u $\mathrm{n} g$ und mit der Definition des Steueropfers als BedürfnisbefriedigungseinbuBe gehört H. Haller (1981, S. 69 ff.) zwar zu den Vertretern der Utilitarismus-'Konzepte, muB dennoch hier eingereiht werden, weil sein Verständnis von Bedürfnisbefriedigung potentialorientiert ist; das erzielte Einkommen erlaubt selnem Verwender eine Bedürfnisbefriedigung je nach dem maximal $m$ ö g $1 \mathrm{i} c \mathrm{~h}$ e $\mathrm{n}$ Nutzen, das aus dem Einkommen hervorgehen kann.

c) Der Possibilitätsansatz wird von D. Schneider ${ }^{4)}$ einer methodischen Kritik unterzogen. Sie erstreckt sich sowohl auf die logischen Unvereinbarkeiten in der Argumentation der Possibilitätstheoretiker als auch auf die falsche Verwendung des Begriffs "Bedürfnisbefriedigung" im Hinblick auf den Sinn des Wirtschaftens.

Schneider knüpft kritisch an die Seligman'sche Potentialbetrachtung an, verwendet diesen Problemangang methodisch $\mathrm{zu}$ einer Trennung der Realsphäre von der Potentialsphäre, greift die Seligman'sche Unterscheidung zwischen der acquisition- und der consumption-Version auf und formalisiert die BezugsgröBen der steuerlichen Leistungsfähigkeit wie folgt (wir haben die verbalen Ausführungen Schneiders in eine Matrix überführt):

A. Gesamtwirtschaftliche Betrachtung:

Entstehung des Volkseinkommens Verwendung des Volkseinkommens

B. Einzelwirtschaftliche Betrachtung:

(1) Erwerbstätigkeit (Faktoreinsatz = "Mittelerwerb")

(2) Ver-/Gebrauchstätigkeit ( Käufe und Sparen = "Bedürfnisbefriedigung")

(a) Realisierungs-Sphäre (verwirklichter Mittelerwerb)

(b) Potential-Sphäre (möglicher Mittelerwerb) (a) Realisierungs-Sphäre (verwirklichte Bedürfnisbefriedigung)

(b) Potential-Sphäre mögliche Bedürfnisbefriedg.

Fn. 3 und 4 auf der folgenden Seite. 
Daraus läBt sich ableiten: In der Realisierungs-Sphäre (a) ist der erzielte Mittelerwerb und die erreichte Bedürfnisbefriedigung ein Ergebnis vollzogener Entscheidungsakte; im Bereich der Erwerbstätigkeit führt das zu einem GeldmittelzufluB bzw. erhöhtem -bestand. Wird dies auch in der finanzwissenschaftlichen Literatur als "a b 11 i $t y$ to pay"-Prinzip bezelchnet, so kann die Verwendung des eher psychologischen Terminus' ability nicht daruber hinwegtäuschen, daß das hier in Rede stehende Ergebnis im materiellen Bereich liegt ${ }^{5}$ ) und daß es sich ferner trotz der im wort "ability" liegenden Possibilitätsbedeutung um einen bereits verwirklichten Vorgang, um ein Leistungsergebnis also, handelt. Vergleicht man die beiden Tätigkeitsbereiche (1) und (2) miteinander und fragt, in welchem Bereich denn mit Blick auf die "Leistungsfähigkeit" die steuer erhoben werden soll, so kommt schneider zu der Antwort, daB sich dies nach dem "Zweck des Wirtschaftens" richten solle. Der aber sei die Bedurfnisbefriedigung (S. 47). Da eine solche nur in der Realisierungs-Sphäre denkbar sei, definiere sich das steueropfer als eine in einem bestimmten Ausma $B$ nicht mehr $z u$ verwirklichende Bedürfnisbefriedigung. Demnach sei eine Besteuerung nach dem Opferkonzept nicht als Besteuerung der Einkommen, sondern der Ausgaben denkbar, es sei denn, man versteht Einkommen als "in Konsumausgaben verwirklichtes Einkommen" (1979a, S. 47).

In seiner Kritik an Haller zeigt Schneider, daB jener Potential und Realisierung vermengt, well er zwar auf das realisierte Einkommen abstelle, zugleich aber mit dem Nutzen aus dem Einkommen potentialbezogen argumentiere: Da sich eine Bedürnisbefriedigung nur aus der Einkommensverwendung ergebe, durfe man nur realisierungsbezogen argumentieren. Obwohl Haller auf die Fähigkeit (siehe auch die Einbeziehung der Freizeit als Ausdruck der Fähigke1t)

3) So wird die Einordnung auch in der Literatur vorgenommen; die Betonung der Argumentationslinie von Schanz uber Haig $z u$ Simons führte $z u$ der Bezelchnung "SHS-Konzept" für die breitest mögliche Einkommensdefinition nach dem Reinvermögenszugang.

4) 1990 , S. $20 \mathrm{f}$. bzw. 1979a, S. $26 \mathrm{ff}$; Schneider befaßt sich hier insbesondere mit dem Beitrag von H. Haller 1977, S. 222 ff.

5) "to pay the same" bzw. "should pay more" heiBt es in der Definition der Leistungsfahigkeit bei Musgrave, R.A. und Musgrave, P.B., 1980, S. 242 . 
abhebe, mache sein Abstellen auf die Bedürnisbefriedigung seine Argumentation verwendungsbestimmt (D. Schneider 1979a, S. 29).

Wir lassen vorerst offen, ob die Leistungsfähigkeit innerhalb der Realisierungssphäre wirklich nur anhand der Mittelverwendung oder nicht etwa auch anhand des Mittererwerbs festgestellt werden kann. Ferner sehen wir davon $a b$, daB die Begriffe Mittelerwerb und Bedürfnisbefriedigung auf nicht vergleichbaren Denkebenen liegen, denn im ersteren Fall liegt eine reale, im letzteren eine seelische GröBe vor. Auch daB die reale sphäre nicht vollständig erfaBt ist, da der Mittelbestand neben dem -erwerb ebenfalls Ausdruck der Verwirklichung sein kann, soll hier nicht als Argument vertieft werden (Vermögen taucht bei schneider stets nur unter den Bedürfnisbefriedigungstatbeständen auf). Wir folgen Schneider jedoch - und das ist hier entscheidend - darin, daB er logische Unvereinbarkeiten offenlegt; Leistung kann tatsächlich nicht am reinen Potential gemessen werden. Die Besteuerung nach der Leistungsfähigkeit kann nicht auf die reine Möglichkeit zur Leistungserzielung abgestellt werden (D. Schneider 1979a, S.38). Demgegenüber ist eine Besteuerung in der Realisierungssphäre auf die Folgen der Entscheidungen ausgerichtet: Steuern kann derjenige zahlen ("ability to pay"), der Leistungserfolge erzielt $h$ a $t$ (das können auch nichtrealisierte Vermögenswertzuwächse sein, denn der zuwachs is $t$ eingetreten, und zwar objektiv nachweisbar, wenngleich noch nicht persönlich realisiert).

II. Ein weiteres Potential-Element liegt in der Besteuerung der Fre i z e i $t$.

a) Musgrave-Musgrave-Kullmer (1975a, S. 117 f.) diskutieren das Freizeitproblem ausschlieblich im Rahmen der Umverteilung und $\operatorname{der} d i s t r i b u t i v e n$ e $i$ e chtigke $1 t$, problematisieren hingegen noch nicht die psychischen Voraussetzungen und zusammenhänge zwischen Freizeit und Arbeitszeit sowie Einkommen (in 1990, S. 110 diskutieren sie das Problem allenfalls peripher, und auch das nur im Zusammenhang mit den Grenzen der Umverteilung. Ausgehend von dem Umstand, daß die Einkommens-FreizeitPräferenzen interpersonal nicht vergleichbar sind, kommen sie 
für die Umverteilung zwischen Personen, die entweder eine hohe Fähigkeit zum Einkommenserwerb haben (und sich dabei in den Präferenzen für groBe bzw. geringe Freizeit unterscheiden) oder eine nur geringe, $z u$ folgender allgemeiner Norm (S. 118): "Das Wohlfahrtsma $B$ und das Verteilungskriterium sollte sowohl Einkommen als auch Freizeit berücksichtigen und die Mischung beider der Entscheidung des einzelnen überlassen." Jedoch geben sie zugleich die Grenzen für die Verwirklichung dieser Norm an, indem sie erstens feststellen, daB für Umverteilungszwecke die Genüsse aus der Freizeit nicht transferierbar sind (S. 118) und daB zweitens die Besteuerung der "potentiellen Einkommensfähigkeit" scheitern muB: sie ist "nicht operational, weil die Einkommenskapazität nicht unabhängig von dem aktuellen Einkommensverhalten eines Individuums bekannt ist" (S. 119). Auch H.C. Simons ${ }^{6)}$ entscheidet sich gegen eine Besteuerung der Freizeit aus denselben steuertechnischen Gründen; er ist im übrigen der Auffassung, daB Freizeit nicht Einkommens-, sondern Konsumbestandteil ist.

b) Was in diesem Zusammenhang interessiert, ist der Umstand, daB die Freizeitproblematik als ein $P \circ t$ e $n t$ a $l$ b e $s t$ e $u$ e $r u n g s k \circ n z e p t$ formuliert wird. Dies unternimmt zunächst B. Hansen (1960, S. 206) mit seiner "leisure tax" als eine Alternative zur Vermögensteuer, ${ }^{1)}$ insbesondere aber H. Haller. ${ }^{8)}$ Er erweitert die bisherigen Betrachtungen dahingehend, daB er die Freizeit als "realen" Bestandteil des Einkommens ansieht; 9) dabei schliebt er sich erstens der Musgrave'schen Knappheitsbetrachtung an (Musgrave, R.A., 1969), greift zweitens auf dessen Nutzenüberlegungen zurück (indem er die Freizeit mit Bedürfnisbefriedigungspotentialen ausstattet) und stellt drittens einen zusammenhang zwischen Vermögenseinkommen und Freizeiteinkommen her. Damit gelingt Haller vollends ein Herüberholen des

6) 1938 , S. $52,111,113,207$.

7) Zur Kritik an einer Besteuerung dieser Art "Vermögenspotential" siehe H. Fecher 1979, S. 477; auch Arbeitslose müBten dann besteuert werden.

8) 1971 , S. 44 ff. u. 62 ff.; 1977, S. 225; 1981, S. $46 \mathrm{ff}$.

9) Er benutzt damit denselben Realeinkommensbegriff wie I. Fisher 1930 , S. $4 \mathrm{ff.:}$ "... real income in general, consists of those final physical events in the outer world which give us our inner enjoyments. ... includes the shelter of a house, the music of a victrola or radio, the use of clothes, the eating of food ...." 
Problems aus den Musgrave'schen Allokationsbetrachtungen in den distributiven Bereich, wandelt die Opportunitätskosten-Fragestellung in eine solche der distributiven Gerechtigkeit und verändert die individuelle Entscheidungssituation in eine gesellschaftliche Lastverteilungsorganisation. 10)

Die Freizeit, für H. Haller (1981, S. 50) ein reales Element der Bedurfnisbefriedigung, ist ambivalent in dem sinne, daß sie einerseits einkommenserzielungsorientiert ist - dies insbesondere im Hinblick auf mehr Freizeit bei denen, die Vermögenseinkommen erzielen ${ }^{11)}$-, daB sie andererseits auch verwendungsorientiert ist, indem Freizeit erst die Einkommensverwendung uberhaupt ermöglicht; und dennoch wird sie nur mit Blick auf die Einkommenserzlelung, nämlich auf die geleistete und vergutete Arbeitszeit bewertet (H. Haller 1971 , S. 47): "Ist die Präferenz zugunsten der Freizeit sehr hoch, die Arbeitszeit und entsprechend das Arbeitseinkommen relativ niedrig, so sollte nicht das freiwillig niedrig gehaltene Geldeinkommen allein als für die Bedürfnisbefriedigung relevantes Einkommen erfaBt werden. Das Mehr an Freizeit ist für die betreffende Person für die Bedürfnisbefriedigung genauso wichtig wie das Mehr an Geldeinkommen, das ein anderer mit abweichender Präferensskala auf Grund seiner Entscheidung fur elne längere Arbeitszeit bezieht." Doch will man das auf Nut zenvorstellungen basierende Verhältnis von Arbeitszeit zu Freizeit besteuern, weist $K$. Schmidt (1978, S. 143) zu recht auf die Probleme hin, die dabei auftreten: Das genannte Verhälnis ist bel den einzelnen Menschen äuBerst unterschiedlich; der Freizeitnutzen ist für alle die sehr gering, die sich in der Arbeit verwirklichen können oder darin ihr Hobby sehen.

10) In diesem Zusammenhang ist auch der Begriff des "opportunity set" zu nennen, den A.B. Atkonson und J.E. Stiglitz verwenden $(1980$, S. 261); er umfaBt die persönliche Ausstattung (endowment) und die Marktmöglichkeiten des einzelnen, die seine "ability to pay" ausmachen und die vom erzielten Geldeinkommen nach dem Reinvermögenszugangskonzept abwelchen können. Auch sie diskutieren das Frelzeitproblem unter Verteilungsaspekten. Gleiche opportunity sets können zu ungleichen Geldeinkommen führen.

$11^{\prime}$ H. Haller 1971 , S. 48; ders. 1977, S. 225 f.: Der Vermögende hat ein höheres Freizeitpotential; kritisch dazu H. Fecher 1979 , s. 476, da Vermögen stets Eigenleistungen erfordere, um Ertrag abzuwerfen. 
Offenbart allein diese Nichtbeachtung der individuellen Entscheidung für Leistung oder Nichtleistung bereits den Normcharakter einer solchen Besteuerung, so geht der Potentialcharakter der Freizeitbesteuerung aus der folgenden Formulierung Hallers (1981, S. 67) noch deutlicher hervor: Wenn erheblich weniger als $n$ or $m$ a 1 gearbeitet wird (z.B. in der Halbtagsarbeit) und in dieser Zeit häusliche Dienste verrichtet werden, so sel beides steuerlich $\mathrm{zu}$ erfassen; allerdings: "Man mübte wissen, was die Betreffenden verdienen $k$ o $n n t e n$, falls sie sich erwerbswirtschaftlich betätigen würden. Man müBte also von jedem einzelnen in Erfahrung bringen, uber welche $F$ ä $h \perp g k$ e $t$ e $n$ und uber welche Ausbildung er verfügt. Unter der Annahme, daB er diese im Falle des Arbeitens voll nutzen würde, könnte man ein entsprechendes $f i k t i v$ e Einkommen errechnen". 12) Hallers normative Vorstellungen enden Im übrigen bei der Arbeitszeit; eine "Normalersparnis" gibt es nach Haller nicht (S. 54). Man ist aber neuerdings geneigt, das anders zu beurtellen, da sie bereits formuliert wurde (z.B. durch J. Rawls) ${ }^{13}$ ) und da die "optimal taxation-Diskussion" ergeben hat, daB ihre Versuche einer selektiven Besteuerung von Arbeits- und Kapitalerträgen in wesentlichen Teilen ein Generationen- und Sparproblem ist (D.F. Bradford). 14) Der "Wert" solcher Postulierungen von Normalerspar-

12) Hervorhebungen durch $\mathrm{HDH}$. So auch in $2981,5.67$.

13) 1975 , S. $319 \mathrm{ff.;}$ der "gerechte Spargrundsatz" ist ein Problem der "Gerechtigkeit zwischen den Generationen", wobei Rawls eine Verbindung $z$ ur Wachstumstheorie herstellt. Als ethisches Prinzip soll der Spargrundsatz dafür sorgen, daB wenn alle Generationen Gewinn haben - jede Generation ihren jeweiligen Antell von ihren Vorfahren empfängt (S. 322). und zwar als Bedingung für die vollständige Verwirklichung gerechter Institutionen und der gleichen Freiheit für alle (S. 326). Danach ist die Sparnorm motiviert durch die politische Anerkennung von MaBnahmen, die den Lebensstandard der am wenigsten Begünstigten in späteren Generationen heben sollen, indem auf augenblicklich verfügbare Vorteile verzichtet wird.

14) 1980, S. 103: "In such models the capital accumulated by one generation becomes the factor cooperating with the next generation's labor in production." Diese Diskussion - gefüht unter dem Aspekt der utilitaristischen Analyse einer wahl der Steuerbasis - geht dann ein in das Problemfeld einer "gerechten Besteuerung", doch - anders als bei Rawls - auf der Basis interpersonaler Nutzenvergleiche. Siehe hierzu auch die Zusammenhänge zwischen Sparen und Wachstumsrate: so als Beispiel bei Phelps, E.S., 1966. 
nissen liegt darin, daB in ihnen das Normative noch deutlicher erkennbar wird als in Arbeitszeitnormen.

d) Kritisch zu solchen Zeitnormen trägt Haller selbst lediglich Erfassungs- und Bewertungsschwierigkeiten vor, die sich aber durch generalisierendes Vorgehen beheben lassen würden. Demgegenüber kann eine profunde Kritik auf drei Argumente gestützt werden: auf ein psychologisches, auf ein wirtschaftspolitisches und schlieblich auf ein gesellschaftspolitisches. ${ }^{15)}$ Erstens ist Nutzen keine meBbare GröBe, selbst wenn man als richtig unterstellt, daB der Freizeitnutzen von Person $z u$ Person variiert. Aber wenn nach Haller Freizeit einen Nutzen vermittelt, kann sie keine "reale" GröBe des Einkommens sein. Zweitens dient die Freizeit der Mehrung des Humanvermögens ${ }^{16)}$ und der menschlichen Fähigkeiten, kommt also auf Umwegen der Einkommenserzielung und damit der Besteuerung von realen ZugangsgröBen zugute. Uberdies entsteht ein Verteilungsproblem, das von vorn herein nicht lösbar erscheint: Wegen der kontraktgebundenen Einkommen ist Freizeit in den oberen Einkommensschichten eher disponibel als in den unteren. Doch bevor man sich entschliebt, Freizeit zu besteuern, muB man erkennen, daB auch oder gerade in den Schichten der unteren Einkommen und erst recht unter den Arbeitslosen die Freizeit mitunter sehr hoch ist. Dies kann nicht als ability to pay definiert werden. Drittens sollten jedwede Normvorgaben auf die Arbeitswelt beschränkt bleiben. Um dem dort herrschenden Leistungsdruck wenigstens zeitweise ausweichen $\mathrm{zu}$ können, sollte ein Freiheitsraum bestehen bleiben. Die Festsetzung von Normen auch für die Freizeit, selbst wenn sie dem Nichtstun dient, ist ein moralisierendes Urteil, das die organisationsvorstellungen der Arbeitswelt auf alle weiteren Lebensbereiche ausdehnen will und freiheitsbeschränkend wirkt.

III. Letztlich sind Possibilitäts-Anschauungen auch mit der Besteuerung des $\mathrm{V}$ e $\mathrm{r}$ ö $\mathrm{g}$ e $\mathrm{n} s$ verbunden, wenn nämlich ungeachtet fehlender Erträge die Substanz des Vermögens besteuert wird ${ }^{17)}$ und wenn ungeachtet der schon vorhandenen vermögensaus-

15) Siehe aber auch insbesondere den überaus umfangreichen Katalog kritischer Kragen bei N. Andel 1979a, S. 342.

16) $\mathrm{Zu}$ den Beziehungen und Rückbeziehungen zwischen Freizeit, Bildung und Humankapital siehe H. Fecher 1979, S. 478.

Fn. 17 auf der folgenden Seite. 
stattung ein Erbanfall lediglich nach Verwandtschaftsgraden unterschiedlich hoch besteuert wird, als ob der entferntere Verwandtschaftsgrad einen höheren Grad von Leistungsfähigkeit auszudrücken vermöchte und als ob der höhere steuersatz für entferntere Verwandte sie $\mathrm{zu}$ höherer Leistung animieren könnte. ${ }^{18}$ Hat der nahe (und niedriger besteuerte) Verwandte bereits Vermögen, der entfernte (und höher besteuerte) aber keines, geht der Zusammenhang zwischen Erbschaftsteuerlast und Leistungsfähigkeit völlig verloren. F. Neumark (1970, S. 171) gibt dieser Unterschiedsbehandlung den besonderen Aspekt der Besteuerung nach der $F$ ä $h i g k$ e $t$, wenn er empfiehlt, die Erwerbsfähigkeit eines Erben (bzw. als deren Indikator das Alter) als einen zusätzlichen Differenzierungsfaktor (neben dem beim Erben bereits vor dem Erbfall vorhandenen vermögen) in Betracht $z u$ ziehen. Die Erbschaftsteuer, die ja ansonsten ihrer Ausgestaltung nach dem Realisierungskonzept (realisierter Erbanfall) folgt, wird durch differenzierte steuersätze in PossibilitätsKonzepte hineingezogen.

AbschlieBend bleibt $z u$ den "Possibilitäts"-Konzepten, seien sie wie bei E.R.A. Seligman offen formuliert, seien sie wie bei $H$. Haller in ein utilitaristisches Konzept eingebettet, kritisch zu sagen, daB sie erstens scheitern müssen, weil sie nichtmeBbare GröBen verwenden und daher für eine Verteilung der Steuerlast, die zudem Vergleichbarkeit der MaBstäbe erheischt, unbrauchbar sind, 19) daB sie zweitens das wesentliche ihrer erwerbsbezogenen $F$ ä $h$ i g $k$ e $t$ s definition verlieren, sobald sie im Bereich der bereits $r$ e $l i s i$ e $r$ e $n$ Einkommen als Ausdruck jener Fähigkeiten Verwendung finden, Konsumausgaben tätigen zu können, oder auf sie zu verzichten. Die Fähigkeit zum Konsum aus realisiertem Einkommen liegt auf einer logisch anderen Ebene als die Fähigkeit, Einkommen zu erzielen.

17) Das reine Vorhandensein von Vermögen ist $z u$ trennen von seinen Erträgen (Einkommen aus Vermögen); H. Haller, der die Besteuerung der Existenz eindeutig bejaht, vertritt somit auch in der Vermögensbesteuerung das Possibilitäts-Konzept.

18) Wenn H. Haller den Zugang des Erbes als Entstehung einer "Leistungsfähigkeit sui generis" interpretiert, kann man nur folgern: generell ja (weshalb mit Höhe des Erbanfalls der Steuersatz ansteigt); speziell - d.h. unter Beachtung des Verwandtschaftsgrades - nicht, denn sonst müBte man konstatieren, daB jemand um so leistungsunfähiger ist, je näher er m1t dem Erblasser verwandt ist.

19) K. Schmidt A 
IV. Einen vortelihaften Effekt der Diskussion um die Possibilitätskonzepte könnte man allenfalls darin erblicken, daB sie den Gedanken der $\mathrm{s} \circ \mathrm{l} l \mathrm{~b}$ e $\mathrm{s} t$ e u e $\mathrm{r} \mathrm{n} \mathrm{g}$, der namentlich von $W$. Andreae $(1927,1928)$ so nachhaltig für die Ertragsteuern vertreten wurde, auch für die Personalsteuern wachgerufen hat und damit zwei Dinge gleichzeitig leistet: zum einen, den Gedanken der Sollbesteuerung vor dem Hintergrund ordnungs- und allokationspolitischer Betrachtung erneut zur Diskussion zu stellen und zweitens, auf den a $l i \circ k$ a $t$ 1 e $n$ Inhalt der Possibilitäts-Konzepte ausdrücklich aufmerksam $\mathrm{zu}$ machen.

Die Problematik einer jeden Sollertragsteuer liegt darin, daB die Lösung des Allokationsziels, nämlich die Umlenkung der Arbeits- und Kapitalströme, ein Urteil uber die relative Wichtigkeit des jeweiligen Wirtschaftszweiges für die Gesamtwirtschaft verlangt. Fehlurtelle zentraler Instanzen oder der Steuerplaner und damit Fehlallokationen sind nicht auszuschlieBen. Auch die steuerpolitische Absicht, die B. Strümpel (1968, S. 150 ff.) äußert, nämlich anstelle der anpassungsverzögernden betrieblichen Gewinnsteuer die "wettbewerbsverschärfenden" Rostensteuern stärker einzusetzen, wurzelt im Normativen.

Das wesentliche allokative Problem der Possibilitäts-Konzepte ist direkt dem in der Ertragsteuer vergleichbar: Da die PossibilitätsKonzepte an sachliche und personale Ausstattungsmerkmale anknüpfen, und da diese Merkmale $\mathrm{zu}$ individuell unterschiedlichen Steuerbelastungen fuhren sollen, ist auch hier eine zentrale Grundentscheldung vonnöten, wer wie mit Blick auf eine möglichst hohe Leistung und einen hohen "Ertragswert" für die Gesamtwirtschaft oder Gesellschaft $z u$ besteuern ist. Damit entpuppt sich aber ein jedes Possibilitäts-Konzept als eine allokative Besteuerungskonzeption reinsten Wassers. ${ }^{20}$ ) Die Besteuerung nach dem Leistungs - $\mathrm{P} \circ \mathrm{t}$ e $\mathrm{n} t \mathrm{i}$ a $l$ hat mit distributiver Politik nicht das geringste zu tun. Und dennoch teilt sie mit der Distributionspolitik etwas Gemeinsames, nämlich ihre abhängigkeit von Werturteilen. Nirgends sonst ist diese Werturteilsbeladung einer wohlfahrtsorientierten Allokationspolitik deutlicher zum Ausdruck gekommen als in der sollbesteuerung ${ }^{21)}$.

20) Probleme der sollbesteuerung werden auch in der optimal taxation diskutiert. So ist in einem Modell von J.A. Mirrless (1971) die Geschicklichkeit eines Arbeiters proportional seinem stundenlohn. Könnte man sie messen, ließe sie sich di- 
10. Kapite1:

Die "Nominalismus"-Konzepte

S 31 Die Konzepte im tberblick und im Gegensatz zueinander

I. Die Abgrenzung zu den "Possibilitäts"Konzepten und der kategoriale Konzeptegegensatz

II. Die steuersystematische Einordnung der Einkommensteuer- und AusgabensteuerKonzepte

III. Der Vergleich der Steuerbasen und Steuerbemessungsgrundlagen

IV. Die allokativen und distributiven Problemschwerpunkte

I. Die "Realisierungs"-Konzepte unterschelden sich von den "Possibilitäts"-Konzepten dadurch, daB sie nicht auf die blobe Möglichkeit zur Erzielung eines Leistungserfolges, sondern auf den bereits erzielten Erfolg abstellen. Die Leistungsfähigkeit soll sich hier in meßbaren EAV - Größen zeigen. Wir verstehen unter Realisierung das erzielte $\mathrm{E} r \mathrm{~g}$ e b $\mathrm{n} i \mathrm{~s}$ des Leistungsprozesses, das sich entweder im Einkommen und Vermögen nach der zugangsregel oder in den getätigten Ausgaben aus beiden zeigt.

a) Der Begriff der persönlichen Leistungs - Fäh $1 \mathrm{~g} k$ e $1 \mathrm{t}$ schliebt psychisch-physische Eigenschaften ein, die sich praktischer Messung und damit intersubjektivem Vergleich von vorn

(Fortsetzung Fn. 20 von der vorigen Seite) rekt besteuern. Eine optimale Steuer wăre dann eine Pauschalsteuer auf Geschicklichkeit. Da in Mirrlees' Modell alle Arbeiter dieselben Präferenzen haben, liebe sich so eln "first best optimum" erreichen (ein allokativ determiniertes "utilitarian optimum", S. 205). - Dasgupta/Hammond (1980) haben die Vereinbarkeit dieser Argumentation mit den Ergebnissen ihrer Analyse des Arbeitsantriebs bel Arbeitern untersucht (incentive compatibility); sie rechnen damit, daB die Arbeiter ihre wahre Geschicklichkeit verbergen und daB - um dem Pareto-Kriterium $z u$ genügen - die Steuer nach einem solchen Schema festzusetzen ist, das niemandem einen Anreiz zum Verbergen seiner Geschicklichkeit gibt, und das nach der Besteuerung "leaves all workers equaliy well off $"$, S. 142. Ein first best optimum der Besteuerung liebe sich dann nur unter restriktiven Modellbedingungen angeben.

21) Zum Gedanken der Sollbesteuerung siehe den Besprechungsauf-

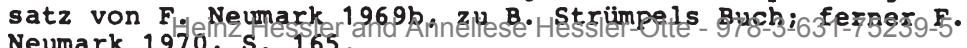
Neumark 1970, S. 165 . 
herein entziehen. "Damit bleibt aber auch die präzise funktionale Beziehung zwischen der Leistungsfähigkeit ... und den $z u$ ihrer Repräsentation ausgewählten ökonomischen Indikatoren unbestimmbar und auf qualitative Plausibilitätsüberlegungen beschränkt" (J. Mitschke 1976, S. 38). Ist aber das konzeptionelle Erfordernis der $M$ e $B$ b a $r$ e i $t$ einmal als notwendig akzeptiert, so folgt, daB auch das sog. "Steueropfer" sich nicht als Nutzenentgang, sondern nur in Zahlen, als Einkommensminderung z.B., feststellen läbt. 1) Die Verwendung des Terminus' Steueropfer, von H. Haller ${ }^{2}$ zudem als BedürfnisbefriedigungseinbuBe aufgefaBt, legt prima facie nahe, die Bedürfnisbefriedigung sei notwendigerweise mit dem Nutzenbegriff verbunden. Das ist aber keineswegs der Fall. So hält R.M. Haig ${ }^{3)}$ die Bedürfnisbefriedigung nur dann für ökonomisch bedeutsam, wenn sie empfänglich ist für eine Bewertung in Geld; aus Gründen der Praktikabilität sei es nötig, psychische Faktoren auBer Betracht zu lassen.

b) Mit dem Abstellen auf die Realisierung ist zugleich eine k a $\mathrm{e} g \circ \mathrm{r} i \mathrm{a}$ l e $\mathrm{E} i \mathrm{n} t$ e $i \mathrm{l}$ u g gewonnen, denn die Notwendigkeit, Leistungsfähigkeit (aber auch Bedürfnisbefriedigung) ökonomisch definieren und praktisch erfassen zu müssen, führt überhaupt nur zu zwei Möglichkeiten: (a) zu einer Ausgaben- bzw. Konsumsteuer (hier drückt sich die Geldbewertung des Bedürfnisses in den Preisen aus), (b) zu einer Einkommensteuer (hier liegt der Geldausdruck des Bedürfnisses im geldwerten $\mathrm{Zu}$ gang an ökonomischen Größen. Eine Vermögensteuer kann ergänzend hinzutreten. Danach kommen wir, was die in den Konzepten enthaltenen Steuerbasen betrifft, $z u$ einer grundlegenden Gegenüberstellung der Konzeptgruppen "Einkommens- versus Ausgabensteuerung". In diesen Gegensatzkategorien hat nach unseren Ausführungen in den $\$ \$ 8$, 11, 21-24 die alte Fragestellung "Quellentheorie oder Reinvermögenstheorie" keinen Platz mehr. Weder die der Quellentheorie zu-

1) K. Littmann 1968 , S. 179: "Der Nutzenentgang eines Wirtschaftssubjekts, der durch eine steuerauflage verursacht wird, bleibt empirisch immer unbestimmbar. Hingegen kann die Einkommensminderung des belasteten Wirtschaftssubjekts prinzipiell festgestellt und auch numerisch ausgedrückt werden."

2) 1971 , S. $69 \mathrm{f}$; Leistungsfähigkeit ist gleich Opferfähigkeit. - So auch in 1981, S. 74 .

3) 1959, S. 58; zur Unterstützung der Haig'schen Argumentation kann angeführt werden, daB die letztlich der Bedürfnisbefriedigung dienenden Bedarfsdeckungs- und Kaufakte sich mone-

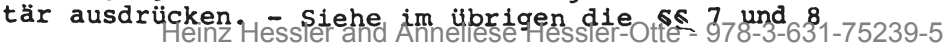


grunde liegende Einkommensperiodizität ${ }^{4}$ noch die mit inr verbundene ökonomische Tätigkeit ${ }^{5}$ ) sind angesichts des in der Reinvermögenszugangstheorie angegangenen "comprehensive tax base-Problems" fürderhin von Interesse ${ }^{6)}$. Umfassender wird nämlich das Indikator- und Basisproblem von dem Gegensatz "E i n k $0 \mathrm{~m}$ e n s vers us A u g a b e $n$ - Besteuerung beschrieben 7) 8).

II. Um die Vielzahl der Konzepte zu ordnen, soll der KonzepteGegensatz "Einkommens- versus Ausgabenbesteuerung" in den Rahmen $\operatorname{der} s t$ e u e r y $s t$ e $m$ a $t i k$ gerückt werden.

a) Dient die persönliche Ausgabensteuer als $E r s$ a $t z$ (replacement) oder zur E r g ä $n z$ u $g$ (supplement) der Einkommensteuer? Letzterenfalls wird sie unter dem Aspekt der Leistungsfähigkeit vorwiegend "einigen wohlhabenden" auferlegt, um entweder extravaganten Aufwand $z u$ besteuern oder etwaige nicht besteuerte Einkommen (z.B. capital gains) nachträglich zu erfassen; 9) als "allgemeine und persönliche", d.h. den gesamten Konsum erfassende und mit persönlichen Freibeträgen ausgestattete steuer vermeidet sie in diesem Fall die allokativen und distributiven Nachteile von "Steuern auf spezielle Güter", da sie ähnlich der

4) Zu den Fragen der Periodizität siehe: G. Cohn 1885 u. 1889; A. Wagner 1892 ; F.J. Neumann 1887 u. 1896; E. V. Philippovich 1926 ; A. Schäffle 1895/97; E.R.A. Seligman 1919.

5) Zu Fragen der ökonomischen Tätigkeit siehe: W.G.F. Roscher 1901 u. 1922; W. Vocke 1894; A. Held 1872; Lexis 1906; พ. Lotz 1931 .

6) Dies nicht zuletzt, weil die Quelle nicht einmal eindeutig definiert ist; B. Moll 1924, S. 127. Siehe ferner die umfassende Darstellung bei H. Laufenburger 1956, S. $460 \mathrm{ff}$.

7 ) Die Kritik von J. Popitz (1926, S. 415) an der Quellentheorie richtet sich u.a. darauf, daB die Unterscheidung des persönlichen Einkommens vom unpersönlichen Ertrag in der Quellentheorie nicht beachtet wird; "der Einkommensbegriff verliert damit an Eigenart, das Einkommen wird $z u$ einem Bündel der Quellenerträge ..."

8) Siehe auch Musgrave/Musgrave 1980 , S. $242 \mathrm{f}$. , die als das wesentliche Indikatorproblem im Rahmen der Besteuerung nach der Leistungsfahigkeit die "Wahl der Steuerbasis (choice of tax base) ansehen als eine wahl zwischen "income versus consumption as tax base". So auch R.M. Haig 1959, S. $58 f$.

9) C.S. Shoup $1969, \mathrm{~S} .345 \mathrm{ff}$. Allerdings ist $z$ u bemerken, da $B$ von der Rechtfertigung der nachträglichen Erfassung auch solche Steuerpflichtige betroffen werden, die bereits vorher ihre

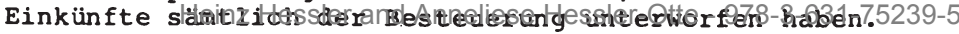


allgemeinen Umsatzsteuer vom Konsumtyp ${ }^{10)}$ den konsumtiven Aufwand generell erfaBt (unter Freilassung eines wie hoch auch immer bemessenen Grundkonsums) und die allokativen Nachteile einer excess burden sowie von Produktionsumlenkungen, die mit den Steuern auf spezielle Güter (das sind traditionell die Einzelverbrauchsteuern) verbunden sind, nicht aufweist. Steuerliche Sonderbelastungen sind mit der Ausgabensteuer systematisch gesehen nicht $z u$ vereinbaren. ${ }^{11)}$

b) Sämtliche in der Literatur vertretenen Realisierungs-Konzepte, seien sie der Einkommens- oder der Ausgabenbesteuerung zuzuordnen, zeigen die auch aus der allgemeinen steuersystemlehre bekannte

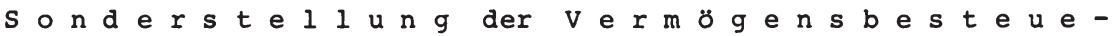
$r$ u $\mathrm{ng}$, und zwar

(1) in Form der (einmaligen oder laufenden) Besteuerung des Vermögensbestandes sowie der Vermögensnutzung,

(2) In Form der Besteuerung des Vermögenszugangs, habe dieser seinen Grund entweder
(a) im Sparakt,
(b) im Erb- und Schenkungsvorgang oder
(c) in öffentlichen UmverteilungsmaBnahmen, und schlieblich

(3) in Form der Besteuerung der Wertsteigerung des vorhandenen Vermögens, die ihren Grund entweder
(a) marktlichen Vorgängen oder
(b) politischen Maßnahmen verdankt.

Aus dem Blickwinkel idealer Rationalsysteme wird einerseits der Vermögensteuer wie der Erbschaft- und Schenkungsteuer ein systemergänzender und gleichrangiger Platz neben der $\mathrm{E} i \mathrm{n} \mathrm{k} \circ \mathrm{m}$ e $\mathrm{n}$-, Körperschaft- und Umsatzsteuer eingeräumt (Neumark), 12) werden

10.) Musgrave-Musgrave-Kullmer 1988, S. 301; so auch H. Timm 1980, S. 194 .

11) DaB Sonderverbrauchsteuern auch in einem Steuersystem ohne persönliche Ausgabensteuer nicht mit der Besteuerung nach der Leistungsfähigkeit $\mathrm{zu}$ vereinbaren sind, interessiert hier nur am Rande.

12) 1970 , S. $390 \mathrm{ff.;}$ die Vermögensteuer $z$ u einem proportionalen Satz; die Erbschaft- und Schenkungsteuer elnschlieBlich der Tote-Hand-Steuer"; die unterschiedliche Leistungsfähigkeit

(Forts. siehe folgende Seite) 
andererseits die Vermögensteuer sowie die Erbschaft- und Schenkungsteuer neben bestimmten Einzelverbrauchsteuern als "Nebensteuern" bezeichnet, die die Besteuerung nach der Leistungsfähigkeit durch die "Hauptsteuern" (Einkommen- und Umsatzsteuer) ergänzen sollen (Haller). 13) Neumark (1970, S. 142-146) konkretisiert die steuersystematischen Bezüge wie folgt: Zunächst besteht ein Zusammenhang zwischen einer allgemeinen Umsatzsteuer und Einzelverbrauchsteuern jedweder Art, nämlich dergestalt, daB letztere, sofern eine Umsatzsteuer existiert (dies zumeist zusammen mit der Einkommensteuer), uberflüssig sind. Unter Leistungsfähigkeitsgesichtspunkten lassen sich Einzelverbrauchsteuern nicht rechtfertigen, da schon die Einkommensteuer in Verbindung mit der allgemeinen Umsatzsteuer diesem Gebot genügen. Nun kann man aber unter den Einzelverbrauchsteuern solche hervorheben, die Neumark als "Spezialabgaben auf Gebrauchsgegenstände von relativ hohem spezifischem Wert" bezeichnet, und die nach Neumark in einem AusschluBverhältnis nicht etwa zur Umsatzsteuer, sondern zur allgemeinen Vermögensteuer stehen. Das Entsprechungs- und AusschluBverhältnis wird deutlicher, wenn wir diese spezialabgaben mit Steuern auf die "Vermögens $n u t z$ u g" gleichsetzen, wobei der "relativ hohe spezifische Wert" sich im Terminus "Vermögen" ausdrücken soll. Nach Neumark soll nun, wenn keine Vermögensnutzungssteuern erhoben werden, wenigstens eine allgemeine Vermögensteuer existieren; wenn aber keine allgemeine Vermögensteuer besteht, soll im Sinne der Leistungsfähigkeitsbesteuerung zumindest eine Vermögensnutzungssteuer erhoben werden. Da Neumark für eine allgemeine Vermögensteuer eintritt, folgt daraus die Ablehnung einer Besteuerung von Nutzungen aus Vermögensgegenständen mit "relativ hohem spezifischem Wert", in die streng genommen die Kraftfahrzeuge und die eigengenutzte Wohnung einzuschlieBen

Forts. Fn. 12:

wird in der Erbschaft- und Schenkungsteuer insbesondere durch die Berücksichtigung des Familienstandes, der Erwerbsfähigkeit des Erben und des bei ihm bereits vorhandenen Vermögens berücksichtigt; 1970 , S. 170 .

13) Die Vermögensteuer mit geringen Freibeträgen und einem allenfalls mäBig gestaffelten Tarif; die Erbschaft- und Schenkungsteuer, nach Verwandschaftsgraden progressiv, soll die Ver-. mögensbildung für die engere Familie unterstützen: 1971, 1981 $\S \S 19$ u. 20. - 1981, S. 358: Die VSt besteuert den von der ESt nicht erfabten Freizeitnutzen, jedoch soll sie nur jenes Vermögen besteuern, das zugegangen ist, ohne da $B$ Konsumverzicht geleistet wurde (S. 359). 
wären. ${ }^{14)}$ Die Vermögensteuer würde demnach alle sonstigen oben in (1) bis (3) aufgewiesenen Tatbestände, also Bestände, Zugänge und Wertstelgerungen, umschlieBen. Die Erhebung einer solchen Vermögensteuer in Verbindung mit der Erbschaft- und Schenkungsteuer wird unter Hinweis auf eine erhöhte Angebotselastizität auf dem Arbeitsmarkt und auf höhere Kreditfähigkeit gerechtfertigt, ${ }^{15}$ ) so daB die Einkommensbesteuerung als ein "erster Ansatzpunkt" für die Bestimmung der individuellen Steuerfähigkeit gilt (F. Neumark 1970, S. 135). Die Vermögensteuer wird also innerhalb der Einkommensbesteuerungs-Konzepte stets als ergänzendes Element gesehen, und zwar entweder als ein inkorporiertes im RVZ/SHS-Konzept oder als ein gesondertes Element neben der "gemischten" Einkommensbesteuerung.

Auch für die A u s g a e n s $t$ e u e $r-k \circ n z$ e $t$ e hat die Vermögensbesteuerung eine besondere Bedeutung, ja sie erweist sich als Abgrenzungskriterium der "reinen" Ausgabensteuer (Kaldor) von den "kombinierten" Konzepten der Ausgabensteuer (I. Fisher, D. Schneider, J. Mitschke). Die reine Ausgabensteuer kennt bewuBt keine Besteuerung des Vermögens (Kaldor befürwortet lediglich die Erbschaftsteuer), vermeidet somit Diskontierungsund Bewertungsnotwendigkeiten und verschiebt bestimmte streitpunkte, die der Einkommensteuer eigentümlich sind, wie Probleme des zugerechneten Einkommens (imputed income), der Kapitalwertsteigerungen (capital gains und damit die Probleme distributiver Vorteile für Vermögensbesitzer) ${ }^{16)}$ bis zur Auflösung des Vermögens (C.S. Shoup 1969 , S. 345 f.).

14) Die von Neumark (S. $141 \mathrm{f}$.) aufgezählten Gegenstände, die mit Spezialabgaben belegt werden könnten (Juwelen, Pelze, Parfums, Champagner) haben eindeutig den Charakter des gehobenen Aufwandes und des Luxus', sind jedoch - da sie von ihm in die Nähe zum Vermögen gerückt werden - ergänzungsbedürftig.

15) F. Neumark 1970, S. 138 u. 165 ff.; H. Haller 1971 , S. 339 ff.: Vermögen und Verzicht auf Arbeitsfron, Vermögen und zusätzlicher Freizeitnutzen, vermögensabhängige Leistungsfähigkeit.

16) Sparen aus laufendem Einkommen und Wertsteigerungen des vorhandenen Einkommens tendieren danach, größere Vermögen stärker wachsen $z u$ lassen als mittlere und kleinere Vermögen, so daB die Vermögensverteilung ungleichmäBiger wird, während der Nettoeffekt staatlicher und privater Umverteilung ungewi B ist; so A. Stobbe 1975, S. 307. 
Das kombinierte Ausgaben-Vermögens-Konzept dagegen sieht in der Vermögensteuer eine leistungsfähigkeitsbezogene Ergänzung der reinen Ausgabensteuer, die zudem die allokationspolitische Einseitigkeit der Sparförderung korrigiert. Schlieblich läBt sich innerhalb des "kombinierten Einkommens-Ausgaben-Konzepts", das die traditionelle Einkommensteuer mit der reinen Ausgabensteuer ergänzen will, sowohl eine stellungnahme gegen als auch für die Vermögensteuer nachweisen: Gegen eine Vermögensteuer votieren W.D. Andrews und N. Kaldor, wobei letzterer seine reine Ausgabensteuer jüngst auch in das Einkommens-Ausgaben-Konzept eingebracht hat. Für eine Vermögensteuer plädiert G. Krause-Junk, der die Ausgaben gegenüber dem Einkommen für den besseren Indikator hält, demnach eine die Einkommensteuer ergänzende Ausgabensteuer befürwortet, diese Kombination aber durch eine Besteuerung des Vermögensbesitzes erweitern will.

c) Die Realisierungs-Konzepte der Besteuerung nach der Leistungsfähigkeit lassen sich systematisch in der Ubersicht 10.1 darstellen, wobei grundsätzlich drei Konzept-Gruppen unterschieden sind:

(1) die Einkommens-Konzepte, (2) die Ausgaben-Konzepte und (3)

das Einkommens-Ausgaben-Konzept für die Kombination von (1) und

(2). Innerhalb der ersten beiden Gruppen ist im Hinblick auf die Sonderstellung der Vermögensbesteuerung eine Zweiteilung vorgenommen worden: Das "Reinvermögenszugangs"-/Schanz-Haig-Simons-Konzept" (1a), das von einer Integration des Vermögens in den Einkommensbegriff ausgeht, und das "gemischte Einkommens-Konzept" (1b), das wie die gegenwärtig in der Bundesrepublik angewendete Besteuerung erstens in der Einkommensteuer Teile des Reinvermögenszugangsund Teile des Quellenkonzeptes enthält und zweitens daneben Vermögen und Erbschaften ergänzend besteuert. Innerhalb der zweiten Gruppe trennt abermals die Vermögensbesteuerung die Untergruppen voneinander: Als "reines Ausgaben-Konzept" (2a) wird bezeichnet, wenn in der Einkommensverwendung allein die Konsum-, nicht die Sparverwendung des Einkommens besteuert wird; kombiniert mit der Vermögensteuer wird eine solche Besteuerung das "kombinierte Ausgaben-Vermögens-Konzept (2b) genannt.

Schlieblich ist in der dritten Gruppe von Konzepten eine Vermögensteuer teils gefordert, teils abgelehnt worden; soweit das Vermögen neben dem Einkommen besteuert werden soll, läBt sich 
Ubersicht 10.1: Die Realisierungs-Konzepte der Leistungsfähigkeitsbesteuerung

1) Einkommens-Konzepte

Einkommens- und Vermögensbesteuerung

- integriert:

- gesondert:
2) Ausgaben-Konzepte

persönliche Ausgabensteuer

- anstelle der Einkommensteuer: $2 \mathrm{a}), 2 \mathrm{~b})$

- ergänzend zur Einkommensteuer: 3) 1a) "RVZ/SHSKonzept" integriertes Einkommens-Vermögenskonzept, s. \$ 32 .
Vermögens-

(und Erbschafts-)

besteuerung 1b) "gemisohtes EinkommensKonzept "

RVZ/Quellen-Besteuerung + ergänzende Vermögens - und Erbschaftsbesteuerung, s. 6.-8. Kapitel
2a)"reines Aus- gaben-Konzept" persönliche Ausgabensteuer ohne Vermögensbesteuerung, s. $\$ 33$.

2b)"kombiniertes AusgabenVermógensKonzept" persönliche Ausgabensteuer + Vermögensteuer (einmalige oder laufende) s. \$34.

3)

"kombiniertes

Einkommens -

Ausgaben -

Konzept"

Persönliche Ausgabensteuer

+ Einkommensteuer, s. \$35 
diese Gruppe entweder als eine Mischung von $1 \mathrm{~b}$ mit $2 \mathrm{a}$ oder als eine Mischung von $1 \mathrm{~b}$ und $2 \mathrm{~b}$ deuten.

Mit Ausnahme des Konzeptes $1 \mathrm{~b}^{17}$ ) werden im folgenden die allokativ-distributiven Probleme der Konzepte dargestellt. Die Konzepte werden auBerdem immer auch im Vergleich miteinander beurteilt, was stets $\mathrm{zu}$ einer Abwägung zwischen Einkommens- und Ausgabenbesteuerung zwingt. Das Schwergewicht liegt auf der Steuerbasis, teilweise auf der Steuerbemessungsgrundlage. Es läBt sich aber - entgegen der sonst in dieser Arbeit durchgehaltenen Abgrenzung nicht vermeiden, immer dann auch Tariffragen $z u$ berühren, wenn das zur vollständigen Beurteilung des Konzeptes notwendig ist; dies 1st bei der Beurteilung von Belastungs- und Wirkungsproblemen regelmäBig der Fall. Wirkungen der unterschiedlichen Konzeptionen werden nur insoweit verfolgt, wie sie auf die steuerbasis ausstrahlen und einen allokativ-distributiven Konflikt hervorrufen.

III. Die folgende Gegenüberstellung der Einkommensbesteuerung (Ubersicht 10.2) ${ }^{18}$ ) $\mathrm{mit}$ der Ausgabenbesteuerung (Ubersicht 10.3) 19) soll eine grundsätzliche Vorstellung davon vermitteln, wie in den beiden Grundkonzepten die $s$ e $u$ e $r$ b $s$ e $n$ und $B$ e $m$ e s u n g s g $x$ u $\mathrm{d} I$ a g e $n$ hinsichtlich der 0 bje $k$ t vierungs - und $p$ e rsonalisierungs be $r$ e $i \mathrm{c}$ h e organisiert sein können. Keineswegs soll darin der

17) Das "gemischte Einkommens"-Konzept ist das in der Bundesrepublik praktizierte; seine Darstellung ist der Inhalt der Kapitel 6 bis 8 . Der Terminus "gemischt" bezieht sich auf den Einkommensbegriff, der neben produktionswirtschaftlichen und transferiellen Zugängen an ökonomischen GröBen auch solche aus der Vermögensnutzung und -wertsteigerung enthält und insoweit eine (besteuerungs-)konzeptionelle "Mischung" genannt werden kann und den wir ferner als elnen allokativ-distributiven "Mischbegriff" beschrieben haben.

18) Die Einkommensbesteuerung wird nachgewiesen in dem für die Bundesrepublik geltenden "gemischten Einkommens"-Konzept, das eine Einkommensteuer samt ergänzender Vermögen- und Erbschaftsteuer umfaBt. Es soll als ein Beispiel einer relativ breit angelegten Einkommensbesteuerung gelten.

19) Es handelt sich um ein Schema der indirekten Konsumermittlung, das im wesentlichen auf $\mathrm{N}$. Kaldor zurückgeht (1955), hier wledergegeben in Anlehnung an die Fassung von R. Peffekoven $1979 a$, S. 420 ff. 
Ubersicht 10.2: Der Objektivierungs- und Personalisierungsbereich im System der Leistungsfähigkeits-Indikatoren und -Gestaltungen in der geltenden Einkommens- und Vermögensbesteuerung der BRD

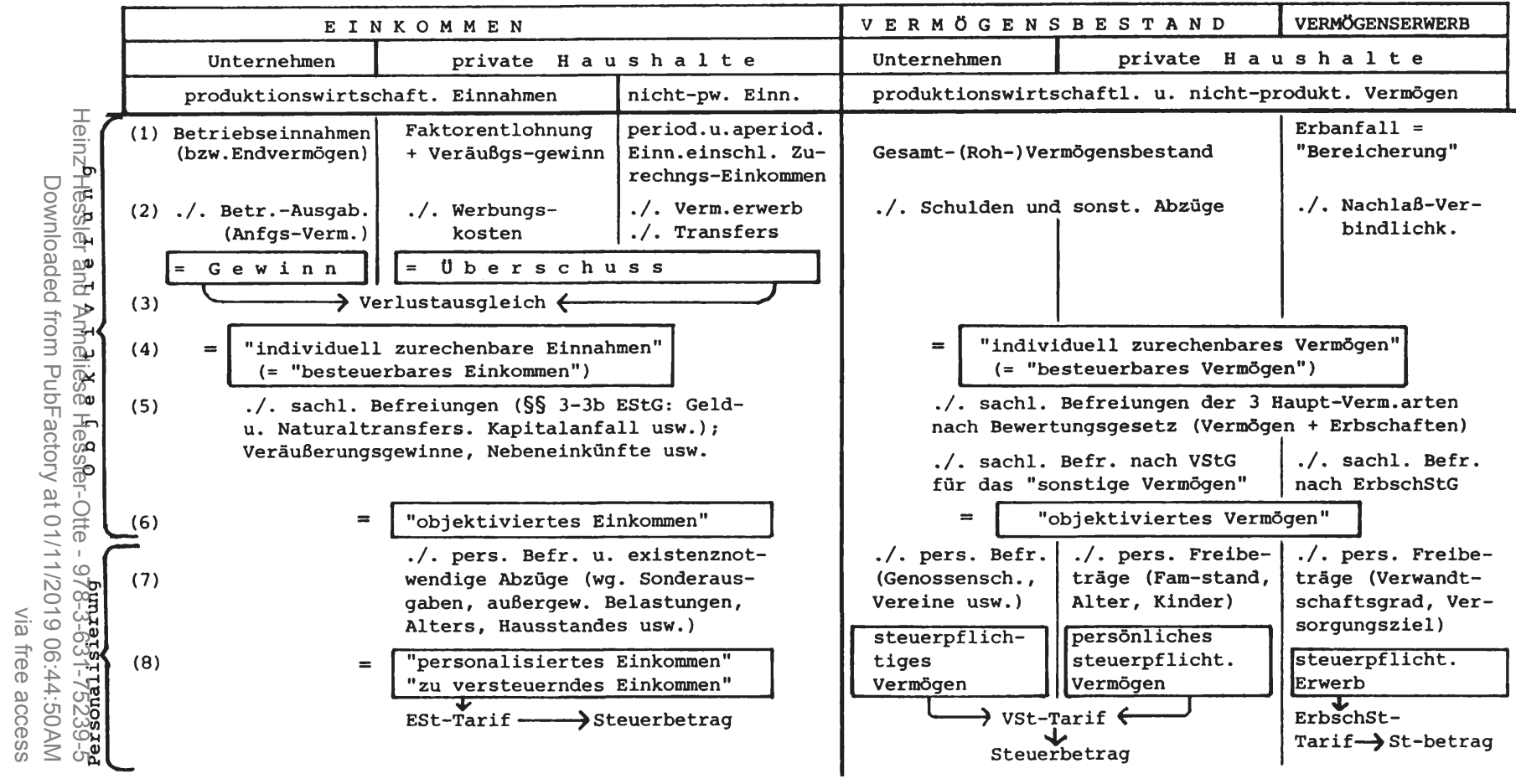




\section{Erläuterungen zu Ubersicht 10.2:}

(1) Die Ubersicht zeigt eine Einteilung der Leistungsfähigkeitsindikatoren Einkommen, Vermögensbestand und -erwerb in einer simultanen Unternehmens- und Haushaltsbesteuerung;

(2) die ubersicht enthält z.T. steuerrechtliche Termini, doch nicht in den drei Kopfzeilen und auch nicht in den GröBen der "individuell zurechenbaren" Wertezugänge und -bestände des Objektivierungsbereichs;

(3) die nichtproduktionswirtschaftlichen Einnahmen enthalten z.B. auch Glūcksspieleinnahmen, Transfers, aperiodische Kapitalanfālle usw., also u.a. sämtliche Befreiungstatbestände der $\S \S 3-3 b$ EStG; der Erbanfall wird eliminiert, weil er gesondert erfaBt wird; Transfers sind st-frei.

(4) "Sachliche" Befreiung heiBt: einkunftsart-, vermögensart- und erwerbsartbezogene Befreiung, obwohl sie (natürlichen und juristischen) Personen zustehen; für den Unternehmensbereich endet mit den sachlichen Befreiungen die Subjektivierung; die persönlichen Befreiungen sind ausschlieBlich Gegenstand der Personalisierung, hier nicht behandelt,

(5) "persönliche" Befreiungen sind an die Existenz und die sozialen Merkmale der natürlichen Personen und der privaten Haushalte gebunden. Insoweit könnte die "persönliche" Befreiung bestimmter juristischer Personen (Genossenschaften, Vereine usw.) von der Vermögensteuer ebenso gut als eine sachliche Befreiung verstanden werden.

\section{Anmerkung zu Ubersicht 10.3, Zeile "Bruttoausgaben":}

xx) Bis zu den Bruttoausgaben entspricht das Berechnungsschema der Formel, die D.F. Bradford (1980, S. 78 f.) für das Konzept des Konsums verwendet. Bradford versucht, eine Analogie zum SHS-Konzept herzustellen.

$\mathbf{x x x}$ ) Wertsteigerungen bei langlebigen Gebrauchsgūtern, bei Wohnungen usw. sollten nach R. Goode (1980, S. 51) in die Bemessungsgrundlage einbezogen werden, da eine Wertsteigerung impliziert, daB der jährliche Nutzungswert dieser Güter gestiegen ist. 
Ubersicht 10.3: Der Objektivierungs- und Personalisierungsbereich in der persönlichen Ausgabensteuer nach der Methode der indirekten Konsum-Ermittlung $(x)$

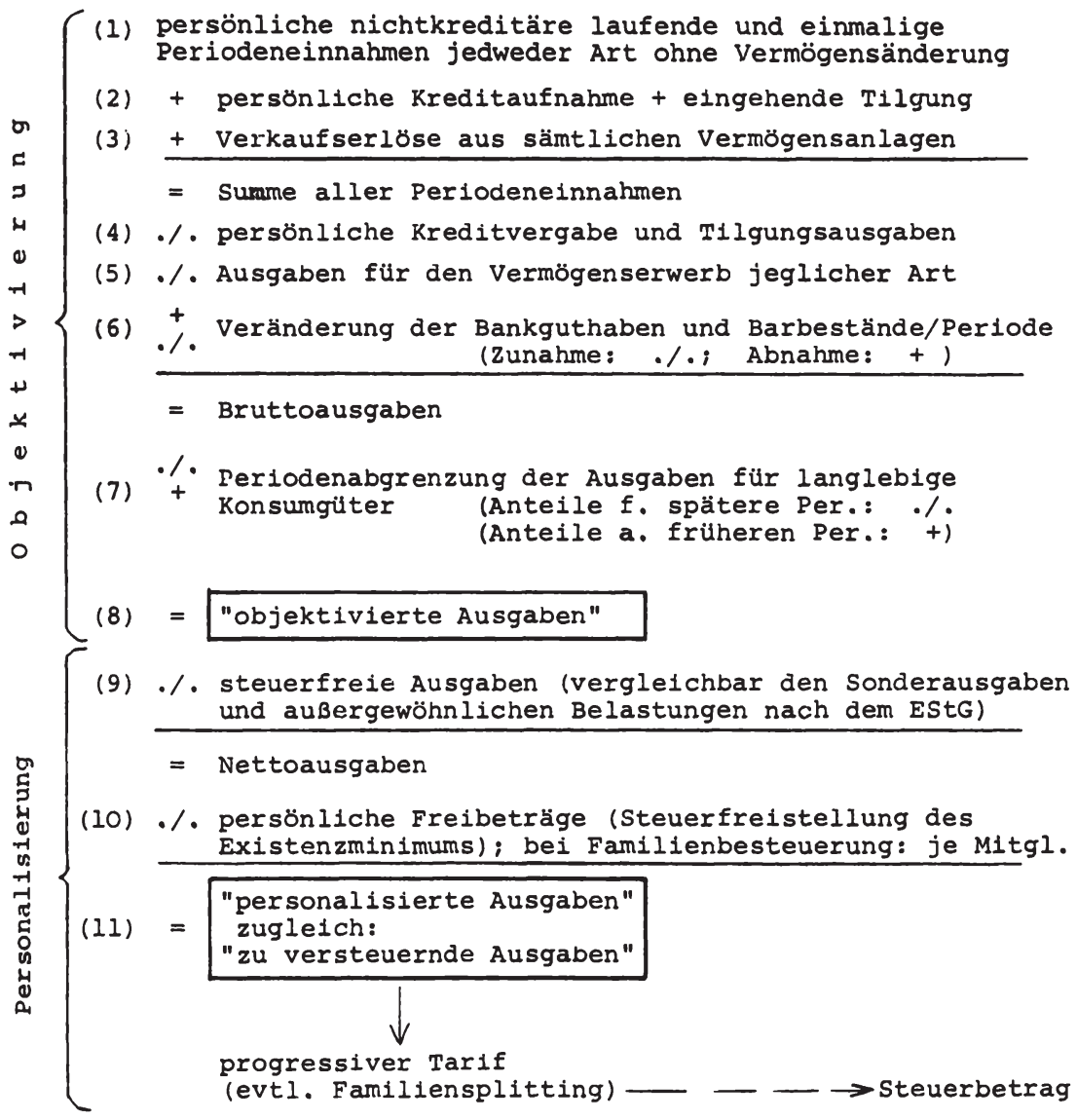

(x) Vgl. dagegen jenes Meßkonzept, das nicht von den Periodeneinnahmen nach den einkommensteuerrecht 1 ichen Vorschrifter. ausgeht, sondern auf'der Zahlungsmittel-, der Geldvermögensund der vermögensebene ansetzt, so J. Mitschke 1976 und 1980. 
logisch unzulässige Versuch erblickt werden, ein Realsystem (Einkommensbesteuerung) mit einem Idealsystem (Ausgabenbesteuerung) zu vergleichen. 20 )

Die Gegenüberstellung zeigt, daB die allokatıv und distributiv unterschiedlichen Probleme in den Konzepten ausschlieblich im objektivierungsberelch angesiedelt sind. Auf den ersten Blick bereits wird deutlich, daB die steuerbasen unterschiedlich breit sind und zudem in sich differenzierende Merkmale aufweisen. Die Basis der Einkommensbesteuerung ist wesentlich breiter.

Das besondere Steuerbasis-Merkmal der Einkommensbesteuerung, das sich genauso im RVZ-/SHS-Konzept findet, ist die simultane Unternehmens- und Haushaltsbesteuerung für natürliche Personen und Personengesellschaften. Allokativ motivierte Abzüge für Betriebsausgaben, Werbungskosten und Schulden (Zeile 2) mindern die distributiven GröBen des "individuell zurechenbaren Einkommens" bzw. "Vermögens" (Zeile 4).

Das ist beim Ausgabensteuer-Konzept nicht der Fall. Steuerbasis ist hier die Summe der Konsumausgaben einschlieblich der kreditfinanzierten, aber nur der persönlichen. Das allokationspolitische Schwergewicht dieses Konzeptes liegt in der Steuerschonung des Sparens, die sich im Schema der indirekten Konsumermittlung wie folgt wiederfinden läBt: Von der summe der Periodeneinnahmen wird die Summe der Netto-Ersparnisse abgezogen, sei sie ein Vermögenserwerb, eine Kreditvergabe samt Tilgung oder eine Zunahme der Bank- und Bargeldguthaben bzw. -bestände (Zeilen 4-6). Allokations- und Abgrenzungsprobleme ruft der ebenfalls $z$ ur Erspar-

20) Ein korrekter Vergleich zwischen Einkommens- und Ausgabenbesteuerung muß anhand der Idealsysteme vorgenommen werden, darf also nicht die Vorzüge einer idealen Ausgabensteuer den Nachteilen einer falsch praktizierten Einkommensteuer gegenüberstellen und umgekehrt. Wenn dennoch Technik- und Praktikabilitätsfragen auch in theoretischen Uberlegungen eine Rolle spielen, so müssen sie für beide Konzepte nachgewiesen werden. Oftmals greifen die Befürworter der Ausgabensteuer bestimmte Fehlkonstruktionen des Einkommensteuerkonzeptes (etwa in der Bewertungsfrage) an, die thr eigenes konzept vermeidet. Insofern kann der Kritik von w. Vickrey $(1970$, S. 117) an der Ausgabensteuer nicht vollständig beigepflichtet werden. Siehe jedoch A.R. Prest (1979, S. 257), der beklagt, daB auch das Meade Committee (1978) in seinem Plädoyer für die Ausgabensteuer die Tendenz zeige "to compare the imperfect present with the perfect future." 
nis zählende Saldo zwischen den Ausgabenanteilen für die langlebigen Konsum (Gebrauchs) güter hervor (Zeile 7). Eine steuerliche Schonung des Sparens ist im RVZ-Konzept gerade nicht beabsichtigt.

Ansonsten zeigt der Vergleich der Personalisierungsbereiche, daB sich distributive Probleme in belden Konzepten durch die Einführung von persönlichen Befreiungen und Freibeträgen in gleicher Weise lösen lassen.

IV. Die Konzepte der Einkommens- und Ausgabenbesteuerung weisen unterschiedliche a $1 \mathrm{l} \circ \mathrm{k}$ a $i \mathrm{v} e$ und $\mathrm{d} i \mathrm{~s} t \mathrm{r}$ b u $t$ $v$ e Probleme auf. Diese entstehen ferner für die drei Instrumentierungsbereiche objektivierung, Personalisierung und Individualisierung verschieden.

a) Weist man die Probleme (s. Ubers. 10.4) schwerpunktmäßig aus, so ist festzustellen, daß distributive Probleme sowohl in der Personalisierung als auch in der Individualisierung auftreten, aber in einer Weise, die nicht konzeptspezifisch ist: Die Freibetrags- wie auch die Tarifregelung bei Individuen und Personenmehrheiten ist keine Frage der Entscheidung für eine Einkommens- oder Ausgabenbesteuerung. Anders bei Allokationsproblemen, die vorwiegend in der objektivierung auftreten.

b) Die allokativ-distributive Problematik im Gegensatz der Konzepte "Einkommens- versus Ausgabenbesteuerung" zeigt sich innerhalb des 0 b jektivi e r u g s b e r e $i c h s$ der Leistungsfähigkeit darin, daB das $E i n k \circ m m e n s k \circ n z p t$ für die $d i s t r i b u t i v e n$ Interessen die breitere Grundlage bietet. Bereits die horizontale Gerechtigkeit erfordert eine breite steuerbasis, und diese verbessert die Möglichkeiten der vertikalen Gerechtigkeit (Atkinson/Stiglitz 1980, s. 567).21)

21) DaB diese breitere Basis evtl. In der steuerlichen Praxis durch vielfältige Befreiungen und Privilegierungen "erodiert" und solchermaBen die Chancen der gerechten Besteuerung verspielt, ist ein Argument aus dem Bereich des Realsystems, nicht des Idealsystems. 
Ubersicht 10.4: Schwerpunkte der allokativ-distributiven Problematik in alternativen Besteuerungs-Konzepten

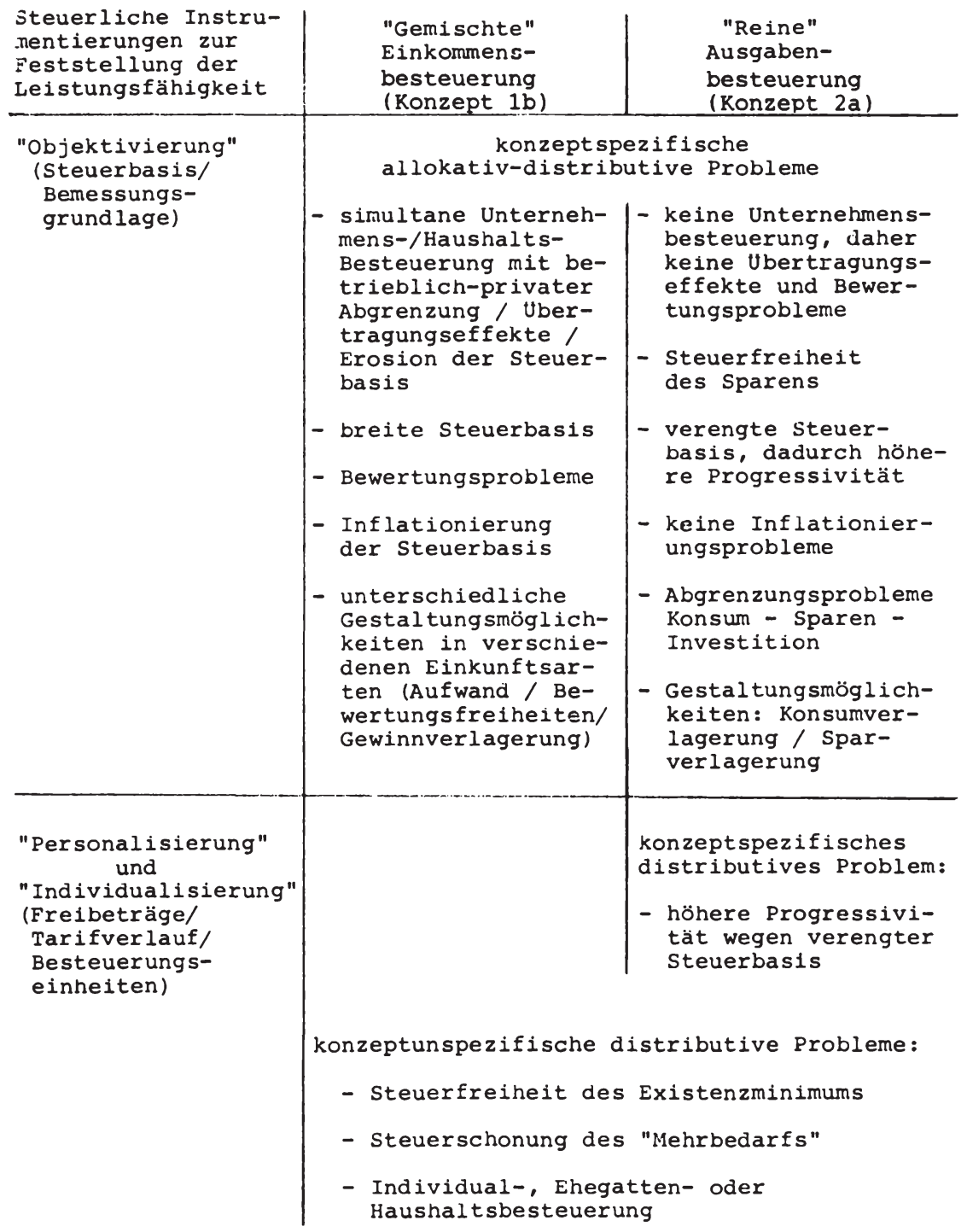


Die allokativ-distributiven Probleme zeigen sich weiterhin darin, $\mathrm{daB}$ im $A$ u $s \mathrm{~g} b$ e $\mathrm{n} \circ \mathrm{nz}$ e $\mathrm{t}$, obwohl es manche seiner Befürworter gerade aus distributionspolitischen Gründen für besser halten als das Einkommenskonzept, das $A 11 \circ \mathrm{k}$ a $\mathrm{i} \circ \mathrm{n} \mathbf{s}-$ I $\mathrm{n} t \mathrm{e}$ e s $\mathrm{s}$ überwiegt. Dies nämlich dadurch, daB die Ausgabenbesteuerung eine Abkoppelung der persönlichen Besteuerung (Haushaltsbesteuerung) von der Unternehmensbesteuerung erlaubt, was eindeutig allokative Vorteile hat, dies ferner dadurch, daß in der Ausgabensteuer das Sparen steuerfrei bleibt, was allokativ ein großes Gewicht hat (mit den distributiven Effekten). Eine Trennung der unternehmerischen von der Haushaltssphäre leistet das RVZ-Konzept - wie auch das gegenwärtige bundesdeutsche Steuersystem - nicht. Wäre sie, wie (vgl. § 8) 1m Konzept der "Betriebsteuer" diskutiert, möglich, lieBe sich damit auch weitgehend eine Trennung in allokative und distributive Probleme erreichen.

Die allokativ-distributiven Merkmale einer Ausgabensteuer sind nach D. Schneider (1971, S. 371 f.) und Musgrave/Musgrave (1980, S. 457), was die Trennung von Haushalts - und Unternehmenssphäre betrifft, die folgenden (es handelt sich nur vereinzelt um "reale", in Mehrheit dagegen um "ideale" Merkmale):

(1) Die Ungleichbehandlungen in der Einkommensteuer (Gewinn- und Uberschußfeststellungen, capital gains, Veräußerungsgewinne, gewillkürtes Betriebsvermögen, Aufwandsverlagerungen usw.) entfallen;

(2) Probleme der Geldentwertung für die Substanzerhaltung bestehen nicht, die Notwendigkeit einer Anpassung der Nominalwerte entfällt; statt dessen besteht allenfalls Interesse an der Indexierung der steuersätze;

(3) Unternehmergewinne (corporate profits) bedürfen keiner näheren Bestimmung; die Trennung der beiden ökonomischen Sphären erlaubt eine allokative Entscheidung ohne EinfluB seitens der Distribution, d.h. insbesondere:

(4) Umverteilungszielsetzungen sind ohne allokative Einflüsse (Leistungslähmung) möglich; schlieblich:

(5) allokative ziele (z.B. Investitionsanregung) können ohne distributive Nebeneffekte verfolgt werden, wie sie ansonsten bei Afa-, Sonderafa- und Wertminderungsregeln auftreten; keine negativen Wachstumseffekte durch Besteuerung des privaten Vermögens. 
Die Ausgabensteuer als "persönliche allgemeine"22) Steuer erfaBt den privaten Konsumbereich und ist von jeglichen Abgrenzungsnotwendigkeiten zwischen betrieblicher und privater sphäre frei. Demgegenüber besteuert die RVZ-Steuer beide Sphären simultan. Dadurch belastet sie sich mit einer Uberschneidung allokativer und distributiver Wirkungen und Absichten und muB alle diejenigen Abgrenzungsfragen lösen, die die Ausgabensteuer einer ergänzenden Unternehmensstever zuweisen würde. 23)

Allerdings ist der Terminus "persönliche allgemeine Ausgabensteuer", vom Schema ihres objektivierungsbereichs (Ubersicht 10.3) her beurteilt, nicht korrekt gewählt, da die Summe der Bruttoausgaben um die Periodenabgrenzung für langlebige Konsumgüter (Zeile 7) verändert wird. Darin kommt zum Ausdruck, daB es sich genau genommen nicht um Ausgaben, sondern um Aufwand handelt, denn die Verrechnung der Periodenabgrenzung betrifft ja gerade nicht die Ausgaben der Besteuerungsperiode sondern jene aus einer früheren Anschaffungsperiode bzw. solche für spätere Nutzungsperioden. Korrekt wäre es, von persönlicher allgemeiner "Aufwandsteuer" oder "Konsumsteuer" zu sprechen. Denn auch die persönliche Kreditvergabe und der Vermögenserwerb sind schlieblich Ausgaben, die ja gerade nicht besteuert werden sollen, well sie nicht dem Konsum dienen.

22) So benannt von F. Neumark 1970, S. 168, und R. Peffekoven $1979 a$.

23) Man kann - was auBerhalb des hier gewählten Themas liegt ergänzend unterstellen, auch die Unternehmensbesteuerung wurde elne Ausgabensteuer sein (sofern nicht die körperschaftsteuer oder eine andere Unternehmenssteuer gewahlt wird). Hierzu siehe R. Peffekoven 1979a, S. $435 \mathrm{ff}$. - Vgl. hierzu auch C.S. Shoup 1969, S. 345, und N. Kaldor 1955, Kap. 5, "Company Taxation". 
Das "Reinvermögenszugangs"( RVZ-) Konzept bzw. das "schanz-Haig-Simons-(SHS-) konzept

I. Bemessungsgrundlage 523

II. Bewertung 525

III. Periodisierung 526

IV. Distributiv-allokativer Konflikt 528

In der Auseinandersetzung, ob dem engen Ansatz der Quellentheorie oder dem weiten der Reinvermögenszugangstheorie der Vorzug zu geben sel, hat heute die letztere aus theoretischer Sicht die Hauptargumente auf ihrer seite.') Das zeigt sich auch in dem von uns gewählten Verfügungskonzept und in der Theorie der "Objektivierung". Die Autoren, soweit sie an der frühen Auseinandersetzung um das Reinvermögenszugangs-Konzept teilgenommen haben, ${ }^{2)}$ aber auch, soweit sie in jüngster Zeit sich mit dem "Schanz-HaigSimons"-Konzept befassen, ${ }^{3)}$ stimmen zusammen mit ihren Kritikern ${ }^{4}$ ) darin überein, daB das Umfassende bzw. das "Summative" des Konzeptes, ausgedrückt schon in der Bennung, ganz bestimmte Problemkomplexe hervorbringt: einesteils liegt der Inhalt des Konzeptes im Terminus $\mathrm{V}$ e $\mathrm{r} \mathrm{m}$ ö $\mathrm{g} \mathrm{n}$, was notwendigerweise die Bewertungsproblematik aufirft (II), anderenteils liegt der Inhalt im $\mathrm{z}$ u g a n $\mathrm{g}$, was genauso zwangsläufig die Periodisierung $\mathrm{zum}$

1) Wenn sie auch nach F. Neumark nicht restlos befriedrigt, so sei sie doch der Quellentheorie überlegen (1961b, S. 30); $z$ ugleich wird aber auch von jenen Theoretikern, die mit dieser Folgerung nicht übereinstimmen und grundsätzlich Ausgabensteuer-Konzepte bevorzugen, immerhin zugegeben, daB der "comprehensive tax base"-Ansatz der Reinvermögenszugangstheorie der theoretisch korrekte ist und daB mit Rücksicht auf die politisch nicht durchzusetzende Reform dem "comprehensive tax base"-Ansatz einer Ausgabensteuer ein politischer Erfolg versagt bleiben muB. An der theoretischen wie politischen Korrektheit eines breiten Besteuerungsansatzes jedoch halten sie in beiden Fällen fest.

2) G.v. Schanz 1896. - Brauckner 1921. - B. Moll 1924 u. 1930. Pistorius 1929. - C.C. Plehn 1924 u. 1931. - J. Popitz 1926. G. Strutz $1927 / 1929$.

3) R.M. Haig 1959. - H.C. Simons 1938. - R. Gocde 1976, 1977 u. 1980.-J.G. Head 1972 u. 1979. - Rcyal Commission (Carter Report) 1966. - Meade Committee 1978. - J.G. Head 1982.

4) D. Schneider 1971 u. 1979a. - J. Mitschke 1976. - M.S. Feldstein 1976b. - Ferner die Autoren der Ausgabensteuerkonzepte unten. 
Thema macht (III). Des weiteren bringt der Reinvermögenszugang eine allokativ-distributive Gesamtproblematik zum Vorschein (IV).

I. Das RVZ/SHS-Konzept stützt sich auf vier tragende $R$ e $\mathrm{g}$ e $1 \mathrm{n}$ (vgl. hierzu oben die \$\$ 8 und 21 bis 23):

a) Erstens die "G e $l$ d r e g e l", die das RVZ-Konzept zu einem "Realisierungs"-Kcnzept macht; sowohl die Erträge jedweder Art und aus jedwedem Faktor als auch die Nutzungen und Leistungen Dritter (so Schanz, S. 23) müssen in Geld ausdrückbar sein. Einkommen besteht nach R.M. Haig (1959, S. 59) in Geld selbst wie auch in allem, was einer Bewertung in Geldausdrücken zugänglich ist. Demnach gehört das sog. "social" oder "national income" nach der Meinung von H.C. Simons (1938, S. 45) nicht zum verfügbaren Geldeinkommen. Zweitens die " $\mathrm{z}$ u $\mathrm{e} c \mathrm{~h}$ e $\mathrm{n}$ b a $\mathrm{r}-$ k e $i t s$ e g e l"; das Einkommen muB einer bestimmten Person zurechenbar sein. Schanz (S. 5) spricht von der Person, die über Einkommen disponiert, und H.C. Simons stellt fest, daB alle Erträge, Gewinne, Vorteile und Nutzen (= "gains") "have to do with persons, not with things" (1938, S. 79). Seiner Meinung nach darf eben deswegen auch die personale steuerbasis grc̈Ber sein als die Summe aller volkswirtschaftlichen Einkommen, dividiert durch die Zahl der Empfänger; einzelwirtschaftliche und gesamtwirtschaftliche GröBen stehen in Bezug auf das steuerpolitische ziel und auf die Bezugsbasis in keinerlei Zusammenhang (1938, S. 57 f.l. Drittens enthält das Konzept die "s u m m a $t$ i o n s $r$ e g e l", die die leistungsfähigkeitsbezogene Vollständigkeit und Umfassendheit des Einkommensbegriffs garantiert; viertens enthält es die "s u b $r a k t i \circ n s r$ e e l", die festlegt, daB z.B. Schuldenabzug, Vermögensverluste usw. das Bruttoeinkommen mindern, und die einerseits zum Bewertungsproblem, andererseits $z$ um allokativen Problem der substanzerhaltung überleitet, die im RVZ-Konzept angelegt sind. Wie sich zeigt, sind die Erfordernisse der theoretischen und praktischen "Objektivierung" des Leistungsfähigkeitsindikators (\$\$ 17 - 21) weitgehend für das RVZ-Konzept begriffsbestimmend.

b) Nach dem RVZ-Konzept setzt sich das Einkommen aus vier B e s $t$ a $n$ d $t$ e $i$ e $n$ zusammen: (1) den Erträgen aus den Faktoren 
Arbelt, Kapital und Boden, (2) dem Vermögensanfall bzw. den zurechenbaren Vermögensantellen, (3) den zufallserträgen und (4) den Transfereinkommen. Wăhrend der Einkommenscharakter der Transfereinkommen direkt aus der Geldregel (Schanz führt lediglich Versicherungsrenten auf) folgt und während die zufallserträge einesteils als Vermögensanfall,5) andernteils als Ergänzungstatbestand zur Periodizität gesehen werden können, ${ }^{6)}$ liegt die das RVz-Konzept kennzeichnende Eigenart im Vermögensbestandtell. Das $\mathrm{V}$ e $\mathrm{r}$ ö $\mathrm{g}$ e $\mathrm{n}$ bzw. die Vermögenswerte bestehen nach Schanz (S. 24) in Versicherungskapitalien sowie in Legaten, Erbschaften und Schenkungen; R.M. Haig (1959, S. 75 u. 62) fuhrt eigens Unternehmungskapitalien und Sonderertrăge auf wie Gratisaktien, unvertellte Gewinne der Kapitaleigner, Wertsteigerungen und VeräuBerungserlöse; H.C. Simons (1938, S. 88) betont den entscheidenden Punkt hinsichtlich der Zurechnung von Vermögensantellen: Wertzuwächse zahlen zum Vermögen und damit zum Einkommen einer Person.

Das Problem der Vollständigkeit der Leistungsfähigkeitsindikatoren läBt sich am Beispiel der nichtrealisierten "capital gains" verdeutlichen: Der alleinige Geldausdruck eines (gestiegenen) Vermögens indiziert (höhere) Leistungsfähigkeit, ungeachtet dessen, woher das Vermögen oder seine Wertsteigerung stammt. Vermögensbestandserhöhungen im Verfügungsrecht einer Person sind entweder das Ergebnis von körperlichen Vermogenszugängen (infolge von Sparakten, Erbschaften oder Transfers) oder das Ergebnis von Vermögenswertsteigerungen (infolge marktlicher Vorgänge oder politischer MaBnahmen). Würde die Vermögensbestanderhöhung und damit der gestiegene vermögenswert aus dem sparen stammen, so würde nach dem RVZ-Knnzept der höhere Vermögenswert von der Einkommensteuer erfaBt; wenn aber die Wertsteigerungen,

5) Schanz nennt hier Lotteriegewinne und Konjunkturgewinne als Beispiele (S. 24); R.M. Haig erwähnt ledlglich summarisch die privaten Zufallsgewinne (1959, S. 75).

6) J. Mitschke rekurriert in der Einkommensdefinition auf die Bedurfnisbefriedigung und stellt in diesem $\mathrm{z}$ usammenhang fest, $\mathrm{da} B$ auch aus irregulären Ertrăgen Bedürfnisse befriedigt werden können; 1976, S. 87. 
also die höheren Verkehrswerte, ${ }^{7)}$ eine andere Ursache haben, welcher Grund sollte akzeptiert werden können, steuerlich abweichend $z$ u verfahren ${ }^{81}$ )

II. Der Vermögens- wie der Einkommensbegriff entspringen nach Auffassung von B. Moll (1924, S. 99) "der gleichen Wurzel, dem Begriff des wirtschaftlichen Könnens, dem Vermögensbegriff im weitesten Sinne". Der Einkommensbegriff wird nach dem RVZ-Konzept der Vermögensebene zugeordnet und aus ihr definiert; dieser Sachverhalt ist mithin "konstitutionelles Merkmal der ganzen Einkommensidee". 9) Die marktliche B e w e r t u n g des vermögens für die "Realisierungs"-Konzepte der Leistungsfähigke1t mithin eine Notwendigkeit und in der Geldregel nach R.M. Haig als Absicht bereits ausgedrückt - ist nun der hauptsächliche Angriffspunkt, den das RVZ-Konzept seinen Kritikern bietet. Noch aus der Argumentation von Schanz könnte gefolgert werden, daB nur der realisierte Vermögenszugang besteuert werden sol1. ${ }^{10)}$ H.C. Simons (1938, S. 88) hingegen spricht klar aus, daB die nichtrealisierten Wertsteigerungen in das Konzept einzubeziehen sind; alle "gains" (= Gewinne, Vorteile usw.) sind in Marktpreisen zu messen.11) Damit jedoch gerät die Vermögensbewertung in das Feld der Unsicherheit. Diese besteht auch schon für die bewerteten Vermögen, sofern man es mit Weisbrod/Hansen 12) unternimmt, Vermögen in Annuitätsbeträge umzuwandeln und dem laufenden Einkommen zuzurechnen; je kürzer man die Einkommenszeitspanne annimmt, desto mehr nähert sich das Einkommen dem Nettovermögenswert, je länger

7) Wenn Kreditinstitute Vermögensobjekte mit ihren Verkehrswerten in ihre Beleihungsüberlegungen einführen, so drückt das reale werte aus, und nicht etwa fiktive, die sie ihren kreditnehmern zurechnen. Siehe W. Albers 1957, S. $78 \mathrm{f}$.

8) J.G. Head 1963, S. 222. - Ferner: R. Ulbrich 1975, S. 48 f.

9) J. Mitschke 1976, S. 106 f., insbes. S. 109.

10) So sieht es jedenfalls D. Schneider (1971, S. 356 f.), da Schanz seine Ableitungen in den Rahmen kaufmännischer Gewinnermittlungsregeln stelle.

11) H.C. Simons 1938, S. 50, 84 u. 97; "according to objective market standards", S. 51 .

12) B.A. Weisbrod und W.L. Hansen 1968, S. 1315 ff.; sie propagieren "a combination of current income and current net worth" (assets minus liabilities). 
man jedoch die Zeitspanne unterstellt, desto mehr nähert sich der Annuitätswert dem des zinses. Die Definition des Einkommens steht und fällt also mit der Veränderung des zinses, eine Kritik, die bereits $\mathrm{N}$. Kaldor (1955, Kap. 1) vorgetragen hat und die ihn veranlabte, einen vom Vermögensbestandswert und $\mathrm{zins}$ unabhängigen Wertestrom, den der Ausgaben, zum Besteuerungstatbestand $\mathrm{zu}$ machen. Ein objektiver, jederzeit nachprüfbarer Gegenwartswert des Vermögens läBt sich aber nach D. Schneider (1971, s. 357) nur ermitteln, wenn erstens GewiBheit über die Zukunft und ihre aus Vermögen flieBenden Zahlungsströme vorliegt und wenn zweitens ein vollkommener Kapitalmarkt mit einheitlichem zinsfuB existiert. Soweit beides nicht gegeben ist, wird die ökonomisch korrekte Grundlage für die Besteuerung nach der Leistungsfähigkeit verfehlt (S. 359). Uber die in den \$\$ 24 bis 27 vorgetragenen Schwierigkeiten der totalen Erfassung und der Gleichbehandlung hinaus ist also mit dem RVZ-Konzept grundsätzlich das Bewertungsproblem konstitutiv verbunden. Es ist nicht zu bestreiten, daB gerade das Ausgabensteuerkonzept solche Probleme nicht aufweist.

III. Aus dem RVZ-Konzept folgt logisch die Forderung nach einer P e r i d is i e r u n g des Einkommens. 13) Der "bestimmte Zeitpunkt" bzw. die "bestimmte Periode" (so Schanz 1896, S. 23 und 5) wie auch R.M. Haigs "between two points of time" (1959, S. 59 u. 75) lassen die Länge der Periode völlig offen, so daB nach dem RVZ-Konzept die Periode nicht notwendig der Naturzyklus des Kalenderjahres sein muB. Sofern man nicht die Lebenszeit des Besteuerten wählt, ist mit diesem Konzept auch ein Mehrjahresabschnitt, evtl. in Form fester oder gleitender Durchschnittseinkommen (s. J. Hackmann 1979) zu vereinbaren. Wesentlich ist, daB überhaupt eine Periodisierung stattfindet, da ohne sie nach H.C. Simons (1938, S. 44) Einkommen nur auf bestimmte Aktivitäten, wie Marktoperationen, die z.B. einen "Ertrag" erbringen, zu beziehen sein würde. Personale Zuordnung solcher "Erträge"

13) Der Ausdruck Periodisierung darf nicht mit "periodisch gleichförmig wiederkehrenden" Einkünften verwechselt werden, wie er der Quellentheorie zugrunde liegt. Einer Periodenbestimmung bedarf auch das RVZ-Konzept. 
und die Feststellung der Leistungsfähigkeit zwischen verschiedenen Personen verlangen demnach die Periodisierung (siehe $\S 9$ ).

Schon die theoretischen überlegungen hatten ergeben, daß die Periodisierung der zugänge ökonomischer Größen zum Einkommensbegriff aehören. Kritik erheben nun die Befürworter der Ausqabensteuer. Von ihnen wird vorgetragen, daB gerade die geltende Einkommens - und Vermögensbesteuerung vielfältige Möglichkeiten der "Umperiodisierung" eröffnet in Form von zeitlicher Gewinnverlagerung durch Aufwandsgestaltung, durch Bewertungsfreiheiten, durch Bildung und Auflösung von stillen Reserven sowie durch Vor- und Rücktrag von Verlusten usw. (\$S 26, 27). Die Gleichbehandlung der Steuersubjekte wird damit unterlaufen. Dieser Einwand ist aber nur dann in voller Schärfe berechtigt, wenn die Ausgabensteuer keinerlei Auswelchung zulieBe. Dem ist aber nicht so; man kann der Steuer sachlich (R. Peffekoven 1979a, S. 425) und zeitlich ausweichen: sachlich durch unvollständiges Deklarieren der Einnahmen ${ }^{14)}$ und zeitlich insofern, als man sowohl den Konsum (R. Peffekoven 1979a, S. 427) - und dies nicht allein bei der Einführung der Steuer - als auch die von der Ausgabensteuer verschonten Sparvorgänge verlagern kann. Letztlich können für die langlebigen Konsumgüter Auffassungsunterschiede bestehen, wann ein solches Gut vorliegt und welche Nutzungsperiode die angemessene ist. Werden langlebige Konsumgüter angeschafft, unterstellt die Ausgabensteuer den Konsum lediglich in Höhe der zeitanteiligen Ausgaben. ${ }^{15)}$ Immerhin läBt sich nicht bestreiten, daB die Umperiodisierung in der Ausgabensteuer quantitativ nicht annähernd so gewichtig sein kann wie bei der Einkommensteuer.

14) Nach Musgrave/Musgrave 1980, S. 457, liegt gerade im Verschweigen von Einkünften eines der Probleme einer indirekten Konsumermittlung.

15 ) Diesen grundlegenden organisatorischen Tatbestand scheint R. Ulbrich $(1975, \mathrm{~S}$. $30 \mathrm{f}$., insbes. S. $36 \mathrm{ff.}) \mathrm{zu}$ übersehen. Bei dem Versuch, zu beweisen, daB u.U. die Einkommensteuer nach dem RVZ-Konzept eine der tatsächlichen Bedürfnisbefriedigung angepaBte Besteuerung eher erreicht als eine Ausgabensteuer, setzt er Ausgaben mit Konsum gleich. Seine Ableitungen sind nicht zwingend, da auch die Ausgabensteuer unterscheiden kann zwischen periodengleichen Konsumausgaben und periodenübergreifenden Ausgaben, die nur zeit- und nutzungsanteilig Konsum sind. Im übrigen wird der Beweis durch Rückgriffe auf die Bedürfnisbefriedigung und deren monetäre $\mathrm{Be}-$ wertung geführt, was unnötig ist. 
Die Nachteile, die die Periodisierung in der Einkommensteuer mit sich bringt, sind eher solche der in die steuer eingebauten Gestaltungsprivilegien und der unterschiedlich erlaubten Gewinnbzw. UberschuB-Feststellungsmethoden als solche der Periodisierung schlechthin. AuBerdem hängt eine Periodisierung ganz wesentlich mit der Gestaltung des Steuertarifs zusammen: Da sowohl die Einkommens- als auch die Ausgaben-Besteuerung einen progressiven Tarif anwenden, besteht in belden Konzepten ein Periodisierungsinteresse der Bemessungsgrundlage in völlig gleicher Weise. In beiden Besteuerungskonzepten läBt sich somit eine Gestaltung des Einkommensbegriffs bzw. Ausgabenbegriffs als die maBgeblichen objektivierungen der Leistungsfähigkeit erreichen.

IV. Der d is $t r i b u t i v-a l l o k$ a $i v e$ Konflikt ist in den Einkommensdefinitionen des RVZ-Konzeptes bereits angelegt; mit voller Klarheit wird er von H.C. Simons formuliert (siehe hierzu auch unsere Darstellungen in $\S$ 7, $11 \mathrm{u} .12$ ).

a) Wenn Schanz (S. 5) von der "selbständigen wirtschaftlichen Kraft" und von "Dispositionen" einer Person spricht, so kommt darin sowohl die personale zuordnung des Einkommens als auch seine Konsumdeterminierung, mithin das d is $t r i b$ u $t$ i v e Element zum Ausdruck. Umfassender beschreibt H.C. Simons (1938, S. 50) insbesondere das personale Element, da er Einkommen definiert als die summe "(1) the market value of rights exercised in consumption" und "(2) the change in the value of the store of property rights", wobei die property rights - gleich, ob durch Konsum- oder durch Vermögensgüter repräsentiert - folgende Ausstattungen vermitteln (S. 97): "increase of power", "greater freedom", "security", "prestige" und "respectability".

Die Subtraktionsregel nun mindert zwar die distributive EinkommensgröBe, hat aber ein a 1 l $\circ$ a $t i v$ e $s i e l$. Sie sagt, daß die Person ihre Dispositionen über finanzielle Mittel treffen solle "ohne daß sie ihr eigenes Vermögen verzehrt oder fremde Mittel (Schulden) hinzunimmt" (Schanz S. 5). In der Formulierung von A.C. Pigou ${ }^{16)}$ verfolgt das RVZ-Konzept die Aufrechter-

Fn. 16 siehe folgende Seite 
haltung der Einkommensquelle, jedenfalls soweit das Vermögen Erträge abwirft. Demnach ist Einkommen ein Netto-Einkommen; von der BruttogröBe des Ertrags ist $z$ unächst die Schuldaufnahme $z u$ subtrahieren, des welteren die Kapitalverluste, schlieblich auch weitere Positionen, die allesamt der allokativ motivierten Kapitalerhaltung und -reproduktion dienen wie Reparaturen, Absetzungen für Abnutzungen und Wertberichtigungen. Diese Subtraktionsregel wird heute entweder uneingeschränkt ${ }^{17)}$ oder wenigstens dem Grundsatz nach ${ }^{(8)}$ akzeptiert, doch betont schon H.C. Simons den widerspruch zum Distributionsziel. Er kritisiert die von anderen Theoretikern des RVZ-Konzeptes erhobene Forderung nach einer "Begrenzung" des Konsums im Sinne der Kapitalerhaltung. 19)

Fn. 16 :

1932, S. 43: "maintaining capital intact". Siehe die in $\$ 7$ erwähnte und unter diesem stichwort geführte Diskussion zwischen Pigou, v. Hayek und J.R. Hicks sowie D. Schneider 1981.

17) So fuhrt J. Mitschke (1976, S. 88), der die comprehensive tax base-Regel sowohl für die Ausgaben- als auch für die Einkommensteuer würdigt, folgendes aus: Werden alle bewerteten Vermögenszugänge als Erträge (die in der Summe das Einkommen ergeben) qualifiziert, "so ist es konsequent, alle nicht-konsumtiven Vermögensabgänge als Einkommens-Aufwand einzustufen. Das bedeutet, daB nicht nur der Aufwand, mit dem von vorn herein das Ziel verfolgt wird, zukünftige Erträge möglich zu machen (investiver Aufwand), von den Erträgen abzuziehen ist, sondern auch jener nicht-konsumtive Aufwand, der ohne jede Planung unvorhergesehen anfällt (z.B. die entschädigungslose Verminderung der Ertragsquelle durch eine Katastrophe)", dessen Berücksichtigung aber die Quellentheorie bei ihrer Einkommensermittelung ablehnte.

18) D. Schneider (1971, S. 357 u. 359) hält die "Erhaltung des Anfangsvermögens" für gerechtfertigt, hält auch die Definition des Einkommens als "Zuwachs an Verfügungsmacht" für systemgerecht, gibt jedoch beidem keinerlei chance, je verwirklicht werden zu können, da MeB- und Bewertungsschwierigkeiten dem entgegenstehen. D. Schneider (1981, S. 154 u. $157 \mathrm{f.})$ kritisiert an Schanz nicht etwa, daB dieser die Kapitalerhaltung zum Definitionsbestandteil des Einkommens macht, sondern nur, daB Schanz nicht sagt, was denn nun als Kapital zu erhalten sei.

19) Die Norm, nur soviel konsumieren $z u$ sollen (dürfen), daB das Anfangskapital substanziell erhalten bleibt, sei allenfalls geeignet, Verwirrung $\mathrm{zu}$ stiften und Ungenauigkeiten $\mathrm{zu}$ produzieren, die dem Einkommensbegriff auferlegt werden, um steuerpolitische Normen festzuschreiben. Ähnlich verhalte es sich mit dem Erfordernis der RegelmäBigkeit von Einkommen in der Quellentheorie (S. $64 \mathrm{ff}$.$) . Die Konsumbegrenzungs-$ und Kapitalerhaltungsnorm bekomme Gewicht allein aus gesamtwirtschaftlicher sicht. Individuell gesehen könne jedermann aber qua Einkommensdisposition auch sein eigenes (und damit

(Forts. siehe folgende seite) 
Aus den Ausführungen Simons' wird deutlich, daB er letztlich die Auseinandersetzung zwischen der Reinvermögens- und der Quellentheorie für einen Werturteilsstreit hält, der auch ein streit zwischen allokations - und distributionspolitischen Zielen ist. Allerdings wird dem Gedanken, $\mathrm{da} B$ es in der Disposition über Einkommen verschiedene Freiheitsgrade geben kann, nicht nachgegangen. Simons geht es um den Nachweis, daB das ökonomische Einkommen vom steuerpolitischen abweichen kann, da letzteres politisch bestimmt ist.20) Wir hatten oben (\$ 7) die Darlegungen von Simons zum AnlaB genommen, eindringlich auf die Trennung der allokativen Sphäre des Wirtschaftens von der distributiven aufmerksam $\mathrm{zu}$ machen.

b) Das RVZ/SHS-Konzept wird von seinen Befürwortern stets auch als ein Konzept gesehen, das die objektive Basis (H.C. Simons) ${ }^{21}$ ) für die Herstellung steuerlicher $G$ l e $i \mathrm{ch}$ m ä B i g k e i $t$ (R.M. Haig 1959, S. 54) bietet, und zwar in sachlicher, d.h. faktorbezogener, und in personaler Hinsicht (R. Goode) ${ }^{22)}, d . h$. als personale Gesamtausstattung. Wie J.G. Head ${ }^{23)}$ im einzelnen darlegt, ist jedoch im SHS-Konzept' lediglich der versuch unter-

Forts. Fn. 19 :

das gesamtwirtschaftliche) Kapital verzehren. Dies sei Einkommen. Was danach steuerpolitisch als Abzug vom Einkommen berücksichtigt werde, könne dennoch Einkommen sein. Für die Steuerpolitik aber gelte: Wenn Einkommen persönliches Einkommen ist, so ist zugleich zu beachten, daB die Umstände, unter denen eine Person Eigentum erworben hat und hält, das Einkommen mit beeinflussen, daB auch Abzüge hierfür das Einkommen mindern (1938, S. 79).

20) So auch R.M. Haig (1959, S. 75): Die Unterschiede in den Einkommensdefinitionen der bkonomen sind eher solche der Politik als solche des Grundsatzes; sie betreffen denn auch z.T. Auffassungen darüber, inwieweit das "Einkommen" eingeengt werden soll, um es für eine tax base sinnvoll zu machen.

21) 1938 , S. 30 f.: "the broadest and most objective income concept provides the base for the most nearly equitable levies."

22) 1980 , S. 51; die Ausstattung (endowment) einer Person gilt als bester Indikator für die "ability to pay" und bestimmt die "taxable capacity"; als Ausstattung gelten "value of marketable goods" und "value of time".

23) 1979, S. 194: "horizontal equity has become the central concept in the Simons-Carter approach". 
nommen, die horizontale Gerechtigkeit als "Gleichbehandlung der Ertragsquellen", also als allokativ aufgefaBte steuerneutralität, $z$ u verwirklichen. SolchermaBen kann das RVZ/SHS-Konzept mit seiner umfassenden "summativen" Einkommensdefinition allenfalls Grundlage für die vertikale, leistungsfähigkeitsbezogene Gerechtigkeit sein. Das Verhältnis von horizontaler zu vertikaler Gerechtigkeit erweist sich als ein Problem der allokativen Wirkungen mit distributiven Effekten: das Gebot der Gleichbehandlung der Ertragsquellen soll die Ressourcenallokation unbeeinfluBt lassen; dadurch wird zugleich die steuerlich neutrale Basis für die distributive Politik gelegt; VerstöBe gegen die Gleichbehandlung setzen negative Bedingungen für distributive Wirkungen und die beabsichtigte distributive Politik. ${ }^{4}$ )

An dieser Absicht des RVZ-Konzeptes, bereits die horizontale Gerechtigkeit herstellen zu können, ist seitens M. Feldsteins (1976b, S. 86ff.) Kritik geübt worden: Wenn das SHS-Konzept bei gleichen Geldeinkommen, gleichen Präferenzen und unterschiedlicher Ausstattung der Besteuerten mit Geistes- und Körperkräften eine gleiche Besteuerung verlange, so verletze es die horizontale Gerechtigkeit, da es eine Gleichheit der Präferenzen aller Individuen unterstelle, ebenso wie eine Gleichheit der Nutzenfunktionen. Nun ist von den Vertretern des SHS-Konzepts - u.a. von H.C. Simons 251 - stets eingeräumt worden, daB eine "ideal tax base" kaum jemals gefunden werden kann; aber um offensichtliche Ungleichheiten und Doppelsinnigkeiten auszuschlieBen, muB sich die Festlegung der Steuerbasis an das "objektiv verfügbare Material" halten. Da sich also die Vertreter des SHS-Konzeptes als Befürworter eines "Realisierungs"-Konzeptes sehen, muB der Vorwurf einer Nichtbeachtung individuell unterschiedlicher Nutzenfunktionen an ihnen vorbei gehen. ${ }^{26)}$ Mit dem Zugrundelegen von Marktwerten repräsentiert das RVz-Konzept den ökonomisch-numerischen, das heibt den quantitativen Bereich gesellschaftlicher Prozesse und damit äuBerlich wahrnehmbare Tatbestände. Erträge aus unter-

24) Vgl. hierzu unsere Ausführungen zur Rolle der "comprehensive tax base" in $\$ 21$ und die Problematik der Ausgrenzungen aus der freien Verfügbarkeit unter dem Aspekt, daB für die GleichmäBigkeit der Besteuerung das Allgemeinheitspostulat grundlegend ist (\$ 17).

Fn. 25 und 26 siehe folgende seite. 
schiedlich rentierlichem Faktoreinsatz, so ungleich sie sein mögen, sind ein Allokationsproblem, das nur durch Ungleichbehandlung in äuBerlicher Hinsicht $z u$ einem Gerechtigkeitsproblem wird. Effizienzunterschiede werden also auch dann bestehen bleiben, wenn eine horizontale Gerechtigkeit im Sinne einer Gleichbehandlung erreicht wurde. 27 )

c) Es läBt sich also zeigen, $d a B$ der allokativ-distributive Konflikt, der die gegenwärtig in der Bundesrepublik praktizierte Einkommensbesteuerung kennzeichnet, bereits in jener konzeption angelegt ist, die der Einkommensbesteuerung als grundlegendes Denkmuster dient. Das RVZ/SHS-Konzept verwendet eben wegen der Subtraktionsregel einen allokativ-distributiven Mischbegriff des Einkommens. So "modern" das Konzept gegenüber dem der Quellentheorie auch genannt werden mag, vernachlässigen seine Befürworter dennoch die Notwendigkeit, den allokativen Bereich des Wirtschaftens vom distributiven zu trennen.

Fn. 25 :

1938, S. 43. - Siehe auch B.I. Bittker, der darauf hinweist, daB selbst eine comprehensive tax base nie eindeutig, sondern in gewissem AusmaB immer willkürlich sein wird; 1967, S. 73.

Fn. 26 :

AuBerdem läßt sich nie objektiv korrekt festlegen, was unterschiedliche Geistes- und Körperkraftausstattungen sind und welches $\mathrm{MaB}$ an unterschiedlicher Anspannung dieser Kräfte die Gleichheit der Einkommen herbeigefürt hat.

27) Wenn Feldstein des weiteren bemerkt, daB eine Abweichung vom SHS-Konzept oft gleichgesetzt wird mit Verzerrungen der "incentives" und mit ökonomischer Ineffizienz sowie mit einem Sinken der ökonomischen Wohlfahrt, und dem dann entgegenhält, daB jede Steuer auBer einer "lump sum tax" (Pauschaloder Kopfsteuer) Verzerrungen und EffizienzeinbuBen hervorruft, so ist letzterem zweifellos zuzustimmen; doch dessenungeachtet muB gelten, daB es graduell unterschiedliche Störbereiche gibt; die Besteuerung nach dem SHS-Konzept mag Störungen hervorrufen, jedoch wäre $z u$ beweisen, daB andere Steuerkonzepte weniger Störungen hervorrufen. Zumeist ist dies bisher von den Steuern auf spezielle Güter in einem ebenso groBen AusmaB $z u$ erwarten wie von Personalsteuern. Aber selbst wenn man innerhalb des Bereichs der Personalsteuern argumentiert, muB ein eventueller Effizienzverlust, den das SHS-Ronzept hervorriefe, ins Verhältnis gesetzt werden zu Distributionsvorteilen, die mit der comprehensive tax base erreicht werden können. 
533 Das "reine Ausgaben"-

I. Bemessungsgrundlage und Bewertung 534

II. Das allokativ-distributive Problem

des Sparens

538

III. Das Distributionsproblem der Personalisierung und des Konsumverhaltens

Ideengeschichtlich wird die Besteuerung des persönlichen Verbrauchs auf J. St. Mill zurückgeführt. "1) Demgegenüber weist der erste steuerpolitische Realisierungsversuch einer "Spendings Tax" auf R.E. Paul. 2) Doch basiert die heutige Diskussion stets auf dem theoretischen Modell der "Expenditure Tax" von N. Kaldor. 3) 4) Uberhaupt hatte in England die Einkommen-Ausgabensteuer-Kontroverse eine seltsame Zweijahrzehnte-Periodizität mit I. Fisher (1937 u. 1942) in den 30er Jahren, mit N. Kaldor (1955) in den 50er und mit dem Meade-Committee (1978) in den 70er Jahren. A.R. Prest (1979, S. 245) vermutet, daB diese Periodizität gar nicht so überraschend ist, wenn man von der Neigung der రkonomen ausgehe "to re-invent the wheel every time they get half a chance." Doch gerade in den 70 er Jahren ist eine allgemeine Reaktivierung

1) 1926, S. 813: the proper mode of assessing an income tax would be to tax only the part of income devoted to expenditure, exempting that which is saved." - F.K. Mann berichtet 11937, S. $258 \mathrm{ff.}$, , daB im deutschen sprachraum die propagierung einer Ausgabensteuer vor allem mit $\mathrm{E}$. Pfeiffer verbunden ist: Die Staatseinnahmen, Stuttgart u. Leipzig 1866, basierend auf J.S. Mill.

2) Nach F. Neumark (1970, S. 169) llegen die Gedanken von R.E. Paul einem Entwurf zugrunde, den das amerikanische Schatzamt 1942 dem FinanzausschuB des senats unterbreitete, siehe A.G. Buehler 1950, S. $8 \mathrm{ff}$. - Musgrave/Musgrave 1980, S. 456.

3) 1955; ferner sein Kommentar zu einem Beitrag von W.D. Andrews 1980. Mittlerwelle ist die Literatur zum Thema Ausgabensteuer sehr umfangreich geworden. AuBer den unten $z u$ nennenden Beiträgen erwähnen wir stellvertretend für viele: Carter Report 1966 (vol. 1, S. 10 f.); Advisory Commission 1974; Meade Committee 1978 (Kap. 8-10); R. Peffekoven 1979a-c; J.E. Pechman (Hg) 1980; auBerdem bietet P. Zumstein 1977 eine Zusammenstellung der Literatur.

4) Zum Begriff des "reinen" Konzepts siehe Meade-Committee 1978, the 'pure' expenditure tax; dieses Konzept läbt das Sparen steuerfrei im Gegensatz zu zwei weiteren Ausgabensteuer-Konzepten, die zum einen lediglich die Vermögenseinkünfte, zum anderen die Kapitalbildung steuerfrei lassen. 
der Ausgabensteuer-Diskussion auch über England hinaus festzustellen (siehe den Reader von J.A. Pechman 1980); Es lassen sich Beispiele dafür finden, daB auf einer spezielleren Basis diskutiert wird: So untersucht M.J. Boskin (1978) das Problem der Besteuerung des income from capital vor dem Hintergrund der Zinselastizität des Sparens und glaubt einen groBen Wohlfahrtsverlust durch die Einkommensbesteuerung festgestellt $\mathrm{zu}$ haben, was ihn zur Befürwortung der Ausgabensteuer bringt. M.S. Feldstein (1978) kommt umgekehrt $z u$ dem SchluB, daB eine kompensierende steuer auf "capital income may increase saving" (S. 49); wenn dennoch der Ubergang $z u$ einer Ausgabensteuer beurteilt werden solle, so liege der Grund dafür in der gröBeren Verletzung der horizontalen Gerechtigkeit durch die Einkommensteuer (vgl. hierzu aber Atkinson/Sandmo 1980, s. $529 \mathrm{ff.l}$. Jedoch soll auf Wirkungsanalysen nicht eingegangen, vielmehr soll die Aktualität des Themas hervorgehoben werden.

I. N. Kaldor entwickelte sein Modell nicht wegen etwaiger Mängel der einkommensteuerlichen Praxis, sondern wegen grundlegender Beschränkungen im RVZ-Konzept. ${ }^{5)}$ Diese zeigen sich insbesondere in der Bewertung. Was aber die Basis und die $B$ e $m$ e $s$ g $r$ u n d l a g e betrifft, so sei in ihr jene "comprehensive base" verwirklicht, die auch das RVZ-Konzept kennzeichnet. ") Als "taxable capacity" bezeichnet Kaldor dabei die "spending power" ("power of an individual to satisfy his own personal needs", 1955, S. 28), gemessen an "actual expenditure as a test of ability to pay" (1955, S. 48). Es geht also in der Ausgaben-Konzeption darum, den Nachweis einer geeigneteren Indikation der steuerlichen Leistungsfähigkeit zu führen. Vorliegend interessiert uns allein das Konzept, nicht der vollständige Nachweis der Wirkungen, Begründungen, Praktikabilitäts- und Umstellungsschwierig-

5) "Because the basic limitations of the income concept make it impossible to implement the Haig-Simons formulation, no matter how the tax laws are framed", N. Kaldor, Comments on W.D. Andrews 1980, S. 153.

6) D.F. Bradford 1980, S. 75 f. Allerdings müBte, wie Musgrave/ Musgrave $(1980$, S. 467) ausdrücklich vermerken, sichergestellt sein, daB z.B. auch "imputed consumption"-Elemente, wie in der Einkommensteuer, die Basis der expenditure tax entsprechend erweitern. 
keiten. Wirkungen interessieren nur insoweit, wie sie auf die konzeptionelle Basis der Ausgabensteuer ausstrahlen.

a) Zunächst wird behauptet, der Endzweck der ökonomischen Aktivitäten des Menschen sei nicht der Einkommenserwerb, sondern die Bedürfnisbefriedigung (ersetzt man diesen Begriff durch Konsum, ist die nicht meBbare psychische Kategorie vermieden). Aber dabei wird übersehen, daB viele Menschen nicht im Konsum den Sinn ihrer Aktivität oder den Antrieb dazu erblicken, sondern in der Art der Tätigkeit selbst oder gar im Geldverdienen. Die Festlegung der Aktivität auf den Konsum ist ebenso einseitig wie die Definition des Einkommens durch den Konsum (vgl. \$ 12 und die Einkommensdefinition durch I. Fisher 1906 u. 1937, die ihn zur Befürwortung der Konsumsteuer = Ausgabensteuer veranlabte). Daher kann auch die $L$ e $i s t u n g s$ f $a \mathrm{~h} i g k$ e $t$ nicht allein im Konsum erblickt werden (R.A. Musgrave 1981, S. 31 f.).

b) Die Ausgabensteuer kann in den "zu versteuernden Ausgaben" einen $\mathrm{e} i \mathrm{n} h$ e $i \mathrm{t} i \mathrm{c} h$ e $\mathrm{n}$ Indikator präsentieren, den die Einkommensbesteuerung nach dem RVZ-Konzept nicht aufweisen kann, weil sie erstens auf stromgröBen der wiederkehrenden Einkünften (dazu noch aus unterschiedlichen Quellen wie Arbeit und Vermögen) basiert, zweitens auf stromgröBen aus aperiodischen Einkünften (wie Erbschaften, capital gains usw.) und drittens auf BestandsgröBen (wie Vermögen, Vermögenswertsteigerungen und auch unrealisierten Wertstelgerungen); sie alle verschaffen nach N. Kaldor (1955, S. 30 f.) dem Individuum eine je Teilindikator verschiedene Leistungsfähigkeit. ${ }^{7)}$ Insbesondere die capital gains, die zufolge dem RVZ-Konzept Einkommen sind, tragen personell differenzierend zur Leistungsfähigkeit bei, wenn - in Kombination mit anderen, laufenden Einkünften - Preissteigerungen

7) Man sollte nicht ubersehen, daB Kaldor hier von der Definition der Leistungsfähigkeit, die durch Einkommen repräsentiert wird, abweicht: Denn nicht die Teileinkommen, sondern die Gesamtsumme vermittelt Leistungsfähigkeit. Jedoch ist ihm darin zuzustimmen, daB die Gesamtsumme, soweit Teileinkommen unterschiedlich sind, $\mathrm{zu}$ differierenden GröBen führt. Die später von ihm eingeführte Differenzierung durch Geldentwertung erstreckt sich aber auf sämtliche Teileinkommen, nicht nur auf jene durch Vermögenswertsteigerung. 
auftreten; dann verletzt die Besteuerung nomineller Wertstelgerungen das Gebot der Gleichbehandlung, weil je nach der Zusammensetzung nominell gleicher Einkommen (aus Markteinkommen und Vermögenswertsteigerungen) die realisierten Einkommen ungleich hoch sein können (N. Kaldor 1955, S. $41 \mathrm{f.}$ ). Auch das Meade Committee (1978) präferiert die Ausgabensteuer gerade unter dem Aspekt der Inflationseinflüsse. Von diesen werde das RVZ-/SHSKonzept in stärkerem MaBe getroffen. Dabel geht es nicht um die inflationsbedingte Aufblähung der jeweiligen Bemessungsgrundlage, denn die muBte bel progressiven Steuersätzen in der Einkommenwie in der Ausgabensteuer steuerentlastend angepaBt werden. Jedoch verlangt das SHS-Konzept zusätzliche Anpassungsregelungen für die aufgelaufenen nominalen Vermögenswertzuwächse und -minderungen mit allen thren Bewertungsproblemen für die verschiedenen Vermögensarten.

Demgegenuber zeigen gleiche Ausgabensummen an, daB ungeachtet aller Preisstelgerungen und Geldentwertungen die Verfügung über Güter und Dienste gleich besteuert wird, und daB ungeachtet der Elnkunftsquellen die Verwendung zur güterwirtschaftlichen Bedarfsdeckung besteuert wird. Die Vortelle einer Expenditure Tax gegenüber einer Besteuerung nach dem RVZ-Konzept liegen also darin, daB

- Bewertungsprobleme entfallen,

- die Besteuerung von preissteigerungs- und inflationsbedingten Schelngewinnen entfälit, da sowohl die Erträge als auch die mit thnen verbundenen verbrauchs- und wiederbeschaffungsbedingten Aufwendungen in gegenwärtigen Preisen ausgedrückt sind und

- die Zweifachbelastung des Sparens entfällt; die Sparbildung selbst bleibt steuerfrei, ein späteres konsumtives Entsparen wird - wie der Konsum in der Gegenwartsperiode - besteuert.

c) Zur Gestaltung der Bemessungsgrundlage im einzelnen werden $k$ r i $t$ i s $c h$ im wesentlichen die folgenden Argumente - von den allgemeinen zu den speziellen geordnet - vorgetragen:

Zunächst fragt R.A. Musgrave (1957, S. 202), wie eine zweifelsfreie Abgrenzung zwischen Konsum und Sparen gefunden werden könne, aber auch, wie sich Konsum von Investitionen trennen lieBe. ${ }^{8}$ )

8) So können Ausgaben für die Erziehung sowohl Konsum als auch Investitionen sein, Musgrave/Musgrave 1980, S. 457. 
Demgegenüber hält A.R. Prest $(1979$, S. 247) es für nicht so entscheidend, wie diese Trennlinie gelegt werde, sondern daB sie auf Dauer in derselben Weise bestehen bleibe, denn entweder nehme man gegenwärtig die laufenden Ersparnisse aus der Besteuerung aus, besteuere jedoch dann korrespondierend die zuküftigen Ertrăge aus dem Ersparten im Moment ihrer Verausgabung oder man besteuert gegenwärtig die sparausgaben bel korrespondierender steuerbefreiung der späteren Verausgabung (so auch P.M. Mieszkowsky 1977 und Department of the Treasury 1977).

C.S. Shoup (1969, S. 351) weist auf Schwlerigkeiten in der Bestimmung normaler und durchschnittlicher Ausgabe-Raten für langlebige Gebrauchsgüter hin; je nachdem, wie die Bestimmung ausfalle, wird die Bemessungsgrundlage weiter oder enger werden. Die Steuerbemessungsgrundlage, die - wie A.R. Prest 11959, S. $483 \mathrm{f.})$ und R. Goode (1980, S. 57) ausdrlicklich hervorheben gegenüber dem RVZ-Konzept ohnehin wegen des Abzugs der Sparausgaben und der Vermogen deutlich schmaler ist, wird dadurch abermals enger werden. Dies nicht zuletzt auch deshalb, well - sollte der Steuersatz für betriebliche Erträge niedriger sein als der Ausgabensteuersatz - "the incentive to dress up final consumption as business expenses will be greater" (A.R. Prest 1979, S. 247).

Uberdies decken sich die Ausgaben, auch wenn man die Sparaufwendungen von ihnen abzieht, nicht mit den "persönlichen" Ausgaben, die das Ausgabensteuer-Konzept zur Bemessungsgrundlage macht: Schenkungen an Dritte sind keine Aufwendungen zum eigenen Vermögenserwerb, sind auch keine "persönlichen" Ausgaben, und müBten dennoch von der Bemessungsgrundlage abgezogen werden, wollte man nur die tatsächlichen persönlichen Ausgaben besteuern und nicht etwa ein Ausgaben-Potential. Macht man aber die "eigene Entscheidung" und die "freie Verfügbarkeit" $z$ u den wesentlichen Inhalten der AusgabengröBe, die sie vom Einkommen abhebt (P. Zumstein 1977, S. 76), so müBten diese Schenkungsausgaben wiederum zur Bemessungsgrundlage gehören.

Soll ferner, wie bei der Einkommensbesteuerung, zur Bestimmung der Leistungsfähigkeit ein existenznotwendiger Ausgabenbetrag von der Bemessungsgrundlage abgezogen werden? Aus rein wirtschaftstheoretischen Gründen nicht, denn auch diese Ausgaben sind verfügbar. Jedoch zur Bestimmung der steuerlichen Leistungsfähigkeit, 
die eine "freie" Verfügbarkeit voraussetzt, ist der Abzug zwingend. 9 )

Neben solchen Zweifeln an der Treffsicherheit des Indikators

"Ausgaben" liegt ein wesentlicher Einwand gegen das Konzept darin, daß der Leistungsfähigkeits-Indikator "Vermögen" aufgegeben wird zugunsten einer die unmittelbare "Bedürfnisbefriedigung" über den Konsum anzeigenden Indikators "Ausgaben". Da bei Aufkommensneutralität gegenüber einer Einkommensbesteuerung unweigerlich höhere Steuersatze existieren werden, entstehen auch hier die aus der Einkommensbesteuerung bekannten steuervermeidungsstrategien mit ihren allokativen und distributiven Effekten.

II. Gerade in der $N$ i $h t$ b e $s$ e u e $r$ u g d e s $v$ e $r$ m 8 e $n s$ und damit in der allokationspolitischen zielorientierung liegt das Wesensmerkmal des Ausgabensteuer-Konzepts. Die Gestaltung seiner Bemessungsgrundlage hangt auf das engste mit der steuerlichen $F$ e 1 s $t$ e 11 u $\mathrm{g}$ der personlichen $s$ p a $r$ b $t$ r a g e zusammen.

a) Der Sparakt als solcher hat den bosonderen "ökonomischen ort" auf einer "Nahtstelle" zwischen Allokation und Distribution, d.h. er beeinfluBt das Kapitalangebot uber die Vermogensbildung (hat damit eine einzel- wie eine gesamtwirtschaftliche Seite) und ist mit der Distribution dergestalt verbunden, daB die Sparleistung erstens von der Hohe des Einkommens und Vermogens abhängt (Sparfahigkeit) und $z$ weitens die weitere Vermorgensakkumulation erleichtert und damit die sparfahigkeit abermals beeinfluBt.

Der Sparvorgang wird im RVZ-Konzept nicht als ein die personliche Steuerlast vermindernder objektivierungsvorgang verstanden; im Gegenteil: jede Sparleistung erhoht über die zunahme des Ver-

9) Anders aber P. Zumstein 1977, s. 45, dem wir nicht zustimmen. Wenn er sagt, daB auch die existenznotwendigen Ausgaben Ausdruck der wirtschaftlichen Leistungsfählgkeit seien, so scheint er das wirtschaftstheoretische Argument mit dem steuerlichen $z u$ vermengen. Wenn er weiterhin die Frage, ob diese Ausgaben steuerlich belastet werden sollen, eine politisch zu entscheidende nennt, so stimmen wir ihm zu; doch will er sie durch die Bestimmung des Tarifs gelost wissen, nicht durch einen Abzug von der Bemessungsgrundlage. Dies aber halten wir nicht für korrekt. Auf Beträge, die eine Leistungsfähigkelt gar nicht erst auszudrücken vermogen, sollte ein Tarif nicht angewendet werden. 
mögenswertes direkt die Bemessungsgrundlage. Anders die Ausgabensteuer, die die sparleistung steuerliche befreit, ein allokatives gesamtwirtschaftliches Effizienzziel formuliert und zugleich darauf verzichtet, die Sparfähigkeit zum Indikator der Leistungsfähigkeit zu machen. darin liegt die Einseitigkeit wie auch die wesentliche Objektivierungsleistung dieses Konzepts ${ }^{10)}$, darin zeigt sich aber auch ein allokativer Widerspruch, wie sich aus einem Argument von R.A. Musgrave (1981, S. 31) ergibt: Letztlich kann die Begünstigung des Sparens mit dem Gerechtigkeitsziel konfligieren, und überdies gilt der Effizienzaspekt keineswegs als unbestritten (R.A. Musgrabe 1981, S. 31).

Nach Ansicht der Ausgabensteuertheoretiker verbessert die Ausgabensteuer die Nettoverzinsung und ändert demzufolge die Sparquote zugunsten des Zukunftskonsums (Sparens). Doch einmal abgesehen davon, daB auch unabhängig vom Nettozins gespart wird, sind $z$ wei Gegenargumente vorzubringen, von denen das erste die Sparmotivation, das zweite die Sparfahigkeit berührt: A.R. Prest (1959, S. 489) stellt fest, daB das langfristige Sparen - sei es nun zwecksparen oder Vorsorgesparen - durch eine Ausgabensteuer nicht gefördert werden könne. J.E. Pechman (1971, S. 65) hebt die geringe Sparfähigkeit der Mehrzahl der Haushalte hervor, die auch durch steigende Nettoverzinsung nicht verbessert werden könne. Im Rahmen dieser Begrenzungen läbt sich also ein Substitutionseffekt der Ausgabensteuer (R.Peffekoven 1979a, S.433) allenfalls feststellen, wenn zusäzlich die Sparformen und Anlagefristen beachtet werden und wenn sich sämtliche Bedingungen der Behandlung der Ersparnisbildung in der Einkommensteuer gegenüberstellen lassen (R. Peffekoven 1979a, S. 434). Definitive Ergebnisse zur Ersparnisbildung lassen sich kaum vorhersagen (R. Peffekoven 1979c, S. 152). Wiederum stehen sich also die Plausibilität der Wirkungen - einschlieblich so optimistischer Einschätzungen wie bei C.S. Shoup ${ }^{11)}$ - und die Schwierigkeit ihrer Feststellung - so zuletzt in Berechnungen von M.J. Boskin (von 1978) ${ }^{12}$ ) einerseits

10) Insofern ist die Ansicht Kaldors, die Einkommensteuer lasse die Entscheidung zwischen Konsum und sparen nicht unbeeinflubt, eben $n i c h t$ überzeugend.

11) Er stellt fest: "But it seems clear that on balance this particular tax substitution must lead to an increase in saving", 1969, S. 347.

12) Er ermittelte eine realtiv hohe und signifikante Elastizität des Sparens im Hinblick auf die "after tax rate of return to saving" 
und Howrey/Hymans (von 1980) ${ }^{13}$ ) andererseits - gegenüber.

b) Abschließend sei zum Argument der Doppel- (oder Zweifach-)belastung bzw. -erfassung ${ }^{14)}$ stellung genommen, die durch die Einkommensteuer erfolgt und das nach den Vorstellungen der Vertreter der Ausgabensteuer dieser einen unbestreitbaren Vorteil verschaffe. Die Doppelerfassung ist sowohl ein Thema der Allokation als auch der Indikation von Leistungsfähigkeit. An der Tatsache selbst ist nichts $\mathrm{zu}$ bestreiten.

Während H. Haller (1971, S. 53) die Doppelerfassung nun damit rechtfertigt, daB der Sparer (wie der konsument) eine "Befriedigung" erfahre, die ihn veranlasse, zu sparen statt zu konsumieren (und diese Befriedigung sel Indikator der Leistungsfähigke1t) ${ }^{15)}$, stellt R. Peffekoven (1979a, S. 431) klar, daB man von einer Doppelerfassung nur sprechen kann, wenn man die Besteuerung der Einkommensentstehung aus dem Blickwinkel der Einkommensverwendung beurteilt. Vermeidet man diesen Fehler, dann muB wie folgt argumentiert werden: Besteuert man - wie es die Einkommensteuer tut - die Einkommensentstehung ungeachtet ihrer Herkunft und sieht darin die Leistungsfähigkeit, so ist zwangsläufig die ursprünliche Elnkommens- wie die spätere Zinsertragserzielung Einkommen. Besteuert man - wie es die Ausgabensteuer tut - nur die Einkommensverwendung, dann ist die summe der Ausgaben - in diesem Falle allein jene für den Konsum - der Indikator der Leistungsfähigkeit. 16) Damit erwelst sich die sog. "Doppelbelastung" (R.

13) Sie fanden keine signifikante Evidenz für einen positiven Effekt auf das Sparen.

14) Vgl. hierzu unsere Darstellung im Verfügbarkeitsansatz (\$ 11) die auf der Trennung zwischen zugang und Verwendung von ökonomischen Größen beruht. Die zugangsregel mit ihrem ad-personamInhalt ( $\$$ 8) ist auch steuerlich anzuwenden, so daß jegliches Doppelzähl- und Doppelbelastungsargument fehl gehen muß; vgl. N. Andel 1979a, S. 340 und 356; R.A. Musgrave 1981, S. 31; siehe auch A. Oberhauser 1979, S. 49lf. und das Meade Committee 1978, S. 27.

15) Haller als ein Vertreter des utilitaristischen Konzepts der Leistungsfähigkeit argumentiert selbstverständlich mit Begriffen aus dem psychischen Bereich, und da jemand sowohl beim Sparen als auch beim Konsumieren Befriedigung empfindet, handelt es sich bei der Besteuerung des Sparaktes sowie des Konsumaktes um eine doppelte bzw. mehrfache, die jedoch systemgerecht ist.

16) So argumentiert auch R. Goode (1980, S. 54), der auf die "Kaufkraft" aus (a) dem originären Einkommen und (b) dem Zinseinkommen abhebt; nicht der sparakt werde besteuert, sondern der Zuwachs an Kaufkraft, und auch der nur, soweit er investiert (nicht gehortet) und nicht von Verlusten aufgezehrt wird. 
Peffekoven 1979a, S. 431) im Kern als eine Frage der Indikatorwahl, und das Argument der Doppelbelastung kann - weil für die Ausgabensteuer gegenstandslos - nicht mehr zur Begründung eines allokativen Vorteils dieser Steuer gegenüber der Einkommensteuer vorgebracht werden. 17 )

III. Die distributiven Wirkungen gehen zum einen vom Sparverhalten, zum anderen von der Freibetrags - und Tarifkonstruktion der Ausgabensteuer, letztlich auch vom Konsumverhalten der Besteuerten aus. Zunächst liegen die distributiven Probleme in der Gestaltung der Besteuerungsgrundlagen, insbesondere durch die P e r s n a $l$ is $i$ e $r$ u $g$ der Ausgabensteuer, wie sie von der Ausgestaltung der persönlichen Freibeträge und des progressiven Tarifs geleistet wird (F. Neumark 1970, S. 168).

a) So haben die unteren Einkommensschichten einen realtiv höheren Anteil ihrer Periodeneinnahmen in den Konsumausgaben $z \mathrm{u}$ versteuern als andere Schichten. Es kommt hinzu, daB das Niveau der Steuersätze im Vergleich zur Einkommensteuer höher sein muB. Der Vorteil der Ausgabensteuer, der in der Vermeidung aller Nachteile einer unvollständigen und uneinheitlichen Einkommenserfassung durch die Einkommensteuer tatsächlich vorhanden ist, wird erkauft durch die Konstruktion der schmaleren Bemessungsgrundlage "Konsumausgaben". 18) Das AusmaB der Progressivität des Ausgabensteuertarifs hängt ganz wesentlich von der Verteilung der ProgressionsmaBe über die einzelnen Stufen der klassenspezifischen Ausgabensummen und von den persönlichen Freibeträgen ab. Erst danach zeigt ein Vergleich, wie regressiv die Ausgabensteuer im Verhältnis zur Einkommensteuer wirkt.

17) Dessenungeachtet wird aber eine andere Doppelbelastung von der Ausgabensteuer vermieden, nämlich die der Vermögenserträge durch die vermögensteuer und durch die Einkommensteuer.

18) Vorausgesetzt, es findet kein Entsparen statt, das die Bemessungsgrundlage der Ausgabensteuer erweitert.

Fn. der folgenden Seite:

19) C.S. Shoup 1969, S. 347; der Ansicht Shoups (ebenda), der Konsum könne durch Kreditaufnahme zeitlich verteilt werden, muB widersprochen werden: jegliche kreditaufnahme wird gem. der indirekten Konsumermittlung (siehe Ubersicht 10.3 Zelle 2 minus Zeile 4, plus $Z .6$ ) den Periodeneinnahmen zugerechnet und unabhängig von ihrer Verwendung als $z u$ versteuernde Ausgabe angesehen. 
b) Der Anrelz zur $\mathrm{K} \circ \mathrm{n} \mathrm{s}$ m a n p a s $\mathrm{s} n \mathrm{~g}$ zwecks "Manipulation" der Steuerbasis - bei hohen Ausgabensteuersätzen nicht unwahrscheinlich - ist schichtenspezifisch: Ausgabespitzen zeitlich $z u$ verschieben, um der Progression der Grenzbelastung $z u$ entgehen, ist vermutlich nur den oberen Einkommensschichten möglich. 19) Eben deswegen verlangt D.F. Bradford ${ }^{20}$ eine Besteuerungsperiode, die zwischen einer Dekade und der Lebenszeit liegen soll. Letzterer entspräche das Gebot der Gerechtigkeit, ersterer das der Praktikabilität.

Einen distributiven Nachteil der Ausgabensteuer gesteht Kaldor ein, da er die Summe, die einerseits der reiche Geizige, andererseits der ärmere Verschwender ausgibt, nicht für den geeigneten Indikator der Leistungsfähigkeit hält. ${ }^{21)}$ Gerade dieser Umstand aber, den er allenfalls als den Grund für eine gewisse Einseitigkeit seines Konzeptes des "second best" ansieht, hätte ihn zwingend auf die Rolle des Vermögens weisen müssen, das dieses im distributiven Bereich spielt. R. Goode (1980, S. 54) sieht dies nun sehr deutlich. Das einzige, wozu sich Kaldor bereitfindet, ist die $\mathrm{zu}-$ lassung einer Erbschaftsteuer. Demgegenüber sieht Goode den Konflikt, der durch Akkumulation des Sparens in den hohen Einkommensklassen auf der einen Seite und hohen Erbschaftsteuersätzen mit ihren allokativen Nachteilen auf der anderen entsteht, etwas entschärft, wenn Geschenke und Vermächtnisse als Ausgaben des Schenkers bzw. Erblassers in die Ausgabensteuer integriert würden.

Gerade die distributionspolitische Einseitigkeit dieses Konzeptes kann als AnlaB gesehen werden, "kombinierte Ausgaben-VermögensKonzepte" zu entwickeln, wle sle nunriehr dargestellt werden.

20) 1980 , S. 103 ff.; bei gleicher Ausstattung des einzelnen mit "life time wealth" doch unterschiedlichem Verbraucherverhalten kommt er zur Bevorzugung der Ausgabensteuer gegenüber der Einkommensteuer (S. 109); die mehrjährige Besteuerungsperiode wird begründet, weil sowohl Ereignisse in einer kurzen Periode wie auch Steuerzahlungen in einer kurzen Periode nicht geeignet sind, die Steuerfähigkeit $z u$ bestimmen bzw. die relativen Steuerlasten $\mathrm{zu}$ vergleichen (S. 107-108).

21 ) N. Kaldor, Comments on W.D. Andrews 1980, S. 153: "If spending power is measured by actual spending, there is an injustice in the allocation of the tax burden as between misers and spendthrifts". 
S 34 Die "kombinierten Ausgabenvermógens"-Konzepte von Dieter sohneider und Joachim Mitsohke

I. Bemessungsgrundlage 543

II. Bewertung 548

III. Allokativ-distributiver Konflikt 549

I. In die Ausgabenbesteuerung auch das Vermögen einzubeziehen, darf als Konsequenz aus der Lückenhaftigkeit des "reinen Ausgaben"-Konzeptes angesehen werden. Damit ist hinsichtlich der Leistungsfähigkeitsindikatoren in der Ausgabenbesteuerung heute jener Diskussionstand erreicht, de vor mahr als 100 Jahren die Einkommens- und vermögensbesteuerung kennzeichnete. Denn einerseist war die aus dem Mittelalter überkommene Ansicht, besonders das Vermögen sei der geeignete Indikator für steuerliche Leistungsfähigkeit, längst überholt; andererseist wurde bald allgemein akteptiert, daß - so F. Neumark (1947, S. 36f.) - Einkommen der beste generelle Maßstab der Leistungsfähigkeit sei, da es der Deckung des laufenden Bedarfs der Menschen dient, während das Vermögen zumindest vorübergehend und in Notzeiten, wenn nicht gar stets ergänzend - so z.B. Musgrave/Musgrave (1980) und auch K. Schmidt (1967, s. 387 ff.) - der Bedarfsdeckung dient und zur Besteuerung heranzuziehen ist. Musgrave/Musgrave (1980, S. 248) führen außerdem vor allem Gründe der Praktikabilität in der Besteuerung an: Obwohl eine Vermögensbesteuerung nicht nötig ist, wenn die Akkumulation korrekt erfaBt und besteuert würde, mag es einen Platz für die Vermögensteuer sehr wohl geben, wenn man die Unvollständigkeit der tatsächlichen Steuerpraxis in Betracht zieht. 
a) Die moderne $D i s k$ u s i $\mathrm{n}$

um die Ausgabenbesteuerung wird auf zwei Ebenen sichtbar: In der

a m e r i k a $\mathrm{n}$ s $\mathrm{ch}$ e $\mathrm{n}$ Literatur wird sie in der alten Kontroverse "Ausgabensteuer versus Einkommensteuer" geführt, ${ }^{1)}$ während sie in der d e u t s c h e $n$ Literatur ${ }^{2)}$ unter dem oben geschilderten Vermögensaspekt den Gegensatz "reine Ausgabensteuer" versus "kombinierte Ausgaben- und Vermögensteuer" betont. In der angelsächsichen Literatur spielt das Vermögen hierbei längst nicht die Rolle, die man $1 \mathrm{hm}$ in der deutschen beimiBt. DaB selbst $\mathrm{N}$. Kaldor unter dem Eindruck der allokativen Einseitigkeit seiner Expenditure Tax (1955, S. 50, 100 f. u. 203 f.) eine Erbschaftsteuer fordert, darf nicht überbewertet werden, läBt er doch damit das nicht ererbte Vermögen nach wie vor auBer Betracht und leistet sich zudem, wie J. Mitschke nachweist, eine definitorische Widersprüchlichkeit hinsichtlich seiner "taxable capacity". "3) Ebenso darf dem Vorschlag von I. und H. Fisher ${ }^{4}$ ) keine übergroBe Bedeutung zugemessen werden, stellen sie ihren Besteuerungsvorschlag von Konsum, Erbschaft und Vermögen doch ausschlieBlich auf die Ersparnisse $a b$, und auBerdem auf die als negativ erachteten einzel- und gesamtwirtschaftlichen Wirkungen einer laufenden Einkommensteuer. ${ }^{5}$ )

Damit läuft die Diskussion im deutschen Sprachraum auf lediglich $\mathrm{z}$ we $\mathrm{i}$ A $t$ e $\mathrm{r} n \mathrm{a} i \mathrm{v}$ e $\mathrm{n}$ des "kombinierten" Konzeptes hinaus: (1) auf die Kombination einer periodischen Ausgabensteuer mit einer Besteuerung des Gesamtvermögens am Ende der Lebenszeit des Besteuerten; letztere ist eine integrierte Vermögens- und Erbschaftsbesteuerung in Form einer NachlaBsteuer, die von J. Mitschke

1) Siehe die Sammelbände hg. von J.E. Pechman 1977 u. 1980 und die dort angegebene Literatur; ferner Musgrave/Musgrave 1980, S. $242 \mathrm{ff}$ u. $455 \mathrm{ff}$. sowie Atkinson/Stiglitz 1980, s. 62-77, 425 u. 563-566.

$2)$ Hier stützen wir uns vorwiegend auf D. Schneider 1971, 1978b (S. 22,27 u. $36 \mathrm{f.}), 1979 \mathrm{a}$ sowie $1979 \mathrm{c}$ (S. $38 \mathrm{f.}$ ); ferner auf J. Mitschke $1980 \mathrm{~b}, \mathrm{~S} .274 \mathrm{ff}$. u. 1976; vgl. aber auch Engels/ Mitschke/Starkloff 1973.

3) 1976, S. 170: actual expenditure ist ihm der einzige MaBstab der "ability to pay"; wenn er jedoch andererseits in Erbschaften akkumulierte Ersparnisse aus Befürchtungen zur Vermögenskonzentration der Erbschaftsteuer unterwerfen will, verbleibt es offenbar nicht beim Konsum als einzigem Leistungsfähigkeitsindikator, gleichgültig, ob man es vom Erben oder vom Erblasser aus betrachtet.

4) 1942, S. 70 f., 87, 95, 160 u. 195 f.

5 ) J. Mitschke 1976, S. 171: "Solche Wirkungen lassen sich jedoch in keinen direkten Zusammenhang mit dem Leistungsfahigkeitsprinzip br|i|aiger|Heselelt and Anneliese Hessler-Otte - 978-3-631-75239-5 
propagiert wird; ${ }^{6}$ (2) auf die Kombination einer periodischen Ausgabensteuer mit einer periodischen Vermögensteuer, die von $D$. Schneider vorgeschlagen wird. Die reine Ausgabenbesteuerung gilt als lediglich effizienzorientiert, wohingegen das Ausgaben-Vermögensteuer-Konzept als ähnlich leistungsfähigkeitsorientiert gelten kann wie das Einkommen-Vermögensteuer-Konzept der geltenden Regelung. Der Unterschied liegt nach den Autoren darin, daB das Ausgaben-Vermögensteuer-Konzept die tatsächliche Bedurfnisbefriedigung besser erfaBt.

b) Beide Autoren sehen in dem umfassenden Ansatz des RVZ-Konzeptes das RichtmaB für ihr eigenes Vorgehen. Insofern verfahren sie bei der Gesamterfassung der Leistungsfähigkeit nur konsequent, wenn sie das Vermögen in ihr Konzept einschlieBen. In dieser Konsequenz geht J. Mitschke (1976, S. 163) weiter als D. Schneider, da er unter Vermögen das gesamte am Lebensende des Besteuerten versteht; am Lebensende nicht realisierte Vermögenswertsteigerungen gelten als realisiert. D. $\mathrm{s} c \mathrm{~h} n$ e 1 d e $r$ hingegen will das Vermögen periodisch besteuern, dabei aber nur die tatsächlich realisierten Vermögenswertzuwächse erfassen. Er stellt sein Konzept allein auf die Bedürfnisbefriedigung ab (siehe $\$ 31$ ) und unterscheidet diese nach tatsächlicher und potentieller (1979a, S. 48). Einkommen ist für ihn zwar verwirklichter Mittelerwerb, doch nur potentielle Bedürfnisbefriedigung. Realisieren läBt sich eine Bedürfnisbefriedigung aber nur mit der Mittelverwendung (aus Ausgaben und Vermögen). Sofern man mithilfe der Einkommensteuer den verwirklichten Mittelerwerb besteuern will, verbietet sich nach schneider eine gleichzeitige Besteuerung des Vermögens, ${ }^{7)}$ da die Erhaltung

6) Nicht übersehen werden sollte, daB Mitschke seine Form der Konsumsteuer auf der Basis einkommenstheoretischer Betrachtungen ableitet und die Besteuerung des Periodenkonsums plus Endvermögen deswegen vorschlägt, weil die Einkommenserfassung rein meBtechnisch nicht $z u$ leisten sel; Mitschke betont (S. 205), der Kern der Einkommensbesteuerung sei dadurch nicht aufgegeben.

7) Nach unserer Auffassung gelingt Schneider die Eliminierung des Vermögens aus der Besteuerungsbasis (Einkommen plus Vermögen) lediglich mit Hilfe eines definitorischen "Tricks": Er postuliert eine Gegenüberstellung der die Leistungsfähigkeit ausdrückenden Vorgänge "verwirklichter Mittelerwerb versus möglicher Mittelerwerb" einerseits und "verwirklichte Bedürfnisbefriedigung versus mögliche Bedürfnisbefriedigung" andererseits $(1979 \mathrm{a}, \mathrm{s} .26 \mathrm{ff} ., 1979 \mathrm{c}, \mathrm{s} .38 \mathrm{ff}$.$) . Rein definitorisch ist$ nur auf der Seite der "Verbrauchstätigkeit" selbstredend eine

(Forts. siehe folgende seite) 
des Anfangsvermögens die Voraussetzung dafür sei, daB Einkommen vorliegt (1979a, S. 49). Ohne auf diesen letzten Sachverhalt näher einzugehen, ${ }^{8}$ ) sei hier festgehalten, daB 1 . Schneider für die Besteuerung nach der Leistungsfähigkeit nur eine Alternative als zulassig gilt: entweder Besteuerung des verwirklichten Mittelerwerbs oder Besteuerung der verwirklichten Bedürfnisbefriedigung. Für letztere hat er sich entschieden; dann aber ist eine selbständige Vermögensteuer angebracht, well Vermögen samt Erbschaft (1979c, S. 40) ein ökonomisches MaB für eine bestimmte Bedürfnisbefriedigung in Form eines erweiterten Entscheidungsspielraums, Kreditspielraums, vermehrter Freizeit, der Sicherheit des künftigen Konsums usw. ist. Das sind Befriedigungen jenseits derer aus Konsum (1979a, S. 49).

Für J. M $i \mathrm{t} s \mathrm{sh}$ e $(1976, \mathrm{~s} .163 \mathrm{f.})$ ergibt sich aus der Uberlegenheit des Gesamtansatzes nach der Reinvermögenszugangstheorie und entsprechend seinem MeBkonzept eine Zerlegung des Lebenseinkommens in "Periodenkonsum" und "Vermögen zum Lebensende (Endvermögen)". Er kann demonstrieren, daB die EinkommensgröBe auf der Entstehungsseite, also der "Nettozustrom nach dem Stromkonzept" ${ }^{9}$ ) identisch ist mit der Einkommensgröße auf der Verwendungsseite, also mit dem "Nettozustrom nach dem Bestandskonzept". ") Beide EinkommensgröBen ergeben sich additiv, wobei in unserem Zusammenhang die letztere interessiert: Das Einkommen nach dem Bestandskonzept ist eine Addition von "Konsum" und "Bestandsveränderungen", beide ex post gemessen in Marktpreisen (VeräuBerungspreisen).

Forts. Fn. 7:

Bedürfnisbefriedigung aus Vermögen denkbar, auf seiten des Mittelerwerbs nicht, weil Vermögen nicht Mittelerwerb sein kann. Das Rätsel löst sich, wenn man die Gleichsetzung von Mittelverwendung und Bedürfnisbefriedigung nicht mitmacht.

8) Wir hatten in $\$ 7$ bereits entwickelt, daB wir es für theoretisch nicht zulässig halten, die Einkommensverwendung, ja überhaupt eine BestandsgröBe zum Definitionselement von Einkommen $\mathrm{zu}$ machen; lediglich unter steuer- und belastungspolitischem Aspekt halten wir das für erlaubt und sinnvoll.

9) Der "accrual type" des Einkommens nach P.H. Wueller 1938, S. 98.

10) Dem "disposition type" des Einkommens nach P.H. Wueller, ebenda. 
Bei volumensmäBiger Ubereinstimmung der beiden EinkommensgröBen begründet er die Bevorzugung des Bestandskonzepts wie folgt (S. 168): "Wenn wir .. im Einkommen als Summe von Konsum und Vermögenszuwachs einen Indikator wirtschaftlicher und steuerlicher Leistungsfähigkeit sehen, so läBt dies auf die Auffassung schlieBen, daB die Leistungsfähigkeit einer Person durch ihren Konsum nicht hinreichend wiedergegeben wird."11) Da Vermögen ein konstitutives Merkmal jeden Einkommensbegriffs ist (S. 109 u. 135 f.), jedoch die an ein Periodeneinkommen anknüpfende Idee der Einkommensbesteuerung ihr ziel unter der Voraussetzung der von Mitschke begründeten MeBaxiomatik (S. $16 \mathrm{f.}$ ) und realitätsnaher MeBumstände verfehlen muB, ${ }^{12)}$ ist ein den Teilperioden der Lebenszeit zugerechnetes Einkommen als Bemessungsgrundlage der Direktbesteuerung ungeeignet (S. 138), erscheint somit - auch unter zusätzlicher Beachtung der periodisierungsbedingten Steuerbelastungsprobleme (S. $138 \mathrm{ff.}$ ) und Inflations-/Deflationswirkungen (S. 147 ff.) - die Wahl des "kombinierten Ausgaben-Vermögens-Konzeptes" nur folgerichtig.

c) Bevor Bewertungsfragen aufgeworfen werden können, sind Probleme der A b g r e $n z$ u $\mathrm{g}$ zu lösen zwischen Konsumausgaben persönlicher Art und Ausgaben für die Einkunftserzielung, ${ }^{13)}$ ferner

11) Und weiter (S. 168): "Schlieblich ist offensichtlich, daB sich wirtschaftliche Dispositionskraft gerade auch in den Einkommensquellen äuBert, die gespart werden. ... Da eine umfassende Einkommensdefinition alle Ersparnisse (= Vermögenszuwächse) erfaBt, die in Konsequenz der alternativen zerlegung des Lebenseinkommens als Endvermögen $z u$ besteuern sind, ist eine zusätzliche Vermögensbesteuerung zumindest in dem MaBe unbegründet, in dem sie sich auf die Nachholung unterlassener Einkommensbesteuerung beruft (Substitut unversteuerter VeräuBerungsgewinne, Wertzuwächse usw.)."

12) Ders., ebenda, S. 12 u. 107; siehe die empirische Anwendung des Konzepts des Periodeneinkommens S. $110 \mathrm{ff}$.

13) Mitschke trifft für Konsum folgende Unterscheidung: Aufwand für die Lebensführung im tatsächlichen Verbrauch; Aufwand für die Erhaltung und den Einsatz der auf Einkommenserzielung gerichteten Arbeitskraft (berufsbezogene Ausbildungs-, Fortbildungs - und Umschulungsaufwendungen); letzterer rechnet nicht zum Konsum $(1976$, S. 94/95). 
- wie schon erwähnt (\$ 33) - zwischen Konsum und Sparen (R.A. Musgrave 1957, S. 202) und schlieBlich zwischen Ausgaben für Sparen und jenen für Vermögensgüter. Hier wird es nicht ganz ohne "Willkür und Manipulationsmöglichkeiten" abgehen; man wird - wie R. Ulbrich sehr richtig in seiner Kritik an D. Schneider feststellt - im wesentlichen auf "Konventionen" zurückgreifen. ${ }^{4}$ )

II. Die theoretische Schlüssigkeit der Indikatorfrage, wie sie $\mathrm{J}$. Mitschke demonstriert, und die $\mathrm{B}$ e w e $r$ u $\mathrm{n} g$ stehen in einem Gegensatz zueinander.

a) Zunächst finden sich die Bewertungsprobleme, die für das RVZKonzept konstitutiv sind, und die dennoch nach $D$. S c h n e i d e r (1971, S. 359) "unter den Bedingungen der Wirklichkeit eindeutig zu definieren" sind, auch in der kombinierten Ausgaben-Vermögensbesteuerung wieder. So übereinstimmend (für Mitschke wie für Schneider) der Marktpreis die Bewertung des Vermögens auch regelt, steht weniger die "verwirklichte Bedürfnisbefriedigung" Schneiders, mehr noch das "Lebenszeiteinkommen in Periodenkonsum und Endvermögen" Mitschkes vor denselben Bewertungsproblemen wie das RVZ-Konzept, Problemen also, die gerade mit dem tbergang zum Ausgabenkonzept umgangen werden sollten. Da Schneider die nichtrealisierten Wertsteigerungen aus seiner Vermögensbesteuerung ausschlieBt, erreicht er nicht die Geschlossenheit der Konzeption wie Mitschke; da dieser die nichtrealisierten Wertsteigerungen mit erfaBt, erreicht er nicht die Befreiung von Bewertungsproblemen wie das Konzept der "reinen Ausgabensteuer".

Somit stellt sich in letzter Konsequenz die Kritik Schneiders am Einkommensbegriff der Reinvermögenszugangstheorie als eine Kritik an der nicht systemgerechten Verwendung der "Bedürfnisbefriedigung" heraus, wohingegen Mitschke die von keinem Einkommens-

14) R. Ulbrich (1975, S. 27, Fn. 2) fragt in seiner Kritik an D. Schneider: "Handelt es sich beispielsweise beim Kauf eines wertvollen Schmuckstückes oder Gemäldes oder auch nur einer Briefmarkensammlung um einen Konsumakt oder um Vermögensbildung? Niemand vermag $\mathrm{zu}$ sagen, in welchem AusmaB hier Konsumbedürfnisse einerseits, Besitzbedürfnisse andererseits befriedigt werden ..." - Wie wir in $\$ 10$ darlegen konnten, liegt die Möglichkeit zu einer Unterscheidung in ders individuellen Widmungs- uns Entscheidungsakt. 
konzept je zu lösenden Erfassungs- und Bemessungsprobleme der Einkommenserzielung kritisch vorbringen kann.

b) Die Bewertungsprobleme sind bei $M i t s c h k$ aufgrund seines Vermögenskonzepts von ganz anderer Art als bei Schneider. Dies nicht nur, weil sein Vermögensbegriff das human capital umfaBt (S. 92), 15) sondern vor allem, weil die Bewertung erst am Lebensende erfolgt. ${ }^{16)}$ Die Grundregel der Bewertung, daB stets der Marktpreis (der VeräuBerungspreis) gilt, muB also am Lebensende aufgegeben werden, ${ }^{17)}$ da dann keine Aktualität der Bewertungsfälle mehr hergestellt werden kann. Die Bewertung kommt $z u$ spät. Zugleich entstehen bei einmaligem Vermögensanfall am Ende der Lebenszeit die Probleme der progressionsausgleichenden Steuerberechnung (J. Mitschke 1976, S. 200 f.), wie sie - anders als bei Erbanfallsteuern - bei jeder Art von NachlaBsteuer auch entstehen.

III. Kann diese Form der Endvermögensbesteuerung die "ökonomischfinanzielle Dispositionskraft einer Person"(F. Neumark) voll erfassen? Sie kann sie während der Lebenszeit nur teilweise anläBlich ständiger oder aperiodischer Dispositionsakte berücksichtigen, z.B. wenn Realisierungen und anschlieBend Konsumakte stattfinden. Vermögensbestandserhöhungen (Werterhöhungen) und die

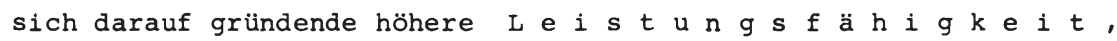
die D. Schneider (1971, S. 369) mit gröBerem Handlungsspielraum, erweiterter Kreditfähigkeit und gröBeren Möglichkeiten zu risikoreicheren Geschäften gleichsetzt, lassen sich mit ihr nicht erfassen.

15) Auch Musgrave/Musgrave/Kullmer 1975b, S. 32) halten dies für unumgänglich, sofern die Ausgabenbesteuerung ein Aquivalent $z u$ einer allgemeinen Einkommensteuer sein soll, von der Mitsche ja ausgeht. In 1988 erwähnen sie die vst nicht mehr.

$16)$ Hier bietet gerade die Bewertung des human capital keine Schwierigkeit, da der Wert $z$ u diesem Zeitpunkt gleich Null ist, Mitschke, S. 200. Das Gesamtvermögen wird nur ein einziges mal bewertet, nämlich am Lebensende.

17) Wenn am Lebensende nichtrealisierte Kapitalgewinne und -verluste vorliegen, gelten sie fiktiv als realisiert. Liegen keine Marktpreise $z u$ Vergleichszwecken vor, sind die Werte $z u$ approximieren mit Hilfe der um $\mathrm{Zu}$ - und Abschreibungen korrigierten Anschaffungs- und Herstellungskosten; Mitschke, S. 200. 
Schneider wie Mitschke können die a 1 l o $k$ a $t$ i v e Einseitigkeit des "reinen Ausgaben-Konzepts" hinsichtlich der steuerlichen Prämilerung der Vermögensbildung (des Sparens, mit allen distributiven Effekten) nicht beheben. Jedoch kann Schneider sie insofern halbwegs korrigieren, als er die Vermögensbestände periodisch besteuert. Hierbei erreicht er darüber hinaus auch eine Gleichbehandlung der verschiedenen Vermögensarten, da er die verwirrende Vielfalt der Wertbegriffe und -bewertungsverfahren (Gemeiner Wert, Teilwert, Ertragswert, Substanzwert, Einheitswertverfahren) durch den stets geltenden Marktwert ersetzt. Dieselbe Gleichbehandlung erreicht Mitschke: Durch Nichtbesteuern während der Lebenszeit (= Vermögensanlagezeit) kann eine Ungleichbehandlung nicht auftreten.

Die d i $s$ r $i$ b u $t$ i e Lücke, die das "reine Ausgaben-Konzept" durch die fehlende Besteuerung des Vermögensbestandes aufweist, wird von Schneider und Mitschke auf unterschiedliche Weise geschlossen: Schneider erreicht dies weitgehend durch die periodische Besteuerung des Vermögens, jedoch nur zum Teil, da unrealisierte Wertsteigerungen, die auch den Handlungs-, Entscheidungsund Kreditspielraum des einzelnen erhöhen und somit Leistungsfähigkeit ausdrücken, auBer Ansatz bleiben. Mitschke verlagert die Lösung des im Vermögensbesitz liegenden distributiven Problems auf den NachlaBzeitpunkt und praktiziert damit eine nachgeholte leistungsfähigkeitsorientierte Besteuerung des nicht mehr Leistungsfähigen. Distributive Effekte treten je nach dem Umfang der gewährten persönlichen Freibeträge (bei Mitschke wird noch der Erhaltungsaufwand für die persönliche Arbeitskraft abgesetzt) und nach der Höhe und dem Verlauf der Progressionssätze unterschiedlich auf. ${ }^{18)}$

18) Es fragt sich, ob bei Geltung der Abgrenzung zwischen allokativem Betriebs- und Berufsbereich und distributivem persönlichen Bereich und bei gleichzeitiger "indirekter Konsumermittlung" in einer "persönlichen Ausgabensteuer" der Erhaltungsaufwand für den Faktor Arbeit nicht bereits im Schritt des Einkommenszugangs von den Einkünften abgezogen werden müßte, da er keine "persönlichen Ausgaben" darstellt.

Heinz Hessler and Anneliese Hessler-Otte - 978-3-631-75239-5 
535 Das "kombinierte Einkommens-Ausgaben"-Konzept von W. D. Andrews

I. Die Diskussion des Für und wider 551

II. Allokativ-distributive Ziele und
Gestaltung

III. Allokativ-distributive Wirkungen der "Supplement Personal Expenditure Tax" (SPET) auf Steuerbasis und Bemessungsgrundlage

I. Da die Wohlstandsquellen vielfältige sind, Leistungsfähigkeitsindikatoren nicht nur in den persönlichen Ausgaben liegen, hat N. Kaldor (1980, Comments to W.D. Andrews 1980, S. 154) in jüngster Zeit seine Auffassung dahingehend konkretisiert, daB aus theoretischen und praktischen Gründen die Ausgabensteuer eher als E r g ä n z u n g denn als Ersatz der Einkommensteuer einzusetzen sei, nachdem kurz zuvor auch in Schweden ein Vorschlag in dieser Hinsicht gemacht worden war. ${ }^{1)}$ Für die US-amerikanischen Verhältnisse halten Musgrave/Musgrave eine solche Besteuerung auf Bundesebene für sinnvoll, weil sie die traditionellen Einwände gegen sales taxes abbauen würde. ${ }^{2)}$ Da das Einkommen nicht mit der gebotenen Zuverlässigkeit ermittelt werden kann, will auch G. Krause-Junk (1977, S. 341) diesen Mangel durch eine Ausgabensteuer kompensieren, obwohl er das Einkommen für den besseren Indikator der Leistungsfähigkeit hält. Solchen Praktikabilitätserwägungen hält D. Schneider (1979a,S. 39) entgegen, daB theoretische Bedenken bestehen: Einkommen- und Ausgabensteuer erfassen unterschiedliche Verwirklichungsweisen der Bedürfnisbefriedigung und seien nicht miteinander kombinierbar. Auch W.A. Klein hebt nicht ohne Sarkasmus ${ }^{3)}$ hervor, daB die Ergänzungsrolle, die man der Ausgabensteuer dadurch zuweist, die Nachteile der

1) S.-0. Lodin 1978. - Ders. in: Wirtschaftswoche Nr. 46, 1976, S. 96 .

2) 1980, S. 458 sowie neuestens R.A. Musgrave 1981, S. 33.

3) Der Sarkasmus Kleins kommt in dem von ihm verwendeten Bild zum Ausdruck: die Kombination von Einkommen- und Ausgabensteuer erinnere $i \mathrm{hn}$ an eine Umarmung zwischen Präsident Sadat und Premierminister Begin; Comments to W.D. Andrews, 1980, S. 157 . 
Einkommensteuer $z \mathrm{u}$ beheben, eigentlich die "Superiorität" der Einkommensteuer (R. Goode 1980) unterstreiche.

II. Für eine Würdigung dieses "kombinierten Einkommen-AusgabenKonzeptes" kommt es auf die $z$ i e $l$ e an, die man mit der Besteuerung verfolgt; es lassen sich distributive wie allokative gleichermaBen anvisieren. Nach C.S. Shoup ${ }^{4)}$ läBt sich - wie das auch von W.D. Andrews vorgeschlagen wird - die Ausgabensteuer so einrichten, daB sie nur den Konsum der oberen Einkommensschichten erfaBt. Damit ist schon ein distributives ziel unterlegt, allerdings mit einem allokativen Effekt: die Ausgabensteuer vermeidet für alle diejenigen, die sparen, den hohen spitzensatz der Einkommensteuer (W.A. Klein, Comments 1980, S. 159). Auf dieser Wirkungsweise beruht auch das Modell von W.D. Andrews (1980, S. $129 \mathrm{ff.}$, das einen Uberblick über die Vor- und Nachteilskombination des Einkommen-Ausgaben-Konzeptes ermöglicht (vgl. hier$z$ die Ubersicht 10.5 , die wir aus der verbalen Darstellung von Andrews entwickelt haben).

Das Modell basiert auf zwei grundsätzlichen $G$ e $s t$ a $l$ t u n g s $\mathrm{m}$ ö $\mathrm{g}$ l $\mathrm{i} \mathrm{ch}$ k e $\mathrm{i}$ e $\mathrm{n}$ einer Kombination von Steuerbasis und Steuertarif in beiden Steuerarten:

a) Die Ausgabensteuer erhält - selbstverständlich bleiben bei ihr die sparvorgänge unbesteuert - entweder dieselbe, eine engere oder eine weitere $B$ a $s$ is als die Einkommensteuer; dies geschieht durch den Ansatz von steuerlichen Abzugsposten, ${ }^{5)}$ die also für beide Steuern identisch oder abweichend ausgestaltet werden.

b) Die Ausgabensteuer erhält ein gleiches, niedrigeres oder höheres Ausgangsniveau des Tarifs wie bzw. als die Einkommensteuer,

4) 1969, S. 345; "imposed on only a wealthy few, chiefly to check or to penalize consumption deemed extravagant or ostentatous".

5) Siehe die Numerierungen in Klammern (), die sich auf die Ubersichten 10.2 und 10.3 beziehen: Betriebsausgaben, Werbungskosten, sachliche Befreiungen, persönliche Befreiungen wie Sonderausgaben und auBergewöhnliche Belastungen; bei der Ausgabensteuer kommen hinzu: Bestandsänderungen im Geld- und Sachvermögen sowie die periodisierten Ausgaben für langlebige Konsumgüter. 
Utersicht 10.5: Ansatzpunkte allokativer und distributiver Entscheidungen im "kombinierten EinkomensAusgaben"-Konzept nach Andrews

Legende: Die Zahlen in Klamern () beziehen sich bel BIT auf die Abzugsposten von der Steuerbasis in Ubersicht 10.2 und bei SPET auf die Abzugsposten in Ubersicht 10.3

$A=$ Allokationsentscheldungen

$D=$ Distributionsentscheidungen

BIT

"Basic Income Tax" + "Supplemental Perso-

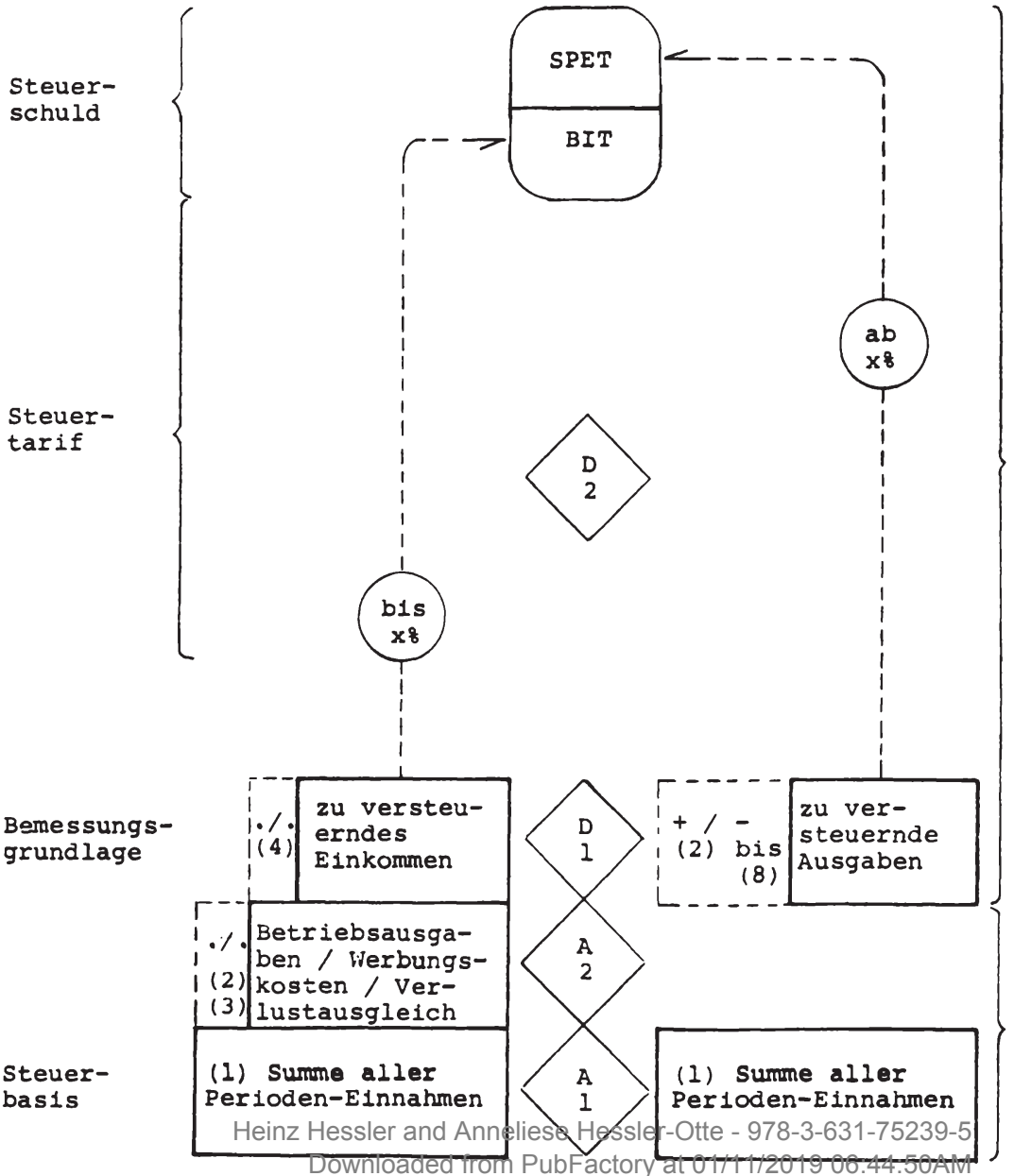
nal Expenditure Tax" 
wobei der Progressionsverlauf gleich, steiler oder flacher sein kann und bel einem gleichen, niedrigeren oder höheren P 1 a f o $\mathrm{n} d \mathrm{~s}$ endet; W.D. Andrews (S. $134 \mathrm{f.}$ ) entscheidet sich, um die Kappung des Spitzensatzes der Einkommensteuer zu erreichen, für einen Einkommensteuerplafonds bei $40 \%$, für den Beginn der Ausgabensteuersätze erst jenseits dieses Planfonds und für einen Ausgabensteuerplafonds bei 50 \%. Dadurch erreicht er, daB steuerzahler, die in der konventionellen Einkommensteuer Grenzsteuersätze von über 40 \& haben würden, diese durch die Ausgabensteuersätze substituieren und jenseits des Plafonds nicht mehr ihr Einkommen, sondern nur noch ihre Ausgaben versteuern. ${ }^{6)}$

Das Modell von Andrews darf nicht verwechselt werden mit der "TwoTier Expenditure Tax" des Meade Committee (1978, S. 8. - 10. Kap.), die als eine progressive Ausgabensteuer auf dem höheren AusgabenLevel liegt und zusätzlich zur linearen Ausgabensteuer auf den Basiskonsum erhoben wird, demnach also eine Abstufung innerhalb der Ausgabensteuer darstellt.

III. Wie sich das Gesamtbild der allokativ-distributiven W 1 r $\mathrm{k}$ u $\mathrm{n} \mathrm{g}$ e $\mathrm{n}$ dieser Besteuerung auf Steuerbasis und Bemessungsgrundlage gestaltet, folgt aus den Entscheidungen, die auf den verschiedenen Ebenen der steuertechnischen Ausgestaltung zu treffen sind (siehe die Rautensymbole in der Ubersicht 10.5).

6) Technisch geschieht das entweder durch einen entsprechend hohen Freibetrag bei der Ausgabensteuer (Andrews, S. 129, z.B. 25.000 Dollar) oder - exakter - durch den Abzug der Einkommensteuer von der Basis der Ausgabensteuer, wie sich durch folgende eigene Berechnung darlegen läBt:

$\begin{array}{llrl} & \text { ESt } & \text { ASt } & \text { ges. Steuer } \\ \text { Brutto-Einkommen } & 200.000 & & \\ \begin{array}{l}\text { Freibeträge angenommen } \\ \text { zu versteuerndes Einkommen }\end{array} & \frac{10.000}{190.000} & & \\ 40 \text { \& davon } & 76.000 & & 76.000 \\ \text { Netto-Einkommen nach ESt } & 114.000 & 114.000 & \\ \text { Sparbetrag angenommen } & & 24.000 & \\ \text { zu versteuernde Ausgaben } & & 40.000 & \\ 50 \text { \& davon } & & 45.000 & \frac{45.000}{121.000} \\ \text { gesamte Steuerbelastung } & & \end{array}$

Der Gesamtsteuerbetrag würde bei aufkommensneutraler Besteuerung allein des Einkommens einen (auf das $\mathrm{zu}$ versteuernde Einkommen bezogenen) Spitzensteuersatz von 63,7 erforderlich machen $(121.000: 190.000)$. 
a) A1: Eine grundlegende Allokationsentscheidung bezieht sich auf die $s$ t e u e $r$ a $s$ e $n$. Insbesondere für die BIT (BasicIncome $\mathrm{Tax}$ ), aber auch für die SPET (Supplemental Personal Expenditure Tax) können bestimmte Einkünfte bzw. Einnahmen, wie VeräuBerungserlöse, ausgeschlossen werden; die Ausschlüsse führen bei der BIT-Basis zum tax erosion-Problem mit den distributiven Nebenwirkungen. Diese negativen Distributionseffekte können gemildert werden, wenn die Ausschlüsse für die SPET nicht gelten. Ein positiver Distributionseffekt läBt sich mit der Existenz der SPET erzielen: Wer es verstanden hat, jegliche Einkommensteuer zu vermeiden, zahlt - sofern er die Freibeträge überschreitet $z$ umindest Ausgabensteuer (Andrews S. 140).

A2: Die allokative Einseitigkeit der steuerprämiierten Sparbildung im "reinen Ausgaben-Konzept" gilt nur noch für jene Steuerzahler, deren frühere Grenzsteuersätze in der konventionellen Einkommensteuer über dem jetzigen BIT-Plafonds lagen (Andrews, S. 141). Der allokativ günstige Effekt kann darin liegen, daB - je nach der politischen zielvorstellung - Sparen nicht mehr generell angeregt wird. Doch hat dieser Mechanismus seinen distributiven Schönheitsfehler darin, daB gerade die Bezieher von Spitzeneinkommen weiterhin steuerprämiiert sparen können. Da sie dies in der Regel ohnehin tun, liegt hier ein hoher Mitnehmereffekt vor, wie wir Andrews entgegenhalten müssen.

b) D1: Man wird davon ausgehen müssen, daB hinsichtlich der B e me s $s$ ng $g r$ u $\mathrm{d} l$ a $g$ e Freibeträge, die für die BIT gelten, gleichermaßen auch für die SPET zutreffen. Dies aber hängt von der technischen Methode ab, die man für den Zusammenhang zwischen den beiden Teilsteuern gewählt hat; sofern man die BIT in voller Höhe von der Basis für die SPET kürzt (siehe das obige Berechnungsbeispiel), kann die Entscheidung hinsichtlich der persönlichen Freibeträge durchaus anders ausfallen. Eine Verbreiterung der SPET-Bemessungsgrundlage durch Nichtanerkennung der 0.9 . Freibeträge erlaubt eine Höhersetzung des BIT-Plafonds mit gleichzeitiger Einschränkung der allokativ-distributiven Vorteile für die Einkommensbezieher und Sparer in diesen Progressionszonen. 
D2: Da es sich im Modell um eine generelle Senkung der Einkommensteuersätze für die höheren Einkommensschichten oberhalb des BIT-Plafonds handelt, werden diese nur dann einer gegenüber der früheren Einkommensteuer höheren Gesamtbelastung (durch BIT + SPET) unterworfen, wenn sie erstens mehr als ihr gesamtes Nettoeinkommen (Einkommen ./. BIT) ausgeben (Andrews, S. 134) und wenn zweitens die SPET-Grundlage über die Freibeträge gegenüber der BIT-Grundlage nicht allzusehr eingeengt wurde. Die Mehrbelastung kann je nach steuerpolitischer Absicht gewollt sein.

c) Allein diese Gegenuberstellung zeigt, daß erstens sich für die Einkommensbezieher unterhalb des BIT-Plafonds nichts $z u$ ändern braucht, daB zweitens die Verănderungen der distributiven Bedingungen und Maßnahmen in einer solchen Kombinationssteuer stets allokative Effekte nach sich ziehen. Zunächst einmal kann darauf verwiesen werden, daB die steuersatzsenkung evtl. Leistungshemmnisse zum Verschwinden bringt, sofern wirklich mit dem Plafonds ein "psychological breaking point" in Verbindung steht (Andrews, S. $137 \mathrm{f.l}$. Weiterhin unterliegen die inflationsbedingten Scheingewinne wegen des BIT-Plafonds einer geringeren Besteuerung; in der SPET werden sie auf lange sicht kaum erfaBt, da auch die Kapitalkosten $z u$ inflationierten Marktpreisen in die Ausgaben eingehen und die Steuer mindern (Andrews, S. $149 \mathrm{f.}$ ).

Das $G$ e $s$ a $t$ u $r$ e $i l$ über das Zusammenspiel zwischen Einkommens- und Ausgabenbesteuerung kann wie folgt gegeben werden: Die a $11 \circ \mathrm{k}$ a $t \mathrm{i}$ e Einseitigkeit der Ausgabensteuer, soweit sie in der Motivation zur Ersparnisbildung liegt, wird einerseits entschärft durch die bloBe Existenz der Einkommensteuer, die Sparen nur aus versteuertem Einkommen zuläBt, wird andererseits aber auch wieder betont, sofern ein Plafonds für die BIT eingerichtet wird, der unterhalb des steuersatzniveaus liegt, von dem ab die SPET-Progression beginnt. Die demnach in einem gewissen Umfang weiterbestehende Betonung der Allokationswirkung hat uberdies einen distributiv nachteiligen Mitnehmereffekt.

Der d i s $t$ r i b u $t$ i $v$ e Nachteil der Ausgabensteuer, der darin lag, daB die unteren Einkommenschichten ihre relativ hohe Konsumquote der auf einem höheren Steuersatzniveau zugreifenden Ausgabensteuer $\mathrm{zu}$ unterwerfen hatten, ist ausgeglichen, sofern 
die SPET erst oberhalb des BIT-Plafonds einsetzt. Jedoch wird die höhere Belastung der oberen Einkommensschichten konsumabhängig gemacht, wodurch wiederum die allokativ-distributive wirkung des Sparens betont wird: der höheren Ausgabenbesteuerung entgehen diese Schichten nur durch Akkumulation des Sparens, was ihnen zugleich distributive Vorteile der Vermögensanhäufung verschafft, die von der Ausgabensteuer nicht, von der Einkommensteuer nur $z$ um Teil erfaBt wird.

\section{S 36 Konzeptvergleichende Dar- stellung der allokativ-di- stributiven Problematik zusammenfassung des 9. und 10. Kapitels}

a) Wie bereits im systematischen Uberblick über die Konzepte der Leistungsfähigkeitsbesteuerung ( $\S 28$ u. 30) festgestellt, lassen sich die Possibilitäts-Konzepte wie auch die nominalistischen Realisierungs-Konzepte dadurch kennzeichnen, daB sie in erster Linie versuchen, das I n d $i \mathrm{k}$ a $t \mathrm{r}$ - Problem zu lösen. Liegt allein deshalb schon das Gewicht der Wirkungsanalyse im allokativen Bereich, so unterscheiden sich die $P \circ$ s s i b i 1 i $t$ ä $t s$ - Konzepte von den nominalistischen RealisierungsKonzepten darin, daB erstere ausschlieblich a 1 l $\circ \mathrm{k}$ a $\mathrm{i} v \mathrm{e}$ Aussagen treffen. Sie formulieren das Indikatorproblem hinsichtlich Einkommen, Vermögen und Freizeit als $F$ ä h i g k e i $t$ zur Leistung, orientieren sich also am Potential. Sie müssen aber selbst dort, wo sie für die Arbeitszeit, die Freizeit und die Erträge der Unternehmen $\mathrm{N} \circ \mathrm{r} \mathrm{m} \mathrm{n}$ verwenden (Andreae, Haller), unverbindlich bleiben, weil sie keine objektiv erklärbare MeBbarkeit der Fähigkeit herstellen können (Seligman, Andreae, Haller), weil sie ferner gegen Fehlbewertungen bei der Festlegung der Allokationsnormen, selbst wenn sie dies unternähmen, nicht gefeit sind. Distributive Effekte des potantialorientierten und normativen Ansatzes werden nicht verarbeitet.

b) Demgegenüber nehmen die verschiedenen Versionen der Besteuerung von $r$ e a $l i s i$ e $r$ e $n$ EAV-GröBen die d i s $t$ r i $b$ u $t$ i $v e$ Probleme in ihre Konzepte auf, Iösen sie aber unterschiedlich. 
b 1) Zunächst nehmen sie hinsichtlich des $T$ a $r$ i f $s$ allenfalls insofern Stellung, als die Konzepte der persönlichen Ausgabensteuern infolge der steuerbefreiung des Sparens eine andere Progressivität verlangen als bei der Einkommensbesteuerung notwendig wäre (siehe Ubersicht 10.6 , Positionen II 3 , III 1, IV 1 und $\mathrm{V} 1$ ).

b 2) Jedoch überwiegt in allen Realisierungs-Konzepten - sei es die Ausgaben-, sei es die Reinvermögenszugangsbesteuerung - das Interesse an der Gestaltung der $B$ e m e s $s$ u g $s g$ r u n $1 \mathrm{a} \mathrm{g} \mathrm{e} \mathrm{n}$. Hier ist es insbesondere die teils simultane, teils getrennte Besteuerung der Unternehmen und Haushalte einerseits (Positionen I 2 und II 2a), sowie die steuerliche Behandlung des Sparens andererseits (Pos. II 2b). In ihnen läBt sich die äuBerst unterschiedliche Lösung wichtiger Allokationsprobleme demonstrieren. Was allerdings die steuerliche Förderung des Sparens in den Alternativen der Ausgaben-Konzepte betrifft, so sind unter allokativem Aspekt Einschränkungen in der Effektivität zu machen: Erstens können grundsätzlich die Motive zu langfristigem Sparen nicht beeinfluBt werden (Pos. III 2); zweitens läBt sich die allgemeine Sparmotivation dann einschränken, wenn man das EinkommensAusgaben-Konzept praktiziert (Pos. V 1a); hier setzt nämlich die Begünstigung des Sparens erst oberhalb des BIT-Plafonds ein. Die negativen distributiven Effekte einer allokativ initiierten Sparbegünstigung hingegen sind im reinen Ausgaben-Konzept und im Einnahmen-Ausgaben-Konzept unübersehbar (Pos. III 3 und $V 1 \mathrm{~b}$ ); sie sind nur im kombinierten Ausgaben-Vermögens-Konzept insoweit indirekt behoben, als hier zumindest der Vermögensbestand besteuert wird.

b 3) Ferner führen Unterschiede in der Bemessungsgrundlagengestaltung zwischen den Konzepten auch $z u$ differentialen Distributionswirkungen auBerhalb des Sparbereichs: Die Steuerbasis im RVZ-Konzept erfährt eine Einengung allenfalls durch die allokativ motivierten Abzüge für die Substanzerhaltung (I 4). Ansonsten ist die Bemessungsgrundlage hier breiter als in sämtlichen Ausgaben-Konzepten, so sehr auch diese dem Prinzip der comprehensive tax gehorchen. In diesen Ausgaben-Konzepten aber wird die relativ höhere Belastung der Haushalte mit hohem Konsumanteil ihrer Einkommen (POS. III 4 und IV) nur im Einnahmen-Ausgaben- 
Ubersicht 10.6: Allokative und distributive Probleme in den Besteuerungs-Konzepten im Uberblick

\begin{tabular}{|c|c|c|c|c|}
\hline$K \circ n z e p t e$ & All & Lokations-Probleme & \multicolumn{2}{|c|}{ Distributions-Probleme } \\
\hline \multirow[t]{2}{*}{$\begin{array}{l}\text { I. RVZ- / SHS- } \\
\text { Konzept }\end{array}$} & \multicolumn{4}{|c|}{$\begin{array}{l}\text { (1) breite Steuerbasis } \\
\text { (2) simultane Unternehmens-/ } \\
\text { Haushalts-Besteuerung }\end{array}$} \\
\hline & (3) & $\begin{array}{l}\text { Substanzerhaltung/ } \\
\text { Konflikt mit (4) }\end{array}$ & (4) & $\begin{array}{l}\text { Erosion der } \\
\text { Steuerbasis }\end{array}$ \\
\hline $\begin{array}{l}\text { II. alle } \\
\text { Ausgaben- } \\
\text { Konzepte } \\
\text { gemeinsam }\end{array}$ & $\begin{array}{l}(2) \\
(2 a) \\
(2 b)\end{array}$ & $\begin{array}{l}\text { (1) verengte } \\
\text { Allokationsinteresse } \\
\text { dominiert } \\
\text { Trennung in Unter- } \\
\text { nehmens- und Haus- } \\
\text { halts-Besteuerung } \\
\text { Sparen Steuerfrei }\end{array}$ & $\begin{array}{l}\text { euerl } \\
\text { (3) }\end{array}$ & $\begin{array}{l}\text { basis } \\
\text { Niveau u. Stelgungs- } \\
\text { maB des Progres- } \\
\text { sionstarifs höher } \\
\text { bzw. steiler als im } \\
\text { RVZ-Konzept, sofern } \\
\text { Aufkommensneutrali- } \\
\text { tät unterstellt }\end{array}$ \\
\hline
\end{tabular}

III. reines AusgabenKonzept

\section{(1) Sparproblem dominiert}

(2) kein EinfluB bei langfristigem Sparen
(3) Sparförderung ohne Effekte bei einkommensschwachen Haushalten

(4) Progressionseffekte bei höheren Konsumquoten

(5) KonsumanpassungsVorteile bet einkommensstarken Haushalten

(6) distributive Lïcke wegen fehlender Vermögensbesteuerung

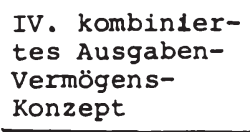

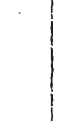

lla

(1) Sparprobleme

(2) ergänzende Vermögensbesteuerung
(1) Sparprobleme / BIT und SPET
a) ESt + BIT-Plafonds: Akkumulation ein- geschränkt, jedoch: $1 \mathrm{~b}$


Konzept behoben (Pos. V 2), da in diesem gemischten Konzept die Ausgabensteuerkomponente (SPET) erst jenseits des BIT-Plafonds eingreift.

c) Aus dem Vergleich geht hervor, daß sämtliche Ausgaben-Konzepte bei besseren allokativen Einsatzchancen gegenüber dem RVZ-Konzept entweder eindeutige distributive Nachteile aufweisen oder - soweit sie diese mildern können - die Nachteile teils nur unvollständig beheben oder auf die Funktionsweise der Einkommensbesteuerung $z$ urückgreifen müssen (siehe das kombinierte AusgabenVermögens-Konzept bzw. das kombinierte Einkommens-Ausgaben-Konzept). Man wird sich also dem Urteil von A.B. Atkinson und J.E. Stiglitz (1980, S. 566) anschlieBen können, daB der Vergleich nicht $z u$ einer eindeutigen Bevorzugung der einen vor der anderen Besteuerungsweise führt; dies insbesondere dann, wenn man versucht, die allokativen Vorteile der Ausgabensteuer näherungsweise (z.B. durch Steuerbefreiung der Zinsen $0 . \ddot{a}$. in der Einkommensteuer) aufzuholen. Aus diesem Grunde können tatsächlich die administrativen Aspekte die entscheidenden werden, wenn man die Ausgaben- oder die Einkommensbesteuerung $z u$ wählen hat. Allerdings bleibt der wesentliche Vorteil allokativer und distributiver Art, die Ausgabensteuer-Konzepte gegenüber den Einkommensteuer-Konzepten haben, die getrennte Besteuerung von Haushalten und Unternehmungen (II 2a); bei diesem Urteil haben wir aber unterstellt, daß es in der Einkommensbesteuerung bei der von uns herausgearbeiteten allokativ-distributiven Mischbesteuerung bleiben wird. Soweit man sich entschließen würde, die persönliche Einkommensbesteuerung von der betrieblichen Ertragsbesteuerung zu trennen, wäre der Vorteil, den die Ausgabenbesteuerung in diesem Bereich hat, aufgeholt. 
Die "utilitarismus"-konzepte

\section{s 37 Die allokativ-distributive Grundproblematik der kon- zepte}

I. Die fragwïrdige Verwendung des wohlfahrtstheoretischen Allokationskriteriums "Nutzen" für die Distributionsproblematik

II. Das Erklärungsinteresse der UtilitarismusKonzepte für den Tarifverlauf

I. Die Utilitarismus-Konzepte stellen auf den $\mathrm{N} u \mathrm{t} z \mathrm{n}$ $a b$, den das realisierte Einkommen ${ }^{1)}$ dem Individuum bzw. der Gesellschaft stiftet. Nutzen kennzeichnet den Inhalt sämtlicher Konzepte, die im folgenden dargestellt werden. Wenngleich diese Konzepte solche der distributiven Steuerlastverteilung sein wollen, muB doch vorab klar herausgestellt werden, daB Nutzenbemessungen und-vergleiche Theorieleistungen im a 1 l $\circ \mathrm{k}$ a $\mathrm{i} v \mathrm{e} n$ Bereich der Wirtschaft sind: Nutzen ist die zentrale GröBe in der Wohlfahrtstheorie (E. Sohmen 1976, S. 21).

Die "individuelle Wohlfahrtsfunktion" nach A. Bergson (1938) ist durch Nutzen definiert. Auch zur Bestimmung des Wohlstandsniveaus einer Gesellschaft wird der Individualnutzen herangezogen, ${ }^{2)}$ wobei uns hier allein diese Tatsache, nicht das dahinterliegende Werturteil ${ }^{3)}$ interessieren soll: Wesentliches Merkmal einer indi-

1) Nutzen aus Vermögen und persönlichen Ausgaben wurden bisher nicht thematisiert; dennoch verschaffen Vermögen (siehe H. Haller und D. Schneider oben) und Ausgaben (D. Schneider) Bedürfnisbefriedigung; zumindest $D$. Schneider benutzt aber den Begriff der Bedürfnisbefriedigung ohne Rückgriff auf die Nutzentheorie.

2) H. Luckenbach 1980, Sp. 1706; auch die Berücksichtigung des Verteilungsproblems in der neueren Wohlfahrtsökonomik stellt auf Nutzenvergleiche ab (Sp. $1217 \mathrm{ff}$.$) .$

3) Dieses liegt aber auf einer anderen Ebene als z.B. die allgemeinen ethischen Grundaussagen der normativen okonomik (E. Sohmen 1976, S. 349), denn es handelt sich hier um den versuch (Forts. siehe folgende Seite) 
vidualistischen Wohlfahrtsfunktion ist nach E. Sohmen (1976, S. 22) das Postulat, "daB jede Anderung der Datenkonstellation das Wohlfahrtsniveau der Gesellschaft nur auf dem Umweg über die Nutzenempfindungen einzelner Individuen beeinflussen darf". Insoweit können in den Opfertheorien der Leistungsfähigkeit, die seit J. St. Mill (1926, S. 804) das Opfer als Verlust an Wohlfahrt definieren, die dort erforderlichen Nutzenvergleiche auch als "Wohlfahrtsvergleiche" (B. Genser 1980, S. 22) bezeichnet werden. Insbesondere das auf der Nutzentheorie basierende Konzept des gleichen Grenzopfers demonstriert eindeutig den allokativen $\mathrm{zu}-$ sammenhang zwischen Nutzen und Wohlfahrt bzw. WohlfahrtseinbuBe: Es ist eher eine "Effizienzregel (die verlangt, daB das Grenzopfer ein Minimum ist) als eine Gerechtigkeitsregel" für den distributiven Bereich 4) (vgl. H. Möller 1983, S. 35-88 und passim).

Die allokative Funktion des Nutzens ergibt sich auch aus der folgenden Uberlegung: Wenn der gröBtmögliche Nutzen, den jemand aus dem Faktoreinsatz ziehen kann (die gröBtmögliche Produktivität ihm also gröBtmöglichen Nutzen verschafft), es ihm erlaubt, höhere Faktorpreise $\mathrm{zu}$ zahlen, als seine Mitbewerber um diese Faktoren zahlen können, entspricht es der Rationalität, den Faktor bei ihm zu allozieren; daB dann derjenige das gröBte Einkommen haben soll, der den gröBten Nutzen aus dem Faktoreinsatz erzielt hat, ist eine Rationalitäts- und Allokationsregel, keine Gerechtigkeitsregel. Anders formuliert: $\mathrm{DaB}$ derjenige das gröBte Einkommen haben soll, der auch den gröBten Nutzen daraus ziehen kann, ist keine Regel der Gerechtigkeit, sondern reine Allokationsbetrachtung. 5) Gerechtigkeitsregeln aber folgen, wie bereits dargestellt, gesellschaftlichen Konventionen über Grundwerte. Steuer-

Forts. Fn. 3:

einer "Messung" von Nutzendifferenzen; eben diese Messung muB nach dem bisherigen Erkenntnisstand der Psychologie (Sohmen, S. 29) und nach dem heutigen Stand der volkswirtschaftlichen Technik rein subjektiven Charakter haben (Sohmen, S. 349).

4) Musgrave/Musgrave 1980, S. 252; in der Finanztheorie von R.A. Musgrave (1969, S. 75) wird ausgesprochen, daB das gleiche Grenzopfer eine "Doppelrolle" als Gerechtigkeitsregel und zugleich als Wohlfahrtsbedingung hat.

5) Dies läBt sich auch ablesen an den Darlegungen von Musgrave/ Musgrave $1980, \mathrm{~S} .92 \mathrm{ff}$, bes. $94 \mathrm{f.l}$ im Rahmen ihrer Ansätze zur distributiven Gerechtigkeit unter der Anwendung von Nutzenkriterien. 
lastverteilungen, die einem allokativen prinzip folgen, können somit keine Lösungen produzieren, die unter Gerechtigkeitsaspekten überhaupt von Belang sind.

Schlieblich vermag auch die dem Utilitarismus entlehnte "Verteilungsregel", es sei die Gesamtbefriedigung in einer Gesellschaft $z$ u maximieren ( $\mathrm{J}$. Bentham 1789, 1948), kelne Regel für die ind1viduelle Verteilung und für die Herstellung einer materiellen Gerechtigkeit anzugeben, die auf Unterschiede in der Verteilung der Steuerlast von Individuen abhebt. Das Denken in Gesamtheiten dieser Art ist ein allokatives; distributive Uberlegungen richten sich demgegenüber auf Einzeleinheiten und die Abstände zwischen ihnen. Distributive Phänomene, wie Freiheiten, wie Gerechtigkeit zwischen Individuen, lassen sich nicht zu Gesamtheiten addieren oder gegeneinander saldieren (siehe J. Rawls).6) 7)

II. Konzepte des Utilitarismus unterscheiden sich von denen des Nominalismus neben dieser Verwendung eines für Distributionsprobleme grundsätzlich fragwürdigen Indikators noch durch ihren anders gearteten Erklärungsansatz: Während die nominalistischen Einkommens-, Vermögens- und Ausgaben-Konzepte die Tragfähigkeit der leistungsgemäBen Besteuerung vorwiegend an ihrem Indikator "Bemessungsgrundlage" testen, geht das Interesse der Utilitaristischen Konzepte auf den $s t$ e $u$ e $t$ a $r$ i als MaB der Steuerlastverteilung und als Realisierungsversuch einer vertikalen Gerechtigkeit. Die Eigenart dieser Erklärungsansätze besteht also in der Verknüpfung von Nutzentheorie und Linearität bzw. Progressivität des Steuertarifs. $\mathrm{DaB}$ aber gerade die innere Abhängigkeit zwischen Tarifverlauf und distributiven Zielen wie Wirkungen vorwiegend von politischen Entscheidungen hergestellt

6) 1975; vgl. Rawls' Vorrang der Freiheit und sein Prinzip, daB sich die Freiheit der einen nicht gegen die Unfreiheit der anderen aufrechnen läBt; ebenso ist der zweite Gerechtigkeitsgrundsatz, das Unterschiedsprinzip, auf Unterschiede zwischen einzelnen Individuen abgestellt, nicht auf ihre Gesamtheit.

7) "Die Verteilungstheorie selbst ... ist wohl am meisten von jeder Nutzwertlehre abgerückt." W. Weber, E. StreiBler 1964, S. 14 . 
wird, können die Utilitarismus-Konzepte nicht darstellen; dies bleibt den Distributions-Konzepten vorbehalten.

Obwohl der erklärte Schwerpunkt unserer Untersuchung im Bereich der Einkommens- und Vermögensbegriffe sowie der aus ihnen zu entwickelnden Steuerbemessungsgrundlagen liegt, muß dennoch im folgenden auf Tarifprobleme eingegangen werden, weil anders es nicht möglich ist, der Aussagefähigkeit der Utilitarismus-Konzepte als Steuerlastverteilungsnormen nachzugehen.

Die Utilitarismus-Konzepte lassen sich unter Verwendung der Analysen von R.A. Musgrave (die Gruppierung ergibt sich aus der Zusammenschau seiner Untersuchungen von 1969, S. 75-89 und 1980, S. 253f., letztere zusammen mit P.B. Musgrave) wie folgt unterscheiden:

- das "Individualnutzen"-Konzept,

- das "Wohlfahrts"- (bzw. "Budget"-) Konzept und

- das "Sozialnutzen"-Konzept.

Dieser Eintelung folgen wir bei er kritischen würdigung ihrer allokativ-distributiven Problematik.

s 38 Das "Individualnutzen"Konzept

I. Einkommen, Einkommensnutzen und Nutzenopfer

1. Die ungeklärten Beziehungen zwischen Einkommen und Nutzen

2. Die Nichtbeachtung positiver Nutzen im Nutzenopfer

II. Die Abhängigkeit zwischen Nutzen und Steuertarif

1. Der Grundgedanke des opfertheoretischen Ansatzes

2. Die unbewiesene Nutzen-Identität gleicher Einkommen bei verschiedenen Individuen

3. Das ungelöste Meßproblem als eine generelle Infragestellung der Tarifbestimmung

4. Die unbestimmbaren individellen Nutzenverläufe als eine spezielle Infragestellung des gleichen Progressionstarifs für alle Individuen 
III. Nutzentheorie und verteilungspolitische Wirkung

1. Die Präjudizierung des Lastverteilungsergebnisses durch die distributive Ausgangslage

2. Die Unvereinbarkeit zwischen allokativen Modellbedingungen und distributiven zielen

IV. Zusammenfassung:

Das Leistungsfähigkeitsprinzip -

opfertheoretische Interpretation

versus politisches Verteilungsziel?

Die a l lok a tiv-distributive Proble $m a t i k$ des Individualnutzen-Konzeptes läBt sich anhand des für die Opferversionen geltenden Prämissenkatalogs darstellen. Sofern nun aber die allokativen Prämissen, wie die funktionale Abhängigkeit des Nutzens vom Einkommen, die Geltung eben dieser Abhängigkeit für alle Individuen, die Möglichkeit einer kardinalen Nutzenmessung nebst interpersonalem Vergleich der Nutzen sämtlich nicht der Wirklichkeit entsprechen, sind auch die an sie geknüpften distributiven Absichten fragwürdig. Uberdies zeigt sich, daB zwei mehr oder weniger deutlich ausgesprochene Voraussetzungen der Opfertheorie, nämlich der als nicht vorhanden unterstellte Zusammenhang zwischen Steuerlast und Vortellen aus den Staatsausgaben einerselts sowie die nicht weiter hinterfragte Geltung der zufälligen Einkommensverteilung vor Besteuerung andererseits ein allokativ-distributives Beziehungs- und Folgewirkungsgeflecht herstellen, das erstens schwierig $z \mathrm{u}$ überblicken ist und das zweitens distributive Wirkungen bereits im Ansatz allokativ präjudiziert.

I. Schon die Ausgangslage des Individualnutzenkonzepts, die eine Abhängigkeitsbeziehung zwischen $E i n k \circ m m e n, N u t z e n$ und $N$ u $t$ e $n \circ p$ e $r$ postuliert, muB als theoretisch fragwürdig erkannt werden.

1. Die grundsätzlich behauptete Abhängigkeit des Nutzens vom $E$ i $n k \circ m m e n$ setzt $z$ unächst voraus, daB Einkommen hinreichend genau definiert 1st. Wie aber schon die Ausfuhrungen zum Indikatorproblem erkennen ließen, gibt es kaum einen "richtigen" Einkommensbegriff (vgl. SS 18 u. 21-24). Wenn außerdem die durch Heinz Hessler and Anneliese Hessler-Otte - 978-3-631-75239-5 Downloaded from PubFactory at 01/11/2019 06:44:50AM 
Einkommen vermittelte Bedürfnisbefriedigung die entscheidende Grobe der Nutzentheorie und der Steueropfer sein soll, muB sie so unterschiedliche Verhaltensweisen wie Konsum und Sparen auf einen "einheitlichen 'seelischen' Nenner" bringen." So plausibel schlieblich eine positive Entsprechung zwischen Einkommen und Nutzen erscheint, ist dennoch das exakte AusmaB der Entsprechung, also der genaue Verlauf der Nutzenfunktionen in Abhängigkeit vom Einkommen nicht bekannt (K. Littmann 1970, S. 124). Da Nutzen und Nutzenempfindungen empirisch nicht nachprüfbar sind, führt jeder Schluß aus der Grenznutzenüberlegung $z u$ einer nicht widerlegbaren Aussage (D. Schneider 1971, S. 366), ist daher theoretisch wertlos.

2. Das Leistungsfähigkeitsprinzip in der Form des Individualnutzen-Konzepts hat einen allokativen Schwachpunkt, da es davon ausgeht, zwischen der optimalen steuerlastverteilung und der Struktur der $s t$ a $t s$ a $s$ g $a$ e $n$ gäbe es keinen zusammenhang. Jedoch ist der $\mathrm{zu}$ erhebende Steuerbetrag immer eine variable Größe, die vom geplanten Ausgabevolumen abhängt. Dadurch wird die gesamte Grundlage für die individuellen Nutzeneinschätzungen verändert. Denn für die individuelle Nutzenstruktur sind nach K. Littmann Staatsausgaben nur dann ohne EinfluB, wenn sie Güter betreffen, die dem Samuelson-Kriterium folgen,2) die nicht radizierbar sind und die von allen Individuen mit gleicher Intensität verlangt werden. Andernfalls ist die Vorteilsschaffung durch offentliche Güter individuell unterschiedlich. Diese positiven Nutzen müssen nach F. Neumark ${ }^{3)}$ gegen die NutzeneinbuBen aufgerechnet werden. Somit kreiert die allokative Rahmenbedingung einer Wirtschaft mit Staatsausgaben ihre distributiven Ef-

1) D. Schneider 1971 , S. 365 f.; auBerdem: auch der etwa aus Zeitmangel erfolgende Nichtkonsum, ohne daB "Sparerlebnisse" vorliegen, müBte nach Haller als Bedürfnisbefriedigung definiert werden, mit der Konsequenz letztlich, daB jede noch so "unsinnige" Entscheidung, führte sie nur zur Bedürfnisbefriedigung, dann ja "theoretisch belangvoll" würde.

2) 1970, S. $122 \mathrm{f} . ;$ das S-Kriterium verlangt, daB die Inanspruchnahme eines öffentlichen Gutes keine Einschränkung im Verbrauch desselben Gutes durch ein anderes Wirtschaftssubjekt nach sich zieht; manche öffentlichen Güter sind lokal radiziert, obwohl sie dem S-Kriterium gehorchen (Leuchtturm).

Fn. 3 auf der folgenden seite. 
fekte, deren AusschluB zwar analytisch möglich, deren Nichtexistenz aber nicht behauptet werden darf.

II. Um die vom Individualnutzen-Konzept behauptete Abhängigkeit $z$ wischen $N$ u $z e n$ und $s t e$ u $r t a r i f z$ prüfen, gehen wir vom Grundgedanken des o p f e $t h$ e $r_{\text {e }} i_{\text {- }}$ $s \mathrm{c}$ e $\mathrm{n}$ Ansatzes aus.

1. Das Individualnutzen-Konzept versucht, die distributive Aufgabe der personalen Steuerlastverteilung mithilfe einer Theorie zu lösen, die einen bestimmten Steuertarifverlauf zweifelsfrei aus den individuellen Nutzen hervorgehen $1 a ̈ B t$. Der $G$ e d a $n-$ $\mathrm{k}$ e $\mathrm{n} \mathrm{g}$ a $\mathrm{n} \mathrm{g}$ ist folgender: Das realisierte Einkommen stiftet dem einzelnen Nutzen; dieser liegt in der Bedürfnisbefriedigung. ${ }^{4}$ ) In Höhe des Bedürfnisbefriedigungsumfangs ist der einzelne leistungsfähig (H. Haller 1971 , S. 15 u. 39). Jede Steuer, die das Einkommen des einzelnen mindert, schmälert zugleich seine Bedürnisbefriedigung; demnach wird Steuer als BedürfnisbefriedigungseinbuBe definiert, bemessen in Nutzenwerten (Nutzenopfer, auch Steueropfer). Da es um die personale Verteilung des steueropfers geht, werden die beiden Gerechtigkeitspostulate der Besteuerung eingeführt: Das Postulat der horizontalen Gerechtigkeit gebietet die Gleichbehandlung der gleich Leistungs-, d.h. Opferfähigen; das Postulat der vertikalen Gerechtigkeit (also das Prinzip der Abgabenzumessung gem. der opferfähigkeit nach H. Haller $(1971$ S. 14) gebietet demgegenüber die Beachtung der individuell möglicherweise ungleich vorhandenen Leistungs- und Opferfähigkeit. Von hier $a b$ ist es nun nicht mehr unbeachtlich, wie man die opfergröBe bemiBt, denn danach richtet sich - entsprechende Verläufe der Gesamt- und Grenznutzenkurven unterstellt - der anzuwendende Steuertarif.

3) 1970 , S. 177; im übrigen ergibt sich aus den Neumarkschen Darlegungen, daB ein Nutzenopfer wohl eher in einer DispositionseinbuBe als in einer BedürfnisbefriedigungseinbuBe $z u$ sehen ist.

4) Unterstellt wird, daB ein zunehmendes Einkommen, sofern es über der existenznotwendigen Mindesthöhe liegt, nur abnehmende $\mathrm{Z}$ uwächse an Nutzen stiftet. 
Schon jetzt kann gefolgert werden, daB bei Vorliegen ungleicher Leistungsfähigkeit das Konzept des "gleichen absoluten Opfers" als ein Versuch, die vertikale Gerechtigkeit zu realisieren, ausschelden muB. Somit konzentriert sich das problem der leistungsangemessenen Besteuerung nach dem Individualnutzen-Konzept auf die beiden Versionen des "gleichen relativen" und des "gleichen marginalen opfers". Hier aber hat die Kritik klar nachgewiesen, daB sich niemals ein bestimmter proportionaler oder progressiver Tarifverlauf als steuer- und belastungspolitisch geboten erweisen kann, um nach der Leistungs- sprich opferfähigkeit zu besteuern. Denn ob z.B. bei Anwendung des gleichen proportionalen Opfers auch ein Proportionaltarif zwingend ist, hängt vom tatsächlichen Verlauf der Nutzenkurven ab. Denn je nach Verlauf dieser Kurven kann bei der Absicht, die Individuen relativ gleich zu belasten, entweder ein Progressions- oder sogar ein Regressionstarif erforderlich sein. Analog sind die Folgerungen zum Konzept des gleichen marginalen Opfers; bei entsprechendem Kurvenverlauf und Anwendung des Progressionstarifs ergeben sich sogar Marginalsteuersätze von $100 \% \mathrm{mit}$ der Folge absoluter Einkommensgleichheit nach der Besteuerung. Dieser extreme Egalitarismus ist aus der Sicht einer Besteuerung nach dem Konzept der Bedürfnisbefriedigung theoretisch allenfalls dann zu rechtfertigen, wenn fallender Gesamtnutzen bzw. negativer Grenznutzen im relevanten Einkommensbereich vorliegen. Das aber ist bis zu einem evtl. exakten Nachweis ein Vorurteil und überdies äußerst unwahrscheinlich.

Musgrave/Musgrave (1980, S. 252) führen überdies aus, daß das nur insoweit Geltung beanspruchen könne, als bei fallenden Grenznutzen eine Progression wenigstens dem Grunde nach sinnnvoll sei; keineswegs stimmen die der Folgerung $z u$, die dieses Prinzip im Extrem verlangt, nämlich der Einebnung der primären Einkommen bis zur völligen Gleichheit.

In ihrem Gesamturteil kommen Musgrave/Musgrave (1980, ebenda), die hinsichtlich des Konzeptes des gleichen Grenzopfers und 
der damjt $z$ u verbindenden Progressivität - ebenso wie z.B. F. Neumark $\left.{ }^{5}\right)$ und T.N. Carver $(1904$, S. 74) - eine gewisse Plausibilität gelten lassen, dennoch $\mathrm{zu}$ folgender Feststellung: Alles in allem ist das Leistungsfähigkeitsprinzip in zweifacher Weise ohne Beweiskraft, da seine Aussage erstens davon abhängt, welche Formullerung des gleichen Opfers gewăhlt wird und zweitens davon abhängt, welchen präzisen Verlauf die Grenznutzenkurven haben .

2. Die grundsätzliche Abhängigkelt des Nutzens vom Einkommen soll nach der opfertheoretischen Auffassung für a 1 e $I$ n d 1 $v i d u$ e $n$ unterschiedslos gelten; alle finden thre Nutzen in derselben, nach rechts fallenden Grenznutzenkurve repräsentiert. Wenngleich - auBer einer prima facie-Plausibilitat, die sich allenfalls auf die grobe Tendenz der Kurvennelgung beziehen kann (R.A. Musgrave 1969 , S. 83) - die Haltloslqkeit einer solchen Unterstellung $^{6}$ ) unmittelbar einzusehen ist, ${ }^{7)}$ hat sie doch eine weittragende Bedeutung und distributionspolitische Konsequenzen: Gerade die postulierte einheitliche Geltung der Nutzenfunktion ist die Rechtfertigung dafür, daB ein allgemein gültiger steuertarif auf die unterschiedlich hohen Einkommen angewendet wird. 8) Aus der den allokativen Mechanismus kennzelchenden Unterstellung fallender Grenznutzenverläufe ergeben sich also die distributiven Probleme einer progressiven Tarlfgestaltung.

5) 1970, S. 177: "In aller Regel nimmt die Fähigkeit, zur Finanzierung sog. kollektiver oder öffentlicher Bedarfe belzutragen, mit wachsendem Einkommen uberproportional zu" ...

6) Da Unterschiedlichkeiten bei allen meBbaren psychischen und physischen menschlichen Eigenschaften bestehen, ist zu erwarten, daB die Fähigkeit der Menschen, Wohlfahrt aus ihrem Einkommen zu ziehen, zwischen ihnen ebenfalls differiert; R.A. Musgrave 1969 , S. 84 .

7) H. Haller selbst $(1971$, s. 75 f. und $1973 \mathrm{~b}$, S. $465 \mathrm{f}$.$) de-$ monstriert in den Typen der "genügsamen" und "begehrlichen" Individuen Unterschiedlichkeiten der subjektiven Wertungen von Nutzen; doch stellt K. Schmidt $(1967$, S. $394 \mathrm{f}$. und 1972, S. $199 \mathrm{f.l}$ fest, daB mit der einheitlichen Nutzenfunktion das Prinzip aufgegeben wird, die Steuerlasten nach der individuellen Bedurfnisbefriedigung $\mathrm{zu}$ verteilen. - Ferner im einzelnen hierzu R. Ulbrich 1975, S. $129 \mathrm{ff}$.

8) Hierzu R. Ulbrich 1975, S. $123 \mathrm{f}$. 
3. Die M e s $\mathbf{s}$ u $g$ der Nutzen hat nach allgemeiner Uberzeugung kardinal zu erfolgen, um letztlich das distributive Problem der Ableitung von Tarifen aus der Nutzenschätzung zu lösen. Musgrave/Musgrave (1980) können nicht umhin, auf Schwierigkeiten in der Messung von Nutzenwerten ausdrücklich hinzuweisen, wobei die Frage der MeBeinheit eine besondere Bedeutung hat. "9)

a) K.G. Zinn (1970) glaubt, das kardinale Wohlstandsma B gefunden zu haben: Die für Vergleichszwecke notwendige gleiche Geltung des NutzenmaBes $z$ e $i t$ entnimmt er Ergebnissen der Individualpsychologie und der Psychotherapie; sie lassen eine gewisse Gleichheit in den Wertstrebungen der Menschen und daher in ihren Wohlfahrts- und Nutzenvorstellungen vorstellbar erscheinen (S. $59 \mathrm{ff}$. u. $75 \mathrm{f.l}$. Ausgangspunkt für seine Uberlegungen ist einerseits die Existenz normativer Urteile zur rechtlichen Gleichheit der Menschen, andererseits das Phänomen der grundsätzlichen Gleichwertigkeit der zeit als Lebenszeit für alle Menschen (S. 97 f.). Unter diesem Aspekt und unter dem weiteren, daB Nutzen zeitabhängig ist, bedeutet ein "gleiches opfer", daB jeder dem staat eine bestimmte Arbeitsstundenzahl zu widmen hat. Arbeit ist "Hingabe von Lebenszeit" (S. 85). Diese Lösung nimmt keine Rücksicht auf die tatsächlichen Einkommenshöhen, die infolge der natürlichen Unterschiede in den individuellen Nutzenfunktionen differieren dürfen, obwohl ansonsten Zinn von der "Lohngleichheit" ausgeht. ${ }^{10)}$ Von jedem staatsbürger würde derselbe absolute steuerbetrag gefordert. Die Individuen mit niedrigen Einkommen würden "infolge höherer subjektiver Einschätzung der Freizeit für den Staat ein höheres Grenzopfer bringen als jene Bürger, die eine relativ stell und hoch verlaufende Nutzenfunktion aufweisen, also das Einkommen relativ höher schätzen als die Freizeit" (S. 185).

9) In seiner Finanztheorie verweist Musgrave darauf, daB in praxi von solchen Nutzenvergleichen ständig ausgegangen wird, wobel eine Normalverteilung unter den Menschen unterstellt wird; dies dient ihm zur Vorbereitung seines "Sozialnutzen-Ansatzes" (siehe unten). Die MeBschwierigkeiten, die Musgrave/Musgrave später nennen, liegen in der MeBeinheit, der Bestimmung des genauen Verlaufs der Nutzenkurve und in der Tatsache, daB es vorläufig keine verläBlichen empirischen MeBergebnisse gibt.

10) Lohngleichheit bedeutet die Lohngleichheit zwischen allen Berufen (S. 203) bei allerdings durchaus unterschiedlichen Entlohnungen, wenn unterschiediliche Leistungen innerhalb der Berufe vorliegen (S. 199). 
"Die gerechte Besteuerung würde damit gewährleistet, daB jeder denselben Prozentsatz seiner Arbeitszeit als Steuer abzufuhren hat." SolchermaBen erlaubt das NutzenmaB "Zeit", durch unterschiedliche Arbeitszeiten veranlagungsbedingte Verschiedenheiten in der Nutzenschätzung von Leben (Freizeit) und Einkommen (Arbeitszeit) $\mathrm{zu}$ berücksichtigen (S. $109 \mathrm{u} .181 \mathrm{ff.}$.

Zweifellos ist Zeit addier- und vergleichbar. Aber hierzu gilt zunächst, was G. Hartfiel (1977, S. 39) kritisch feststellt, daB nämlich eine Tendenz besteht, in erster Linie das zu messen, was überhaupt meBbar ist, unabhängig davon, ob es auch das trifft, was als das $z u$ Messende gelten muB. AuBerdem wăre $z u$ dem MeBkonzept von Zinn festzustellen, daB die Nutzeneinschätzungen der Arbeitenden hinsichtlich ihrer Präferenzen für Arbeits- oder Freizeit von der Fähigkeit abhängen, sich über das Einzuschätzende klar zu sein. Insoweit ist auch dieses Konzept den grundsätzlichen Einwänden aller Präferenzanalysen ausgesetzt; ferner werden nicht zeiten, sondern Nutzeneinschätzungen im $\mathrm{H} i \mathrm{n} b \mathrm{l} i \mathrm{ck}$ auf die zeit versucht $z u$ messen, was die Vergleichbarkeit wiederum beeinträchtigt und die bereits aus den traditionellen Nutzenkonzepten bekannten Kritikpunkte wachruft. Schlieblich ist nicht $z u$ übersehen, daB das $\mathrm{Zinn}$ 'sche MeBkonzept unter der einengenden Bedingung der Lohngleichheit formuliert ist. Gilt sie, dann ist in der Tat das Konzept gleichen Zeitopfers bestechend einleuchtend: solange allen ihre zeit gleich wertvoll ist, ist es auch das Steueropfer. Doch das Gerechtigkeitsproblem, das in der $\mathrm{zu}-$ messung vertikal unterschiedlicher OpfergröBen besteht, ist in Zinn's Konzept in die Entlohnung für die Berufstätigkeit verlagert, so daB das Opferkonzept hier von solchen Fragen der vertikalen Gerechtigkeit frei bleiben kann. Die vertikale Gerechtigkeit aber ist hier insofern bereits "gesellschaftspolitisch" entschieden, als eine gleiche Entlohnung in allen Berufen postuliert ist.

b) Was die MeBbarkeit angeht, so ist nach wie vor mit $k$. Littmann (1970, S. 124) und E. Sohmen (1976, S. 29) zu fragen, ob nicht doch die Möglichkeit einer kardinalen Nutzenmessung "nach dem gegenwärtigen Stand der Forschung verneint werden muBn" bzw. ob ein interpersonaler Vergleich "beim bisherigen Erkenntnisstand der Psychologie und verwandter Wissenschaften" denn möglich "oder 
auch nur vorstellbar" ist. ${ }^{11)}$ zum Versuch der "Neumann-Morgensternschen Nutzenaxiomatik" fuhrt E. Sohmen (1976, S. 377 ff.) aus, daB auch ein Nutzenindex dieses Typs keine objektive interpersonelle Vergleichbarkeit der Nutzenintensitäten verschiedener Individuen zuläBt, da in diesem Konzept immerhin noch zwei GröBen frel wählbar bleiben und nicht determiniert sind: der Nullpunkt und die skaleneinheit des Nutzens.

G. Gäfgen (1974, S. 157) erkennt, daB mithilfe der Neumann-Morgenstern'schen Nutzenfunktion nicht die Verhältnisse von NutzengröBen, sondern jene von Nutzenunterschieden verglichen werden können, was aber - wie R. Ulbrich 1975, S. 110) feststellt - für Opferkonzepte nicht ausreicht. Zudem ist der Neumann-Morgenstern' sche Nutzen - und dies ist auch nach dem Urteil von E. Sohmen (1976, S. 385) der entscheidende Unterschied - ein mit den Risikopräferenzen des Entscheidenden vermischter Nutzen und darf daher nicht mit dem für die opfertheorien maBgeblichen Nutzen der subjektiven Bedurfnisbefriedigung verwechselt werden ( $R$. Ulbrich 1975 , S. $110 \mathrm{f.l}$. Somit festigt sich das Urteil, daB bis heute die Prămissen des opfertheoretischen Modells, die Nutzenmessung und der interpersonelle Vergleich der Nutzen, nicht realistisch sind. Daraus ist $z u$ folgern, daB auch die Voraussetzungen fur die Bestimmung eines Tarifverlaufs nicht gegeben sind, da der Tarif Leistungsfahigkeltsunterschiede zwischen den Personen ausdrücken soll, jedoch ein interpersoneller Vergleich mangels MeBgroben nicht angestellt werden kann.

4. Die Absicht, einen progressiven Tarifverlauf nutzentheoretisch $z u$ begründen, ruft auBerdem die Frage wach, ob denn überhaupt der Grenznutzenverlauf für das Einkommen notwendiger- und erlaubterweise dem für Güter entspricht. Im Hinblick darauf, daB diese Verläufe für die Gütersphäre entwickelt wurden, kann elngewendet wer-

11) Weber/StreiBler (1964, S. 10) aber stellen dazu fest, daB der interpersonale Vergleich nicht aus dem Blickwinkel der Psychologie und der menschlichen Veranlagungen angestellt werden düre, sondern daB sich vielmehr die Verschiedenheit der Individuellen Nutzen aus der Verschiedenheit der die Wirtschaftssubjekte formenden sozialen Umwelten ergebe; daher würden wohl solche Vergleiche innerhalb relativ homogener sozialer Gruppen hinlänglich genau durchführbar sein. 
den, daB sich die Gossen'schen Gesetze nicht so einfach auf das Einkommen übertragen lassen. ${ }^{12)}$ zudem braucht bei steigendem Einkommen keine Konstanz der Bedürfnisse und ihrer struktur vorzuliegen (J. Hackmann 1972, S. 124 f.). Mit variierendem Einkommen ändert sich auch die struktur der Bedürnisse und des Konsums (Blum/Kalven 1963, S. 59). Es können überdies mit Einkommen nicht nur die Bedürfnisbefriedigungsmöglichkeiten, sondern auch sozialer Aufstieg (Weber/StreiBler 1964, S. 9) und Ansehen, wohl auch Macht (M.S. Kendrick 1939, S. 94 f.) verbunden sein, was ein gleichförmiges Verhalten trotz gleicher Einkommenshöhen unwahrscheinlich macht. Sind alle diese Phänomene schon geeignet, Zweifel in den modelltypischen verlauf der Nutzenkurven auch nur eines einzelnen Individuums $z u$ setzen, so erst recht bel einem Vergleich zwischen den Individuen: Mit 1dentischen Einkommenshöhen können verschiedene Individuen durchaus verschiedene Bedürfnisbefriedigungsgrade erreichen und unterschiedliches verhalten motivieren.

Mithin kann die Geltung gleicher fallender Grenznutzenkurven für alle Individuen nur mit äuBerst rigorosen Unterstellungen begründet werden. Damit aber steht und fallt die unterschiedslose Anwendung eines für alle identischen steuertarifs, der ja eine Verteilung der steuerlast nach $i \mathrm{n} d i \mathrm{v}$ i $\mathrm{d}$ e 1 l e $\mathrm{n}$ Bedurfnisbefriedigungs - und Opferfähigkeit erreichen will. Wenn auBerdem der nach rechts fallende Kurvenverlauf nicht gewährleistet ist, d.h. wenn der Gesamtnutzen mit zunehmendem Einkommen sogar noch größer werden sollte, würde bei opfergleichheit für alle Individuen eine progression des Steuertarifs sich nicht mehr begrüden lassen.

III. Um darstellen zu können, welche verteilungspolitischen $\mathrm{zie-}$ le und wirkungen das Individualnutzenkonzept enthält bzw. anstrebt, ist es erforderlich, einerseits die distributive Ausgangslage $z u$ erfassen, die die Nutzentheorie unterstellt, andererseits $\mathrm{zu}$ untersuchen, wie die allokativen Voraussetzungen sind, von denen die Nutzentheorie ausgeht.

i2) M.S. Kendrick 1939, S. 95. - E.D. Fagan 1966. 
1. Mit der Präisse, positive Nutzen in das Nutzenopfer nicht einzuschließen, wie auch mit der jetzt darzustellenden, welche die $v \circ r$ der Besteuerung a $n g$ e $r$ of $\mathrm{f} n$ e p e r s o -

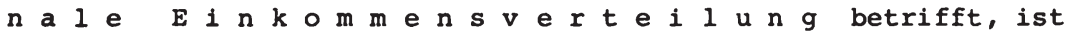
das grundsatzliche Problem einer allokativen und distributiven Staatsaktivität in der Wirtschaft aufgeworfen. Empirisch ist in entwickelten Gesellschaften eine Wirtschaft ohne staat nicht anzutreffen; das heiBt, daB seine Existenz weder ohne Ausgabennoch ohne Steueraktivitäten denkbar ist. Die Ausgabenaktivitäten führen unter den $0 . g$. Voraussetzungen zur Veränderung der Einkommen, der Nutzenstruktur und der Wohlfahrt. Von allen diesen veränderten Strukturen kann nicht gesagt werden, ob sie "gerecht" sind, da die Verteilungsziele der Ausgabenpolitik nicht immer eindeutig, da die Ausgabeninzidenz nicht immer feststellbar ist. Die hier zu beurteilende Prämisse der Opfertheorie geht aber davon aus, $\mathrm{daB}$ eine "g e $\mathrm{r}$ e $\mathrm{c} h \mathrm{t} e$ " Einkommensverteilung für die steuerlastverteilung bereits vorliegt. Darin offenbart sie zum einen die distributive "Lücke" der Wohlfahrtstheorie schlechthin, einer Theorie, die als Allokationstheorie jede zufällig herrschende Einkommensverteilung voraussetzungsgemä ${ }^{13}$ ) als gerecht ${ }^{14}$ ) ansieht, sie gar nicht verändern will. Darin offenbart sie $z$ um anderen aber auch einen wesentlichen Mangel der Opfertheorie selbst (K. Littmann 1970, S. 116). Wenn H. Haller (1971 S. 91), bevor er die steuerlast leistungsangemessen verteilt, erst eine gerechte Einkommensverteilung durch redistributive Politik herstellen will, zielt er damit genau auf diesen systemfehler, doch ist dessen Behebung, wie K. Littmann (1970, S. 119) feststellt, mit dem rein allokativen Ansatz der Opfertheorie nicht $z$ u vereinbaren. Gerade die opfertheorie ist geeignet, den Unterschied zwischen Steuerlastverteilung und redistributiver (Steuer-) Politik zu demonstrieren. Die vorgefundene distributive Ausgangslage präjudiziert das opfertheoretische Allokationsergebnis. Die hier und oben in I 2 vorgelegte Prämissenkritik hebt ein

13) K. Wicksell 1896, S. 143: "Gerechtigkeit der Besteuerung hat offenbar Gerechtigkeit der bestehenden Vermögens- und Einkommensverteilung selbst zur stillschweigenden Voraussetzung."

14) H. Sidgwick 1883, S. 262: Das Leistungsfähigkeitsprinzip akzeptiert die bestehende Einkommens- und Besitzordnung als gerecht. 
allokativ-distributives Beziehungsgeflecht der staatsaktivität hervor, das von der opfertheorie nicht verarbeitet werden kann.

2. Die Opfertheoretiker gehen davon aus, daB nur Wirkungen im distributiven Bereich des Wirtschaftens auftreten, daB es also dort $z u$ "Einkommenseffekten" kommt. Dazu müssen sie unterstellen, $\mathrm{daB}$ Wirkungen im $\mathrm{a} l \mathrm{l}$ o $\mathrm{a} t \mathrm{i} \mathrm{v}$ e $\mathrm{n}$ Bereich nicht auftreten. Von diesen schlieben sie allerdings expressis verbis nur die Uberwälzung aus. Deshalb wird von F.K. Mann (1930b, S. 42) und G. Krause-Junk (1977, S. 345) zu Recht kritisiert, daB dieser AusschluB nicht ausreicht. Vielmehr seien j e g 1 i c h e $s u b s t i t u t i \circ n s$ e f $\mathrm{f}^{\mathrm{k}} \mathrm{k} t \mathrm{e}$ der Besteuerung auszuschlieBen. Die weitere Fassung - Unzulässigkeit von Steuerauflagen mit Substitutionseffekten - trifft nach K. Littmann (1970, S. $121 \mathrm{f.l}$ viel eher den Bedingungskatalog der Opferhypothesen, denn es soll ja gerade "unmöglich sein, daB ein Steuerzahler mittels ökonomischer Reaktionen auf den SteueranstoB sein Einkommen verändern, also den Grad der steuerlich verursachten Nutzeneinbuße selbst bestimmen oder zumindest doch beeinflussen kann". Der AusschluB von Substitutionseffekten aber umfaBt mehr als nur den AusschluB der Uberwälzung, nämlich auch die nicht von der Uberwälzung berührten allokativen Phänomene der Steuereinholung und der steuerausweichung. ${ }^{15)}$ Wenn man nun aber mit Littmann die weitere Fassung als die mit dem opferkonzept einzig kompatible akzeptiert und zugleich davon ausgeht, daB unvermeidlicherweise die Einkommensteuer Substitutionseffekt auslöst, so ergibt sich konsequent, daB ausgerechnet die Opfertheorie mit einer Kopfsteuer, der als einziger steuerart Substitutionswirkungen nicht nachgesagt werden, operieren muB. Wenn aber das ziel der Be-

15) Nach Littmann (1970, S. 121) sind sowohl Steuereinholung als auch Steuerausweichung (wie auch Steuervermeidung) Substitutionseffekte; wir halten es dagegen für richtig, daB zu den eigentlichen Substitutionseffekten nur die aus der gelungenen Uberwälzung resultierenden Markt- und Preiswirkungen gezählt werden sollten, ferner die aus dem Steueranstob sich ergebenden Steuerausweichungen. Dagegen wären Steuereinholungen als die im Zuge der nicht gelungenen Uberwälzung entstehenden "Ertragseffekte" zu bezeichnen. Somit bestehen im allokativen Bereich zwei Arten von Reaktionen auf den Steueransto $B$ bzw. die Steuerzahlung: die Ertragseffekte und die Substitutionseffekte; von "Einkommenseffekten" wäre dann erst im distributiven Bereich zu sprechen. 
steuerung nach der Leistungsfähigkeit nach wie vor gelten soll, ist die Kopfsteuer als eine Konsequenz aus dem Prinzip der gleichen Steueropfer nicht tragbar. Das Individualnutzen-Konzept setzt also einerseits, um $z$ u selnem distributiven Lastverteilungsergebnis $\mathrm{zu}$ kommen, unvollständige und unrealistische Allokationsbedingungen; es kommt andererseits, wenn die Allokationsbedingungen konsistent gemacht werden, $z u$ einem dem Konzept nicht entsprechenden Distributionsergebnis.

\section{Zusammentassung:}

Also kann man sagen: Nach allem steht entweder das Leistungsfähigkeitsprinzip selbst zur Disposition oder zumindest seine opfertheoretische Interpretation im Sinne des Individualnutzenkonzepts. Die Kritik an den Voraussetzungen und Folgen der opfertheoretischen Interpretation ist durchschlagend. Es ist $\mathrm{zu}$ prüfen, inwieweit das Leistungsfähigkeitsprinzip, statt es mit theoretischer Fundierung $\mathrm{zu}$ versehen, eher mit politischem zielinhalt gefüllt werden könnte, um sich seiner doch unübersehbaren politischen Anziehungskraft $z u$ bedienen. Dabei fallt auf, daB Fragen der $p o-$ 1 i t i s c h e $n \quad z i$ e $l$ e einerseits schon in den 0 p f e r $\mathrm{v}$ e r s $i \circ \mathrm{n}$ e $\mathrm{n}$ teilweise enthalten sind, andererseits teilweise von den Vertretern der opfertheoretischen Interpretation des Prinzips offen ausgesprochen werden.

a) Nachweislich verfolgt das Konzept des gleichen absoluten Opfers eindeutig die ziele der Vermeidung von substitutionseffekten und excess burden-Wirkungen bei völliger Abstinenz von einem politisch akzeptablen Verteilungsziel; hier scheint die Präferierung des

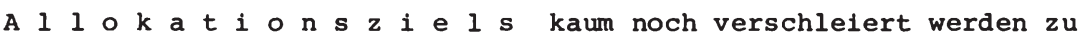
können. Ahnliches kann vom Prinzip des gleichen marginalen Opfers gesagt werden, das eher eine Effizienzregel ist, wobei Verteilungsfragen allenfalls als Randprobleme auftauchen; wollte man die Anwendung dieser Opferversion in den Zusammenhang mit politischen Entscheidungen bringen, und zwar solcher Entscheidungen, die den trade off zwischen Redistribution und Wachstum $z u$ bewerten haben (so bei D. Pohmer 1970), so wäre dem entgegenzuhalten, daB Umverteilungsziele dem persönlichen und moralischen Engagement entspringen, daB sie auf werturteilen beruhen und $\mathrm{da} B$ es dazu der Annahme sinkender Grenznutzenkurven des Einkommens nicht bedarf. ${ }^{16}$ ) 
b) Die Rolle des gleichen proportionalen Opfers ist weniger eindeutig dem a 1 lok a $i v e n$ oder dist $r i b u t i$ $\mathrm{v}$ e $\mathrm{n}$ Bereich zuzuordnen. Zwischen Nutzenkurvenverlauf und Steuertarifzumessung liegt soviel Unbestimmtheit, daB hier nahezu jede politische Position und Auffassung uber den Grad der Progressivität des Tarifs untergebracht werden kann, daB hier vollig offen bleibt, ob sich mit diesem opferkonzept eher allokative oder eher distributive ziele koordinieren lassen. So hat es denn auch hier nicht an dem Versuch gefehlt, den ProzeB der politischen Entscheldung über Verteilungsziele in das Opferkonzept einzubauen. Beispielhaft ist hier die Forderung H. Hallers 11970 ; 1971, S. 74 f., 84 u. insbes. S. 95 f.l, die Politiker sollten sich bei ihrer Entscheidung für eine Besteuerung auf eine solche Nutzenkurve einigen, die zu dem erwünchten Proportionaltarif führt. Doch dies ist nur eine Umgehung der Entscheidung für einen bestimmten Tarif, da solchermaBen die Entscheidung auf die Vorstufe, nämlich auf eine solche uber die Nutzen verlagert wird: Nicht mehr der Tarif wird normativ verordnet, sondern der Nutzenkurvenverlauf. So zeigt denn auch K. Schmidt (1972, S. 199), daB es eine "finale Submission" ist, nur solche Nutzenkurven für die politische Entscheidung zuzulassen, die $z u$ einer proportionalen Besteuerung führen. Hier sind nutzentheoretische Ableitungen durchsetzt mit "fundlerenden" und "lückenfüllenden" Rollen der politischen Entscheidung. 17$)$

c) Mittlerweile ist der Diskussionsstand in dieser für die Finanzwissenschaft und ihr Selbstverständnis so wichtigen Frage dadurch gekennzeichnet, daB weithin anerkannt wird, die $p \circ 1$ i $t i$ $\mathrm{s} c \mathrm{~h}$ e $\mathrm{E} \mathrm{n} \mathrm{s} \mathrm{c} \mathrm{h}$ e $\mathrm{d} u \mathrm{ng}$ bestimme, was als Leistungsfähigkeit zu gelten haben (vgl. \$ 17). Die Ansätze zu dieser kritischen Haltung gegenüber dem Leistungsfahigkeitsprinzip in der bisherigen nutzentheoretischen Interpretation sind allerdings erkennbar differenziert: Musgrave/Musgrave (1980, S. 238) betonen erstens die schwierige Anwendung des Prinzips und zweitens die mangelnde Eignung, die gesamte Funktion der Steuerpolitik zu er-

\footnotetext{
Fn. 16: Siehe die Kritik von K. Schmidt (1972, S. 201 f. u. 204 f.) an dem Beitrag von D. Pohmer.
}

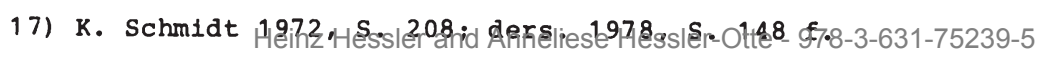


fassen. Demgegenüber beanstandet F. Neumark (1970, S. 122) die opfertheoretische Begründung, da sie zu normativ-dogmatisch sei. Auch K. Schmidt (1967, S. 396; 1978, S. 149) hält eine Vermischung von Opfertheorie und Leistungsfähigkeitsprinzip für nicht sinnvoll; das Prinzip mithilfe eines bestimmten Theorems $z u$ interpretieren, erweise sich als unfruchtbar, weil das Verständnis von Leistungsfăhigkeit - ähnlich wie das von Gerechtigkeit auf einer sich mit der soziorkonomischen BewuBtseinslage wandelnden gesellschaftlichen Konvention beruhe. Die weitestgehende Konsequenz in dieser Richtung zieht K. Littmann (1970, S. 120), der vorschlägt, das gesellschaftlich konvenierte Distributionsziel zum Inhalt des Prinzips zu machen und das Opferprinzip durch das "Verteilungsprinzip der Besteuerung" vollständig zu ersetzen (siehe Kapitel 12).18)

18) Der Vollständigkeit halber ist zu erwähnen, daß nach der Kritik durch K. Schmidt und K. Littmann H. Haller nochmals seine Auffassung verteidigt hat (1973). Dort diskutiert er auf einer Ebene, die das Problem nicht weiterführt. Die Unhaltbarkeit der Voraussetzungen in den Opfertheorien ist sein Problem nicht. Um das von ihm favorisierte "proportionale gleiche opfer" $z u$ begründen, muß von dem "verantwortungsbewußten Politiker" rein "gefühlsmäßig" abgewogen werden, welche Steuerlast individuell zuzumessen ist. Haller: "Zugegeben, die Abschätzung der einzelnen Steuersätze für elne gleiche relative Belastung ist alles andere als einfach, doch man hat dafür ein Organ" (S. 472). Wie immer dieses auch beschaffen sein mag, mit seiner Hilfe gelingt es aber nicht, etwa auch das Maß an Redistribution festzulegen, die ja nach Haller elner jeglichen Besteuerung nach der Leistungsfähigkeit vorauszugehen hat. Haller aber sagt selbst: "Ich möchte die Polltiker sehen, die es sich zutrauen, ein normatives Verteilungsschema für die Einkommen zu entwerfen, die die Staatsbürger übrig behalten dürfen" (S. 488). - Darf es sich aber der Wissenschaftler zutrauen, für ein gleiches relatives opfer zu votieren, da doch die Unhaltbarkeit der opfertheorie evident ist? 


\section{s 39 Das "Wohlfahrts"- (oder \\ "Budget"-) Konzept}

I. Das Ziel: Die äquivalenztheoretische Lösung allokativ-distributiver Probleme

II. Die Lösungshindernisse: Unmögliche Nutzenmessung, unterschiedliche Nutzenintensitäten und fehlende Inzidenzinformationen

III. Das Ergebnis: Die fehlende Eignung des Konzepts für verteilungspolitische Lösungen

I. Die Abwendung vom Leistungsfähigkeitsprinzlp lieB einige Autoren die Attraktivität des $\AA$ q u i v a $l$ e n z p r i n z i p s neu entdecken. Dies ergibt sich aus der dem Leistungsfähigkeitsprinzip auferlegten Selbstbeschränkung, nämlich der "Entkoppelung von Staatsleistungen und öffentlichen Abgaben". ") Die nunmehr empfundene Notwendigkeit, über das Leistungsfähigkeitsprinzip hinauszugehen, rückt die Besteuerungsfrage in den gesamtgesellschaftlichen Zusammenhang der allgemeinen wohlfahrts- oder Budgetbestimmung. Der Attraktivität des Äquivalenzprinzips soll hier aber nur insoweit nachgegangen werden, wie dadurch eine Erweiterung des bloBen Individualnutzen-Konzepts deutlich gemacht und wie darin die allokativ-distributive Problematik aufgesucht werden kann.

Das "Wohlfahrts"- (bzw. "Budget"-) Konzept, das R.A. Musgrave (1969 , S. $87 \mathrm{ff.}$ ) nach den beiden grundlegenden Budgetprinzipien von A.C. Pigou (1928, S. 31 u. 43) und H. Dalton (1936, Kap. 2) entwickelt - er nennt es auch das "Wohlfahrtsmaximierungsprinzip der Budgetbestimmung" -, dient der simultanen Bestimmung von öffentlichen Leistungen und privater Einkommensverteilung. Die Festlegung sowohl der öffentlichen Ausgaben als auch der Steuerlasten geschieht nutzentheoretisch. ${ }^{2)}$ Das Konzept er-

1) W. Wittmann 1979, S. 289; siehe auch G.P. Ziemes 1980, passim.

2) Das erste Budgetprinzip verlangt eine Verteilung der Ressourcen auf verschiedene öffentliche Leistungen in der Weise, daB ihr Grenzertrag für jede Ausgabenart gleich ist; das zweite Prinzip verlangt eine Ausdehnung der öffentlichen Ausgaben bis zu dem Umfang, bei dem der zugewachsene Grenznutzen durch die Staatsausgaben gleich dem entgangenen Grenznutzen durch die weggesteuerte Einkommenseinheit ist. Beide Prinzipien bestimmen so zusammen Volumen und Struktur des Budgets, siehe Pigou und Dalton. 
laubt die Ableitung der optimalen BudgetgröBe aus der Differenz der Netto-Nutzen: "Grenznutzenzuwachs aus öffentlichen Ausgaben" minus "durch Steuern verursachte marginale Nutzeneinbußen im privaten Bereich". ${ }^{3)}$ Es fullt die "allokative Lucke" des Individualnutzen-Konzepts insoweit, als es den Zusammenhang zwischen Steuerlastverteilung und Ausgabenvolumen wie -struktur aufzeigt und damit die vom Leistungsfähigkeitsprinzip aufgegebene Aquivalenz wieder herstellt. Das Modell fullt aber auch die "distributive Lücke" der Opfertheorie, da die bestehende Einkommensverteilung nicht akzeptiert, sondern als eine staatliche Aufgabe formuliert wird. "Da der gesellschaftliche Nutzen der offentlichen Leistungen als gegeben angenommen wird, kann die Besteuerung durch die Allokationsabteilung mit der Steuern und Transferzahlungen der Distributionsabteilung kombiniert werden." 4 )

II. Insgesamt aber gibt auch Musgrave diesem Modell elner "Theorie der Budgetplanung" wegen ihres $n u t z$ e $n t h$ e $r$ e $t i$ $s \mathrm{c}$ e $\mathrm{n}$ Inhalts keinerlei Chance auf allgemeine Akzeptanz (1969 , S. 89), denn weder bietet das Prinzip des gleichen marginalen Nutzens einen konkreten MaBstab, an dem die Effizienz der Ausgabenprogramme gemessen werden kann, noch läBt sich aus dem Prinzip des geringsten Gesamtopfers" ein operationales Mittel zur Aufteilung der Steueranteile" ableiten."

a) Soweit die erstrebte "Kombination" allokativer und distributiver Probleme sich mit dem Wohlfahrts-Konzept erreichen lassen soll, liegt die Unmöglichkeit dieses Unterfangens gerade in dem verwendeten $\mathrm{N} u t z$ e $\mathrm{k} \circ \mathrm{n} z$ e $\mathrm{p} t$. Die Attraktivität des Aquivalenzprinzips besteht in diesem Zusammenhang nur scheinbar. Auch der Versuch von H. Timm, ${ }^{6)}$ die "erwünschten" Leistungen des

3) R.A. Musgrave, The Theory of Public Finance and the Concept of Burden of Taxation. Harvard University, Cambridge, 1938, S. 113 (Dissertation Musgraves, zitiert nach 1969 , S. 87).

4) R.A. Musgrave 1969 , S. 88. Die Kombination ergibt sich nach den Spielregeln der Musgrave'schen "multiplen Theorie des öffentlichen Haushalts" (S. 5-32).

5) Zur Kritik siehe auch R. Ulbrich 1975, S. $203 \mathrm{f}$.

6) 1980 , S. 181 ff.; Timm stellt eine Verknüpfung her zwischen dem Aquivalenz- und dem Leistungsfähigkeitsprinzip, die er im

(Forts. siehe folgende seite) 
Staates vorwiegend nach dem Leistungsfähigkeitsprinzip zu finanzieren, 7) die "unverzichtbaren" hingegen nach einem nutzentheoretisch definierten Aquivalenzprinzip, ${ }^{8)}$ kann daran nichts ändern.

b) AuBer einer Kritik an dem nutzentheoretischen Gehalt des Wohlfahrts-Konzepts ${ }^{9}$ ) werden Einwendungen einerseits $z$ um $\mathrm{U} \mathrm{m}$ a $\mathrm{n} g$, andererseits zu den Wirkungen des $B$ u d g $t \mathrm{p} l$ a $\mathrm{n}$ u $\mathrm{g} s$ a $n$ s a $t z$ e $s$ erhoben. Nach Musgrave (1968a,s. 54 f.) sollen in das Einkommen den einzelnen zuzurechnende vortelle aus der freien und subventionierten Versorgung mit öffentlichen Gütern einbezogen werden. Das jedoch fuhrt nach B.I.Bittker (1967, S. 925 f.) zu Diskriminierungen dann, wenn Individuen in identischen Einkommenslagen unterschiedliche Vorteile aus öfentlichen Gutern ziehen; da eln gleicher Konsum von öfentlichen Gütern ein in praxi nur sehr selten vorkommender Fall ist, sind Diskriminierungen bel der Einbeziehung der Vortelle aus öffentlichen Gütern unvermeidlich. ${ }^{10)}$ Dieser Einwand Bittkers, der sich zunächst gegen die Aus-

Forts. Fn. 6:

"Nutzen" sleht: Nutzen ist sowohl für die verschiedenen Opfertheorien konstitutiv als auch für die Bestimmung des Aquivalents zwischen den "unverzichtbaren" und präventiv wirkenden (existenzsichernden) Staatsleistungen und dem Finanzierungsbeitrag des einzelnen.

7) Die volle Deckung dieser Ausgaben für erwünschte Leistungen (merit goods) durch Abgaben nach dem Aquivalenzprinzip kommt nach Timm nicht in Betracht, vielmehr muB die Kostendeckung durch Steuern nach dem Leistungsfähigkeitsprinzip ausgeglichen werden.

8) Timm, S. 183: "Von der Konzeption und der Logik her gebührt dem Aquivalenzprinzip sogar der unzweifelhafte Vorzug. Denn wie soll konsistent über Volumen und Struktur der Steuerbelastung entscheiden werden, ohne zugleich über volumen und Struktur der an der Präventivwirkung orientierten und mit unterschiedlichen individuellen Nutzen verbundenen Staatsleistungen zu entscheiden?" "Gerade weil die Nutzen, die die Staatsbürger aus diesen Leistungen ziehen, ungewollt unterschiedlich sind, mübten diese Unterschiede bei der Bestimmung der Steuerlastverteilung berücksichtigt werden"; nach Timm geben weder Unkenntnis der Präferenzen noch Informationsmängel AnlaB, das Leistungsfähigkeitsprinzip dem Aquivalenzprinzip vorzuziehen.

9) Diese wird von Musgrave selbst vorgetragen; siehe auch $G$. Kirsch 1980 , S. 322 .

10) Siehe hierzu auch die Diskussion zwischen Aaron/McGiure (Public Goods and Income Distribution, in: Econometrica, Vol. 38, 1970, und G. Brennan, The Distributional Implications of Public Goods, in: Econometrica, Vol. 44, 1976; auch J.G. Head 1979 , S. 201 ff. 
dehnung des Einkommensbegriffs richtet, kann selbstverständlich auch aus dem Blickwinkel der Budgetbestimmung gegen das Wohlfahrtskonzept insgesamt erhoben werden.

c) Hinslchtlich der $\mathrm{W}$ i $\mathbf{r}$ k $\mathrm{n}$ g e $\mathrm{n}$ steht ein solcher Budgetansatz vor dem Problem, die gesamte Budgetinzidenz ${ }^{11)}$ verläBlich abschätzen und in die VerteilungskorrekturmaBnahmen einbauen $z u$ müssen. Dies gilt nicht nur in Bezug auf die steuern und die Transfers, sondern auch, worauf $G$. Bombach hinweist, ${ }^{12}$ ) in Bezug auf die Realausgaben. ${ }^{13)}$ Schlieblich ist aber dem versuch einer Bestimmung des Optimalpunktes für Volumen und Struktur des Budgets die Kritik von K. Mackscheidt (1973) entgegenzuhalten, der nachweist, daB ein solcher Punkt nicht gefunden werden kann, und der deshalb den Lösungsweg in politischen Problemen der Konsensfindung sucht. Wenngleich diese Kritik nicht die steuerbestimmung, sondern die Volumens- und Strukturbestimmung des Budgets betrifft, so hat sie dennoch für den Gesamtansatz des Wohlfahrts-Konzepts Gewicht.

III. Dennoch kann gerade das Phänomen der "Entkoppelung" von Staatsleistungen und öffentlichen Abgaben das a $110 \mathrm{k}$ a $\mathrm{i} v$ d i s $t$ r $i$ b $t i v e$ P $r \circ b l$ e m nochmals deutlich machen. Die nichtmarktliche Allokationspolitik richtet sich auf die Entscheidung, neben privaten auch öfentliche Güter anzubieten und zu ihrer Finanzierung Steuern zu erheben, nach welchem Prinzip auch immer. Die Ausdehnung des offentlichen Sektors der Gesamtwirtschaft ist nun aber direkt weder ausschlieblich dem Aquivalenzprinzip noch ausschlieBlich dem Leistungsfähigkeitsprinzip anzulasten, sondern den gesellschaftspolitischen Entscheidungen

11) Siehe die empirischen. Arbetten von K.-D. Grüske 1978 und $\mathrm{U}$. Wartenberg 1979.

12) 1969, S. 815: zu Unrecht wird die Redistributionstätigkeit des Staates häufig nur nach den Transferausgaben beurteilt; ferner derselbe, 1972 , S. 15 f.

13) J. Bowen 1970, S. 103: "What we have to imagine is an attempt to change seriously and significantly the dispersion of real incomes, after tax costs and social benefits from government expenditure have all been imputed correctly." 
oder auch den parteipolitischen Verlockungen. Sofern vermehrtes Steueraufkommen - durch eine stärker wirksam werdende Progression unterstützt - diese Politik erleichtert und möglicherweise initiiert hat, ist das der Effekt der Besteuerung schlechthin, nicht der ihrer Prinzipien. Zwar ist zuzugeben, daB das Leistungsfähigkeltsprinzip das "Kainsmal" der Entkoppelung trägt, und daB die Absicht, dem Aquivalenzprinzip für bestimmte staatsleistungen mehr Geltung $z u$ verschaffen, ${ }^{14)}$ Vortelle hat; was aber festzustellen bleibt, ist dies: Allokative ziele $z$ u verfolgen heibt nicht automatisch, das Aquivalenzprinzip anzuwenden; anders formuliert: Fehlallokationen sind nicht ausschlieblich auf die Anwendung des Leistungsfähigkeitsprinzips zurückzufüren. ${ }^{15)}$ Dies hieBe, die Attraktivität des Aquivalenzprinzips zu uberschätzen. ${ }^{16)}$

Auf die politischen Implikationen des Wohlfahrtskonzeptes weist R.A. Musgrave (1969 , S. 111) selber hin; das Konzept zeigt nicht, wie die sozialen Präferenzen zu bestimmen sind, wie also die Vorlieben für eine Ausdehnung des Staatssektors, für diese oder jene Art der Besteuerung, für diese oder jene Art des Angebots an offentlichen Gütern zustande kommen; ohne solche Präferenzbestimmung bleiben die Erfordernisse der Wohlfahrtsmethode eine "leere Hulle". Dies weist auf die Bedeutung der politischen Entscheidungen und auf die Rolle der Konsensfindungsverfahren hin, der K. Mackscheidt ${ }^{17)}$ in seiner Theorie des optimalen Budgets eine so groBe Bedeutung einräumt. Die Bedeutung politischer Entscheidungen soll auch innerhalb der anschlieBend $z u$ analysierenden SozialnutzenKonzepte aufgesucht werden.

14) Siehe W. Wittmann 1979, S. 294, für bestimmte Versorgungs-, Entsorgungs- und Versicherungsleistungen.

15) Anders Wittmann 1979, S. 288 f., demzufolge das Leistungsfähigkeitsprinzip ab dem Jahre 1960 eine partielle Uberversorgung mit staatsleistungen bewirkte.

16) Wir möchten auch nicht so weit gehen, einen Teil der progressiven Einkommensteuern als Aquivalent für das Gut "Marktwirtschaft" anzusehen; zu dieser Ansicht und zu den Bedingungen, unter denen sie $z u$ begründen sei, siehe G.P. Ziemes 1980, S. 28 .

17) Für Mackscheidt stehen die Fragen im Vordergrund, wie intensiv die individuellen Bedürfnisse bei der Budgetoptimierung berücksichtigt werden und welche Konsequenzen es hat, daB es ein free rider-Problem gibt; die Konsensfindung steht im Mittelpunkt der Lösungsversuche um das optimale Budget. 
540 Das "sozialnutzen"-Konzept

I. Die theoretische Belanglosigkeit eines

"kollektiven Imperativs"

584

II. Der Widerspruch in Musgraves

"Social Utility Approach"

III. Die "entpersönlichte" politische Entscheidung als Emanzipation von theoretischen Verhüllungen

I. Das "Sozialnutzen"-Konzept für die Konstruktion einer Besteuerungsregel heranzuziehen, muB als ein Versuch gewertet werden, die Besteuerung mehr oder weniger elegant aus dem Bereich einer Theorie, deren (in gesamtgesellschaftlichen Nutzennormen liegende) Werturteilsbehaftung nicht zu verbergen ist, in den Berelch der politisch offen formulierten Postulate $\mathrm{zu}$ uberführen.

a) Uber das oben dargestellte Budget-Konzept geht das Sozialnutzen-Konzept insoweit hinaus, als die Besteuerung sich nummehr nicht nur an den öffentlichen Ausgaben und Gütern, sondern an

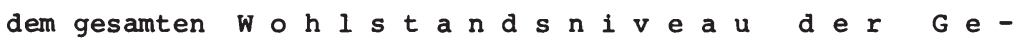
$s e l l s c h$ a $t$ t $z$ orientieren hat. Denn die Erstellung eines optimalen Tarifverlaufs hängt nach dem Sozialnutzen-Konzept unter anderem ${ }^{1)}$ von der sozialen Wohlfahrtsfunktion ab, die die Gesellschaft "anzuwenden wünscht". 2) Nun aber besteht das Problem in der Bestimmung eben dieser sozialen Wohlfahrtsfunktion, die ihren Verlauf den Aggregationsversuchen von Individualnutzenvorstellungen verdankt. Mit der Absicht jedoch, der Besteuerung zwar einen Fluchtpunkt im Bereich der Politik zu eröffnen, $1 \mathrm{hr}$ aber eine Rückzugsmöglichkeit in das Feld der Theorie zu erhalten, bleibt sie den Angriffen auf das Nutzen-Konzept nach wie vor ausgesetzt.

1) (1) von der Vertellung der Verdienstmöglichkeiten in der Bevölkerung, (2) von den Verhaltensweisen der Arbeltnehmer, aus denen sich ergibt, wieviel sie bei verschiedenen Nettolohnsätzen arbeiten werden; siehe Musgrave/Musgrave/Kullmer 1988 , S. 114

2) Musgrave/Musgrave/Kullmer 1988, S. 114. 
b) Zunächst ist schon allein die Aggregation der Einzelnutzen eine MiBachtung aller kritischen Einwände gegen die Nutzenkonzepte; insofern ist die Annahme, das Wohlstandsniveau einer Gesellschaft werde durch die Nutzenniveaus des einzelnen Menschen bestimmt, ein Werturteil (E. Sohmen 1976, S. 21). Der entscheidende Punkt für die Besteuerung aber ist, daB die soziale Wohl-

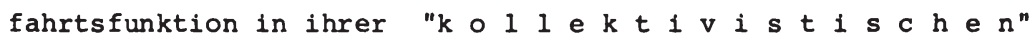
Bestimmung (H. Giersch 1960, S. 99) von der Normvorstellung ausgeht, das Individuum sei nicht der beste Sachwalter seiner wahren Interessen und wohl auch nicht der kollektiven; das Kollektiv, das die soziale Wohlfahrtsfunktion festlegt, bestimmt, welche "Irrtümer des Individuums" vermieden werden sollten ( $\mathrm{H}$. Giersch 1960, S. 100). Damit ist zwar die notwendige kollektive Finanzierung von öffentlichen Leistungen qua Steuern zu sichern, doch unter Zuhilfenahme einer untauglichen und für politische Zwecke auch unnötigen theoretischen Grundlage, nämlich der Aggregation von nicht meB- und vergleichbaren GröBen, vor allem aber einer verordneten "Gleichheit der allgemeinen Wertsysteme". 31

c) Das für die Besteuerung so wichtige Distributionsmoment kommt hinzu: Für viele beginnt erst jenseits des Paretianischen Werturteils die Daseinsberechtigung der sozialen Wohlfahrtsfunktion (E. Sohmen 1976, S. 336). So verlangt H. Giersch (1960, S. 104 f.) von ihr, wenn sie vollständig sein will, auch eine $V$ e $r$ e $i$ l u $\mathrm{n} g \mathrm{~s} \mathrm{n} \circ \mathrm{m}$, die uberdies zu gewichten sei. Dann aber liegt das Problem in der Definition von "Distributionsgewichten", die nach H. Giersch das Gemeinwohl erst vollständig definieren und Ausdruck der Gerechtigkeitsvorstellung sind. ") Da aber die Gerechtigkeitsfrage notwendigerweise den Vergleich von Bedürfnissen verlangt, muB man E. Sohmen darin zustimmen, daB eine soziale

3) Weber/StreiBler 1964, S. 10; "Die Erkenntnis, daB eine Aggregationsregel der Nutzen bewuBt aus einem Wertsystem abgeleitet und auf ein wertendes subjekt bezogen werden muB, hat zur Einführung des Begriffs der Social Welfare Function (Abram Bergson, Abba P. Lerner, Paul A. Samuelson) gefüht."

4) H. Giersch 1960, S. 105; hat jedes Individuum das gleiche Distributionsgewicht, ist das lediglich horizontale Gerechtigkeit (S. 106) und bedeutet die Unterstellung, der Markt schon produziere die gesellschaftlich konvenierte Gerechtigkeit; für die vertikale Gerechtigkeit liegt das Problem im Vergleich von Bedürfnissen und deren Gewichtung sowie deren ständige zeitliche Anpassung. 
Wohlfahrtsfunktion ${ }^{5)}$ nur AufschluB geben kann (iber die Gedanken dessen, der sie aufstellt; von der Gruppe aufgestellte Wohlfahrtsfunktionen können, wie das Arrow-Theorem (1963) beweist, die Bedingungen logischer Konsistenz nicht erfüllen (E. Sohmen 1976, s. 337). Wir flugen hinzu: da Politik selten unter das Postulat einer logischen Konsistenz gestellt wird, ist auch in dieser Hinsicht der Umweg einer theoretischen Fundierung der Steuerpolitik überflüssig.

II. In der Finanzwissenschaft wird das Sozialnutzen-Konzept als "S O c 1 a $1 \quad U t i l i t y$ A p $x \circ$ a $c h "$ neuerdings von Musgrave/Musgrave ${ }^{6)}$ diskutiert, doch hatte es in $\mathrm{K}$. Wicksell (1896) und E. Lindahl (1919) frühe Befürworter. Das WicksellLindahl'sche Steuerprinzip der "rein finanziellen Sphäre" (diese ist, wie oben ausgeführt, der "sozialpolitischen" gegenüberzustellen) enthält die Forderung, daB jeder für den Gesamtnutzen der öffentlichen Betätigung Steuern zahlen solle gemäB der Bewertung seines marginalen Anteils. Die intensive Kritik, die G. Myrdal (1963, S. $174 \mathrm{ff.})$ an dieser Regel ubt, stimmt im grundsätzlichen mit seiner Kritik am gesamten Marginalismus uberein und braucht hier, da oben ausgeführt, nicht wiederholt zu werden. 7) Auch heute noch steht im Mittelpunkt der Diskussion das Verhältnis von Nutzentheorie und steuerprogression.

Nach Auffassung von Musgrave/Musgrave (1980, S. $253 \mathrm{f.}$ ) ist der politische ProzeB, in dem das ProgressivitätsmaB beschlossen wird, durch drei Entscheidungsarten gekennzeichnet: Zunächst postuliert

5) Sie ist jene Leerformel, die dazu dient, "Hilfsmittel zur Ordnung der Gedanken und zur Auffindung der logischen Konsequenzen verschiedener $\mathrm{Zlelvorstellungen} \mathrm{über} \mathrm{die} \mathrm{wünschenswerte}$ Gestaltung einer Gesellschaft zu sein, E. Sohmen 1976, S. 15.

6) 1980 , jedoch auch in den früheren Auflagen ihrer Public Finance in Theory and Practice; es dürfte von Interesse sein, daB R.A. Musgrave diesen Ansatz in seiner "Finanztheorie" noch nicht vertritt.

7) Auch auf M. Masoin (HdF 1956) soll nicht näher elngegangen werden, da er zwar die Ausgabenseite des Budgets mit Nutzenerwägungen und "gesellschaftlichen Bedürfnissen" in Beziehung setzt, eine Verbindung zur Besteuerung jedoch nicht herstellt. 
die Gesellschaft, die Individuen hätten tatsächlich gleiche Nutzenfunktionen; dies ist die notwendige Bedingung, um die soziale Nutzenfunktion konstruieren zu können, doch sollten wir hier schon festhalten, daB zwar eine "politische" Entscheidung eingeführt wird, jedoch eine solche über ein "Theorie"- oder "Verhaltenselement". Zweitens werden den Nutzen bestimmte gesellschaftliche Werte zugemessen, was Ausdruck findet in Diskussionen uber Wohlfahrtsprogramme, die Festlegung von Armutsgrenzen, Tarifprogressionen und Bewertung von Ausgabenprogrammen. Diese Wertzumessung ist der Dreh- und Angelpunkt des Konzepts, da in ihm die Begründung für staatliche Aktivitäten $z u$ sehen ist. Die Autoren sehen in der gesellschaftlichen Wertzumessung den augenblicklich besten Lösungsweg für die Begründung, solange nicht die Schwierigkeiten subjektiver Nutzenvergleiche behoben sind. ${ }^{8)}$ Schlieblich werden Abwägungen zwischen einer gröBeren Glelchheit in der Verteilung und möglichen Effizienzverlusten notwendig werden.

Obwohl dieses Konzept auf politische Entscheidungen hin angelegt ist, löst es sich nicht vom vermeintlich sicheren Boden der Theorie. Zwar wird der Rückzug auf die Nutzentheorie nur als vorläufig angesehen, doch wird die Unhaltbarkeit der Nutzenkonstruktionen im theoretischen Kontext nicht akzeptiert; vielmehr wird der Sozialnutzen als eine Norm überindividuell verordnet, zum Gegenstand politischer Entscheidungen gemacht und dadurch sanktioniert. Politisch entschieden wird dann nicht über offen vorgetragene Werturteile, sondern über Werturteile in theoretischer Verkleidung. Ahnlich war schon H. Haller') vorgegangen, der verlangt hatte, die Politiker sollten statt eines allgemeinen Konsenses über Tarifverläufe einen solchen über Nutzenverläufe herbeiführen.

8) Hierzu siehe auch Musgrave/Musgrave/Kullmer 1975, S. 112, und 1977, S. 129. Auf die Literatur $z$ um Problem der Optimal Taxation wird ausdrücklich verwiesen, vorzugsweise auf Mirrlees 1971 , S. $175 \mathrm{ff.}$, und Cooter/Helpmann 1974, s. $656 \mathrm{ff}$.

9) 1970 , passim und 1971, S. 76: "Die politische Entscheidung, die $z u$ einer bestimmten, generell anzuwendenden Nutzenfunktion führt, stellt die objektivste unter den möglichen Lösungen dar." Die "verantwortungsvoll handelnden Politiker" bestimmen das allgemein verbindliche MaB, gehen dabei von einem politisch festgesetzten Normalma $B$ aus. Siehe auch die Kritik hieran von K. Schmidt 1972, S. 199 u. 208; ferner ders., 1978, S. 148 f. 
III. Wenn J.G. Head ${ }^{10)}$ feststellt, daB Probleme der $p \circ 11 t i$ $s \mathrm{c} h \mathrm{n} \quad \mathrm{E} \mathrm{n} t \mathrm{~s} \mathrm{c}$ e $i \mathrm{~d} u \mathrm{n} g$ bereits im Konzept der Bergson'schen Wohlfahrtsfunktion angelegt sind, so meint er exakt den vorbeschriebenen Tatbestand, zumal er darüber im Kontext der vertikalen Gerechtigkeit berichtet. Einen solchen Zusammenhang kann er deswegen herstellen, weil in beiden Fällen, sowohl bei der Konstruktion von sozialen Wohlfahrtsfunktionen als auch bei der Festlegung einer vertikalen Gerechtigkeit Werturteile praktisch werden. Verteilungsprobleme lassen sich nicht durch nutzentheoretische Bemühungen, sondern auf grund politischer Entscheidungen 1ösen. 11) E. Sohmen (1976, S. 364) trifft eine interessante Unterscheidung hinsichtlich der sozialen Wohlfahrtsfunktion, die zwei Auffassungen aus "völlig verschiedenen Welten" offenlegt: Soziale Wohlfahrtsfunktion als "gesellschaftliche Bewertungsvorschrift" aus dem Bereich der $E t h i k$, und soziale Wohlfahrtsfunktion als "gesellschaftlicher Entscheidungsmechanismus", der konkrete Ergebnisse für die $\mathrm{G}$ e $\mathrm{s}$ a $l \mathrm{t}$ u $\mathrm{n}$ g einer Gesellschaft zustande bringen soll. Die Einsicht in bestimmte logische und organisatorische Unmöglichkeiten der theoretischen Wohlfahrtsbestimmung beläBt im politischen Abstimmungsverfahren nur die Hoffnung, $d a B$ die Mehrheit der Individuen in ihren grundlegenden Werturteilen übereinstimmt und in den Entscheldungen klar zum Ausdruck bringt. ${ }^{12}$ ) Dennoch bleiben die Schwierigkeiten einer konsistenten politischen Meinungsbildung. Es bleibt das Problem, wie sich bestimmte, ethisch fundierte und gemeinsame Grundvorstel-

10) 1979, S. 193: "Perhaps the most constructive interpretation of the Simons approach to vertical equity would seem to be that the decision on this issue is left open to be determined in the Bergson-Samuelson welfare function tradition by the 'external observer' or, perhaps more meaningfully, in the political process."

11) E. Sohmen 1976, S. 363: "Die Vorstellung einer logisch konsistenten Wertordnung der Gesellschaft als Derivat der individuellen Präferenzen ihrer Mitglieder, wie sie der Interpretation des Begriffes 'Wohlfahrtsfunktion' durch Arrow zugrundeliegt, kann ohne Umschweife als nicht existent bzw. realisierbar verworfen werden."

12) E. Sohmen 1976, S. 365: "Die wertvollste Erkenntnis, die uns die Analyse Arrows und die Untersuchungen der auf seinem Werk aufbauenden Autoren vermitteln können, ist zweifellos negativer Art: sie schärfen unseren Blick für die unerhörten Schwierigkeiten, die der Konstruktion einigermaBen leistungsfähiger gesellschaftlicher Entscheidungsmechanismen entgegenstehen." 
lungen uber Gerechtigkeit und Allokation von sozialen Positionen in einer Gesellschaft in Handlungen und Gestaltungen umsetzen lassen. Und es bleibt das Problem, wie sich diese Vorgänge von theoretischen Verhüllungen lösen lassen.

Bel der Frage nach Lösungen müssen wir von einer Möglichkeit zur "E $n t p$ e $s$ o $n 1$ i $c h$ u g" der Grundentscheidungen ausgehen. Ausgangspunkt ist, daB zwar die Allokation der Distribution zeltlich und logisch vorangeht und die Möglichkeit zur Verteilung überhaupt erst schafft, daB andererseits aber ein gerechtes Verteilungssystem den Bestand der grundsätzlich individualistisch organisierten Gesellschaft sichert. Da bedenkenloser Individualismus das system auflöst, ${ }^{13)}$ liegt die Chance der Stabilisierung des Systems in der Entpersönlichung der Entscheidungen, seien sie als Arrow's "erweltere Sympathie" (1963), seien sie als Rawls' "Gerechtigke1t als FairneB"14) vertanden. Die Rawls' schen Gerechtigkeitsgrundsätze, nämlich einerseits das Freiheitsprinzip und andererseits das Unterschiedsprinzip, sind als Moglichkelten zu sehen, Allokations- und Distributionsprobleme im wechselseitigen Zusammenhang und politischer Abstimmung zu analysieren und in Form von qualitativen Aussagen über Lösungstendenzen (E. Sohmen 1976, S. 370) zu formulieren. Nach wie vor aber bleiben dann die konkreten Verteilungsziele der Besteuerung, wie das Progressionsmaß des Tarifs, die Höhe der Freibetrăge usw. kontrovers, doch erscheint ihre elnvernehmliche Festlegung um so wahrscheinlicher, je näher die Auffassungen daruber beieinander liegen, auf welchen Einigungswegen man $z u$ Kompromissen im Verteilungsziel gelangen kann. ${ }^{15)}$

13) Siehe die Ergebnisse von K.J. Arrow 1963.

14) 1975 ; siehe den ersten und zweiten Gerechtigkeitsgrundsatz, §5.

15) Dieser Gedanke wird im AnschluB an die Darstellung des "Verteilungs"-Konzeptes unten nochmals aufgegriffen. 
12. KAPITEI:

Die "Distributions"-Konzepte

s 41 Gesellschattspolitische Bedarfsnormen anstelle modelltheoretischer Nutzenfiktion : Konzeptiberblick

Die nutzentheoretisch begründete Besteuerung nach der Leistungsfähigkeit ist unklar und unbestimmbar, die praktische Handhabung schwierig zu leisten, wenn nicht unmöglich. Soll aber die dahinter stehende Idee als Fremdherrschaft der Ethik (F.K. Mann) ${ }^{1}{ }^{1}$ völlig abgelehnt oder soll die "sozialethische Begründbarkeit" (F. Neumark) ${ }^{2)}$ akzeptiert und dem ethischen Postulat eine Bedeutung für die praktische Steuerpolitik zuerkannt werden? Dazu ist notwendig, sich über die Stellung von Besteuerungspostulaten im gesellschaftlichen Ziel- und Normengefüge im klaren zu sein: Sinn der Politik ist primär nicht die Besteuerung nach der Leistungsfähigkeit oder nach Gerechtigkeitsvorstellungen, sondern das Verfolgen allokativer, distributiver oder anderer Ziele, wobei die steuerliche Gerechtigkeit als eine notwendige Bedingung hinzutritt. ${ }^{3)}$ Wenn auch der wert ethischer Normen für das vertellungspolitische ziel als Ausgangspunkt der Uberlegungen und Handlungen unbestritten sein sollte, so muB doch bis hin $z u$ einer verbindlichen politischen Handlungsanweisung ein bestimmter Denkund Abstimmungsweg beschritten werden, ${ }^{4)}$ der sich wie folgt

1) SinngemäB so in: 1930, S. 41: "Es gibt kein geschichtliches Steuersystem, das der Fähigkeitslehre entspricht; oder auch nur eine Steuerpolitik, die ihren Weisungen folgt." "Das Hauptziel der Lastenverteilung kann nicht eine nach Klassengefühl und Weltanschauung fast beliebig ausdeutbare Steuergerechtigkeit oder eine ebenso vieldeutige SteuergleichmäBigkeit sein, sondern nur eine Anpassung an die finanzwirtschaftlichen, volkswirtschaftlichen und sozialen Bedürfnisse."

2) 1970, S. $124:$ :...daB es vernünftig und gerecht ist, wenn diejenigen, die im Vergleich $\mathrm{zu}$ anderen über eine gröBere Steuerfähigkeit verfügen, auch mehr ... Steuern zahlen müssen?"

3) Littmann (1970, S. 129) demonstriert, wie in der Diskussion um Steuerreformen zwar allokative ziele formuliert werden, Gerechtigkeitsbedingungen hingegen nicht.

4) J. Mitschke 1980a, S. 122: "Die ... gesellschaftlich-parlamentarische Anerkennung einer bestimmten Steuerbemessungsgrundlage entspringt nicht der Uberzeugungskraft einer formal ge-

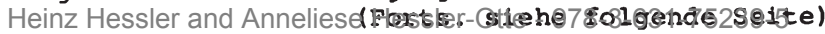


skizzieren läBt (siehe $\S 26$ ): Da Verteilungsgerechtigkeit als eine "materiale" Gerechtigkeit formuliert werden soll, müssen die den Inhalt der Verteilungsgerechtigkeit ausmachenden zurechnungsmasstäbe festgelegt werden. Diese mögen sich in der "Pareto-optimalität", in den Rawls'schen Gerechtigkeitsgrundsätzen bzw. -konventionen oder schlicht in politischen Abstimmungen iber die gewünschten Verteilungsergebnisse zeigen; ${ }^{5)}$ als solche sind sie vorerst allgemeiner Natur. Die Verbindung zwischen ihnen und der politisch-praktischen Realität stellen d i $s$ t $i$ b u $t i v$ e $\mathrm{B}$ e d a r $\mathrm{s} k$ on $\mathrm{z}$ e $\mathrm{t} e$ her, die als meBbare GröBen der individuellen Lebensgestaltung und -vorsorge $z u$ formulieren sind (Existenzminima, Versorgungsmehrbedarf, Sozialhilfesătze usw.).6) Leistungsfähigkeit des einzelnen zeigt sich dann jenselts aller Nutzenerwägungen in solchen GröBen, die der politisch-praktischen Gestaltung direkt zugänglich sind. ') So ist die Formulierung dieser konkreten GröBen nach der Selbstauflösung der Nutzenkonzepte nur konsequent. Diskussionswürdig bleibt jedoch, ob die theoretische Ausformulierung von Distributions-Konzepten gleich so weit $z u$ treiben ist oder ob man sich mit der Formulierung von Verfahrens- oder Rahmenregelungen für das Verteilungsziel vorerst begnügen sollte. Sofern man alle diese Konzepte weiterhin mit einer Besteuerung nach der "Leistungsfähigkeit" bezeichnen will, ist dies ein völlig neuer Inhalt. Der aber ist deutlich zu machen.

Forts. Fn. 4:

schlossenen und positivistisch fundierten Interpretation des obersten Besteuerungsprinzips, sondern entpuppt sich letzten Endes als $E r g e b n i s$ e $i n e r e h r e i t-$

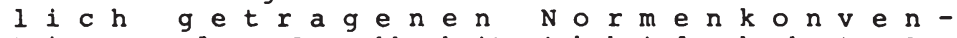
$t i \circ n$, deren Brauchbarkeit sich bei der konkreten Anwendung entscheidet" (Hervorhebungen bei Mitschke).

5) Siehe diese Zusammenstellung bei G. Krause-Junk 1977.

6) Solche Konzepte theoretisch zu fundieren und praktisch nachzuweisen, wäre der Inhalt einer Theorie von der "Personalisierung" der Elnkommensteuer, die hier nicht geleistet werden kann (vgl. \$15).

7) H. Laufenburger 1956, S. 454: "Wie aber kann die Leistungsfähigkeit festgestellt werden? Nicht entsprechend einem absoluten, starren Prinzip, sondern durch eine souveräne Entscheidung der Nation, $d . h$. in einer Demokratie durch eine Mehrheit von Abgeordneten 
Die Leistungsfähigkeitsbesteuerung als ein distributives "Handlungsrahmen"Konzept

a) Grundsätzlich wollen z.B. K. Schmidt (1967), K.-H. Hansmeyer (1974), G. Krause-Junk (1977) und Bea/Fischer (1970) das Leistungsfähigkeitsprinzip erhalten. ${ }^{1)}$ GewissermaBen auf halbem Wege zwischen Gerechtigkeitsziel und endgültiger Formulierung von konkreten VerteilungsgröBen und -maBstäben soll das Prinzip die Blldung von $g$ e $s$ e l s $c h$ a $t s-p \circ l i t i s c h e n$ $K \circ n v$ e $n t i \circ n$ e $n$ dadurch erleichtern, daB es - als eine Art gesellschaftspolitischer Besinnungs- und Orientierungsinstitution fungierend - lediglich in Form eines "Handlungsrahmens" (K. Schmidt 1967, S. 403) formuliert wird. Die Konturen dieses Rahmens sind, wie jeder Versuch einer Gerechtigkeitsorientierung, im politischen Versuch eines Ausgleichs kontroverser Positionen aufzusuchen; dadurch hält man das Handlungsfeld für die sich wandelnde sozioökonomische BewuBtseinslage (K. Schmidt 1967, S. 402) offen. In dieser Interpretation bleibt das Leistungsfähigkeitsprinzip der politischen Aufgabe, die es unbestritten hat, erhalten, wenngleich sich aus $1 \mathrm{hm}$ die konkrete Ausgestaltung der Bemessungsgrundlage oder des Tarifverlaufs noch keineswegs herleiten läBt (K. -H. Hansmeyer 1974, S. 136).

Wenn nun aber das von Theoretikern in dieser Weise vorgetragene Prinzip und seine Funktion nicht ausschlieblich politisch mit Inhalt gefullt, vielmehr auch theoretisch-inhaltlich bestimmt werden soll, müssen schon konkretere Angaben für die Konturenziehung des Rahmens, und sei es auch nur in Form eines Negativkatalogs (so K. Schmidt 1967, S. 403) gemacht werden; ohne einen solchen Versuch bleibt es gegen Kritik immum und eine Leerformel. $K$. Schmidt beschreibt als $M i n d e s t a n$ f $r$ d e $r$ u $n g$ e $n$ an einen Handlungsrahmen die folgenden:

1) Siehe hierzu den Uberblick von R.L. Frey 1973, S. 7, in dem er die "Rettungsversuche" zum Leistungsfähigkeitsprinzip auf im wesentlichen zwei Motive zurückführt, erstens zur Abgrenzung der Finanzierung der Staatsaufgaben durch Steuern von der Umverteilung durch Steuern (H. Haller 1970 und F. Neumark 1970), zweitens zur Abwehr von Gruppeninteressen sowie zur Versachlichung der Diskussion um die gerechte Familienbesteuerung (K. Schmidt 1971, Bea/Fischer 1970). 
- Ausmerzung dirigistischer Praktiken, 2)

- Vermeldung regressiver Gesamtsteuerbelastung der Einkommen und

- Beachtung der Familienverhältnisse. ${ }^{3)}$

Die erstgenannte Anforderung ist nicht als ein typisch distributives Kriterium anzusehen, ${ }^{4)}$ denn die Gleichbehandlung oder "horizontale Gerechtigkelt" durfte auch allokative Bedeutung haben. Die beiden weiteren Postulate sind im Zusammenhang mit der Forderung $z u$ beurtellen, daB der Handlungsrahmen offen bleiben solle für eine Ausrichtung an Globalzielen der Wirtschaftspolitik unter Hinnahme von Zweckkollisionen (K. Schmidt 1967, S. 403 f.). Dazu ist zu sagen, daB sowohl die Regressionsvermeldung als auch der Familienschutz in der Besteuerung distributiv geprägte Postulate sind; deutlich wird das auch in der Formulierung von K. $-\mathrm{H}$. Hansmeyer $(1974$, S. 136), der als Kern des Leistungsfahigkeitsprinzips die Steuerbefreiung des Existenzminimums (und die Berücksichtigung der persönlichen Situation bel der Steuerbemessung) konkretisiert.

Insofern ist es fraglich, inwieweit ein Rahmenkonzept noch für andere Ziele der Wirtschaftspolitik "offen" bleiben kann; wahrscheinlicher ist, daß ein Rahmen allenfalls zieleinbuBen (in der Allokation, in der stabilisierung) in sich aufnehmen kann. Das sieht auch H. Haller $(1973 \mathrm{~b}$, S. 484) so, wenn er in dem Handlungsrahmen elne strikte, wenngleich sehr allgemeine vertellungspolitische Norm vermutet. Da das unbestreitbar so ist, liegt in dem anschließend darzustellenden Konzept von K. Littmann durchaus Kons equenz.

Es durfte schwierig werden, im Abstecken des distributiv orientlerten Handlungs $-\mathrm{R}$ a $\mathrm{h}$ e $\mathrm{s}$ noch konkreter $\mathrm{zu}$ werden,

2) In seiner Kritik an Schmidt verweist $H$. Haller darauf, daB es uber den Begriff "dirigistisch" kaum $z$ u einer Einigung käme (1973b, S. 484); dieser Elnwand trägt, da ja das Prinzip an dieser Stelle nicht politisch sondern theoretisch mit Inhalt gefullt werden soll.

3) H. Haller kritisiert auch dieses Postulat mit dem Hinweis, daB die Berulcksichtigung von Familienlasten keine steuertypische Forderung sei, da das auch durch Transfers geschehen könne $(1967$, S. 484); dieser Einwand jedoch scheint unerheblich, da auch in der Transferpolitik dann von ebendenselben Normen auszugehen ist.

4) Diesem Gebot schlieBt sich auch G. Krause-Junk an, 1977, s. 353. 
ohne zugleich in das Feld der handfesten politischen Forderungen zu geraten. Allerdings läBt sich denken, daB im Hinblick auf das Existenzminimum die Theorie schon etwas deutlichere Formulierungen $\mathrm{zu}$ bieten hätte, insbesondere, was die Einheitlichkeit der sozialen sicherung in der Steuer- und Sozialpolitik anbetrifft (Einheitlichkeit zwischen dem Grundfreibetrag und den Sozialhilfesätzen). Zum anderen wäre wünschenswert, wenn im Hinblick auf den über dem Existenzminimum liegenden Mehrbedarf, soweit er der eigenbestimmten finanziellen Dispositionsfreiheit entzogen ist, schärfere Konturen entwickelt werden könnten, die noch diesseits konkreter politischer Forderungen theoretisch $\mathrm{zu}$ Aussagen hinsichtlich der Disponibilität über Einkommen kämen. So wäre das Handlungsrahmen-Konzept in seinen Konturen erst dann prägnanter, wenn es zu jener Problematik, die wir die "P e r $s$ n a 1 i s $i$ e $r$ u $n$ g" genannt haben (vgl. $\$ 15)$, konkrete Aussagen machen würde.

b) Orientierungspunkte für die steuerpolitik werden auch aus s t e u e r e c h t li c h e r Sicht z.B. von R. Walz 11980, s. 190 f.) gefordert, der grundsätzlich das Leistungsfähigkeitsprinzip erhalten will, die orientierungspunkte allerdings für den spezielleren Fall der Redistributions- und Progressionsproblematik formuliert. ${ }^{5)}$ Auch wenn K. Tipke $(1981$, S.18; 1991,S.57) das Leistungsfähigkeitsprinzip als ein "sachgerechtes", weil der "materiellen" Gerechtigkeit dienendes Prinzip kennzeichnet, das

5) Danach sind die orientierungspunkte die folgenden:

- Verbot, die gesetzlich bestimmte progressivität durch eine leistungsfähigkeitsirrelevante privatrechtliche Gestaltung zu unterlaufen,

- Auslegung der Steuergesetze im Zweifel so, daB die "dynamische Umverteilungszielsetzung" (dazu zăhlt Walz die Ermöglichung des Vorsorgesparens und der Aus - und Fortbildung) unterstützt oder jedenfalls nicht konterkariert wird,

- Ausgestaltung der Steuergesetze in der Weise, daB verwaltungsökonomische Praktikabilitätsregelungen, die unvermeidlicherweise den Leistungsfähigkeitsgrundsatz beeinträchtigen, dennoch eher eine redistributive Wirkung haben (nach Walz belastet die Einbeziehung der Nutzen aus der eigenen Wohnung eher die oberen Einkommensschichten, wohingegen der Verzicht auf die Einbeziehung der "realen Einkommensteile" häusliche Dienste eher die unteren Schichten begünstigt). 
zugleich eine "Finanzzwecknorm" ist, 6) nach dem sowohl das Existenzminimum als auch die verschiedenen Freibeträge (S. 151) die Leistungsfähigkeit bestimmen, sind damit steuerbelastungspolitische Orientierungspunkte formuliert.

Der Vergleich zwischen den ökonomischen und den rechtlichen orientierungspunkten zeigt eine Ubereinstimmung in wesentlichen $z$ ügen, wobei die unterschiedliche schwerpunktlegung entweder auf die generelle Verteilungs- oder auf die spezielle Umverteilungspolitik verschwindet: dem Verbot dirigistischer Praktiken entspricht das Verdikt privilegierender Gestaltungen; die Vermeidung regressiver Gesamtsteuerbelastung ist in beiden Katalogen zu finden. Die eher "statische" Verteilungszielsetzung, die Familienverhältnisse im gegenwärtigen Lebenszustand $z u$ beachten, wird durch die "dynamische" ergänzt, bestimmte notwendige Aufwendungen für die zukünftige Lebenslage steuerlich anzuerkennen.

c) Zum Rahmenkonzept insgesamt ist zu sagen, daB die Diskriminierungs- und Privilegierungsverbote aus dem Grundsatz der formalen Gerechtigkeit, d.h. aus dem Grundsatz der Gleichbehandlung folgen und nicht eigentlich Inhalt des Leistungsfähigkeitsprinzips (i.s. von Besteuerung nach der "VerhältnismäBigkeit" à la F. Neumark) sind. Die beiden anderen orientierungspunkte des steuerpolitischen Handlungsrahmens (die Regressionsvermeidung und der Existenz- und Familienschutz) liegen nun aber durchaus auf dem Wege zum "V e r $t$ e $i$ l u n g $k \circ n z e p t "$ (das nachfolgend dargestellt wird), da sie beide einen Richtpunkt formulieren, der auch für eine Politik gelten mu, die distributive Steuerlastverteilung und Redistribution $i \mathrm{n} t$ e g $r$ a $t i v$ lösen will.

6) Walz und Tipke unterscheiden sich darin, daB Tipke die Redistribution nicht $z u$ den Finanzzwecknormen, sondern $z u$ den Sozialzwecknormen zählt (1991, S. 20 u. 52); erstere dienen lediglich dazu, den Finanzbedarf zu decken (wir ergänzen: und personal zu verteilen). DaB aber Walz die Redistribution ebenfalls dem Leistungsfähigkeitsprinzip anheimstellt, braucht aus unserer sicht nicht $\mathrm{zu}$ stören: Da nach unserer Auffassung die personale Verteilung der Steuertraglast für die Umverteilung die notwendige Voraussetzung ist, kommen die steuerpolitischen Orientierungspunkte (Existenzminimum, Freibeträge, Progressivität des Tarifs) auch in der Umverteilungspolitik zum tragen. 


\section{S 43 Das "Verteilungs"-Konzept} der besteuerung

I. Die Formulierung durch K. Littmann 596

II. Integrationserfordernisse für einen distributiven Gesamtansatz

III. Das "sozialpolitische Konzept" von A. Wagner als Vorläufer des Gesamtansatzes 599

IV. Skizze eines allokativ-distributiven Entscheidungsablaufs in einem verteilungspolitischen Gesamtansatz

I. Das "Verteilungs"-Konzept der Besteuerung, so wie es K. Littmann (1970, S. $126 \mathrm{ff.})$ formuliert hat, geht davon aus, daB im politischen Raum eine Gerechtigkeltskonvention festgelegt wird, daB das alte Leistungsfahigkeitsprinzip wegen des rekurrenten Anschlusses an die vor der Besteuerung herrschende zufällige Einkommensverteilung eine "gerechte" Steuerlastvertellung nicht herstellen kann und schon deshalb aufgegeben werden muB und daB die Besteuerung einer $G$ e $s a m t k \circ n$ e $t i \circ n z u$ folgen hat, die sowohl die Steuerlastverteilung als auch die Korrektur der Einkommensverteilung $u n \circ$ a $c t u$ regelt und solchermaBen Distributions - und Redistributionsprobleme einheltlich löst. Die Aneutralität der Steuer soll bewuBt zur Erreichung distributiver ziele genutzt werden (S. $127 \mathrm{u}$. 133); fiskalische und auBerfiskalische Zwecke kann die steuerpolitik nur integriert verfolgen (s. 128) und einer zentralen $g$ e $s$ e $l \mathrm{~s} c h$ a $t s p o-$

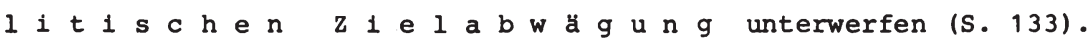
Die Besteuerung ist danach ein wirtschaftspolitisches Instrument (s. 132) und dient - unter Beachtung der Entscheldung für das gewünschte Volumen und die gewünschte Struktur des Angebots an öffentlichen Gütern - der Korrektur mancher Abweichungen von soziobkonomischen Optima (S. 131).

II. Einen Gesamtansatz dieser Art, der sowohl die Gerechtigkeitsorientierung als auch die systemimmanenten Deflzite des Leistungsfähigkeitsprinzips berücksichtigen will, kennzelchnen zumindest drei "i $n$ e g r a $t i v e "$ Aspekte, die auf unterschiedlichen Ebenen liegen und vom Littmann-Ansatz nicht sämtlich erfaBt werden 
(können): erstens die integrative Gestaltung und Beurtellung von Steuern und offentlichen Ausgaben im distributiv-personalen Bereich (a), zweitens die integrative Gestaltung und Beurteilung von Steuern und öffentlichen Gütern (b) und drittens die Ausrichtung der Besteuerung und aller weiteren genannten MaBnahmen an der Gerechtigkeitskonvention (c).

a) Die Roordinierung der personalen Besteuerung mit ö $f$ f e n t $1 \mathrm{i} c \mathrm{~h} e \mathrm{n} \quad \mathrm{A} u \mathrm{~s} \mathrm{~g} a \mathrm{~b}$ e $\mathrm{n}$ ist, soweit es sich um personale Transfers handelt, durchaus zu leisten, zumal für sie eine identische Orientierung an Gerechtigkeitskonventionen gelten soll. Die Konzepte der "negativen Einkommensteuer" folgen im Grunde stets einer solchen Koordinierungsvorstellung. Allerdings wird hier schon deutlich, daB der integrative Lösungsansatz nicht ausschlieblich ein Besteuerungspostulat mehr sein kann, ") sondern ein die Ausgaben mit umfassendes "Umverteilungsprinzip" (G.P. Ziemes 1980, S. 27). Probleme tauchen auf, soweit auch die nichtpersonalen Transfers, d.h. allokationspolitisch motivierte subventionen mit ihren distributiven Effekten in die Gesamtbetrachtung einbezogen werden sollen.

b) Der zweite Aspekt des Gesamtansatzes verlangt eine Entscheidung dahingehend, ob auch die distributiven Wirkungen des Angebots an of $f$ e $n t l i c h$ e $n$ u u $t$ e $r n$ in das "Verteilungs"-Ronzept einbezogen werden sollen. Einige Inzidenzstudien über die Verteilungswirkungen öffentlicher Budgets in der Bundesrepublik Deutschland 2 l können belegen, daß z. zt. einerseits der Umverteilungsumfang sehr gering ist, daB andererseits wegen der verwirrenden Fülle redistributiver Elemente in fast allen offentlichen Projekten eine vollständige Information über die Verteilungswirkungen nahezu unmöglich ist und daB schlieblich - bel relativ plausiblen Uberwälzungshypothesen für die Steuern - die Zurechnungskriterien für öffentliche Leistungen

1) Vgl. unsere Darstellung in $\$ 22$ III mit unserer Kritik am "öffentlichen Lastverteilungsprinzip".

2) Auf die Methodik hinsichtlich der personalen zuordnung, der BezugsgröBen und der Uberwälzungshypothesen in solchen Studien muB nachdrücklich hingewiesen werden, wenn deren Ergebnisse interpretiert werden sollen; siehe U. Wartenberg 1979, K.-D. Grüske 1978 und W. Hake 1972. 
sehr spekulativ sind und kaum $z u$ konkreten Verteilungserkenntnissen führen (U. Wartenberg 1979, S. 237 u. 241). Vorerst wäre somit eine integrative Betrachtung der Verteilungswirkungen von Steuern und öffentlichen Leistungen nicht erfolgversprechend; daher erscheint das von Littmann vorgeschlagene Konzept in seiner Ausrichtung auf die lediglich monetäre Verteilungsstruktur als angemessen.

c) Der dritte Aspekt bringt zum Ausdruck, daß sämtliche Verteilungsmaßnahmen, seien sie solche der Rahmensetzung für die Primärverteilung, ${ }^{3)}$ seien sie jene der sekundärverteilung, auf ein und dieselbe $\mathrm{G}$ e $\mathrm{r}$ e $\mathrm{ch} t \mathrm{~g} \mathrm{k}$ e $\mathrm{t} \mathrm{s} \mathrm{n} \circ \mathrm{r} \mathrm{m}$ ausgerichtet sein müssen. Denn selbst wenn man vor der Besteuerung eine "gerechte" Einkommensverteilung unterstellte und darauf das Leistungsfähigkeitsprinzip anwendete, könnte sie es nachher gerade wegen der Besteuerung nicht mehr sein, folgert G. Myrdal (1963, S. $176 \mathrm{ff.}$. Myrdal, der sich kritisch die Frage vorlegt, welche Gerechtigkeit denn vor und nach der Besteuerung herrschen solle und dazu die "rein finanzielle" Besteuerung E. Lindahls gegen die "sozialpolitische" A. Wagners abwägt, kommt zu dem Ergebnis, "daB es ein fruchtloser Versuch sein muB, ein rein ökomisches Teilproblem von seinem politischen Hintergrund $z u$ isolieren. Der Versuch führt entweder nur $z u$ Tautologien oder $z u$ reiner Willkürlichkeit" (G. Myrdal 1963, S. 178). Daraus läBt sich ableiten, daB erstens grundsätzlich eine Scheidung des Gerechtigkeitsproblems in der Besteuerung nach dem Leistungsfähigkeitsprinzip einerseits und nach der Umverteilungszielsetzung andererseits nicht möglich ist (R. Ulbrich 1975, S. $215 \mathrm{ff.}$ ) und zweitens als Gerechtigkeitskriterium der Verteilungszustand nach der Besteuerung $z u$ gelten hat (R. Ulbrich 1975, S. 155). Der Gesamtansatz Littmanns ist also im Hinblick auf die steuerliche Problematik und auf ihre Verknüpfung mit den distributiven Fragen der Sozialtransfers $z u$ würdigen; diese Würdigung offenbart die Folgerichtigkeit des "Verteilungs"-Konzeptes.

3) Mit dem Vorteil, daB eine gerechtigkeitsorientierte Beeinflussung der Primärverteilung generell den Progressivitätsgrad der Einkommensteuer senkt und dadurch der Sekundärverteilung weniger Verantwortung auflastet, somit auch einen methodischen Vorzug bewirkt, siehe R. Ulbrich 1975, S. 224. 
Auch die Rechtswissenschaft folgt heute z.T. der gesamtgesellschaftlichen Betrachtungsweise in der Besteuerung, und zwar unter ausdrücklicher Abkehr von allen Opfertheorien: Dem Steuerjuristen geht es "um den Grad der gesellschaftspolitischen Priorität der Bedürfnisse", die er durch Ausgestaltung des Progressionsgrades und -verlaufs im Einkommensteuertarif $z u$ treffen trachtet. Von da aus betrachtet erscheint ihm die Progression an sich als juristisch tragfähig (R. Walz 1980, S. 89 u. 155 f.). Nach W. Flume (1974, S. 63) sei das Leistungsfähigkeitsprinzip nicht auf die Nutzenkonzeption $z$ u gründen, es sei vielmehr ein $R$ e $c h t p r i n z i p ;$ die progressionsfrage sei im Rahmen der Rechts- und Wirtschaftsordnung zu lösen (S. 64). Bei jeder Anderung des Steuertarifs habe der Gesetzgeber mit Blick auf den rechtspolitischen charakter seiner Entscheidung zu begründen, "wie seine Anderung des Steuertarifs in Hinsicht auf den bisherigen Rechtszustand als eine bessere Verwirklichung des Rechtsgedankens zu rechtfertigen ist" (S. 67). Worin die Finanzwissenschaft der Rechtswissenschaft wird folgen können, ist die Anerkennung der Bedeutung gesellschaftspolitischer Entscheidungen für die Verteilungsgerechtigkeit und den Tarifverlauf. ${ }^{4}$ )

III. Soweit ausschlieblich Besteuerungsprobleme angesprochen werden, kann in A. Wagner (1890) ein Vorläufer des "Verteilungs"Konzeptes gesehen werden. ${ }^{5)}$ Basierend auf der umfassenden sozialethischen Funktion des Staates nach A. Schäffle (1873, S. 32) geht der Gesamtansatz Wagners aus dessen "sozialer" Funktion der

4) Nach W. Flume (1974, S. 65) betone die Finanzwissenschaft den rechtspolitischen Charakter der Besteuerung nach der Leistungsfähigkeit $z$ u wenig, da es dort üblich sei, über die Progression ohne Bezug auf die geltende Ordnung zu räsonnieren. Flume will auch die Progressionsfrage ohne unmittelbaren Bezug auf die "Gerechtigkeit" lösen. Hier liegen in der Tat Unterschiede $z$ wischen der rechtswissenschaftlichen und der finanzwissenschaftlichen Fragestellung. Letztere will die steuerliche Gerechtigkeitsfrage nicht aus dem Blick lassen und hat sich nicht von vorn herein darauf festgelegt, daB ein progressiver Tarif der allokativ-distributiv gebotene ist.

5) Zur Trennung der Wagner'schen Position und seines "socialpolitischen" Konzeptes von dem der Leistungsfähigkeitsbesteuerung siehe auch F.K. Mann 1937, S. 305 ff. und E.D. Fagan 1938, S. 49 f. 
Steuer hervor, ein "Hebel der Gesellschaftsreform" (F.K. Mann 1937, S. 314) zu sein. Was die theoretische Begründbarkeit angeht, akzeptlert wagner die Plausibilitätsannahmen der Opferkonzepte (S. $444 \mathrm{f.}$ ) und folgert daraus die progressive Besteuerung des "freien Einkommens" (S. 447), ohne daB er aber die nutzentheoretischen Implikationen ubernimmt (S. 446). Den sozialen Aspekt der Progression begrüdet wagner mit der in hoheren Einkommensschichten gröBeren Quote des "freien Einkommens" (S. 456). Letztlich ist für Wagner das Postulat der Gerechtigkeit (S. 458, 485) für die Forderung nach progressiver Besteuerung relevant. Diese Ausrichtung auf die dominierende GerechtigkeitsKonvention, ferner sein Vertrauen in die gesellschaftsreformierende Kraft der Besteuerung, machen ihn $z u$ einem Befürworter des verteilungspolitischen Gesamtansatzes der Besteuerung.

IV. Ausgehend von der Anziehungskraft des distributiven Gesamtansatzes soll abschlieBend versucht werden, den $E$ n $t s c h$ e 1 d u n g s a b 1 a $u f$, der innerhalb eines solchen Konzeptes notwendig wird, zu skizzieren, weil damit wohl am ehesten an den Ansatz von Littmann angeschlossen werden kann. Dabei wird allerdings die gesellschaftlich empfundene Lösungsnotwendigkeit von Verteilungsproblemen einfach unterstellt, was keineswegs bedeuten darf, daB in der Besteuerung stets distributive Probleme die anderen dominieren sollen. Es soll hier nur unter Rationalitätsgesichtspunkten der Weg zuende gegangen werden, der mit dem ziel der Besteuerung nach der Leistungsfähigkeit, die ja ein distributives Problem ist, begonnen wurde. Durchaus diskussionswürdig ist, ob tatsächlich die Besteuerung nach der Leistungsfähigkeit als "Fundamentalprinzip" der Besteuerung bezelchnet werden soll, müBte man ihm doch entnehmen, das distributive sei das Hauptproblem in der Besteuerung schlechthin. Aus Gründen der ausbalancierenden Behandlung wäre diesem Prinzip das allokative der "Motivierung zur Leistungsfähigkeit" zur Seite zu stellen. Es soll aber nicht verkannt werden, daB die Möglichkeiten (und Risiken) der distributiven Besteuerung gröBer sind als die der allokativen, da letztere allenfalls anregend wirken können und auf die Motivation der Besteuerten angewiesen sind, wohingegen die distributive Besteuerung ihre Wirkung aus der Wegnahme von Einkommensteilen 
entfaltet. Die deutliche restriktive Entzugswirkung mag einer der Gründe gewesen sein, dem Leistungsfähigkeitsprinzip diesen besonderen Platz eingeräumt zu haben.

a) Als Ordnungsraster dient uns ein Kontinuum, das von allgemeinen zu spezielleren Problemen übergeht. Angefangen also von qualitativen Entscheidungen, die in der Präferierung des Verteilungsziels begründet liegen und die zugleich zielverzichte auf der allokativen Seite deutlich zu machen haben, kommt man schlieblich zur Festlegung von quantitativen GröBen der Bestimmung der Bemessungsgrundlage und des Tarifs, in denen Verteilungsgerechtigkeit konkret wird, in denen sich letztlich die Umverteilungszielsetzung ausdrücken soll. ${ }^{6)}$

Danach wären - ausgehend von in der Verfassung, in sozialrechtlichen Grundnormen und von den in einer Kulturgesellschaft konvenierten ethischen Grundwerten und dem Gerechtigkeitsempfinden die distributiven und redistributiven Entscheidungen nach dem folgenden logischen Ablaufschema $\mathrm{zu}$ treffen:

(1) Grundsätzliches Anerkenntnis, daB der a 1 l 0 k a $t$ v e Bereich mit seiner Motivation zur wirtschaftlichen Aktivität $\mathrm{V}$ or r a $\mathrm{g}$ vor dem distributiven hat, da er das konvenierte wirtschaftssystem stabilisiert auch die umverteilungsmasse überhaupt erst bereitstellt (siehe auch das Rawls'sche Freiheitsprinzip in "lexikalischer ordnung" vor dem Unterschiedsprinzip, \$4);

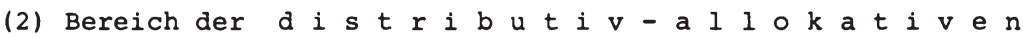
$\mathrm{Z}$ i e 1 a b w ä $\mathrm{g}$ u $\mathrm{g}$ auf der Basis des vorgefundenen konvenierten Verhältnisses von marktlicher und nichtmarktlicher Allokation (Angebot an privaten und öffentlichen Gütern):

6) Wenn Bea und Fischer $(1970$, S. 24) vermuten, daB in der Umverteilungszielsetzung unausgesprochen die Voraussetzung einer standardisierten Nutzenfunktion stecke, so ist dem entgegenzuhalten, daB das keineswegs zwingend so ist; hinter der Umverteilung können auch konkrete Bedarfskonzepte stecken, die allerdings unbestritten ein normatives Element enthalten, siehe hierzu G. Gäfgen 1972, S. 23; er spricht von der "fiktiven Gleichheit genormter Bedarfsbilder". Bedarfe werden nicht an Nutzen gemessen, sondern an der Notwendigkeit von Einkommensverwendungen für die Lebensgestaltung. 
(2a) Ef fi z i e $n z$ e $r$ b e s s e $r$ u g imprivaten Bereich und Gegensteuerung von Allokationsmängeln, soweit diese Maßnahmen geeignet sind, verbesserte Bedingungen für die Primärverteilung $z u$ schaffen (siehe auch die Kritik an der sog. "Marktgerechtigkeit", $\$ 6)$;

(2b) Verbesserung der P r i mär ver t e $i \mathrm{l} n \mathrm{~g}$, soweit sie gleichzeitig effizienzsteigernd und leistungsmotivierend ist; Anerkenntnis einer systemstabilisierenden Wirkung von distributiven MindestmaBnahmen; Anerkenntnis, daB verbesserte Primärverteilung Zurückhaltung in der Sekundärverteilung erlaubt ( $\S 3$ u. 5: Interdependenz); (2c) Einführung von Aspekten der B e d a r f s g e r e c h $t i g k$ e $i t$ dort, wo die reine Leistungsangemessenheit einer gerechtigkeitsorientierten distributiven Grundauffassung zuwiderläuft; zugleich grundsätzliche Anerkenntnis, daB die Bedarfsgerechtigkeit auf einem relativ niedrigen Niveau allokative Vorteile der Effizienzsteigerung haben kann, daB aber ab einem (vorerst noch unbestimmten) höheren Niveau AllokationseinbuBen eintreten können. Anerkenntnis, daB grundsätzlich AllokationseinbuBen aber der gesellschaftlich konvenierte Preis für eine höhere Bedarfsgerechtigkeit sind und in gewissem AusmaB auch sein soll (siehe auch das Rawls'sche Unterschiedsprinzip).

(3) Bereich der d i $s$ r i b u t i e n I n t $r u m$ e $t$ e : (3a) Anerkenntnis, daB für den koordinierten finanz- und sozialpolitischen Instrumenteneinsatz $\mathrm{g} l \mathrm{e} i \mathrm{ch}$ e $\mathrm{B}$ e d a r f $\mathrm{s} \circ \mathrm{rm}$ e $\mathrm{n}$ gelten sollten (Rationalitätsgebot; zugleich Gerechtigkeitsgebot, da verschiedene Personenkreise betroffen sein können);

(3b) Steuerpolitische 0 b je k t i v i e r u n g s 1 e i $s$ t $\mathrm{u} \mathrm{n} \mathrm{g}$ : Entscheidung über die Erhebung bestimmter Personalsteuern und über deren systematisches und belastungspolitisches Verhältnis zueinander, im Hinblick auf die Chancengleichheit, die Leistungsmotivation und die Belastungsfähigkeit der Besteuerten ( $\$ 14$ sowie das 6 . bis 8 . Kapitel); (3c) Steuerpolitische $\mathrm{P}$ e $\mathrm{s}$ s $\mathrm{n}$ a 1 is $\mathrm{i}$ e $\mathrm{r}$ u g s 1 e $i s t$ u $\mathrm{g} I$ : Entscheidung über die die $\mathrm{B}$ e $\mathrm{m}$ e $\mathrm{s}$ - 
$\mathrm{s} u \mathrm{ng} \mathrm{s} \mathrm{g}$ u $\mathrm{n}$ d $\mathrm{l}$ a $\mathrm{g} \mathrm{n}$ der Personalsteuerarten mindernden BedarfsgröBen "Existenzminimum", "Mehrbedarf" und "Disponibilitätsgrade" des Einkommens und Vermögens (Freibetragsprobleme und Probleme der Abzugsfähigkeit, \$ 15);

(3d) Steuerpolitische $\mathrm{P}$ e $\mathrm{r}$ s $\circ \mathrm{n}$ a $\mathrm{l}$ i $\mathrm{s}$ e $\mathrm{r}$ u $\mathrm{g} s$ 1 e $i s t u n g$ II: Entscheidung über den anzuwendenden $\mathrm{T}$ a $\mathrm{r}$ i $\mathrm{f}$ und seine Eckwerte (Nullzonen, ProgressivitätsmaBe, Plafonds; (\$ 15);

(3e) Steuerpolitische I $\mathrm{n}$ d $\mathrm{i}$ i d u a $\mathrm{l}$ is $\mathrm{i}$ e $\mathrm{r}$ u g s 1 e $i s$ t u $g$ : Entscheidung über die $z u$ besteuernde "Einheit": Individuum, Ehepaar, Familie oder Haushalt der zusammenlebenden Personen ( $\$ 16)$.

(4) Bereich der distributiv-allokativen I n $s$ r u m e $n t$ e $n$ und $\mathrm{z}$ i e $\mathrm{l}-\mathrm{R}$ ü $\mathrm{c} k \mathrm{k} \circ \mathrm{p} \mathrm{p}$ e $\mathrm{l}$ u n g (§§ 2, 3 u. 6):

(4a) Grundsätzlich: Anerkenntnis des "t $r$ a 1 a $n d$ e $r$ r $r$ " - Verfahrens im sozioökonomischen Bereich dort, wo feste Uberzeugungen, wie distributive Mindestanforderungen (z.B. ExistenzminimumsgröBen, Sozialhilfesätze, Kündigungsschutz usw.) einer Reversibilität von Instrumenten nicht entgegenstehen;

(4b) Entscheidung über die Akzeptanz des e r $r$ e i c h t e $\mathrm{n}$ G $r$ a $d$ e $s$ an erwünschter Verteilung und Umverteilung;

(4c) Entscheidung über die Hinnahme oder Vermeidung von a $110 k$ a $t i v n$ a $h t$ e $i$ i g e $n$ Effekten der distributiven Politik.

b) Es zeigt sich mithin, daB auch in einem primär distributiv orientierten Besteuerungskonzept das allokative Problem zur Geltung kommt, angefangen vom systemstabilisierenden Vorrang bis hin zu den Rückkoppelungsvorgängen. Die Abkehr von $m \circ d$ e 11 $t h e \circ r e t i s c h e n \quad N u t z$ e $n f i k t i \circ n e n$ und die Hinwendung $z u$ p $\circ$ I $t i s c h$ g e f u n d e $n$ e $n$ B e d a $r$ f $n \circ r m e n$, die der Kern der "Rahmen"-Konzepte wie auch des "Verteilungs"-Konzeptes sind, zwingen dazu, trotz vorherrschendem Interesse am Distributionsziel die allokativen Grundbedingungen und Nebeneffekte mit in den Entscheidungszusamenhang aufzunehmen. Dabei ist ausdrücklich nochmals auf den Entscheidungs- 
schritt (2) hinzuweisen, nämlich auf die vorgefundene gesellschaftlich konvenierte Aufteilung in der marktlichen und nichtmarktlichen Allokation im Bereich der allokativ-distributiven Zielabwägung: das Angebot an öffentlichen Gütern ist durchaus In das Verteilungskonzept einzubeziehen, da solche Güter von den Einkommensempfängern unterschiedlich intensiv genutzt werden und demnach mit distributiven Wirkungen ausgestattet sind; doch ist das Einbeziehen der unterschiedlichen Vorteile aus öf-

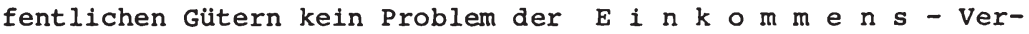
teilung, da es den Vorteilen aus diesen Gütern nämlich am konstituierenden Einkommensmerkmal der Verfügbarkeit und am beschreibenden Merkmal der Konsumorientierung (siehe §§ 11 u. 12) gebricht. Das "Verteilungs"-Konzept macht insoweit also auch seinen Gesamtansatz deutlich, als es über den Einkommensbegriff hinausreicht. Bei der Entscheidung über die individuelle Gesamtverteilungssituation kann also durchaus sowohl die Einkommensverteilung als auch die Vorteilsverteilung simultan beurteilt und "gelöst" werden, sofern verläBliche Angaben für die Vorteilsunterschiede zur Verfügung stehen. ${ }^{7)}$ Einzelheiten der Festlegung von Grundsätzen und der Einigung über die Verfahren werden hier nicht weiter geboten, da sie über das uns gestellte Thema weit hinausreichen.

Es erweist sich überdies, daB das "Verteilungs"-Konzept, will man es umfassend darstellen, einer Theorie der "Personalisierung und Individualisierung der Besteuerung" bedarf, in der sich jenseits aller nutzentheoretischen Vorstellungen die mit den Abzügen, Freibeträgen und Tarifverläufen verfolgten distributionspolitischen Absichten niederschlagen.

c) Eine umfassend ausgestaltete steuerbasis nach dem theoretischen Konzept der Verfügbarkeit über ökonomische GröBen (\$ 11) führt, wenn man es steuerlich umsetzt, direkt in die "comprehensive tax base" nach dem Allgemeinheitspostulat (\$21). Diese ist - neben den Vorteilen für eine allokative Politik - für die distributiven ziele der Steuerpolitik die bestmögliche Ausgangs-

7) Eine Analogie zum Musgrave'schen Wohlfahrtsplan besteht nur prima facie, da dort auf Nutzenkurven rekurriert wird, hier jedoch auf politische Entscheidungen. 
basis und Grundlage. Wegen des Einschlusses auch der Vermögensnutzungen und Vermögenswertzuwächse, aber auch der vermögensbestände ist die Einkommens- und Vermögensbesteuerung dem Konzept der Ausgabenbesteuerung, erst recht dem der "reinen Ausgabensteuer", überlegen. Mithin kann gefolgert werden, daB die Konzepte der Ausgabensteuer mit dem breit angelegten "Verteilungs"Konzept der Besteuerung nicht vereinbar sind. Allzusehr stehen nämlich in den Ausgabensteuer-Konzepten allokative Ziele im Vordergrund. Wegen ihrer unmittelbaren Ausrichtung auf konkrete verteilungspolitische ziele und GröBen sind selbstredend auch die utilitaristischen Realisierungs-Konzepte mit dem VerteilungsKonzept nicht vereinbar.

d) Gerade im allokativ-distributiven Entscheidungsablauf kann das Leistungsfähigkeitspostulat "modale" Funktionen ubernehmen. Es kann näml1ch jenselts aller nutzen- und opfertheoretischen Begrïndungsversuche seine ureigenen Aufgaben behalten. Diese liegen darin, ziel und Instrumente der Besteuerung mit der allgemeinen Ver $t$ e $i l$ u $g s$ - Politik zu koordinieren, um auf diese Weise die Besteuerung als eine geschlossene $k \circ n z$ e $t i \circ n \quad z u$ formulieren. Zugleich besteht die Aufgabe des Postulats darin, neben einer orientlerung auf das Vertellungsziel durch eine Besinnung auf den allokativen Ausgangspunkt des wirtschaftlichen Leistungsprozesses das Vertellungsziel der Besteuerung zu kontrollieren. Denn die Leistungsmotivation und -kraft der güter- und einkommenschaffenden Faktoren muB erhalten bleiben, soll auf Dauer die Ergiebigkelt der Steuerquellen gewährleistet blelben. Dies also ist die Aufgabe des Postulats im Hinblick auf das $z 1$ e 1 . Das Postulat kann $1 \mathrm{n} s \mathrm{t}$ u m e $\mathrm{n}$ e 11 erst konkreter werden, wenn im Bereich der "Personalisierung" der Leistungsfähıgkeit und der Besteuerung bestimte Bedarfsnormen und letztlich die Bemessungsgrundlagen $\mathrm{zu}$ formulieren sind und wenn Im Bereich der "Individualisierung" der Besteuerung zu entscheiden sein wird, ob der Einzelpersonen, dem Ehepaar oder dem Haushalt die steuerlast zuzuweisen, wenn also die "t a $x$ u n $i t$ "festzulegen ist. Im Bereich der "Objektivierung" hat das Postulat die Aufgabe, als orientierungsmaßstab für die Allgemeinheits- und Gleichmäßigkeitspostulate zu dienen, damit sowohl eine "comprehensive tax base" als auch deren Gleichbehandlung bei allen Einkommensempfängern garantiert werden können. 


\section{S 44 zusammentassung des Dritten Teils}

a) Das System der Indikatoren der Leistungsfähigkeit muB in Besteuerungskonzepte integriert werden, denn eine Theorie der Personalsteuern soll über die Definition der Indikatoren hinaus zu Aussagen über die steuerliche Belastung kommen. Dazu sind letztlich auch Aussagen über Tarifprobleme unumgänglich. Trotz der eingangs begründeten thematischen Begrenzung müssen also tarifliche Fragen in diesem zusammenhang zumindest angedeutet werden.

Im Dritten Teil wurde versucht, die Indikatoren Einkommen, Vermögen und Ausgaben derart in einen konzeptionellen zusammenhang zu bringen, daB sowohl die steuerliche Lastverteilungsnorm als auch das ziel der sekundären Verteilung deutlich wird. Der Indikator "Ausgaben" konnte erst hier Konturen gewinnen, da er erstens ein aus Einkommen und Vermögen abgeleiteter ist (siehe das Schema der indirekten Konsumermittlung) und da er zweitens auch in der Literatur stets nur im Zusammenhang mit Besteuerungskonzepten problematisiert wird.

So nimmt die Anordnung der Konzepte folgende Systematik an: Mit den "Nominalismus"-Konzepten geht sie von den Indikatoren der Leistungsfähigkeit aus, greift aber stellenweise auch Tarifprobleme auf (9. und 10. Kapitel). Mit den "Utilitarismus"Konzepten geht sie, ohne allerdings völlig auf die Problematisierung von Indikatoren $z u$ verzichten (\$ 38), nun schon intensiver auf Tarifprobleme ein (11. Kapitel). Die Distributionskonzepte schlieblich (12. Kapitel) nehmen zu den Indikatorfragen kaum noch Stellung, formulieren jedoch nicht ausnahmslos Tarifprobleme, sondern sind - dies allerdings in unterschiedlicher Intensität - auf das Verteilungsziel und das ziel der Steuerlastverteilung ausgerichtet.

b) Die Inhalte der drei Gruppen von Besteuerungskonzepten lassen sich wie folgt zusammenfassen: Für die allokativ-distributive Problematik sind die Konzepte in unterschiedlichem MaBe offen. Die Ausgabensteuer-Konzepte kennzeichnet generell eine besondere Affinität für die allokativen ziele; Sparen als Vermögensbildung und Voraussetzung zum Kapitaleinsatz bleibt 
steuerfrei. Das distributive Problem einer Besteuerung des Vermögensbestandes wird entweder ausgeklammert (\$\$ 33 u. 35) oder nicht $(\$ 34)$. Teils wird versucht, das jenseits von sparen und Vermögensbestand existierende Problem einer distributionspolitisch orientierten Belastung der persönlichen Ausgaben dadurch zu lösen, daB sowohl Ausgaben als auch Einkommen besteuert werden $(\$ 35)$.

c) Die "eigenwillige" Position der Nutzenkonzepte zeigt sich darin, daB sie vorgeben, Steuerlastverteilungs-Konzepte zu sein, sich jedoch des Allokationsmaßes "Nutzen" bedienen. Dies gilt für alle drei Versionen, doch lassen sich darüber hinaus die folgenden Unterschiede erkennen:

Das Individualnutzen-Konzept untersucht ausschlieBlich - im Gegensatz zu den beiden anderen - das distributive ziel der Steuerlastverteilung. Wenn es trotz seiner Unzulänglichkeit hier dargestellt wird, so deswegen, weil die Untauglichkeit jeglichen nutzentheoretischen Ansatzes für Steuerlastverteilungskonzepte nicht eindringlich genug geschildert werden kann; dies trifft sowohl auf die Beziehungen zwischen Einkommen und Nutzen, auf die Abhängigkeit zwischen Nutzen und Steuertarif als auch auf bestimmte allokativ-distributive wirkungen und Abgrenzungen zu, von denen das Konzept ausgeht.

Demgegenüber will das Wohlfahrts-Konzept auch das Problem der vom Individualnutzen-Konzept nicht erfaBten Verteilung der Einkommen vor Steuern einschlieBen, will darüber hinaus die Argumentation auch auf die Ausgabenseite des Budgets erweitern und insoweit ähnlich wie die späteren Fassungen des Äquivalenzprinzips argumentieren, ohne indes die öffentlichen Leistungen direkt und unmittelbar bestimmen zu wollen. DaB es schlieblich scheitert, liegt daran, daB es sein Hauptproblem, "simultane Allokations- und Distributionsentscheidungen" zu treffen, nicht zu lösen vermag.

Das Sozialnutzen-Konzept schlieblich, das Musgrave in dieser Form des "social utility approach" erst später als ein Konzept innerhalb der Theorie der optimalen Verteilung formuliert hat (Musgrave/Musgrave 1980, S. 97 u. 253 f.), verdankt seine Heraus- 
hebung insbesondere den kritischen Einwänden gegen das Individualnutzen-Konzept mit seinen Nutzenmessungs- und vergleichsproblemen. In der von Musgrave präsentierten Form muB es als ein miBgluckter Versuch bezeichnet werden, eine Synthese von Allokationstheorie und Distributionspolitik zu erreichen. Der Sozialnutzenansatz läuft im Grunde - wie z.T. auch der Wohlfahrtsansatz - auf das komplexe Feld einer Theorie der politischen Entscheidungen $z u$ und wird, so z.B. bei E. Sohmen (1976, s. $364 \mathrm{ff.l}$ in einen wohlfahrtstheoretischen Zusammenhang gerückt: politische Entscheidungen über die zu verteilende soziale Wohlfahrt können nicht ohne Reflex auf die "erweiterte Sympathie" eines K.J. Arrow (1963, S. 114 f.: "extended sympathy") bzw. nicht ohne Beachtung der "Gerechtigkeit als FairneB" eines J. Rawls (1975, passim) gewürdigt werden. Im Sozialnutzen-Konzept sind demnach typischerweise die politischen Entscheidungen immer auch Abwägungen zwischen allokativen und distributiven zielen und Wirkungen.

d) In der Gruppe der Distributions-Konzepte (12. Kapitel) versuchen die Handlungsrahmen-Konzepte, Mindestanforderungen der steuerlichen Belastungspolitik zu formulieren, bleiben jedoch unverbindlich. Sie definieren nicht eigentlich den Umfang und den Inhalt der Indikatoren, formulieren also nicht Bedingungen für die steuerliche Basis, sondern für die Bemessungsgrundlage. Denn die Steuerfreiheit für das Existenzminimum und den steuerlichen Schutz für die Familie zu postulieren, bedeutet, die Formulierung steuerlicher Freibeträge und Tarifverläufe zu fordern. Damit aber gehören die Konkretisierungen der Rahmenkonzepte bereits $z$ den in dieser Untersuchung ausgegrenzten "Personalisierungs-" und "Individualisierungsmaßnahmen" der Besteuerung. Das Dilemma, in dem die Rahmenkonzepte stehen, liegt darin, daB sie einerseits das Leistungsfähigkeitspostulat erhalten und lediglich (dankenswerterweise) die nutzentheoretische Begründung aufgeben wollen, daB sie andererseits konkrete Verteilungsziele nicht benennen wollen.

Der entscheidende Unterschied zwischen den Rahmenkonzepten und dem "Verteilungskonzept" ist nun der, daB letzteres die Formulierung der steuerpolitischen ZwischengröBe "Leistungsfähigke1t", die durch ihre traditionsbeladene Bedeutung diskreditiert ist, 
vermeiden will. Eine solche ZwischengröBe erscheint im Zusammenhang mit dem Distributionskonzept insofern nicht notwendig, als über das ziel der Regressionsvermeidung auch oder gerade in der distributiven zielsetzung ohnehin Einverständnis besteht und darüber hinaus bei der Festlegung der steuerpolitischen DistributionsmaBe "Existenz- und Familienschutz" sogar uber die Regressionsvermeidung hinausgegangen wird; denn es kann angenommen werden, daB in jedem Falle $\mathrm{P} r \circ \mathrm{g} r \mathrm{~s}$ i $\circ \mathrm{n}$ s $m a e$ formuliert werden. In diesen Handlungszusammenhang aber wollen sich die Rahmenkonzepte gerade nicht zwingen lassen.

e) Da die Formulierung konkreter und quantifizierter Verteilungszielgrößen zum Inhalt des Verteilungs-Konzeptes gehört, rückt dieses Konzept nun nahezu vollständig in den Bereich der steuerlichen Personalisierung und Invididualisierung. Um für die hier vorliegende Untersuchung, die ja auf den Umfang und den Inhalt der Indikatoren begrenzt wurde, dennoch $z u$ themenbezogenen Aussagen zu kommen, haben wir für die Formulierung verteilungspolitischer Ziele und GröBen einen Entscheidungsablauf skizziert. Diese Entscheidungsablauf-Typik soll verhindern helfen, daB die im Verteilungs-Konzept anvisierten Verteilungsziele völlig absolut gesetzt werden. Der Entscheidungsablauf für distributive Ziele der Besteuerung hat nach unserer Vorstellung von einer Besinnung auf den allokativen Vorrang in der Problematik (Leistungserstellung, Dauerergiebigkeit der Steuerquellen) auszugehen. Auf diese Weise gelingt es uns, die eingangs als Grundlage für eine Theorie der Personalsteuer herausgearbeitete allokativ-distributive Interdependenz bis zum Ende der Untersuchung zu wahren. 


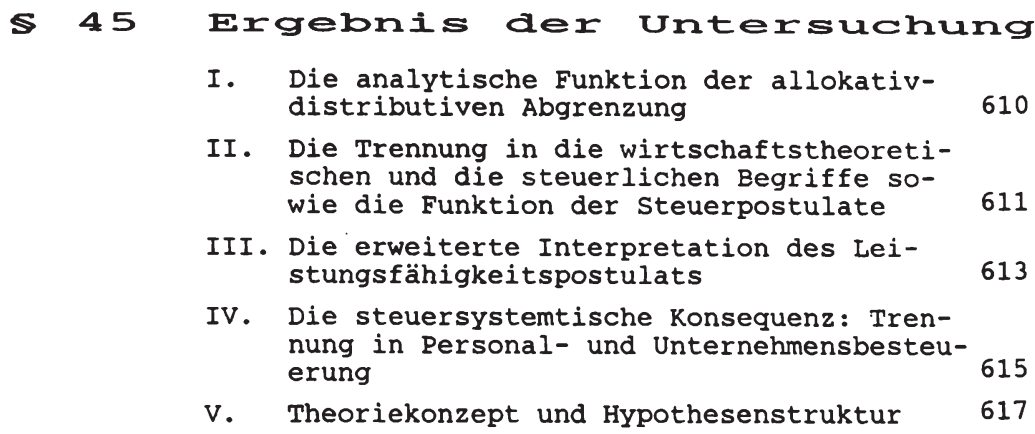

I. Die klare a $l i \circ k$ a $t i v-d i s t r i b u t i v e$ Abgrenzung hat einen realwirtschaftlichen Grund und eine analytische Bedeutung. $R$ e a $l$ w i $t s c h$ a $t ~ l i c h$ unterscheiden sich das produktionswirtschaftliche vom haushaltswirtschaftlichen Aggregat, die Produktions- von den Verteilungszielen und -problemen, realwirtschaftlich kennt man den "efficiency versus equity-trade off". A $n$ a $l y t i s c h$ ziehen wir aus den realwirtschaftlichen Gegebenheiten die Konsequenz, beurteilen wirtschaftliche Entwicklungen und politische MaBnahmen nach ihren allokativen und distributiven wirkungen und Absichten und machen uns letztlich die allokativ-distributive Unterscheidung auch für das Begriffsinstrumentarium zunutze: Wir erkennen, daB die "Objekte", auf die sich die Maßnahmen richten und von denen die Wirkungen ausgehen, in die allokativen (nämlich Kapital und Ertrag) einerseits und in die distributiven (also Vermögen und Einkommen) andererseits zu unterscheiden sind. Wir haben untersucht, ob eine solche Trennung in der literarischen Diskussion um die für die Personalbesteuerung zentralen Begriffe "Einkommen" und "Vermögen" eingehalten wird und kommen zu dem Ergebnis, daB das nur selten geschieht und daB niemals klar die analytische Notwendigkeit dieser Abgrenzung ausgesprochen wird. Zwar kennen die Steuerwissenschaften die termirologische Unterscheidung in die Betriebs- und Privatsphäre, doch werden innerhalb dieser Sphären die allokativen und distributiven Begriffe nicht immer auseinandergehalten. 
II. Die Analyse führt uns zu der Notwendigkeit, die $w$ i $r t$ -

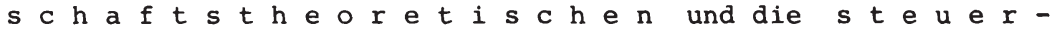
1 i $c h$ e $n$ Einkommens- und Vermögensbegriffe streng auseinanderzuhalten, um der Gefahr zu entgehen, daB steuerliche Interessen bzw. tatsächliche oder vermeintliche belastungspolitisch unerwünschte Wirkungen die Begriffsbildung bereits im "vorsteuerlichen" Stadium verbilden. Es liegt nämlich der Verdacht nahe, daB Einkommensteile, deren Besteuerung man grundsätzlich nicht für opportun oder möglich hält oder die man nicht gerade der Progression unterwerfen will, von vorn herein als Nicht-Einkommen definiert oder "übersehen" werden.

Mithilfe des "Zugangskonzeptes" folgern wir, daB Einkommen und Vermögen aus der wirtschaftstheoretischen sicht nur personale GröBen (die "ad personam-Regel") und zugleich nur GesamtgröBen (die "Totalitätsregel") sein können.

Mit diesem Totalitätsansatz ist aber die steuerliche Erfassung und Belastung keineswegs vorherbestimmt oder festgeschrieben, denn es bleibt dem steuerpolitiker freigestellt, vom Totalitätskonzept immer dann abzuweichen, wenn er das belastungspolitisch für notwendig oder wirtschaftspolitisch für günstig hält. Tatsächlich ist ja auch die Steuerwirklichkeit durch eine Fülle von Abweichungen vom wirtschaftstheoretischen Einkommens- und Vermögensbegriff geprägt, die nicht in allen Fällen rational geboten sind. Die Abweichungen müssen sich somit stets einen Vergleich mit den wirtschaftstheoretisch entwickelten GröBen gefallen lassen, und das ist gerade der Sinn der wirtschaftstheoretischen Begriffsbildung.

Als Kennzeichen des Unterschieds zwischen den wirtschaftstheoretischen und den steuerlichen Begriffen erkennen wir, daB erstere mithilfe des $k r i t$ e $r i$ e $n-A n s$ a $t$ e s (zugang, Verfügbarkeit, Entscheidung) zu entwickeln waren, die letzteren dagegen durch die $s t e u$ e $p \circ s t u l$ a $t$ e ihren Begriffsumfang und -inhalt erhalten. Eine entscheidende Position für die Theorie der Personalsteuern nimmt dabei das Leistungsfähigkeitspostulat ein. In letzter Konsequenz soll es dazu dienen, das steuerpolitische $\mathrm{ziel}$ der personalen $\mathrm{B}$ e $\mathrm{l}$ a $\mathrm{s} t \mathrm{u} \mathrm{n}$ insgesamt zu konkretisieren, d.h. sowohl die Bemessungsgrundlage als 
auch den Tarif zu bestimmen. Wir nennen diese Aufgabe des Postulats die "Personalisierungs"- und die "Individualisierungsleistung". Da wir uns jedoch angesichts des Gesamtkomplexes thematisch auf die "Indikatoren" der Leistungsfähigkeit beschränkt haben, und da die postulate der A 1 l g e m e i n -

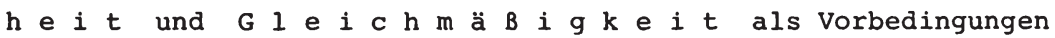
des Leistungsfähigkeitspostulats gelten, steht im Mittelpunkt unserer Untersuchung der EinfluB dieser beiden Postulate auf die Umfangs- und Inhaltsprägung von Einkommen und Vermögen. Wir nennen diese Aufgabe der Postulate die "O b j e $k t i \mathrm{v} i$ e $r u n g s l$ e $i s t u n g "$. In unserem Konzept vom "DreiStufen-System" begründen wir, daB sich solchermaBen noch am besten die Konkretisierungsaufgaben der Postulate beschreiben lassen. Als Ergebnis stellen wir fest, daB zwar von der politischen ratio her die postulate nach wie vor die wesentliche Rolle bei der steuerlichen Begriffsprägung spielen, daB sich aber die steuerlichen Einkommens- und Vermögensbegriffe in der Realität als ein Bündel von Abweichungen vom Allgemeinheitspostulat und als ein "System" von Verletzungen des GleichmäBigkeitspostulats darstellen. Dennoch bleibt die Funktion der Postulate für die Begriffsprägung erhalten. Da diese in den Steuerwissenschaften wie in der Politik akzeptiert ist, können sie als RichtmaBe und Kritikbasis für die praktische steuerliche Begriffsbildung in Anspruch genommen werden. Die Nichterfassung der Zurechnungseinkommen, der Vermögenswertzuwachseinkommen und der Transfereinkommen (\$22) würden sich ohne Rückgriff auf das Allgemeinheitspostulat nicht beurteilen lassen. Wenn man erkennt, daß für eine freie Verfügbarkeit über Einkommen und Vermögen der innerperiodische Verlustausgleich bzw. der Schuldenabzug sowie der Nichtansatz des Humanvermögens notwendig sind, geschieht das mit Blick auf das Allgemeinheitspostulat, damit nicht als besteuerbar erscheint, was keine Verfügbarkeit repräsentiert ( $\$ 23$ ). So ist auch die lediglich inflationsbedingte Erhöhung der Steuerbasis ein Versto $B$ gegen das Allgemeinheitspostulat $(\$ 24)$, da die Geltentwertung die Verfügbarkeit nicht erhöht. Analog ist die Rolle des Gleichmäßigkeitspostulats zu sehen. GleichmäBigkeit der Besteuerung bedeutet Gleichbehandlung ( $\$ 25$ ); die Unterschiede in den Einkunftsermittlungsarten, die in einigen Fällen $z u$ ungleich großen Ein- 
kommensgröBen bei ansonsten gleicher ökonomischer Ausgangslage führen ( $\$ 26$ ), und auch die Unterschiede in den Bewertungsverfahren, die ungleiche Vermögenswerte zur Folge haben (\$27), sind Ungleichbehandlungen, erkennbar nur anhand des Prinzips als solchem.

III. Trotz unserer Konzentration auf die Aufgaben der Allgemeinheits- und GleichmäBigkeitspostulate bleibt die Funktion des

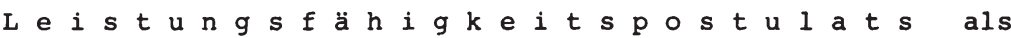
RichtmaB aller Objektivierungsleistungen erhalten. Wie im Dritten Teil der Untersuchung belegt wird, liegt den Konzeptionen der Besteuerung stets die Leistungsfähigkeitsidee zugrunde. Die Analyse der literarischen Diskussion um dieses postulat hat aber ergeben, daB einige Autoren es - weil es sich theoretisch nicht begründen läBt - aufgeben oder zumindest anders interpretieren wollen. Wir konnten nun an früherer stelle darlegen, daB auf dem wege der Umsetzung politischer Absichten vom ziel bis zum Instrumenteneinsatz Postulate oder Prinzipien eine bestimmte Aufgabe übernehmen, die in der zielinterpretation und in der Kontrolle darüber liegt, ob die Instrumente dem ziel jeweils entsprechen. Somit erscheint uns vom grundsätzlichen her die Rolle eines modalen Prinzips vom "moralischen Handeln" ( $\$ 6$, Abschn. II u. III) durchaus sinnvoll, zumal in einem Bereich, der wie die "gerechte Besteuerung" auf Werturteilen und Normen basiert. Jedoch sollten wir uns auch daran erinnern, daB in dem Wort Leistungsfähigkeit das Phänomen "Leistung" als definitorische Basis enthalten ist und daB wir die fehlende Tragfahigkeit dieser Basis bereits offengelegt haben (\$\$ 4-5). Wer also nach der Leistungsfähigkeit besteuern will und dabei davon ausgeht, daB es ja die marktlich erzielte Entlohnung, das Leistungsergebnis ist, das er (um personen- und bedurftigkeitsbezogene Beträge) korrigiert und dem (politisch beschlossenen) Tarif unterwirft, muB in Rechnung stellen, daB die Leistungsentlohnung nicht in jedem Falle tatsächlich entlohnt, was der einzelne leistet. Insofern verspricht allein der Name und der Ausgangspunkt des postulats mehr, als es halten kann. Wenn dennoch das postulat eine Funktion haben soll, so muB man aus der Diskussion um das völlige Abgehen von diesem Prinzip (\$ 43) 
und um seine Erhaltung ( $\$ 42$ ) einige Lehren ziehen: Erstens sollte man es schon eher auf die $v$ e $r$ e $i \mathrm{l}$ u $\mathrm{g} s \mathrm{p}$ o1 i $t i s c h$ e $n$ zielvorstellungen beziehen, also auf den Zielpunkt hin orientieren, wenn sich der Ausgangspunkt (Leistung) als irreal erweist. Aber: Es braucht zweitens überhaupt nicht zu stören, daß die im Nutzen- und opferkonzept (\$\$37-40) gesuchte theoretische Begründung nicht mehr akzeptiert wird. Die politische ZweckmäBigkeit eines Prinzips bleibt erhalten, auch wenn es theoretisch falsch begründet wurde. Dann muB man eben die Begründung aufgeben und eine neue suchen. Wir schlagen - drittens - vor, diese im politischen und im ökonomischen Bereich zu suchen: Was unter würdigung der ökonomischen Verhältnisse und Lebensumstände des einzelnen (unter der strikten Bedingung der fiskalischen Mittelaufbringung) als individuelle steuerliche $B$ e $l$ a $s$ t u n golitisch (verteilungspolitisch) entschieden wird, ist Besteuerung nach der Leistungsfähigkeit. Dabei wird der Konflikt zwischen dem "Individualzweck" und dem "Steuerzweck" des Einkommens und Vermögens (\$\$ 18 u. 19 । politisch ausgetragen. Ob das Prinzip dabei seinen Namen wegen der Affinität $z u$ "Leistung" beibehält, ist eine zweitrangige Frage. Die wesentliche zweite Bedingung ist, daB die verteilungspolitische zielorientierung nicht ohne die Besinnung auf die a 1 $\mathrm{l} \circ \mathrm{k}$ a $\mathrm{i} \mathrm{v}$ e $\mathrm{n}$ Grundlagen einer jeden Besteuerung vorgenommen wird: Bei einer Erhaltung der Rolle des Leistungsfähigkeitsprinzips halten wir es also für unverzichtbar, die Motivation zur persönlichen Leistung, also die "Fähigkeit zur Leistung" und damit die "Dauerergiebigkeit der Steuerquelle", die im Einsatz der produktiven Faktoren liegt, neben der verteilungspolitischen zielorientierung mit zum Postulatsinhalt zu machen. $\mathrm{Zu}-$ gleich wollen wir darauf hinweisen, daB der verteilungspolitische Gehalt nur unvollständig formuliert ist, wenn nicht auf die im Einkommen und Vermögen repräsentierte Kaufkraft(erhaltung) abgestellt wird (s. $\$ 24$ ). Inflationsentwertete Einkommen und Vermögen sind keine verfügbaren GröBen. Das Leistungsfähigkeitspostulat in dieser nunmehr nach zwei Seiten hin erweiterten Interpretation sollte demnach allokative wie distributive Grundbedingungen des Wirtschaftens und der Verfügbarkeit über ökonomische Größen gleichzeitig beachten. Danach kann es weiterhin als personale steuerlastverteilungsregel gelten, dient aber zugleich der zielinterpretation und Instrumentenkonkontrolle. 
IV. Aus der realwirtschaftlichen und analytischen Bedeutung der allokativ-distributiven Abgrenzung sowie aus der Funktion des Leistungsfähigkeitspostulats als personale steuerlastverteilungsregel ziehen wir die folgende $s t$ e u e r s y $t$ e m a $t$ i $s$ c h e Konsequenz: Ein unter diesen Aspekten rationales Steuersystem wäre das einer reinlichen Trennung in "Allokationssteuern", denen die allokative zielsetzung vorbehalten bliebe, von den "Distributionssteuern", die gemäB dem distributiven ziel nach dem Leistungsfähigkeitsprinzip zu gestalten wären. Selbstredend läBt sich diese Vorstellung in der politischen Praxis nicht verwirklichen, denn erstens wäre es vermutlich wegen der allokativ-distributiven Interdependenz äuBerst schwierig, "reine" Allokations- bzw. Distributionssteuern zu konstruieren, und zweitens sprechen die gewachsenen Strukturen des geltenden Steuersystems sowie die politischen und steuerpsychologischen widerstände prima facie dagegen. Und doch sollte - auch in Ansehung der mittlerweile durchgeführten Mehrwertsteuer - und Körperschaftsteuerreform - die Formulierung einer idealen und rationalen Zielvorstellung hinsichtlich des steuersystems nicht gänzlich als chancenlos abgetan werden. Zunächst einmal ist als ein pures Erkenntnisfaktum festzuhalten, daB die Diskussion um die Ausgabensteuerkonzepte offengelegt hat, in welch unterschiedlichem MaBe sich Steuern den reinen allokativen Fragestellungen öffenen (10. Kapitel). Weiterhin hat die Untersuchung ergeben, daB ein grundlegender Unterschied besteht zwischen zielen und Auswirkungen einer $U \mathrm{n} t$ e $\mathrm{n}$ e $\mathrm{h}$ m e $\mathrm{n}$ $\mathrm{b}$ e $\mathrm{s} t \mathrm{e} u \mathrm{e} u \mathrm{n} g$ einerseits und einer Personal-bzw. $\mathrm{H} a \mathrm{u} s \mathrm{~h} l \mathrm{t} \mathrm{s}$ e $\mathrm{s} t \mathrm{e}$ e $\mathrm{r}$ u $\mathrm{g}$ andererseits. Der wichtigste Punkt ist, daB die Unternehmensbesteuerung sich nicht mit dem Leistungsprinzip vereinbaren läßt (\$20). Weder kann man mit den "Disponibilitäts"- noch mit den "Organisationsargumenten" beweisen, daB Unternehmen wie die Privatpersonen leistungsfähig sind; betrachtet man sie gleichwohl als "steuerfähig", was sie durchaus sind, so sind sie dies allenfalls nach den Vorstellungen der "Ertragsfähigkeit", nicht der Leistungsfähigkeit (Exkurs III).

Wir konnten darlegen, daB es Besteuerungskonzepte gibt, in denen die Unternehmensbesteuerung sich durchaus von der Haushaltsbesteuerung völlig abkoppeln läßt (siehe die Ausgabenbesteuerung). 
Die Frage ist nur, ob das geltende System der Ertrags- und Einkommensbesteuerung diese Abkoppelung erlaubt. Wie die Untersuchung ergibt, läge der Vorteil eines Aufbrechens dieses "Mischkonzeptes" ( $\$ \$ 18$ u. 19 sowie das 8. Kapitel) klar auf der Hand: Die Verwechslung des betrieblichen Ertrages mit dem persönlichen Einkommen, des betrieblichen Kapitals mit dem persönlichen Vermögen wäre endlich unterbunden; der Betriebsertrag oder -gewinn könnte so besteuert werden, wie es seiner ökonomischen Funktion und der allokationspolitischen Zielsetzung entspricht, ohne daB er kraft des "Ubertragungseffektes" Ungleichbehandlungen unter den Einkommensbeziehern, die teils Unternehmer, teils Nichtunternehmer sind, hervorriefe (\$\$ 26 u. 27). Auch das Totalitätskonzept des Einkommens lieBe sich verwirklichen, weil in die steuerliche Definition des Einkommens keine betrieblich orientierten Bewertungsfreiheiten und Aufwandsgestaltungen mehr hineinspielen würden. Dies wäre der distributionspolitische Vorteil in der Personalbesteuerung. Sollen die Unternehmen aus fiskalischen Gründen besteuert werden, hätte das nach ihrer Ertragsfähigkeit zu geschehen; desgleichen, wenn sie aus allokationspolitischen Gründen besonders schonend oder besonders belastend besteuert werden sollen. Der letztere Fall bedürfte eigener Begründung, da er den Faktoreinsatz und die Produktion mutwillig verteuerte. Die gegenwärtige Praxis wie auch die theoretischen Konzepte der Unternehmensbesteuerung (Exkurs III) lassen den SchluB zu, daB die Notwendigkeit einer allokativ-distributiven Abgrenzung in Analyse und Steuerpraxis nicht erkannt sind. Nur so kann erklärt werden, daB die präzise Argumentation bei Böhm-Bawerk und in der Betriebsteuerdiskussion ( $\$ \$ 7 \mathrm{u} .8$ ) vollends verschüttet ist. So münden unsere Untersuchungsergebnisse in die Aufforderung, die Diskussion um den Einkommensbegriff und um die Unternehmensbesteuerung fortzusetzen. DaB man damit auch zu einer klareren Einstellung gegenüber der Personalbesteuerung kommt, dürfte nach allem fraglos sein. 
V. Wie in $\$ 11$ (Punkt V: "Rationalität und Theorie-Inhalt") näher dargelegt, betrachten wir die vorliegende Untersuchung als einen Beitrag $z u$ theoretischen Aussagen "mit eingeschränkter Reichweite", als einen Beitrag zu der alleinigen Absicht, $\mathrm{B}$ e $\mathrm{g} r \mathrm{i} f \mathrm{f}$ in Inhalt und Umfang, möglicherweise auch in ihrem Zustandekommen zu erklären. Die Fassung der wirtschaftstheoretischen Einkommens- und Vermögensdefinitionen, die wir in $\$ 11$ ("Fazit 2") formuliert haben, wie auch die Analysen $\mathrm{zu}$ den steuerlichen Einkommens- und Vermögens-Begriffen im Zweiten Teil, insbesondere im 6. Kapitel, können und sollen sich demnach nicht auf die Erklärung und die Voraussage individuellen Verhaltens der Einkommensbezieher und Vermögensbesitzer erstrecken.

a) Insofern werden auch die von Th. S. Kuhn (1978, S. 422 ff.) formulierten "Eigenschaften" für die Theoriewahl nur teilweise für unsere bescheideneren Absichten zutreffen. Um einen möglichst umfassenden Beschreibungsansatz in der Theoriewahl zu gewinnen, hält Kuhn insbesondere die folgenden Eigenschaften für wichtig: (1) die Tatsachengerechtigkeit, da von der quantitativen und qualitativen Tatsachenkonformität die Erklärungsund Voraussagekraft abhängt; (2) die gröBtmögliche Reichweite mit Beschreibung aller Konsequenzen; (3) die Einfachheit, die je für sich als verworren Existierendes ordnet und zusammenhänge aufzeigt; (4) die Widerspruchsfreiheit in sich sowie die Verträglichkeit mit anderen $z$. Zt. anerkannten und verwandten Theorien und (5) die Fruchtbarkeit, die neue Forschungsergebnisse aufzeigt und ordnet oder bisher unbekannte Beziehungen zwischen bekannten Erscheinungen aufdeckt.

Die erste Eigenschaft erachten wir als für unser Vorhaben nicht zutreffend, da eine begrifflich intendierte Theorie sich dem Erfordernis der Kuhn'schen Tatsachenkonformität verschliebt. Wenn wir unser Vorhaben zweitens als ein solches mit begrenzter Reichweite klassifizieren, so erreichen wir zwar nicht die Kuhn'sche zweite Eigenschaft, jedoch wurde unser Vorhaben innerhalb des von uns abgegrenzten Untersuchungsbereichs mit äuBerst tiefgreifender Intensität durchgeführt, wie die umfänglichen Analysen gerade im zweiten Teil der Arbeit belegen. Es war unsere Absicht, ein lückenloses system aller mit den steuer- 
postulaten zusammenhängenden Einflüsse (Realisierungen wie VerstöBe) auf die Einkommens- und VermögensgröBen vorzulegen. Zur dritten Eigenschaft, der Einfachheit, haben wir eine zwiespältige Einstellung: Soweit die Materie komplex ist, versuchten wir, sie anhand der Ubersichten und schaubilder in ihren Bestandteilen und Zusammenhängen deutlicher zu machen und so zu ordnen, daB sie zwar übersichtlich, aber gerade nicht ungebührlich vereinfacht erscheinen; in gewisser Weise widerspricht die Darstellung vielfältiger Zusammenhänge der Einfachheit, wohingegen die Anfertigung von Ubersichten der Einfachheit entgegenkommt. Eine Einfachheit im Kuhn'schen Sinne sehen wir allerdings in dem von uns benutzten Analyseinstrument der allokativ-distributiven Abgrenzung.

Zur vierten und fünften Eigenschaft, der Widerspruchsfreiheit und der Fruchtbarkeit, können wir uns selbst nur insoweit äuBern, als wir die Absicht hatten, sie zu verwirklichen. Dies wird sich erweisen müssen. Die Verträglichkeit mit anerkannten bzw. verwandten Theorien, die Kuhn verlangt, darf man selbstverständlich nur auf dem Felde solcher Theorien erwarten, die ein Erklärungsinteresse haben, das der hier versuchten begrifflichen Theorie "verwandt" ist. Zur Fruchtbarkeit begnügen wir uns mit dem Hinweis, daB wir hoffen, die in den vorgenannten Punkten I bis IV dieses Paragraphen hervorgehobenen Ergebnisse als bedeutsam genug ausgewiesen und ausreichend abgesichert zu haben. ${ }^{1)}$

b) Es bietet sich die Frage an, wie es zu erklären ist, daB sich die Eigenschaft des steuerlichen Einkommens und Vermögens gerade an den vielfältigen Verstößen ausgerechnet gegen jene Postulate herausbildet, die den idealtypischen Inhalt der Begriffe ausmachen. Bereits im 6 . Kapitel hatten wir einige hypothetische Ansätze mit dem "Individualzweck" und dem "Steuerzweck" des Einkommens bzw. Vermögens in Verbindung gebracht, um $\mathrm{zu}$ belegen, daB wir keine Hypothesen über das Verhalten der Einkommensbezieher und Vermögensbesitzer planen, sondern solche, die die Entscheidungs- und Handlungsweisen derer betreffen, die steuerliche Begriffe "machen", nämlich der Steuerpolitiker. Zum "zweckbezogenen Einkommensbegriff" (\$ 18 IV) hatten wir sinngemäB ausgeführt: Die Geschichte der interventionsausdehnenden

1) am Ende vople $\{$-45 5 essler and Anneliese Hessler-Otte - 978-3-631-75239-5 
Staatstätigkeit belegt, daB der staat, sofern der Individualzweck des Einkommens auch nur halbwegs gewährleistet ist, seine Möglichkeiten zur engeren oder weiteren Definition von Einkommen so ausnutzt (also seinen steuerzweck so verfolgt), wie es in seine interventionistischen steuerpolitischen Pläne paBt. Und zum steuerlichen Vermögensbegriff ( $\$ 19$ IV) hatten wir gesagt: Angesichts der geschichtlichen Erfahrung mit Geldentwertung und Vermögensverfall, aber auch angesichts der verfassungsmäBigen Eigentumsgarantie ist die Einstellung der Politiker zum Vermögen und seiner Besteuerungsmöglichkeit "ambivalent"; einerseits wünschen sie aus mancherlei Gründen eine Vermögensumverteilung, andererseits haben sie nie den Mut aufgebracht, dazu die Vermögen- und Erbschaftsteuer zielentsprechend umzugestalten; ganz im Gegenteil lieBen sie trotz der merklichen Geldentwertung den Kaufkraftverfall für bestimmte Bevölkerungsgruppen tatenlos $\mathrm{zu}$, ohne zugleich vorhandene aktive Vermögensbildungspläne in die Tat umzusetzen.

Wir können darüber hinaus nur vorsichtig "singuläre Hypothesen" (H. Seiffert 1975a, S. 153) formulieren, wobei wir für die ersten drei die Autorenschaft keineswegs beanspruchen, denn allzusehr sind sie mittlerweile herrschende Meinung geworden:

(1) Wie das Leistungseinkommen, bildet sich auch der steuerliche Einkommensbegriff als das Ergebnis eines Verteilungsstreites zwischen den gesellschaftlichen Gruppen, als deren Vertreter die Politiker gelten können. (2) Die jeweils gefundenen steuerlichen Definitionen reflektieren die unterschiedliche Einstellung der Gruppen und Politiker gegenüber dem "efficiency versus equity-trade off". (3) Mehr und mehr zeigen sich die Ergebnisse der Gruppeneinflüsse in der "Auswahl" und der "Verunstaltung" der steuerbasen und steuerbemessungsgrundlagen. Sie haben offensichtlich die gröBere Anziehungskraft als die Gestaltung der Tarifverläufe, da sich in ihnen die gruppenspezifischen "Gestaltungen" besser und unauffälliger unterbringen lassen. Dies gilt nicht nur für die Personalsteuern, sondern auch für die Sozialabgaben.

Aufgrund unserer eigenen Analysen zum Individual- und Steuerzweck des Einkommens bzw. Vermögens unterstützen wir diese 
Hypothesen und fügen die folgenden an, die sich allerdings auf die Begriffs- und Theoriebildung erstrecken, ihren Einfluß auf die Steuerpolitik aber nlcht leugnen können:

(4) Da wir in der geltenden Einkommensteuer ein "gemischtes" Konzept verwirklicht sehen, das sowohl die Gewinnbesteuerung des Einzel-, Mit- und Personengesellschafts-Unternehmers als auch zugleich deren persönliche Einkommensbesteuerung regelt, schlagen allokationspolitische steuerinterventionen auch auf die distributive Lage der Unternehmer durch, was nicht zieleffizient ist, da das zumeist nicht den distributiven zielen entspricht. Es läBt sich kallm ausmachen, ob dies von den Steuerpolitikern so gewollt ist. (5) Es gibt kaum noch eine allokationspolitische Intervention ohne die "obligatorische soziale Komponente", weil wir das genannte gemischte Konzept realisiert haben. Auch dies ist ziel-ineffizient, weil die Komponenten allokative ziele konterkarieren. (6) Das geltende Einkommensteuerrecht kennt keine allgemeine Einkommensdefinition, sondern begnügt sich mit einer erfassungs-ineffizienten Aufzählung einzelner Einkunftsarten. Begründet wird dies mit dem Fehlen einer anerkannten Einkommenstheorie. Es erfolgt in diesem $\mathrm{Zu}-$ sammenhang stets der Hinweis auf die einander ausschlieBenden Quellen- und Reinvermögenszugangstheorien. Wir haben in $\$ \$ 7$ und 8 nachgewiesen, daB diese Theorien keine wirtschaftstheoretischen Einkommensbegriffe intendieren, sondern steuerliche, und daB sie zudem wegen ihres Erfordernisses der Kapitalerhaltung "allokationsdominiert" sind. Das macht sie tatsächlich für einen allgemeinen Einkommensbegriff untauglich. So fehlt dem Steuergesetz zwar eine allgemeine Theorie, aber aus anderen als den stets angeführten Gründen. (7) DaB keine steuerliche Theorie des Einkommens und Vermögens entwickelt wurde, liegt nach unserer Auffassung an der bisher nicht verwirklichten allokativ-distributiven Abgrenzung. Diese ist für die Analyse wie für die Theoriebildung gleichermaßen unumgänglich. Aus einer solchen Abgrenzung würde sich klar ergeben, daB man Gewinne und Einkommen nicht gleich behandeln kann, daB man Unternehmen nicht wie Privatpersonen besteuern kann und daB bei einer klaren Abgrenzung die Chance für die zieladäquate Besteuerung des $\mathrm{E} i \mathrm{n} \mathrm{k} \circ \mathrm{m} \mathrm{m} \mathrm{n} s$ gröBer ist. (8) Die Klage über das Fehlen eines allgemeinen Einkommensbegriffs und über 
das Fehlen einer Theorie übersieht, daB zwischen einem wirtschaftstheoretischen und einem steuerlichen Einkommen zu trennen ist. Letzteres ist politisch bestimmt. Soll das steuerliche Einkommen "zieloffen" in der Weise sein, daB es jede Art von distributiv gemeinter Einengung oder Ausdehnung (\$ 18) erlaubt, so muB es von vorn herein zunächst einmal ein Totaleinkommen sein. Uber seine Belastung kann dann immer noch in Form von Abzügen entschieden werden. Diese Eigenschaft des steuerlichen Einkommens als "comprehensive tax base" (\$21) erreicht man am ehesten, wenn man es stets an dem wirtschaftstheoretischen Einkommensbegriff messen kann, der nach dem Kriterien-Ansatz gebildet ist (\$ 11 ).

c) Die Formulierung einer "Theorie der Personalsteuern" ist mit den hier vorgestellten begriffstheoretischen Elementen selbstredend nicht vollständig zu leisten. Wie aus der thematischen Abgrenzung ( $\$ 1$ ) hervorgeht, hatten wir uns hier auf die Analyse der Einkommens- und Vermögensbegriffe zu beschränken, auf jene Indikatoren also, die in der Lage sind, die Leistungsfähigkeit des einzelnen zu "objektivieren" ( $\$$ 14). Eine vollständige Theorie der Personalsteuern wäre zu erweltern um die Gebiete der "Personalisierung" und der "Individualisierung" von Leistungsfähigkeit, deren Grundfragen wir in den $\S \S 15$ und 16 zumindest andeuten konnten. Solche Theorien gehen über die hier vorgelegte deswegen hinaus, weil die Personalisierung (in Form von steuerlichen Abzügen von der Bemessungsgrundlage wie in Form von progressiven Tarifen) und weil die Individualisierung (als Entscheidung über die Besteuerungseinheit Individuum, Ehepaar oder Haushalt) nicht ohne Bezug zu den Verhaltensweisen der Steuerpflichtigen und $z u$ den Wirkungen der Steuerprogression $z u$ formulieren ist. In solchen Theorien muB also die Fortsetzung der hier begonnenen Untersuchung gesehen werden.

1) H. G. Johnson, Recent Developments in Monetary Theory - A Commentary, in: D.R. Croome and H.G. Johnson (Hg), Money in Britain 1959-1969, London 1970, S. 86: "The crucial principle is that the test of a good theory is its ability to predict something large from something small ..." Wenn also aus wenigem viel abgeleitet werden soll, so sehen wir das "wenlge" in dem elnfachen Prinzip der allokativ-distributiven Abgrenzung, das "viele" in den steuerlichen Folgen und Wirkungen elner getrennten Personal- und Unternehmensbesteuerung. 
Heinz Hessler and Anneliese Hessler-Otte - 978-3-631-75239-5 Downloaded from PubFactory at 01/11/2019 06:44:50AM via free access 
A $\quad \mathbf{N}$ H A $\mathbf{N}$ G

Exkurs $I=$

Exläuterungen zur Ưbersicht 3.2 "Arten una euellen des zugangs an ökonomischen Größen" in 58

Ubersicht 3.2 ist auf den Totalnachweis aller geld- und güterlichen Zugangsarten sowie auf den Totalnachweis aus sämtlichen denkbaren Zugangsquellen (aus dem Ertrags-, dem Vermögens- und dem Transferbereich) angelegt. Die Systematik dieser Arten- und Quellen-Matrix wird anhand von zwei Einteilungen geprüft, die jüngst von W. Albers (1979a, S. 197-201) und N. Andel,1979a,S.337355) vorgelegt worden sind. Ubereinstimmungen und auch Unterschiede zwischen diesen Systematisierungen sollen nachfolgend dargelegt und für das Schema der Zugangsarten und -quellen nutzbar gemacht werden.

W. Albers weist vier Einkommensbestandteile bzw. Einkunftsartengruppen aus: (a) Geldeinkommen, (b) Naturaleinkunfte und geldwerte Vorteile aus der Nutzung von Vermögen, (c) Ubertragungseinkommen und (d) Vermögensveränderungen. Die Naturaleinkommen sind güterliche Einkommen (Deputate, freie Kost und Station usw.) ${ }^{1}$ ebenso wie die Vermögensnutzungen. So enthält die Aufzählung sowohl eine Trennung in die beiden geld- und güterlichen Einkommensarten als auch einen Katalog der Einkommensquellen, wie die (marktliche und nichtmarktliche) Faktorentlohnung, die Elnkommen aus dem Transferbereich sowie jene aus dem Vermögensbereich.

Die sieben Einkommensbestandteile von N. Andel lassen sich in Art und Quelle ebenfalls wie oben gruppieren, lauten aber zunächst wie folgt: (a) Bruttonominalentgelte für Marktleistungen, (b) Bruttonaturalentgelte für Marktleistungen, (c) zugerechnete Einkünfte, (d) Wertzuwächse, (e) Erbschaften und Geschenke, (f) Glücksspiel-

1) Ferner: die Entnahme von selbst hergestellten Gütern für den Verbrauch im eigenen Haushalt; die Verwendung von selbst hergestellten Gütern für die Produktion im gleichen Betrieb; die nicht uber den Markt entlohnte Wertschöpfung im eigenen Haushalt und der Einsatz von nicht entlohnten familieneigenen Arbeitskräften im eigenen Betrieb; letztlich die Verzinsung des Eigenkapitals, das in selbst genutzten Vermögensgegenständen investiert ist. 
gewinne und (g) Lohnersatzleistungen und Unterstützungen. 2) Auch in diesem Katalog läBt sich eine Gruppierung wie oben dargestellt wiederfinden, nämlich eine Trennung in geldliche und güterliche Einkommensarten sowie in verschiedene Quellen aus dem Bereich des Faktoreinsatzes, der Transfer und des Vermögens.

Die Einteilung der Ubersicht 3.2 nimmt diese Gruppierungsmöglichkelten sowie die Trennung in Arten und Quellen des Einkommens auf; sie vollzieht somit zunächst die Dreiteilung der Quellen in einen allokativen Bereich des Faktoreinsatzes samt seiner Entlohnung, in einen Bereich des Vermögens, und zwar sowohl des gegenständlichen Zugangs von Vermögen als auch seiner Nutzungen ${ }^{3)}$ sowie in einen (distributiven) Bereich der Transfers. Innerhalb eines jeden dieser Bereiche wird elne Trennung in die belden geld- und güterlichen Einkommensarten vorgenommen. Dies u.a. auch deswegen, um klar auszuweisen, daB das Problem der Zurechnung sowie auch das des Wertzuwachses allein im güterlichen Sektor auftreten können.

Da hinsichtlich der Transfers keine wesentlichen Interpretationsund systematisierungsunterscheidungen auftreten, $\left.{ }^{4}\right)$ sind die folgenden Punkte erklärungsbedürftig: das marktliche Leistungs- und Entlohnungsproblem, das Zurechnungsproblem und das Vermögensproblem.

N. Andel diskutiert sowohl die nominalen als auch die naturalen Faktorentgelte als Entlohnungen für Marktleistungen; das Marktliche liegt in der $\mathrm{L}$ e i s $\mathrm{u} \mathrm{n} \mathrm{g,} \mathrm{d.h.} \mathrm{im} \mathrm{Faktorangebot.}$

2) Die Reihenfolge wurde von uns in der Welse geändert, daB c-f als zum Bereich des Vermögens gehörende Tatbestände hintereinander auftreten. Der gesonderte Ausweis von (f) Glücksspielgewinnen bei Andel läBt sich aber auch als Ausweis von elnmaligen Einnahmen interpretieren, womit die Aufzählung eine Sonderstellung einnähme, da andere diese Einmaligkeit nicht aufführen; zum Charakter der Einmaligkeit vgl. die schon 1957 von Albers vorgetragene Kritik, S. 67.

3) Dies ist der distributive Bereich I; distributiv, well die Trennung in Kapital und Vermögen bereits oben begrundet wurde.

4) Sie werden von Albers und Andel vorwiegend unter steuerlichem Aspekt gesehen, wobei Albers die tatsächliche Verfügbarkeit uber Transfers betont; demgegenüber will tbersicht 3.2 den maximalen Umfang von Transfers ausweisen und anhand dessen die Einkommenseigenschaft generell überprüfen. 
Auch Entlohnungsarten, die nicht über den Markt erfolgen, wie solche als Gewährung von Werkswohnungen, Kantinenessen, Deputate usw., sind Entgelte für Marktleistungen. Lelstet demgegenuber jemand nicht uber den Markt, sondern "an sich selbst", müssen ihm Einkünte "zugerechnet" werden.

Dagegen sieht $\mathrm{W}$. Albers das Geldeinkommen nicht aus dem Blickwinkel der Leistung, sondern aus dern der $E \mathrm{n} t \mathrm{l}$ o h $\mathrm{n}$ u $\mathrm{n} g$; diese unterteilt er in die geldliche und die naturale; letztere geschieht nicht-marktlich.

In Ubersicht 3.2 wird nun dem Gedankengang von W. Albers insoweit gefolgt, als dort auf die Entlohnungsweise abgestellt 1st, die innerhalb des allokativen Berelchs erfolgt; die Trennung in den geldlichen und den güterlichen Zugang erfordert es, nur den ersteren als Markteinkommen, als Bruttonominaleinkommen im Sinne Andels, $z u$ bezeichnen (besser: Bruttomonetäreinkommen als Gegensatz zu -naturaleinkommen). zum güterlichen zugang werden Andels Bruttonaturalentgelte, aber auch Albers' vielfältige Entnahme- und Selbstverbrauchsformen gezählt; sie geschehen aber im Gegensatz zu Andel - ausnahmslos nichtmarktlich, wenngleich das Faktorangebot marktlich erfolgen mag, z.T. aber auch nichtmarktlich, wie z.B. bei Albers' Entnahme- und Verwendungstatbeständen sowie beim Einsatz familieneigener Arbeitskräfte im eigenen Betrieb. Aus der rein güterlichen Betrachtung dieser Entlohnungen folgt, daB sie sämtlich zum Gegenstand des sog. Zurechnungsproblems gemacht werden.

Als Zurechnungsproblem sleht aber $W$. Albers nur die Tatbestände der "geldwerten Vortelle aus der Nutzung von Vermögen" an, nicht die Naturaleinkünfte, obwohl ja letztere der marktlichen zurechnungsregel entbehren. ${ }^{1}$

Demgegenuber sind bei $\mathrm{N}$. Andel sowohl die Einkünfte aus der Vermögensnutzung als auch die Naturaleinkünfte für entnommene Güter und Dienste zuzurechnende Einkünfte, nicht hingegen die naturalen Entlohnungen, die - wie erwähnt - Entlohnungen für Marktleistungen

5) Zumindest geht aus seiner Uberschrift auf S. 197 "Naturaleinkünte und $z$ u $r$ e $c h n$ u $g$ von geldwerten vortellen ..." nichts anderes hervor; Hervorhebung HDH; die weiteren Ausfuhrungen befassen sich dann ausschlieblich mit den Bewertungsproblemen. 
sein sollen. 6) Die zwischen Albers und Andel $\mathrm{zu}$ vergleichenden Entlohnungs-, Verbrauchs-, Entnahme- und Nutzungstatbestände sind nicht einheitlich und erschweren die eindeutige Abgrenzung. Es wird deshalb in Ubersicht 3.2 auf eine Trennlinie mitten durch die nichtmarktlichen Tatbestände verzichtet. Weder Albers noch Andel diskutieren die Einkommenseigenschaft der Arbeitgeberantelle zur Sozialversicherung, wohl weil sie steuerlich nicht als Einkommen gelten. In der Literatur werden diese Antelle aber z.T. als nicht ausbezahlter Arbeltslohn definiert. Soweit dies geschieht, müssen sie in Ubersicht 3.2 in der Position $A / G E$ (a) erfaBt werden. Ihr zugang ist ebenso wie die vom Betrieb einbehaltende Lohnsteuer ein "fiktiver" beim Einkommensbezieher. Das zugangsprinzip erfordert jedenfalls die Erfassung dieser Anteile als personales Einkommen.

Im weiteren wird danach unterschieden, ob die Zurechnungstatbestände solche mit einer Bindung an das Vermögen oder solche ohne diese Bindung sind; letztere werden als zurechnungstatbestände im allokativen Bereich ausgewiesen, da sie aus dem Faktoreinsatz hervorgehen. Auf eine Trennung in marktliche und nichtmarktliche Vorgänge wird verzichtet. Die Faktorentlohnung ist einerseits als Entlohnung und Entnahme möglich; dies sind die "Natural-zugänge", vgl. A/GU1 in tbersicht 3.2. Andererseits ist die Faktorentlohnung auch in Form von in der Unternehmung verbleibender Kapitalakkumulation denkbar, somit als "Kapital-zugänge" bezeichnet, vgl. A/GU2 in Ubersicht 3.2 .

6) Als zuzurechnende Einkünfte diskutiert Andel: (a) den Nutzungswert des vom Eigentümer genutzten Vermögens (wie Wohnung, Auto, Hausrat), (b) entnommene bzw. selbst erstellte Güter und Dienste (im Einzelhandel, im privaten Haushalt und in der Landwirtschaft) und (c) die Freizeit.

7) So ist z.B. dem Katalog der Naturaleinkünfte und Vorteile aus der Vermögensnutzung von Albers nicht genau zu entnehmen, wo die Trennlinie zwischen beiden verläuft; während Naturalentlohnungen, Eigenverbrauch und Selbstverbrauch noch als Naturaleinkünfte gelten können, vermutet man dieses auch hinter der Bezeichnung "nicht über den Markt entlohnte Wertschöpfung im eigenen Haushalt", sofern man an die Hausfrauenarbelt denkt; doch dann erfährt man, daB zu dieser Wertschöpfung auch die Nutzung der Wohnung im eigenen Haus gehört, die man eher als (zuzurechnende) Vermögensnutzung erwartet hätte. 
Zurechnungsprobleme treten aber auch in Verbindung mit dem Vermögen auf, und diese sind - gemäB der mehrfach gegebenen Begründung - im distributiven Bereich auszuweisen. Hier kann es sich zum einen um die Nutzung des Sachvermögens handeln, werde dieses nun durch das selbst akkumulierte oder das erworbene Vermögen repräsentiert oder durch nicht realisierte Wertvermögenswertzuwächse, vgl. DI/GU1 in Ubersicht 3.2. Zum anderen kann es auch die Nutzung des Human-Vermögens betreffen, vgl. DI/GU2 der Ubersicht 3.2. Mithin erfaBt das Zurechnungsproblem den gesamten nichtmonetären Bereich der "Allokation" und der mit vermögen verbundenen "Distribution I" und dürfte damit einen gröBeren Umfang aufweisen als bei Albers und Andel dargestellt.

Das Vermögensproblem ist mit einigen Bemerkungen zu versehen: Ungeachtet bestimmter Einteilungen in Vermögensarten ${ }^{9}$ ) ist hier das Problem des $\mathrm{z}$ u $\mathrm{g}$ a $\mathrm{n} g \mathrm{~s}$ von Vermögen grundsätzlich $\mathrm{zu}$ unterscheiden in erstens den gegenständlichen Zugang von Vermögen und zweitens den Wertzugang von Vermögen. Der Zugang von Vermögensgegenständen als Einkommensbestandteil ist sowohl in Form des selbst akkumulierten Vermögens als auch in Form des durch Erbschaft, Schenkung oder Glücksfall erworbenen Vermögens möglich. In den überwiegenden Fällen kommt es dabei aber auch zu einem Wertzugang am Gesamtvermögensbestand. Die zweite $\mathrm{zu}-$ gangsform, der Wertzugang, ist nur ohne gegenständlichen zugang möglich und hier auch nur so gemeint; er ist danach zu differenzieren, ob er realisiert wird oder nicht.

Als Nutzung des Vermögens kann nur der güterliche zugang auftauchen, da eine "Nutzung" des Geldvermögens nur in Form von Erträgen geldlicher Art denkbar ist (Faktorenentlohnung).

Ferner: Dem Vermögenszugang entspricht die Vermögensauflösung (siehe Ubersicht 3.1), doch die ist ja uno actu geldlicher Art und demnach kein neuer Einkommenszugang. ${ }^{10)}$

9) Das Gütervermögen - im Gegensatz zum Geldvermögen - unterteilt N. Andel in das Sach-, das Grundstücks- und das Wertpapiervermögen.

Fn. 10 siehe folgende Seite 
Vor diesem Hintergrund der Begriffe sowie der Vermögensbildungs-, auflösungs - und zugangsvorgänge, die ja auch die als modern geltende Reinvermögenszugangstheorie widerspiegeln, sind die mit dem Vermögen zusammenhängenden Einkommenselemente von $N$. Andel und $w$. Albers $z u$ würdigen. Albers diskutiert die Probleme der Akkumulation, der Realisierung und der Wertsteigerung von Vermogen ausschlieblich unter steuerlichen Aspekten; die Reinvermögenszugangstheorie wird nicht thematisiert, demnach bleiben auch Erbschaften usw. auBerhalb seines Systems der Einkommensbestandteile.

Demgegenüber geht Andel auf Erbschaften und Geschenke sowie auf Glückssplelgewinne ein, die man allesamt als die gegenständlichen Vermögenszugänge bezeichnen kann, thematisiert weitere Vermögensgegenstandzugänge nicht, sondern diskutiert intensiv den Einkommenscharakter von Wertzuwächsen samt ihren steuerlichen Wirkungen und Konsequenzen, sowie die gesamte Realisierungsproblematik.

In Ubersicht 3.2 ist der Vermögenszugang (Bereich D I) erstens aus sämtlichen gegenständlichen und wertmäBigen Quellen ausgewiesen, zweitens in allen geldlichen und güterlichen Arten. Einkommenselemente aus der güterlichen Vermögensart bestehen in der Nutzung. Akkumuliertes wie auch erworbenes Vermögen läBt sich entweder aufzehren, dann ist es Geldeinkommen, oder nutzen, dann ist es Gütereinkommen (und birgt - wie oben dargestellt - das Zurechnungsproblem). Ausdrücklich ist auch hier auf die Trennung der Kapitalnutzung von der Vermögensnutzung hinzuweisen, wobei die erstere in den allokativen Bereich gehört.

\footnotetext{
Fn. 10: siehe F. Neumarks "Umschichtung der Vermögensstruktur" als ein die Erhöhung der Dispositionskraft nicht beruhrender "Aktivtausch", 1961b, S. 33.
} 
ExkuIs II:

Einzeldarstellung zu $s$ l = Das

"Verfigungseinkommen" im spektrum der Individualeinkommensbegriffe

I. Die Abgrenzung zum "persönlich verfügbaren Einkommen" $\quad 629$

II. Vom Verfügungseinkommen zum Konsumeinkommen 630

III. Von den Bruttoeinnahmen zum "zu versteuernden Einkommen"

IV. Das Verhältnis der wirtschaftstheoretischen zur steuerlichen und statistischen Einkommensdefinition

I. Die Gröbe des "V e $r$ ü $g$ u n $g$ s e $i \mathrm{n} k$ om e n s" ist gegenüber dem "p e $r$ s ö $n l 1 c h \quad v$ e $r$ f ü $g$ b a $r$ e $n$ E $1 \mathrm{n}$ k $\circ \mathrm{m}$ e $\mathrm{n}$ " der Sozialproduktsberechnung abzugrenzen. Ausgehend vom Netto-Sozialprodukt zu Faktorkosten, also dem Volkseinkommen," enthält das "verfügbare (disponible) Einkommen der privaten Haushalte" zwar die Transferzahlungen, nicht dagegen die unvertellten Gewinne der körperschaften; es entspricht insoweit dem oben entwickelten Verfügungskriterium im Sinne einer Verfügbarkelt uber die wirtschaftstheoretisch bestimmte GesamtverfügungsgröBe. Jedoch ist die makroökonomische GröBe des "persönlich verfügbaren Einkommens" um sămtliche indirekten und direkten steuern (also um die persönlichen direkten und die Körperschaftsteuern) wie gleichfalls um sämtliche Sozialversicherungsbeiträge (des Arbeitnehmers und des Arbeitgebers) gekürzt. Allein: Einkommenstheoretisch ist der Umfang der Verfügbarkeit aber weiter zu ziehen: Verfügt wird vom einzelnen in

1) DaB dieses gegenüber dem BSP un die Abschreibungen vermindert und um die subventionen erhöht ist, entspricht sehr wohl den oben dargelegten betrieblichen Verfügungen, die ja für die privaten und einkommensbezogenen Verfügungen insofern ausschelden, als sie allokative sind. Was aber nicht unserem Verfügungsverständnis entspricht, ist der vollstände Abzug der indirekten Steuern, denn diese fallen teils im betrieblichen, tells im privaten Bereich an. Insoweit ist schon der Ausgangsbetrag "Volkseinkommen" unter dem Aspekt der Verfügung für unsere mikroökonomische Betrachtung nicht brauchbar. 
seinem privaten Bereich auch über seine für diesen Bereich anfallenden Steuern, ${ }^{2}$, und zwar uber direkte wie indirekte. Denn aus dem Gesamtverfügungsbetrag wird die gesamte Einkommensverwendung bestritten, und $\mathrm{zu}$ letzterer gehört neben den Konsum- und Sparverwendungen auch die Zahlung der Steuern, nämlich die der persönlichen Steuern direkt ${ }^{3}$ ) und die der in Kauf-, Miet- und sonstigen Preisen enthaltenen indirekt.

Die aus der Sozialproduktsberechnung hervorgehende makroökonomische GröBe des "persönlich verfügbaren Einkommens" ist für unsere einkommenstheoretischen Analysen nicht zu verwenden; sie weist die Verfügungssume nämlich das "Verfügungseinkommen", zu gering aus. Denn die Abfuhrung von Abgaben ist wirtschaftlich gesehen Einkommensdisposition 4 ).

II. Bezugspunkt für das $V$ e $r$ fü $g$ n $g$ s e $i \mathrm{n} k \mathrm{~m} m$ e $\mathrm{n}$ ist das Prinzip der Totalerfassung ökonomischer GröBen. Die Markteinkommen, d.s. die Brutto-Nominal- und-Naturalentgelte für Marktleistungen (N. Andel 1979a, S. 337), enthalten auch die $\mathrm{Zu}$ - und Abgänge aus VermögensveräuBerungen. ${ }^{5)}$ Im Sinne des Reinvermögenszugangskonzeptes sind nunmehr $z u$ addieren: Das Zurechnungseinkommen aus dem Faktoreinsatz und den Vermögensnutzungen

2) So auch K. Tipke 1991, S. 196; durch den Abzug bestimmter privater Aufwendungen gelant man $z u$ dem "für die Steuerzahlung disponiblen Einkommen".

3) Das Kriterium der Verfügbarkeit macht es streng genommen notwendig, die Quellenabzugsteuern hier auszunehmen, da diese Beträge gar nicht erst in die Verfügungsgewalt des Einkommensund vermögensbeziehers bzw. -besitzers gelangen. Dies aber hieBe, den Begriff des Verfügungseinkommens von steuertechnischen Vereinfachungspraktiken abhängig $\mathrm{z} u$ machen. Daraus würde resultieren, daB die unten erwähnten verteilungsvergleiche für bestimmte Klassen von Einkommensbeziehern nicht anzuwenden wären. Somit empfiehlt es sich, den Quellenabzug als für den Berechtigten und Verpflichteten vorgenommene Verfügung $z u$ verstehen.

4) Auch hier gilt wieder, was oben mehrfach festgestellt wurde, daB nämlich unter Leistungsfähigkeitsaspekten die steuer- und belastungspolitischen Regelungen eine andere Vorgehensweise nahelegen mögen.

5) Zur Erinnerung: die "Einkommen aus Vermögen", also Zinsen, Mieten, Pachten usw., sind nach unserer Nomenklatur Ertrăge aus dem eingesetzten Kapital und somit in den Entgelten für Marktleistungen enthalten. 
(imputed income), das Transfereinkommen und die Vermögenszugănge einschlieblich der Vermögenswertzuwächse. Die Summe ergibt die TotalgröBe des "Verfügungseinkommens" (siehe Ubersichten A.1, A.2). Das mikroökonomisch entwickelte Verfügungseinkommen ist die individuell zurechenbare und tatsächlich verfügbare ökonomische GröBe. Sie ist der Ausgangspunkt für die nun unter Kaufkraftund Bedarfsgesichtspunkten vorzunehmenden Minderungen. Ohne die zugerechneten Einkommen, also ohne die aus dem Faktoreinsatz stammenden naturalen Entlohnungen und naturalen Vermögensnutzungen, ergäbe sich das "ausgabefähige Einkommen" (nach W. Schmähl 1978, S. 191), eine GeldeinkommensgröBe, die im Hinblick auf die am Markt $z u$ entfaltende Kaufkraft ${ }^{6)}$ Bedeutung hat. Das Verfügungseinkommen enthält aber noch den Abgabenantell, der selbstverständich beim Besteuerten nicht kaufkraftwirksam wird, soweit es sich um die direkten, d.h. nicht in den Preisen enthaltenen Steuern und Sozialabgaben handelt.

Die Zahlung von Abgaben ist als eine Ubertragung der Ressourcen vom privaten in den öffentlichen Sektor der Wirtschaft, nach F.K. Mann ${ }^{7)}$ und D. Pohmer (1976, S. 193) als eine tbertragung von Kaufkraft $z u$ verstehen; demnach läBt sich das nach der Abgabenzahlung verbleibende Einkommen auch als "Kaufkrafteinkommen" 8 ) bezeichnen. Es drückt die gegenwärtig am Markt entfaltbare kaufkräftige Nachfrage aus, enthält aber auch die Möglichkeit der Kaufkraftverlagerung in die Zukunft. Zieht man diesen Sparanteil vom Kaufkrafteinkommen ab, erhält man dasjenige Einkommen, mit dem man die Konsumgüter kauft, d.h. seinen Güterbedarf deckt. Mit diesem "Bedarfseinkommen" sind aber noch die in den Preisen

6) $\mathrm{zu}$ beachten ist, daB diese EinkommensgröBe neben den monetären Transfers auch solche Einkommenselemente enthält, die zwar als Vermögensnutzungen und Sachtransfers zugehen, jedoch in dieser Höhe Marktnachfrage kompensieren; würden sie monetär zugehen, wäre das ausgabefähige Einkommen um diesen Betrag gröBer. $Z u$ beachten ist ferner, daB die Schmähl'sche Definition nicht mit jener der EVS identisch ist: letztere (s.u.) ist bereits um die direkten Steuern und Sozialabgaben gekürzt, enthält aber die Zurechnungseinkommen.

7) 1930, S. 36: "Eine Steuer im volkswirtschaftlichen Sinne liegt immer dann vor, wenn die Kaufkraft zwangsweise umgeschichtet wird."

8) H. Laufenburger 1956, S. 463: Einkommen entspricht einem periodischen Zuwachs an Kaufkraft einer Person. - Bülow 1957, S. 387 : wirtschaftlich ist Einkommen Kaufkraft. 
Ubersicht A.1: Bestimmungsschema der Einkommensbegriffe

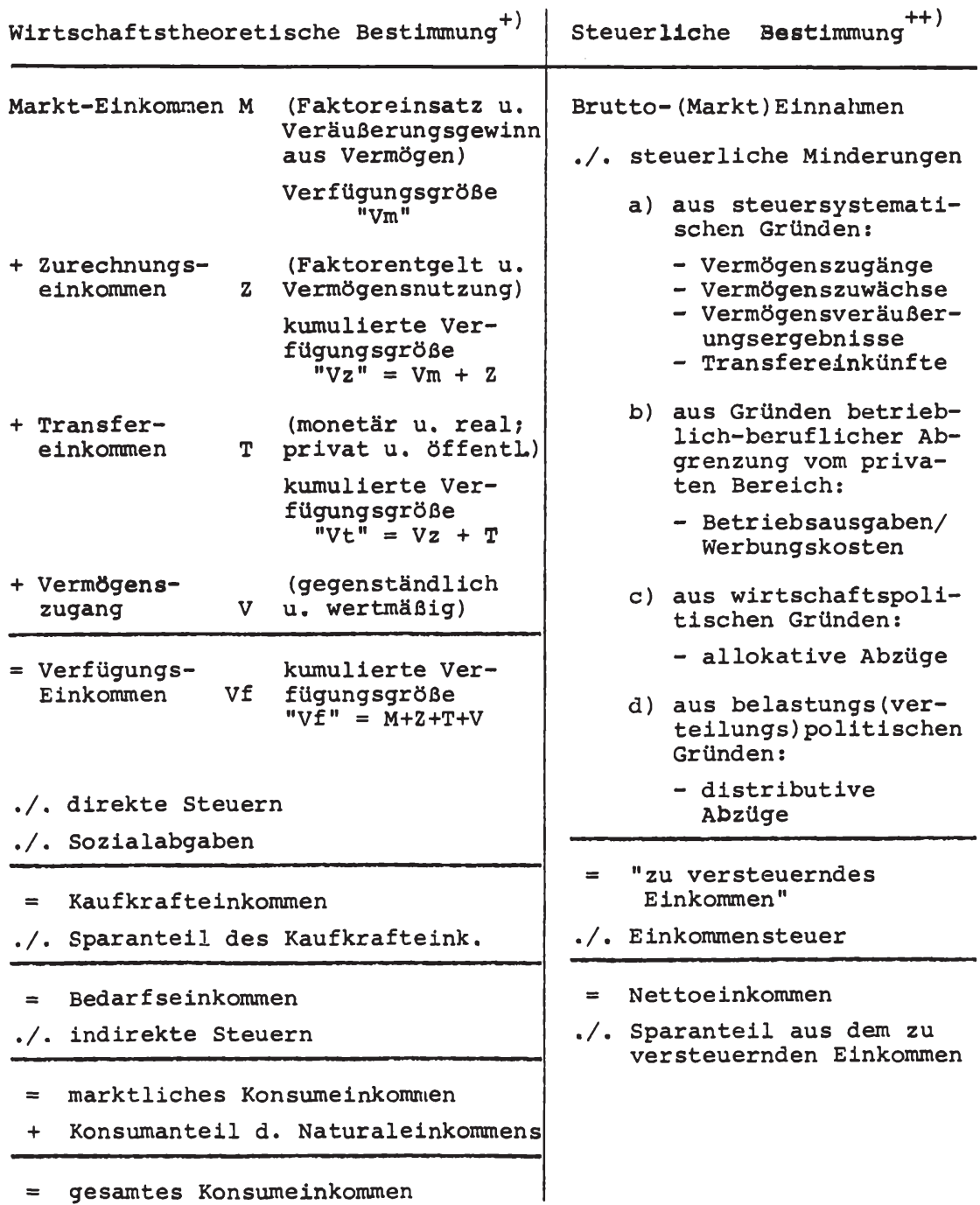

+ ) Siehe $\$ \$ 7$ u. 8 (Ubersicht 3,2) und die dort erwähnte Diskussion um die Einkommensbegriffe; siehe auch tbersicht A.2 mit der graphischen Darstellung der hier geb11deten Teilverfügungsgrößen.

++ ) ohne die quasisteuerliche Bestimmung (Sozialabgaben). 
Ubersicht A.2: Matrix-Darstellung der Teil- und GesamtverfügungsgröBen nach Art und Quelle des Zugangs ökonomischer GröBen

\begin{tabular}{c|c|c|c|} 
& $A$ & $D I$ & DII \\
\hline \multirow{4}{*}{ GE } & $a$ & $a$ & $a$ \\
\cline { 2 - 4 } & $b$ & $b$ & $b$ \\
\hline \multirow{4}{*}{ GU } & & $c$ & $c$ \\
\hline & $1 a$ & $1 a$ & $1 a$ \\
\cline { 2 - 4 } & $1 b$ & $1 b$ & $1 b$ \\
\cline { 2 - 4 } & $1 c$ & $1 c$ & $1 c$ \\
\hline & $2 a$ & $2 a$ & $2 a$ \\
\hline & $2 b$ & $2 b$ & $2 b$ \\
\hline
\end{tabular}

"Vm" = A / GE

Geldzugang aus der Entlohnung produktionswirtschaftlicher Tätigkeit

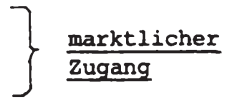

(siehe die Ubersicht 3.2;

hinzukommende Verfügungsbereiche sind jeweils schraffiert ausgewiesen)

\begin{tabular}{|c|c|c|c|}
\hline & A & DI & DII \\
\hline \multirow[t]{3}{*}{ GE } & $a$ & a & $a$ \\
\hline & $\mathrm{b}$ & $b$ & $\mathrm{~b}$ \\
\hline & & c & c \\
\hline \multirow[t]{5}{*}{ GU } & & ISIII & $1 \mathrm{a}$ \\
\hline & & 3 & $1 \mathrm{~b}$ \\
\hline & 3 & sall & $1 c$ \\
\hline & $2 a$ & $2 a$ & $2 a$ \\
\hline & $2 b$ & $2 b$ & $2 b$ \\
\hline
\end{tabular}

"Vz" = $\mathrm{V}_{\mathrm{m}}+\mathrm{A} / \mathrm{GUt} 1 ; \mathrm{DI} / \mathrm{GU1}$

Geldzugang aus der Entlohnung produktionswirtschaftlicher Tătigkeit marktlicher $+$ Güterzugang aus Faktorentlohnung (in Form von Leistungen u. Entnahmen) und Sachvermögensnutzung (imputiertes Einkommen) zugang

nichtmarktlicher Zugang

= Gesamtzugang aus Entlohnung und Nutzung

\begin{tabular}{c|c|c|c|} 
& $A$ & $D I$ & DII \\
\hline \multirow{4}{*}{$G E$} & $a$ & $a$ & \\
\cline { 2 - 4 } & $b$ & $b$ \\
\cline { 2 - 4 } GU & & $c$ & \\
\cline { 2 - 4 } & $1 a$ & $1 a$ & \\
\cline { 2 - 4 } & $1 b$ & $1 b$ & \\
\hline & $1 c$ & $1 c$ & \\
\hline $2 a$ & $2 a$ & \\
\cline { 2 - 4 } & $2 b$ & $2 b$ & $2 b$ \\
\hline
\end{tabular}

"Vt" = Vz + DII/GE + GU1, 2a $\left.\begin{array}{l}\text { marktlicher und nichtmarkt- } \\ \text { licher Gesamtzugang aus } \\ \text { Entlohnung und Nutzung }\end{array}\right\}$ Gesamtzugang aus privater Leistungswirtschaft $+$ $+$ Geld- und Gūterzugang aus der privaten und offentlichen Transferwirtschaft

Gesamtzugang aus der, Transferwirtschaft

= Gesamtzugang aus dem vermögenswertIosen Bereich

\begin{tabular}{|c|c|c|c|}
\hline & A & DI & DII \\
\hline \multirow[t]{3}{*}{ GE } & a & SIf & $a$ \\
\hline & $b$ & IIIII & $\mathrm{b}$ \\
\hline & & Mllesles & $c$ \\
\hline \multirow[t]{5}{*}{ GU } & $1 a$ & $1 a$ & $1 a$ \\
\hline & $1 \mathrm{~b}$ & $1 \mathrm{~b}$ & $1 \mathrm{~b}$ \\
\hline & \multirow{3}{*}{$\frac{1 \mathrm{c}}{28}$} & $1 c$ & $1 \mathrm{c}$ \\
\hline & & $2 a$ & $2 a$ \\
\hline & & $2 b$ & $2 b$ \\
\hline
\end{tabular}

"Vf" = Vt + A / GU2; DI / GE

$\left.\begin{array}{l}\text { leistungs- und transfer- } \\ \text { wirtschaftlicher Gesamt- } \\ \text { zugang einschl. Vermögens- } \\ \text { nutzung } \\ + \\ \text { Zugang an bewerteten ver- } \\ \text { mögensgegenständen und } \\ \text { Vermögenswerten }\end{array}\right\}$

leistungs- und transferwirtschaftlicher Gesamtzugang einschl. Vermōgensnutzung

Zugang an bewerteten Ver mögensgegenstãn
Vermōgenswerten
Gesamtzugang aus dem vermögenswertlosen Bereich $+$ Vermögenswertzugang

= Totalzugang 
enthaltenen indirekten Steuern zu tragen. Erst wenn man diese aus den Preisen eliminiert, ergibt sich ein Einkommen, das vollständig und ausschlieblich dem Konsum gewidmet ist, soweit sich der Konsum über den Markt decken läBt. ${ }^{9)}$ Soll das g e s a m $t$ e $\mathrm{K} \circ \mathrm{n} \mathrm{s}$ u $\mathrm{m} i \mathrm{n} \mathrm{k} \circ \mathrm{m} \mathrm{m}$ e festgestellt werden, muB dem marktlichen Konsumeinkommen wieder jener Tell des Naturaleinkommens hinzugerechnet werden, der bereits vor Ermittlung des Kaufkrafteinkommens abgezogen wurde, weil Naturaleinkommen nicht unmittelbar am Markt wirksam wird; jedoch darf nur der Teil des Naturaleinkommens wieder addiert werden, der direkt in den Konsum geht. ${ }^{10}$

III. Die s $t$ e $u$ e $r l i c h$ e Bestimmung des Einkommens ist dagegen von der wirtschaftstheoretischen grundverschieden, wenngleich auch sie das Totalitätsprinzip verfolgt. Ihre Ausgangsgröße ist nicht das Markt- oder das verfügungseinkommen, sondern die Summe der Markt-Einnahmen. Die steuerlichen Minderungen lassen sich in einer subtraktiven Verfahrensweise darstellen; sie erfolgen in vier prinzipiell unterschiedlichen Schritten. Zunächst wird berücksichtigt, daB nach dem Nettoprinzip nur der betriebliche bzw. berufliche Gewinn sowie der private UberschuB der Besteuerung unterworfen werden soll; Betriebsausgaben bzw. Werbungskosten gehören der allokativen sphäre an und sind kein Bestandteil des distributiven Einkommensbereichs. Im Sinne der Besteuerungsrechnung sind diese Beträge kein Verfügungsbestandteil. Während das wirtschaftstheoretisch verstandene Verfügungseinkommen derlei allokative Elemente nicht mehr enthält, sind sie hier als Minderungen aufzuführen, da die steuerliche Berechnung nicht von Markteinkommen, sondern von Markteinnahmen oder -erlösen ausgeht.

9) $\mathrm{Zu}$ beachten ist, daB durch inflationäre Preissteigerungen und wegen des Gewichts der Wertsteuern unter den indirekten Steuern das Kaufkrafteinkommen und das Bedarfseinkommen aufgebläht sind und den güterlich konsumierbaren Teil des Einkommens nicht aufdecken kann.

10) Vgl. hierzu die von H. -J. Krupp (1968, S. 140) erstellte Ubersicht der wichtigsten Systembeziehungen zwischen den EinkommensgröBen "Faktor-, Basis-, verfügbares und preisbereinigtes Einkommen sowie ihre Beziehungen zum Sicherungsanspruchsniveau, zur Geldillusion und Besteuerung, zum Konsum und Sparen. 
Im zweiten Korrekturschritt der steuerlichen Einkommensbestimmung wird zu entscheiden sein, ob die Vermögenszugänge und Vermögenswertzuwächse zum steuerlichen Einkommen zăhlen sollen oder nicht; aus der Diskussion dieser Frage ergibt sich, daB dies insbesondere unter dem Aspekt der progressiven Belastung entschieden wird. Vermögenszugänge und -wertzuwächse erhöhen im Jahr des zugangs die Bemessungsgrundlage und führen $\mathrm{zu}$ überproportionaler Steuerlast. Allein dies macht deutlich, daB in der steuerdiskussion die Einkommensdefinition unter dem Aspekt der erst später ins Bild kommenden Steuersatzfrage vorwegentschieden wird. Konsequent folgt dann aus der Trennung in Einkommen und Vermögen die getrennte Besteuerung durch Einkommen-, Vermögen- sowie Erbschaftund Schenkungsteuer.

GleichermaBen steuersystematische Bedeutung hat der AusschluB der Transfers aus der Bemessungsgrundlage, wenngleich hier für die privaten Transfers oft nur Teilausschlüsse vorgesehen werden (z.B. bei Unterhaltsleistungen). Der TransferausschluB hat zur Folge, daB mitunter - insbesondere, wenn öffentliche Transfers zugehen die Netto-Verfügungssumme bei den Empfängern höher ist als bei den Beziehern von besteuertem Arbeitseinkommen.

Die beiden weiteren Korrekturschritte sind die Zulassung von $\mathrm{Ab}-$ $z$ ügen; diese sind entweder allokativer oder distributiver Art und Motivation. Hierher gehören sowohl die Befreiungen von Einkommensteilen in der Zugangsphase (die somit oftmals gar nicht erst steuerliches Einkommen werden) als auch die Abzüge von Einkommensverwendungen. Prinzipiell widerspricht dem Konzept der Totalerfassung jegliche wirtschaftspolitisch motivierte Befreiung bzw. steuerliche Abschreibungserleichterung zur strukturellen Entwicklung (z.B. des Schiffsbaus, des Wohnungsbaus, der Regionen), zumal sie auch Verteilungs- und Umverteilungswirkungen zeitigen ( $W$. Albers 1974 , passim). Soweit allokative und distributive Befreiungen vorgesehen sind, werden solche Einkommensbestandteile der Finanzverwaltung gar nicht erst "zur Kenntnis gebracht" (W. Albers ebd.); sie tragen dazu bei, daB die maximale Besteuerungsbasis unbekannt bleibt. ${ }^{11)}$

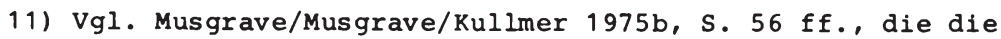
quantitative Auswirkung unter makroökonomischem Aspekt berechnet haben. 1988, S. 145, Fn. 15: Bei der letzten... Lohnu. ESt-statistik von 1977 wurde das "zu versteuernde Einkommen" nicht ermittelt. 
Die distributiven Abzüge (Sonderausgaben und auBergewöhnliche Belastungsaufwendungen in der bundesdeutschen Rechtsnomenklatur) dienen der Herstellung einer die persönlichen Verhältnisse des Steuerpflichtigen spiegelnden Bemessungsgrundlage, die zugleich seine steuerliche Leistungsfähigkeit ausdrückt. Solche Abzüge werden im allgemeinen aus Gründen der Existenzsicherung, der Vorsorge und auch des Zwangscharakters weiterer Aufwendungen zugelassen. Hier handelt es sich um Verwendungen des Einkommens mit eingeschränkter bzw. kaum vorhandener Verfügungsmacht.

Der EinfluB der allokativ und distributiv motivierten Abzüge von der Gesamtverfügungssumme, Ausdruck steuertheoretischer und -politischer Argumentation, Einflüsse und Belastungsvorstellungen, vermindert das totale Verfügungseinkommen $z u m ~ " z u$ versteuernden Einkommen" (so die bundesdeutsche Bezeichnung im Einkommensteuerrecht); es handelt sich dabei um eine aus steuersystematischen wie belastungspolitischen Gründen verengte Einkommens- und Bemessungsgröße.

IV. Schon wegen der völlig anderen Ausgangslage sind das Nettoeinkommen der steuerlichen Definition und das Kaufkrafteinkommen der wirtschaftstheoretischen nicht identisch. Selbst wenn man die steuerlichen Ausgangslagen (Markteinnahmen statt -einkommen) einander dadurch anpassen würde, daß man von den steuerlichen Einnahmen die Betriebsausgaben und Werbungskosten abzieht, um dergestalt das sich ergebende Nettomarktergebnis mit dem Markteinkommen der wirtschaftstheoretischen Bestimmung distributiv vergleichbar $\mathrm{zu}$ machen, liegen wesentliche Unterschiede im folgenden: Die wirtschaftstheoretische Bestimmung stellt ein $t o-$ $t$ a 1 e s $V$ e $r$ ü $g$ u $g s$ e $n k \circ m m$ e her, das die steuerliche Bestimmung nicht kennt, da hier aus steuersystematischen Gründen der Vermögens- und Transferzugang ausgegrenzt wird. Des weiteren verengt das Bündel der allokativen und distributiven Abzugspositionen die "steuerliche Verfügungssumme" abermals. Beim Vergleich zwischen Nettoeinkommen und Kaufkrafteinkommen ist auBerdem $z u$ berücksichtigen, $d a B$ in den distributiven Abzügen bereits Sparbeträge zur zukunftssicherung (Vorsorge) enthalten sind, so daB der aus dem Nettoeinkommen abzuzweigende sparanteil geringer ist als der vergleichbare Sparanteil des Kaufkraftein- 
kommens. Das steuerliche Nettoeinkommen repräsentiert somit ein wesentlich geringeres kaufkräftiges Einkommen, selbst wenn man bedenkt, daB es noch nicht um die Sozialabgaben vermindert ist.

Bei einem Urteil über die Brauchbarkeit der wirtschaftstheoretischen Einkommensbestimmung haben wir $z u$ unterscheiden, daB man sie erstens der steuerlichen, zweitens der statistischen Einkommensbestimmung in der Einkommens- und Verbrauchsstichprobe gegenüberstellen kann.

a) Vergleicht man das "z u ve rs t e u e r n d e E 1 n $k \circ \mathrm{m} \mathrm{m}$ e $\mathrm{n}$ " mit dem Verfügungseinkommen, lassen sich sowohl die im Steuersystematischen begründeten Verzichte auf eine vollständige Erfassung der "comprehensive tax base" deutlich machen als auch die zu vielerlei Ausgrenzungen, Befreiungen und Abzügen führenden Gruppeneinflüsse im Vertellungskampf, in der Auseinandersetzung um ökonomische Freihelt, soziale sicherheit und steuerliche Gerechtigkeit. Selbst wenn man das Verfügungseinkommen um die Zugänge aus dem Vermögensbereich mindern würde, würden sich noch genügend Einflüsse der oben genannten Art zeigen, die darzulegen geeignet sind, daB das $z u$ versteuernde Einkommen einen erheblich geringeren Umfang hat als das Verfügungseinkommen ohne Vermögenszugänge. ${ }^{12)}$ Auch ungeachtet der erwähnten "einkommensmindernden" Effekte von steuerlichen Abzugsbeträgen ergibt sich eine erhebliche Abweichung der "deklarierten" Einkommen - ausgedrückt in dem steuerrechtlichen Terminus "Summe der Einkünfte" vom "Verfügungseinkommen ohne Vermögenszugang". 13) Diese Abwei-

12) Aus der erwähnten Untersuchung von Musgrave/Musgrave/Kullmer (1975b, S. 57) läBt sich errechnen, daB von dem 1968 entstandenen Nettosozialprodukt $z u$ Faktorkosten nur ein Anteil von 44 \& als "zu versteuerndes Einkommen" ermittelt werden kann; die wesentlichen Minderungsbeträge im auBersteuerlichen $\mathrm{Be}-$ reich entfielen auf unverteilte Gewinne und Sozialaufwendungen der Arbeitgeber; die wesentlichen Minderungsbeträge im steuerlichen Berelch entfielen auf allgemeine Freibeträge, Sonderausgaben, sonstige Freibeträge, Werbungskosten aus nichtselbständiger Arbeit und - dies in überraschend hohem AusmaB, wenngleich als RestgröBe ermittelt - auf Steuervergünstigungen und Lücken im steuerlichen Nachweis.

13) W. Albers 1974 , S. 100, ermittelt makroökonomlsch diese Einkommensdeklarationsdifferenz mit einem Wert von 26,4 \& des Volkseinkommens der Bundesrepublik im Jahre 1968, siehe auch S. $69 \mathrm{ff.;}$ auf die Schwierigkelten der Methodik angesichts fehlender Statistiken über die personale Aufgliederung der Zahlen und damit auf die Möglichkeit von Fehlerquellen wird ausdrücklich aufmerksam gemacht. 
chung ergibt sich aus den zahlreichen Steuerbefreiungen, die viele zugänge gar nicht erst als besteuerbare in Erscheinung treten lassen. Insoweit, wie weder eine vollständige Information noch eine totale Erfassung des Verfügungseinkommens angestrebt werden, ist sowohl eine nachvollziehbare steuerliche Allokationspolitik als auch eine integrierte Finanz- und Sozialpolitik ${ }^{14}$ von vorn herein unmöglich.

b) Nicht Sinn und Anwendungsverfahren der Verteilungsrechnung ${ }^{15)}$, wie sie in der Bildung von sozioökonomischen Gruppierungen und Einkommensklassifizierungen zum Ausdruck kommen, sollen hier thematisiert werden, sondern allein die Ubereinstimmung oder Nichtubereinstimmung der wirtschaftstheoretischen Einkommensbegriffe mit denen der $v$ e $r$ e $i l$ u g $\mathrm{s}$ e $c h n$ u $g$ aus dem Mikrozensus und der Einkommens- und Verbrauchsstichprobe (EVS). Das Einkommen- und Einnahmenberechnungsschema der EVS 1973, auf Monaiseinkommen und -einnahmen sämtlicher Mitglieder von Privathaushalten abgestellt, gestaltet sich wie folgt: ${ }^{16)}$

Bruttoeinkommen aus unselbständiger Arbeit

+ Bruttoeinkommen aus Unternehmertätigkeit

+ Einkommen aus Vermögen

+ Einkommensübertragungen aus öffentlichen und privaten Renten und Pensionen

+ nichtöffentliche laufende Einkommensübertragungen

+ Einnahmen aus Untervermietung

+ einmalige Einkommensübertragungen unter $1.000 \mathrm{DM}$

= Haushaltsbruttoeinkommen

./. gesetzliche Abzüge: ESt, VSt, Arbeitnehmeranteile der Pflichtbeiträge zur Sozialversicherung

= Haushaltsnettoeinkommen

+ sonstige Einnahmen: private Verkaufserlöse sowie einmalige Vermögens übertragungen von über $1.000 \mathrm{DM}$

+ statistische Differenz

= ausgabefähige Einkommen und Einnahmen

+ Einnahmen aus der Minderung von Sach- und Geld-Vermögen sowie aus der Kreditaufnahme

= Gesamteinnahmen

14) Vgl. hierzu M. Pfaff 1978a; M. Pfaff 1978c; W. Albers 1976. Ferner unter besonderer Beachtung des WohlfahrtsstaatsAspektes W. Albers 1977a; C. Watrin 1977; C. Helberger 1978 und M. Pfaff $1978 \mathrm{~b}$.

Fn. 15 und 16 auf der folgenden Seite 
Dieses Strukturbild macht prima facie deutlich, daB erstens neben den Markteinkommen vielerlei Transfereinkommen das Haushaltsbruttoeinkommen bestimmen und daB zweitens das Haushaltsnettoeinkommen keinesfalls mit dem steuerlichen Nettoeinkommen übereinstimmt, da das hier ausgewiesene Bruttoeinkommen noch sämtliche steuerlichen (allokativen und distributiven) Abzüge enthält, die aber das " $\mathrm{u}$ u versteuernde Einkommen" gemindert haben.

Um allerdings festzustellen, ob und Inwieweit sämtliche Marktund Transfereinkommen, vor allem aber die Zurechnungseinkommen und Vermögenszugänge im Haushaltsbruttoeinkommen bzw. in den Gesamteinnahmen wiederzufinden sind, bedarf es einer inhaltlichen Detaillierung, die in Ubersicht A. 3 vorgenommen wurde. Dabei wurden die Positionen der EVS so umgegliedert, daB sie den Einkommensbegriffen der wirtschaftstheoretischen Bestimmung gegenübergestellt werden konnten.

(1) Der Vergleich ergibt das folgende Ergebnis: Die Markteinkommen sind vollständig erfaBt, ja sie sind teilweise - soweit sie nämlich aus Verkăufen privater Geld-, Sach- und Beteiligungsvermögensguter stammen - hoher ausgewiesen als es nach der wirtschaftstheoretischen Bestimmung korrekt wäre (siehe die Anmerkung in Ubersicht A.3)

(2) GröBere Abweichungen zwischen der wirtschaftstheoretischen Einkommensbestimmung und dem Bruttohaushaltseinkommen der EVS bestehen im $\mathrm{Zurechnungs-Einkommen.}$

(3) Da ein Verfügungseinkommen in jedem Falle samtliches Sparen umschliebt, enthält es auch die im Unternehmensbereich akkumulierten Kapitalien, seien sie nicht entnommene Gewinne, seien

15) Als Beispiel für viele siehe H.-J. Krupp 1968, S. 181 ff., der mithilfe von Simulationsprogrammen insbesondere die Verteilungswirkungen folgender EinfluBgruppen untersucht: Sparverhalten und -förderungsmaBnahmen, Besteuerung von Einkommen, Vermögen und Vermögenstransfer, Steigerung des Einkommens aus unselbständiger Arbeit und aus Transfers, Zinsniveau und -struktur, Preisänderung für verschiedene Gütergruppen.

16) Statistisches Bundesamt 1977, S. 6, 13 u. 21 ff.; im folgenden zitiert als "SB". Ferner SB 1992, S. 11 (ESV 1990: Totaleinkommen) sowie SB 1988, H.6 (EVS 1983: Einkommensarten). 
Ubersicht A.3: Verfügungseinkommen versus Haushaltsbruttoeinkommen

Begriffe und Bestandteile der wirtschaftstheoretischen Einkommensbestimmung

\section{Markt-Einkommen}

(aus Faktoreinsatz und VeräuBerungsgewinnen aus Vermögen)
Begriffe und Bestandteile der Einkommens- und Verbrauchsstichproben nach der Bestimmung durch das Statistische Bundesamt
Zurechnungs-Einkommen

(als Faktorentgelt u. Vermögensnutzung)
Bruttoeinkommen aus unselbständiger Arbeit: und zwar aus haupt- und nebenberuflicher Tătigkeit (vor Abgabenabzug) einschl. aller Zuschläge, Prämien, Zuschūsse usw.

Bruttoeinkommen aus Unternehmertätigkeit: einschl. der Nebeneinnahmen, aus Land- und Forstwirtschaft, aus Gewerbebetrieb und freiberuflicher Tãtigkeit

Einkommen aus Vermögen:

Vermietung, Verpachtung, Zins- und Ausschüttungseinnahmen aus Vermögensanlage und Beteiligungen

Einnahmen aus Untervermietung:

(kann auch als Einkommen aus Vermögen behandelt werden)

Einnahmen aus dem Verkauf von privatem und betriebIichem Geld- und Sachvermögen:

Gebãude, Grundstücke, Wohnungen, Garagen, usw.; Wertpapiere, Anteile.

(nur zum Teil als Markteinkommen anzusehen) ${ }^{+}$)

Einnahmen aus dem Verkauf von im Haushalt hergestellten Erzeugnissen und aus verkauften Gebrauchsgegenstănden usw.

Bruttoeinkommen aus unselbstăndiger Arbeit: Sachleistungen wie Deputate, freie Kost, freie Wohnung usw.

Einkommen aus Vermögen:

der fiktive Mietwert für Eigentümerwohnungen abzüglich Unterhaltungsaufwand, jedoch nicht des Finanzierungsaufwandes (Zinsen, Abschreibungen)

+) Diese Einnahmen sind nur teilweise als Markteinkommen anzusehen, da hier die Bruttoeinnahmen erfaBt sind; nach dem wirtschaftstheoretischen Konzept sind jedoch als Markteinkommen nur die VerăuBerungsgewinne zu erfassen, denn die Minderungen des Bruttoerlöses, wie die Anschaffungs- bzw. Herstellungskosten der Vermögensgüter sowie deren Verkaufsaufwendungen sind Abzüge allokativer Art. 
Forts. der Ubersicht A.3:

\section{Transfer-Einkommen}

(monetäre und reale; private u. offentliche)
Empfangene Einkommensübertragungen: Offentliche Renten (der Sozialversicherungstrăger, der Arbeitslosenversicherung, der Gebietskörperschaften, der Sozialhilfe), sonstige öffentliche Zahlungen wie Kindergeld, Wohngeld, Sozialhilfe usw. Offentliche Pensionen (einschl. der Pensionen Uff. Unternehmen), Unterstützungen und Beihilfen für Pensionāre usw.

Einmalige Einkommensübertragungen unter $1.000 \mathrm{DM}$ : seitens der Sozialversicherungstrăger (Erstattungen, Zuschüsse, Abfindungen usw.). seitens der Gebietskörperschaften (Kriegsopferversorgung, Lastenausgleich, Wiedergutmachung, Sozialhilfe, Sparprämien, Wohnungsbauprämien), seitens der privaten Versicherungen (ärztl. Behandlung, Krankenhauskosten, Schadenserstattungen usw.)

Sonstige laufende Ubertragungen: Werkspensionen, Streikgelder, Kirchliche Unterstützungen, private Unterstützungen für Familienangehörige.

Sonstige Vermögensübertragungen über $1.000 \mathrm{DM}$ : seitens der Sozialversicherungstrăger, der Gebietskörperschaften, der privaten Versicherungen.

Einmalige Einkommensübertragung unter 1.000 DM: Erbschaften, Geschenke, Aussteuer, Spielgewinne

Sonstige Vermögensūbertragungen über 1.000 DM: Erbschaften, Geschenke, Aussteuer, Spielgewinne, Kapitalauszahlungen und Gewinnbeteiligungen aus Versicherungen.

Anmerkung $z u$ den Einkommens- und Vermögensübertragungen:

Die Statistik der EVS 1973 führt unter der Rubrik "Einnahmen aus Minderung von Sach- und Geldvermögen, Kreditaufnahme" verschiedene Tatbestānde auf, die zwar beim Haushalt zu Einnohmen führen, jedoch teils als Markteinkommen gelten kónnen (Verkaufserlöse), teils aber als Vermögens-Umschichtungen anzusehen sind: So ist die Abhebung vom Sparbuch, die Auszahlung des Bausparguthabens und eines Lebensversicherungsguthabens eine Umschichtung von Forderungen gegen Bargeld; entsprechend ist die Rückzahlung einer Einlage in ein Unternehmen eine Umschichtung; letztlich ist die Kreditaufnahme eine Umschichtung von Bargeld gegen einen Schuldbestand). Diese Einnahmen haben somit wirtschaftstheoretisch keinen Einkommenscharakter. Auch die Statistik der EVS zăhlt diese Einnahmen nicht zum "Haushaltsbruttoeinkommen", sondern erfaBt sie unter den "Gesamteinnahmen". 
sie nicht realisierte Kapitalwertsteigerungen. Da - wie nachgewiesen - Verfügbarkeit vorliegt, sind diese "Kapitalzugănge" (siehe Ubersicht 3.2: A/GU2) den Berechtigten nur insoweit zuzurechnen, wie sie nach deren Entscheidungen nicht aus allokativen Motiven im Unternehmen belassen werden. Dabei entsteht jedoch das Beweisproblem und die statistische Schwierigkelt. In der augenblicklichen EVS-Statistik fehlen diese Einkommensbestandteile vollig.

(4) Schlieblich zeigen sich die gröBten Abweichungen zwischen den beiden Methoden der Einkommensbestimmung im Bereich des Vermögens. Es ist daran $z u$ erinnern, daB für die wirtschaftstheoretische Einkommensbestimmung nicht der Vermögensbestand, sondern sein z u g a n g interessiert. Dazu können Bestandsvergleiche dienen, die sowohl den gegenständlichen als auch den wertmäBigen $\mathrm{Zu}-$ gang repräsentieren. Die EVS führt als gegenständlichen zugang zum Zeltpunkt der Erhebung an: Erbschaften, Geschenke, Spielgewinne, Aussteuer (obwohl diese auch erspart werden könnte!); ferner Kapitalauszahlungen aus Lebensversicherungen, doch durfte es sich bei diesen nur dann um einen Vermögenszugang handeln, wenn die Auszahlung uber den Rückkaufswert hinausgeht, andernfalls ware es eine Vermögensumschichtung. Auszahlungen von Gewinnbeteiligungen aus Versicherungen sind fraglos Vermögenszugänge. Abfindungen beim Ausscheiden aus einem Arbeits- und Dienstverhältnis sind in der EVS unter dem Bruttoeinkomen aus unselbstandiger Arbeit erfaBt.

(5) Entscheidend für unsere Fragestellung zur Brauchbarkeit des wirtschaftstheoretischen Einkommensbegriffes und seiner Teilbegriffe sind

Tatsachen, die aus ihrer Anwendungspraxis hervorgehen. Erstens: Die Notwendigkeit einer umfassenden Information über Vermögensbestände und -wertzuwächse wird gesehen. Zweitens: Gleichwohl wird die Vermögensproblematik als ein Verteilungsrechnungsthema getrennt von der Einkommensproblematik gesehen und behandelt, da zwei getrennte Rechenwerke erstellt (und verbessert) werden (sollen). Drittens: Dennoch wird Vermogen in der Einkommensbestimmung unterschiedlich behandelt, denn die gegenständlichen Zugänge wie Erbschaften, Kapitalanfall usw. werden in den Erhebungsjahren der 
Stichprobe in die Definition des $\mathrm{E} 1 \mathrm{n} \mathrm{k} \circ \mathrm{m} \mathrm{m} \mathrm{n}$, genauer: des Haushaltsbruttoeinkommens aufgenommen, Werterhbhungen dagegen uberhaupt nicht. Dies ist unter methodischen Aspekten widersprüchlich und inkonsistent. Unsere wirtschaftstheoretische Einkommensdefinition, die als einen wesentlichen Bestandteil nach dem Reinvermögenszugangskonzept neben den zurechnungseinkommen auch den Vermögenszugang enthät, wird implizit von der praktizierten Verteilungs rechnung einesteils anerkannt, 17) anderenteils aber nicht. ${ }^{18)} \mathrm{DaB}$ die statistische Auffullung eines solchen Einkommensinhaltes $z$. $z t$. Schwierigkeiten macht oder z.T. nicht moglich ist, steht auf einem anderen Blatt; dann wird man evtl. für die Verteilungsrechnungen mit anderen, praktikablen Einkommensbegriffen umgehen müssen, doch spricht das nicht gegen die stringenz in der theoretischen Entwicklung des Einkommensbegriffes. Somit labt sich als Fazit festhalten, daB von der Intention her auch die Verteilungsrechnung an einem umfassenden Einkommensbegriff interessiert ist und $d a B$ sie in der praktischen Anwendung zu einer teilweisen Akzeptanz des Verfügungseinkommens gelangt 1st.

ExkuIS III:

Einzeldarstellung zu $s 20=$ Das Leistungstähigkeitspostulat und seine personale Bedingung = Der Leistungsträger "Individuum" / personalbesteuerung versus unternehmensbesteuerung

I. Das ökonomische Problem: Die angebliche "Leistungsfähigkeit" von Unternehmungen

1. Die Nichtbeachtung der allokativen Verfügungsentscheidungen in der Unternehmensbesteuerung

2. Die "Einkommenseigenschaft" von Unternehmensgewinnen im Lichte der Disponibilitäts- und organisations-Argumente

17) Anerkannt wird, daB die zurechnungseinkommen und die gegenständlichen Vermögenszugănge Einkommen darstellen; darin liegt die Akzeptanz des Zugangsprinzips im Grundsatzlichen.

$18)$ Widersprüchlicherwelse werden die Einzelfälle des zuzurechnenden Sparens wie auch der zuzurechnenden Vermögenswerterhbhungen nicht in den Einkommensbegriff aufgenommen. 
II. Das steuerpolitische Problem: Die Effektivität in

der Erreichung von Unternehmenszielen

1. Indikatorbezogene "Ertragsfähigkeitssteuer" versus gewinnbezogene "Allokationssteuer"

2. Besteuerung der Kapitalakkumulation

III. Das steuersystematische Problem: Die "Leistungsfähigkeit" in den Konzepten der Unternehmensbesteuerung

1. Extrempositionen objektivierter und personalisierter Konzepte

2. Ausgestaltung und "Leistungsfähigkeits"-Gehalt objektivierter Unternehmensbesteuerungsformen

I. Wir knüpfen an unsere Ausführungen zur angeblichen Leistungsfähigkelt von Unternehmungen in $\$ 20$ an und ergänzen wie folgt:

1 . In $\$ 11$ hatten wir herausgearbeitet, daß in personalen Institutionen des Wirtschaftens (Individuen und private Haushalte) die Verfügungen das Einkommen und das Vermögen betreffen, in den nichtpersonalen Institutionen (Unternehmen) dagegen den Ertrag und das Kapital. Distributive Verfügungen richten sich auf die Erzielung und Verwendung (von Einkommen und Vermögen) und begründen bzw. verändern solchermaBen die Versorgung und die Vertellungsposition der Individuen und Haushalte. Allokative Verfügungen richțen sich auf die unternehmerischen und produktionswirtschaftlichen Abläufe und letztlich auf die Transformation des Unternehmensgewinns in personales Einkommen; Umfang und Inhalt dieser Verfügung bestimmen sich letztlich nach der Unternehmereigenschaft des Verfügers. Für die Abgrenzung der allokativen von den distributiven Verfügungen gilt als Kriterium das Verfügungsziel, gilt das vom Entscheider $G$ e $w \circ 1 \mathrm{l} e$. Eine solche Abgrenzungsnotwendigkeit tritt immer dann ein, wenn der Entscheider Einzel- bzw. Mitunternehmer wie auch Einkommensbezleher in einer Person ist und eine Transformationsentscheidung fält uber die Verwendung des Gewinns: Bestimmt er den Gewinn zur Reservebildung oder Investition, ist das eine allokative Verfügung; bestimmt er ihn zur Entnahme, ist diese Verfügung ebenfalls eine allokative, denn dieser Gewinnanteil ist die Entlohnung für die unternehmerische dispositive Arbeit und für den Kapitaleinsatz. ${ }^{1)}$ Erst die tatsächliche Entnahme des Gewinns, also seine Entgegennahme in der Privatsphäre, ist Einkommenserzielung.

Fn. 1 auf der folgenden seite. 
Demgegenüber ist bei Kapitalgesellschaften bzw. juristischen Personen der Unternehmer und der Anteilseigner nicht unbedingt dieselbe Person. Als Unternehmer fungiert der unter Vertrag genommene Manager, der Antellseigner hingegen gilt als Kapitalanleger. Seine verfügungsmacht beschränkt sich - entsprechend der gesellschaftrechtlichen bzw. der vertraglichen Regelung - u.U.

allein auf die Mitwirkung bei dem Beschluß iber die Gewinnverwendung. So eindeutig aber auch die Verfügungsmacht des Kapitalanteilseigners letztlich auf die Einkommenserzielung aus der Rapitalanlage gerichtet sein mag, so eindeutig ist seine Entscheidung luber die Gewinnverwendung und die Ausschüttung zunächst einmal eine allokative: Der Faktor Rapital soll - wie hoch auch immer entlohnt werden. Erst die Inempfangnahme dieser Entlohnung ist für ihn Einkommen.

Gemeinsam für Unternehmer und Nichtunternehmer labt sich also festhalten: Die Frage der Disponibilität von Gewinnanteilen ist unter dem Aspekt der in $\$ 8$ entwickelten "Zugangsregel" dahingehend $z u$ beantworten, daB alles, was dem einzelnen als Entnahme bzw. Ausschüttung zugeht, Einkommen ist, daB aber alles, was ihm nicht zugeht, nicht Einkommen sein kann, auch wenn es sich un Gewinnantelle handelt, die $1 \mathrm{hm}$ "zurechenbar" sind. Die Zurechenbarkelt 1st zwar die Voraussetzung der freien Verfügbarkeit, doch entscheldend für die Einkommensqualität ist die tatsächlich Verfügbarkeit.

Soweit die Idealvorstellung aus der sicht der wirtschaftstheoretischen Analyse bei Anwendung auf den steuerlichen Einkommensbegriff und auf die Unternehmensbesteuerung. Wie aber sieht die steuerliche Praxis aus? Zunächst ist festzustellen, daB es eine rein aus der allokativen Sicht erklärbare und begrundete Besteuerung des Unternehmensgewinns als "Unternehmungsteuer" oder "Betriebsteuer" nicht gibt. Statt dessen existiert eine "dualistische" Besteuerung der Erträge bzw. "Einkommen" je nach der Rechts-

1) Selbst eine "ubermäBig hohe" Gewinnverwendung zur Entnahme ist zunächst Entlohnung des dispositiven Faktors, ohne daB hier ein der "verdeckten Gewinnausschütung" etwa vergleichbarer Tatbestand vorläge oder die Gefahr einer Steuervermeidung entstüde; denn erstens wird der Wettbewerb daruber entscheiden, eine wie hohe Entlohnung der Unternehmer sich erlauben darf, und zweitens wird ja die Entnahme "in derselben logischen Sekunde" zu Einkommen, das der Besteuerung unterliegt. 
form der Unternehmen. Für natürliche Personen (Einzelunternehmer, Mitunternehmer und Nichtunternehmer) gilt: Gewinne werden als Einkommen definiert, bei Nicht-Unternehmern als Einkünfte aus Kapitalvermögen, bei allen anderen als Einkünfte aus Gewerbebetrieb. Die Gewinne werden - ob entnommen oder im Unternehmen belassen den Einzel- bzw. Mitunternehmern zugerechnet und von ihnen als ihr persönliches Einkommen progressiv versteuert. Thesaurierte Gewinne der juristischen Personen sind Erträge der Unternehmen (in $\S \S 7 \mathrm{ff}$. KStG gleichwohl als "Einkommen" bezeichnet) und unterliegen der "Körperschaftsteuer".

Die Konstruktion des Anrechnungsverfahrens macht aus der Körperschaftsteuer zwei qualitativ verschiedene Steuerarten: Eine Unternehmensteuer in Form der Gewinnsteuer und eine von der Gesellschaft im Quellenabzug zu erhebende und zu zahlende Personalsteuer (als anrechenbare Einkommensteuer des Anteilsinhabers). Die Gewinnbesteuerung im deutschen steuersystem ist also trotz der in allen Unternehmungen identischen allokativen Funktion von Kapital und Ertrag unterschiedlich, und zwar nach der Rechtsform und der Ausschüttungsabsicht. Aber Erträge des Unternehmens können niemandem persönlich zugerechnet werden ${ }^{2}$ ).

2. Wie sieht die steuerwissenschaftliche Würdigung der Diskrepanz zwischen wirtschaftstheoretischer und steuerlicher Lösung aus? Die Konsequenz aus der dargestellten differenzierten Verfügbarkeit wird zunächst nur für die Anteilseigner rückhaltlos gezogen:

a) "Für eine differenzierte Besteuerung von Gewinnen juristischer Personen spricht ...., daB die Anteilseigner unmittelbar nur über die ausgeschütteten Gewinne bestimmen können, daB aber ihr EinfluB auf die Höhe und Verwendung nicht ausgeschütteter Gewinne ... nur gering ist, was eine eigenständige Besteuerung dieser Gewinne nahe legt" (W. Albers 1979a, S. 195) 3), zumal sich einbehaltene Gewinne von Aktiengesellschaften zumindest für die kleinaktionäre

$2)$ So die Kritik von K. Tipke (1981a, S. 100) an der Teilhabersteuer von Engels/Stützel. Derselbe Fehler wird wiederholt in dem Vorschlag einer Staatsbürgersteuer von Engels/Mitschke/ Starkloff 1973, S. 11 u. S. 15 ff.; dort sollen nämlich die Einkünfte der Körperschaften in die persönlichen Einkommen einbezogen werden, und zwar in Form der Teilhabersteuer.

Fn. 3 auf der folgenden seite. 
als "reichlich imaginäre" erweisen können (G. Krause-Junk 1981 , S. 265). 4) In dieser Argumentation liegt das Gewicht eindeutig in $\operatorname{der} D i s p \circ n i b i l i t a t$. Notwendigerweise muB die Unternehmenssteuer von der Einkommensteuer verschieden sein. Auch K. Tipke stellt fest (1980c, S. 1080): "So sind Gewinne, die die Kapitalgesellschaft nicht ausschüttet, für die Anteilseigner rechtlich und wirtschaftlich nicht disponibel; sie sind kein den Anteilseignern zurechenbares Einkommen." Und an anderer Stelle (K. Tipke 1981a, S. 100 f.): "Erst auf Grund der Ausschüttungen können die Gesellschafter über die (ausgeschütteten) Mittel verfügen. Thesaurierte Gewinne stehen thnen ... nicht zur Verfügung." Bis hierher ist eine völlige Ubereinstimmung der rechtlichen und der wirtschaftlichen Betrachtung des Problems festzustellen.

b) Neben dem Versuch, eine eigenständige bzw. besondere Unternehmensbesteuerung mit Disponibilitätsargumenten $\mathrm{z} u$ begründen, steht die Diskussion um die steuerliche Leistungsfähigkeit der Unternehmungen aus dem "I $n s t i t u t i \circ n s "$ - oder "Organ $i$ sations a r gument". 5) R. Fecht (1979, s. 219 f.) sieht in den Kapitalgesellschaften eigenständige organisationen mit durch das Management selbständig wahrgenommenen Interessen und selbständig getroffenen Entscheidungen, unabhängig von den Interessen der Anteilseigner. Insofern sei "zwischen einem Individuum und bestimmten Körperschaften in ihrer Funktion als $\mathrm{E} i \mathrm{n} \mathrm{k} \circ \mathrm{m} \mathrm{m}$ e $\mathrm{s}$ b e $\mathrm{z} i \mathrm{e} \mathrm{h}$ e (Hervorhebung HDH) kein Unterschied $z u$ sehen", falls man den körperschaften "den gleichen Status als autonome Entscheidungsträger zubilligt". Eine ähnliche Auffassung vertritt K. Schredelseker (1975, S. 325), der fordert,

3 ) M.a.W. der ausschüttbare, also noch nicht ausgeschüttete Gewinn ist ebensowenig Einkommen wie der thesaurierte, der zur Ausschüttung gar nicht erst vorgesehen ist. "Eigenständig" sollte hier buchstäblich verstanden werden: das heiBt nicht etwa eine zusätzliche Besteuerung, sondern eine steuer eigener, selbständiger Art, soll heißen anderer Art als der Einkommensteuer .

4) Allerdings ist Krause-Junk (ebda) der Meinung, daB sich am ehesten noch Vermögen und Einkommen der privaten Unternehmen entsprechend den Eigentumsverhältnissen zurechnen lieBen, auch wenn unmittelbar keine Verfügungsmacht bestünde. Demnach wären nicht entnommene Gewinne Einkommen, nicht ausgeschüttete dagegegen nicht.

5) Nach w. Koch 1955, S. 8 f. sind dies die wirtschaftssoziologischen Verschiedenheiten zwischen den Einzelunternehmungen und den meisten Kapitalgesellschaften. 
die Steuerwissenschaft solle endlich anerkennen, was die Betriebswirtschaftslehre mit ihrer systemtheorie, die Volkswirtschaftslehre mit der Anerkennung autonomer, von den Eigentumerinteressen losgelöster Wirtschaftseinheiten, die Soziologie mit der Theorie der institutionell verselbständigten organisationen längst bewiesen habe, nämlich die Existenz von Organisationen, die "oberhalb der Summe 1hrer Mitglieder" bestehen (S. 325). Wenn man nur der naturlichen Person eine Leistungsfähigkeit zuerkenne und dennoch Unternehmen besteuere, so sel das eine "individualistisch verkürzte" Unternehmensbesteuerung (s. 324).

Einer solchen institutionalistischen und organizistischen Argumentationsweise 6) läBt sich - von der Durchschlagskraft "systemtheoretischer" und "sozlologischer" Bewelse abgesehen - wie folgt begegnen: Zwar ist zuzugeben, da $B$ in den Unternehmen autonome Entscheidungen getroffen werden und daB die Unternehmen als verselbständigte organisationsformen bestehen; aber was ist damit bewiesen? Etwa, daB das Management eigene unternehmerische Entscheidungen trifft? Dazu bedarf es nicht dieses argumentativen Aufwandes.

Wenn GroBaktionäre oder Vorstände das Kapitalerhaltungs- oder -mehrungsinteresse der Unternehmen $z u$ Lasten der Kleinaktionäre durchsetzen, so liegen ja diesen Handlungen gerade rein allokative Entscheidungen zugrunde, die diese Art der Gewinnverwendung keinesfalls zu Einkommen machen. Die Eigenständigkeit in Institutionen und organisationen macht aus der Entscheidung über ein ökonomische GröBe noch kein Einkommen. Nicht d a B die Unternehmen

6) Sie stellt im allgemeinen auf den Gegensatz zwischen Kapitalund Personengesellschaften ab (sofern wir einmal die Entscheidungsabläufe in den letzteren annähernd jenen in Einzelunternehmen gleichsetzen); doch schon die Existenz von "Zwischenrechtsformen", wie die "kapitalistische Personengesellschaft" und die "personenbezogene Kapitalgesellschaft" zeigen, daB es an den wirtschaftlichen Realitäten vorbeigeht, eine "reine" rechtsformabhängige duale Besteuerung durchzufuhren; die Konstruktion der Zwischenrechtsformen ist das zugeständnis der Rechtspolitik an die Variabilität der Wirklichkelt im Hinblick auf die Entscheidungsinstitutionen. Siehe auch W. Albers 1979a, S. 196 .

7) D. Pohmer (1955, S. 385 f.) hatte ähnlich argumentiert: Kapitalgesellschaften sähen die Aufspaltung einer einheitlichen Unternehmerfunktion in Geschäftsführer und Risikoträger vor. K. Schmidt (1963, S. 37) welst nun nach, daB je nach organisationsform die Ubergänge flieBend sein können und sich eine eindeutige Trennung der Kapital- und Personengesellschaften nicht herstellen lasse. 
eine autonome Entscheidung treffen, sondern nur, we $1 \mathrm{c} \mathrm{h}$ e $r$ A $r t$ diese Entscheidung ist, kann für die Einkommensqualität der ökonomischen GröBe wesentlich sein. Und die Art der Entscheidung betrifft das Verfügungsziel: Gewinnthesaurierung oder Gewinnausschüttung; beides sind allokative Entscheidungen und betreffen den $E r t r a g$, nicht das Einkommen.

Schredelseker mag das Richtige meinen, wenn er feststellt (S. 325), daB sich die Finanzwissenschaft längst von der "utilitaristischindividualistischen Steuerrechtfertigungslehre gelöst" habe; nur: Eine Steuerrechtfertigungslehre hat nichts $\mathrm{zu}$ tun mit einem Steuerlastverteilungsprinzip, und letzteres will das Leistungsfähigkeitsprinzip sein, nichts anderes. DaB das Leistungsfähigkeitsprinzip auch seinerseits "utilitaristisch-individualistisch" interpretiert wurde, steht auf einem anderen Blatt. DaB der ultilitaristische Interpretationsversuch fehlging, ist heute längst erkannt; doch eindeutig wird das Lastverteilungsprinzip als ein individualistisches gesehen, als der Versuch, nach einer politisch akzeptierten Vorstellung die Steuerlast auf die Individuen $z u$ verteilen. Was aufgegeben wurde, ist der Versuch, diese Lastenverteilung nach Nutzenkurven $z u$ begründen; was aber beibehalten wird und was ökonomisch und politisch auch gar nicht anders möglich sein kann, ist die Lastverteilung auf Individuen, denn die Analyse der entstandenen und durch Besteuerung geminderten Einkommen ist ja gerade der Gegenstand der "personellen Verteilung". Solange eine Gesellschaft grundsätzlich nicht "organizistisch-kollektivistisch" (F. Neumark 1959, S. 96) organisiert ist sondern eher individualistisch in dem Sinne, daB über die ökonomische Lage und die soziale Stellung in erster Linie die eigene Leistung und Selbstbestimmung entscheidet, ist auch die Verteilung der steuerlasten konsequenterweise individualistisch, wird sie also ausgerichtet am individuellen Einkommen und Vermögen. Wenn dennoch neben den Personalsteuern Ertragsteuern erhoben werden, so wollen diese gar nicht "individualistische" Steuern sein; also kann eine Unternehmensteuer nicht als "individualistisch verkürzt" bezeichnet werden.

Auch D. Schneider (1990, S. 159ff) versucht, die Leistungsfähigkeit von Unternehmen und die Einkommenseigenschaft von Gewinnen anhand der organisationsstruktur von Unternehmung und Unter- 
nehmer bzw. Anteilseigner $z u$ belegen.

8) Er geht von den beiden Grundsätzen aus, daB stets die Organisation im Interesse der sie $\mathrm{b}$ e $\mathrm{h}$ e $\mathrm{r} s \mathrm{c}$ h e $\mathrm{n}$ d e $\mathrm{n}$ (Hervorhebung $\mathrm{HDH}$ ) natürlichen Personen handelt, und daB eine steuerliche Belastung nur natürliche Personen empfinden können (S. 159).

9) Schneider differenziert die Organisationsstruktur zunächst nach der "wirtschaftlichen Einheit" ihrer Organisationsglieder im Hinblick auf die Gleichheit der Interessenslage, ferner nach der Gewinnverwendung (Ausschüttung oder Thesaurierung) :

Für Kapitalgesellschaften, die "mit ihren wirtschaftlichen Anteilseignern eine wirtschaftliche Einheit" bilden ("alle Kapitalgesellschaften aus der Sicht eines die Mehrheit Besitzenden", wie Einmann-GmbH, Familien-AG), sind die Gewinne, soweit sie den leitenden Anteilseignern zustehen, als Einkommen der die Kapitalgesellschaft leitenden Anteilseigner anzusehen. Dem können wir nach dem oben Gesagten nicht zustimmen; solange diese Gewinne den Anteilseignern zwar zurechenbar, aber noch nicht ausgeschüttet (oder entnommen) sind, kann kein Einkommen mit der Eigenschaft der freien Verfügbarkeit vorliegen. Die Beherrschungs- und Entscheidungsmacht kraft "wirtschaftlicher Einheit" stellt zwar eine

8) Hier ist ebenfalls zu beachten, daB Schneider die Frage prüft, ob eine "selbständige" Ertragsbesteuerung von Organisationen "neben" die Einkommensbesteuerung von natürlichen Personen treten darf; diese Untersuchung dient zwar der Begründung der Körperschaftsteuer, doch lassen sich aus ihr auch für unsere Fragestellung unterstützende und Gegenargumente herleiten.

9) Daher scheiden Organisationen, hinter denen keine gewinnberechtigten natürlichen Personen stehen, wie Gewerbebetriebe der offentlichen Hand oder Stiftungen, aus unserer Betrachtung aus; Probleme, die hier entstehen können, sind in erster Linie ordnungspolitischer und wettbewerbspolitischer Art.

10) Insofern ist auch die Steuerzahlung, die Schneider völlig zu recht als eine "ertragsabhängige" kennzeichnet, keine Steuerbelastung des "Einkommens dieser Gesellschaften". Wie Schneider in einem der oben genannten Grundsätze sagt, können nur natürliche Personen eine steuerliche Last empfinden, so daB eine "Steuerbelastung ... dieser Gesellschaften" nicht denkbar ist. Wie überdies Schneider an anderen Stellen ausführt $11978 \mathrm{~b}$, S. 35,36 u. 38), ist Einkommen das finanzielle Ergebnis der "persönlichen" Unternehmenstätigkeit; ist Einkommen der Betrag, den "eine Person ... konsumieren" darf; ist Einkommen ein UberschuB, über den die Mitglieder eines "Haushalts verfügen können, nicht der UberschuB eines Betriebs oder eines einzelnen Ubernehmungsmittels (erstes Abgrenzungsmerkmal zu den Begriffen Gewinn und Reinertrag)". Diese Begriffsabgrenzungen halten wir, was ihren personalen Bezug angeht, für korrekt. 
interessensmotivierte Einheitlichkeit in der Entscheidung uber den Gewinn her, aber eine Einheitlichkeit in einer Allokationsentscheidung. 10)

Soweit nun Organisationen mit ihren Anteilseignern keine wirtschaftliche Einheit bilden, wie die Publikumsaktiengesellschaften, die Genossenschaften und die GmbHs mit ihren nichtgeschäftsführenden Minderheitsgesellschaftern, trennt Schneider zwischen ausgeschütteten und nicht ausgeschütteten Gewinnen. Die Ausschüttung ist Einkommen der Empfänger, ein Unterschied zwischen einem Minderheitsgesellschafter und einer die Kapitalgesellschaft beherrschenden Person existiert nicht. Wir halten dies für korrekt und in Ubereinstimmung mit der oben entwickelten zugangsregel und dem Verfügbarkeitskriterium .

Sind nun aber die nicht ausgeschütteten Gewinne als Einkommen der Anteilseigner anzusehen? Bei Mehrheitsbesitzern bejaht Schneider die Einkommenseigenschaft dieser Gewinne, weil diese Personen die Gesellschaft $b$ e $h$ e $r$ s $c h$ e $n$ und weil diese Personen auch jene sind, die die Entscheidung treffen über die "Art der Einkommensverwendung" (1990, S.160) .11) Auch für Minderheitsbesitzer bejaht Schneider die Einkommensqualität der einbehaltenen Gewinne, weil sie durch ihre Kapitalhingabe einen "A n s p r u c h" auf das wirtschaftliche Ergebnis erwirkt häten (S. 160). Nach unserer Auffassung jedoch entscheiden die Minderheitsbesitzer über dieselben Gegenstände wie die Mehrheitsbesitzer, auch wenn sie sich nicht durchsetzen können und ihr Interesse vorwiegend distributiver Art (Ausschüttung) sein sollte: Entweder sie beschlieben die Thesaurierung aus den oben angeführten allokativen Gründen, oder sie befürworten die (eigene) Faktorentlohnung, welche eben-

Fn. 10 auf der vorigen seite.

11) Abgesehen davon, daB auch hier ein begrifflicher widerspruch vorliegt, weil die Entscheidung nicht die Einkommens-, sondern die Ertragsverwendung betrifft, ist der Entscheidungsinhalt eindeutig allokativer Art: Entschieden wird die Nichtausschüttung mit Blick auf die Finanzierung und die Kapitalmarktlage (Selbstfinanzierung / Schütt aus - Hol zurück), auf die Dividendenpolitik, auf die Liquiditätslage, die Abschreibungs-, Reserven- und Rentabilitätsverschleierungspolitik usw. Die Beherrschungsmacht der Mehrheitsbesitzer zeigt sich ausschlieBlich in den unternehmenspolitischen Mechanismen und gerade nicht in der privaten verfügbarkeit. Überdies ein widerspruch zu s. 159, wonach Institutionen kein Einkommen haben können. 
falls eine allokative Entscheidung ist. 12) Uberdies ist ein "Anspruch" ein Begriff aus der Rechtslehre, der mit den ansonsten angezogenen Gründen einer "wirtschaftlichen" Beherrschung und der tatsächlichen Verfügung über ökonomische Größen in Form von zugeflossenen "Ausschüttungen" nicht denselben Realitätsgrad der einkommenswirksamen Vorgänge gemein hat. Dies ist überhaupt das Uberraschende in der Argumentationsmethodik schneiders, daß er bei der Begründung der Einkommenseigenschaft die Argumentationsebene von den Mehrheitseignern zu den Minderheitseignern wechselt. Thesaurierte Gewinne sind für die Mehrheitsaktionäre deswegen Einkommen, weil sie die Gesellschaft tatsächlich $b$ e $h$ e $r \mathrm{~s} c h$ e $n$. Für die Minderheitsaktionäre jedoch sind die thesaurierten Gewinne deswegen Einkommen, weil sie einen "A $n s p r u c h$ " haben. Die eine Gruppe beherrscht (nämlich die Gesellschaft), die andere beansprucht (nämlich eine Auszahlung). Für die Minderheitsaktionäre also wird, da eine unternehmerische Entscheidungs- und verfügungsgewalt nicht zu ausgemacht wird, gleichwohl aber die Einkommenseigenschaft begründet werden soll, das Beherrschungsparadigma ausgetauscht gegen das Anspruchsparadigma. Der Paradigmenwechsel ist aber um so erstaunlicher, als Schneider an anderer stelle (1978b, S. 35) der $E n t s c h$ e 1 d u $n g$ allein die schlüsselrolle im unternehmerischen Bereich zuschreibt: Man könne "Unternehmung nur von der Person des oder der Entscheidenden her definieren". Somit wäre auch für Minderheitsaktionăre die (hier eingeschrankt vorhandene) Entscheidungsbefugnis als Kriterium heranzuziehen gewesen. Dann hätte sich ergeben müssen, daB bel ihnen die Einkommensqualität der Erträge $z u$ verneinen gewesen wäre. So aber ist abschlieBend festzuhalten, daB "keineswegs" der "SchluB von den Kompetenzen der Organe einer Kapitalgesellschaft auf die Leistungsfahigkeit letzterer zulässig" ist (H. Fecher 1979, S. 480).

12) Wenn Schneider tatsächlich der Meinung ist, daß die Mehrheit sich auf Kosten der Minderheit "bereichern" kann, so ist die Frage der Verhinderung dieser Politik nicht durch das Steuerrecht, sondern durch das Wirtschaftsrecht zu lösen, so ändert der (moralisch evtl. nicht gebilligte) Bereicherungsvorgang nichts daran, daB sich die Mehrheit am Ertrag, nicht am Einkommen, "bereichert". Es kann nicht der Sinn des Steuerrechts sein, durch ein Umdefinieren von Wirklichkeitsvorgängen im allokativen Bereich in Einkommen ein wirtschaftliches Verhalten $z u$ beeinflussen. Wie Schneider richtig sagt (S. 160), liegt im Ertrag des Unternehmens als dem Ergebnis des Kapitaleinsatzes eben nur ein "Anspruch auf das wirtschaftliche Ergebnis". 
c) Übereinstimmung in den steuerwissenschaftlichen Auffassungen liegt vor hinsichtlich der Gewinnausschüttungen an die Anteilseigner von Kapitalgesellschaften und der Gewinnentnahmen seitens der Einzelunternehmer und Personengesellschafter: Diese Art der Gewinnverwendung ist Einkommen. Damit ist sowohl die von den Steuerwissenschaften angestrebte Gleichbehandlung der Personen erreicht, denen diese Gewinne zugehen, als auch eine Ubereinstimmung der wirtschaftstheoretischen Analyse mit der steuerpraktischen Regelung. Aber dies ist im Grunde keine Frage der "Unternehmensbesteuerung", sondern eine solche der Personalbesteuerung.

Hinsichtlich der Unternehmensbesteuerung, d.h. der Besteuerung der im Unternehmen verbleibenden Gewinne, bestehen Auffassungsgegensätze. Aber es läBt sich mit den Disponibilitäts- und Organisationsargumenten weder begründen, warum diese Gewinne Einkommen und warum Unternehmen "leistungsfähigkeitsorientiert" $z u$ besteuern sind, noch läBt sich begründen, warum die thesaurierten Gewinne in Rapitalgesellschaften anders zu besteuern sind als in Personengesellschaften oder bei Einzelunternehmern.

II. Eine Besteuerung der Unternehmen nach der "Leistungsfähigke1t" hat nur Sinn, wenn man in der Lage ist anzugeben, welche $s t e u-$ e r p l i $t$ is c h e $\mathrm{z}$ i e 1 e mit ihr verfolgt werden sollen. Liegen dem Leistungsfähigkeitspostulat eindeutig distributive Motive zugrunde, so müBten sich für die Unternehmensbesteuerung entweder ebensolche distributionspolitischen ziele ausmachen lassen, ein widerspruch in sich, wie wir glauben nachweisen zu können; oder es müBten sich allokationspolitische ziele, wie die Erleichterung der Kapitalerhaltung und -beschaffung oder auch die Wettbewerbsneutralität, angeben lassen, die sich ausschlieblich mithilfe eines auf den individuellen Betrieb abgestellten Besteuerungsprinzips erreichen lassen oder jedenfalls effektiver erreichen lassen als ohne ein solches Prinzip. Denn das wäre die Rechtfertigung für die Inthronisierung eines Besteuerungsprinzips: Die Effektivität in der Zielerreichung. ${ }^{13)}$

1. Man müBte sich Klarheit darüber verschaffen, was denn die "Faszination" elnerseits einer "leistungsfähigkeitsorientierten", andererseits einer ausschlieblich allokativ motivierten Unternehmens-

13) Fiskalpolitische ziele sind hier, wenngleich unbestritten, ausgeklammert, da sie nicht problematisiert werden. 
besteuerung ausmacht. Wenn Besteuerung nach der Leistungsfähigkeit - die auch Besteuerung nach der "Verhältnismäßigkeit" genannt wird (F. Neumark 1970, s. 121 ff.) - bedeutet, die "persönlich-individuellen" Verhältnisse des steuerpflichtigen für seine steuertragfähigkeit entscheiden $z u$ lassen, was könnte das für die Unternehmensbesteuerung analog bedeuten?

a) Sind es im persönlich-individuellen Bereich bestimmte sozioökonomische Merkmale, so müBten es im "betrieblich-individuellen" Bereich betriebsbezogene, objektive Indikatoren sein, die eine unterschiedliche betriebliche steuerfähigkeit auszudrücken in der Lage wären. Nach diesen müBte dann eine unterschiedliche Höhe der Steuer festgesetzt werden, sofern der Gedanke einer die "Leistungsfähigkeit" ausdrückenden Besteuerung im Unternehmensbereich überhaupt Sinn machen soll. Solche $I \mathrm{n} d \mathrm{i}$ a $\mathrm{t}$ o $\mathrm{e} n$ könnten z.B. die folgenden betriebs-individuellen sein:

(a) im Bereich der Faktoreffizienz:

(1) die erzeugte Gütermenge je eingesetzte Kapitaleinheit;

(2) die erzeugte Gütermenge je eingesetzte Arbeitseinheit;

(3) allokationswirtschaftlich positiv zu wertende (energieund ressourcensparende) Produktionsverfahren.

Hier müBten die unterschiedlichen Faktorbeschaffungsmöglichkeiten (regional und in der Finanzierung) ebenso berücksichtigt werden wie der vorhandene Informationsstand über die Produktionsverfahren.

(b) im Marktbereich:

(1) die Wettbewerbsposition am Beschaffungsmarkt für Faktoren;

(2) die Wettbewerbsposition am Absatzmarkt;

(3) die Wettbewerbsposition am Finanzmarkt.

Hier ist $z u$ entscheiden, welche Positionsveränderung an den Märkten vor und nach der Besteuerung noch als "neutral" zu gelten hat und wie die unterschiedlichen Finanzbeschaffungsmoglichkeiten in den Unternehmen verschiedener Rechtsformen $\mathrm{zu}$ beurteilen sind.

(c) im Ertragsbereich:

(1) die absolute Gewinnhöhe, evtl. angesichts einer Progression; 
(2) die verschiedenen Gewinnarten, wie Zufallsgewinne, windfall profits oder nur sog. "normale" Gewinne;

(3) bestimmte Gewinn-Faktor-Relationen, wie der Gewinn je eingesetzte Arbeitseinheit oder Kapitaleinheit;

(4) bestimmte andere Gewinn-Relationen wie Gewinn : Umsatz, Gewinn : Kosten, Gewinn : Investitionen usw.

Auch hier wird deutlich, daB im Zweifel ein ganzes Bündel von Normvorstellungen entwickelt werden muB, die angeben, ab welcher Gewinnhöhe oder -relationswertüberschreitung die je nach "Leistunasfähigkeit" unterschiedliche Besteuerung einzusetzen hätte.

Schon dieser kursorische Uberblick macht folgendes deutlich: Werden Normen vorgegeben, sind ordnungspolitische Wertungen impliziert; was der distributiv motivierten Besteuerung oftmals vorgeworfen wird, nämlich die Werturteilsabhängigkeit und Anfechtbarkeit ihrer Normen, würde auch im allokativen Bereich registriert werden müssen. Uberdies liegt der Schritt $\mathrm{zu}$ einer allokativen Sollbesteuerung sehr nahe, wodurch die bisherige ergebnisorientierte Besteuerung ihren Charakter vollständig ändern würde. Werden die für die Unternehmens-Besteuerung vorzugebenden Normen allzu rigoros gesetzt und mit erheblichen Steuersatzunterschieden gekoppelt, sind Störungen in der Faktorallokation $z u$ erwarten. Schlieblich ist elne recht komplizierte Normenvielfalt nicht auszuschlieBen; würde man nämlich einer "leistungsfähigkeitsorientierten" Unternehmensbesteuerung ausschlieblich die Gewinnhöhe zugrundelegen, lüde man sich den Vorwurf der Einseitigkeit auf, denn die Leistungsstärke einer Unternehmung zeigt sich nicht allein in der Gewinnhöhe (die überdies noch bilanziell manipulierbar ist), sondern auch in der Wettbewerbsposition, der Kapitalausstattung, dem Vorsprung in Fertigungstechniken, usw. Versucht man dagegen, den gesamten Katalog der Leistungsstärkeindikatoren a bis c $z$ u berücksichtigen, wird die Besteuerungstechnik kompliziert.

Ist die ertragsabhängige Belastbarkeit der Unternehmen mit Steuern beabsichtigt und werden zugleich die allokationspolitischen ziele wie die Nichtbeeinflussung der Faktorallokation, die Kapitalerhaltung, die Neutralität in der Finanzierung und im Wettbewerb, wirklich ernst genommen, so ist aus dem oben Gesagten $z u$ folgern, daB die Unternehmensbesteuerung gerade $n i c h t$ nach betrieblichindividuellen "Leistungsfähigkeits"-Indikatoren mit evtl. Steuer- 
satzunterschieden $\mathrm{zu}$ erfolgen hätte.

b) Demgegenüber liegt - vorausgesetzt, man will an der dualistischen Besteuerung der volkswirtschaftlichen Wertschöpfung im Zuge der Elnkommensentstehung durch eine Ertrag- plus Einkommensteuer festhalten - die "Faszination" der Unternehmensbesteuerung ohne das Leistungsfähigkeitsprinzip darin, daB eine "Allokationssteuer" auf $U n t e r n e h m e n s g e r i n n e$ die gröBere Chance hat, möglichst ohne die erwähnten Allokationsnachteile durchgeführt $z u$ werden. Weitgehend war das auch die Absicht der Betriebsteuer. Eine zielkonsistent ausgestaltete Allokationssteuer auf Gewinne würde im Ertrag das Ergebnis aus der betrieblichen Kombination beider Produktionsfaktoren erfassen, müBte sämtliche Kombinationsergebnisse - seien sie in gewerblichen Betrieben, seien sie in selbständiger Tätigkeit entstanden - umschließen und würde die steuerlich motivierten Manipulationen mit der Absicht der steuervermeidenden Betriebsspaltung, der Gründung von $\mathrm{GmbH}$ \& Co KG überflüssig machen (W. Flume 1974, S. 69; W. Albers 1979a, S. 196). Bei einem Verzicht auf eine Anknüpfung an besondere Indikatoren der Ertragsfähigkeit hätte sie bei weitem nicht mit so intensiven Verzerrungen der Allokation zu rechnen wie eine "indikatorbezogene" Ertragsbesteuerung. Allerdings liegt für eine "gewinnbezogene Allokationssteuer" die Gefahr des nicht gewollten Einflusses auf die Allokation in der Höhe des Steuersatzes. Sowe1t der Unternehmensgewinn im Unternehmen verbleibt, ist es nach w. Flume sachgerecht, ihn einer "objektivierten Unternehmensteuer" (1975) zu unterwerfen, die proportional $z u$ erfolgen habe (w. Flume 1971, S. 692; 1974, S. 68) und keinerle1 Beziehung zum Gerechtigkeitsproblem aufweise; die Höhe des Steuersatzes bestimme sich demnach nicht nach dem Spitzensatz der Einkommensteuer, sondern nach ZweckmäBigkeitsgesichtspunkten und der Funktion des Gewinns (W. Flume 1971, S. 693).

2. Analog zum privaten Bereich ist für den Unternehmensbereich zu prüfen, ob Kapitalakkumulation Leistungsfähigkeit anzeigt bzw. ob der $k$ a $p$ i $t$ l b e s t a $n$ Ausdruck der $E r t r a g s-$ $f \ddot{a} h$ i g $k e i t$ ist.

a) Wäre die von den Unternehmen zu zahlende Vermögensteuer der Ausdruck einer "Leistungsfähigkeit" (evtl. einer solchen, die mit der Kapitalhöhe zunimmt), müBte diese Steuer leistungsdifferen- 
ziert ausgestaltet sein, so z.B. nach der Bestandshöhe, nach bestimmten Relationen zwischen Bestand und erzeugter Lelstungsstückzahl oder nach bestimmten Relationen zwischen Kapitalbestand und Gewinn. Sie ist es gegenwärtig nicht; vielmehr wird sie auch dann erhoben, wenn eine Leistung in Form eines Ertrages uberhaupt nicht vorliegt; sie wird ferner in der gleichen Weise erhoben wie von den Privaten, nämlich bei Einzelunternehmern und Mitunternehmern als eine persönliche Steuer unter Berücksichtigung persönlicher Freibeträge, und sie wird schlieblich nach den Rechtsformen der Unternehmen differenziert erhoben: "natürliche" Unternehmer zahlen 0,5 \& des steuerpflichtigen vermögens an vermögensteuer; körperschaften, Personenvereinigungen und vermögensmassen (also insbesondere die Kapitalgesellschaften) zahlen hingegen $0,68.14$ )

Kritisch ist also zur Vermögensteuer der Unternehmen $z u$ vermerken, dab sie nicht rechtsformneutral ist, daB sie innerhalb bestimmter Rechtsformen (hier der Einzelunternehmen und Personengesellschaften) eine Trennung des allokativ-betrieblichen Kapitalbereichs vom distributiv-privaten Vermögensbereich nicht kennt und daB sie in ihrer Form als ertragsunabhängige sollsteuer nicht "leistungsdifferenziert" zugreift. Von dieser Kritik grundsătzlich $z u$ trennen ist aber die Frage, ob denn überhaupt die Besteuerung eines Kapitalbestandes im Unternehmensbereich ahnlich sinnvoll ist wie die Besteuerung eines Vermögensbestandes im privaten Bereich, ob also die distributiven Leistungsfähigkeitsvorstellungen einfach $z u$ übertragen sind auf die betriebliche sphäre. ${ }^{15)}$

14) Zwar liegt hierin die Unterstellung, daB Kapitalgesellschaftsvermögen möglicherweise wegen der bel ihnen vermuteten gröBeren Bestandshöhe ertragreicher einzusetzen 1st, doch: "Der Sondersteuersatz für das Vermögen von Kapitalgesellschaften und anderen Körperschaften ... ist m.E. nicht $z$ u rechtfertigen. Es gibt sicher gute Gründe dafür, das Betriebsvermögen vermögenssteuerlich anders $\mathrm{zu}$ belasten als das Privatvermögen. Die unterschiedliche Belastung des Betriebsvermögens von Einzelunternehmern und Mitunternehmern einerseits und des Betrlebsvermögens von Kapitalgesellschaften andererseits ist aber nicht einsichtig. Die Leistungsfähigkeit muB an der Höhe des Vermögens, sie kann aber nicht an der Rechtsform gemessen werden" (K. Tipke 1980c, S. 1082).

15) Wir fassen hier die vermögensteuerlichen und die gewinnsteuerlichen Argumente zusammen und diskutieren sie anhand der Funktionen, die das Kapital für die Unternehmen hat; siehe hlerzu auch \$ 10 III. 
b) Ob überhaupt der Kapitalbestand - wie auch die durch Gewinnthesaurierung ermöglichte Kapitalakkumulation - besteuert werden soll, läBt sich zum einen mit allokationspolitischen, $z$ um anderen mit distributionspolitischen Argumenten beantworten. Für eine weitestgehende, wenn nicht völlige steuerliche schonung des Kapitals spricht zunächst seine "Produktionsfunktion": Die Aufrechterhaltung der produktionswirtschaftlichen Betätigung der Unternehmen auf kurze und mittelfristige sicht ist die Voraussetzung dafür, daB ein besteuerbarer Ertrag sowie ein besteuerbares Einkommen daraus entstehen können. Auch die "Risikofunktion" des Kapitals, die die Existenz des Unternehmens auf mitcel- bis langfristige sicht sichert und zugleich die kreditfahigkeit fundiert, erfordert eine steuerliche Schonung. Soll marktlich wie produktionswirtschaftlich eine Betriebserweiterung möglich sein, würde eine steuerliche Schonung bzw. Freistellung auch die "Ausdehnungsfunktion" des Kapitals stützen. Und warum sollte letztlich die steuerliche Unterstützung der "EinfluB"- oder "Beherrschungsfunktion" des Kapitals keine allokativen Vorteile bringen, wenn sie die Ressourcen- und Energiebeschaffung, die Produktion und den Absatz im Verbund mit anderen Unternehmen sichert? Die allokativen Argumente sprechen $z$ unächst einmal für eine deutliche Trennung der allokativen von der distributiven Sphäre des Wirtschaftens, um zu verhindern, daB Argumente, die im distributiven Bereich hinsichtlich des sparens und der Vermögensakkumulation vorgebracht werden, voreilig auf den allokativen Bereich übertragen werden.

c) Gegen eine allokativ motivierte Steuerbefreiung oder -schonung der Kapitalakkumulation wird aus der distributiven Sicht im wesentlichen das "S $p$ a - A r g u m e $t$ " vorgetragen, wenngleich es sich dabei um eine falsche Firmierung handelt, weil die Trennung der beiden Sphären des wirtschaftens nicht beachtet wird. Schon um die Gefahr der Steuerausweichung zu vermeiden, müsse nach $K$. Schmidt (1963, S. 39) der im Unternehmen belassene Gewinn "zweifellos" besteuert werden. Ahnlich argumentiert $H$. Schulte (1967, S. 41), da gerade die Betriebsteuer eine Art Zwischenbesteuerung von der Gewinnentstehung bis zur Ausschlittung garantieren könne; sie überbrücke "das Zeitintervall zwischen Gewinnerzielung und Einkommensbildung"; implizit häl auch er die Besteuerung der Kapitalakkumulation grundsätzlich für notwendig, 
und zwar aus distributiven Gründen.16) H. Weber nun befürchtet, daß bei Einführung der Betriebssteuer, die die thesaurierten Gewinne mit einem Steuersatz weit unter dem Einkommensteuer-Spitzensatz belegen wollte (seinerzeit wurden 25 \& vorgeschlagen), dazu einladen würde, daB die einbehaltenen Gewinne von Personengesel1schaften aus der Einkommensteuer "desertieren", d.h. im Unternehmen vermehrt angespart werden. ${ }^{17}$ ) Und tatsächlich wird immer wieder angeführt, das "Verstecken"18) privaten Vermögens im Unternehmen sei die hauptsächliche sparform der selbständigen und der Einzel- wie auch der Mitunternehmer. Und so führe die "Nichtentnahme", die hier sogleich als sparen bezeichnet wird, zu einer Kapitalakkumulation, die mit privater Vermögensakkumulation mit all ihren verteilungspolitischen Implikationen gleichgesetzt wird.

c 1) Das "D e s e r t i n s a g u m n t" - so wollen wir es nennen, weil damit die Flucht vor der Einkommensteuer ausgedrückt werden soll - ist nun allein deswegen nicht mit leichter Hand abzutun, weil der sparakt als solcher gewissermaBen auf der "Nahtstelle" zwischen dem Allokations- und dem Distributionsbereich des Wirtschaftens liegt. "Sparen" ist erstens abhängig von der Höhe des Einkommens und des bereits vorhandenen Vermögens (Sparfähigkeit), führt zweitens zur Vermögensakkumulation (was die Sparfähigkeit abermals erhöht). Die Vermögensakkumulation - hat sie ein allokativ interessantes und erforderliches AusmaB erreicht - beeinfluBt das Kapitalangebot dadurch, daB es im unternehmerischen Bereich als Faktor eingesetzt werden kann, entweder in Form der nichtunternehmerischen (Anteils-)Beteiligung oder in Form der unternehmerischen Betätigung. Allzuschnell wird nun Vermögensakkumulation mit Kapitalakkumulation, die allein

16) Aber Schulte irrt, wenn er das als eine Gleichbehandlung bezeichnet, denn Gewinn ist nicht gleich Einkommen. Wie bereits mehrfach dargelegt, ist eine "Gleichbehandiung" von Unternehmern und Nichtunternehmern nicht zwingend und ergibt sich auch nicht aus dem Gleichmäßigkeitspostulat.

17) Chr. Flämig (1981, S. 167) berichtet über diese AuBerung Webers auf der Arbeitssitzung der Steuerrechtlichen Abteilung des 53. Deutschen Juristentages.

18) Man muB hier zwei Arten des "Versteckens" unterscheiden: $z$ um einen in Form von Ausnutzen der Bewertungsfreiheiten, der Bildung von stillen Reserven usw. (das von allen Unternehmen, auch den Kapitalgesellschaften angewendet wird) und in der Form der Nichtentnahme, die zwar offen ausgewiesen ist, wobei jedoch das Verstecken in der Investierung (Einkleidung) in das Unternehmen besteht ("Verkleidung" könnte man sagen). 
in der Unternehmung denkbar ist, gleichgesetzt, was dazu führt, daB die werturteilsbehafteten Abneigungen, die man der Vermögensakkumulation entgegenbringt, auf die allokative Kapitalakkumulation übertragen wird (vgl. hierzu Ubersicht 3.1).

Was die Lage des Sparens auf der Nahtstelle zwischen Allokationsund Distributionsbereich angeht, so sind demnach zwei Abgrenzungen voranzustellen: Erstens ist privates Sparen, also das Sparen durch natürliche Personen, nur nach einem Einkommenszugang, nämlich als eine Einkommens-"Verwendung" möglich. Insofern ist die "Nichtentnahme" von betrieblichen Gewinnen, die dadurch gar nicht erst Einkommen werden können, keine Vermögens-, sondern Kapitalakkumulation. DaB evtl. der Entscheidung für die Nichtentnahme in erster Linie Steuervermeidungsmotive zugrunde liegen, die in diesem Falle $\mathrm{zu}$ einer Nichtverwirklichung des einkommensbegründeten Tatbestandes führen, ist vorerst nicht von Bedeutung. 19) Zweitens werden vom Desertionsargument, da nur private (natürliche) Personen über Einkommen verfügen und demnach sparen können, allein Einzel- und Mitunternehmer, nicht aber Kapitalgesellschaften betroffen; denn Kapitalgesellschaften akkumulieren durch den BeschluB zur Nichtausschüttung der Gewinne Kapital, und nicht entstandenes Einkommen kann nicht desertieren. 'Dennoch ist aber das Desertionsargument auch unter dem Aspekt der rechtsformneutralen Besteuerung zu sehen.

c 2) Nach solcher grundsätzlicher Abgrenzung kann dem Desertionsargument zunächst mit einem " $\mathrm{i}$ e $\mathrm{l}$ a $\mathrm{rg}$ u $\mathrm{m} \mathrm{n}$ " begegnet werden: Die steuerpolitische Entscheidung, in Unternehmen gleichwelcher Rechtsform thesaurierte Gewinne als Sparen der Person zu besteuern, bedeutet neben dem methodisch unzulässigen Hinüberziehen von distributionspolitischen Absichten in den allokativen Berelch insbesondere das Präferieren des verteilungspolitischen ziels vor dem allokativen. Wie an anderer stelle nachgewiesen wurde (\$\$ 7 u. 8), gehen die beiden für die Besteuerung stets als grundlegend herangezogenen Theorien, sowohl die Quellen- als auch die

19) Steuervermeidung selbstverständlich nur dann, wenn die steuersätze der persönlichen Einkommensteuer luber denen der Thesaurierungssteuer liegen, oder wenn das Nichtentnommene $\mathrm{zu}$ abzugsfähigen Betriebsausgaben führt. 
Reinvermögenszugangstheorie, davon aus, daB die der Kapitalerhaltung dienenden Ertragsanteile nicht als Einkommen $z$ definieren sind, insbesondere nicht als steuerliches Einkommen. Es läge in derselben Argumentationslinie, ausgehend von den o.g. ökonomischen Funktionen des Kapitals, auch die Kapitalneublldung nicht als zu versteuernden Gewinn anzusehen. Der Sinn einer schonenden Besteuerung oder Steuerbefreiung der Kapitalbildung kann in ordnungspolitischen und allokationswirtschaftlichen Vorteilen gesehen werden, die die Kapitalausstattung für die Unternehmen hat. Soweit nun befüchtet wird, daB auf diese Weise eine Uberkapitalisierung der Unternehmen stattfände, könnte - von steuersystematischen ErgänzungsmaBnahmen abgesehen - auf die Funktion des Wettbewerbs hingewiesen werden: Eine Uberkapitalisierung ist angesichts des marktlich $\mathrm{zu}$ erzielenden Gewinns unter Rentabilitätsaspekten niemals das unternehmenspolitische ziel, da sie immer mit einer EinbuBe an Kapitalverzinsung einhergeht. Die Funktionsfähigkeit des Wettbewerbs ${ }^{20}$ ) entscheidet somit letztlich darüber, inwieweit sich tberkapitalisierung begrenzen läBt. Diese Funktionsfähigkelt des Wettbewerbs herzustellen, ist Aufgabe der Wettbewerbspolitik, nicht der Steuerpolitik. Letztere kann nur die Bedingungen bereitstellen, unter denen Wettbewerb $z$ umindest nicht gestört wird (passive Wettbewerbspolitik). Zu diesen gehört freilich auch die Festlegung der Differenz zwischen den Steuersatzen auf die thesaurierten Gewinne und denen auf die persönlichen Einkommen. Die Ansicht, eine Uberkapitalisierung etwa mit Gerichtsurteilen und steueradministrativen MaBnahmen ${ }^{21}$ ) verhindern zu wollen, läBt sich anhand der theoretisch nicht schlüssigen Versuche widerlegen, das sog. "betriebsnotwendige" Kapital vom privaten oder nicht unbedingt betrlebsnotwendigen abzugrenzen (s. die Begriffe "notwendiges Betriebsvermögen", "gewillkürtes Betriebsvermögen" und

20) In Kapitalgesellschaften, die auf Kapitalmärkten um Finanzierungsmittel konkurrieren, kommt hinzu, daB einerseits die unternehmenspolitisch angestrebte Dividendenausschüttung zur Befriedigung der Aktionärswünsche, andererseits die kapitalmarktpolitisch angestrebte Förderung des Aktiensparens eine Grenze für die Uberkapitalisierung (in Form von Reservebildung und Uberabschreibung) bilden können.

21) Man übersehe nicht, daB das Einkommensteuerrecht den Begriff "Betriebsvermögen" voraussetzt, daB die Abgrenzungsversuche statt dessen in der Rechtsprechung, der Verwaltung und der Literatur angestellt werden; das Handelsrecht interessiert sich für eine solche Abgrenzung gar nicht, da der Kaufmann mit seinem gesamten Vermögen haftet; s. hierzu K. Tipke 1991, S. 296. 
"notwendiges Privatvermögen" im Steuerrecht). 22) Einziges wirtschaftstheoretisches Abgrenzungskriterium, wie wir es oben in $\S$ 7 und 10 entwickelt haben und wie es auch im Steuerrecht vertreten wird (K. Tipke 1981, S. 233) ist der Entscheidungsinhalt des Wirtschaftenden, ist der Zweck des Wirtschaftsgutes vom Standpunkt des Handelnden aus. 23) Steuerverwaltungsakte müssen dem folgen, sofern sie sich als im Einklang mit den rationalen Kriterien gerieren wollen.

Was hier nicht "bewiesen" werden soll, ist etwa die politische Notwendigkeit einer steuerschonenden Behandlung des Kapitals; was aber deutlich zu machen war, ist, daB eine steuerliche Belastung der einbehaltenen Gewinne und damit der Kapitalakkumulation nicht zwingend geboten und nicht mit der Leistungsfähigkeit begründbar ist und schon gar nicht als eine notwendige MaBnahme steuerlicher Gleichbehandlung gelten kann (weil Vermögen und Kapital nicht Gleiches sind), und daB eine Besteuerung der Kapitalakkumulation eine politische Entscheidung ist; ihr liegt die Präferenz eines allokationspolitischen ziels zugrunde.

c 3) Dem Desertionsargument läBt sich ferner ein "Tarif-oder $s t e u$ e s a $t z a r g u m$ e $n t "$ entgegenhalten. Zunächst mübte eine Allokationssteuer auf thesaurierte Gewinne einen proportionalen Satz aufweisen, da jeglicher Progressionstarif angesichts ungleich hoher absoluter Gewinne die Unternehmen mit den höheren Gewinnen benachteiligen würde (W. Albers 1979a, S. 212). Sind nun die Steuersätze für eine Unternehmensteuer auf einbehaltene Gewinne und die Einkommensteuer auf entnommene Gewinne gleich hoch, 24 ) besteht zwar keinerlei Desertionsgefahr, doch

22) K. Tipke 1981, S. 234 : "Die Einteilung in notwendiges Betriebsvermögen, gewillkürtes Betriebsvermögen und notwendiges Privatvermögen schadet mehr als daB sie nützt. Jedes Wirtschaftsgut kann nämlich je nach Situation zum Betriebs- oder zum Privatvermögen gehören. ... Nicht gefolgt werden kann insb. der Auffassung, gewillkürtes Betriebsvermögen setze keine betriebliche Funktion dieses Vermögens voraus, sondern werde allein durch Aufnahme des Wirtschaftsguts in die Buchfuhrung und die Bilanz, durch buchmäBigen Widmungsakt also, begründet. Buchführung und Bilanz müssen die Wirklichkeit widerspiegeln; ungekehrt geht es nicht."

23) Zumindest für das "gewillkürte" Betriebsvermögen wird die-Abgrenzung nach dem "Willen des Steuerpflichtigen" vorgenommen, s. G. Wöhe 1978 , S. 324 . 
existiert auch kein steuerlich induzierter Anreiz zur Kapitalbildung im Unternehmen.

Ohne eigenständige Unternehmensteuer würde sich, da das Progressivitätsmaß des Tarifs verteilungspolitisch und umverteilungspolitisch motiviert ist, eine ständige Abhängigkeit auch der Unternehmensgewinnbesteuerung von der Einkommensbesteuerung ergeben ${ }^{25)}$. Eine allokative Besteuerung befände sich stets im Schlepptau der distributiven.

Liegt nun der Thesaurierungssatz nur geringfügig unter dem Einkommensteuersatz, könnte sich ein Anreizeffekt allokativer Art einstellen, ohne daB das distributionspolitische Belastungsziel wesentlich beeinträchtigt wäre ${ }^{26)}$.

Je gröBer aber der Unterschied zwischen den beiden Steuersätzen wird - und dies hängt davon $a b$, in welchem Bereich der Progressionszone der Unternehmer sich mit seinem persönlichen Einkommen jeweils wiederfindet -, desto gewichtiger wird der allokative Kapitalbildungsanreiz. Denn gerade bei denjenigen Unternehmern wird der Steuersatzunterschied groß sein, die ein höheres persönliches Einkommen $\mathrm{zu}$ versteuern haben. Ob diese hoch verdienenden Unternehmer in großem Umfang Unternehmenskapital akkumulieren statt Gewinne $z u$ entnehmen, ist ja durchaus fraglich. Entnehmen sie,trifft sie die Einkommensteuer; das ist gewollt. Tun sie es nicht, ist das einerseits allokationspolitisch kein Nachteil, ist das andererseits auch distributionspolitisch wegen ihrer nunmehr geringeren persönlichen Leistungsfähigkeit eine zielkonforme Besteuerung.

24) Wir diskutieren hier nur die Besteuerung der Nicht-Kapitalgesellschaften, da für Kapitalgesellschaften eine Gefahr der Desertion nicht bestehen kann. Dennoch versucht $W$. Flume (1975) dieser Desertionsgefahr dadurch zu entgehen, daB er für Personen- wie Kapitalgesellschaften einen einheitlichen Steuersatz auf thesaurierte Gewinne (von z.B. 50 \%) anwenden will.

25) Es wäre also gerade nicht so, wie Chr. Flämig (1981, S. 167) vermutet, daB nämlich die Unternehmensbesteuerung ständigen Versuchen der Umverteilung und der zunehmenden Tendenz der Fiskalisierung ausgesetzt sei.

26) Die Kapitalbildungsförderung durch einen im Verhältnis zur Einkommensteuer niedrigeren Steuersatz hatte im Grunde auch bereits der WB BMF 1953 (Organische Steuerreform) akzeptiert. 
Wenn solchermaBen auch eine Abhängigkeit der allokativen Effekte von den distributiven Maßnahmen demonstriert werden kann, so wird dadurch die analytisch klare Trennung beider Bereiche und Wirkungen nicht überflüssig, wird doch gerade dadurch deutlich, daB eine Ubernahme des Leistungsfähigkeitsdenkens aus dem distributiven in den allokativen Bereich nicht erlaubt ist. Progressionselemente sind in einer Allokationssteuer Fremdkörper.

III. AbschlieBend soll aus der $s t e u$ e $r$ y $t$ e m a $t$ i s c h e $n$ sicht gefragt werden, wie die tatsächlichen und die in der Literatur vorgeschlagenen Formen der Unternehmensbesteuerung hinsichtlich der "Leistungsfähigkeit" von Unternehmungen $z u$ beurteilen sind und welche Konsequenzen sich für das Steuersystem ergeben, wenn in der Tat eine "sachlich-generische" Leistungsfähigkeit von Objekten (wie Vermögensgegenständen oder Betrieben) zu bejahen wăre.

1. Wenn man die praktizierte Unternehmensbesteuerung nebst älteren Regelungen und Reformvorschlägen in dem unten abgebildeten Kontinuum der $k \circ \mathrm{n} z \mathrm{e} t \mathrm{e}$ anordnet, das links mit einer vollig objektivierten Unternehmensbesteuerung beginnt und rechts mit e1ner vollig personalisierten endet, so läbt sich der Gehalt an Leistungsfahigkeitsgedanken in den einzelnen Besteuerungsformen ablesen. Ahnlich 1st die Breite der Bemessungsgrundlage fur die Besteuerung skaliert; sie beginnt links mit der breitest moglichen unternehmerischen Wertschbpfung, mundet dann sehr schnell in den Unternehmensertrag und verengt sich bereits ab dem folgenden Punkt zum Unternehmensgewinn (Ubersicht A.4).

Das Konzept " 0 " wurde in das Kontinuum aufgenommen, um einen extremen Standpunkt der Diskussion nicht zu übergehen und um seine Position hichsichtlich Breite der Bemessungsgrundlage und objektivierungsgehalt aufzuzeigen. Die Diskussion wird allerdings nicht unter dem Aspekt der Leistungsfähigkeit und der allokativdistributiven Bereichsabgrenzung gefuhrt. Es handelt sich um die Kontroverse "Mehrwertsteuer versus Körperschaftsteuer"; die Besteuerung soll rechtsformneutral durchgefüht werden: das allokative Interesse uberwiegt, wie aus den Motivationen einer Schonung 
der Gewinne im Sinne der Investitions- und Wachstumsanreize, der Wettbewerbsneutralität und der orientierung am Außenhandel hervorgeht. Auf Einzelheiten wird hier nicht eingegangen ${ }^{27)}$.

Die Einordnung der "Cash-Flow-Steuer"-Konzepte wurde auf Position

3 vorgenommen, weil sie sich als betriebsteuerähnliche Konzepte verstehen, demnach einen hohen Objektivierungsgehalt aufweisen und gegenüber Ertrag und Gewinn eine "ungewisse" Bemessungsgrundlage haben. Gro gesagt wird der Zahlungsüberschuß (also Einzahlungen minus Auszahlungen) besteurt; ein proportionaler Tarif, wie in der Betriebsteuer, soll Allokationsneutralität gewährleisten. Die Summe der Einzahlungen enthält die Verkäufe von Gütern und Vermögensgegenständen, die empfangenen Fremdfinanzierungsleistungen (wie Kreditaufnahme, Kreditrückzahlung von Schuldner uns zinseingänge). Die Summe der Auszahlungen setzt sich zusammen aus Käufen (von Material, Leistungen und Vermögen) aus Lohnzahlungen aus zahlungen zur Kredittilgung, Kreditkvergabe und für zinsen.

Daneben werden die folgenden Zahlungsvorgänge erfaßt: Unter den Einnahmen die empfangenen Zahlungen aus der Beteiligungsfinanzierung (Einlagen, Kapitalerhöhungen und Gewinnausschüttungen); unter den Ausgaben die Entnahmen aus Kapitalherabsetzungen, Auszahlungen im Zusammenhang mit Beteiligungen an anderen Unternehmungen und Gewinnausschüttungen. Das Ergbnis des Saldos "Einzahlungen minus Auszahlungen" ist die "Änderung des Zahlungsmittelbestandes" ( $z u$ erhöhen um die gezahlte cash flow-Steuer, zu mindern um erstattete cash flow-Steuer) 27 a).

27) Zu diesem Thema siehe die folgende Literatur: R. Peffekoven, Die Besteuerung des internationalen Handels in den USA, FA NF 28, 1969, S. $419 \mathrm{ff}$.; H. Mesenberg, Der steuerliche Ausgleich beim Grenzübergang im internationalen Handel, SR Steuerrecht und Steuerpolitik, H. 9, 1970; R.W. Lindholm, Integrating a Federal Value Added Tax with State and Local Sales Levies, NTJ 24, 1971, S. 410 f.; R. Peffekoven, Das Bestimmungs- und Ursprungslandprinzip bei Steuern im grenzüberschreitenden Verkehr, SVS NF 68, 1972; S.P. Dresch, A. Lin und D.K. Stout, Value Added Tax for the Corporative Income Tax, First Round Analysis, Cambridge/Mass. 1977; R. Peffekoven, Die Besteuerung des internationalen Handels, Wist 1978; M. Höhn, Zur Diskussion "Mehrwertsteuer versus Körperschaftsteuer", Bochum 1980 (untersucht die MWSt in der Form des Vorsteuerabzugs; angewendet wird die MWSt vom Konsumtyp, Consumption Value Added Tax, CVAT).

27a) Die hier zu erwähnende Literatur ist im wesentlichen die folgende: Brown, E.C., Business-Income Taxation and Investment Incentives, in: Income, Employment and Public Policy, Essays in Honor of Alvin H. Hansen, New York 1948, S. $300 \mathrm{ff}$. - Cansier. D. , Cash-flow-Steuern: Neue Wege der Unternehmensbesteuerung?

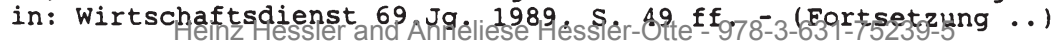


Ubersicht A.4:

Kontinuum der unternehmensbesteuexungs-konzepte

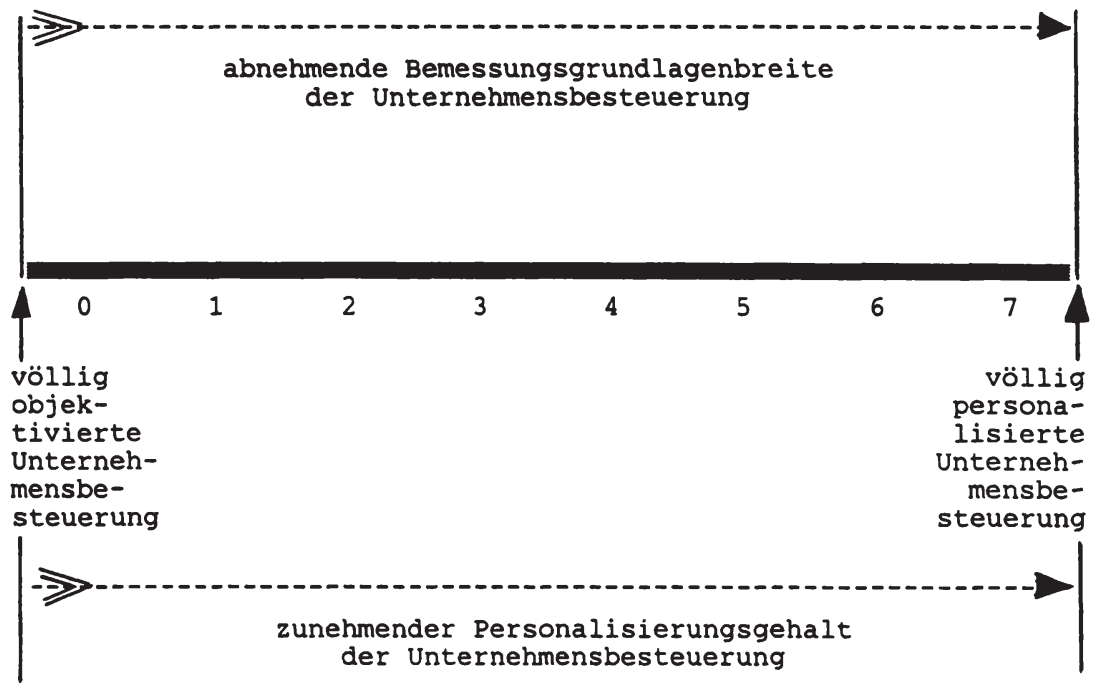

Die Ziffern 0 bis 7 entsprechen den folgenden BesteuerungsKonzepten:

0 = Ersatz der Körperschaftsteuer durch die Mehrwertsteuer

1 = "Unternehmensteuer" nach $W$. Flume, rechtsform-neutral

2 = "Betriebsteuer" nach den Vorschlägen des Betriebsteuerausschusses, rechtsform-neutral

3 = "cash-flow-Steuer"-Konzepte, rechtsform-neutral; eine Art Betriebsteuer

4 = "alte" Körperschaftsteuer (vor 1977) mit der Zweifachbelastung der Ausschüttungen; rechtsform-aneutral

5 = "Körperschaftsteuer 1977" mit dem Anrechnungsverfahren für Ausschüttungen; rechtsform-aneutral

6 = Einkommensbesteuerung der nicht entnommenen Gewinne der Personengesellschaften und Einzelunternehmer sowie Freiberufler (das gegenwärtig geltende Einkommensteuerrecht)

$7=$ "Teilhabersteuer" nach Engels/Stützel; Einkommensbesteuerung des gesamten, auch nicht ausgeschütteten Unternehmensgewinns gleich welcher Rechtsform 
Die Körperschaftsteuer 1977 wurde der alten Körperschaftsteuer nachgeordnet, nicht etwa weil der Allokationsgehalt geringer ist, sondern weil wegen des Anrechnungsverfahrens der Personalisisierungsgehalt höher und damit auch der Leistungsfähigkeitsgedanke stärker ausgeprägt ist als bei einer Zweifachbelastung der Ausschüttungen durch die alte Steuer. Die Zweifachbelastung stellt gerade nicht auf die Leistungsfähigkeit der Empfänger ab. Die Teilhabersteuer (Konzept 6) wurde in die Extremposition gerluckt, weil sie gegenüber dem Konzept 5 (Einkommensbesteuerung nur der Gewinne aus Personengesellschafts - und Einzelunternehmen) den breiteren distributiven Ansatz hat, da sie alle Unternehmen gleich welcher Rechtsform erfassen will. Mit ihrer völligen Personalisierung des Gesamtgewinns aller Unternehmensformen hat sie den Charakter einer Unternehmensteuer aufgegeben.

2. Demgegenüber 1st die in Position 1 angesiedelte "Unternehmensteuer" Flumes eine objektivierte steuer par excellence. Von dieser anderen Extremposition aus läBt sich das gesamte Kontinuum und der Gehalt an Ertragsfähigkeit bzw. "Leistungsfähigkeit" in den Konzepten beurteilen. Als die wesentlichen und mit dem Leistungsfähigkeitsgedanken zusammenhängenden Diskussionstopics lassen sich drei ausmachen: erstens die steuersystematische Position

(Fortsetzung Fn. 27a)

Cansier, D., Anwendungsmöglichkeiten der Cash-flow-Steuer, in: Finanzwissenschaft im Dienste de Wirtschaftspolitik. Dieter Pohmer zum 65. Geburtstag, hrsg.v. F.X. Bea und W. Kitterer, Tübingen 1990, S. $143 \mathrm{ff}$. - Meade Commettee, Institute for Fiscal Studies, The Structure and Reform of Direct Taxation, Report of a Commettee chaired by Prof. J.E. Meade, London 1978. - Lang, J., Reform der Unternehmensbesteuerung, in: Steuer und wirtschaft, 66.(19.) Jg. 1989 , S. $3 \mathrm{ff}$. - Lang, J., Reform der Unternehmensbesteuerung auf dem Wege zum europäischen Binnenmarkt und zur deutschen Einheit, in: Steuer und Wirtschaft, 67. (20.) Jg. 1990, S. $107 \mathrm{ff}$. Schneider, D., Sofortabschreibung und sofortiger Verlustausgleich, in: Besteuerung und Unternehmenspolitik, Festschrift für Güter Wöhe, hrsg.v. Gerd John, München 1989, S. $311 \mathrm{ff}$ - Schneider, D., Reform der Unternehmensbesteuerung aus betriebswirtschaftlicher Sicht, in: Steuer und Wirtschaft, 66. (19.) Jg. 1989, S. $328 \mathrm{ff}$. Sinn, H.-W., Systeme der Kapitalenkommensbesteuerung, ein allokationstheoretischer Vergleich, in: Beiträge zur neueren steuertheorie, hrsg.v. D. Bös u.a., Berlin 1983, S. $209 \mathrm{ff}$. - Sinn, H.-W., Neuere Wege der Unternehmensbesteuerung, in: Wirtschaftsdienst, 64. Jg. 1984, S. $328 \mathrm{ff}$. - Sinn, H. -W. , Kapitaleinkommensbesteuerung. Eine Analyse der intertemporalen, internatrionalen und intersektoralen Allokationswirkungen, Tübingen 1985; - Sinn, H.W. Cash-flow-Steuer noch einmal. Antwort auf die Antwort von Cansier, in: Wirtschaftsdienst, 69. Jg. 1989, S. $256 \mathrm{ff}$. 
dieser objektiven Unternehmensteuer, auch im Verhältnis zur Einkommensteuer, zweitens die Breite der Bemessungsgrundlage in Ertrag und Betriebsvermögen, und drittens der Unterschied $z$ um Anrechnungsverfahren der Körperschaftsteuer 1977, der eine ganz bestimmte Position Flumes zur Einkommensbesteuerung der Ausschüttungen $z$ um Vorschein bringt.

a) Die steuersystematische Position der "Unternehmensteuer" nach Flume (1971, S. $694 \mathrm{f.}$ ) ist dadurch beschrieben, daB sie als Körperschaftsteuer gelten soll und daB - ähnlich wie bei der alten Betriebsteuer und auch bei der Unternehmungsteuer nach $\mathrm{K}$. Schmidt (1963) - keine gesonderte Gewerbesteuer erhoben wird. Allerdings will Flume die Unternehmensteuer auf alle Gewerbebetriebe auBer den kleinsten ausdehnen. Diese somit rechtsformunabhängige Unternehmen-Ertrag-steuer soll ergänzt werden durch eine Betriebs-Vermögensteuer nach dem objektivierten zuschnitt der Gewerbekapitalsteuer; letztere soll in der Betriebs-Vermögensteuer aufgehen. ${ }^{28)}$ SolchermaBen sei die gesamte Unternehmensbesteuerung wegen der hier nicht angebrachten Leistungsfähigkeitsgedanken ${ }^{29}$ ) eine objektivierte "Realbesteuerung". Dies wird dadurch unterstrichen, daB Flume im Personalsteuerbereich eine generelle Freistellung verlangt: Weder solle eine private Vermögensteuer erhoben werden noch sollten die ausgeschütteten bzw. entnommenen Erträge aus den "Körperschaften" der persönlichen Einkommensteuer unterliegen, sofern nicht zumindest hohe Freibeträge einzurichten seien (1971, S. 694 f.). 30)

28) Allerdings nimmt Flume zur Betriebsvermögensteuer eine ganz spezifische Haltung ein (1972, S. 44): Sie sei nichts anderes als eine "fixierte Ertragsteuer", die u.U. bei juristischen Personen (nach den damals geltenden Steuersätzen) nicht 1 , sondern 3,3 \& ausmache und infolge der Doppelbelastung sogar bis zu 5,5 \& betragen könne $(1972$, S. 46). Sie demnach sogleich in die Ertragsbesteuerung einzubauen, sei aber $z$. zt. nicht möglich, würde nämlich eine Erhöhung der Ertragsteuersätze um ca. 15 \& erforderlich machen (S. 44). So sei sie nolens volens getrennt $z u$ erheben.

29) Flume 1972, S. 44: Mit recht habe der WB BMF 1967 (S. 58) erkannt, daB die Vermögensteuer unter dem Gesichtspunkt der Besteuerung nach der Leistungsfahigkeit auf juristische Personen nicht angewendet werden könne. Dies aber gelte dann ebenso für das Betriebsvermögen der Personenunternehmen, folgert Flume.

30) Lediglich der Unternehmerlohn soll vor der Ertragsfeststellung als Betriebsausgabe abgezogen werden und der persönlichen Einkommensteuer des Unternehmers unterliegen (1972, s. 53). 
In dieser "verabsolutierenden" Unternehmensertragsbesteuerung erkennen wir teilweise die oben erwähnte "systemreine" Allokationsbesteuerung wieder, zu der wir bereits festgestellt hatten, daß sie aus Gründen der GleichmäBigkeit zu einer allgemeinen Ertragserfassung aller am WertschöpfungsprozeB beteiligten Quellen einschlieblich der nichtunternehmerischen ausgeweitet werden mübte. Flume aber legt zwischen die Unternehmensbesteuerung und die Einkommensbesteuerung einen solch markanten Abstand (1972, S. 38 ff.), daB keinerlei Verknüpfung zwischen ihnen erkennbar wird. Was völlig akzeptabel ist, daB nämlich die unternehmerische und die private Sphäre zwei durch unterschiedlich zielgerichtete wirtschaftliche Betätigungen sich auszeichnende Bereiche sind, gerăt Flume $\mathrm{zu}$ einer solchen Uberbetonung des unternehmerischen Bereichs (1972, s. 40 : "Verselbständigung als Gebilde des Wirtschaftsprozesses"), daB er ihn mit dem gesamten produktionswirtschaftlichen sektor der Kreislauftheorie schlichtweg gleichsetzt, daB er dem Unternehmensertrag wegen seiner Gleichsetzung mit der Sozialprodukterstellung die herausragende gesellschaftiche Funktion zuerkennt (1971, s. 693 f.). Er kennt keine außerunternehmerische Ertragsquelle.

Geht man von Flume aus, so wird - wenn die den Empfängern zuflieBenden Erträge nur deshalb nicht Einkommen sein sollen, weil sie aus Unternehmen stammen - jegliche Definttion des Einkommensbegriffes fragwürdig, weil sie unvollständig bleibt. DaB Flume eine solche Definition nicht versucht, läbt den steuersystematischen Mangel seines Konzepts hervortreten: Zwar hat Flume überzeugend argumentieren können, daB der betriebliche Bereich strikt zu trennen ist von dem persönlichen und daB nur für den letzteren das Leistungsfähigkeitsprinzip seine Berechtigung habe, aber es fehlt in seinen Darlegungen die Verknüpfung der aus dem allokativen Ertragsbereich hervorgehenden ökonomischen GröBen mit dem distributiven Bereich, was gerade unter dem Leistungsfähigkeitsaspekt erst interessant und auch unumgänglich ist. Jeder Ertrag, der die Unternehmung verläBt, wird bei den Empfängern zu Einkommen; man kann zwar die Freistellung dieses Einkommens von der Einkommensteuer 
evtl. verlangen, aber nicht begründen mit dem Hinweis, daB die Erträge bereits der Besteuerung unterlegen hätten (1971, S. 694). Dies wäre eine Nichtbeachtung der oben entwickelten Zugangsregel für den Einkommensbeqriff und eine Einengung des Leistungsfähigkeitsverständnisses. 31)

b) Als mit dem allokativen Charakter der Unternehmensteuer vereinbar kann gelten, daB Flume statt des Gewinns die breitere Bemessungsgrundlage des Ertrags wählt (1971, S. 695; 1972, S. 52 f.). Schon allein wegen der Einbeziehung der Zinsen für Dauerschulden in den Ertrag ${ }^{32}$ ) wird die allokativ nachteilige Ungleichbehandlung der Finanzierung vermieden. ${ }^{33)}$ Es kommt hinzu, daB der dann niedrigere Steuersatz (evtl. 40 o) mögliche allokationsnachteilige Besteuerungswirkungen mindert.

Jedoch fordert diese Art der Ertragsbesteuerung aus gesamtwirtschaftlichen und steuersystematischen Gründen $\mathrm{zu}$ der Frage heraus, warum nicht sämtliche Ertragserzielungen auch außerhalb des unternehmerischen Sektors, die ebenfalls an der volkswirtschaftlichen Wertschöpfung teilhaben, ${ }^{34}$ ) in diese grundsätzliche Besteuerungs-

31) Wir hatten oben in $\$ \$ 8$ und 18 bereits dargestellt, daB im Hinblick auf die für den einzelnen sich jeweils neu darstellende Leistungsfähigkeitslage Steuern, die von irgendwem vorher auf einen Leistungsfähigkeitsindikator gezahlt worden sein mögen, kein Grund sein können, anzunehmen, der Empfänger der Zugänge sei eben gerade deswegen nicht leistungsfähig (so W. Flume 1972, S. 54).

32) Siehe die Regelung in der Gewerbesteuer; die Gewerbesteuer soll ja in der Unternehmensteuer aufgehen.

33) Als Pendent dazu soll in der Betriebsvermögensteuer das Eigenund Fremdkapital zusammengefaBt werden; im übrigen soll sie der allokativen zielsetzung einer Kapitalbildung und -erhaltung entsprechend - nicht zu einer Substanzbesteuerung führen können.

34) Wie vor allem die private (haushaltswirtschaftliche) Grundstücks - und Wohnungsvermietung; ferner - sofern nicht schon eingeschlossen - die Land- und Forstwirtschaft und die freien Berufe. 
weise, die auf den allokativen Bereich des Wirtschaftens gelegt werden soll, einzubeziehen sind.

Ferner gibt gerade die Bemessungsgrundlage "Ertrag" AnlaB zu einer wirtschaftstheoretisch-analytischen Frage, die mit einer speziellen Abzugsregelung von Flume in Verbindung steht. Nach Flume soll unter den Faktorentlohnungen lediglich der Unternehmerlohn (als Betriebsausgabe gewissermaßen) abzugsfähig sein vom $z u$ versteuernden Ertrag und dann der persönlichen Einkommensteuer des Unternehmers unterworfen werden. Die weiteren nichtunternehmerischen Entlohnungsformen - die des Kapitals und der Arbeit sollen $\mathrm{zu}$ versteuernde Ertragsbestandteile bleiben. Die Kapitalentlohnung (Ausschüttungen bzw. Entnahmen) sollen auch nicht - oder nur in äuBerst geringem Unfang - der Einkommensteuer ihrer Empfänger unterliegen; zur Arbeitsentlohnung - ebenfalls ein Ertragsbestandteil - äuBert sich Flume nicht, so daB angenommen werden kann, diese würden von $i \mathrm{hm}$ als persönliche Einkommen gelten und entsprechend $\mathrm{zu}$ versteuern sein.

Ein erstes Bedenken gegen eine solche differenzierte Behandlung der Unternehmenserträge liegt in der Unmöglichkeit, das Ertragszuordnungsproblem auf die Faktoren ${ }^{35}$ l lösen zu können; demnach müBte der Unternehmerlohn allenfalls näherungsweise geschätzt werden, was der Besteuerung nach der tatsächlichen Leistungsfähigkeit nicht entspricht. Ein zweites Bedenken liegt in der Ungleichbehandlung der Faktorerträge: Gesetzt den Fall, das zuordnungsproblem liebe sich lösen, so ist nicht einzusehen, daB die von Flume geforderte Steuerbefreiung für die Erträge des Faktors Kapital nicht auch für die anderen gelten soll; auch sie sind an der Entstehung des Ertrags insgesamt - es handelt sich ja um den "Unternehmens"-Ertrag! - beteiligt. Oder anders argumentiert: Auch die Erträge der Faktoren Kapital und Arbeit, nicht nur des Faktors Unternehmerarbeit, sollten als Betriebsausgaben den $z u$ versteuernden Ertrag schmälern dürfen; auch sie sollten - wie der Unternehmerlohn - der privaten Einkommensteuer unterworfen werden. Ergebnis: Die Sonderbehandlung des Faktors Kapital (im ersten Fall) und die Sonderbehandlung des Faktors Unternehmerarbeit (im

35) Die Wirtschaftstheorie kennt dieses Problem im Zusammenhang mit der Grenzproduktivität, der Steuertheorie ist es aus der Diskussion um die Gewerbesteuer bekannt. 
zweiten Fall) ist weder gesamtwirtschaftlich noch steuersystematisch $z u$ begründen.

c) Konsequenterweise muB Flume, da er ja die Freistellung der Ausschüttungen bzw. Entnahmen von der Einkommensteuer fordert, gegen das körperschaftsteuerliche Anrechnungsverfahren Stellung beziehen (1971, S. 694). Zunächst läBt sich hinslchtlich der Auswirkungen der Regelungen des Körperschaftsteuergesetzes 1977 theoretisch durchaus die Ansicht vertreten, daB die Besteuerung des ausgeschütteten Unternehmensgewinns durch eine eigene "Ausschüttungsteuer" eine auf dem Wege des Quellenabzugs vorweggenommene Einkommensbesteuerung ist, wobei die Ausschüttungsteuer als eine Gliedsteuer der Einkommensteuer gilt, wie das bei der Lohnsteuer der Fall ist; nur die Steuer auf den thesaurierten Gewinn kann als Körperschaftsteuer bezeichnet werden. ${ }^{36)}$ Demnach macht das Anrechnungsverfahren sowohl die Trennung des (körperschaftsteuerbelasteten) allokativen Bereichs vom (einkommensteuerbelasteten) distributiven Bereich deutlich, aber auch die Verknüpfung zwischen diesen Bereichen, nämlich den Ubergang des (allokativen) Gewinns qua Ausschüttung in das (distributive) Einkommen. Diese Regelung, so wettbewerbs - und rechtsformaneutral sie allein im allokativen Bereich auch ist, bringt immerhin zum Ausdruck, daB das Leistungsfähigkeitsprinzip einzig und allein im distributiven Bereich gelten soll: Die Ausschüttungen werden der persönlichen Einkommensteuer unterworfen; die vorweggezahlte Ausschüttungsteuer wird angerechnet.

36) So H.D. Hessler 1976 , S. 122; wörtlich gleichlautend später Musgrave/Musgrave/Kullmer 1977, S. 71; so auch D. Schneider 1990, S. 161 : "Einkommensteuervorauszahlung" als Quellensteuer wie die Kapitalertragsteuer und die Lohnsteuer. Geht man nur von der gesetzestechnischen wortf $\mathrm{f} s \mathrm{~s} n \mathrm{~g}$ aus, so handelt es sich um die "von der Gesellschaft gezahlten Körperschaftsteuer in Höhe der Ausschüttungsbelastung" (G. Wöhe 1978, S. 132) bzw. "be1 der ausschüttenden Körperschaft werden auf den ausgeschütteten Gewinn 36 v.H. Körperschaftsteuer erhoben" (K. Tipke 1981, S. 296. - Sofern man aber auf die Auswirkungen, die letztendich sich bei den Anteilseignern einstellen, abhebt, kommt auch $\mathrm{k}$. Tipke $\mathrm{zu}$ der folgenden Wortfassung (1991, S. 438): "Das Rörperschaftsteuergesetz 1977 belastet im Ergebnis nur die thesaurierten (nicht ausgeschutteten) Gewinne einer Körperschaft mit körperschaftsteuer. Ausgeschüttete Gewinne werden letztlich nur beim Auschüttungsempfänger (Anteilseigner) mit Einkommensteuer oder, wenn Ausschilttungsempfänger eine körperschaft ist, mit körperschaftsteuer belastet". Wir folgern aus dem steuertechnischen $s i \mathrm{n} n$ die Gliedsteuereigenschaft der Ausschüttungsteuer. Vgl. Wöhe 1988, s.190. 
Flume hingegen kommt nach seiner rein allokativ motivierten Grundauffassung von der Unternehmensbesteuerung $z u$ einer anderen Einschätzung der steuerlichen Auswirkungen. Bezugspunkt ist für ihn das allokative Zeil der Förderung der Unternehmenskapitalbildung und - damit zusammenhängend - über die Befreiung der Privaten von der Vermögensteuer auch die Förderung der Vermögensbildung. Zwar erkennt auch er die Ausschüttungsteuer als eine "Personensteuer" (1971, S. 693). Aber: DaB die ausgeschutteten Gewinne ungeachtet der Technik der Steuererhebung gar nicht mehr als Gewinne der Kapitalgesellschaften, sondern als unmittelbare Einkommen der Aktionäre verstanden werden, nennt Flume (1974, S. 68) die "Personalislerung der Besteuerung der Kapitalgesellschaften". Das Anrechnungsverfahren sei abzulehnen, weil der Gewinn der Kapitalgesellschaften nicht von den Anteilsbesitzern, sondern von der Unternehmung erzielt worden sel. Dem halten wir entgegen: Das stimmt, was die Erzielung angeht; das ist nicht mehr richtig, was die Verwendung angeht. Zwischen Erzielung und Verwendung liegt die Entscheidung der Verfügungsberechtigten. ${ }^{37)}$

Demnach ist mit Flumes Hinwendung zur objektivierten Ertragsbesteuerung eine Abwendung von der distributiven Fragestellung verbunden. Zuzustimmen ist ihm, wenn er - wie andere Autoren auch die Teilhabersteuer ablehnt, weil sie wegen der Anwendung der Einkommensteuer auf den ungeteilten Gewinn die Unternehmensbesteuerung völlig personalisiert. ${ }^{38)}$ Doch ist Flume nicht bereit, dem Anrechnungsverfahren seinen Platz in dem ökonomischen und steuertechnischen Verfahren einzuräumen, den objektıven Ertrag in ein persönliches Einkommen $z u$ überführen. Was andere Autoren etwa im Sinn eines Ausgleichs zwischen allokativen und distributiven Zielvorstellungen empfehlen, so z.B. eine geringere Belastung des Unter-

37) Siehe im einzelnen hierzu unsere Ausführungen in $\$ 7$ über die Rolle der Individualentscheidungen für die Abqrenzung $\mathbf{z w i s c h e n}$ dem allokativen und distributiven Bereich und in $\$ 11$ zur verfügbarkeit als begriffsbildendes Kriterium für Einkommen.

38) W. Flume 1971, S. 693: die technische Funktion der Körperschaftsteuer ist nur noch die des Quellenabzuges; den Publikumsaktionär als persönlichen Eigentümer des Unternehmens anzusehen, sei ein Anachronismus, sei Teil einer gesellschaftspolitischen Ideologie; der Gewinn sei eben nicht persönliches Einkommen. - Den weiteren, im Aquivalenzdenken wurzelnden Ausfuhrungen Flumes soll hier nicht nachgegangen werden. 
nehmensgewinns bel Anrechnung der Steuer auf die persönliche Einkommensteuer (BetriebsteuerausschuB 1949) oder die Abschaffung der Vermögensteuer für Kapitalgesellschaften, ${ }^{39)}$ will Flume exakt umgekehrt geregelt wissen: Die Einkommensteuerbefreiung für die Ausschüttungen bzw. Entnahmen (auBer beim Unternehmerlohn) sowie die Abschaffung der Vermögensteuer für Private. Obwohl er intensiv für die Fernhaltung des Leistungsfähigkeitsgedankens von der Unternehmensbesteuerung eintritt, liegt in seiner steuerlichen Grundvorstellung dennoch eine starke Eingrenzung des Leistungsfähigkeitsprinzips für den privaten Bereich.

d) Im einzelnen mögen die Vorstellungen einer allokativ bestimmten Unternehmensbesteuerung von denen Flumes durchaus abweichen, mögen durchaus auch offen sein für den Ubergang in den distributiven Bereich. Was wir anhand des Denkmodells von Flume indessen glauben illustrieren zu können, ist die Tatsache, daB eine "systemreine" Allokationsbesteuerung, auch wenn sie nicht auf das Leistungsfähigkeitsprinzip zurückgreift, den Grundgedanken der Besteuerung nach der Leistungsfähigkeit immer dann verfehlt, wenn die Verknüpfung der Unternehmensbesteuerung mit der Individualbesteuerung (bzw. Haushaltsbesteuerung) nicht beachtet wird, wenn nicht erkannt wird, daB die Entscheidungen über die Verwendung des Gewinns aus dieser ökonomischen Größe Einkommen machen.

d) Höchstwahrscheinlich ist das "Sachlich-generische" an der Leistungsfähigkeit (F. Neumark 1951, S. 73 ff.) allenfalls eine Bezeichnung für die jeweils unterschiedlich hohe Ertragsfähigkeit von Kapitaleinsätzen und Vermögensanlagen. Gewerbe-, Handels-, Industrie- sowie landwirtschaftliche Betriebe, aber auch die verschiedenen Kapitalanlageformen haben eine unterschiedliche Ertragsfähigkeit. ${ }^{40)}$

$39)$ G. Wöhe 1988, S.385ff., wegen der Doppelbelastung; der WB BMF 1967 (S. $65 \mathrm{ff.}$ ) lehnt die Befreiung der juristischen Personen von der Vermögensteuer $a b$ und will statt dessen das Anrechnungsverfahren oder die Vermögensteuerbefreiung für Anteilseigner; die Steuerreformkommission 1971 (S. 641) will weder anrechnen noch befreien.

40) Neumark selbst stellt im Zusammenhang mit der Unterscheidung in ertragbringende und ertraglose Vermögensgegenstände fest, daB, was erstere anlangt, - "okonomisch exakte und für alle Elemente an gleichen Kriterien orientierte Bewertungen voraus(Forts. siehe folgende seite) 
Es wäre nach allem nur sinnvoll, die Vorstellung einer sachlichgenerischen Leistungsfähigkeit, einer Leistungsfähigkeit von Vermögensgegenständen und objekten endlich aufzugeben, denn zu sehr ist sowohl die zielrichtung als auch der instrumentelle Inhalt des Leistungsfähigkeitsprinzips mit der individuell-persönlichen Sphäre des Steuerpflichtigen und mit der verteilungspolitischen Motivation der Steuer besetzt. Es wäre begrifflicher klarheit und den Bedingungen und zielen einer Unternehmensbesteuerung nicht angemessen, wollte man die Vorstellung der Besteuerung nach der Leistungsfähigkeit am "untauglichen objekt" praktizieren. Die Unternehmung mag dessenungeachtet als "steuerfähig" weil ertragsfähig angesehen werden, doch entscheidet sich das nach rein allokativen Gesichtspunkten. ${ }^{41}$ )

Wir erinnern daran, daß wir die fiskalpolitischen Probleme aus dem Thema der Unternehmensbesteuerung ausgegrenzt hatten. Selbstverständlich ist in der finanzwissenschaftlichen würdigung der Unternehmensbesteuerung die Belastung des Unternehmensertrages bzw. -gewinns auch unter dem fiskalischen Aspekt zu sehen. Bleibt sie gering, sind auch allokativ negative wirkungen der Belastung weniger zu erwarten als bei hoher fiskalischer Belastung. Der Konflikt zwischen Fiskalaufkommen aus unternehmenssteuern und allokativen Effekten ist hier aber nicht zum Thema gemacht worden.

Forts. Fn. 40:

gesetzt" - "den einzelnen Vermögensarten (also insbesondere land- und forstwirtschaftlichem, Grund- und Betriebsvermögen) eine unterschiedliche Leistungsfähigkeit nicht imputiert werden kann", 1970, S. 168. Aus diesem Grunde hält er letztlich, auch wegen der Existenz einer allgemeinen Vermögensteuer neben der Einkommensteuer, eine Differenzierung nach Einkunftsarten zu Lasten von "fundierten" Einkünften für nicht erforderlich, 1970 , S. 397.

41) Um ein MiBverständnis gar nicht erst aufkommen zu lassen: Selbstverständlich kann man Unternehmungen mit dem $\mathrm{Ziel}$ belasten, mehr Umverteilungsmasse in die staatlichen Kassen zu lenken; dennoch muB dann die Unternehmensteuer nach allokativen Gesichtspunkten ausgestaltet werden, nicht nach den Vorstellungen der Leistungsfähigkeit mit ihren personengebundenen Beträgen und Tarifen. 
Heinz Hessler and Anneliese Hessler-Otte - 978-3-631-75239-5 Downloaded from PubFactory at 01/11/2019 06:44:50AM via free access 


\section{Iiteraturverzeichnis}

AARON, H.J. 1969, What is a Comprehensive Tax Base Anyway?, NTJ 22.

- (Hg) 1976, Inflation and the Income Tax. The Brookings Institution, 2. Serie, $\mathrm{Nr}$. 4, Washington.

ABEL, A.B. 1981., Taxes, Inflation, and the Durability of Capital. JPolE 89, Nr. 3.

ADVISORY COMMISSION 1974 on Intergovernmental Relations: The Expenditure Tax: Concept, Administration, and Possible Applications, Washington.

D'ALBERGO, E. 1953, Theoretische Darstellungsmethoden des Problems der unterschiedlichen ErfaBbarkeit der Steuerobjekte bei direkter Besteuerung. Beitrăge zur Finanzwissenschaft und Geldtheorle. Festschrift für R. Stucken, Göttingen.

ALBERS, พ. 1957, Die Einkommensbesteuerung in Frankreich seit dem Ersten Weltkrieg. Eine Analyse ihrer wirtschaftlichen, sozialen und administrativen Probleme. KS 42, Kiel.

- 1958, Die Berücksichtigung der Leistungsfăhigkeit in der deutschen Einkommenssteuer. FA NF 18.

- 1960 , Vermögensbesteuerung. PF 15.

- 1970, Einige Ubberlegungen für die Ausgestaltung von Transferzahlungen an Haushalte. WWA 105/II.

- 1974 , Umverteilungswirkungen der Einkommenssteuer. W. Albers (Bg): రffentliche Finanzwirtschaft und Verteilung. SVS NF 75/II.

- 1975, Ziele und Bestimmungsgründe der Finanzpolitik. HaF I., 3.A.

- 1976, Möglichkeiten einer stărker final orientierten Sozialpolitik. Skw 119, Gottingen.

- 1977 a, Grenzen des Wohlfahrtsstaates. H. -D. Haas, B. Külp (Hg), Soziale Probleme der modernen Industriegesellschaft. SVS NF 92/II.

- 1977 b, Sozialpolitik IV: in der Bundesrepublik Deutschland. HdWw 7.

- 1977 c, Transferzahlungen an Haushalte. HdF I, 3.A.

- 1978, Einkommensumverteilung durch Transferzahlungen. WD 58. Jg. H. 12 .

- 1979 a, Einkommensbesteuerung I: Einkommensteuer. HdWW, 19./20. Lfg.

- 1979 b, Einkommensvertellung II. Verteilungspolitik. HdWW 19./20. Lfg.

- 1982, Soziale Sicherung. Konstruktionen für die zukunft, Stuttgart. - 1982a, Die Behandlung von Vorsorgeaufwendungen in der Einkommensteuer, FA,

- 1988, Steuerreserven in der deutschen Einkomensteuer, FA NF 46.

ALCHIAN, A.A., DEMSETZ, H. 1972, Production, Information Costs, and Economic Organisation. AER 62 .

ALDRUP, D. 1971, Das Rationalitätsproblem in der politischen Okonomie, Tübingen.

ALIINGHAM, M.G. 1975, Towards an Ability Tax. JPuble 4.

AMMON, A. 1949, Gerechtigkeit und ZweckmäBigkeit in der Besteuerung. Probleme der offentlichen Finanzen und der wăhrung. Festgabe für Eugen GroBmann, Zurich.

ANDEL, N. 1970, Die einkommensteuerliche Behandlung der Beitrăge an und der Leistungen von Altersversicherungen. H. Haller u.a. (Hg): Theorie und Praxis des finanzpolitischen Interventionismus. F. Neumark zum 70. Geburtstag, Tübingen.

- 1979 a, Einkommensteuer. HdF II, 3.A.

- 1979 b, Nettoanpassung und Besteuerung der Rente. Renten im Lichte der GleichmåBigkeit, der Verteilungsgerechtigkeit und des Sanierungsbedarfs der Rentenversicherungen. Bohley/Tolkemitt (Bg), Wirtschaftswissenschaft als Grundlage staatlichen Handelns. Heinz Haller zum 65. Geburtstag, Tübingen.

- 1992, Elnanzwissenschaft, 3.A., Tübingen

ANDREAE, C.-A. 1979, Grundsteuern, HdF II, 3.A.

ANDREAE, W. 1927, Bausteine zu einer universalistischen Steuerlehre. Deutsche Beitrăge zur Wirtschafts- und Gesellschaftslehre, Bd. 3, Jena. 
ANDREAE, W. 1928, Die Zukunft der Ertragsbesteuerung unter wirtschaftspolitischen Gesichtspunkten. B. Teschemacher (Bg), Beitrăge zur Finanzwissenschaft. Festgabe für Schanz, II, Tübingen.

- 1930, Grundlegung einer neuen Staatswirtschaftslehre, Jena.

ANDREWS, W.D. 1974, A Consumption-type or Cash Flow Personal Income Tax. HLR 87.

- 1980, A Supplemental Personal Income Tax. J.E. Pechman (Hg), What Should Be Taxed?, Washington DC.

ARNIM, H.H.v. 1978, Die Besteuerung von Zinsen bei Geldentwertung. SR KBI 40.

ARROW, K.J. 1963, Social Choice and Individual Values, New York/London 2.A.

- 1973, Some Ordinalist-Unitarian Notes on Rawls's Theory of Justice. Journal of Philosophy, 70 .

- 1979, The Trade-off Between Growth and Equity. Greenfield, H.J., Levenson, A.M., Hamovitch, W., Rotwein, E. (Ed.), Theory for Economic Efficiency. Essays in Honor of Abba P. Lerner, Cambridge/Mass. u.a.

ATKINSON, A.B., HARRISON, A.J., STARK, T. 1979, Wealth and Personal Incomes.

ATKINSON, A.B., SANDMO, A. 1980, Welfare Implications of the Taxation of Savings. EJ 90.

ATKINSON, A.B., STIGLITZ, J.E. 1980, Lectures on Public Economics, Maidenhead.

BADURA, P. 1979, Eigentumsordnung, in: Sozialrechtsprechung - Verantwortung für den sozialen Rechtsstaat. Festschrift zum 25-jährigen Bestehen des Bundessozialgerichts, Bd. 2, Köln u.a.

BÄCHLI, พ. 1978, Nominalwertprinzip und Inflation der Einkommensbesteuerung, Zürich.

BÄCKER/BISPINCK/HOFEMANN/NAEGELE 1981, Sozialpolitik, Köln.

BAILEY, M.J. 1969, Capital Gains and Income Taxation. A.C. Harberger, M.J. Bailey (Hg), The Taxation of Income from Capital, Washington.

BARRY, B. 1973, The Liberal Theory of Justice: A Critical Examination of the Principal Doctrines in 'A Theory of Justice' by John Rawls, Oxford.

BARTMANN, H. 1981, Verteilungstheorie, München.

BATOR, F.M. 1958, The Anatomy of Market Failure. QJE 72.

BAYER, H.-W. 1975, Das System des Steuerrechts. BB, H. 13.

BEA, F.X. und FISCHER, K. 1970, Steuerpolitische Grundsatzfragen. Kritische Bemerkungen zu einem Aufsatz von Jürgen Pahlke. FA NF 29.

BECKER, Ch., FULLERTON, D. 1980, Income Tax Incentives to Promote Saving. NTJ 33.

BECKER, E. 1940, Die Grundlagen der Einkommensteuer, München-Berlin.

BECKER, E., LION, M. 1925, Verhandlungen des 33. Deutschen Juristentages in Heidelberg 1924, hg. v. Schriftführer-Amt der stăndigen Deputation, Berlin/ Leipzig.

BECKER, J. 1970, Der "Grundsatz der Individualbesteuerung" im deutschen Einkommensteuerrecht. Diss. Münster.

BEHRENS, J., SMOLENSKY, E. 1973, Alternative Definitions of Income Redistribution. PF 28 .

BEISSE, H. 1981 a, Einkommen. HwStR 2.A.

- 1981 b, Pension, HwStR 2.A.

BEKER, M. 1978, Steuerrecht und Wirtschaftsordnung, Baden-Baden.

BENDA, E., KREUZER, K. 1973, Verfassungsrechtliche Grenzen der Besteuerung, DStZ/A.

BENDER, D. 1977, Angebot des Haushalts, I: Arbeitsangebot; II: Kapitalangebot. HdWW, I.

BENTHAM, J. 1948, An Introduction to the Principles of Morals and Legislation (London 1789). Neudruck unter dem Titel: A Fragment on Government and an Introduction to the Principle of Morals and Legislation, Oxford.

BERGSON, A. 1938, A Reformulation of Certain Aspects of Welfare Economics. QJE. Wieder abgedruckt in: K.J. Arrow, T. Scitovsky (Hg), Readings in Welfare Economics, Homewood/Ill. 1969. 
BERIE, H. 1979, StöBt die staatliche Umverteilung an die Grenzen der Belastbarkeit mit Steuern und Beitrăgen?, Weizsäcker, C.C.v. (Bg), Staat und Wirtschaft. SVS NF 102 .

BERNHOLZ, P. 1975, Grundlagen der Politischen Okonomie, 2. Bd., Tübingen. BETRIEBSTEUERAUSSCHUSS der Verwaltung für Finanzen 1949, Bericht und Gesetzentwïrde zur Betriebsteuer. Stuw 26. Jg., Sonderheft "Betriebsteuer".

BEYER, J. 1976, Die Grundprobleme des Erbschaftssteuerrechts in der Bundesrepublik Deutschland. Diss. Regensburg.

BICKEL, W. 1949, Die Steuer als Instrument des Einkommens- und Vermögensausgleichs. Probleme der öffentlichen Finanzen und der wăhrung. Festgabe fūr Eugen Großmann, Zürich.

BICKEL, W. 1960, Die Vermögenssteuern in der Schweiz. PF 15.

BIEG, H. 1981 , Realisationsprinzip. HwStR 2. A.

BIERLE, K. 1981, Gewinnermittlung, steuerliche. HWStR 2.A.

BIERSACK, H.L. 1850, Uber Besteuerung, ihre Grundsätze und ihre Ausführung, Frankfurt a.M.

BIRD, R.M. 1980, Income Redistribution Through the Fiscal System: The Limits of Knowledge. AER PP 70 .

BIRK, D. 1982, Das Leistungsfähigkeitsprinzip als MaBstab der Steuernormen. Ein Beitrag zu den Grundfragen des Verhăltnisses Steuerrecht und Verfassungsrecht. Köln

- 1991, Verfassungsrechtliche Grenzen der Konsumbesteuerung, in: M. Rose (Hg.), Konsumorientierte Neuordnung des Steuersystems, Berlin u.a.

BITTKER, B.I. 1967, A 'Comprehensive Tax Base' as a Goal of Income Tax Reform, HLR 80 .

BITTKER, B.I., GALVON, C.O., MUSGRAVE, R.A., PECHMAN, J.A. 1968, A Comprehensive Income Tax Base?, A Debate, Bradford/Conn.

BLUMICH/FALK/UELNER/HAAS O.J., Einkommensteuergesetz. Kommentar, 11.A.

BLUMLE, F. 1975, Theorie der Einkommensverteilung. Eine Einführung, Berlin u.a. BLUM, W.J. 1957, A Handy Summary of the Capital Gains Arguments, Taxes 35.

- 1965, Taxation of Capital Gains in the Light of Recent Economic Development Some Observations. NTJ 18.

BLUM, w.J. und KALVEN JR., H. 1963, The Uneasy Case for Progressive Taxation. Forth Impr., Chicago u.a. (1952).

BLUMENSTEIN, E. 1926, Schweizerisches Steuerrecht, I. Halbbd.

BOHM-BAWERK, E.V. 1921, Kapital und Kapitalzins. Teil II: Positive Theorie des Capitales (1889), 4.A. Jena (unveränderter Abdruck der 3.A., der Ausgabe letzter Hand; Neudruck Stuttgart 1961).

BOETTCHER, C. 1947, Vorschlag eines Betriebsteuerrechts. Stuw 24. Jg.

- Betriebsteuerausschuß 1949 mit folgenden Beiträgen Boettchers: a) zur Reform der Ermittlung des steuerpflichtigen Gewinns (Sp. 951-974); b) Vergleichende Darstellung der drei Entwürfe im allgemeinen (Sp. 10011-1015); c) Steuerliche Behandlung des Betriebsgewinns (Sp. 1015-1018).

- 1960, Zur Problematik der Besteuerung des Gewinns einerseits und der Ausschüttungen andererseits. FA NF 20.

BOHLEY, P., TOLKEMITT, G. (Bg) 1979, Wirtschaftswissenschaft als Grundlage staatlichen Handelns. Heinz Haller zum 65. Geburtstag, Tübingen.

BOMBACH, G. 1959 , Die verschiedenen Ansätze der Verteilungstheorie. Einkommensverteilung und technischer Fortschritt, SVS NF 17.

- 1965, Wirtschaftswachstum. HDSW 12.

- 1969, Möglichkeiten und Grenzen einer Verteilungspolitik. H. Arndt (Bg), Lohnpolitik und Einkommensverteilung, sVS NF 51.

- 1972, Neue Dimensionen der Lehre von der Einkommensverteilung. Basler Universitätsreden, H. 66 .

- 1978, Löhne und Beschăftigung. Schwerpunktheft $3 / 78$ der Mitteilungen aus der Arbeitsmarkt- und Berufsforschung.

- 1981, Die Sozialversicherungsansprüche in der volksvermögensrechnung, in: Mücki-ott (Hg.), Wirtschaftstheorie und Wirtschaftspolitik, Passau.

BOMBACH, G., FREY, R.L., GEHLEN, B. (Hg) 1974, Neue Aspekte der Verteilungstheorie, Tübingen.

BOMBACH, G., GEHLEN, B., OTT, A.E. (Hg) 1982, Möglichkeiten und Grenzen der Staatstätigkeit Heiübihgers.er and Anneliese Hessler-Otte - 978-3-631-75239-5 
BOSKIN, M.J. 1978, Taxation, Saving and the Rate of Interest. JPolE 86.

BOSKIN, M.J., SHESHINSKI, E. 1978, Optimal Redistributive Taxation When Ind1vidual Welfare Depends Upon Relative Income. QJE 92.

Bossons, J.D. 1970, The Value of a Comprehensive Tax Base as a Tax Reform Goal. JLE 13.

BOULDING, K.E. 1950, A Reconstruction of Economics, New York.

- 1973, Equality and Conflict. Income Inequality, The Annals of the American Academy of Political and Social Science, 409.

- 1981, Gerechtigkeit und Verteilung - Die Wechselwirkung von Mărkten und Transfers. Ubersetzung von F. Klanberg in: Klanberg/Krupp (Hg), Einkommensverte1lung, NWB 92, Konigstein (Original: Equity and Distribution - The interaction of markets and grants, 1n: M. Pfaff (Hg), Grants and Exchange, 1976).

BOULDING, K.E. und PFAFF, M. (Hg) 1972, Redistribution to the Rich and the Poor, Belmont/Cal.

BOULDING, K.E., WILSON, T.F. (Hg) 1978, Redistribution through the financial system: The grants economics of money and credit. Praeger Special Studies, New York u.a.

BOWEN, J. 1970, Acceptable Inequalities, London.

BRADFORD, D.F. 1980, The Case for a Personal Consumption Tax. J.E. Pechman (Hg), What Should be Taxed?, Washington DC.

BRADFORD, D.F., TODER, E. 1977, Consumption vs. Income Base Taxes: The Argument on Grounds of Equity and Simplicity. National Tax Association - Tax Institute of America, Proceedings of the Sixty-ninth Annual Conference on Taxation 1976, Columbus.

BRAUER, K. 1927, Ertragøteuern. Hdr II., Tübingen.

BRAUKNER, A. 1921, Der privatwirtschaftliche Einkommensbegriff, München.

BRAUN, H. 1983, Leistung, Leistungsprinzip und Gerechtigkeit - Einige Uberlegungen zu einer aktuelien Diskussion, in: Blum/Braun/Wohlfahrt (Hg.), Leistungsprinzip und soziale Gerechtigkeit, Köln

BREAK, G.F. 1954, Capital Maintenance and the Concept of Income. JPolE 62 . BREDT, J.V. 1912, Die Besteuerung nach der Leistungsfăhigke1t, Leipzig. BREITENBACH, E. 1969, Erbschaftsteuer. SR KBI 15, Bad wörishofen. BRENNAN, H.G. 1971, Horizontal Equity: An Extension of an Extension. PF 26.

- 1972, Second Best Aspects of Horizontal Equity Questions. PF 27.

- 1975, "Pareto-Optimal Redistribution" - A Perspective. FA NF 33.

BRENNAN, H.G., WALSH, C. 1973, Pareto-Optimal Redistribution Reconsidered. PFQ 1 .

- 1974, Hochmann and Rodgers on Brennan and Walsh; Reply. PFQ 2.

BRENNECKE, R., KLANBERG, F. 1974, Auswirkungen alernativer Vorschlagge zur Einkommensbesteuerung in einer inflationaren Wirtschaft. FA NF 33 .

BRINNER, R.E. 1973, Inflation, Deferral, and the Neutral Taxation of Capital Gains. NTJ 26.

BROWN, E.C., BULOW, J.I. 1977, The Definition of Taxable Business Income, in: J.A. Pechman (Hg) 1977.

BRUCK, G.W. 1981, Allgemeine Sozialpoltik. Grundlagen, Zusammenhănge, Leistungen, 2.A. Kס̈ln.

BRUMMERHOFF, D. 1974, Nominal- oder Realprinzip in der Einkommensbesteuerung?, FA NF 32 .

- 1979, Die Einkommensbesteuerung der Sozialversicherungsrenten. StuW 56. (9.) Jg. H. 3 .

BUCHANAN, J.M. 1968, What Kind of Redistribution Do We Want? Eca NS 35.

BUCOVETSKY, M.W. 1977, Inflation and the personal tax base, the capital gains issue. CTJ.

BUCHNER, R. 1956, Erbschaft- und Schenkungsteuer: HdF II, 2. A.

BUEHLER, A.G. 1950, The Spendings Tax. PF 5.

BÜLOW 1957, Volkswirtschaftslehre, München.

BURGHARDT, A. 1979, Kompendium der Sozialpolitik. Allgemeine Sozlalpolitik. Lohnpolitik. Arbeitsmarktpolitik. Politik der Sozlalversicherung, Berlin. BUSCH, R. 1975, Steuerentlastungen oder Transferzahlungen. Eine Untersuchung anhand geltender Steuerentlastungsnormen. Diss. Köln. Kölner Wirtschafts- und Sozialwissenschaftliche Abhandlungen, Bd. 13. 
CARLE, D., FELIX, G. 1981, Land- und Forstwirtschaft. Einkünfte aus. HWStR 2.A.

CARTER REPORT, siehe Royal Commission 1966.

CARVER, Th. 1904, The Minimum of Sacrifice Theory of Taxation. PSQ 19.

CASSEL, D., GUTMANN, G., THIEME, H.-J. (Hg) 1972, 25 Jahre Marktwirtschaft in der Bundesrepublik. Konzeption und wirklichkeit, Stuttgart.

CHAMLEY, Chr. 1981, The Welfare Cost of Capital Income Taxation in a Growing Economy. JPolE 89, Nr. 3.

CLAASSEN, E.-M. 1980, Grundlagen der makroökonomischen Theorie, München

COASE, R.H. 1937, The Nature of the Firm, Eca 4.

COHN, G. 1885, Grundlegung der Nationalokonomie.

- 1889, System der Nationalokonomie, II. Finanzwissenschaft, Stuttgart.

COOTER, R., HELPMAN, E. 1974, Optimal Income Taxation for Transfer Payments under Different Social Welfare Criteria. QJE 88.

DAHRENDORF, R. 1959, Reflektionen über Freiheit und Gleichheit. HJ 4; Zur Ordnung von Wirtschaft und Gesellschaft, Festausgabe für Eduard Heimann.

- 1975, Die neue Freiheit: Uberleben und Gerechtigkeit in einer veranderten Welt, München.

- 1980, Chancengleichheit ist nur ein Traum. Möglichkeiten und Grenzen des sozialen Aufstiegs, Die Zeit $\mathrm{Nr} .46$ vom 07.12.1980, S. 12.

DALTON, H. 1936, Principles of Public Finance, I. 9. A., London.

DANIELS, N. 1975, Reading Rawls. Critical Studies on Rawls' A Theory of Justice, Oxford.

DASGUPTA, P., HAMMOND, P. 1980, Fully progressive taxation. JPuble 13.

DAVID, M. 1972, Alternative Approaches to Capital Gains Taxation (1968), 2.A. Brookings Institution, Washington.

DELIUS, H. 1958, Ethik, A Diemer, I. Frenzel (Hg), Philosophie, Frankfurt a.M.

DENISTON, O.L. und ROSENSTOCK, J.M. 1972, Evaluation of Programm Effectiveness and Programm Efficiency. F.J. Lyden und E.G. Miller (eds), Planning, Programming, Budgeting. A Systems Approach to Management, Chlcago, 2nd. ed.

DEPARTMENT OF THE TREASURY 1977, Report of the U.S. Department of the Treasury, "Blueprints for Basic Tax Reform", Government Printing Office.

DETTLING, W., HERDER-DORNEICH, P., KEVENHORSTER, P., ADENAUER, G., HOFFMANN, C.H., STAHL, H. 1977, Die neue soziale Frage und die Zukunft der Demokratie, 2.A., München.

DEUTSCHE BUNDESBANK 1979, Berücksichtigung der Geldentwertung bei der Besteuerung von Einkünften aus Kapitalvermögen. Gutachten der Deutschen Bundesbank vom 22. September 1977 für das Bundesverfassungsgericht. BBk-M August 1977.

DEUTSCHE BUNDESBANK 1980, Der Produktivitătsfortschritt in der Bundesrepublik und seine Bestimmungsfaktoren. BBk-M Januar 1980.

DIAMOND, P.A. 1975, Inflation and the Comprehensive Tax Base. JPuble 4.

DIEHL, K. 1918, Die einmalige Vermögensabgabe. SVS 156, I. Teil (B. Herkner, Hg, Die Neuordnung der deutschen Finanzwirtschaft, München-Leipzig).

- 1933, Vermögen. WaV 3, Jena 4.A.

DIEMER, A. 1958 , Ontologie, A. Diemer, I. Frenzel (Hg), Philosophie, Frankfurt a.M.

DOBSON, J.H. 1976, An Analysis of European Wealth Taxes. Bulletin für International Fiscal Documentation 30.

DREYER, B., OBERBORBECK, W. 1981, Betriebliche Altersversorgung. HWStR 2.A.

DUE, J.F. 1960, Net Worth Taxation. PF 15.

- 1977, Personal Deductions, J.A. Pechman (Hg) 1977.

EBNET, O. 1978, Die Besteuerung des Wertzuwachses. Ein theoretischer Ansatz im Rahmen der Einkommensbesteuerung. Schriften zur offentlichen verwaltung und offentlichen Wirtschaft, Bd. 31, Baden-Baden.

EDGEWORTH, F.Y. 1958, The Pure Theory of Taxation (EJ 7/1897), R. Musgrave, A.R. Peacock (Bg), Classics in the Theory of Public Finance, London-New York. EGNER, E. 1956, Baushalt. BDSW 5. 
EHRLICHER, พ. 1956, Geldkapitalbildung und Realkapitalbildung, Tübingen.

- 1964, Probleme langfristiger Strukturwandlungen des Kapitalstocks. SVS NF 30/II, Berlin.

EISEMMANN 1977, Die Grundbegriffe Einnahmen - Einkünfte - Einkommen im Einkommensteuerrecht. Diss. Tubingen.

ELSCHrN, R. 1991, Entscheidungsneutralität, Allokationseffizienz und Besteuerung nach der Leistungsfähigkeit. Gibt es ein gemeinsames Fundament der Steuerwissenschaften? in: Stuw Nr. 2

ENGELAARDT,. พ. 1978, Alte und neue soziale Fragen - zu ihren begrifflichen, historischen, zeitanalytischen und systematischen Zusammenhăngen, B.P. Widmaier (Bg), Zur Neuen Sozialen Frage. SVS NF 95.

- 1981, Selbstverantwortung. Solidaritat, Subsidiarităt und andere Sinnstrukturen der industriellen Gesellschaft. Ph. Herder-Dorneich (Bg) 1981.

ENGELS, พ. 1979 a, Die Rolle des Staates in der Wirtschaftsordnung, C.C.v. Weizsăcker. SVS NE 102.

- 1979 b, Eine konstruktive Kritik des Wohlfahrtsstaates. Walter Eucken Institut. Vortrag Nr. 69, Tubingen.

ENGELS, W., MITSCHKE, J., STARKLOFF, B. 1975, Staatsbürgersteuer. Vorschlag zur Reform der direkten Steuern und personnlichen Subventionen durch ein integriertes Personalsteuer- und Subventionssystem. SR KBI 26, 2.A. Wiesbaden.

ENGELS, W., STUTZEL, W. 1968, Teilhabersteuer. Ein Beitrag zur Vermögenspolitik, zur Verbesserung der Kapitalstruktur und zur Vereinfachung des Steuerrechts, 2.A., Frankfurt.

ENGISCH 1971, Auf der Suche nach Gerechtigkeit. Hauptthemen der Rechtsphilosophie, München.

EUCKEN, พ. 1968, Grundsătze der Wirtschaftspolitik, hg.'v. E. Eucken und K.P. Hensel (1952), 4.A., Tübingen u.a.

EULER, M. 1970, Probleme der Erfassung von Vermögensbestånden privater Haushalte im Rahmen der Einkommens- und Verbrauchsstichprobe 1969. Wista 12.

FAGAN, E.D. 1966, Recent and Contemporary Theories of Progressive Taxation (JPole 46, 1938), R.A. Musgrave, C.S. Shoup (Bg) 1966.

FARNY, D. 1977, Sozialversicherung. BdWW 7.

FECHER, B. 1979, Persönliche allgemeine Vermögensteuer. HaF II, 3.A.

FECHT, R. 1970, Kritische Untersuchung der Einkommensbesteuerung der deutschen, franzosischen, US-amerikanischen und britischen Landwirtschaft, Frankfurter Wirtschafts- und Sozialwissenschaftliche Studien, B. 25, Berlin.

- 1979, Etnkommensbesteuerung II: Körperschaftsteuer. HdWW 19./20. Lfg.

FELDSTEIN, M.S. 1975, The Theory of Expenditures. Discussion Paper, Barvard Institute of Economic Research.

- $1976 \mathrm{~b}$, On the Theory of Tax Reform. JPuble 6.

- 1976 c, Taxing Consumption, The New Republic.

- 1978, The Welfare Cost of Capital Income Taxation. JPolE 86, Supplement.

- 1979, Taxes, Inflation and Capital Formation. NTJ 32.

FELDSTEIN, M.D., YITZHAKI, S. 1978, The Effects of the Capital Gains Tax on the Selling and Switching of Common Stock. JPubl. 9.

FELS, G. 1978, Gespråch WW Nr. 50 vom 08.12.1978, S. 80 ff.: "Vlellelcht eine Illusion".

FINDEISEN, F. 1924, Die Unternehmungsform als Rentabilitatsfaktor, Berlin. FISCHER, C.E. 1942, Um ein Unternehmungssteuerrecht. StuW 21.

FISHER, I. 1897, The Role of Capital in Economic Theory, E J

- 1906, The Natur of Capital and Income. New York u.a. (uberarbeitet zusammen mit 1907 und neu veróffentlicht unter dem Titel "Income and Capital" in: R.H. Parker, G.C. Barcourt (Bg) 1969)

- 1912, The Nature of Capital and Income, 2. ed. London. 
FISHER, I. 1927, The Income Concept in the Light of Experience, New York.

- 1928, Der Einkommensbegriff im Lichte der Erfahrung, H. Mayer (Ag), Die Wirtschaftstheorie der Gegenwart, 3. Bd.: Einkommensbildung, Wien.

- 1930, The Theory of Interest as Determined by Impatience to Spend Income and Opportunity to Invest it (1907 als: The Rate of Interest, basierend auf 1906: The Nature of Capital and Income), New York (überarbeitet zusammen mit 1906 und neu veróffentlicht als "Income and Capital", in: R.B. Parker, G.C. Harcourt (Hg) 1969).

- 1937, Income in Theory and Income Taxation in Practice. Etra 5.

FISHER, I, FISHER, H.W. 1942, Constructive Income Taxation. A Proposal for Reform, New York u.a.

FLAMING, Ch. 1981, Rechtsformunabhängige Besteuerung der Unternehmen?, StuW 3. FLUME, W. 1971, Die Betriebsertragsteuer als Möglichkeit der Steuerreform. DB Jg. 24.

- 1972, Einige Gedanken zur Steuerreform. StbJb 1971/72.

- 1974, Besteuerung und Wirtschaftsordnung. StbJb 1973/74, Köln.

- 1975, Jetzt müBte eine Steuerreform auch für die Wirtschaft kommen. Das Betriebsvermögen kann nicht den Unternehmern zugerechnet werden. $\mathrm{BB} 13$ vom 18./19.01.1975.

- 1980, Zur Reform der Vermögensteuer. Stuw 57. (10.) Jg.

FOLKERS, C. 1979, Vermögen I: Struktur und Verteilung. HaWW, 17./18 . Ifg.

- 1980, Vermögensverteilung und staatliche Aktivităt - Zur Theorie distributiver Prozesse im Interventionsstaat.

FOLSOM, R.N., RUBIN, R.J. 1980, Marginal Effective Income Tax Rates with Averaged Capital Gains and Losses. PF 35.

FRANK, D. 1969, Erbschaftsteuer und Unternehmung, Berlin.

FRANKE, S.F. 1981, Entwickıung und Begrūndung der Einkommensbesteuerung. Wissenschaftliche Buchgesellschaft. Ertrāge der Forschung Bd. 154, Darmstadt.

- 1983, Theorie und Praxis der indirekten Progression.

FRANKEL, S.H. 1969, 'Psychic' and 'Accounting' Concepts of Income and welfare, R.H. Parker, G.C. Harcourt (Hg) 1969 (basierend auf S.H. Frankel, OEP IV 1952).

FREY, B.S. 1981, Theorie demokratischer Wirtschaftspolitik, München.

FREY, R.L. 1973, Finanzpolitik und Verteilungsgerechtigkeit. FA NF 31.

- 1974, Theorie und Messung der finanzwirtschaftlichen Umverteilung, Bombach/ Frey/Gahlen (Hg) 1974.

FRIAUF, K.H. 1975 a, Steuerrecht und Verfassungsrecht. DStz/A.

- 1975 b, Besteuerung von Kapitaleinkünften und Geldentwertung. Stuw 52. (5.) Jg.

- 1977, Substanzeingriff durch Steuer-Kumulation und Eigentumsgarantie. Bemerkungen zum BeschluB des Bundesverfassungsgerichts vom 27.10.1975. Stuw 54. (7.) Jg., H. 1 .

FRICKE, D. 1972, Einkomen und Anspruchsniveau. Forschungsberichte des Landes Nordrhein-Westfalen, Nr. 2213, Opladen.

FRIEDMAN, M. 1953, The Welfare Effects of an Income and Excise Tax (JPolE 60), wieder abgedruckt in M. Friedman, Essays in Positive Economics, Chicago.

FRITSCH, B. 1979, Die Uberforderung des Staates, P. Bohley/G. Tolkemitt (Hg), 1979.

FROESE, H. 1977, Die Berücksichtigung von Geldwert- und Sachwertschwankungen in der Einkommensbesteuerung, Frankfurt/M. u.a.

FUEST, w. 1980 a, Grundsätze einer rationalen staatlichen Einkommensumverteilungspolitik. Wirtschaftswissenschaftliche Forschung und Entwicklung, Bd. 50 (zug1. Diss. Münster), München.

- 1980 b, Umfang und Problematik der offentlichen Einkommens- und Vermoggenstransfers. Beitrăge zur Wirtschafts- und Sozialpolitik, Institut der deutschen Wirtschaft 79 , Köln.

FUISTING, B. 1902, Die PreuBischen direkten Steuern. 4. Bd.: Grundzüge der Steuerlehre, Berlin.

FUX, B. 1927, Die Vermögensteuer. HdF II. 
GADDUM, J.W. 1978, "Gaddum-Papier". Diskussionsentwurf eines vereinfachten Einkommensteuergesetzes vom 05.07.1978 des Mainzer Finanzministers Gaddum und der Arbeitsgruppe Finanzen bei der Vertretung des Landes Rheinland-Pfalz beim Bund.

GAFGEN, G. 1972, Leistungsprinzip und Bedarfsprinzip in Wirtschaft und Gesellschaft, G. Găfgen (Hg) 1972 .

- (Bg) 1972, Leistungsgesellschaft und Mitmenschlichkeit, Limburg.

- 1974, Theorie der wirtschaftlichen Entscheidung. 2.A., Tübingen.

- 1975, Theorie der Wirtschaftspolitik. Kompendium der Volkswirtschaftslehre, hg. v. W. Ehrlicher u.a., II., 4.A., Gottingen.

GARTNER, F.W. 1898, ther den Einkommensbegriff. FA 15.

GARTNER, W. 1981, Rawlsianism, Utilitarianism, and Profiles of Extended orderings. ZgS 137 .

GANDENBERGER, O. 1974, Lăuft die Besteuerung von Wertzuwächsen auf eine Doppelbelastung hinaus? KK 7 .

GEIGER, w. u.a. (Hg) 1971, Der Wirtschaftende Staat. Theorie und Praxis. Festschrift zum 70. Geburtstag von Prof. Theo Keller, Bern u.a.

GELTING, J. 1979, Einkommenspolitik. HdWW 19./20. Lfg.

GEMPER, B.B. 1971, Die Vermögensteuer im Rahmen der modernen allgemeinen Einkommensteuer. Eine steuerwirtschaftliche Betrachtung. vS 159.

- 1972, Geldentwertung, Nominalwertprinzip und Besteuerung. BB 18.

GENSER, B.B. 1980, Lorenzgerechte Besteuerung. Ein normatives Konzept für einen neuen Steuertarif. Verőfentlichungen der Kommission für Sozial- und Wirtschaftswissenschaften, Nr. 16, hg.v. W. Weber, Wien.

GERLOFF, W. 1913, Die Wertzuwachssteuern in Literatur und Gesetzgebung, SchJ. - 1926, Steuerwirtschaftslehre. HdF I, Tübingen.

GEYER, H. 1960, Probleme der fiskalischen Einkommensredistribution. FA NF 20. GIERSCH, H. 1959, Zur Theorie des Bestmöglichen. Ordo 11, Düsseldorf u.a.

- 1960, Allgemeine Wirtschaftspolitik, I: Grundlagen. Die Wirtschaftswissenschaften, hg.v. E. Gutenberg, Wiesbaden.

- 1977, Konjunktur- und Wachstumspolitik in der offenen Wirtschaft - Allgemeine Wirtschaftspolitik, Bd. 2. Die Wirtschaftswissenschaften, hg.v. E. Gutenberg, Wiesbaden.

GILOY, J. 1978, Vieldeutige Einkommensbegriffe: Zur geeigneten BezugsgröBe staatlicher Transferleistungen, Herne-Berlin.

- 1979, Das Existenzminimum im Steuerrecht, DStz/A.

GOLD, St.D. 1979, Property tax relief, Lexington/Mass. u.a.

GOODE, R. 1949, The Income Tax and the Supply of Labor. JPole 58.

- 1960, Imputed Rent of Owner-Occupied Dwellings under the Income Tax. JF 15.

- 1962, Income, Consumption, and Property as Bases of Taxation. AER PP 52.

- 1964, The Individual Income Tax, Washington D.C.

- 1976, The Individual Income Tax. Brookings Institution (1964), rev. ed. Washington.

- 1977, The Economic Definition of Income, J.A. Pechman (Hg) 1977.

- 1980, The Superiority of the Income Tax, J.E. Pechman (Hg) 1980.

GORDON, R.H., BRADFORD, D.F. 1980, Taxation and the stock market valuation of capital gains and dividends. JPuble 14.

GRAETZ, M.J. 1980, Expenditure Tax Design, J.E. Pechman (Hg) 1980.

GREEN, J.R., Sheschinski, E. 1978, Optimal Capital-Gains Taxation under Limited Information. JPOlE 86.

GREYTAK, D., MCHUGH, R. 1980, Indexation and the Redistributive Nature of the Individual Income Tax. SEJ 47.

GROSSMANN, E. 1947, Das Gerechtigkeitsproblem in der Steuerpolitik. SZVS 83.

- 1956, Die Vermögensteuer. HdF II, 2.A.

GROVES, H.M. 1946, Personal versus corporate income taxes. AER PP 36.

- 1969, Grundzüge einer sozialökonomischen Theorie der Steuerprogression. Recktenwald, H.C. (Hg), NWB-W 33 (orig.: Towards a Social Theory of Progressive Taxation. NTJ 9, 1956). 
GRUSKE, K.-D. 1978, Die personale Budgetinzidenz. Eine Analysa für die Bundesrepublik, Göttingen.

GUTENBERG, E. 1957, Grundlagen der Betriebswirtschaftslehre. Erster Band: Die Produktion, 3.A., Berlin u.a.

GUTH, F. 1878, Die Lehre vom Einkommen in dessen Gesamtzweigen, Leipzig. GUTMANN, G. 1978, Marktwirtschaft. HaWW 13. Lfg.

HACKMANN, J. 1972, Zur wohlfahrtstheoretischen Behandlung von Verteilungsproblemen, Berlin.

- 1973, Ein Vorschlag zur Ehegattenbesteuerung. FA NF 31.

- 1976, Interperiodische Durchschnittsbesteuerung des Einkommens. FA NF 34.

- 1979, Die Besteuerung des Lebenseinkommens: Ein Verglelch von Besteuerungsverfahren, Tübingen.

- 1980, Lebenseinkommensbesteuerung durch interperiodischen Progressionsausgleich. Stuw 57. (10.) Jg.

- 1983, Die Bestimung des steuerrechtlichen Einkomensbegriffs aus finanzwissenschaftlicher Sicht, in: K.-H. Hansmeyer (Hg.), Staatsfinanzierung im Wandel, svs Berlin.

- Konsequenzen einer einkommensteuerlichen Freistellung von vermögenswertänderungen, in: FA NF 42.

- 1986, Analyseprobleme einer Erörterung der Einkomensqualität unrealisierter Wertsteigerungen, in: FA NF 44.

- 1990, Totalanalytische Implikationen einer Einkommensteuer und Sofortabschreibung, in: FA NF 48.

HALUSER,K. 1963, Theorie der Staatswirtschaft und gerechte Besteuerung. WWA 91.

BAIG, R.M. 1921, The Concept of Income - Economic and Legal Aspects. R.M. Haig u.a. (Hg): The Federal Income Tax, New York.

- 1959, The Concept of Income - Economic and Legal Aspects. Wiederabdruck von 1921, Kap. 1 in: R.A. Musgrave, C.S. Shoup (Hg), Readings in the Economics of Taxation, London.

HAKE, W. 1972, Umverteilungseffekte des Budgets, Göttingen.

HALLER, H. 1956, Sparen. HDSW 9.

- 1960, Bemerkungen zur progressiven Besteuerung und zur steuerlichen Leistungsfăhigkeit. FA NF 20.

- 1967, Wie kann die Steuerpolitik das wirtschaftliche Wachstum beeinflussen?, Veroffentlichungen des Wiener Instituts für Finanzwissenschaft und Steuerrecht, Februar.

- 1970 , Probleme der progressiven Besteuerung. Walter Eucken Institut. Vortrăge und Aufsătze, H. 27, Tübingen.

- 1971 , Die Steuern. Grundlinien eines rationalen Systems öffentlicher Abgaben, 2.A. (3.A. 1981), Tübingen.

- 1972, Finanzpolitik. Grundlagen und Bauptprobleme, 5.A., Tübingen/Zürich.

- 1973 b, Zur Diskussion über das Leistungsfăhigkeitsprinzip. FA NF 31.

- 1973 c, Grundsătzliches zur Besteuerung von Grundstücksgewinnen. KK 6 .

- 1978, Gedanken zur Vermögensbesteuerung. FA NF 36.

- 1981, Die Steuern. Grundlinien eines rationalen Systems offentlicher Abgaben, 3.A., Tübingen. (Die von uns verwendeten Passagen stimmen mit denen der 2. Auflage überein, weshalb wir teilweise an der zitation aus der 2 . A. festhalten, HDH).

- 1984, Die steuerliche Behandlung von Ersparnissen - ein Dauerthema? In: W.A.S. Koch und H.-G. Petersen (Hg.), Staat, Steuern und Finanzausgleich, Probleme nationaler und internationaler Finanzwirtschaften im zeitlichen Wandel, Festschrift für H. Kolms zum 70. Geburtstag, Berlin.

HALLER/KULLMER/SHOUP/TIMM (Hg) 1970, Theorie und Praxis des finanzpolitischen Interventionismus. F. Neumark zum 70. Geburtstag, Tübingen.

HAMBURGER DENKSCHRIFT 1978 zur Weiterentwicklung des Steuerrechts vom 29.06. 1978, erstellt vom Hamburger Finanzsenator Seeler in zusammenarbeit mit Praktikern der Hamburger Finanzverwaltung, Typoskript.

HAMER, E. 1982, Von Freikarten bis zur Ministerialzulage. "Selbstbedienung im offentlichen Dienst", FAZ Nr. 84 v. 10.04.1982, S. 12.

HANSEN, B. 1960, Aspects of Property Taxation. PF 15. 
HANSMEYER, K.-H. 1963 a, Effekte der Einkommensumverteilung in der sozialen Krankenversicherung, w. Schreiber (Bg), Gesetzliche Krankenversicherung in einer freiheitlichen Gesellschaft, Berlin.

- 1963 b, Finanzielle Staatshilfen für die Landwirtschaft. Zur Theorie einer sektoralen Finanzpolitik, Tübingen.

- 1974, Zwischenbilanz der Steuerreform. BJ 19.

- 1979, Steuern auf spezlelle Güter. HdF II, 3.A.

- 1981, Grundsteuer. HaWw 34./35. Lfg.

HANSMEYER, K.-B, RURUP, B. 1975, Staatswirtschaftliche Planungsinstrumente, 2.A., Tübingen/Düsseldorf.

HARRISS, C.L. 1968, Property Taxation: Economic Aspects, New York.

HARTFIEL, G. (Bg) 1977, Das Leistungsprinzip. Merkmale - Bedingungen - Probleme, Opladen.

HAX, K. 1957, Die Substanzerhaltung der Betriebe, Köln/Opladen.

- 1960, Unternehmenserhaltung und Gewinnbesteuerung. FA NF 20.

HAYEK, F.A.v. 1935, The Maintenance of Capital. Eca.

- 1940, The Pure Theory of Capital, London.

- 1941, Maintaining Capital Intact: A Replay. Eca NS 8.

- 1971 , Die Verfassung der Freiheit, Tübingen. (Orig.: The Constitution of Liberty).

HEAD, J.G. 1963, The Case for a Capital Gains Tax. PF 18.

- 1972, Canadian Tax Reform and Participatory Democracy. FA NF 31.

- 1979, The Simons-Carter Approach to Tax Policy: A Reappraisal. P. Bohley, G. Tolkemitt (Hg) 1979.

- 1979 a, Fisher-Kaldor Regained. Report of the Meade Committee in the U.K. FA NF 37.

- 1982, The Comprehensive Tax Base Revisited, in: FA NF 40.

HECKEL, M.V. 1911, Vermögensteuer, HdStW 8, Jena

HEDTKAMP, G. 1980, Finanzwissenschaftliche Untersuchung: Finanzwissenschaftliche Aspekte der Sozialversicherung, H.F. Zacher (Hg.).

- 1988, Eine allgemeine persönliche Vermögensteuer in einem rationalen Steuersystem, in: FA NF 46.

HEDTKAMP, F., KREIIING, H.-W. 1979, Einkommenseffekte im Lichte steuertheoretischer Grundbegriffe, P. Bohley, G. Tolkemitt (Hg.).

HEIDINGER, G. 1982, Nochmais: Für und wider Betriebsteuer, in: Stuw 59 (12.Jg.)

HEIDRICH, P. 1929, Die Lehre von den obersten Steuerprinzipien. Ein Beitrag zur Theorie der offentlichen Wirtschaft, Jena.

HEILMANN, M. 1976 , Die Umverteilungswirkungen der Einkommensteuerreform 1975. SKW 94.

HEINEMANN, K. 1972, Soziale Kosten in der Leistungsgesellschaft, G. Gãfgen (Hg) 1972 .

HELBERGER, C. 1978, Strategien der Verteilungspolitik ohne Gefăhrdung des Wachstums? in: Krupp/Glatzer (Hg) 1978.

HELBERGER, C., WAGNER, G. 1981, Beitragsăquivalenz oder interpersonelle Umverteilung in der gesetzlichen Rentenversicherung?, Eine Analyse auf der Grundlage von Lebenseinkommen, $\mathrm{Ph}$. Herder-Dorneich (Hg) 1981.

HELD, A. 1872, Die Einkommensteuer, Bonn.

HELIIWELL, J.F. 1969, The Taxation of Capital Gains. CJE 2.

HELMSTÄDTER, E. 1974, Wirtschaftstheorie, Bd. 1: Dispositionsgleichgewicht, Marktgleichgewicht, München.

- 1976, Wirtschaftstheorie, Bd. 2: Kreislaufgleichgewicht, Expansionsgleichgewicht, München.

- 1991 Wirtschaftstheorie, 4. A. Bd.

HEMPEL, C.G. 1974, Grundzüge der Begriffsbildung in der empirischen Wissenschaft, Dūsseldorf (Original: Fundamentals of Concept Formation in Empirical Science, vol. 2, Nr. 7 der International Encyclopedia of Unified Science, Chisago 1952).

HENSEL, K.P. 1964, Planwirtschaft. HDSW 8.

- 1972, Grundformen der Wirtschaftsordnung, Mûnchen. 
HERDER-DORNEICH, Ph. 1979 b, Solidarităt - Subsidiarităt - Emanzipation. Stimmen der Zeit, H. 6.

- 1979 c, Soziale Ordnungspolitik.

- 1981 (Hg), Dynamische Theorie der Sozialpolitik. SVS NF 123, Berlin.

- 1981 a, Ansatzpunkte einer dynamischen Theorie der Sozialpolitik, Ph. HerderDorneich (Hg) 1981.

- 1982, Der Sozialstaat in der Rationalitätsfalle. Grundfragen der sozialen steuerung. Stuttgart u.a.

HERMANN, F.B.W.v. 1832, Staatswirtschaftliche Untersuchungen über Vermögen, Wirtschaft, Productivität der Arbeiten, Kapital, Preis, Gewinn, Einkommen und Verbrauch (Neudruck 3.A. mit einem Geleitwort von Karl Diehl, Leipzig 1924), München.

HERRMANN, K.A. 1961, Vermögenstatistik. HDSW 11.

HERRMANN/HEUER, Kommentar zur Einkommensteuer und Körperschaftsteuer. 19.A. Köln.

HERZOG, R. 1975, Eigentum. Evang. Staatslex. 2.A.

HESSLER, H.D. 1973, Fundamentalprinzipien der Besteuerung, wisu 2.Jg., H. 4 und 5 .

- 1976, Finanzwissenschaftliches System der Besteuerung, Tübingen u.a.

- 1978, Die Chance der Steuerdiskussion: Die Vorschläge von Gaddum und Seeler. WD 8 .

- 1981, Gesellschaftspolitik und Besteuerung, Handworterbuch des Steuerrechts, 2.A. München.

HETTICH, W. 1979, Henry Simons on Taxation and the Economic System. NTJ 32.

HEWETT, W.W. 1925, Definition of Income and 1ts Application in Federal Taxation, Philadelphia.

HICKS, J.R. 1942, Maintaining Capital Intact: A Further Suggestion. Eca NS 9

- 1946, Value and Capital: An Inquiry into Some Fundamental Principles of Economic Theory (1939), Oxford University Press, 2.A. (reprinted 1965).

- 1968, Public Finance, Cambridge 3.A.

HOCHMAN, A.M., RODGERS, J.D. 1969, Pareto Optimal Redistribution. AER 59.

- 1970, Pareto Optimal Redistribution: Reply. AER 60.

- 1971, Is Efficiency a Criterion for Judging Redistribution? PF 26.

- 1973, Brennan and Walsh Reconsidered (Mutt and Jeff Ride Again). PFQ 1.

HOCFE, O. 1977, Kritische Einfūhrung in Rawls' Theorie der Gerechtigkeit, $O$. Höffe (Hg) Uber John Rawls' Theorie der Gerechtigkeit, Frankfurt a.M.

HOFFMANN, G. 1978, Steuervorteile durch Freibetrăge, Freigrenzen, Höchstbetrăge, Pauschalierungen, 5.A., Freiburg.

BOFMANN, W. (Bearb.) 1965, Einkommenstheorie. Vom Merkantilismus bis zur Gegenwart. Sozialökonomische Studientexte, Bd. 2, Berlin.

HoLT, C.C., Shelton, J.P. 1962, The Lock-In Effect of the Capital Gains Tax. NTJ 15.

HOWREY, E.P., HYMANS, S.H. 1980, The Measurement and Determination of LoanableFunds Saving, J.E. Pechman 1980.

INSTITUT FINANZEN UND STEUERN 1969, Zur Reform der Einkommensteuer, Brief 112, Bonn.

- 1972, Zur Steuerreform: Die Erbschaftsteuer, B. 100, Bd. III.

- 1973, Zur Besteuerung der Bodenwertsteigerungen, Bonn.

- 1977, Zur Frage einer Begrenzung der Vermögensteuer im Wege einer Plafondierung der Vermögensteuer und der Einkommen-Körperschaftsteuer, Brief 165, Bonn.

ITO, H. 1960, The methodological basis of the priciples of taxation. FA NF 20.

JAHRMARKT, M., BAREIS, H.P. 1981, Abschreibungsgesellschaft. HwStR 2.A.

JECHT, В. 1957, Staatliche Wirtschaftspolitik und Einkommensverteilung. Einkommensbildung und Einkommensverteilung, hg.v. W.G. Hoffmann. SVS NF 13.

JరHR, W.A. 1943, Theoretische Grundlagen der Wirtschaftspolitik, Bd. I. Sankt Galler Wirtschaftswissenschaftliche Forschungen, st. Gallen. 
JOHANSEN, L. 1966, Wirkungen des Steuersystems auf die Einkommensverteilung. B.C. Recktenwald (Bg), Finanztheorie. NBW-W 33. (Orig.: Kap. 7,7 aus: Public Economics, Amsterdam/Chicago 1965, gestrafft).

JOINT ECONOMIC COMMITTEE 1979, Report of the Joint Economic Committee Congress of the United States of the 1979 Economic Refport of the President, Senate Report No. 96-44, Washington.

KALDOR, N. 1955, An Expenditure Tax, London.

- 1980, Comments. J.E. Pechman (Hg) 1980.

KALMBACH, P. 1972, Wachstum und Verteilung in neoklassischer und postkeynesianischer sicht. vs 187.

KANTZENBACB, E. 1967, Die Funktionsfähigkeit des Wettbewerbs. Wirtschaftspolitische Studien aus dem Institut für Europăische Wirtschaftspolitik der Universităt Hamburg, hg. v. B. Jürgensen, H. 1, 2.A., Göttingen.

KARL-BRÄUER-INSTITUT des Bundes der Steuerzahler 1973, Geldentwertung und Steuerrecht, 24, Wiesbaden.

KARL-BRAUER-INSTITUT des Bundes der Steuerzahler 1974, Zur Reform der Bodenbesteuerung, Wiesbaden.

- 1979, Inflation und steuerliche Abzüge, Wiesbaden.

KELLENBERGER, E. 1957, Die Steuern und ihre Reform, Bern.

KELLER, M. 1933, Die abgeleiteten Einkommen. JNS 138.

KELLER, T. 1963, Mehr Steuergerechtigkeit. Zukunftsaufgaben in Wirtschaft und Gesellschaft. St. Galler Wirtschaftswissenschaftliche Forschung, Bd. XIX, zürich/st. Gallen.

KEMPSKI, J.v. 1956, Sozialwissenschaft. EDSW 9.

KENDRICK, M.S. 1939, The Ability-to-Pay-Theory of Taxation. AER 29.

KIEFER, D.W. 1980, Depreciability of Assets and the Taxation of Capital Gains: A Comment and Extension. NTJ 32.

KIRSCH, G. 1980 , Finanztheorie. HdV 2.A., Wiesbaden.

KISKER, K.P. 1964, Die Erbschaftsteuer als Mittel der Vermögensredistribution, Berlin.

KLANBERG, F. 1978 a, Armut und 8konomische Ungleichheit in der Bundesrepublik Deutschland. SPES, Schriftenrethe Bd. 13, Frankfurt/New York.

- 1978 b, Die empirischen Grundlagen der Neuen Sozialen Frage, H.P. Widmaier (Hg), Zur Neuen Sozialen Frage. SVS NF 95.

- 1981, Paradigmen in der Erklärung der Einkommensverteilung. F. Klanberg, B.-J. Krupp (Bg), Einkommensverteilung. NWB-W 92, Königstein/Ts.

KLANBERG, F., KRUPP, H.-J. 1981, Einkommensverteilung. NWB-W 92.

KLAPPBOLZ, K. 1972, Equalitiy of Opportunity, Fairness and Efficiency, M. Peston und B. Corry (Bg), Essays in Honor of Lord Robbins. International Art and Sciences Press.

KLAUS, J. 1972, Durchbrechung des Leistungsprinzips in der Marktwirtschaft, G. Gägen (Hg) 1972 .

KLEIN, Franz 1966, Gleichheitssatz und Steuerrecht, Köln.

- 1977, Zur VerfassungsmäBigkeit des geltenden Einkommensteuerrechts. DB.

KLEIN, Friedr. 1949, s. BetriebsteuerausschuB 1949 mit dem Beitrag Kleins "zur Stellung der Betriebsteuer im Steuersystem".

- 1970, Art. 14 des Bonner GG als Schranke steuergesetzlicher Intervention? H.Haller u.a. (Hg) 1970.

KLEIN, W.A. 1980, Comments to W.D. Andrews 1980, J.E. Pechman (Bg) 1980.

KLEINWACHTER, F.v. 1896, Das Einkommen und seine Verteilung, Leipzig.

KNIEF, P. 1968, Steuerfreibetrăge als Instrument der Finanzpolitik, Köln/ Opladen.

KNOBBE-KEUK, B. 1981, Die Betriebsaufspaltung - ein "Rechtsinstitut"? Stbub $1980 / 81$.

KOCH, พ. 1955, Zur Diagnose der Steuerreform. FA NF 15.

- 1963, Das Verhăltnis zwischen gesellschaftlicher und steuerllcher Gerechtigkeit bei Adolph Wagner. FA NF 23.

- 1966, Eine neue Deutung der Steuergrundsătze. FA NF 25.

кolms, н. 1961, Yermőgensteuern, ADsw 111. Hessler-Otte - 978-3-631-75239-5 
KOMMISSION LANDWIRTSCHAFT 1978, (Kommission zur Begutachtung der Einkommensbesteuerung der Landwirtschaft), Gutachten zur Einkommensbesteuerung der Landwirtschaft. SR BMF B. 24, Bonn.

KOPPELMANN, K.-P. 1979, Intertemporale Einkommensumvertellung in der gesetzlichen Rentenversicherung in der Bundesrepublik Deutschland. Eine theoretische und empirische Analyse, Göttingen.

KORTMANN, K. 1978, Probleme der Armut im Sozialstaat, M. Pfaff, 日. Voigtlan$\operatorname{der}(\mathrm{Hg}) 1978$.

KOSING, G.E. 1978, Die steuerliche Erfassung von Bodenwertsteigerungen als ein Ansatzpunkt für eine Reform der Bodenbesteuerung, Bad Honnef.

KRAUSE-ABLASS, G.B. 1971, Verfassungsrechtliche Grundlage und Grenzen der Erbschaftsteuer. BJ 16.

KRAUSE-JUNK, G. 1974 a, Probleme einer Bodenwertzuwachsbesteuerung. WD 54.

- 1974 b, Zur Theorie des distributiven Marktversagens. SVS 75/II: "Offentliche Finanzwirtschaft und Verteilung".

KRAUSE-JUNK, G. 1977, Steuern IV: Verteilungslehren. BdWW 7.

- 1981, Finanzwirtschaftliche Verteilungspolitik. BdF III, 3.A.

KRECKEL, R. 1973, Mobilitat, G.v. Eynern (Bg), worterbuch zux politischen Okonomie, Opladen.

KRELIE, W. 1962, Verteilungstheorie, Wlesbaden.

KRIELE, M. 1963, Kriterien der Gerechtigkeit, Berlin.

- 1979, Recht und praktische Vernunft, Gôttingen.

KROCKOW, C.v. 1977, Die überflüssige Leistung, G. Bartfiel (Bg) 1977.

KRUPP, B.-J. 1967, "Personelle" und "Funktionelle" Elnkommensverteilung. JNS 180 .

- 1968, Theorie der personellen Elnkommensverteilung. Allgemeine Grundzüge und verteilungspolitische Simulationen. VS 127.

- 1975, Möglichkeiten der Verbesserung der Einkommens- und Vermögensstatistik. SKW 50, Göttingen.

- 1977, Vertellungswirkungen der Steuerfinanzierung des sozialen Alterssicherungssystems, B.-J. Krupp, W. Zapf (Bg), Sozlalpolitik und Sozialberichterstattung, Frankfurt u.a.

- 1978, Bedingungen und Prinzipien einer integrierten Sozialpolitik, M. Pfaff und $\mathrm{B}$. Voigtlander (Bg) 1978.

KRUPP, B.-J., GLATZER, W. (Bg) 1978, Umverteilung im Sozialstaat: Empirische Einkommensanalysen $f u ̈ r$ die Bundesrepublik Deutschland. SPES, Schriftenreihe Bd. 11, Frankfurt/New York.

KRUPP, H.-J., HECHELTJEN, P., SCHMAUS, G., WEIGEND, A. 1972/1973, Ergănzung der Volkswirtschaftlichen Gesamtrechnung durch Vermögensrechnungen: Anforderungen an die Einkommens- und Verbrauchsstichprobe im Hinblick auf die Bere1tstellung von Ausgangsdaten für gesamtwirtschaftliche Vermögensrechnungen. Forschungsbericht im Auftrag des Bundesministers für Arbeit und Sozialordnung. Zwei Bde.

KUBICA, J. 1976, Bestimmungsgründe der staatlichen Umverteilungstătigke1t. Bochumer Wirtschaftswissenschaftliche Studien $\mathrm{Nr} .32$.

KULP, B. 1971, Verteilungspolitik, stuttgart.

- 1974, Vertellungstheorie, stuttgart.

- 1975, Umverteilung zugunsten der nicht ganz Armen und zu Lasten der nicht ganz Reichen?, Dürre, E., Jöhr, W.A., Rothsch1ld, K.W. (Bg), Beitrăge zur Wirtschafts- und Gesellschaftspolitik, Festschrift für Theodor Pütz, Berlin.

KULP, B., BAAS, H.-D. (Bg) 1977, Soziale Probleme der modernen Industriegesel1schaft. SVS NF 92.

KUtTP, B., SCHREIBER, W. (Bg) 1971, Soziale Sicherheit. NWB-W 40.

KULP, B., STUTZEL, $W$. (Bg) 1973, Beitrăge zu einer Theorie der Sozlalpolitik. Festschrift fü E. Llefmann-Reil, Berlin.

KUWG, E. 1971, Die Einkommensbesteuerung in der Freizeitgesellschaft, . Gelger u.a. (Eg) 1971 .

KUEN, T.S. 1976, Die Struktur wissenschaftlicher Revolutionen, Frankfurt a.M. 3.A. (Original: The Structure of Scientific Revolutions, Chicago 1962).

- 1978, Die Entstehung des Neuen. Studien zur Struktur der wissenschaftsge-

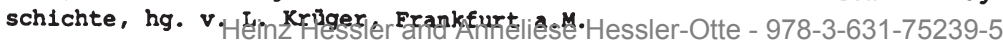


KULLMER, L. 1960, Die Ehegattenbesteuerung. Ihre Geschichte, Problematik und Neuregelung in Deutschland, diskutiert unter Berücksichtigung der Erfahrungen in den USA, Frankfurt.

KURTZ, J., SURREY, St.S. 1970, Reform of Death and Gift Taxes: The 1969 Treasury Proposals. Their Criticism and a Rebuttal. Columbia Law Review.

LAMPE, A. 1931, Erbschaftssteuern. WdV I, 4.A. Jena.

- 1933 a, Schenkungsteuer. WDV III, 4.A. Jena.

- 1933 c, Tote-Hand-Abgabe. WdV III, 4.A. Jena.

- 1933 d, Vermögensteuer. WdV III, 4.A. Jena.

- 1955, Neue Verteidigung der Einkommensteuer. FA NF 3.

LAMPERT, 日. 1980, Sozialpolitik, Berlin u.a.

LANG, J. 1974, Das Einkommensteuergesetz 1975 - Gewinn an Steuergerechtigkeit und Steuervereinfachung? StuW 51. (4.) Jg.

- 1978, Die Besteuerung der Baushalte.Stuw 55. (8.) Jg.

- 1988, Die Bemessungsgrundlage der Einkommensteuer. Rechtssystematische Grunclagen steuerlicher Leistungsfähigkeit im deutschen Einkommensteuerrecht, Köln

LANGE, K. 1971, Systemgerechtigkeit. DV.

LAUFENBURGER, H. 1956, Die Einkommensbesteuerung. BdF II, 2.A.

LAUX, H. 1976, Absurditäten der Steuerreform. StuW 53. (6.) Jg.

LEIBENSTEIN, B. 1976, Beyond Economic Man. A New Foundation for Microeconomis, Cambridge/Mass., London/England.

LEINFELLNER, พ. 1965, Einführung in die Erkenntnis- und Wissenschaftstheorie, Mannheim.

LEIPOLD, B. 1976, Einkommensverteilung nach der Leistung als Preisbildungsproblem, D. Cassel, B.J. Thieme (Bg), Einkommensverteilung im Systemvergleich, Stuttgart.

LEISNER, W. 1970, Verfassungsrechtliche Grenzen der Erbschaftsbesteuerung. Schriften zum Steuerrecht 6, Berlin.

- 1978, Wertzuwachsbesteuerung und Eigentum: Zugleich ein Beitrag zur Lehre vom Leistungseigentum, Berlin.

LENSKI, E. 1952, Erbschaftsteuer, Stuttgart.

LEXIS, W. 1906, Einkommen. BdV 2.A.

LIEDSCBULTE/ZINK 1973, Die Erfassung von Wertzuwăchsen Im Rahmen der Einkommens- und Ertragsbesteuerung, Opladen.

LIEFMANN-KEIL, E. 1961, రkonomische Theorie der Sozialpolitik, Berlin u.a.

- 1972, Die Koordination von Lelstungs- und Bedarfsprinzip im System der sozialen Sicherung, G. Găfgen (Bg) 1972.

LINDAEI, E. 1919, Die Gerechtigkeit der Besteuerung. Eine Analyse der Steuerprinzipien auf der Grundlage der Grenznutzentheorie, Lund.

- 1933, The Concept of Income. Economic Essays in Bonour of Gustav Cassel, London (wieder abgedruckt in R.H. Parker, G.C. Harcourt (Bg) 1969).

LION, M. 1928, Der Einkommensbegriff nach dem Bllanzsteuerrecht und die Schanz'sche Einkommenstheorie, H. Teschemacher (Bg) 1928.

LITTLE, J.M.D. 1956, An Expenditure Tax. EJ 66.

LITTMANN, E./GRUBE, G. 1978, Das Einkommensteuerrecht: Kommentar zum E1nkommensteuergesetz, 12.A. Stuttgart, Bd. 1.

LITTMANN, K. 1956, Schenkungsteuer. HDSW 9.

- 1968 , Kritische Marginalien zur Kontroverse "Individuelle Veranlagung oder Haushaltsbesteuerung". FA NF 27.

- 1970, Ein Valet dem Leistungsfahigkeitsprinzip, B. Baller u.a. (Bg) 1970.

- 1980, Die Besteuerung von Renten, Pensionen und anderen Altersbezúgen als aktuelles Problem steuerlicher Gleichhelt und Gerechtigkeit. Vortrag, gehalten am 31. Okt. 1979 an der Universităt zu Koln. Sonderveroffentlichung/ Finanzwissenschaftliches Forschungsinstitut der Universităt zu Koln, Nr 2, Koln.

LODIN, S.-0. 1978, Progressive Expenditure Tax - an Alternative? A Report of the 1972 Government Commission on Taxation, Stockholm (Original erschienen in Schwedisch 1976). 
LOMPE, K. 1966, Wissenschaftliche Beratung in der Politik. Ein Beitrag zur Theorie anwendender Sozialwissenschaften, Göttingen.

LOTZ, W. 1931, Finanzwissenschaft (1917), 2.A. Tubingen.

LUCKENBACB, В. 1979, Grundzüge der Theorie des Angebots von Bumankapital. Wist $\mathrm{H.} 7$.

- 1980, Wohlfahrtsökonomik. BdV 2.A. Wiesbaden.

LUTZ, F.A. (Hg) 1975, Der Streit um die Gesellschaftsordnung. Sozialwissenschaftliche Studien für das Schweizerische Institut für Auslandsforschung, Bd. 3 (NF), zürich.

MACRUUP, F. 1963, Essays on Economic Semantics, Englewood Cliffs, New. York. MACKSCBEIDT, K. 1973, Zur Theorie des optimalen Budgets, Tübingen.

MACKSCEEIDT, K., STEINEAUSEN, J. 1978, Finanzpolitik I: Grundlagen fiskalpolitischer Lenkung, 3.A. Tübingen/Düsseldorf (1.A. 1973).

- 1977, Finanzpolitik II: Grundfragen versorgungspolitischer Eingriffe, Tubingen/Düsseldorf.

- 1983, Transfers, in: wisu 12. Jg. H. 1 u. 2.

MANN, F.K. 1928 a, Die Gerechtigkeit in der Besteuerung, B. Teschemacher (Bg) 1928.

- 1928 b, Vermögensteuer. HwStw 8, 4.A. Jena.

- 1930 a, Die Staatswirtschaft unserer Zeit. Eine Einführung, F.K. Mann (Bg), Finanzwissenschaftliche Forschungen, B.1, Jena.

- 1930 b, Die Erhöhung der Erbschaftsteuer, G. Colm, B. Neisser (Bg), Rapitalbildung und Steuersystem, 2. Teil, Berlin.

- 1937, Steuerpolitische Ideale. Vergleichende Studien zur Geschichte der okonomischen und politischen Ideen und ihres Wirkens in der offentlichen Meinung 1600 - 1935. F.K. Mann (Bg), Finanzwissenschaftliche Forschungen, B.5, Jena. (Unverănderter reprografischer Nachdruck, um ein Nachwort und ein Schriftenverzeichnis ergănzt: Wissenschaftliche Buchgesellschaft, Darmstadt 1978).

- 1976, Distribution and Redistribution in the Public Sector of Economy, M. Pfaff (Ed.), Grants and Exchange, Amsterdam.

MARSB, D.B. 1943, The Taxation of Imputed Income. PSQ 58.

MARSHALL, A. 1920, Principles of Economics, 8.A. London.

MAUNZ/DURIG/HERZOG/SCBOLZ 1980, Grundgesetz. Kommentar. 5.A. München.

MCDONALD, S.L. 1979, Depreciability of Assets and the Taxation of Capital Gains. NTJ 32 .

MCINTYRE, M.J., OLDMAN, O. 1977, Taxation of the Family in a Comprehensive and Simplified Income Tax. HIR 90.

MCLURE, Ch.E. JR. 1977, The "New View" of the Property Tax: A Caveat. NTJ 30.

MEADE, J.E. 1955, Trade and Welfare. The Theory of International Economic Policy, Vol. II, London u.a.

- 1964, Efficiency, Equality and the Ownership of Property, Barvard University Press, London.

MEADE COMMITIEE 1978, Institute for Fiscal Studies, "The Structure and Reform of Direct Taxation", Report of a Committee chaired by Professor J.E. Meade, London.

MEERMAN, J.P. 1974, The Definition of Income in Studies of Budget Incidence and Income Distribution. The Review of Income and Wealth, S. $515 \mathrm{f}$.

MENICIONI, F. 1954, Theorie des Einkommens. Diss. Basel.

METZE, I. 1974, Soziale Sicherung und Einkommensvertellung. Eine empirische Untersuchung uber die Wirkungen staatlicher MaBnahmen zur sozialen Sicherung sowie der Einkommen- und Umsatzsteuer auf die verfügbaren Einkommen der privaten Baushalte. Sozialpolitische Schriften B. 34, Berlin.

- 1982, Negative Elnkommensteuer. BdWW 36./37. Lfg.

MEYER, M. 1977, Partiell zu versteuern. Bundesarbeitsblatt.

MEYER, R. 1884, Die Principien der gerechten Besteuerung in der neueren Finanzwissenschaft, Berlin.

MIESZKOWSKI, P.M. 1969, The Effects of Taxes on the Distribution of Income. JEI 7. 
- 1972, The Property Tax: An Exercise Tax or a Profits Tax? JPE 1.

- 1977, The Cash Flow Version of an Expenditure Tax. OTA Paper 20, Department of the Treasury, Washington $D C$.

MILI, J.St. 1926, Principles of Political Economy (1848), ed. by w.J. Ashley, London. (Deutsch: Grundsatze der politischen రkonomie, Hamburg 1852, Bd. I: 2.A. Jena 1924; Bd. II: Jena 1921).

MINARIK, J.J. 1977, The Yleld of a Comprehensive Income Tax. Appendix, J.E. Pechman (Bg) 1977.

- 1980, Conference Discussion, in: J.E. Pechman (Bg) 1980.

MINTE, 甘. 1978, Konsum- und Arbeitsinteressen des privaten Haushalts, Bochum.

MIRRLEES, J.A. 1971, An Exploration in the Theory of Optimum Income Taxation. REStud 38.

MISES, L.v. 1940, Nationalokonomie. Theorie des Handelns und wirtschaftens. Reprogr. Nachdruck München 1980.

MITSCBKE, J. 1975, Trivialarithmetik der Staatsbürgersteuer. Eine Replik auf Dieter Schneiders Rezension "Staatsbürgersteuer - ein Schildbürgerstreich". Stuw 52. (5.) Jg.

- 1976, Uber die Eignung von Elnkommen, Konsum und Vermögen als Bemessungsgrundlage der direkten Besteuerung. Eine meBtechnische Analyse. VS B. 244.

- 1980 a, Lebenseinkommensbesteuerung durch interperiodischen Progressionsausgleich. Stuw 57. (10.) Jg.

- $1980 \mathrm{~b}$, Methoden der Indirekten Konsummessung für Zwecke einer persönlichen allgemeinen Ausgabensteuer. FA NF 38.

- $1980 \mathrm{c}$, Textentwurf einer EStG-Änderung zur Lebenseinkommensbesteuerung durch interperiodischen Progressionsausgleich. Stuw 57. (10.) Jg.

- 1985, Steuer- und Transferordnung aus einem GuB. Entwurf einer Neugestaltung der direkten steuern und Sozialtransfers in der Bundesrepublik Deutschland, Baden-Baden.

MÖLLER, R. 1983, Interpersonelle Nutzenvergleiche. Wissenschaftliche Möglichkeiten und politische Bedeutung, Göttingen.

MOSBAUER, H.H. 1975, Das Steuerrecht - Auf der Suche nach dem System, DStR B. 24. MOLITOR, B. 1961, Elgentum (I) Soziologie des Eigentums. BdSW 3.

- 1979, Vermőgen II: Vermogenspolitik. BdWW, 17./18. Ifg.

MOLL, B. 1911, Zur Geschichte der Vermögenssteuern, Leipzig.

- 1924, Probleme der Finanzwissenschaft, Leipzig.

- 1930, Lehrbuch der Finanzwissenschaft, Berlin.

- 1961, Gerecht1gkeit in der Wirtschaft, 2.A. Bonn.

MOMBERT, F. 1964, Zur soziologischen und okonomischen Problematik der modernen Einkommensteuer. JSW 15.

MOMBERT, P. 1916, Eine Verbrauchs-EInkommensteuer für das Relch als Ergänzung zur Vermögenszuwachssteuer, Tübingen.

MOXTER, A. 1978, Steuerliche Gewinn- und Vermögensermittlung. BdF II, 3.A.

MUCKL, W.J., OTT, A.E. (Bg) 1981, Wirtschaftstheorie und Wirtschaftspolitik. Gedenkschrift für Erich Preiser. Schriften der Universitat Passau, Reihe Wirtschaftswissenschaften, Bd. 2, Passau.

MULLER, J.H., WALLRAFF, H.J. SJ 1958, Einkommen. Staatslexikon, 6.A., Bd. 2, Freiburg 1.Br.

MUTHLING, H. 1965, Wertzuwachssteuer. BDSW 12.

MUSGRAVE, R.A. 1957, An Expenditure Tax. AER 47.

- 1968 a, In Defense of an Income Concept. HLR 81.

- 1968 b, The Carter Commission Report. CJE 1.

- 1969 , Finanztheorie. Tubingen 2.A. (Original: The Theory of Public Finance, New York u.a. 1959).

- 1970 a, Allocation, Distribution and the Theory of Public Finance, B. Baller u.a. (Bg) 1970.

- 1970 b, Pareto Optimal Redistribution. Comment. AER 60.

- 1974, Is a Property Tax on Bousing Regressive? AER PP 64.

- 1976, ET, OT and SBT. JPuble 6.

- 1979, Tax Policy and Capital Formation. NTJ 32.

- 1981, Der gegenwartige Stand der Theorie der Besteuerung. FA NF 39. 
MUSGRAVE, R.A., MUSGRAVE, P.B. 1980, Public Finance in Theory and Practice, 3.A., Tokyo u.a.

MUSGRAVE/MUSGRAVE/KULLMER 1975 a, Die offentlichen Finanzen in Theorie und Praxis, Bd. 1, Tübingen.

- 1975 b, Bd. 2 .

- 1977, Bd. 3 .

- 1978, Bd. 4.

MUSGRAVE/MUSGRAVE/KULLMER, 1988, Die öffentlichen Finanzen in Theorle und Praxis, Bd. 2, 4.A. Tübingen;

- 1990, Die öffentlichen Finanzen in Theorie und Praxis, Bd. 1, 5.A. Tubingen;

- 1992, Die öffentlichen Finanzen in Theorie und Braxis, Bd. 3, 4.A. Tubingen;

MUSGRAVE, R.A., PAZNER, E.A. 1980, Llability Rules, Efficlency, and Equity. PF. MUSGRAVE, R.A., SHOUP, C.S. (Bg) 1966, Readings in the Economics of Taxation. (Selected by a Committee of the American Economic Association), London (1959), 2.A.

MYRDAL, G. 1963, Das politische Element in der nationalobonomischen Doktrinbildung. Schriftenrelhe der Forschungsstelle der Friedrich-Ebert-Stiftung, Hannover. (Eine Bearbeitung durch M. Schüler auf der Grundlage der ersten deutschen Fassung von 1932 (tbersetzung durch G. Mackroth) anhand der engIischen Ausgabe von 1953; Original in Schwedisch: Stockholm 1930).

NAUST, H. 1983, Direkte Steuern und intertemporale Allokation, Köln u.a.

NEIL-BREUNING, O.v. 1956 b, Einkommensgestaltung in der sozialen Marktwirtschaft, O.v. Nell-Breunling (Bg), Wirtschaft und Gesellschaft heute, Bd. 1.

- 1956 c, Wertzuwachssteuer. BdF II, 2.A.

- 1968, Uber Wirtschaft und Gerechtigkeit. FA NF 27.

- 1970, Steuern als Instrumente der Bodenpolitik, B. Baller U.a. (Bg) 1970.

NEUMANN, F. J. 1887, Die progressive Einkommensteuer.

- 1889, Grundlagen der Volkswirtschaftslehre, Tübingen.

- 1896, Die persönlichen Steuern vom Einkommen, verbunden mit Ertrags- oder mit Vermőgenssteuern mit besonderer Bezlehung auf wirttemberglsche Verhaltnisse, Tübingen.

NEUMANN, M. 1979, Nutzen. HdWw, 21. Ifg.

NEUMARK, F. 1947, Theorie und Praxis der modernen Einkommensbesteuerung, Bern.

- 1951, Zum Problem der Klassifikation der Steuerformen, F. Neumark u. B. Sauermann (Bg) 1951.

- 1953 , Möglichkeiten einer finanzpolitischen Beeinflussung von Kapitalbildung und Kapitalverwendung. G. Albrecht, B. Arndt (Bg), Kapltalbildung und Kapitalverwendung. SVS NF 5, Berlin (wieder abgedruckt: F. Neumark, wirtschafts- und Finanzprobleme des Interventionsstaates, Tübingen 1961).

- 1959, Steuer (I) Theorie der Besteuerung. BDSW 10.

- 1961 a, E1nkommensteuer. HDSW 3.

- 1961 b, Probleme der allgemeinen Einkommenstheorie. (te1lw. überarb. bzw. ergănzte deutsche Fassung der 1944 in Istanbul unter dem Titel "Problems of General Income Theory" erschienenen Abhandlung), F. Neumark, Wirtschaftsund Finanzprobleme des Interventionsstaates, Tubingen.

- 1961 d, Probleme einer qualitativen Differenzierung (Differentiation) der steuerlichen Einkommensbelastung, in: F. Neumark, Wirtschafts- und Finanzprobleme des Interventionsstaates, Tübingen.

- 1961 f, Wirtschafts- und Finanzprobleme des Interventionsstaates, Tübingen.

- 1965, Grundsäze der Besteuerung in Vergangenhelt und Gegenwart, Wiesbaden.

- 1970, Grundsätze gerechter und ökonomisch rationaler Steuerpolitik, Tubingen.

- 1970 a, Einkommensteuer und Umsatzsteuer im Lichte des Gerechtigke1ts- und Wachstumspostulats, Wien.

- 1975, Zur Problematik einer Indexierung von Einkommensteuern. FA NF 35.

- 1977, Ein neues Buch über die Vermőgensteuer. FA NF 35.

- 1979 , therblick über die Personalsteuern. HdF II, 3.A.

- 1988, Steuerpolitische Ideale der Gegenwart, in: H. Zimmermann (Hg.), Die Zukunft der Staatsfinanzen, Marburger Forum Philipoinum, Stuttgart. 
NEUMARK, F., SAUERMANN, H. (Hg) 1951, Beiträge zur Geld- und Finanztheorie. Wilhelm Gerloff zum siebzigsten Geburtstag, Tübingen.

NÖLL V.D. NAHMER, R. 1980, Die verhăngnisvolle Formel. Der Gesetzgeber darf den Schwund des Geldvermögens nicht einfach hinnehmen. DZ Nr. 16 v. 11.04.80.

OBERHAUSER, A. 1965, Bewertungsprobleme im Steuerrecht. HDSW 12 .

- 1974, Erbschafts- und Vermögensbesteuerung als Mittel zur gleichmäBigeren Verteilung des Vermögensbestandes, W. Albers (Hg), రffentliche Finanzwirtschaft und Verteilung I. SVS NF 74/I.

- 1979, Erbschaft- und Schenkungsteuern. HdF II, 3.A.

- 1980, Wertzuwachssteuer. HaWW, 22. Lfg.

- 1983, Kommunale Wertschöpfungssteuer - ein Ersatz für die Gewerbesteuer, in: Bundesforschungsanstalt für Landeskunde und Raumordnung, H. 6/7, Bonn

OFFE, C. 1970, Leistungsprinzip und industrielle Arbeit, Köln u.a.

OGURA, S. 1977, More on Rawlsian Optimal Income Taxation: A Complementary Note on E.S. Phelps's "Taxation of Wage Income for Economic Justice". QJE 91.

OBM, H. 1972, Allgemeine Volkswirtschaftspolitik, I: Systematisch-theoretische Grundlagen, 4.A. Berlin.

OKUN, A.M. 1975,Equality and Efficiency: The Big Tradeoff. The Brookings Institution, Washington DC.

ORDOVER, J.A. 1976, Distributive justice and optimal taxation of wages and interest in a growing economy. JPolE 5.

ORTLIEB, H.-D. 1973, Das Gleichheitsprinzip als politische und ökonomische Forderung, A. Rauscher (Hg), Kapitalismuskritik im Widerstreit, Köln.

OSSENBUHL, K.H. 1972, Die gerechte Steuerlast. Prinzipien der Steuerverteilung unter staatsphilosophischem Aspekt, Heidelberg u.a.

PALMER, R.W. 1980, Equality, Incentives, and Economic Policy. AER PP 70.

PARETO, V. 1927, Manuel d'économie politique, 2.A., Paris.

PARKER, R.H. 1969, Introduction. Readings in the Concept and Measurement of Income, R.H. Parker, G.C. Harcourt (Hg) 1969.

PARKER, R.H., HARCOURT, G.C. (Hg) 1969, Readings in the Concept and Measurement of Income, Cambridge University Press.

PATTERSON, K.D., SCHOTT, K. (Hg) 1979, The Measurement of Capital: Theory and Practice, London.

PATZIG, G. 1958, Logik, Logistik, in: A. Diemer, I. Frenzel (Hg), Philosophie, Frankfurt a.M.

PAULY, R. 1977, Besteuerung und Umverteilung. Institut fūr Orkonometrie und Operations Research, Universität Bonn.

- 1979, Planung und Analyse steuerlicher Umverteilungspolitik, C.C.v. Weizsäcker (Hg), Staat und Wirtschaft. SVS NF 102.

PECHMAN, J.A. 1957, Erosion of the Individual Income Tax. NTJ 10.

- 1968, Comprehensive Income Taxation: A Comment. HLR 81.

- 1971, Federal Tax Policy, 2.A., Washington DC.

- (Hg) 1977, Comprehensive Income Taxation. A Report of a Conference Sponsored by the Fund for Public Policy Research and the Brookings Institution, Washington DC.

- (Hg) 1980, What Should Be Taxed: Income or Expenditure? A report of a conference sponsored by the Fund for Public Policy Research and the Brookings Institution, STudies of Governmant Finance: The Brookings Institution, Washington DC.

PECHMAN, J.A., OKNER, B.A. 1972, Individual Income Tax Erosion by Income Classes. The Economics of Federal Subsidy Programs. A Compendium of Papers Submitted to the Joint Economic Committee, Pt. 1, General Study Papers, 92 Cong. 2 sess., Brookings Reprint 230.

PEFFEKOVEN, R. 1979 a, Persónliche allgemeine Ausgabensteuer. HdF II, 3.A.

- 1979 b, Zur Problematik einer persönlichen Ausgabensteuer. FA NF 37.

- 1979 C, Zur Diskussion um die Ausgabensteuern. WiSt H. 11.

PEFFEKOVEN/FISCHER 1982, Ausgabensteuer (persönliche, allgemeine). HdWW 36./37. Lfg. 
PELKA, J. 1975, Die Einheitsbewertung des Grundbesitzes unter verfassungsrechtlichem Aspekt. Stuw 52. (5.) Jg.

PEN, J. 1973, Income Distribution, London.

PERELMAN, Ch. 1967, Uber die Gerechtigkeit. Mit einer Einleitung von Theodor Viehweg, München.

PETER, H. 1934, Das Problem der Gerechtigkeit und die Theorie der Steuerverteilung. FA NF 2 .

- 1956, Kapital (II) Gesellschaftliche Theorie des Kapitals. HDSW 5.

- 1959, Wann sind zwei Personen gleich reich?, Zur Kritik der okonomischen Grundvorstellungen. FA NF 19.

PETERSEN, H.-G. 1977, Personelle Einkommensbesteuerung und Inflation. Finanzwissenschaftliche Schriften. Bd. 5, Frankfurt a.M. u.a.

PFÄHLER, W. 1978, Normative Theorie der fiskalischen Besteuerung: Ein methodologischer und theoretischer Beitrag zur Integration der normativen Besteuerungstheorie in der Wohlfahrtstheorie, Frankfurt u.a.

PFAFF, M. 1978 a, Grundlagen einer integrierten Sozialpolitik, M. Pfaff, H. Voigtlănder (Hg) 1978.

- 1978 b, Grenzen der Verteilungs- und Sozialpolitik, M. Pfaff (Hg), Grenzen der Umverteilung, Schriften des Internationalen Instituts für Empirische Sozialökonomie (Inifes), Bd. 1.

- (Hg) 1978 c, Problembereiche der Verteilungs- und Sozialpolitik. Vortrăge bei der internationalen wissenschaftlichen Tagung der Deutschen Forschungsgemeinschaft vom 30.06. bis 03.07.1976 in Augsburg zum Thema "Grenzen der Verteilungs- und Sozialpolitik in einer stagnierenden bzw. wachsenden Wirtschaft. INIFES-Schriften, Bd, 2, Berlin.

PFAFF, M., VOIGTLÄNDER, H. 1978, Soziale Sicherheit zwischen Anspruch und wirklichkeit, M. Pfaff, H. Voigtländer (Hg) 1978.

PFAFF, M., VOIGTLANDER, H. (Hg) 1978, Sozialpolitik im Wandel. Von der selektiven zur integrierten Sozialpolitik, Bonn.

PFISTER, R.L. 1976, A Reevaluation of the Justifications for Property Tax Exemptions. PFQ 4.

PHELPS, E.S. 1966, Golden Rules of Economic Growth, Norton.

- 1973, Taxation of Wage Income for Economic Justice. QJE 87.

- (Hg) 1973, Economic Justice, Harmondsworth.

PHILIPPOVITCH, E.V. 1926, GrundriB der Politischen Okonomie I: Allgemeine Volkswirtschaftslehre, 19.A. Tübingen.

PICOT, G. 1978, Gewinnumverteilung und Verfassungsrecht. Eine Studie über die verfassungsrechtliche Grenzmarkierung einer obligatorischen Gewinnumverteilung, insbesondere der "Grundlinien eines Vermögensbeteiligungsgesetzes". Schriften zum öfentlichen Recht, Berlin.

PIGOU, A.C. 1928, A Study in Public Finance, London (Neudruck 1956).

- 1932, The Economics of Welfare, 4.A. London (Neudruck 1960).

- 1941, Maintaining Capital Intact. Eca NS 8.

- 1951, Some Aspects of Welfare Economics. AER.

PISTORIUS, 1929, Unser Steuerrecht, Stuttgart.

PLATTNER, M.F. 1979, The Welfare State vs. the Redistributive State. The Public Interest, No. 55, New York.

PLEHN, C.C. 1924, The Concept of Income as Recurrent, Consumable Receipts. AER 14.

- 1931, Introduction to Public Finance (1896), London/New York/Toronto, 5.A.

POHMER, D. 1955, Zur Abstimmung des Steuersystems auf die Wirtschaftsordnung. FA NF 15.

- 1970, Leistungsfăhigkeitsprinzip und Einkommensumverteilung, H. Baller u.a. (Hg) 1970.

- 1976, Wirkungen finanzpolitischer Instrumente. HdF I, 3.A.

- 1988, Einige Bemerkungen zu Inhalt und Bedeutung des Leistungsfähigkeitsprinzips. in: FA NF 46. 
POLLACK, H. 1975, Die progressive Einkommensteuer als Instrument der Einkommensumvertellung in einer wachsenden und inflationären Wirtschaft. Institut International de Finances Publiques: The Impacts of Economic Growth, Barcelona. POPITZ, J. 1926, Einkommensteuer. HwStW, 4.A., Bd. 3.

POPPER, K.R. 1966, Logik der Forschung. 2.A. Tübingen. Band 4 der "Die Einheit der Gesellschaftswissenschaften. Studien in den Grenzbereichen der Wirtschafts- und Sozialwissenschaften. (engl. Originalausgabe: The Logic of Scientific Discovery, London 1959).

- 1977, Die offene Gesellschaft und ihre Freinde. Bd. I: Der Zauber Platons. 5.A. München. (engl. Originalausgabe: The Spell of Plato, London 1944).

PREISER, E. 1943, Das Rationalprinzip in der Wirtschaft und in der Wirtschaftspolitik. JNS 158.

- 1953, Erkenntniswert und Grenzen der Grenzproduktivitătstheorie. SzVS 89. Jg.

- 1959, Distribution. (I) Theorie. HDSW 2.

- 1964, Theoretische Grundlagen der Vermögenspolitik, Bonn.

- 1970 , Wachstum und Einkommensverteilung. Sitzungsberichte der Heidelberger Akademie der Wissenschaften (1961), 3.A. Heidelberg.

PREST, A.R. 1959, The Expenditure Tax and Saving. EJ 69.

- 1979, The Structure and Reform of Direct Taxation. EJ 89.

RAUPACH, A. 1985, Niedergang oder Neuordnung des deutschen Einkommensteuerrechts? Raupach, A., Tipke, K., Uelner, A., Münsteraner Symposion Bd.1, Köln

RAWLS, J. 1975, Eine Theorie der Gerechtigkeit, Frankfurt. (engl. Original: A Theory of Justice. The President and Fellows of Harvard College, Cambridge/ Mass. 1971).

RECKTENWALD, H.C. 1981 , Nationalökonomie und Gerechtigkeit. Grundsätzliches und Kritisches zur Verteilung und Umverteilung der Einkommen. W.J. Mückl, A.E. Ott (Hg) 1981.

- (Hg) 1969 a, Finanztheorie. NWB-W 33, Köln/Berlin.

- (Hg) 1969 b, Finanzpolitik. NWB-W 36, Köln/Berlin.

- (Hg) 1978, Der Wohlstand der Nationen, s.u. Smith, A.

RECKTENWALD, H.C., GRUSKE, K.-D. 1980 a, Umverteilung via Staat. Ergebnisse einer empirischen Budgetanalyse. in: K.-D. Grüske (Hg), Horst Claus Recktenwald: Markt und staat. Fundamente einer freiheitlichen ordnung in wirtschaft und Politik, Göttingen.

- 1980 b, Justitia distributiva durch Umverteilung? Eine Analyse der personalen Budgetinzidenz. Ky 33 .

REES, J.C. 1976, Soziale Gleichheit. Frankfurt u.a. (Orig.: Equality, London 1971).

Ricardo, D. 1823, On the Principles of Political Economiy and Taxation (London 1817); deutsch von $\mathrm{H}$. Waentig: Grundsatze der Volkswirtschaft und Besteuerung, 3.A., in: Sammlung sozialwissenschaftlicher Meister, hg. v. H. Waentig, Bd. 5, Jena.

RIEDMAIER, K. 1976, Das Prinzip der Leistungsfăhigkeit und der Einkommensteuertarif. DStR 13.

RITSCHL, H. 1928, Die Erbschaftssteuer als Hemmnis der Kapitalbildung und Spartătigkeit. Sparkasse Bd. 48.

- 1961, Erbschaftsteuer. HDSW 3.

ROBERTS, Ch.C. 1980, Verteilungstheorie und Verteilungspolitik. Problemorientierte Einführungen, 9, hg.v. D.B. Simmert, Köln.

ROBINSON, J. 1980, Time in Economic Theory. Ky 33.

RÖSSLER, R., TROLL, M., LANGNER, J. 1981, Bewertungsgesetz und Vermögensteuergesetz, 12.A. München.

ROSCHER, W.G.F. 1922, 1901, System der Volkswirtschaft, Bd. 1 (1922): Die Grundlagen der Nationalökonomie, Stuttgart 26.A.; Bd. 4 (1901): System der Finanzwissenschaft, 5.A. Stuttgart.

- Grundlagen der Nationalökonomie, 25. A., Stuttgart U. Berlin 1918 (1.A.1854), System der volkswirtschaft, 1. Bd. 
ROSE, G. 1975, Substanzbesteuerung und Substanzerhaltung, P. Mertens (Bg), Die Unternehmung in ihrer gesellschaftlichen Umwelt, Wiesbaden.

- 1976, Was heiBt und zu welchem Ende studiert man Steuerwissenschaften? DStz/A 10 .

- 1982 a, Betrieb und Stever. Grundlagen zur Betriebswirtschaftlichen Steuerlehre. Erstes Buch: Die Ertragsteuern. 4.A. Wiesbaden.

- 1982 b, Betrieb und Steuer. Grundlagen zur Betriebswirtschaftlichen Steuerlehre. Drittes Buch: Die Substanzsteuern. Wiesbaden.

- 1980, Zur Bestimmung der Einkunftsart bei gemischten wirtschaftlichen Aktivitaten von Einzelpersonen. DB В. $51 / 51$, S. $2464 \mathrm{ff}$.

ROSE, M. 1977, Finanzwissenschaftliche Verteilungslehre: Zur Verteilungswirkung finanzwirtschaftlicher Staatsaktivităten, München.

- 1979, Vermögensteuern. BaWw, 17./18. Lfg.

ROSENSTEIN-RODAN, P.H. 1934, The Role of Time in Economic Theory, Eca 1,5.77-97.

ROSKAMP, K.W., FORTE, F. (Bg) 1981, Reform of Tax Systems - Réformes des systemes fiscaux. Proceedings of the 35 th Congress of the International Institut of Public Finance, Taormina 1979, Detroit.

ROSTOW, W.W. 1980, Why the Poor get Richer and the Rich Slow Down: Essays in the Marshallian Long Period, London u.a.

ROYAL COMMISSION 1966, Report of the Royal Commission on Taxation (Carter Report) vol. 1-4 u. 6, Ottawa (Repr. 1968).

ROYAL COMMISSION ON TAXATION 1968, Who Benefits and who Pays. Study for the Royal Commission on Taxation Nr. 26. Toronto.

ROYAL COMMISSION on the Taxation of Pofits and Income 1955, Second Report, Cmnd 9105; London, HMSO 1954. Final Report Cmnd 9474, London 1955.

RUGER, G. 1976, Steuerliche Vergunstigungen für die Landwirtschaft als M1ttel der Agrarpolitik. Bochumer Wirtschaftswissenschaftliche Studien, Nr. 22.

RUPP, в.甘., v. ZEZSCHWITZ, F., v. OLSHAUSEN, H. 1970, Zur Ungleichheit in der Einkommensbesteuerung der Versorgungsbezüge und Sozialrenten, Mainz.

SANDFORD, C.T. 1965, Taxing Inheritance and Capital Gains, London.

- 1971 a, Realistic Tax Reform, London.

- 1971 b, Taxing Personal Wealth. London.

SANDFORD, C.T., WILLIS, J.R.M., IRONSIDE, D.J. 1975, An Annual Wealth Tax, London.

SARRAZIN, Th. 1976, Kumulative Effekte der Finanz- und Sozialpolitik auf die Einkommensverteilung. FA NF 34.

SAX, E. 1887, Grundlegung der theoretischen Staatswirtschaft, Wien.

SCHACHTSCBNABEL, B.G. 1960, Der Wandel des Gerechtigkeitsbegriffs, H.J. Seraphim (Hg), Zur Grundlegung wirtschaftspolitischer Konzeptionen. SVS NF 18, Berlin.

SCHAEFER, K.B. 1981, Lastenausgleich. BwStR 2.A.

SCBÄFFLE, A. 1873, Das gesellschaftliche System der menschlichen Wirtschaft, 3.A. Tübingen.

- 1895/1897, Die Steuern. 2 Bde. Leipzig.

SCHANZ, G.v. 1896, Der Einkommensbegriff und die Einkommensteuergesetze. FA 13.

- 1898, Gărtner's Einkommensbegriff. FA 15.

- 1900, Studien zur Geschichte und Theorie der Erbschaftssteuer. FA 17.

- 1926, Erbschaftsteuer. BdStw 3 Jena.

SCBEELE, E. 1979, Einkommensverteilung I: Theorie. BdWW 19./20. Lfg.

SCBERHORN, G. 1959, Bedürfnis und Bedarf, Berlin.

- 1978, Eine andere Meinung, In: Sachverstăndigenrat zur Begutachtung der gesamtwirtschaftlichen Entwicklung, Jahresgutachten 1977/78, Deutscher Bundestag, 8. Wahlperiode, Drucksache 8/1221.

SCEEWE, D. , SCBENKE, K., MEURER, A., HERMSEN, K.-W. 1977, thersicht ulber die soziale Sicherung. Bundesminister für Arbeit und Sozialordnung, 10.A. Bonn.

SCBIMKE, P. 1940, Wandlungen der Einkommensteuer, Breslau.

SCHIPPOREIT, E. 1979, Grundsătze und Möglichkeiten einer Unternehmungsteuer. SR Wirtschaftswissenschaftllche Forschung und Entwicklung, Bd. 47, Minchen.

- 1980, Ziele und Möglichkeiten einer Unternehmungsteuer. Grundzüge elnes Reformvorschlags. Stuw 57. (10.) Jg. 
SCHLOTTER, H.-G. 1981, Intertemporale (intergenerative) Gerechtigkeit und Chancengleichheit, Ph. Herder-Dorneich (Hg) 1981.

SCHMAHL, W. 1974, Systemänderung in der Altersvorsorge, Opladen.

SCHMÄHL, W. 1977 a, Alterssicherung und Einkommensverteilung. Theoretische und empirische Untersuchungen zur Finanzierung, Leistungsgewährung und zur Verteilung zwischen Generationen, Tübingen.

- 1977 b, Einkommensumverteilung im Rahmen von Einrichtungen der sozialen Sicherung - Einige Probleme ihrer Ermittlung und Ausgestaltung am Beispiel der gesetzlichen Rentenversicherung, B. Külp, H.-D. Haas (Hg) 1977.

- 1978, Zur Einkommenssituation alter Menschen in der Bundesrepublik Deutschland - Probleme ihrer Ermittlung und Beurteilung, H.P. Widmaier (Hg) 1978.

- 1981, Lebenseinkommens- und Langsschnittanalysen - Methodische und empirische Fragen sowie ihre verteilungs- und sozialpolit1sche Bedeutung, Ph. HerderDorneich (Hg) 1981.

- 1981a, Elemente einer künftigen Rentenreform: Veränderungen der Anpassung und der Besteuerung von Renten, in: BMA (Hg.), Langfristige Probleme der Alterssicherung in der Bundesrepublik Deutschland, Bd. 3, Bonn.

SCHMAUS, G. 1978, Personelle Einkommensverteilung im Vergleich 1962/63 und 1969, H.-J. Krupp, W. Glatzer (Hg) 1978.

SCHMIDT, K. 1959, Zweckkollisionen in der modernen Steuerpolitik. FA NF 19.

SCHMIDT, K. 1960, Die Steuerprogression. Veröffentlichungen der List-Gesellschaft e.V. Bd. 20, Basel/Tübingen.

- 1963, Zur Reform der Unternehmungsbesteuerung. FA NF 22.

- 1966, Entwicklungstendenzen der öffentlichen Ausgaben im demokratischen Gruppenstaat. FA NF 25.

- 1967, Das Leistungsfăhigkeitsprinzip und die Theorie vom proportionalen Opfer. FA NF 26.

- 1972, Renaissance der Opfertheorien? Zur ökonomischen Sinngebung politischer Entscheidungen. FA NF 30.

- 1978, Grundprobleme der Besteuerung. HaF II, 3.A.

SCHMITT-RINK, G. 1978, Verteilungstheorie, Tübingen/Düsseldorf.

SCHMÖLDERS, G. 1949 a, s. BetriebsteuerausschuB 1949 mit folgenden Beitrăgen Schmölders': a) Die geschichtliche Entwicklung der Betriebsbesteuerung (Sp. 973-980); b) Bemessungsgrundlagen der Betriebsbesteuerung (Sp. 985-994); c) Vergleichende Darstellung der drei Entwürfe:"Wirtschafts- und finanzpolitische Gesichtspunkte" (Sp. 1018-1020) und "Zum Problem des Steuersatzes" (Sp. 1020-1022).

- 1949 b, Leitsätze zur organischen Steuerreform, Denkschrift der Volkswirtschaftlichen Gesellschaft e.V. Hamburg.

- 1950, Irrwege und Umkehr der Betriebsbesteuerung. PF 5.

- 1953, Umbau des Steuersystems? Gutachten Köln.

- 1960 , Der fehlende Einkornensbegriff. StuW 37. Jg.

- 1964, Das Gerechtigkeitspostulat in der Besteuerung. FA NF 23.

- 1965, Allgemeine Steuerlehre. 4.A. Berlin.

- 1970 , Finanzpolitik. 3.A. Berlin u.a.

- 1981 a, Sollbesteuerung. HwStR 2.A.

- 1981 b, Steuerwissenschaften. HwStR 2.A.

- 1981 c, GleichmảBigkeit der Besteuerung. HwStR 2.A.

- 1981 d, Leistungsfähigkeit. HwStR 2.A.

SCHMOLDERS, G., HANSMEYER, K.-H. 1980, Allgemeine Steuerlehre. 5.A. Berlin.

SCHMOLIER, G.v. 1863, Die Lehre vom Einkommen und ihrem Zusammenhang mit den Grundprincipien der Steuerlehre. ZgS 19.

SCHNEIDER, D. 1963, Bilanzgewinn und okonomische Theorie. ZfhF NF 15.

- 1971, Gewinnermittlung und steuerliche Gerechtigkeit. ZfbF NF 23.

- 1974, "Staatsbürgersteuer" - ein Schildbürgerstreich. StuW 51. (4.) Jg.

- 1975 , Körperschaftsteuerreform und GleichmäBigkeit der Besteuerung. StuW 52. (5.) Jg.

- 1976 a, Besteuerung von VeräuBerungsgewinnen und Verkaufsbereitschaft: der fragwürdige "lock-in-Effekc". Stuw 53. (6.) Jg. 
- 1976 d, Realisationsprinzip uns Einkommensbegriff, J. Baetge, A. Moxter, D. Schneider (Hg), Bilanzfragen. Festschrift zum 65. Geburtstag von Prof. Dr. Ulrich Leffson, Düsseldorf.

- 1978 a, Grundzüge der Unternehmensbesteuerung. 2.A. Wiesbaden.

- 1978 b, Steuerbilanzen. Rechnungslegung als Messung steuerlicher Leistungsfāhigkeit, Wiesbaden.

- 1978 c, Insgesamt unzweckmäBig. Brauchen wir den Paragraphen 6b EStG? WW 29 vom 14.07.1978, S. 76-79.

- 1979 a, BezugsgröBen steuerlichen Leistungsfăhigkeit und Vermögensbesteuerung. FA NF 37.

- 1979 c, Zur Rechtfertigung von Erbschaft- und Vermögensteuer. StuW 56. (9.) Jg.

- 1981, Die Wissenschaftsgeschichte der Trennung von Kapital und Einkommen: Ükonomische Zwänge gegen gesellschaftliche Konventionen, F. Neumark (Hg), Studien zur Entwicklung der ökonomischen Theorie I. SVS NF 115/I Berlin.

- 1984, Der Einkommensbegriff und die Einkommensteuerrechtsprechung, in: FA NF 42.

- 1986, Verbesserung der Allokation durch Besteuerung unrealisierter Vermögenswertänderungen? In: FA NF 44.

- 1990, Grundzüge der Unternehmensbesteuerung, 5.A. Wiesbaden.

SCHNEIDER, E. 1961, Fisher, Irving. HDSW 3.

SCHNEIDER, H.K. (Hg) 1968, Grundlagen der Wettbewerbspolitik. Schriften des Vereins für Socialpolitik. NF 48.

SCHNEIDER, H.K., WATRIN, Chr. (Hg) 1973, Macht und ökonomisches Gesetz. SVS NF 74.

SCHREDELSEKER, K. 1975, Wider eine individualistisch verkūrzte Theorie der Unternehmensbesteuerung. Anmerkungen zu dem Aufsatz von Dieter Schneider: Körperschaftsteuerreform und GleichmãBigkeit der Besteuerung. StuW 52 . (5.) Jg.

SCHREIBER, W. 1959, Existenzminimum (in ökonomischer Sicht), Staatslexikon 3. - 1971, Zum System sozialer Sicherung, Kōln.

SCHREIBER/STORCK 1979, Prinzip der gleichmāBigen Besteuerung, Allgemeinheitsund Leistungsfähigkeitsprinzip. Wist 8.Jg.

SCHREYER, M. 1977, Probleme der Besteuerung der Renten. KP 23. Jg.

SCHULTE, H. 1967, Der Vorschlag einer "Betriebsteuer" und das geltende deutsche Steuersystem, Berlin.

SCHULTZ, T.W. (Hg) 1962, Investment in Human Beings. JPole 70, Nr. 5. SCHUMPETER, J. 1929, Erbschaftsteuer. Der Volkswirt III.

- 1929 b, Okonomie und Soziologie der Einkommensteuer, Der deutsche Volkswirt, IV v. 20.12.1929.

SCHUSTER, E. 1926, Das Einkommen. Eine kritische Untersuchung, Tübingen.

- 1961, Einkommen. HDSW 3.

SEEBERG, S. 1963, Eigentum und Vermögen.Ein Beitrag zum Wandel ihrer Funktionen. JNS 175.

SEIDMAN, L.S. 1981, Equity and Tradeoffs in a Tax-Based Incomes Policy. AER PP 71. SEIFFERT, H. 1975 a, Einführung in die Wissenschafts-Theorie 1: Sprachanalyse. Deduktion. Induktion in Natur- und Sozialwissenschaften. 8.A. Mūnchen.

- 1975 b, Einführung in die Wissenschafts-Theorie 2: Geisteswissenschaftliche Methoden: Phānomenologie. Hermeneutik und historische Methode. Dialektik. 6.A. München.

SELIGMAN, E.R.A. 1894, Progressive taxation in theory and practice. Baltimore. Publications of the American Economic Association, Vol. IX, Nos. 1 \& 2 (2.A. Princeton 1908).

- 1919, Are Stock Dividends Income? AER.

- 1921, The Income Tax. A Study of the History, Theory and Practice of Income Taxation at Home and Abroad /1911). 2.A. New York.

- 1931, Essays in Taxation. 10.A. New York (Repr. 1969).

SELMER, P. 1976, Besprechung von Ulrich Moebus, Die verfassungsrechtliche Begründung der progressiven Einkommensteuer und ihre systemgerechte Durchführung. FA NF 34 . 
SELTZER, L.H. 1968, The Personal Exemptions in the Income Tax. NBER, Fiscal Studies No. 12, New York.

SEN, A.K. 1970, Collective and Social Welfare, San Francisco u.a.

SHOUP, C.S. 1956, Kriegsgewinn- und Wertzuwachssteuern. HdF II, 2.A.

- 1967, Federal Estate and Gift Taxes. The Brookings Institution. Washington.

- 1969, Public Finance, London.

- 1975, Surray's Pathways to Tax Reform - A Review Article. JF 30.

SIDGWICK, H. 1883, Principles of Political Economy. Buch 3, London.

SIEVERT, O. 1988, Änderung der Steuerstruktur in Richtung auf mehr Ausgabenbesteuerung? In: H. Z1mermann (Hg.), Die Zukunft der Staatsfinanzlerung, Marburger Forum Philippinum, Stuttgart.

SIMONS, H.C. 1938, Personal Income Taxation. The Defintition of Income as a Problem of Fiscal Policy. Chicago.

SLITOR, R.E. 1969, The Carter Proposals on Capital Gains: Economic Effects and Policy Implications for the United States. NTJ 22.

SMITH, A. 1978 (1776), An Inquiry into the Nature and Causes of the Wealth of Nations. 2 Bde., London 1776. Zuletzt nach der in 5.A. (letzter Hand) in London erschienenen Ausgabe vollständig neu ins Deutsche übertragen von H.C. Recktenwald unter dem Titel "Der Wohlstand der Nationen. Eine Untersuchung seiner Natur und seiner Ursachen". München 1978.

SరEN (Hg) 1980, Die Abgrenzung der Betriebs- oder Berufssphăre von der Privatsphäre im Einkommensteuerrecht, Köln.

SOBMEN, E. 1976, Allokationstheorie und Wirtschaftspolitik, Tübingen.

SOLOMONS, D. 1969, Economic and Accounting Concepts of Income, R.H. Parker u. G.C. Harcourt (Hg) 1969.

SPABN, B.P. 1972, Die Besteuerung der persönlichen Einkommen in der Bundesrepublik Deutschland, System und Modell, Diss. Berlin.

SPICER, M.W., BECKER, L.A. 1980, Fiscal Inequity and Tax Evasion: An Experimental Approach. NTJ 33.

SPRINGER, W.L. 1973, Windfalls, Temporary Income Taxes, and Consumption Behavior, Diss. Princeton.

SRAFFA, P. 1968, Warenproduktion mittels Waren, Berlin (Original: Production of Commodities by Means of Commodities, Cambridge 1960).

STATISTISCHES BUNDESAMT Wiesbaden 1977, Einkommens- und Verbrauchsstichprobe 1973. Fachserle 15: Wirtschaftsrechnungen. Heft 4: Einnahmen und Ausgaben privater Haushalte, Stuttgart/Mainz.

STATISTISCHES BUNDESAMT Wiesbaden 1978, Einkommens- und Verbrauchsstichprobe 1973, Fachserie 15: Wirtschaftsrechnungen. Heft 7: Aufgaben, Methode und Durchführung, Stuttgart/Mainz.

- 1988, Einkommens- und Verbrauchsstichprobe 1983, H. 6, Stuttgart und Mainz.

STEDEN, W. 1979, Erbschaft- und Schenkungsteuern. HdWW 19./20. Lfg.

STEGMLLER, W. 1973, Probleme und Resultate der Wissenschaftstheorie und Analytischen Philosophie. Bd. II: Theorie und Erfahrung; 2. Halbbd.: Theoriestrukturen und Theoriedynamik, Berlin u.a.

- 1975, Hauptströmungen der Gegenwartsphilosophie, II. Stuttgart.

STEINBERG, W. 1981 a, Vermögen. HWStR 2.A.

- 1981 b, Vermögensabgabe. HwStR 2.A.

- 1981 c, Vermögen, land- und forstwirtschaftliches. HwStR 2.A.

- 1981 d, Einheitsbewertung. HwStR 2.A.

STEINBERG, W., WÖHE, G. 1981, Vermögensteuer. HWStR 2.A.

STEINKAMP, G. 1971, ther einige Funktionen und Folgen des Leistungsprinzips in Industriellen Gesellschaften. HJ 16.

STERN, K. 1976, Rechtliche und ökonomische Bedingungen der Freiheit. WC H1, 25. STEUERLE, E. 1982, Is Income from Capltal subject to Individual Income Taxation? PFQ 10 .

STEUERREFORMKOMMISSION 1971, Gutachten der Steuerreformkommission 1971. SR BMF, H. 17 , Bonn.

STIGLITZ, J.E. 1969, The Effects of Income, Wealth, and Capital Gains Taxation on Risk Taking. QJE 83.

- 1976, Estate Taxes, Growth, and Redistribution. Public and Urban Economics, Lexington u.a. 
STOBBE, A. 1960, Kurzfristige und langfristige Bestimmungsgründe der Einkommensverteilung. Szws 96 .

- 1962, Untersuchungen zur makroökonomischen Theorie der Einkommensverteilung. KS 59.

- 1975, Gesamtwirtschaftliche Theorie. Berlin u.a.

- 1976, Volkswirtschaftslehre I: Volkswirtschaftliches Rechnungswesen, Berlin U.a., 4.A.

- 1987, Makroökonomik, 2.A. Berlin.

- 1989, Volkswirtschaftliches Rechnungswesen, 7. A. Berlin.

- 1991, Mikroökonomik, 2.A. Berlin U.a.

STONE, I.M. 1969, A Comprehensive Income Tax Base for the U.S.? Implications of the Report of the Royal Commission on Taxation. NTJ 22.

STREETEN, P. 1979, Growth, Redistribution, and Basic Human Needs, K. Lask1, E. Matzner, E. Nowotny (Bg), Beitrăge zur Diskussion und Kritik der neoklassichen రkonomie, FEstschrift fur K.W. Rothschild und J. Steindl, Berlin u.a.

STREISSLER, E. 1981, Zu einer Theorie der Einkommensverteilung bei Unsicherheit, Klanberg/Krupp (Hg), Einkommensverteilung. NWB-W 92.

STREISSLER, E., WATRIN, Chr. (Hg) 1980, Zur Theorie marktwirtschaftlicher ordnungen. Unter Mitarbeit von M. Streissler, M. Supper u. W. Teufelsbauer, Tübingen.

STRUMPEL, B. 1968, Steuersystem und wirtschaftliche Entwicklung. Funktion und Technik der Personalbesteuerung im sozioökonomischen Wandel, Tübingen.

STRUTZ, G. 1910, Betrachtungen zur Reichszuwachssteuer.

- 1927/1929, Kommentar zum Einkommensteuergesetz vom 10.08.1925, 2 Bde., Berlin (Erg.bd. 1930).

STUCKEN, R. 1949, Die große Vermőgensabgabe und das heutige Finanzproblem. FA NF 11 .

STUTZEL, W. 1979, Das Mark-gleich-Mark-Prinzip und unsere Wirtschaftsordnung. Uber den sog. Nominalismus, insbesondere im Schuld- und Steuerrecht. Schriften zur Monetăren రkonomie 7, Baden-Baden.

SUNLEY, E.M. 1977, Employee Benefits and Transfer Payments, J.A. Pechman (Bg) 1977.

- 1979, Indexing the Income Tax for Inflation. NTJ 32.

SURREY, St.S. 1973, Pathways to Tax Reform. The Concept of Tax Expenditures. Cambridge/Mass.

SVR 1972, Jahresgutachten 1972/73: "Gleicher Rang für den Geldwert".

- 1977, Jahresgutachten 1977/78, Deutscher Bundestag, Drucksache 8/1221 vom 22.11 .1977 .

- 1978, Zur wirtschaftlichen Lage im Juni 1978, Sondergutachten vom 19.06.1978. Typoskript.

SVR 1979, Jahresgutachten 1979/80. Deutscher Bundestag, Drucksache $8 / 3420$ vom 22.11.1979.

- 1982, Jahresgutachten 1982/83. Deutscher Bundestag, Drucksache $9 / 2118$.

TAIT, A.A. 1960, Death Duties in Britain. PF 15.

- 1966, A Comment on Rates of Taxation Varied According to Consanguinity. FA NF 25.

- 1967, The Taxation of Personal Wealth, Urbana u.a.

TANZI, V. 1977, Inflation and the Incidence of Income Taxes on Interest Income: Some Resultes for the United States, 1972-1974. IMF-Staff Papers Vo1. 24.

- 1980, Inflationary Expectations, Economic Activity, Taxes, and Interest Rates. AER 70.

TAUTSCHER, A. 1954, Grenzen der Besteuerung, Berlin.

TESCBEMACBER, H. 1927, Einkommensteuer. BdF II, 1.A.

- (Bg) 1928, Beitrăge zur Finanzwissenschaft, Festgabe für G.v. Schanz zum 75. Geburtstag. Bd. 2, Tübingen.

THUROW, L.C. 1972, Net Worth Taxes. NTJ 25.

- 1973, Toward a Definition of Economic Justice. Public Interest 31.

- 1975, Generating Inequality, New York. 
TIEDE, M. 1971, Konsequenzen der Forderung nach Chancengleichheit im Erwerbsleben für die personelle Einkommensverteilung, sowie einige Folgerungen für den Einkommensteuertarif. JNS 185.

TIEPELMANN, K. 1963, Die Problematik der Vermögensteuer. FF NF 26.

TIMM, H. 1980, Finanzwirtschaftliche Allokationspolitik. HdF III, 3.A.

TINBERGEN, J. 1977, Gerechtigkeit als gesellschaftspolitisches Ziel. Der Beitrag der Theorie der Wirtschaftspolitik zur Entwicklung gesellschaftspolitischer Zielsystem. SVS NF $92 /$ I.

- 1980, Two Approaches to Quantify the Concept of Equitable Income Distribution. Ky 33.

TIPKE, K. 1971, Steuerrecht - Chaos, Konglomerat oder System? StuW 48. (1.) Jg.

- 1972, Steuerrechtswissenschaft und Steuersystem. Festschrift für Gerhard Wacke, Köln.

- 1974, Das Bundesverfassungsgericht zum Nettoprinzip. Stuw 51. (4.) Jg.

- 1979 , Zur Abgrenzung der Betriebs- oder Berufssphăre von der Privatsphăre im Einkommenssteuerrecht. Stuw 56. (9.) Jg.

- 1980 a, Bezüge und Abzüge im Einkommensteuerrecht. Ein kritischer Beitrag zum Aufbau und zur Terminologie des Einkommensteuergesetzes. StuW 57. (10.) Jg.

- $1980 \mathrm{~b}$, Uber Steuergerechtigkeit in Steuergesetzgebung, Steuerverwaltung und steuergerichtsbarkeit. Vom politischen Schlagwort zum Rechtsbegriff und zur praktischen Anwendung. Stuw 57. (10.) Jg.

- 1980 c, Zux Problematik einer rechtsformunabhängigen Besteuerung der Unternehmen. NJW 33. Jg., 1. Hbd.

- 1981, Steuerrecht. 8.A. Köln.

- 1981 a, Steuergerechtigkeit in Theorie und Praxis. Vom politischen Schlagwort zum Rechtsbegriff und zur praktischen Anwendung, Köln.

TIPKE/LANG, 1991, Steuerrecht. Ein systematischer GrundriB. 13.A. Köln (zitiert als "Tipke 1991")

TRANSFER-ENQUETE-KOMMISSION 1979 (TEK 1979), Zwischenbericht zur Einkommenslage der Rentner. Typoskript.

- 1981, Das Transfersystem in der Bundesrepublik Deutschland. Bericht der Sachverständigenkommission zur Ermittlung des Einflusses staatlicher Transfereinkommen auf das verfügbare Einkommen der privaten Haushalte (SchluBbericht), Stuttgart.

TREUARBEIT 1976, Gutachten: Vergleich des beamtenrechtlichen Versorgungssystems mit den Versorgungssystemen für Arbeitnehmer im offentlichen Dienst und in der privaten Wirtschaft. Bundestags-Drucksache 7/5569 vom 06.07.1976.

TROEGER, (Hg) 1958, Denkschrift zur Verbesserung der Einkommensbesteuerung, Stuttgart.

TROLL, M. 1981, Erbschaftsteuer. HwStR 2.A.

TURVEY, R. 1960, Equity and a Capital Gains Tax. OEP 12 .

ULBRICH, R. 1975, Das Leistungsfähigkeitsprinzip der Besteuerung. Eine kritische Würdigung seiner opfertheoretischen Grundlagen und Konsequezen für die Steuerpolitik, Bern u.a.

UPMEIER, W. 1970, Die neue Klassensteuer, Diss. Köln.

VARIAN, H.R. 1980, Redistributive Taxation as a Social Insurance. JPublE 14.

VICKREY, W. 1966, Averaging of Income for Income-Tax Purposes (1959), R.A. Musgrave, G.S. Shoup (eds) 1966.

- 1970, Expenditure, Capital Gains and Progressive Taxation (Excerpt from $w$. Vickrey 'Expenditure, Capital Gains, and Progressive Taxation', Manchester School of Economic and Social Studies, vol. 25, 1957), in: R.W. Houghton (ed). Public Finance, Penguin Modern Economic Readings, Harmondsworth.

VOCKE, พ. 1894, Die Grundzüge der Finanzwirtschaft, Leipzig.

VOGEL, E.H. 1922, Das Gerechtigkeitsproblem in der Besteuerung. Eine kritische Untersuchung zur werttheoretischen Richtung innerhalb der Finanztheorie. JNS 118. 
VOGEL, K. 1975, Steuergerechtigkeit und soziale Gestaltung. DStZ/A.

- 1979, Verkehrswert, Ertragswert und andere Werte. Bemerkungen zum Begriff des "Wertes" im Steuerrecht. DStZ/A.

voIGT, F. (Hg) 1953, Beitrăge zur Finanzwissenschaft und zur Geldtheorie, Festschrift für Rudolf Stucken, Göttingen.

WACKER, W.H. (Hg) 1975, Steuerlexikon, München.

WAGNER, A. 1880, Finanzwissenschaft. Zweiter The1l: Gebühren und allgemeine Steuerlehre, Leipzig/Heidelberg.

- 1890, Finanzwissenschaft. II. Theil: Theorie der Besteuerung, Gebührenlehre und allgemeine Steuerlehre, 2.A. Leipzig (in: A. Wagner (Hg), Lehr- und Bandbuch der politische Okonomie, Vierte Hauptabtheilung: Finanzwissenschaft).

- 1891 , Uber die soziale Finanz- und Steuerpolitik. Archiv für soziale Gesetzgebung und Statistik, Bd. 4.

- 1892, Grundlegung der politischen Okonomie. 3.A., Teil I: Grundlegung der Volkswirtschaft, Lehr- und Handbuch der Politischen Okonomie, Leipzig.

WAGNER, F.W. 1976 a, Kapitalerhaltung, Geldentwertung und Gewinnbesteuerung. Eine entscheidungslogische Analyse der Kapitalerhaltung als Zielsetzung der Investitionstheorie, betriebswirtschaftlicher Bilanztheorien und des steuerlichen Einkommensbegriffs. Unveröffentliche Habilitationsschrift, Regensburg.

- 1976 b, Einkommensbesteuerung und Inflation - Ein betriebswirtschaftlicher Beitrag zum steuerlichen Einkommensbegriff. Stuw 53. (6.) Jg.

- 1989, Die zeitliche Erfassung steuerlicher Leistungsfähigkeit, In: H. Hax, W. Kern, H.H. Schröder (Hg.), Zeitaspekte in betriebswirtschaftlicher Theorie und Praxis, Stuttgart.

WAGNER, F.W., DIRRIGL, H. 1980, Die Steuerplanung der Unternehmung, Stuttgart u.a.

WALLICH, H.C. 1965, Taxation of Capital Gains in the Light of Recent Economic Developments. NTJ 18.

WALZ, W.R. 1980 , Steuergerechtigkeit und Rechtsanwendung, Hamburg.

WARTENBERG, U. 1979, Verteilungswirkungen staatlicher Aktivitaten. FF 49.

WATRIN, Chr. 1976, Eine liberale Interpretation der Idee der sozialen Gerechtigkeit. Bemerkungen zum Buch von John Rawls "Eine Theorie der Gerechtigkeit", HJ 21.

- 1977, Ordnungspolitische Aspekte des Sozialstaates. SVS NF 92/II, Kūlp, B., Haas, B. -D. (Hg) 1977.

- 1979, Grenzen der Gleichheit in einer freiheitlichen Ordnung. Ordo 30.

- 1980, Zur sozialen Dimension marktwirtschaftlicher Ordnungen, Streissler/ Watrin (Bg) 1980.

- 1982, Das Gleichheitsideal des Wohlfahrtsstaates. WC H. 1.

WATRIN, Chr., WILLGERODT, В. (Hg) 1976, Widersprüche der Kapitalismuskritik, Festgabe für Alfred Mūller-Armack. Institut für Wirtschaftspolitik an der Universität zu Köln. WC B.2/3.

WB BMF 1953, Bericht des Wissenschaftlichen Beirats beim Bundesminister der Finanzen vom 04.02.1953 zur Organischen Steuerreform, Bonn.

- 1967, Gutachten vom 11. Februar 1967 zur Reform der direkten Steuern (Einkommensteuer, Körperschaftsteuer, Vermōgensteuer und Erbschaftsteuer) in der Bundesrepublik Deutschland. SR BMF H. 9, Bonn.

- 1969, Stellungnahme von 25.01.1969 zum Gesetz über steuerliche MaBnahmen bei Anderung der Unternehmensform vom 14.08.1969 - Gesetzentwurf Bundestags-Drucksache $v / 3186$.

- 1976, Gutachten über Probleme und Lōsungsmöglichkeiten einer Bodenwertzuwachsbesteuerung vom 05. Dez. 1975. SR BMF H. 22, Bonn.

WB BMF 1986, Gutachten zur einkomnensteuerlichen Behandlung von Alterseinkünften, Schriftenreihe des BMF, H. 38 , Bonn 
WB BMW 1975, Gutachtliche Außerung: Indexierung wirtschaftlich relevanter GröBen, Der Bundesminister für Wirtschaft (Bg), SR 9.

- 1979, Gutachten "Staatliche Interventionen in einer Marktwirtschaft", Göttingen.

WB BMWF 1971, Gutachten zur Neugestaltung und Finanzierung von Alterssicherung und Familienlastenausgleich vom 01 . Juli 1971 (wieder abgedruckt in: WB BMF, EntschlieBungen, Stellungnahmen und Gutachten 1949 bis 1973, hg.v. BMF, Tübingen 1974).

WEBER, H. 1980, Zu einigen rechtspolitischen Grundfragen der Besteuerung selbstăndiger Unternehmen. JZ 35. Jg., Nr. 17.

WEBER, W. 1961, Zur sozialpolit1schen Redistributionsproblematik in der offentlichen Finanzwirtschaft, J. Höfner u.a. (Hg), Naturordnung in Gesellschaft, Staat und Wirtschaft, Innsbruck.

- 1964, ther die Bedeutung von "Gleichheit" und "Gerechtigkeit" in Finanzwissenschaft und Finanzwirtschaft. Die Steuern als "pars pro toto". JSW 15.

- 1970, Wohlfahrtstheoretische Aspekte der Besteuerung: Zielkonflikte und Theorie des Zweitbesten, H. Haller U.a. (Hg) 1970.

WEBER, W., JOCHIMSEN, R. 1965, Wohlstandsökonomik. HDSW 12.

WEBER, W., STREISSLER, E. 1964, Nutzen. HDSW 8.

WEINBERGER, O. 1956, Kapital (I): Geschichte der Kapitaltheorie. HDSW 5.

WEISBROD, B.A., HANSEN, W.L. 1968, An Income-Net Worth Approach to Measuring Economic Welfare. AER 58.

WEISE, H. 1979, Rentenfinanzierung und Rentenbesteuerung. Das Besteuerungspotential der Renteneinkommen in der Bundesrepublik Deutschland. FA NF 37.

WEISS, B. 1878, Die Lehre vom Einkommen. ZgS 34.

WEISSER, G. 1959, Distribution (II) Politik. HDSW 2.

- 1961, Vermögen und Vermögenspolitik. HDSW 11.

- 1979, Zur Erkenntniskritik der Urteile über den Wert sozialer Gebilde und Prozesse, H. Albert, E. Topitsch (Hg), Werturteilsstreit,Darmstadt (1971) 2.A.

WEIZSÄCKER, C.C.v. 1974, Intergenerationelle Einkommensverteilung. Einfache Beispiele für Wirkungen steuerlicher MaBnahmen und für die optimale Steuerstruktur. Bombach, G. (Hg), Neve Aspekte der Verteilungstheorie, Tübingen.

- 1979 (Hg), Staat und Wirtschaft. SVS NF 102.

WERNER, J. 1951, Wohlstand, Freiheit und Gerechtigkeit, thre Verwirklichung als Problem der Wirtschaftspolitik. Verōfentlichungen der Handels-Hochschule St. Gallen. Reihe A, H. 29, Zürich/St. Gallen.

- 1971 , Uber wirtschaftspolitische Ziele. Szvs 107.

- 1979, Verteilungspolitik, Stuttgart/New York.

WETZLER, J.W. 1977, Capital Gains and Losses, J.A. Pechman (Hg) 1977.

WHALLEY, J. 1979 a, A Simple Neutrality Result for Movements Between Income and Consumtion Taxes. AER 69, Shorter Papers.

- 1979 b, Capital Gains Taxation and Interest Rate Chages: An Extension of Paish's Argument. NTJ 32 .

WICKSELL, K. 1896, Finanztheoretische Untersuchungen nebst Darstellung und Kritik des Steuerwesens Schwedens, Jena.

WIDMAIER, H.P. (Hg) 1978, Zur Neuen Sozialen Fragen. SVS NF 95.

WILLGFRODT, H. 1973, Das Leistungsprinzip - Kriterium der Gerechtigkeit und Bedingung des Fortschritts? A. Tauscher (Hg), Kapitalismuskritik im Widerstreit, Köln.

WILLGERODT, H. 1975, Die gesellschaftliche Aneignung privater Leistungserfolge als Grundelement der wettbewerblichen Marktwirtschaft, H. Sauermann u. E. -J. Mestmăcker (Hg), Wirtschaftsordnung und Staatsverfassung, Tübingen.

- 1978/79, Eigentumsordnung (einschl. Bodenordnung). HaWW, 15. Lfg. und 19./20. Lfg.

- 1982, Eigentum und Wirtschaftsordnung. WC H. 1.

WILLMS, E. 1979, Eigentumsdifferenzsteuern. HdF II, 3.A.

WINDISCH, R. 1980, Staatseingriffe in marktwirtschaftliche ordnungen, Streissler/ Watrin (Hg) 1980.

WINKLER, W. 1926, Einkommen. HwStW III, 4.A. 
WINTERSTEIN, B. 1978, Armut: Grundlage der Neuen Sozialen Frage, B.P. Widmaier (Bg) 1978.

WITTMANN, W. 1979, Steuerung der Versorgung mit Staatsleistungen uber das Aquivalenzprinzip, P. Bohley, E. Tolkemitt (Bg) 1979.

WOHE, G. 1978, Betriebswirtschaftliche Steuerlehre, Bd. 1, 5.A. Munchen.

- 1988, Betriebswirtschaftliche Steuerlehre I/1: Die Steuern des Unternehmens, das Besteuerungsverfahren, 6.A. Müchen;

- 1992, Betriebswirtschaftliche Steuerlehre I/2: Der EinfluB der Besteuerung auf das Rechnungswesen des Batriebes, 7.A. Winchen.

WoLL, A. 1974, Allgemeine Volkswirtschaftslehre, 4.A. München.

WUELLER, P.H. 1938, Concepts of Taxable Income. (I: The German Contribution; II: The American Contribution). PSQ 53.

ZACHER, H.F. 1978, Der Sozlalstaat als ProzeB. ZgS 134.

- (Bg) 1980, Die Rolle des Beitrags in der sozialen Sicherung: Colloguium der Projektgruppe für Internationales und Vergleichendes Sozialrecht der MaxPlanck-Gesellschaft, Berlin.

ZECKHAUSER,R.J. 1971, Optimal Mechanisms for Income Transfer. AER 61.

ZEPPERNICK, R. 1974, Die Bedeutung der Finanz- und Sozlalpolitik für die Einkommensverteilung. FA NF 32 .

- 1976, Staat und Einkommensverteilung. Bd. 11 der Reihe Wirtschaft und Gesel1schaft, hg. v. N. Kloten und F. Neumark, Tübingen.

- 1977, Kumulative Effekte der Finanz- und Sozialpolitik auf die Einkommensverteilung. Eine Replik. FA NF 35.

- 1980, Probleme der Umverteilung. DRiz.

- 1986, Transfereinkommen und Einkommensvertellung. Schriftenreihe des Rhein.Westf. Instituts für Wirtschaftsforschung Essen, NF H. 47, Berlin.

2IEMES, G.P. 1980, Ein Salve dem Aquivalenzprinzip, Siegener Studien, B. 27. ZIMMERMANN, B. 1976, Instrumente der Finanzpolitik. BdF I, 3.A.

ZIMMERMANN, H., HENKE, K.-D. 1982, Einführung in die Finanzwissenschaft,3.A. München.

ZIMMERMAN, P. 1978, Das Problem der Gerechtigkeit in der Einkoumensbesteuerung, dargestellt und untersucht an den Beispielen der Ermittlung der Einkünte aus Gewerbebetrieb und aus nichtselbståndiger Arbeit, Frankfurt a.M.

zINK, G. 1972, Neue Aspekte einer Vermögenspolit1k durch Besteuerung. WD S. 314 . ZINK, G., LIEDSCBULTE, W. 1971, Die Erfassung und Besteuerung der Wertzuwăchse im derzeitigen Steuersystem der Bundesrepublik Deutschland. Stuw 48. (1.) Jg.

ZINN, K.G. 1970, Basistheorle des okonomischen Wohlstandes in der Demokratie. Die Interdependenz von Gleichheit, zeit und Nutzen und die verteilungspolitische Konsequenz, Wlesbaden.

ZITZELSBERGER, G. 1979, Theoretische und empirische Zusammenhange zwischen "funktioneller" und "personeller" Einkommensvertellung. KP 25. Jg.

ZUMSTEIN, P. 1977, Die Ausgabensteuer. Volkswirtschaftliche Begründung und praktische Durchführbarkeit, Reihe Offentliche Finanzen Bd. I, Diessenhofen.

2wINTZ, R. 1975, Sinn und Unsinn einer Pigou-Steuer. Eine Erwiderung zu Bolger Bonus' Bemerkungen. ZgS 131. 


\section{FINANZWISSENSCHAFTLICHE SCHAIFTEN}

Band 1 Werner Steden: Finanzpolitik und Einkommensverteilung. Ein Wachstums- und Konjunkturmodell der Bundesrepublik Deutschland. 1979.

Band 2 Rainer Hagemann: Kommunale Finanzplanung im foderativen Staat. 1976.

Band 3 Klaus Scherer: Maßståbe zur Beurteilung von konjunkturellen Wirkungen des offentlichen Haushalts. 1977.

Band 4 Brita Steinbach: "Formula Flexibility" - Kritische Analyse und Vergleich mit diskretionărer Konjunkturpolitik. 1977.

Band 5 Hans-Georg Petersen: Personelle Einkommensbesteuerung und Inflation. Eine theoretisch-empirische Analyse der Lohn- und veranlagten Einkommensteuer in der Bundesrepublik Deutschland. 1977.

Band 6 Friedemann Tetsch: Raumwirkungen des Finanzsystems der Bundesrepublik Deutschland. Eine Untersuchung der Auswirkungen der Finanzreform von 1969 auf die Einnahmenposition der untergeordneten Gebietskőrperschaften und ihrer regionalpolitischen Zieladăquanz. 1978.

Band 7 Wilhelm Pfăhler: Normative Theorie der fiskalischen Besteuerung. Ein methodologischer und theoretischer Beitrag zur Integration der normativen Besteuerungstheorie in der Wohlfahrtstheorie. 1978.

Band 8 Wolfgang Wiegard: Optimale Schattenpreise und Produktionsprogramme für öffentliche Untermehmen. Second-Best Modelle im finanzwirtschaftlichen Staatsbereich. 1978.

Band 9 Hans P. Fischer: Die Finanzierung des Umweltschutzes im Rahmen einer rationalen Umweltpolitik. 1978.

Band 10 Rainer Paulenz: Der Einsatz finanzpolitischer Instrumente in der Forschungs- und Entwicklungspolitik. 1978.

Band 11 Hans-Joachim Hauser: Verteilungswirkungen der Staatsverschuldung. Eine kreislauftheoretische Inzidenzbetrachtung. 1979.

Band 12 Gunnar Schwarting: Kommunale Investitionen. Theoretische und empirische Untersuchungen der Bestimmungsgründe kommunaler Investitionstătigkeit in NordrheinWestfalen 1965-1972. 1979.

Band 13 Hans-Joachim Conrad: Stadt-Umland-Wanderung und Finanzwirtschaft der Kernstådte. Amerikanische Erfahrungen, grundsătzliche Zusammenhănge und eine Fallstudie für das Ballungsgebiet Frankfurt am Main. 1980.

Band 14 Cay Folkers: Vermógensverteilung und staatliche Aktivităt. Zur Theorie distributiver Prozesse im Interventionsstaat. 1981.

Band 15 Helmut Fischer: US-amerikanische Exportförderung durch die DISC-Gesetzgebung. 1981.

Band 16 Günter Ott: Einkommensumverteilungen in der gesetzlichen Krankenversicherung. Eine quantitative Analyse. 1981.

Band 17 Johann Hermann von Oehsen: Optimale Besteuerung. (Optimal Taxation). 1982.

Band 18 Richard Kössler: Sozialversicherungsprinzip und Staatszuschūsse in der gesetzlichen Rentenversicherung. 1982.

Band 19 Hinrich Steffen: Zum Handlungs- und Entscheidungsspielraum der kommunalen Investitionspolitik in der Bundesrepublik Deutschland. 1983.

Band 20 Manfred Scheuer: Wirkungen einer Auslandsverschuldung des Staates bei flexiblen Wechselkursen. 1983. 
Band 21 Christian Schiller. Staatsausgaben und crowding-out-Effekte. Zur Effizienz einer Finanzpolitik keynesianischer Provenienz. 1983.

Band 22 Hannelore Weck: Schattenwirtschaft: Eine Möglichkeit zur Einschränkung der offentlichen Verwaltung? Eine ökonomische Analyse. 1983.

Band 23 Wolfgang Schmitt: Steuern als Mittel der Einkommenspolitik. Eine Ergănzung der Stabilitătspolitik? 1984.

Band 24 Wolfgang Laux: Erhőhung staatswirtschaftlicher Effizienz durch budgetäre Selbstbeschrănkung? Zur Idee einer verlassungsmäßig verankerten Ausgabengrenze. 1984.

Band 25 Brita Steinbach-van der Veen: Steuerinzidenz. Methodologische Gundlagen und empirisch-statistische Probleme von Lánderstudien. 1985.

Band 26 Albert Peters: Ókonomische Kriterien für eine Aưgabenverteilung in der Marktwirtschaft. Eine deskriptive und normative Betrachtung für den Allokationsbereich. 1985.

Band 27 Achim Zeidler. Möglichkeiten zur Fortsetzung der Gemeindefinanzreform. Eine theoretische und empirische Analyse. 1985.

Band 28 Peter Bartsch: Zur Theorie der lăngerfristigen Wirkungen 'expansiver' Fiskalpolitik. Eine dynamische Analyse unter besonderer Berücksichtigung der staatlichen Budgetbeschrảnkung und ausgewăhtter Möglichkeiten der öftentlichen Defizittinanzierung. 1986.

Band 29 Konrad Beiwinkel: Wehrgerechtigkeit als finanzpolitisches Verteilungsproblem. Möglichkeiten einer Kompensation von Wehrungerechtigkeit durch monetäre Transfers. 1986.

Band 30 Wolfgang Kitterer: Effizienz- und Verteilungswirkungen des Steuersystems. 1986.

Band 31 Heinz Dieter Hessler. Theorie und Politik der Personalsteuem. Eine Kritik ihrer Einkommens- und Vermógensbegriffe mit Blick auf die Leistungsłăhigkeitstheorie. 1994.

Band 32 Wolfgang Schert: Die beschäftigungspolitische und fiskalische Problematik der Arbeitgeberbeitrăge zur Rentenversicherung. Eine Auseinandersetzung mit der Kritik an der lohnbezogenen Beitragsbemessung. 1987.

Band 33 Andreas Måstle: Die Steuerunion. Probleme der Harmonisierung spezifischer Gütersteuem. 1987.

Band 34 Günter Ott: Internationale Verteilungswirkungen im Finanzausgleich der Europåischen Gemeinschaften. 1987.

Band 35 Heinz Haller: Zur Frage der zweckmăßigen Gestalt gemeindlicher Steuem. Ein Diskussionsbeitrag zur Gemeindesteuerreform. 1987.

Band 36 Thomas Kuhn: Schlüsselzuweisungen und fiskalische Ungleichheit. Eine theoretische Analyse der Verteilung von Schlüsselzuweisungen an Kommunen. 1988.

Band 37 Walter Hahn: Steuerpolitische Willensbildungsprozesse in der Europaischen Gemeinschaft. Das Beispiel der Umsatzssteuer-Harmonisierung. 1988.

Band 38 Ulike Hardt: Kommunale Finanzkraft. Die Problematik einer objektiven Bestimmung kommunaler Einnahmemoglichkeiten in der gemeindlichen Haushaltsplanung und im kommunalen Finanzausgleich. 1988.

Band 39 Jochen Michaelis: Optimale Finanzpolitik im Modell überlappender Generationen. 1989.

Band 40 Bernd Raffelhüschen: Anreizwirkungen der sozialen Alterssicherung. Eine dynamische Simulationsanalyse. 1989.

Band 41 Berend Diekmann: Die Anleihe- und Darlehenstransaktionen der Europåischen Gemeinschaften. 1990.

Band 42 Helmut Kaiser: Konsumnachfrage, Arbeitsangebot und optimale Haushaltsbesteuerung. Theoretische Ergebnisse und mikroßkonometrische Simulation für die Bundesrepublik Deutschland. 1990. 
Band 43 Rüdiger von Kleist: Das Gramm-Rudman-Hollings-Gesetz. Ein gescheiterter Versuch der Haushaltskonsolidierung. 1991.

Band 44 Rolf Hagedorn: Steverhinterziehung und Finanzpolitik. Ein theoretischer Beitrag unter besonderer Berücksichtigung der Hinterziehung von Zinserträgen. 1991.

Band 45 Comelia S. Behrens: Intertemporale Verteilungswirkungen in der gesetzlichen Krankenversicherung der Bundesrepublik Deutschland. 1991.

Band 46 Peter Saile: Ein ökonomischer Ansatz der Theorie der intermediăren Finanzgewalten Die Kirchen als Parafisci. 1992.

Band 47 Peter Gottfried: Die verdeckten Effizienzwirkungen der Umsatzsteuer. Eine empirische allgemeine Gleichgewichtsanalyse. 1992.

Band 48 Andreas Burger: Umweltorientierte Beschåftigungsprogramme. Eine Effizienzanalyse am Beispiel des "Sondervermögens Arbeit und Umwelt". 1992.

Band 49 Jeanette Malchow: Die Zuordnung verteilungspolitischer Kompetenzen in der Europăischen Gemeinschaft. Eine Untersuchung aufgrund einer Fortentwicklung der ökonomischen Theorie des Föderalismus. 1992.

Band 50 Barbara Seidel: Die Einbindung der Bundesrepublik Deutschland in die Europäischen Gemeinschaften als Problem des Finanzausgleichs. 1992.

Band 51 Ralph Wiechers: Markt und Macht im Rundfunk. Zur Stellung der offentlich-rechtlichen Rundfunkanstalten im dualen Rundfunksystem der Bundesrepublik Deutschland. 1992.

Band 52 Klaus Eckhardt: Probleme einer Umweltpolitik mit Abgaben. 1993.

Band 53 Oliver Schwarzkopf: Die Problematik unterschiedlicher Körperschaftsteuersysteme innerhalb der EG. 1993.

Band 54 Thorsten Giersch: Bergson-Wohlfahrtsfunktion und normative Ökonomie. 1993.

Band 55 Li-Fang Chou: Selbstbeteiligung bei Arzneimitteln aus ordnungspolitischer Sicht. Das Beispiel der Bundesrepublik Deutschland. 1993.

Band 56 Harald Schlee: Einkommensteuerliche Behandlung von Transferzahlungen. Zur Neuordnung der Familienbesteuerung sowie der Besteuerung von Versicherungsleistungen und Sozialtransfers. 1994.

Band 57 Alexander Spermann: Kommunales Krisenmanagement. Reaktionen baden-württembergischer Stadtkreise auf steigende Sozialhilfekosten und Einnahmenausfälle (198092). 1993.

Band 58 Otto Roloff / Sibylle Brander / Ingo Barens / Claudia Wesselbaum: Direktinvestitionen und internationale Steuerkonkurrenz. 1994.

Band 59 Claudia Wesselbaum-Neugebauer: Intemationale Steuerbelastungsvergleiche. 1994.

Band 60 Stephanie Miera: Kommunales Finanzsystem und Bevolkerungsentwicklung. Eine Analyse des kommunalen Finanzsystems vor dem Hintergrund der sich abzeichnenden Bevölkerungsentwicklung am Beispiel Niedersachsens unter besonderer Berücksichtigung des Landkreises Wolfenbüttel und seiner Gemeinden. 1994.

Band 61 Wolfgang Schert: Die Bedeutung des kaldorianischen Verteilungsmechanismus für die gesamtwirtschaftlichen Wirkungen der staatlichen Neuverschuldung. 1994.

Band 62 Rainer Volk: Vergleich der Vergünstigungseffekte der verschiedenen investitionsfördernden Maßnahmen. 1994.

Band 63 Hans-Georg Napp: Kommunale Finanzautonomie und ihre Bedeutung für eine effiziente lokale Finanzwirtschaft. 1994. 2., unveränderte Auflage 1994. 
Band 64 Bernd Rahmann / Uwe Steinborn / Günter Vornholz: Empirische Analyse der Autonomie lokaler Finanzwirtschaften in der Europäischen Gemeinschaft. 1994.

Band 65 Carsten Kühl: Strategien zur Finanzierung der Altlastensanierung. 1994. 


\section{Konrad Aigner}

\section{Einkommensverteilung und Einkommensumverteilung}

Frankfurt/M., Berlin, Bern, New York, Paris, Wien, 1993. II, 173 S., 22 Abb., 9 Tab.

Europäische Hochschulschriften: Reihe 5, Volks- und Betriebswirtschaft. Bd. 1404

ISBN 3-631-45941-6

br. DM 59.--

In der vorliegenden Arbeit werden verschiedene Modelle von Einkommensverteilungsfunktionen vorgestellt und es wird versucht, diese Funktionen an die Daten der bundesdeutschen Steuerstatistik anzupassen. Zur Messung der Einkommenskonzentration wird üblicherweise das statistische Konzept der Lorenzkurve verwendet. Dieses Konzept wird hier auf beliebige Verteilungen verallgemeinert und als ökonomisch adäquatere Referenzverteilung die Normalverteilung vorgeschlagen. Es wird ein Einkommensteuersatz berechnet, der unter ceteris-paribus-Bedingungen für die bundesdeutschen Einkommen von 1986 eine Normalverteilung der Nach-Steuer-Einkommen erzeugt hätte.

Aus dem Inhalt: Modelle von Einkommensverteilungsfunktionen Lorenzkurvenkonzept - Distanzmessung - Lorenzkurve und Schiefe von Verteilungen - Steuersatz und Normalverteilung der Nach-SteuerEinkommen

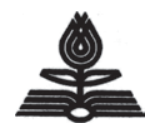

Verlag Peter Lang Frankfurt a.M. Berlin $\cdot$ Bern $\cdot$ New York $\cdot$ Paris $\cdot$ Wien Auslieferung: Verlag Peter Lang AG, Jupiterstr. 15, CH-3000 Bern 15 Telefon (004131) 9411122, Telefax (004131) 9411131

- Preisănderungen vorbehalten - 
Heinz Hessler and Anneliese Hessler-Otte - 978-3-631-75239-5 Downloaded from PubFactory at 01/11/2019 06:44:50AM via free access 
Heinz Hessler and Anneliese Hessler-Otte - 978-3-631-75239-5 Downloaded from PubFactory at 01/11/2019 06:44:50AM via free access 